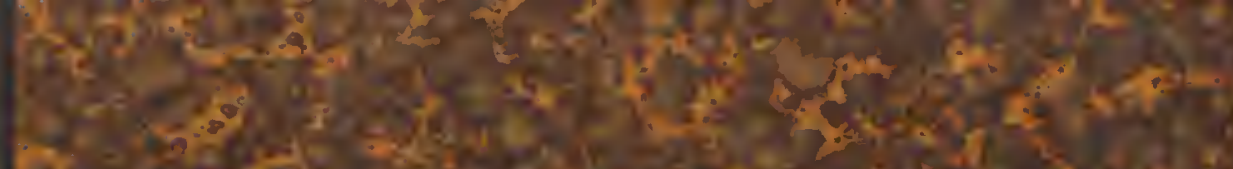

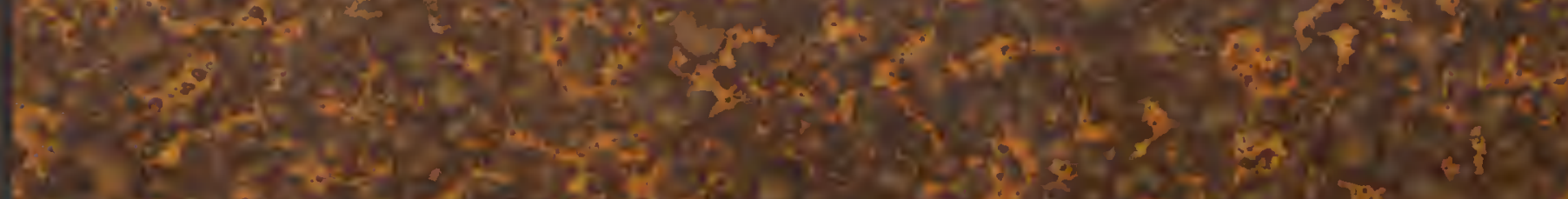

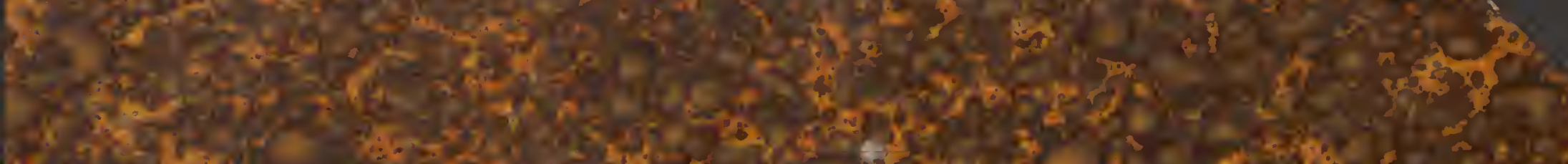

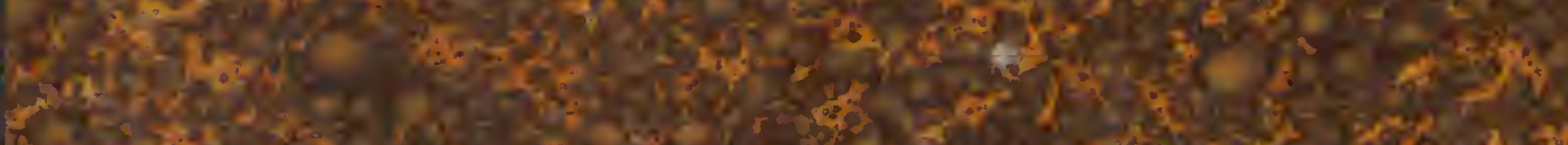

Mrt

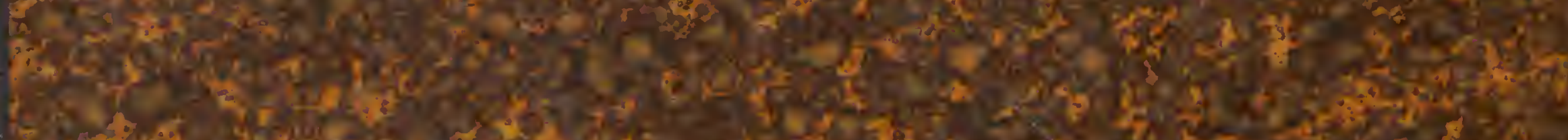
9.9.

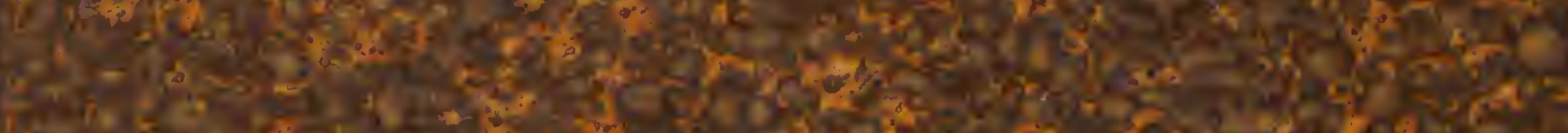

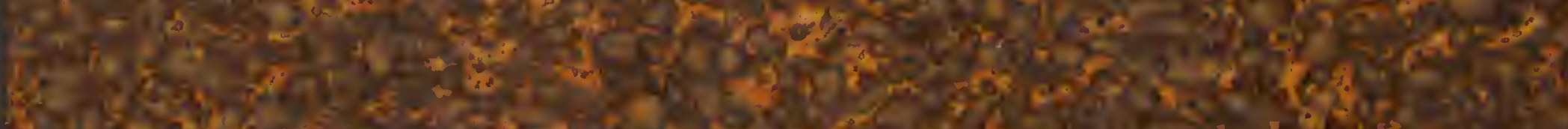

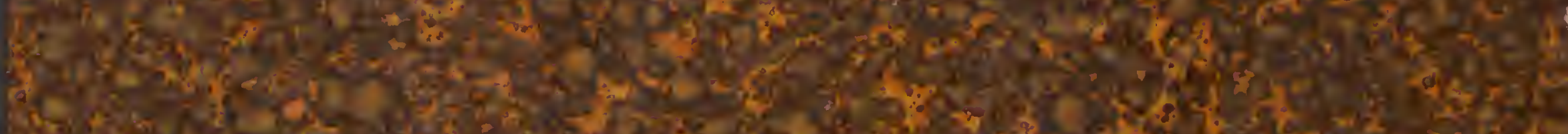

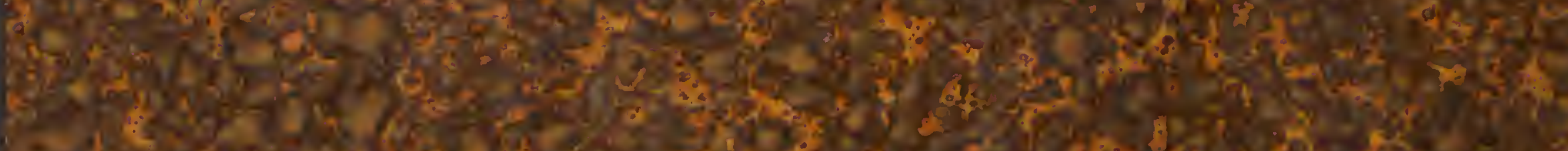

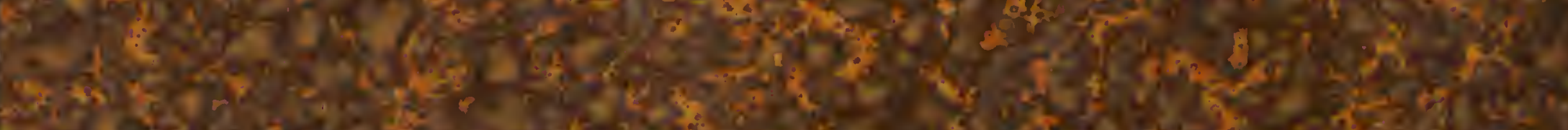

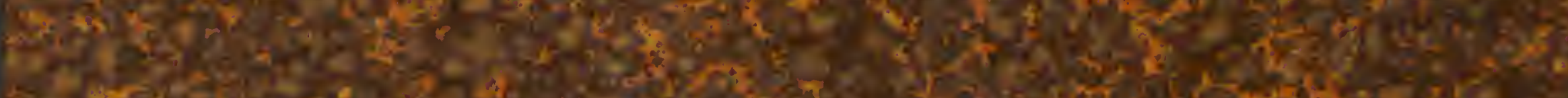

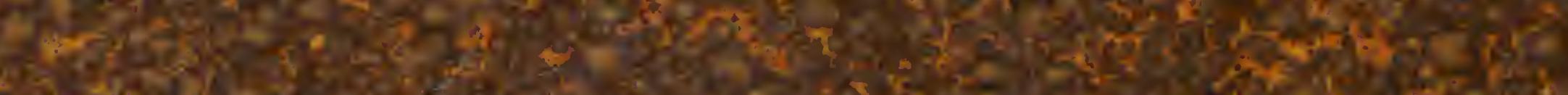

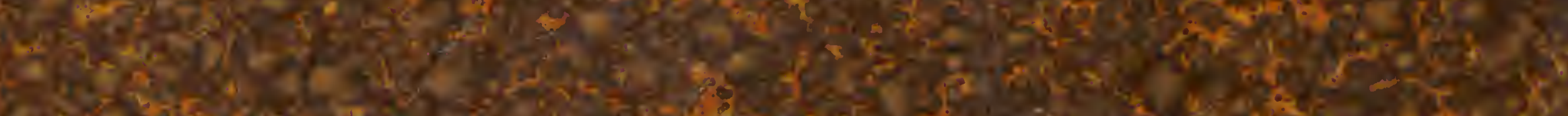

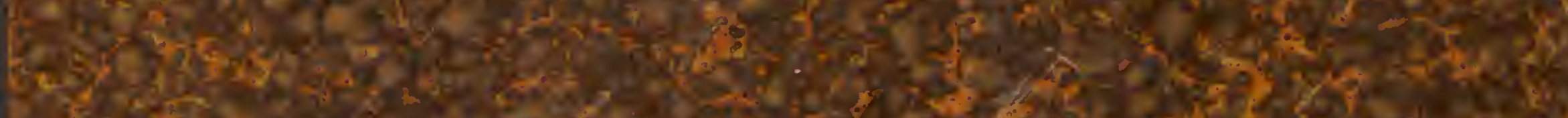

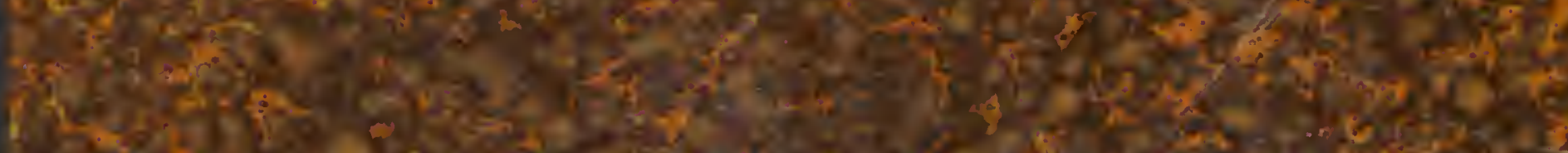
2rats

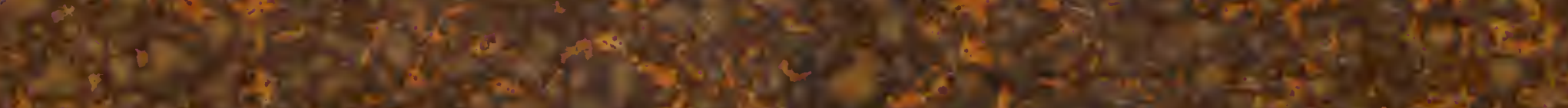

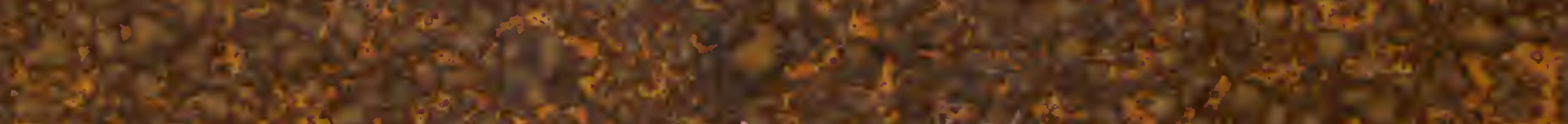

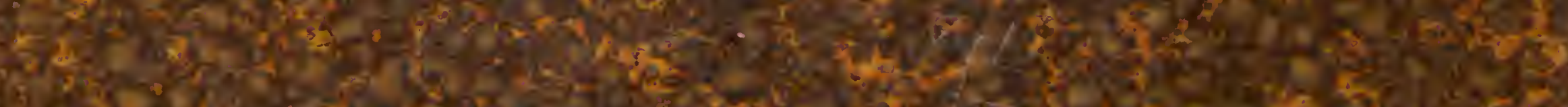

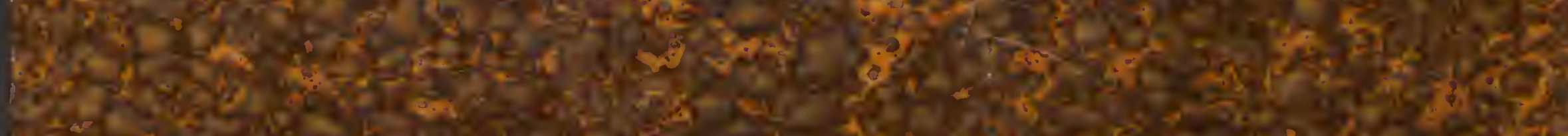

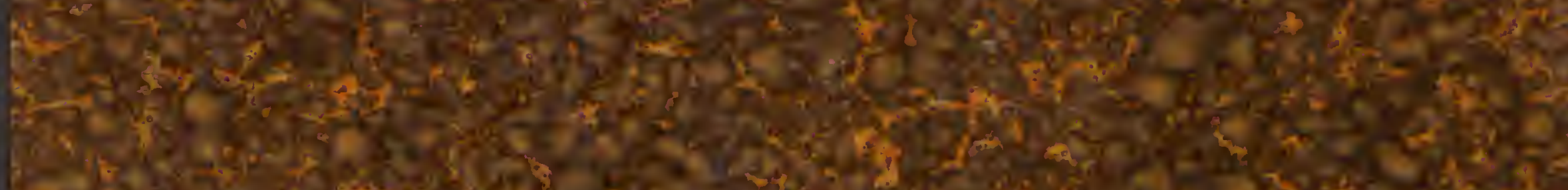
G)

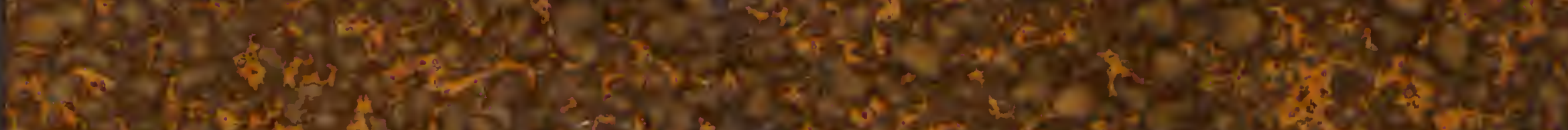

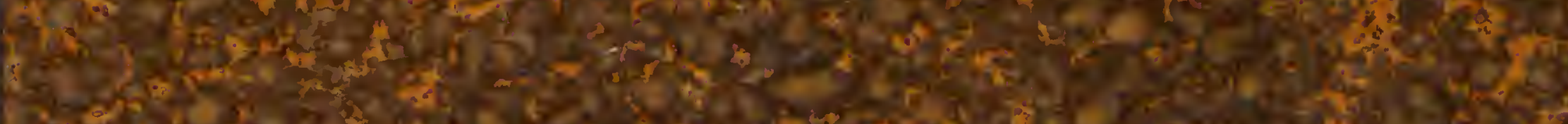

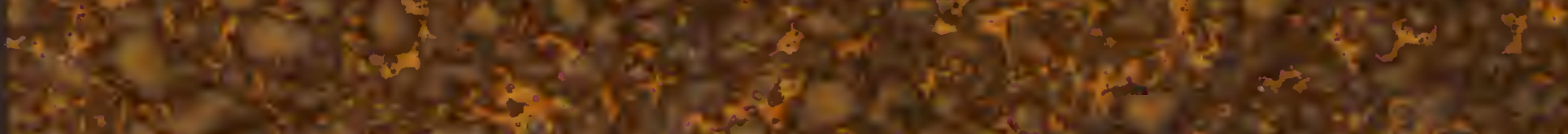

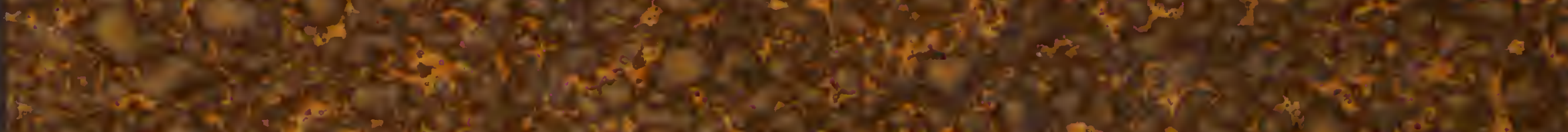

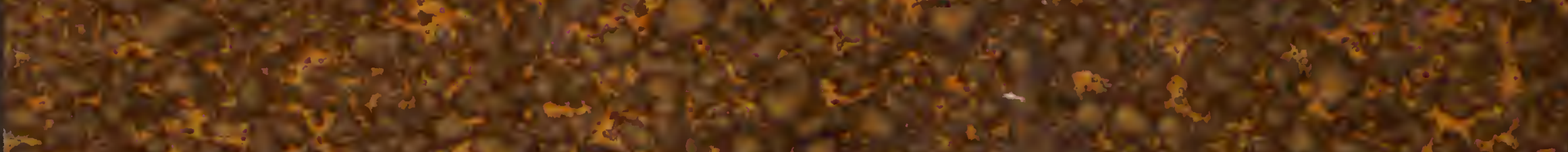

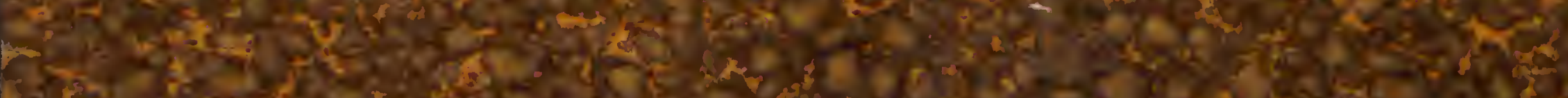

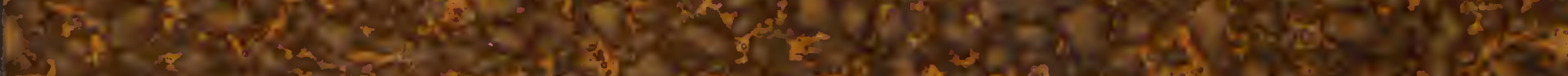

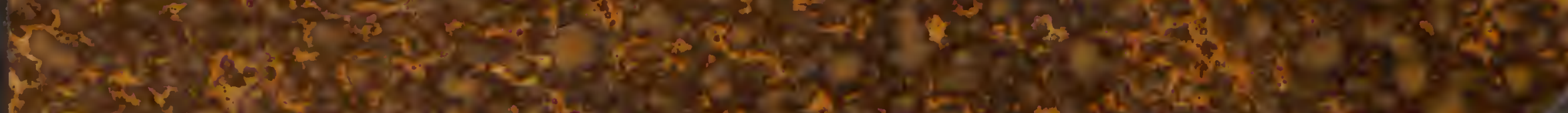

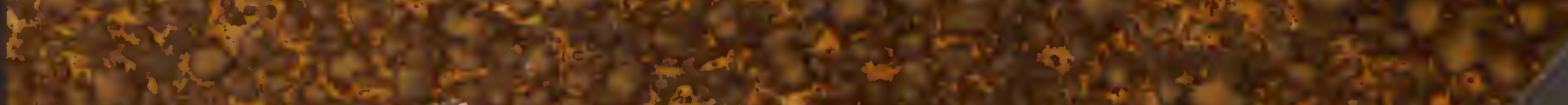

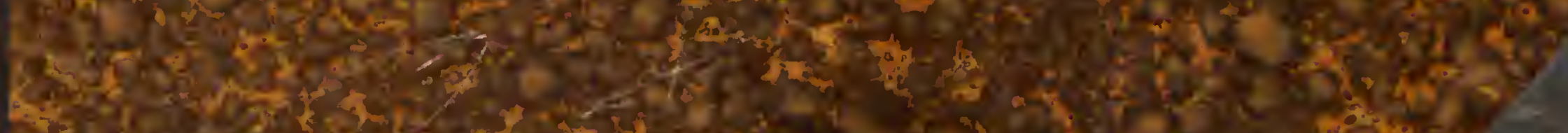

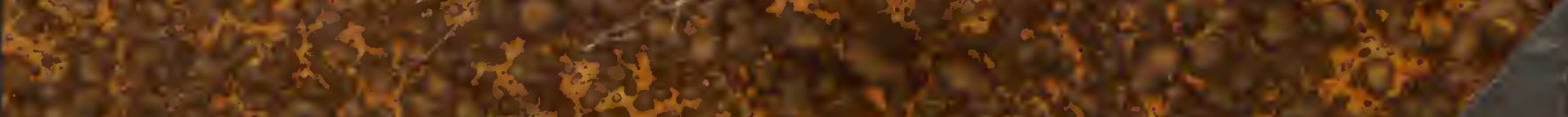

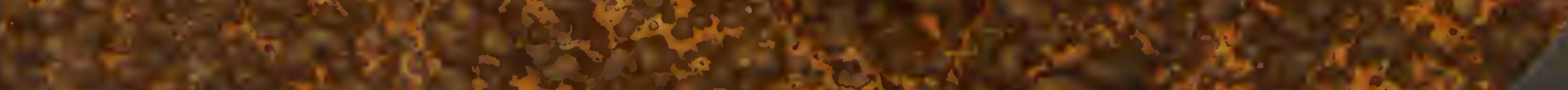



seres

तखि

तर बति

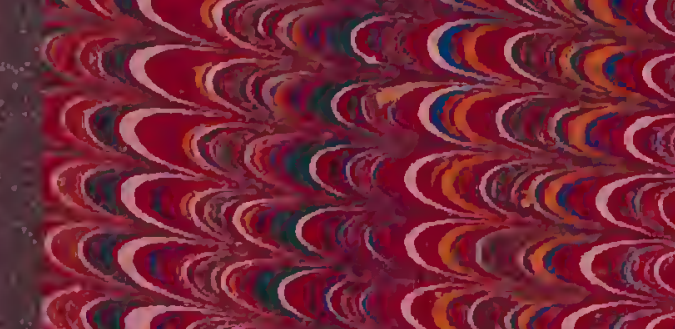

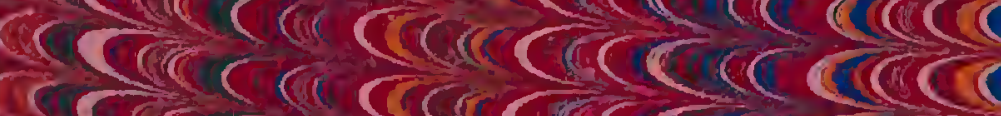

CC

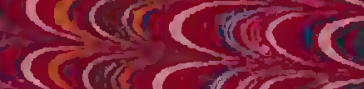

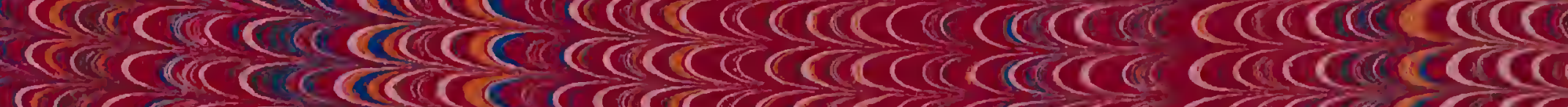

बत बतर

C C (c)

बत्व तब

C

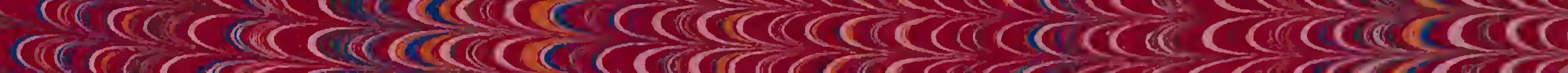

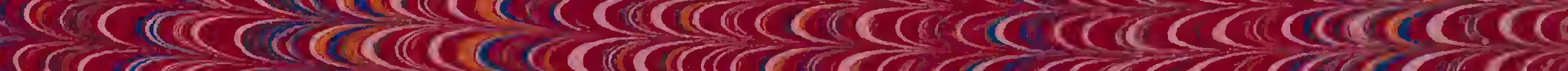

-

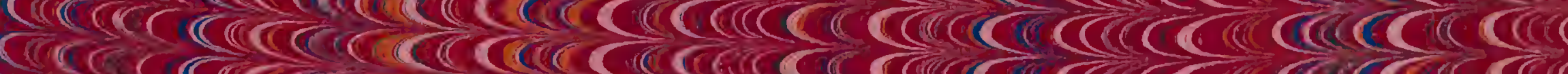

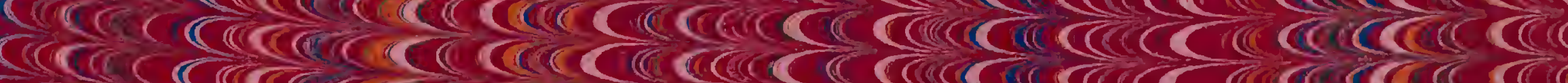

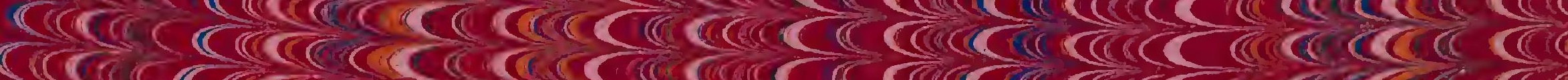

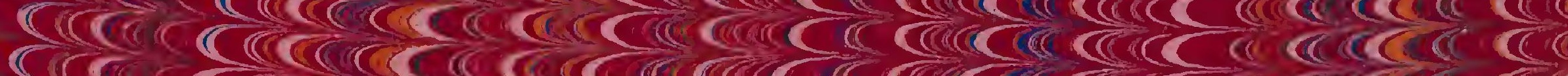

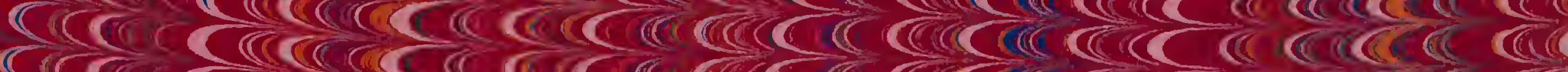

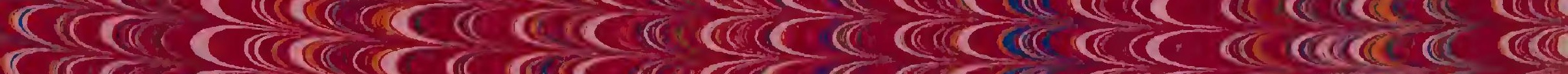

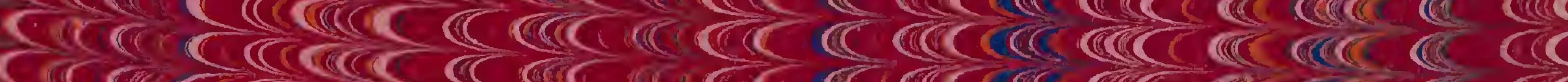

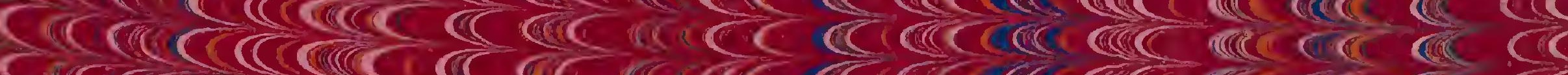

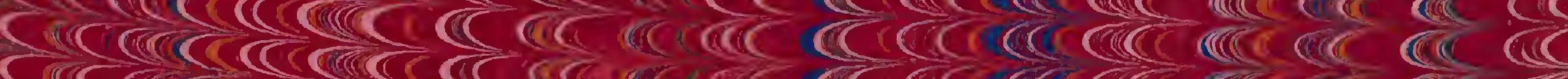

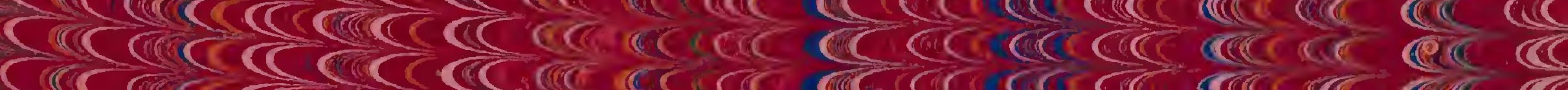

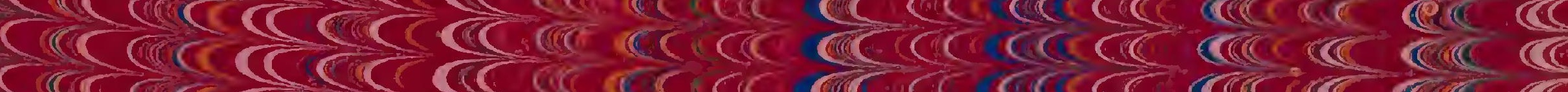

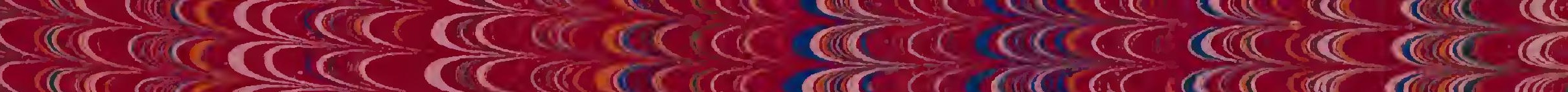

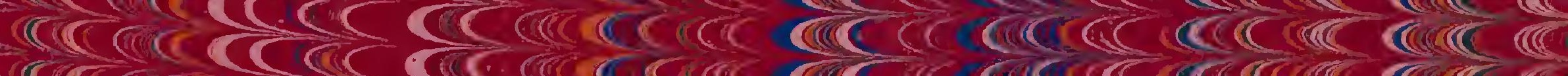

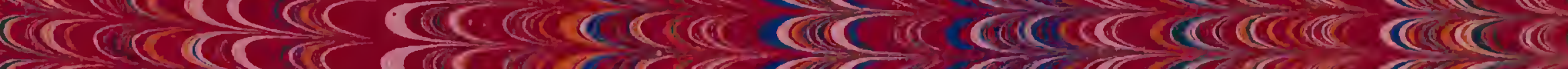

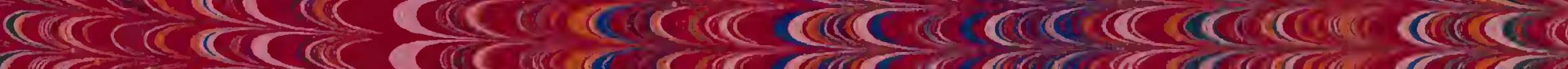

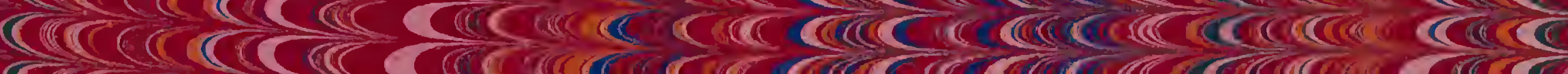

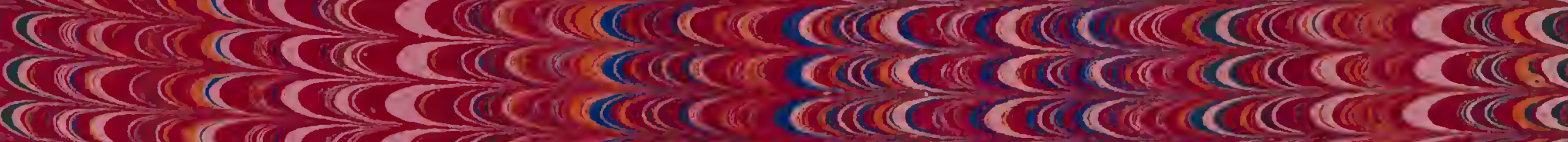

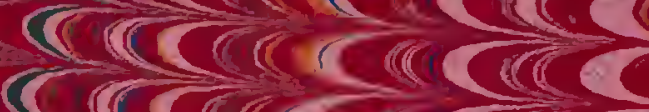

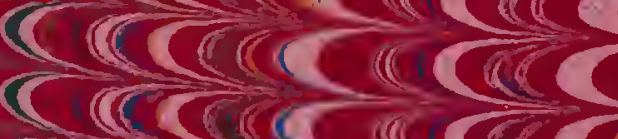

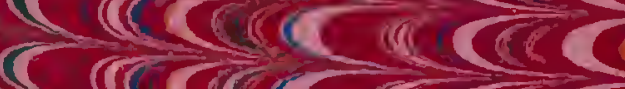

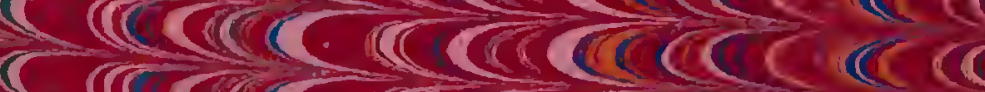

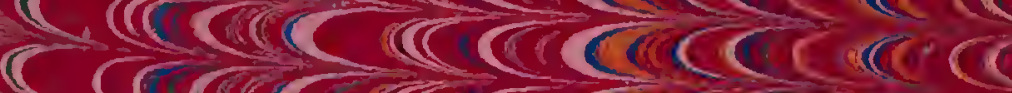

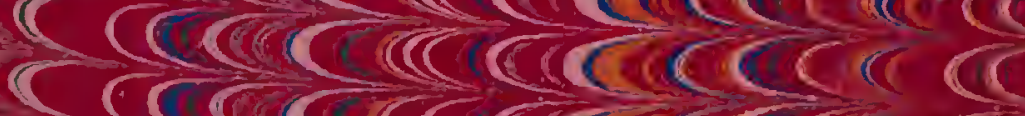

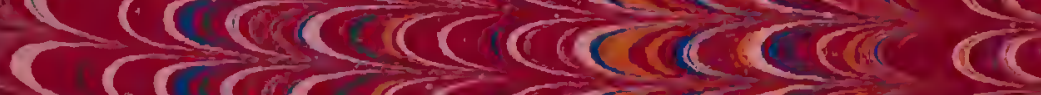

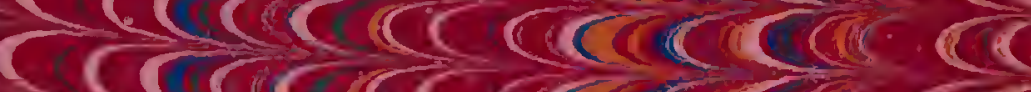

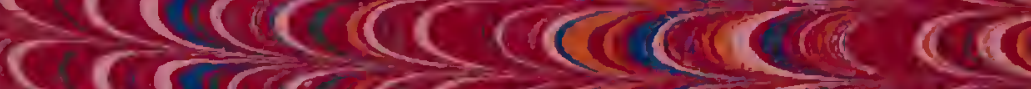

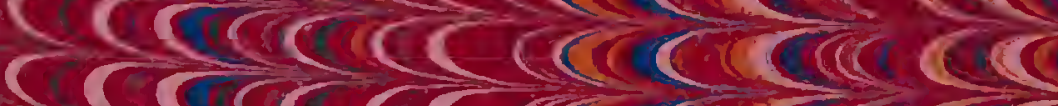

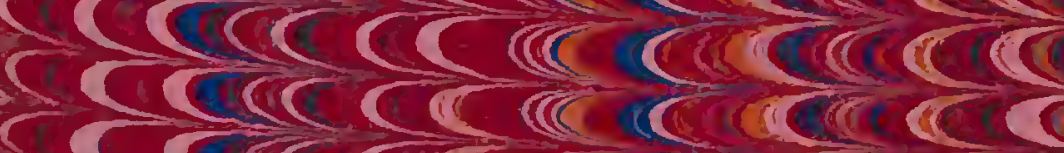

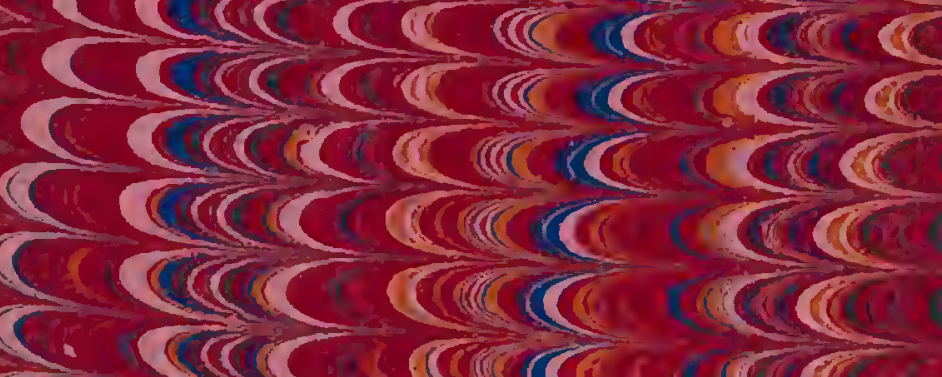

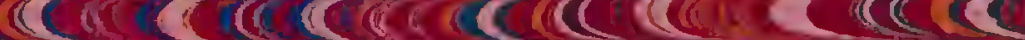

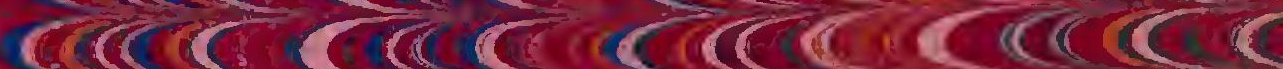

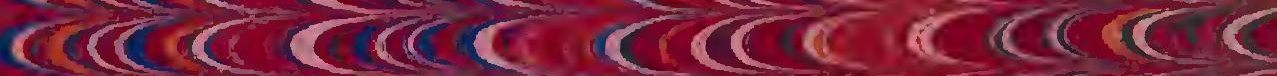

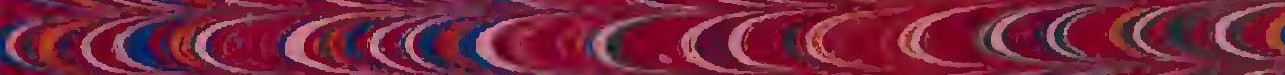

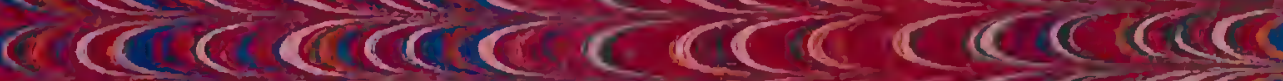

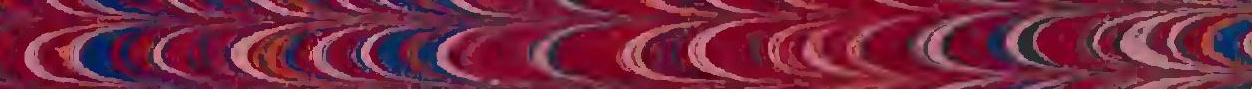

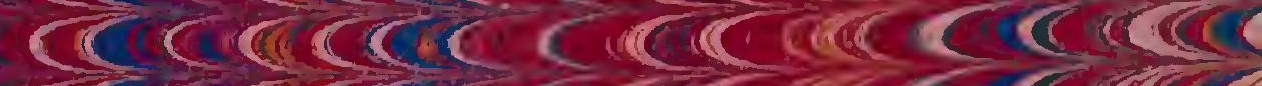

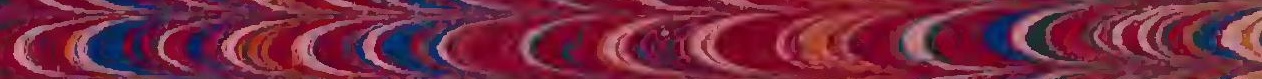

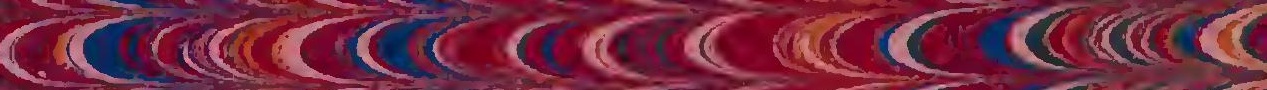

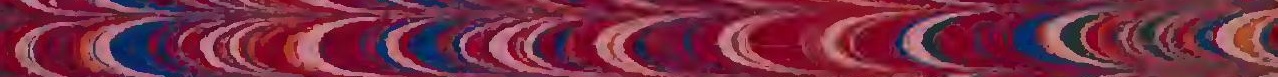

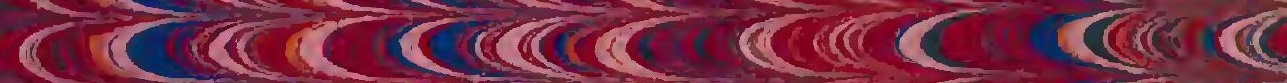

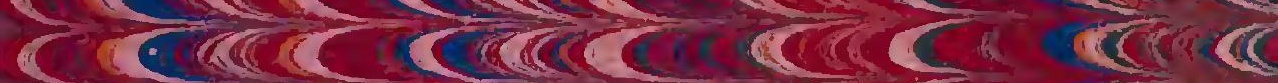

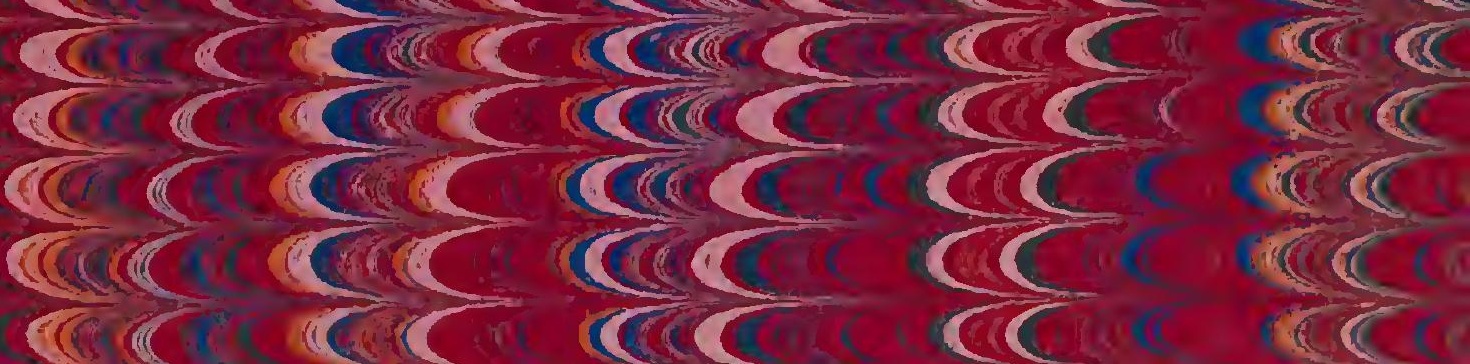



<smiles>C1=CC=CCCC=1</smiles> 



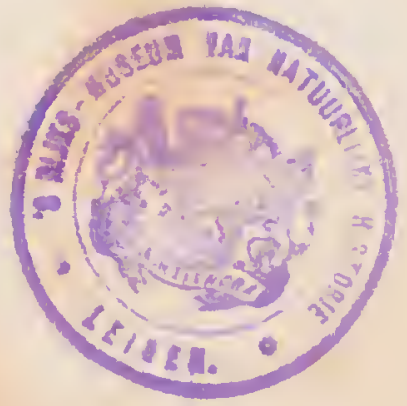





\title{
MISSION SCIENTIFIQUE
}

\author{
AU MEXIQUE \\ ET DANS L'A MÉRIQUE GENTRALE. \\ OUVRAGE
}

PUBLIÉ PAR ORDRE DE S. M. L'EMPEREUR

ET PAR IES SOINS DU MINISTRE DE L'INSTRUCTION PUBLIQUE.

\section{GÉOLOGIE.}





\title{
VOYAGE GEOLOGIQUE
}

\author{
DANS LES REPUBLIOUES
}

\section{DE GUATEMALA ET DE SALVADOR

IN. A. DOLLFUS ET E. DE WONT-SERRAT.
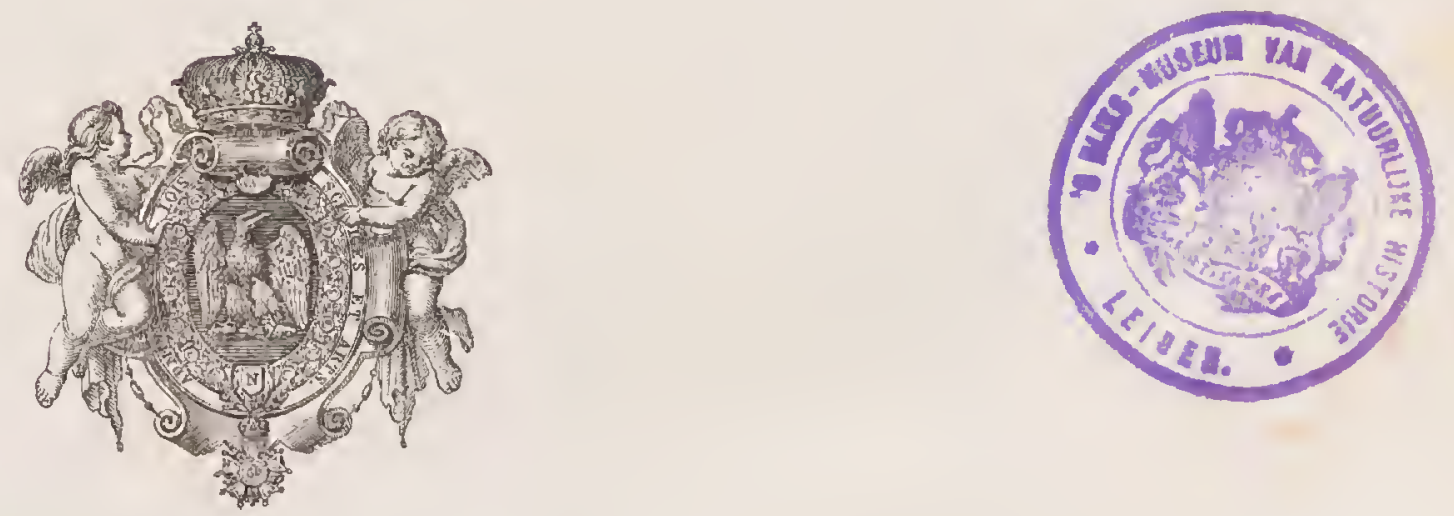

PARIS.

I MPRIMEPIE IMPERIALE.

IJ D C C C L X V III. 



\section{PRÉFACE.}

Lorsque, dans le cours de l'année 1864, M. le Ministre de l'instruction publique voulut bien nous attacher, comme géologues, à l'expédition scientifique du Mexique et de l'Amérique centrale, it savait qu'aucun itinéraire ne pouvail nous être tracé d'avance d'une manière absolue, ct que nous devions avant tout nous laisser guider, à deux mille lieues de distance des maitres qui nous avaient donné nos instruclions gónérales, par les hasards du temps et des saisons, ou par la force mème des choses. Une entière liberté d'allures nous fut donc, avec raison, accordée. Après avoir consacré plus de dix-huit mois à parcourir dans divers sens les régions centrales du Mexique, voyant les difficultés s'auggmenter à mesure que nous tendions à nous écarter de lit métropole, la situation gónérale du payś nous offrir de moins en moins la sécurilé et les ressourecs indispensables, nous nous décidàmes à profiter de la lalitude rui nous était laissée, pour aller demander à l'Amérique centrale un nouveau champ d'études et de travaux. Une scule crainte nous accompagnail dans ce voyage : c'était, après environ deux années déjà écoulées depuis notre départ d'Europe, de ne pouroir con- 
sacrer aux pays que nous nous proposions de parcourir autant de temps que semblaient devoir en réclamer leurs grandes chaînes de montagnes, leurs profondes vallées, leurs vastes solitudes el leurs mystérieux volcans. En effet, après huit mois à peine d'excursions et de travaux, nous fûmes obligós par les événements de quitter Guatemala et de nous arracher ì des études dont le début pouvait nous faire regretter l'interruption.

L'Amérique centrale offrait à notre activité et à notre désir d'apprendre un champ moins vaste peut-être, mais è coup sùr moins exploré, et, jusqu'à un certain point, plus intéressant. L'attrait de l'inconnu, l'inappréciable avantage de pouvoir acquérir quelques notions générales sur un pays où les distances, quoique considérables, n'atteignent pas un développement aussi effrayant que dans les immenses plateaux du Mexique, tont était fait pour nous inspirer un vif désir d'employer activement et utilement l'année que nous espérions avoir encore devant nous. Aussi bien avions-nous déjà pu nous faire quelque idéc des méthodes scientifiques à employer et des moyens à mettre en œuvre dans une régoion dont nous devions ètre, à peu de chose près, les premiers explorateurs au point de vue spécial des recherches géologiques.

Ce n'est point chose aisée que d'étudier d'une manière complète la géologie d'un pays, et de traduire les résultats de cette étude dans une carte géologique dont toutes les parties puissent mériter une égale confiance. Il a fallu des générations d'observateurs, et à leur suite l'apparition d'un homme de génie comme M. Élie de Beaumont, pour que le sol de la France füt connu avec une exactitude que l'on peut considérer aujourd'hui comme à peu près absolue. Mais aussi que de temps, que d'efforts, que de science! Un peu d'hésitation, et pourquoi ne pas l'avouer, un peu de crainte aussi, ne sont-elles pas permises à ceux qui se trouvent tout à coup en présence d'une parlie de la terre encore inconnue et sur laquelle it leur est réservé de dire les premiers mols? Au début d'un 
semblable travail, deux manières de procéder, deux méthodes de recherche, si l'on veut, peuvent être mises en œuvre, l'une et l'autre avec profit, mais avec des résultats qui nous paraissent différer d'une façon absolue. S'arrêter dès l'abord aux points saillants, aux endroits qui semblent présenter un intérêt de premier ordre, les éludier à fond, n'en pas laisser un recoin qui n'ait été examiné, fouillé, analysé, créer ainsi quelques monographies complètes, sérieuses, d'une véracité indiscutable, destinées à être reliées après coup par une série d'autres travaux du même goenre, et à amener plus tard à la connaissance entière d'un pays, c'est là assurément une manière de procéder qui a sa valeur, qui a même l'avantage de donner de prime saut beaucoup de notions certaines, immédiatement applicables, sur lesquelles il ne sera pas besoin de revenir. Mais si, regardant de plus haut, on s'attache moins à obtenir, pour le début, la vérité sur quelques points isolés, que des notions grrandes et laroges sur le tout, que des coups d'œil d'ensemble permellant de relier d'avance les parties les plus éloiognées, on ne saurait manquer d'être frappé de certains défauts inhérents à ce système. Un même observateur, surtout sil ne dispose que d'un temps relativement restreint, ne pourra se flatter de créer que bien peu de monographies; il inondera de lumière certains points, mais il aura laissé les antres dans l'obscurité la plus complète, et, lorsqu'un nouveau pionnier de la science viendra à son tour pour éclairer ces parties sombres, n'y aura-t-il pas bien des chances pour que, leurs idées scientifiques n'étant pas les mêmes, il ne reste sur tout cela un reflet d'opinions personnelles, produisant une fàcheuse disparate el nécessitant des efforts de génie pour constituer un tout harmonieux de ces fragments dont la juxtaposition ne produit, au premier abord, qu'un mélange un peu confus?

Qu'on nous permette de faire une comparaison, et d'assimiler pour un instant une étude géologique à quelque vaste représentation de la 
nature, à .quelque grand tableau auquel doivent coopérer plusieurs artistes. Si chacun en compose successivement et isolément quelque partie sous l'empire de ses gounts, de ses idées, de ses préoccupations personnetles, il est à supposer que l'harmonic de l'ensemble laissera fort à désirer. Mais, si l'un d'entre eux, laissant de côté la satisfaction de mettre la dernière main à quelque partie de l'œuvre, se contente de plıs humbles fonctions et vient tracer pour tous une esquisse qui indique à l'avance l'ensemble du dessin, l'œuvre commune pourra marcher ensuite vers un but unique, chaque fragment conservant une physionomie originale, et concomrant néanmoins au travail sans se séparer de l'idcée goénérale, qui n'est autre, après tout, que la reproduction fidète de la nature, de sa noble el vaste harmonie, de ses détails variés et infinis.

De même pensons-nous que, pour un travail góólog̣ique, avant d'examiner les détails, il faut avoir trouvé le tracé de la gigantesque esquisse posée par les soins de la nature. La mission de l'observateur appelé à étudier le premier un pays encore inconnu sera donc de voir beaucoup, quitte à ne pas approfondir toujours ce qu'il aura vu, d'obtenir ainsi des aperçus généraux, de se préoccuper surtout des vues d'ensemble. Les défauts inhérents à ce système ne doivent pas être dissimulés; il est évident que, voyant beaucoup, rapidement, superficiellement même, le voyageur sera exposé à se tromper quelquefois, à supposer des assimilations là où une observation plus attentive ne révélera que des différences, à trouver peut-être la continuité quand elle n'existe pas dans la nature. Mais ces défauts eux-mêmes peuvent devenir des avantagoes, si l'on sait en profiter sagement. Si l'observateur a soin de poser des hypothèses plutôt que des affirmations, il pourra ètre utile, même dans le cas où ses suppositions porteraient à faux. It vaut souvent mieux dire quelque chose qui ne soit pas absolument exact que de ne rien dire du tout. On attire ainsi les contradictions ou les affirmations postérieures, on donne 


\section{PRÉFACE.}

un but aux travaux futurs, on guide les recherches vers des points déterminés, on appetle la lumière après avoir commencé à dissiper l'obscurité. La méthode que nous préconisons possède donc de véritables avantages; laissant de côté les examens délicats et approfondis, elle évite de se spécialiser, et peul alors laisser errer son investigation sur divers ordres de questions, góographiques, météorologiques, voire même ethnographiques et sociales, toujours intéressantes et utiles lorsqu'il s'agit d'un pays presque vierge encore pour l'observation.

C'est sous l'empire de ces idées que nous avons établi le plan de notre voyage. Nous eussions pu nous borner à l'examen de quelquesuns des magnifiques volcans qui se dressent auprès des rivages du Pacifique; consacrant à chacun un mois ou même plus, nous eussions pu, vivant sur la montagne, parcourant dans tous les sens ses ravins et ses contre-forts, mesurant avec les plus grrands détails toutes ses dimensions, approfondissant l'analyse de ses roches et de ses produits, recueillir ainsi les matériaux de quelques mémoires savamment étudiés, de quelques monographies complètes. Mais ce n'est pas ainsi que nous avons agi; nous avons préféré jeter un coup d'œil d'ensemble sur la zone la plus vaste possible, pour nous faire, sur ses traits saillants, une idée générale, pour envisager d'un point de vue élevé les phénomènes qui ont pris jadis cette région pour théâtre el pour sig̣naler les particularités intéressantes qui mériteront plus tard d'être approfondies avec le plus grand soin.

Montés sur nos chevaux, suivis par deux domestiques mexicains qui avaient laissé loin derrière eux leur patrie pour ne pas nous abandonner, accompagnés de deux mules portant quelques vivres, quelques effets et des instruments scientifiques, parcourant tantôt les chemins battus, tantôt les sentiers où ne passe guère que l'Indien voyageur, nous avons marché devant nous, gravissant les montagnes et franchissant les fleuves, exami- 
nant toul ce que la nature nous offrail de sujets d'études, dans les pies rocheux et dans les vastes forêts vierges, ne songeant aux distances et au repos que lorsque la fatigue ou le besoin venaient à se faire trop impéricusement sentir. En moins de sept mois, nous avions ainsi visité le pays sur un parcours de plus de 150 o kilomètres, nous avions traversé d'un bout à l'autre la république de Salvador, nous ne nous étions arrêtés, dans la république de Guatemala, que tout auprès de la frontière du Mexique, nous avions visité dans tous les sens les provinces de la Vera Paz et des Altos, jelant un coup d'œeil sur tout ce qui pouvail exciter l'intérêl, éprouvant quelquefois cette singulière jouissance dont on ne saurail se défendre lorsqu'on traverse un district où l'on n'a été précédé par aucun Européen, lorsqu'on atteint la cime d'une inontagne où le pied de l'homme ne s'est encore jamais posé!

Malgoré l'importance des résultats que nous pouvons avoir obtenus, il ne faut pas nous dissimuler que nous sommes loin d'avoir atleint le but que nous nous étions proposé, et que, notre voyage eût-il été dix fois plus longo, c'est à peine encore si nous aurions pu terminer l'examen d'ensemble desliné à constituer le canevas primitif d'une étude complète de l'Amérique centrale. It nous a fallu laisser entièrement inexplorés de vastes espaces compris entre nos ilinéraires, beaucoup de volcans éteints et de montagnes élevées dont nous avons dû renoncer à faire l'ascension; nous avons passé à côté de bien des fails remarquables sans pouvoir leur consacrer un lemps suffisant, de bien des problèmes sans oser' en rechercher la solution; cet surlout, il faul l'avouer, nous n'avons parcouru qu'une partie relativement faible de la superficic totale de l'Amérique centrale. Avec quels reogrets nous avons dù renoncer à visiler' le Péten, ce mystérieux empire qui se perd dans les solitudes du Yucatan, le Honduras, cette belle république à laquelle semble être réservé l'honneur de créer le nouveau chemin de fer interocéanique! Combien 
nous cussions désiré pouvoir compléter nos aperçus sur les volcans, en orravissant les pics fumeux du Nicaraģua et du Cosla Rica, en poursuivant le prolongement du système jusque dans les régions sauvages du Soconusco!

Nos regrets sont légitimes, mais nous devons reconnaitre aussi qu'il ne nous eût pas été facile de faire beaucoup plus que nous n'avons fait. Ce qui nous a manqué d'abord, c'est le temps, qui nous élait limité, et l'activilé, quelle qu'elle soit, ne parvient janais à y suppléer complétement. Il faul le dire aussi, les moyens d'action nous ont quelquefois fait défaut; te mauvais état des voies de communication, le manque de ressources, le peu de concours à espérer de certaines races indiennes inhospitalières ou paresseuses, ct, pourquoi ne pas l'avouer, la fatiguc qui atteint lôt ou tard te corps le plus vigoureux, il y a bien là de quoi paralyser souvent les efforts.

Mais, si nous avons eu à lutler contre des difficultés sans nombre, nous ne pouvons nous dispenser de reconnaîlre que nous avons eu, d'un aulre côté, une aide précieuse, un énergique soulien dans l'appui matériel el moral que nous ont prêté les hommes avec lesquels nous avons eu te bonheur d'être mis en rapport. Que l'on nous permelte de témoigner hautement ici notre gratitude à toutes les personnes qui ont bien voulu contribuer au succès de notre mission par leur bienveillant accueil, leur aimable hospitalité et leurs intelligents conseils. Nous devons avant tout manifester notre reconnaissance pour les gouvernements des républiques de l'Amérique centrale, qui, loin de rester indifféreuts à nos recherches, en ont compris l'utilité pratique et ont cherché à favoriser nos travaux par tous les moyens en leur pouvoir. M. Dueñas, président de la république de Salvador, M. Cerna, président de la république de Guatemala, VM. les ministres marquis de Aycinena et Echeverria, M. le sous-secrétaire d'Étal Gavaretle, nous ont toujours prêté leur concours le plus em- 
pressé. Comme nous pouvions nous y attendre d'avance, nous avons trouvé, de la part des personnes qui représentent la France dans ces lointains pays, un accueil aussi dévoué que bienveillant. MM. Tallien de Cabarrus, consul général à Guatemala, Hardy, chancelier du consulat général, Courtade, agent consulaire à La Union, voudront bien nous pardonner, si nous ne savons pas résister au désir de leur exprimer ici toule notre gratitude.

Dans presque loutes les ograndes villes où nous nous sommes arrêtés, il devait se trouver quelques personnes, propriétaires indigènes ou négociants étrangers, dont la franche cordialité devait nous faire oublier, pour quelques instants, que nous étions isolés et loin de la patrie. Nous ne saurions citer ici les noms de tous ceux qui ont bien voulu nous recevoir; mais, si le hasard jette ce livre entre leurs mains, qu'its sachent que nous n'avons pas oublié l'accueil qu'on nous a fait à San Migguel, à San Salvador, à Sonsonate, à Guatemala... à Guatemala surtout. C'est là que nous avons fail la connaissance de tant d'aimables personnes, parmi lesquelles nous ne pouvons passer sous silence MM. Oscar et Xavier Du Theil, Georges et Henri Bramma, Rossignon, qui nous ont offert par la suite la plus gracieuse hospitalité dans leurs belles haciendas d'Escuintla, de San Agustin et de Coban; c'est lì que la Sociedad Economica, qui devait plus tard nous faire l'honneur de nous recevoir parmi ses membres correspondants, nous a ouvert avec empressement les portes de ses dépôts scientifiques et de sa bibliothèque; c'est là que nous avons trouvé au Collegio Tridentino un établissement de premier ordre, dont un des savants professeurs, M. Lizarzaburu, a toujours mis à notre disposition avec la plus grande affabilité les intéressantes collections et le remarquable observatoire.

A côté des difficultés malérielles qui nous ont quelquefois arrêtés, nous avons donc trouvé souvent, pour nous faciliter notre tâche, l'appui des 
gouvernements et des particuliers. Ce sont là des choses dont la mémoire ne s'efface pas; el, si nous voyons souvent passer dans nos souvenirs les paysages grandioses des Cordillères, les campements pittoresques dans la forêt viergee, les ascensions péritleuses aux gigantesques volcans, nous pouvons aussi goouter par la pensée la jouissance d'une estime réciproque acquise par le contact mutuel, te scntiment de vigoureuses amitiés nées sous le bean ciel des tropiques. Heureux si à ces jourssances nous pouvions en ajouter une autre plus précieuse encore; si, convaincus d'avoir employé utilement notre temps dans ces lointains pays, et assurés d'avoir fait quelque chose pour le bien général en soulevant une partie du voile qui cache ces régions mystérieuses, nous pouvions terminer notre travaił avec la douce pensée que nous avons apporté notre pierre, quelque petite qu'elle soit, au sublime édifice de la science et du progrès.

Paris, septembre 1868 .

Aug. DOLLFUS. Eug. DE MONT-SERRAT. 



\title{
VOYAGE GEOLOGIQUE
}

\author{
DANS LES RÉPUBLIQUES
}

\section{DE GUATEMALA ET DE SALVADOR}

\author{
(AMÉRIQUE CENTRALE).
}

\section{LIVRE PREMIER.}

ITINÉRAIRE DESCRIPTIF.

Le 31 mars 1866 , an matin, nous débarquions à la Union, petit port de la république de Salvador, silué sur l'océan Pacifique presque au fond de la magnifiqne baie de Fonseca, où pourraient, dit-on, manœuvrer loules les escarlres du monde, ce qui nous semble parfailement exact. Celle admirable silualion, qui permeltrait de créeı un des plus beaux ports qui aient jamais existé, n’a malloureușenent guère été mise à profit, el à peine existe-t-il une petite levée de piertes sèches, décorée du nom de jelée, qui reste complétement à sec à marée basse, et ne permel l'accès, à marée haute, qu'aux barques ou aux gros haleaux plats nommés lanchas servant au débarquement des marchandises el des pilssagers. Lus navires, mème ceux d'un faible tonnage, sont obligés do mouiller au milion de la bile à environ 1 mille de terre, dans une posilion qui présente, dı reste, toutes les garanlies de sécurilé. Quoi qu’il en soit, grâce à la nalure, qui a fail ici ce que les lıommes ne fout gुuère dans l'Amérique espagnole, le port de la Union u'en est pas moins le seul véritable port que l'on rencontre sur la còte onest de

Rifintilique

de

Salvidor.

Consilfrations rrónériales. 
l'Amérique centrale, el il contribuera puissamment un jour, s’il n'y a déjà contribué, au développement commercial et industriel du Salvador.

Cette république, quoique la plus petite du groupe centro-américain, est en effet aujourd'hui la plus riche el la plus florissante de toules, sauf peut-être le Costa-Rica. Cela lient à plusieurs ordres de considérations. Et d'abord la population y est infiniment plus condensée que dans tous les Élats voisins; elle s'élève en effet à près de 400,000 habitants, répartis sur une surface de 9,594 milles carrés, ce qui correspond à peu près à 41 labilants par mille carré, le double de re que présente la plus peuplée des autres républiques centro-américaines, et près de liuil fois plus que celle qui l'est te moins.

La manière dont celle population est composéc, au point de vuc des races, n’est pas nou plus sans imporlance : elle ne comprend guère en effet qu'un cinquième d'Indiens purs, race improduclive el ne comptant pour ainsi dire point pour la richesse du pays, tandis que, dans les contrées limitrophes, ces mèmes Indiens forment au moins les deux licrs de la population; un autre cinquième se compose de blancs, auxquels appartiennent le laut commerce ou les positions élevées du gouvernement, et le reste enfin est formé de mélis ou ladinos, gens le plus souvent industrieux el travailleurs, qui mettent en œuvre les nombreux éléments de richesse du pays. Presque toutes les cultnres tropicales trouvent en effel à se développer aisément sur un sol dont la fertilité proverbiale est due en grande partie aux déjections volcaniques qui l'ont recouvert autrefois.

Le Salvador ne se composant que d'unc bande assez élroite, jetée le long de l'océan Pacilique, pénètre peu dans l'intérieur dı conlinent, et n’atleint point, par conséquent, la zone des hautes montagnes; il pourrait done n'y avoir que très-pen de terrain perdu, puisqu'on laisse ainsi dans le Honduras les parties impropres aux végétations tropicales par leur allitude el lcur climat, el presque impossibles à mottre en cuvre à cause de lenrs allures brisées, de leurs dénivellations brusques el de leur's rochers arides. Ontre leurfertilité, les plaines du Salvador ont encore l'avanlage de faciliter les voies de communicalion, avantage dont il faut espérer que l'on profitera dans l'avenir plus qu'on ne l'a fail jusqu'à présent, quoiqu'il faille reconnaître que c'est encore là une des partics de l'Amérique centrale les plus avancées sous ce rapport. 
Un réseau de routes, mellant presque loutes les villes principales en conmmunication directe avec les trois ports que cette république possède sur le Pacifique, aidera puissamment au développement de son industrie el de son comneree.

La ville de la Union, qui est le principal port du Salvador, n'est d'ailleurs qu'un grand village, d'environ 1,800 ì 2,000 habilants, la plupart de sanģ inêlé on de race indienne pure. On y dislingrne cependant quelqnes Européens, de diverses nations, et deux ou trois Américains du nord, qui sont les principaux commerçants ou entrepositaires de marchandises, qu’ils expédient dans l’mtérieur du pays.

Le climal de cette Jocalilé est pen fail, du reste, pour allirer une nombreuse population; sa posilion, en effet, au fond de la baie de Fonseca, où elle est entourće de tonles parts par les terres qui se dressent d'un côté à une certaine hauleur au-dessus du niveau de la mer, contribue pour beaucoup à l'élévation de la tempéralure qu'on y observe; pendant les mois de mars et d'avril, il u'est pas rare, vers les deux lıcures de l'après-midi, de voir le thırmonètre placé à l'ombre marquer $35^{\circ}$ el $36^{\circ}$, el c'est à peine si, vers le soir, une légère brise, s’élevant du côté de la haule mer, vient rafraichir un peu ces plagges brülées par le soleil. Les environs immédials de la Union sont très-pen cultivés, el sur le bord de la mer croissent des forèts de palétuviers, qui sont autant de repaires de crocodiles énormes vivant à l'embonchnre de nombreux pelits cours d'eau qui se jettent dans la bair en formant ce qu'on appelle dans la langue du pays des esteros.

La baie de Fonseca est parsemée de nombreuses îles d'inégale grandeur', loules déserles, sanf une dite l'íle du Tigre. Ces îles, à peu près incultes, sont convertes d'une épaisse régétation, très-boisées, grénéralement montueuses, el d’un abord difficile à cause des récil’s quil les entourent; quelques-unes, où croissent de lautes lıcrbes, ont été mises à profit pour l'élevage de nombreux troupeanx de houl's, dont les cuir's sont très-recherchés, mais les bêtes féroces, telles que jaģriars, occlots, couguars, ctc. qu'on n'a pas encore pu éloigoner lont à lait, lont de grands lavages au milien de ces troupeaux.

L'île dn Tigre, par sa position, est de heaucoup la plus importante de la baice: sa circonférence est d'environ zo milles, mais il n'est pas possible d'alorder indifféremment sur toul son pourtour, car, tandis que, du côté du nord et der (Iste del tigre.) l'est, on rencontre de pelites criques ou anses, très-accores el à plage de sabte: 
fin, du còté du sud el de l'ouest, ce ne sont que des falaises de basalte abruptes el assez élevées, qui interdisent tout accès. Le port d'Amapala est situé précisément au fond d'me de ces anses, dans une position très-pilloresque, et il est parfaitement abrité contre les fortes brises par le pic qui domine lỉle et qui s'élève à une hauteur de 700 à 800 mètres an-dessus du niveau de la mer. Le mouillage y esl sùr et commode, è des navires d'un assez fort lonnage peuvent venir jeter l'ancre presque à un quart de mille de terre. Ce port, aulrefois refuge des pirates du Pacifique, ful déclaré port franc, il y a quelques années; il concentra, pendant un certain temps, tout le commerce du Honduras, mais peu à peu les navires cessèrent de s'y rendre, et il devint ce qu'il est aujourd'hui, un misérable amas de cases, défendu par un fort imaginaire, où le gouvernement entretient une garmison forle de douze hommes, commandés par un général qui s’intitule pompeusement gonverneur de l'ile. Gràce au mauvais vouloir de ce potenlat, il nous fut impossible de débarquer le jour de notre arrivée à l'ìle du Tigore, sous le prélexte que le soleil étail couché, et nous dùmes passer la nuit dans notre embarcation, allendant que le bon plaisir du gouverneur nous permit de visiter le pays sur lequel s'étend sa puissance.

La distance de l'île du Tigre à la Union est d'environ 12 milles, et trois on quatre heures, par le bean temps, suffisent pour la franchir.

Après avoir séjourné à la Union le temps nécessaire pour visiter les envirous et laire nos préparalifs en vue d'un long voyage par terre, nous nous dirigeàmes vers San Miguel. La route, au sortir de la Union, s'écarte rapidement de la côte, el l'on gagne par des pentes insensibles, au milieu d'une végétation toulfue et rał ougrie, le pelit village de los Almendros, qui offre au voyageur une maison hospitalière, où, moyennant quelques réaux ${ }^{(1)}$, il lui est possible de passer me nuil, el où il rencontre ce dont il a besoin pour lni et pour ses animaux. Nous avions oublié de mentionner que, dans le pays, il n'y a pas d'aulre moyen de transport que la mule ou le cheval; la plupart même des habilants préfèrent les mules, qui ont le pied plus sùr et peuvent supporter plus longtemps les fatigues, la soif et la privalion de nourriture. On rencontre bien, il est vrai, sur celle route de San Miguel, une foule de chariols à roues pleines, larges et épaisses, trainés par des bœufs et 
DANS LES RÉPUBLIQUES DE GUATEMALA ET DE SALVADOR. 5 chargés de marchandises; mais la vue seule de ces chariots et l'aspect du chemiu. en certains points, suffisent amplement pour faire hésiter celui qui voudrait tenter l'aventure, el se donner le plaisir de se promener en voiture sur des roules diles cependant carreteras (clrarretières), et que les documents officicls traitent de caminos reales (routes royales). Ce camino real n'est, en eflet, qu'un sentier plus ou moins bien tracé au nilieu de la végétalion, très-poussiéreux en cerlains endroits, rempli de fange un peu plus toin, suivant que l'ardeur' du soleil ou l'épaisseur de la végétation a enlevé ou liuissé séjourner l'humidité.

I environ trois lieves de los Almendros on traverse une magnifique forèt, on voltigent les oiseaux aux plus riches couleurs, et qui renferme dans son seiu nombre d'animaux plus sauvages que féroces. Nous avons surtoul remarqué, sur La lisière de celte forèt, ume prodigieuse quanlité d'iguanes, dont quelques-unes alteignaient des dimensions vraiment remarcuables; les habilanls du pays font lit chasse à cet animal inoffensif, dans le but de s'en nourrir: sa chair est, dit-on, succulente, et ses oufs mèmes ne sont point à dédaiguner. Plus foin, à environ 1 kilomètre de San Miguel, on passe, sur un pont en fer, le seul peut-être qui existo dans tout le pays, une rivière profonde et encaisséc, et qui était autrefois un vérilable obstacle pendant la saison des pluies. Cette rivière, qui se rend dans lr Parifique, porte le nom de la ville dont elle baigne presque les murs.

San Miguel se trouve à 56 kilomètres de la Union, dans une vaste plaime, au pied d'un des plus beaux volcaus du Salvador sous le rapport de la forme cxtérieure. et l'un des plus intéressauts par sa constitution zéologique. Celte ville est, sans contredit, la plus importante du pays, après San Salrador, et, dans peu d'années. si te commerce continne à s'accroître, elle prendra lacilement le premier raug. Lujourd'hui, c'est une ville régoulièrement bàtie, à rues lonğgues et élroiles, à maìsous généralement basses el à toils inclinés; quelques édifices particuliers, consIruits daus ces dernières amnées, ont cependant deu étages, avec vérandas, gaileries et balcons. Quant aux édifices publics, c'est à peine si l'ou peut en parler' : une église en rumes, un hôtel de ville qui s'écroule, tel est le bilan d'une ville. fondée en 1530 , mais qui, depuis cette époque, a eu fort à souffirir, à différentes reprises, des siéges et des combals qui s’y sont livrés.

La chaleur encore plus intense qu’à la Union, qui règegne pendant trois ou 
quatre mois de l’année à Sin Miguel, rend cet endroit très-malsain; le typhus y esl endémique, el l'on y voil aussi une foule d'enfants rachiliques, landis que les hommes déjà robustes sont atteints de fièvres pernicieuses. La population de San Viguel s'élève à environ 8,000 ou 10,000 àmes, et se compose en grande parlie de métis; les blancs cependant s'y rencontrent aussi en assez grand nombre, car il s'y fail généralement beancoıp de commerce. San Miguel est singulièrement animé ì deux époques de l'année, pendant la durée de ce qu'on appelle dans le pays las ferius, les foires. Ces immenses marchés ont le privilégge de réunir les principaux commerçants des cinq républiques de l'Amérique centrale, et même reux de cerlains Étals du sud du Mexique, el l'on traite alors sur une vaste échelle toules les aflaires relatives au café, à l'indigo, à la cochenille, etc. Suivant que la foire re San Miguel a élé beaucoup ou peu fréquentée, le Salvador est dans une siluation prospère, ou dans une sorte de stagnation, car le marché est en quelque sorte le thermomètre du bien-être de tout le pays pendant l'année qui s'écoule.

Dans les mois qui suivent ou qui précèdent ce moment intéressant au plus haut point, les routes sont encombrées de marchandises se dirigeant sur San Migouel, ou prenant le chemin de la Union pour gagner l'Europe, sur les paquebols de la compagnie du Panama Railroad. Ce ne sont point seulement les marchandises et les produits agricoles qui se donnent rendez-vous dans les murs de San Miguel à l'éporque des foires, on y voil encore des échantillons des riches mines d'or è d'argent du Honduras, de Depilto, de San Marcos, ele. Les opales d'Intibuca, dans te département de Gracias, attirent anssi les regards par leurs reflets mutticolores et leurs dimensions vraiment remarquables. On peut, en un mot, parfaitement se rendre comple des productions de toute nature de ces beaux pays, en parcourant pendant deux ou trois jours ces aggolonérations élranges, où les costumes les plus hizarres el les plus variés se montrent aux yeux élonnés de l'Européen qui voyago pour la première fois dans ces régions.

Notre séjour à San Migguel avait surtout pour but l'ascension du volcan silué à trois ou quatre lienes au sud-onest de la ville; sans entrer ici dans des délails relatil's ì celle ascension, délails que l'on trouvera plus loin, au chapitre des volrans, nous dirons cependant que, soit par inertie, soil par crainte, pen de personnes du pays avaient lenté jusqu'alors de monter au sommel du volean, el ì 
DANS LES RÉPUBLIQUES DE GUATEMALA ET DE SALVADOR. ; peine en eûmes-nous manifesté le désir sérieux, que tont le monde demanda ì nous accompagner. Le 9 avril, nous sortions donc, de la ville, suivis d'une nombrense cavalcade, nous dirigeant sur le volcan, avec l'intention de passer la nuil au pied du cône, de manière à ponvoir, le lendemain an point du jour, coumnencer l'ascension principale. Tous nos compagnons de roule élaient heureux de celte occasion qui leur permeltail de respirer au moius pendant quelques instants, salls ètre accablés par la température torride qui règne à San Vignel. Après avoir traversé les riches plantations qui forment comme nne ceinture verdoyante el boisée à la base du volcan, nous rencontràmes une immense coulće de lave dalanl de la dernière éruption, qui eut lieu le 25 juillet 1844 . On raconte, au sujet de celle éruption, un épisode assez émouvant :

Sur les flanes de la monlagne vivail, daus ume hulte en bambous, un pauver bùcheron qui trouvail à s'occuper dans les hois des environs. Le jour, ou plutòt la nuil de Péruption, ce bùcheron fut réveillé brusquement par le bruil des détonations répétées partant du fond du cralère, el par la vive luenr qui s'échappait du sommet de la montagne. Aussitôt cet homme veut fuir, mais il cherche en vain $11 n$ passage : de tons cólés il se voil entouré par une muraille de feu, qui s'approche de plus en plus du rocher qui porte sa maison, et il se regarde comme condamné à une mort inévilable. Ilenrensement pour lui, ce rocher, sur lequel it croyait périr, se trouvait à l'extrémilé d'un pli de terrain qui divisa en deux luranches le courant de lave, el il ful épargné. Peu à peu, l'éruption se calma, cessa mème tout à fait de ce coté-là du volcan, et, quoique sauvé, notre mallıeureux bìcheron dut se résigner à attendre, avant de pouvoir sortir, que la lave fùt refroidie, voyant ainsi s'ajouter aux terribles émolions de la nnil précédente tontes les angoisses de la faim.

Au pied du còne, à la limite des cendres el des scories, nous découvrìmes um" misérable habitation en bambous, dile la casa de Chavez, où vil une pauvre famille indienne qui nous offrit la plus cordiale hospilalité. Le lendemain, frais el dispos. et munis des instruments nécessaires, nous commencions à monter bien avant le lever du soleil, afin de pouvo ir alleindre de bonne heure le sommet, car nous avious à faire de nombreuses el intéressantes observations. Au point culminant du volcan, du côté est du cratère, on a devant soi un superbe panorama : la magnifique baie 
de Fonseca ef ses iles verdoyantes, que l'on distingue avec une nelleté admirable, la côle du Pacifique sur une immense longueur, les innombrables sommités coniques et les volcans principaux du Salvador, presque tout le pays enfin se déroule à vos yeux, el celte vue augomente cncore le désir déjà bien vif que l'on éprouve de voir de près loute celte rógion si pittoresque.

Route

d:

San Miguel

à San Viennir.

Chinaments.

De San Miguel à Chinameca la roule serpente à la base du volcan, et s'élève peu à peu à quelques centaines de mètres au-dessus du niveau de la mer : cette route n'est encore qu'un chemin de mules oì de grossières charreltes peuvent passer à la rigueur; en plusienı's points elle est taillée dans le roc, ou bien elle s'avance dans des sables qui s'éboulent, et alors sa largeur diminiue sensiblement.

Après avoir traversé le misérable bourg de Moncagua, qui n’offre rien de remarquable, on arrive à Chinameca, gros villago de 1,200 habitants, Indiens el mélis, silué dans un climial plus agoréable el plus tempéré que celni de San Miguel. Chinameca se trouve au pied d'un pelit volcan dont on ne connaît pas d'éruption; loutefois, à environ 2 kilonètres du villaģe, on remarque des dégagements de gaz assez importants, se faisant jour en plusieurs points d'une immense fissure. On entend de tous colés des sifflements assez forts, et on perçoil une vive odeur sutfurense; c'est, d'ailleurs, la seule particularité remarquable qui puisse arrêter le royageur dans cette localité. Le climat de Chinameca permet à ses liabitants de culliver quelques fruils et quelques légumes, el ce sont eux qui alimentent ordinairement le marché de San Miguel, lequel, sous ce rapport, laisse beaucoup ì désirer.

Laissant Chinameca à l'ouest, la ronte de la capitale, fue nous suivions, se dirige sur le rio Lempa, le principal fleuve du Salvador, el presque le seul un peu important qui traverse cette république. Nous retrouvons encore lì la végétation des terres chaudes, et le hasard nous fail arrêter à l'heure de midi, au moment où le soleil an zénitlı brûlait la route de ses rayons perpendiculaires, dans une sorte d'oasis de fraichemr, an pied d'une superbe cascade, et dans un site ombragé de tons côtés par des arbres el des végélaux à largos feuilles, entremèlés de lianes pendantes et de convolvulus aux couleurs les plus variées. Cet endroit privilégié dépend d'une immense plantation de cannes à sucre, qui porte le nom d'hacienda d'Umaña. 
DANS LES RÉPUBLIQUES DE GUATEVALA ET DE SALVADOR.

Au delà, toujours au travers de forêts vierģes plus ou moins épaisses, où les défrichements ont cependant été commencés sur une grande élendue, on descend progressivement jusqu'au bord du rio Lenpa, qui roule ses eaux fort peu limpides jusqu'à l’océan Pacifique. Sur la rive droite du fleuve, vivent quelques misćrables Indiens qui dépendent de la hacienda de la Barca, et qui ranconnent un peu les voyageurs tout en teur offrant quelques morceaux de viande découpéc en lanièress et séchéc au soleil, portant dans le pays le nom de cesina.

Le Lempa est un fleuve d'environ 200 mètres de large, en lace de la Barca; sa profondeur est de 3 ou 4 mètres pendant la saison sèche, el on le franchit an moyen d'un bac assez solide, qui sert à la fois pour les voyaggeurs el leurs montures. Il serail imprudent d'essayer de passer ì goú ce fleuve dont les eaux pen rapides ne semblent pas présenter d'obslacles; des crocodiles sont ordinairement cachés dans la vase, sur les bords ou au milieu du fleuve, et l'on a cu souvent ¿̀ enregistrer de graves accidents dus à l'imprudence de cerlains voyageurs qui, pour ne pas payer la modeste rétribulion du bac, Lraversaient le Lempa à la nage.

De l'autre côté du fleuve, la roule se continue ì travers d'épaisses forèts; elle devient bientôt de plus en plus accidentée el enfin toul à fail impraticable, mème pour les lourds chariots dont nous avons parlé plus haut. Pendant la saison des pluies c'est à peine si l'on peut circuler à cheval el avec des mules chirrgées, el ce n'est qu'à environ 6 licues de la Barca, aux abords de la plaine de San Vicente, que le chemin redevient un peu carrossable.

San Vicente est un gros bourơ moins imporlant que San Mignel, situé commus ce dernier daus une belle plaine et au pied d'une montagne conique, qui présente Sinl licente. lous les caraclères d'un volcan. On n'a gardé le souvenir d'aucume éruption de co volcan, mais il existe au sommet de la montagne une dépression assez considérable, qui, s'ćtant remplie d'eau, faillit amener, il y a quelques amées, une calastrophe analogne à celle du Volcan de agua, si fameux au Gualemala. L'eau ayant commencé à s'échapper à travers une fissure, il se forma bientôt me sorle d'avalanclie el un torrent, dont le cours, heureusement délourné par quelques profonds ravins silués au pied de la monlaģne, ne pul alleindre San Vicente. Celte ville, fondée en-1638 par Alvarez de Quiñones Osorio, avec le concours de quelques familles espagnoles, occupe à peu près la position la plus centrale du pays, el se 
trouve à 15 lieues de la capitale. Le commerce toutefois n'a pu profiter de cetle situation avantageuse, car les voies de communication sont encore dans un état déplorable aux environs de San Vicente, soit du côté de la Union, soit du côté de San Salvador, et les efforts teutés par le gouvernement du Salvador pour créer un port à la Concordia à 10 licues de San Vicente n'ont pas été, jusqu’ici, couronnés de succès.

San Vicente, qui compte aujourd'hui 6,000 habitanls, est une pelite ville régúlièrement bâlie, mais dont les rues sont étroites et pour la plupart assez mal entretenues; les constructions particulières sont très-analogues à celles de San Miguel et des autres villes du pays, car ce sont encore des maisons basses sans étages ou à un senl élagge au plus, el à toils inclimés. La calhédrale toulefois, qui se trouve sur une grande place entourée d'arcades diles portales, est d'un style assez originat mélangé de slyle mauresque et de celui de la Renaissance. Au milicu de cette mème place s'élève une fontaine surmontée d'un groupe remarquablement sculpté. Cette fontaine est un des seuls monuments du pays qui soient dignes d'attirer l'attention.

Intiernillos de San Vicente.

La vallée de San Vicente, anx environs immédiats de la ville, est très-bien cullivée, et les cours d'eau frâtche et limpide qui la sillonnent dans tous les sens contribuent beauconp à la puissance et à la beauté de la vógébation. Lorsque l'on quitte San Vicente pour gagner San Salvador, il suffil de s'écarter pendaul quelques heures de la grande route, dite camino real, pour rencontrer, à environ 2 lieues dans l'ouest de la ville, une remarquable manifestalion des phénomènes volcaniques. Au pied du volcan se trouve une sorte de dépression ou de ravin creusé dans les flancs mêmes de la montağne, et d'où l'on entend sortir une sorte de sifllement aigu, tandis que l'on perçoit en mème temps une violente odeur sulfureuse.

L'endroit précis où se trouve celle dépression est indiqué à une grande dislance par le nuagoe de vapẹr qui s'en dégage, el, à mesure que l'on s'approche, on entend un bruit de plus en plus fort, tout à fait comparable à celui de la vapeur sorlant d'une chaudière à haute pression. Cet intéressant phénomène, dont il sera question plus loin avec détail, se manifeste principalement sous la forme de jels de vapeur qui s'échappent avec violence des fissures du rocher et pénètrent le sol enviromant de telle manière que les eaux des sources du voisinage sont 
DANS LES RÉPUBLIQUES DE GUATEMALA E'T DE SALVADOR.

considérablement échauffées par leur contact. Les indigènes, dans leur langage pittoresque el imagé, désignent l'ensemble de ces phénomènes par le mol d'infiernillos (pelits enfers), qui dépeint les choses mieux qu’il ne les explique; lont ce que nous dirons, c'est qu'il est à regretter qu'on ne puisse mieux utiliser ces Paux thermales et sulfureuses, qui alimenteraient facilement plusieurs immenses établissements. Les labbitants du pays ont déjì reconnu la valeur de ces eanx au point de vue pathologique, et ils viemnent fréquemment lemr demander la gonérison d'affections rhumatismales cl autres; ils sont souvent arrètés toutefois par' les difficultés natériclles qui se présentent, car la nature seule a créć ces piscines d'ean Jienfaisante, et la main de J'homme n’a encore rien tenté pour en améliorer la disposition.

Lin quiltant les infiernillos pour rejoindre la route de la capitale, el ì 5 lienes au deli de San Vicente, on traverse, un immense ravin, au fond duquel coule le rio de Jiboa, quí nous rappela les barrancas ${ }^{(1)}$ si pilloresques de la roule de Colima, au Mexique, el en particulier la barranca dite de Beltram. De l'aulre côté de ce ravin, la route s'élève en serpentant sur le flanc de collines plus ou moins escarpées, ef devient sensiblement meilleure à mesure que l'on approche de Cojulepeque; il faut dire, à la vérilé, que la ville que nous venons de ciler a 'nl l'honneur, après la ruine de San Salvador, de devenir pendant quelque temps le siége du gouvernement de la république, et que l'on s'étail empressé de créer, aux abords de cette capitale par intérim, quelques kilomètres de roule plus 011 moins carrossable.

Cojutepeque, à 8 lieues de San Vicente, est comme juché sur une bande de terres: Gojutepenut. étroite, qui sépare d'une manière brusque la zone tempérée des terres claudes dı côtri de l'océan Pacifique, el s'abaisse en pentes donces sur le revers opposé. Nous arrivons donc ici en pleine terre tempérée, el les habitanits de Jiboa, grrande harienda située à 3 lieues de là, qui sont en rapports continuels avec ceux de Corjutepeqne, se plaignent de la transition brusque de température; Cojutepequr est regardé parmi eux comme une localité froide, el il est vrai de dire que,

1) Les barrancas du Mexique sout d'inmenses ravins profonds et étroils, dont on n'aperçoit quelquefois l'existence qu'at moment de les traverser. Ces barrancas du
Mexique portent, dans l'Amérique centrale, le nom de barrancos. 
landis qu'à Jiboa le thermomètre marquail, à 1 lıeure après midi, à l'ombre, $32^{\circ} 5$, ̀̀ Cojutepeque, à 5 heures, nous n'avions plus que $25^{\circ}$. Cette petite ville ue présente rien de bien remarquable el mériterail à peine d'ètre citée; cependant elle a acquis, depuis quelques années, une certaine inportance par son indıstrie. ou plutôt par l'industric particulière qui s'y concentre. C'est là, en elleel, qu'on fabrique la plıts grande partie des cigares qui sont confectionnés avec le tabac du pays. Malheureusement, malgré la valeur du tabac qu'on emploie, on est encore toin de la perfection sous le rapport de la fabrication, el ces cigares sont de qualité assez inférieure. Leur prix varie de 5 o à 15 o francs le mille.

Lax d'liopango. La ville de Cojutepeque est dominée par une colline volcanique d'environ 200 mètres d'élévation, du sommet de laquelle on a une vue ravissante sur les environs. C'est lì que nous nous trouvàmes pour la première fois en vue du lac: d'Ilopango, qui est profondément encaissé entre des falaises abruptes et cependant couvertes, en certains points, de la plus splendide végétalion. Cie lac, de 5 ou 6 lieues de largenenr, au milieu de ce pays si pittoresque et si découpé, rappelle assez bien cerlains lacs de la Suisse; ses eaux sont d'un bleu peut-être plus intense el d'uno limpidité parfaite; il est parsemé çà et là d'îles verdoyantes, sur lesquelles planent. encore de mystérieuses légendes. A certains montents de l'année, racontent ces légrendes, au milieu de la unit, une foule de barques ghlisseut en silence sur les eaux tranquilles du lac, se rendant toutes d'un commun accord dans la plus grande des ìles, à l'une des extrémilés; et là, dit toujours la légende, on offre en sacrifice, nous ne savons trop à quelle divinité sangotante des temps passés, une victime’ lummaine, un enfant de trois ou quatre ans, désigné par le sort. Nous iognorons jusqu’à quel point il faut ajouter foi à ce que l'on nous a raconté à cet égard; lonjours est-il que les riverains du lac sont tous des Indiens de race pure se livrant exclusivement à la pêche, et qui, tout en professant ouvertement la religoiou catholique, ont conservé une foule de leurs praliques païennes. Si les sacrifices hunains doul nous avons parlé n’ont lieu que dans l’imagination des clıroniqueurs, ces réunions nocturnes n'en existent pas moins, et iudiquent certainenıent que, malģré les efforts des missionnaires, le paganisme conserve encore de profondes racines chez ces populations inculles et barbares.

Vallée

de San Salvalor.

En quittant Cojulepeque, nous longeons, pendant 4 ou 5 lienes, les falaises 
DANS LES RÉPUBLIQUES DE GUATLMALA ET DE SALVADOR.

qui dominent le lac d'Hopango, ayant constamment sous les yeux le paysage admirable qui s'était offert pour la première fois à nos regards au sommel de la colline volcanique dont nous avons fait mention, et, en 5 heures de marche, nous atleignons le village de San Martin, à l'entrée de la vallée de San Salvador, ou plutôt, pour lui restituer son vérituble nom, de la vallée de Cuscutlan. Gelte expression, qui, si elle n'est pas aztèque, a, du moins, bien do l'analog̣ie avec les dénouninalions du plateau de l'Anahuac, signifie, dit-on, vallée des hamacs. Ce nom pittoresque et terrible lout à la fois nous rappelle que la vallée de San Salvador est sujette à de fréquents mouvements d'oscillation, à de violents tremblements de lerre, qui, dans certains cas, comme nous le verrons tont à l'heure, acquièrent une intensité effrayante. Les plus anciennes chroniques les mentionnent déjà, el il ne parait pas que l'on doive les considérer comme en voie de décroissance, car quelque temps après nolre passage, au mois d'aviil on de mai 1867 , beancoup de. maisons de San Salvidor et des environs ont été renversées.

Quoi qu’il en soit, nous pénétrons dans eelle riante vallée, et nous avous peinc a déconvirir la ville elle-même an milieu de la végétation qui l'entoure; aucuu édifice no l’indique de loin; ils onil tous, lıélas! élé réduits en poussière pendant le dernier tremblement do lerre, el nous étions déjà depuris longtemps dans les rues de San Salvador, sans nous douler que uons parcourious une capitale. A claque pas on voil une maison menaçant ruine, les butrs sont lézardés, el les pans de muraille de la maison voisine n’unt point encore été relevés.

Pour donner une idée de la violence des tremblements de terre dans celle partie de l'Amérique, nons reproduirons ici la relation du journal officiel de la localité, relation écrite quelques jours après le tremblement de terre qui détruisit San Salvador, au commencement de 1854 .

\section{EXTRATT DU ROLETIN EXTRAORDINARIO DEL GOBIERMO DEL SALIADOR DU 2 MAI 1854.}

* La nuit du 16 avril 1854 restera toujours prolondément gravée dans lia mémoire des habilants de San Salvador. Dans celle nuil terrible, nolre capilale, si henrense et si belle, devint un monceau de ruiues. Dès le jeudi saint, 13 arrit. on ressentit quelques faibles secousses, précédées par un bruil sourd comparable an roulement produit par une pesante artillerie sur mure lonte pavée, nut an gron- 
dement du tonnerre. Les habitants furent un peu alarmés par ce phénomène, mais ils se rendirent néanmoins en foule dans les égolises pour célébrer la solennité du jour. Le samedi tout étail calme, la confiance commencail à renaitre, et tous les habitants du voisinage étaient assemblés pour les fètes de Pàques. La nuit de samedi fut tranquille, et le jour du dimanche également; la chaleur, à la vérité, était intense, mais l'atmosphère était calme, et le ciel serein. Dans les premières heures de la soirée, il ne survint rien d'extraordinaire, mais, à neuf heures et demie, une forte secousse de trembiement de terre précédée des bruits accoulumés répandil l'alarme dans la cité. Beaucoup de familles abandonnèrent leur demeure el vimrén camper au milieu de la ville, tandis que d'autres faisaicnt leurs préparatils pour passer la nuit dans les cours intérieures de leurs luabitations. Enfin, à onze heures moins quelques minutes, sans avertissement d'ancune sorte, la terre commença à Irembler d'une manière si violente et si continue, que, dans l'espace de dix secondes, la ville entière s'écroula... Les craquements non interrompus des églises et des autres édifices qui tombaient arrivaient aux oreilles des habilants terrifiés, et la poussière s'élevant de ces monceaux de ruines reudait encore plus intense' l'obscurité de la nuit. On était enveloppé de toutes parts par cette poussière, et c'est à peine si l'on pouvait se procurer de l'eau pour empècher la sufiocation, car Ins fontaines étaient ensevelies, et les puits presque desséchés.

« Le clocher de la calhédrale avait entrainé dans sa ruine une gorande partie de cet édifice, qui s'était ćcrouté. Les tours de l’église de San Francisco étaient tombées sur l'évèché; l'église de Santo Domingo avait enseveli sous un amas de décombres le collége de l'Assomption, qui élait entièrement détruit. L’Université, qu'on venait à peine de reconstruire, n'était plus qu'un monceau de ruines. Quelques maisons particulières avaient seules résisté, el toutes avaient été rendues inhabitables; on remarquait mème que, si quelques-unes avaient échappé à cefte immense catastrophe, c'était surtoul parmi les plus anciennes, car lous les bâliments nouvellement construits étaient en ruines.

"Ce malheur avait eu licu, comme nous l'avons dit, daus l'espace de dix secondes, car, malgré le nombre el la violence des secousses qui suivirent les premières, leurs effets furent moins désastreux par cela seul qu'il ue restait plus que peu de dommage à causer. 
DANS LES RÉPUBLIQUES DE GUATEMALA ET DE SALVADOR.

"Cet inslant ćlait vraiment terrible et solemel : une nuit profondément obscure, tout un peuple rassemblé sur les places publiques et le front dans la poussière, priant et demandant gràce, les cris et les voix plaintives des blessés el đes agơ nisants, les désespoirs de ceux qui appelaient, au milicu des décombres, leurs parents el leurs amis. Une atmosphère d'une opacité de mauvaise atgure, une snccession de secousses et d'oscillations rapides causant une terreur indescriplible. une vive odeur sulfureuse remplissant l'air et annonçant une éruption prochinine du volcan, les rues remplies de ruines, encombrées de pans de murailles el dre débris de toute sorte, un épais nuage de poussière rendant la respiration presque impossible, tel était l'horrible spectacle qu'offrait celte malhenreuse cité, pendanl cette nuit funchbre el à jamais mémorable.

*Une centaine de jeunes gens et d'enfants faillirent ètre écrasés par l'écroulenent du collége, les blessés encombraient l'hôpilal, et cependant ce ne fut qu'aprè̀s quelques moments de réflexion que l'on puljigger de la grandeur de celle calastrophe. Le gouvernement fit tout ce qu'il étail possible pour se rendre compte anssitôt de l'étendue du désastre el calmer l'esprit public. On trouva ainsi que le nombre des victimes ćtail bien plus faible cqu'on ne l'avait d'aloord supposé, d maintenant il est à peu près certain qu'il n'y eut grè̀re plus de 100 personnes Lućes et 15 o blessćes; parmi ces dernières, se trouvèrent l'évèque de Salvador. qui reçut une forte contusion ì la tète, et le président Duenias.

" Le tremblement de terre eut lieu heurcusement sans accompagrnement de pluie ni d'orage, de sorle que l'on retrouva les archives enterrées dans la poussiere. ainsi que beancoup de documents précieux, qui n’eussent pu être remplacés.

"Le sol est toujours en mourement ì l'heure qu'il est, douze jours après la forth secousse, el les habitants, craignant que l'emplacement mème de la cité ne virmne à disparaitre comme dans un gooffre, el redoulant d'être surpris, comnı Pompéi et Herculanum, par les pluies de cendres du volcan, se hâtent de se relirer emportant avec eux leurs dieux domestiques et les doux souvenirs de leur enfince. en s'écriant avec Virgile :

"Nos patriæ fines et dutcia linquimus arva."

On comprendra facilement qu'après une ruine aussi complète la ville de San 
Salvador ne présente pas, à première vue, an voyageur l'aspect d'une capitale, et, malgró l'intelligence, l'activilć el le bon vouloir du Gouvernement actuel, les travaux de reconslruction n’avancenl que lentement. Quelques mois après le désastre, beaucoup de familles, qui avaient cherché un refuge à Santa Técla, à 3 lieues de San Salvador, y résidaient encore, el, plus tard, on conçut l'idée d'y transporter le siége du Gouvernement, en donnant à la ville nouvelle le nom de Nueva San Salvador, qu'elle porte eucore quelquefois. Les rues sont déjà en partie tracées sur le terrain, quelques maisons ont été construites, mais on paraîl avoir abandonné ce projel. Pourquoi d'ailleurs cherclıer ì Santa Técla un abri contre des seconsses souterraines, qui ont lieu un peu dans loules les direclions, el peut-ètre aussi fréquemment dans cette dernière locilité qu’à San Salvador? On se trouve loujours à égale proximité du volcan, et peut-être même, jusqu’à un cerlain point, selail-on plus exposé à Santa T'écla qu'à Sau Salvador, car près de là s'élèvent deux ou trois cônes adventifs qui seraient les premiers à laneer une pluie de cendres, au cas où une éruption viendrait à éclater, el donneraient certainement quelque coulée de lave.

Siluation de San Salvador an pinint de vir politique.
La capilale actuctle est construite sur un petit plateau presque entièrement formé de pierres ponces el de scories volcaniques; elle est entourée d'une foule de ravins ou de crevasses, qui se sont formés successivement pendant les divers tremblements de lerre, el qui ont élé plus ou moins agrandis par le cours des eaux. Ces ravins lui servent de remparts naturels, et il n'y a pas bien longtemps encore, en 1863 , pendant la dernière guerre avec le Guatemala, ce ne fut qu'ì grand'peine que le président Carrera, qui commandait en personne l'armée gouatemalienne, put entrer dans San Salvador, qui n’était défendu que par quelques mauvaises pièces d'arlillerie.

Celle guerre avait pris naissance dans certains dissentiments exislant entre les partis au Salvador pendant la présidence du général Barrios, homme énerơique, d'un esprit libéral el éclairé, peut-être un peu trop ambilieux, el qui avail voulı irop rapidenent assurer au Salvador une certaine prépondérance sur les autres ÉLats de l'Amérique centrale. Les mécontents avaient appelé à łeur secours l'Indien Carrera, qui régnait en maître au Gualemala depuis plus de vingt ans, el qui saisit avec empressement cette occasion d'affirmer sa puissance. La mauvaise or- 
DANS LES RÉPUBLIQUES DE GUATEMALA ET DE SALVADOR.

ganisation des troupes, les finances restreintes, puis la trahison d'un clief de corps que nous ne nommerons pas, avec 8,000 hommes, amenèrent la défaite de Barrios, qui s'enfuil au Nicaragua. Livré plus tard au nouveau goouvernement du Salvador, il passa en conscil de guturre, et, comme on craignait encore qu'il ne suscitâl de nouveaux embarras, on le condamna ì mort. Nous avons vu les traces des balles et quelques goultes de sango contre les murs d’une clıpelle dépendant du cimetière où il fut fusillé. Il mourut en héros, et les vêtements qu’il portait ce jour-lì, distribués entre ses annis, devinrent comme les reliques d'ın martyr de la liberté. Oı nous pardonnera, nous l’espérons, cetle petite incursion dans le domaine de la politique, qui peut faire juger, à certains égards, du caraclère de cos populatious, el permel de constater, une fois de plus, la mobilité el la grande légò̀reté d'esprit de la plupart des races hispano-américaines.

Dans une des plus profondes vallées qui entourent San Salvador, on voit de magnififques bassins naturels, alimentés par des sources tièdes, dont les eaux, parrfaitement limpides, ne présentent pas de réactions chimiques remarquables. Ces eaux se réunissent toutes ensuite pour se jeter dans le rio Asclgualc, petil cours d'ean, qui, serpentant dans le ravin, y répand la fraìcheur en mème temps qu’il y apporte la fertilité. Un de nos compatrioles a parfaitement utilisé les bords de ce cours d'eau, et l'on pourrait se croire un instant transporté dans un jardin de la mère patrie, lorsqu'on admire la variélé des fruits et des légumes de nos climats tempérés, qu’il est parvenu à faire croìlre sous le ciel des tropiques.

Le climat de San Salvador permet, du reste, ainsi que nous l'avons vu, presque toules les cultures, sauf celles du blé, de l'orge el des autres céréales, qui ne se De liggrirultuse aux environs récoltent, sous les tropiques, qu'ì des altitudes dépassant 2,000 mètres, altitudes de San Salvador. que l'on ne trouve que rarement dans le pays dont nous nous occupons. Les habitants se sont adonnés surtout à la culture de l’indigo, et à celle du café, qui leur présente tes résultats les plus satisfaisants. La camne à sucre, qui n'est exploilée que dans la région supéricure de la bande élroite longeant la mor et portant te nom de Terres Chaudes, a élé un peu négligée dans les dernières années, cal la consommation du pays n'est pas suffisante pour l'écoulement des sucreries importantes, et les moyens d'exportation font souvent défaut; ajoutons encore à cela que le bénéfice du petit producteur de sucre est faible, et ne suffit pas 
souvent à convrir les frais d'établissement qu'entraîne la moindre plantation de cannes.

Un produit qui devient de jour en jour l'objet d'un commerce plus important, est une sorle de résine liquide, appelée depuis de longues années baume du Pérou, el qui se recucille à la Cosla del Balsamo, sur un espace d'environ 30 lieues de longueur el 10 à 12 lieues de largeur, entre le port de la Libertad et celui d'Acajutla, le long de l'océan Pacifique. Ce produil porte le nom de baume du Pérou. par la raison qu'au temps où le Salvador faisait partie de la capitainerie gónérale de Guatemala sons la domination espagnole, les pelites goëlettes qui venaient. charger le long de la côte transportaient ce produit dans les ports du l'éron, d'où les galions espagnols le conduisaient en Europe. Les Indiens seuls sont exercés ì la récolte du baume, et ils sont, du reste, très-jaloux de leur expérience à cet égard; il est souvent difficile pour uı étranger do pénétrer dans les diverses localités qui sont des centres d'exploilation, el ce n'est qu'avee une sorte de réquisition officielle, émanant du Gouveruemeut central, réquisition qui u’est pas toujours bien accueillie par les caciques des villages, que l'on pent voyager dans l'intérieur du terriloire comnu sous le nom de Cóte du Baume.

Voici, d'ailleurs, en peu de mots, comment on récolte ce produit. On pratique plusicurs incisions profondes daus le tronc de l'arbre dit myroxylon perniferum, on y insère des lambeaux d'étoffe de coton ou de laine, et, après les y avoir laissés séjourner plus ou moins longtemps, suivant la profondeur de l'incision el la vigueur de l'arhre choisi, on les retire impréónés de baume, pour les placer dans des hassins ou chandières remplies d'eau, où on les soumel à une température modérée. Le baume, sous l'ạction de la chaleur, esi séparé du colou qui l'a absorbé, il monte à la surlace de l'cau, à cause de sa faible densité; on l'écume alors. on le recueille dans des calebasses, puis on l'enferme dans des vases bien bouchés, et on l'expédie sur San Salvador, d'où il gagne l'Europe. L'arbre qui le fournit est, comme nous le disions, le myroxylon peruilerum; son bois, d'une lexture fine, un peu veiné de rouge, a de l'analogic avec le mahogany (acajou), it est susceptible d'un beau poli, et conserve pendant assez longlemps une odeur fiue et agréable. Les habitants de la Côte du Baume sonl, d'après Herrera et luarros, célèbre 
les anciens habitants du plateau de l'Analuac. Les historiens ne sont pas d'accord sur la question de savoir si les habitants de la vallée de Mexico sont aborigènes de localilés plus méridionales, ou bien si ce sont les Aztèques qui, dans leurs mighàlions, sont venus habiter ces côles de l'océan Pacifique; il ne nous apparlient mullement de décider quoi que ce soit à cet égard, mais nous croyous qu’il est intéressant de faire connaître les mours el les contumes de ces Indiens, qui ont conservé dans leur purelé prinilive presque tous leurs antiques usages.

Leur's villages sont généralement silués sur les sommets d'une langée de collines el d'ondulations boisées qui bordent l'océan Pacifique. Les habilations dos indigènes sont construites en banbous el couvertes en jonc on en fenillos de concotier. Les églises senles ont des toits converts on tniles. Ces édilices occupenl ordinairement te point culminant de ta colline sur laquelle est bati le villagge. Celte disposition est fréquente chez les Indiens d'ancienne race mexicaine; nous uous rappelons en effel avoir souvent remarqué des constructions analogues sur le grand platean mexicain, et en particulier an milieu de ruines intéressantes, siLuées non loin de la ville de Pérole, dans une localité qui dépend acluellement de la hacienda de Tenixtepetl. Le plus grand des villages de la Côte du Baume renlerme environ 1,500 ì 1,800 habilants; pen d'entre eux savent lire et écrire, mais jls ont fail néanmoins quelques progrè̀s sous le rapport de l'instruction depuis la déclaration de l'indépendance de ces colonies espaguoles.

D'après Squiess ${ }^{(1)}$, les arts industriels soul, en général, pen en houneur parmi ces populations, et elles sont tout à liait ignomantes des boanx-arts. La musique, tontefois, a quelque attrait pour elles. Les Indiens professent pour la plupart li religion ratholique, mais sans avoir une idée bien netle des principaux dogomes de cette religion, ol ils mèlent aux cérémonies de l'Égólise une foule de lenrs anciens rites païens. Leurs besoins sont très-limités. Les femmes sont vêtues d'uur sorte de jupon en étoffe de colon qu'elles tissent elles-mêmes, et sont nues jusqu’à liı ceinture. Elles parlagent leurs cheveux en deux longues tresses, qu'clles entomrenl de rubans rouges ou de nuance un peu criarde, el s'en font une sorte de diadèmo autour de la têle. Les hommes portent un pantalon très-large également en colon

\footnotetext{
(2) Sifuicrs, Notes on Central dmerica, etc. London $18 ; 6$.
} 
fahriqué sur place; ce pantalon, avec un chapeau de paille à bords plus ou moins larges, constitue tout Jeur costume.

Le mariage est regardé, chez les Indicns, comme un engagement civil et un sacrement religieux, ainsi que dans le reste du pays, mais il est précédé de cérémonies particulières. Aussitôt que les jeunes garçons atteiģnent l'àge de quatorze ans, et que les jeunes filles ont seulement douze ans, leurs parents les fiancent sans consulter leurs inclinations muluelles, ct quelquefois même en les combatlant énergiquement. Après la cérémonic des fiancailles, le père du jeune homme prend la jeune fille chez lui, et il est obligóé de l'élever comme si elle était son propre enfant. Les deux jennes gens lui doivent leurs services, mais, quand on suppose que le jeunc couple est capable de se soutenir de lui-même, les parents lui construisent une maison à frais communs, et lui donncnt les moyens de s'élancer seul dans les senticrs de la vie.

Il n'est pas rare de voir parmi ces Indiens une famille de trois générations, dont les membres, tous mariés, vivent sous le même toit et dépendent du parent le plus àgé. Ils out un respect très-profond, non-seulement pour leurs parents ou pour les autorités civiles, mais cncore pour les vicillards, dans leurs relations publiques ou privées. Ils désignent ces persomnes respectables par le nom général d'ahuales (aïeux). Ce litre est conféré seulement à ceux qui, àgés de plus de quarante ans, ont occupé des fonctions publiques, se sont distimgués dans une circonslance quelconque, ou jouissent d'une rare capacité. Le rang plus ou moins élevé de ces persomnages est strictement observé parmi eux.

Ostensiblement, leur code est le mème que celui de l'État, mais, en réalité, ils ont des lois qui leur sont propres pour les décisions qu’ils rendent, soit daus les procès civils, soit daus les aflaires criminelles. L'habilude et le bon sens sont leurs seuls guides dans leur procédure. Ils ont souvent des réunions qui ont licu pendant la nuit, de sept heures à minuit et même plus tard, si cela est nécessaire. Le cabildo (maison municipale) est ćclairé par un immense feu de bois sec enduit de résine, placé à un de ses angles. Là, le peuple assemblé, la tête découverte, écoute et observe ensuite respectueusement les décisions des autorités.

Leurs connaissances agoricoles ne s'étendent pas au delà de la culture du maïs, dont ils ont besoin pour leur subsistance, et ils concentrent tous leurs efforts sur 
DANS LES RÉPUBLIQUES DE GUATEMALA ET DE SALVADOR, 21 la récolte du baume. Au physique, ces Indiens ont des traits plus anguleux el plus durs que les autres races du Guatemala el du Nicaragua; ils sont aussi moins bien conformés, ont la peau plus noire, sont plus tacilurnes, el en apparence moins intelligents. Leurs femmes sont beaucoup plus petiles que celles des Indiens des autres nations, généralement laides, et même presque hideuses à un àgge avancé.

Outre les trois produits importants, l'indigo, le café el te baume, les trabilants du Salvador cullivent encore, ainsi que nous te disions plus haut, le sucre, puis

De layricoilture daus la république de Silvador. le tabac, le caoulchouc, le cacao, la vanille, le coton, et enfin le maïs el le laricol (frijol), dont ils font pour la plupart leur principale nourrilure.

Les plantations de canne les plus importantes se trouvent dans les envirous d'Aluachapam, dans une immense vallée, d'où l'on lire chaque année envirou 230,000 kilogrammes de sucre.

Le tabac, qui croil surtout dans le districl d'Istepeque, est malheureusement récoltć d'une manière défectueuse, el, sans pouvoir atteindre l'arome et la délicatesse du tabac de la Vuella de abajo dans l'íle de Cuba, il est pourtant d'une qualité relativement bonne. On en exporte une assez grande quantité dims les Élals voisins, et c'est un des principaux oljets de contrebande dans le Guatemala el to Honduras, qui ont élabli de forts impôts sur cel objel de cousonımation.

La cochenille n'a pas, jusqu’ici, donné dans le Salvador les résultats vraiment merveilleux obtenus au Guatemala, et la culture du nopal s'en est naturellemenl beaucoup ressentie.

Quant au coton, on a fait plusieurs essais qui presque lous ont été pen liructueux, et ont entraîné plus ou moins la ruine des planteurs qui les avaient tentés. Au moment où la guerre entre les Étals du sud el ceux du nord sévissait dans l'Union américaine, on renouvela les essais sur une plus grande échelle, mais tonjour's avec le mème insuccès. Le défaut d'expérience, le sol peul-ètre trop riche al trop sec pour celle culture, la lempérature peul-être trop élevée el diverses alutres causes encore, parmi lesquelles il faut ciler les écureuils, qui dévastent les plantations pour s'emparer des graines, dont ils sont très-friands, et les chenilles, dont on iơonorait les moyens pratiques de se débarrasser, ont malheureusement influé sur les récoltes, el l'on n'a, pour ainsi dire, rien retiré d'ćtablissements qui 
Cоминесе

d'iuportation

d'exporiation

du Solvalor. avaient coùté de forles sommes d'argent, de sorte qu'en définitive ta culture dı coton a été sensiblement délaissée. Mais il est imporlant de constater que les tentatives de culture en grand ont seules échoué, tandis que les petits champs de cotomniers soignés par les Indiens, d'après ta routine de teurs ancètres, ont contimué à donner des produits de quantité et de qualité constantes.

Les deux tableaux suivants, tirés de documents officiels insérés dans le Faro del Sciluador (1), peuvent donner nne idée du commerce de cette république pendant l'année 1865.

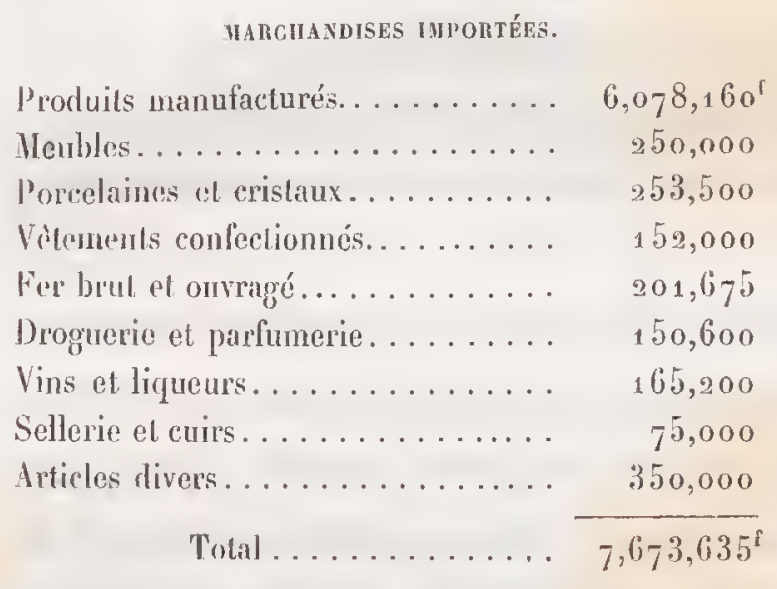

YARGIIANDISES EXPONTÉES.

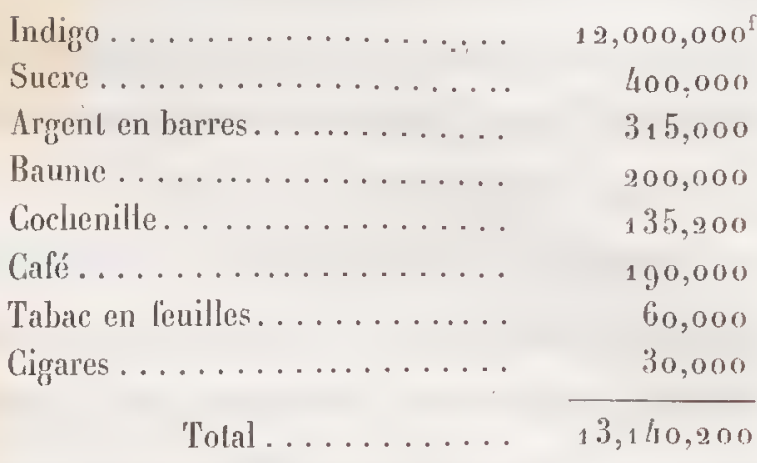

On voit donc, d'après ces chiflres, que l'indigo est en quelque sorte le principal et presque le scul objet d'exporlation dn pays, el que, si, par malheur, cette plants venail à manquer, la gorande majorité des habitants se trouverait dans la misère, tandis que, si lenr travail ou leur industrie se portaient simultanément sur plusieurs denrées ì exporter, la richesse publique en serait fort augrmentée. Nous devons avoucr cependant que le café commence à faire une sérieuse concurrence à l'indigo, el bientòt d'immenses plantalions de cet arbuste couvriront les versants tempérés du Pacifiqne of les plateaux peu élevés du centre du pays. Ce calé, vendu en Europe sous le nom de café de Costa-Rica, possède un arome ol nue saveur très-ippréciés, et, dans quelques années, l'Amérique centrale sera peut-ètre une des parlies du. monde oì, sur un espace donné, on cullivera le plus de calé.

Les finances du Salvador ont en grande partie pour base les droits de donane, qui varient de 18 à 50 p. o/o sur la valeur des marchandises importées. Le mo-

\footnotetext{
(1) Le Furn del Saltador est le journal ofliciel de la République.
} 
D INS LES RÉPUBLIQUES DE GLATEMILA ET DE SALVADOR.

nopole des tabaes et celni de l'ean-de-vie font aussi rentrer an trésor des somnes imporlantes; ce dernier cependant est quelquefois obéré, quoique le gouveruement ne fasse pas encore beaucoup pour l'entrelien des roules el pour les travanx publics en général. Le Salvador toulefois n'a pas de dette flotlante, et si, à certains moments, il n’était point forcé d'abandonner nue partie des impòls et dre créér. une sorte de papier rembonrsable sur les revenus des donanes dit vale, papien. pour lequel il paye de gros intérèts, les finances de l'Étal seraient dans la situation la plus prospère.

Linstruction publique a fail aussi de grands progrès depuis juclques années; l'Université de San Salvador est dans une situalion florissante, lre gonvernement

[1). l"iustruction puhlicipu ant Solualer. actuel y a appelé des protesseurs étrangers, parmi lesquels on rencontre des hommes assez dislingués, et le pays a aussi fourni son contiugenl d'hommes instruits. Les études secondaires sout poussées assez loin dans celte Université; il ur nous a pas paru toutefois que les jennes gens sorlant de cet ćlablissement fusserul ì la hauleur des élèves de rios lycées; quelques-uns cependant, douŕs d’iptitudes spéciales, seraient parfaitement rapables de subir les examens de bachelier soil pour les lellres, soil pour les sciences. L'Université de Sim Salvador est fréquentér par 140 jeunes gens environ, et c'est nu des principaux álablissennuls d'instruction secondaire de l'Imérigne centrale.

Les jeunes gens du Salvador qui fréquentent res ćroles sont, en général, intelligents; ils saisissent promptement ce qu'on leur enseigne, mais ils l'oublient d'ordinaire aussi promplement, car sonvent lis loggique ot le raisonnement lonl défaut dans ces esprits, peut-ètre un pen légers. Is ont beancoup de dispositions naturelles pour la nusique, le dessin et la peinture; malhemreusement, sons co rapport, ils ne recoivent pas un enseignement suffisant, car l'école centro-inuéricaine est encore à former, et les arlistes européens de quelque distinclion prétiorent rester dans leur pays.

Quant à l'instruction primaire, elle s'est beancoup répandue dans ces dernières années; presque chaque village a son école, plus ou moins liréquentée il est vrai. mais nous n'avons rencontré dans le Salvador' que bien pen do localités qui n’aient pas à poste fixe un instituleur, et une salle daus la maison municipale, uniquement destinée à l'édncation première des entauts. 
Climat he San Salvador.

Population de San Salvalor.

Khoul. Le San Salrador it Sonsonate.

Callojom del Gummonl.

Le climat de San Salvador est très-agréable et passe généralement pour être trèssain; il faut cependant avouer qu'au mois d'avril, époque à laquelle nous nous trouvions à San Salvador, la température est assez élevée au milieu du jour el dépasse souvent 28 ou $29^{\circ}$. Les soirées el les nuils sont fraîches, pas assez cependant pour auloriser l'usage des croisées vitrées, et l'on est habilué, comme dans nos colonies des Antilles, à n'avoir à la plupart des habitations d'autre fermeture qu'une sorle de fenctres avec un treillis de jonc ou de rolin, qui remplace les carreaux de vitres.

San Salvador, qui ne renferme aujourd'hui que 15,000 habitants environ, en contenait autrefois, avant le tremblement de terre de 1854 , de 25,000 à 30,000 , et occupait, avec Léon de Nicaragua, te second ranģ daus l'Amérique centrale. La population est génćralement composée de blaucs el de inélis, el c'est à peine si quelque Indien se montre sur la place le jour du marché. On remarque d'ailleurs peu de mouvement et peu de commerce dans la capitale; deux fois par mois, à l'arrivée du paquebot de Panama, l'animation semble renaîlre avec les nouvelles d'Europe et des Élats-Unis, puis tout relombe dans le calme habituel. Le trajet de San Salvador à l'océan Pacifique se fail en diligence; douze lieues séparent la capilale du port de la Liberlad où s'embarquent marchandises et passagers. Celte ville de la Liberlad, décorée du nom de port, possède, comme toules les villes de la côte, une immense rade ouverte à tous les vents, où le débarquement et l'embarquement sont très-difficiles à cause de la barre, qui, à cerlaines époques de l'année, aux équinoxes par exemple, est presque impralicable; souvent les marchandises sont noyées ou au moins très-avariées, dans le petil parcours du steamer à la côte.

En sortant de la capitale, el en avançant vers le nord-ouest, on rencontre environ à trois lieues, comme nous l'avons dit, le bourg de Santa Técla, qui est un peu plus élevé que San Salvador el jouit d'un climat tout à fait tempéré. On y remarque aujourd'hui de superbes plantations de café, qui s'étendent sur tout le platean de Santa T'écla jusqu'ì cette sorte de uuraille abrupte qui sépare brusquement la terre chaude de la terre tempérée. Nous avons à franchir cette muraille pour poursuivre notre route, et pour cela nous nous engageons dans un sentier dont la pente est effrayante, et qui, en certains points, est disposé de telle 
sorte, que le moindre faux pas peut entraîner tout d'un coup cheval et cavalier au fond d'un immense ravin, que nous atteignons cependant sans accident; au bas de la descente, le sentier se transforme en torrent, et c'est dans le lit de ce torrent qu'il faut continuer sa roule. Au premier abord, il paraît presque impossible de franchir les obstacles qui, de tous côtés, semblent s'amonceler sous les pas du voyageur; mais peu à peu il suit plus facilement le lit du torrent, et son altention est d'ailleurs vivement excitée par la ricliesse extraordinaire de la végétation qui couvre les flancs escarpés de ce ravin. A la base, les plantes aquatiques étalent leurs larges leuilles; un peu ant-dessus, de magnifiques fougères arborescentes, disposées capricieusement sur les pentes, laissent tomber leurs élégants rameaux qui viemnent presque plonger leurs extrémités fines et déliées jusque dans l'eau du torrent. Au-dessus encore, des arbres gigantesques au feuillage épais, tellement couverts de végétations parasites qu'on peut à peine distinguer leurs troncs, obscurcissent presque la lumière du soleil, si bien que, malgré l'ardeur du climat, on se trouve comme enveloppé dans une humidité tiède, exhalant les plus douces et les plus agrréables senteurs. Ce paysagoge véritablement féerique se continue ainsi pendant près d'une liene, et à chaque pas l'enivrement du premier moment ne fait que s'accroître. Il n'est pas besoin de dire que, pendant la saison des pluies, ce sentier, appelé Callejon del Guarumal, devient absolument impraticable; mais, au mois d'avril on de mai, malgré la profondeur du torrent en quelques points, et malgré les énormes quartiers de rocher's qui barrent le clıemin, on peut forl bien s'aventurer sur celte roule d'un nouveau genre, où la beaulé du site fait facilement oublier les dangers de la traversée. Il y a deux ans à peine il n'existait pas d'autre clımin entre San Salrador et Sonsonate, de sorte que les relations étaient forcément interrompues pendant la plus grande partie de l'hiver, c'est-à-dire pendant la saison des pluies. Dans ces derniers temps, après maintes enquêtes, le gouvernement a lait établir une nouvelle voie moins pittoresque que la première, nais plus sûre et plus utile.

Au delà du Guarumal, la route parcourt d'immenses forèts vierges, que l'ou commence à défricher en quelques endroits : c'est un spectacle curieux et triste

Défrichements dans les forêts virrges. tout à la fois que celui de ces grrandes forêts au moment où le défrichement est assez avancé et où il reste encore quelques troncs d'arbre à demi cousumés et 
presque entièrement noircis. L'incendic, en eflet, est le premier moyen employé pour pénétrer dans celte végétation si épaisse et si inextricable, que la haclıe pourrait à peine y frayer un cliemin; on met le fen aux quatre coins d'un espace qu'on essaye de circonscrire, et on laisse brûler ainsi jusqu'à ce que les flammes, ne trouvant plus d'aliments, s'éteignent d'elles-mêmes. Il reste encore, à ce momentlà, une assez grande quantité d'arbres debout, la terre est jonchée de cendres, et les végétaux qui ont brûlé au-dessus du sol conservent, dans la profondeur de la terre, de fortes racines, qu'on est obligé d'exlirper. C'est alors que commence le travail le plus long et le plus pénible, et il faut bicu des mois encore avant que la charrue puisse passer sur ces terres d'une incroyable fertilité, et avant que de belles récoltes de sucre el de café viennent lenir compte au planteur persévérant. de ses fatigues el de ses labeurs.

A mesure que ces défrichements ont lieu, les Indiens ou les ladinos ${ }^{(1)}$ qui concourent à cette opération construisent de petites huttes de bambou couvertes d'écorce de cocolier ou de feuilles de bananier, et forment ce qu'ils appellent des ranchos, ou des rancherias quand ces constructions sont plus nombreuses; tels sont, sur la roule que nous parcourons, les ranchos du Callejon, du Sitio, et la rancheria d'Ateos. Quelquefois, dans d'immenses espaces compris entre deux forèts, croissent de hautes herbes, an milieu desquelles paissent de nombreux troupeaux de bœul's, qui constituent tonle la richesse des habitants de ces ranchos; on a vu souvent mème plusieurs de ces animaux repasser presque à l'état sauvage lorsque depuis longtemps on ne les a pas réunis, et il faut alors faire des chasses suivies el quelquefois dangereuses pour les ramener dans l'enceinte où l'ou a l'habitude de les parquer.

Guaimoco. De la rancheria d'Ateos jusqu'au bourg de Guainıco nous traversons un pays boisé, faiblement ondulé, et nous trouvons à Guaimoco, à onze lieues de San Salvador, une gracieuse hospitalité chez un des principaux habitants de la localité, demeurant sur la grande place du village en face de l'église. Cet édifice, qui ne présente d'aillcurs rien de remarquable, atlira cependant nolre attention par une étrange particularité : une foule de perroquets au plumage d'un vert foncé,

1) On donne te nom général de ladiros, dans toute l'Amérique centrale, aux habitants de race croisée de blanc

et d'Indien, c'est-à-dire à ceux que nous désignons par l'expression de métis. 
DANS LES RÉPUBLIQUES DE GUATEMALA E'T DE SALVADOR.

qui semblaient venir chercher sur le monument leur gite pour la nuit, aiusi que le font les lirondelles dans nos climats, recouvraient le fronton el les corniches de la façade, à tel point que la maconnerie disparaissait presque sous ce rideau vivant.

A partir de Guaimoco nous descendons en pente douce toujours au milieu des forêts, et nous gragnons le grand village d'Izalco à six lieues plus loin. Déjà, depuis quelque temps, nous apercevions, à travers de haules fulaies, le volcan d'Izalco et son panache de fumée, qui dérobait encore à nos yeux la cime de la montagne presque toujours iucandescente. De la place principale d'Izalco on a devant soi un admirable panorama : landis que, d'un côté, le volcan se dresse, sombre el majestueux, de l'autre, une pente insensible, toute brillante de la végélation des terres chaudes, mollement fondue dans un léger voile de brume, s'enfuil jusqu'à l'océan Pacifique, dont les flots azurés viennent mourir doncement au pied des dermières ondulations de la Côte du Baume.

Iprès avoir contemplé ce maguifique spectacle, nos yeux se portèrent sur le volean, dont nous avions entendu parler déjà bien des fois; et, comne on nous avail dit que, jusqu'alors, aucun pied humain n'avait foulé sa cime presque toujours en feu, notre désir de réussir dans notre projet d'ascension n'en étail que plus vif. Nous prìmes donc lous les renseignements nécessaires, et, munis d'un guide, le lendemain à la pointe du jour nous étions en roule; ce ne ful que tard dans l'après-midi que nous atteignîmes un rancho dil Rancho del volcan, silué ì peu près à la hauteur du volcan lui-même el sur me sorte d'épaulement qui est séparé de la base du cone par un profond ravin. Cet épaulement est altcuant à une partie de la montagne sur le flanc de laquelle le volcan a pris naissance el qui porte le nom expressif de Madre del volcan (mère du volcan). Le rancho où nous étions arrivés est merveilleusement placé pour permettre d'observer ce qui se passe au sommet de la montagne pendant les éruptions, el, jusqu'ici, les habitants de cette cabane, quoique assez voisins du volcan, ont eu moins ì en souflipir que ceux de la plaine d'Izalco, siluée à une grande distance. Pendant la nuil, de sourdes détonations parvinrent de temps à autre à nos oreilles, on ne voyait pas de flammes, mais, le malin, une fumée épaisse sortail du cratère et l'on ue distinguail pas le sommel. Nous eùmes bientôt franchi les pentes dı ravin mentionné plus laaut, et nous nous trouvâmes à la base du cône, au milieu d'un amas 
énorme de laves et de scories noires, comparable à une mer faiblement agitée; la traversée de cel espace fut assez pénible, et plus d'une fois nos chaussures en lambeaux attestèrent combien élaient aigus et tranchants les angles de ces blocs plus ou moins vitrifiés. La coulée de lave paraissait toute récente, et la végétation, interrompue brusquement jadis par ce torrent de feu, n'avait pas encore eu le temps de donner de nouveaux rejetons. Au delà de ce fleuve immobile, nous arrivons dans une zone de cendres et de débris cinériformes uniformément répandus sur les flancs du cône, dont les peutes; d'ailleurs, sont excessivement roides. Le terrain, d'abord ferme sous les pieds, finit par devenir d'une mobilité désespérante, et ce n'est qu'après les plus grands efforts que nous parvenons à la cime. Peut-être aussi n'avions-nous pas suivi la route la plus facile, mais notre guide avait jugé bon de s'abstenir, el il nous serait difficile de rendre compte de la terreur qu'il avait éprouvée quand nous lui avions proposé de nous accompagner; un abîme se serail ouvert sous ses pas que sa fig̣ure, ordinairement impassible comme celle de tous les gens de sa race, n'eût pas pris si brusquement une telle expression de stupeur; bref nous avions pris le chemin le plus court, el le succès avait heureusement couromé nos effor's. Nous touchions donc de près ce volcan inconnu, au moins quant à son cratère, et nous parcourions en tous sens les bords du gouffre profond et presque insondable qui s'ouvrait devant nous; le sol qui nous porlait étail entièrement décomposé, brùlant en certains points, et de toutes parts sortaient des émanalions acides. De temps à autre nous étions obligés de nous retourner subitement du côté opposé à celui d'où venait le vent pour nous soustraire à la violence des émanations sulfureuses et arsenicales qui arrivaient en nuages épais, accompagnées d'un bruit sourd, semblable au roulement du tonnerre; mais nous ne voulons pas.insister davautage ici sur la description de cette curieuse montagne, qui sera étudiée plus loin dans tous ses délails. Après quelques heures passées au sommet du volcan, nous reprîmes le chemin d'Izalco, en nons dirigeant directement sur le village; dans la soirée du mème jour, sans nous arrêter à Izalco, nous entrions à Sonsonate, à deux lieues de là, assaillis par un orage épouvantable qui annoncait le commencement de la saison des pluies, dont le développement ne devait plus tarder beaucoup, car nous étions déjà à la fin d'avril. 
Sonsonate, dont le nom, en langage nahuat, signifie la Ville aux mille sources, est piltoresquement situé au fond d'une riante villée dont la végétation dépasse en richesse tout ce que nous avions vu jusqu'alors. Les fruits des jardins des cnvirons, les ananas en parliculier, ont une saveur exquise et alteignent des dimensions vraiment extraordinaires; le climat chaud et humide, la couche puissante de terre végétale, fertilisée encore par les cendres volcaniques el par les nombreux cours d'eau qui sillonnent la vallée, favorisent singulièrement le développement de toutes les cultures.

On arrive à Sonsouate au milieu d'une forèt de cocotiers et de palmiers qui s'étend presque jusqu'à la mer; ces grracieux végótaux, tantôt en formant un bois presque touffu, tantôt en s’isolant les uns des autres, domnent au paysage unc gaielé et une fraîcheur remarquables. La ville elle-même, en quelque sorte noyée dans la verdure, attire à peine l'attention el disparaît presque à côté des beautés naturelles qui l'environnent. Sonsonate, d'ailleurs, a beaucoup perdu de son ancienne splendeur. Du temps des Espagnols, celle ville jouait un rôle important par son commerce; elle était le principal marché de cacao el de baume de toute la côte, et, quoique située à six lieues de la mer, elle était presque considérée comme un port.

Les marchandises s'embarquaient comme aujourd'hui à Acajutla, qui se compose de quelques misérables hutles d'Indiens et d'un bâtiment destiné an capitaine de port, ainsi qu'à l'agent des douanes, et qui sert en mème temps d'entrepot aux Port d'Acajulla. Mode d'embarquement et marchandises soumises aux droits d'entrée. Là, comme à la Liberlad, la mer vient se briser sur les rochers, et trois lames successives défendent l'accès de la côte. On a voulu perfectionner le système employé jusqu’alors pour le débarquement des marchandises, et l'on a imaginé un appareil aussi dangereux qu'incommode. Qu'on se figure, en effet, une sorte de passerelle suspendue à sept ou huit nic̀tres audessus du niveau de la mer, relenue à terre par des câbles, et qui peut se soulever à volonté quand la mer devient grosse et menace de tout détruire. Deux poutres énormes dépassent de $1^{\mathrm{m}}, 50$ à 2 mètres environ l'extrémité de la passerelle el portent des poulies sur lesquelles passent des chaines munies d'un crochet. Un siége grossier, retenu par quelques cordes, sert à recevoir les passagers; quanl aux marchandises, une simple amarre permet de les fixer au crochet, et elles 
s'enlèvent à force de bras. Tel est le môle d'Acajulla dans toute sa simplicité. Souvent, quand les bateliers font une fausse manœuvre el que la barre est un peu haute, le malheureux passager qui ne saisit pas au. moment opportun le fauteuil qu'on lui présente ou la corde qui le soutient, est lancé avec violence contre les poutrelles, ou bien est précipité ì la mer; cel inconvénient est encore bien plus fréquent avec lẹs marchandises. Depuis longlemps on a projeté de remplacer cet appareil par un môle s'avançant davantage dans la lıute mer, mais, jusqu'ici, les bonnes résolulions du gouvernement à cet égard sont demeurées à l'état de projet.

La roule d'Acajutla ì Sonsonate s'avance au milieu des forêts et des plantations de cannes à sucre; la pente est presque insensible, aussi les eaux séjournent-elles longtemps dans les parties ombragées, "et il devient presque impossible de circuler pendant la saison des pluies. A la chule du jour, des myriades d'insectes phosphorescents sortent des grands bois et voltigent au milieu du chemin; gràce à cette étrange illumination, le voyageur peut encore diriger ses pas sans s'égarer' malgré le tracé un peu indécis de la route dans beaucoup d'endroits.

Les environs de Sonsonale sout très-piltoresques, et, malgré l'élévation de la température, la végétation, au lieu d'ètre chétive el rabougrie comme dans d'autres tocalilés situées en terre chaude, est, au contraire, dense el touffue gorâce aux caux pures et limpides qui sillonnent ce district. Nous cilerons en parliculier, parmi nos nombreux souvenirs, le village indien de Naholingo, dont les grands arbres et le frais ruisseau qui serpente au milien de splendides cacaoyers resteront toujours profondémenl gravés dans notre mémoire.

Route de Sunsonate à la frontière lı Guatemala. 1pancei.
Au sortir de Sonsonate, en se dirigeant vers Gualemala, on suit une route trèsaccidentén, peu carrossable, quoique très-fréquentée, et qui s'élève sur les contreforts d'un vaste plateau où les anciens Indiens Nahuatl avaient construit une ville fortifiée. Cette ville, qui portail le nom d'A paneca, n'est plus aujourd'hui qu'un misérable villagoge silué dans un climat froid, où loutes les cultures tropicales ont disparu el où l'on voil à peine quelques rares champs de maïs. On a découvert à Apaneca des tonbeaux anciens, des tumuli dans lesquels, parait-il, on a trouvé des ornements d'or et d'argent et des poteries ayant appartenı aux anciens abol'igènes, dont la trace n'est point encore tout à fait perdue, car bien souvent, sur notre route, il nous est arrivé de rencontrer des types indiens parfaitement ana- 
bANS LES RÉPUBLIQUES DE GUATEMALA ET DE SALVADOR.

logues à ceux que nous avions pu observer à la Côte du Baume. Leurs inceurs, uı peu antiques, n'ont point encore subi les effets de la civilisation qui les entoure, et, malgré de fréquents conlacts avec les populations espagnoles el créoles, ils sont restés tels que la conquête les avait trouvés. Apaneca occupe à peu près le point culminant du plateau qui sépare la vallée de Sonsonale de celle d'Mhuachapam, où nous descendons par une pente rapide.

Le village d'Ahuachapam est silué au pied des derniers contre-for's du massil" monlagneux qui donne naissance au volcan d'Izalco, et à l'une des extrémilés d'une Nhuachapam. les ausolps. riante vallée aussi fertile que bien cultivée. Nous élions surtoul appelés dans celle localité par le vif désir de visiter ce que l'on nomme dans le pays des ausoles, qui ne sont autre chose que des phénomènes volcaniques de la mêne nature que ecux que nous avions déjà observés à Chinameca et à San Vicente, el qui en diffèrent cependant par une intensité bien plus considérable el par quelques disposilious spéciales. Nous arrivions là, en effet, en face d'une plaine d'où jaillissent de tous còtés des jets de vapeur sulfureuse, où se forment des lacs boueux d'une asse\% grande élendue, el où s'élèvent des cônes de boue dont la formalion incessante a lieu sous les yeux du voyageur. Tous ces phénomènes concentrés dans une valléc de deux ou trois lieues de largeur sont du plus vif intérêt pour le gócologue. iussi passàmes-nous bien des heures à les élndier à lous les points de vue; le résultat de cette élude est consigné dans un chapitre spécial de notre onvrage. nous n'essayerons donc point, quant à présent, d'anticiper sur celle description.

Avant de quiller Ahuachapam, qui compte environ 2,500 habitauts tous ladinos, nous voulons témoigner ici combien nous avons élé charmés et reconnaissauls de l'accueil que nous y avons reçu el de la prévenance avec laquelle on s'est mis à

Huspilalit. des habitants du Salvador. notre disposition pour nous aider à alteindre le but de notre mission. Nous devous dire, du reste, que, pendant notre voyagoe à travers le Salvador, nous avons élé reçus parlout avec la plus grande bienveillance, el, chose bien rare de nos jours, presque partout on nous a offert l'hospitalité la plus gracieuse el la plus empressée.

Eir suivant cette belle vallée d'Ahuachapan, couverle, du côté dı sud, de vastes plantalions de cannes, el, du còté du nord-ouest, d'immenses prairies où paissent de nombreux troupeaux, nous avancions peu à peu vers la frontière de l'État de

in Pax. Fronlien dis Salvador at dur Gitatemnilit. 
Guatemala, qui est séparé du Salvador par le rio Paz. Nous franchissons un ravin profond, et nous sommes au bord de cette rivière, en face d'un gưé très-praticable en toute saison, à l'exception cependant du moment des très-fortes eaux, en septembre par exemple, quand les pluies torrentielles tombent sans interruplion pendant plusieurs jours consécutifs. Ces pluies de longue durée portent, daus te pays, le nom de temporales, et, quand elles sont violentes, elles entrainent des désastres incalculables; on a vu souvent, pendant ces époques fatales, de petits cours d'eau à peine perceptibles en temps ordinaire, devenir subilement des torrents impétueux qui balayent lout sur leur passage; tes plantations de toute nature, les grrands végétaux, les habilatious, sont emportés par le courant dévastateur, et rien ne peut opposer une barrière à l'envahissement des eaux; les voies de communication sont naturellement rompues par ces masses d'eau énormes, qui entrainent à leur suite lout ce qu'elles ont détruit. Tout le monde connait les affreux désastres causés dans nos Antilles par les ouragans, el nous avous souvent entendu comparẹr les temporales de l'Amérique centrale à ces mèmes ouragans.

District sud - est du Guatemala. Jalpatagua. Los Esclavos. Haciendas des Dominicains. Population de Zambos.
La rive Guatemalienne du rio Paz présente un singulier contrảste avec les riches vallées que nous venions de quitter; toul est sec, tout est aride, partout la roche à nu, une maigre végétation couvre les flancs des collines, en un mot la transition semble d'autant plus brusque qu'on peut difficilement en expliquer la cause. Le premier village que l'on rencontre dans le Guatemala est Jalpatagua, à 48 kilomètres d'Ahuachapam, et à 30 du rio Paz. Ce village esl, en grande partie, peuplé de ladinos et de métis de nègres el d'Indiens qu'on appeile zambos; la population s'élève à environ 800 âmes. Cette localité ne nous a frappés que par son apparence misérable et par le manque de ressources de toute nature; aussi bien le sol des environs n'est-il pas encore entièrement livré à la culture, et l'éloignement de la capitale, ainsi que les difficultés des communications, est pour beancoup dans cette siluation, qui n'est rien moins que florissante. Nous traversons après Jalpatagua un pays fortement accidenté, et peu varié d'aspect; ce ne sont que de vastes prairies un peu desséchées, dont la monotonie n'est interrompue que par de petits bouquets de bois; on y rencontre quelques habitants clairsemés, et leur mauvais vouloir à l'égard de l'étranger contraste singulièrement 
DANS LES RÉPUBLIQUES DE GUATEMALA ET DE SALVADOR. 33 avec la bienveillance de leurs voisins du Salvador. Nous nous élevons ì une grrande lauteur au-dessus du niveau de la ner au hameau de l'Oratorio, puis nous redeseendons en pentes douces à travers d'immenses plantations de cammes à suere jusqu'au village de los Esclavos, célèbre autrefois par les belles propriélés ou haciendas appartenant aux Dominicains. C'est là, rn effet, que ces redigieux avaient établi les grandes cultures importées des Antilles, el, pour pousser encore plus loiu l'analogie avec les plantalions de la riche île de Cuba, ils y avaient amené avec eux ume? nombreuse population de nègres. Ces nègores se sont alliés aux labilants de la localité, el, quoique aujourd'hui on n’en tronve plus trace, presque tous les labilants sont zambos, c'est-à-dire quills ont pour la plupart du sang africain daus les veines. Le village de los Esclavos, dont te nom nous a conservé te souvenir de sal première origine, est traversé par une rivière porlant le mème non, qui, tantôt profondément encaissée, lanlôt tombant en largoses cascades, va ferliliser de ses caux les récentes plantations de calé que de tous côtés on vient d'établir.

On pressent déjà à los Esclavos les approches de la capitale, qui en est éloigonée de 15016 lieues, car le mouvement devient de plus en plus accentué sur la roule; mais il faut encore, pour y parvenir, s'élever à ume hauleur de 2,000 mèlıes entviron, sur des plateaux assez analogues à ceux de la Suisse; de temps en temps, les magnifiques bouquels de pins, les maisons isolées, les clocheltes des troupeaux, l'air frais et vif produisent une illısion complète, of l'on se croirait volontiers dins certains parages de l'Oberland.

I Cerro Redondo, à neuf lienes de Guatemalit, existe encore 111 convent do Dominicains; res religienx travaillent à la culture de trois ou quatre plantations immenses, dont le revenu suffit amplement ì teur entretien, cl lenr permet même de fournir des ressources aux convents de teur ordre élablis à Guatemala. Ce niest qu'à mue distance d'environ 2 lieues que l'on commence ì apercevoir la capilale, gracicusement assise dans une vallée large, profonde el sillonnée de toules parts d'immenses fissures. Les tours de la calléedrale et les dômes des édifices religicux a tirent de loin les regards du voyageur, et, à mesure qu’il s'approche, il découvre peu à peu au milieu de la verdure une ville dont la surface correspondrait, en France, à une population de 80,000 011 100,000 habilants. Gualemala on Quauhtemalan, suivant l'élynologie mexicaine, lut ainsi nommé

Cerro liedouto. Approrteses de lis capilatse.

Guatemila. 
par les Indiens Tlascalans qui avaient suivi Alvarado dans son voyage de conquètes. La capilale de l'État n'a pas été inaugurée dans l'emplacement qu'elle occupe aujourd'hui; ce ne fut qu'à la suile d'un concours de circonstances locales, de catastrophes affreuses, sur lesquelles, d'ailleurs, nous aurons à revenir, que les habiLants de l'Anligưu Guatemala résolurent de venir s'établir dans la vallée dile de las Vracas, en mémoire des premiers troupeanx de bétail introduits dans le pays, en 1529 , par Hector de la Barreda (I), officier de la suite d'Alvarado, auquel étail échı en partage, dans la répartition de toutes les terres, le terrain oì se trouve mainienant la Nueva Guatemala.

Aspect de la ville. Nature des halvitations.

Celte ville, régulièrement bàtie, à rues droites, tirées au cordeau, rappelle, par l'archilecture de ses édifices privés, la plupart des cités de l'Amérique centrale; les liabilations sont vastes, bien aćrées, et consistent, pour la plupart, en quatre corps de bàliment entourant une enceinte de forme carrée dite patio, au milien de laquelle on remarque généralement un bassin plus ou moins ornementé, suivant le luxe répandu dans le reste de l'habitation; ce bassin est alimenté par une eau assez fraìche et plus rarement pure, amenée à grands frais à Guatemala au moyen d'aqueducs. Aux quatre angles de celte cour sont disposés de petits parterres généralement peu fournis de fleurs; le sol et le climat de Guatentala sont cependant excessivement favorables à la vógétation, el nous avons vu entre autres certain jardin enrichi d'une des plus belles et des plus rares collections d'orchidées qui se puissent voir peut-être dans le monde entier. Un simple clayonnage à une légère distance du sol, ombragé par un caléier ou par quelque autre arbuste un peu feuillu, permet de reproduire par milliers ces plantes parasites, dont les fleurs délicates el àu mille nuances, embaument l'air des plus suaves parfums. La conr' intérieure de l'liabitation, enlourée d'une sorte de portique couvert, assez analogue à un cloìtre de couvent, donne accès dans tes appartements éclairés par

(1) "Pasando al Valle de las Vacas, es denotarse que esta fue la primera lıcienda de ganado vacuno que hubo en estos paises; pues siendo repartimiento de Hector de la Barreda, uno de los conquistarlores mas acreditados de este reyno; y viendo dicho caballero la falta de curne de vaca, fure se padecia on esta tierra, trajo a su costa de la isla de Guba cantitad de vacus, que puestas en este valle, fucron procreando y undtiplicandose, liasta abastecer el reyno de vacas y toros: y jor esta razon se llamo ef Valle de las Vacas. Consta del libro $2^{\circ}$ de Cabildos, que en el que se celebro a 20 de Julio de 1530 se acordo, que para la fiesta de Santiago se compre un toro del Hato de Barreda y se le den por el 25 presos de oro marcado de ley perlecta,n (Compendio de la Historia de la Ciudnd de Gratemala por Dosisco Jusnnos, t. 1I, 1. 35\%.) 
quelques baies qui prennent jour sur celte cour; trois on quatro fenc̀tres seutement sont ouvertes sur ta rue. Celte disposilion est hemreuse pour entretenir la fraîcheur dans les appartements, mais les pièces sont gééćralement sombres. On courprend facilement que ces liabitations occupent un vaste espace, et, comme la plupart servent de domicile à mne famille peu nombreuse, on se trompe aisément Jorsqu'on cherche à estimer la population de la ville d'après la surface reconverta: parr les coustructions. Aussi, comme nons le disions, Gualemala, qui paraît contonir près de 100,000 habilanls, u’en renferne en réalité que 50,000, d'après le dernier recensement effectué en 1865 . Nous n'avous vonlu parler ici lien entendu que des habitations de la partie aisée de la populalion; dans les faubonrogs, les labiliants sont bien plus condensés, et l'on passe par me lámsition presque iusensiblr de la demeure la plus luxueuse à la pauvre hulle de l'Indien. La grande majorilé des constructions n'ont qu'un rez-de-claussée, quelques aulres n’ont qu'un seul élagge, el il ne peut guc̀re en être autrement dans um pays où, chaqure annće, on éprouve vingt ou trente secousses de tremblements de terre.

Les édifices religieux abondent à Guatemala : on y compte près de 20 églisess, ḱdifires religirenr. dont 5 ou 6 seulement altirent l'altentión de l'élranger par leur architceture; nous ritcrons, en particulier, la cathédrale, qui n’est point encore aclıevéc, cl les églises des couvents de San Francisco et de la Merced. L'ornemenlation intérienre do cess éğlises est gónénealement lourde et de mauvais goûl, el, à part cincr ou six liableaux de grands inailres espagnols ou flamands et quelques seulptures, nous n'avons réen rencontré qui soit récllement arlistique. Les ódifices publics, le palais national, l'Université, efc. sont de grandes constructions basses, rectanguliaires, sins Io moindre luxe architectural, ce qui n'empèche pas les indigènes de lemr prodigruer le nom pompeux de palais.

La Sociedad economica de Guatemala, qui est en quelque sorte l'Académie dess sciences de ce petit État, a fait construire dernic̀rement un liôtel pour y lonir des séances, et donner asile aux écoles de dessin, de peinture el de sculpture, qu'ell. entretient; cet édifice nous paraîl peu cn larmonie avec le bul qu'on s'est proposé, car on a réservé peu de place pour les salles d'élnde, pour la bibliohlìque et les collections, tandis qu'on a beancoup développé la partie centrale dı bâtiment, oi se lieunent quelques rares séances mensuelles, ot qui a été singulièrenıent dé- 
lournée, du moins dans les derniers lemps, de sa première destination. Disons lout de suite cependant, à l'honneur de celle socićté, qu'elle compte dans son sein des hommes distingués, instruits, savants même, dont le plus vif désir est de contrihuer au développement intellectuel de leur patrie; nous avons eu souvent à nous louer de nos rapports avec ces hommes d'élite, qui, sans se préoccuper outre mesure des événements exlérieurs, travaillent de toules leurs forces et de tous leurs moyens à la transformation sociale d'un pays profondément bouleversé par 30 ans de guerre civile, et qui jouit depuis quelque temps seulement des toisirs de la paix, dont nous sommes certain qu'il saura profiter.

Les habilants de Guatemala, composés en grande partie de blancs el de mélis, ont un caractère doux et aflable; ils se renferment beaucoup dans leur intérienr el ont peu de prédilection pour la vie mondaine. Le calme est 'quelquefois effrayant dans celte ville, et, si de temps à autre on ne voyait pas sorlir d'un édifice quelque persomme errante, on pourrait croire, à certains moments de la journée, qu'on se promène dans les rues d'une ville antique et inhabilée, d'une nécropole dont les constructions sont encore debout. Le climal est bien pour quelque chose dans cette atonie générale qui semble régner à Gualemala. En elfet les molles douceurs d'un printemps perpéluel endorment facilement l'esprit et les sens; les jours, lonjours égaux, se suivent sans qu'on s'en aperçoive, et à peine une très-faible variation dans la lempérature fait-elle sentir le passage d'une saison à l'autre. L'industrie, le commerce, d'importantes transaclions avec l'Europe et les Étals-Unis, ont produit, dans ces derniers temps, un peu plus de mouvenrent dans cette capitale qui, autrefois, n'était troubléc dans sa somnolence que par le son des cloches des éçlises el des monastères appelant les fidèles à quelque Pète ou annonçant quelque procession. La fréquence des communications avec: l'Europe a ćté aussi pour beaucoup dans le réveil de la population de Guatemala. II y a dix ans à peine, deux ou trois goëlettes seulement venaient chaque année compléter leur chargement sur la côte du Pacifique, tandis que, aujourd'hui, un steaner de la Compagnie du Panama-Railroad vient deux fois par mois aborder à San Jose de Guatemala et défraye, pour quinze jours, par les nouvelles qu’il apporte, les deux ou trois journaux qui se publient dans le pays.

L'aspect général de la cilé, lorsqu'on la considère dans son ensemble du haul 
DANS LES RÉPUBLIQUES DE GUATEMALA ET DE SALVADOR. 37 d'une des collines qui la dominent, et en particulier de celle dite du Carmen, est cependant riant et agréable à l'œil. Dans le lointain s'élèvent deux pics immenses, se réunissant presque à lenr base, et dont la cime se détaclıe d'une manic̀re admirable dans un ciel toujours pur; l'un de ces pics est souvent couronné d'une auréole blanchâtre de fumcee, dont l'intensité est quelquefois un sujel d'eflroi pour les populations, mais, comme pour reposer la vue de ce spectacle grandiose, on a ì ses pieds Guatemala avec ses maisons blanches, ses dômes brillants, ses bcaux arbres et ses jardins lout en fleurs.

Sous le rapport du commerce el de l'industrie, l'Élat de Guatcmala n'oceupe que le troisième rang dans l'Amérique centrale, car les deux républiques de Costi-
Rica et de Salvador, proportionnellement à leur étendue, ont acquis nne bien plus grande importance.

Le Guatemala possède cependant trois ports, situés sur l'Allantique :

Santo Tomas de Castilla, un des plus beaux, des plus grands el des plus sùrs du monde;

Livingston, port de transit, à l'embonchure de la rivière d'Izabal;

Izabal, un peu dans l'intérieur des lerres et au bord du lac du mène nom, dit aussi golfo dulce; ce dernier est. seulement praticable pour les goëlettes, rar la barre de la rivière en défend l'entrée à des navires de fort lonnage.

Sur l'océan Pacifique on rencontre encore trois antres ports :

San Jose de Guatemala, San Luis el Champerico : ce sont des rades onvertes, où l'embarquement est difficile. Izabal et San Jose sont les deux ports importants de la République; le premier est silué à soixante ot dix lieues de la capitale, le second ì trente lienes seulement.

L’agriculture est singulièrement favorisée, à certains points de vuc, dans ce pays, par les saisons qui divisent l'année en deux parties bien distinctes, l'une sèche, Cunditions: de la production. dite été, et la seconde pluvieuse, dite hiver. Année commune, la saison sèche dure six mois, à compter du mois d'ochobre, el la saison des pluies dure pendant les six autres mois. Cependant, sur les côles, la saison des plıies se prolonge encore pendant les mois de novembre et de décembre. Pendant l'élé, l'ardeur du soleil paralyse la végélation, la nalure semble se reposer pour se réveiller au mois de février, el c'est alors que la population agricole se unet en monvemenl; c'est aussi

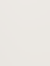


le moment où l'on sème, el la fertilité de cortains districts silués près des côtes est telle, que, pendant les six ou huil mois que dure la saison des pluies, on fail jusqu’ì trois el qualre récolles consécutives de maïs. Pour le reste du pays, les pluies suffisent aumplement à assurer les récoltes de céréules et fournissent assez d'lumidité au sol pour alimenter convenablement les plantes dont la croissance est de plus longue durée.

Un pays aussi lertile que le Guatemala devrail enguger nu grand nombre de ses habilants à se livrer aux travaux agricoles, el cependant, durant de longues années, la production a été réduite à la seule consommation intérieure, el la richesse publique en a considérablement soull'ert. Parmi les obstacles qui se sont opposés au progrès rapide du pays, les uns appartiennent à nṇe époque anlérienre à la déclaration de l'indépendance, d'autres sont postérieurs, et ils sont, à pen de chose près, comnums à la grande majorilé des pays liispano-américains.

L'Espagne ne permetlait aux sujets récemment soumis à son empire ni le libre exercice d'aucune grande industrie, ni la culture des produits qu'elle pouvaii envoyer de la Péninsule. Les ports de l'Amérique étaient fermés au commerce du monde entier, et fréquentés seulement par les galions qui, en échangege des oljets de première nécessité, qu'on livrait à des prix labuleux, emportaient des chargements énormes de mélaux précieux et de denrées coloniales.

Iprès l'indépendancé, la guerre civile a déchiré, pendant do longues années. ce malheureux pays, et l'agriculture, livrée seulement à des mains inhabiles, qui, se contentant de per, ne se donnaient pas la peine de défricher le sol, resta presque complélement stationnaire. Une fois qu'ou eut traversé ces époques de troubles, il se présenta encore des difficultés d'un nouvean genre.

Cochenills. La grande majorité des possesseurs de terrains se livra à la culture du nopal (cáchs opuntia), pour élever des cochenilles, qui avaient été apportées d'Oajaca dans l'Amrérique centrale, en 1818 , par le général Bustamante. Ce produit arcquil en peu de temps une si grande valeur, qu’il devint te seul objet de culture; i) défrayail, à hui seul, lout le commerce d'exportation du pays, et produisait, ì l'avantage de l'agriculteur et du commerçant, des bénéfices vraiment fabuleux. Pent. à peu cependant, les brillants avantages fournis par la culture du nopal commencèrent à diminuer, car l'arbre et l'insecte se virent tour à lour menacés dans leur 
DANS LES RÉPUBLIQUES DE GUATEMALA ET DE SALVADOR.

existence; puis deux ou trois années, où la saison des pluies ful d'une longueur démesurée, apportèrent aussi le trouble dans les récoltes. Les planteur's, momenlanément découragés, se rejetèrent sur le calé, dont les brillants débuls semblaient annoncer une nouvelle ère de prospérité, et la cochenille tomba bientòt au second rang, non sans avoir amené par ses fluctuations de nombrenses perturbations dans l'agriculture, dans le commerce el dans la richesse publique.

Le tableau ci-contre donnera une idée de la valeur de ce produil, pendint sat période d'accroissement el pendant celle de sa décroissance.

\begin{tabular}{|c|c|c|}
\hline I N NÉES. & $\begin{array}{l}\text { PRODUCTION } \\
\text { Dr. Lochexifus } \\
\text { estimé } \\
\text { en kilogrammes. }\end{array}$ & $\begin{array}{l}\text { VALEUR } \\
\text { en francs. }\end{array}$ \\
\hline 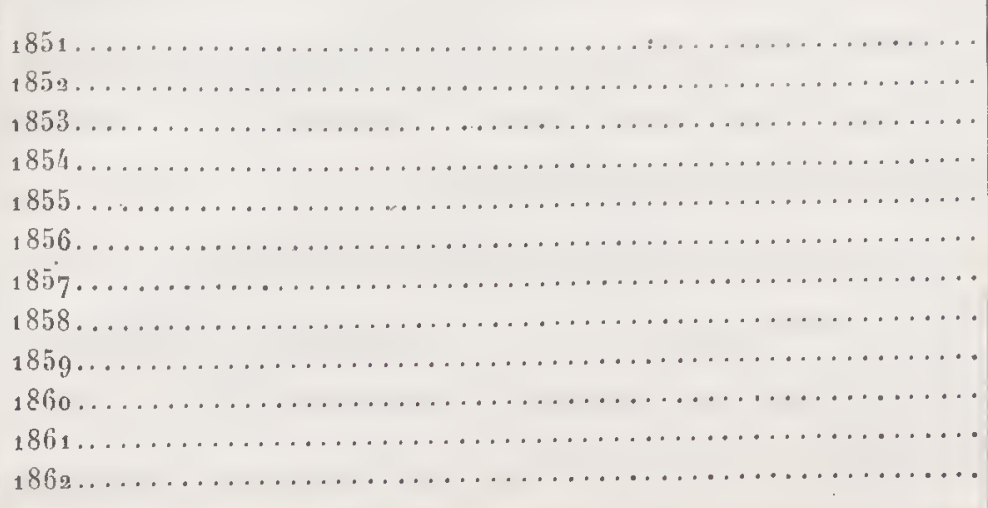 & $\begin{array}{r}1,020,550 \\
340,050 \\
166,775 \\
1,293,600 \\
605,180 \\
891,175 \\
735,070 \\
1,009,220 \\
893,235 \\
839,080 \\
779,890 \\
829,092\end{array}$ & $\begin{array}{l}6,159,900 \\
2,8110,650 \\
1,617,555 \\
8,786,500 \\
1,932,800 \\
6,906,200 \\
5,090,350 \\
7,650,200 \\
6,840,500 \\
6,470,000 \\
3,925,350 \\
4,200,600\end{array}$ \\
\hline
\end{tabular}

Moyenne de douze années:

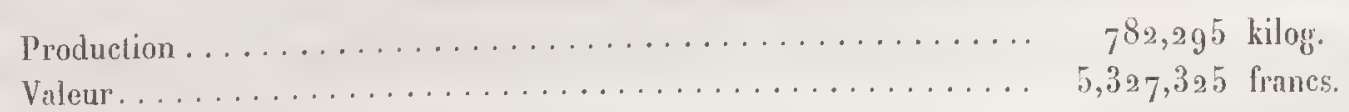

La cochenille est surtout recueillie dans les environs des villes de la Antigua of d'Amatitlan, et les terrains propres ì la culture du nopal y ont alteint des prix élevés. Cette récolte a lieu généralement dans le mois de mai, avant le commencement des fortes pluies, car un seul orage suffil quelquefois pour anéanlir le travail. de toule une année. Nous ajouterons ici quelgués délails relatils à la récolte de ce produit, telle qu'on la pratique encore à lis Antigua Guatemala. Lorsque les insectes ont atteiul, sur les leuilles du nopal qui les porte, une grosseur convenable, on phutôt quelque temps avant l'époque de la reproduclion, on coupe 
toutes les feuilles de l'arbuste, sur lesquelles on passe un balai de chiendent. Les insectes tombent dans des corbeilles d'osier, et le soir même on place toules les corbeilles dans une éluve à $40^{\circ}$ pour tuer les cochenilles; on les passe ensuite au ventilateur pour enlever les poussières et les corps étrangers, el on les rassemble dans des sacs recouverts de peaux de boufs pour les expédier en Europe. La cochenille, qui jouit de propriétés colorantes très-puissantes, a une grande valeur, prise sur place; après la récolte, elle vaut 75 piastres $(375$ francs $)$ Jes 5o kilogrammes. Malheureusement c'est un produit soumis à de grandes fluctuations : il suffit, comme nous le disions, d'un coup de vent, d'un orage, pour ruiner une plantation; aussi, malgrée les exemples de fortunes fabulenses créées par la cochenille, celte industrie est-elle de jour en jour plus délaissée.

Aujourd'hui, la culture du café a remplacé en quelques points celle du nopal, et a pris une extension considérable dans quatre ou cinq districts privilégoiés, à la Antigua Guatemala, par exemple, dans les environs d'Amatitlan, à Escuintla, sur tout le revers ouest du volcan d'Alitlan, dans la région tempérée siluée entre la ville de Qnezaltenango et la mer, et enfin dans la haute Vera Paz. Ce produit, qui, en 1856, n'élail exporté que pour une somme de 1,500 piastres ( $7,500 \mathrm{fr}$.) a été exporté, en 1866 , ponr la somme relativement énorme de 300,000 piastr'es (1,500,000 francs). Ce chiffre seul peul fixer les idćes sur l'extension prodigieuse donnéc à la culture de cet arbuste. Quoique nous ne possédions malheureusement pas les chiffres exacts de l'exportation dı café pour les deux dernières années, nous pouvons néanmoins affirmer que le nombre des planlations nouvellement inises en rapport ou en voie de créalion étant très-cousidérable, la produclion doit avoir au moins doublé depuis l'époque de notre voyagge.

Le sucre, pour des raisons semblables à celles que. nous avons rappelées en parcourant l'Étal de Salvador, ne paraît pas devoir suivre celte marche ascendante.

Nous avons, d'ailleurs, dressé ci-dessous un tableau des quatre principales denrées d'exportation, et on y verra immédiatement däns quelle voie de progrè̀s est entré, depuis une dizaine d'années, le pays dont nous nous occupons. 
DANS LES RÉPUBLIQUES DE GUATEMALA ET DE SALVADOR.

TABLEAU COMPARATIF DE QUELQUES PRODUITS agRiCOLES EXPORTÉS DU GUATEMALA.

\begin{tabular}{|c|c|c|c|c|c|c|c|c|}
\hline \multirow[t]{2}{*}{ PRODUITS. } & \multicolumn{8}{|c|}{ MMVÉES 1856-1865. } \\
\hline & 1856. & 1857. & 1858. & $185 \%$. & 1860. & 1861. & 1862. & 1865. \\
\hline 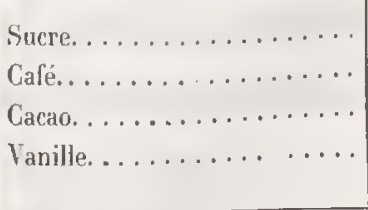 & $\begin{array}{r}27,500 \\
7,500 \\
2,700 \\
7,500\end{array}$ & $\begin{array}{r}311,390 \\
8,500 \\
17,000 \\
2,500\end{array}$ & $\begin{array}{r}504,200 \\
5,200 \\
1,100 \\
1,500\end{array}$ & $\begin{array}{r}315,700 \\
23,200 \\
1,200 \\
1,000\end{array}$ & $\begin{array}{r}.357,200 \\
78,200 \\
1,500 \\
1,000\end{array}$ & $\begin{array}{r}463,450 \\
250,600 \\
300 \\
1,000\end{array}$ & $\begin{array}{r}47,500 \\
6: 9,000 \\
3,700 \\
1,500\end{array}$ & $\begin{array}{r}300,000 \\
1,250,000 \\
4,500 \\
2,500\end{array}$ \\
\hline
\end{tabular}

Dans la seule année 1865 ,

Les importations ont été de.................. 8,500,000 francis

Les exportations, de....................... 10,000,000

Les droits sur les marchandises importées sont fort élevés, et il est difficile qu’il en soit autrement, car ils constituent, à peu de chose près, avec le monopole de l'eau-rle-vie el du labac, les seules ressources du trésor public, attendu qu'il est parfaitement impossible d'imposer la propriété foncière en l'absence de lout radastre.

Les linances, d'ailleurs, sont dans un état relativement prospère, car', de mène que le Salvador, te Guatemala ı'a pas de dette flotlaute; l'Élat est seulement obligé, daus cerlains cas, pour subvenir à ses dépenses, de créer des hons, payables sur les revemus des douanes, et pour tesquels il serl un intérêt de 10 à 15 p.o/o. Nous devons, du reste, ajouter que le taux ordinaire el moyen de l'argent, daus tout le pays, est 12 p. $0 / 0$.

L’instruction publique, au Guatemala, a suivi égalenent les progrès grénéraı accomplis dans le pays. L'Université de San Carlos, fondée en 1690 , est le seul établissement d'enseignement supérieur de toute l'Amérique rentrale; on y suil des cours de droit, de médecine ef de théologie, mais ils ne sont encore fréquentés que par un petil nombre d'élèves, généralement de race indiģène, ou plutôt issus de familles dans lesquelles le sang espagnol n'est pas sans mélangé. Dans les hautes classes de la société, les jeunes gens vont terminer leur éduca- 
lion en Europe, en Angleterre, en France ou en Allemagne; ils y trouvent l'intappréciable avantage de se familiariser avec les langues étrangères, et rapportent dans leur pays une sorte de vernis de civilisation européenne qu'on se plaìt à remarquer chez beaucoup d'entre eux.

La Sociélé économique, fondée en $179^{5}$, a traversé heureusement toutes les époques de trouble qui ont suivi cette dale; c'est une sorte d'académie qui lavorise surtout les beaux-arls, tout en s'occupant aussi, dans ses séances el daus ses publications mensuelles, des questions d'un. haut intérèt scientifique, social, industriel et même commercial. Ainsi que nous le disions plus haut, elle a appelé dans son sein un grand nombre d'intelligences supérieures, et si, pendant un certain laps de temps, elle n'a pas produit tout ce qu'ou pouvait attendre d'elle, il est de toute notoriété aujourd'luui que plusieur's de ses membres ont publié, et publient tous les jours, des mémoires du plus grand intérèt pour le pays.

A côté de ces deux établissements d'un ordre supérieur, on en distingue un antre qui rend peut-être encore de plus grands services, el qui est destiné à l'enseignement secondaire. Cet établissement, dit Collegio Tridentino, est sous la haule direction des pères Jésuites, dont l'influence ì Guatemala ne saụrait passer inaperçue. Le collége dont nous parlons reçoit une grande partie des jeunes gens des cinq Républiques de l'Amérique centrale, qui trouvent là un euseignement complet, soit au point de vue littéraire, soit au point de vue scientifique. Nous avons eu souvent l'occasion de visiter les collections d'histoire naturelle, le cabinet de physique, elc. de cet établissement, el nous devons dire, à la louange de ceux qui le dirigent, que ces accessoires indispensables de l'enseignement ne laissent riell à désirer.

Population. La population du Guatemala, d'après le recensement effectué en 1865 , s'élève à un total de 1,180,000 habitants, qui se répartissent comme il suil, dans les divers climats.

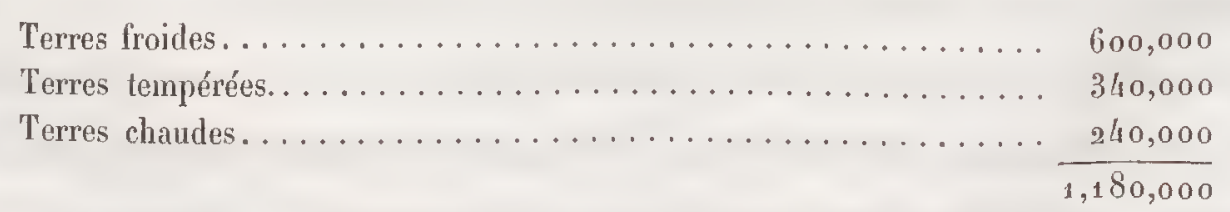

Au point de vue des races, cette population peut être répartie en quatre 


\section{DANS LES RÉPUBLIQUES DE GUATEMALA ET DE SALVADOR.}

mroupes principaux, dont les uns se rapportent à des races pures, les autres à des races mélangées. La race blanche et surlout la race cuivrée ont de nombreux représentants; leur mélange a produit les mélis ou ladinos, qui sont un des éléments importants de la population. Quant à la race noire pure, elle a presque absolument disparu; mais elle a laissé, comme trace de son passagee, quelques mulâtres, ot un grand nombre de métis de nègres el d'indiens dits Zambos.

Le tableau suivant établit à peu près la proportion de chacune de ces divisions dans le Guatemala.

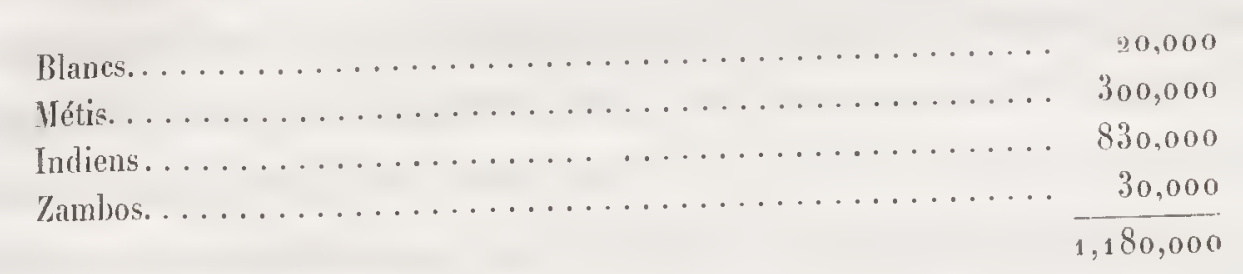

Relativement à la surface du Guatemala, la population est de :

$$
\begin{aligned}
& 1 \text { hahitant pour } 14 \text { hectares. } \\
& 7 \text { d } \mathrm{d}^{0} \text { pour } 1 \text { kilomètre carré. }
\end{aligned}
$$

landis qu'en France nous avons :

68 habilants pour 1 kilomètre carré.

Le Salvador est plus peuplé relativement que le Guatemala, on y comple :

1 habilant pour 9 heclares.

Aı Honduras, la population est moins condensée, on ne comple que :

1 habitant pour 22 hectares.

Notre première excursion, à notre arrivée dans le pays, eut pour but les trois volcans voisins de Guatemala : le volcan de Fuego, le volcan de Agna el le volcan de Pacaya. La station la plus favorable pour entreprendre l'ascension de ces montagnes est sans contredit la Antigua Guatemala, belle ville située à neuf' lienes de la capitale el au pied du volcan de Agua. On avait beancoup exagéré devant nous les difficultés insurmontables que nous devions rencontrer pour atleindre lit rime du volcan de Fuego pendant la saison pluvieuse, et cependant, après quelques hésilations, nous résolûmes de tenter l'aventure. Parfaitement secondés dans nos projets par plusieurs personnes de la Antigna Guatemala et des environs, ef 
en particulier par un planteur anglais, morl aujourd'hui, D. Thomas Wyld, il nous fut facile d'arriver au cratère de ce fameux volcan, et, grâce à un temps exceptionnel pour la saison, nous pûmes séjourner assez lonģtemps au sommel de la monlagne pour en donner une description exacte, qu'on trouvera plus loin. Là comme partout ailleur's, nos gouides indiens refusèrent de nous suivre jusqu'à la cime, et se tinrent à une distance respectueuse des premières fumerolles. Ni pour or ni pour argent nous ne pûmes les décider à laire un pas de plus. Le cratère du volcan est pour eux la porte de l'enfer, et leur courage ne va pas jusqu'à affronter' de semblables dangers. Seul, un domestique mexicain, qui, depuis près deux ans, nous accompagnait dans nos voyages, arriva avec nous au point culminant. L'atmosphère était ce jour-là d'une pureté admirable, le soleil brillait de tout son éclat, el la vue qui s'étendait à nos pieds était vraiment splendide. Toutes les beaulés de celle merveilleuse régợon de l'Amérique centrale, qui constitue la république de Guatemala, se voyaient en détail el comme réunies dans un vaste tableau. D'un còté s'élevait la masse immense du volcan de Agua, dont le sommet semblait arriver jusqu'à nous; de l'autre, les verles campagnes d'Escuintla, dont les teintes, en diminuant par degrés insensibles, allaient mourir peu à peu daus les flots bleus de l'océan Pacifique; plus loin, les sommités nues et déchirées de la province de Los Attos, entourant comme d'une couronne le lac pittoresque d'Atitlan; enfin, bornées au loin par les hautes montagnes de la Vera-Paz, les riantes vallées de la Antigua el de Guatemala, avec leurs plantations, teurs villes et leurs villages.

L'ascension de cette montagune est plutòt pénible que vraiment difficile, el le sentier, à peine frayé au milieu de l'épaisse végétation qui couvre les pentes jusquu'ì une grande lauteur, devient presque impraticable lorsqu'on est obligé d'emporter avec soi, comme nous devions le faire, quelques instruments délicats dont nous ne pouvions guère nous passer pour faire des expériences précises. On trouvera plus loin, au chapitre spécial, tous les détails relatifs à nos observations scienlifiques.

Le volcan de Fuego, outre le vif intérèl géologique de sa constitution, présente plusieurs particularilés naturelles déjà observées, el qui méritent d'être citées; nous voulons parler, en premier lieu, d'une sorte d'excroissance ligneuse qui se 
DANS LES RÉPUBLIQUES DE GUATEMALA E'T DE SALVADOR. 45

forme sur cerlains arbres; ce lissu ligneux s'épanouil el constitue comme de gros champignons qui prennent quelquefois des figures singulières rappelant à s'y tromper diverses fleurs, telles que la rose et la tulipe; ces excroissances sont connues par les indigènes sous le nom de flores de palo, fleurs de bois. Connne parlicularité du règne animal, on rencontre, au milien des bois touffus qui convenen cette mème montagne, un oiseau de la fámille des gallinacés, qui tient à lia lois. par son aspect extérieur, du vantour el du cog de bruyère; deux ou trois individus seulement de cette espèce ont été étudiés jusqu’ici, el, chose simgoulière, on n'en a pas retrouvé un seul en dehors du volcan de Fruego.

Deux jours après, nous entreprenions l'ascension du volean de Igua, quii ne présente aucune difficulté sérieuse; on peut, à la riggueur, se servir de mulcts jusqu'à la région des pins, à 3,000 mètres au-dessus du niveau de la mer, et de là. après quelques efforts, on gagone facilement une dépression en forme d'entonnoir', qui constitue le cratère de cel ancien volcan. $\Lambda$ une certaine époque, colle cavité peu profonde était entièrement remplie d'eau; en 1541 , probablement à la suitc de quelque violente seconsse de tremblement de terre, il se forma soudain unc immense fissure; l'eau, se déversant alor's, entraina par sa masse d'énormes blocs de rocliers, les terres s'éboulèrent en pirtie, et une avalanche épouvantable fondit sur la vallée; lout fut détruit sur son passage, et la ville de Ciudad Vieja, fondée par Alvarado, disparut dans ce désastre. La femme de l'illustro concuérant fint également viclime de celle catastrophe, et il ue resta debout, comme lémoin muet de ce malheur, qu'un arbre au tronc gigantesque el an feuillage épais, sous lequel les premiers Espagnols s'étaient réunis, après leur victoire sur les Indiens. pour rendre grràces au Seigneur el le remercier de sa divine protection.

Aujourd'hui, Ciudad Vieja se compose à peine de quelques constructions modernes élablies pour la culture du café el du nopal, et ne forme, pour ainsi dire. qu'un faubouror de la Antigua.

Cetle dernière ville, fondée après la ruine de Ciudad Vieja, porla d'albord le nom de Santiago de los Caballeros, el acquit bientòt par sa situation, ses envirous enchanteurs, le luxe de ses demenres of de ses labilants, et aussi par la licencer de ses mœurs, une renommée immense dans toute l'A mérique espagnole. Un historien da lemps, un Angolais, entré par dépil dans un couvent de moines espat- 
gnols, Thomas Gage (1), nous a conservé quelques curieux délails sur cette cité, qu'il compare à Sodome el à Gomorrhe, et qu'il menace dı feu du ciel, arrivant sous la forme d'une éruption du volcan de Fuggo. La ville fut détruite, en effet, en 1773 , par un violent tremblement de terre, qui laissa cependant encore deboul un certain nombre d'édifices; mais les habilants, tour à tour éprouvés par les éruptions et les secousses incessantes de tremblements de terre, tinrent conseil, el résolurent de transporter la capitale de l'Étal dans une position moins dangereuse et sur un sol moins mouvant; c'est alors que furent jetés les fondements de la Nueva Guatemala.

De nos jours, la Antigua ${ }^{(2)}$ esl encore la seconde ville de la république, elle occupe une étendue immense, el tend peut-être à se relever chaque jour davanlage; sa population est d'environ 12,000 habitants. Les r'uines magnifiques que l'on rencontre à chaque pas attestent sa splendeur passéc, el bien des fois nous nous sommes surpris dans une muette admiration en parcourant les superbes vestiges de la cathédrale, dn couvent de San Francisco et de l'ancien palais des gouverneurs espagnols.

Risces indiennes An Guatemalin. Costumes.
La place principale de la Antigoua, à certains jours de la semaine, offre d'ailleurs plus d'un enseignenent, ef l'on peul étudier lì en quelques heures les types les plus variés et les plus étranges des diverses races d'Indiens qui peuplent le Guatemala. Ces races ont déjà élé décrites, au poinl de vue ethnographique, par M. l'abbé Brasseur de Bourbourg ${ }^{(3)}$, et nous rappellerons seulement ici quelques détails relatifs à l'élat actuel des Indiens. Leurs vêtements diffèrent bien peu aujourd'luui de ceux qu'ils portaient jadis: ils se composent, pour les hommes, d'une sorle de veste de laine à manches très-courtes, ne dépassant pas l'avant-bras, el d'un pantalon bouflant ceint autour des reins par un cordon ou, plus élégamment, par une écharpe en tissu de soie; ce pantalon, très-court, couvre seulement la cuisse et s'arrête aux genoux. La plupart d'entre eux portent des sandales, ou plutôt une simple bande de cuir taillée sur la forme de leur pied, et relenue par des lanières également en cuir. Quclques-uns, habitués dès leur plus tendre enfance à nar'-

\footnotetext{
(1) A new Survey of the West-Indies; Journey from Mexico through the provinces of Oajuca, Chiapas, ete. London, 1865.

(2) Dans le pays, la Autigua Guatemala s'appelle plus simplement la Antigua.

(3) Histoire des nations civilisces du Mexique et de l'Amerique centrale dans les siècles antéricurs it Cler. Colomt. Paris, 1857 .
} 
DANS LES RÉPUBLIQUES DE GUATEMALA E'T DE SALVDOR.

cher nu-pieds, se passent de tonte espèce de chaussure. Ils ont la tête couverte d'un chapeau de paille de conleur sombre, et le plus souvent, sous ce chapeau, ils portent encore une sorte de bonnet de tissu de colon. Ge dernier est surlout en usage chez les Indieus des hauls plateaux, qui passent par une lransition Irès-brusque d'une température élevée à un froid vif el piquant pendant les mois d'hiver.

Les femmes ont un jupon court de tissu de coton rayé, ol sur les épaules une diemisclte blanclic de coton écru, ornée de dessins brodés en soie. Ces dessius aux vives nuances dénotent un gount assez prononcé, el les couleurs y sont géníralẹment disposées avec une certaine harmonie; pour les jours de fète on relèr. encore l'éclat de ces vêtements par une loule de paillettes métalliques qui soul d'un bel effet au soleil. Ce vètement supérieur des lemmes se nomme un gü̈pril. et, d'après la forme des dessins et les coulcur's usitées, les indigènes disling'uent. à première vue, à quel village apparticnt cetle qui le porte. Dans les terres chandes, ces mèmes vètements sont beaucoup plus légors, el tellement transparents, dans certaines localités, que la décence est à peine respectée; de plus, dans toules les terres chaudes, l'usage des chaussures est généralement inconmu.

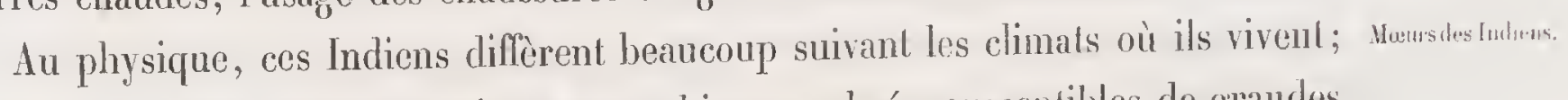
ceux do la tierra fria sont petits, trapus, bien membrés, susceptibles de grandes fatigues, et très-adomnés à l'ivrognerie, tandis que ceux de la tiemra caliente sonl grands, maigres, paresseux, et encore plus sensibles à l'allrail des looissons alcooliques. Ces derniers ne travaillent que pendant une failble parlie de l'améée, pour ensemencer te petit champ de maïs qui entoure leur hulle, sans se donner mème la peine de le labourer, et vivent le plus souvent de frrits et de racines yur la nature leur fournit en abondance. Pendant ce temps, leurs femmes restent dans leur demeure, où elles fabriquent leurs vêtements. Ce sont elles-nèmes qui recueillent le coton, te nettoient, le filent, le cardent et le tissent avec des métiers à la main aussi simples que primitifs; toutes ces opérations sont fiales avec le plus grand soin, et au bourgo de Santa Maria, silué sur le llanc du volcan de Agua, nous avons pu admirer de très-belles étofles brodées de soie, qui avaient été fabriquées dans une misérable hutle, et qu'uue pauvre Indienne avait mis pròs de six mois à terminer. Les riverains de l'Océan possèdent lous un canol friil d'un 
trouc d'arbre creusé, et la pêche suffit amplement à leur subsistance. Pendant le jour, on les voit souvent étendus sur le sol de leur hulte de bambous, ou plus rarement dans un hamac, s'abandonnant ì la plus complète inaction. Quelques-uns, cependant, qui ont un véritable instinct musical, étudient sur leur instrument de prédileclion, la marimba, les morceaux qu'ils joueront à la fète la plns prochaine, et Dieu sail si ces fètes se renouvellent souvent.

Iptiludesmusicales Hes Indiens. -

La marimba est un instrument très-harmonieux, quoique fabriqué exclusiveI. marimla. ment en bois; il se compose d'une série de tubes verticaux de différentes longueurs, lous reliés les uns aux autres par des bandes d'écorce, et resserrés entre deux larges pièces de bois; on en comple jusqu'à vingt ou trente dans une seule marimba. Ces tubes sont fermés à nute extrémité par une membrane, et ouverts ì l'autre extrémilé. Au-rlessus de cliaque tube est dispósée une petite planchetle horizonlale molile, sur laquelle le musicien frappe avec une baguette légère munie d'mu tampon; le son est produit par les vibrations de la membrane, et diffère naturellement suivant la longueur du lube; chacun de ces lubes correspond donc à unr note distinctr, et l'instrument entier constitue une sorte de clavier. La marimba se touche des deux mains comme le pinno, mais nous avons vu souvent aussi deux Indiens jouant à quatre mains et mème trois' artistes exéculant un air sur le mème instrument; d'autres fois encore ce sont deux marimbas qu'on essaye de mettre d'accord en tendant plus ou moins la membrane en baudruclie aver: de la cire. Les Indiens ont une sorte de passion pour la musigue, et its exécutent cerlains morceaux de mémoire avec une justesse el un accord remarquables. Leurs chants, cependant, sont d'une monotonie désespérante el fort désagréables à l'oreille, el nous nous rappellerons toujours les voix criardes que nous entendions chaque utitin bien avaut le lever du soleil, et chaque soir après son couchere, pendant notre séjour dans les haciendas de la Trerre Chlaude. Ces chants constituent lia prière de l'Indien; il nous a toujours été impossible, dans l'ignorance complète où nous étions de leurs dialectes, de rleviner ì qui s'adressaient ces invocations.

Indiens labourcurs. Tous les travaux des haciendas sont géénéralement faits par des Indiens nomades, qui vivent plutôt momentanément qu'à poste fixe sur le sol même de la propriété, dans des hultes mises ì lcur disposition par le proprićtaire. Ces Indiens 
travailleurs, qui ont beaucoup de rapport avec les peones du Mexique, sont ordinaircment d'une sobriété exemplaire, soumis et obéissants jusqu'ì l'obséquiosité, et leur salaire journalier ne dépasse pas deux ou trois réaux ( 1 fr. 25 cent. à 1 fr. 85).

Un grand nombre d'Indiens exercent le métier de portefaix; chaque jour ils Indiens portetaix transportent à de grandes distances et dans des sentiers à pcine frayés des charges énormes, et cela pour une sonme fort modique; nous en avous vu qui faisaient jusqu’à soixante lienes en quatre jours pour porter une dépêche, el on leur donnait deux piastres, dix francs de notre monnaie, pour ce long trajet. Ils voyagcul ordinairement en troupe portant leur charge sur les épaules au moyen d'une sorte de crochet de portefaix dit cacuste soulenu par une large baude de cuir qui vient passer sur le front; au-dessus de ce cacaste est enroulé un loug maulcau de feuilles de palmier ou de maïs qui les met parfaitement à l'abri, eux el leur farrdeau, pendant la saison pluvieuse. Cic mantcau imperméable se uomme suyacal; ils s'en servaicnt déjà au moment de la conquête, aimsi qu'on le voil dans les chroniqnes de Fuentes et de Herrera. La nuit, ces Indiens nomades allument do grands feux, el lous, étendus sur le sol sans autre oreiller que les cailloux du chemin, et à peine couverts de leur sarape, ils prennent quelques heures d'un repos bien mérité.

Dans les villes ou villages, la municipalité indienne est presque toujours indépendante de la municipalité blanche ou ladina, lorsque les deux éléments de la population sont en proportion suffisante pour cela; elle est à l'élection, sauf approbation du corregidor ou préfel dı département. Elle se compose, premic̀rement, d'un gobernador, gouverneur, qui a l'autorité suprême, el qui, à de rares exceptions près, ne relève que de lui-nıême. On le choisil le plus souvent parmi les descendants des ancicis chefs de tribu, ou caciques, dont la trace n'est point encore perdue. Ces hommes qui, dans plusieurs circonstances, nous ont rendu les plus grands services, ont une tenue digne el sévère; ils en imposent à leurs conciloyens, qui professent pour eux le plus grand respect et leur sont très-soumis. En second lieu, nous trouvons deux ou trois alcaldes et deux ou trois regidores. Les premiers sont chargés de rendre la justice, et les autres onl dans leurs attributions le service de la voirie. Comme, dans la plupart des cas, les Indiens ne comprennent 
pas. la langue espagnole, le secrélaire de la municipalité est généralement choisi parmi les ladinos, et il sert d'intermédiaire entre le gouvernement central et le gobernador du district. Enfin, dans tout village, il y a des mayores, environ douze pour mille habitants, qui sont les gondarmes de la localité; ils sont chargés des arrestations, de la police et de ses détails, et servent de courriers pour aller porter les dépèches de la municipalité.

Les attributs du pouvoir sont, pour le gobernador, une canne d'ébène surmontée d'une croix en argent; pour les alcaldes, une canne également en ébène surmontée d'une simple pomme du même métal; quant aux mayores, ils portent uin fouet en cuir tressé et fixé à un bàton en bois très-dur de $0^{\mathrm{m}}, 80$ de longoveur.

Les peines corporelles, quoique défendues par la loi, sont cependant tolérées el mème publiques; elles consistent surtout dans la fustigation sur la place principale de la localité : on altache à un poteau le patient nu jusqu'à la ceinture, et là, un des mayores, armé de son fouet, lui administre un certain nombre de coups sur les épaules, avec un calme et un sangfroid imperturbables.

Outre celte peine, il y a encore l'amende, la prison et une sorte d'exposition au pilori dite cepo. Voici en quoi consiste ce moyen correclionnel. Devant tous les cabildos ou maisons municipales on remarque des pièces de bois évidées de distance en distance par des entailles semi-cylindriques, et telles qu'en rapprochant deux de ces pièces on forme autant d'évidements circulaires. Le condamné passe une jambe, ou mème les deux, suivant la gravité de l'infraction, dans ces cavités, et on rejoint alors, pour les fermer au mojen d'un cadenas, des cercles de fer disposés aux deux extrémités des pièces de bois. Quelquefois deux ou trois individus subissent leur peine dins le mème moment, et on les laisse ainsi au milieu de ta place pendant un temps plus ou moins long. Pour les crimes, la loi comporte les travaux forcés à temps ou à perpétuité; il est rare que la peine de mort soit appliquée.

L'Indien est exempt du service militaire et ne paye pas les impôts; il est mineur devant la loi, et ne peut contracter la moindre obligation sans la présence de l'autorité; il n'est susceplible d'ètre requis de force que pour porter les bagages des troupes en marche. Chaque année il est soumis à une capitation qui varie de 
DANS LES RÉPUBLIQUES DE GUATEMALA ET DE SALVADOR.

4 réaux à 1 piastre ( 2 fr. 50 cent. à 5 francs), suivant l'imporlance des localilés; cette capilation entre dans la caisse de la municipalité; enfin il est tenu de travailler quatre ou cinq jours par an à l'entretien des roules qui avoisinent lr village où il se trouve; il n'a aucun moyen de se dispenser de cette corvée.

La route de la Antigua à Antatitlan passe par le col de Santa Maria, et, après quatre ou cinq licures de marche, on débouche dans une vallée parallèle à celle de la Antigua, où s'ćlève aujourd'hui la ville d'Amatitlan. Cette localité, dont la population est d'environ 13,000 habitants ${ }^{(1)}$, s'agrandit chaque jour; originairement, c'élait une vaste hacienda des Dominicans, analogue à celle de los Esclavos. Lorsque les religieux se retirèrent, les terrains furent divisés entre plusienrs proprićlaires, et, comme la fertilité et le climal de cette région se prêtaient admirablement ì la culture du nopal, l'agglomération actuelle se constitua rapidement, sans que la formation d'une ville nouvelle puit altérer en aucune façon le but qu'on s'élait proposé primitivement. Aussi la ville d'Amalitlan est-elle devenue le centre d'me immense exploitation de cochenille, el, gràce aux intermittences nalurelles el forcées que subit la culture du nopal, la majeure partie de la population peut ćtre considérée conme flotlante. Les vrais habilants indigènes, qui descendent tous plus ou moins des anciens esclaves des Dominicains, portent gónéralement les traces de leur origine.

Amatitlan est situé sur le bord d'un petil lac dont les eaux, mêlées probable:- lact'dmatittan ment avec celles de quelques sources minérales, sont très-chargées de sels de soude el de magnésic. On pèche cependant dans ce lac d'excellents poissons dits mojaras el des écrevisses (cangrejos), qui ne paraissent pas sonffrir de la mauvaise qualité de l'eau. Le niveau du lac n'est pas constant, il baisse beancoup ì certaines époques de l'amnée, et, comme il est peu profond, il laisse à déconver une foule de végétations aquatiques. Nous ne pouvons mieux comparer le lracé indécis des rives de ce lac, surtout du côté nord-est, an voisinage du villigor de Petapa, qu'ì celui des grands lacs de la vallée de Mexico el du lac de Tezcuco en parliculier. Les eaux, en se retirant, laissent derrière elles d'immenses marécages, où s'engendrent des miasmes putrides, qui vout porter sur la ville les fièvres les plus pernicieuses. Le climat d'Amatitlan est en effet réputé pour (1) Recensement de 1865 ; Ia Semana, periodico politico y litterario; Guatemala, 5 de novieubre de 1865. 
très-malsain, et la mortalité y est plus grande qu'en aucun autre point du Guatemala.

Volcan de Pacaya. Le volcan de Pacaya est situé à environ cinq lieues d'Amatitlan, et l'on y arrive très-facilement par un assez bon sentier tracé dans les bois. Sur la route se trouve le pelit village de Pacaya dans une position analogue à celle de Santa Maria; mais, landis que le dernier est exclusivement habité par des Indiens, on ne voit guère dans le premier que des ladinos. Le volcan est aujourd'lui presque enlièrement ćtcint; il ne șe dégage plus du cratère que de rares fumerolles; mais, dans les premières années de la conquète, ses éruptions ont été d'une fréquence et d'une vịolence redontables. Francisco Fuentes, dans sa clıronique, rapporte qu’il lançait continuellement, et tous les jours de l'année, d'énormes flammes par une de ses sommités les plus élevées. D’après Juarros, sa dernière éruption eut lieu le 11 juillet 1775 . Il ne présente, à l'heure qu'tl est, aucune particularité remarquable; mais de sa cime, qui s'élève à 2,553 mètres au-dessus du niveau de la mer, on se rend parfaitement comple de l'ensemble du système des deux autres volcans de Fuego et de Agua.

Eseuintla. Les temporadas.

Les plantations de café La cascade de la Hichatoya.

Amatitlan se trouve sur la grande voie de communication qui conduil de Guatcmala à l'océan Pacifique. En s'approchant de la mer, et à huit licues d'Amatitlan, après avoir descendu une longue pente qui traverse toute la régoion tempérée, on rencontre le gros bourg d'Escuintla, autrefois rendez-vous favori des habilants de Guatemala, qui venaient, pendant l'hiver, jouir du soleil de la T'erre Chaude et mettre à profit les eaux fraîches el limpides de la Michatoya. Il n'existail pas lì, à proprement parler, d'établissement hydrothérapique d'aucune sorte, mais les habitants d'Escuintla vivaient sous la tente durant deux ou trois mois, pour louer leurs demeures aux baigneurs, el la seule rémunération qu'ils en retiraient suffisait à leur entretien pendant toute l'année. Escuintla était ainsi en quelque sorte le Baden-Baden du Guatemala; mais l'usage de ces saisons d'eau, dites temporadas, est tombé peu à peu en désuétude, à Escuintla du moins, car les baigneurs ont choisi une localité plus rapprochée de Guatemala.

Aujourd'hui Escuintla a acquis une certaine importance par les plantations de café qui y sont installées depuis environ dix ans. A cette époque, c'est à peine si l’on cultivait le café au Guatemala, lorsqu'une famille française vint jeter là les 
DANS LES RÉPUBLIQUES DE GUATEMALA ET DE SALVADOR.

bases d'un commerce immense; ses premiers essais, après quelques tattomements, furent suivis de résultats remarquables ${ }^{(1)}$, et, grâce ì l'expérience acquise, d'autres planteurs purent, à leur tour, se consacrer en toute sécurité au développement de cette même culture. Il faul dire toutefois que, de mème que tous les autres vógétaux, le café ne réussit bien que dans une cerlaine zone, et cette zone, pour l'arbuste en question, est siluée entre 600 et 1,000 mètres au-dessus du niveau de la mer. Escuintla est déjà bien au-dessous de cette moyenne, el les plantations faites ensuite dans un climat plus tempéré donnèrent des résultats bien supérieurs ì ceux qu'on pouvait prévoir d'après les premières tenlatives.

Les environs d'Escuintla offrent encore au touriste une série de beautés naturelles que l'on ne peut trop adnirer, el quoique un peu blasés, s'il est possible de s'exprimer ainsi, sur la magnificence des points de vue tropicaux, nous fùmes émerveillés une fois de plus à l'aspect de la superbe cascade de la Michatoya, qui tombe de cent mètres de haut et sur une largeur de près de vingt mòtres au milieu d'une exubérance prodigieuse de végétalion. Les rayons du soleil des tropiques animant cetle pluie fine comme la rosée, et semant comme une multilude de perles sur les larges feuilles de ces grands arbres éternellement verts, nous rendirent témoins d'un spectacle qui défie toute description.

Après avoir parcouru en tous sens les vallées de Guatemala el de la Antigua, nous étions vivement engagé à meltre à exécution un projet de voyage dans le nord du pays, et principalement dans la provinee qui porte le nom de Vera Paz. Nous partîmes done de Guatemala dans les derniers jours du mois de juin, en pleine saison des pluies, mais avec l'espoir de rencontrer daus la haute Vera Paz un temps plus favorable.

On sort de la capitale en se dirigeant au nord-est, par le faubourg de la Candelaria, dont la morue tristesse, el plus encore la malpropreté, sont devenues proverbiales. Au début, et pendant près de trois lieues, le chemin est peu accidenté; mais tout à coup on se trouve en face d'une de ces profondes fissures dont nous

(1) Qu'il nous soit permis d'adresser ici un juste tribut de reconnaissance à cetle famille, dont la bicuveillance et l'amabilité à notre égard ne se sont pas démenties un seul instant.

Un de ses membres, M. le baron 0 . du Teil, étail membre correspondant de la Commission scienlifipue du Nexique, et les nombreuses relations que sa juste influence lui avait créécs daus le pays n'ont pas peu contribué à nous rendre plus facile la mission qui nous était confiée. 
avons déjà fait mention, et les sables mouvants qui constituent les flancs du ravin arrivent peu à peu à masquer presque entièrement la route et à la rendre singulièrement périlleuse. Au fond de ce ravin de deux cents mètres de profondeur environ serpente un frais ruisseau qui arrose le bourg de Chinautla, dont le climal tempéré altire en foule chaque année les hahitants aisés de Guatemala, heureux de clanger d'air et de pouvoir se livrer dans une eau pure et limpide, courant sur un lit de sable fin, à l'exercice salutaire de la natation. Ces réunions annuelles u'ont point encore altéré l'aspect du village indien de Chinautla, les liabitants ont conservé leur costume et leurs usages, et, à part quelques métis qui exploitent les baigneur's, toute leur industrie consiste, comme par le passé, à laire du charbon de bois qu'ils vendent en ville, et à confectionner quelques grossières poteries.

Après Chinaulla nous traversons plusieurs fois le cours sinueux du Rio de los Platanos, el la roule que nous suivons devient de plus eu plus mauvaise et presque impraticable; elle franchit d'énormes ressauts taillés dans le roc, et la côte dite de Quesada serait capable d'eflrayer l'Européen le plus intrépide qui serait fraichement débarqué dans ces régions presque vierges. Au sommet des collines que uous gravissons, nou sans quelque peine, nous retrourons les belles forêts de pius et de chênes qui couvrent fréquemment les hauleurs dans les environs de Guatemalı. L'aspect du pays est quelque peu monolone, les voyageurs sont très-rares, et, à part quelques Indiens courbés sous leurs pesants fardeaux, on ne r'encontre gutère que d'immenses convois de porcs descendant des montagnes de la VeraPaz, ef qui sont tous munis d'une sorte de chaussure de cuir ou de vieux linge destinée à leur protéger les pieds contre les cailloux de la route. zal. La canne à sucre est la principale culture de cette lacienda, située à sept ou hnil lienes de Gualemala; elle offre toujours au voyagenr un gite pour y passer la nuit, el on pent, à là riguenr', s'y procurer quelques aliments. Au delà, on descend pendant longtemps et d'une manière presque insensible; peu ì peu, les pins disparaissent, les chènes deviennent plus rares, et, après avoir traversé deux unisérables villagoes, San Bernardino et San Buendventura, situés dans un climat Irès-chaud, humide el malsain, où la population ne trouve pour se désaltérer que de l'eau bourbeuse et chargée de débris organiques qui eugendre de terribles 
DANS LES RÉPUBLIQUES DE GUATEMALA ET DE SALVADOR. 55 maladies, on arrive au bord du Rio Grande, qui descend des montagnes de los Altos, traverse toute la basse Vera Paz, décrit une courbe de plus de quatre-vingts lieues, et finit par se jeter dans l'océan Atlantique sous le nom de Rio Motagua.

C'est en vain que nous cherchons un pont sur cette rivière de près de soixante mètres de largeur; nous ne voyons qu'une arche en r'uine, seul reste de l'unique pont à plusieurs arches de tout le Guatemala, qui passait pour une merveille La Garucha. d'élégance et de solidité, et qui a été détruit par une crue subite du Rio Grande; le goué, d'ailleurs, est tout ì fait impraticable à cette époque de l'année. Nous sommes contraints dès lors, pour arriver sur l'autre rive, de nous servir du moyen primilif imagginé par les peuplades de l'Amérique du sud, les Gauchos et les Patagons, et qui est connu au Guatemala sous le nom de gamucha. Voici en quoi consiste ce pout d'un nouveau genre : Un càble en fil d'aloès est tendu à une dizaine de mètres au-dessus du fleuve et solidement fixé aux falaises qui forment les deux rives; sur celle corde court une poulie qui supporte une large courroie; le voyageur passe cetle courroie autour de son corps, saisit à deux mains les brins qui sont fixés ì la poulie, et, comme la corde, par son propre poids, décrit une courbe dont la flèche est assez grande, la poulie descend facilement jusqu'au point correspondant au milieu du fleuve; mais, à partir de ce moment, il faul remonter, et, dans ce but, les ferrures de la poulie portent une amarre que les Indiens préposés au passage tirent à eux, de sorte qu'ils parviennent ainsi à vous faire gagner l'autre rive. La traversée ne présente donc d'antre danger que celui de la ruplure du càble; nous devons avouer toutefois que le voyageur susceptible d'être pris de vertige aurail tort de se confier à cet appareil, et nous avous vu quelquefois rétrograder des lıommes, aguerris cependant par de longs voyages, mais qui se souciaient peu de se voir suspendus pendant quelques instants à une trentaine de pieds au-dessus d'un torrent écumant et entièrement livrés au bon vouloir de quelques Indiens. A chaque voyage, la garucha ne peut transporter qu'un homme ou un coffre, ou l'équipement d'un cheval; quant aux animaux eux-mêmes, il faut leur faire traverser le courant ì la mage, non sans quelque péril. Le passage du fleuve devient ainsi, pour une petite caravane comme la nòtre, une aflaire de plusieurs heures, qui n'est pas exempte de quelques émotions. 
Sources sulfureuses.

A peu de distance du Rio Grande et près d'un de ses affluents, le Rio de las Tejas, sont de belles sources d'eau sulfureuse, à température élevée, et probablement voisines de quelques filons; leur odeur se perçoit de très-loin et contraste désagréablement avec ce parfum de fleurs tropicales sortant des magnificues forêts que nous avions traversées jusqu'alors. Ces mêmes forêts changent d'aspect rapidement, car nous nous élevons encore sur l'autre versant du Rio. Grande, et, après avoir franchi, au col de Chuacus, un des principaux chainons ou rameaux transversaux de la Cordillère, nous redescendons encore une fois, presque au niveau de la même rivière, dans la vaste et fertile plaine où s'élève la pelite ville de Salama.

De loin, Salama semble être un agréable séjour, mais les illusions tombent rapidement à mesure qu'on en approche. Celle ville en effet ne renferme pas un monument; on n'y voit pas la moindre animation, la chaleur qui y règne une partie de l'année est pénible el irritante; somme toute, l'aspect général de ce bourg de 6,000 liabilants est misérable et triste. Le sol des environs, cependant, est assez fertile, très-sec, et le climat permet à la fois les cultures des terres chandes et celles des terres tempérées. Le nopal y a beaucoup moins souffert qu’à la Antigua et à Amatillan, et les vers à soie qu'on a essayé d'y implanter ont assez bien réussi. Nous avons pu remarquer aussi dans les jardins de Salama de magnifiques ceps de vigne, et des treilles gigantesques donnant des grappes de raisin d'un poids fabuleux, qui rappellent presque cetles du pays de Chanaan; mais la qualité du grain était loin de répondre à sa grosseur; cetle culture promel, d'ailleurs, de devenir l'objet d'un commerce assez lucratif, lorsque les habitants s'y adonneront avec quelque soin.

Toute la vallée de Salama est couverte de belles plantations, et on apercoit au loin sur la droite, en sortant de la ville, les magnifiques cultures de canne ì sucre de la hacienda de San Geronimo, dont les teintes d'un vert émeraude se perdent presque à l'infini dans l'azur du ciel. Nous nous élevons quelque peu en quittant la vallée sur la côle dite de Kachil, et de là, par une suite de ravins plus ou moins profonds, nous gagnons le village de Santa Rosa, petit amas de cases habitées par quelques Indiens ou ladinos, entièrement dénués de toute espèce de ressources.

A peine a-t-on quilté Santa Rosa, qu'au détour d'une petite colline, en même temps que la roche change de nature, le paysage change aussi d'aspect, et dans 
DANS LES RÉPUBLIQUES DE GUATEMALA ET DE SALVADOR.

un si court espace de temps, qu'on pourrait presque croire qu'un rideau s'est levé subitcment devant les yeıx du voyaggeur, ct qu'un décor entièrcmeńt nouveau sc présente à ses regards. En effot, à P'aridité, à la monotonie, à la nudilé, succèdent la fraîcheur, une agrréable varićté de sites, el unc végétalion qui, sans être aussi luxuriante et touffue que celle des terres chaudes, n'cn est que plus agrréable à l'mil. Le délicicux vallon où mous pćnétrons est arrosé par un ruisseau qui nous accompagne en serpentant au milicu des bois et des prairies juscułà Tactic, où nous le franchissons sur un pont rustique.

Tactic, premier village de la haute Vera Paz, est pitloresquement situé an fond d'une pelite vallée, au milieu de collines ou plutôt de inamelons excessivemen! boisés. Les habitants, au nombre de 3,50o, sont presque tous Indiens, bons travailleurs, généralement bùchıerons ou charbonniers. Le climat de celte localité csł un peu lumide; il y pleut fréquemment, el il y fait presque froid dans les mois de novembre, décombre et janvier.

Déjà, aux abords de Taclic, nous avons reconnu arec plaisir la végétation des terres tempérées; le feuillage des arbres est plus vert et plus gai, le sol est convert de plantes qui rappellent jusqu'ì un cerlain point la flore du midi de l'Europe, et les prairies sont ćmaillées de boutons d'or et de marguguerites. De T'actic à Coban, nous descendons légèrement, en suivant lé cours sinueux et magnifiquement ombragé du Rio de Cajabou, qui prend sa source dans les environs de El Patal et va se jeter dans le Polochic, à quelque distance de Teleman.

A 3 lieues de Tactic, un peu avant d'arriver au village de Santa Cruz, on apercoit à gauche de la route un site véritablement enchanteur. Une pelouse d'une éblouissante fraîcheur, converte du gazon le plus fin, scmée de ci el de lì de liquidambars au feuillage transparent, disposés avec une rare élégance autour d'un étang capricieusement dessiné par un petit ruisseau, nous transporte soudaiu dans un de ces magnifiques pares du nord de l’Anglelerre; la lumière seule, plus vive que dans nos climats, et le ciel d'un bleu plus intense, ce qui rend encore te paysage plus brillant, nous ramenent sous les latitudes tropicales.

Santa Cruz est un pauvre villagge perdu dans le fcuillage; deux ćnormes cyprès, qui s'élèvent sur la place principale, contribuent beaucoup à lui donmer un aspect lugubre. Les Indiens de ce village se tiennent aux champs, où ils cultivent le maïs 
et le frïol (laricol), qui composent leur principale nourriture; ils sont, en géuéral, peu sociables, et passent pour détester les ladinos.

Croltes

les environs

de

Santa Ciruz.

De Sanla Cruz à Coban, il y a encore 3 lieues par une route accidentée, mais très-J zonne pendant l'été. Quelques instants avant d'arriver à Coban, on rencontre au pied d'une colline une grotlo peu profonde creusée dans la roche calcaire et recouverte par la végétation; ces grrottes sont très-communes dans toute la haute Vera Paz et rarement apparentes an grand jour. Quelques-unes d'entre elles sont très-profondes, les eaux de pluie s'y réunissent, et, conme la régélalion les rend presque invisibles, il arrive fréquemment que des animaux, tels que chevaux, bœufs, etc. se perdent dans ces antres, d'où ils ne reparaissent plus à la lumière du jour. On peut presque dire qu'une grande partie de la haute Verat Paz repose sur d'immenses voûtes calcaires, qui communiquent entre elles, et permeltent aux eaux, qui tombent en abondance pendant la sajson des pluies, de se rassenbler aux points bas; quelquefojs mème, ces eaux arrivent au jour el viennent former des marais ou des étangs qui augrmentent ou diminuent tout à fail indépendamment des pluies, et dont on saurait difficilement expliquer l'origine d'une autre manière.

La grolle de San Agustin de Lanquin, si bien décrite par M. A. Morelel ${ }^{(1)}$ dans son voyage au Guatemala, est une des curiosités naturelles de la Vera Paz, el c'est au sein de cetle grolle que prend naissance une petite rivière dont les eaux se rendent au Polochic. Il résulte de cette structure du sol que, malgré l'abondance et la fréquence des pluies, la terre n'est jamais complétement imbibée d'eau, ef que la végétation n’a jamais à souffrir de cet excès d'humidité.

1)

quelques végélaux remarquabics de la hantr Vera Paz.

Dans les forêts des environs de Coban domine le liquidambar (styraciflua), bel arbre qui alteint quelquefois jusqu’à 15 et 18 mètres de hauleur en prenant unc forme pyramidale régulière, avec un tronc droil et lisse. Ses branches sont faiblement colorées en rouge, et ses feuilles deviennent presque semblables à celles de la vigne vierge en automne lorsqu'elles sont sur le point de lomber'; elles onl de l'analogie avec celles de notre platane, mais elles sont plus minces, plus légères, el les nervures sont aussi colorées en rouge; quand on les presse dans la main, on perçoit une odeur qui rappelle celle de l'ambre. On voit aussi, dans les envi-

(1) Voyage dans l'Amérique centrule, lile de Cuba el le Vueatan, par A. Morelet. Paris, 1857. 
DANS LES RÉPUBLIQUES DE GUATEMALA ET DE SALVADOR.

rons de Coban, un arbuste qui domne la cire végétale (myrica cerifera), produit qui, depuis quelque temps, est devenu un objet de consommation, unais dont on ue connaîl l'usage que depuis une vinğtaine d'années. La couleur verdàtre de cette cire et la difficulté de la décolorer sont les principaux obstacles à son emploi; nous l'avons cependanl vue servir nombre de fois dans les babitations de Colvan.

Ciest du point dit las Cruces, à deux kilomètres de Coban, que l'on commence ì apercevoir la ville, qui est entièrement perdue dans te leuillage; on pourrait difCioban. isjert général. ficilement se donter de la présence d'une population de 120413,000 habitants, en voyant éparses deux ou trois maisons, dont les murs blanchis à la chanx percent au unilieu de la verdure. Plus on approche, plus lillusion est grande, at déjà depuis longlemps nous parcourions les rues de la ville, prescue sans nous apercevoir que nous y élious entrés. Toules les habitations des indigènes sont entourées de jardins émaillés de fleurs, et séparées de la voie publique par une haic très-élevée, formée d'une sorte d'ortie arborescente qui en défend très-bien l'approche. Au milieu de ces orties croissent à profusion les dahlias sauvages, et les daturas, dont le parfum, aux premières heures de la soiréc, est tellement vif et pénétraut, qu'on a peine à s'y accoulumer.

Coban porte cependant le titre de ciudad imperial, ville impériale, que lui a conféré Charles Quint en 1537, en mème temps qu'il donna à tonte la région le nom de Vera Paz en mémoire des moyens employés pour en eflecher la soumission. La civilisation, en effel, fut portée chez ces peuplades sauvages par un illusire évêque, Las Casas, qui, par ses seules prédications, parvint à conquérir à l'Espagne un vaste pays qui avait toujours résisté jusqu'alors aux armes viclorieuses d’Alvarado. Celte conquète toute pacifique porta ses fruits pour l'avenir, et, malogré les révolutions qui ont souvent agité le pays, la Vera Paz resta toujours dans ume pais profonde. "

Les habitants de Coban, sont presque tous Indiens; on y compte cependant 2,000 blancs et ladinos. Les Indiens portent un costume à peu près semblable Population de Conban. ì celıi que nous avons déjà décrit, tes femmes seulement ont une coiffure singulière, et du reste très-pittoresque : leurs clieveux, réunis derrière la tête, forment une Inngue natte complétement entourée de rubans rouges, qui retombe entre les 
deux épaules el tranche nettement par sa nuance éclatante sur un guipil d'une éblouissante blancheur. Elles porlent, en outre, un collier composé de pièces d'argrent de tous les pays el de tous les temps; certain de ces colliers formerait à lui seul une remarquable collection pour un numismate. Presque tous les Indiens travaillent dans tes plantations de café qui abondent à Coban, ou bien ils vont dans différentes directions porter au loin les produits de leur industrie, qui consistent surtout en hamacs de fils d'aloès et en calebasses plus ou moins bien sculptées, qu’ils vendent jusque dans le Honduras.

Quelques-uns, cependant, se livrent exclusivement à la chasse de certains oiseaux très-répandus aux environs de Coban, déjà surnommé, el avec raison, le paradis de l'ornithologiste. Nous voulons parler surtout du Quezal(1), l'oiseau par excellence, que nous nemmons couroucou resplendissant, et dout les plumes, d'un vert mordoré, et la queue longue de près d'un mètre, concourent aujourd'hui à l'ornement de nombreuses coiffures. Chaque année il sort de Coban près do 300 peaux de couroucous, qui onl déjà une grande valeur à Guatemala.

Jadis, les plumes de la queue de cel oisean étaient envoyées en tribut aux empereurs du Mexique, qui les porlaient les jours de grande cérémonie; et les artistes mexicains les recherchaient pour leur's plus beaux ouvrages de plumes. II étail défendu dans ce temps-là de tuer les quezales; on se contentait de les prendre au piége pour leur arracher les plumes do la queue et on les rendait ensuite à la liberté. Ces oiscaux eux-mêmes, dit Juarros ${ }^{(2)}$, ont conscience de la beanté de leur principal ornement, car leur nid possède deux ouvertures, de manière qu'ils puissent entrer et sortir sans briser leur queue: On a fait une telle guerre à cel oiseau daus ces dernières années, que l'espèce commence à en devenir très-rare.

Presque tous les artisans de Coban sont des ladinos, gens industrieux, mais moins bons travailleurs que les Indiens el ue présentant que peu de garanties de moralité ou d'énergie. Ils semblent avoir conservé le plus souvent les vices des deux races dont ils proviennent, et n'en ont pas toujour's gardé les qualités. Lucur'

(1) Tromon pavoninus.

(2) -Los mismos Quezales, parece que conocen el valor rde su cauda, y asi fabrican sus nidos con dos puertas. "para que entrando por una, y saliendo por otra, no se restrugen sus preciosas plumas." (Juarros, t. I, c. III. p. 32.) 
DANS LES RÉPUBLIQUES DE GUATEMALA ET DE SALVADOR.

religion, mélange singulier d'ignorance et de fanalisme, les conduit aux conséquences les plus déplorables : on voit des mères, après avoir perdı un enfant, tui faire de magnifiques funérailles, qui ont presque le caractère d'une fête publique, et se réjouir laautement d'avoir un ange dans le ciel pour implorer Dieu en leur' faveur. Ils sont faibles, et, si quelque coutume indienne flatte la tendance de leur esprit, on peut ètre certain qu'ils l'adopteront avec empressement. Ils sont ficrs de parler l'idiome des indigènes, la lengua, comme ils disent, mais pas un d'eutre eur ne songerait à enseigner l'espagnol aux Indiens, qui ne le savent que bien rarement. Il est à remarquer, d'ailleurs, que l'influence des métis sur les races indigènes est plutôt mauvaise que bonne. Le caractère de l'Indien est, en général, doux et flexible, de sorte qu'il cède aisément à l'entrainement des fàcheux exemples qu'il a presque chaque jour sous les yeux. Sans perdre les délauts inléérents ì son origine, il en acquiert de nouveaux, et l'on peut entrevoir' le moment où les babilants primitifs du pays, corrompus par un contact incessant, auront perdu les vertus qui leur permeltaient jadis de luller avec la nalure vierge, sans s'ètre assimilé celles qui leur seraient nécessaires pour vivre au milieu de la civilisation. Les Indiens et les ladinos sont d'ailleurs rarement d'accord, et la jalousie de race va quelquefois jusqu’à la haine. Tous les ans, dans un village voisin de Cobau, à San Pedro Carclia, dont la population, composée exelusivement d'Tndiens, disséminés de tous côtés, s'élève à 40,000 âmes, le gouvernement double la nilice au moment de la fète du villagoe, et, malgoré ce déploiement de forces, nous avons entendu parler de rixes sanglantes, qui dégénéreraient facilement en guerres de races, si les Dominicains résidant dans la localité, et qui ont une grande influence sur les Indiens, n’intervenaient énergiquement dans le combat, courant souvent le risque de perdre la vie dans la mèlée.

Le climat de Coban est excessivement doux et tempéré; l'humidité ne le reud peut-ètre pas toujours très-sain, mais il est agréable, et on s'y laisse aller volonliers à l'indolence, tant la vie y paraît facile, el tant la nature s'est plù à embellir ce séjour.

Le café commence à couvrir tous les manrelons des alentour's; il est d'excellente Plinlativas dis culfe. qualité, et les plus grandes plantations de cet arhuste sont entre les mains d'uı de nos compatriotes, qui a introduil dans ce pays, pour le service de son exploi- 
lation agricole, la première el la seule machine à vapeur qu'on y ail jamais vue ${ }^{(1)}$. La présence d'une locomobile, au milieu de forêts presque vierges, a quelque chose de tellement élrange, qu'on éprouve soi-même, à la vue de celte machine, la mêmo impression de surprise que les Indiens, qui restent comme ébahis en la voyant marcher.

Mallıcureusement, Coban est situé à 45 lieues de la capitale, et les voies de communication pour rejoindre l'Atlantique sont encore presque ì créer aujourd'hui, de telle sorte que les produits nalurels sont grevés d'un transport énorme avant d'arriver au port d'embarquement.

Sall Cristnba!.

Mines

de plomb argontifing.

En nous éloignant de Coban dans la direclion de los Alos, nous parcourûmes d'abord le district minier de San Cristobal, où se tronvent des gुisements de gà-. lène assez argentilère, qu'on exploite par les procédés les plus primilifs; mais prochainement, paraîl-il, on doit construire dans ce pays une usine ın peu plus complète, pour tirer un meilleur parti de ces gisements abondants. Ces mines sont situées an milieu de collines assez élevées, qui longent le cours impétuenx dı Rin Chisoy et servent de frontières à la Vera Paz. En effet, du haut d'une de ces collines, en regardaut dans deux directions opposées, on aperçoit denx régoions essentiellement distinctes. D'un côté, c'est la Vera Paz avec ses prairies boisées, ses faibles ondulations et ses eaux limpides; de l'autre, ce sont les Altos avec leurs montagnes élevées, leurs profondes déchirures et leurs torrents impétueux; ici, un aspect frais et gracieux; là, un spectacle sauvage et grandiose.

Sur la lisière des forêts qui couvrent le pays, à quelques lieues de San Cristobal, dans une atmosphère à la fois tiède el lumide, on remarque les plus magnifiques orchidées de ce pays, dont la flore est si riche à co point de vite. Ces plantes parasiles se mêlent aux broméliacées et à quelques autres goenres dı même lype pour couvrir les branches des arbres, et laissent pendre presque jusque sur le sentier leurs grappes odorantes, ou brillent toutes tes couleurs dro l'arc-en-ciel. Parmi les arbres principaux qui forment les forêts de ces régions, nous devons surtout signaler les chênes, dont les espèces sont aussi nombreuses que variées; les types les plus intéressants se rapportent à des espèces caractó-

(1) Elles sont dirigées par M. J. Rossignon, inembre que nous tenons à remercier ici de sa charmante hospicorrespondant de la Commission scientifique du Mexique, talité. 
risées, soit par une feuille pelite et lincéolée, d'un vert sombre et luisant, soil par une feuille très-large et longue de plus de Irente centimètres, soit enfin par d'énormes glands, dont le volume dépasse de beancoup celui d'une grosse noix.

Après avoir quitté San Cristobal, nous prìmes la direction de l'onest, dans l'intention de gagner directement Quezaltenango, en traversant tout le nord de lat province de los Altos. C'était presque un voyagge de déconverte que nous entreprenions là, car ces régions, qui n’avaient encore été visitées par aucun Européen, forment pour ainsi dire l'extrème frontière de la civilisalion, et ne sont habilécs que. par des Indiens purs, sur lesquels le gouvernenent de Guatemala exerce unc domination plus nominale que réelle. Outre les difficultés inhérentes au pays luimème, nous devions en rencontrer d'autres tenant d'abord à la tournure d'esprit de ces populalions, qui passent pour être très-hostiles à l'élément blanc, et ensuite à leur peu de connaissance de la langue espagnole. Il nous fallut, en effet, nous servir continuellement d'interprètes, el nous eùmes mêne lieu de remarquer que, les dialectes indigènes étant très-nombreux, très-différents les uns des ąutres. et très-intimement mélangés, nos interprètes eux-mèmes avaient souvent de la peine à se faire comprendre.

Un peu au delà de San Cristobal, lè sentier, à peine frayé sur le llanc d'une immense vallée, devient tellement étroit, qu'un de nos mulets lut précipité dans Rivin du hít Chisoly. l'abîme et se perdit avec sa chargèe. Le chemin n'est, on eflet, jamais parcouru que par des Indiens qui voyagent ì pied, et, pour conlinuer notre route avec nos bêtes de selle et de somme, il nous fallut improviser sur place de nouvelles dispositions. Malgré les difficultés qui s'opposent à l'exploitation de ces régions, les Dominicains y possèdent pourlant encore une propriété qui porte le nom d'Hacienda de los Padres.

A quetques kilomètres plus loin, on arrive subitement en présence d'une inmense vallée, on pourrait presque dire d'un gigantesque ravin, au fond duquel le Rio Chisoy roule avec impétunsité ses eaux rapides, et forme la frontière entre la Vera Paz et les Altos. Quoique dominant de fort près le fleuve, il nous fallut plusieurs henres pour arriver sur ses bords par un sentier qui ne méritr gonère ce nom, et nous n'atteignîmes le point où nous complions passer la nuit qu'au moment où le soleil disparaissail à l'horizon. Nous eùmes encore lo bonheur' 
de pouvoir élire domicile sur un pont couvert qui nous servit d'asile en même temps qu'à une troupe d'Indiens voyageurs, arrivant des environs de Quezalleuango avec leur cacaste, chargé de farine ou de pain.

Le Rio Chisoy se dirige vers le nord-est pour aller rejoindre l'Usumacinta et se perdre avec luj dans les régions inconnues qu'habitent les tribus sauvages el mystérieuses des Lacandons el des Mayas.

Sur la rive gauche du Rio Chisoy on aborde les Altos, qui se composent, dans cette partie de la province, de chaînes montagneuses assez élevées, entremêlées de quelques hauts plateaux. La population y est presque nulle, et se concentro dans quelques hameaux isolés au milieu des immenses forêts vierges. Tel est to village de Chicaman, le seul qui existe avant San Miguel Uspantan, où nous devions trouver un gîte et un peu de fourrage pour nos animaux.

San Migguel Uspantan joua jadis un rôle important à l'époque de la conquête.

C'ćlait la résidence d'un cacique puissant, dont la domination s'étendait an Ioin sur les deux rives du Chisoy, et qui s'opposait vigoureusement à l'envahissement des Espagnols. Plusieurs assauts successifs furent livrés à cette antique sille d'Uspantan, sans te'moindre résultat, et dans un de ces combats, qui ful plas meurtrier que les autres, une foule d'Espagnols perdirent la vie, tandis que leurs alliés les Indiens faits prisonniers par les guerriers d'Uspantan furent sacrifiés à l'idole Esbalanquen; on leur arracha le cœur pendant qu'ils vivaient encore, pour l'offrir au dieu de la guerre(1).

lujourd'hui, San Migguel Uspautan est un pauvre village, habité exclusivement par des Indiens au nombre de 1,200 à 1,500, qui se souviennent peu de leur ancienne origgine. Après quelques pourparlers avec le cacique de l'endroit, on nous accorda, à titre gracieux, l'autorisation de séjourner au Cabildo ou maison municipale, dans la salle qui sert ordinairement d'école el qui était vacante en ce moment-lì. Deux Indiens corvéables furent envoyés à la recherche des vivres et fourrages dont nous avions besoin, et ces approvisionnements nous furent délivrés

\footnotetext{
(1) . . . . Los de Uspanlan cortaron por la retaguarda, - enn grande asolacion de nuestros Indios amigos, y no poco "daño de los Españoles que salieron muchos heridos de ensta pelea, entro ollos, el capilan Olmos. Pero lo mas dom
}

« loroso rle este inlortunio fue que quedando muchos Inrdios prisonieros del enemigo, fucron sacrifieados a el ridolo Esbalanquen, sacandoles los corazones vivos para "ofiecerlos al Demonio. (Fuentes, t. II, c. ri.) 
DANS LES RÉPUBLIQUES DE GUATEMALA ET DE SALVADOR.

en présence des mayores qui surveillaient attentivement de l'œil et du fouet la conduite de nos Indiens.

Le curé de San Mignel Uspantan nous raconta de quels singuliers arguments il était quelquefois obligé de se servir pour convaincre son troupeau, malgré tout le respect qu'il lui inspire. On nous permettra de ciler ici un fait qui peint ì merveille la manière dont les Indiens entendent la religion qu'ou s'est efforcé de teur enseigner. Il y a queldue temps, lis slatue du saint, patron de la localité, qui avait déjà bien des années d'exislence, et qui avait servi un nombre incommensurable de fois dans les processions, fut cassée en plusieurs endroils, de sorte qu’il ne restait plus de cetle ouvre d'art qu'un trone mutilé et informe. Le curé, désireux de remplacer cette statue, en fait venir une autro d'Europe, et, sans prévenir les habitants, opère le changement pendant la nuit. Le lendemain, grand émoi dans le villagge : on a enlevé le saint qui protégeail te pays, le nouveau venu n'y est pas encore habitué, son inlercession ne servira de rien, etc. Les plaintes s'exhatent de toutes parts, deviennent même? de plus en plus menaçantes, à tel point que le curé se voil obligé de réintégrer la vieille image sur son piédestal. L'aflaire fut néanmoins portée devant te président de la République, el, pour concilier tous les intérèts, il fut décidé que les deux statues seraient placées l'nne à côté de l'autre, afin que le saint le plus ancien pût mellre son successenr au courant de ses nouvelles fonctions.

Après Uspantan, nous traversàmes Cunen, villagge entièrement indien, où il n'y a qu'un seul ladino, le secrétaire de la municipalité, dont les fonctions sont loin d'ètre une sinćcure. De là, toujours en nous avançant vers le nord, nons passàmes près de Nebak, à la frontière de la civilisation; après ce villagoe, ce. n'est plus que mystère, et c'est à peine si, dans nos entretiens avec les indigò̀nes de Cunen, nous avons pu obtenir un renseignement sur les Lacandons, qui paraissenl vouloir s'éloigner de jour en jour des localités qu'ils fréquentaient autrefois. L'intérêt d'un voyage dans ce pays entièrement neuf élait bien vif; malheureusement nous ćtions pressés par le temps, el les moyens d'exécution nous auraient manqué au bout de quelques jours, dans ces vastes solitudes et dans ces lorêts presque impémétrables. On ne sait rien, ou à peu près rien, jusqu’ici, do ces Vovage géologique. 
Lacandons, sur les mours desquels on a forgé mille descriptions plus burlesques et plus exagérées les unes que les autres.

Sicapulas.

Au delì de Nebak, la route incline vers le sud-onest et descend encore une fois au bord du Chisoy que nous traversons à Sacapulas, sur un pont des plus primitits. Sacapulas élail autrefois, comme Quiché et Uspantan, la résidence d'un cacique puissant dont la soumission aux Espagnols ne s'obtint qu'après de longues années. Ce n'est plus arjourd'hui qu'une petile bourgade de 3,5 o o habitants, dans Inn climat chaud el malsain, el où la principale industrie consiste à extraire le sel de quelques sources salées ou salines du voisinage.

Santa Cruz del Qirishé.

De Sacapulas à Quiché, ancienne capilale du royaume de Quiché, dont les ruines, visitées par Stephens et Daly, attestent encore l'antique splendenr, on compte près de douze lieues, par une route épouvantable, même pendant la saison sèche. Près des ruines de Quiché, dans une belle vallée, s'élèvo aujourd'hni la petite ville de Santa Cruz del Quiché, d’où les Indiens ont presque entièrement disparu. La populaion est à peu de chose près entièrement composée de ladinos, au nombre de 4,500 environ. Au moment de notre passage dans celle ville, les ladinos étaient en grand émoi, car les Indiens menaçaient de se soulever, el déjà un ou deux mélis avaient payé de leur vie les torts de leurs conciloyens envers les Indiens; il s'agissail, autant que nous le croyons, de quelque portion de territoire d'une municipalité indienne, qui en avait été dépossédée par d’autres Indiens pour lesquels les ladinos avaient pris parti. Les Indiens, voyant que leurs droits étaient si facilement lésés, avaient résolu de résister, et l'on avail eu jusque-là beaucoup de peine à concilier le différend.

Voici, d'après Juarros ${ }^{(1)}$, la description de Quiché à l'époque de la conquète: "Cet endroit (Santa Cruz del Quiché) est surlout remarquable pour avoir été autrelois la grande et opulente cilé d'Utallan, cour des rois de Quiché, el sans contredil la plus somplueuse que rencontrèrent les Espagnols dans cetle province. L'intéressant écrivain D. Francises de Fuentes, chroniqueur de ce royaume, fit le voyage de Quiché pour éludier ces anliquilés, et, irràce en partie aux ruines qu'il étudia, en partie aux manuscrits qu'il examina, il a pu nous donner une description de celle cour. Elle se trouvait à l'endroit où existe aujourd'hui le vil-

\footnotetext{
(1) Juarros, Compendio de la Historia de la ciudad de Guatemalu, ete., t. I, p. 66 et suiv.
} 
DANS LES RÉPUBLIQUES DE GUATENALA ET DE SALVADOR.

lage de Santa Cruz del Quiché, ol l'on peut se convaincre que ce qui reste n’est qu'un faubourg de l'anlique cité. Elle élait entourée par une profonde barranca qui lui servail de fossé, et on n’y voyait que deux entrées fort étroiles, défendues par le château du Resguardo, qui les rendait inexpugnables. Le centre de la capitale était occupé par le palais royal, entouré des maisons de la noblesse; to peuple vivail aux extrémilés de la ville. Les rues élaicut fort étroites, et la population si nombreuse, que le roi put y trouver 72,000 comballants pour arrêter la marche des Espagonols.

"Cette opulente cité renfermail de nombreux el somptueux édifices, parmi lesquels on remarquait surtout le séminaire où étaieut élevés el instruits 5 à 6,000 enfants, nourris et entretenus aux frais du lrésor royal. Soixante mailres et professeurs s'occupaient de leur éducation. Comme chose grrandiose il faul encore citer le château de la Alalaya, qui, s'élevant de quatre élages, pouvail recevoir une innombrable quantité de défenseurs. Le chàleau du Resgruardo n’élait pas moins considérable; celte forteresse, longue de 188 pas el profonde de 230 , se composait de cinq corps de batiments principaux.

* Mais ce qu’il y avait de plus magnifique était le grand Alcazar on palais des rois du Quiché : d'après Torquemada, il ne le cédail en sompluosité ui à celui de Moctezuma à Mexico, ni à celui des Incas dans te Cuzco. La façade, dirigée de l'est à l'ouest avail 376 pas góométriques de longo, et il était profoud de 728 . II était construil en pierres de laille de couleurs varićes, suivant un plan aussi élégant que majestueux. Il se divisail en six départements : le premier servait de logemenl à une nombreuse troupe de lanciers, d'archers el d'autres soldats expérimentés qui gardaient la personne royale. Le second ćtait l'habitation des princes ef des parents du roi, qui y vivaient dans la plus grande magnificence aussi longtemps quills nétaient pas mariés. Le troisième était la maison et le retrail du roi; il y avait des appartements et des chambres distincts pour la matinée, l'après-midi et la nuit. Dans une des salles était le trône royal; il s'élevait au-dessous de quatre éventails de plumes et on y montait par plusieurs gradins. Il y avait encore dans cette partic du palais la maison du trésor, le tribunal des juges du peuple, le dépòt d'armes, les jardins, vergers, volières d'oiseaux, ménageries de bètes faures et une multitude d'autres choses. Dans le qualrième et le cinquième dépar- 
tement élait le palais des reines et des concubines du roi; il étail immense, contenaut d'abord une quantité d'habilations pour toutes les reines, et, en outre, uı grand nombre de jardins, de vergers, de bains, de réservoirs, où l'on élevait les canards dont les plumes servaient à confectionner des tissus et diverses autres choses. Tout près de là élail le sixième, qui servait de collége des vierges, et l'on élevait là les infantes et autres jeunes filles de sang̛̣ royal.

e La nation des Indiens Quichés ou Tultèques exerça sa domination sur la plus grande partie de ce royaume. On voit dans cerlains manuscrits (composés par quelques-uus de leurs principaux caciques qui apprirent à écrire), qu'entre le règne dé Tamub, qui les conduisit de leur ancien royaume à leur nouveau, el celui de Tecum Uman, qui était sur le tròne quand arrivèrent les Espagnols, vingt rois se succédèrent dans l'exercice du pouvoir. Celte race s'était d'abord élablie dans l'empire mexicain, où elle fonda la fameuse ville de Tula, à l'endroit où se trouve aujourd'hui le village de Tula, à 14 lieues de Mexico. Peu de temps après, le roi $\mathrm{Ni}$ muquiche, obéissant à un oracle, les emmena de Tula pour fonder un nouveaı royaume. Après bien des années de pérégrination, ils s'établirent ì Quiché, qu’ils nommèrent ainsi en souvenir de leur roi. Ce prince élait mort pendant le voyage, et ce fut son fils Exopil qui pénétra dans cette région à la tète de son peuple. II se rendit célèbre non-seulement pour avoir fondé le royaune de Quiché, mais encore pour l'avoir divisé plus tard en trois, restant lui-mème à Quiché el donuant à son fils añé Jiutemal (on peut y trouver une étyuolog̛̣ie très-naturelle du nom de Guatemala) le gouvernement des Kachiquels ou de Guatemala, et à son second fils Axiquat celui des Zutugites ou d'Atitlan."

Girucle arète montagnense, entre Quiché t Tolonikapam.
Sur la route, en quiltaut Quiché, on ne rencontre plus que quelques pauvres villages, situés à des hauteurs comparables à celles du grand plateau mexicain, c'est-ì-dire à 2,800 ou 3,000 mètıes au-dessus du niveau de la mer. Nous traversions une magnifique forêt de sapins, au sommet de la Cordillc̀re, lorsque nous fûmes surpris par un orage épouvantable, qui nous accollpagna presque jusqu’ì Totonikapam. La pluie tombait à torrents el détrempait l'argile du chemin, dont leș pentes, en certaius points, étaient d'une roideur désespéraute. Des escaliers taillés dans le roc remplaçant tout à coup la roule dans plusieurs endroits, nos mulets ne pouvaient avancer qu'avec mille précautions. Enfin, 
DANS LES RÉPUBLIQUES DE GUATEMALA ET DE SALVADOR.

après qualorze heures de marche, sur une roule extrêmement accidentée, dont les plus grandes dénivellations diffèrent d'au moins 1,500 mètres, nous arrivàmes ¿ Totonikapam, préfecture du département le plus considérable des Altos, dont la population s'élève à près de 20,000 habitanls.

Tolonikapam est bàti sur une hauteur comme loutes les anciennes villes indiennes, et au pied de la colline serpente une pelite rivière, dont les eaux reçoivent celles de plusieurs sources minérales el thermales, qui paraissent avoir donné leur nom ì la localité. Les construclions irrégulières de cette ville sont rópandues d'une manière peu uniforme sur les flancs de la colline, el elle est hiıbitéc presque exclusivement par les Indiens des Altos, qui diffèrent beaucoup, comme nous l'avons vu, de ceux des terres chaudes.

Lia tempéralure de ces régions est en effet beaucoup plus basse, el la végétation se rapproche de celle de nos climats tempérés d'Eirrope. Le blé, le maïs, l'orgo' et l'avoine, y sont cultivés avec succès, el la province des Altos est, en quelqur sorte, le grenier du Guatemala.

'Totonikapam est une ville industriclle, où l'on fabrique beaucoup d'élofles de laine dite jerga, el des instruments de musique; les marimbas et les guilares de Totonicapam jouissent d'une réputation mérilée. Deux fois par semaine la placr principale de la ville est singulièrement animéc par d’immenses rassemblements d’Indiens, qui apportent en foule les denrées qu'ils ont récollées dans les environs de leurs ranchos.

Les Indiens des Altos ont cela de particulier' qu’ils travaillent généralement jour leur propre comple, el vont rarement s'élablir dans les grandes haciendas de sucre et de calé. Leur pelit champ de blé, de maïs ou de frijol, lenr milpa, comme ils disent, suffit à leur existence, et avec l'excédant de ces productions naturelles ils cutreliennent leur famille. Ils sont généralement donx el honnêtes, mais un peu méfiants et toujours excessivement jaloux des métis; ils reconnaissent toutcfois clıez les blancs une certaine supériorité intellectuelle, et, s’ils n’étaient pas aussi enclins ì l'ivrognerie, ils tendraient plutôt à se relever de l'abaissement où les avait plongés la domination trop exclusive de l'Espagne. Le gouvernement de Guatemala a d'aillents lout à gağier en gardant à leur égard beaucoup de ménagements, car, réunis en masse, ils constituent une force imposante, el, dans plusieurs occat- 
sions, le président Carrera s'est servi de ces puissants auxiliaires pour demeurer all pouvoir.

hioute

de Totouikipam

à t)mozaltenangro.

La vallće qui sépare Totonikapam de Quezaltenango nous rappela à s'? Iromper res vastes plaines du Mexique, situées aux environs de P'érote, près de Tepeyahualco par exemple; cétait la mème limpidité daus l'almosphı̀re, la mème température très-basse au lever du soleil, les mèmes végétanx : le nopal, avec ses feuilles épineuses el ses fleurs d'un rouge écarlate, l'agavé (maguey), dont les rejetons couvraient une partie de la plaine, et enfin le yuca arborescent, qui de lemps en temps rompt la monotonie de ces éternelles plantes à feuilles govasses it charnues.

On commail goénéralement le procédé employé par les habitants des hauts plaleaux de l'Amérique équinoxiale pour retirer du maguey lia boisson qu'ils appelleut le pulque; mais ce qu'ou sait moins généralement, c’est que cel arbuste joue dans les lierras frias le mème rôle que le cocotier dans les terres chaudes. Avec le pulque on fait de l'excellent vilnaigre el aussi de l'eau-de-vie; les feuilles du magouey peuvent servir à couvrir des huttes el fournissent une sorte de fil très-dur, dont on fabrique des lissus el des cordages. Les anciens Indiens n'avaient pas d'autre papier que cetui qu'ils reliraient du tissu fibreux de l'aloc̀s: Fuentẹ̀s, dans ses chroniques, assure avoir vu un gorand nombre de pétitions présentées aux successeurs d'Alvarado, écrites sur' ce papier. Les lougues épines du maguey peuvent très-bien remplacer tes épingles, même les clous, el l'on voit encore aujourd'hui beaucoup de ranchos couverts en feuilles du même arbuste. Enfin, les feuilles, soumises à une ébullilion prolongée, deviennent très-comestibles, légèrement purgạatives, et le suc qu'on en extrail est souvent employé pour guérir les blessures récentes.

Quezaltenango, silué à 5 lieues de Totonikapam et à 42 lieues de Guatemalia, dans une vallée lougue, étroite el entrecoupée de quelques barrancas, est la denxième ville fondée dans le pays par Alvarado, pendant son expédition contre le roi des Quichés. Le nom indien de Quezalltenango provient de ce qu'autrefois on rencontrail dans les environs beancoup de quezales (Quezal-lenango, village des quezales).

Il a ćté souvent question de diviser le Guatenala en deux parties distinctes, et de laisser Quezaltenango comme capitale des Altos; mais cette situation, qui n'a 
DANS LES RÉPUBLUUES DE GUATEMALA ET DE SALVADOR,

duré que quelques mois pendant la fédération des ḱtats de l’Amérique centrale, n’a point été rétablie depuis lors. Celte ville est très-intéressante à beaucoup de points de vue; sa population d'environ 20,000 àmes, dont 15,000 Indiens, se compose de gens très-industrieux et d'arlisans adroits dans tous les corps de métier. Il semblerail presque que l'ancienne judustrie des Indieus, qui a alsandonné toules les autres parties du Guatemala, s'est réfugiéc à Quezaltenangoo. On y compte en effet vingt fibriques plus ou moins importantes de tissus de linine, et une grande fabrique d'ean-de-vie. De neême qu'à Tolonikapam, la coulection des iustrnments de musique y occupe plusien's cenlaines d'onviers, qui savent, avec des outils aussi simples que primilifs, créer de toutes pièces des guilares qui rivaliseraient presque avec les instruments du mème genre construits en Europe. Nous applaudirons moins à l'établissement de la girande fabrique d'eau-de-rie, où le gouvernement, qui a gardé le monopole de ce produit, affer'né d'ailleurs à de. puissants proprićtaires, spécule ainsi sur les passions des Indiens. L’ivrognerie esl en eflet poussée à un point extrême chez ces populations, qui trouvent peut-citru dans les fumées de liviesse une compeusation à l'anertume d'une existence véritablenent dure el misérable. Ou a peine à croire cependant que l'can-de-vie remplace chez ces Indiens l'opium des Chinois; car le plus souvent l'Indien à moitié ivre est triste el sombre, el rarement la gaieté illumine sa physionomie impassible.

Tous ne dirons rien de la ville elle-même, de ses édifices, de ses ressources; l'étranger n'y est pas toujours accueilli avec, une exlrème bienveillance, et Qnezaltenaugo nous représente plutôt un village manufacturier de France que la calpitale d'un État imporlant. A une heure environ de (Quezaltenango, dans mur localité du nom d'Almolonga, on voil de belles sources llermales soi-disant sulfureuses; il y existe depuis pen un étahlissement llermal, qui est devenu le but de promenade favori des habitants de la ville. Almolonga est situé au pied d'un volcan éteint qu'on nomme le Zuñil.

I l'ouest de Quezaltenango s'élèvent aussi deux très-bcaux volcans connus soís les noms de volcan de Sinla Maria el de Cerro Quemado. Le Cerro Quenado est encore très-actif, etnous en avons fait l'ascension; son peu de hauteur eu rend l'accès lacile, et unc faible partie du cône sculement est recouverte par la régétation. 
Koule

de Quezaltenango

à Giratemala.

Quezaltenango est relié à la capitale par une route carrossable assez bien tracée, qui passe au sommel de la Cordillère, el suit presque la crète des plus hautes montagnes du pays. Le point culminant de cette roule, situé à quatre lieues de Totonikapam, est ì environ 3,180 mètres au-dessus du niveau de la mer. Les conifères qui couvrent cette région très-élevée sont de dimensions très-remarquables, et ils descendent jusqu'à 2,200 ou 2,300 mètres de hauteur.

Près du point culminant de la Cordillère, par une sorte d'échappée entre deus longues chaînes transversales, on aperçoit d'un seul coup d'œil toute la côte du Pacifique, el la longue série des volcans qui suil la direclion de cetle côte; ils sont tous silués presque à égrale distance les uns des autres, et leurs alternances. an point de vue de la lanteur, sont très-curicuses à observer.

1 quelques lieues de l'anlique cilé de Tecpan-Guatemala, capitale autrefois du Poyaume des Kachiquels, nous laissâmes à gauche la roule de Gualemala, pour nous diriger du còté du lac d'Atitlan el de la ville de Solola. Cette dernière localité ne présente rien de remarquable, et, à part le mouvement qu'une grande fahrique d'eau-de-vie y occasioune, c'est à peine si elle mérilerait une mention spéciate. Elle est située au bord des falaises verticałes qni environnent te magnifique lac d'Atillan sur presque tout son pourtour.

Ce lac, d'environ six à sept lienes de tour, est placé au milieu d'un des siles les plus pittoresques du Guatemala. Toule la partie septentrionale est entourée de hautes falaises, qui permettent à peine de s'approcher de la rive, tandis que, sur la côte du sud, s'élèvent plusieurs volcans, dont le principal, le volcan d'Atitlan, projette son ombre gigantesque dans les eaux limpides et transparentes du lac.

Les rives et les environs de celle belle nappe d'eau sont couverts de villages très-peuplés, parmi lesquels nous cilerons Atillan, qui renferme 20,000 Indiens, San Pedro, et en parliculier Santa Catarina Ixtlahuacan, dont les liabilants, au nombre de 15,000, tous Indiens, ont des liabiludes de travail el de sobriété qui contrastent singulièrement avec la paresse et l'ivrognerie de leurs voisins. Un autre villagge, San Antonio, juché comme un nid d’aighle, s'élève en amphithéâtre sur une falaise ahrupte, et il est complétement inabordable du côté du lac; il 
faut, pour y arriver, gravir les falaises voisines, et descendre ensuite jusqu’à mihauteur de ces immenses amas de rocher's.

Quclques pirogues formées de trones d'arbres creusés et deux ou trois barques plus modernes sillonnent ce lac, dont la profondeur est énorme, et telle que, jusqu'ici, on n'a pas encore pu la déterminer avec des sondages à plus de deux cents mètres. L'eau est pure, linpide el polable; elle ne renferme aucun principe minéral. On y pèche d'assez bon poisson, mais en petite quantité.

Nous traversâmes le lac dı nord au sud, du village de Panajachel au village de San Lucas : c'est Je moins peuplé des villages des bords du lac, et de lì un senticr tracé dans les forêts nous conduisit à la grande hacienda de San $\Lambda_{g}$ gustin.

Il y a huit ou dix ans, les terrains de cette hacienda étaient courerts d'épaisses San Igustin. forêts, lorsque deux Français ${ }^{(1)}$, aussi intelligents que courageux, se mirent à défricher une partie de ces immenses étendues de territoire inculte et sauvago que le gouvernement de Guatemala possède sur le versant du Pacifique, et qu’il a le bon sens de savoir aliéner à un prix extrèmement modique. Les cendres provenạnt de la combustion des bois, jointes à celles du volcan, donnc̀rent au sol une fertilité inconnue jusqu'alors, et les produits des nouvelles plantations dépassèrent toules tes espérances. Aujourd'hui on a défriché plus de trois cents hectares, et San Agustin sera bientòt une des plus riches plantalions de calé du Guatemala. La situalion de San Agustin au pied du volcan d'Atitlan promettait de nous en laciliter l'ascension, el ce ful de lì en effel que nous partîmes en dirigogeant nos pas vers cette montagne.

La base du volcan est entourée d'une ceinture de forêts excessivement touffues et tout à fait impénétrables. C'est à peine si quatre Indiens, que nous avions envoyés en éclaireurs, parvinrent, en deux jours, à nous ourrir un chemin presque invisible, et où il était très-facile de s'égarer. On ne peut se rendre compte des difficultés et des fatigues que l'on éprouve pour circuler au milieu de ces forêts vierges, lorsque, à chaque pas, sur un terrain rendu élastique par les détritus des végélaux, on est arrêté par les plantes grimpantes et par les lianes qui s'entrelacent de toutes parts. A certains moments, on est littéralement obligé de ramper

(1) MVI. G. et H. Bramma, auxquels nous devons donner un témoignagge tout spécial de bon souvenir et de recounaissance.

Voyage géologiquc. 
pour éviler quelque branche qui u’a pas été coupée, ou bien encore le terrain eșt si marécageux, qu’il faut presque sauter de branche en branche pour franchir un hourhicr fangeux dont on ne pourrait sortir.

Bolcan d'Mtitlan.

Après aroir traversé la forêt, nous étions arrivés au pied du cône, mais l'absence de tout guide venait encore créer de nouvelles difficultés; anssi bien eùt-il été impossible d'en trouver un, car nous élions les premiers à tenter l'ascension de ce volcan. De.tous côlés la roule nous élait barrée par d'immeuses ravins à parois verticales, et nous ue voyions, au premier abord, aucum moven de lourner la difficulté. Il fallut cependant preudre un parti; après avoir iuslallé notre tente, uous partìmes chacun de notre còlé à la recherclıe d'un endroit praticable. Après bien des tàtonnements, un passagge fut enfin découvert, et, dès le lendemain, nous commençàmes l'ascension. Après avoir lourné deux ou trois de ces profonds ravins qui uous effrayaient la veille, nous nous trouvions, à sept lienres du matiı, à lu limite de la végétation arborescente. Là, pendant le court moment de repos qui nous était nécessaire, nous ressentimes une violente secousse de tremblement de terre, et des frağments de rochers se détachèrent de la crète qui for'me le hord du cratère pour venir rouler jusqu'ì nos pieds, taudis que, dans les ravins que nous venious de traverser, il se produisail des éboulements sous lesquels nous eussions élé infailliblement ensevelis, si le phénomène avait eu lieu une leure plus tôt. Nous n'en continuâmes pas moins à monter, mais nous avious un peu trop préjugé de la faible hauteur du pic, car ce ne fut qu'à cinq lieures de l'après-midi que l'un de nous réussit ì en atteindre la cime.

A peine eut-on le temps de faire quelques observations au sommel avant l'arrivée d'un orage terrible qui enveloppa la montagne, et nous n'étions pas à trois cents mètres du bord du cratère que la foudre s'y précipita avec fracas. L'obscurilé devenait de plus en plus grande, et, lorsque nous eûmes regagné la limite de la végétation arborescente, où nous nous élions arrètés dans la matiuée, il étail nuit close. La pluie, qui était lombée à torrents, avait rafraichi l'atmosphère, et nous n'avions d'autre abri que deux ou trois arbustes à peine garnis de feuilles; le bois élait tellement détrempé, qu’il élait impossible d'allumer du fen; ser'rés les uus contre les autres, exténués et à moilié transis, nous alleudions le jour avec impatience, et, aux premiers rayons du soleil levant, nons reprìnes promp- 
tement le chemin de notre tente, puis enfin celui de San Agrustin, où la cordiale réception de nos compatriotes nous fit bientôt oublier les fatiggues des nuits précédentes.

San Agustin fut la dernière ćlape importante de notre voyagge dans le Guatemala, et, quoique éloigús de près de 15 o kilomètres de la capilale, il ne nous fallut que trois jours de marche ponr y revenir, en parcourant rapidenent une région qui ne nous offrait que peu d'inlérêt au point de vue scientifique.

Nous devons néanmoins en signaler les principales particularilés el mentionner tout d'abord les admirables points de vue dont on jouit sur Je lac el le volcan d'Atillan aux abords de la maison de refuge de Godines, élablie par les Indiens du village de San Antonio. Un peu an delà de Godines, il faul franchir de prolondes barrancas creusées par les cours d'eau qui prenuent naissance dans les hauls plateaux avant de se précipiler sur le versant du Pacifique. Ces ravins abrupts contribuent beaucoup à isoler et à appauvir les gros villagges de Patsum et de Pasesilla, qui, situés au milieu de plaines fertiles et habilés par une population iıdienue assez intelligente et travailleuse, sont uéanmoins en voie de décadence prononcée. Parmi les causes multiples qui contribuent à ce fàcheux résultat, il faut citer la dépopulation, amencé en peu d'amnées par le développement quionl pris les plantations de café dı versant du Pacifique, an détriment des cultures de céréales des lauts plateaux, plus pénibles el moins lucratives.

Chimaltenango, situé, comme Patsum et Pasesilla, au milieu de grandes plaines assez analogues à celles du Mexique central, mais à quelques lieues seulemenl de La Antigna, ne se trouve pourtant pas daus une situation beaucoup plus florissante.

De La Autigua à Guatemala nous prîmes l'ancienne roule, non carrossable, qui passe par Mixco, gros village indien situé à trois lieues seulement de ta capitale, et qui liut jadis une imporlante cilé, presque rivale de Tecpau-Guatemala. Au sortir de Mixeo il nous fallut traverser une profonde barranca creusée à sa naissance par le torrent qui doit etre plus tard la Michaloya, el bienlôt après nous rentrions à Guatemala, ayant recueilli, pendant plusicurs mois de voyage, les éléments des travaux scientifiques qui feront l'objet des livres suivants. 
Déjà nous préparions de nouveaux projets d'excursion, lorsque des circonstances particulières hâtèrent notre retour. Nous prîmes donc congé de celte ville et de ce pays, dont nous emportions les mcilleurs et les plus agréables souvenirs, et, gagnant rapidement l'océan Pacifique, nous trouvâmes un paquebol qui nous prit à son bord. Longtemps nos regards restèrent fixés sur celte terre amie, et lorsque, aux derniers feux du soleil couchant, les pics fumeux de cette belle région disparurent pour toujours dans la brume, la joic du retour dans la mère patrie n'était pas sans mélange de quelque regret pour le pays que nous laissions derrière nous. 


\section{LIVRE II.}

GÉOGRAPHIE PHYSIQUE, CLIMATOLOGIE, MÉTÉOROLOGIE.

\section{CHAPITRE PREMIER.}

gh́ogRAPHIE PHYSIQQUE.

Aspect général de la partic du continent américain dite Amérique centrale. - Grandes dénivellations du sol; allures orographiques; directions des principales chaines de montagnes. - Hypsométrie. lignes de partage des caux. - Cours des fleuves les plus importants. - Laes.

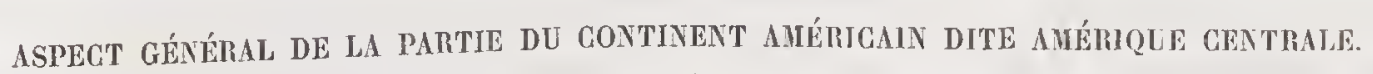

Unissant entre eux deux vastes continents, ouvrant ses ports sur deux océans. l'Amérique centrale réalise en quelque sorte l'antique et belle idée du centre du globe: Baignée par le golfe du Mexique et la mer des Antilles d'un côté, par l'acéan Pacifique de l'autre, se reliant par le Darien aux hautes régions de la Nouvelle-Grenade, par l'isthme de Teluantepec aux immenses plateaux du Mexique, cette contrée privilégiée semble appelée à concentrer un jour sur elle la majeure partie des intérêts du globe, autant peut-être par sa position unique au monde que par ses remarquables allures topographiques, qui condensent sur un espace de quelques centaines de lieues carrées tous les climats et toutes les productions.

L'Amérique centrale, telle que nous la comprenons, est une étroite bande de terre comprise à peu près entre les $8^{\mathrm{e}}$ et $18^{\mathrm{c}}$ degrés de latitude, de l'isthme de

Amérique centralr. Côtes du Parifique. Panama à l'isthme de Tehuantepec; malgré les iirégutarités el les siuuosilés de son contour, elle peut se ramener approximativement à une direction rectiligne courant de l'est $35^{\circ}$ sud à l'ouest $35^{\circ}$ nord, entre le $80^{\circ}$ et le $95^{\circ}$ degró de ton- 
gitude ouest. Il est à remarquer que cela est beaucoup plus vrai pour la côte du Pacifique que pour celle de l'Atlantique, où sont réunis presque tous les accidents brusques. La côte du Pacifique, abstraction faite du rentrant asse\% profond de Panama, peut être considérée comme composée de deux ligones presque droites se coupant au golfe de Fonseca, sous le $13^{\mathrm{e}}$ degré de lilitude. La première de ces lignes, courant au N. O., forme les côtes du Costa-Rica et du Nicaragua, dentelées, il faut le reconnaitre, par un certain nombre de golfes plus ou moins prolonds; la seconde, s'incliuant un peu sur la précédente, se dirige vers l'ouest $20^{\circ}$ nord, Ir longr du Salvador el du Guatemala, et ne présente le plus souvent qu’une plage rectiligne el continue, dont rien n'égale ta monotone régularité.

Cides de l'Allantipur.

Groupe particulici des Litais

de Salvadn.

et de Guatomala.
Du côté de J'Atlantique, au contraire, la lig̣ne des côles est brisée dans tous les seus el projelte rers le N. E. deux régions saillantes séparées par de profondes échancrures. Presque immédiatcment après la baie de Mosquilos, dont la courbe profonde se combine arec le golfe de Panama pour déterminer le principal rétrécissement de l'isllime, les terres se développent an loin, vers le nord, pour former ces régoions basses el insalulıres, à peine habitées el à peine connues, diles Pays des Mosquitos. Le cap Gracias a Dios termine l'avancée, que limile dans l'autre sens le "Teux profond de la haie de Honduras. Vient ensuite la grande presquîile du Yucalan, qui se prolonge fort avant dans le nord-est jusqu'au cap Catoche, et dont les deux faces, presque parallèles entre elles, naissent, l'une au golfe d'Analique, ant fond de la baie de Honduras, l'antre à la Laguna de Terminos, extrémité du golle du Mexique. Il existe donc, en quelque sorte, trois étranglements successifs, conprenaut entre eux des élargissements correspondants, élargissements qui ne sont pas seulement des accidents du dessin des côtes, mais qui dépendent du relief général de la coultée; car, si l'on y regarde de près, on verra que leur naissance, si l'on ose s'exprimer ainsi, correspond à de puissants nouds montagneux vigoureusement accusés sur l'arète saillante qui dessine l'ossature de l'Amérique rentrale.

La région que nous nous proposons d'examiner avec quelques délails correspoud au plus considérable de ces élargissements, c'est-ì-dire au point d'où diverge presque transversalement la grande presqu'île du Yucalau, et comprend, avec: une petite partic de lis république de Honduras, les républiques de San Salvador et de Guatemala presque tout eutières. C'est une zone remarquable à tous 
DANS LES RÉPUBLIQUES DE GUATEMALA E'T DE SALVADOR. 79 égards, riche en promesses d'avenir, fertile en observalions nouvelles, aussi intéressante pour l'économiste que pour le savant. Ses montagnes colossales el ses profoudes vallées, ses plaines lécondes el ses rochers ardus, ses pics glacés par le vent. du nord et ses sables brùlés par le soleil des tropiques, tout y porte la vigoureuse empreinle d'une nature vierge encore et qui n'a point livré tous ses secrets. La góologie, nous le montrerons en son temps, y trouve une ample moisson de sujets d'éludes; la géographie physique, quelque peu complets que soient malheureusement encore les éléments du travail, ne doil pas néģigger d’y porter son regard investigateur. Mais, nous dévons l'avouer tout d'abord, il ne nous sera ğuère possible de présenter autre chose que des considéralions générales, et par cela mème un peu vagues, car les observations précises ont fail, jusqu’à présent, presque absolument défaul. S’il est vrai que le tracé des còles a élé élabli avec ıne exaclitude presque toujours suffisante, souvent mème parlaite, gràce aux remarquables Iravaux hydrographiques des savants marins qui ont séjourné dans ces paraģes, il faut recommaitre, d'autre part, que nos connaissances géographliques relatives ì l'intérieur des terres sont restées dans une déplorable infériorité. Il suflit, pour s'en convaincre, de jeter un coup d'ceil sur les différentes cartes qui ont été publiées, el dont quelques-unes jouissent mème d'une grrande notoriété; on y verra des différences inexplicables, relalivement à la position des grandes chaines de montagnes, à la direction des principaux cours d'eau, el mème ì la siluation des villes les plus importantes. Il faudra bien admeltre, pour s'en rendre comple, que ces cartes ont été composées au moyen d'observalions imparfaites on de renseignements vagues, et y faire entrer, comme un des ćléments les plus imporlants, l'appréciation personnclle des géographes sur des fails mal connus.

POSITIONS GÉOGRAPHIQUES.

Lin ce qui concerne l'étude des còtes, on est surtout redevable de recherches imporlantes aux marines des ÉLats-Unis, de l'Angleterre el de la France. MM. de

Eilude des cóte: dı Guatemala. Lapelin et le comle de Gueydon, qui furent tous deux gouverneurs de la Martinique après avoir commandé nos stations navales du Pacilique, ont contribué, pour leur part, à fournir les premiers éléments d'une carte de l'Amérique cen- 
Irale. Ainsi M. de Gueydon, entre autres observations, nous a laissé l'importante détermination de la position de l'embouchure du Rio Lempa, qui se trouve, d'après lui, par $13^{\circ} 12^{\prime} 30^{\prime \prime}$ de latitude nord, et $91^{\circ} 1^{\prime}$ de longitude onest du móridien de Paris. De son côté, M. de Lapelin, étant en rade de San José de Guatemala, a pu délerminer approximalivement de là la position de quelques-uns des principaux volcans qui se dressent à quelque distance du rivage.

Comnaissance des positions de l'intérimur.

Il y a quelques années encore, on n'avait, sur les positions géogoraphiques des points les plus imporlants de l'intérieur des terres, que des données entièrement vagues. Les éléments de la position de la ville de Guatemala n'avaient même pas été lixés définitivement, ainsi que le prouve ta liste suivante des différentes valeurs qu'on leur avait assignnées depuis le commencement du siècle.

\begin{tabular}{|c|c|c|}
\hline & $\begin{array}{l}\text { Lalitude } \\
\text { nord. }\end{array}$ & $\begin{array}{l}\text { Longitude onest } \\
\text { du méridien de Paris. }\end{array}$ \\
\hline Juarros, Histoive de Guatemala, $1802 \ldots \ldots \ldots$ & $14^{\circ} 40^{\prime}$ & $94^{\circ} 30^{\prime}$. \\
\hline Balby, Geograplic universelle, .... & $14^{\circ} 28^{\prime}$ & $9^{5^{0}} 0^{\prime}$ \\
\hline Gazette de Guatemala, $1809 \ldots \ldots \ldots \ldots \ldots$ & $"$ & $9^{3^{\circ}} \quad 11^{\prime}$. \\
\hline Demos (Gazette de Guntemala), $1809 \ldots \ldots \ldots$ & $n$ & $95^{\circ} 11^{\prime}$. \\
\hline Anonyme (Gazette de Guatemala), $1809 . . \ldots \ldots$ & $n$ & $94^{\circ} \quad 11^{\prime}$. \\
\hline Anonyme (Gazelte de Ciuatemala), $180 \eta \ldots \ldots \ldots$ & $" 1$ & $9^{3^{0}} \quad 11$ \\
\hline Anonyme (Gazette de Cuatemala), $1809 \ldots \ldots$. & $14^{\circ} \quad 15^{\prime}$ & $"$ \\
\hline Kirklıot, Plan de la Antigua, $1825 \ldots \ldots \ldots \ldots$ & $14^{\circ} 37^{\prime}$ & $92^{\circ} 50^{\prime}$. \\
\hline Pivera Maestre, Atlas de Guatemala, $1832 . . . .$. & $14^{\circ} \quad 32^{\prime}$ & $91^{\circ} \quad 17^{\prime}$. \\
\hline Van den Gehühte (Gazette de Guatemala), $1852 \ldots$ & $14^{\circ} 35^{\prime} 51^{\prime \prime}$ & $92^{\circ} 48^{\prime} 52^{\prime \prime}$ \\
\hline Cervantes, $1856 \ldots \ldots \ldots \ldots \ldots \ldots \ldots$ & $14^{\circ} 36^{\prime}$ & $"$ \\
\hline R. P. Cornette, par une éclipse, $1856 \ldots \ldots \ldots$. & $"$ & $92^{\circ} 24^{\prime} 45^{\prime \prime}$ \\
\hline R. P. Cornette, par le fil à plomb, $1856 \ldots \ldots$. & $14^{\circ} 37^{\prime} 31^{\prime \prime}$ & $"$ \\
\hline R. P. Cornette, par les hauteurs méridiennes, 1856 & $14^{\circ} 35^{\prime} 30^{\prime \prime}$ & " \\
\hline Baily, Carte du Guatemala, $1853 . . .$. & $14^{\circ} \quad 36^{\prime}$ & $92^{\circ} 58^{\prime}$ \\
\hline
\end{tabular}

Aujonrd'hui les travaux de l'observatoire du Collegio Tridentino de Guatemala ont permis de fixer la position de cette ville d'une manière à peu près certaine. Voici quelles sont les coordonnées géographiques que l'on y a admises pour le bìtiment principal du collége des Jésuites, et qui probablement n'auront pas à subir de nouvelles corrections :

GUATEMALA.

Latitude nord. . . . . . . . . . . . . ${ }_{14} 4^{\circ} 36^{\prime}$

Longitude ouest du méridien de Paris........ $92^{\circ} \quad 44^{\prime} 39^{\prime \prime}$. 
DANS LES RÉPUBLIQUES DE GUATEMALA ET DE SALVADOR. 81

A l'époque où l'observatoire du Collegio Tridentino élait sous la direction du R. P. Cornette, on s'y est aclivement occupé, pendant quelque temps, de la détermination des positions géographiques, et l'on a obtenu ainsi un grand nombre du Collegio Tridentino de Guatemata. d'éléments importants. Ces documents nous ont été communiqués avec la plus aimable complaisance, et c'est grâce à eux que nous avons pu établic le réseau qui sert de base à notre esquisse d'une carte géologique. Nons allons analyser ces travaux en quelques mots. La première chose à faire était de poser un essai de triangulation dont les éléments étaient naturellement fournis par les grands volcans, dont les pics isolés environnent Guatemala comme des jalons naturels. Les hases de cette triangulation ont été établies ainsi quili suit :
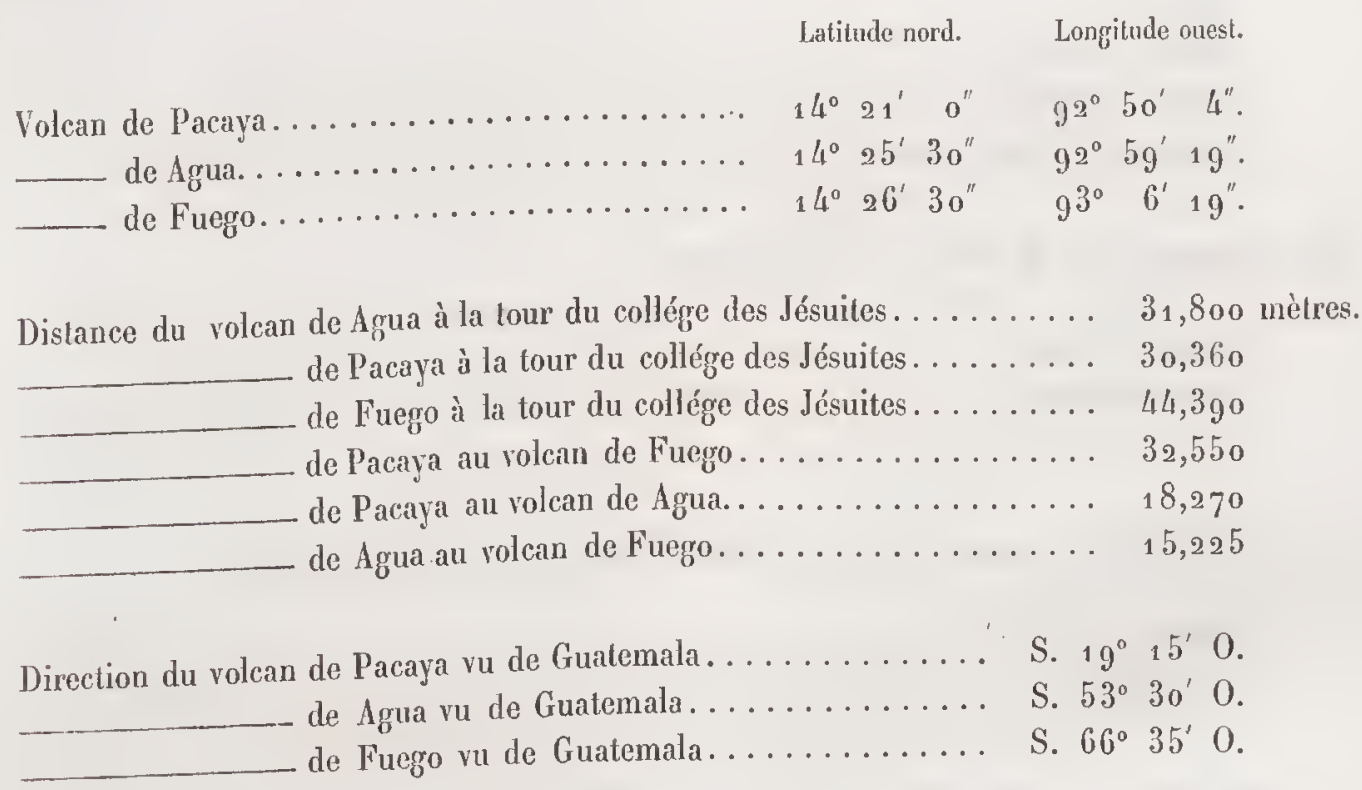

Une fois cela fait, les grrands volcans eux-mêmes sont devenus des observatoires d'où l'on a relevé les posilions des traits saillants de la topographie du pays. De ces points, reliés ainsi au système de triangulation primordial, on a fail encerc des séries d'observations qui ont recouvert le pays d'un réseau de directions, dont les intersections ont pu servir à appuyer, sur une base presque malluémaliquement exacte, un grand nombre de positions ćvaluées avec une grande approximation. En même temps, on a exécuté plusieurs voyages dans lesquels on a déterminé directement la latitude et la longitude d'un très-grand nombre de localités, el l'on a pu ainsi construire une esquisse de la carte du Guatemala, ayant 
pour fondement des séries d'éléments qui se vérifient ou se corrigent muluellement, et dont voici les principaux :

Du sommet.du volcan de Agua :
La Antigua .
N. $4^{\circ} \mathrm{E}$.
Amatitlan .
N. $79^{\circ} \mathrm{E}$.

Du sommet du volcan de Fuego :

La Antigua............... N. $75^{\circ} 52^{\prime \prime}$ E.

Du sommet du volcan de Pacaya :
Amatitlan .
N. $10^{\circ} \mathrm{O}$.

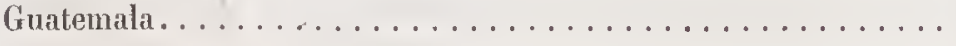
N. $19^{\circ} 15^{\prime} \mathrm{E}$.
Volcan de Agua.
O. $31^{\circ} 57^{\prime} \mathrm{N}$.

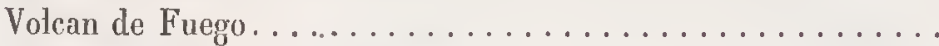
0. $19^{\circ} 34^{\prime} \mathrm{N}$
Volcan de Chingo. .
E. $14^{\circ} \mathrm{S}$

Du sommet de la crête de Chuacus :
Volcan de Agua..
S. $30^{\circ} 0$.
Volcan de Fuego . . . . . . . . . . . . . . . . . .
S. $39^{\circ} 28^{\prime} 30^{\prime \prime} 0$.
Salam
N. $6^{\circ} 0$.

Du sommet du mont Chatun (entre Zacapa et Chiquimula) :
Zacapa . .
N. $6^{\circ} 30^{\prime} 0$.
Chiquimula.
S. $22^{\circ} 0$.

Du sommet du Derrumbadero de Alotepeque :

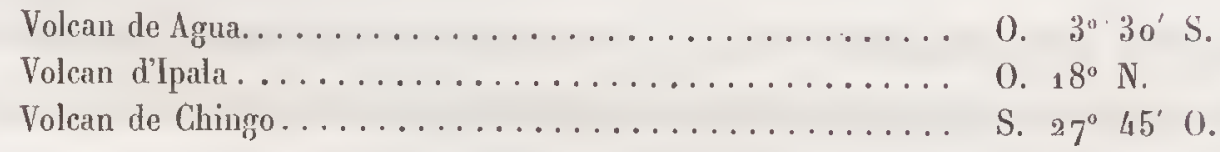

Du sommet du volcan d'Ipala :
Volcan de Santa Catarina.
S. $40^{\circ} 0$.

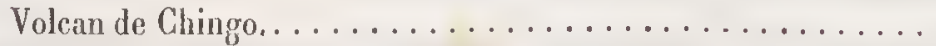
S. $8^{\circ}{ }_{2} 6^{\prime} 0$.
Chiquimula .
N. $20^{\circ} \mathrm{E}$.

Du sommet oriental du plateau d'Aracualpa : 


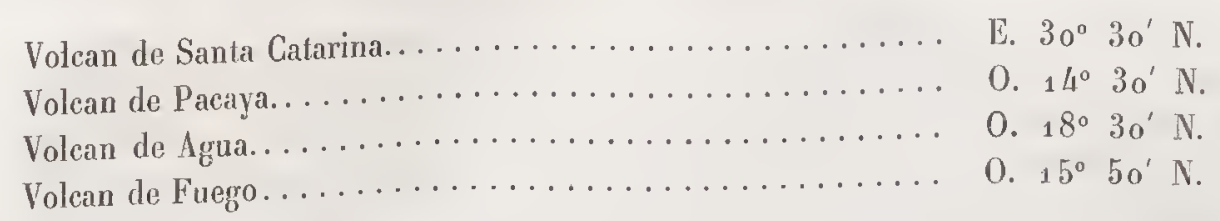

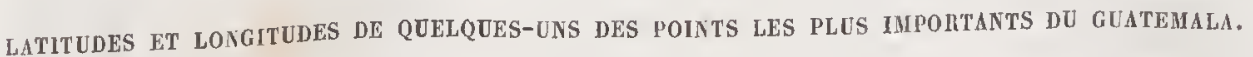

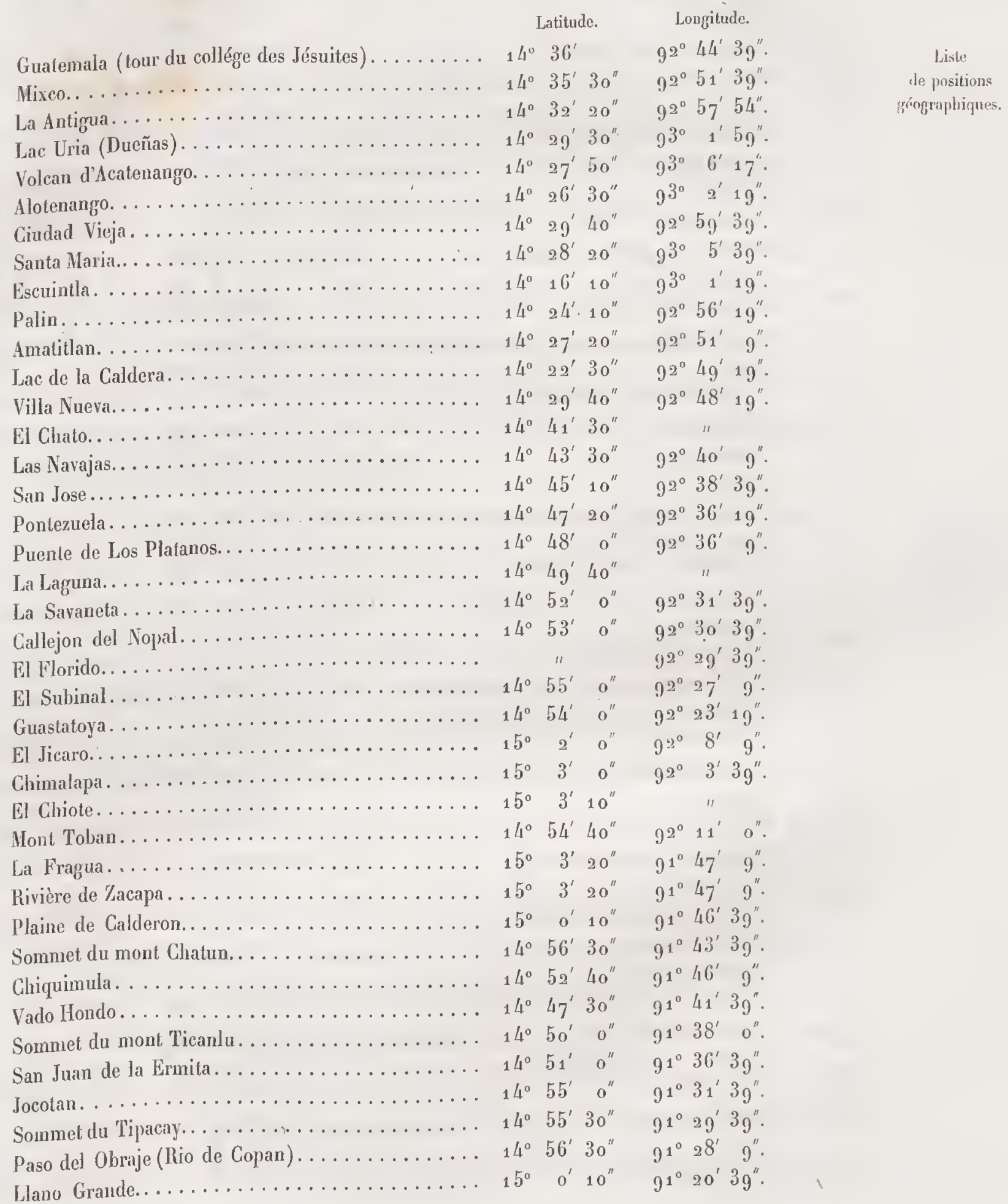


Copan . . . . . . . . . . . . . . . . . . . . . . . . . . . . .

Latitude. $14^{\circ} 56^{\prime} 40^{\prime \prime}$ $14^{\circ} 50^{\prime} 30^{\prime \prime}$

Piedra de Amolas..................... $14^{\circ} 47^{\prime} 0^{\prime \prime}$

Sommet de Los Horcones. . . . . . . . . . . . . . .

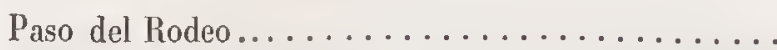

Llano San Juan. . . . . . . . . . . . . . . . .

Esquipulas.

$14^{\circ} 42^{\prime} 0^{\prime \prime}$

$14^{\circ} 42^{\prime} 0^{\prime \prime}$

$14^{\circ} 41^{\prime} 20^{\prime \prime}$

Sommet de Los Apantes. . . . . . . . . . . . . . .

Conception. . . . . . . . . . . . . . . . .

Alotepeque. . . ...................

Sommel du Derrumbadero..

$14^{\circ} 40^{\prime} 0^{\prime \prime}$

$14^{\circ} 34^{\prime} \quad 0^{\prime \prime}$

$14^{\circ} 31^{\prime} 0^{\prime \prime}$

$14^{\circ} 30^{\prime} 10^{\prime \prime}$

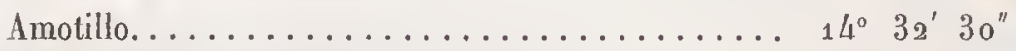

Monterico..................... $14^{\circ} 32^{\prime} 50^{\prime \prime}$

Lac du volcan d'Ipala................. $14^{\circ} 35^{\prime} 0^{\prime \prime}$

Extrémité ouest du lac Guija.............. $14^{\circ} 17^{\prime} 10^{\prime \prime}$

Volcan de Ghingo................... $14^{\circ} 6^{\prime} 30^{\prime \prime}$

Volcan de Monte Rico................. $14^{\circ} 32^{\prime} 40^{\prime \prime}$

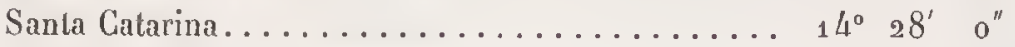

Suchitan........................ 14... $4^{\circ} 5^{\prime} 20^{\prime \prime}$

Volcan de Santa Calarina............... $14^{\circ} 23^{\prime} a^{\prime \prime}$

Achuapa....................... $14^{\circ} 21^{\prime} 10^{\prime \prime}$

Volcan Guma ...................... $14^{\circ}{ }_{1} 8^{\prime} 0^{\prime \prime}$

Intiapa. ...................... $14^{\circ} 17^{\prime} 0^{\prime \prime}$

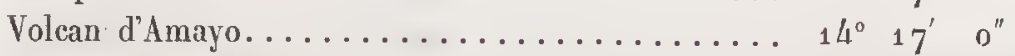

Llano de San Matias.................. $14^{\circ} 13^{\prime} 40^{\prime \prime}$

Sommet de la còte d'Aracualpa............ $14^{\circ} 13^{\prime} 0^{\prime \prime}$

Aracualpa...................... $14^{\circ} 13^{\prime} 10^{\prime \prime}$

El Voladero...................... $14^{\circ} 13^{\prime} 20^{\prime \prime}$

Los Esclavos (au pont) ................ $14^{\circ} 14^{\prime}$ on $^{\prime \prime}$

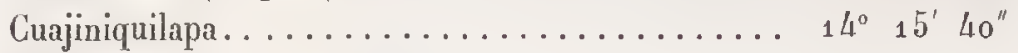

Berberena......................... $14^{\circ} 18^{\prime} 0^{\prime \prime}$

Lac de $\operatorname{Los} \operatorname{Pinos} . \ldots \ldots \ldots \ldots \ldots \ldots . . \ldots \ldots 4^{\circ} 20^{\prime} 0^{\prime \prime}$

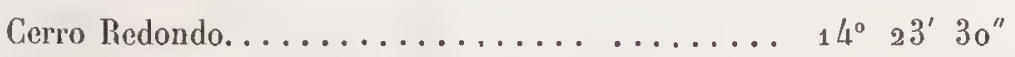

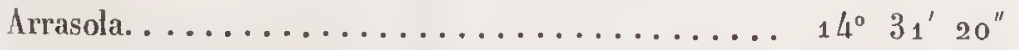

Pinula......................... $14^{\circ} 32^{\prime} 0^{\prime \prime}$

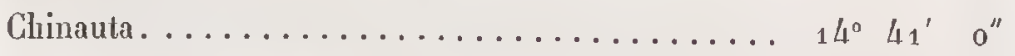

Sant Antonio...................... $14^{\circ} 43^{\prime} 40^{\prime \prime}$

La Canoa (paso du Motagua) ............. $14^{\circ} 57^{\prime} 40^{\prime \prime}$

Llano Grande..................... $15^{\circ} 0^{\prime} 40^{\prime \prime}$

Cumbre de Chuacus.................. $15^{\circ} 4^{\prime} 0^{\prime \prime}$

Salama......................... 15. $5^{\circ} 5^{\prime} 40^{\prime \prime}$

San Geromino....................... $15^{\circ}{ }_{1} 3^{\prime} 0^{\prime \prime}$

Cumbre de Los Trozos................. $15^{\circ} 10^{\prime} 30^{\prime \prime}$

Gerro Gordo...................... $15^{\circ} 5^{\prime} 0^{\prime \prime}$

San Clemente..................... $15^{\circ} 9^{\prime} 10^{\prime \prime}$

Tocoy........................... $15^{\circ} 5^{\prime} 30^{\prime \prime}$

San $\operatorname{Aguslin} \ldots \ldots \ldots \ldots \ldots \ldots \ldots \ldots \ldots \ldots 5^{\circ} 4^{\prime} 0^{\prime \prime}$

Longitude.

$91^{\circ} 19^{\prime} 3 g^{\prime \prime}$

$91^{0} 28^{\prime} 9^{\prime \prime}$.

$91^{\circ} 31^{\prime} 19^{\prime \prime}$.

$91^{\circ} 32^{\prime} \quad 9^{\prime \prime}$.

$91^{\circ} 34^{\prime} 39^{\prime \prime}$.

$91^{\circ} 33^{\prime} 1 g^{\prime \prime}$.

$91^{\circ} 33^{\prime} 39^{\prime \prime}$.

$91^{\circ} 36^{\prime} 19^{\prime \prime}$.

$91^{\circ} 41^{\prime} 3 g^{\prime \prime}$.

$91^{\circ} 39^{\prime} 3 g^{\prime \prime}$.

$9^{1^{\circ}} 38^{\prime} 9^{\prime \prime}$.

$91^{\circ} 47^{\prime} 29^{\prime \prime}$.

$91^{\circ} 51^{\prime} 19^{\prime \prime}$.

$91^{\circ} 50^{\prime} o^{\prime \prime}$.

$91^{\circ} 46^{\prime} 0^{\prime \prime}$.

$91^{\circ} 56^{\prime} \quad 0^{\prime \prime}$.

$91^{\circ} 49^{\prime} 30^{\prime \prime}$.

$91^{\circ} 58^{\prime} 30^{\prime \prime}$.

$92^{\circ} 2^{\prime} 0^{\prime \prime}$.

$9^{2^{\circ}} 1^{\prime} 20^{\prime \prime}$.

$92^{\circ} 4^{\prime} 30^{\prime \prime}$.

$92^{\circ} 6^{\prime} 10^{\prime \prime}$.

$92^{\circ} 6^{\prime} 0^{\prime \prime}$.

$92^{\circ} 8^{\prime} \quad 0^{\prime \prime}$.

$92^{\circ} 17^{\prime} 20^{\prime \prime}$.

$92^{\circ} 19^{\prime} 10^{\prime \prime}$.

$92^{\circ} 21^{\prime} 3 g^{\prime \prime}$.

$9^{2}{ }^{\circ} 6^{\prime} 3 g^{\prime \prime}$.

$92^{\circ} 28^{\prime} 10^{\prime \prime}$.

$92^{\circ} 30^{\prime} 3 g^{\prime \prime}$.

$92^{\circ} 32^{\prime} 19^{\prime \prime}$.

$9^{2} 36^{\prime} \quad 0^{\prime \prime}$.

$92^{\circ} 40^{\prime} 10^{\prime \prime}$.

$92^{\circ} 42^{\prime} 19^{\prime \prime}$.

$92^{\circ} 44^{\prime} 20$ ".

$92^{\circ} 43^{\prime} 40^{\prime \prime}$.

$92^{\circ} 38^{\prime} 39^{\prime \prime}$.

$92^{\circ} 38^{\prime} 39^{\prime \prime}$.

$92^{\circ} 37^{\prime} 29^{\prime \prime}$.

$92^{\circ} 38^{\prime} 39^{\prime \prime}$.

$9^{\circ} 33^{\prime} 40 "$.

$92^{\circ} 27^{\prime} 29^{\prime \prime}$.

$92^{\circ} 27^{\prime} 39^{\prime \prime}$.

$92^{\circ} 25^{\prime} 40^{\prime \prime}$.

$92^{\circ} 21^{\prime} 40^{\prime \prime}$.

$92^{\circ} 12^{\prime} 0^{\prime \prime}$. 


\begin{tabular}{|c|c|c|}
\hline & Latitude. & Longitude. \\
\hline$\ldots \ldots \ldots \ldots \ldots \ldots$ & ${ }_{1} 5^{\circ} \quad 0^{\prime} 30^{\prime \prime}$ & 11 \\
\hline 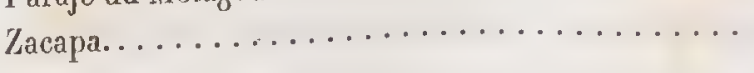 & $15^{\circ} \quad 4^{\prime} \quad 0^{\prime \prime}$ & $9^{1^{\circ}} 45^{\prime} \quad 40^{\prime \prime}$. \\
\hline 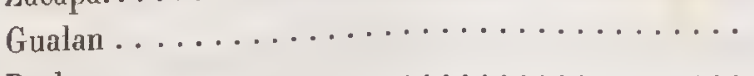 & ${ }_{1} 5^{\circ} \quad 9^{\prime} \quad 0^{\prime \prime}$ & $91^{\circ} 38^{\prime} 40^{\prime \prime}$. \\
\hline 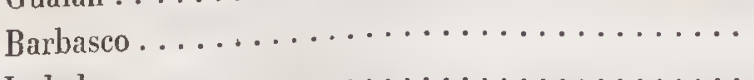 & $15^{\circ} 12^{\prime} \quad 0^{\prime \prime}$ & $91^{\circ} 26^{\prime} 40^{\prime \prime}$. \\
\hline$\ldots \ldots \ldots \ldots \ldots \ldots$ & $15^{\circ} 25^{\prime} \quad 0^{\prime \prime}$ & $"$ \\
\hline Levingston. . . & $15^{\circ} 48^{\prime} \quad 0^{\prime \prime}$ & $90^{\circ} \quad 58^{\prime} \quad 40^{\prime \prime}$. \\
\hline Thomas & $15^{\circ} 42^{\prime} \quad 0^{\prime \prime}$ & $90^{\circ} 50^{\prime} 40^{\prime \prime}$. \\
\hline
\end{tabular}

Cette série d'observations jette une vive lumière sur les environs de Guatemali, dans un rayon assez étendu, sur le département de Chiquimula et sur une petite partie de la basse Vera Paz. Malheureusement il n'a rien été fait de semblable pour le reste de cette province, non plus que pour celle des Allos, et pour la presque totalité du versant du Pacifique. La solution des intéressants problèmes que soulèyent ces vastes régions reste donc soumise à une incertitude d'aulant plus regretlable, que les conditions dans lesquelles nous avons exéculé notre voyage ne nous ont pas permis de faire des observations précises, mais senlement de relever journellement nos itinéraires avec tout le soin dont nous étions capal)]es, en ce qui touche aux distances et aux directions.

Si l'on jette sur les pays dont nous nous occupons un coup d'œil d'ensemble, et, disons-le, si l'on porte dans ce travail l'espril du philosophe plus peut-être que celui du savant, on ne saurait nanquer d'ètre frappé de tout ce qui lend à introduire dans l'orographie du Centre Amérique le terme de transition, les précurseurs, pour ainsi dire, de l'orographie du Mexique. Au Mexique, lout est étrange. et si distinct de ce que nos yeux sont accoutumés à contempler en Europe, que facilement on se laisserait entrainer à n'y voir qu'une giganlesque ébauche à laquelle a manqué le concours des siècles. Ces inmmenses plaines, portées à la hauteur de nos plus grandes montagnes, ces pics gigantesques, si régulièremen! taillés en cônes, ces brusques coupures, si profondes que l'wil en peut à peinè scruter les ténébreux abîmes, rien, dans nos formations régulières, ne nous a préparés à les voir el à les comprendre, rien n'a comblé la distance qui, dans nolre esprit, existe entre nos connaissances antérieures el ce qui apparaît lout ì coup ì nos yeux. Eh bien, ces termes de transition, c'est l'Amérique centrale qui peul nous les offrir. Ce n'est pas encore cet immense plateat, large de plusieurs centaines de kilomètres et élevé de plus de 2,000 mètres au-dessus du niveau de 
la mer, ce ne sont point ces brusques pentes qui le raccordent aux plaines basses de la plage, mais quelques-uns des principaux caractères y sont déjà. Voici d'abord, en particulier, celte vaste arête montagneuse qui dessine presque à elle seule les allures caractéristiques du pays; elle est, ou peu s'en faut, linéaire encore, cela est vrai; mais de temps en temps n'y voit-on pas des sortes d'épatements où se développent de hautes plaines, le plus souvent riches et fertiles? Les versants y sont aussi; mais, el c'est là ce qui donne à l'Amérique centrale son cachet particulier, ils sont fort loin d'ètre égaux et de se précipiter vers la mer aussi abrupts l'un que l'autre. La chaine principale, fort rapprochée de l'océan Pacifique, se raccorde à ses rivages par de brusques pentes dont l'inclinaison naturelle es/ encore augmentée par les bouleversements dus aux pliénomènes volcaniques qui ont pris pour théâtre ces déclivités rapides sillonnées de torrents impétueux. Vers l'Allantique, an contraire, descendent peu à peu, soit des amoncellements de monlagones se succédant comme les marches d'un gigogantesque escalier et séparées par de profondes vallées, soil de grandes plaines ondulées, mollenent reliées aux bas plateanx de l'extrême Yucatau.

('BANDES DÉTIVELA'TIONS. - ALLURES OROGRAPIIQUES. - DIREGTIONS DES PRITGIPALES GHAIAES DE HONTAGNES.

Essayons maintenant de faire sentir avec quelque netteté les détails caracléristiques, les points saillants de cet ensemble, et, pour faciliter le travail en le divisant, occupons-nous d'abord de la grande arête montagneuse qui domine le pays, pour descendre ensuite successivement à l'Allantique et au Pacifique.

CHAîne CENTRaLE.

Quoiqu'elle soit fort loin de constituer une ligne d'ıne rectitude malhématique, l'arête montağneuse principale dessine néanmoins une direction assez nette, qui suit à peu de cliose près celle de la côte du Pacifique. Elle tend néanmoins ¿̀ s'en rapprocher peu à peu vers le nord, et ce rapprochement, pour le dire en passant, coïncide précisément avec un surélèvement, ce qui contribue puissamment à accuser les pentes de ce côté. La direction moyenne peut ètre, ì peu près, E. $20^{\circ} \mathrm{S} .-0.20^{\circ} \mathrm{N}$, de sorte que, si, à la hauteur de San Miguel (Sal- 
DANS LES RÉPUBLIQUES DE GUATEMALA ET DE SALVADOR. 87 vador), la ligne des hautes cimes est à 120 kilomètres environ de la mer, elle n'en est plus guère qu'à 80 kilomètres un peu plus loin que Totonikapam (Güittemala). Le noud montagneux du haut Nicaragua est séparé de celui du Honduras par. Hautes monlagras un abaissement assez considérable correspondant à la naissance du Rio Ulua, qui passe à Comayagua, capitale du Honduras. La liğne principale des crêtes atteint à peine un millier de mètres en ce point; mais elle se relève bientôt en prenant des altitudes moyennes comprises entre 1,500 el 2,000 mètres, of suil à peu près la frontière du Salvador et du Honduras, où elle est représentéc successivement par les puissants massifs des Montes de San Juan, de Opalara, de Selaque, de Pacaya et de Merendon, reliés entre eux d'une manicre plus ou moins complète.

Eı entrant sur le territoire du Guatemala, près d'Esquipulas et d'Alotepeque, petiles villes situées à des altitudes de 910 el 1,384 mètres sur les conlre-forts de la gorande chaîne, on trouve des altitudes assez considérables, en particulier aul

$$
\begin{gathered}
\text { du Guatemala. } \\
\text { Sirrélawoment } \\
\text { vers }
\end{gathered}
$$
10. And-thuest. Derrumbadero, dont le sommet alteint 1,636 mètres, et dans les montignes d'Alotepeque, dont le sommet dépasse notablement la mine de San Pantaleon, située elle-mème à 1, 175 mètres. Gette tendance à s'élever se caractérise encore plus dans les montagnes de Jalapa, et, en approchant de la ville de Guatemala, on rencontre, à 1,909 mètres, le col de Pinula, entouré de sommités plus élevées encore. La grande plaine de Guatemala, située presque exactement sur le sommet de l'arête montagneuse et sur la direction de la ligne de partage des eaux, se développe à une allitude moyenne de 1,500 mètres, bornée à l'ouest pal des montagnes qui dépassent 2,200 mètres (col de Barsenas, 2,178 mètres; Cordillère de Mixco, 2,161 mètres). On se maintient assez longtemps à une srimblable altitude, au milieu des pelits plateaux de Chimaltenango, de Pasesilla (2,114 mètres) elc., pour s'élever encore plus en se rapprochant de Tecpan Guiltemala. La chaine court alors presque au nord plein pendant un instant, mais reprend sa direction primilive en rejoignant la partic la plus élevée de l'arête, qui court jusqu'au delà de Tolonikaparn en dessinant une ligne d'une remarquable régularité. Les principaux sommets atteignent ou dépassent 3,50o mètres, call les cols par lesquels on franchit ces montagnes s'élèvent jusqu’à 2,854 mètres 
(route de Santa Cruz del Quiché à Totonikapam) et 3,169 mètres (route de Totonikapam à Tecpan).

Hauls plateanx. Parmi les nœuds d'où divergent ces contre-forts se développent de hautes plaines, comme celles de Santa Cruz de Quiché (2,018 mètres) el de Tolonikapam $(2,484$ mètres $) ..$; elles n'atteignent guèrè plus de 20 à 25 kilomètres dans tous les sens, mais rappellent en miniature, aussi bien par leur climat que par leur disposition générale, la constitution dı plateau mexicain.

Après Totonikapam, la chaîne principale, suivant sa direction générale, s'enlonce dans le Soconusco, puis enfin dans l'État mexicain de Chiapas, en conservant probablement longtemps encore des hauteurs comparables à celles qu'elle vient d'atteindre. Nous n'avons plus sur ces régoions d'observations précises, mais les vues prises du sommet de hautes montagnes et les renseignements recueillis permettent d'admettre l'existence d'une crète élevée, s'étendant vers le N. 0. jusque près de l'abaissement qui correspond à l'isthme de Tehnantepec.

Versant DE L'ATLANTIQUe.

Disposition

nos'male

du versant

de l'Atlantigue

an

Honduras.

L'existence de cette arête principale et dirigeante étant ainsi élablic, et ses particularités passées en revue, descendons successivement de chaque coté en continuant le cours de nos recherches. Marchons d'abord vers l'Atlantique. Dans te Ilonduras, d'après des observations qui ne nous sont point persomelles, mais dont l'exactitude n'est pas douteuse, le système orographique se développe d'une façon tout à fait normale. De la chaine principale se délachent des contre-forts qui divergent presque normalement, s'en vont mourir à la côte en conservant feur direction transversale, et séparent l'une de l'autre de grandes et profondes vallées, telles que celles des Rios Hunaya, Santiago el Chamelicon, qui portent directement à l'Océan les eaux tombées daus les hautes régions du centre el celles que recueillent leurs petits affluents dans les chaînons transversaux. Les montagnes, s'abaissant progressivement, laissent encore un espace assez vaste, composé de plaines basses sablonneuses ou de marécages, entre elles et la côte, qui, quoique peu accidentée par elle-même, est bordée d'une ceinture d'îles, dont la plus considérable est celle de Roathan.

brírangements [Tne fois que l'on a franchi les massifs montagneux de Espiritu Santo et de 
Grita, qui servent de frontière entre le Honduras et le Guatemala, on trouve d'itbord, dans le département de Chiquimula, une région assez embrouilléc et sur laquelle nous ne possédons pas assez de renseignements pour lit décrire d'une manière complète. Il est néanmoins constant qu'une série de chainons, dont les hauteurs varient entre 500 et 700 mètres, s'entrecroisent dans divers sens, sans former de longues chaines bien définies et sans diverger nettement non phus de l'arête centrale, à laquelle ils se raccordent progressivement, mais sans isoler, d'une façon bien définie en direction, les bassins des diverses rivières. Il semble que la nature se prépare peu à peu au régime particulier qui règơne dans la majenre partie du versant Allantique du Guatemala. En effet, ces chainons transversaux en arrivent bientôt à disparaître presque complétement, et c'est à peine si, à partir de ce point, la grande arête projelle quelques pelites branches vers te nord.

On voit s'établir alor's un système de longues chaines, sensiblement parallèles entre elles el dirigcées à peu près dans le même sens que l'arête centrale, c'est-ìdire de l'E. S. E. à l'O. N. O., dessinant en quelque sorte une sćrie d'ondulitions auxquelles succèdent chaque fois de profondes vallées, parcourues par' de puissants cours d'eau; ces cours d'eau, pour s'échapper ver's la mer, doivent profiter de quelque brisure, et s'y précipiter en se déviant brusquement de lenr conrs jusque-là dirigé presque parallèlement à la côte. Il ne faudrait pourlant pas croire que, dans loute cette partie du versant Allantique de l'Amérique centrale, on n’a absolumenl affaire qu'ì des rides parallèles, séparées par des fossés correspondants; les contournements de chaines, les séparations, les conpuress brusques, ne manquent pas. Mais il n'en est pas moins vrai que le voyargeur, qui, d'un point quelconque de l'arête centrale dans le Guatemala, veut se diriger' vers le nord, devra franchir successivement une infinité de chaines plus ou moins exactement concordantes en direction, séparées par de profondes coupures inctilignes sur des espaces souvent fort étendus. Il n'en est pas moins vrai que, sams vouloir asservir les faits à une théorie conçue d'avance, on retrouverà dans la majeure partie des provinces de la Vera Paz et des Altos un alignement à peu près constant des chaînes el des vallées dans un sens assez rapproché de celui de l'arête centrale; alignement explicable du reste, il faut le dire, par l'analyse des phénomènes purement géologơiques dont ces réggions furent le théàlre. 
liassin In Rio Grande ou Motagua.

Les rudiments d'une première chaine, assez mal indiquée pourtant, peuvent se trouver près de Chiquimula, Guastatoya, el mème au Carrizal, limitant néanmoins vers le sud, d'une manière assez nette, une parlie du bassin du Rio Grande on Molagua. Cette puissante rivière courl dans une profonde vallée, qui, depuis Zacapa jusque près de Santa Cruz del Quiché, sur un développement de près de 200 kilomètres, suit une direction presque exactement rectiligone de l'est à l'ouest. Elle se relève ensuite un peu vers lo nord-est, en suivant l'allongement do la ogrande chaine de la Sierra del Mico, nettement dessinée en direction, mais un peu oblique sur les autres alignements de celte régoion. La vallée du Rio Grande ne s'élève que lentement et progressivement : à plus de 300 kilomètres de son embouchure, au Paso de la Canoa, elle n'est encore qu'à 466 mètres an-dessus du nireau de la mer et constitue donc ainsi une sorte de profond lossé, entouré de crêtes montagneuses linéaires, qui la dépassent de 1,000 mètres environ, un peu plus ou un peu moins. La partie supérieure de la vallée el les thalwegs de presque tous les affluenls au nord sont très-nettement limités par une série de rides rectilignes, dirigées ì peu près E. $20^{\circ} \mathrm{S} .-0.20^{\circ} \mathrm{N}$., longues de 50 kilomètres environ et liautes de 1,000 à 1,200 mètres en moyenne. Leur conlinuation peul se retrouver au sud de Zacapulas, où elles dépassent 1,500 mètres, et impriment à la vallée du Rio Blanco la direction mentionnée ci-dessus; puis, dans les environs de Gueguetenango, où elles atteignent des altitudes probablement plus considérables encore et séparent assez nettemenl, sur une longueur d'au moins 100 kilomètres, les bassins parfaitement parallèles d'une série de petits affluents du Rio de Comilan, dirigós régulièrement vers l' $0.20^{\circ} \mathrm{N}$.

La gorande ride que l'on franchit à Chuacus, à une altitude de 1,632 mètres, est peut-être plus remarquable encore. Elle naît près de Tocoy, séparant d'abord le Rio Grande de son aflluent le Rio de Tocoy, court nettement à l' $0.20^{\circ} \mathrm{N}$. cn limitant au sud la grande vallée de Salama, puis, en suivant tout l'allongoement de la vallée de Rabinal, se coupe brusquement et profondément pour laisser passer le Rio Chisoy, puis reparaît près de Gunen, pour se continuer dans les Altos avec des allitudes supérieures à 2,000 mètres. Le fossé qui lui succède, en comprenant les vallées de Salama, de Rabinal, etc., se maintient presque toujours 
DANS LES RÉPUBLIQUES DE GUATEHALA ET DE SALVADOR.

à un millier de mètres au moins en contre-bas des crètes, el conlribue pour sa part à donner à la Vera Paz ses allıı'es si caractéristiques.

Il est limité, au nord, par une grande chaine, décomposée quelquefois en chaìnons parallèles, peu distints les uns des autres. Celte ride puissante commence non loin de la Laguna d'Izabal, conrt jusqu'au Cerro Verde, au nord de Salama, avec des altiludes assez considérables, puis se décompose : un chainon constitue la crête de Kachil, que l'on franchit à $1, \dot{5} 73$ mìtres de hauteur; limile, au nord, le bassin du Rio de Rabinal; s’interrompt un instant, puis reparầt à San Miguel Uspantan, el dirige la vallée du Rio Calag en dépassant des niveaux de «, 000 mètres. Un autre constitue les montagues de Santa liosa, qui atteignent 1,600 mètres, el d'autres enfin limitent, toujours suivant la direction générale, les vallées de Tactic, de San Cristobal, etc. .., en se maintenant à 400 ou 500 mètres au-dessus des lossés, qui sont eux-mêmes à 1,400 mètres environ nu-dessus du niveaı de la mer. Ils forcent pendant quelque temps le cours du Rio Chisoy, puis, brusquement coupés par lui à une immense profondeur, ils vont se perdre dans lo pays des Lacandons.

Les closes deviennent un peu moins nettes ensuite, et les observalions exacles font presque absolunent défaut, car, en même temps que le terrain s'abaisse progressivement, les chan̂nes ne se dessinent plus avec autant de précision. Mais, datis te Pelon. d'après les rapports de voyageurs dignes de foi, on peut avancer néammoins, sans crainte d'altérer la vérité, que bien des parties des rios Polochic, de Cajabon, Santa Izabel, de la Pasion, el des pelits cours d'eau qui se jellent dans le gollo de Honduras, sur la côte E. dı Yucatan, sont encore régies par cette direction approximativement E. - O que nous avons signalée dans la Vera Paz et les Altos. Plus au nord encore, on alteint les régions presque inconnues du Pelen, les pays mystérieux des Lacandons et des Mayas, habités par des tribus saurages el inhospitalières; aussi nous est-il impossible de pousser plus loin nos éturles et de suivre l'abaissement du pays jusqu'aux plaines du Yucatan, qui viennent mouril' insensiblement dans le golfe du Mexique, à Sisal et au cap Catoche. 
VERSant DU PacifiQue.

Dispusitions zénérales. Rapprocliement de l'arête contrale et de la chaine votranigne.
Chaine secondaire du Salvartor. Bassin dı Rio Lempa.

Occupons-nous maintenant du versant du Pacifique, qui n'est pas moins remarquable et intéressant que celui que nous venons d'étudier. Il semblerait, à première vue, que, l'arête principale étant ici très-rapprochée de la mer, il n’a rien pu se passer de particulier, et que l'on n'a affaire qu'à une déclivité plus ou moins abrupte et normalement séparée en vallons divergents par de petits chainons transversaux; el c'est en effet ce qui eùt peut-ĉtre existé, si les phénoniènes subséquents, dus à l'action volcanique, n'étaient venus compliquer tes choses. Il existe, en effet, une série de sommités volcaniques, affectant une direction presque exactement linéaire, et tellement disposée que, suivant de fort près la grande arête, elle ne fait avec elle qu'un anggle d'une dizaine de degrés environ; de telle sorte que la première étant diriggée à peu près à l' $\mathrm{l}^{\prime} .20^{\circ} \mathrm{N}$., l'autre courant à $\mathrm{l}^{\prime} 0.30^{\circ} \mathrm{N}$., elles se trouvent, à leur maximum de distance, à une centaine de kilomètres environ, à l'extrémité S. E. du Salvador, el presque en contact au N. O. du Guatemala. Ajoutons, sans en rechercher actuellement la raison, que, dans presque loule la république de Salvador, la direction volcanique coincide avec une surélévation du sol constiluant presque une claâne continue, tandis que, dans le Guatemala, elle n'est que jalonnée, pour ainsi dire, par des pics isolés, et cherchons l'effet produit sur l'orographie gónérale par cette intéressante disposition.

Dans le Salvador, comme la chaîne centrale est reléguće dans le Honduras à son maximum d'éloignement de la mer, et n'est représentée que par des massifs d'une médiocre ćlévation, la pente primitive du versant est régoulière et faible. C'est ce que l'on peut observer dans les régions du S. E. où se développe le bassin du Rio de Goascoran, qui forme quelque temps la limite entre le Ilonduras el le Salvador, avant de se jeter au fond de la grande baie de Fonseca. C'est ce qui existe encore dans tes pays doucement inclinés que fertilise lo Rio de Sau Miguel; mais, dès que l'on dépasse San Miguel à l'o., l'état des choses se modifie.

On voit s'établir alors une surélévation du sol, correspondant à une ride montagneuse continue; elle se développe à une quarantaine de kilomètres du ri- 
DANS LES RÉPUBLIQUES DE GUATEHALA ET DE SALVADOR. 93 vage, comprenant une succession de pelits plateaux plus ou moins étendus, el Jaissant au N. une vallée très-large mais peu profonde, presque un immense plateau à légères pentes syuclinales, comprise entre elle et les premiers contreforts des montagnes du Honduras. C'est le bassin du Rio Lempa, qui y coule doucement, presque parallèlement au rivage de l'océan Pacilique, sur une longugueur' de plus de 1 oo kilomètres, el auquel se rallache toul un système de petites vallées transversales régulièrement distribuées au nord et au sud. La ride monlagneuse commence au volcan de San Miguel, qui se délache brusquement des plaines environnantes et s'élève jusqu'à 2,150 mètres. Elle devient alor's continuc, se maintient, aux environs de Chinameca, à des hauteurs de 700 ou 800 mètres, puis se coupe brusquement à la Barca, non loin de San Vicente, pour laisser passer, presque au niveau de la mer, la vallće du Rio Lempa. Elle reprend presque immédiatement, se soutient à des liauteurs de 800 mètres environ, sans parler du volcan de San Vicente qui la domine, alleint 891 mòtres à Cojutepeque, s'itbaisse à 667 mètres à San Salvador, pour se relever encore au plateau de Santa Tecla (9o3 mètres), d'où le brusque ressaut du Guarumal, semblable à mur vaste marche d'escalier, conduit aux plaines un peu plus basses de Guainoco (573 mètres) el des euvirons de Sonsonate. La chaine se relève ensuite définitivement pour atteindre 1,480 mètres ì la Cumbre d'Apaneca, après laquelle elle meurt tout à coup, un peu avant d'alteindre le bassin dı Rio Paz.

Ainsi que nous l'avons dil, au nord de celle espèce d'axe anticlinal secondaire se développe le bassin que parcourt le Rio Lempa; da colé du sud on voil une pente assez courte, d'abord brusque, puis se reliant progressivement au rivage; elle est sillonnée de ravins séparés par de petils contre-forts transversaux et parcourus par des ruisseaux torrentiels. Le rivage lui-mème est, le plus souvent, terminé par une petite falaise et ne présente que rarement des plages de sable oì puissent se former les lag̣nnes saumâtres dites esteros.

Le bassin du Rio Paz, qui forme la limite entre le Salvador el te Guatemala. inaugure un nouvel ordre de choses. It correspond à une région excessivement tourmentée qui constitue le sud du département de Chiquimula et joue ì peu Dérangements. près, sur le versant du Pacifique, le mème rôle que le nord de ce département sur'
le versant de l'Atlantique. De nombreuses chaines de montagnes s'èutrecroisent 
dans tous les sens, sans quiil soil possible de définir neltement leurs attures, el impriment au régime des eaux un trouble profond dont on retrouve la trace dans la grande laggune de Guija, qui possède à elle seule toul son petit système orographique.

Régularité Hans le surl-ouest du ruatemala.

Disposition des voleans fins to frualemala.
Mais bientôt la régularité reprend te dessus, sauf dans cerlains cus particuliers. et l'on voil une innombrable quantité de vallées plus ou uoins prolondes, ueltement séparées par de pelits contre-forts qui divergoent de la chaỉne centrale, descendre parallèlement vers le Pacifique, où elles viennent tomber normalement. Plus on avance vers le nord, plus, l'arête principale se rapprochant de la mer, les vallées deviennent abruptes et profondes; mais partout elles commencent par tomber brusquement pour se raccorder ensuile dorrement aux basses plaines qui ront mourir dans la mer. Ces plaines basses, composées prosque uniquement de sables et de dunes, donnent fréquemment lieu à la production d'esteros, laguues saumâtres formées par l'accumulation des eaux aux barres des rivières et découpant plus ou moins profondément la côte en dedans de la première liggne do sables qui conslitue la plage.

Nous avons dil que, dans le Guatemala, les cimes volcaniques, qui, au Salvador, correspondent à un șurélèvement continu du sol, ne sont plus que des cônes isolés et sans relations orographiques entre eux. Ce sont alors d'immenses pics dépassant tous 2,500 mètres de hautenr, el dont quelques-uus alteignent même jusqu'à 4,000 mètres, placés en quelque sorte à cheval sur les premières pentes du versant, avec une tendance remarquable à se disposer de plus en plus haut à mesure que l'on marche vers te nord-oucst. Ainsi, par exemple, le groupe des grands cònes des volcans de Pacaya, de Aggua et de Fuego, qui s'élèvent respectivement à $2,550,3,753$ et 4,001 mètres, est placé à peu près aux deux liers de la distance, entro la mer el la ligne des crèles; vers te sud, leurs pentes indéfiniment prolongées vont se raccorder progrressivement, en dessinant des courbes d'une admirable régularité, aux plaines doucement inclinées qui des altiludes de 300 mètres environ vont mourir dans l'Océan, tandis qu'au nord les cònes brusquement interrompus se perdent à 1,500 mètres de hauteur au milieu des massils monlagneux qui entourent Gualemala. Au contraire, le volcan de Quezallenango, et plus encore les volcans de Tajomulco et de Tacana, presque semblables à des 
cimes faisant partie de la grande arête, appartiennent par leur flanc nord à la région des hauls plateaux, tandis que leur flane sud se confond, jusqu'à un celtain point, avec quelques-uns des contre-forts qui séparent, à leur naissance, les torrents tribulaires du Pacifique. La posilion de ces sommilés volcauiques présente quelquefois d'autres particularités rqui méritent d'attirer l'altention. Leur lormation ayant été postérjeure, ce n’est pas ici le cas de le dénıntrer, à la grande disposilion oroğraplique de la contrée, il est arrivé, dans certians cas, qu'ils sont venus se placer précisément sur le parcours des vallées précxistantes. Ils les ont alors barrées d'une façon plıs ou moins complète el déterminé ainsi la formation de lacs. Quelques-uns des lacs du Gualemala sont dans ce cas, et noms reviendrons sur ce sujet lorsque nous aurons ì les étudier spécialement.

IIYPSOMÉTRII:

Pour compléter et résumer celle élude d'orographie nous placerons ici un lableau contenant les principales hauleurs que nous avons en occasion de déterminer au Guatemala el au Salvador. Eilles sont dédurtes, par le calcul, do l'observation du baromètre, el la coincidence de quelques-unes d'entre elles ave: des chiffres obtenus pas d'aulres voyageurs dans des ćtudes antérienres peut sorvir de garantie qu’elles sont, en général, fort rapprochées de la vérité. Nous conserverons daus ce tableau la classification que nous avons admise dans la discussion, en répartissant les hauteurs sur la chaine principale el sur chacun des versants, et en les groupant de plus suivant les itinćraires les plus habiluels. 


\section{HYPSO MÉTRIE.}

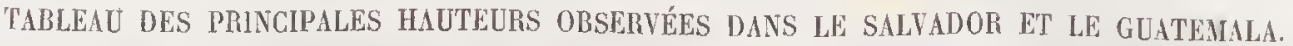

listes de hauteurs.

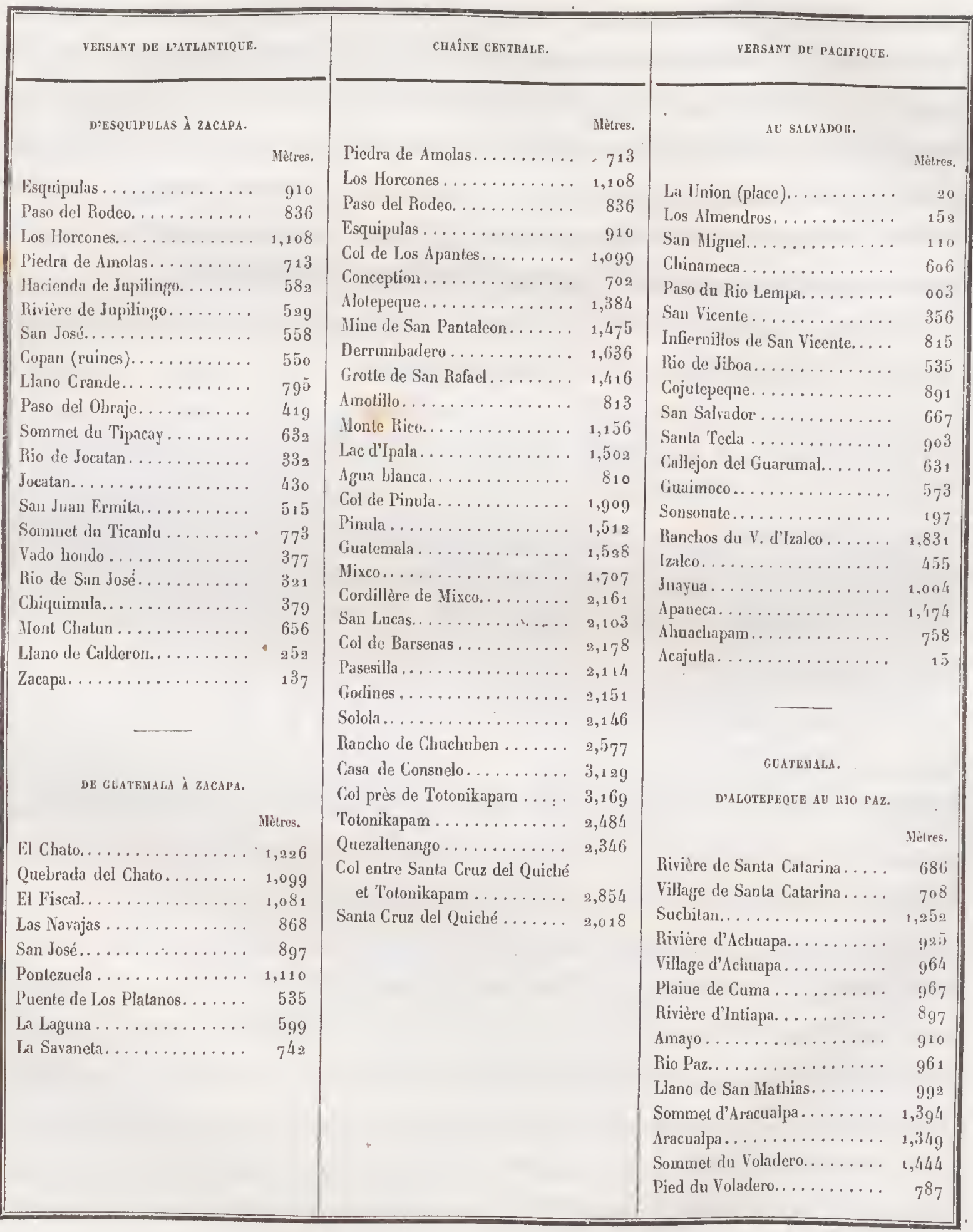


DANS LES RÉPUBLIQUES DE GUATEMALA ET DE SALVADOR.

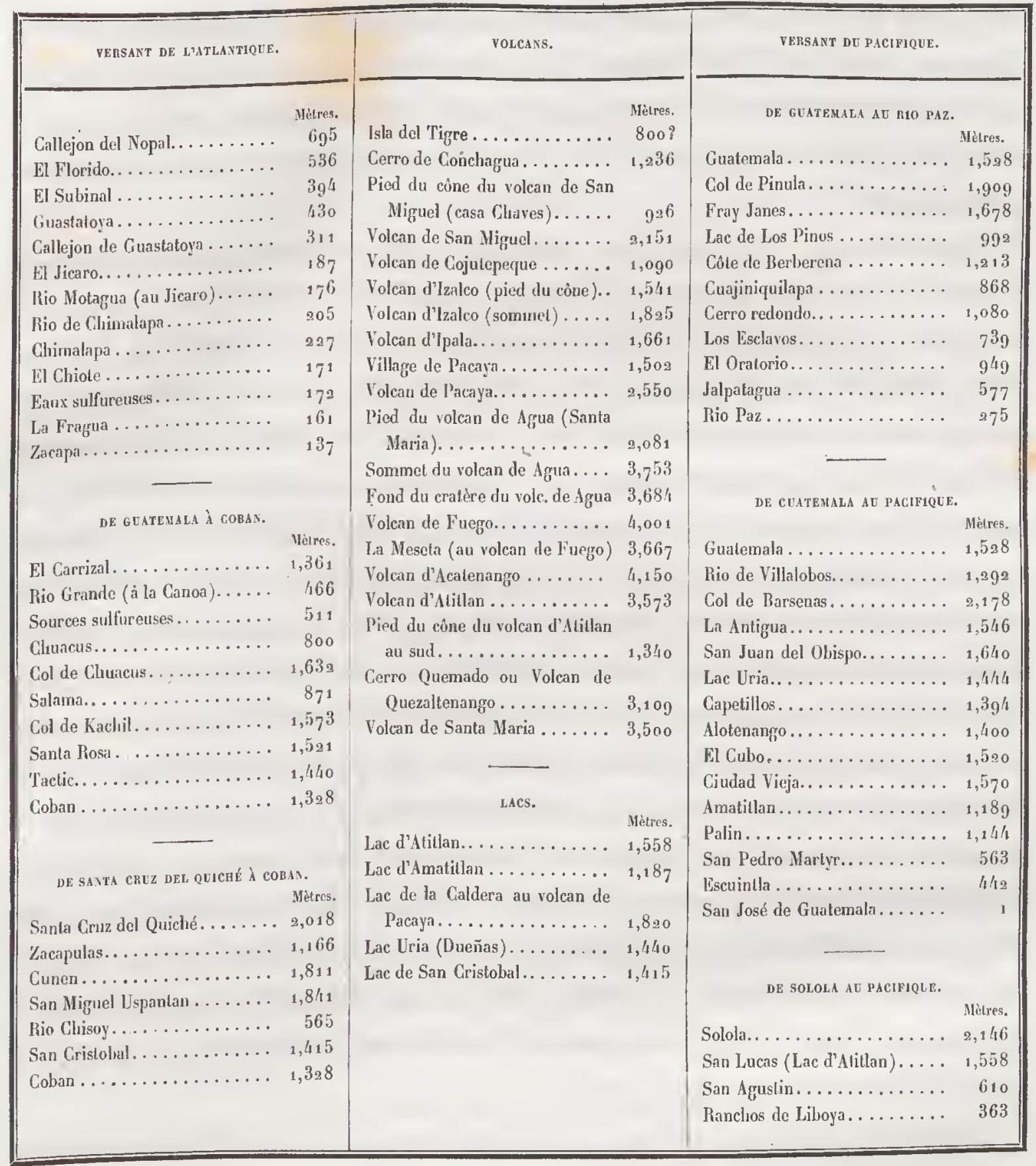

LIGNES DE PARTAGE DES EAUX.

(PI. 1.)

Il est facile, après tout ce qui vient d'être dit, d'établir la direction de la liğne Ligne principale partage des eaux entre l'océan Pacifique et l'océan Atlanlique, car elle coïncide de partage presque exactement avec la ligne principale des crêtes, et, pour ne pas nous répéter, nous pouvons renvoyer à l'un des paragraphes précédents. Qu'il suffise 
de rappeler qu'elle existe dans les montagines qui dominent immédiatement Totonikapam, passe à côté de Tecpan Guatemala, se place dans la plaine de Guatemala presque exactement dans la même position que cette ville, suit les haules crêtes de Jalapa el d'Alotepeque, et va se perdre enfin dans les hautes montagnes du. Honduras.

ligne

de

partage secondaire sur le versant de l'illantique.

Ligne de partage des eaux secondaire sur le versant 4u Pacifique.

Sur le versant de l'Allantique il existe une répartilion secondaire des eaux lort importante. En effet, les unes vont dans te golfe de Honduras avec deux fleuves principaux, le Molagua et le Polochic, laudis que les autres gagnent le golfe du Mexique avec loutes les grandes rivières, te Clissoy, le Rio de la Pasion, etc., yui se rémnissent pour former le fleuve Usumacinta. Malgré cela, la ligne de partage des eaux ne suit nettement la direction d'aucune des importautes chaines de montagnes qui accidentent celte région; on ne peut la défulir d'une façon alssolue, el ce n'est, en quelque sorte, qu'une liğne idéale sautant de l'une à l'aulre de ces chaines parallèles dont nous avons déjà parlé, el affectant, pour ainsi dire, l'allure brisće d'une série de Z superposés. Ainsi uous la voyons commencer près de Santa Gruz del Qniché et marcher d'abord longlemps de l'ouest à l'est, ladissant au sud tout ce qui se jette dans le Rio Grande, et au nord tout ce qui va au Rio Chisoy par les rios Negro, de Rabinal et de Salama. Non loin de Salama, elle se détourne brusquement et court au nord-ouest jusque vers San Cristobal, par les chaines du Patal ct de Tactic, pour s’infléchir encore tout à coup el s'enfóncer dans le nord-est jusqu’à des distances considérables, en sépar‘unt les eaux qui vont au Rio de Cajabon et celles qui gagnent les nombreux aflluents du Rio de la Pasion. Plus au nord encore, quoique les choses soient peu comnues, il est évident qu'il y a un nouveau relour pour isoler le bassin du Rio de Belize.

Du côté du Pacifique, quoiquill n’y ait pas, à proprenuent parler, de réparlition secondaire, il se passe, pour le Rio Lempa, un fait si remarquable, qu'il faut en faire une mention toute spéciale. Ite bassin de ce fleuve est isolé de la manière li plus complète par la ride montagneuse qui court parallèlement à la chaine principale et à la iner, depuis lzalco jusqu’à San Migrnel, et laisse les eaur s'écouler vers le Pacifique par l'étroile el profonde coupure de la Barca. Cetle cliaine esl presque une ligne de partage des eaux secondaire, car elle ne laisse au sud, pou' aller se jeter directement dans l'océan, que des cours d'eau infiniment petils, 
DANS LES RÉPUBLIQUES DE GUATEMALA ET DE SALVADOR. 99 presque des ruisseaux, parmi lesquels il faut citer les innombrables filets d'eau claire et pure qui sillonnent les environs de Sonsonate, "la ville aux mille sources," d'après son élymologgie indienne. Au nord, d'autres petiles rivic̀res courent dans nu sens opposé, comme si elles voulaient gagner l'Allantique, mais elles rencontrent. tout à coup le Lempa, qui reçoil en même temps d'autres cours d'eau descendus des montagnes du Honduras. Le fleuve ainsi confinć dans ce vaste bassin particulier, nellement défini, coule lonģtemps parallèlement à la mer, puis se délourne brusquement pour traverser les montagnes el alleindre le Pacifique.

Les autres lignes de parlage des eaux, que l'on pourrait presque appeler lertiaires, n'ont pas grande importance sur le versant du Pacifique; ce ne sont gुuère que des rides transversales, qui divergoent de la chaine centrale et courent parallèlement vors la mer en isolant les pelits bassins des torrents qui se précipitent sur ces pentes abrnples. Du còté de l'Allantique, an IIonduras, les grandes rivières, comme le Chamelicon et l'Ulua, qui recoil trois affluents importants, le Santiago, le Santa Barbara el le Humaya, sont nellement séparées par de grandes chaines de ınontagnes, qui, très-importanles an point de vue orographique, ne le sont pas autant comme ligones de partage des eaux. Au Guatemala, les fleuves qui vont se jeter dans le golfe de Iloniduras ont aussi des hassins bien isolés; ainsi le Molagua est nettement séparć du Polochic par les montagues qui vont de Santo Thomas à Izabal, puis par la grande cliaine du Mico qui court jusque près de Salana; et le Polochic lui-mème est nettement séparé de son aflluent, le Rio de Cajahon, par la forte ride qui commence près de Santa Cruz, entre Tactic el Coban.

\section{ÉTUdE DU COURS DES PRINCIPALES RIVìRes.}

Il est difficile de dire quelque chose de parfailement précis sur les rivières de l'Amérique ceutrale, car elles présentent toutes des différences considérables, suivant qu'on les observe pendant la saison sèche ou la saison des pluies; el tel cours d'eau que l'ou franchira facilement à goué, sans que l'eau dépasse les genoux des chevaux, au mois de février, deviendra, au mois de septembre, une effrayante massę d'eau, impossible à traverser sans appareils spéciaux, et entrainant tout sur son passage. Ious allons néaumoins développer les quelques observations que nous avons pu recueillir.
lignes de partagra
des eaux tertiaires.

- 13. 
Du côté du Pacifique il n'y a guère, sauf le Rio Lempa, de fleuves très-importants.

Rio Grascoran.

Le Rio Goascoran, qui forme, sur une partie de son cours, la limite entre le Honduras et le Salvador, atteint une longueur totale d'environ 120 kilomètres. C'est une grande rivière pendant la saison des pluies, mais, pendant la saison sèche, on peul presque partout la passer à gué; peut-être y aurail-il moyen de la rendre navigable jusqu’à quelques kilomètres au-dessus de son embouchure.

Le Rio de San Miguel est à peine plus important que le précédent, quoique son cours soil peut-ĉtre un peu plus élendu. Près de la ville qui tui donne son nom if n'a gguère plus d'une quinzaine de mètres de largeur et environ un mètre de profondeur en saison sèche; mais, en saison des pluies, il roule un volume d'eau plus considérable, et l'on a été dans la nécessité de construire plusieurs ponts pour' assurer le passage en tous temps. Les régions qu’il traverse et fertilise ćtant relativement peu inclinées, son cours est naturellement peu précipilé.

Rio Lenpa. Le Rio Lempa est un fleuve remarquable à tous les points de vue; il est navigable sur une partie de son cours, el semble appelé à devenir un jour un sérieux élément de civilisation pour la république de Salvador. Il courl au sud-cst, parallèlement à la côte, sur plus de 18 o kilomètres, puis, tournant brusquement au sud, il suit cette nouvelle direction sur près de $9^{\circ}$ kilomèlres, et va se jeter dans le Pacifique en un point dont les éléments seraient, d'après $\mathrm{M}$. de Gueydon, latitude $13^{\circ} 12^{\prime} 30^{\prime \prime} \mathrm{N}$. el longitude $91^{\circ} 1^{\prime} 0$.

It reçoil un grand nombre d'affluents plus ou moins importants, dont un, eu particulier, sert de déversoir au grand lac de Guija.

Le volume d'eau qu'il roule est considérable en toute saison : à la Barca, à environ 5 o kilomètres au-dessus de son embouchure, c'est un fleuve magnifique, large de près de 200 mètres; après six mois de sécheresse, en avril, il présente encore, au milieu, une profondeur de 3 mètres à $3^{\mathrm{m}}, 5 \mathrm{o}$, profondeur qui augomente considérablement et atteint 8 à 9 mètres en saison des pluies. Des sondages ont été exécutés par le gouvernement de Salvador, un peu au-dessus de la Barca, en 1852, probablement daus les premiers mois de la saison sèche. Jee fleuve, resserré entre de hautes falaises, ne présente que 130 mètres de largeur en ce 
DANS LES RÉPUBLIQUES DE GUATEMALA ET DE SALVADOR. 101 point, et les profondeurs mesmrées de 10 en 10 mètres sont respectivement, en partant de la rive gauche:

$$
2^{\mathrm{m}}-3,30-4-5-4,60-4-3,30-3-2,30-2-1,60-1,30-1,16-1 .
$$

A près de 200 kilomètres au-dessus de son embouclure, près de Suchitoto, le Lempa atleint, au mois de juillet, une largeur de près de 120 mèlres, avec une profondeur supérieure à 1 mètre el une gorande rapidilé (Squiers); mais plus bas, le courant ne dépasse pas 100 mètres par minute en saison des pluies, el n'atteint de hien loin pas ce chiflre en saison sèche. Le fleuve est par'cour'u jusqu'ì une assez grande lauteur par des batcaux plats, mais, pour que les navires pussent y pénétrer, il serait essentiel de corriger sa barre, qui n’a guère que 2 mètres d'eau en moyenne.

Le Rio Paz, qui forme, sur une partie de son cours, la frontière entre le Guatemala et le Salvador, est hien moins important. A une vingtaine de kilomètres au-dessus de son embouchure il n'a guère que 25 à 30 mètres de largeur, avec une profondeur de $0^{\mathrm{m}}, 75$ à 1 mètre en saison sèche; mais, en saison des pluies, il devient très-difficile à franchir à gué. Son courant est considérable el doit neème ètre coupé de cascades el de rapides, car, au point qui vient d'être mentionné, on est encore à près de 300 mètres au-dessus du niveau de la mer.

Les aulres cours d'eau que l'on rencontre, en marchant vers le nord, méritent Rio Michatoya. à peine d'ètre mentionnés; citons encore néanmoins la Michatoya, qui commence presque à Guatemala mème sons le nom de Rio de Villalobos, forme le lac d'Amatittan, devient un torrent fouguenx qui se précipite en volumineuses cascades près d'Escuintla, rachetant un millier de mètres en quelques kilomètres, el va se perdre enfin dans les plaines basses et sablonneuses, où elle forme de nombreux "esteros" avant de se jeter dans la mer. Celte parlie de la rivière, complétement abandonnée aujourd'hui par la navigation, ne fut pas tonjours négligée pourtant, car là se trouvait autrefois le port d'Istapa, et il est constant qu’à l'époque de la domination espagnole on construisil en dedans de la barre des navires d'un assez fort tomnage.

Le grand développement du versant de l'Allantique permet l'existence de fleuves considérables; mais ils sont malheureusement peu connus, et surtout peu 
utilisés par la navigalion, gràce, en grande partie, à l'insalubrité des régions basses qu'ils traversent arant de se jeter dans la mer.

Le Molagua ou Rio Grande est un beau fleure dont le cours entier embrasse un espace d'au moins 1400 ou 500 kilomètres. A La Canoa, à peine à 100 kilomètres au delì de sa source, c'est un cours d'eau encaissé dans une profonde vallée el large déjà de $7^{0}$ mètres environ; sa profondeur ne dépasse gùère un mètre en saison sèche, mais, en lemps des pluies, elle augmente considérablement. Quoique ce point ne soil qu'à 466 mètres au-dessus du niveau de la mer', le courant est assez considérable el atteint 110 mètres à la minule. Il augomente cncore un peu plus bas, mais dans un endroit où la largeur n'est que d'une trentaine de nètres et la profondeur laible; il diminuc, au contraire, jusqu’à 40 mòtres par minute, au Paso de los Ranchos, où la largeur est à peu près de 150 mètres. Au Jicaro, ¿̀ 1 - 6 mètres au-dessus de la mer, le Motagua est très-large el peu profond, avec un courant de 80 mètres à la minule. Ton loin de là, à 130 mètres au-dessus de la mer, il reçoit un affluent important, le Rio de Zacapa, largóe. de 60 mètres, arec une profondeur de $2^{\mathrm{m}}, 5$ o et un courant de 80 mètres par minute. Le volume de ses eaux en est considérablement augmenté, et, quoique à Gualan, grràce à sa profondeur el à la rapidité de son courant (120 mètres par minute), il n'ail que 40 mòtres de largơeur, il se développe bientòt darantage et atteint, à Barbasco, une Jargeur qui peut aller jusqu'à 300 mètres, avec une prolondeur de 6 à 10 mètres et un courant de 115 mètres à la minule. Celte rapidité doil diminuer en mème temps que la quantité d'eau augomente, à mesure que l'on se rapproche de la mer, car la pente n'est plus que faible, el il est probable que ce fleuve serait aisément navigable, sinon jusqu’à Barbasco même, du moins assez loin dans l'intérieur des terres.

Quoique te Polochic n’ait pas un cours aussi considérable, c'est néanmoins un lleuve d'une grande importance pour le développenent commercial des provinces centrales du Gualcmala. La branche la plus puissante des haules parties est le Rio de Cajabon; à une soixantaine de kilomètres de sa source, à Sau Pedro Carcha, c'est déjà une rivière large d'une vingtaine de mètres, el assez prolonde pour qu'on ail dû y construire des ponts el que les Indiens indigònes y fassent naviguer de pelits canols; mais le cours est interrompu un peu plus bas par des cascades et 
DA IS LES RÉPUBLIQUES DE GUATEMALA ET DE SALVADOR. 103 des rapides. Ce n'est qu'à Teleman, au point où se réunissent le Rio de Cajabon el le Polochic proprement dil, que ce fleuve large et profond devient aisément navigable pour d'assez gros bateaux. Son courant, déjà assez fiible, car il ne dépasse pas 25 mètres à la minute, dininue encore et atleint à peine 20 mètres au moment où le fleuve, large d'une centaine de mètres et profond de 5 ì 9 mètres, se jelte dans le Golfo Dulce, non loin d'Izabal. Le Gollo Dulce est une sorte de vaste estuaire, presque un lac, car on l'appelle quelquefois aussi Lagguna de Izabal. II est à peine élevé au-dessus du niveau de la mer, et communique avec elle par un canal étroit el profond, presque sans courant, qui présente uu élargissemenl dil "golfete," où la profondeur est de 7 mètres en moyenne. La profondenr du Golfo Dulce est de 12 mètres en général; aussi pourrait-il facilement, après reclification de li barre, recevoir des navires d'un plus fort tomnage que les goöleltes qui établissent la communication entre leseports d'Tzabal el de Belize.

Le fleuve le plus important de l'Amérique centrale est sans contredit l'Usumacinta, qui se jelte daus ta Laguma de Terminos, el que de gros bateaux peuvent remonter jusque fort loin. Il se forme par la réunion de plusieurs volumes d'ean considérables, fournis principalement par le Rio de San Pedro, le Rio de li Pasion el le Rio Chisoy. Les deux premiers parconrent les solitudes du Pelen el ne sont guère connus que de nom; le dernier prend naissance dans la province 111 peu moins sauvage des Altos. Il se forme près de Zacapulas, par la réunion des rios Negro et Blanco, cours d'ean impétueux et mal régglés, el descend lui-mème de 600 mètres en moins de 80 kilomètres, roulant avec fureur au fond d'une immense vallée ses eaux largées et profondes, qui font pressentir un grand fleuve.

\section{LACS}

Il existe dans l'Amérique centrale, outre un nombre considérable de lacs ordinaires, une cerlaine quantilé de cratères-lacs. Ces dernierss sont généralement lort petits, mais souvent assez profonds, quoicu'il ne laille point ajouter foi aus traditions populaires qui les donnent comme insondables. Presque toujours asse\% exactement circulaires, ils n'ont ancun déversoir apparent, ne recoivent pas de ruisseaux, et ne doivent ètre considérés que comme des accumulations d'eanx pluviales relenues dans des cratères éteints par une sorte de ciment, produil de la 
décomposition des roches volcaniques alumineuses. Assez fréqueminent aussi leurs eaux sont imprégnées de matières minérales, soit préexistantes, soit dues à la présence de sources thermo-minérales qui naissent dans le voisinage. Tels sont, au Salvador, les cratères-lacs de Tecapa el de San Salvador, situés au sommet de hautes montagrnes; la IIoya de Cunscatlan, qui s'ouvre brusquement à une centaine de mètres en contre-bas du sol environnant; peut-être même le lac de Cualepeque, non loin d'Izalco, derrière le volcan de ce nom. Telle est, au Guatemala, la lagune de la Caldera, établie dans un ancien cratère an pied du volcan de Pacaya; tel était encore le lac formé dans le cratère éteint du volcan de Agua, dont les digues rompues tout à coup par un tremblement de terre amenèrent la terrible inondation qui détruisit Giudad Vieja, el dont l'hisloire a conservé le souvenir.

Mais ce ne sont là que des exceptions, et presque toujours les lacs d'une certaine imporlance sont simplentent établis dans des replis montagneux, ainsi qu'il arrive dans toutes les régions fortement tou'mentées. Le plus considérable de tous, mais aussi le moins conmı, est probablement le lac de Yojoa, au Honduras, qui déverse ses eaux dans l'Mllanlique par le Rio Blanco, affluent de l'Ulua. Le Salvador possède aussi, oulre les petites lagunes de Camalolal, de Zapotitlan, etc., deux masses d'eau d'une grande importance, les lacs d'Ilopango el de Guija.

Le lac d'llopango peut avoir 20 kilomètres de longuenr sur 8 ou 9 dans sa plus grande largeur; sa forme est irrégulière, et il présente quelques îlots dans sa régoion sud. Il s'ouvre à 300 ou 400 mètres en contre-bas des plateaux environnants, au milieu d'une région fort accidentée. Ses eaux sont très-profondes, douces, poissonneuses, et s'échappent par un ravin étroit et fort encaissé qui communique avec le Rio de Jiboa. Malgré l’opinion assez généralement établie, el admise par M. Squiers, il ne nous semble pas qu'on doive le considérer comme remplissant un gigantesque cratère d'eflondrement, el, si l'on veut que la puissance volcanique ait joué un rôle dans sa formation, ce ne peut être qu'accessoirement el de la manière que nous aurons à définir à propos des lacs d'Amatitlan et d'Atitlan.

Le lac de Guija est situé sur la frontière du Guatemala et du Salvador, entre $91^{\circ} 46^{\prime} 30^{\prime \prime}$ et $91^{\circ} 51^{\prime} 40^{\prime \prime}$ de longitude ouest. Sa plus grande longueur peut être 
DANS LES RÉPUBLIQUES DE GUATEMALA ET DE SALVADOR. 105 de 25 kilomètres, et sa plus grande largeur de 10 à 12 ; mais sa forme est trèsirrégulière. Il est entouré d'un système d'assez hautes montağnes, reçoil un grand nombre d'affluents, quelques-uns d'une cerlaine importance, et se décharge lui-même dans le Rio Lempa, dont il peut être considéré, jusqu'à un cerlain point, comme une des sources principales.

Au Guatemala, nous ne citerons que pour mémoire le lac d'Ayarces, à peu près inconmu, ainsi que les grandes étendues d'eau du Pelen, et les petits lacs pittoresques mais insignifiants d'Uria près de la Antigua, de San Cristobal près de Coban, etc., mais nous nous arrêterons un peu plus aux lacs d'Atitlan et d'Amatillan, situés l'un et l'autre à des allitudes considérables, non loin de la chaine centrale, mais sur le versant du Pacifique.

Le lac d'Amatitlan est à 1,185 mètres environ au-dessus du niveau de la mer ; lac d'Amatillan. borné au nord par d’assez abruples falaises, il atteint, de ce côté, une profondeur plus considérable que vers le sud, où ses bords se raccordent progressivement aux dernières pentes du massif du volcan de Pacaya. Il peut avoir de 15 à 16 . kilomètres dans sa plus grande longueur el de 5 à 6 en largeur. Ses caux seraient parfaitement douces et polables, si elles ne devaient une salure accidentelle à la présence de quelques sources thermo-minérales qui jaillissent en différents points de ses bords. It reçoit au nord le Rio de Villalobos, se déverse au sud par la Michatoya el ne doit évidemment son existence qu'ì une interruption des eaux de celte rivière produite dans les circonstances suivantes. Il est probable que le Rio de Villabobos descendait autrefois directement ì la mer par une vallée régulièrement transversale à la chaine principale; mais, lorsque vinrent ì se produire les phéuomènes volcaniques qui caractérisent ces régions d'une manière si remarquable, la formation des volcans de Pacaya et d'Agua, cöncidant avec uue surélévation du sol, interrompit le cours des eaux el en délermina l'accumulation en ın lac plus vaste el plus profond que le lac d'Amatitlan actuel, et dont on voil encore nettement les traces anciennes jusque près de Palin. Mais peu à peu les eaux, entamant leur barrage, creusèrent dans les derniers contre-forts du Pacaya la gorge profonde par laquelle se précipite la Michaloya, qui peul-être, avec le cours des siècles, finira par ronger entièrement l'obstacle el à gagner un niveau tel que le lac d'Amalitlan n'existcra plus qu'ì l'état de souvenir. 
Le lac d'Atitlan maintient ses eaux à 1,558 mètres au-dessus de celles du Pacifique; sa plus grande longueur est d'une vingtaine de kilomètres, et sa pilus grande largeur d'une quinzaine, la forme étant irrégulièrement circulaire. Borné au nord par les hautes falaises de Solola, au sud par les pentes mourantes du volcan d'Atitlan, il a partout une profondeur considérable et qui n'a jamais été estimée, même approximalivement. Ses eaux sont parfaitement douces et potables, et alimentent à elles seules plusieurs villagres placés sur ses bords. II reçoit au nord les rios de Solola (ou Iboy) el de Panajachel, et il n'y a pas à douter que ces rivières ne fussent autrefois des aflluents des rios de Cutzan et de Sanla Barbara, qui vont, eux, se jeter directement dans le Pacifique. Mais le soulèvement des volcans de San Pedro et d'Atillan vint harrer leur cours et forcer leurs eaux à s'accumuler pour former le beau lac d'Atillan. Il est à remarquer que, quoique le niveàu du lac soit constant et qu'il reçoive de grandes masses d'eau, il n'a pas d'écoulement visible; mais, si l'on examine les choses de plus près, on verra que les eaux doivent filtrer en partie à traver's les massifs de déjections volcaniques qui les retiement, et aller former, à quelques kilomètres plus au sud et à quetques centaines de mètres plus bas, une partie des petits ruisseaux qui vont se jeter dans les rivières citées ci-dessus. 
DANS LES RÉPUBLIQUES DE GUATEMALA ET DE SALVADOR. 107

\title{
C H A P ITRE I I.
}

\author{
CIL I M A T O L O GIE.
} Climat des différentes zones. - Aspects physiques. — Cultures et végétations. _ Limites des végétations.
_- Terres chaudes. - Terres tempérées. - Terres froides.

L'Amérique centrale, comme la plus gorande partie des régions tropicales du variétés de climat: nouveau monde, doit à sa constitution orographique de jouir d'une variété de climats presque infinie, grâce à laquelle peut s'établir une diversité de cultures l'Amérique qui groupe à côté les uns des autres les produits des différents points du golobe. En effet, les régions les plus centrales de son continent se trouvant à une clévation considérable au-dessus du niveau de la mer, l'altitude y remplit le rôle que joue la latitude dans les autres parlies du monde el y produit des phénomènes à peu près comparables. Elle modifie le climat, qui n'est, en réalité, brûlant que sur les côtes, au niveau de la mier, là où la tempéralure moyenne atteint le chiffre de $28^{\circ}$, que l'observation assigne pour les contrées basses situées entre 12 et 15 degrés de latitude nord, et l'adoucit progressivement pour les points situés sur les vastes pentes qui constituent les versants, jusqu’à le rendre comparable à celui de la France, sauf certains détails caractéristiques, pour les hauts plateaux qui naissent aux élarợissements de l'arête centrale.

Comme au Mexique, on est conduit à considérer trois divisions principales, auxquelles on donne les noms de terres chaudes, terres tempérées et terres froides (lierras calientes, tierras templadas et tierras frias); noms auxquels il faut attacher une signification beaucoup plutôt relative qu'absolue, car les terres froides, par exemple, ne sont froides que par comparaison avec les terres chaudes, et 
non point en réalité, puisqu'on y voit prospérer presque lous les végétaux de nos pays européens. Si l'on voulait pousser l'observation plus loin dans les détails, on pourrail, à la rigueur, considérer une quatrième division, la zone glacée, qui acquiert une certaine importance au Mexique, où les très-haules montagnes sont nombreuses, mais qui n'a guère d'extension dans l'Amérique centrale, où quelques pics isolés viennent seulement y plongoger leur cime dont aucune n'atteint même la limite des neiges estivales persistantes.

La ligne de démarcation entre les diverses zones n'est pas alisolue.

Bases sur lesquelles s'appuie la subdivision.

On concevra aisément qu'il soit presque impossible de donner avec précision les limiles en altitude qui correspondent à ces différentes zones; en effet, quoiqu'elles soient parfaitement caractérisées, à un point de vue un peu gónéral, par leur's cultures et leurs végélalions, et que l'on trouve dans les allures des saisons, surtout en ce qui louche aux métćores aqueux, des caraclères différentiels très-nets et très-réels, il surgit une telle quantité de faits accidentels ou locaux, que les lignes de démarcation qui pourraient exister en sont de toutes parts déviées et troublées, et que c'est par des mélanges infunis, par des transitions iusensibles, que les diverses zones passent les unes aux aulres. Cela est si vrai, qu'au Mexique, par exemple, sur les côtes du golfe, où la limite eutre la terre chaude et la terre tempérée coïncide avec un fait pathologique de la plus grrande importance, la cessation de la fièvre jaune ou vomito, on n'en est pas moins dans une incertitude perpétuelle pour savoir si tel ou tel point doit être considéré comme appartenant à la première ou à la seconde de ces divisions, tant les faits locaux s'opposent à une ligne de démarcation régulière.

Tout en y attachant une imporlance considérable, nous laisserons un peu de côté les données purement météorologiques, qui sont trop susceptibles de modifications dues soit au relief du sol, soit aux allures mèmes et au développement de la végétation. Nous chercherons plutôt nos limites dans les ogroupes de cultures, quoiqu'ils soient fort dépendants eux-mèmes de causes parliculì̀res, telles que nature du terrain, disposition plus ou moins accidentée et plus ou moins boiséc naturellement, station plus ou moins abritée des vents régonants et plus ou moins soumise aux pluies abondantes, toutes canses qui agissent d'une façon puissante pour arrêter ou favoriser, suivant les cas, le développement en altitude de telle ou telle plante utile. Il restera donc bien entendu qu'un peu d'incertitude doil né- 
DANS LES RÉPUBLIQUES DE GUATEMALA ET DE SALVADOR. 109 cessairement planer sur les déterminations, el que ce n'est qu'en se plaçant à un point de vue très-ớnéral que l'on peut établir les linites suivantes :

Les terres chaudes comprennent les régions à haute température moyenne, caractérisées surtout par la présence du palmier et du cocotier, qui s'étendent depuis le niveau de la mer jusqu'ì une altitude de 400 mètres environ.

Les terres tempérées sont celles où se développent les cultures spécialement dites tropicales, comme le bananier, la canne à sucre, le caféier, elc., et occupent les régions comprises entre les altitudes de 400 mètres et celles de 1,500 mètres environ.

Les terres froides comprennent la zone où l'on voit prospérer les arbres et les céréales de nos clinats d'Europe, et cette zone, qui commence à 1,500 mètres, se termine à peu près aux altiludes de 2,500 mètres:

Plus haut, les conifères seuls vivent encore et caractérisent avec les graminées les premières parties de la zone glacée, qui va se perdre dans la région des neiges éternelles.

Ces divisions étant en relation immédiate avec les altitudes, il est évident qu'elles dépendront aussi, au point de vue de leur extension horizontale, des des diverses zones. mouvements el du relief du sol; c'est-ì-dire qu'elles occuperont un espace plus ou moins étendu, suivant que la déclivité des pentes sera plus ou moins rapide. Cela est vrai surtout pour les terres tempérées, car les terres chaudes sont presque toujours limitées à une assez étroite bande, qui occupe les bords de la mer ainsi que les premic̀res ondulations qui les raccordent anx parlies surélevées de l'intéricur; et les terres froides, de teur côté, ne peuvent se développer que dans les régions montagneuses à allitude assez considérable, sur les sommets des chaines, ou bien dans les petits plateaux auxquels donnent naissance les élargissements de la grrande arète centrale. Du côlé du Pacifique, les pentes sont en général assez brusques, dans la république de Guatemala du moins, et les terres tempérées n'y peuvent point acquérir une très-grande largọeur. Mais it n'en est pas de mème pour la plus grande partie de la république de Salvador, où la chaîne centrale s'éloigone de la mer, en même temps qu'une liğne de faîte secondaire vient s'établir dans cet espace el déterminer l'existence de vastes ondulations assez donces, presque de plateaux, comprises entre des altitudes de 500 
à 1,000 mètres. Du côté de l'Atlantique, en ce qui concerne le Guatemala, les terres tempérées prennent, au contraire, un développement considérable, car les vallées étagées el les plaines mamelounées de la Vera Paz ne s'abaissent que trèsprogressivement, pour se raccorder aussi doucement que possible aux basses régions du Yucalan.

Prédominance des terres tempérées.

Irautages qui en résultent. Comparaison aver le Mexiqur.

On peut donc affirmer que beaucoup plus de la moitié des territoires du Salvador et du Guatemala appartient aux terres tempérées, el c'est à cela précisément que sont dus les grrands éléments de richesse qui promettent à l'Amérique centrale le plus brillant avenir. La terre tempérée est la zone productive par excellence. C'est la régoion où l'on cultive les végétaux qui fournissent le sucre, le café, le tabac, le coton, la cochenille, etc...., en un mot toutes ces matières premières et toules ces denrées coloniales dont la consommation va grandissant chaque jour; produits d'exportalion avant tout, dont l'abondance attire les capilaux, qui amènent avec eux le développement du travail, la prospérité matérielle et l'avancement intellectuel et moral.

L'Amérique centrale est destinée à devenir, dans un temps plus ou moins éloigoné, le pays peut-être le plus riche du gobe, lorsque les matériaux dont elle possède le germe seront mis en œuvre avec énergie et vigueur par une race révivifiée par l'émigration européenne. Elle dépassera rapidement en prospérité et en civilisation le Mexique, ce pays légendaire, aux mines d'argent fabuleuses, et elle le devra moins encore à sa position géographique, unique au monde, qu'à ses allures orog̣raphiques, qui y donnent à la terre tempérée un développeinent si considérable.

Au Mexique, en effet, la terre tempérée n'occupe qu'une bande relialivement restreinte, sur des pentes généralement assez accentuées, aussi bien du côté de l'Allantique que de celui du Pacifique; de profondes vallées ou des ravins abrupts y rendent les communicalions difficiles, quelquefois même dangereuses, et, quoique riche partout où elle pent ètre mise en œuvre, elle est loin d'ètre pour le pays un élément de fortune proportionné à l'immnensité de ses territoires. Les hauts plateaux, au contraire, constituent plus de la moitié de la République mexicaine, el, goràce à leur climat, les travaux agricoles qui s'y développent ne peuvent lirer du sol, le plus souvent ingrat, que des produils qui ne sont pas 
DANS LES RÉPUbLiQUES DE GUATEMALA ET DE SALVADOR. 111 susceptibles d'introduire, par l'échange, la ricliesse dans le pays. I.e haricot, le maïs, l'orge, le froment, ont une valeur vénale faible, qui ne leur permet pas de supporter les frais de transport inhérents à l'exportation, et obligge presque loujours à les consommer sur place; de sorte que les métaux précieux étant presque les sculs articles d'exportation de ces vastes régions, elles sont presque inévitablement condamnées à un avenir plutòt médiocre que brillant. La constitution orographique de l'Amérique centrale lui lera éviter un semblable sort, car les hauts plateaux y occupent peu d'espace et produisent à peine assez de céréales pour la consommation du pays, tandis que les terres tempérées, qui s'y développent d'une manière remarquable, lui fourniront toujours, et de plus en plus, d'inépuisables matériaux d'exportation, d'échange et de richesse.

TELRES CHAUDES.

Les terres chaudes, comme leur nom l'indique, sont soumises à un climat brülant. La température moyenne de l'année varie entre $25^{\circ}$ et $28^{\circ}$, suivant les altitudes et les conditions locales, mais la chaleur du jour y est généralement intolérable, et le thermomètre dépasse souvent $40^{\circ}$. Au bord de la mer, une brise du large vient rafraîchir l'atmosphère le soir et le matin; mais, à quelques kilomètres dans l'intérieur, ces conditions ne se retrouvent plus, et un soleil de plomb condamne les étrangers et même les indigènes à la retraite et à l'inaction pendant les heures torrides du milieu de la journée.

Le climat des terres chaudes est caractérisé par une assez grande régularité dans l'alternance des saisons au point de vue des météores aqueux; non-seułement la saison des pluies n'y est pas très-longue, car elle ne dure que 4 à 5 mois au plus, mais il ne tombe que rarement des pluies accidentelles pendant le reste de l'année ${ }^{(1)}$. Il faut ajouter que le sol est généralement sablonneux ou graveleux el mal ou irrégulièrement arrosé, les eaux des régions supérieures s'étant déjà groupées en grandes rivières séparées par de vasles espaces desséchés. Toutes ces conditions réunies sont peu favorables à la vie humaine et à l'agriculture.

(1) La quantité d'eau déversée par les orages de l'été est tellement plus faible que celle qui tombe sur les versants des montagnes, que le climat des terres chaudes pourrait presque être qualifié de sec par comparaison avec cclui des' terres tempérées. 
aussi les terres chaudes sont-elles généralement peu habitées et peu cultivées, du moins dans les régions inférieures, près des rivages de la mer, où quelques ports seulement sont établis de loin en loin. Plus haut, la transition à la terre tempérée commence à se faire sentir, quelques centres importants sont élablis dans les tieux les plus favorablement situés, el les tribus indigènes occupent la campagne.

Extension des terres chandes du côté de l'Atlantique.

Extension des terres chaudes din còté du Pacifique.
Du côté de l'Atlantique, les terres chaudes du bord de la mer sont en goénéral excessivement malsaines, et, par conséquent, à peine habitées, sauf daus quelques ports de mer échelonnés sur la baie de Ilonduras; aussi n'aurons-nous que quelques mots à en dire. Au Guatemala, elles acquièrent une certaine importance dans les grandes vallées des fleuves principaux, comme le Polochic ou le Motagua, dont les rives sont bien cultivées, et habitées par une assez nombreuse population jusqu'à une distance notable de leur embouclıure; mais, dans l'intérieur des terres, on ne peut plus guère citer que pour mémoire ces mèmes vallées, et d'autres encore comme celle du Rio Chisoy, dont le fond, très-déprimé, alteint brusquement une altilude correspondant à la terre chaude, et qui jouissent d'une température d'autant plus élevée que la chaleur y est comme concentrée par les montaggnes qui les environnent. Mais elles sont, en général, tellement encaissées, qu'elles ne peuvent plus avoir aucune signification au point de vue de la population et de l'agriculture.

Sur les còtes du Pacifique, les terres chaudes occupent généralement une bande dont la largeur ne dépasse que rarement une cinquantaine de kilomètres; mais elle est très-souvent moindre, en particulier dans le Soconusco et dans la partie de la république de Salvador connue sous le nom de Cóte du Baume (Costa del Balsamo). Dans ces points, les montagnes se rapprochant de la mer, les terres chaudes deviemnent étroites et accidentées; elles se couvrent d'épaisses forêts habilées par des tribus indigònes qui y exploitent, par des procédés excessivement primitifs, le caoutchouc (Jatropha elastica, Hevea Guianensis), et le baume du Pérou tiré du Myroxylon peruiferum. En gónéral, et c'est le cas pour tout ce qui dépeud du Guatemala, les terres chaudes se composent de plaines sablonneuses étendues le long de la côte et reliées prog̣ressivement aux terrains plus élevés par des pentes donces ou de légères ondulations. 
DANS LES RÉPUBLIQLES DE GUATEMALA ET DE SALVADOR. 11:

Cette première bande de sable, parfailement plane, se développe au bord de la mer sur une targoenr de quelques kilomètres, el joue uin ròle imporlant daus Bords de lat uner. [nsalulurité. la configuration des côtes. Le vent déplace et accumule à son gré ces matérian meubles pour en former des dunes el des barrières qui interceptent le cours des rivières au moment oì elles vont se jeler dans l'Océan. Les eaux, ainsi arrètées, constituent de vastes lagunes saunâtres (esteros), de formes el de dintensions peu constantes, tantòt séparées de la mer, lantôt communiquant avec elle. Sur les rives de ces esteros croissent d'épaisses forèts de palétuviers (Rizophoria), qui plongent leurs racines dans les eaux saumâtres et servent de repaire à d'innombrables quantités de serpents el de caïmans. Sous l'iulluence d'un soleil hrùlant, les eaux croupissantes el les matières organiques en décomposilion rendent le voisinage des esteros extrèmement malsain; la fièvre y règne presque contiuuellement, el l'on n'y trouve pas d'habitants, saul aux endroits que le commerca a choisis pour y établir des ports. Dans quelques points, la baie de La Lnion par exemple, les rivages de la mer sont marécageu, mais les palétuviers ri! prospèrent pas moins, et les fièvres les accompagnent.

Les premières pentes qui succèdent aux plaines de sable sont un peu plus propices à la végétation; les bords des rivières se couvrent de belles el épaisses forèts, mais, en général, la terre est encore brùlée par le soleil, peu fertile, el ne nourrit tirnélation. que d'inextricables taillis d'arbustes rachiliques el épineru, surtout des acucias et des mimosas. Plus haul, le climat devient de plus en plus favorable à la vie et à l'agriculture. Lorsque, par hasard, l'eau est abondante, comme dans la vallée de Sonsonale (Salvador), qui est arrosée par d'innombrables sources el ruisseaux, la lerre chaude devient un séjour enchanteur, et les merveilles de l'agrriculture ne le cèdent en rien aux beaulés de la nature. Quoique les conditions soient loin d'être toujours aussi brillantes, on voil les villagoges se unuliplier, el aulour d'eux se développent différentes cultures, en particulier celles de l'indigo (Indigotera linctoria) et du cacao (Theobroma cacao), qui sont tout à fait spéciales à la terre chaude, puisque ces plantes ne supportent pas des températures moyennes inférieures à $23^{\circ}$ ou $24^{\circ}$, c'est-ì-dire ne peuvent pas dépasscr des altitudes moyennes de 500 mètres. Le palmier et le cocolier, qui abondent daus les mêmes régions, exigent mème une tenpéralure moyenne plus élevée ( $25^{\circ} 5$ environ), car ils ne Tojaģe géóogrique. 
montent pas au-dessus de 400 mètres. Mais, en revanche, ils descendent plus aisément jusqu'au bord de la mer, el on les voil en grand nombre aussi bien dans la plupart des ports que dans les lieux où la culture est régulièrement établie. Les pentes incultes nourrissent d'épaisses forêls où l'on récolte la vanille (Epidendrum vanilla); celte plante, qui appartient essentiellement à la terre chaude, IIe supporte pas une température moyenne inférieure à $25^{\circ}$, el s'arrète à 450 mètres environ. Nais, parmi les innombrables essences qui composent les forêts de ces régoions, il en est beaucoup qui sont communes à celles de la terre tempérée et continuent à y tronver, dans la majorité des cas, leurs conditions normales d'existence.

\section{TERRES TEMPÉRÉES.}

Caraclires des Lerres tempérées

Le climal des terres tempérées, presque brûlant encore dans les régions qui confinent aux lerres chaudes, devient doux et réellement tempéré dans les points dont les altitudes sont plus considérables. La température moyenne annuelle oscille entre les limites de $24^{\circ}$ et de $18^{\circ}$, et ces écarts n'ont rien qui doive nous étonner, puisque la zone dont il est question occupe un espace qui mesure plus de 1,000 mètres de développement vertical. Mais le caractère commun le plus saillant de ce vaste ensemble se trouve dans les allures des météores aqueux, car le climal des terres tempérées est partoul remarquablement humide. Non-seulement la saison des pluies y est longue, car elle dure au moins six mois, et quelquefois sept, mais encore le resle de l'année n'est presque jamais d'une sécheresse absolue; el il est excessivement rare, dans certaines localités du moins, qu'un mois entier se passe sans quelques aver'ses qui rafraîchissent l'almosphère et entreliennent la végétation. Les pluies sont extrêmement abondantes, surtoul dans la zone moyenne, el déversent sur le pays, pendant la saison d'été(1) en parliculier, une quantité d'eau considérable. Celle enu forme d'innombrables ruisseaux qui se réunissent en grandes rivières et arrosent admirablement les provinces qu'elles traversent. Le sol est, en ggénéral, de bonne qualilé, formé souvent

\footnotetext{
(1) Il va sans dire qu'alssi bien ici que dans tout ce qui va suivre nous prendrons les mots d'été el d'hiver avec la signification quilis out en Europe, et non pas avec celle

ils représentent la saison sèche et la saison des pluies, renversant ainsi complétenent les époques, puisqu'il fait beau pendant notre hiver et quil pleut pendant notre qu'on leur donue dans les pays hispano-américains, ò̀ été.
} 
DANS LES RÉPUBLIQUES DE GUATEMALA ET DE SALVADOR. 115 d'éléments volcaniques sur le rersant du Pacifique, à sous-sol calcaire du côlé de l'Allantique. Toutes ces conditions réunies contribuent puissamment à faire des terres tempérées les plus beanx et les plus heureux pays du monde, habilés par de nombreuses populations qui y trouvent tous les élémenls d'une existence facile et agréable, couverts de champs aux cultures les plus florissantes et les plus précieuses, aussi bien que de forêts les plus denses et les plus variées.

Les terres tempérées, nous l'avons dil, s'étendent depuis les limiles des terres chaudes jusqu'à une allilude de 1,500 mètres en moyenne. Elles occupent, sur le versant du Pacifique, toutes les pentes plus ou moins accidentées qui descendent vers la mor el les petites plaines qui forment le fond de quelques larges vallées; sur le versant de l'Mllantique, les vastes espaces mamelonnés de la liaute Vera Paz, Extension
des
lerres tempérées,
du
còlé du Pacifiruse
de l' Nandique. les flancs des chaines de montagnes de la basse Vera Paz, el les plateau compris entre elles comme ceux de Salama et de Rabinal. Celte cxtension considérable, correspoudant précisément aux régions plus ou moins inclinées où se trouvent accumulés en plus grand nombre les divers accidents du sol, pentes abruptes, rallées profondes, brusques déchirures, entraine nécessairemeut des variations de climat nombreuses el quelquefois soudaines. Ces varialions ne sont pas considérables, il est vrai; mais, augomentées encore par d'autres causes locales, parmi lesquelles le vent et la pluie sont en première ligöne, elles acquièrent souvent assez. d'importance pour avoir une influence directe sur l'habilat de certaines plantes cultivées dans les terres tempérées.

Ces plantes, du reste, sont loin de s'arrêter toutes exactement au mème niveau; ot leurs limiles, infléchies par tes accidents topographiques, se mêlent de telle facon, que toulc observation qui ne serail pas faite dans un sens extrêmement général, ne pourrait ètre considérée comme vraie que pour un seul point en particulier. Une scule plante peul servir à caractériser la zone tempérée d'une manière tout à fait générale; c'est le bananier, qui vit déjà en terre clande, et qui traverse toute la terre tempérée, jusqu’à des attitudes de près de 1,600 mètres correspondant à des températures moyennes un peu inféricures à $18^{\circ}$. C'est, du reste, le bananier qui a déjà été choisi par M. A. de Humboldt, pour définir les limites de la terre tempérée au Mexique.

Dans les réggions cultivées, de fertiles campagnes produisent en abondance les cinttures tropicales. 
diverses plantes dites de culture tropicale. La plupart sont susceptibles de vivre déjà dans les terres chaudes, mais n’y réussissent que dans des conditions spériales de fertilité et d'arrosement, landis qu'elles acquièrent tout leur développemenl sous les henreux climats qui nous occupent. Mais, si toutes produisent de bons résultals dans les régions inférieures de la zone tempérée, elles n’en alleignent pas toutes les limiles supérieures.

De ce nombre est surtout la canne ì sucre (Sacharum officinarum) qui ne peut supporter, non plus que l'ananas (Bromelia ananas), des températures movennes inférieures à $20^{\circ}$, el ne dépasse donc pas les altitudes de 1,350 à 1,400 mètres. Son vérilable niveau est entre 600 el 1,200 mètres, avec une lempérature sontenue el de l'eau en abondance.

Le colon (Gossypium), le ricin (Ricinus), et le nopal (Cactus opuntia), craignent In peu moins le froid, et peuvent nonter jusqu’à 1,450 mètres environ. Le nopal, qui nourril la cochenille, préscnte d’inléressantes particularités, car on semble rechercher pour sa culture bien moins la température élevée qui lui est propre, et que l'on trouverait partout dans la terre tempérée, que la combinaison d'une chaleur modérée avec les conditions climatériques de la partie supérienre de celle zone, presque de la terre froide. C'est surtont dans les vallées d'Amatillan el de la Anligua, que l'on récolte la cochenille, pour laquelle il faut une saison des pluies commençant le plus tard possible, vers la fin de mai, et ne s'annoncant que par peu de pluies préalables, espacées, très-nuisibles à cel insecte quand il approche du moment de la ponte.

Le labac (Nicotiana tabacum), le caléier (Coffea arabica), et surtout le bananier (Musa paradisiaca), penvent supporter des températures noyennes encore uu peu moins douces ( $18^{\circ} 5$ à $18^{\circ}$ ), ce qui leur permet d'atteindre aux limites de la terre tempérée, caractérisées, comme nous l'avons dil, par le point où cesse Jiı frnclification du bananier. Le caléier porte encore fruit à Guatemala (1,520 mèIres), quoique la température moyenne de cette.ville ne soil que de $17^{\circ} 7$; mais cela ne se voit que dans des jardins, et il est douteux qu'une plantation de cet arbrisseau pùt réussir en plein vent à nue pareille altitude.

La vigne pourrait donner d'excellents résultats en un grand nombre de localités de la zone dont il vient d'ètre question, ainsi que le prouvent les essais qui ont été 
DANS LES RÉPUBLIQUES DE GUATEMALA ET DE SALVADOR. 117 faits à Salama (871 mètres) dans la basse Vera Paz, et qui ont été conronnés de succès.

Le maïs et le haricot noir (frijol), qui sont les éléments fondamentaux de la nourriture des populations indigènes, sont abondamment cultivés en terre tempérée. Mais ils peuvent supporter les tempéralures de la terre chatule anssi bien que celles de la terre froide, et leur habitat est tellement étendı, qu'ils ne caractérisent en aucune façon les régions oì on les cultive principalement.

Parlont où la nature est abandonnée à elle-mème, les forì̀ vierges règnent sans partage el couvrent la terre d'un dòme impénétrable de verdure. Des arbres immenses, enlacés de lianes pendantes, aux branches couvertes de brométiacées ct d'orchirlées ì fleurs resplendissantes, des fongères arborescentes, des plantes de loutes espèces, forment un ensemble merveilleux. Une clairière dans une lorèt vierge, traversée par une petite rivière aux cascades écumantes, couverte d'unc voùte de feuillage qui tamise les rayous du soleil, émaillée de fleurs aux mille couleurs, est un spectacle qui défie lonte description. Les aspects sont anssi variés que splendides, et telle vallée touffine de la Vera Paz, telle pelouse entourée de liquidambars au feuillage si léger et si harmonieux, resteront toujonrs dans le souvenir de celui qui les a vues, comme le plus frappant exemple des beautés que crée la nature vierge clans la terre tempérée.

TERRES FROIDES.

Le climat des terres froides se lie insensibjement par en bas à celıi des terres. tempérées, car on en peul déjà observer bien des traits primcipaux à Guatemala,

Caracleres des terros froides. qui est sur la limile; et par en haut, à celui de la zone glacée, qui en fail mème partic, à la rigoneur, jusqu'aux limiles de la véçélation. Parmi les caractères les plus saillants du climat des terres froides, il faut uoter d'abord l'abaissement de la température moyenne annuelle. Il. est ì remarquer que cet abaissement tient beaucoup plus au froid des nuits qu’à la Lempéralure de la journée. En ell’el. les rayons du soleil, quoique traversant un air raréfié, frappent d'aplomb el développent cncore, pendant le milieu du jour, une chaleur considérable qui échauffe le sol, tandis que le rayonnement nocturne, facilité par la faible densité de l'almosphère, te refroidil rapidement aussilôt que le soleil est conché. Lu 
mème fail s'observe plus nettement encore dans les vastes plateaux du Mexique, où les journées sont souvent brùlantes et presque aussi intolérables qu’en terre chaude, tandis que les nuits sont glaciales.

Il faut signaler aussi la différence qui s'accuse entre les températures moyennes des deux saisons extrêmes. Lc refroidissement de l'hiver est assez notable pour que cela seul puisse suffire à le séparer très-nettement de l'été, contrairement à ce qui se passe généralement sous les latitndes tropicales. Cela est aussi facile ì expliquer que les écarts journaliers, car, à de semblables altiludes, l'ćlévalion de la température étant due uniqnement à l'influence directe des rayons du soleil, olle doil diminuer notableinent lorsqu'ils prennent une certaine obliquilé.

Au point de vue des allures des météores aqueux, les caractères sont aussi assez nettement tranchés. La saison des pluies est presque aussi longue que dans les terres tempérées, car elle dure généralement près de six mois, avec une certaine régularité; mais le reste de l'année est d'une sécheresse presque absolıe, et les pluies accidentelles y sont beaucoup plus rares encore que dans les terres chaudes. L'allernance entre les deux saisons se produit avec une remarquable précision. En outre, quoique les jours de pluie soient peut-être plus nombreux que dams les terres chaudes, la quantité d'eau tombée est infiniment moins considérable que dans ces dernières, el, à plus forte raison, que dans les terres lempérées. On peut donc dire que les terres froides constituent la zone la moins bien arrosée. Il faut ajouter que, dans les montagnes, les caux s'écoulent rapidement sur les pentes abruptes, et que, sur les plateaux, on a te plus souvent affaire ¿̀ un sous-sol composé de débris volcaniques ponceux et par conséquent trèsperméible.

Les terres froides occupent, outre les cimes des pies voleaniques isolés, où elles dessinent des ceintures extrêmement nelles, la majeure partic des sommités de la réggion nord des Altos, et surtout tout ce qui dépend, dans cette même province, de l'arête montagncuse centralc, comprenant des plateaux d'un cerlaiu développement, comme ceux de Totonikapam, de Quezaltenaugo, de Santa Cruz del Quiché, etc.

Les pays de monlagnes sont, en général, exposés aux vents froids du nord; la terre y est le plus souvent mauvaise el percéc de tous côtés par le roc vif. Ils 
DANS JES RÉPUBLIQUES DE GUATEMALA ET DE SALVIDOR. 119 ne produisent guère que des forêts plus ou moins épaisses, susceptibles de dovenir fort helles, il est vrai, lorsque les conditions sont favorables, et dans tesquelles on voit dominer d'abord des essences ayant des rapports intimes aver celles de la terre tempérée, puis des genres européens, surtout chènes el conifìres.

Il se présente mềme souvent un fait assez curieux. Sur les volcans, cônes parfaitement isolés, dont le pied plonge directement dans la terre tempérée el va d'un côté se raccorder à la terre cliande, les essences analogues à celles de la des terres froides.

Chemes ef coniferes. terre tempérée gagnent en altitude el envahissent le domaine des conilères, qu'elles repoussent dans les régions plus élevées. Sur plusieurs pies dont nous avous fail l'ascension (rolcans de Fuego, d'Agua, d'Alitlan, elc.), nous n’avons jamais vu ces derniers commencer avant 3000 mètres, et il n'y a que rarement des chènes daus les forêts qui les précèdent. Au contraire, dans les terres froides proprement dites de l'intéricur, qui ne se lient que très-progressivement aux terres tempérées. et en sont, en quelque sorte, isolées par do rastes espaces horizonlaux, les forc̀ts de chènes commencent dájà avec un assez grand développement sur des crêtes de montag̣nes, à des allitudes de 1,600 à 1,700 mètres, et on les voil mèlées à une assez forte proportion de pins, dans la province des Allos, ì des altiludes dr 1,900 à 2,000 mètres. Quelque chose de parfaitement analogue se présente: d'ailleurs dans les hauts plateaux du Mexique, où la végétation forestière dominante est celle des conilères, qui règnent seuls aussi à la base des grands pies volcaniques, brusquement surélevés au milien de la terre froide, sans aucunc relation avec les réơions basses où la température est plus élevée. Le chêne est une essence appartenant absolument à la terre froide, car, comme la plupart des cérćales, il ne supporte pas de températures moyennes inférieures ì $15^{\circ}$, el ne monte donc guère au-dessus de 2,400 ou 2,500 mètres, tandis qur le pin, ainsi que nous le montrerons plus loin, vit à des altitudes bien plus contsidérables.

Les cultures de la terre froide occupent principalement les versants pen inclimés el abrités, où la terre végétale n’a pas été complétement enlevée par les Culfures
des terres froides. Circíates. eaux, et les hauts plateaux plus on moins arrosés, dont le sol, quoique zónéralcment trop perméable, est quelquelois assez fertile. Ges cultures sont d'abord celles 
du mais et du harricot, dont il a déjà été question, et qui ue dépassent pas la température moyenue de $15^{\circ}$, correspondant à une allitude de 2,400 mètres cnviron. Le froment el les arhres fruiliers d'Europe (poiriers, pommiers, cerisiers, pêchers, elc.) sont exaclement dans les mèmes conditions comme limiles supérieures, mais leur hahitat u'est pas aussi étendu, car ils ue penvent commencer' aussi bas dans la terre tempérée, ne supportant pas des températures moyennes supéricures à $20^{\circ}$ ou $21^{\circ}$. Il faut encore y ajouter l'orge, l'avoine et lit pomme de terre, qui, tout en ayant une limite inférieure à peu près analog̣ue, peuvent supporter, surtout l'avoine, des températures moyennes un peu plus rigoureuses, puisque ces végétaux s'élèveut dans certaines condilions lavorables jusqu’à 2,800 mètres. Nous avons même vu un champ̣ d'orģe à une hauteur de plus de 3,000 inc̀tres, mais il élail uniquement destiné à produire du fourrage vert pour les bestiaux, el jamais on n'aurait songé ì altendre une fructificalion qui n'aurail pas eu lieu. On peul donc admeltre que la culture des plantes utiles s'arrête, à un point de vue gónéral, à des allitudes fort peu supérieures ì 2,500 mètres.

Gette limile de la fructilication des céréales est assez intéressante, si ou la compare à celle qui existe en Europe. En effet elle correspond à des températures moyennes annuelles de 14 ou $15^{\circ}$, el nous sommes habilués, dans nos clinats, ì voir ces plantes prospérer avec des moyennes aunuelles incomparablement plus basses. Mais il ne faut pas oublier que les céréales, ayant leur puissance végétative développée pendant l'été seulement, dépendent de la clialenr accumulée pendant cette saison, el ont des limites parallèles aux lignes isothères, c'est-ì-dire anx lignes correspondant aux moyennes estivales égales. Or, dans nos climats, tes différences de température entre les saisons sont considérables, l'été dépassan! de beaucoup la température moyeune, et l'hiver lui restant notablement inférieur; landis que, sous les tropiques, ces écarts annuels sont relativement très-peu de chose. La dilférence y existe surlout entre la nuit el le jour, de sorte que, mème arec une température moyenne annuelle de $15^{\circ}$, les plantes ont à subir, pendant l'éte, des alternatives journalières de grande chaleur et de froid intense. Quelle que soit alors la moyenne estivale el l'influence des rayons solaires pendant la journée, la répétilion régulière des nuits presque glaciales ne permet pas aux 
DANS LES RÉPUBLIQULS DE GUATEMALA ET DE SALVADOR. 121

céréales d'accumuler la quantité de chaleur qui leur est nécessairc pour la fructification, el en lixe ainsi les limites.

Les réģions dont l'allitude dépasse 2,500 mètres ne nourrissent guère plus que des fọrêts. Sur les volcans isolés, ces forêts, comme nous l'avons déjà dit, se composent, jusque vers 3,000 mètres, d'essences mêlées qui font reculer le doınaiue des pins; mais, sur les grands massifs monlagueux, il n'en est pas de mìme. Presque toujours, aussitôt que les cultures uliles disparaissent, elles sont remplacées par les conifères. Nous avons pu vérifier dans l'Amérique centrale une observation déjà faile au Mexique par M. de Saussure et par nous, c'est que la zone des conilères se décompose très-fréquemment en trois groupes distincls : le prenier se compose uniquement de pins; le second, qui commence en général vers 3,000 mètres et n’alleint guère que 20000300 mètres de développement, est caractérisé par les sapins, qui y sont presque seuls; dans le troisième, enfin, reparaissent des pins, spécifiquement distincts peut-être de ceux du premier groupe, et qui convrent les sommets des montagnes.

Celles-ci ne sont pas assez élevées, du reste, pour qu'on puisse suivre ce qui se passe jusqu'aux linites de la végélation arborescente, et l'on ne peut l'étudier que sur les cônes volcaniques, où ce sont d'ailleurs tes pins seuls qui vivent arboreseente. aussi aux grrandes altitudes. Malheureusement les volcans de l'Amérique centrate ne peuvent fournir que peu de documents pour cet intéressiut travail, car presque tous, ou bien ne sont pas assez élevés pour atteindre les limiles de la végéélation arborescente, on bien présentent eucore un degré d'activité qui la reponsse dans les régoions inférieures:

Sur te volean d'Atillan, qui s'élève à 3,572 mètres, le domaine des conifères s'arrète fort au-dessous du sommel à cause de la présence des scories roulantes ou des cendres meubles el acidifiées par les dégagements de gaz.

Sur le volcan d'Agua, qui est complétement éteint et arrive à 3,753 inèlres, les conifères existent jusqu'au sommet, mais, vers la fin, ils sont un peu espacés et rabougris, ce qu'il faut probablement attribuer aux forles pentes.

Sur le volcan de Fuego, les pins ne dépassent pas la Mesela (3,670 mètres), mais pour des raisons aualogues ì celles qui existent au volcan d'Alitlan.

Enfin, sur le volcan d'Acatenango, dit aussi Pico Mayor du volcan de Fingo, 
qui s'élève à 4,150 mètres, on voil les conifères monter jusqu'à 100 mètres environ au-dessous du sommet, sans être ni trop espacés ni trop rabougris à celte limite.

Ce serait assurément se hasarder beaucoup que de vouloir établir une loi sur l'observation d'un seul fait; mais, en le mellant en regard de ce que nous avons eu occasion de voir au Mexique, nous pourrons en induire qu'il nous donne. avec une approximation suffisante, la véritable limite de la végétation arborescente, car les conditions du volcan d'Acatenango sont tout à fait normales, et it ne se présente sur cetle montagne aucune parlicularité qui puisse avoir sur les choses une influence notable. Tous avons observé, au Mexique, les limites suivantes sur plusieurs hautes monlagnes siluées toutes à peu près sur le mème parallèle de $19^{\circ} 30$.

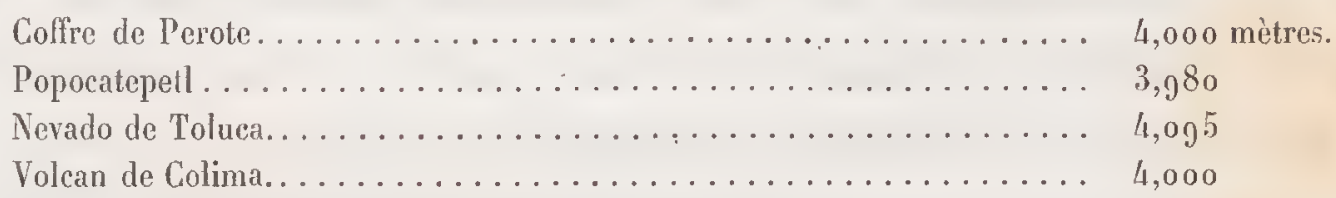

C'est donc très-approximativement une moyenne de 4,000 mètres, et on admetlra facilement qu'à la latitude de $14^{\circ} 30$, qui est celle du volcan d'Acatenango, la limite soit un peu plus élevée et corresponde à 4,050 mètres à peu près. On pourrait peut-être s'étonner que la différence ne soit pas plus grande, mais il faut rélléchir que la limite de la végétation arborescente est soumise à des causes parliculières au moins aussi dignes de remarque que celle des céréales.

Ce n'est certainement pas à l'altitude seule que peut être dù l'arrêt de la vie des conifères, car à 4,050 mètres la température moyenne n'est pas excessivement basse, peut-être 7 ou $8^{\circ}$ tout au plus, et elle est en tout cas beaucoup plus élevée que celle qui permet aux grands arbres de prospérer encore très-bien en Europe. On admet dans nos climats que les limiles des gorands végótaux sont parallèles aux lignes isochimènes, c'est-di-dire aux lignes d'égale température hibernale; car, devant conserver pendant toute l'année une certaine puissance végétative, ils dépendent directement du degré de rigueur de lhiver, qui ne leur fournit plus les condilions nécessaires à leur existence lorsque le froid devient trop intense et trop continu. Mais, dans les régions intertropicales, les choses ne sont pas compara- 
DANS LES RÉPUBLIQUES DE GUATEMALA ET DE SALVADOR. 123

bles, puisqu'il n'y a pas, à proprement parter, d'hiver rigoureux, et que, comme nous l'avons déjà dit, les jourróés sont toujours chaudes. Les causes de l'arrèt de la végétalion doivent bien plutôt ètre cherchées, comme l'a très-bien fail M. de Saussure (IIydrologie du Mexique), dans les conditions climatériques de ces hautes régions. En effet, quoiqu'il il y ait une partie de l'amnée où il fait plus froid, cel hiver coincide avec la saison où la séchieresse est presque alssolue. II n'y a donc aucune chule de neige qui vienne se joindre à l'abaissement de la tempéralure pendant celle période, pour soumeltre les végétaux à des condilions nuisibles. Mais, en été, quoiqu’il fasse chand pendant le jour, il fait lroid, souvent trèsfroid, le soir et pendant la nuit. Or c'est précisément à ce moment qu'éclatent les violents orages quolidiens qui, pendant la soiréc el une parlie de la nuil, déversent des quantités de pluie considérables dans les régions inférieures, mais so résolvent en ncige à ces hauteurs, surtout au conmencement el à la fin de la saison. Cette neige séjourne peudant la nuit sur les branches des arbres, le soleil du matin la fail foudre, mais la soiréc suivante la ramène, et celle alternance se répète pendant plusieurs mois. Les conilères doivent certainement souffrir beancoup de cette neige de tous les jours, transformée en eau, puis reformée de nouveau sur leurs aiguilles, et cela surtout au printemps, au moment où la force végétalive est en pleine activité. Ce serait là, beaucoup plutôt que dans le froid sec de l'hiver, peu intense du reste, qu'il faudrail chercher, suivant M. de Saussure, tes causes de l'arrêt de la végélation arborescente. Peut-être aussi la rarćfaction de l'air dans les grandes altitudes n'est-elle pas tout à fait indiflérente. Quoi qu’il en soil, nous croyons que la limile de la végétation arborescente doil ètre placée, dans l'Amérique centrale, à une élévalion comprise entre 4,000 et 4,100 mètres en moyennc.

Quant à la limile de la végétation herbacée, nous ne pouvons rien en dire, puisqu'elle se place, au Mexique, à une altilude de 4,200 mètres à peu pròs, hau-

Limite de la végétation lierlineréc. teur qui n'est atteinte par aucune des montagnes de l'Amérique centrale. Il est ì remarquer, néammoims, que, dans la région où les pins commencent à s'espacer, il sc développe une herbe épaisse et touflue, et que cette herbe persiste jusqu'à la pointe extrême da volcan d'Acatenanģo.

La limite des neiges étermelles, qui est, an Mexique, entre 4,400 el 4,500

des nejges ífernelles. 
mètres, serait peut-ètre un peu plus élevée encore dans l'Amérique centrale. II faudrait bien se garder de croire qu'elle est atteinte par certains points, tels que la Neveria du volcan d'Agua, située seulement à 3,500 mètres de hauteur, et où de la neige se conserve pendant presque toute l'année. On a affaire à des neiges tombées à la fin de la saison des pluies, au moment où le froid commence à s'accentuer, et qui, accumulées dans des trous ou des creux où clles sont à l'abri des rayons du soleil, peuvent persister pendant la plus grande partie de la saison sèche et donner lieu à de petites exploitations. Mais ce n'est évidemment qu'un lait exceptionnel dù à des causes absolument locales.

Résumé. Ces considérations sur les allures des climats, aussi bien que sur la répartilion et sur la limite des végétations, sont toin assurément d'ètre aussi claires que ce que la nature elle-mème met sous les yeux de l'observateur. Rien ne saurail rendre la netteté avec laguelle elle en oflire au voyageur l'illustration vivante, pour ainsi dire, le tableau coloré des nuances les plus vives el les plus tranchées.

Un des plus frappants exemples en est, si notre souveniu ne nous trompe pas, l'aspect du volcan d'Agua, tel qu'il se présente, vu d'une sommilé voisine, comme le volcan de Pacaya. Ce beau còne étcint s'élève, complétement isolé, précisément au milieu des régions les plus peuplées et les plus cultivées, el ses pentes, par des courbes d'une admirable régularité, se relient doucement et progressivement vers le sud-est aux plaines de la terre chaude, eu traversant toule la zone tempérée. Sur la surface du còne se dessinent des lignes régulières et parallèles qui correspondent aux limiles des végétations ${ }^{(1)}$. On distingue aisément à la base du volcan les pentes boisées de la terre chaude, parsemées, comme de taches plus claires, de petits espaces cultivés, au milieu desquels se dressent les élégants panaches des palmiers et des cocotiers; puis c'est la zone des plantalions de canne à sucre et de café dont la verdure étincelante forme une ceinture vivemen léclairée; quelques restes des épaisses forêts vierges y jeltent de loin en loin une lache sombre qui s'étend quelquelois jusqu'à travers la terre froide dont les cultures particulières dessinent une nouvelle bande, claire encore, quoique moins brillante. Vient ensuite le domaine

(1) II faut remarquer, en passant, que ces courbes ne sont pas tout à fai des cercles concentriques, mais plutôt des sortes d'ellipses, car elles se relèvent un peu vers le sud, du côté que les rayons du solcil frappent pendant un peu plus longlemps et que n'atteint pas le souffle des vents froids du nord. 
DANS LES REPUBLHOES DE GUATEMALA ET DE SALVDOR. T25 des grandes forèts à essences variées, vaste ceinlure sombre, limilée en lianl el en bas par des lignes d'une étonnante régularilé. Enfin, c’est la zone des hois de pins, où la végétation, moins condensée, laisse croìlre en abondance nue herbe jamàtre, dont le ton elair tranche vivement avec la nuance des espaces sitnés en dessous.

En résumé, il résnlte rle cette étude que la grande variété de climals dont l'Amérique contrale est redevable à sa constitulion orographique consiste surtont dans mue décroissance progressive ef infinie des tempéralures moyemes annuelles. Car il ne fiut pas oublier que cortains caractères fondamentaur des climats intertropicaux, en parliculier l'inégale répartition des pluies pendant les saisons, ot la varialion de lempérature journalière plutòt quammuelle, se retrouvent partout, à un degré plus on moins álevé, mème dans les terres froides, dont lo climat semble se rapprocher le plus de celui des pays européens. Ce sonl là des conditions auxyuelles ne se plieront jamais complétement les végétaux non indigènes, et gràce auxquelles la zone la plus lertile, la plus cultivéc. la plus peuplée el la plus riche. sera tonjours relle des terres tempérées. 


\title{
CHAPITRE III.
}

\author{
MÉTÉOROLOGIE. \\ Saisons. - Températures. - Ptuies. - Vents. - Varialions baromélriques. \\ Effets électriques et magnétiques.
}

Considétations rénérales.
Observatoire méténologrique lu Collége Trivilentin do rualemala.

Avant d'entrer dans le détail des diverses questions dont se compose ce claapitre, nous devons faire rentarquer que nous ne pourrons présenter que pen d'observations qui nous soient tout à fait personnelles sur la plus grande partie des régions que nous arous parcourues. Les observations méléorologriques sérieuses exigent un séjour prolongé dans une même localité, elles obligent ì un établissement, sinon définitif, du moins à pen près régulier', la plupart des instruments ne peuvent pas se prèter à des déplacemenls répélés, elc. Aussi le voyage rapide ne permet-il guère d'aborder de pareils sujets d'études. Quelques lails plus ou moins généraux, quelques phénomènes isolés ou locanx, peuvent seulement être observés en passant, el, pour leur donner une valeur quelconque, il faut les rapprocher de renseignements recucillis à la hâte, rarement précis ct pas toujours dignes de foi. Aussi ne pourrons-nous pas insister beaucoup sur ce que nous avons ohservé on appris pendant le temps qui a élé consacré à de nombreux et rapides voyages dans tous les sens. Ce n'est que dans la vitle de Guatemala que nous avons pu passer quelques semaines, et encore nos observations, embrassant un espace de temps aussi court dans une seule saison de l'année, n'auraient-elles pas une très-grande significalion si nous ne pouvions pas leur substiluer presque complétement celles qui sont faites par les révérends pères jésuites au Collége Tridentin de Guatemala.

Cet établissement possède un observatoire météorologique dont les bases ont été posées avec la plus gorande intelligence, et qui a été largoement muni d'excellenls instruments. Les observations y sont faites avec aulant de régularité que de scienrer, surtout depuis l'énergique impulsion qu'un Frauçais, le révérend père 
DANS LES RÉPUBLIQUES DE GUATEMALA ET DE SALVADOR. 127 Cornette, a donné, il y a une dizaine d'années environ, à ce genre d'ćtudes, et l'on peul accepter en toute confiance les résultals obtenus, pour en lirer d'intéressantes conclusions. On a bien voulu nous communiquer les registres d'observations de manière à nous permeltre de compléter une période de quelques mois, correspondant aux époques les plus intéressantes de l'année 1866, pendant laquetle nous arons séjourné dans la république de Guatemala, et nous avons. réuni les séries de cliffres journaliers dans des tableaux qui se trouveront ciaprès. On a cu aussi l'obligeance de mettre à notre disposition quelques feuilles de résumés aunuels, et nous avons pu recucillir ainsi, pour une période de cinq années, de 1859 à 1863 , des données précieuses dont nous avons tiré de nombreuses et intéressantes déductions. Quoique les lendances actuelles de l'observatoire des pères jésuites de Guatemala sojent de se préoccuper, trop exclusivemenl peut-être, de la recherche des moyennes, ce qui prive de quclques faits dont ha connaissance serait fort utile, il n'en faut pas moins ètre heureux d'avoir pu trouver un aussi grand nombre de précicuses observalions, et féliciler hautemenl cet établissement d'avoir accumulé, pour la science, des matériaux dont clle saura profiter.

Il demeure donc établi que c'est aux pères jésuites du Collége Tridentin de Guatemala que nous sommes redevables de la presque totalité des chiffres, que nous avons groupés dans nos tableaux de manière à en rendre la discussion el l'élude aussi claires et aussi aisées que possible. Il ne faudra pas oublier non plus que tous ces tableaux d'observalions, ainsi que les réflexions qui les accompagrnent, se rapportent ì la ville de Guatemala, c'est-à-dire à un point situé à un peu phis de 1,50o mètres d'altitude, presque à la limite supérienre de la terre tempérée, au milieu d'une plaine assez vaste pour que les montagnes qui l'entourent no puissent-avoir qu'une influence presque mulle sur la marche des phénomènes atmosphériques.

\section{SAISONS.}

L’Amérique centrale est, dans son ensemble, une régoion éminemment lro- partage de lauméc picale; aussi les fractions qui nous occupent plus spécialement participent-elles dens saisons très-neltement des caractères bien tranchés quij distinguent cette zone. Les diffé- prineipales. 
rences entre les saisons sont peu accusées au point de ve de la température, quoique les pays dont l'altitude est considérable, sans cependant tomber dans les exlrêmes, offrent des contrastes un peu plus frappants que les plaines basses. II ll'existe, à proprement parler, que deux saisons, moins caractérisćes elles-mêmes par les variations de la chaleur et du froid que par les allures différentes des méléores aqueux. Les termes de transition, le printemps et l'aulomne, disparaissent presque complétement; leurs noms mèmes sont à peu près absents de la langue, el il ne reste qu'un été et un biver, dont les noms europćens sont le plus sonvent néğligés par les idiomes locaux à cause des idcées de froid et de chiud que ces lermes impliquent dans nos climats. On les remplace par des dénominations beaucoup plus rationnelles, celles de Tiempo de Aguas, saison des pluies, pour l'élé, et de Tiempo de secas, saison sèche, pour l'hiver. Ce partage de l'annéc en deux saisons est important et constituera un des traits distinclif's de la météorologie dans l'Amérique centrale. Remarquons en passant, mais ponr y revenir avec plus de délails lorsque nous parterons spécialement des météores aqueux, que les pays dont il est question dans ce travail se trouvant dans lo voisinage plus ou moins immédiat du quinzième degré de latitude, ils présentent déjà quelques-uns des caraclères de la zone à double saison pluvicuse. Mais on n'est encore que dans les régions de transition, pour ainsi dire, et la saison des pluies, sans se dédoubler complétement, présente des périodes d'intensité plus considérable, séparées par une accalmie plus on moins sensible. Le fail est assez net et important pour mériter qu'on s'y arrête, mais il ne constilue pas quelque clıose d'assez saillant pour motiver un partage de l'année autre que celui qui nous conduit à considérer seulement deux saisons, celle des pluies et celle de la sécheresse.

lliures des saisons dans les terres chaudes.

Dans les terres chaudes, la saison sèche est gónéralement beaucoup plus tongune que la saison des pluies proprement dite, caraclérisée par les orages quotidiens. Sur les côtes du Pacifique, celte dernière ne dure que quatre mois environ; annoncée par quelques averses espacées, quelquefois oragenses, elle commence au mois de juin au plus tôt, el se développe alors avec mne certaine intensité, caractérisée par d'abondantes chutes de pluie journalières accompagnées le plus souvent de phénomènes électriques. Pendant cette période, il rèợne aussi parfois un vent du sud-est qui amène d'épouvantables tempêtes; ce vent est proba- 
DANS LES RÉPUBLIQUES DE GUATEMALA ET DE SALVAOR. 129

blement le mème que celui qui reçoil te nom de Cordonazo de San Francisco (flagellation de Saint-Francois) sur le lilloral du Mexique, el canse l'effroi des navigialeurs indigènes.

Au mois d'octobre, plutòt au commencement qu’à la fin, la saison des pluies se termine d'une facon complète pour laisser la place à la saison sèche, qui, de son còté, ne présente presque jamais de pluies accidentelles pendant tout le temps qu'elle dure. Le vent du nord règrne pendant la plus grande parlic de cette saison, quelquefois avec une certaine violence, et vient rafrachir l'almosphère de manière à rendre les bords de la mer un peu plus habitables. La barrière que lui opposent les hautes montagnes qui séparent le versant du Pacifique des régions voisines de l'océan Atlantique ne lui permetlent pas de s'élablir avec une très-grande régularité, el, torsqu'il souflle avec certaine intensité, on peut observer ce phénomène remarquable de courants puissants qui filtrent en quelque sorte à travers les interstices des monlagones, ravagent toul sur leur passage et respectent les localités abrilées par une sommilé qui arrête ou brise la masse d'air en mouventent. Il faut ajouter que le vent du nord arrive presque sec dans les pays qui bordent le Pacifique, et n'est plins que rarement issez saturé d'humidité pour déverser de la pluie sur les endroits dont la végétalion abondante est susceptible de déterminer un refroidissement et par suile une condensation. C'est dans les obstacles qui s'opposent à la marche régonlière du vent qu'il faut cliercher aussi les causes grâce auxquelles les côtes de l'Mtlantique ont une saison des pluies plus prolongée et un hiver qui r'est pas absolmment sec. Chaque fois qu'une cause quelconque permet la condensation des vapeurs que te veut du nord amène avec lui et dont il est encore saluré, la précipitation s'accomplit, el les terres chaudeș sont arrosées par d'abondantes pluies.

I la base de la terre tempérée la répartition des saisons est déjà un peu diflérente, et l'on peut remarquer, en parliculier, que l'époque des pluies embrasse ıu espace de temps bien plus considérable. La région dite Boca Costa, qui cor-

Allures des saisons lans la zone inférienre iles terres tempíries. respond, dans le Guatemala, sur le versant du Pacifique, à la zone que nous éludions en ce moment, est assurément un des pays les plus pluvieux qui se puissent voir, sauf peut-être les parties correspondantes du versant de l'Allantique, où les causes qui déterminent la précipitation des vapeurs de l'atmosphìre sont encore 
plus développées. Non-seulement la saison des pluies est très-longue, car elle dure près de sept mois, commençant en mai pour finir en novembre, mais encore l'autre saison est rarement absolument sèche, grrâce aux pluies accidentelles el aux autres météores aqneux. En effet, les mois de février, de mars et d'avril, semblen I déjì annoncer l'approche de la saison des pluies par des rosées abondaules et des brouillards qui règunent souvent le matin.

Nous ne devons pas passer sous silence un fail assez remarquable, qui prouve combien est grande linfluence de la végétation sur la répartition des météores aqueux. Depuis mne dizaine d'années l'époque de la saison des pluies a élé progressivement modifiée par te défrichement, à tel point qu'à l'hacienda de San Agrustin, on a dù retarder d'un mois le moment du travail de la canne à sucre. Des observations analogues ont été lailes à Coban, dans la terre tempérée du versant de l'Atlantique. Il y a vingt ans, celle région, couverte d'épaisses forèts. élail arrosée toule l'année par des pluies diluviennes, tandis que, depuis que les grandes cultures y ont été introduites, on commence à jouir d'une période de sécheresse, très-courte encore, il est vrai, mais néanmoins caractéristique.

Voici, pour résumer ces quelques considérations, le tablean de ce qui se passe mois par mois à San Agustin :

Janvier. Très-sec.

Février. Sec, sauf quelques pluies, dites lhwias de la Candelaria (pluies de la Chandeleur), qui viennent se placer dans les trois ou quatre premiers jours de la lunaison qui commence dans ce inois.

Mars. Très-sec.

Avril. Très-sec.

Mai. Environ quinze jours de pluies distancées, plus ou moins intenses, réparties dans le mois. C'est l'époyue des semailles.

Juin. Pluies réguliòres.

Juillct. Pluies régulières.

Août. Pluies, sauf pendant. une dizaine de jours an commencement du mois et quelquefois aussi dans Jes derniers jours de juillet. C'est ce que l'on nomme le verano de Agosto (printemps d'août) et cetle dénomination prouve, comme nous le disions plus haut, combien les noms des saisons, tels que nous les comprenons en Europe, ont été détournés de leur signification réelJe, printemps ne signifiant plus ici que temps bean et sec.

Septembre. Les plus fortes pluies. Tempètes du sud-ouest. Orages violents.

Octobre. Pluies distancées. Les mal tiempos, ou périodes des pluies fines, continues pendant qualre ou cinc jours, sans orage et sans vent, apparaissent surtout daus ce mois et annoncent l'approche de la fill de la saison des pluies.

Novembre. Quelques pluies distancées au commencenent ciu mois.

Déeembre. Ser. 
DANS LES RÉPUBLIQUES DE GUATEMALA ETT DE SALVADOR. 131

Daus la partic supéricure des lerres tempérées, à Guatemala par exemple, les allures des suisons choses sont encore un peu diflérentes el l'on peut aisćment saisir la transition in- la zone supérieure sensible qui relie la répartilion des saisons telle que nous l'avons indiquée daus terres tempérén. les régions inférieures el telle que nous la trouverons dans les terres froides. La saison des pluies est cucore longue, car elle occupe la bonne moilić de l'année, de la fir d'avril à la fin d'octobre; mais l'hiver est généralement assez sec, el il s'y manifeste déjà un abaissement de lempérature assez notable. Il faut remarquer aussi que, si le passago de la saison des pluies à la saison sèche se produil avec une singulière nelletó, presque brusquement, le passagre inverse est, au contraire, caractérisé par de nombrenses irrégularités. Pendant tont le mois d'avril, souvent même déjà ì la fin de mars, des pluies distancées préludent à l'élablissement défunilil el normal des orages du soir. Nous n’insisterons point ici sur ce qui se passe à Guatemala, puisque presque tous les délails météorologiques qui seront domnés ci-après se rapportent à celte ville el suffisent amplement ì en faire connaître le climat dans les différentes parties de l'ammée.

Dans les lerres froides, la différence entre les saisons est peul-être plus accusée que partout ailleurs. Cela lient d'abord à ce que l'abaissement de température, sans être en rien comparable à ce que l'on observe dans nos climals, est pourtant assez considérable pendant l'hiver pour le distingoner nettement de l'été. II faut ajouter que l'hiver est d'une sécheresse pour ainsi dire absolue, et que ce caractère est presque spécial aux terres froides. La saison des pluies dure environ cinq mois, depuis te commencement de mai jusqu'aux premier's jours d'octobre; mais on doil remarquer que, quoique les orages y soient nombreux el violents, les chules de pluie n'acquièrent que rarement cette soudaineté et celte abondance si renarquables dans les terres tempérées. Nous aurons, du reste, à reparler de ce fail dans le paragraphe spécial. Le manque de documents certains el d'observations suivies ne nous permet pas d'en dire davanlage sur les allures des saisons dans les terres froides, et nous le regorettons vivement, car il eùt été fort intéressant de comparer les conditions des plaines telles que celles de Totonikapam el de Quezaltenango avec celles des grands plateaux du Mexique. Il nous semble, en eflet, que la différence entre l'hiver et l'été doit être moindre pour les mêmes altitudes dans l'Amérique centrale que dans les environs de Mexico, d'abord à 
cause de l'abondante végélation qui couronme encore presque toutes les crêtes de la Cordillère centro-americaine, tandis que celles de l'Anahuac sont généralement dénudées, ensuite parce que l'éloignement plus ou moins considérable des rivagges de l'Océan doil exercer une influence assez importante sur les climats qui présentent, en général, des divergences notables, suivant qu'ils sont marins ou continenlaux.

TEMPÉRATURES.

Avant d'étudier en détail les variations de la température à Guatemala, nous allons jeter un coup d'œil sur les observations que nous avons recueillies dans le cours de nos voyages dans l'Amérique centrale. Il serait fastidieux d'en transcrire ici la liste complète, el ces chiffres isolés, sans lien entre eux, n'auraient aucune signification scientifiqne; mais nous allons essayer d'en grouper quelques-uns, de manière ì laire voir les modifications qui peuvent être dues aux saisons et aux conditions locales.

Tempéralures extrèmes.

Sérics

d'olservations de températures faites pendant des ascensions de montagnes.
Il faul d'abord mentionner les extrêmes que nous avons eu occasion d'observer' dans les deux sens : la plus liaute température que nous ayons eu à supporter s'est élevée à $42^{\circ} 50$, ̀̀ 1 heure $1 / 2$ de l'après-midi, au mois d'avril, le moment le plus chand de l'année; c'étail près des mines de Los Encuentros, silućes aux environs de San Miguel (Salvador), à 150 mètres à peu près au-dessus du niveau de la mer, dans le fond d'une vallée environnée de tous côtés de collines rocheuses, par une journée de calme absolu, où pas un souffle de brise n'agitait l'almosphère.

La température la plus basse à laquelle nous ayons été soumis n'a été que de $+3^{\circ}, 20$, sur le sommet isolé du volcan d'Agua (Guatemala), à une altitude. de 3,753 mètres, par un vent violent du sud-est qui précipitait lès nuages autour de nous avec une effrayante rapidité. C'était à 9 heures du malin, à la fin de mai, dans la premic̀re partie de la saison des pluies.

Quelques séries d'observations faites, dans des points très-rapprochés dans l'horizontale, mais séparés par de grandes distances verticales, pendant des ascensions de montagnes, ne seront pent-être pas lout à fait sans intérêt.

A La Union, le $1^{\text {er }}$ avril, nous avons trouvé $32^{\circ}$ 5o à 8 . heures du matin, au 
DANS LES RÉPUBLIQUES DE GUATEMALA ET DE SALVADOR. 133 bord de la mer, tandis qu'à midi le thermomètre ne marquait plus que $27^{\circ}$, et ${ }_{2} 6^{\circ}$ à 1 hèure de l'après-midi, au sommet du Cerro de Conchagrua, qui s'élève à 1,236 mòtres de hauteur.

$\Lambda$ Sin Miguel, ì 110 mòtres au-dessus du niveau de la mer, de nombreuses observations dans tes premiers jours d'arril (moment le plus claud de l'année) nous ont donné pour moyennes : à 9 lıeures du matin $32^{\circ}$; ¿̀ 11 heures du matiu $38^{\circ}$; à 2 heures de l'après-midi $38^{\circ} 75$. - En nous élevant sur le volcan qui domine immédiatement celte ville, nous n’avons plus trouvé, à 926 mètres, que $19^{\circ}$ à 5 lienres du matin et $25^{\circ}, 75$ à 6 heures du soir, et, ì 2,153 mètres, an sommet de la montagne, que $15^{\circ} 60$ à 8 heures $1 / 2$ du matin et $19^{\circ} 80$ à midi.

Les observations que nous avons faites au volcan d'Agrua, réunies à celles du révérend père Cornette en 1856 , pourront ètre groupées dans le tableau suivant:

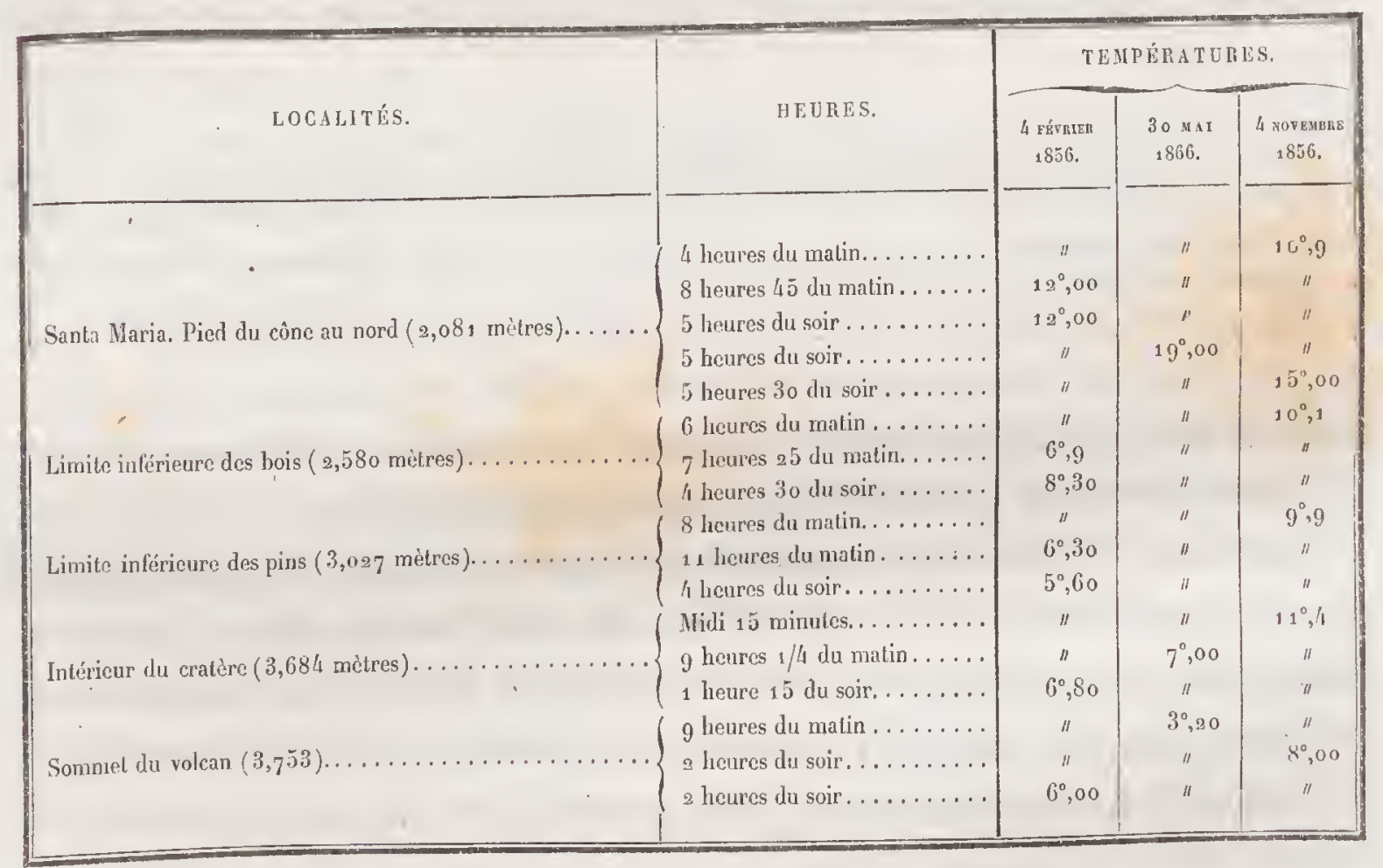

On y peut voir avec une certaine netteté la décroissance progressive de la température avec l'altitude, favoriséc ou entravée par les circonstances inhérentes à la saison dans laquelle les obscrvalions ont été faites. Ainsi, dans le mois de mai, qui correspond à l'époque la plus chaude de l'année dans li région de l'Amérique centrale où s'élève le volcan d'Agria, la température est en effet maximum ì 
Saula Maria, au pied de la monlagne; mais elle est, au contraire, minimum au sommet, sous l'influence d'un courant d'air golacé el chargé de vapeur d'eau vésiculaire correspondant au commencement de la saison des pluies.

L'ascension du volcan de Pacaya fournit des résultats analogues. Au sommet de la monlagne, à 2,550 mètres de hauleur', on trouve, en décembre, à 11 heures du nalin, el en juin, à 8 heures du matiu, la mème tenpérature de $13^{\circ} 00$, cer qui lient évidemment à ce que l'observalion faite pendant la saison. des pluies l'a été à une heure où l'oragoge quolidien n'avait pas encore rafraîchi l'almosphère.

Iu volcan de Fuego, à la fin de mai, nous avons encore trouvé quelque cluse d'entièrement comparable. Dans la matinée, quoique l'on gagne en altitude, les lempératures auggmentent à mesure que le soleil s'élève au-dessus de l'horizon, tandis que, dans la soirée, lorsque les nuages se sont accumulés et que la pluie est tombée, la température s'abaisse, quoique l’on regagone les niveaux inlérieurs. Ainsi :

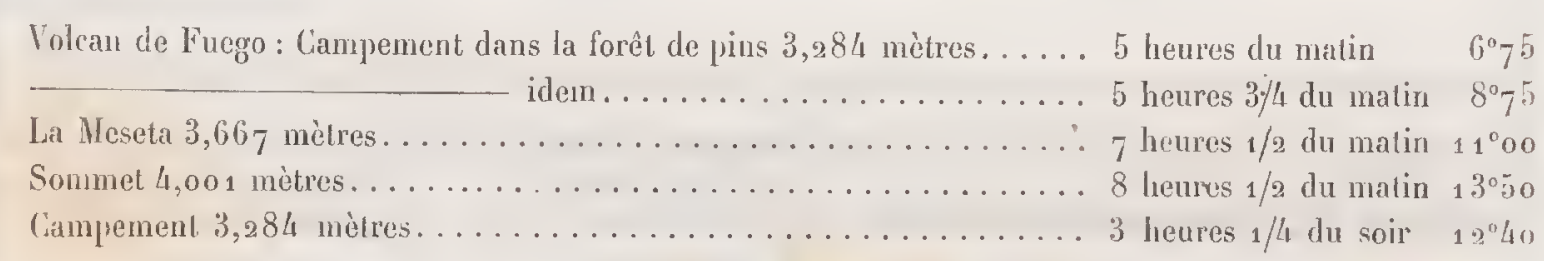

Séries

l'observatious

de températures faitrs à des altitudes corrospendianiss.

Voici encore quelques groupes d'observations recueillies, à différents monents de l'année, dans des points d'allitudes à peu près équivalentes.

Entre 500 et 600 mètres, plusieurs observations de la fin d'arril, à 5 heures du soir, nous donnent des lempératures de 28 à $30^{\circ}$ (Rio Jiboa, Guaimoco, Jalpalagua, elc.), tandis qu'en juin et en juillet, en pleine saison des pluies, on ne trouve plus que 23 ì $25^{\circ}$, même dans le fond des vallées encaissées où la la chaleur doit s'accumuler aulant que possible (Rio Grande à la Canoa, Rio Chisoy, etc).

De mème, aux allitudes de 800 à 900 mètres, entre 9 el 10 heures du maliıt, nous avons trouvé, en avril (Infiernillos de San Vicente, Cojutepeque, Santa Tecla, etc.) des tenpératures de 26 à $27^{\circ}$, landis qu'à la fin de juin (Cluuacus, Salama), on n'a plus que 23 à $25^{\circ}$.

Aux environs de 1,400 mètres, à la fin d'avril, des observatious de 10 heures 
DANS LES RÉPUBLIQUES DE GUATEMALA E'T DE SALVADOR. 135 du matin (pied du Volcan d'Tzalco, Apaneca), donnent à peu près $2401125^{\circ}$. landis qu'en juillet, c'est à peine si les observations faites à l'heure du maximum, entre midi et 2 heures, atteigneul $24^{\circ}$ (Carrizal, Taclic, Coban, San Cristobal, ctc.).

A 1,800 mètres il y a près de 2 degorés de diflérence entre les lempératures observées à des heures correspondautes en avidil (Volcan d'lzalco, Ranchos del Volcan : 5 heures du soir $19^{\circ} 50$ ) el en juillel (San Miguel Uspantan, Cunen : $17^{\circ} 5$ o.) II faut remarquer, ce qui a peut-ĉtre son importance, que loutes les observations d'avril sont faites sur le versant du Pacifique, landis qur celles qui sont postérieures appartiennent à celui de l'Allantique.

Pour des allitudes un peu supérieures à 2,000 mètres, un grand nombre d'obscrvations, toutes exécutées au milien de la saison des pluies (Godines, Pasesilla, Solola, Santa Gruz del Quiché), nous montront la température très-variable. suivant que la journée a été très-pluvieuse on non; mais, ou général, lo maximum ne dépasse pas $20^{\circ}$.

Enfin, pour les grandes allitudes comprises entre 3,000 et 3,500 mètres, (Cerro Quemado de Quezallenango, Casa de Consuelo, Volcan d'Alitlan, clc.), le maximum est compris entre $14^{\circ} 50$ et $12^{\circ} 50$, tonjours pour le uois de juillet, mais il doit assurément être plus élevé pendant la saison sèche.

Quoique ces groupes de chiffres n'aient par une très-grande valcur scientilique par eux-mèmes, et que les comparaisons ne soient pas alssolument précises, puisque les heures ne sont pas toujours tout à fait les mèmes et que les conditions
topographiques locales doivent avoir une influence considérable qui nous échappe, il n'en est pas moins vrai qu’ils ont une certaine signification pour prouver le décroissement graduel des températures avec les augmentations d'altilude, el l’influence considérable des météores aqueux sur la marche du thermomètre.

Si nous abordons enfin l'étude des allures de la lempérature à Guatemali, ¿ une altilude de 1500 mètres, nous nous trouvons en présence de documents inde la tempésalure finiment plus précis et beaucoup plus nombreux. Les éléments en sont consignés dams les tableaux suivants $\left(\mathrm{n}^{\text {os }} 1 \mathrm{cll} 2\right)$ dont le premier réunit les chiffres relatifs à la marche journalière de la température pendant les mois de janvier, lévrier, mars, mai, juin, août el octobre 1866 , et le second les maxima, les minima el les moyennes mensuelles pour une période de cinq années, de 1859 ì 1863 . 
MARCHE DE LA TEMPERATURE JOURNALIERE

\begin{tabular}{|c|c|c|c|c|c|c|c|c|c|c|c|c|c|c|c|c|c|c|}
\hline \multirow{2}{*}{$\begin{array}{l}\text { JOURS } \\
\text { DU Mors. }\end{array}$} & \multicolumn{6}{|c|}{ JAXVIER. } & \multicolumn{6}{|c|}{ FÉVRIER. } & \multicolumn{6}{|c|}{ MARS. } \\
\hline & mактех. & матимеม. & $\left|\begin{array}{c}7 \text { agunss } \\
\mathrm{du} \\
\text { matin. }\end{array}\right|$ & $\begin{array}{c}2 \text { ugtres } \\
\text { du } \\
\text { soir. }\end{array}$ & $\begin{array}{c}9 \text { uEunes } \\
\text { du } \\
\text { soir. }\end{array}$ & MOYEXYE. & Maximen. & YA IIUUМ. & $\begin{array}{c}7 \text { घxenes } \\
\text { du } \\
\text { matin. }\end{array}$ & $\begin{array}{c}2 \text { azenes } \\
\text { du } \\
\text { soir. }\end{array}$ & $\begin{array}{c}9 \text { aemans } \\
\text { du } \\
\text { soir. }\end{array}$ & Morexas. & MIXIMLY. & я.химем. & $\begin{array}{c}7 \text { aEvres } \\
d \mathfrak{u} \\
\text { matin. }\end{array}$ & $\begin{array}{c}2 \text { uevers } \\
\text { du } \\
\text { seir. }\end{array}$ & $\left|\begin{array}{c}9 \text { aecues } \\
\text { du } \\
\text { soir. }\end{array}\right|$ & xorst \\
\hline $1 \ldots$ & 9,9 & 24,2 & 12,9 & 21,8 & 15,7 & 16,3 & 8,8 & $24,1-$ & 11,4 & 23,6 & 16,5 & 17,2 & 14.2 & 26,7 & 14,4 & 25,5 & 17,3 & 10,1 \\
\hline $2 \ldots \ldots$ & 11,7 & 20,0 & 12,6 & 18,5 & 14,2 & 15,1 & 8,6 & 24,5 & 12,0 & 23,5 & 16,6 & 17,4 & 14,0 & 27,2 & 15,3 & 25,8 & 17,5 & 19,5 \\
\hline $3 \ldots \ldots$ & 7,2 & 17,4 & 10,2 & 16,4 & 7,3 & 11,3 & 8,9 & 25,8 & 11,9 & 24,2 & 17,0 & 17,7 & $1 /, 5$ & ${ }^{2} 7,6$ & 15,0 & 27,0 & 17,0 & $10 \%$ \\
\hline $4 \ldots \ldots$ & 6,0 & 12,5 & 6,5 & 12,4 & 9,0 & 9,3 & 8,4 & ${ }_{2} 5,2$ & 11,3 & 23,7 & 16,4 & 17,1 & 12,5 & 30,2 & 14,0 & 29,4 & 18,0 & 30,1 \\
\hline $5 \ldots \ldots$ & 5,8 & 12,2 & 6,6 & 11,8 & 9,2 & 9,3 & 8,5 & 26,5 & 10,7 & $\because 4,0$ & 15,3 & 16,6 & 14,6 & 26,7 & $1 \bar{\partial}, 9$ & $4,5,7$ & 16,9 & 10,5 \\
\hline $6 .$. & 6,0 & 12,6 & 8,2 & 11,4 & 10,2 & 9,9 & 10,0 & 26,8 & 13,9 & 24,8 & 16,0 & 18,2 & 12,8 & 27,2 & 14,0 & 26,5 & 17,0 & $190^{.2}$ \\
\hline 7 . & 6,6 & 18,0 & 10,3 & 13,9 & 12,0 & 12,0 & 10,1 & 26,3 & 14,5 & 26,3 & 17,2 & 10,3 & 11,0 & 24,9 & 12,9 & $24, \overline{3}$ & 17,0 & 18,1 \\
\hline $8 \ldots \ldots$ & 8,1 & 19,0 & 10,4 & 17,0 & 12,8 & 13,4 & 9,9 & ${ }_{2} 5,9$ & 14,3 & ${ }_{2} 5,9$ & 14,0 & 18,1 & 14,6 & 23,4 & 16,0 & 22,1 & 16,8 & 18,3 \\
\hline $9 \ldots \ldots$ & 9,5 & 18,0 & 12,0 & 14,6 & 11,6 & 12,7 & 12,0 & 25,4 & 13,5 & 23,0 & 16,1 & ${ }_{17}, 5$ & $1 / 4,0$ & 24,6 & 15,8 & 22,8 & ${ }^{1} 7,0$ & 18,3 \\
\hline $10 \ldots$ & 8,0 & 17,5 & 11,4 & ${ }_{17}, 6$ & 12,0 & 13,7 & 11,5 & 26,9 & 13,8 & 26,5 & 17,2 & 19,2 & 14,5 & 93,1 & 16,0 & 22,0 & 18,0 & $17 \%$ \\
\hline $11 \ldots \ldots$ & 8,0 & 18,8 & 9,1 & 18,2 & 12,5 & 13,3 & 11,9 & 27,2 & 13,9 & 36,4 & 16,0 & 18,8 & 12,5 & $2^{4,2}$ & 14,4 & 83,0 & 15,5 & $177^{6}$ \\
\hline $12 \ldots \ldots$ & 7,0 & ${ }_{2} 5,4$ & $8, \overline{5}$ & 23,5 & 14,8 & 16,2 & 11,0 & $27: 0$ & 13,8 & 26,3 & 15,6 & 18,6 & 12,6 & 22,8 & 14,9 & 21,0 & 16,2 & $17,^{4}$ \\
\hline $13 \ldots \ldots$ & 8,0 & 26,6 & 12,8 & 24,2 & 17,0 & 18,8 & 11,6 & 27,5 & $1 / 4,0$ & 26,2 & $1 /, 3$ & 18,2 & 11,0 & 25,3 & 12,5 & 23,7 & 16,0 & $177^{4}$ \\
\hline $14 \ldots \ldots$ & 10,5 & 20,0 & 13,6 & 25,4 & ${ }^{17}, 6$ & 19,2 & 9,6 & 25,7 & 13,6 & 23,7 & 13,6 & 17,0 & 13,0 & 27,2 & 14,0 & 25,0 & $1, \overline{7,5}$ & ${ }_{1} 8,{ }^{3}$ \\
\hline 15. & 13,0 & 28,9 & 13,2 & 27,6 & 18,0 & 19,6 & 12,8 & 23,5 & 13,7 & 32,9 & 12,6 & 16,4 & 15,0 & 27,5 & 17,0 & 26,0 & 17,3 & 20,3 \\
\hline $16 \ldots \ldots$ & 13,1 & $36,0$. & 18,1 & 26,0 & 17,6 & 20,6 & 7,4 & 32,5 & 11,4 & 21,9 & 11,8 & 15,0 & 11,0 & 3.), 7 & 14,6 & 23,5 & 16,3 & 18,1 \\
\hline 17. & 11,0 & 25,1 & 13,1 & 24,6 & 13,6 & 16,9 & 10,5 & 24,5 & 13,3 & 23,1 & 12,9 & 16,4 & 14,0 & 20,0 & 14,8 & 18,4 & 15,5 & $16, ?$ \\
\hline 18 & 9,5 & 26,0 & 10,6 & 37,9 & 15,6 & 18,0 & 13,0 & 28,4 & 13,0 & 27,3 & 15,6 & 18,6 & $12, \bar{j}$ & 21,8 & $1 / 1,2$ & 20,7 & 15,1 & ${ }_{10,7}$ \\
\hline $19 \ldots \ldots$ & 10,0 & ${ }_{2} 6,2$ & 13,0 & 23,7 & 14,3 & 17,0 & $\mathbf{1} / 1,9$ & 37,8 & 16,8 & 25,8 & 17,6 & 20,1 & 11,5 & 25,7 & 13,2 & 23,6 & 16,3 & 17,7 \\
\hline $20 \ldots \ldots$ & 12,5 & 26,0 & 15,2 & 23,6 & 15,4 & 18,1 & $\mathbf{1} 3,8$ & 29,3 & 14,5 & 28,7 & 18,5 & 20,6 & 11,9 & 26,9 & 13,7 & 26,5 & 16,5 & 18,9 \\
\hline 21 & 13,1 & 20,0 & 14,0 & 19,4 & 14,6 & 16,0 & 14,3 & 27,3 & 16,4 & 26,5 & 18,9 & 20,6 & 14,2 & 39,5 & 16,5 & 27,3 & 17.7 & $20,0^{3}$ \\
\hline $22 \ldots \ldots$ & 11,5 & 20,2 & 13,2 & 17,9 & 14,0 & 15,0 & 15,0 & 28,6 & 17,9 & 28,3 & 18,1 & 21,4 & 14,0 & $27: 3$ & 15,4 & 26,4 & 18,7 & $20,^{3}$ \\
\hline 23 & 9,5 & 27,4 & 10,1 & 22,0 & 14,3 & 15,5 & 15,4 & 28,3 & 16,0 & 27,3 & 17,9 & 20,4 & 13,5 & 27,4 & 14,8 & 25,0 & 18,2 & $19,3^{3}$ \\
\hline 24. & 9,4 & 26,1 & 11,6 & 25,1 & 18,0 & 18,2 & 13,9 & 37,6 & 15,1 & 25,1 & 18,3 & 19,6 & 12,6 & $2 f, 1$ & 12,9 & 24,7 & 17,7 & ${ }_{1} 8,4$ \\
\hline 25. & 11,5 & 27,0 & 13,2 & 22,7 & 17,6 & ${ }_{17}, 8$ & 15,2 & 28,6 & 15,4 & 28,1 & 18,6 & 20,7 & 14,2 & 25,2 & 16,9 & 25,0 & $17, \bar{j}$ & 19,8 \\
\hline 26 & 10,4 & ${ }_{2} 6,9$ & 11,3 & 22,9 & 16,3 & 16,9 & 16,0 & 28,9 & 17,0 & 27,5 & 19,1 & 21,2 & 14,3 & 25,7 & 16,8 & 25,4 & 17,7 & 20,0 \\
\hline 37 & 10,5 & 25,0 & 13,3 & 34,4 & 17,5 & 18,4 & 15,3 & 27,5 & 15,9 & 26,8 & 18,2 & 20,3 & 15,3 & 25,5 & 17,6 & 25,2 & 17.7 & 30,9 \\
\hline 28. & 11,0 & 23,0 & 11,4 & 19,6 & 16,6 & 15,9 & 13,8 & 36,3 & 15,0 & 24,3 & 17,9 & 19,1 & 15,0 & 26,0 & 17,1 & 24,5 & 17,0 & $199^{j}$ \\
\hline 29 . & 8,9 & 23,6 & 8,9 & 20,9 & 14,9 & 14,9 & $"$ & $"$ & $"$ & " & $n$ & $"$ & 15,0 & 26,0 & 17,6 & 24,9 & 17,5 & ${ }_{3} 0,0$ \\
\hline $30 \ldots \ldots$ & 9,2 & 23,9 & 10,3 & 22,6 & 16,3 & 16,4 & $"$ & $"$ & $"$ & $" 1$ & " & $"$ & 14,8 & 25,0 & 17,5 & 24,3 & 16,2 & \\
\hline $31 \ldots$ & 8,9 & 24,4 & 11,4 & 23,7 & 17,1 & 17,4 & " & " & $\|$ & $" 1$ & $"$ & $"$ & 12,5 & 25,7 & 13,9 & 24,1 & 13,9 & 17 \\
\hline Mois entier & 5,8 & 29,0 & 11,50 & 30,82 & 14,4 & 15,59 & 7,4 & 29,3 & 14,07 & 25,4 & $16,3 / 4$ & 18,61 & 11,0 & 30,2 & 15,15 & 24,5 & $17,7^{5}$ & \\
\hline
\end{tabular}


TABLEAU N०2.

OSGILLATIONS MENSUELLES DE LA TEMPÉRATURE A GUATEMALA POUR LES ANNÉES SUIVANTES :

\begin{tabular}{|c|c|c|c|c|c|c|c|c|c|c|c|c|c|c|c|}
\hline \multirow{2}{*}{ MOIS. } & \multicolumn{3}{|c|}{1859.} & \multicolumn{3}{|c|}{1860.} & \multicolumn{3}{|c|}{1861.} & \multicolumn{3}{|c|}{1862.} & \multicolumn{3}{|c|}{1863.} \\
\hline & MINIMUnar. & maxนacs. & MOSEKK E. & sininum. & M.xixum. & MOTENNE. & мгхмин. & 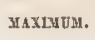 & MOSENSE. & แกวกบห. & maximox. & MOYEXYE. & 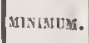 & миттания. & НОРБพYE. \\
\hline Janvier. & $8^{\circ}, 0$ & $25^{\circ}, 6$ & $16^{\circ}, 77$ & $9^{\circ}, 9$ & $24^{\circ}, 0$ & $15^{\circ}, 93$ & $7^{\circ}, 7$ & $27^{\circ}, 4$ & $16^{\circ}, 17$ & $7^{\circ}, 6$ & $28^{\circ}, 1$ & $16^{\circ}, 7^{5}$ & $5^{\circ}, 3$ & $27^{\circ}, 7$ & $1 n^{\circ}, 09$ \\
\hline Février. & 8,1 & 27,6 & 18,29 & 8,8 & 26,1 & $16,9^{6}$ & 7,3 & 27,7 & 16,59 & 10,0 & 28,7 & 17,84 & 6,3 & 29,4 & 17,33 \\
\hline Mars... & 10,0 & 29,5 & 19,94 & 8,5 & 25,4 & 17,00 & 9,8 & 29,2 & 18,16 & 8,5 & 29,1 & 17,69 & 10,5 & 28,7 & 17,80 \\
\hline Avril. . & 11,8 & 29,4 & 20,39 & 11,6 & 29,1 & 19,43 & 9.7 & 30,6 & 18,84 & 11,8 & 29,0 & $18,7^{1}$ & 8,5 & $\because 9,0$ & 18,08 \\
\hline Маi... & 12,6 & 30,4 & 20,61 & 11,1 & 36,7 & 18,45 & 13,5 & 36,0 & 18,08 & 12,5 & 29,6 & 19,63 & 12,0 & 29,1 & 18,87 \\
\hline Juin. . & 13,5 & 26,2 & 19,142 & 13,3 & 27,8 & 19,39 & 13,2 & 26,8 & 13,05 & เ3,3 & 28,1 & 18,31 & 13,6 & 26,11 & 18,54 \\
\hline Juillet .. & $13, ?$ & 27,0 & 19,55 & 13,6 & 24,8 & 18,07 & 13,3 & 24,7 & 17,199 & 13,5 & 25,0 & 18,38 & 12,6 & 25,4 & 18,04 \\
\hline Août... & 13,9 & 37,8 & 19,63 & 12,8 & 26,0 & 18,31 & 13,0 & 27,1 & 18,04 & 13,4 & 35,11 & 18,37 & 13,9 & 25,8 & 17,88 \\
\hline Septembre. . & 13,5 & 25,8 & 18,74 & 13.9 & 25,3 & 18,42 & 13,5 & 25,6 & 17,74 & 13,9 & 26,9 & 18,18 & 13,0 & 27,0 & 18,38 \\
\hline Octobre.... & 12,1 & 25,0 & 18,01 & 10,3 & 36,1 & 17,24 & 12,8 & 25,6 & 17,52 & 10,6 & 24,9 & 17,06 & 10,8 & 25,6 & 17,69 \\
\hline Novembre.. . & 7,4 & 25,0 & 16,58 & 11,4 & 27,0 & 17,30 & 11,1 & 26,1 & 16,85 & 6,8 & 24,3 & 14,75 & 8,5 & 28,2 & 16,85 \\
\hline Décembre... & $8, \cdots$ & 24,6 & 16,40 & 7,0 & 27,3 & 16,14 & 9,2 & $2 h, 4$ & $15,5 \mathrm{t}$ & 8,9 & 27,0 & 15,53 & 8,3 & 28,4 & 15,33 \\
\hline Année entière & 7,4 & 30,4 & 18,76 & 7,0 & 29,1 & $17,7^{2}$ & 7,3 & 30,6 & 17,42 & 6,8 & 29,6 & 17,59 & 5,3 & 29,4 & 17,48 \\
\hline
\end{tabular}

l'rédominance remarquable des ecarts journaliers sur les écarts anmels.
Les conclusions que l'on peut lirer de ces séries de chiffres parâtront plus neltes encore, si l'on jette un coup d'œil sur les courbes graphiques (pl. II, fig. 1, et pl. III, fig. 1) qui les rendent en quelque sorte palpables.

Un premier groupe de courbes (pl. II, fig. 1) se rapporte aux oscillations journalières de la lempérature pendant des séries de 10 jours choisies aux moments tes plus intéressants de l'année. Ainsi nous voyons à côté les unes des autres les marches fiğnrées du thermomètre, du premier au 10 janvier, période du refroidissement le plus intense; du 20 au 3 o mai, moment du premier maximum de chaleur qui est cn mème temps le maximum absolu; du 20 au 30 août, époque où la tempéralure s'abaisse sous l'influence de l'humidité constante que la saison des pluies introduil dans l'atmosphère; enfin du premier au 1 o octobre, période voisine de celle où il y a presque toujours une légère recrudescence due au deuxième passage du soleil au zénith. Ces deux dernières courbes se tenant assez rapprochées de la moyenne, il n'y a pas grand'chose à en dire; mais la comparaison des deux autres met en lumière un fail remarquable.

Nous avons eu déjà plus d'une fois l'occasion d'affirmer que les écarts de tem- 
DANS LES RÉPUBLIQUES DE GUATEMALA ET DE SALVADOR. 139 pérature d'une saison à l'autre sont moins considérables que ceux qui se procluisent entre le jour el la nuit dans un même moment de l'année, et que c'est là le trail caractéristique des climats tropicaux. Or, si l'on suil la marche des courbes des mois de mai el de janvier, qui sont les époques la plus chaude et la plus froide de l'année, on en voit immédialcment la confirmation. Fn faisant alsstraction des journées du 4 au 6 janvier, où la tempéralure s'est abaissée d'une manière loul à fait anomale, on remarquera que la courbe de janvier se mainlient parallèlement à celle de mai, à une distance au-dessous d'elle qui correspond en moyenne à 8 degrés, tandis que les ondulations propres de ces mêmes courbes, prises isolément, présentent des dépressions correspondant au moins à 10 degơrés en moyenne. Il est done évident que la différence entre les températures du jour el de la nuil, dans une même saison, est supérieure au moins de 1/5 à la différcnce des tempéralures d'une même heure de la journće ou de la nuit dans les époques de l'année où les écarts sont les plus considérables. On ne saurail trop insister sur' ce fait, dont les importantes conclusions ont apparu dans le chapitre précédent, et dont l'influence se retrouve, agissant d'une manière plus ou moins directe, sur presque tous les traits de la inéléorologie des climats tropicaux.

L'examen des chiffres renfermés dans le tableau $n^{\circ} 2$ peut apporter une preuve de plus à ce qui vient d'être avancé. On y voit en effet que, pour plusieurs années consécutives, la différence aussi bien entre les minima de janvier et de mai, qu'entre les maxima correspondants à ces mêmes mois, est, cn moyenne, de 4 à 5 degrés, tandis que les écarts entre te maximum ef le minimum d'un même mois, qui se rapportent au milieu du jour et à la fin de la nuit, peuvent aller jusqu’à une moyenne d'une vingtaine de degrés.

Quoi qu'il en soil de ces oscillations, diurnes plutòt qu'annuelles, el dur caraclère particulier qu'elles impriment à l'ensemble du climat de ces régions, it faut remarquer pourlant que la marche de la température à Guatemala, comparée ì ce qu'elle est dans nos pays, jouit d'une singulière uniformité relative. La lempérature moyenne déduite de toutes les observations que nous avons pu recueillir élant de $17^{\circ} 79$, les écarts les plus considérables en dessus el en dessous ne dépassent pas $12^{\circ} 6$ et $12^{\circ} 4$, ce qui est remarquablement peu de chose. En effet, la température la plus basse qui ait été observée pendant les années dont nons 
avons eu connaissance est de $5^{\circ} 3$, en janvier 1863 , et la plus élevée de $30^{\circ} 4$, en mai 1859 , ce qui ne donne qu'un intervalle de $25^{\circ} 1$ entre les limites supérieure et inférieure des oscillations du thermomètre. Dans une mème année, cet intervalle est toujours compris entre 22 et $24^{\circ}$, et l'on peut affirmer que cette absence singulière d'écarts importants dans la marche du thermomètre constitue aussi un des traits les plus saillants de la méléorologie de l’Amérique centrale.

Intluence combinée de

In chule des pluies

et de la marclie du soleil

sut lis mourements

de

la température

moyeme.

La figure 1 de la planche III réunil un groupe de courbes qui représentent les oscillations annuelles par moyemes mensuelles pour 5 annćes, de 1859 à 1863 . Il s'en dégogage aussi la confirmation d'un fail considérable, nettement indiqué d'ailleurs par les considérations théoriques. On sait que l'influence de la saison des pluies sur la température se fait sentir d'une manière très-directe, antant à cause du refroidissement que détermine la transformation en vapeur des grandes quantités d'eau qui vont pénétrer d'humidité les couches de l'atmosphère, que parce que les nuages, sinterposant entre la terre et le soleil, paralysent l'action des rayous calorifiques. Aussi faut-il chercher dans les actions combinées de la saison des pluies et de la marche du soleil les causes qui régissent les allures de la tempéralure; on doil admettre a priori qu'il y aura deux minima,.,au milieu de la saison sèche el au milieu de la saisou des pluies, époques qui correspondent aux dislances zénithales les plus fortes du soleil au midi et au nord, et deux maximia, l'un avant le début, l'autre à la fin de la saison des pluies, moments où le soleil passe au zénith de Guatemala. Les courbes nous montrent en effet que la tenipérature, minimum en janvier, s'élève proggressivement jusqu'à la fin d'avril, époque du premier passage du soleil. Le commencement de la saison des pluies exerce un eflet presque instantané, el détermine un abaissement brusque de la température, angomenté encore, en juillet, par l'obliquité des rayons du soleil, qui s’incline vers le nord. Le second passage du soleil amène, vers la fin de septembre, un relèvement qui ne s'accuse que faiblement, car liufluence des pluies, alors à leur maximum, agit en sens contraire. Enfin, avec le retour de la saison sèche, on voit le froid revenir en mème temps que le soleil goagne en inclinaison vers le sud. Le peu d'intensité du second maximum de septembre est un fait caractéristique et qui se manifeste toutes les années, quoique d'une manière plus ou moins accentuée. 
DANS LES RÉPUBLIQUES DE GUATEMALA ET DE SALVADOR. 141

PLUIES.

Lorsque nous avons parlé des saisons, nous avons déjà eu occasion d'insister sur la répartition des pluies daus les différentes parties de l'année, el nous avons vu que, si, dans certains cas, l'hiver est absolument sec et l'été seul phuvieux, dans d'autres, la saison sèche n'est pas entièrement privée de chutes de pluies. Nous savons que l'allitude a une influence remarquable sur cetle jéparlition, el qu'on peut la formuler de la manière suivante :

En terre chaude, il pleul beaucoup en saison des pluies, el, pour ainsi dire. pas du tout en saison sèche; - à la base des terres tempérées, il pleut énormément en saison des pluies et souvent en saison sèche; - à la partie supérieure des terres tempérées, il plent beaucoup en saison des pluies et assez souvent en saisou sèche; - dans les terres froides, il plent assez abondamment en saison des pluies el pas du tout en saison sèche.

Nous allons tâcher d’accompaguer ces notions générales de quelques données plus précises.

Il serait intéressant d'étudier l'état de saturation de l'atmosphère el la force b́at de saturatim élaslique de la vapeur d'eau qui y est contenue, aux diverses allitudes et pendaut l'atmosphere. les différentes périodes de l'année. Malheureusement les observations font défaut pour la presque totalité des points. Pour les terres chaudes, nous savons seulement que la haute température qui y règne toujours permet à l'air de contenir une quantité considérable de vapeur d'eau. Aussi le vent du nord, qui part saturé des régoions glacées de l'Amérique septentrionale, mais saturé à une basse température, reste-t-il relativement sec lorsqu'il arrive sous les tropiques, quoique, en avaucant vers le sud, il ait continué à se charger de vapeurs. Pour quilil se produise un refroidissement suffisant pour amener la saluration et la condensation, il faut des causes spéciales, telles que celles qui sont dues à la végétalion. Il arrive quelquefois, en effet, qu'il pleut en hiver en terre chande, daus les endroits oǹ d'épaisses forèts exercent une notable aclion réfrigérante en arrètant les rayons du soleil el empèchant ainsi le sol de se réchaufler, en augonentant la superficie susceptible de se refroidir par rayonnement, et eufin en déterminant à la surface des feuilles

Repartition

des pluies dans

les différentes époques de l'annér. 
une évaporation constante qui consomme de la chaleur. Mais c'est surtout à la base de la terre tempérée, là où les premiers versants des montagones opposent une barrière à la marche des vents, que l'air se refroidit au contact des rocher's et des forêts, que la saluration s'opère, et que la précipitation de la vapeur d'eau amène des averses plus ou moins abondantes pendant l'hiver.

Eitat de saluration de Tatmosphère. à Gulıtemala.

A Guatemala, il pleut aussi quelquefois pendant la saison sèche, pour des raisons à peu près analogues. Mais la condensation se produit plus rarement et requierl pour cela des canses plus intenses, car l'air amené par le vent du niord, qui règne pendant presque tout l'hiver, s'est dójà débarrassé de la majeure partie de sa vapeur d'eau en passant au-dessus des terres tempérées du versant de l'Atlantique. Le Lableau suivant (tableau $n^{\circ} 3$ ) fait connaitre les fractions de saturation de l'air par moyennes mensuelles, à différentes heures de la journée, pendant cing années consécutives.

TABLEAU No 3.

FRACTIONS DE SATURATION DE L'AIR A GUATEMALA

par MOYENAES MENSUELLES

ET A DIFFERENTES hEURES DE LA JOURNÉF, PENDANT LES ANNÉES SUIVANTES:

\begin{tabular}{|c|c|c|c|c|c|c|c|c|c|c|c|c|c|c|c|c|c|c|c|c|c|}
\hline \multirow[b]{2}{*}{ moIs. } & \multicolumn{5}{|c|}{1859.} & \multicolumn{4}{|c|}{1860.} & \multicolumn{4}{|c|}{1861.} & \multicolumn{4}{|c|}{1862.} & \multicolumn{4}{|c|}{1863.} \\
\hline & $\begin{array}{c}4 \text { anvngs } \\
\text { du } \\
\text { matin. }\end{array}$ & $\begin{array}{c}10 \text { महारEs } \\
\text { du } \\
\text { matin. }\end{array}$ & $\begin{array}{c}4 \text { IEURES } \\
\text { du } \\
\text { soir }\end{array}$ & $\mid \begin{array}{c}10 \text { Hevres } \\
\text { du } \\
\text { soir. }\end{array}$ & MOXENTE. & $\left|\begin{array}{c}7 \text { uecress } \\
\text { du } \\
\text { matin. }\end{array}\right|$ & $\begin{array}{c}2 \text { Hecaes } \\
\text { du } \\
\text { soir. }\end{array}$ & $\begin{array}{c}9 \text { मEr ues } \\
\text { du } \\
\text { soir. }\end{array}$ & MOTEME. & $\begin{array}{c}7 \text { Hev Res } \\
\text { du } \\
\text { matin. }\end{array}$ & $\begin{array}{c}2 \text { medies } \\
\text { du } \\
\text { soir. }\end{array}$ & $\mid \begin{array}{c}9 \text { urures } \\
\text { du } \\
\text { soir. }\end{array}$ & Morexse. & $\begin{array}{c}7 \text { ueunes } \\
\text { du } \\
\text { malin. }\end{array}$ & $\begin{array}{c}\text { aetres } \\
\text { du } \\
\text { soir. }\end{array}$ & $\begin{array}{c}9 \text { HEURES } \\
\text { du } \\
\text { soir. }\end{array}$ & MOYRMXE. & $\begin{array}{c}7 \text { azuras } \\
d u \\
\text { matin. }\end{array} \mid$ & $\left|\begin{array}{c}2 \text { nguass } \\
\text { du } \\
\text { soir. }\end{array}\right|$ & $\left|\begin{array}{c}9 \text { beunes } \\
\text { du } \\
\text { soir. }\end{array}\right|$ & yOTENXE. \\
\hline Janvier ..... & 92,0 & 57,5 & 17,0 & 83,0 & 69,8 & 88,5 & 48,9 & 80,4 & 79.6 & 90,9 & $4 h, 5$ & 83,1 & 72,8 & 94,3 & 116,1 & 8,5 & 74,0 & 90,5 & 51,5 & 84,0 & $7^{5,3}, 3$ \\
\hline Février...... & 91,5 & 57,5 & 44,0 & $8_{2}, 5$ & 68,8 & 88,3 & 44,4 & 80,9 & $7^{1,2}$ & $9^{1,1}$ & 40,9 & 80,4 & 70,8 & $9^{1,5}$ & 40,5 & 81,6 & 71,2 & $9^{0,2}$ & 37,2 & 80,0 & $6 y, 1$ \\
\hline Mars.. ...... & $9^{3,0}$ & 55,0 & 54,0 & 85,5 & $7^{3,8}$ & 86,2 & 46,1 & 79,3 & 70,6 & 88,4 & 42,5 & 79,0 & 70,0 & 87,2 & 43,2 & 79,7 & 70,1 & 91,3 & 41,0 & 82,3 & 71,5 \\
\hline Avril. . & $9^{6,0}$ & 50,5 & 60,5 & $8_{9}, 0$ & $7^{6,7}$ & 86,5 & 45,5 & 82,2 & 71,4 & 90,1 & 52,4 & 87,8 & 76,7 & 89,4 & 41,3 & 79,2 & 70,0 & 87,4 & 41,5 & 78,7 & 60.2 \\
\hline Mai......... & $9^{5,0}$ & 57,5 & 59,0 & $9^{0,0}$ & $7^{5,3}$ & $8_{9}, 4$ & $56 i, 9$ & 83,7 & 76,7 & 94,6 & $7^{5,2}, 2$ & 99,3 & 87,11 & 86,5 & 46,6 & 79,3 & 70,8 & $9^{0,2}$ & 56,1 & 88,8 & $-8,5$ \\
\hline Juin . . . . . & 97,5 & $7^{0,0}$ & $7^{5,5}$ & $9^{4,0}$ & 84,3 & $92, a$, & 62,5 & 89,3 & 81,5 & $9^{4,4}$ & 73,5 & $9^{4}, 6$ & 87,5 & 92,6 & 68,1 & 91,9 & 84,2 & $9^{3,5}$ & 66,3 & 88,4 & 82,7 \\
\hline Juillet. . . . . . & 97,0 & 69,0 & 63,5 & 93,0 & 80,6 & 92,7 & $6.3,3$ & 87,6 & 81,2 & 92,7 & 75,0 & $y^{3}, 8$ & 87,2 & 92,0 & 63,2 & 91,3 & $8_{2,2}$ & $9^{5,22}$ & $60, h$ & 87,8 & 81,1 \\
\hline Août. . & 97,5 & 69,0 & 69,0 & 95,0 & 82,6 & $9^{3,7}, 7$ & 68,8 & $9^{3,4}$ & $8.5,3$ & 99,3 & 65,2 & 93,6 & 8.3 .7 & $9^{3,0}$ & 65,5 & 92,0 & 83,5 & 92,6 & 58,7 & 87,1 & 79,6 \\
\hline Seplembre. & $99, \mathrm{C}$ & 72,0 & $7^{4,5}$ & $9^{5,0}$ & 85,1 & 94,1 & 66,6 & 92,7 & 84,5 & 94,6 & $7^{1,5}$ & $9^{3}, 6$ & 86,6 & 95,2 & 67,9 & $9^{3}, 3$ & 85,4 & $9^{5,4}$ & 63,3 & $9^{1,3}$ & $8: 3,3$ \\
\hline Octobre..... & 97,0 & 71,0 & 71,5 & 93,0 & 84,1 & $9^{1,1}$ & 65,2 & $9^{1,0}$ & 82,4 & 96,6 & 78,2 & 95,5 & 90,1 & $8,9,7$ & $6: 2,7$ & 86,6 & $79 \cdot 7$ & $9^{5,3}$ & 64,5 & $9 ? 2,9$ & 84,2 \\
\hline Novembre.... & 90,5 & 65,0 & 58,5 & 85,0 & 74,7 & 93,8 & 53,4 & 87,0 & 78,1 & $9^{4,9}$ & $6_{7}, 0$ & $9 \div, 7$ & 84,9 & 85,8 & 55,3 & 83,0 & $7 / 1,7$ & $9 \pm, 7$ & 66,1 & $8_{7}, 9$ & $8:, 2$ \\
\hline Décembre.... & $9^{3,0}$ & 63,0 & 54,0 & 88,5 & $7^{4,6}$ & $9^{22,7}$ & 49,1 & $8 / 4,6$ & $7^{5,5}$ & $9^{2,5}$ & 65,4 & 90,7 & 82.9 & 89,7 & 56,6 & 85,7 & 77,3 & 91,5 & 67,4 & 89,5 & 82,8 \\
\hline Année entière.. & $9^{4,9}$ & 63,8 & 60,9 & 89,5 & 77,3 & $9^{\circ}, 8$ & 56,1 & 86,0 & 77,6 & 928 & $6 ., 6$ & 89,8 & 81,7 & 90,5 & 54,7 & 85,4 & $7^{6,9}$ & $9^{2}, 1$ & 56,2 & 86,6 & 78,3 \\
\hline $\begin{array}{c}\text { De novembre i } \\
\text { avril ..... }\end{array}$ & $"$ & $"$ & $"$ & $"$ & 73,1 & $"$ & $"$ & $"$ & $7^{3,2}$ & $"$ & " & $"$ & 76,4 & $"$ & $"$ & $"$ & 72,7 & $"$ & $"$ & $"$ & 75,0 \\
\hline $\begin{array}{c}\text { De mai à oclo- } \\
\text { bre....... }\end{array}$ & $" 1$ & $"$ & $" 1$ & $"$ & 82,0 & " & $"$ & " & 81,9 & $"$ & $n$ & $\|$ & 87,1 & $"$ & $\|$ & $"$ & 80,9 & " & $"$ & $\|$ & 81,6 \\
\hline
\end{tabular}


DANS LES RÉPUBLIQUES DE GUATEMALA ET DE SALVADOR. 143

On y voit aisément que les heures du matin el du soir, où la température est relativement très-basse, correspondent toujours à une élévation du degré de saturation, tandis que, pendant le milieu du jour, l'accumulation de la chaleur permettant à l'air de contenir plus de vapeur, la fraction de saturation s'abaisse notablement.

La différence entre les extrèmes est beaucoup plus considérable en liver qu'en été, et cela s'explique aisémient. En effet, pendant l'hiver, la quantilé de vapeur contenue dans l'air restant sensiblement la mème, celui-ci est plus ou moins saturé, suivant que sa température est plus ou moins élevée; mais, pendan! l'été, au moment où le pouvoir dissolvant auğmente au milieu dı jour avec l'accumulation de la chaleur, il se produil un afllux constant de vapeur d'eau pompée par le soleil, qui est presque au zénith, el l'air tend à rester à peu près complélement saturé. Aussi, dès que la température baisse, se produit-il une condensation qui précipite un énorme volume d'eau sur le sol, toul en laissant l'almosphère encore presque à saluration dans la soirée.

Ainsi, pendant la saison sèche, aux heures froides du matin, la fraction de saturation est de 0,90 à 0,91 en moyenne, c'est-à-dire que l'air renferme à per près tout ce qu'il peut contenir de vapeur d'eau; à 2 heures, au moment du naximum de lempérature, elle n'est souvent plus que de o,40, et l'atmosphère est relativement sc̀che, quoique le même volume de vapeur y soil demeuré; ì 9 heures du soir, on se rapproclıe de la saturation à mesure que la température baisse. mais en restant encore à 0,81 ou 0,82 , parce qu'il ne fait pas aussi froid que le matin.

Au contraire, pendant la saison des pluies, l'air étant toujours presque absolument saturé pendant la matinée (fraction de saturation $=0,95$ ì 0,97 ), il contient encore, pendant le milieu du jour, une énorme proportion de vapeur d'eau, telle que la fraction de saluration peut aller jusqu'à 0,75 , malgré l'augmentation considérable du pouvoir dissolvant produil par la grande élévation de température. Et le soir, à 9 heures, quoiqu'il ne fasse pas encore bien froid, la saturation est presque complète encore (fraction de saturation $=0,90$ à 0,95 ), parce que, avec l'abaissement de température, il ne s'est précipité de vapeur d'eau que ce que l'air ne pouvail absolument plus renfermer. 
Quoique moins instructives que les chiffres que nous venons de citer, les moyennes peuvent aussi servir à montrer d'une manière assez précise la différence qui existe entre l'état de saturation de l'atmosphère pendant les diverses parties de l'année. On voit ainsi que les quanlités moyennes de vapeur d'eau contenues daus l'air pendant t'hiver et l'été sont entre elles à peu près comne 7 est à 8 . On peut aussi constater qu'il y a presque toujours un abaissement de la moyenne vers le milien de la saison des pluies, et cela correspond à un fait sur lequel nous aurons occasion de revenir un peu plus loin.

Fiat de saturation de l'almosphère dars

Pour les haules altitudes, nous n'avons que peu de renseignements en ce qui concerne l'état hygrométrique de l'atmosphère, mais il est probable que les écarts que nous venons de signaler pour Guatemala doivent s'y manifester d'une malnière plus nette encore, puisque les extrêmes de la température s'éloignnent darantage. Le degrré de saturation doit aussi être très-faible en hiver, puisque l'air amené par le vent du nord a déjà abandonné la presque totalité de son humidité aux régions inférieures.

Voici quelques chiffres oblenus pendant des ascensions sur des montagnes asse élevées; ils montrent que, même dans ces hautes régoions, l'air, à cause de la température peu élevée, renferme encore une assez forte proportion de la quantité de vapeur d'eau qu'il pourrail contenir.

SOMHET DU VOLCAN DE PAGAYA, 2,550", DÉCEMBRE :

Thermomètre sec $13^{\circ}$. Thermomètre humide $10^{\circ} 5$. Différence $2^{\circ} 5$.

Tension de la vapeur d'eau $8^{\mathrm{mm}} 33$.

Fraction de saluration 0,73 .

VOLCAN D'AGUa a $3,330^{\mathrm{m}}$, 4 NOVEMBRe, 10 HeURES 30 MINUTES DU MATIS:

Thernomètre sec $9^{\circ}$. Thermomètre humide $6^{\circ} 5$. Différence $2^{\circ} 5$.

Tensiou de la vapeur d'eau $6^{\mathrm{mm}}, 20$.

Fraction de saluration 0,69 .

SOMBET DU VOlGAN D'AGUA, $3,753^{\mathrm{m}}, 4$ NOVEMBRE, 2 HEURES DU SOlk :

Therınounètue sec $8^{\circ}$. Thermomètre humide $6^{\circ}, 5$. Différence $1^{\circ}, 50$.

Tension de la vapeur d'eau $6^{\mathrm{mm}}, 87$.

Fraction de saturation 0,81 . SOMMET DU VOLCAY D'AGUA, 4 FÉVRIER, 1 HEURE 15 MINUTES DU SOIR :

Thermomètre sec $6^{\circ}, 5$. Thermomètre humide $5^{\circ}, 2$. Différence $1^{\circ}, 3$.

Tension de la vapeur d'eau $6^{\mathrm{mm}}, 97$.

Fraction de saluration 0,77 . 
D ANS LES RÉPUBLIQUES DE GUATEMALA ET DE SALVADOR. 145

SOHMET DU VOLCAN D'AGUa, 30 Mat, 9 HEURES DU MATH :

Thermomètre sec $3^{\circ}, 20$. Thermomètre humide $3^{\circ}, 20$. Différence $0^{\circ}, 0$.

Tension de la vapeur d'cau $6^{\mathrm{mm}}, 17$.

Saluration complète.

Il résulte de ce qui rient d'ètre dil qu'on est amené à considérer deux ordres de pluies parfaitement distiuctes, et quant à leurs causes et quant à leur manière d'ètre, les pluies hivernales et tes pluies esliviles.

Les premières, qui ne tombent pas dans toul le pays, mais seulement daus tes tocalités qui présentent les condilions particulières indispensables, sont dues a la condensation, par les montagnes ou les forèts, des vapeurs contenues dans l'air amené par les vents régnants, généralement par le vent du nord. Les caraclères extérieurs de ces pluies sont assez nets, car elles ne sont que rarement orageuses ut ne tombent presque jamais en goutles rolumineuses el pressées. A mesure que le courant d'air refroidi arrive au-dessus du sol, une sorte de hâle se répand sur le pays, un brouillard se forme peu à peu, s'épaissit progressivement en constituant un vérilable nuage vésiculaire, puis finit par se résoudre en une pluie fine, qui augmente d’intensité à inesure qu'elle gàgne les régions inlérieures. Il faut remarquer aussi que ces phénomènes se produisent presque aussi souvent le matin que te soir et durent parfois toule la journée. Néanmoins te volume d'eau déversé, quoique souvent considérable, n'est janais comparable à relui que fournissent les pluies de l'élé.

Les pluies estivales sont dues à une cause très-différente. Elles provicnnent de l'évaporation aclive qui se produit au moment où, lo soleil passant au zénill, ses payous échauffent puissamment le sol et déterminent la formation dans l'almosphère de puissants courants ascendants charogés de vapeur d'eau presque jusqu'ì saluralion. Aussitôt que les couches d'air, ainsi imprégnées d'lumidité pendant te moment de la plus haute température, commencent à se refroidir, lorsfue le soleil tend à s'abaisser sur l'horizon, le pouvoir dissolvant diminue avec rapidité, lo point de précipitation est bientôt atteint, et d'immenses volumes d'eau retournent i) la terre en quelques inslants.

Les choses se passent le plus souvent de la manière suivante. Le ciel restant Vọague gúologịure. 
parfaitement scrcin peudaut lonte la matinée, on voil, entre 2 el 3 heures de l'après-midi, quelques pelits nuages blancs s'accrocher aux sommités des pics les plus élevés; ce sout les premières vapeurs qui se condensent el s'accumulent peu à peu en volumineux eumulus blanchàtres qui enveloppent toutes les montagues. Les mages s'agolomèrent progressivement et envaluissent toul te ciel en formant d'épais nimbus et des stratus gris ou noirâtres. Tout à coup l'éclair brille, le tonnerre gronde, et la pluie éclate avec ıne soudaincté et une violence inouies, déversant des torrents d'eau en quelques heures sous la forme de goutles épaisses el serrées. Tout rentre dans l'ordre au bout de peu de temps et la nuit est presque inujours claire et étoilée.

Dininution

l'intensité

vers to milion de

Les faits auxquels est due la formation des pluies estivales sont aussi la ciuse d'uu phénomène sur lequel nous devons nous arrêter. Puisque l'accumnlation des vapeurs dans l'atmosphère est produile par l'action puissante des rayons du soleil lorsque cet astre est très-voisu du zénith, il est maturel de penser que, lorsquỉil tend à s"incliner sur l'lorizon, l'effel produit doit diminuer en raison directe de l'obliquité. Or on sait parfaitement bien que, pour les pays silués entre l'équateur

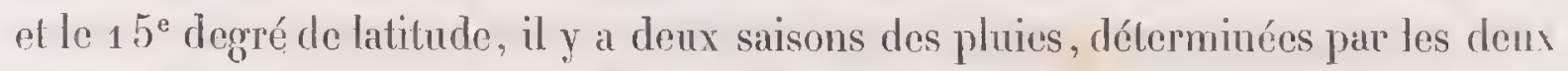
passigges du soleil au zénith, ct deux saisons sèches, qui correspondent aux époques où cet astre est le plus loin possible dans le nord et daus le sud.

La ville de Guatemala étant située par $14^{\circ} 36^{\prime}$ de latilude nord, on voil aisément que les deux passages du soleil au zénith sont très-rapprochés l'un de l'autre et que l'inclinaison de cel astre vers le nord est loin d'être aussi considérable que celle qui a lieu vers le sud. Néanmoins l'obliquilé des rayons du soleil pendant les mois de juillet et d'aoùt, quelque faible qu'elle soit, doit se 'manifester par une action directe sur l'allure des météores aqueux. En effet, quoiqu'il n'y ait pas deux saisons des pluies, on remarque deux périodes très-marquées d'intensité maximum, gónéralement en juin el ì la fin de septembre, tandis qu'il y a une notable diminulion, quclquefois même un arrèt de quelques jours (verano de Agrosto dans la Boca Costa), à la fin de juillet ou dans la première moitié d'aoùt. Quoique le phénomène ne se manifeste pas toujours avec la mène nelleté, on en trouve tonjours une trace plus ou moins complète, et on peut affirmer que l'observation confirme ainsi les inductions théoriques. Il suffil de jeler 
DANS LES RÉPUBLIQUES DE GUATEMALA ET DE SALVAOR. 147 les yeux sur le lableau no 4 , et surloul sur les courbes graphiques de la planche IV, qui figurent la marche noensuelle des pluies pendant les amnées 1859-1863, pour constater le fiil, particulièrement en ce qui concerne les années $\mathbf{1 8 5 9}$, 1861,1862 .

Relativement aux quantilés de pluies, nous ne possédons mallıeureusement de Quantitís de pluie. renseignements précis que pour la ville de Guatemala. Les chiffres dont il sera liait mention ci-après nous montrent que la moyenne de pluie pour 5 années, dans celte ville, est de $1^{\text {mn }}, 371$. C'est un peu plus qu’à Tepic, au Vexique, où il ne lombe que $1^{\mathrm{m}}$, ogo par an en moyenne; mais cette ville, située aussi sur l'océan Pacifique, est beancoup plus près du bord de la mer, presque à la limile supérieure des terres chaudes. C'est beaucoup moins, par contre, qu à Cordova, qui est siluée à la lase des lerres tempérées de l'Mtlantique, et où il tombe en moyenne $2^{\mathrm{m}}, 732$ de phuie par an. On peut admettre que, dans la Boca Costa (San Aguslin) où il plent beaucoup plus qu’à Gualemala, il tombe au moins a mètres d'eau par an, el que les conditions des hydrométéores dans celte région se rapprochent beancoup de co qu'elles sout à Cordova. Dans les hauls pays, il est probable que les choses onl une cerlaine analogie avec ce qui se passe dans les plateaux élevés du Vexique, et que, à Quezaltenango et à Totonikapam, il ne tombe guère plus dr $0^{\mathrm{m}}, 500$ de pluie par an. Celte faible quantilé tieul à deux causes; d’abord à la sécheresse presque complète de l'hiver, el ensuile à la nature même des pluies de l'été, qui ne sont ni aussi violentes, ni aussi prolongées que celles des terres tempérées. Les averses peuvent se comparer ì celles de nos clinats, et se composent de goutles dont les dimensions n'ont rien de particulièrement remarquable. Cela lient probablement à ce que la précipitation n’est pas aussi soudaine et à ce que les goulles tombant de moins haut n'out pas à traverser, comme dans les terres lempérées, d'épaisses couches d'air saturées de vapeur d'eau où elles s'agrandissent en accumulant antour' d'elles l'eau formée par la condensalion due au refroidissement que produit leur passage. II faut remarquer que les hautes régions du Guatemala ne constiluent pas des plateaux aussi élendus que ceux du Mexique, el surloul qu'elles sont encore presque partout recouvertes d'une abondante végétition, de sorte quion ne peut pas comparer d'une façon précise les fails observés dans ens denx pays. 
Quaulité d'eau tombée par an ì Giuatemala.

A Guatemala, la moyenne d'eau tombée par an est, comme nous l'avons dit, de $1^{\mathrm{m}}, 371$, ct correspond à 141 jours de pluie. Le tableau suivant (lableaú $\mathrm{n}^{\circ} 4$ ) donne pour 5 années (1859-1863) les chiffres qui permettent d'élablii cette moyenne.

TABLEAU N゚ 4 .

RÉSUMÉ MENSUEL DE LA RÉPARTTTION DES HYDROMÉTÉORES A GUATEMALA PEVDATT CINQ ANXÉES CONSÉCUTIVES.

\begin{tabular}{|c|c|c|c|c|c|c|c|c|c|c|c|c|c|c|c|}
\hline \multirow{3}{*}{ Mo Is. } & \multicolumn{5}{|c|}{$\begin{array}{l}\text { QUANTITÉ DE PLUIE TOMBÉE, } \\
\text { EN MLLHMETREs, } \\
\text { pendant les années }\end{array}$} & \multicolumn{10}{|c|}{$\begin{array}{l}\text { NOMBIRE DE JOURS DE PLUIE ET DE GRÉLE } \\
\text { PENDINT LES ANNEES }\end{array}$} \\
\hline & \multirow[b]{2}{*}{1859.} & \multirow{2}{*}{1860.} & \multirow{2}{*}{1861} & \multirow{2}{*}{1862.} & \multirow{2}{*}{1863.} & \multicolumn{2}{|c|}{1859.} & \multicolumn{2}{|c|}{1860.} & \multicolumn{2}{|c|}{3861.} & \multicolumn{2}{|c|}{1862.} & \multicolumn{2}{|c|}{1863.} \\
\hline & & & & & & Pluie. & Grô. & Pluie. & Grểle: & Pluie. & Grèle. & Pluie. & Grêle. & Pluie. & Grểe. \\
\hline Janvier.. ....... & 9,9 & 3,9 & 3,1 & 12,2 & 9,5 & 4 & $\|$ & 4 & $" 1$ & 3 & $"$ & 4 & 1 & 9 & $" \prime$ \\
\hline Février.......... & 3,2 & 1,8 & 3,9 & 1,8 & 0,8 & 1 & 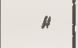 & 2 & $"$ & 2 & $"$ & 3 & $\cdot "$ & 2 & $"$ \\
\hline Mars............ & 49,3 & 2,6 & 13,3 & $" 1$ & 38,7 & 4 & $\|$ & 1 & $"$ & 2 & 1 & $"$ & $"$ & 8 & $"$ \\
\hline Avril ........... & 58,1 & 52,3 & 174,5 & $" 1$ & 9,7 & 7 & $"$ & 7 & 1 & 14 & 1 & $"$ & $"$ & 4 & $"$ \\
\hline Mai. . . . . . . & 204,8 & 82,0 & 207,0 & 84,5 & 185,4 & 16 & $n$ & 13 & $"$ & 19 & " & 8 & i & $1 / 4$ & $"$ \\
\hline Juin.. . . . . . . . & 255,8 & 162,8 & 326,7 & 319,3 & 262,6 & 21 & $u$ & 17 & 1 & 26 & $1^{*}$ & $2 / 1$ & " & 18 & " \\
\hline Juillet . . . . & 151,2 & 178,2 & 333,8 & 208,7 & 164,0 & 18 & $"$ & 20 & $"$ & 27 & $" 1$ & 20 & $"$ & 16 & $\|$ \\
\hline Août.... & 223,7 & 235,1 & 232,0 & 281,0 & 149,9 & 22 & $"$ & 22 & $"$ & 22 & $"$ & 20 & $"$ & 14 & $"$ \\
\hline Septembre....... & 390,1 & 237,7 & 241,3 & 203,4 & 150,7 & 19 & 1 & 20 & $"$ & 21 & $"$ & 26 & $"$ & 16 & $"$ \\
\hline Octolire......... & 240,8 & 249,5 & 252,9 & 102,1 & 96,9 & 17 & $"$ & 18 & $"$ & 26 & $"$ & 12 & $"$ & $1 \mathrm{is}$ & $"$ \\
\hline Novembre... . . . . & $i 3,0$ & 2,5 & 16,6 & 2,7 & 65,9 & 4 & $"$ & 4 & $"$ & 12 & $"$ & 4 & $"$ & 9 & $"$ \\
\hline Déccmbre....... & 4,8 & 18,7 & 16,7 & 3,3 & 3,4 & 4 & "l & 5 & $"$ & 6 & $"$ & 4 & $"$ & 2 & $\|$ \\
\hline Année entière.... & 1505,0 & 1228,0 & 1821,8 & 1219,0 & 1137,5 & 137 & 1 & 133 & 2 & 183 & 3 & 125 & 2 & 136 & 0 \\
\hline De novemlıre à arril & 138,6 & 81,8 & 228,1 & 20,0 & 128,0 & 24 & $" 1$ & 23 & $"$ & 39 & $"$ & 15 & $"$ & 34 & $"$ \\
\hline De mai à octobre.. & 1366,4 & 1146,2 & 1593,7 & 1199,0 & 1019,5 & 113 & $" 1$ & 110 & $"$ & 144 & $" \prime$ & 110 & $"$ & $9^{2}$ & $\|$ \\
\hline
\end{tabular}

Les courbes graphiques de la planche IV reproduisent les mêmes documents sous une autre forme, et permetlent à l'œil d'en suivre plus facilement la discussion. On y verra notamment que la saison des pluies présente presque toujours un ralentissement d'une certaine importance vers le mois de juillel, qui correspond à son milieu; ce fait a déjà été étudié avec tous les détails qu'il comporte. Les courbes montrent aussi que la quantité de pluie qui tombe pendant la saison sèche, quoique le plus souvent très-faible, n’est presque jamais absolument nulle. Les mois de mar's et d'avril 1862 sont les denx seuls qui soient totalement privés de clıutes de pluie.

Il faul remarquer encore que, si la saison des pluies se termine presque toujours d'une façon remarquablement brusque, entre octobre el novembre, elle 
D ANS LES RÉPUBLIQUES DE GUATEMALA ET DE S.ILVADOR. 149 présente, au contraire; des alternatives sans nombre au moment de son établissement, el que ce sont les mois de mars et d'avril qui voient se développer les pluies accidentelles de plus en plus fréquentes qui préludent au nouvel ordre de choses. Le contraire a lieu au Mexique, comme nous avons pu le remarquer nons-mème, el comme 1I. de Saussure l'indique dans son Hydrologie du Mexique. C'est le commencement de la saison des pluies qui est net, tandis que la fin présente des intermiltences de mauvais el de beau temps. Cela tient probablement à ce que les vents du nord, qui ramènent la sécheresse avec le froid, peuvent se terminer plus brusquement dans les vasles plateaux où rien u'entrave leur marche, que dans les régions accidentées, où its sont coupés el déviés à toul instant.

Les quantilés de pluie journalières sont excessivement variables, et les intermiltences entre les jours de pluie et de sécheresse ne sont soumises à aucune règle appréciable. En 1866 on a observé :

En janvier : $4^{\mathrm{mm}}, 30$ le 16 , et $0^{\mathrm{mm}}, 43$ le 21 , soit $4^{\mathrm{mm}}, 7^{3}$ pour le mois.

En lévrier : $2^{\mathrm{mm}}, 30$ le $19,1^{\mathrm{mm}}, 29$ le 20 , el $1^{\mathrm{mm}}, 34$ le 22 , soil $4^{\mathrm{mm}}, 93$ pour le mois.

En mars : $0^{\mathrm{mm}}, 8$ le $1^{\mathrm{cr}}, 0^{\mathrm{mm}}, 2$ le 2 , soit $1^{\mathrm{mm}}, 0$ pour le mois entier.

Leess mois de mai, juin el août ont donné les chiffres suivants :

QUANTITÉS JOURNALIÈRES DE PLUIE (EN MILLIMETTRES)

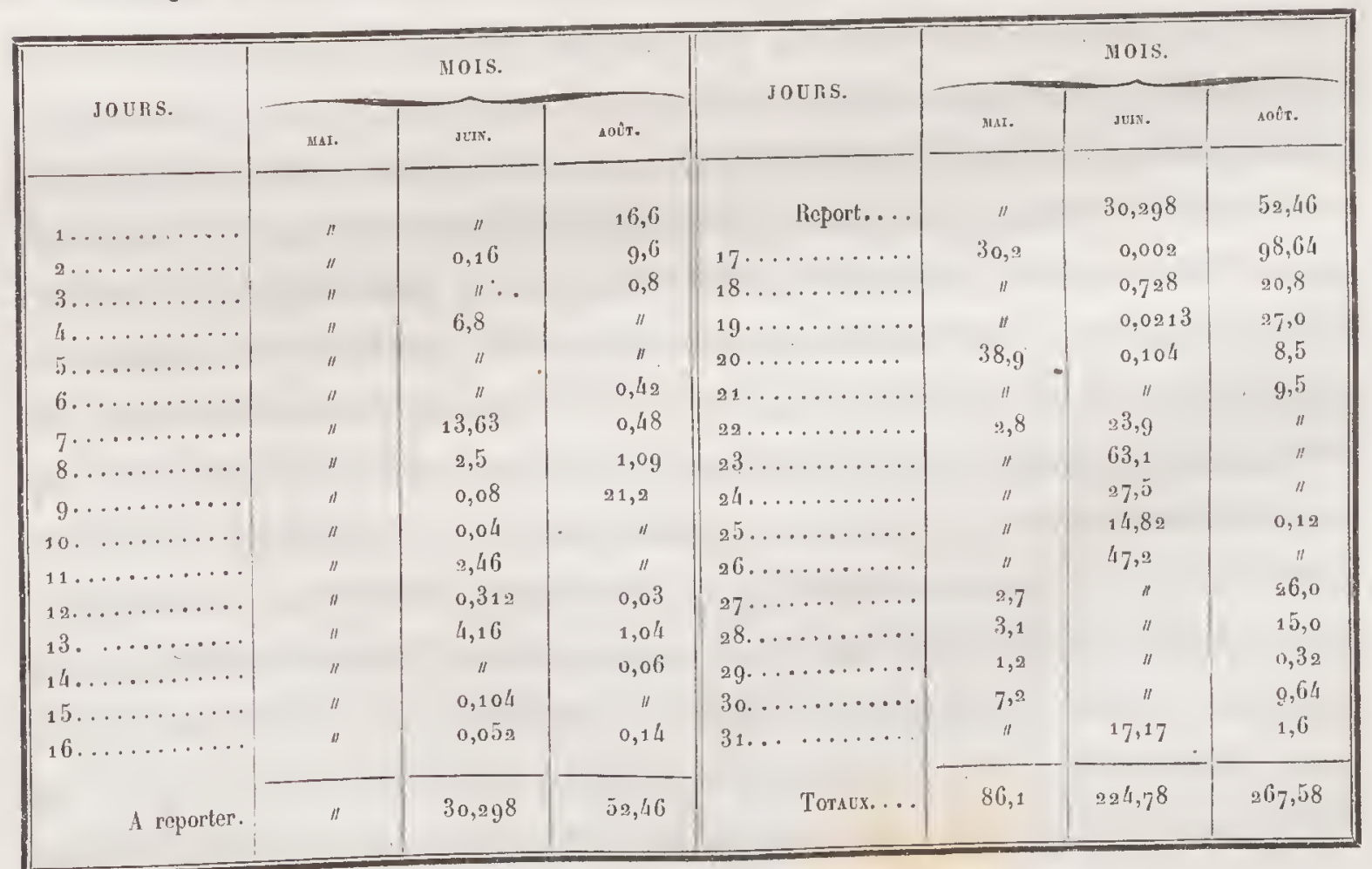


On y roil des varialions infinies dans l'abondance des chutes d'eau el des arrèts momentanés que rien ne faisail présager. Ces pluies sont presque tonjours orageuses, au mois d'soût en particulier, el l'énor'me volume d'eau qui tombe, quelquelois en lort peu de temps, ne peul s'expliquer que par le développement incroyable que les goulles peuvent acquérir dans certaines conditions. Le chiffre le plus élevé que nous puissions relever dans le lableau précédent est de $9^{8 \mathrm{~mm}}, 64$, correspondant au 17 aoùt. C'est ume quantité remarquable, el nous nous souvenons fort bien que l'orage épouvantable qui déversa la majeure partie de cetle trombe d'eau sur le sol ne dura guère plus d'une heure. En moins d'une demi-henre, l'eau s'était accumulée en telle abondance, que tes rues basses de Guatemala furent parcourues, pendant quelque temps, par des torrents violents, qui dépassaient liı lıateur du gononou. Le total du mois d'août dọnne $267^{\mathrm{mm}}, 58$; cette quantité n’est que rarement dépassée dans les amées extrêmement pluricuses.

Quoique les mois de septembre ou d'oclobre soient, en général, plus pluvienx que le mois d'aoùl, c'est-ì-dire que le nombre des jours de pluie y soit plus considérable, et que souvent il pleuve pendant plusieurs jours sans interruption, néanmoins la quantilé d'eau tombée est plus laible. Cola tient à ce que la mature des pluies est quelquefois différente et que ces mois sont ceux dans lesquels apparaissent les phénomènes connus sous les noms de temporales ou de mal tiempos; phénomènes qui annoncent généralement la fin de la saison des pluies. Les temporales sont des périodes de 4 ou 5 jours environ, pendant lesquelles les averses perdent leur caractère orageux el momentanć pour se transformer en une pluie fine, qui dure toute la journée el même la nuit. L'approche d'un temporal est annoncée par un mage gris el épais, qui recouvre progressivement le pays sauls être poussé par aucun vent appréciable; la pluie commence à tomber peu à pen, par goultelettes fines et serrées, sans aucun caraclère de soudaineté; le tonnerre ne gronde pas, et l'averse s'établit à peu près conme les averses de nos climals, pour durer un temps indéterminé, souvent assez long el lonjonı's fort redoulé des voyageurs. Quand un temporal ne dure que quelques jours, il déverse à pène aulant d'eau que si chaque journée avail eu son orage du soir, car la pluie fine ef pénétrante ne peul ètre comparée à des torrents de gonlles larges et serrées. 
D INS LES REPUBLIQLES DE GUATEMALA E'T DE SALADOR. 151 Mais, quand it se prolonge pendant longtemps, il pent devenir redoutable et donner lieu à des inondations; ainsi le gorand temporal du commencenent d'or:tolse 1865 dura 9 jours sans discontinuer, el convrit le pays d'une effrayante quantité d'eau. Il est probable que les temporales sont dus aux premiers courants froids de vent du nord qui circulent dans les haules conches de l'atmosphère sans tronbler la tranquillité de celles d'en bas, el dont le voisinage détermine un refroidissement qui produit une sorte de préeipitation en masse au moment où l'air est, pour ainsi dire, smirsaturé d'humidité.

Avant de laisser de còté les hydrométéores de Guatemala, il convient de dire un mol des brouillards, qui y sont assez fréquents, comme on pent le voir par les listes de chiffres ajoutées au tableau $n^{\circ} 5$. On y verra quil y a en moyenue go jours de brouillards du matin par an à Guatemala, répartis aussi bien dans la saison des pluies que dans ha saison sèche, quoiqu'ils soient nalurellement moins fréquents dans celte dernière. Cela tient à ce que, l'atmosphère étant tonjours chargée d'uue assez forte proportion de vapeur d'eau, mème pendant l'hiver (Lableau $1^{\circ} 3$ ), le refroidissemenl, souvent intense, qui se produit un peu avant le lever du soleil, détermine une précipilation parlielle de vapeur, redissonte aussilôt que la température s'ćlève sous linfluence des rayons solaires. On peut voir aussi dans le tableau $n^{0} 5$ qre les journées nuageuses ou convertes ne sont pas excessivement rares pendant la saison sìche, ce qui est assez remar(fuable, car. daus d'autres contrées tropicales, dans les hauts plateaux du Moxique en particulier, te ciel conserve, en général, pendant tout l'hiver, une sérénité absolue.

Quoique la grèle doive ètre mentionnée à l’article des phénomènes électriques. uous dirons en passant qu'clle n'est pas excessivement rare à Guatemala. On peut voir, dans te tableau no 4 , qu’il en tombe souvent jusquà deux on trois fois par all, et surlout pendant les mois de mars, d'avril on de mai, voire mème au mois de janvier, ce qui est assez remarquable.

La neige ne se montre janais ì Guatemala, el il n'y a pas à s'en étonner, puisque la température n'y descend pas au-dessous de $5^{\circ}$. Mais aux allitudes plus considérables elle. est assez fréquente. Remarquons pourtant que, pour trouver des neiges continues, il faut monter assez lıaut, au moins à 3,500 mètres, parce que la condensation des nuages s'opère toujours dans la période la moius froide 
de l'année, el généralement dans la soirée, arant que la température se soil abaissće d'une manière très-nolable. Sur le volcan d'Ağua, il tombe pourtant assez de neige pour que, cachée dans des creux abrités des rayons du soleil, elle puissn persister"pendant la totalité de la saison sèche.

VENTS.

Conditions tans lesquelles se trouve l'Amériquecentrak au point de vie des mouvements lo l'almosphière.

Conditions n:éaniques.

Condilious montinentales.
L'Amérique centrale est, au point de vue des courants almosphériques, dins une situation tout à fait particulic̀re, dont linfluence se fait directement sentir sur les vents régnants. Elle ne forme, en effet, qu'une ćtroite bande de terre, sourent asse\% élevée, il est vrai, serrée entre l'océan Pacilique el l'océan Allinlique, et l'ou comprend aisément qu'elle doive, jusqu'ì un certain point, participer aus conditions qui régissent les phénonìnes atmosphériques dans les régoions océ́tniques, tout en leur faisant subir certaines modificalions spéciales antx zones conlimentales, mais avec infiniment moins d'intensité que ne te font d'autres vastes ćtendues de terres tropicales, comne le Hexique, par exemple.

Les mers qui baignent les côtes de l'Amérique centrale et l'envirounent presque cnlic̀rement, ćlant l'une el l'autre soumises à l’influence des ronts alizés. qui y règnent pendinnt la presque totalité de l'année, on doit admellere que te continent, rétréci comme il l'est an Guatemala, el surtout daus les républiques plus méridionales, n’oppose pas aux mouvements de l'air un barrage suflisanl pour interrompre complétement la continuilé des phénoniènes entre l'Allanlique et le Pacifique. Ainsi s'expliquerail la singulière prédominance des vents du norriest qui soufflent toute l'annéc dans l'Amérique centrale, non pas avec une conlinuité absolue, mais néanmoins dans toules les saisons et pendant la majorité des journćes de chaque mois : ils ne seraient en réalité que les vents alizés enx-mêmes, passant de l'Allanlique au Pacifique par-dessus une bande de terre trop étroite pour les arrêter ou pour modifier leurs allures.

Mais, si l'Amérique centrale parlicipe en quelque sorte aux condilions ocćaniques par l'existence prédoninante dans tous les temps des vents du nord-est, qui ne sont probablement pas aulre chose que les vents alizés de Punc des mers, traversant les terres pour aller soufller dans l'autre, il ne faut pas oublier qu'clle jonit aussi de certaines conditions continentales dont les effets se manifestent dans 
DANS LES RÉPUBLIQUES DE GUATEMALA ET DE SALVADOR. 153 les différentes saisons de l'année. Un premier ordre de faits se ratlache à ceux qui règlent en grande partie l'alternance des saisons dans le grand continent mexicain, où les vents du nord règunent avec violence pendant l'liver et se montrent à peine pendant l'élé. Ces vents du nord, dus, au fond, ì des causes analogues à celles qui donnent naissance aux alizés, acquièrent une puissance et une intensité incomparablement plus considérables que ces derniers, parce que, sur le conlinent, la différence est énorme, en liver, entre les températures des pays brûlés de l'équateur et des plaines glacées du nord de l'Amérique. Or ces courants atmosphériques, qui se manilestent surtout avec violence dans le golfe du Mexique, se propagent fréquemment jusque dans l'Amérique centrale, el il n'est pas rare d'y ressentir, pendant la saison sèche, de terribles coups de vent du nord, qui sont parfailement distincts des vents de nord-est habituels. On peut voir dans le tableau $n^{\circ} 8$, où est consigné un registre des lempêtes, que les mois d'hiver n'en sont pas exempts, quoiqu'elles n'y soient pas, en réalité, extrêmement fréquentes. Ces tourmentes de vent du nord, entravées par les hautes sommilés volcaniques, qui hérissent le versant du Pacifique à peu près comme pourraient le faire les dents d'um peigne, se précipitent avec une intensité inouie dans les intervalles qui séparent ces montagnes et produisent des effels de destruction dont nous avons déjà eu occasion de mentionner les terribles résultats.

Les conditions continentales de l'Amérique centrale se manifestenl surtont par l'existence des vents de sud-ouest, qui apparaissent à tous les moments de l'année, mais en bien moins grande abondance que les vents de nord-est, et dont l'origine doit se rapporter à des causes fort simples à expliquer. Les terres étant bien plus fortement échauflées que la mer par l'action directe des rayous du soleil, il en doil résulter une rupture dans l'équilibre almosphérique, qui provoque des courants dirigés des mer's vers le continent; du côté de l'Atlantique, ces courants se confondant avec les vents alizés, ils sont en quelque sorte absorbés par eux, et l'on ne peut pas reconnaître directement leur existence. Mais, du côté du Pacifique, au contraire, ils se dirigent du sud-ouest vers le nord-est, entrent en lutte avec les alizés, el sont quelquefois assez forts pour en triompher; c'est alors que souffle le vent du sud-ouest, qui est susceplible d'acquérir, dans certains cas, une intensilé assez considérable. On comprendra que, l'échauffement du sol 
étant plus considérable en été qu'en hiver, ce soil surtout dans cette saison que la ruplure d'équilibre puisse se produire d'une manière efficace. C'est ce qui a lieu en effet, et les vents du sud-ouest, plus fréquents pendant la saison des pluies que pendant la saison sèche, donnent parfois lieu à de terribles tourmentes pendant les mois de la fin de l'été. Le reơistre des tempêtes, tableau $n^{\circ} 8$, fera voir qu'elles sont abondantes depuis le mois de juin jusqu'à celui de novembre, et nous pouvons ajouter que c'est toujours le vent de sud-ouest qui les accompagne dans cette saison.

Analogie des tourmentes du

sud-ouest, dans f'Amérique centrale, avec le Cordonazo de san Franscisco an Mexique.

M. de Saussure donne, dans son Ilydrologie du Mexique ${ }^{(1)}$, des détails fort intéressants sur un vent de sud-onest qui souflle avec une épouvantable violence pendant les mois d'été, le longo des côtes septentrionales du Mexique, du còté du Pacifique. A Guaymas, à Mazatlan et dans les, autres ports de cette côte jusqu'aux limites de l'Amérique centrale, on donne le nom de Cordonazo de san Francisco (Flagellation de saint François) à ces terribles ouragans, qui sont capables, à ce qu'il paraîl, de submergerer toute espèce de navire qui aurait la témérité de s'y exposer, et qui interrompent complétement la navigation dans ces parages pendant la saison où ils règnent. L'époque de l'apparition du Cordonazo de san Francisco n'est pas tout à fait constante, et, quand il devance son moment habituel, il peut causer de terribles malheurs; ainsi, à Mazallan, où il commence généralement au mois d'août, on le vit, en 1853 , arriver subitement au milieu de juin et coûter la vie à un gorand nombre de marins. Ces tempètes cessent gónéralement dans le courant du mois de novembre; leurs ravagoes s'étendent habituellement jusque sur la terre ferme, où, avec une effrayante violence, ils déracinent les arbres et renversent les maisons.

Le Cordonazo de san Francisco est évidemment en relation directe avec les tourmentes de sud-ouest, qui règnent dans l'Amérique centrale pendant les mèmes moments de l'année, et il doit être attribué aux mêmes causes, qui n'agoissent henreusement pas partout avec une égale inlensité. Étant admis.que ces monvements de l'atmosphère ont une origine commune, il devient facile de prouver d'une manière péremptoire qu'ils sont dus en réalité à des conditions continen-

(1) Coup d'xil sur l'Hydrologie du Mexique, Soeiété de Géographie de Genève. - Mémoires et bulletins, L. III. $1^{\text {re }}$ livraison, p. 99. Genève 1862. 
DANS LES RÉPUBLIQUES DE GUATEMALA ET DE SALVADOR. 155 tales, puisqu’il est avéré que le Cordonazo de san Francisco ne sévit que sur une bande d'une largọeur trìs-restreinte étendue le longo de la côte, el qu’à 1 oo ou 150 milles au large les perturbations violentes cessent pour laisser la place aux alizés du nord-est, qui soufflent régulièrement en pleine mer quand bien même l'ouragan exerce ses ravages près des rivages.

En résumé, il résulte de tout ce que nous venons de dire que les mourements de l'atmosphière, dans l'Amérique centrale, peuvent se rapporter à deux groupes

Denx groupes de vents principaux : Vents du nord-est; Vents du sud-onest. dant toute l'année, mais avec bien moins de fréquence, tendant à se développer davantage pendant l'été el dus à l'échauffement différentiel du sol et de la mer. Ajoutons qu’il y a, pendant la saison sèche, quelques ouragans du nord, prolonge-ment des Norles du golfe dı Mexique, et, pendant la saison des pluies, de nombreuses tempêtes dı sud-ouest.

Sur les rivages de l'Océan, on peut observer tous les jours, quoique plus ou moins modifićes par les vents régnants, la brise de terre de la matinée el la brise de mer de la soirée. Il suffit de mentionner l'existence de ces courants d'air, dont l'origine est parfaitement connue, sans entrer dans de plus amples détails.

A Guatemala, les mouvements de l'atmosphère sont soumis à des lois assez régulières, qui peuvent se déduire des observations faites par les R. P. jésuites, et dans lesquelles nous avons puisé les matériaux du tablean suivant: 


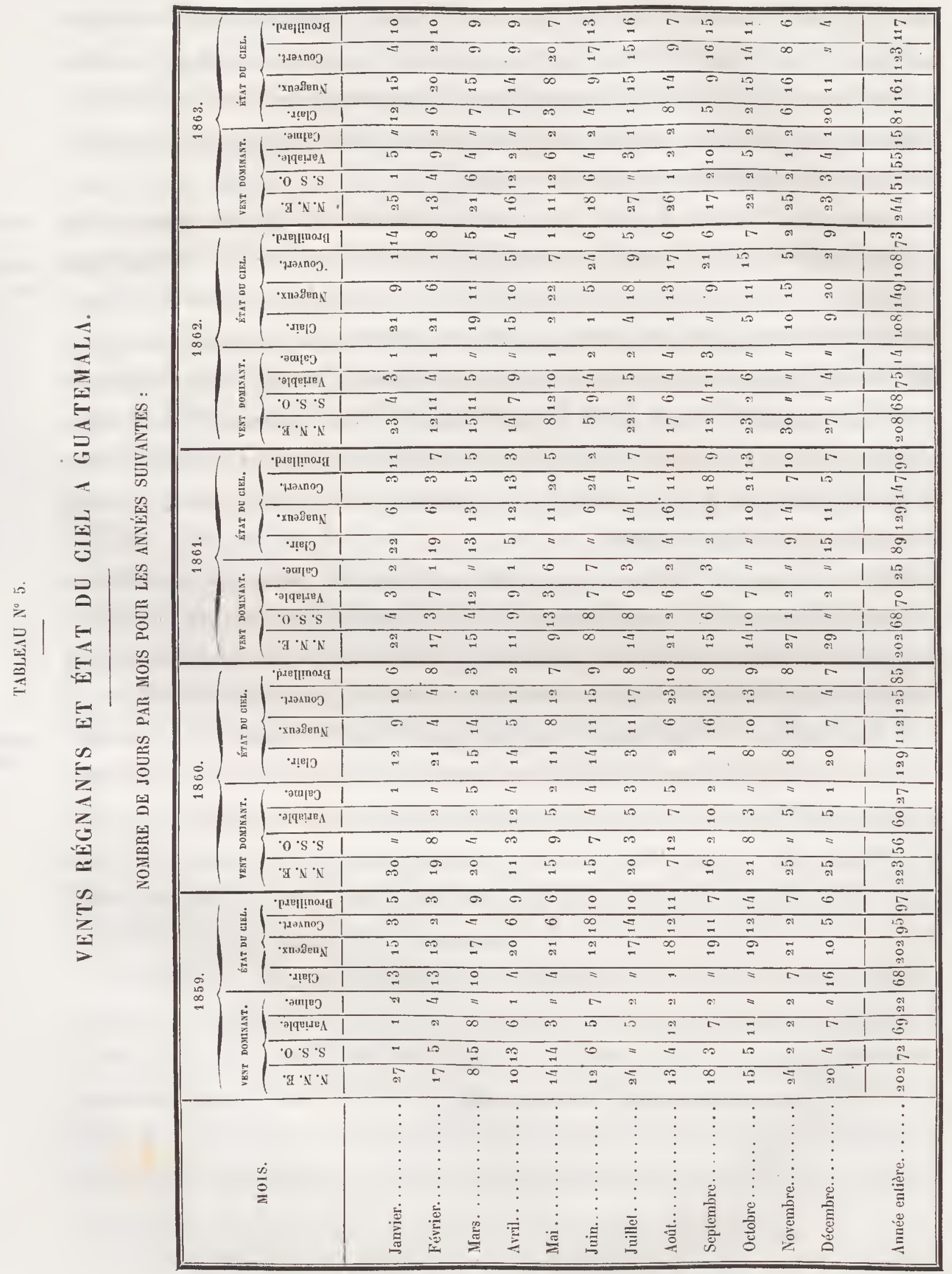


DANS LES RÉPUBLIQUES DE GUATEMALA ET DE SALVADOR. 157

La discussion des chiffres réunis dans ce tableau donne des résultats qui sont parfailement d'accord avec les faits généraux énoncés dans les pages précédentes. On voit en effet, en formant les totaux relatifs à cinq années consécutives, que l'on a 1,080 jours de vent de nord-nord-est contre 315 de vent de sud-sud-ouest, 329 de vent variable, et enfin 103 de calme absolu; ce qui prouve que le vent de nord-nord-est souffle en moyenne pendant les $3 / 5$ du temps, et prend un caractère de prédominance remarquable.

Si nous comparons seulement les fréquences relatives des vents de nord-nordest et de sud-sud-ouest, nous verrons que, pour l'ensemble des cinq années, les 1,080 journées où le premier a soufflé sont aux 315 pendant lesquelles le second s'est montré comme 1 est à 0,291 , c'est-à-dire qu'il y a environ 4 fois plus de vents de nord-est que de vents de sud-ouest. Mais, en faisant la répartition par saisons, on trouve, pour la somme des hivers, 601 jours contre 137 , qui sont entre eux comme 1 est à 0,227 , et, pour la somme des élés, 478 jours contre 178 , qui sont entre eux comme 1 est à 0,372 ; c'est-ì-dire que, pendant la saison sèche, le vent du nord-est est à peu près 5 fois plus fréquent que le vent du sud-ouest, et 3 fois plus fréquent seulement pendant la saison des pluies. Il est donc clail que le vent de nord-est, quoique toujours prédominant, tend à te devenir encore plus pendant l'hiver, tandis que le vent de sud-ouest est soumis, pendant l'été, ì une recrudescence assez sensible.

Les vents variables ne sont pas rares, puisqu'ils soufllent en moyeme pendant 65 jours par an. Il est évident qu'ils sont dus à une sorte de lutte entre les vents du nord-est et du snd-ouest, qui, à peu près aussi puissants l'un que l'autre dans certains moments, ne parviennent ni l'un ni l’autre à triompher d'une façon absolue et déterminent dans l'atmosphère des espèces de courants giratoires ou de tourbillons, grâce auxquels le vent soufille successivement de tous les points du compas. On pourra observer que les vents variables s'établissent surtout au printemps et en automme, soit dans les époques de transition où le courant du sud-ouest est en voie de recrudescence ou de diminution.

Les journées de calme complet ne sont pas fréquentes, car il y en a toul au plus une vingtaine par an en moyenne; elles se produisent surtout pendant la saison des pluies, et il est important de remarquer que l'almosphère est généra- 
lement en repos absolu quand apparaissent les temporales ou sćries continues de plusieurs journées entièrement pluvieuses, sans orages. Cela tient probablement à la rencontre et au mélange intime de deux courants d'air également puissants venant de deux directions opposées; les masses d'air saturé d'humidité venant du sud-ouest sont arrêtées et pénétrées dans tous les sens par l'air froid du nord-est, qui détermine ainsi un refroidissement général et une précipitation lente el calme sur une grande étendue de pays à la fois.

État du ciel

is Guatemala.

Le tableau $n^{\circ} 5$ donne, à côlé des chiffres relatifs aux vents régnants, ceux qui se rapportent à l'état du ciel aux différentes époques de l'année, nombre de journées clai'es, nuageuses ou couvertes. Ges faits ne sont en quelque sorte que des intermédiaires reliant directement les allures des hydroméléores à celles des courants atmosphériques qui en sont au fond la cause primordiale. A ce titre, il peut êlre intéressant de les examiner en même temps que l'on étudie les quantités de pluie et les directions des vents, mais les déductions se trouvent si naturellement d'elles-mêmes, qu'il nous semble au moins inutile d'insister sur ce point.

L.es t'emolinos dans les hautes altitudes.

Dans les régions dont l'altitude est considérable, et surtout dans les hauts plateaux, les mouvements de l'atmosphère se trahissent par un phénomène assez remarquable, auquel on donne le nom de remolinos ou tourbillons. Nous n'avons pas observé fréquemment nous-même les remolinos dans l'Amérique centrale, parce que nous avons surtout voyagé dans les plaines élevées pendant la saison des pluies, époque de l'année la moins favorable à leur production, mais nous savons qu'ils s'y manifestent presque aussi souvent qu'au Mexique, où nous ell avons assez vu pour pouvoir en parler.

Pendant l'hiver, chaque matin, au lever du soleil, les rayons de cet astre échauffent avec une grande rapidité les couches inférieures de l'atmosphère qui sont le plus directement exposées à la réverbération du sol. Cet air, ainsi éclıauffé, se dilate et devient plus léger que celui qui est au-dessus de lui; à un certain moment, la différence se trouve assez considérable pour que l'équilibre soit rompu, et il se forme un courant ascendant qui s'élève dans les hautes régoions en traversant les couches moyennes de l'atmosphère. Ces dernières ne sont aucunement dérangées de la position qu'elles occupent, mais l'air inférieur y perce, en quel- 
DANS LES RÉPUBliquES DE GUATEMALA ET DE SALVADOR. 159 que sorte, un trou par. lequel il s'écoule en tourbillonnant et s'élève en formant une espèce de tire-bouchon, de vis ascensionnelle, dont la puissance aspiratrice est souvent très-considérable.

Les remolinos peuvent atleindre jusqu’à 10 niètres de diamètre, et s'élèvent à une hauteur qui varie de 300 à 400 mètres, si l'atmosphère est assez calme pour leur permettre un développement continu. Ces trombes forment alors de vastes colonnes qui s'élèvent au-dessus du sol et deviennent visibles à l'œil, à cause de l'énorme quantité de menus objets, et surtout de poussière, qu'elles entrainent avec elles gràce à leur force de succion. Les vents qui ne sont pas assez intenses pour les détruire entrainent les remolinos avec une rapidité plus ou moins grande, et leur font parcourir de vastes étendues de pays, jusqu'd̀ ce qu'il se rencontre un obstacle qui brise la trombe, en arrêtant la continuité du courant d'air ascensionnel.

\section{VARIATIONS BAROMÉTRIQQES.}

Nous avons fait, pendant le cours de nos voyages, un nombre très-considérable d'observations barométriques, mais on conçoit aisément que nos séjours dans une mème localité n'ayant jamais été prolongés au delà de quelques jours, c'est à peine si nous avons pu obtenir quelques séries continues, dont la plus longue ne dépasse pas une semaine. De semblables éléments sont extrêmement précieux pour la détermination des altiludes, et e'est en effet dans ce but qu'ils ont élé principalement recueillis; mais ils ne présentent ni assez de suite ni assez de lien entre eux pour servir de base à une discussion quelconque sur la marche du baromètre et doivent être négligés à côté des documents aussi importants que nombreux qu'il nous a été permis de puiser dans les registres d'observalions du Colleģio Tridentino de Guatemala, et qui nous serviront ci-après à étudier d'une manière à peu près complète les phénomènes complexes que présentent, à Gualtemala, les variations barométriques.

Disons pourtant quelques mots, en passant, de ce qui a lien sur le bord dé la mer. On sait que, sous l'équaleur, la lauteur barométrique moyenne est de 758 millimètres environ, et que ce chiffre auggmente à mesure que l'on s'élève en latitude, jusqu’à une limite déterminée; or les côtes de l'Amérique centrale étant 
comprises entre 12 el $15^{\circ}$ de latitude nord, il est permis de supposer que la pression barométrique moyenne y est de 759 millimètres environ.

Le tableau suivant domne les oscillations du baromètre à Panama pour le mois de juin 1854; Panama n'étant que par $7^{\circ} 30^{\prime}$ de latitude nord, et le mois de juin étant fort voisin, comme nous le démontrerons plus loin, de l'époque du minimum, il n'y a pas lieu de s'étonner de la moyenne de $7^{5} 7^{\mathrm{mm}}, 10$, qui n'infirme en aucune façon ce que nous venons de dire.

\section{VARIATIONS BAROMÉTRIQUES}

AU BORD DE L'OCÉAN PACIFIQUE, A PANAMA (JUIN 1854).

\begin{tabular}{|c|c|c|c|c|c|c|}
\hline \multirow{2}{*}{ JOURS } & \multicolumn{3}{|c|}{ BAROMĖTRE RÉDUIT A $0^{\circ}$. } & \multicolumn{3}{|c|}{ TEMPÉRATURES CORRESPONDANTES DE L'AIR. } \\
\hline & 7 HEURES DU MITLX. & 2 กЕटnEs pe soln. & 9 มอบ & 7 MEURES DU MaTE. & 2 IELCRES nu soir. & 9 HEERES DU SOIR. \\
\hline $1 \ldots \ldots \ldots \ldots \ldots$ & $7^{56,03}$ & 755,61 & $755,8_{2}$ & $25^{\circ}, 00$ & $29^{\circ}, 44$ & $25^{\circ}, 00$ \\
\hline $2 \ldots \ldots \ldots \ldots$ & $7^{55,94}$ & 755,58 & 755,36 & 26,11 & 32,22 & 25,56 \\
\hline $3 \ldots \ldots \ldots \ldots \ldots$ & 755,86 & 755,41 & 755,56 & 25,56 & 29,44 & 26,11 \\
\hline $4 \ldots \ldots \ldots \ldots \ldots$ & 754,80 & 754,52 & $7^{56,83}$ & 28,33 & 28,80 & 25,56 \\
\hline $5 \ldots \ldots \ldots \ldots \ldots \ldots$ & 754,67 & 755,21 & 755,92 & 25,56 & 30,56 & 27,22 \\
\hline $6 \ldots \ldots \ldots \ldots \ldots$ & $7^{55,9^{4}}$ & $7^{56,37}$ & $7^{56,63}$ & 25,56 & 29,44 & 25,56 \\
\hline $7 \ldots \ldots \ldots \ldots \ldots$ & 756,53 & $7^{5} 7,09$ & 757,21 & 25,00 & 26,67 & 24,44 \\
\hline $8 \ldots \ldots \ldots \ldots \ldots \ldots$ & $7^{5} 7,21$ & $7^{5} 56,63$ & 759,07 & 26,67 & 29,44 & ${ }_{3} 5,00$ \\
\hline $9 \ldots \ldots \ldots \ldots \ldots$ & $7^{5} 7,46$ & $7^{5} 7,39$ & $7^{5} 9,17$ & 26,11 & 26,67 & 24,44 \\
\hline $10 \ldots \ldots \ldots \ldots \ldots$ & $7^{57}, 34$ & $7^{56,9^{4}}$ & $7^{5} 7,14$ & 24,44 & 31,11 & 27,22 \\
\hline $11 \ldots \ldots \ldots \ldots \ldots$ & 757,14 & $7^{56,80}$ & $7^{5} 7,46$ & $27,7^{8}$ & 31,11 & 27,22 \\
\hline $12 \ldots \ldots \ldots \ldots \ldots$ & $7^{56,63}$ & $7^{57,19}$ & 757,59 & 26,67 & 24,44 & 24,44 \\
\hline $13 \ldots \ldots \ldots \ldots \ldots$ & $7^{58,10}$ & $7^{58,00}$ & $7^{5 i j, 32}$ & 25,00 & 31,11 & 24,44 \\
\hline $14 \ldots \ldots \ldots \ldots \ldots$ & 757,46 & 757,69 & $7^{5} 7,39$ & 27,22 & 25,56 & 25,00 \\
\hline $15 \ldots \ldots \ldots \ldots \ldots$ & 757,29 & 758,15 & $7^{5} 7,97$ & 26,56 & 26,11 & 25,56 \\
\hline $16 \ldots \ldots \ldots \ldots \ldots$ & $7^{5} 7,97$ & 758,83 & 758,15 & 25,00 & 27,22 & 25,56 \\
\hline $17 \ldots \ldots \ldots \ldots \ldots$ & 758,56 & $7^{5} 9,29$ & $7^{58,28}$ & 26,67 & 27,78 & $\mathrm{2}^{\bar{E}}, 56$ \\
\hline $18 \ldots \ldots \ldots \ldots \ldots$ & $7^{58,56}$ & 758,26 & 756,75 & 25,00 & 26,67 & 26,67 \\
\hline $19 \ldots \ldots \ldots \ldots \ldots$ & $7^{5} 7,77$ & $7^{5} 7,19$ & $7^{5} 56,7^{5}$ & 27,78 & 31,11 & 26,67 \\
\hline $20 \ldots \ldots \ldots \ldots \ldots$ & $7^{56,7^{\circ}}$ & 757,34 & $7^{56,96}$ & 26,11 & 27,22 & 25,00 \\
\hline $21 \ldots \ldots \ldots \ldots \ldots$ & 757,21 & 757,44 & 757,14 & 26,67 & 28,33 & ${ }_{2} 5,00$ \\
\hline $22 \ldots \ldots \ldots \ldots \ldots$ & $7^{5} 7,59$ & 757,24 & $7^{5} 7,56$ & 24,44 & 30,00 & 26,67 \\
\hline $23 \ldots \ldots \ldots \ldots \ldots$ & $7^{58,23}$ & $7^{5} 7,7^{0}$ & $7^{5} 7,7^{0}$ & 26,11 & 31,67 & 36,11 \\
\hline $24 \ldots \ldots \ldots \ldots \ldots$ & $7^{5} 7,46$ & $7^{5} 7,49$ & $7^{5} 7,26$ & 26,11 & 28,89 & ${ }_{2} 6,67$ \\
\hline $25 \ldots \ldots \ldots \ldots \ldots$ & $7^{56,96}$ & $7^{56,94}$ & $7^{55,7^{4}}$ & 26,11 & 28,89 & 26,11 \\
\hline${ }_{2} 6 \ldots \ldots \ldots \ldots \ldots$ & $7^{56,32}$ & $7^{56,60}$ & $7^{56,07}$ & 24,44 & 30,56 & 26,11 \\
\hline $27 \ldots \ldots \ldots \ldots \ldots$ & $7^{56,19}$ & $7^{56,55}$ & $7^{5} 7,34$ & 26,11 & 30,00 & $22,7^{8}$ \\
\hline $28 \ldots \ldots \ldots \ldots$ & 757,80 & $7^{58,28}$ & 758,21 & 22,22 & 28,89 & 23,89 \\
\hline $29 \ldots \ldots \ldots \ldots \ldots$ & $7^{5} 7,9^{2}$ & 757,64 & $7^{5} 7,04$ & 23,89 & 27,22 & 24,44 \\
\hline $30 \ldots \ldots \ldots \ldots \ldots$ & 757,41 & 757,09 & 757,34 & 24,44 & 29,44 & 26,67 \\
\hline
\end{tabular}


DANS LES RÉPUBLLUES DE GUATEMALA ET DE SALVADOR. 161

Si nous arrivons à l'étude des variations baromélriques à Gualemala, nous devrons, dès l'abord, en considérer de deux ordres : les varialions diurnes et les variations annuelles, qu'il nous faudra isoler et examiner séparément, quoiqu'elles soient intimement mélangées dans la nature et doivent leur origine à des causes analogues.

On sait que, dans tous les pays, mais surtout sous les tropiques, le baromètre est soumis, pendant le cours d'une journée, à des oscillations telles, qu'elles présentent deux maxima et deux minima, qui ont lieu à des moments se reproduisant chaque jour avec une grande régularité, et auxquels on donne le nom d'heures tropiques. Guatemala, élant situé par $14^{\circ} 36^{\prime}$ de latitude nord, se trouve daus la zone où ces phénomènes se manifestent de la manière la plus remarquable, el nous devrons pouvoir les faire ressortir aisément des séries de chiffres que nous possédons. A cet effet, nous avons réuni dans le tableau suivant (tableau $n^{\circ} 6$ ) les observations journalières, exécutées à plusieurs heures de la journée, pendant plusieurs mois de l'année $\mathbf{1} 866$, et nous avons traduit en courbes graphiques les résultats saillants correspondant à des périodes de dix jour's choisies daus diverses saisons (pl. II, fig. 2). Nous devons dire pourtant que les observalions d'une mème journée ne sont, en général, ni assez nombreuises, ni exécutées à des lieures suffisamment bien choisies pour amener à des résultats absolument rigoureux; nous avons été obligéé, pour arriver à une discussion léconde, de déduire d'un calcul d'interpolation quelques données qui, quoique probablement très-voisines de la vérité, ne peuvent ètre aussi complétement certaines que si elles avaient été fournies par une observation directe. Les chiffres des mois de septembre et d'octobre onl été oblenus par nous-même, au moyen de notre baromètre de voyage, tandis que les autres ont été fournis par le baromètre fixe du Collegio Tridentino de Guatemala; mais les deux instruments ayant donıé, dans plusieurs cas où noụs les avons comparés, des résultats concordants, on peut admettre que la série des observations est continue. 
MARCHE JOURNALIÈE DU BAROMETRE (RÉDUIT À $0^{\circ}$

\begin{tabular}{|c|c|c|c|c|c|c|c|c|c|c|c|c|}
\hline \multirow[b]{2}{*}{ JOURS. } & \multicolumn{4}{|c|}{ JAYVIER. } & \multicolumn{4}{|c|}{ FÉtriEl. } & \multicolumn{4}{|c|}{ MARS. } \\
\hline & $\begin{array}{c}7 \text { ueunes } \\
\text { du } \\
\text { matin. }\end{array}$ & $\begin{array}{l}2 \text { IIEURES } \\
\text { du } \\
\text { soir, }\end{array}$ & $\begin{array}{l}9 \text { मEURes } \\
\text { du } \\
\text { soir. }\end{array}$ & MOY ENNE. & $\begin{array}{c}7 \text { HEURES } \\
\text { du } \\
\text { matin. }\end{array}$ & $\begin{array}{l}\text { 9 нвยn.Bs } \\
\text { du } \\
\text { soir. }\end{array}$ & $\begin{array}{l}9 \text { MEUREs } \\
\text { du } \\
\text { soir. }\end{array}$ & MOYEXXE, & $\begin{array}{c}7 \text { neures } \\
\text { du } \\
\text { matin, }\end{array}$ & $\begin{array}{l}2 \text { HeUREs } \\
\text { du } \\
\text { soir. }\end{array}$ & $\begin{array}{c}9 \text { Hetres } \\
\text { du } \\
\text { soir. }\end{array}$ & \\
\hline $1 \ldots \ldots$ & 641,22 & 639,55 & $6 / 11,26$ & 640,61 & 641,54 & 640,96 & 642,96 & $6 / 12,15$ & 642,05 & 641,28 & 642,67 & $642,0^{0}$ \\
\hline 2 . & 639,47 & $638,3_{2}$ & 640,23 & 639,3 / & 642,49 & 640,84 & 642,88 & 642,07 & $6 / 12,84$ & 641,54 & 641, 19 & $641,9^{6}$ \\
\hline $3 \ldots \ldots$ & 642,00 & 641,22 & 642,50 & 641,91 & 641,66 & $6 / 10,98$ & 643,56 & 612,40 & 642,25 & $640,7^{2}$ & 641,54 & 611,30 \\
\hline $1, \ldots$ & 643,40 & 644,20 & 645,00 & 644,20 & $6 / 12,00$ & 6410,22 & 642,88 & 611,70 & $6^{\prime} 10,67$ & 639,00 & 641,39 & 610.34 \\
\hline $5 \ldots$ & $6 / 15,44$ & $61,3,64$ & 644,87 & 644,65 & 642,22 & 640,18 & 642,75 & $641,7^{2}$ & 639,84 & 637,60 & 639,56 & $638,9^{\prime}$ \\
\hline $6 .$. & $64 / 4,23$ & 642,41 & 644,38 & 643,67 & 642,611 & $6 / 11,00$ & 643,60 & 642,42 & 6410,00 & 638,02 & 639,13 & $6390^{0^{3}}$ \\
\hline $1 \ldots \ldots$ & 643,12 & $642,9^{\circ}$ & $64 /, 05$ & 643,36 & 642,15 & $6 / 10,14$ & 643,26 & 641,85 & 639,40 & 638,50 & 639,13 & $639.0^{1}$ \\
\hline $8 \ldots \ldots \ldots \ldots$ & 644,29 & 641,81 & 643,75 & 643,61 & 642,40 & 640,65 & 641,82 & 641,62 & 638,55 & 637,48 & 639,13 & 638,39 \\
\hline $9 \ldots \ldots \ldots \ldots$ & 645,71 & 642,92 & 644,21 & 643,61 & 641,83 & 640,63 & 641,51 & 641,33 & 638,05 & $637,8 / 1$ & 638,04 & $637,9^{8}$ \\
\hline $10 \ldots \ldots \ldots$ & 644,05 & 641,91 & 643,54 & 645,16 & 639,82 & $638,7^{2}$ & $6 / 10,12$ & 639,55 & 639,00 & $637,9^{5}$ & 638,99 & $638^{60^{\circ}}$ \\
\hline $11 \ldots \ldots$ & 642,91 & 610,43 & 641,97 & 641,77 & $640,9^{8}$ & 639,56 & $6 / 11,24$ & 640,59 & 639,47 & 637,89 & 639,20 & $638^{88^{\circ}}$ \\
\hline $12 \ldots$ & 641,40 & $6 / 10,00$ & 641,30 & 640,90 & 641,38 & 640,16 & $6 / 12,21$ & 641,25 & $6 / 10,44$ & 639,00 & 639,26 & $630 m^{3}$ \\
\hline 13. & 642,27 & 641,31 & 641,63 & 641,40 & 640,49 & 638,49 & 641,16 & 640,05 & 641,34 & 640,23 & 6110,86 & 640,81 \\
\hline $14 \ldots$ & 641,78 & 639,95 & 641,43 & 641,05 & 640,38 & 639,14 & $640,9^{2}$ & 640,15 & $6 / 12,23$ & 640,89 & 642,61 & $6\left\{11,9^{9}\right.$ \\
\hline $15 \ldots \ldots$ & 640,91 & 639,05 & $6 / 11,29$ & 640,42 & 639,76 & $63_{0,00}$ & 640,11 & 639,62 & 641,87 & 640,63 & $6 / 12,14$ & $641, x^{50}$ \\
\hline $16 \ldots \ldots$ & 641,41 & 640,28 & 642,20 & 641,50 & 640,92 & 639,16 & $6 / 1,64$ & $6 / 10,57$ & $641,9^{8}$ & 640,82 & 641,69 & $64,0^{50}$ \\
\hline $17 \ldots \ldots$ & 642,57 & 641,08 & 642,19 & 641,88 & 641,59 & 641,12 & 643,89 & 642,20 & $6 / 12,04$ & 640,80 & 641,99 & $310^{60^{3}}$ \\
\hline 18. & $6 / 42,15$ & 639,44 & 641,20 & $640,9^{3}$ & $6 / 12,05$ & $6 / 41,98$ & 643,74 & 642,58 & 642,10 & 640,35 & $641,9^{5}$ & 34,14 \\
\hline 19. & 641,67 & 640,02 & 642,19 & 641,29 & 641,33 & $642,9^{4}$ & 643,89 & 642,72 & 641,97 & 640,01 & $6 / 11,11$ & \\
\hline $20 \ldots$ & $6 / 42,98$ & 641,00 & 642,36 & 642,11 & 644,05 & 642,70 & $6 / 13,29$ & 613,35 & 641,63 & 638,97 & 641,88 & \\
\hline $21 \ldots$ & $6 / 13,7^{3}$ & 6112,16 & $6133,9^{5}$ & 643,28 & 642,30 & 640,86 & $6 / 42,16$ & 641,77 & 630.97 & 638,39 & 611,08 & $330 n^{34}$ \\
\hline 29. & $6 / 13,64$ & 642,22 & 643,34 & 643,07 & 641,79 & 640,90 & 641,57 & 641,12 & 639,54 & 638,58 & $639,3{ }_{1}$ & $630^{1^{j}}$ \\
\hline 23. & 642,86 & 640,75 & $6 / 12,89$ & $6 / 12,17$ & 641,42 & 610,93 & 642,60 & 641,65 & 0110,15 & 638,67 & $6 / 10,05$ & $630 . i^{-4}$ \\
\hline $24 \ldots$ & 641,90 & 639,82 & 641,61 & 641,11 & 640,70 & 640,90 & 642,05 & 641,22 & 640,89 & 639,75 & $640,5 / 1$ & \\
\hline $25 \ldots$ & $6 / 12,53$ & 640,10 & 642,00 & 641,54 & 641,08 & 641,30 & 642,17 & 641,52 & 641,28 & 640,76 & $6 / 11,14$ & $0^{6}$ \\
\hline 26 . & 640,87 & 639,05 & 641,22 & 640,38 & 641,11 & $6 / 10,12$ & $6 / 11,31$ & 640,85 & $6 / 1,37$ & 640,00 & $6 / 11,56$ & $3,1,31$ \\
\hline $27 \ldots \ldots$ & 640,55 & $6 / 1,09$ & 6112,10 & 641,35 & 642,29 & 640,82 & 612,30 & 641,77 & 642,90 & 611,25 & $642,9^{6}$ & y \\
\hline 28 . & 642,08 & 640,43 & 642,23 & 641,38 & 642,38 & 640,44 & 642,40 & 641,76 & 641,44 & $6 / 10,1 / 1$ & $6 / 1,60$ & 1,09 \\
\hline 29 . & $642,9^{8}$ & 640,86 & 643,08 & 642,31 & $"$ & $"$ & $u$ & $\|$ & 640,99 & $639,6 /$ & 640,81 & \\
\hline 30 & 619,41 & 640,144 & 643,00 & 641,95 & $"$ & " & "l & " & 640,50 & 638,52 & $6 / 12,52$ & \\
\hline 31. & $6 / 12,65$ & $6 / 40,7^{5}$ & 643,09 & 642,16 & $"$ & $"$ & $"$ & $"$ & 639,68 & 638,22 & $639,7^{5}$ & \\
\hline Mois entier... & $64 n, 48$ & 640,96 & $64 \%, 36$ & 642,00 & 641,67 & 640,60 & 642,52 & 64153 & 6110,86 & 639,51 & 640,80 & \\
\hline
\end{tabular}


DANS LES RÉPUBLIQUES DE GUATEMALA ET DE SALVADOR.

I GUATEMALA, EN 1866, POUR LES MOIS SUIVANTS:

\begin{tabular}{|c|c|c|c|c|c|c|c|c|c|c|c|c|}
\hline \multicolumn{4}{|c|}{ mat. } & \multicolumn{4}{|c|}{ JUIN. } & \multicolumn{4}{|c|}{ AOUิT. } & \multirow[b]{2}{*}{ JOURS. } \\
\hline $\begin{array}{r}7 \text { Melings } \\
\begin{array}{c}\text { du } \\
\text { matin. }\end{array}\end{array}$ & $\begin{array}{c}2 \text { HELnes } \\
\text { do } \\
\text { soir. }\end{array}$ & $\begin{array}{l}9 \text { Herres } \\
\text { du } \\
\text { soir. }\end{array}$ & MOSEYYE. & 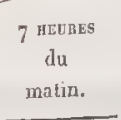 & $\begin{array}{c}2 \text { uEchns } \\
\text { du } \\
\text { soir. }\end{array}$ & 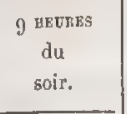 & MOYENKE. & $\begin{array}{c}7 \text { abunEs } \\
\text { du } \\
\text { matin. }\end{array}$ & $\begin{array}{l}\text { 22 Heunes } \\
\text { du } \\
\text { soir. }\end{array}$ & $\begin{array}{c}9 \text { teures } \\
\text { du } \\
\text { soir. }\end{array}$ & MOXESะB, & \\
\hline$"$ & $"$ & $"$ & $"$ & 641,14 & 640,00 & 642,37 & 641,17 & $641,9^{\circ}$ & 640,37 & 641,83 & 641,39 & 1 \\
\hline$"$ & $"$ & $"$ & $"$ & 640,89 & $63 \mathrm{~g}, 8 \mathrm{4}$ & 641,23 & 640,65 & 642,36 & 640,87 & 643,00 & 642,07 & 2 \\
\hline " & " & " & $"$ & 640,77 & 639,16 & 641,16 & 640,36 & $642,4: 3$ & 640,11 & 642,66 & $641,7^{3}$ & 3 \\
\hline$"$ & " & $"$ & $"$ & 639,66 & 638,09 & 640,08 & 630,28 & $641,9^{\circ}$ & 640,00 & 641,90 & 641,27 & 4 \\
\hline$"$ & " & $"$ & " & $63_{9}, 88$ & 638,00 & 640,16 & 639,31 & 641,66 & $639,9^{6}$ & 641,84 & 641,15 & 5 \\
\hline " & " & " & " & $6 / 10,63$ & 639,26 & 641,64 & 640,51 & 613,00 & 640,13 & 642,66 & $6^{\prime} 11,59$ & 6 \\
\hline " & " & " & " & 641.06 & $63_{9,2 / 4}$ & 641,12 & 640,47 & 641,80 & 640,46 & $6 / 12,09$ & 641,45 & 7 \\
\hline " & " & $"$ & $"$ & 641,16 & 640,00 & 641,63 & $640,9^{3}$ & 641,53 & 640,19 & $641,6 n$ & 641,10 & 8 \\
\hline " & " & " &. & 640,84 & 630,54 & 641,00 & 640,40 & 642,48 & 641,02 & 642,80 & $6 / 12,10$ & 9 \\
\hline " & $"$ & " & " & 640,43 & $63_{9}, 88$ & 641,61 & 040,64 & 642,16 & 641,02 & 642,69 & 641,94 & 10 \\
\hline " & $"$ & " & " & $63_{9,04}$ & 639,24 & 640,16 & $63_{9}, 48$ & 641,48 & 640,89 & $641,7^{4}$ & 641,37 & 11 \\
\hline " & " & " & " & 641,65 & 640,58 & 649,00 & 641,41 & 641,63 & 640,00 & 642,18 & 641,27 & 12 \\
\hline " & $"$ & " & " & 641,83 & 640,45 & $6 / 1,9^{5}$ & 641,41 & 641,39 & 640,00 & 641,66 & 641,01 & 13 \\
\hline " & $"$ & $"$ & " & $64:, 0.5$ & 640,50 & 642,16 & 641,57 & 640,68 & 639,13 & 641,54 & 640.45 & 14 \\
\hline " & $"$ & " & $"$ & 640,99 & 640,28 & 641,28 & 640,85 & 640,06 & 640,01 & $6,10,84$ & 640,30 & ${ }_{15}$ \\
\hline " & " & " & " & 641,33 & 640,36 & 641,47 & 641,02 & 639,98 & 638,91 & $639,{ }_{7} 7$ & $63_{9,35}$ & 16 \\
\hline 641,65 & $63_{9}, 81$ & 641,09 & 640,86 & 641,22 & 639,44 & 641,67 & 640,77 & 640,54 & 639,24 & 640,60 & 640,16 & 17 \\
\hline $6,40,13$ & 638,20 & 640,30 & 639,54 & 640,08 & 639,53 & 641,26 & 640,29 & 639,63 & 638,12 & $639,9^{\circ}$ & 639,35 & 18 \\
\hline 640,40 & 638,24 & 640,63 & $63_{9,7} 6$ & 640,26 & 638,96 & 641,80 & 640,34 & 640,70 & 639,09 & 640,11 & 639,97 & 19 \\
\hline${ }^{6} 40,90$ & 6440,09 & 641,98 & 640,77 & 642,09 & 639,44 & 642,68 & 641,110 & 641,08 & 639,55 & 641,63 & 640,75 & 20 \\
\hline $6 \%$ & 640,34 & 641,96 & 641,59 & 642,00 & 639,36 & 642,16 & 641,17 & 641,00 & $63_{9}, 4^{\prime \prime}$ & 641,13 & 640,52 & 21 \\
\hline $6 / 2,10$, & 640,15 & 642,26 & 641,52 & $64 \mathbf{1}, 99$ & 639,49 & 641,60 & 641,03 & $63 y, 50$ & $638,9^{2}$ & 641,16 & 639,86 & 2.2 \\
\hline 613,46 & Gito,18 & 643,00 & $6 / 12.21$ & 640,11 & $63 \eta, 60$ & 641,08 & 640,26 & 639,16 & 638,63 & 639,84 & $639,21^{\circ}$ & ${ }_{2} 3$ \\
\hline $6,1,3,63$ & 640,08 & $641,7^{0}$ & $6 ! 3,10$ & 642,56 & 641,30 & 642,86 & 642,24 & 640,27 & $639,9^{\circ}$ & $6 / 10,36$ & $6,40,17$ & 24 \\
\hline $0,40,09$ & $633_{9,30}$ & 641,22 & 640,22 & $641,9^{\circ}$ & 641.45 & 642,00 & $641,7^{8}$ & 640,18 & $63_{9}, 63$ & 641,00 & 640,04 & 2.5 \\
\hline $6 / 4_{2}, 4_{11}$ & 038,54 & 642,60 & $6 / 1,18$ & 641,61 & 640,06 & $641,9^{3}$ & 641,20 & $63 \eta, 16$ & 638,35 & $640,0 / 4$ & 639,17 & 26 \\
\hline $6 / 1, g / 2$ & $63_{9,63}$ & 641,99 & 641,18 & 610,60 & 640,15 & 641,00 & 640,25 & 640,11 & 639,84 & $6 / 10,34$ & 640,09 & ${ }^{27}$ \\
\hline $61_{2,0}$ & $63_{9}, 8$ 2 & 642,14 & 641,34 & 641,47 & 640,28 & 642,48 & 641,41 & 641,13 & 639,58 & 641,16 & $640,6: 3$ & 28 \\
\hline $6\{1,63$ & 638,64 & 642,06 & 640,77 & $641,9^{3}$ & $640,7^{0}$ & 642,11 & 641,58 & 641,44 & $63_{9}, 03$ & 641,53 & 640,70 & 29 \\
\hline 641,30 & 639,06 & 641,56 & 640,64 & 641,84 & 640,63 & 642,84 & 641,77 & $6 / 10,16$ & 639,10 & 640,40 & $63_{9}, 88$ & 30 \\
\hline 64,16 & 610,43 & 642,63 & $641,7^{\prime}$ & " & " & " & " & 640,84 & $63_{9,11}$ & 641,06 & $6 / 10,30$ & 31 \\
\hline " & " & $"$ & " & $61 \mathrm{i}, 10$ & 639,49 & $64 \mathbf{1}, 6 \mathbf{1}$ & 640,83 & 640,98 & 639,65 & 641,32 & 640,65 & \\
\hline
\end{tabular}


APPENDICE AU TABLEAU No 6 .

VARIATIONS BAROMÉTRIQUES JOURNALIÈES (RÉDUITES A $0^{\circ}$ ), PEADANT UNE PARTIE DES MOIS SUIVANTS A GUa'EMALA.

\begin{tabular}{|c|c|c|c|c|c|c|c|c|c|c|c|c|c|}
\hline \multirow{2}{*}{ 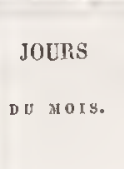 } & \multicolumn{6}{|c|}{ SEPTEMBRE. } & \multirow{2}{*}{$\begin{array}{l}\text { JOURS } \\
\text { De yors. }\end{array}$} & \multicolumn{6}{|c|}{ ОСТОВRE. } \\
\hline & $\begin{array}{c}7 \text { Urours } \\
\text { du } \\
\text { matin. }\end{array}$ & $\left|\begin{array}{c}9 \text { unverss } \\
\text { du } \\
\text { matin. }\end{array}\right|$ & $\begin{array}{c}2 \text { aruress } \\
\text { du } \\
\text { soir. }\end{array}$ & $\begin{array}{c}4 \text { Heuris } \\
\text { dn } \\
\text { soir. }\end{array}$ & $\mid \begin{array}{c}7 \text { HECrRs } \\
\mathrm{dn} \\
\text { soir. }\end{array}$ & $\begin{array}{c}11 \text { uzenRs } \\
\text { du } \\
\text { soir. }\end{array} \mid$ & & $\begin{array}{c}7 \text { MrURRS } \\
\text { du } \\
\text { matin. }\end{array}$ & $\begin{array}{c}9 \text { arukes } \\
\text { du } \\
\text { matin. }\end{array} \mid$ & $\begin{array}{l}\text { 2 urURES } \\
\text { du } \\
\text { soir. }\end{array}$ & $\left|\begin{array}{c}4 \text { mEURES } \\
\text { du } \\
\text { soir. }\end{array}\right|$ & $\mid \begin{array}{c}7 \text { neunes } \\
\text { du } \\
\text { soir. }\end{array}$ & $\begin{array}{c}11 \text { vevines } \\
\text { du } \\
\text { soir. }\end{array}$ \\
\hline & 639,89 & 639,32 & " & $63_{9}, 37$ & " & 640,37 & $1 \ldots$ & 639,6 & 639,9 & 639,0 & 638,0 & $63_{9,7}$ & 639,9 \\
\hline & $"$ & 640,78 & 638,75 & 638,20 & 639,00 & 640,000 & a... & 639,6 & 640,0 & 638,9 & 638,1 & 639,6 & 640,0 \\
\hline & 640,86 & 639,61 & 638,07 & 638,36 & 639,37 & $639,50 \mid$ & $3 \ldots$ & 639,7 & 639,9 & 639,0 & 638,1 & 639,5 & 640,0 \\
\hline 18. & 639,71 & 640,29 & $638,7^{6}$ & $"$ & " & $"$ & $4 \ldots .$. & 639,9 & 640,0 & 639,1 & 638,3 & 639,6 & 640,1 \\
\hline & 639,77 & 640,05 & 637,74 & 638,10 & 639,07 & $63_{9}, 48$ & $5 \ldots \ldots$ & $63_{9}, 8$ & 640.1 & $63_{9}, 1$ & 638,4 & 63,5 & 639.9 \\
\hline 90. & 639,73 & 639,79 & $638, \cdots 9$ & 638,10 & $639,3 \mathrm{~g}$ & $639,63 \mid$ & $6 \ldots \ldots$ & 639,7 & 639,9 & 638,4 & 638,2 & $63,9,4$ & 639,7 \\
\hline 21 & 639,64 & 640,00 & $"$ & 638,19 & 639,31 & $639,72 \mid$ & $7 \cdots$ & 639,4 & 639,9 & 639,0 & 638,4 & 638,9 & 639,9 \\
\hline & 639,19 & $633_{9}, 81$ & 637,79 & 638,09 & 639,21 & $63_{9}, 62$ & $8 \ldots$ & 639,2 & 639,7 & 638,3 & 638,5 & $633_{9,0}$ & 639,9 \\
\hline 23. & $639,9^{2}$ & 639,71 & 637,89 & 638,18 & $639,3 \mathrm{a}$ & 639,73 & $9 \ldots \ldots$ & 639, , & 639,6 & 638,4 & 638,2 & $63_{9,1}$ & " \\
\hline 8 . & 639,63 & 63,40 & $633_{7}, 67$ & 638,08 & $63_{9}, 63$ & $63_{9}, 83$ & $10 \ldots .$. & 639,6 & 639,9 & 638,5 & 638,1 & 639,4 & 640,0 \\
\hline 25. & 639,70 & 639,47 & $|638,27|$ & 638,36 & 639,82 & $639,9^{2} \mid$ & $11 \ldots \ldots$ & 639,5 & $63_{9}, 8$ & 638,8 & 638,3 & 639,7 & 640,2 \\
\hline 26. & 639,60 & 640,00 & $|639,36|$ & 638,57 & 639,70 & 639,83 & $12 \ldots \ldots$ & 639,7 & 639,6 & 638,0 & 638,8 & $"$ & " \\
\hline 27. & 639,79 & $63,9,68$ & 639,07 & 638,17 & 639,49 & $(0 ; 3,9,91)$ & $13 \ldots \ldots$ & 639,6 & $63_{9}, 8$ & 638,1 & " & 639,9 & 640,0 \\
\hline & 639,12 & 639,70 & 638,77 & 638,09 & $63 \mathrm{~g}, 6 \mathrm{~s}$ & 639,89 & & & & & & & \\
\hline 39 & 639,17 & $633_{9}, 55 \mid$ & 638,55 & 638,37 & $639,8_{9}$ & 640,00 & & & & & & & \\
\hline & 639,39 & $63_{9}, 76$ & 638,55 & 638,09 & 639,80 & 639,91 & & & & & & & \\
\hline
\end{tabular}

Les oscillations diurnes du baromètre sont caractérisées par deux éléments principaux, les époques auxquelles elles apparaissent el l'amplitude qu'elles atteignent.

Si nous envisageons d'abord le premier de ces éléments, nous pourrons constater aussi bien dans les tableaux de chiffres que sur les courbes graphiques que le baromètre commence à s'élever dans la matinée pour atteindre, entre neuf heures et demie et dix heures, un premier maximum; il redescend ensuite jusque vers trois heures et demie ou quatre heures, moment du premier minimum; puis la marche ascensionnelle reprend le dessus jusque vers dix heures du soir, et l'on voit lui succéder une période d'abaissement qui persiste jusqu'à quatre heures du matin environ. Nous avons donc :

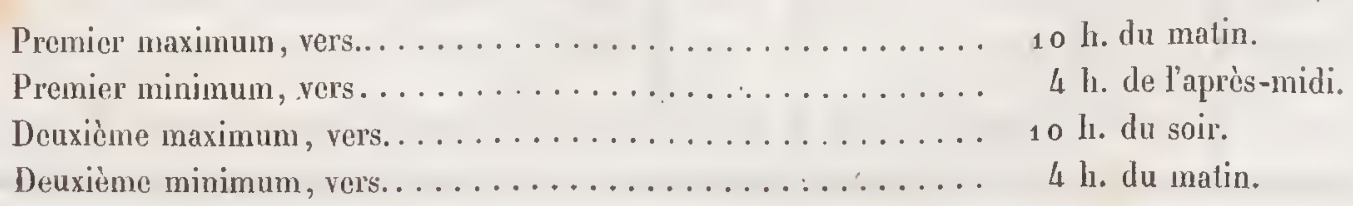


DANS LES RÉPUBLIQUES DE GUATEMALA ET DE SALVADOR. 165

Sauf de rares exceptions, le maximum et le minimum de la nuit sont beaucoup moins énerơiquement caractérisés que ceux de la journée, et l'on voit même, dans certains cas, le minimum de quatre heures du malin disparaître complétement, lorsqu'une journée où le baromètre doil atteindre une grande élévation succède à une autre où il était relativement très-loas : c'est encore un minimum pour la période qui commence, mais ce n'en est plus un pour celle qui se termine.

Il est probable que tes heures tropiques doivent se déplacer un peu iver les saisons, et que le maximum de la matinée, par exemple, doit avoir lieu un peu plus tòt en hiver qu'en été, et ainsi des autres. C'est pour cela que nous n'avons pas précisé les moments d'une manière absolue, en ayant soin de dire qu'un maximım ou un minimum se produit vers telle on telle heure; mais nous ne possédons malheureusement pas d'observations assez précises pour pouvoir élúcider celle importante question et donner des chiflres relatifs au déplacement des heures tropiques suivant les saisons.

Il est certain, d'un autre côté, que l'amplitude des oscillations diurnes varie d'une manière assez notable avec les saisons. On a déjà observé dans les latitudes élevées que cette amplitude atteint son minimum pendant l'hiver, el son maximum soit pendant l'été, soit aux approches de cette époque de l'année; à Guatemala. elle est incontestablement moindre pendant la saison des pluies que pendant la saison sèche. Des observations faites en 1859 donnent les chiffres suivants :

\begin{tabular}{|c|c|c|c|c|c|c|c|}
\hline \multirow{2}{*}{ MoJs. } & \multicolumn{3}{|c|}{ OSCILLATIONS DIURNES, } & \multirow{2}{*}{ MOIS. } & \multicolumn{3}{|c|}{ OSCILLATIOXS DIURXES. } \\
\hline & manimum. & ma smüs. & MOTENNE. & & MINLMCX. & MaвiмL:. & MOTБМЕ. \\
\hline 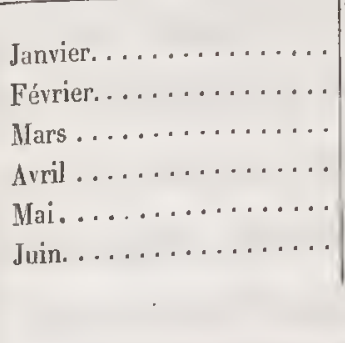 & $\begin{array}{r}1,79 \\
1,65 \\
1,75 \\
1,69 \\
1,35 \\
1,02 \\
M\end{array}$ & $\begin{array}{r}3,21 \\
3,34 \\
3,50 \\
3,66 \\
2,74 \\
2,78\end{array}$ & $\begin{array}{l}2,37 \\
2,76 \\
2,65 \\
2,52 \\
2,09 \\
1,87 \\
\ldots\end{array}$ & 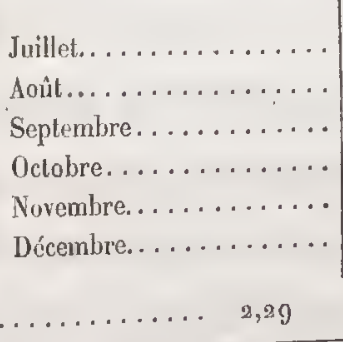 & $\begin{array}{l}1,11 \\
1,36 \\
1,68 \\
1,45 \\
1,28 \\
1,68\end{array}$ & $\begin{array}{l}2,87 \\
2,51 \\
3,35 \\
3,29 \\
3,14 \\
2,96\end{array}$ & $\begin{array}{l}1,75 \\
2,05 \\
2,30 \\
2,51 \\
2,33 \\
2,37\end{array}$ \\
\hline
\end{tabular}

On voit dans ce tableau que, du mois de mai au mois de septembre, il y a une décroissance considérable dans l'amplitude de l'oscillation diurne, qui reprend 
son importance d'octobre en avril. Nos propres observations, combinées avec les calculs d'interpolation que nous avons dû faire sur les chiffres de l'observatoire du Collége Tridentin de Guatemala, pour élablir les courbes de la figure 2, pl. II, nous ont montré aussi que l'amplitude de l'oscillation diurne étail très-grande pendant les noois de janvier et de mai, tandis qu'elle perdait sa valeur en août el en octobre. Le mois de mai ayant été très-sec en 1866, landis que la saison des pluies s'est lonģtemps prolongée en oclobre, il est permis de supposer qu’il y a une relation entre ces mouvements barométriques et les méléores aquenx, relalion que l'on pourra peut-être préciser quand on possédera des documents plus nombreux.

Variabilité de l'oscillation thimrne.

) Scillations accidentelles.
Quoi qu'il en soil, l'oscillation diurne présente assurément une cerlaine variabilité. que l'on peut évaluer en moyenne à $2^{\mathrm{mm}}, 24$. En effel, nous avons pour deux années :

Ce chiffre de $2^{\mathrm{mm}}, 24$ est parfailement naturel, car on sait que l'oscillation dinrne moyenne est de ${ }_{2}^{\mathrm{mm}},{ }_{2} 6$ sous l'équateur, et qu'elle diminue lorsque l'on s'élève en latitude, à mesure que les écarts annuels dus aux dérangements accidentels tondent à augmenter de leur côté.

Il est évident que les oscillations diurıes doivent être plus ou moins troublées par des oscillations irrégulières qui viennent s'y mêler, tantôt pour les auggmenter, lantôt pour en diminuer l'amplitude, et qui sont dues à des phénomènes accidentels, indépendants des causes générales auxquelles on doit attribuer les monvements réguliers et horaires du baromètre. Il suffil, pour s'en convaincre, de jeter les yeux sur les courbes graphiques de la planche II, fig. 2, où l'on voit des sćries d'oscillations diurnes, rełatives à dix journées consécutives du même mois, se déplacer notablement dans la verticale, dans un sens ou dans l'autre, tout en conservant une amplitude moyenne qui ne s'écarte que peu du chiffre correspondant à la parlic de l'amée à laquelle elles appartiennent. Ces oscillations irrégulières proviennent probablemeut de l'action des vents, qui, troublant l'étal calo- 
DANS LES RÉPUBLIQUES DE GUATEMALA ET DE SALVADOR. 167 rifique de l'atmosphère, introduisent des causes accidentelles par lesquelles les mouvements horaires du baromètre sonl plus ou moins affectés. Ainsi, pour ne cilcr qu'un seul exemple, qui, isolé de cette façon, n’a peut-čtre pas une trèsgrande valeur, nous devons le reconnaître, on voil par nos courbes graphiques que le plus gorand nombre d'irrégularités journalières se trouve dans le mois de mai, mois qui correspond à l'époque de transition entre la saison sèche et la saison des pluies, moment où il y a précisément lutte el alternance entre te vent du nord-est et le vent du sud-ouest.

Les oscillations annuelles sont d'un autre ordre que les oscillations diurnes, et ne sont point affectées par elles, de sorte que, dans l'étude que nous allons en faire, nous pourrons négliger ces dernières et ne nous occuper que des moyennes journalières ou mème mensuelles. Nous avons réuni dans le tablean suivant (tableau $n^{\circ} 7$ ) les moyennes mensuelles relalives à cinq années conséculives, de 1859 ì 1863 , et nous y avons trouvé les éléments des courbes graipliiques de la planche III, fiğ. 2.

TABLEAU $N^{\circ} 7$.

MARCHE DU BAROMETTRE PAR MOYENNES MENSUELLES.

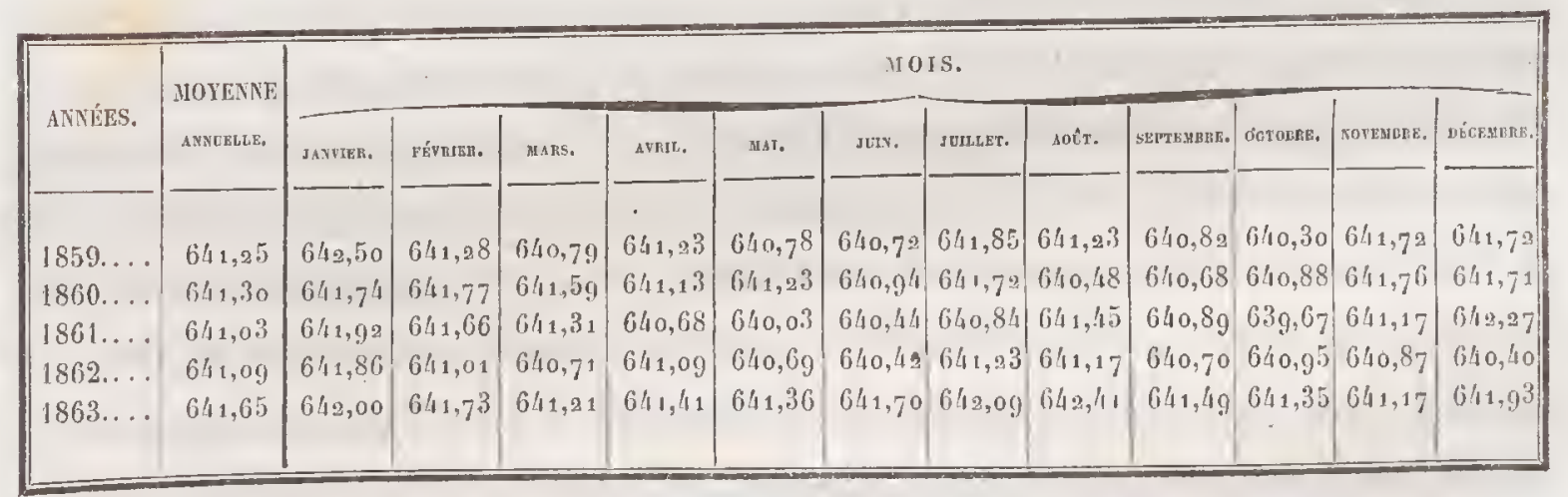

On y verra aisément que les moyennes barométriques sont sensiblement phs élevées dans certaines parties de l'année que dans d'autres, el que, saul quelques irrégularilés inévitables en semblable malière, les mouvements annuels obéissent à la toi snivante. Le maximum d'élévation du baromètre se place généralement an milieu de l'hiver, entre décembre et janvier, puis il $y$ a une diminution gratduclle, el, en mai ou en juin, on atteint un minimum après lequel il y a de nou- 
veau élévation, amenant un second maximum, qui a lieu entre juillet et aoùt, el ne présente pas toujours une intensité tout à fait comparable à celle du premier; à partir de ce moment, le baromètre baisse de nouveau, atteint un second minimum entre les mois de septembre et d'octobre, puis se relève progressivement pour reprendre en décembre ses hauteurs les plus considérables.

Nous avous donc en résumé :

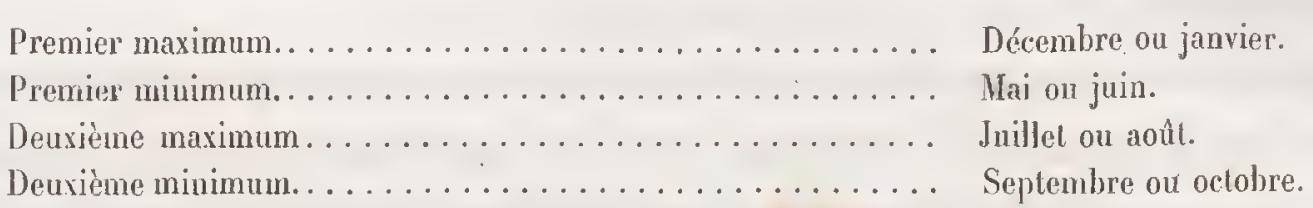

II n'y a absolument rien d'extraordinaire à ce que les moments des maxima et des minima soient un peu indécis, car ils dépendent directement, comme nous aurons à le prouver, des variations de l'atmosphère, qui dépeudent elles-mêmes des allures de la saison des pluies, souvent hésitantes et un peu irréogulières, nous l'arons montré en temps et lieu.

Les mois d'avril et de septembre correspondent, en gónérat, à la moyenne, qui est de $641^{\mathrm{mm}}, 27$, d'après le calcul fail sur un nombre très-considérable d'observations, ramenées elles-mêmes à une série de moyennes annuelles qui forment une des colonnes du tableau $n^{\circ} 7$. Les oscillations qui se produisent dans tout le cours de l'année ne s'écartent janais beaucoup de cette moyenne, ni en dessus ni en dessous; ainsi, en 1856 (moyenne $641^{\mathrm{mm}}, 32$ ), le minimum absolu a élé de $63 \tau^{\mathrm{mm}}, 30$, et le maximum absolu de $645^{\mathrm{mm}}, 20$; en $185 \mathrm{~g}$ (moyenne $641^{\mathrm{mm}}, 25$ ), le minimum alssolu a été de $636^{\mathrm{mm}}, 5 \mathrm{o}$, et le maximum absolu de $645^{\mathrm{mm}}, 83$. Ce sont donc des écarts inférieurs de toute façon à 5 millimètres au-dessus el au-dessous de la moyenne, et qui atteignent seulement d'une manière absolue $7^{\mathrm{mm}}, 90$ en 1856 , et $9^{\mathrm{mm}}, 33$ en 1859 , quantités bien peu considérables, si on les compare aux oscillations de plus de 30 millimètres auxquelles le baromètre est fréquemment sujet dans les hautes latitudes.

D'ailleurs, les maxima et les minima absolus des diflérents mois suivent euxmèmes une marche qui est directement en rapport avec celle des oscillations annuelles, telle que nous l'avons établie précédemment. 
On peut le voir par les chiffres suivants, relatifs à l'année 1859 .

\begin{tabular}{|c|c|c|c|c|c|}
\hline MOIS. & $\begin{array}{l}\text { M I IIML M } \\
\text { absoLu } \\
\text { du mois. }\end{array}$ & $\begin{array}{l}\text { M A X I MU I } \\
\text { ABSOLD } \\
\text { du mois. }\end{array}$ & MOIS. & $\begin{array}{l}\text { II I Y I M U M } \\
\text { ABsoLu } \\
\text { du mois. }\end{array}$ & $\begin{array}{l}\text { MAXI Y U M } \\
\text { ABsolt } \\
\text { du mois. }\end{array}$ \\
\hline 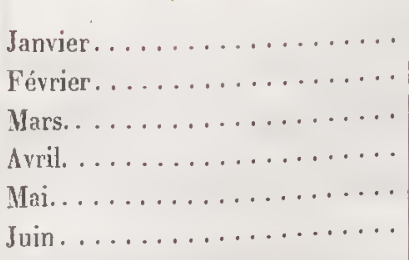 & $\begin{array}{l}639,47 \\
638,54 \\
637,52 \\
637,74 \\
638,22 \\
637,54\end{array}$ & $\begin{array}{l}645,42 \\
641,21 \\
641,54 \\
644,65 \\
612,97 \\
643,24\end{array}$ & 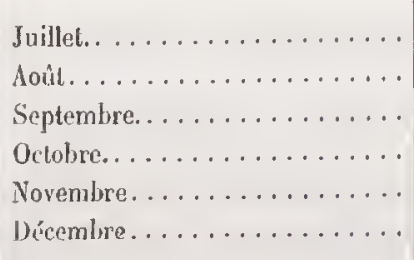 & $\begin{array}{l}639,34 \\
638,24 \\
637,50 \\
636,50 \\
637,37 \\
638,40\end{array}$ & $\begin{array}{l}643,80 \\
643,50 \\
642,78 \\
643,26 \\
645,83 \\
645,51\end{array}$ \\
\hline
\end{tabular}

On y voit que les minima ont été les plus bas en inars el en octobre, landis que les maxima ont atteint leur plus grande élévation en janvier el en juillet.

Ce n'est pas sans intention que nous avons réuni sur une mème planche less conrhes graphiques journalières du thermomètre et du baromètre, el sur une autre, les courbes graphiques annuelles des mèmes instruments. On peut y voir,

Varche iuverse du

thermomitre et du haromèt en eflet, avec une précision remarquable, que la marche de la température el celle de la pression barométrique sont presque tonjours inverses, ce qui lient, d'ailleur's, à la cause elle-mème des oscillations barométriques, que l'on doit chercher dans l'action calorifique proggressive du soleil. En prenant les courbes journalières de la planche II, on voit que le minimum du baromètre suil à peu de distance, dans l'après-midi, le maximum du thermomètre qui se place vers me heure, et que lí minimum de la température, à peu près au moment du lever du soleil, ne précède que de quelques heures le maxinum de la pression barométrique. De mème, dans les courbes annuelles de la planche III, on peut observer cet antagonisme constant, le baromètre s'ćlevant très-haut en décembre et en janvier, au moment où il fait le plus froid, landis quill se maintient à son plus bas en avril et mai, période de la plus grande chaleur. Nous pourrions pousser plus loin l'étude de cette marche inverse du baromètre et du thermomètre, faire voir qu'elle existe aussi bien pour les autres maxima et minima que pour ceux que uons avons cités, montrer même qu'elle se retrouve dans les oscillations irrégulières dues à des vents plus ou moins chauds qui dépriment ou relèvent la colonne barométrique en même lemps qu'ils échauffent ou refroidissent l'atmosphère; mais notre role est plutôt de présenter des faits que de chercher à en tirer des conclu- 
sions absolues, et ces phénomènes d'antagonisme sont encore expliqués d'une manière trop peu précise pour que nous nous hasardions bien loin dans cette voie.

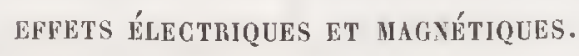

Phénomines ilectriques. Oragres.

L'Amérique centrale, conme toules les autres contrées tropicales, est soumise à des oragges extrèmement violents, qui sont surlout aboudants pendant la saison des pluies, et ces orages sont caractérisés par des plıénomènes électriques d'une intensité remarquable. On a si souvent décrit les orages des tropiques, la soudaineté avec laquelle ils se forment, les pluies diluviennes qui les accompagrnent, les éclairs brillants, les coups de tonnerre épouvantables, les chntes de la foudre qui se manifestent pendant leur durée, que nous ne pensons pas avoù à revenir sur ce sujel. Mais nous aurons pourtant ì dire brièvement quelques mots de certaines parlicularités dont les principaux éléments sont consignés dans le lableau suivant ( lableau $n^{\circ} 8$ ).

TABLEAU No 8 .

PHÉNOMENES ELLCTRIQUES A GUATEMALA

PENDANT LES ANNÉES SUIVANTES :

\begin{tabular}{|c|c|c|c|c|c|c|c|c|c|c|c|c|c|c|c|c|c|c|c|c|}
\hline \multirow[b]{2}{*}{ Nous. } & \multicolumn{4}{|c|}{1859.} & \multicolumn{4}{|c|}{1860.} & \multicolumn{4}{|c|}{1861.} & \multicolumn{4}{|c|}{1862.} & \multicolumn{4}{|c|}{1863.} \\
\hline & 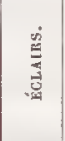 & 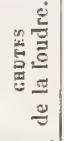 & 兽 & 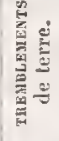 & 总 & 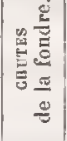 & 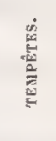 & 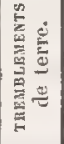 & 总 & 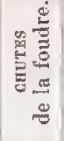 & 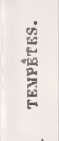 & 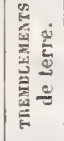 & 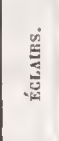 & 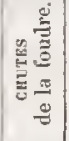 & 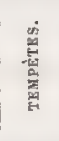 & 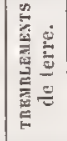 & 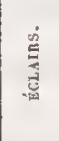 & 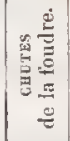 & 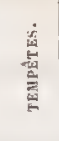 & 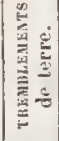 \\
\hline Janvier. . . . . . . . . & 2 & $" 1$ & $"$ & 3 & 2 & $\|$ & $?^{\prime \prime}$ & 2 & 2 & 3 & $"$ & 1 & 7 & 7 & 1 & $"$ & $"$ & $" 1$ & 1 & 7 \\
\hline Février............ & 3 & $"$ & $"$ & 2 & $"$ & $"$ & $"$ & 1 & 1 & $"$ & $"$ & 2 & 8 & 1 & 1 & $"$ & $"$ & $\eta$ & 1 & 1 \\
\hline Mars............. & 6 & 1 & 2 & $"$ & 2 & 3 & $"$ & $n$ & 4 & $"$ & 2 & $"$ & 3 & $" 1$ & $"$ & $"$ & 4 & $"$ & 3 & 3 \\
\hline Avril ............ & 8 & $\check{5}$ & 4 & 4 & 12 & 4 & 8 & $"$ & 16 & 4 & 9 & $"$ & 8 & 2 & $"$ & $"$ & 3 & 1 & 3 & 3 \\
\hline Mai. . . . . . . . . & 19 & 4 & 5 & $u$ & 13 & 1 & 7 & 3 & 11 & 3 & 4 & $"$ & 18 & 5 & 4 & 3 & 5 & 3 & 7 & $"$ \\
\hline Juin. . . . . . . . . . & 17 & 3 & 5 & $"$ & 14 & 5 & 13 & 1 & 2 & 6 & 11 & 1 & 9 & 3 & 9 & 1 & 14 & 2 & 6 & $u$ \\
\hline Juillet . . . . . . . . & 34 & 3 & 4 & $"$ & 18 & 6 & 16 & $\because$ & 7 & 4 & 8 & $"$ & 18 & 3 & 6 & $"$ & 13 & 2 & 6 & $"$ \\
\hline Août. . . . . . . . . & 87 & $" 1$ & 12 & 1 & 9 & 3 & 7 & 1 & 10 & 2 & 10 & 4 & 5 & 5 & 9 & $"$ & 19 & 1 & 3 & $" 1$ \\
\hline Septembre........ & 15 & 1 & 4 & 1 & 13 & 5 & 9 & $"$ & 13 & 3 & 6 & $"$ & 10 & 1 & 10 & $"$ & 7 & 1 & 7 & $n$ \\
\hline Octobre.......... & 17 & 1 & 4 & $\|$ & 5 & 3 & 5 & $"$ & 7 & 1 & 6 & $"$ & 10 & 1 & 1 & $"$ & 7 & $n$ & 2 & $"$ \\
\hline Novembre.......... & $u$ & $"$ & $" 1$ & $"$ & 2 & 2 & $" \prime$ & $\|$ & 6 & $" 1$ & 1 & $"$ & $"$ & $"$ & $n$ & 1 & 1 & $"$ & $"$ & 1 \\
\hline Décembre.......... & 2 & $"$ & $"$ & 2 & 5 & $\|$ &.$n$ & $"$ & 3 & $"$ & 1 & $"$ & 1 & $"$ & $"$ & 6 & 2 & 2 & 1 & 2 \\
\hline Année entière... & 140 & 18 & 40 & 13 & $9^{5}$ & 30 & 66 & 8 & 82 & 25 & 58 & 8 & 97 & 28 & 41 & 11 & 68 & 12 & 40 & 17 \\
\hline
\end{tabular}

Les orages qui viennent éclater au-dessus de Guatemala, deux ou trois heures 
DANS LES RÉPLBLIQLES DE GUATEMILI ET DE SILADOR. 171

avant le coucher du soleil, commencent généralement de la manière suivante : le ciel élant resté parfaitement clair jusque vers midi ou deux lieures, on voit de petites vapeurs blanches se suspendre aux sommets des hiutes montagnes qui s'élèvent an sud el au sud-ouest de la ville, telles que les volcans de Fucgo, d'Agua ou de Pacaya. Une fois formés, ces nnagges rudimentaires grossissent rapidement par la précipitation des vapeurs qui les entourent et devienuent peu à pen d'épais cumulus blanchâtres, qui roulent dans tous les sens autour des montagyes et finissent par les cuvelopper complétement. En nıême temps, leur for'une et leur couleur se modifient, et ils passent à l'état de cumulo-stratus et de slralus grisittres ou même presque noirs, qui remplissent les vallées el s'arancent progressivement, poussés par les courants du sud-ouest qui sont alors dominants dans les régóions supérieures de l'almosphère. Le vent du sud-ouest, qui coïncide presque loujours avec la formation des orages, alteint souvent les couches inférieures de l'atmosphère el sonfflle alor's avec une extrême violence; on peut voir, en effet, dans là liste des tempêtes que nous avons unie ì dessein au tableau nº 8 , que les ouragans sont relativement beancoup plus abondants dans les mois auxquels apparliennent les orages les plus fréquents.

Liélectricité des nuages élant due surtout à l'évaporation, qui amène dans les régions élevées de lalmosphère les vapeurs puisées à la surface de la lerre par les rayons du soleil, el cetle évaporation ayant lieu à toutes les épóques de l'année, quoique avec des degrés d'iulensilé très-différents, on ne sera pas surpris de voir que, même pendant la saison sèche, les nuages qui parcourent quelquefois to ciel sont chargés d'une certaine quantité d'électricité susceptible de manifester s:t présence par des éclairs. Mais ces éclairs sont presque toujours dus à des orages atmosphériques, si l’on use s'exprimer aimsi, à des déchargóes de nuage à nuage, car ils ne sont pas toujours accompagués par le tonnerre, et il est excessivement rare, comme on peut le voir au tablean $n^{\circ} 8$, que la foudre tombe à Guatemala pendant les mois d'hiver.

Pendant la saison des pluies, la terre elle-même est électrisće; les oragoes deviennent presque journaliers, ils sont toujours caractérisés par des éclairs en rig̈zagg réminsant les nuagges au sol, accompagnés d'épouivautables éclats de lomnerre scmblables à un déchirement général, el il n’est pas rare que los édifices de Guit- 
temala soient frappés par la foudre, qui y produit quelquefois des désordres considérables. On pourrail, d'ailleurs, citer des excmples mallicureusement trop fréquents de personnes foudroyées, soil dans les villes, soit dans les campagnes, et il nous souvient fort bien d'un effrayant orage pendant lequel trois ouvriers indiens furent tués par la foudre dans une hacienda des environs de Coban (haute Vera Paz). Nous-mème, nous avons vu l'éclair frapper des rochers on des arbres à quelques pas de nous, soit au sommet da volcan d'Atillan, soil daus les monlagnes de Totonikapam, el nous pouvons nous estimer henreux d'en avoir été quilte à ce prix.

La grèle accompagne quelquefois les orages ì Guatemala, mais, comme nous n'avons jamais été témoin nous-mème de ce phénomène, nous ne pouvons rien dire des condilions dans lesquelles il se produit, non plus que de la grosseur el de la lorme des grèlons. Nous arons dù réunir, au tableau no 4 (p. 148), la liste des chntes de grèle à Guatemala, parce qu'elles ont leur signification pour la quanlité d'eau tolale; ọ y voit que, quoique assez rares, clles peuvent aller néanmoins jusqu'au nombre de trois par an (1861), el qu'il y en a eu en janvier, mars, avril, mai, juin et octobre, pendant les cinq années dont nous possédons les tistes d'observations. Il est probable que la formalion de la grêle exige la combinaison d'une température assez basse el d'un état ćlectrique assez intense, ce qui expliquerait pourquoi elle a lien surtout entre les mois de mars el de juin, c'est-ìdire à l'époque de transition entre la saison sèche et la saison des pluies.

Retumbos.

Yous ne quilterons pas la question des phénomènes électriques sans dire un mot des retumbos ou bruits souterrains qui se produisent parfois dans certaines montagnes couvertes d'une épaisse végétation, et qui agoissent vivement sur l'imagination des indigènes. Lorsqu'on a entendu des retumbos dans ume montagne, on s'empresse de dire que c'est un volcan, et pourtant nous avons eu occasion de constatẹ plusieurs fois que ces prétendus volcans élaient des montagnes formées de couches sédimentaires parfaitement caractérisées, schistes, calcaires ou autres. Il faut remarquer que les retumbos, dont le bruil, quoique un peu plus sourd, ressemble singulièrement à celui du tomerre, ne se produisent que lorsque la montagne est entourće d'épaisses nuées qui l'envcloppent entièrement et peuvent y déterminer des actions électriques. Il n'est pas extraordinaire qu'un peuple 
DANS LES REPUBLIOLES DE GUA'TEMALA ET DE SALVADOR. 173 habilué à vivre au milien des volcans et à y entendre des détonations soulerraines se soil empressé de chercher dans cel ordre d'idées la cause des retumbos, et à les attribuer à des phénomènes volcaniques; mais cette explication est en désaccord complet avec les faits góólogiques observés, et ne peul plus suflire aussilôt que l'on vent approfondir et sonder scientifiquement les choses. Il est fort probable que c'est à l'électricité, dont les effets sont si intenses dans ces régions. que l'on devra altribuer le rôle principal dans la produclion des retumbos lor'squn l'on voudra établir une théorie rationnelle de ces phénomènes.

Nous n'avons pas eu occasion d'éludier les choses assez longtemps et avec asse\% de soin par nous-mème pour pouvoir donner une explication en conuaissance de cause; mais nous avons pu recueillir les avis de quelques hommes intelligents et liabitués aux recherches précises qui ont vécu longtemps dans te pays. L'opinion de ces personnes est que les retumbos ne se manifestent que lorsqu'une montague élant entièrennent baiguéc dans d'épais nuages clargés d'électricité, il peut sr produire des déchargeses, soit du sol aux nuages, soit entre différents points du sol lui-mène et des forèts qui le recouvrent. Quoi qu'il en soit, la question demeure assez obscmre, el c'est saus aucune preuve péremptoire que nous altribuons lorigine des relumbos à des mauifestations électriques.

Tous avons joint au tablean $11^{\circ} 8$ m registre des tremblements de terre pentdant les cinq anuées de 1859 à 1863 , quoique nous considérions les tremblements de terre comme dépendant directement de l'action volcanique el uullement de l'électricité ou du magnélisme terrestre. Mais il semble prouvé, d'un autre còté, que les tremblements de terre ont quelquefois une action directe sur les manifestations de ces derniers phénomènes, el l'on pourra plus aisément ainsi chercher entre les faits des rapprochements el des comparaisons.

Le magnćtisme terrestre est soumis, à Guatemala, aux mêmes lois que sur le reste du globe. Nous donnons dans le tableau suivant (tableau ${ }^{\circ}$ g) les observations recueillies, pendant cinq anuées conséculives, de 1859 à 1863 , sur les l'aiguille aimantée. oscillations diurues de l'aiguille aimantée el sur la variation angulaire ammuelle de la déclinaison. 


\begin{tabular}{|c|c|c|c|c|c|c|c|c|c|c|c|c|}
\hline \multirow{3}{*}{ WOIS DE LANNÉE. } & \multicolumn{6}{|c|}{1859} & \multicolumn{6}{|c|}{1860} \\
\hline & & MIATros dyur & & & 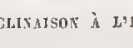 & & & R:MTLEX DITR & & & CLLASLSOS \& L'E & rst. \\
\hline & $\stackrel{\dot{\Xi}}{\dot{\Xi}}$ & 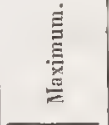 & 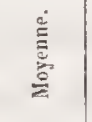 & 竧 & 玄 & : & 咅 & 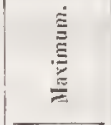 & 咅 & 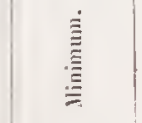 & 咅 & \\
\hline Janvier....................... & $2^{\prime} 11^{\prime \prime}$ & $8.53^{\prime \prime}$ & $5^{\prime} 06^{\prime \prime}$ & $7^{\circ} 11^{\prime} 20^{\prime \prime}$ & $7^{\circ} 21^{\prime} 00^{\prime \prime}$ & $7^{\circ} 15^{\prime} 28^{\prime \prime}$ & $3^{\prime} \circ 6^{\prime \prime}$ & $534^{\prime \prime}$ & $5337^{\prime \prime}$ & $\left|7^{\circ} 04^{\prime} 29^{\prime \prime}\right|$ & $7^{\circ} 14^{\prime} 0 g^{\prime \prime}$ & $7^{\circ} 09$ \\
\hline 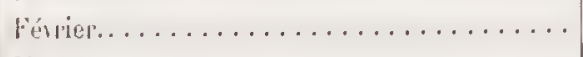 & 047 & 509 & 333 & 71111 & 71802 & 71459 & 115 & 728 & 414 & 70352 & 71350 & $709^{33}$ \\
\hline 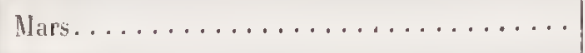 & 211 & 651 & 416 & 71014 & 71830 & 71425 & 105 & 632 & 333 & 70352 & 71233 & 709 \\
\hline Avril $\ldots \ldots \ldots \ldots \ldots \ldots \ldots \ldots \ldots$ & 258 & 844 & 537 & 71006 & 71908 & 714.35 & 11 & 806 & 436 & 70490 & 71235 & 70.092 \\
\hline Mai . . . . . . . . . . . & 230 & 1131 & 527 & 71006 & 79246 & 71442 & 125 & 824 & $5: 4$ & 70.352 & 71.331 & $7093^{2}$ \\
\hline Juin........................ & 39 & $9^{3} 9$ & 519 & 70851 & 71849 & 71424 & 248 & 902 & 539 & 703.33 & 71331 & 707 \\
\hline Juillet . . . . . . . . . . . . & 211 & 921 & 524 & 70851 & 71908 & $71 / 26$ & 230 & 2847 & 654 & 64350 & 71351 & $7 u^{\left(i^{10}\right.}$ \\
\hline Aoút.................... & 258 & 1707 & 726 & 70640 & 72521 & 71412 & 422 & 1303 & 803 & 64359 & $658 \quad 16$ & 6501 \\
\hline 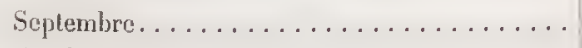 & 211 & 1841 & 659 & 70736 & 72847 & 73406 & $24_{7}$ & 1129 & 608 & (i) 4541 & (65) 20 & \\
\hline Oclobre..................... & 124 & 958 & 414 & $7 \circ \lg _{2} 8$ & 7394 & 71407 & 028 & 633 & $35 i$ & 64609 & $6531 !$ & $650^{10}$ \\
\hline Novembre. . . . & 058 & 546 & $25 / 1$ & 71050 & 71638 & 71348 & 1114 & 507 & 319 & $616 \cdot 28$ & $\begin{array}{llll}6 & 53 & 10\end{array}$ & $650 \%$ \\
\hline Décembre $\ldots \ldots \ldots \ldots \ldots \ldots \ldots \ldots$ & 220 & 55 & 359 & 70535 & 71725 & 70956 & 138 & 1150 & 301 & 61705 & 65301 & (i) 49 \\
\hline Année entière......... & $0^{\prime} 47^{\prime \prime}$ & $18^{\prime} 41^{\prime \prime}$ & $55^{\prime \prime}$ & $7^{\circ} 05^{\prime} 35^{\prime \prime}$ & $7^{\circ}=8^{\prime} 47^{\prime \prime}$ & $7^{\circ} 14^{\prime} 06^{\prime \prime}$ & $0^{\prime} 28^{\prime \prime}$ & $28^{\prime} 47^{\prime \prime}$ & $4^{\prime} 57^{\prime \prime}$ & $66^{\circ} 43^{\prime} 50^{\prime \prime} \mid$ & $7^{\circ} 11^{\prime} 09^{\prime \prime}$ & \\
\hline
\end{tabular}

Ce Iableau en dil assez par lui-mème pour que nous ne disculions que trèsbrièvement des particularités fort intéressantes, sans doute, mais dont les explications ne sont pas encore connues avec assez de précision pour que nous puissions nous étendre longuement sur ce sujet. En ee qui concerne les variations diurnes, on verra qu'elles sont beaucoup plus prononcées pendant l'élé que pendant l'hiver, ce qui est parfaitement d'accord avec ce que l'on a observé en Europe; il eu est de mème pour le chiffre relativement faible qui représente l'intensilé moyenne mensuelle de ces variations diurnes (en moyenne générale trois ou (quatre minutes de degré), car on sail qu'elles diminuent proggressivement depuis le pôle jusqu’à l'équateur. Mais on remarquera les diflérences énormes qui existent entre les intensités maxima et mimima observées en deux journées du même mois, et qui sont dues probablement à l'adjonction d'oscillations accidentelles dont les causes nons échappent; on sera pent-être surpris ansṣi de voip 
D) AS LES REPUBLIQUES DE GUATEMILA ET DE SILVADOR. 175

WMITEE A GUATEMALA, MOIS PAR MOIS,

STINTES :

\begin{tabular}{|c|c|c|c|c|c|c|c|c|c|c|c|c|c|c|c|c|c|}
\hline \multicolumn{6}{|c|}{1861.} & \multicolumn{6}{|c|}{1862.} & \multicolumn{6}{|c|}{1863.} \\
\hline \multicolumn{3}{|c|}{ Pinjation dierve. } & \multicolumn{3}{|c|}{ DŔGLLIMAISON ¿̀ L'BST. } & \multicolumn{3}{|c|}{ VARLATLON DIURXE. } & \multicolumn{3}{|c|}{ DÉCLINAISQN A Z'BST. } & \multicolumn{3}{|c|}{ TARAATION DIURNE. } & \multicolumn{3}{|c|}{ DËCINYALOK $\lambda$ LיEST. } \\
\hline 棓 & $\stackrel{\bar{E}}{E}$ & & 音 & . & 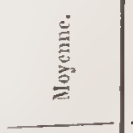 & 竞 & & & $\begin{array}{l}\bar{E} \\
\underline{\underline{\underline{E}}} \\
\underline{\underline{E}}\end{array}$ & & $\begin{array}{l}\stackrel{\varrho}{E} \\
\stackrel{\bar{E}}{\Xi}\end{array}$ & 音 & 章 & & $\stackrel{\bar{\Xi}}{\stackrel{\Xi}{\Xi}}$ & E & 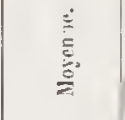 \\
\hline $1^{\prime}{ }_{1 / 1^{\prime \prime}}$ & $9^{\prime} 11^{\prime \prime}$ & $3^{\prime} 33^{\prime \prime}$ & $6^{\circ} 46^{\prime} 0 g^{\prime \prime}$ & $6^{\circ} 56^{\prime} 35^{\prime \prime}$ & $6^{\circ} \mathrm{Jo}^{\prime} 13^{\prime \prime}$ & $1^{\prime} 34^{\prime \prime}$ & $6^{\prime}{ }_{1} 4^{\prime \prime}$ & $408^{\prime \prime}$ & $6^{\circ} 45^{\prime} 32^{\prime \prime}$ & $6^{\circ} 52^{\prime} 42^{\prime \prime}$ & $6^{\circ} 18^{\prime} 19^{\prime \prime}$ & $0^{\prime}+8^{\prime \prime}$ & $3^{\prime \prime} 15^{\prime \prime}$ & $2^{\prime} 02^{\prime \prime}$ & $6^{3} 43^{\prime} 02^{\prime \prime}$ & $6^{\circ} / 18^{\prime} / 11^{\prime \prime}$ & $6^{\circ} 45^{1} 39^{\prime \prime}$ \\
\hline 238 & $6+4$ & 351 & 64647 & 65415 & 65022 & 114 & 441 & 237 & 64551 & 65223 & 64827 & 618 & 308 & 128 & 64320 & 64803 & 64545 \\
\hline $1 \%$ & $7 \begin{array}{lll}7 & 10\end{array}$ & 413 & 64532 & $65 \% 145$ & 64950 & 126 & 440 & .311 & 64513 & 65051 & (6) 1802 & $\begin{array}{lll}0 & 19\end{array}$ & 520 & 201 & 64243 & $648 \times 1$ & 61538 \\
\hline $\begin{array}{r}52 \\
398\end{array}$ & 845 & 542 & $64 / 16$ & $65 \% / 615$ & 64919 & 057 & 615 & 339 & 64302 & 65109 & 64833 & 019 & 617 & 2 33 & 64224 & (i 19.37 & 64.534 \\
\hline 23 & 747 & 425 & 64513 & 6.5424 & 64938 & 135 & 721 & 353 & 64416 & 65146 & 64821 & - 39 & 459 & 241 & 64148 & 64803 & 64421 \\
\hline${ }^{4} 9$ & 6,4 & 441 & $64.53 \%$ & 65357 & 64927 & 211 & $8{ }_{3} 6$ & 1.88 & 64320 & 65205 & $6170^{3}$ & o 34 & $6: 7$ & 25.5 & $6 \lcm{1148}$ & 64841 & 6416.5 \\
\hline $\begin{array}{ll}21 \\
94\end{array}$ & 728 & 448 & 64513 & 65357 & 61918 & 153 & 739 & 443 & 64111 & $65.51: 7$ & 64704 & 035 & 554 & 345 & 64014 & 64705 & (i) 4344 \\
\hline 40 & 939 & $6 \geq 2$ & 6) 4436 & 65548 & 61927 & 211 & 854 & 510 & 64243 & $653 \times 3$ & 64716 & 1331 & 615 & 336 & 611111 & $648=1$ & (5)449 \\
\hline $\begin{array}{l}31 \\
131\end{array}$ & 71,8 & 518 & 641459 & $65 / 144$ & 61927 & 115 & 748 & 440 & 64224 & 65137 & 64715 & 037 & 421 & 230 & 64448 & 64841 & 64521 \\
\hline 12.5 & 606 & 339 & 64551 & 65301 & 64904 & 114 & 635 & 250 & 64320 & 65013 & 64637 & 0 38 & 314 & 221 & 641129 & $62_{2} 3^{1 / 1}$ & 644.39 \\
\hline 150 & 518 & 306 & 64532 & 65233 & $6 / 1835$ & $\begin{array}{lll}0 & 09\end{array}$ & 328 & 129 & 64339 & 64937 & 64638 & 019 & 611 & 208 & 6.1206 & $65 \pm 46$ & 64506 \\
\hline 2 & 536 & $3 / 12$ & $6 / 4551$ & 65240 & $6 / 855$ & $\begin{array}{lll}0 & 19\end{array}$ & 500 & 205 & 63910 & 648.21 & 6450.8 & 018 & 601 & 221 & $6 / 1148$ & 64803 & 6 价 39 \\
\hline & $9^{\prime} \cdot 39^{n}$ & $4^{\prime} 27^{\prime \prime}$ & $6^{\circ} 44^{\prime} 16^{\prime \prime}$ & $6^{\circ} 56^{\prime} 35^{\prime \prime}$ & $6^{\circ} 49^{\prime} 28^{\prime \prime}$ & $0^{\prime} 09^{\prime \prime}$ & $854^{\prime \prime}$ & $3^{\prime} 14^{\prime \prime}$ & $6^{\circ} 39^{\prime} 10^{\prime \prime}$ & $6^{0} .122^{\prime} 12^{\prime \prime}$ & $6^{\circ} 47^{\prime} 27^{\prime \prime}$ & $0^{\prime} 18^{\prime \prime}$ & $6^{\prime}: 7^{\prime \prime}$ & $" 30 "$ & $6 " 10^{\prime} 1 h^{\prime \prime}$ & $6^{0 .} .71^{\prime} 466^{\prime \prime}$ & $6^{\circ} 14^{\prime} 59^{\prime \prime}$ \\
\hline
\end{tabular}

les oscillations diumes devenir plus faibles d'année en annéc, lout en conservant leurs variations correspondantes aux saisons, de telle laçon que la moyenne des intensités étant do $5^{\prime} 1^{\prime \prime}, 2$ en 1859 , elle n'est plus que de $2^{\prime} 30^{\prime \prime}$ en 186.3 . après avoir passé par une série d'intermédiaires proportiomels.

La variation angulaire annuelle de la déclinaison reste indépendante do ces variatun angulaire perturbations journalières, et suit sa marche régoulière, quoicue avec une rapi- to annnellé dité un peu plus considérabłe qu'elle ne le fail en Europe. Ninsi la déclinaison moyeune de 1859 élant de $7^{\circ} 14^{\prime} 5^{\prime \prime}, 7$ à l'est, celle de 1863 n’est plus que do $6^{\circ} 44^{\prime} 59^{\prime \prime}$ à l'est, ce qui correspond à un déplacement moyen de $7^{\prime} 32^{\prime \prime}$ par an. largement dépassé en 1860 el 1861 , tandis qu’il a été nolablement plus faible. en 1862 el 1863 . Pent-être y a-t-il une relation entre le décroissement des variations diurnes et la diminution de la déclinaison, mais te sujet est trop délicarl pour que nous nous permettions de l'aborler. 



\title{
LIVRE III.
}

\author{
GÉOLOGIE GÉNÉRALE.
}

Au point de vue des études géologiques, l’Amérique centrale est encore presque absolument inconnue. Les voyageurs qui l'ont parcourue en divers sens ne se sont presque jamais occupés de ce genre de reclierches, el c'est à peine s’ils nous ont donné quelques renseiguements épars, quelques observations isolées qui ne constituent, à l'heure qu'il est, qu'un bagago scientifique de bien médiocre importance. Les savants qui ont visité le Salvador et le Guatemala y ont ćté amenés par l'attrait des travaux archéologiques dont ces régoions presque vierges encore oflrent une mine féconde; des ingénieurs se sont livrés à d'intéressantes recherches sur la possibilité de créer, ici un canal interocéanique, là un chemin de fer reliant les porls assis sur les deux mers; des voyageurs diplomatiques se sont occupés avec ardeur de slatistique et de colonisation; des géographes sont venus clıercher des éléments de cartes souvent fort remarquables; et l'ensemble de ces études a déjì produit une bibliographice aussi riche en aperçus nouveaux qu'en documents précieux. Mais, il faut l'avouer, le sol lui-même, envisagé au point de vue de sa conslitution intime, des variétés de roches qui le composent, des origines de son relief actuel, a, le plus souvent, été relégué au second plan, et c'est à peine si l'on pourrait se faire une vague idée de la nature géologique de ces régions en extrayant à grand'peine, de tous les ouvrages spéciaux publiés jusqu’à ce jour, les quelques lignes qui sont consacrées de loin en loin à des observations de ce genre. Ce n'est pas à dire pourtant que les renseignements fassent absolument défaut, car il ne manque pas d'ouvrages, comme le tivre de M. Squicrs, inlitulé, The Stales of central America, comme le Voyage dans l'Amérique centrale, de M. Morelet, ou les travaux de M. l'abbé Brasseur de Bourbourg, qui en donnent et de nombreux; 
mais ils sont vagues, mal coordonnés, sans dépendance intime entre eux, et cela seul suffit pour leur ôter une grande partie de leur valeur.

Lorsqu'on songe à ce qu'il a fallu de temps el de travaux pour arriver à la connaissance, même élémentaire, de la constitution dn sol d'un pays facile à parcourir, civilisé et fécond en ressources comme le nôtre; lorsqu'on songe à tous les hommes studieux et énergiques qui ont accumulé leurs recherches depuis près d'un siècle pour arriver à un résultat, la carte géologique de France, qui n'a pas encore atteint la perfection, quoique ce soit un des plus beaux monuments de la science moderne; lorsqu'on songe aux eflrayantes difficultés qui naissent, à chaque pas, dans un pays presque vierge encore pour l'observation, à peine peuplé par des races à demi sauvages, hérissé de montagnes giọantesques, coupé de torrents fouggueux, couvert de forèts impénétrables, on ne peut espérer que le voile soit déchiré de bien longtemps encore. Aussi sommes-nous bien éloig̣nés de vouloir faire attribuer à nos recherches plus de valeur qu'elles n'en peuvent avoir, en insistant sur ce que les voyageurs qui nous ont précédé ne nous ont que rarement préparé la voic, et sur ce que les habitants du pays eux-mêmes ne songent guère, en général, à s'occuper de spéculations scientifiques; si nous parlons ainsi, c'est, tout au contraire, pour en faire excuser la médiocrité, car on doil pardonner beaucoup aux premiers pas tentés dans un chemin qui ne fut encore jamais frayé.

Il y aurail une singulière présomption à vouloir donner une descriplion géologique générale des pays que nous avons visités, après n’y avoir séjourné qu'une année à peine et les avoir parcourus forcément avec une grande rapidité. La généralisation est un instrument dangereux quand il n'est pas manié par un génie de premier ordre, par un Humboldt par exemple; elle entraîne facilement à des erreurs, et, préoccupé de la pensée de poursuivre une théorie souvent préconçue, on se laisse facilement aller à accréditer des idées fausses. On ne peut aflirmer que ce qu'on a vu, étant admis encore que l'on est certain d'avoir bien vu, et, sur tout le reste, on ne peut avoir que des présomptions, jamais de certitudes.

Ces considérations nous ont conduit à éviter, pour la partie géologique de cet ouvrage, une forme dogmatique, el, par conséquent, empreinte d'une tendance généralisalrice, pour adopler une liggne de conduite plus sage et plus logique, quoique forcément moins brillante. Quitte à sacrifier un peu de l'intérèl qui pourrait s'atta- 
DANS LES RÉPUBLIQUES DE GUATEMALA ET DE SALVADOR. 179 cher à de belles théories plus ou moins bien fondées, nous nous astreindrons, dans un premier chapitre, à suivre pas à pas nos ilinéraires, reprenant ume à une nos observations, relevant tout ce que nous avons vu. Ce sera peut-ètre un peu aride, mais au moins ce sera vrai. Après avoir ainsi accumulé des faits et avoir posé des bases solides, nous essayerons, dans un second chapitre, de grouper entre elles les observations, de chercher les liaisons qui peuvent exister entre les choses, et d’en déduire peut-être quelques idées plus ou moins générales.

Nous partagerons nos itinéraires en quatre séries, ce qui aura l'avanlage de rompre un peu l'uniformité el de se rapporter plus commodément aux profils géotogiques donnés dans les planches VI et Vll.

Nous marcherons d'abord parallèlement à l'allongement du continent centroaméricain, à travers les républiques de Salvador et de Guatemala; puis transversalement à ce mème continent, du Pacifique jusque près de l'Atlanlique; enfin nous ferons deux voyages dans les provinces de la Vera l'az et des Altos.

Une fois cela accompli, nous déduirons quelques réflexions de l'ensemble des faits exposés dans la partie précédente. 


\section{CHAPITRE PREMIER.}

ITINÉRAIRES GÉOLOGIQUES.

Voyage de la Union (Salvador) à Guatemala. - Voyage de San José de Guatemala au Rio Grande. Voyage dans la province de Vera Paz. - Voyage dans la province des Altos. - Renseignements sur le département de Chiquimula.

\section{VOYAGE DE LA UNION (SALVADOR) I GUATEMALA}

Nous suivrons dans ce voyage une direction à pen près parallèle à celle de la côte du Pacifique, mais à une certaine distance dans l'intérieur des terres, parcourant à peu près dans tout son allongement, mais en le recoupant plusieurs fois, l'axe anticlinal secondaire qui traverse le Salvador pour aller rejoindre, dans le Guatemala, la ligne de faite principale. La chaîne secondaire du Salvador coüncide presque exactement, dans la majeure partie de son étendue, avec la direction d'une fissure volcanique, jałonnée par des cònes assez considérables, dont quelques-uns sont encore en éruption. Les déjections anciennes ou récentes des volcans ont souvent recouvert les autres formations, qui elles-mêmes ne sont pas extrèmement variées, puisqu'on suit la direction d'une mème chaine; aussi n'aurons-nous à considérer qu'un groupe de roches assez restreint, en nous occupant surtout de la manière dont la disposition orographique du pays a influé sur leur répartition.

Iles de la baie de

Fonseca. Formation basalrique.
Après avoir pris terre à La Union, nous avons commencé par visiter quelquesunes des îles qui se groupent dans le golfe de Fonseca, celle immense et profonde échancrure où pénètrent les eaux de l'océan Pacifique. Parmi les principales, il faul citer l'Isla del Tigre, l'Isla de Zacate Grande, l'Isla de Mianguera, l'Isla de Conchaguita et l'Isla de Punla Zacate. Il y a, en outre, un très-grand nombre d'îlots dont les plus considérables sont ceux d'Espocecion et de Violin.

Presque toutes ces îles ont une tendance à affecter une forme à peu près circu- 
DANS LES RÉPUBLIQUES DE GUATEMALA ET DE SALVADOR. 181 laire, qui s'accuse surtout dans l'Isla del Tigre. Cependant l'Isla de Punta Zacate est très-déchiquetée, et l'îlot d'Espocecion offre à peu près la disposilion d'un croissant. Les grandes îles peuvent avoir, en moyenne, de 6 à 9 licues de tour, et ont 400 à 800 mètres de hauteur; elles s'élèvent assez brusquement de la mer en présentant des falaises lavées par la vague, où la roche est aisément visible à nu. Cette roche présente, d'ailleurs, des caractères tels, qu'il est difficile de la définir nettement; souvent c'est un vérilable trapp basaltique; d'autres lois clle présente un cachet semi-volcauique très-remarquable. Les falaises de l'lsla d'Espocecion montrent d'immenses parois verticales et de gigantesques blocs accumulés, composés d'une roche très-compacte, noiràtre ou brune, auxquels l'action des eaux de la mer donne un singulier poli.

A la base de l'Isla del Tigre, on voit comme une immense coulée qui viendrait se précipiter dans les flots de la mer; clle se compose d'une roche absoluRoches basaltique: at volcaniques. ment noire, très-compacte dans les couches inférieures, mais présenlant un aspecl singưulièrement scorifié à la surface. Dans l'intérieur de l'île, on rencontre de gros blocs d'une roche noirâtre ou brun foncé, quelquefois un peu celluleuse. qui a certains caractères des trapps basaltiques. D'antres morccaux sont toul mouchetés de petits points blancs dans lesquels il faut voir des restes informes de cristaux de feldspith disséminés dans la pàte, et font penser à des tracliyles porpliyriques pnissamment altérés. Au sommet du cône qui constitue l'Isla del Tigore. on trouve enfin des blocs plus ou moins volumineux, blancs ou rougedtres, quelquefois mouclietés de points blancs, souvent bulleux ou mème tout ì fiit scorifiés. Les populations indigènes considèrent l'Isla del Tigre comme un volcan éteint; il est certain que sa forme caractéristique peut corroborer celte opinion, mais il faut reconnaître que, si c'en est un en réalité, il doit remonter ì une époque fort ancienne et où les manifestations ne revètaient pas des caractères identiques à ceux qu'elles présentent aujourd'hui dans les volcans du voisinage. Nous aurons, d'ailleurs, à revenir sur ce sujet dans le chapitre spécialement consacré aux volcans.

A La Union même on trouve une roche qui ressemble beaucoup à celle des iles de la baie de Fonseca. Elle est plutôt brunâtre que noire, et, quoique plus compacte que celluleuse, elle rappelle toujours ces magmas indécis aussi voisins des trapps basaltiques que des trachytes porphyriques. La plagee ne montre la roche 
que dans certains endroits où elle est à pic; le plus souvent elle s"incline assez doucement et est recouverte d'un fin sable blanc, ou d'une boue vaseuse grisàtre, apportés l'un et l'autre par les rivières qui descendent de l'intérieur du pays.

Cenos de Conchagua. Roches liasaltiqques.

Nous avons fait de La Union l'ascension d'um pàté montagneux, dit e Cerros de "Conchagua, qui domine immédiatement la ville au sud. Les roches du hord de la mer existent encore dans l'inlérieur des terres avec lous leurs caraclères; mais alles n'apparaissent que sur les bords des ravins ou dans les endroils dénudés, et sont recouverles parlout ailleur's d'une couche plus ou moins épaisse d'argile jaune on rougeàtre. Ces argiles, dues probablement à la décomposition des matières sous-jacentes, sont évidemment colorées par de l'oxyde de fer en proportion variable; elles deviennent liantes sous l'action de l'eau, el conslituent le plus souvent de véritables golaises. A parlir du villagge de Conchagua, les pentes s'accusent de plus en plus, et la roche se montre presque toujours, noire, compacte et mouchelée de petits points blancs.

Cerro de la Bandera. Roches scoriacées.

Des deux sommités dont se compose le massif montagneux, l'un, le Cerro de la Bandera (1,170 mètres), n'est qu'une pointe assez ardue formée uniquement de scories el de basaltes scorifiés passant par toules les teintes depuis les noirs jusqu'aux rouges par les bruns. Les basaltes scorifiés présentent souvent un aspect de surfusion et ressemblent alors à des laves; les scories rouges sont souvent légères el bulleuses, mais toujours mouchetées de points blancs. Malgrré ces particularités dans la nature de la roche, il est assez difficile de s'associer complétement à l'opinion des habitants du pays, qui cousidèrent le Cerro de Conchagua comme un volcan éteint, car la montagne dont. nous venons de parler, quoique d'apparence à peu près conique, n'est qu'un pic isolé et sans aucune trace de cratère ${ }^{(1)}$. Quoique l'autre sommité, le Cerro del Ocote (1,236 mètres), soit composée d'une roche beaucoup plus compacte et ne présentant que rarement des traces de scorification, la forme en est toute différente et ne permet pas d'affirmer avec autant de probabilité qu'il n'y ait pas là les rudiments d'un très-ancien volcan éteint, ayant presque complétement perdu ses caractères distinctifs. Le sommet ment aux volcans, le récit d'une éruption qui s'est produite à peu près à mi-hauteur du Cerro de la Bandera,

environ un an après notre voyage. Il est done certain que le Cerro de Conchagna est un volcan, et que l'opinion populaire devait prévaloir sur nos scrupules scientifiques. 
DANS LES RÉPUBLIQUES DE GUATEMALA ET DE SALVADOR. 183 de la montagne, au lieu de se terminer en pointe, se développe sous la forme d'un pelit platcau de 500 à 600 mètres de diamètre environ, environné de légères éminences rocheuses qui sont disposćes circulairement alentour, au nombre de cinq ou six, et le dominent d'une cinquantaine de mètres. La plaine, parfaitement horizontale, se compose d'argites jaunâtres, qui sont peut-être les dépôts d'une antique lagune forméc jadis dans un cratère étcint et progressivement comblé. Au milieu du plateau se trouve un enfoncement circulaire d'environ 100 mètres de diamètre, et dont la profondeur ne dépasse pas 5 à 6 mètres; il est rempli d'une végétation touffue, tandis que le reste de la plaine ne nourrit que quelques herbes. Les eaux s'y accumulent pendant la saison des pluies, s'infiltrent à travers la montagne, el se déversent peu à peu en alimentant les sources qui coulent toute l'année au pied du Cerro del Ocote, sans qu’il soit besoin, pour expliquer le fait, d'invoquer, comme le font les Indiens de Conchagua, l'existence d'une vaste et mystérieuse laggune souterraine dans le cour de la montagne. Quoi qu'il en soit, l'ensemble des Cerros de Conchagua forme un massif aussi intŕressant que difficile à bien comprendre, et il faut invoquer l'appui de quelque fail décisif, comme une éruption, pour pouvoir affirmer d'une manièrc péremptoire qu’il constilue réellement une sommité volcanique.

En partant de La Union pour s'enfoncer dans l'intéricur des terres, on marche pendant longtemps sur une formation analogue à celle que l'on voil au pied des montagnes de Conchagua. Le terrain est plutôt ondulé qu'accidenté, quoiqußil s'élève proggressivement jusqu' à atteindre 150 mètres à Los Almendros. La roche pscudo-basallique, compacte, altéréc, noire, mouchelée de points blancs, ne se montre quie dans les flanes de quelques pelits ravins. Le plus souvent elle est masquée par d'abondantes masses d'argiiles ocreuses, jaunes ou noiràtres, qui s'étendent sur le pays en adoucissant les inégalités du sol sous-jacent.

Mais bientôt tout disparait sous une nouvelle formation, qui s'est déposéc avec; une telle égalité, qu'elle a complétement nivelé te terrain et constitué une vaste plaine. Ce sont les déjections du volcan de San Miguel qui commencent à se moutrer à 8 kilomètres environ avant la ville du même nom et qui recouvrent au loin tous les environs dans un rayon assez étendu. Ces dépòts sc composent de couches alternantes de lapilli et de cendres très-fines, grisìtres ou d'un noir 
violacé; les lits de nuances différentes, d'une épaisseur très-faible, souvent de quelques centimètres tout au plus, se succèdent en nombre infini el inserivent en quelque sorle le registre des éruptions successives du volcan. La puissance de l'ensemble est considérable, car des ravins de 4 à 5 mètres de profondeur, formés par les eaux courantes de la saison des pluies, sont creusés tout entiers dans ces amas de déjections sans en atteindre la partie inférieure.

San Mignel. Sables volcaniques. Dépôts tufacés. sourees thrimales.

Source He La Gueva.

La ville de San Miguel (110 mètres) est construite au milieu de cetle plaine de cendres, à deux pas d'une immense coulée de lave qui, pendant l'éruption de 1844, vint s'arrèter près des faubourgogs après avoir jeté l'épouvante dans la cité, qu'elle menaçait d'une destruction complète. Près de la ville, au nord, on voil se développer, et sortir du linceul de dépòts volcaniques qui recouvre les régoions voisines, des masses de lufs calcaires blancs et jaunàtres, dus probablement aux concrélions accumulées des sources qui en jaillissent aujourd'lui encore, quoique avec une intensité et un degré de minéralisation bien moindres que ce qu’ils ont dù être jadis. Au sortir des faubourggs, on voit de vastes bassins alimentés par quatre ou cinq sources assez abondantes, donnant une eau claire et limpide, à une température de 28 ou 29 degorés, et dont les propriélés sont les mèmes que relles de la grande source de La Cueva, qui se trouve à environ 2 kilomètres plus loin dans la même direction.

La Cueva est une assez grande voûte naturelle creusée dans un pelit mameIon de luf, et d'où sort un courant assez puissant d'une eau parfaitement claire et limpide, qui ne présente ni odeur ni saveur caractéristiques. La température de l'eau s'est trouvée être de $28^{\circ}, 30$, celle de l'air étant de $26^{\circ}, 90$. Traitée par dilférents réactifs, cette eau a donné les résultats suivants :

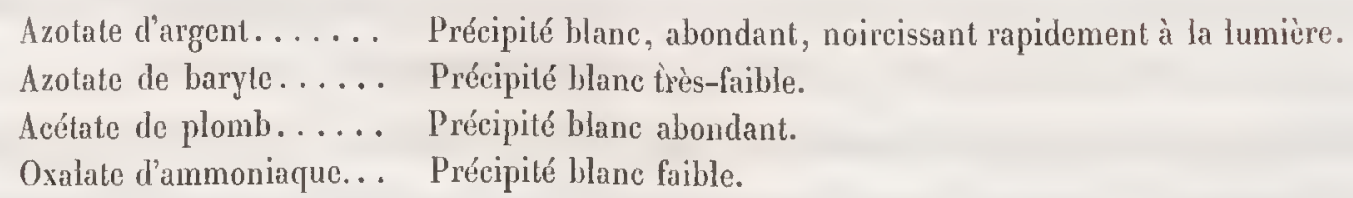

Elle est donc un peu calcaire el assez fortement alcalino-chlorurée. Il ne se produisail aucun dégagoment de gaz. Il est intéressant de faire observer que, maloré la température de celte eau et les substances salines qu'elle contient en assez grande abondance, il y vit un grand nombre de pelits poissons, non-seule- 
DANS LES RÉPUBLIQUES DE GUATEMALA ET DE SALVADOR. 185

ment dans te pelit ruisseau qui se forme à quelque distance, mais encore sous la voûle mème de La Cueva.

De San Mioguel nous arons rayonné dans diverses directions, el notre première excursion a élé entreprise en parliculier dans le but de faire l'ascension du magnifique volean qui domine la ville. Les délails de l'ascension elle-mème devant ètre donnés plus loin, qu'il nous suffise de dire que l'on traver'se d'abord, pendaut longhtemps, une plaine doucement inclinće, presque entièrement rccouverte de cendres volcaniques, el, en quelques points, de lufs jaunàtres. A mesure que les pentes s'accusent, les roches sous-jacentes, laves anciennes et trapps basalliques, se montrent par moments à travers les déjections cinćriformes et les argiles jaunes. On traverse ensuite deux branches de la grande coulće de lave de 1844, qui, se précipitant sur une pente fortenent inclincée, est recouverte, ì sa surface, d'une effravante accumulation de blocs noirs, scorifiés, bulleux, déchirés de toute façon, el entassés dans le plus pittoresque désordre; el l'on alteint enfin le pied du cône à la Casa de Chaves, à l'endroil où il se soude en quelque sorte par sa base au conmencement de la chaine de montagnes qui forme l'axe auliclinal dn Salvador.

Lne autre excursion nous a conduit aux mines de Los Eucuentros, situées à une trentaine de kilomètres au nord de San Miguel. Le chemin est assez ondulé et recoupe plusicurs fois le cours du Rio de San Miğuel, mais on ne s'élève en somme que fort peu, et Los Encuentros sont à quelques mètres au plus au-dessus de San Miguel. On commence par traverser, pendant six kilomètres environ, la région recouverte de lapilli, mais on voit néanmoins apparaitre de temps en temps, notamment dans le ravin profond que s'est crensé. le Rio près de la ville, des trapps basalliques noirs, bruns on rongeâtres, assez bulleux, mais pourlant trèscompactes. Ils se dógagent neltement pour former la première liģone de collines quil limilent la plaine, mais disparaissent bientôt après pour faire place ì des tratchyles porphyriques qui sortent de dessous eux el qui doivent conslituer la conche inférieure du pays, car on les trouve rolevés au sommel du volcan de San Miguel. Ces roches, mal délinies encore dans cette partic du Salvador, doivent probablement devenir plus netles dans les régions de l'intérieur, où elles semblent prendre un développement considérable, et il ne serait pas étomnanl qu'elles fussent en 
relation avec les porphyres du Honduras, où se trouvent les beaux filons d'opale d'Intibuca (département de Gracias). Près de Los Encuentros les trachyles porphyriques sont généralement très-compactes, un peu altérés et désagrégése à la surface, ì texture très-emmèléc, sans cristaux bien définis, mais à mouches blanches sans forme caractéristique noyées dans une pàte brune, violacéc ou verdàtre. Audessus de ces roches on voit, en phrsieur's points, des masses blanchâtres à texture désagrégée qui onl une certaine ressemblance avec les tuls des plateaux du Mexique. Ces mèmes dépòts alteigrnent, près des mines de Tabanco, jusqu’ì 15 mètres de puissance (M. Lachat), et présentent une texture dure el compacte englobant des cristaux assez nets de feldspath. Leur liaison intime avec les conglomérats porphyriques, auxquels ils passent insensiblement, comme à San Antonio par exemple, fait penser qu'ils ne doivent ètre que des masses superficielles formées par la destruction lente des porplıyres, atlaqués peut-être par des caux minérales. II se présente néanmoins un fait singulier el qui complique la question, c'est qu'à Lus Encuentros aussi bien qu’à Tabanco, ces roches sont traversées par les filons mélallifères qui se développent dans les porphyres trachytiques sous-jacents.

Les filons sont presque toujours dirigés du nord-ouest au sud-est (ils varient du nord 36 degrés ouest au nord 72 degrés ouest), et présentent une inclinaison variable. Elle est, en inoyenne, de 28 degrés à Los Encuentros, mais, à Tabanco, elle alleint jusqu’à 75 degrés el mème davantage. La gangue est toujours du quartz; plus il est compacte et tend à devenir hyalin, moins le filon est riche; souvent mème ce sont des masses quartzeuses, grrenues, sans aucune trace apparente de minerai, qui donnent les meilleurs résultats; tel est le filon de Virginia à Los Encuentros. A Tabanco, le minerai est répandu dans tout le filon; à Los Encuentros, au contraire, on a affaire à des espèces de clous riches, qui ne dépassent pas 40 mètres dans la direction du filon, mais qui sont indéfinis en profondeur, et qui se répartissent à des intervalles indéterminés.

Les mincrais sont de deux classes : on nomme metales les sulfures d'argent riches qui dépassent une teneur de 5 millièmes el qui sont envoyés en Europe ponı' ètre trailés, après enrichissement par préparation mécanique sur place. Sous le non de broza, on réunil les minerais pauvres d'une tencur moyenne de 2 millièmes, composés de sulfures d'argent, souvent peu ou point apparents à l'œil 
DANS LES RÉPUBLIQUES DE GUATEMALA ET DE SALVAOR. 187 nu, et de chloro-bromo-iodures d'argent (plata noble), qui sont assez abondants. Les brozas sont trailées sur place, aux nsines de Los Encuentros et de Tabanco, par la méthorle des barils. Tous ces ninerais contiennent une certaine proportion d'or, soit en moyenne 30 grammes par kilogramme d'argent fin, et l'ou a remarqué que l'or est surtout abondant dans les matières qui proviennent du voisinagre de l'affleurement des filons. Des faits analogues ont, d'ailleurs, été déjà observés plusieurs fois au Mexique. Par la distillation de l'amalgame, on obtient un argent brut qui, à Los Encuentros, contient $9^{\circ}$ p. o/o d'argent fin, mais seulement 55 p. o/o à Tabanco, où il y a une forte proportion de cuivre et de plomb.

On a recomnu, à Los Encuentros, cinq ou six filons principaux plus ou moins riches el un beau filon de calcaire cristallin de 3 ou 4 mètres de puissance, exploité pour la fabrication de la chaux. Les filons de Tabanco sont à peu près du mène genre que ceux de Los Encuentros el se trouvent dans des conditions géologriques sensiblement identiques. Dans les deux localités, on a observé des sources thermales calcaires et alcalines, en connexion avec le système des filons et siluées dans le prolongement de l'un d'eux. A Los Encuentros, la tempéralure d'une de ces sources s'est trouvée de 36 degrrés.

Si l'on part de San Migguel par la route qui mène à la capitale, on marche vers le nord-ouest en longeant d'abord pendant quelque temps la grande coulée de lave de 1844 , puis en traversant jusqu’à Moncaggrna une vaste plaine où les dépòts cinériformes et les lapilli rejetés par le volcan sont accumulés, sur nme épaisseur qui dépasse 4 ou 5 mètres, en lits minces el alternants de couleur orisìtre et violacée. Après Moncagua, on s'élève progressivement pour rejoindre un chainon transversal qui diverge de la ligne secondaire du Salvador. Le sol, de plus en plus accidenté, se compose le plus sonvent d'argiles jaunàtres recouvrant des roches porphyroïdes, qui ne se dégagent netlement que dans la partie la plus élevée de l'arête montagneuse. De l'autre colé se trouve la pelite ville de Chinameca, non toin d'un volcan éteint dont la cime peu élevée se perd au milieu des autres sommités qui l'entourent. Au pied de la montagne, dans le fond d'un ravin et sur le flanc d'une côte, se trouvent des dégagements de gaz extrêmement remar-

1). San Miguel à Chinameca. Sahles volcaniques. lioches porplyyriques. Argiles jaunes. quables, qui ont recu les noms de Ervedor et de Boqueron; ils traversent, en les 
transformant en une masse argilo-sableuse de couleur grisàtre, les roches porphyroïles noiràtres dont se compose le sol. Ces phénomènes se ratlachent trop directement à l'action volcanique pour que nous ne reportions pas leur description détaillée an livre suivant.

De Clinameca au Rio Lempa. Dépoits superficiels.

)u Rio Lempia

i San Vicente. Roches. porpliyroildes.

'Tisate.

A partir de Chinameca (206 mòtres), longeant à distance les montaggnes qui renferment plusieurs cònes volcaniques éteints, entre autres celui de Tocapa, ou franchil une série d'ondulations plus ou moins accusées, dans lesquelles des amas puissants el alternant d'une façon indéfinie de sables, de cendres volcaniques et d'argịiles jaunes, engglobant des cailloux roulés de basalte et de porplyyre tracliylique, masquent partout les formations inférieures. A peine, à Umaña, peut-on voir un instant la roche porphyroïde foncée dans une pelite falaise qui domine un ruisseau pittoresque; on retombe presque immédiatement dans un immense plateau d'argiles jaunes qui conduit jusqu'au bord de la vallée du Rio Lempa, dont les flanes sont composés de sables et d'argiles. Quoique à près de 100 kilomètres de son embouchure, le fleuve, large el profond, est franchi ì 3 mètres seulement au-dessus du niveau de la mer.

Après une pelite plaine de sable qui s'élend jusqu'au point où l'on passe le Rio Acaltuate, on s'élère progressivement, en suivant le cours de la rivière, par une série d'ondulations dans lesquelles la roche se dégrage des dépòls superficiels chaque fois que l'on monte sur les flancs des contre-forts. Celto roche est un porplyyre trachytique, rougeàtre ou violacé, d'aspect un peu scoriacé parfois, et présentant, dans certains cas, des cristaux de feldspath orthose assez bien définis. A mesure que l'ou s'élève, les conches superficielles deviennent plus fréquentes, et l'on arrive enfiu à une plaine assez longue, formée uniquement d'un tuf argileux blanchàtre, auquel les indigènes donneut le nom de tisute. Après avoir passé un dernier ressaut porphyrique assez accusé, on tombe enfin dans la plaine de San Vicente (356 mètres), où l'aboudance de la végétation dissimule la nature du sol.

Non loin de la ville de San Vicente, dans la direction du sud-ouest, se lrouve un massif assez considérable, auquel les labitants donnent le nom de Volcan de San Vicente. C'est assurément un volcan éleiut depuis fort longgtemps déjà, car sa forne caractéristique a été notablement altérée; mais il n’en présente pas moins 
DANS LES RÉPUBLIQUES DE GUATEMALA ET DE SILTADOR. 189 un très-vif intérèt, car on peut observer à sa base des dégagements de gaz ì haute tempéralure assez analogues ì ceux que nous avons déjà eu occasion de siģnaler à Chinameca. Sans nous occuper acluellement de la description détaitléc de co phénomène, qu’il nous suffise de dire quil prend naissance dans un ravin profond d'une trentaine de mètres, entaillé dans le flanc de la montagne. Les jets de vapeurs acides accompaģnés d'eau bouillante s'échappent tantôt par des fissures ourertes directement dans la roche porphyrique compacte, mais un peu altérée à sa surface, tantòt du milieu des masses argoilenses gorisàtres formées par la déconposition de ces mêmes roches.

En partant de San Vicente et en se dirigeant vers l'ouest, on commence par triverser, pendant une dizaine de kilomètres, un platean plus ou moins ondulé, dans lequel la roche porphyroïde sous-jacente, presque conlinuellement masquée par des dépóts superficiels de cendres volcaniques, d'argiles jaunes et de masses tufacées blanchàtres, n’apparaît que dans quelques coupures. Après Tepetillan, on passe un assez fort ressaut porphyrique, puis on franchit le ravin du Rio de Jiboa (535 mètres), complétement recouvert, sur ses deux bords, de Luls blancs contenant une assez notable proporlion de ponces. Pour arriver à Cojutepeque (891 mètres), il faut remonter le long d'une pente assez prononcée, dans laquelle on apercoil quelquefois le porphyre, dissimulé le plus souvent sous des argiles, auxquelles viennent se mêlẹr des scories volcaniques rouges et brunes en assez grande abondance.

La ville de Cojutepeque est, en effet, domince au sud par un joli petil volcan d'une centaine de mètres de hauteur, parfailement conique, et qui semble reposer de Cojutepeque. sur un massif doléritique dont on aperçoil quelques lambeaux à l'ouest de la ville. Du haul de ce volcan on jouit d'une vue admirable sur l'ensemble du pays, et, en particulier, sur le beau lac d'Ilopango, qui n'est point un ancien cratère rempli d'eau accumulée, comme le pensent cerlains voyageurs, mais bien plus probablement un simple repli de la liggne de partagge des eaux qui, en se dédoublant, à permis au lac de s'y former. Le lac d'Ilopango n'est, du reste, pas complétement isolé, car il déverse son trop plein dans le Rio de Jiboa par une étroile el profonde coupure, creusée à l'est dans la ceinture de montagnes porphyriques qui l'entoure. 
1)e Gojulepeque

iा

San Marlin.

Tufs ri ponces.

Envirolss

de San Salvador.

Pavin du Rio Asedguate.

Borhes

porphyroides.

Entre Cojutepeque et San Martin, le pays, formé de roches porphyroides masquées de temps en temps par des argoiles el des tuf́s blanchâtres, s'abaisse progressivement par ondulations successives; puis on entre dans une grande plaine converte de masses tufacées à ponces blanches dont on peut mesurer l'ćpaisseur dans la grande barranci du Rio Aselguale, profonde d’au moins une centaine de mètres, et dont le fond seulement est entaitlé dans les porphyres. Ce ravin est situé à environ 2 kilomètres au sud de la ville de San Salvador, qui s'élève à 667 mètres aut-dessus' du niveau de la mer.

Les environs de San Salvador sont intéressants à plus d'un titre, et d'abord parce qu'ils éveillent les tristes souvenirs du terrible tremblement de terre du 16 avril 1854 , qui produisit de si épouvantables ravages, et ensuite à cause du voisinage du grand volcan éteint qui domine la ville au nord. Nous y avons lait aussi quelques recherches dans le fond du ravin que parcourt te Rio Aselguate à peu de distance de la ville, el dans lequel on peut voir assez nettemeut, en certains points, les masses de roches porphyroïdes du sous-sol, mascquées partout ailleurs sous une puissance considérable de tufs à ponces. La roche est tantòt parfailement compacte, tantòt tlivisée en une infinité do pelits lits contournés et comme substratifiés: elle est alors d'une teinte noire violacée, rayée de nombreuses bándes d'un blanc verdàtre, et contient des facelles cristallines de feldspath ainsi que quelques paillettes de pyroxène. Dans d'autres cas, elle est bullense, comme scorifiée, et de couleur noire ou brunàtre, ressemblant tellement alors à une lave ou à un basalte, qu'on éprouve quelque difficulté à la réunir aux massil's voisins; on voit cependant tout le système passer d'un type à l'autre par les transitions les plus insensibles, groupées à côté les unes des autres aussi bien doms la verticale que dans l'horizontale. On a évidemment aflaire à des roches profondément attúrées par les phénomènes volcaniques qui ont donné naissance au volcan de San Salvador, et il est difficile de les faire entrer dans une classification normale qui ne serail pas basée sur la composition chimique.

Les petites falaises abruptes que forment ces massifs rocheux au bord du Rio Aselguate sont fissurées dans divers sens, et de ces fentes s'épanchent une série de sources plus ou moins volumineuses, formées d'une eau parfaitenient claire et limpide sans aucune odeur ui aucun goûl caractéristiques. Nous avons pris la 
DANS LES RÉPUBLIQUES DE GUATEMALA ET DE SALVADOR. 191 température d'une quinzaine de ces sources, el constaté qu'elle varie entre $31^{\circ}$ el $34^{\circ}, 50$; mais les essais chimiques n'ont donné aucun résultat, et c'est à peine si l'action des divers réactifs produit un trouble comparable à celui qui apparail dans les eaux de source les plus pures. On est donc conduit ì admettre qu'il y a là une nappe aquifère, nullement minéraliscée, mais simplement portée à nue tempéralure élevée par l'échauffement préexistant du sous-sol, persistanl encore malgré l'arrèt apparent des phénomènes volcaniques dans la montargne voisine.

A l'ouest de San Salvador se développe une vaste plaine fortile et peuplée. La sol se compose de tufs blancs épais de 4 à 5 mètres qui englobent de nombreux fragments de ponces, et recouvrent, en s'amincissant progressivement, une couche puissante de cendres violacées el de lapilli grisitres. Ce nouvel ensemble se dégage complétement près du vaste cratère éteint appelé La Hoya, qui s'ouvre brusquement à plus de 150 mètres en contre-bas du sol de la plaine; il se continue ensuite jusqu'au delà de Santa Tecla ( $9_{0} 3$ mètres), où il prend une importance décisive en se mêlant à des débris de scories rougeâtres qui proviennent probablement d'un petit cône éteint posé au nord de la ville, à une certaine hauteur, sur les derniers contre-forts du massif du volcan de San Salvador. Les argiles jannes reparaissent bientôt et deviemnent prédominantes près du point où te plateau que l'on vient de traverser cesse brusquement, et où une chute presque soudaine sópare tes plaines de la terre chaude de celle de la terre tempérée.

Le chemin rachète cette dénivellation assez considérable en s'enfonçant diun le grand ravin dit Callejon del Guarumal, dont il suit te fond pendant. 4 ou 5 kilomètres; le senlier franchit au moins une cinquantaine de fois le cours d'un ruisseau qui te recouvre le plus souvent et le rend absolument impraticable en saison des pluies. Le Callejon del Guarumal est, en réalité, une véritable fente à parois absoIument verticales, profonde de 150 à 100 mètres, large de 3 à 4 tout au plus, el qui présente au voyageur un des plus curieux exemples de barrancas qui se puisse voir. Malgré cela, les observations géologiques n'y sont pas très-aisées, car il y a dans ce point une assez grande complication; au moment où le ravin s'ouvre tout à coup, les argiles jaunes règnent avec une très-orrande puissance et semblent s'ètro déversées jusqu'au fond, sauf en un point, à peu de distance du sommel, où l'on apercoit un banc de roches noiràtres qui est peut-ètre du basalte, pent- 
ètre l'extrémité d'une coulée de lave, masquée jusque-là dans la plaine de Santa Tecla par des couches plus modernes. Au fond du Guarumal, mais au commencement du défilé, il semble que l'on voie pendant quelque temps le porplyyre en place; mais il disparait bientôt sous des amas de conglomérats porplyriques et de sables volcaniques, môlés commè s’il y avail eu plusieurs éboulements parliels; ce sont ensuitc ces mèmes roches qui composent pendant presque tout le tempss les parois de la coupure.

Collines porphyrignes.

Solbles volcauiques 4 laves anciennes a El Revedern.

Ce qu'il y a de cerlain, c'est qu'au sorlir du Guarumal te porphyre apparait très-nctlement ponr constituer une sćric de collines qui s'élèvent dans loules les directions. C'est alor's une jolic roche de couleur claire, grise ou un peu lilas, contenant des cristaux blanes jaunàtres de feldspath orthose et quelques mouches de quartz et de pyroxène noir. Mais les collines, toujours formées du même porphyre, s'écartent de plus eu plus el l'on entre progressivement dans une plaine dont te sol est composé de sables volcanicues gris violacés. A Guaimoco (573 mètres), ou roil plusieurs mamelons assez prononcés où l'argile jaune domine, mais percéc par le porpliyre dans les points culniuants. Ces argiles cessent tout à coup, un peu avant El Bevedero, et l'on aborde une immense coulée de lave ancicnne, recouverte en quelques points de sables volcaniques en couclies plus ou moins puissantes, et descendue probablement du volcan d'lzalco, qui s'élève au nord ì peu de distance. Cette coulée s'étend sous le villago d'lzalco et le dépasse mème un peu au sud; si, de là, on marche au nord dans la direction du volcan, on ne trouve absolument que de la lave sur laquelle s'élèvent d'épaisses forc̀ts, vieilles au uloins d'une cinquantaine d'années. Mais en arrière se dresse un groupe monLagneux porphiyrique, connu sous le nom de Midre del Volcan, el sur lequel le volcan d'Izalco vient en effet se souder par son flanc nord.

La coulée de lave qui s'étend sous te village d'lzalco a peut-être élé arrètéc par un pelit ressant porphyrique, peu saillant du reste, que rencontre bientòt le chemin qui conduit à Sonsonate. En entrant dans l'admirable vallée qui s'ouvre alors pour descendre jusfu'à la mer, on ne trouve plus que des argiles jaunes, qui constiluent tout le sol inlérieur el sont souvent recouvertes de terre végétale ferlile et nourrissant d'abond antes cultures. $\Lambda$ Sonsonate mème, on pent voir une roche noire basallique daus le fond du ravin où coule le Rio de Izalco; mais les argiles 
DANS LES RÉPUBLIQUES DE GUATEMALA ET DE SALVADOR. 193 jaunes forment des falaises de 5 à 6 mètres de hauteur, el cette couche s'étend aussi sur le petil contre-fort qu'il faut franchir pour gagner San Antonio, où les basaltes se montrent encore dans le lit du ruisseau qui passe à côlé de ce village. Il en est de mème jusquì la mer; mais là, dans les falaises d'Acajutla, on peut voir que les argiles n'ont plus qu'une épaisseur d'un on deux mètres au plus et surmontent un banc d'une douzaine de mètres de puissance, formé d'un congglomérat assez remarquable, qui doit avoir été déposé sous tes caux de la mer à en juger par la régularité de ses allures. Ce conglomérat se compose d'une succession de couches d'un magrma plus ou noins fin, à base argilo-terrense jaunàtre ou brune, empàtant des blocs plus ou moins volumineux de porpliyre de toutes nuances, de basalte, de scories, etc. en un mol de toutes les roches qui se rencontrent dans l'intérieur du pays.

Reprenant à Sonsonale (197 mòtres) la route que nous avons suivie jusquici, nous gagnons le flanc ouest de la valléc pour franchir, par une série de contreforts étagés, les laauteurs qui terminent en ce point l'axe anticlinal montagneux du Salvador. Les argiles jaunes disputent toujours la place aux porplyres, qui ne se montrenl guère avec netteté que dans le dernier ressaul succédant au pelit plateau d'Apaneca ( 1,474 mètres).

Une descente précipitée de 1,000 mètres amène alors dans la plaine d'Thuachapam ( 758 mètres), ò̀ se trouvent les magnifiques volcans de boue ou ausoles dont nous nous occuperons plus loin avec détail. Le sol de la plaine d'Ahuachapam est composé d'une sorte de tuf volcanique blanc jaunàtre ou franchement jaune, qui n'est pas sans avoir quelque analogie avec cerlaines assises de la formalion volcanico-lacustre de la vallée de Mexico. C'est une pàte assez fine, produile peut-ètre par la trituration des ponces ou des lapilli, et englobant de petils morceaux de ponce blanche, des blocs plus ou moins volumineux de scories noires, voire même quelques fragments d'obsidienne.

Le Rio Paz, frontière des républiques de Salvador et de Guatemala, coule dans une prolonde vallée qui s'ouvre brusquement en limitant la plaine d'Ahuachapam.

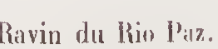
Porplyres. Les falaises, aussi bien d'un còté que de l'autre, se composent de perphyres assez nettement caractérisés; ils sont, en goénéral, à pâte grise ou plus souvent noire, bien compactes, englobant de jolis cristaux de feldspath orthose. En un point de 
la rive gauche, ces porphyres sont allérés comme s'ils avaient élé traversés par un dégagement gazeux acide, et quelques blocs sont recouverts, à leur surface, d'un enduit blauc de carbonate de chaux, épais de quelques millimètres.

Vallee de Jalpatagua. Porphyres ut contrlomerats porplyriques. Basaltes.

Iprès avoir descendu une còte assez alorupte, on passe le fleuve à 276 mòtress d’altitude, et, après avoir remonté une paroi un peı moins élevée que la précédente, on s'engage dans une grande vallée entourée de hautes cimes porplyriques. Le sol s'élève progressivement et se compose presque exclusivennent de conglomérals porphyriques à plus ou moins gros éléments reliés par un ciment terreux, alternanl quelquefois avec des arogiles jaunes ou des tufs semblables ì ceux d'Ahuachapam, dont la couche supéricure blanche à grain très-fin est un vérilable lisale peut-être siliceux. Ce u'est qu'après Jalpatagual ( 578 mètres) que l'on arrive au fond de cette vallée, qui est timitée par' un vigoureux contre-fort, dit Cuesta de la Leona, où les porphyres noirs compactes se montrent en abondance. I El Oratorio (950 mètres), on recommence à desceudre dans une vallée du mème genre que la précédente, mais un peu moins large, dont lès flancs sont également porphyriques el le sol composé d'alternances indéfinies de congolomérals el d'argiles.

A Los Lisclavos (740 mètres), la nature de la roche se modifie tont à coup. Le lit de la rivière qui traverse le village est profondément enciassé entre des fataises d'un lrapp basallique noir, un peu bulleux en dessus, compacte en profondeur, ì grandes cassures grossièrement prismatiques dans la verlicale, mais dout la surface ressemble un peu, par ses contournements, à celle d'une coulće de lave.

Le Rio de los Esclavos roule quelques cailloux d'un beau diorile vert, Irèscompacte, qui doil provenir des hautes montagones de l'intérieur du pays.

Quoique recouvert dans bien des cas par des malières supericielles, ce trapp basaltique continue néanmoins ì constituer partout le sous-sol, mais il est susceptible de certaines variations : ainsi on le voit souvent moucleté de petits cristaux blancs informes, el à Berberena il devient une superbe dolérite très-cristalline, avec cristaux dissémiués de pyroxène, de feldspath et de péridot.

A Cuajiniquilapa, on remarque des couches épaisses el alternantes de lapilli jaunàtres et de fragnments scoriacés et cimériformes brunâtres ou noirs. Les argịiles 
DANS LES RÉPUBLOLES DE GUATEMALA ET DE SALUIDOR. 195 jaunes se montrent souvent et en particulier dans la grande descente qui suit Berherena.

Les luds volcaniques à ponces blanches constituent tout le sol de la plaine qui précède Cerro Redondo (1,080 mètres). Ce village doil son nom à un petit volcan éteint qui s'ćlève vers le nord, et an pied duquel passe le chemin; on en voil de Cierro liedondo. Tufs a ponces. encore un autre un peu plus loin au sud.

A l'ouest de Cerro Redondo, on trouve un congtoméral contenant une forte proportion de cailloux granitiques, de dimensions souvent fort considérables, et qui Congroméral granitiquı. doivent, par conséquent, provenir de inontagnes assez voisines dans le nord. Ce granil est blanc ou un peu rosé, el contient de grandes paillelles de mica blanc ou noir, ainsi que d'assez volumineux crislaux d'amphibole.

La plaine de Cerro Redondo est limilée au nord-ouest par un puissant ressaul monlagneux que le chomin franchit par la longue montée dite Cuesta Verde. Le Cinesta Verde. Aryiles james à tix trapp basaltique que l'on avail encore vu tout près de Cerro Redondo existe certainement aussi dans le sous-sol de la montagone sur laquelle s’élève lir Cuesta Verde; mais il est presque conlinuellement masqué par de puissantes masses d'une argile jaune qui contient d'assez abondantes paillettes de fer oligisle cristallisé et brillant. Lorsqu'une forte pluie a lavé la surface du terrain, les granules de fer oligiste, entrainés par les pelits ruisseaux qui courent daus tons les sens, se déposent les premiers et forment des couclıes d'un on deux millimètres d'épaissenr composées de paillettes noires à reflets mélalliques, dont les dimensions ne dépassent pas celles du quart d'une tête d'épingle. Nous avons déjà remarqué des faits analogues dans diverses localités des plateaux du Mexique, el ils ne sont pas sans rendre plus iutéressante encore la formation de ces argiles jaunes, donl lorigine est fort difficile ì saisir.

Après çure arrivé au sommet de la Cuesta Verde, on a devant soi un vaste plalean très-oudulé, dont les couches inférieures sont certainement porphyriques, sans qu'il soit possible de saisir le momeut où la nouvelle roche remplace les trapps basaltiques. Le porphyre, d'ailleurs, n'apparait qu'en très-peu de points, car il est presque toujours recouvert par d'importantes assises daus lesquelles apparaissent des conglomérals porphỹriques, des arghiles jaunes el surlout des luts blanchałtres contenant une forte proportion de ponces. La puissance de ce système 
est très-considérable, car on le voit quelquefois atteindre ou même dépasser 150 mètres daus les ravins abruptes qui s'ouvrent au bord de la route.

Vallec de Guatemala. Tufs à ponces.

Direction de l'itinéraire.

Près de Pinula, on alteint un point culminant (1,909 mètres), el, après avoir vu un instant, au sommet de la côte, des porphyres gorisàtres très-altérés à la surface, on tombe dans la vaste plaine de Guateuala ( 1,528 mètres), ou se développent des tufs à ponces, blancs, jaunâtres ou rosés, assez semblables à cenx de la vallée de Mexico. Quoique la position des deux capitales, assises l'une et l'autre au milieu de vastes bassins enlourés de hautes nonlagnes, semble, à prémière vue, avoir une certaine analogie, il faut néanmoins constater une différence importante : c'est que l'une est environnée d'une ceinture continue, tandis que, près de l'autre, les eaux peuvent s'écouler dans deux sens différents, vers le Pacifique ou l'Atlantique, ce qui ne permet pas d'invoquer les mèmes faits pour expliquer l'étrange formation des tufs à ponces et leur origine un peu mystérieuse.

VOYAGE DF SAN JOSÉ DE GUATEMALA (BORDS DU PAGHIQUL) AU RIO GRANDE.

(Planche VI, figure 2.)

Le voyage qui fera l'objet des pages suivantes n'a pas été exécuté tout à fait comme ou pourrait le croire d'après la manière dont seront présentés les laits que nous avons observés et l'ordre dans lequel ils apparaitront. Nous avons fait autour de Guatemala, de la Antigua, d'Escuintla, un nombre considérable d'excursions, qui nous ont ramenés fréquemment dans les mènıes endroits; et nous avons pensé que toutes ces marchies et ces contre-narches, très-utiles pour faire comprendie plus complétement les choses au voyageur', qui les voit à diverses reprises daus un étal d'esprit différent et avec des idées plus ou moins modifiées par des recherches ultérieures, ne l'élaient pas autant, au contraire, pour le lecteur, qui demandr. avant tout, dans une description, la suite el la liaison qui ne peuvent se trouver que dans un itinéraire continu et régulier.

Nous nous attacherons donc à grouper les faits de manière à partir de l'Océan Pacifique et à marcher vers le nord, de facon à recouper transversalement. la grande arête montagneuse qui constitue la ligne de faîle principale du pays, ainsi que les cliainons accessoires qui lui sont plus ou moins exactement parallèles. 
DANS LES RÉPUBLIQUES DE GUATEMALA ET DE SALVADOR. 197 Arrivés à la vallée du Rio Grande, au lieu de continuer à nous enfoncer dans l'intérieur des terres, comme nous l'arons fait nous-mèmes, nous chercherons, par des renseignements que nous avons puisés à diverses sources, à compléter une coupe enlière de San José de Guatemalà à Izabal, c'est-à-dire de l'un à l'antre océan.

Le profil géologique donné daus la planclıe VI (fig. 2) se rapporte en grande partie à l'itinéraire que nous allons suivre et pourra en faciliter l'intelligence, si l'on a soin de se rappeler' que les hauleurs sont figurées à une échelle dix fois plus forte que celle des distances.

Les bords de la mer, à San José de Guatemala, offrent un cachel de nudité et de désolation qui u'est pas sans frapper assez vivement l'esprit de l'observateur. La grève proprement dite, sur une largeur d'une vingtaine de mètres, se compose d'un sable blanc et fin, pétri de coquilles brisées, sur lequel ta vague déferle avec furenr. Ces mèmes sables se prolongent encore à un kilomètre au moins daus l'intérieur des terres, mais iłs sont coupés de lagunes et d'esteros, et recouverts souvent d'épais taillis de mangliers el de palétuviers, qui recèlent des animaux venimeux et engendrent des fièvres malignes. C'est là que sont construiles les quelques hultes malsaines qui forment te village.

En quittaut San José, on commence à s'élever progressivenent sur une vaste plaine doucement inclinée, coupée de quelques ruisseaux, accidentée de quelques rares ondulations, animée par quelques petits villages indigènes semés au bord de la route. Une terre végétale, souvent assez fertile et nourrissant d'épaisses forèts, recouvre presque partout les argiles jaunes ou noires, les masses sableuses. les conglomérals qui constituent le sous-sol. Ces dépôts modernes.peu délerminés. dus probablement ì la destruction progressive par les eaux des abondantes déjections volcaniques qui existent dans les parties plus élevées du pays, semblent diminuer de puissance dans quelques points des environs d'Escuintla (442 mìtres) et laissent voir les conglomérats porphyriques qui constituent les masses inférieures du lerrain.

Non loin d'Escuinlla, à la gorande cascade de la Michatoya, on pourrail facilement étudier ces congołomérats, qui y présentent une épaisseur de 80, mètres au moins, et se relient, d'une façon assez difficile à saisiri, à la roche en place dont les parlies

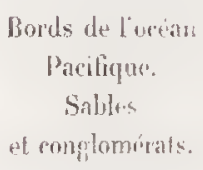

Einviron:s

I'Escuintia Congylomérat porphyrigares. 
supéricures sonl tellement altérées, qu'elles ne se distingnent guère du conggloméral lui-mème. Téanmoins, an-dessous de la cascade, les énormes blocs angulęux que lavent incessamment les eaux de la rivière doivent appartenir aux masses porphỵriques compactes sur lesquelles reposént les autres formations. Près de là, il y a de haules falaises composées d'une sorte de magma confus, gris foncé on violacé, à base peut-être arogileuse, empâtant des morceaux plus ou moins voluminenx de porpliyre el qui paraissent être un conglomérat. On y a creusé de rastes excavations à la recherche d'un filon mélillifère dont nous devons avouer n'avoir vu que des Iraces bien fugilives, et l'on affirme avoir trouvé nue cerlaine teneur en argent anx matières oblemes par ces travaux, sans qu'on ail pu nous en donner de prewres bien cerlaines.

lioute d'Escuintla à Amalitlan.

congloménits.

J'atile

d'Amalitlan. tllurions lacuatres.
Deux cliemins permettent de monter d'Escuinlla à la capitale, et, comme nous les avous parcourus l'un el l'autre, nous allons les décrire successivement. Le premier, qui est celui des voitures, suit à peu près le cours dn Rio Michaloya el commence par s'élever sur des pentes qui n’ont rien d'exagéré jusqu’à Sim Pedro Martyr (563 mòtres), laissant à gauche les grandes peutes qui se relient progressivement au volcan d'Agna, et à droite les haules falaises porplyriques de la livière, poince extrème du massil monlagneux sur lequel s'est formé le rotcan de Pacaya. Le terrain que l'on foule est recouverl d'une épaisseur considérable de congolontérats porphyriques masqués eux-mêmes en quelques points par des argites jaunes ou des cendres volcaniques. Après San Pedro Martyr, on monte assez brusquement jusqu'ì Palin (1,144 mètres), toujours sur des conglomérats dont la profourle coupure de Barranca Honda permet d'apprécier la puissance. Après avoir franchi les gorges resserrées où la Michatoya s'est frayé un passage entre les falaises porphyriques qui dépendent des systèmes des voleaus de Pacaya el d'Agran, on débouche dans la plaine d'Analitlan (1,189 mètres).

Celle plaine ful évideminent recouverte tout-entière autrefois, el la nalure des sédinents suffit pour le prouver, par un lac aux proportions plus restreintes aujourd'hui : c'est le lac d'Anatitlan formé par les eaux du Rio de Villalohos, arrêtées dans lour écoulement par la barrière que leur opposa subitement le soulèvement de la ligne volcanique dont deux des principales sommités, Ic Paraya of lo volcau d'Agua, se touchent presque par leurs bases. Les alluvions 
DANS LES RÉPUBLIQUES DE GUITEMALA ET DE SALVADOR. 199 propres de cet ancien lac ont une épaisseur indéterminée, mais qui doil ètre assez considérable; ce sont des masses argileuses grisàtres, recouvertes souvenl de terre végélate, quelquefois de dépòts marécageux.

Dans la plaine d'Amatitlan, tout à côté de la ville et sur les bords de la Michattova, on rencontre des masses tufacées jaunàtres assez compactes, dont la forniation doit ètre attribuée à des sources thermo-minérales qui jaillissent encore en cr: point. Ces sources constituent un groupe condensé sur un espace de 300 mètres environ de longueur et jaillissent au nombre d'envirom une douzaine, mais aved une abondance très-variable, les unes remplissant des hassins où l'eau se reiouvelle à chaque instant, les autres formant à peine de petites flaques. Les températures ne sont pas toutes les mèmes, probablement à cause du mólangoge des eaux de la rivière qui s'infiltrent dans le sol; nous avons trouvé en divers points :

$$
50^{\circ}, 30 .-59^{\circ}, 75-65^{\circ}, 75 .-68^{\circ}, 00, \text { etc. }
$$

l'eau est franchement alcalino-chlorurée, ainsi que le prourent les réaclions suivantes, qui sont exactement les mèmes pour toutes les sources:

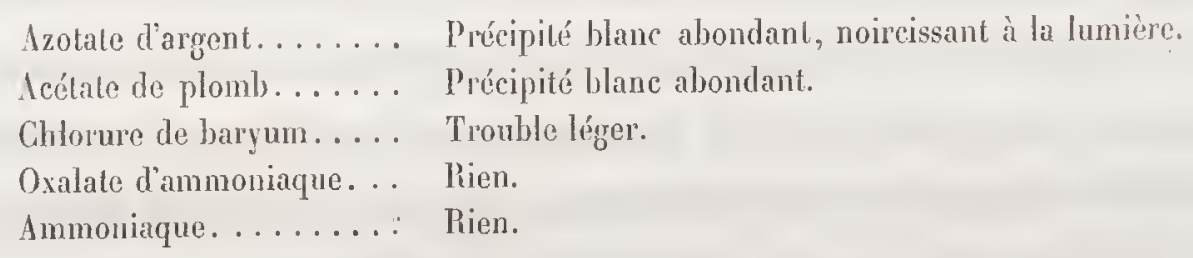

Leur goùt et teur odeur rappeltent vaguement les caractères des eaux de Baréges. II y a aussi probablement quelques sources dans le bassin mème du lac, car ses caux présentent, à un faible degré, les réactions des chlorures, et possèdent un léger goùt saumâtre qui les rend un peu désagréables à boire, voiro mèmo malsaines el purgatives, sil faut en croire les habitants d'Amalitlan.

Le lac d'Analitlan n'a pu prendre autrefois une extension plus considérable que du côté du sud-ouest et du nord-est, car il est borné au sud el au nord par d'assez hautes falaises rochenses. Au sud ce sont les derniers contre-forts du massif moulagneux sur lequel s'élève le volcan de Pacaya : toules les parois abruples on sont composées d'un beau porphyre trachytique gris, un peu fissile, landis que le petit plateau où est bâti le village de Pacaya est entièrement recouvert de cendres 
pulvériscées el de fins lapilli noirs. Au nord c'est un puissant ressaut qui sépare le bassin du lac d'Amatitlan de la vallée de Guatemala; on y voil de beaux porpiryres gris ì cassure columnaire tellement accusée, que de loin on serait presque tenté de les prendre pour des basaltes prismatiques, erreur qui d'ailleurs a été commise par quelques voyageurs. Mais aussitot qu'on arrive au sommet de la côte, ces roches disparaissent sous des amas tufacés, recouverts eux-mêmes d'mne croûte f́paisse d'argiles jaunes, qui s'emparent de tout le terrain el rèğnent uniquement jusqu’ì Villa-Nueva. Un peu plus loin que celle petite ville, la ronte se réunil ì celle qui arrive de La Antigua, et donl nous allons à présent dire quelques mols.

lionte d'lisenuthit à Lad Antignta. Déjections volraniques.

1al Intigua. Dépôts miniformes it ponceux i la base du volran if liump.
En partant d'Escuintla par le second chemin, on commence par longer la base dn volean d’Agua, en la contournant en quelque sorte, et en s'élevant progressivement au milieu de forèts épaisses qui dissimulent presque toujours la nature dı sol, formé uniquement de déjections volcaniques altérées el décomposées par les eaux al le conlact de l'air. Ce n'est qu'à Alotenango que l'on aborde la belle vallée qui s'onvre entre les massifs des volcans de Fuego el d'Agua, el où coule le Rio Guacalale. Le terrain est composé de détritus de déjections volcaniques qui disparaissent sous des argiles jaunes un pen marneuses, dont le plus grand déveIoppement se manifeste au petit manıclon qui précède l'entrée du village de Ciudad-Vieja, où commence la bolle plaine connue sous le nom de Vallée de la Antigua. La terre végétale y est extrêmement épaisse, et doit sa lécondité aux produits cinériformes, décomposés dont elle est principalement formée.

La ville de La Antiğua ( 1,546 mètres), ancienne capitale de ce pays, s'élève in milieu de cette belle et riche vallée, el le séjour que nous y avons fait nous " permis de rayonner dans divers sens.

Dans une première excursion, qui avait pour but l'ascension de l'important volcan de Fuego, nous nous sommes dirigés vers le surl-onest en traversant la vallér de La Antigua jusqu'au village de San Antonio. Là se dresse un petit ressaul, complétement revêtu de tufs à ponces entamés profondément par un chemin creux, et qui limite un bassin parliculier où les eaux se sont accumulées pour former le joli petit lac Uria, adossé de l'autre côté aux derniers contre-forts du puissant massif d'Acatenango. Les. bords du lac sont couverts de dépôts marécageux et de terre arable mêlés de détritus volcaniques; mais, au nord- 
DANS LES RÉPUBLIQUES DE GUATEMALA ET DE SALVADOR, 201 ouest, le porphyre, qui sert de base à tout cel ensemble, se montre dans quelques petites sommilés dénudées. Au sud du lac Uria, les déjeclions cinériformes sont surlout abondantes, el, quoique recouvertes, entre Dueñas el Capetillos, par une terre végétale noire, argileuse, excessivemeut fertile, elles reparaissent dins les premières pentes du volcan de Fuego, où l'on ne voil bientôt plus que de pelits lapilli noirs très-fins, sur lesquels sont de temps en temps déposés des blocs plus ou moins volumineux d'un porphyre trachytique légèrement altéré ou scorifié, tombés des régions supérieures de la montagne.

Pour faire l'ascension du volcan d'Agua, nous avons commencé par traverser. la vallée de La Anligua, dans la direction de l'est, jusqu’à San Juan del Obispo. Là commence la montée, el te chemin est entièrement entaillé dans de puissants amas de cendres el de lapilli accumulés sous une épaisseur énorme. Les lits st succèdent, plus ou moins puissants, à éléments plus ou moins fins, noirs, jaunes on violacés, et pourraient presque servir à compter les anciennes éruptions du volcan.

Santa Maria (2,081 mètres) est au pied du cône proprement dit, du còté nord, sur une sorte de vaste platean très-ondulé, recouvert de dépòts volcaniques décomposés et mis à profit par l'agriculture. De ce village nous sommes descendus sur Amalillan, d’abord par me grande vallée peu inclinée, puis par une gigantesque pente abrupte, où l'on voil successivement des déjections cinériformes el ponceuses recouvrant des conglomérats porphyriques, et enfin des porphyres en place, très-netlement indiqués à la base des monlagnes qui font partio de la ceinture du bassin lacustre d'Amatillan.

Entre autres intéressanls sujets d'études, la vallée de La Antigua présentr quelques sources thermales, qui sont probablement en rapport avec celles que; Souretes thermates res environs: nous avons indiquées à Amatitlan. Dans la vallée mème et nou loin de la ville sont de La Intigna. les sources diles de Medina et d'El Cubo, qui présentent des caractères presqur absolument identiques. La température de la première est de $26^{\circ} 0_{0}$, el celle do lit scconde de $27^{\circ}$; l'une el l'autre sont parlaitement claires el limpides, sịus sitveur ni odeur; de petils poissons vivent dans les bassins où les eaux sont recueillies. I l'éporgue où nous avons visilé ces sources, il ne s'y produisail ancun dégagement de gaz, et il est probable qu'il en est toujours de mèmu.

bles volcaniques la hase dic intrail

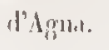


Elles présentent, avec les réaclifs chimiqués, les actions suivantes :

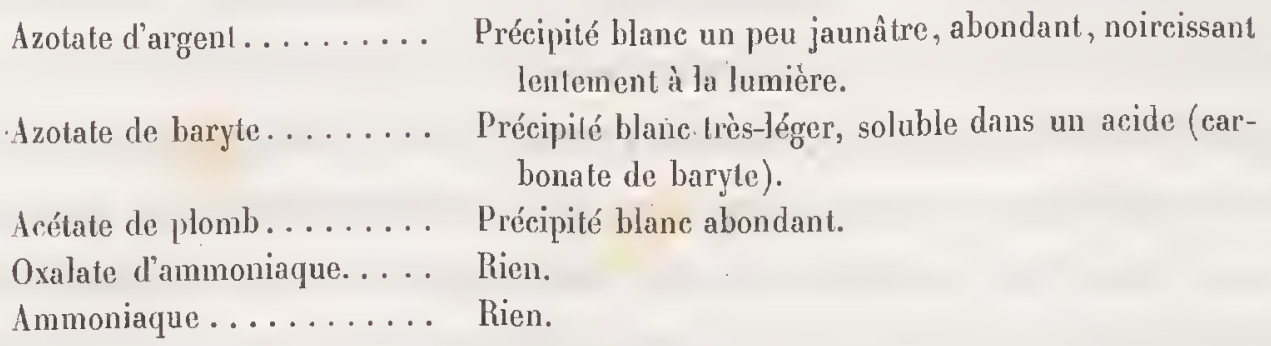

Ce sont donc des eaux alcalines carbonatées et un peu chlorturées.

Il en est de mème d'une autre source très-remarquable, qui prend naissance an fond d'un petil ravin excessivement pittoresque, divergeant du vallon de San Lorenzo qui court à l'ouest de la vallée de La Anligua. Les eaux s'échappent assez abondanment de la salbande d'un magonifique filon de résinite opaline, dirigé à peu près nord-sud, au milieu des porphyres qui constituent toules les hauleurs avoisinantes. Elles sont aussi claires el limpides que possible, inodores, mais possédant une saveur légèrement alcaline. Il n'y a pas de dégagement de gaz. La tempéralure ast de $37^{\circ}$. Les réactions sont les suivantes :

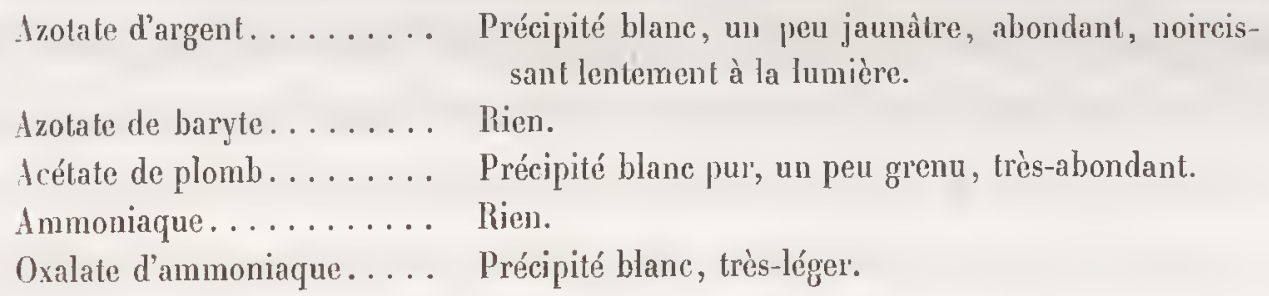

Cot de Barsenas. Conglomérals porphyriquess el magrmas ponrux.
La nuance un peu jaunâtre du précipité obtenu par l'action de l'azotate d'argent indique peut-ètre la présence d'un peu d'iode.

En partant de La Antigua, on commence par suivre te fond de la vallée du Rio Pensalivo, marchant toujours sur des dépôls alluvionnaires très-fertiles. Le ravin se resserre progressivement vers son extrémilé, el l'on commence ì apercevoir des porphyres qui percent le sol el se montrent des deux cótés à la baso des montagnes. Mais, comme ils sont recouverts d'une immensépápaisseur de roches arlventives, on cesse de les voir aussitôt que le thalweg n'est plus très-profondément. entaillé. Il ne recoupe bientôt plus que des amas de cailloux roulés de porphyre, lormant une masse d'une cinquantaine de mètres de puissance, puis des couches 
DANS LES RÉPUBLIQUES DE GUATEMALA ET DE SALVADOR. 203 épaisses de tufs à ponces qui recouvrent tout le ressaut que l'on franchit d'Embaules à Barsenas. Mème au point culminant (2,178 mètres), on ne voit que des dépòts superficiels anxquels se joiğnent mème des argiles jaunes, qui recouvrent tout le plateau de San Lucas, plateau que l'on doit traverser quand on veut passer par Mixco, comme nous l'avons lail une fois. Que l'ou descende par Mixeo ou par Barsenas, on trouve, dans les deux cas, le versant entièrement garni de tuls à ponces.

Une fois que l'on est arrivé dans la vallée de Gualemala, on marche sur uu sol horizontal, mais qui se trouve tout à coup prolondément entaillé par les graudes parois verticales de la Barranca de Viltalobos. Ce ravin, profond au moins d'une centaine de mètres, est parcouru par une rivic̀re qui va se jeter dans le lac d'Amitlitlan en contournant, par la plaine inclinée de Pelapa, l'arête montagneuse qui domine Villa Nueva. On y peut voir une belle coupe des matériaux dont se compose le lerrain de la vallée de Guatemala. Tout au fond il y a quelques traces de conglomérat à cailloux roulés de porplıyre, puis deux ou trois mètres de lapilli ef de cendres jaunes el violacées en petites couches altermantes, mais lout le reste est formé presque uniquement de ponces blanchâtres en morceaux de la grosseur d'une noix. Des assises successives les montrent tantòt complétement indépendants tes uns des autres et seulement entassés par la compression; lantôt mnis et comme cimentés par une fine pâte jaunàtre qui les engolobe el en forme une masse compacte; la couche supérienre en particnlier, sur laquelle repose directement la terre végétale ou ce qui en tient lieu, prend presque une apparence nassive el devient un véritable tul. Au milieu des ponces il y a deux on trois pelits lits de cendres violelles, intercalés à peu près à mi-hauteur de la coupe.

La vallée de Guatemala n’est, en réalité, qu'un haut plateau installé de la facon la plus singulière, précisément sur la direction de la tigne de partage des eaux. De haules cimes la bordent à l'est el à l'onest, mais, au sud et au nord, gràce à des lignes de faîte interrompues, les caux peuvent trouver leur écoulement, d'uu còté, llis paur. vers le Pacifique, de l'autre, vers l'Allantique, en se creusant elles-mèmes de profonds ravins qui leur permettent de chercher leurs niveaux. Car il faut remarquer que ce vaste espace culminaut redeviendrait peut-être un bassin assez analogue ì celui de Mexico, si l'on supprimail tous les dépôts moderues qui l’onl prog̣essive- 
ment comblé, en accumulant les uns au-dessus des autres les produits de chacune des éruptions des innombrables volcans du voisinage.

D’un autre côté, si les eaux coulaient à la surface du sol au lieu d'être dirigóés par de profondes tranchées, il est probable qu'elles ne suivraient pas les chemins qu'elles prennent aujourd'hui el se répartiraient d'une façon tout à fail différente. Cette ligne de partage des eaux, large de plusienrs kilomètres, hésitinte, pour ainsi dire, u'exislant telle qu'elle est anjourd'hui que par suite d'actions purement mécaniques attribuables au mouvement même des eaux, et graàce à la facile destruction des malériaux meubles qui forment le sol, est un des phénomènes les plus intéressants qui se puissent voir.

a Pedier pris

do cinalemala. Cialcaires grịisâtres compretes.

Barrauce

Io. Chinaula.

Grand

developpement. Jes tul's ì ponces. Granils.
En sorlant de la capilale par la route du uord, on rencontre presque immédialement un petil lambeau de calcaire grisàtre, compacte, sans traces de fossiles, traversé par quelques veines de carbonate de chaux et formant un mamelon liant à peine d'une douzaine de mètres. On le nomme La Pedrera, et c'est probablement le fragment d'un système qui se dessine plus nettemont à San Juan Zacatepeque et d'où proviennent presque tous les pavés calcaires de Guatemala, amenés sous la forme de cailloux roulés par les eaux d'une rivière qui, dans les environs de la capilale, atteint cetle assise gràce à la profondeur du ravin qu'elle parcourl.

Mais on n'apercoit qu'un instant la colline calcaire, noyée par sa base dans des couches puissantes de dépôts superficiels, dont on peut bientôt après évaluer un minimum d'épaisseur dans les parois presque verlicales de l'immense Barranca de Chinauta. Il y a là plus de 200 mètres d'amas ponceux plus ou moins complétement cimentés, qui occupent encore pendant quelque temps le fond du lit du Rio de Las Vaccas, dont le chemin suil le cours.

Peu à peu on voil s'en dégager un sable granitique qui passe progressivement au granit décomposé dans les petits contre-forts qui avoisinent San Antonio, el enfin à la roche compacte et non altérée dans la grande côte de la Quesada. Les granits s'accusent de la façon la plus nette dans la série de fortes ondulations qui précèdent l'Hacienda de Sau Rafael. C'est une roche à assez gros éléments, d'une couleur brune claire dans son ensemble, formée d'un seul feldspath orthose d'un brun ferrugineux, de mica noir et de quarlz blanc; elle est traversée par un 
DANS LES RÉPUBLIQUES DE GUATEMALA ET DE SALVADOR. 205 grand nombre de filons de quartz plus ou moins puissants et peut-être métallifòres.

Près de San Rafael, on voit un assez grand nombre de cailloux ronlés d'me: belle roche verte, qui semble ètre un diorite et provient des sommités voisines. $A$ mi-chemin, à peu près, entre l'hacienda de San Rafacl et l'hacienda del Carrizal. (1,361 mètres), on rencontre une couche, puissante d'une dizaine de mètres environ, relevéc presque verlicalement et composée d'mne matière schisloïde verdâtre, qui semble formée d'une pâte feldspathique blanche un peu altérée, renfermant de petits cristaux verts de pyroxène. Peut-être est-ce un diorite en profonderr.

Quoi qu'il en soit, celte assise marque le point où les granites cessent brusquement pour faire place aux micaschistes bien caractérisés qui se développent. avec une grande puissance. Leur nuance varie du blanc au brun par les jaunes. et ils forment parfois d'immenses dalles lisses et brillantes, qui scintillent de lat facon la plus étrange sous les rayons du soleil, el sur lesquelles les chevaux peuvent facilement glisser de la manière la plus dangereuse. Les micaschisles sont de temps en temps traversés par des filons de quartz blanc oparque, daus l'mu desquels nous avons recucilli de petites baguettes noires que nous croyons ponvoir rapporter à de la tourmaline.

A la côte de Chiquin, les micaschistes sont brusquement remplacés par un épanchement de porphyre quartzilère, jolie roche très-compacte, d'nu gris un peu violacé, contenant quelques pelites paillettes de mica noir brillant. L'éruption do ces porpliyres semble avoir déterminé une large trouée dans le système des micaschistes et amené une certaine perlurbation dans la superposition des conches voisines; car, quoique cette roche se trouve encore plus loin parfaitement caractérisée, les diverses formations se mêlent entre Las Minas et San Bucnaventura, de manière à dérouter l'observateur, qui ne peut consacrer un temps prolongé à l'étude d'une localité en particulier.

Près de Las Minas, dans la vallée que domine l'hacienda de Trapiche Grande, on voit les porphyres quartzifères disparaitre sous de puissantes masses d'une

Las Miriat Arriles brune:s et rongutitis. argile d'un brun rougeâtre, dont la nuance varie quelquefois comme celle de nos marnes irisées d'Enrope. Ces argiles, un peu marneuses, en effet, car elles se

del Carrizal. Vicaschistus.

Chiquin. Puspliytes ynarizifères. 
partagent aisément en petils frağments prismatiques lor'squ'elles se dessèchent, se séparent complétement des argiles jaunes que nous avous déjà rencontrées plus d'une fois, aussi bien par leur composition et leur aspect que par leur gisement el leur origine probable. Ensuite viennent des conglomérats de couleur lie de vin à pelits galets roulés de composilion variable, d'où se dégage un ensemble fort complexe.

Velange de roches diverses. Filous do quato.
On y voit des schisles argilo-talqueux, d'un vert foncé ou quelquefois brunàtres, d'où émergent quelques mamelous de calcaire compacle bleu grisàtre, el sur lesquels sont répandus des fragmeuls de grauwacke brune subschistoïde. Ces conches sont traversées par de nombreuses veines de quarť, probablement méIallilères, car on reucontre quelques blocs de couleur brune, impréğnés de carbonate de cuivre vert, el provenant sans nul doute du chapeau de fer de l'un des lilons qui onl lail donner son nom caracléristique au village de Las Minas.

Non loin de là, on peut voir aussi nne sorte de dyke forl remarquable, composé d'unc belle roche très-compacte, à pàte feldspathique blanche, mouchetée de toules petites aiguilles verles d'amphibole el de gros cristaux de feldspath orthose d'un blanc laiteux. L'épanchement de ces porphyres doil avoir contribué, pour sa part, au plissement complexe qui englobe ainsi des restes divers de couches sus-jacentes presque entièrement délruites ou ravinées.

Les micaschistes reparaissent d'ailleurs avec un plongement presque verlical et une direction sensiblement parallèle à celle dı cours de la rivière daus les pentes abruptes qui couduisent au fond de la vallée que parcourt le Rio Grande ou Molaģua. La roche, tantôt d'un blanc éblouissant, tantôt d'un jaune d'or ou d'un gris à reflets mélalliques, forme d’inmenses plaques régulièrement feuilletées, composées presque uniquement de mica pur cimenté de loin en loin par une trèslaible proportion de pàte foldspalhique ou quartzeuse, et représente un des plus beaux types qui se puissent voir de la formation des micaschistes. Les variétés sont d'ailleurs infinies, el il serail presque impossible de les décrire toules; mais il ne laut pas oublier de signaler quelques échantillons que nous avons reucontrés à San Bernardo, avant le complet développement des nicaschistes, dans le point où le mólange des rochıs est peul-être le plus complexe, el qui semblent manifestru' unc lendauce très-prononcée à passer ạ goneiss. L'un se compose d'une masse 
DANS LES RÉPUBLIQUES DE GUATEMALA ET DE SALVADOR. 207 quartzeuse blanche, opaque, grenue, très-fine, renfermant des micas blancs brillants et nacrés, ainsi que des fragomenis vert foncé d'amphibole ou de pyroxène; ın autre a pour pàte un quartz blanc laiteux translucide, séparant des lits presqur. continus de mica vert clair en paillettes orientées.

D'énormes blocs de micaschiste, empilés dans le désordre le plus pittoresque, forment une sorte de chaos enserré dans le fond d'une étroite vallée où, au milien de forêts épaisses, le Rio Grande, large d'une soixanlaine de mètres, ronte ses eaux jusqu'au golfe de Honduras. Il sert de fronlière à la province de la Vera laz, dont nous parlerons en délail dans un parag̣raphe snivant, mais ne limile pas le domaine de la formation des micaschistes, qui ne sont que fortement repliés sur eux-mèmes el reparaissent sur l'autre rive du fleuve (460 mètres) en vastes dalles, inclinées souvent d'une quarantaine de degrés, plongeant vers le sud $15^{\circ}$ ouest, el dirigéées de l'ouest $15^{\circ}$ nord à l'est $15^{\circ}$ sud.

La roule que nous avons étudiée jusqu’à présent ne mène que dans la province de la Vera Paz, et l'on ne pourrait pas gagner l'océan Allantique en snivanl le cours du Pio Molagua, à partir du point où nous l'avons franchi. Pour arriver' à Irabal et à Santo Thomas, il laut, de Guatemala même, obliquer un pen plus ì l'est, en suivant un chemin que nous n'avous pas parcourı nous-mèmes, mais sur lequel des noles mamuscrites du R. P. Cornelle de la compagnie de Jésus nons ont fourni quelques données géologiques.

En partant de Guatemala par le nord-est, on marche pendant quelque temps : El chato. Calcarres. sur des tufs analogues à ceux qui constituent le sol de toul le reste de la vallée. Vais déjà, près d'El Chato (1,226 mètres), on rencontre de nombrenx blocs de calcaire gris qui proviennent évidemment du massil que nous avons déja en occasion de signaler, et dont quelques pointes émergent seules au-dessus des dépòts superficiels, tandis que l'ensemble de la formation reste masqué par cel épais revêtement. Les tuls volcaniques mêlés de ponces reprennent bientòt ten' enupire absolu, et à El Fiscal aussi bien qu'ì San José on n'aperçoil que des dépôls de cette nature. Près de Pontezuela (1,110 mètres), le chemin gagane un massil montagneux, dans lequel les couches sédimenlaires inféricures se dégagent d'une manière assez netle; ce sont des calcaires gris hleuàtres, passant quelquefois ì it schistes. des masses un pen schisterises, qui prennent un développenent consid́rable, car 
ils constituent encore toutes les roches que l'on aperçoil daus la profonde vallée où l'on doil descendre pour franchir le petil Rio de Los Platanos (535 mètres). A La Lagmma (60o mòtres), les calcaires existent encore, mais reposent direclemeul sur des schistes plus anciens. A parlir de ce point, on est dominé, au sud, par une arète montagneuse dont toutes les sommités sont calcaires, tandis qu’à la hase, les roches, souvent masquées par les alluvions propres de la pelite rivière que suit le chemin, sont, tantòt des schistes à aspect ferrugineux, tantòt des congoglomérals à pelits éléments, ou des poudingues couleur lie de vin, assez ana-

Shistes .4. poudingurc.

El Jicaro. El Clivele. Piranits.

Ghaine d'El Mico. Vicaschistes. logues à ceux que uous avons signalés près de Las Minas. Les schistes se voient surloul à la Savanela (700 mètres), et les poudingues autour de Guastatoya (4.3o mètres), où ils prennent une assez grande extension, à l'ouest jusqu'à El Subinal, et à l'est dans une partie du défilé comnu sous le nom de Callejon de Cruastutoya. Dans ce défilé, des granits à gros éléments, passant peut-ètre ì la pegmalite, se montrent au-dessous des poudingues et se développent dans les monlagnes qui existent an nord.

A El Jicaro, on rejoint le Rio Motagua ( 175 mètres), dont on suit pendant quelques instants le cours, sur les bords d'une assez large vallée, dont le sol est formé surtont de sédiments de transport de natures diverses, sables, argiles et cailloux ronlés; mais les granils passant aux gneiss schistoides apparaissent déjì près du village. A El Chiote (170 mètres), où se trouve une intéressante source sulfurcuse sortant des granits, à la lempérature de $74^{\circ} 26$, on aborde un pelit massif monlagneux enlièrement composé d'un granit pouvant devenir gneissique comme à la Fragua, el dont le point culminant est le mont Toban. Près de Zacapa (140 mètres), on rencontre une vaste vallée remplie des alluvions propres de la grande rivière qui y coule, mais on relrouve presque immédiatement le granil dans les hauteurs qui dominent à l'est la ville de Zacapa. A Gualan, on reIrouve des poudingues lic de vin, et, après avoir franchi le Rio Motagua à Barbasco, on se tronve bientôt en présence de la ggrande chaîne montağneuse d'El Mico, qni sépare les bassins du Motagua et du Polochic. Ces hauteurs sont lormées de micaschisles qui se conlimment jusque près de Santo Thomas, pour reparaitre à Omoil dans le Ilonduras, et plus loin encore dans l'ỉle de Roalhan, dessinant ainsi un alignentent d'une remarquable nelteté. 
DAMS LES RÉPLBLIQUES DE GUATEMALA ET DE SALVADOR. 209

Iu nord de la lagune d'Izabal, il y a, parail-il, des calcaires dont feraicnt partic les couches à lignites de Levingston, sur le bord de la baie de Honduras; mais le fait, quoique possible et même probable, demande à ìtre vérifié par des investigations plus précises que cclles auxquelles sont dus ces derniers renseignements.

TOYAGE DANS IA PROVIVCE DE LA VERA PAZ.

(PJ. VI, fig. 2.)

La Vera Paz est administrativement divisée en deux départements, qui correspondent assez exactement aux divisions formées par la nature elle-même, el dont les aspects physiques et les productions, aussi bien que la composition géologiquque, Séographiques al géologriquess le la Vara Par. diffèrent d'une manière assez remarquable. La Basse Vera Paz (Baja Vera Paz), dont la capitale est Salama, comprend toutes les parties sud de la province, et se rompose de larges vallées, dont l'altitude correspond presque aux limiles de lat terre chaude, séparées par des arêles monlagneuses rectilignes et parallèles, souvent assez élevées. Le sol est lormé de roches sédimentaires anciennes, pent-ètre mélamorphiques dans certains cas, recouvertes d'alluvions modernes dans les thalweggs des vallées. La Haute Vera Paz (Alta Vera Paz), qui a Coban pour cheflieu, est moins une succession de monlagnes qu'une sorte de vaste plateau f́nergiquement ondulé, mais d'une façon plutor molle que brusque, si l'on ose s'exprimer ainsi. Le sous-sol est presque partout calcaire, mais les aroriles jaunes le recouvrent en abondance, et sont susceptibles de former ì l'occasion une terre' végétale d'une grande fertilité.

Le voyage que nous avons fait dans celle province, quoique susceptible d'ère isolé par la nature des observations auxquelles il donne lieu, se relie pourtant d'une manière intime à celui qui précède, et l'on en trouvera les ćléments condensés sous une forme graphique dans la partio extrême du profil géologoiquc: qui est donné à la figure 2 de la planche VI. La. direction que nous avons suivie est toujours celle du sud au nord, et ne s'arrête qu'au moment où, trouvanl devant nous les immenses solitudes du Pelen, où la saison des pluies ne nous permeltait pas de nous enfoncer, nous avous dù nous détourner ver's l'ouest pour 
La lienoúl. llieaschistes.

Agntas Calicutes. Sources thermales sulfureuses. pénétrer dans la province des Illos, dont la description fait partie du paragraphe suivant.

C'est au bord du Rio Molagua, près du villagge de la Canoa (466 mètres), que s'est arrêté notre précédent itinéraire, en un point où les micaschistes, parfois un peu gueissiques, couvrajent le sol de gigantesques dalles, inclinées d'une quarantaine de degrés vers le sud $15^{\circ}$ ouest, el faisaient briller au soleil les grandes lamelles de mica blanc ou jaunâtre qui les composent. Le clıemin s'élève alors en suivaul le thalwegr d'un petil ruisseau, qui se jette dans le Rio Molağaa à côté de la Canoa; et, non loin du village, à 511 mètres d'altitude, on se trouve en présence d'un ensemble de sources thermales extrèmement remarquables, groupées en un endroit connu sous le nom d'Aguas Calientes.

On a devant soi un vaste espace irrégutièrement circulaire, d'un dianıètre de 150 mètres environ, d'où s'échappent de volumineuses colonnes de vapeur dont les influences acides ont repoussé complétement la végétalion. Quelques troncs morls el dénudés s'élèvent encore au milieu des amas de pierres entassées qui garnissent cette plaine, et ajoutent à l'aspect de désolation qui est un.des trails les plus saillants du paysage. L'eau brûlante, qui s'échappe de six à sept ouvertures plus ou moins béantes ouvertes entre les rochers, court daus tous les sens, lorme de petits bassins, s'infiltre entre les pierres et finil par se réunir en un courant assez aboudant qui se jette dans le ruisseau voisin, qu’il atliédit et rend impropre aux usages domestiques.

Nous avons examiné successivement six de ces sources, qui présentent des caraclères absolument identiques, et dont l'eau est toujours claire el limpide, mais qui offrent une odeur et-un goût assez prononcés rappelant ceux des œufs pourris. Lat lempérature moyenne que nons avons trouvée oscille entre les limites de $9^{3} \mathrm{el}$ do $93^{\circ} 50$ : elle est donc la même pour toules les sources; mais il n'est pas sans inlérêt de remarquer que, dans ses notes nıanuscriles, relatives à un voyage cxéculé en 1856 , le R. P. Cornette de la compagnie de Jésus indique, pour ces mèmes sources, une températuré de $96^{\circ} 35$. La différence est importante, et, comme l'observateur nommé ci-dessus n’indique pas s'il a examiné un seul des épanchements d'eau thermale ou plusieurs, on ne peut émettre que très-limidement l'hypothèse d'un refroidissement graduel, qui n'est d'ailleurs que fort peu probable. 
DANS LES RÉPUBLIQUES DE GUATEMALA ET DE SALVADOR. 211

Ces eaux présentent les caractères suivants lorsqu'on tes traite par les réactifs rhimiques :

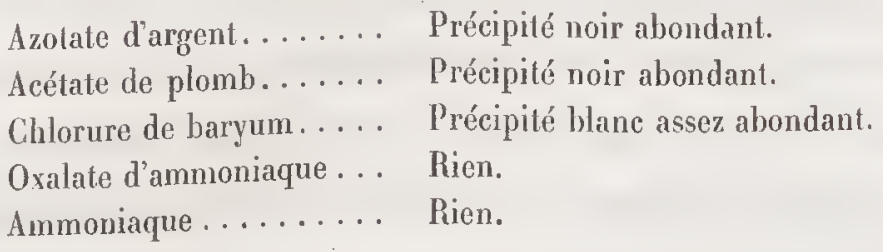

Le soufre y existe donc à l'étal de sulfures alcalins dissous et d'acide sulfurique. D'ailleurs les essais sulfhydrométriques, fails par la méthode de Dupasquier, donnent $3^{\circ} 75$ du sulfhydromètre, ce qui correspond à $0^{\text {gr }}, 080478$ de soufre par litre. D’abondantes bulles de gaz se dégagent des points où l'eau s'épanche, el, en analysant ce gaz, on le trouve presque exclusivement composé d'acide carbonique mêlé d'une très-faible proportion d'azote. Il est probable que l'hydrogène sulfuré, dont on perçoit l'odeur el qui devait y être mêłé, est dissons presque en tolalité par l'eau, où il se retrouve à l'état d'acide sulfurique.

Au-dessus des Aguas calientes, le chemin s'engage dans une forle montée, dont l'ascension est rendue. plus ardue encore par la présence de vastes assises de micaschistes qui continuent à se montrer partout au-dessous de la terre végétale. du petil village de Llano Grande, on atteint un point culminant qui correspond all commencement d'une plaine ou plutôt d'une vallée extrèmement évasée, où court une petite rivière qui marche longtemps presque parallèlement au Rio Grande et le rejoint plus loin dans l'est. Entre Llano Grande el Cluacus $\left(800^{\mathrm{m}}\right)$, les roches anciennes sont généralement recouvertes par des formations superficielles plus ou moins argilo-terreuses, souvent par de la terre végétale fertile qui produit de beaux pàturages et des champs bien cultivés. Mais elles reparaissent dans le lit du pelit Rio de Chuacus, el se développent alors avec une puissance remarquable dans ta grande arête montagoneuse qui courl à peu près de l'ouest à l'est et où elles sont portées jusqu'à une hauteur qui dépasse 1,632 mètres. La montée psl rude, et le chemin que l'on suit ne manque pas d'occasions pour entamer la roche, dont la surface, il faut l'avouer, est fréquemment altérée par l'action des iggents atmosphériques. Néanmoins on peul observer un nombre infini de variétés, depuis les unicaschistes parfaitement purs, formés uniquement de grandes lameltes

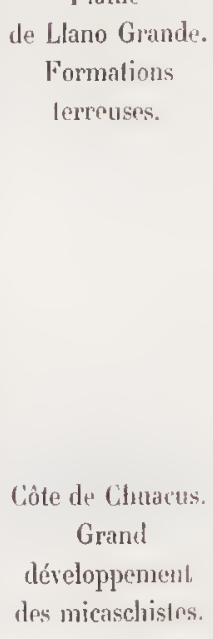
Cồte de Clutuacus. Grant développenent 
orientées de mica blanc on jaunàtre, jusqu'à ceux qui contiemnent du quartz et du mica en proportions plus ou moins considérables et semblent passer aux gneiss, et à ceux qui deviemnent des schistes amphiboliques renfermant de orandes amphiboles vertes empâtées dans une masse blanche composée de mica nacré el de feldspath grenu. La descente vers le nord est presque aussi escarpée que la montée, et permet aussi aisément d'observer la formation des micaschistes qui y règnent encore sans partag̣e.

Vallée de Salama. Tufs à ponces.

Vicaschistes

et schistes talqueux ì l"est de Salama.
Au petil village d'el Rincon les pentes s'adoucissent, et l'on gragne presque tout à coup une vaste plaine où les micaschistes disparaissent complétement sous des dépôts beaucoup plus modernes qui remplissent la vallée de Salama. Quelques coupures de 4 à 5 mètres de profondeur, creusées par de petits ruisseaux, permettent de voir que le sol se compose de lits parfaitement horizontaux, dout le premier est une couche d'une sorte de tuf jaunàtre assez compacte, semblable à celui qui cxiste dans li vallée de Guatemala; au-dessous se trouve un magma blanchàtre assez régulièrement stratifić, absolument composé de ponces blanches en morceaux de la gुrosseur d'une noix environ. La présence de ces tufs à ponces à une distance anssi considérable de la ligne principale des évents volcaniques n’est pas sans mériter une mention spéciale. Quelques collines, laautes d'une cinquantaine de mètres tout au plus, ćmergent de cet ensemble au sud-est de la ville (871 mètres), et semblent se composer d'une sorle de schiste ardoisé, noiràtre, tendant quelquefois à passer au calcaire; nous ne pouvons y voir qu'un lambeau isolé des formations qui se développent vers le nord, lémoins peut-être de phénomènes de ravinement compliqués qui auraient accompagné la formation de la vaste ride dont il s'agit.

Quoique large d'une douzaine de kilomètres dans la direction du nord au sud et au point où nous la considérons, la vallée de Salama prend son grand développement dans le sens perpendiculaire. Vers l'ouest, elle se développe jusqu'au Rio Chisoy, dans lequel se jette la rivière qui la parcourt; mais, du còté de l'est, elle ne se prolonge que d'une trentaine de kilomètres jusque vers San Geromino, hacienda renommée par ses belles plantations de canne à sucre. D’après les observalions du R. P. Cornette qui a fait le voyage de Salama au Rio Molagua par Tocoy et San Augustin Acazahuastan, on aborde à San Geromino une 
DANS LES RÉPUBLIQUES DE GUATEVALA ET DE SALVADOR. 213 chaine composée de micaschistes et de goneiss analogrues ì ceux du massif de Chuacus, ce qui est parfaitement naturel, puisque l'on n'a très-probablement affaire yu'au prolongement d'une mème arète montagneuse dont on trouve le point culminant à la Cumbre de Los Trozos. Les micaschistes, très-développés à San Clemente, seraient remplacés, un peu plus loin que Tocoy et jusqu’au Rio Motagorua, par des schistes talqueux verdìtres, ce qui semblerait impliquer un dérangement assez remarquable dans la direclion des chaines telle que nous avons eu occasion de la relever eu bien des points.

Au nord de Salama, la vallée est limitée par une haule arète montagneuse, parfaitement rectiligne, ì pentes très-accusées, el que l'on aborde par la grande

Citle de hishis Sehistes falinur:11: virts. montée dile Cuesta de Kachil, qui la franchil ì une hauteur de 1,573 mètres. Ony voit se développer avec une grande puissance un ensemble de schisles, probablement sédimentaires, en tous les cas fort anciens el qui ont probablement subi en bien des points une action métamorphique assez intense. Ce sont tantôt des masses schisloïdes bleues et noiràtres passant à la grauwacke, très-compactes quand elles sont respectées par les agents atmosphériques, mais devenant argoileuses par l'altération; tantôt des schistes très-fimement stratifiés, d'une nuance verdàtre plus ou moins caractérisée, composés d'une sorle de pàte feldspathique hlanchàtre. susceptible de dispiraitre presque absolument, cimentant de grands feuillets d'une malière talquense d'un grris verdàtre, nacrée, douce au toucher, ou des lamelles de chlorite d'un vert sombre franchement accusé. -

Ces roches ne sont pas limitées à la tocalité dont nous venons de parler at s'étendent plus loin encore vers le nord, ou l'on voit, du point culminant de tá côte de Kachil, une série très-remarquable de rides successives parallèles el aflectant toules une direction qui est sensiblement de l'est $25^{\circ}$ sud à l'ouest $25^{\circ}$ nord. Les masses schisteuses ne se voient qu'en quelques points de la haute vallée de Santo Thomas, dont te sol est formé d'alluvions terrenses el de conģlonérats ravinés par le cours d'eau qui y circule; mais elles reparaissent, très-netlement dégagées, dans le ressiut suivant, pour disparaitre de nouveau lorsqu'on aborde la pelite vallée de Santa Rosa $\left(1,5_{2} 1\right.$ mètres), où une terre végótale noire, rèmarquablement épaisse, masque la formalion sous-jacente.

Un peu au nord de Sauta Rosa, à deux pas du village, on rencontre toul à coup 
Vodilications dans le rèzgne vémrital.

1) Jhe de calcaire. Sistème des schistes, grès pol porrimgues. une hrusque modificalion dans la nature des roches qui composent le sous-sol, et l'on assiste avec étomement à la différence immédiate que ce changement imprime aux allures de la végétation. Jamais peut-ètre nous n’avons pu saisir d'mne facon plus caractérisée, plus vivante pour ainsi dire, l'influence de la composition góéologique sur la répartition des espèces végétales; jamais nous n’avons aussi bien compris jusqu'à quel poinl tout est uni dans la ualure par des liaisons profondes, qui nous échappent fréquemment, mais qui n’en sont pas moins les causes intimes, secrètes souvent, toujours existantes, des phénomènes les plus divers. Jusqu’à Santa Rosa le paysage a revêtu un aspect sévère, quelquefois presque morne et désolé; de hautes monlignnes, des rochiers ardus, une végétation souvent sombre el disséminée, des herbes rares et de gorands arbres isolés, arrachés par le vent, en maint endroil, du sol trop pauvre en terre végétale pour leur permeltre d'y fixer solidement leurs racines. Toul à coup, comme par une puissance magique, les pentes amollies se couvrent de la plus riche verdure; un fouillis de plantes variées, d'arbustes feuillus, d'arbres puissants, de fougères gigantesques, de lianes pendantes entrelacent leurs branches et leurs fleurs; de chairs ruisseaux murmurent an fond des vallées herbeuses, el l'on se trouve dans cette belle région de la Haute Tera Paz qui a bien mérité d'ètre comparće à un jardin angolais créé par la nature.

Vais revenons aux sujels moins poétiques, oil se trouve pourtant la cause réelle de ce qui vient d'exciter notre admiration, el reprenons notre itinéraire góologique. Iu sortir de Santa Rosa, le chemin vient buter tout à coup contre une petite arête de calcaire grrisàtre el compacte, qui forme en quelque sorte près du flanc. de la vallée un nur vertical, un dyke large d'une dizaine de mètres el émergeant de 4 ou 5 mètres du sol environnant. C'est le prélude d'un nouvel ordre de faits qui se dessine plus netlement dans une ride monlagueuse, conıanl dans la même direction que celles que nous avons signalées précédemment, et limitant au nord ha vallée de Santa Rosa. Les calcaires qui, momentanément du moins, n'existent que dans l'espèce de mur dont il vient d'ètre question, font place à la série suivante. C'est d'abord un poudingue rougeâtre, moucheté de granules jaunàtres et empâtanl des galets arrondis assez volumineux d'un quartz blanc el opaque. A mesure que l'on gravil la cote, les galets deviennent de plus en plus petits, et l'on 
DANS LES RÉPUBLIQUES DE GUATEMALA ET DE SALVADOR. 215 arrive progressivement ì un véritable grès compacte el dur, composé de granules de quartz plutôt anguleux qu'arrondis, gros comme des oufs de poisson, el cimentés par une pàte argoilense rougge el jaune. I $c_{0}$ grè̀s lui-mème se modifie progressivement : il devient de plus en plus fin, tend à se stratilier un peu, puis forlement, et finit par passer, avec des transilions infinies el insensibles, à une masse schisteuse, d'abord grossière, presque une grauwacke, grise jaunàtre veinée el ınouchetée de rouge, puis à des schistes de plus en plus fins qui occupent le sommet de la montagne. A leur élat complet de développement, ces schistes sont composés de feuillets excessivement minces, un pen contournés, très-visibles à l'œil nu, quoique adhérant énergiquement les uns aux autres; leır nuance passe dı jaune au rouge vif el an rouge brun assez foucé, présentant des reflets brillants, presque un peu nacrés sur les plans de joint; ta roche est d'un grain très-fiı. douce el mème onctueuse au toucher, offrant une odeur irogiteuse assez intense, el happant à la langue.

L'ensemble de ce système, surtout dans les points où la stratification est nettement accusée, est dirigé de l'est $40^{\circ}$ sud à l'ouest $40^{\circ}$ nord avec un pendage de $45^{\circ}$ en moyenne vers le sud-ouest. Malhenreusement ces chiffres ne signifient pas grand'chose, car on a évidemment affaire ì un vaste plissement dont nous retrouverons d'ailleurs les traces autre part. En offet, après avoir vu le schiste pur au point culminant, on rencontre, en descendant de l'autre còté, une série de passages absohment idenliques à ceux que l'on avait observés pendant la montée, trouvant, à la limile inférieure des schistes, une première intercalation de grès formant un banc assez net d'environ 2 mètres d'épaisseur, puis de nouveau ü peu de schistes et enfin la série des transformations qui conduisent au grès et au poudingue de plus en plus grossier. La puissance de l'ensemble est d'uine centaine de mètres environ, les schistes parfaitement nets et purs occupant à peu près lia moilié supérieure de la colline, aussi bien d'un côté que de l'aulre, et le reste appartenant aux grà̀s el aux poudingues, qui se le partaggent en parties à peu près égales. Il est bon de noter que, malgré nos recherches, nous n'avons trouvé aucune trace de fossiles. Au pied de la côte du côté du nord, on trouve encore une assise de calcaire compacte et grrisâtre, puissante d'unc dizaine de mètres, qui complète l'analogie absolue des deux versants de la ride montagneuse; ce n'est probablement 
Tallée de Tactic. Sommités calcaires. Cialcaires

plus ou moins schisteux dans la vallór.

Sauta Cruz.

trigiles juunes

inasquant

les calcaires compactess. que la reproduction du dyke de Santa Rosa, el cela prouve que la chaine qui nous occupe ne doit pas seulement son relief actuel à un soulèvement compliqué de plissement, mais encore à un ravinement considérable, qui a dénudé la plus grande parlic des régions circonvoisines et isolé un simple lambeau des formalions qui accompagnent ici les calcaires.

Aprè̀s avoir franchi la côte de Santa Rosa, on atteint une large vallée naissanl plus à l'est, près du villagge d'el Patal, dirigée vers l'ouest 35 ou $40^{\circ}$ nord, el dominée par des rides monlagneuses qui doivent être calcaires à en juger par les cailloux qu'anènent les ruisseaux qui en descendent. Les alluvions modernes, plus on moins abondantes dans le fond de la valléc, laissent fréquemment apercevoir les couches sous-jacentes composées en majeure parlie de schistes argileux gris jaunàtres, alternant avec quelcques bancs compactes de calcaires blenâtres, auxquels ils passent par modifications progressives. Un peu après le village de Tactic (1,440 mètres), où la rivière commence à dessiner un coude très-prononcé, la proportion des calcaires mèlés aux schistes argiteux tend à s'auggmenter de plus en plus, et l'on arrive enfin daus une région où cette roche compose à elle seule, non-seulement les saillies un peu prononcées du terrain, mais anssi les couches inférieures de tonles les parties planes.

Il faut reconnaître que, dans la majenre partie des ondulations en face desquelles on se trouve, le calcaire u'est que rarement visible, car il est presque toujours recouvert par des amas puissants d'argiles jaunes, qui reposent au-dessus de lui en conches épaisses, sans aucun passage et sans trace de ravinements; mais, chaque fois que tes mouvements dn terrain se prononcent, la roche solide émerge el forme des mamelons comme ceux qui existent entre Santa Cruz et Cobau, où l'on peut voir de petites grottes tapissées de dépôts de carbonate de clarux affectant parfois une disposition un peu stalactitiforme.

Les argiles jaunes apparaissent pour la première fois dans les croupes qui dominent Tactic; elles couvrent le plateau de Santa Cruz et sont excessivement abondantes autour de Coban. Elles sont d'un jaune d'ocre parfaitement pur, à pâte fine, liante, serrée, ne contiemnent pas de galets roulés d'aucune roche avoisinante, el ne peuvent pas ètre altribuées à la destruction des couches de celte région, surtoul pas des calcaires. 
DANS LES RÉPUBLIQUES DE GUATEMALA ET DE SALVADOR. 217

Dans les environs de Coban ( 1,328 mètres), où nous avous séjontné quelque temps, nous avons pu observer le calcaire dans tous les ravins el dans toules les

Collin.

Calcaires

compactes. collines, avec des directions el des pendages nécessairement très-variés suivant les accidents du terrain. La roche est toujours nettement stratifiée, bien compacte, d'un gris plus ou moins blenàtre, mêlée de quelques assises jaunâtres, pénétréc dans lous les sens par des veimules blanches et cristallines de carbonate de cliaux.

Malgré toutes nos recherches, nous n'avons pu parvenir à y découvirir un seul reste de corps organisé fossile, et il est certain que, s’il y en a, ils doivent nécessairement ètre très-rares, puisque la roche calcaire compacte ne présente nulle part de couches mamenses plus tendres. Les Indiens indigènes ignorent absolument ce que peut être une coquille fossile, une coquille transformée en pierre; et cette observation, quelque puérile qu'elle puisse paraître, n’est pas inntile, puisque, dans nos pays où existent des couches fossilifères, on voit tous tes enfants joner avec ce qu'ils appellent des pétrifications; si donc il y avail des fossiles abondants, on en verrait évidemment entre les mains des enfants des villagoges indiens.

C'est ici le cas d'ajouter que, sur les bords du Rio Chisoy, à une cinquantainr de kilomètres dans le nord-ouest, nous avons trouvé nous-mêmes une trace de coquille fossile dans un des blocs calcaires accumulés le long de la rivière. Quoique l'échantillon fùt très-fruste, el engagó dans une roche très-dure, nous avons cru pouvoir y reconnailtre un mollusque gastéropode, probablement un Ptérocère. Un peu plus lard, alors que nous élions déjà de relour à Gualemala, une personne à laquelle nous avions parlé de nos travaux, et dont nous avions dirigé les recherches dans ce sens, nous a fail parvenir un échantillon qu'elle avail recueilli près de Pansos, dans une vallée adventive du Rio Polochic, au pied de channes montagneuses qui prolongent celles de Coban; c'est un petit morceau de calcaire noir renfermant l'empreinte d'un mollusque acéphale appartenant certainement an gremre Pecten, mais à peu près indéterminable spécifiquement. Pour épuiser cetr question, disons encore que, dans ta collection du Collegio Tridentino de Guatemala, il y a quelques échantillons, malheureusement sans indication précise do localité, que l'on assure provenir des environs de la lagune d'lzabal, ce qui serait encore sur la direction prolongée des montagnes calcaires de la Vera Paz. II est 
bien regrettable que l'on u'ait pas de renseignements certains sur la provenance de ces fossiles, car ils seraient d'une importance décisive pour établir l'àge des couches qui les renferment.

San Agustin

Lanquill.

Calriires.

San Crislobal. Argiles jaumes et catcaires bleuâtres. Lac. Allavions propres.

L'ouvrage de M. Morelet ${ }^{(1)}$ nous dome quelques renseignements sur ce qui existe au mord-est de Coban, dans tes régions que parcourt la route du P'elen. et nous allons les esquisser rapidement. Nous avons pu voir nous-mèmes, jusqu'an delà de San Pedro Carcha, les calcaires exister uniquement dans les collines aussi bien que dans le lil de la rivière, mais abondamment recouverts d'arogiles jaunes dans les parties planes du pays. Les calcaires prédominenl encore à Sill Agustin Lanquin, et forment les monlagnes dans lesquelles est creusće la vaste grotte à stalactites qui rend cette localité célèbre dans la Vera Paz. Ce sont em qui constituent les ondulations successives qui s'albaissent jusque vers Cajabon. mais il parait qu’ils commencent à se mélanger avec des schistes dans la série des grands ressauts qui se développent en avant dı Rio de Santa Izalbel. Les argiles jaunes, néanmoins, sont encore extrèmement abondantes, et constituent, pendant la saison des pluies, une des principales difficultés du chemin. Le mélangre des calcaires et des schistes arģileux, se trouverait encore, d'après V. Morelet. dans les petites monlagnes qui précèdent San I tuis; mais c'est leur dernière apparition, et ils s'enfoncent bientôt sous les amas tufacés, les dépôts alluvionuaires, el les aroiles qui, dans le Peten, après avoir formé les collines de Dolorès, s'étendent en immenses plaines qui préludent aux formalions madréporiques modernes du Yucatan.

Continuant notre voyage, nous sommes partis de Coban en nous dirigeant vers le nord-ouest pour gagner San Cristobal, revenant d'abord sur nos pas jusqu'ì Santa Cruz. A partir de ce village on traverse une région très-doucement ondulée, dans laquelle les calcaires compactes gris hleuadtres existent parlout en profondeur. masqués très-fréqnemment par des argiles janmes. Ces dernières prennent surtout un développement considérable aux approclıes de San Cristobal, daus une plaine bien cultivée, au milieu de laquelle un joli petit lac aux caux bleues contribue ì douner au paysage une grâce et une fraicheur pleines de charme. Le lac

(1) Voyagóe dans l'Amérique centrale, etc. 
DANS LES RÉPUBLIQUES DE GUATEMALA ET DE SALADOR. 219 de San Cristobal, assez régulièrement circulaire, peut avoir 4 ou 5 kilomètıes de diamètre; il est entouré par une bande assez large d'alluvions propres, susceptibles de fournir une lerre végétale très-fertile, sur laquelle croissent avec vigueur les plantes des champs et des jardins qui environnent le village. La plaine de San Gristobal est bornée, au sud-ouest, par une grande chaine de montagues qui court de l'ouest $20^{\circ}$ nord à l'est $20^{\circ}$ sud et la sépare de la profonde vallée du Rio Chisoy. Rien ne saurait rendre l'effet surprenant que produisil sur nons le paysage qui se déroulail à nos pieds, lorsque, dans une petite excursion, nous eùmes atteint le point culminant de cette arête : d'un còté, la ravissaute plaime de San Cristobal, le lac, le village, les molles ondulations de la Vera Paz couvertes de verdure el respirant le calme et le repos; de l'autre, J'immense ravin où gorondaient less eaux furienses du fleuve, puis, sur le bord opposé, de gigrantesques montagnes, des rochers ardus, quelques arbres suspendus aux flanes des ravins, en un mot les aspects àpres, sauvages el tout ì la fois grandioses de la province des Altos.

Celte chaine de montagnes, qui se compose, en ce que nous 'avons pu en voir, de calcaires gris bleuâtres mêlés d'une faible proportion de calcaires schisteus of de schistes argileux noirâtres, renferme, paraît-il, un nombre assez considérable de filous métallifères plombeux, dont la direction commune est à peu près du sud-ouest au nord-est. Deux seulement de ces filons sont exploités ou plutòt l'ont été, car les travaux, reconnus trop improduclifs, ont ćté momentanément arrètés : l'un, sur le versant qui regarde le Rio Chisoy, à 500 mètres an-dessous du sommet, l'autre, non toin de San Cristobal, un peu au-dessus de lia plaine dans la direction du sud-ouest. Le dernier, que nous avons surtout vu de près, se développe au milieu des calcaires compactes sur une puissance de $0^{\mathrm{m}}, 70$ ì 1 mètro environ; la gangue est formée de carbonale de claux, mêtée peut-c̀tre d'un peu de quartz, qui se montre en petils cristaux brillants, presque microscopiques, interposés entre les plans de clivage des caleaires schisteux qui conslituent les salbandes. Le minerai est une belle galène, compacte, très-pure, finement grenue et renfermant, paraît-il, une assez notable proportion d'argent. Ces galènes, srrìce à leur purcté, pouvaient ètre réduites directement par l'action du charbon dans de pelits four's à dòme en briques, d'un diamètre de $0^{\mathrm{m}}, 80$ et d'une liauleur de $0^{\mathrm{m}}, 50$, construits à peu près sur le type des fours gallois, mais avec une simpli-

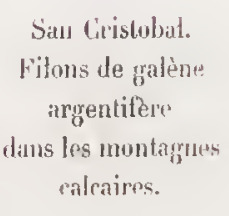


cité qui fait honneur ì la métallurgoie centro-américaine. Les plombs d'œuvre étaient envoyés en Angleterre par voie de terre jusqu’à Teleman et de là par le Polochic jusqu'au port d'emharquement définitif. Des recherches récentes ont permis de relier, par une série presque continue de gisements métallifères, le groupe des filons de galène de San Cristobal à celui de Chiantla, situé dans l'alignement de la chaine montagneuse un peu au nord de Gueguelenango, et exploité autrelois avec quelque profit par le président Carrera. Il y a douc là un système complet, qui sera fort intéressant à étudier de près quand la civilisation croissante du pays aura permis d'établir des exploitations régunlières, chose à peu près impossible aujourd'hui, surlout dans la province des Altos, si accidentée ef encore si sauvage.

De Sin Cristubal ili Rio Chisoy. Calcaires compartes et schistoux.

Schistes, wries el poudingues rappelant renx de San la Piosa.

Ce n'esl pas auprès de San Cristobal que l'on passe le Rio Chisoy pour pénétrer dans les Altos : il faut d'abord franchir un petit col qui domine le village au nord-ouest, puis marcher longtemps dans ta direction du nord-nord-ouest, en suivant, jusqu’à l'Hacienda de Los Padres, les flancs d'une profonde vallée à peu près parallète à celle du Chisoy. Les roches auxquelles on a aflaire sont uniquement des calcaires grisâtres très-compactes, ou des calcaires un peu schisteux d'un bleu noiràtre qui dominent dans le premier ressaut. Après l'hacienda de Los Padres, les calcaires gris se poursuivent encore quelque temps dans la montée que suit le chemin; puis, dans un pelit plateau ondulé, on alteint des couches puissantes de poudingues rougeâtres à gros galets de quartz blanc. On se trouve alors en haut d'une formidahle descente dans laquelle on recoupe successivement des schistes plus ou moins fins, gris ou rouges, puis des grès rouges et gris passant progressivement aux poudingues, et enfin des calcaires gris très-compactes. L'analogie de ce groupe avec celui de Santa Rosil est frappante anssi bien en ce qui concerne la nature des roches, qui sont tellement analogues que nous ne croyons pas devoir les décrire en détail une seconde fois, que pour ce qui touche à la superposition des assises. On pourrait presque croire que les couches sont dans leur superposition normale el redressées verticalement; maisil faut remarquer que les tranches des schistes ne se voient pas dans la descente, et quà Santa Rosa nous avons constaté qu'ils étaient inclinés de $45^{\circ}$, ce qui ramène forcément à l'hypolhèse du plissement que nous discuterons en temps et lieu. Ajoutons que les 
DANS LES RÉPUBLIQUES DE GUATEMALA ET DE SALVADOR. 22I schistes sont ici beaucoup moins épais qu’à Santa Rosa, et les poudingues, par contre, beaucoup plus; el, encore, que la direction reconmue est telle, que les deux groupes ne peuvent pas faire partie dı prolongement d'une mème série.

An bord du Rio Chisoy, on trouve des calcaires schisteux noirs en grande abondance, el quelques assises de calcaire compacte bleuàtre. C'est dans un bloc dr celte dernière roche que nous avous vu la trace de coquille fossile dont il a élí question plus laut.

VOYAGL DANS LA PROVIXCE DE LOS ALTOS.

(PI. VI, fig. 1.)

La province de Los Altos, qui comprend, d'après les nouvelles divisions arlministralives, tout ou partie des trois départements de Totonikapam, Quezallenango el Solola, constitue une région naturelle assez franchement caractérisée.

Province Ie Los Altos. Caractiones particulier's Son nom, dont la traduction française littérale serait eles hauts pays, " est parfaitement approprié à la nalure des choses, car elle comprend en effel les parlies les plus élevées de la république de Guatemala, depuis les territoires accidentés du nord jusqu'aux élargissements de la grande arête montagneuse qui atteignent, dans la partie la plus peuplée el la plus riche du pays, des allitudes comparables el supérieures mème à celles des plateaux mexicains. Les caraclères particuliers de cette région dépendent direclement, pour la plupart, de ses allures orographiques; tels sont ses champs de blé el d'orge, ses cultures d'arbres fruitiers curopéens, ses épaisses forêts de pins el de chènes; mais elle se dislingrue aussi par les races indigènes, qui sont presque seules à l'habiler, par leurs types, leur's mœeurs el leurs costumes, qui se rapprochent plus que partout ailleurs des inliques traditions antérieures à la conquête espagnole. Les paysages des Altos ont un cachet de màle beauté el de grandeur sauvage qui impressionne vivement le voyageur; ses lautes monlagones couvertes d'une puissante végétation, ses plaines herbeuses, ses lacs, qui réflètent l'admirable ciel des tropiques, ont un je ne sais quoi qui rappelle les aspects du nord au milieu des pays cliauds; on y retronve nos belles régions montagneuses des $\Lambda$ lpes, colorées par te voisinage revivilianl de l'équateur, el l'on ne saurait ètre laxé d'exagúration en appelant celle pilloresque province la Suisse de l'Amérique centrale. 
C'est par la frontière du nord-est que nous avons abordé les Altos, pour tratverser d'abord une des parties les moins connues el les plus pittoresquement saurages de celle province, à une vinglaine de kilomètres tout au plus des terres vierges qu'llabitent les tribus barbares des Lacandons el des Mayas, el que n’a point encore foulé le pied d'un lıonme civilisé, qu’il soit blanc ou mélis, européen on indigène de l'Amérique centrale. Les immenses territoires que possèdenl ces peuplades sont censés faire parlie des Altos et constituer le nord de la province; mais la suprématie du gouvernement de Guatemala y est purement nominale, théorique, pour ainsi dire, car personne n’y a jamais pénétré, et le village de Nebak est le dernier, dans celle direction, où apparaisse tous les trois mois un agent de l'iutorité el du fisc qui sert de lien entre le pouvoir central el les municipalités indiennes, à peu près indépendantes de fail.

Direction

in l'itinépaim.

La limite entre la Vera Paz et les Altos est formée en ce point par le Rio Chisoy, dont nous avous alteint les bords dans un précédent itinéraire el décril sommairement la gigantesque vallée. A partir de ce fleuve, nous avons marclié, dims le voyage dont il est arctucllement question, vers le sud-ouest, jusqu'à Queyaltenango, capilale de la province des Altos; mais, de celle ville, notre roule se détourne au sud-est pour regogagner Guatemala, en suivant à peu près la direction de la ligone de faîle dont elle s'écarte parfois, mais pour y revenir bienlòt après. On pourra suivre cet itinéraire sur la figure 1 de la planche VI el la figrure 1 de la planche VII, représentant des profils géologiques qui se rapportent, le premier presque en enlier, à la parlie du voyage qui va du Rio Chisoy à Quczallenangog, le second, dans une de ses extrémités seulement, à la roule de Quezaltruango à Guatemala. Il n'est pas sans importance d'observer que, du Rio Chisoy à Quezallenango, on suit un chemin qui fail un angle d'une quarantaine de degrrés tout au plus avec celui de Coban à Guatemala, el recoupe ainsi le prolongement des mèmes chaines lout en s'éloignant beaucoup plus que lui de la nolinale à leur dircetion générale. Comme on peut aisément le prévoir d'avance, les grands trails géologiques du pays resteront à peu près semblables, mais il s’introduira des différences de détail quelquefois assez saillantes pour donner un vivant intérè̀ ì la comparaison. On remarquera surtoul le déplacement et le singulier rétrécissement de l’arète granilique ainsi que de son escorte de schistes méli- 
DANS LES RÉPUBLIQUES DE GUTTEMALA ET DE SILVADOR. $22 ?$ morphiques, absorbées d'un còté par le système des calcaires, de l'autre par celui des porphyres qui prennent un développement considérable.

An point où l'ou franchit le Rio Chisoy (566 mètres), le fleuve courl presque directement à l'est entre d'immenses monlagnes à peules excessivement roides. presque des falaises, qui dominent de près d'un millier de mètres le fond de la valléo où il roule ses eaux profondes el rapides pendant la saison des plnies. On se trouve douc en présence de l'un de ces passages brusques de la lerre lentpérée à la terre chaude, où les végétations et les aspects subissent des modificalions si rapides et si radicales, que l'on en est presque toujours élonné, bien que l'on puisse aisément les prévoir d'avance. Tandis que les palmiers entonrent la misérable cabane où vit isolé le gardien du pont, on peut voir, en levant los yeur, les pins agiter leurs branches sur le hant des rochers qui couronnent les sommilés environnantes.

Sur l'une et l'autre rive du fleuve, les calcaires compactes bleuàtres et les calcaires arogileux d'une nuance un peu plus foncée constiluent aussi bien le sol luimème que les blocs el les cailloux roulés qui se mèlent aux sables blancs déposés par les eaux sur les bergeses aux points où elles ne sont pas trop aljruptes.

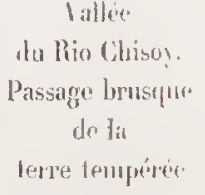
lerte temperere. La vallée, qui, d'un côlé, cour' à perte de vue dans l'ouest avec des ondulations assez prononcées et, de l'antre, se délourne vers le sud après s'ètre prolongére neltement dans l'est pendant une quinzaine de kilomètres, semble ètre'due bien moins à un ravinement qu’à un de ces immenses plissements dont les traces so retrouvent à chaque instant dans les traits géologiques de celte réggion. Un ravinement aurait dù être trop giggantesque pour qu'on puisse aisément admeltre son existence, et d'ailleurs rien ne viendrait ì l'appui de cetle hypolhèse en monIrant une coucordance quelconque dans les allures des couches sur les deux flancs de la vallée; un plissement, au contraire, est d'accord avec les faits généraux de la góóogogie des chainnes de montagnes parallèles qui sillomnent le versant de l'Allantique. La vallée du Rio Chisoy est done une véritable vallée de plissement, et diffère essentiellement des barrancas, qui doivent tenr existence et leurs parois verticales à l'érosion directe produite par les eaux.

Quoi qu'il en soit, le chemin par lequel on pénètre dans la province des Altos, après avour franchi le cours du Rio Chisoy, se conlinue pendant assez longtemps

$$
\begin{aligned}
& \text { La vallée } \\
& \text { du Rio Chisos } \\
& \text { est une vallée } \\
& \text { de plissement. } \\
& \text { Calcaires compactes } \\
& \text { et schislentx. }
\end{aligned}
$$


dans la direction de l'est en suivant le cours du fleuve, mais en s'élevant peu ì peu sur le flanc des montagnes qui longent en la dominant sa profonde vallée. Les roches que recoupe le sentier se composent presque uniquement de calcaires gris bleuatres compactes, dans lesquels s'intercalent de temps en temps quelques lits peu puissants de schistes argुileux gris jaunâtres assez amalogoues à ceux que nons avons vus dans la vallée de Tactic. Après avoir ainsi alteint une élévalion assez considérable au-dessus du cours du Rio Clisoy, dont on n’a cessé de longer la vallée pendant une douzaine de kilomètres, on la quille brusquement ponr se détourner ver's le nord en s'enfonçant dans une petite gorgae adventive, où to chemin monle avec une grande rapidité, et rejoint bientôt une lig̣ne de crètes plus ou moins accidenlées.

Patuau ondulé.

Calcaires

ot schistes. Dépôts superfiriels.

Schisinos. grise of poulingures.

On se mlaintient toujours dans les calcaires, tout en s'élevant doncement, jusqu'ì la pelite plaine du Rimcho de la Cruz, où ces roches sont souvent dissimulées par une conche plus on moins puissante de lerre végélale. Ce sont encore les calcaires, entrecoupés de lemps en lemps par de pelites assises de schistes argilenx gris jaunâtres, et nème parfois de schistes talqueux colorés en gris verdàtre, qui constituent toutes les ondulations suivantes jusqu'au pelit village de Chicanan, silué dans une sorte de liaute vallée entourée de grandes crètes monlagneuses el comblée en partie par d'épais dépôts d'argiles jaunes. Le pelil cours d'eau qui y circule se dirigge assez nettement vers l'est et doit rejoindre le Rio Chisoy, en rachelant par d'innombrables cascades la forte dénivellation qui l'eu sépare.

Un peu au delà du village de Chicanan, les accidents de terrain se prononcent de plus en plus, tout en s'élevant d'une manière assez franchement accusée, et l'on aborde bientòt une petite assise fortement inclinée de schistes gris et rougeàtres, auxquels succède bientôt an développement considérable de poudingues plus ou moins grossiers passant par points aux grès dur's el compactes, colorés en jaune ou en rouge. Qunoique l'ensemble ne soil pas très-facile à éludier sous les dépoìs superficiels el les masses d'altération qui le masquent assez fréquemment, on ne peut pas douter que l'on n'ail affaire à un système absolument semblable à celui que nous avons étudié à Santa Rosa el sur la rive droile du Rio Chisoy (voir au voyage dans ta province de la Vera Paz); inais, grâce à l'incertilude des 
DANS LES RÉPUBLIQUES DE GUATEVALA ET DE SALVADOR. 225 positions géeographiques, il est assez difficile de décider si la présence de ces assises dans celte localité doit être attribuée à un nouvean plissement, ou si l'on est resté dans l'alignement naturel des couches rencontrées dans les falaises du Rio Chisoy. Au groupe des schistes, des grès el des poudingues, succèdent des assises calcaires grises, qui ne sont visibles que peu de temps, car le tout disparait bientôt sous une puissante formation superficielle.

Ces dépôts modernes commencent à recouvrir les dernières ondulations que l'on doit franchir avant d'atteindre le pelit plateau où est construit le villigge de San Miguel Uspantan (1,840 mèlres); mais ils se développent surtout dans cette plaine, qui n'est en réalité qu'un élargirssement assez notable d’une laute vallée que l'on suit déjà depuis quelque temps el où court un ruisseau qui rejoint le Rio Chisoy en descendant rapidement vers l'est. Les argiles jaunes forment la couche supérieure, souvent assez épaisse, et laissent apparâille de temps en temps, surtout dans les points où elles ont été entaillées par le cours de la petite rivière, des masses de sables blancs fins et pur's, peut-être siliceux, qui ne sont probablement que le résultat de la destruction des margmas lufacés à ponces blanches qui leur sont subordonnés et se voient dans les flancs de quelques ravins. La vallée, au delà de San Miģuel Uspantan, s'élève doucement, mais d'une manière continue, dans la direction de l'onest, et, à mesure que les dépôts superficiels diminuent de puissance, on voit revenir par moments au jour les calcaires bleus el gris noirâtres, qui n’ont évidemment pas cessé de constiluer le sous-sol à une profondeur plus ou moins considérable.

Ces mêmes calcaires sont remplacés progrressivement, puis d'une manière prèsque absolue, par des schistes argileux gris jaunàtres, très-fissiles, souvent un peu décomposés à la surface; ces schistes forment le ressaut laiblement ondulé qui sépare le bassin du ruisseau de San Mignel Uspantan de celui d'une autre rivière un peu plus importante, dont le cours est sensiblement parallèle à celui de ce dernier, et qui va, comme lui, rejoindre le hio Chisoy, du côté de l'est.

Au moment d'aborder la profoude vallée où se précipilent les eaux de cel important aflnent du Rio Clisoy, on rencontre une puissante assise de calcaire compacte bleu noiràtre, à laquelle succèdent, dans les flancs mèmes du ravin, des alternances infinies de calcaires et de schistes argileux. La succession de ces

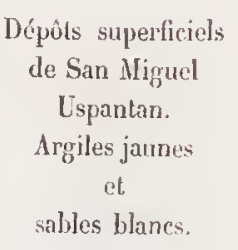

Schistes argileux.

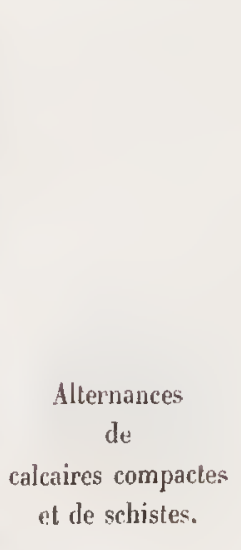


deux roches est trop souvent répélée pour ne pas amener à supposer que les choses sont, en réalité, plus simples qu'elles ne le paraissent, et que l'on recoupe plusieurs fois les mèmes couches, ramenées au jour à plusieurs reprises par les vigoureux plisscments auxquels la vallée elle-même doit assurément son existence. Arrivé au fond du ravin, on franchil successivement deux cours d'eau qui se réunissent à une centaine de mètres plus bas, mais qui sont encore séparés, au point où le chemin les traverse à gué, par une pelite arête calcaire qui s'élève peu à peu et prend, dans la direction de l'ouest, un développenent assez considérable. Celle des deux rivières qui descend de la vallée de Gunen roule un volume d'eau assez imposant, el, dans l'endroit où elle vient barrer le sentier, au fond d'une gorge abrupte el sauvage, entre des rochers à pic, au-dessus d'une cascade bouillonnante, le passage à gucé au milieu de ses flots profonds et rapides n’est pas sans inspirer au royageur de légitimes appréhensions. En suivant la rive droite - de ce torrent, on remonte sur les flancs fortement inclinés dn ravin où il se précipile, et l'on retrouve les alternances de calcaires et de schistes que l'on avait observées sur la rive opposée.

Vallée de Ciunen. Alluvions unorlernes.

IIontagnes entre Ciunen et Zacapulas. Schistes argilenx
Tout à coup, après une pénible ascension, ou débouche dans une plaine l'ertile où les roches ci-dessus mentionnćes disparaissent sous des alluvions modernes et de la terre végétale, qui permeltent d'établir les champs que cultivenl les lndiens du village de Cunen (1,811 mùtres). Celte plaine, large de 5 ou 6 kilomètres el longue d'une vingotaine, n'est en réalité qu'une haute vallée dominée à droite el à gauche par de gorandes montagnes qui se rejoignent vers l'ouest et la ferment ainsi complétement. La rivière, dont les eaux y circulent paisiblement, y pénètre au point où les sommités se rapprochent, on formant une imposante cascade, qui prouve qu'il existe en arric̀re une autre vallée plus élevée encore et de hautes régoions assez étendues pour donner naissance à un cours d'eau d'une certaine importance.

Au sortir de la vallée de Cunen pour gagner Zacapulas, le chemin se dirige quelque temps vers le sud, et franchit la ligne de hauleurs qui la limite de ce côté. Les roches que l'on y observe se composent presque essentiellement de schistes argileux gris ou verdâtres, alternant de loin en loin, avec de puissantes assises de calcaires bleus très-compactes. Une fois arrivé au sommet de celte arète 
DANS LES RÉPUBLIQUES DE GUATEMALA ET DE SALVADOR. 227 montagneuse, on s'aperçoit qu'elle sépare du bassin de l'un de ses affluents, qui lui est à peu près parallèle pendant une partie de son cours, la vallée du Rio Chisoy lui-même, qui roule ses eaux ì plus de mille mètres au-dessous de l'endroit d'où on le domine alors presque immédiatement. Du point culminiant on jouit d'une admirable vue d'ensemble sur les régions environnantes, et l'on peut éludier en particulier, sur une assez grande étendue, le cours du Rio Chisoy, qui, descendaut d'abord à peu près de l'ouest à l'est, so dévie brusquement vers le nord et reçoit alors, aussi bien d'un còté que de l'autre, une série d'affluents dont les vallées sont ì peu près paratlèles ì la direction prinitive du fleuve principal.

La descente de la grrande còte, qui, de la sommité que l'on vient d'alteindre, conduit jusque daus le fond de la vallée du Rio Chisoy, est fort instructive au point de vue géologique. On commence par marcher obliquement le long des flanes de la montagne, en recoupant des schistes argileux grisitres alternant avec des calcaires, sensiblement analogues à ceux qui apparaissent sur le versant opposé, du còté de Cunen. Cela se prolongoge pendant près de 500 mètres dans la verticale, mais tout à coup, à peu près au milieu de la descente, la nature du sol change complétement, et l'on se trouve sur une puissante assise de poudingues grossier's à pâte jaune ou rougeàtre el à goros rogunons de quartz blanc laiteux. On a évidemment affaire à un des membres de la série de Santa Rósa; mais il ne nous est malheureusement pas possible de dire si les couches concomilantes de schistes et de grès sont simplement dissinulées par des masses d'altération superficielles, ou si elles ont été amincies et presque réduites ì néant pir les phénomènes de plissement et les dérangements considérables dont cetle chaỉne a cerlainement été le théàtre. Quoi qu’il en soit nous n’avons vu en ce point que les poudingues à gros galets de quartz, assez puissants, il est vrai, puisqu'ils altejognent une épaisseur d'au moins 80 mètres dans la verticale, mais en contact immédiat par en bas avec des couches tout à fail différentes, sur lesquelles ils reposent.

Ce soult des schistes talqueux et chloriteux, tantôt verts, tanlôt presque noiràtres, qui occupent lout le reste de la montagne jusqu'au fond de la vallée, avec Schistes talqueux el chlorileux. une puissance qui est donc d'environ 400 mètres dans la verticale et une inclinaison moyenne d'environ $45^{\circ}$ vers le nord. Il ne serait pas étonnant que ces

chistes argileu. el calcaires. Pourlingues. 
schistes, presque certainement sédimentaires et fort anciens, aient subi une action mélamorphique assez intense, à laquelle ils dussent, au moins en partie, leur aspect actuel et les substances qui entrent dans leur composilion; ils ne sont pas tonjours absolument semblables à eux-mèmes, et si, dans certains cas, on les voit sous la forme de masses noirâtres, assez compácles, ressemblant à des ợrauwackes, dans d'autres, les couches finement stratifiées se composent d'une pâte d'un blanc laileux dans laquelle se disposent des feuillets de talc ou des paillettes de chlorite colorées en vert plus ou moins foncé.

Fond de la ralléc. Granits.
Sources thermales alcalino-chlorurées de Zacapulas.
Tout à la base des parois presque verticales qui plongent leur pied dans le fleuve, les schistes dont il vient d'être question sont brusquement arrètés par des granits qui occupent le fond mème de la vallée, et semblent avoir été mis à nu gràce aux érosions produiles par les eaux du Rio Chisoy dans une profonde vallée due en grande partie à des phénomènes géologiques antérieurs. Ce granit forme des masses compactes mais un peu fissmrées el altérćes dans les points où efles ont été soumises à l'action des aggents almosphériques; il se conpose de deux feldspalhs, dont aucun ne présento les stries caractéristiques de l'oligoclase, le plus abondant étant d'un blanc rosé, l'autre d'un vert tendre; de quartz, presque transhucide, est d'un violel qui rappelle la nuance de l'amétlysste; enfin le mica est d'un noir à reflels mordorés; l'ensemble de ces couleurs donne à la roche une fort jolie teinte. Le granit n'apparaît que dans fort peu de points de la vallée, car il est presque partoul recouvert par les énormes quantités d'alluvious, de sables et de cailloux roulés qu'amònent aulour de Zacapulas $(1,160$ mètres) les deux rivières, le Rio Blanco et le Rio Negro, qui se réunissent un peu au-dessus de cetle ville pour former le Rio Chisoy proprement dit. Néanmoins, c'est encore celte roche qui, après avoir disparu pendant assez longtemps sous les dépôls superficiels de la rive ganche, forme, sur la rive droile, le petit mamelon surélevé où est construit le gros bourgo de Zacapulas, à l'ahri des eaux du fleuve, qui coule rapide et impétneux au pied de ses parois polies par les llots.

Tout à côté de Zacapulas, on peut observer des sources thermales assez intéressantes, dont la plupart s'épanchent directement du granit. Un premier groupe se compose au moins d'une vingtaine de sources réparties le lonğ du Rio Chisoy, sur une longueur d'une centaine de mètres environ, sorlant des berges dı fleuve, 
DANS LES RÉPUBLIQUES DE GUATEMALA ET DE SALVADOR. 229 et si près de lui, qu'il en recoure quelques-unes lorsque ses eaux sont hautes. Les tempéralures sont assez variables, ainsi que l'attestent les chiffres suivants, résullats de nos observations en 7 points différents :

$$
41^{\circ}, 80 .-47^{\circ}, 20 .-49^{\circ}, 00 .-52^{\circ}, 80 .-53^{\circ}, 20 .-58^{\circ}, 00 \cdot-70^{\circ}, 10 .
$$

Les eaux de ces sources présentent un goùt à la fois salé et amer, qui rappelle celıi de l'eau de mer et semble dù à la présence simultanée du chlorure de sodium el du sulfate de magnésic, ainsi que le prouve la manière dont elles se conduisent avec les divers réactifs suivants :

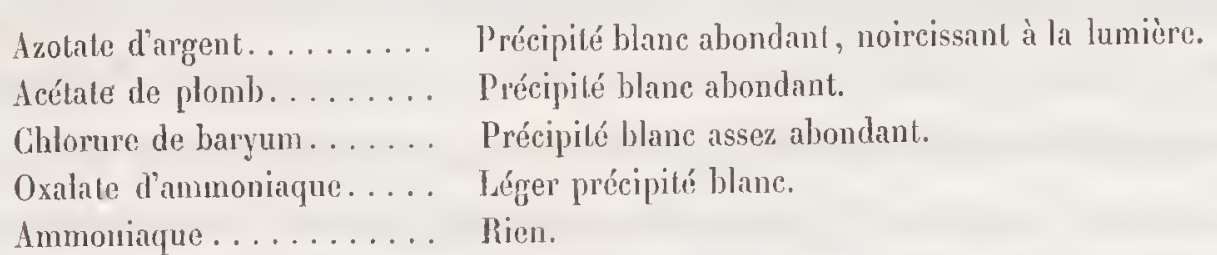

Un autre groupe de somrces existe à l'est de la ville; mais elles sont un peu moins nombreuses, el ne présentent pas des caraclères aussi nettement accenlués. Leur température n'est que de $33^{\circ}, 50$, probablement parce qu'elles sont mêlées à des sources froides ordinaires, el leur's réaclions sont moins énergiques, surtout en ce qui concerne la présence des chlorures. Ce sont pourtant ces dernières sources qui ont été clioisies par les indigènes pour en faire le siége d'une exploitation de sel, dont les procédés primilifs ne sont pas absolument dénués d'intérêt.

Aulour de quatre ou cinq des points oì l'ean salée s'épanche hor's du sol, on a crensé de main d'homme de pelits bassins circulaires, d'environ $1^{\mathrm{m}}, 50$ de dianıètre, grossièrement muraillés en pierres sèches et répartis indifféremment sur une pirc lins Indicns. sorte de pelite plaine, longue de 300 à 400 mètres et large de 200 à 250 mètres, qui s'étend le long du Rio Chisoy. Cette plaine, probablement déjà préparée par la nature, a été artificiẹllement arrangée d'une façon plus complète el disposée de manière à ce que le sol en soit composé d'une couche assez épaisse de sable terreux, à travers laquelle circulent des rigoles qui divergent des bassins dont il a été question. L'eau salée est ainsi répartie dans les différents points de la plaine, et imprègne le sable dont le sol est formé; lorsque l'on juge que la quantilé d'eau 
doit ètre suffisante, on arrête l'arrivée de l'eau, el le terrain est soumis à l'influence des rayons solaires; on voit ljientòt la couche supérieure se garnir d'efllorescences salines qui la couvrent d'une sorte de neige blanche et cristalline. On produil ainsi des terres riches en sel, qu'il est beaucoup plus aisé d'oblenir pendant la saison sèche que pendant la saison des pluies, ainsi qu'on le comprend liicilement. Ces terres salées, après avoir élé recueillies soigneusement à la surface de la plaine oì elles se produisent et conservées en tas à l'abri de l'humidilé, si l'on ne peut pas s'en occuper immédiatement, sont traitées de la manière suirante. On en remplit une sorte de claic prismatique en osier tressé, qui forme un filtre carré, de 80 centimètres de còté el profond de 60 centimètres. Celle claie est maintenue par un cadre de bois an-dessus d'une énorme jarre eu terte cuile, destinée à recueillir les eaux, et le cadre lui-mème est soutenu par des tas de terre qui environnent la jarre de trois côtés. Lorsque la claic a été bien remplie de terres salées comprimées, on y verse de l'eau recueillie aux sources dont il élait question plus haul, et on laisse celte eau s'écouler lentement ì travers la masse dont elle dissoul progressivement les efflorescences salines; on répète le passagge deux ou trois fois, si c'est nécessaire, pour entever à la terre toutes les matières dont elle est imprégnée. Les terres pauvres sont rapportées dans la plaine voisine des sources, oì elles sont soumises à un nouvel enrichissement; quant aux eaux salées, on les introduit dans une série de petils pols en terre cuite, lauts de 18 centimètres el larges de 8 centimètres, dans lesquels elles doivent être soumises à la concentration. A cet effel, on en empile plusieurs centaines le long des murs d'une petite maisonnette en pierres, dont la surface peut ètre de 4 mòtres carrés el la hauleur de $1^{\mathrm{m}}, 50$, en séparant les couches successives an moyen de planches, et l'on allume au milieu un bon feu de fagots, que l'on entretient pendant loute une journće. Au bout de ce temps, l'eau étant entièrement évaporée, les parois de chacun des pelits vases en terre cuite sont recouvertes de croûtes salines d'une blancheur qui n'est pas absolument irréprochable. Les croûtes sont détachées par un gratlage à la main, puis rédrites en poudre entre deux pierres, et l'on obtient ainsi un sel grisâtre et impur qui est vendu aux tribus indiennes du voisinage. Ces procédés datent probablement d'un nombre considérable de siècles, et sont tellement enracinés dans l'esprit des 
DANS LES RÉPUBLIQUES DE GUATEMLLA ET DE SALVADOR. 231 indigènes de Zacapulas, que, malợré tous les efforts qui ont été faits par quelques personnes intelligentes pour introduire des perfeclionnements aussi utiles qu'élémentaires, il leur a été impossible d'amener une modification quelconque dans les méthorles primilives, mais vénérées, que charque Indien a reçes, par tradilion, de ses pères, et qu'il doil laisser intactes et immuables ì ses enfants.

I l'ouest de Zacapulas, les granits rosés à deux feldspalhs, parfaitement semblables à ceux dont nous arons parlé plus haut, constiluent pendant assez longtemps les berges du Rio Chisoy, sur les deux rives; mais, si l'on s'élève un peu sur les flancs de la vallée, on les voit bientòt disparaitre sous des conglomérats sableux à gros cailloux roulés graniliques, qui sont peut-ètre des alluvions propres ilu fleure. En quelques points, ces conglomérals contiennent dans leurs conches supérieures un nombre considérable de blocs de schiste talquo-chlorileux verdàlre, anģnleux el non roulés, ce qui permet de supposer qu'ils proviennent d'un lambeau sous-jacent de cette roche, masqué par les formations superficielles, ou plutôt, peutl-être, d'un éboulement descendu des monlağnes qui couronnent le llane sud de la vallée. Quoi qu’il en soit, on ne voit pas les schistes talquo-chloritenx en place, el l'on se retrouve bientòt sur des granits qui émergent des congglomérats; mais ces granits ne sont pas les mèmes que ceux du fond de la vallée: ils ne renferment qu'un senl feldspath, et tour nuance générale jaunàtre rappelle ceux que nous avons olsservés ì El Carrizal (voyage dans la Vera Paz). La présence, dans deux points extrèmement voisins, de deux granits différant complétement d'aspect el de coinposilion, est un fait fort intéressant, qui mériterait d'être étudié avec plus do soin que nous n'avons pu le faire.

Le chemin continne à s'élever vers le sud-ouest, en moulant progressivement le long du flanc de la vallée et sans quitter les granits jaunàtres à un seul feldspath, qui règonent jusqu'ì une petile plaine où sont établies quelques pelites hulles d'Indiens. Ce point est une sorte de noud où l'on voil me chaine adventive venil'
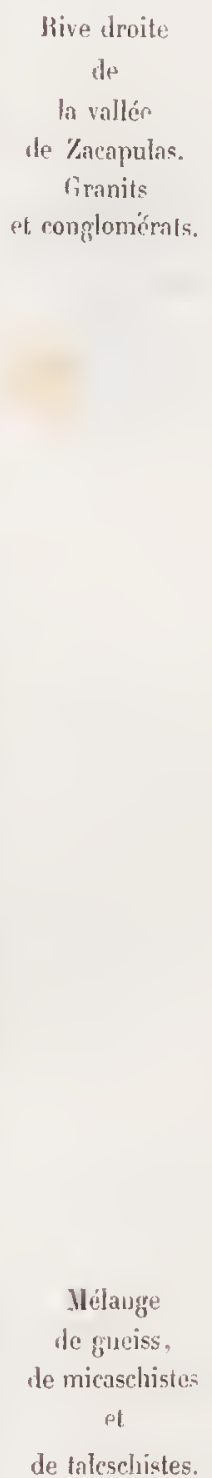
se souder, pour ainsi dire, sur la chaine principale, el continuer, après un pelit crochet, ì suivre une direction parallèle à celle de la première. La chaîne advenlive longe le cours du Rio Blanco, l'une des branches du Rio Chisoy qui se dédouble près de là, et semble se eomposer de granits qui continuent la formation sur laquelle on a marché jusqu'alors. La chaîne principale, au contraire, s'un- 
fonce dans lintérieur des terres en dominant un vallon secondaire, et le chemin qui la recoupe y montre nne série de roches assez mal définies en général el entremólées de manière à rendre la délermination des limiles ì peu près impossible, sans un examen beaucoup plus prolongé que celui que nous avons pu en faire. C'est un mélange de goneiss, de micaschisles el de talcschistes, blancs, jaunitres, on légèrement colorés en vert, qui se snccèdent el se remplacent à plusieurs reprises, et dont l'étude est de plus singulic̀rement compliquée par les éboulements et les altérations superficielles rendus fréquents par la nature friable de ces roches.

Phatcau

te Sauta Cruz del nuiché

Ponplyyrus.

Une lois arrivé au sommel de la côte, on s'aperçoit qu'au lieu d'une véritable chaine de montagnes on vient de gravir le flanc d'une gigantesque entaille formant le bord extrême d'un plateau fort étendu. En effet, après avoir franchi uu pelit ressaut dans lequel le granil se montre encore une fois avec des caractères assez nets, quoique fortentent altéré à la surface, on voil se développer devant soi une plaine très-vaste, dont le sol est accidenté de nombreuses ondulations plus ou moins prononcées, el où la constitution géologique subil une nouvelle modificafion. Le remplacement des granils par les porphyres se fail assez brusquemenl, et, dans la seconde colline que l'on rencontre, on voil nellement la nouvelle roche; c'est une pâte feldspallique assez compacte, d'un gris violacé caractéristique, renfermant des cristaux à peu près définis d'orthose blanc et de nombreuses mouches noires, probablement d'amphibole. Mais ces porphyres n'apparaissent au jour que pour fort peu de temps, et ils sont presque immédiatement recouverts par d'épaisses masses d'argiles jaumes qui enveloppent tonles les ondulations suivantes; mais on peut néanmoins affirmer qu’ils continuent à constituer les couches inférieures du terrain, car ils percent le sommet de quelques collines et se montrent notamment avec une grande puissance dans la profonde entaille creusée, non loin de Santa Cruz del Quiché, par la cascade d'une petile rivière.

Les argites jaunes prennent un développement énorme dans la belle plaine de Santa Cruz del Quiché (2,018 mètres), el persistent dans les environs avec une telle intensilé, qu'elles opposent un obstacle sérieux aux investigations géologiques dans le puissant ressaut monlagnens qui sépare ce plateau de celui de Totonikapam. Pourtant, dans le profond ravin que l'on doil franchir quelque temps 
DANS LES RÉPUBLIQUES DE GUATEMALA ET DE SALVADOR. 233 après avoir dépassé le village de Palsite, on atteint les assises inférieures, que l'on trouve composées d'un porphyre gris, tantôt nuancé de rose, tantòl violacé, parfaitement analogue à celui que l'on avait rencontré précédemment. Celte même roche se distingue encore en quelques points de la grande còte qui suit, mais ce n'est en quelque sorte que par accident, et les argiles jaunes déposées sur le sol se retrouvent avec une grande épaisseur jusqu'au point culminant de la crête montagneuse à 2,854 mètres d'altitude.

Cette hauteur correspond à un col environné de tous côtés de sommilés bien plus élevées encore; c'est qu'en eflet on vient d'alleindre la ligne de partage des eaux, représentée par la gigantesque châne de montagnes qui constitue l'arète principale du pays et atteint, dans cette région, ses allitudes les plus considérables. 11 est étrange de voir la roche constiluante masquée par des dépôls superficiels d'origine myslérieuse, dans les points mêmes où elle a été soulevée aux plus grandes liauteurs et où il semble que les porphyres, qui sont l'ossature de tout le système montagneux, eussent dû se dégager aisément de ce manteau d'argoiles jaunes que l'action destructive des agents atmosphériques el en particulier des averses terribles de la saison des pluies suffiseut à peine pour entamer en quelques endroits. En descendant sur le versant opposé, on voil les porpliyres assez nettement mis au jour dans les ravins creusés par quelques torrents, qui se précipitent entre la chaîne montagneuse principale et une autre ligue de crêtes parallèle à la précédente et presque aussi élevée, qui se soude à elle ì quelque distauce dans l'est. On passe ce second ressaut à une altitude considérable, mais encore dans les argiles jaunes qui recouvrent même, comme on peut le voir dans la descente suivante, une forte épaisseur de conglomérats porphyriques, interposés par points entre elles et la roche solide, sur des pentes où il semblerait que le porphyre compacte puisse seul résister à la dénudation. Il n’en est pourtant pas partout ainsi, et en bien des endroits le porphyre grisâtre ou violacé apparait au jour, le long du clıemin qui serpente sur les flancs de la montagone pour descendre à Tolonikapam.

La vallée de Totonikapam (2,484 mètres) est profondément entaillée, dans le voisinage de la ville, par le cours d'une rivière qui s'y est creusé une vaste barranca, dans les parois de laquelle on peut étudier la composition du sol. On y

Chaîne centrate.

Porplyyre souveut recouvert d'argiles jaunes et de conglomérats. 
voit, sur une épaisseur d'environ 130 mètres, des masses énormes de ponces blanches accumulées en petils fragments et reliés par une sorte de sédiment sablonneux; au-dessus vient une assise assez puissante d'un magma argilo-tufacé blanchâtre, que recouvrent des argiles jaunes supportant elles-mêmes directement une terre végétale plus ou moins abondante. Les argiles jaunes continuent d'ailleurs à être l'élément principal des portions apparentes du sol; ce sont elles qui recouvrent la majeure partie des collines, dont est accidenté le plateau ondulé qui s'étend entre Totonikapam et Quezaltenango, aussi bien que les plaines plus basses et les larges vallées où circulent lentement quelques rivières. Dans les falaises qui bordent ces pelits cours d'eau, on voit qu'elles sont superposées à de puissants dépôts de magomas ponceux, qui onl en quelque sorte nivelé el comblé les creux plus ou moins profonds existant entre les sommités porphyriques, dont les pointes roclieuses percent parfois encore les argites jaunes dans les endroits les plus accidentés.

Roches vitrifiées antour de Quezaltenango.
La belle el vaste plaine de Quezaltenango ( 2,346 mètres), dont le sol a la mème composition el sans doute la même origine que celui de la large vallée de Totonikapam, ì laquelle elle se relie d'ailleurs insensiblement par une série d'ondulations plus ou moins prononcées, vient s'appuyer, vers le sud, sur des crêtes montagneuses qui servent en quelque sorte de base à la ligne volcanique arrivée ì se rapprocher sensiblement de l'arête principale de l'Amérique centrale et à se confondre presque avec elle. La majeure partie de ces sommités se composent d'un porphyre trachytique toujours parfaitement reconnaissable, quoique parfois un peu altéré dans divers sens; mais dans les contre-forts rocheux qui forment la base de la montagne volcanique, connue sous le nom de Cerro Quemado, on rencontre en ahondance des masses assez singulic̀res exploilées près de la ville pour ses construclions. C'est une roche se rapprochant plus de la phonolite que de toule autre chose, composée d'une pâte feldspathique du blanc le plus pur, percée d'une multitude de cavités qui lui donnent l'apparence boursouflée des picrres ponces, mais beaucoup plus dure et sensiblement plus vitrifiée que ces dernières, renfermant de nombreuses mouches noires d'amplibole, s'écrasant avec difficulté, mais sans se rompre, sous le choc du marteau. Il semble que l'on ait affaire à la surfusion en masse d'une montagne porphyrique tout entière, ramollie par le voisinage 
DANS LES RÉPUBLIQUES DE GUATEMALA ET DE SALVADOR. 235 d'une puissante éruption volcanique, modifiée dans sa composilion minéralogique et traversée dans tous les sens par des bulles de gaz qui lui ont donné l'apparence caverneuse qu'elle a conservée.

Il existe autour de Quezaltenango, dans un rayon assez élendu, un groupe de sources minérales dont nous devons dire quelques mots. Les plus importantes se Sources thermales des environs trouvent dans la vallée d'Almolonga, à environ 5 kilomètres au sud-sud-ouest de de Quezaltenangon. Quezaltenango. Il y en a deux seulement, et elles ont respectivement pour température 51 et 45 degrés; l'eau est à peu près insipide et inodore, mais comme grasse el onctueuse au toucher; les réactions chimiques de ces sources sont les suivantes :

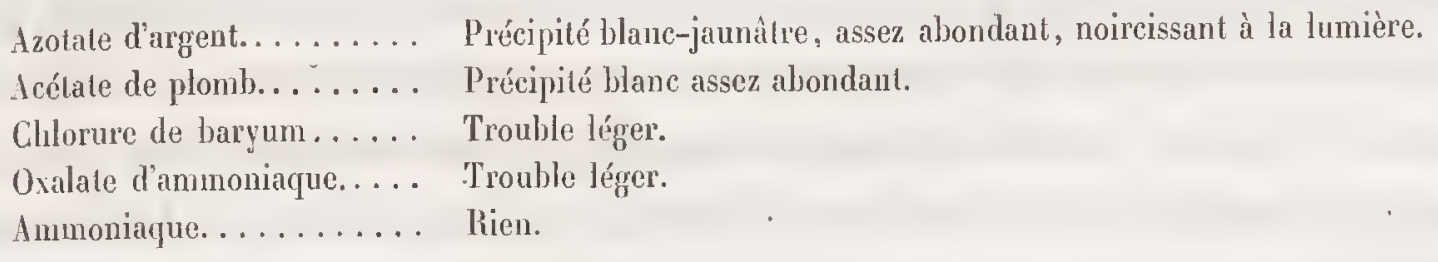

I San Cristobal, au nord-est de Quezallenango, il y a une source puissante dont la température ne dépasse pas $31^{\circ}, 30$. L'eau présente un goùt acidulé et comme savonneux el se conduit avec les réactifs d'une façon analogoue à la précédente. Il parât qu'il existe une sonrce du même genre à un kilomètre de Totonikapam: nous n'avons pas pu aller la visiter, mais il est probable qu'elle doit ètre alcalino-chlorurée conme celles que nous venons d'énumérer.

Si, de Quezaltenango, nous reprenons notre itinéraire pour nous diriger sur Guatemala, nous avons à revenir sur nos pas jusqu'à Totonikapam, par le chemin saux de quartz disséminés qui traverse le grand plateau recouvert de dépôts modernes dont nous avons déjà parlé. C'est près de là que doil se trouver une localité indiquée dans la collection des R. P. jésuites de Guatemala pour des échantillons assez intéressants que nous n'avons malheureusement pas pu voir en place par nous-mèmes. Il s'agit d'une nuasse argilo-sableuse renfermant une proportion très-considérable de petits cristaux de quartz bi-pyramidés, longs̀ tout au plus de 2 à 3 millimètres, largese à peine de 1 .ou 1 1/2, parfaitement hyalins, brillants comme des diamants, et s'isolant très-facilement par le lessivage méthodique de la pâte qui les englobe. Il eût été intéressant de voir si les cristaux de quartz ont pu être produits directement 
dans l'argile, comme on en connaît des exemples, ou si l'ensemble n'est que le produit de l'altération d'une autre roche préexistante.

Girandes inontagnes entre

Tolonikapam (c) Terpan fivalemala. l’orphyres plus ou moins reconver's d'argiles jaunes.

Au sortir de Totonikapam, la route, car c'est une vérilable roule carrossable construile ì grands frais sous l'inspiration et pendant le gouvernement du président Carrera, s'élève par d'interminables lacels jusqu'au haut des montagones qui dominent la ville du côté du nord, et atteint ainsi la crête mème du massif qui conslitue la ligne de faìte de l'Amérique centrale. Pendant longtemps on ne recoupe que les conglomérats porphyriques et les argiles jaunes; mais enfin on arrive à une altitude suffisante pour voir les porphyres se dégager complétement, el ce sont eux seuls qui constituent les amas de rochers au milieu desquels circule lia route. Fille suit toujours, à très-peu de chose près, la série des points culminants, pour atteindre une élévation de 3,169 mètres, tout près de la maison de refugge dite Casa de Consuelo, où elle est encore dominée par des sommités plus laautes de quelques centaines de mètres. Les porplyyres sont, en goénéral, de belles roches assez compactes, gorises ou colorées en rouge et en violet, semblant contenir dans quelques points une certaine proportion de quartz, mais toujours netlement caraclérisées. Dans un endroit, on peut voir ces porphyres se diviser en feuillets épais de 2 ou 3 centimètres et prendre, sur un espace long de près de un kilomètre, une apparence de stratification extrèmentent remarquable. Peu à peu la ligne de faite s'abaisse et la roule avec elle, de sorte que l'on retombe dans le domaine des argiles jaunes, qui reprennent un développement considérable.

Au Rancho de Chuchuben (2,577 mètres), au lieu de coutinuer la roule qui se mainlient sur le sommet de la ligne de partage des eaux et se dirige vers Tecpan Guatemala, nous avons olliqué vers le sud pour gagoner la ville de Sololi. On prend, à sa naissance même, la vallće d'une petite rivière qui va se jeler dans le lac d'Atitlan, et l'on pénètre avec elle dans un ravin assez profond, dont les parois laissent voir des masses puissantes de congoglomérats à base argilo-lerreuse et à cailloux porphyriques, mèlés de magymas tufacés à ponces blanches et recouverts le plus souvent d'argiles jaunes; mais, quiltant bientôt ce vallon, on se mainticut sur une sorte de plateau fortement ondulé, où la roule ne recoupe guère que les argoiles jaunes el parfois les couches à ponces.

Solola (2,146 mètres) est construit sur les bords extrèmes de cette espèce de 
DANS LES RÉPUBLIQUES DE GUATEMALA ET DE SALVADOR. 237 table qui, se reliant progressivement vers le nord aux montagnes de l'inlévieur, est bornée, à l'est el à l'ouest, par les profonds ravins où courent le Rio de PanajaArgilus jaunes, tuls à ponces et congrinmérats. chel et le Rio Thoy, tandis qu'elle se termine brusquement, au midi, par les immenses falaises à pic qui dominent le niveau du lac d'Atitlan d'une liauteur verlicale de près de 600 mètres. Si l'on s'avance un peu au delà des dernières maisons de Solola du côté du sud, on peul jouir du point de vue tout à la fois te plus étrainge et le plus beau peut-être qui se puisse rencontrer; on se trouve sur une pointe avancée limilée de tous còtés par de giganilesques murailles à pic, formées de rochers et de blocs empilés, maintenus par un ciment aroileux qui semble à peine pouvoir les retenir et donner à ce chaos assez de consistance pour qu'il ne se précipite pas dans le lac d'Atillan, dont les eaux limpides paraissent dormir ì vos pieds à une profondeur incommensurable au-dessous de vous. $\Lambda$ droile, le Rio Iboy roule avec fracas ses eaux jaunàtres, daus le fond d'un effrayant ravin qui présente le plus étomnant exemple de destruclion et de désolation; en avant, le magnifique lac d'Atillan s'étend calme et bleu dans son bassin complétement fermé, limité d'un còté par les grandes falaises à pic nues el rocheuses, de l'autre par les pentes douces, herbeuses et boisées, qui descendent eu courbes gracieuses des imposants massifs des volcans d'Alitlan el de San Pedro.

De Solola nous avons rejoint le nivean du lac (1,558 mètres) en descendant le long des falaises par un sentier entaillé dans des masses puissantes de conglomérats porphyriques, de magomas tufacés à ponces et d'argoiles jaunes; mesurant ainsi l'épaisseur extraordinaire de ces dépôts superficiels, qui est, au minimum, de et confrlnmérats. 60 o mètres, puisqu'on ne rencontre en aucun point la roche solide en place. On arrive ainsi au bord du lac, el, après l'avoir longé pendant quelque temps, on atteint bientôt le gros villagoge de Panajachel, construit à l'entrée de la vallée, ou plutôt du ravin, où coule le rio du même nom, sur une petile plaine de sables et d'alluvions qui n'est en réalité que le delta du torrent. On n'avait pour bul en descendant ainsi que de franchir la grande coupure creusée par le Rio de Panajachel; car le chemin remonte immédiatement après avoir passé la rivière, et s'élève le long des falaises, dont la composition est loujours la mème, pour arriver à Godines (2,151 mètres), hacienda siluée presque exactement à la mème allitude que Solola, sur un plateau qui ne serait en réalité que la continuation de celui 
où s'élève cette ville, si l'on pouvait supprimer, par la pensée, les profondes barrancas entaillées par les flots des torrents.

Lac d'Atillau. Formation du lac.

Mais, avant de continuer notre route, nons devons placer ici quelques détails sur une excursion que nous avons faite dans la direction du sud, pour aller étudier le volcan d'Atitlan. Nous nous sommes d'abord embarqués à Panajachel pour Iraverser le lac d'Atitlan, dans un canot conduil par des Indiens. Dans cette traversée, longue de 15 à 16 kilomètres tout au plus, nous avons pu examiner avec quelque loisir la disposition des montagnes qui entourent le lac, et admirer à notre aise les paysages splendides qui se déroulaient devant nos yeux, soit que nous fussions auprès des falaises abruptes, au pied desquelles se sont établis quelques villages d'Indiens, qui n'ont de communication avec le dehors qu'au moyen de leurs embarcations, soit que notre barque longeat les derniers contre-forts des volcans, dont les pentes harmonicuses viennent mourir insensiblement dans les eaux.

C'est alors que nous avons pu nous expliquer aisément comment s'était formé le lac d'Alitlan, dì à l'accumulation des eaux de quelques rivières, arrètées brusquement dans leur cours vers l'océan Pacifique par le soulèvement des massifs volcaniques d'Alitlan el de San Pedro. Quoique la présence des imposantes falaises qui s'élèvent au nord soit assez singulière, on peut, jusqu'à un certain point, comprendre qu'clles aient pris naissance grâce à une érosion progóressive et prolongée; les caux, poussées par le vent du sud-ouest, auront fini par avoir raison des espèces de triangles aigus, interceplés entre tes barrancas convergentes qui renaient se réunir en ce point, ct composés de matériaux meubles, mal agoglntinés par un ciment argilo-terreux facile à désagréger.

1). San Lucas is San Arustin. Saliles et déjections

Après avoir pris terre à San Lucas (1,563 mètres), misérable villagge situé au’ fond d'un repli du lac, sur un petit plateau élevé de 5 ou 6 mètres tout au plus au-dessus du niveau des eaux, entre les derniers contre-forts du volcan d'Atitlan el les montagnes de San Gabriel, nous avons continué notre marche vers le sud. La plaine de San Lucas se prolonge pendant 2 ou 3 kilomètres en arrière, et c'est évidemment par là que se déverserait le lac d'Atitlan, si le niveau de ses eaux s'élevait un peu; mais ce barrage, quoique suffisant pour lès retenir en apparence, doil plus que probablement les laisser filtrer en profondeur, à travers les maté- 
DANS LES RÉPUBLIQUES DE GUATEMALA ET DE SALVADOR, 239 riaux meubles dont il est composé, pour former ainsi les sources qui jaillissent en une multilude de points des premières pentes. On n'y voit grıère, en effel, que des cailloux roulés, disséminés au milieu de déjections volcaniques noirîtres, sables et matières terreuses, qui les recouvrent en partie, et ainsi s'expliquerait le uiveau presque conslant du lac d'Atitłan, malggré les énormes volumes d'eau qu'il recoit à certains moments de l'année. Après avoir traversé ce petit espace à peu près plane, on aborde presque tout à coup des pentes extrêmement abruptes, entremêlées de ressauts plus ou moins brusques, de ravins assez profonds et composées presque uniquement d'un chảos de rochers anguleux el de blocs roulés, accumulés presque toujours sans interposition d'autre matière qu'un peu de terre argoilo-sableuse noirâtre. Ces rochers et ces blocs semblent formés d'un porphyre souvent altéré et mème scorifié à la surface, et il ne serait pas impossible que la plupart d'entre eux aient été amenés par des éboulements du sommet du volcan d'Atitlan, ou mème aient été projetés hors de son cratère pendant une violente éruption. Près de quelques huttes qui portent le nom de San Geromino, les pentes commencent à se régulariser, en mème temps qu'elles sont recouvertes d'épaisses conclies d'argites jaunes et brunes qui masquent les formations sous-jacentes. Nous ne sonmes pas descendus, dans cette direction, plus bas que les Ranchos de Liboya (363 mètres), où se développent les plaines doucement inclinées qui se raccordent aux rivages de l'océan; mais nous sommes remontés vers le volcan d'Alitlan, jusqu'à l'hacien da de San Agustin, située presque au pied de la montagne, et c'est de là que nous sommes partis pour en faire l'ascension. Autour de San Agustin (6 1 o mètres), le sol se compose presque uniquement de déjections volcaniques, formées surtout de sables noiràtres phus on moins fins, englobant des cailloux porphyro-trachyliques, quelquefois scorifiés à la surface, el susceptibles de donner par leur décomposition une terre végétale extrèmement fertile, surtout quand la couche d'argiles jaunes qui les recouvre assez souvent n'est pas trop' épaisse.

Mais entre San Agustin et les Ranchos de Liboya, sur une largeur de plus de 8 kilomètres, le cours des torrents mel au jour une bande de roches primitives dont la présence en ce point est fort intéressante. Ce sont de beaux granits passant Rancluss de Lihoya. Granits et grneiss. au grneiss dans la majorité des cas et quelquefois très-remarquablement feuilletés: 
la roche est d'une nuance généralement grisâtre, composée de feldspath blanc, de quartz blanc aussi, et de mica noir en petites pailleltes. La présence de ces granits n'est d'ailleurs pas accidentelle en ce point, el ils doivent se montrer beancoup plus nettement dans les endroits où le terrain est plus accidenté, car nous avons vu dans la collection du collége des RR. PP. jésuites de Guatemala plusieurs échantillons d'un beau granit compacte, portant cette désignation, "Chaîne de collines entre le volcan d'Atitlan et la mer." Non loin de San Agguslin, on voit sortir de ces granits une source thermo-minérale dont la température ne dépasse pas 35 degrés, et dont les eaux sont légèrement alcalino-chlorurées.

Platean de Godines, Pasesilla et Patsum. Profondes harrancas. Dépûts superfiriels.
Pour revenir à notre ilinéraire primilif, il nous faut reprendre le chemin qui vient d'ètre décrit ci-dessus, et qui nous est donc connu à l'exception des quelques kilomètres qui séparent San Lucas de Godines; cet espace se compose d'une longue còte entaillée dans les conglomérats à cailloux porphyriques et à magmas ponceux, suivie d'un plateau ondulé recouvert d'argites jaunes, d'où l'on jouit par moments des plus charmantes échappées de vue sur l'ensemble du lac d'Atitlan et des montagnes qui l'environnent. $\Lambda$ Godines (2,151 mètres), on se trouve, comme nous l'avons déjà dit en partie, sur un plateau, peu accidenté par lui-même mais coupé de profondes barrancas, qui s'étend du côté du sud, au pied de l'axe montagneux principal du Gnatemala. Mais les sommités montagneuses s'abaissant peu à peu après Tecpan Guatemala, elles finissent par se confondre avec le plateau lui-mène, qui devient la liggne de partage des eaux aux environs de. Pasesilla $(2,114$ mètres) et joue un rôle à peu près analogue à celui que nous avons indiqué pour la plaine de Guatemala (voir le voyage de San Jose an Rio Grande). Le sol se compose d'une épaisseur très-considérable de dépôts superficiels, réparlis de la manière suivante : à la surface quelques mètres d'argoiles jaunes au-dẹssous desquelles se développent des magnas tulacés à ponces blanches, passant graduellement à des congolomérats à base argilo-terreuse jaunàtre et à cailloux roulés de porphyre devenant de plus en plus volumineux et grossiers à mesure que l'on gagne en profondeur. L'ensemble dı système peut avoir 250 à 300 mètres de puissance el repose directement sur les porphyres compactes que l'on ne peut voir que dans un très-pelit nombre de points. Entre Godines et Patsum, on rencontre trois profondes barrancas qui entaillent le sol jusqu'aux roches solides qui 
DANS lES RÉPUBLIQUES DE GUATEMALA ET DE SALVADOR. 241

en forment la base, et dans lesquelles on peut voir les porphyres en place sur une épaisseur de 5 à 6 mètres. La plaine de Patsum, complélement recouverle d'argiles, est séparée de celle de Pasesilla par un ravin qui s'ouvre brusquement lout auprès du village, mais qui n'est pas encore assez profond pour atteindre les porphyres; c'est là que commence le cours du Rio Istacate, qui longe le massif du volcan de Fuego, dont on voit le groupe imposant paraissant soutenir les matériaux meubles dont sont formées les haules plaines de ces régions.

La naissance des barrancas présente d'ailleurs, dans ces roches faciles à désatgrégerer, des caractòres tout à fail remarquables et particuliers. Rien n'annonce l'approche du cours d'un torrent; il n'y a ui vallće ni thalweg, mais les eaux, après avoir circulé quelque temps à la surface du plateau argileux, dans de petites rigoles qui n'entament pour ainsi dire pas le sol mais se bornent ì le rendre lisse et brillant, se réunissent en un point où une fissure ou tout autre accident leur permet de fraverser la cuuche supérieure argileuse el imperméable partout ailleurs. $\Pi$ y a alor's comme un effondrement subil, un énorme tron à parois verticales à peu près semi-circulaire, d'une douzaine de mètres de diamètre, profond de 5o mètres et plus, qui se continue par un ravin entaillé à pic, dans lequel les eaux se précipitent en cascades successives, creusant de plus en plus à mesure qu'olles avancent et jusqu'ì ce qu'clles rencontrent la roche solide qui ne se laisse pas aussi aisément entamer. Il n'est pas rare de rencontrer de semblables cnfoncements lout à côté des chemins qui, minés en dessous, ne tardent gouère à s'y abìmer.

Après avoir suivi, sur un parcours d'une douzaine de kilomètres, la plaine de Pasesilla, qui tend à s'onduler sensiblement vers son extrémité, on lombe par un assez brusque ressaut dins celle de Chimaltenango, dont la composition góoloPlateau
de Chimaltenango.
Dépôts
superfiriels. giqque est toujours exactement la mème, et où l'on continue à suivre de très-près la ligne de partage des eaux. Le plateau de Chimaltenango se relie directement à celui de San Lucas, qui domine la vallée de Guatemala; on ne tarde pas d'ailleurs à rejoindre le chemin que uous avons déjà suivi pour descendre à Mixco, par une côte très-ardue, qui relic ce que l'on pourrait appeler deux marches de cet escalier giganlesque. Il n’y a point à faire d'ohscrvations géologiques importantes dans ces dernières régions, qui n'ont de caraclère saillant que par l'aspect asse\% 
triste el nu des haules plaines argileuses enveloppant, pour ainsi dire, la ligne de faite du pays.

RENSEIGNEMENTS SUR LE DÉPARTEMENT DE CHQUHULA.

Direction de l'itinéraire (hi R. P. Comette.

Les observalions qui vont suivre se rapportent à un voyage que nous n'avons pas fail nous-mêmes, mais qui a été exécuté, en 1856, par un savant jésuite, le R. P. Cornette, dont il nous a été permis de consulter une nole manuscrite. donnant me relalion succincle des fails scientifiques étudiés dans les localités les plus importantes. Nous avons d'ailleurs corroboré l'exactilude des assertions par l'inspection d'une petite série d'échantillons déposés dans la collection du collégre des RR. PP. jésuites à Guatemala el provenant du voyage en question. L’itinéraire suivi par le R. P. Cornelte part de la ville de Zacapa, près des bords du Rio Molagua, pour s'enfoncer dans l'inlérieur des terres en se dirigeant presque continuellement vers le sud, sauf quelques inflexions, et rejoindre, après avoir franchi la crête montagneuse principale de l'Amérique centrale, le chemin que nous avions suivi nous-mêmes des frontières du Salvarlor à Guatemala, non loin des bords de l'océan Pacifique.

A Zacapa ( 150 mètres), on trouve, comme nous avons déjà en occasion de le dire, une assez profonde et vaste vallée, qui se fraye un chemin au milieu d'un massif granitique d'une grande puissance, dont on retrouve la prolongation aussi bien à l'est qu'à l'ouest. Le chemin remonte jusqu'à Chiquimula (379 mètres) la vallée du Rio de Zacapa, dont le thalweg est assez fortement incliné, el l'on quitte bientòt les granils pour atteindre des roches sédimentaires; en effel, déjà avant d'arriver à Chiquimula, on a passé au pied du mont Chatun (656 mètres), donl lo sommel se compose de gòs, et aux environs de cette ville on trouve une grande quantité de cailloux roulés de calcaire bleu dans le lit de la rivière et dans les ravins des torrents.

De Chiquimula

it Copan.

Couches sédimentaires.
Iprès Chiquimula, le chemin prend, pendant quelque temps, la direction de l'est pour rejoindre le Rio de Copan el remonter avec lui jusqu'à celte ville; on pénètre alors dans une régoion qui est entièrement formée de roches sédimentaires, plus ou moins masquées dans les points bas par des dépôts superficiels, mais apparaissant au jour dès que le terrain s'accidente. Il doil y avoir là plusieurs chainons paral- 
DANS LES RÉPUBLIQUES DE GUATEMALA ET DE SALVADOR. 243

lèles de composition probablement à peu près identique, dont les priucipaux seraient celui qui règne au sud de San Juan Ermila, et dont le point le plus élevé est le mont Ticanlu ( 773 mètres), au pied duquel se trouvent des sources ferrugincuses; celui qui, passant à Jocotan et à Camotan, limite au sud le Rio de Copan; enlin celui qui te borne au nord, et dont le point culminant se trouve au mont T'ipacay (632 mètres). Pour ce qui est de la conslitution géolog̣ique, lout nous porte à croire que les couches inféricures sont formées de schistes arogileux, tandis que les parties plıs élevées sont couronnées de masses de grès. Ainsi, près de San Juan Érmila (515 mètres), il y a des schistes argịleux, traversés par quelques banes de calcaire siliceux, comme en font foi des échantillons de la collection de Guatemala; à la rivière de Jocolan (332 mètres), ces mèmes schistes argileux se retrouvent, pénétrés de veines métallifères, et on les voit encore ì la rivière de Camolan. Les grès, au contraire, existent dans la chaine de collines de JocoIan, au Paso del Obraje sur le Rio de Copan ( 419 mètres), où ils contiennent des bandes de silex pyromaque jaspé; on les retrouve enfin à Llano Grande (79.5 mòtres), au-dessus de Copan, d'où ils scmblent se continuer dans tes plaleaux du Ilonduras, comme paraissent le confirmer certaines assertions de M. Squiers (The slales of central America, etc.). Quoi qu'il en soit, à Copan ınême (55o mètres), où il existe des ruines célèbres, la plaine est recouverte par des dépôts superficiels abondants, qui sont peut-ètre quelquefois des masses tufacées à ponces blanches; il continne à en être de même vers le sud jusqu'à la châne de montagnes assez ćlevée que l'on franchit à Los Horcones ( 1,108 mètres), cl où il paraîl que les grrès reviennent ì jour. Mais, dans les ondulations suivantes, on ne voil plus, de nouveau, que des formations alluvionnaires modernes.

Dans les sommités qui dominent, du còté du sud, la ville d'Esquipulas (910 mètres), une des plus importantes du département, on alteint la chaine de monlagnes qui forme à la fois la liggne de faîle et la ligne de partage des eaux dans celtc partic du Guatemala. Elle se compose de porphyres qui arrivent au jour pour la première fois dans le col de Los Apantes ( 1,1 oo mètres), où ils sont Esquipulas
et Alotepeque.
Porphyres
plus on moins
recouverts
de
dépôts superficiels. noirs et partiellement décomposés à la surface. Ces porphyres se développent plus complétement encore dans les montagnes des environs d'Alotepeque (1,384 mètres), où ils constiluent à eux seuls presque toutes les roches apparentes; près de la ville 
d'Alotepeque, ils sont verdàtres, et ils se montrent très-netlement dans la sommitê connue sous le nom de Derrumbadero, où ils s'élèvent jusqu'ì 1,636 mètres. Il existe dants ces porphyres des veines métallifères qui sout exploitées, en particulier aux environs d'Alotepeque, dans les mines de San Pantaleon et de Carlos, où elles renferment surtout de la galène très-argentifère, accidentellement mélangée, à ce qu'il parait, de minerais de zinc, de fer et d'antimoine.

La chaine de montagnes qui s'étend à l'ouest d'Alotepeque, jusqu'au delà de Jutiapa, près dè la Laguna d'Ayarces, doit probablement ètre composée de roches sédimentaires el métamorphiques. Déjà près d'Alotepeque, on trouve des calcaires (un échantillon dans la collection de Gualemala) el des schistes argileux qui existent aussi au nord de Jutiapa. Ces assises, relativentent modernes, seraient appuyées sur un soulèvement de micaschistes qui, très-développés près de Juliapa, viendraient passer sous les déjections des volcans de Monte Rico et d'Ipala, pour se perdie enfin à la base des montaģnes d'Alotepeque.

1) Slolepey au Série de volcans. Déjections volcaniques.

In sud-ouest d'Alotepeque le sol est presque partout recouvert de couches plus on moins épaisses de déjections volcaniques, sables, roches scorifiées ou argiles, qui proviennent d'une série de cônes, tous complétement éteints, aliggnés suivant une direction sud $40^{\circ}$ ouest, c'est-à-dire sensiblement normale à la direction volcanique principale du Salvador et du Gualemala. La présence de cette ligne volcanique adventive serait excessivement intéressante el elle mériterait d'ètre étudiée avec le plus gorand soin; malheureusement les détails renfermés dans les notes manuscrites dont nous avons parlé ne sont que bien peu explicites, quoique suffisants cependant pour ne pas laisser de doutes sur la vérilable nature des . sommités dont il s'agil, car les mots de volcan, de cratère, de laves, elc. sout répélés trop souvent pour que l'on ne doive pas y voir une intention bien marquuce et une observation attentive des faits. Les volcans d'Ipala (1,661 mètres) et de Monte Rico seraient environnés d'une grande quantilé de laves plus ou moins poreuses, remplacées peu après, dans la direclion du sud, par des sédiments volcaniques diver's, des sables, des tufs à ponces qui prenment surlout un grand développement près d'Agua Blanca ( 810 mètres). D’immenses coulées de laves, recouvertes en beaucoup de points d'argiles, viendraient jusqu'aux villages de Santa Catarina ( 708 mètres) et de Suchitan $(1,252$ mètres) en descendant du volcan 
DANS LES RÉPLBLIQUES DE GUA'TEMALA ET DE SALVADOR. 245 de Santa Calarina, dont le gigantesque cratère serait entouré de laves brisées el de roches scorifiées. Ces mêmes laves, mêlées d'argoiles et de cendres, atteindraient aussi, dans le sens opposé, le village d'Achuapa ( 964 mètres). Plus au sud vient une plaine dont le sol se compose de sédiments arénacés contenant des caillous de granil, ce qui prouverait la présence de cette roche dans les montagnes qui s'élèvent au nord-ouest. Non loin de là seraient encore deux cònes volcaniques éteints el per élevés, ceux de Cuma el d'Amayo.

Un peu après, on franchil le Rio $\mathrm{Paz}_{2}$ ( $66_{1}$ mètres), qui n'esl encore qu'un putit ruisseau, inais qui devient, plus bas, une rivière asse\% importante et forme la fronGote in Voladero. Réapparition tière entre les républiques de Salvador et de Guatemala. On luaverse une plaine des porphyres. couverte de dépòts superficiels, et, par une montée de plus de 400 mètres, on s'ćlève jusqu'au village d'Aracualpa ( 1,349 mètres) en marchant presque toujour: sur des conglomérats porphyriques. II en est de mème dans la grande còle dite EI Voladero, par laquelle on redescend pour rejoindre, entre Et Oratorio et Los Esclavos, le chemin que nous avons décrit dans notre premier itinéraire de lak Enion à Guatemala. 


\title{
CIIAPITRE II.
}

\author{
CONSIDERATIONS GÉOLOGIQUES.
}

RÉPARTITION, ÂGE ET HODE DE FORMATION DES ROCHES.

(Planche V.)

Des soulèrements successifs qui ont modifié le relief de l'Amérique centrale. - Roches éruptives. Roches sédimentaires. - Dépôts superficiels.

Considérations. sencrales.
On a pu remarquer que, dans la première partie de ce livre, nous avons toujours eu soin de nous abstenir prudemment de toute espèce de discussion sur les faits que nous avous observés, et que nous nous sommes borués à signater, à chaque pas, la nalure de la roche qui composait le sol sans jamais vouloir rien préjuger', ni sur les conditions dans lesquelles cette roche pouvait s'ètre formée, ni sur l'époque à laquelle son apparition, son dépôt ou son soulèvement, pouvaient ètre rapportés. Nous avions pour but, en divisant ainsi le travail, de réunir dans une partie tous les laits que nous avons pu constater par nous-mêmes, toutes les observations précises dans lesquelles l'hypothèse n'entre pour rien, en un not, tont ce qui est parfaitement certain et ne peut pour ainsi dire pas être discuté.

Il y a une grande différence, en effet, entre les faits en eux-mêmes et les conclusions que l'on en peut tirer : lorsqu'un voyageur consciencieux affirme que to ralcaire, par exemple, existe dans tel ou tel point où il l'a vu de ses propres yeux, it n'y a aucune raison qui puisse faire douter de son assertion, car c'est là un fait d'observation brulale, pour ainsi dire, et il ne dépend pas de lui que ce calcaire ne soit pas du calcaire. Mais, s'il vient dire que ce calcaire appartient à telle on telle formation et a vu le jour à lelle ou telle époque géologique, il s’introduil 
DANS LES RÉPUBLIQUES DE GUATEMALA ET DE SALVADOR. 247

immédiatement un élément de discussion individuelle qui est propre à ce voyigeur en particulier, qui dépend de ses idées théoriques, de ses opinions scienlifiques, de ses doctrines, el qui, par cela mème, est susceptible d'ètre apprécié de façons différentes par les différentes personnes s'occupant de géolog̣ie. Mais, quel que soit l'avantage que l'on puisse trouver en se bornant à énumérer des lait. successifs, en présentant sculement des itinéraires comme nous venons de le faire. il est évident que cela ne peut suffire pour donner une idéc, mème vague, de lat géologie d'un pays; et le lecteur, en suirant ces listes sèches et arides, malogré tout le soin qu'on aura pu prendre d'y introduire quelques éléments d'animation. ne possédera, comme vue d'ensemble, aucune donnée générale sur les régions dans lesquelles il vient de voyager par la pensée.

Aussi longtemps qu'un pays n’aura pas ćlé étudié dans ses moindres détails, il faudra bien, pour envisager les choses d'un peu hant, laisser une certaine place

Des dayrget: lo la généralisalion trup aboolue. à l'hypothèse, quand ce ne serait d'aillenrs que pour accumuler des idées plus ou noins théoriques, destinées à diriger les travaux el les recherches des observaleur's et des savants qui viendront ensuite, qu' elles doivent y trouver leur confirmation ou leur destruction. Il importe moins, à notre avis, de dire quelque chose qui soit absolument vrai (et où est à présent la vérité absolue?) que de dire quelqü chose qui puisse altirer l'attention sur un certain ordre d'idées, amener drs recherches, susciter des travaux, déterminer un courant d'opinions dans le vème sens ou en sens contraire. Le danger, après tout, n'est pas lant daus la généralisation en elle-mème que dans la généralisation absolue, dans la gónéralisation pousséc jusqu’à ses dernières limites, avec des aflirmations posées sur des bases insulfisantes. Il sera dangereux de dire : etelle chose existe dans tel on tel point que je n'ai pas vu, "mais il ne l'est pas de dire: « d'après mes observations à droile et à gauche, je suis conduil à supposer que telle ou telle chose existe au cenţre que je n’ai pas eu le loisir d'étudier; il serait bon que ceux qui viendront après aillent examiner si cela est vrai ou faux."

Donc nous nous laisserons aller à généraliser un peu, mais elr cherchant à le faire avec sagesse et modération. Nous avons traversé un pays par deux chemins à peu près parallèles el dislants d'une centaine de kilomètres au plus, où nous Hode
de généralisation
que nous
emploierons. avons rencontré, des roches comparables, quelquefois mème tout à fail sem- 
blables; nous essayerons de voir si les allures gónérales de la région, la direclion des cliaines de montagones et des valtées, permettent d'almettre la continuilé de celte formation, et nous nous ferons ainsi une idće de l'extension qu'elle peut avoir par rapport ì celle de la contrée. Nous avons recoupé, dans deux voyagges successifs, des séries de couches reposant les unes sur les autres dans un ordre déterminé et toujours le même; nous nous demanderons si l'on pout penser qur cette disposition soit constante, el si l'on en peut tirer quelques conclusions pour se rendre compte des àges relatifs de ces assises, des époques où elles ont été amenćes à l'état dans lequel nous les observons. Nous avons rencontré dans diverses locatités un même grroupe de roches, présentant des caractères analogues qui permellent, jusqu’à un certain point, de saisir les phénonènes qui ont dủ présider à son origine; nous ferous une supposition sur son mode de formation, sous Inute réserve des faits semblables ou contradictoires que pourrail ajouter au dossier l'étude d'une autre localité. Marchant ainsi, nous n'aurons rien à redouter de nos généralisations, qui ne sèront cerles pas excessives; nous n'aurons fait que poser, en quelque sorte, des jalons pour l'avenir, appelant les éludes et les recherclies sur les points que nous aurons signalés comme imporlanls et mérilant d’ètre approfondis. Et, que nos hypothèses soient vérifićes ou non plus tard, nous n'en aurous pas moins la conscience d'avoir fourui quelques matériaux à la science, qui saura bien, dans sa marche incessante vers le, développement, le progrès el la vérité, les conserver pour ce qu’ils valent, ou les faire servir de base à des travaux de rectification postérieurc.

Dillicultés

Nous ne devons pas nous dissimuler qu'aussitôt que nous entrons dans le domaine de la géologie théorique, c'est-ì-dire aussilôt que nous voulons trouver, dans la direction des chaines de montagnes ou dans les alignements des points composés de la même roche, des éléments qui puissent nous aider à rechercher l'ìgo relatif des assises ou leur dévcloppement horizontal, nous venons nous butler contre une difficulté d'autant plus gorande qu'elle n'est pas encore prête à disparaître de longotemps; nous voulons parler de l'insuffisance des données géogräaphiques. Il est cerlain que c'est là un obstacle sérieux, qui complique étrangement l'incertitude des spéculations anxquelles on peut avoir à se livrer, et qui doil imprimer la plus grande réserve à la marche des liypothèses, puisqu'il peut amener 
DANS LES RÉPCBLIQUES DE GUATEMALA ET DE SALVADOR. 249 à considérer comme étant en liggne droile des points disposés eu réalité sur une ligne plus ou moins brisée. Ainsi que nous l'avons prouvé dans un chapitre précédent, on peut admettre que les còles sont connues avec une parfaite précision, gràce aux travaux hydrog̣raphiques auxquels la marine française a contribué pour sa large part; mais il n'en est pas de même pour l'inlérieur des terres, quoique la position d'un grand nombre de points des environs de Gualemala el du versant du Pacifique ait élé délerminée d'une façon scientifique au moyen d'observations astronomiques de longitude et de latilude. Si done, pour les réggions du sud-ouest de la république de Guatenala on peul avoir une certaine confiance dans les dernières cartes qui ont élé publićes, on ne doil, au contraire, leur en accorder aucune pour les provinces du nord et du nord-est, la Vera Paz et les Nitos en particulier. Dans ces réggions, les distances sont évaluées au moyen des journées des conducleurs de mules, voire mème des individus royageant à pied; et, quelle que soit, il faul le reconnaitre, la rare habileté arec laquelle ces individus calculent, par la durée de leur trajet, le nombre de lieues parcourues en tenant comple des montées, des descentes, ctc., on conçoit aisément que le procédé est trop grossier pour domner une précision géogoraphique quelconque. I] en est de mème poúr les directions, qui sont simplement évaluées d'après la position dı soleil, sans tenir comple de ses déplacements suivant les saisons. On comprend ainsi que les cartes de la Vera Paz et des Altos fourmillent d'erreurs, aussi bien pour la position relative des lieux que pour la direction des rivières el des chainnes de montagnes.

Pour pouvoir nous faire à nous-mêmes, et présenter au public avec quelque nelleté, des idées góologiques générales sur les républiques de Guatemala el de Salvador, il nous fallail évidemment commencer par leur donner un corps, en quelque sorte, c'est-ì-dire par les représenter graphiquement dans un essai de Établissement de la carte géologique qui accompagne ce Iravail. carle géologique. Pour cela, nous avons dù d'abord tracer une carte topographique à l'échelle d'un sept cent soixante et un millième $\left(\overline{76} \frac{1}{\overline{000}}\right)^{(1)}$, dans laquelle nous avons eu soin de conserver toules les déterminations précises ulilisées déjà pour d'autres carles, mais en cherchant à reclifier autant que possible, d'après

\footnotetext{
(1) L'échelle primitive de notre carte était beaucoup plus simple, mais nous avons été forcément amenés à un chiflie un peu bizarre par les exigences du format du texte, au-

Voyage géolugique.
}

quet les plauches ont dû se conformer en partie, au moyen d'une réduction photographique. 
nos propres travaux, tout ce qui ne nous semblait pas pouvoir concorder avec nos observalions. Il est certain qu'au point de vue topographique seulement, notre carte doil renfermer encore bien des erreur's (la position de Zacapulas en particulier est tout à fait incertaine, ce qui est extrêmement reggreltable), mais nous croyons néanmoins avoir introduit quelques rectificalions importantes, notamment pour les environs du chemin de Salama à Cohan, pour quelques parties du cours du Rio Chisoy, et pour les pays qui y confinent, etc. etc. Sur cette carte géographique, nous avons reporté d'abord tous nos itinéraires góologiques, puis cerlains renseignements très-précis qui nous ont été communiqués, el nous avons figuré la nature du sol en teintes plates, par des nuances différentes pour les diverses espèces de roches, daus tous les points dont la constitulion géologique nous était ainsi connue d'une façon incontestable. Les mênıes couleurs en teintes fondues ont été appliquées sur les localités où la composition du terrain ne nous élail donnée que par des renseignements vagues ou par des hypothèses plus ou moins plausibles; enfin nous avons lạissé en blanc les régions sur lésquelles nous ne possédons aucune notion. Nous avons ainsi obtenu l'esquisse d'une carte géologique des républiques de Guatemala et de Salvador qui forme la cinquième des planches dont ce volume est accompagré. Comme son titre l'indique, ce n'est encore qu'une modeste esquisse, susceptible de modifications el d'additions de tous gemres, mais qui représente l'étal acluel de nos connaissances góóogogiques sur une partie de l'Amérique centrale, el à laquelle nous renverrons le lecteur pour suivre les discussions dont nous allons nous occuper.

Baude centrale le roches éruptives, rejetant les terrains sédimentaires d'un côté nt

DES SOULÈVEMENTS SUCCESSIFS QUU ONT MODIFIÉ LE RELUF DE L'AHÍRIQLE CENTRALE.

Si l'on jette les yeux sur la carle géologique, on ne saurail manquer d'ètre l'appé par quelques traits saillants, qui se retrouvent très-neltement anssi daus les profils géologiques des planches VI et VII. On remarqquera d'abord qu’il existe, vers le milieu du.continent centro-américain, mais plus près de l'océan Pacifique les dépoits superficiels que de l'océan Allanlique, une bande plus ou moins large de roclies éruptives, dont la direction est à peu près la même que celle du continent en général, et qui coincide presque partout avec la série des haules montagnes, auxquelles on donne souvent le nom de Cordillère ou de Sierra Madre, constituant l'arète principale à 
DANS LES RÉPUBLIQUES DE GUATEMALA E'T DE SALAdOR. 251 la fois ligne de faîte el ligne de partage des caux. En envisageant de plus près cette bande de roches éruptives, on voil qu'elle se compose presque exclusivement de porpliyres trachytiques, mais que ses flancs sont jalonnés en différents points, aussi bien d'un cólé que de l'autre, par des lambeaux de granil dont on ne peut saisir nettement la continuité. Cette zone saillante élant ainsi définic, on observera sans difficulté que le versant qui s’incline vers l'océan Allantique présente un déreloppement remarquable de terrains sédimentaires, schistes ou calcaires, occupant une série de chaînons montagneux parallèles, et qưil y a mème, en certains points, quelques lambeaux de ces terrains sédimentaires serrés entre l'arètc porphỵrique et les sommités où apparaît le granit. De mème, on se convaincra que le versant très-incliné du Pacifique est presque alssolument recouvert de dépôts modernes superficiels, et jalonné par une série non interrompue de gigantesques cònes volcaniques disposés suivant une lig̣ne droile, inclinée senlement d'une dizaine de degrés sur la direction de l'arète centrale.

Ces points principaux étant ainsi établis, il nous faut chercher quelles peuvent ètre les causes qui ont amené une semblable répartition des roches el dans quel ordre les actions de ces causes ont dû̀ se faire scntir, tout en maintenant les réserves que nous avons déjà posées au sujel de l'incertitude des domnées géographiques qui contribue, pour sa part, à enlever leur caractère de précision à certaines observations.

Nous sommes portés à croire que le premier soulèvement qui ail eu lieu dans cette parlie du goblob, ì une époque excessivement reculée, il n'en faut pas douter, Sonlèvemenl granilique. doit ètre celui des granits. Ils seraient venus former une chaîne de montag̣nes, ou peut-c̀tre plusieurs chaines parallèles composées de cette roche, en cntrainant dans leur mouvement certaines assises métamorphiques ou sćdimentaires trèsanciennes, tolles que les micaschistes et les schistes talqueux cambriens déjà formés à celte époque. Le premicr rudiment du Guatemala, isolé peut-être cncore à ce moment des autres parties de l'Amérique centrale, en lous cas vers le sud, aurait donc été une île à chânes saillantes granitiques et à contre-forts de micaschistes et de schistes cambriens, ce qui ferait remonter l'origine de ce continent à une très-haute antiquité dans la séric des temps góolog̣iques.

Ce qui nous fail penser que les granits doivent avoir constitué le premier de ce soulèrement. 
noyan émergé du Guatemala, c'est qu’ils ont été percés violemment pour donner passage ì la châne porphyro-trachylique qui les a traversés et divisés en quelque sorte. Cela est évident, quelle que soil la direction que l'on suppose avoir été celle des montagnes granitiques, puisque l'on trouve des lambeaux de granit des deux côtés de l'arête principale acluelle, sur le versant du Pacifique aussi bien que sur celui de l'Atlantique, ce qui prouve bien que cetle ligne de montagones est postérieure ì celle dont il est question en ce moment.

Quant à savoir suivant quelle direction se sont soulevées les chaines de montagnes grranitiques, cela est plus délical el plus difficile à dire, puisque l'on n’a affaire qụ̂à des lambeaux isolés de granit, qu’il est assez peu aisé de réunir par un aliggnement précis à cause de l'incertilude des données géographiques. Néanmoins il u’est pas impossible que ce soulèvement se soit effectué suivant une direction très-bien indiquée par les montagónes des environs de Zacapa, par les granits dı Chiote, par ceux du Carrizal, et dont on retrouve très-exactement la prolongalion, de l'autre côté de la clıaine porphryro-trachýtique, aux mamelons de granit et de gneiss de la base du volcan d'Alitlan. Cetle direction serail à peu près ouest $22^{\circ}$ sud - est $22^{\circ}$ nord, el correspondrait sensiblement à l'un des grands cercles les plus importants du réseau pentagonal de M. Élie de Beaumont. Avec celte liypothèse, il faudrail admeltre qu'il s'est soulevé en même temps, non pas une seule chaine granilique, mais plusieurs, car on en trouve d'abord une aux environs de Zacapulas, où le granit est d'ailleurs assez netlement orienté suivant la direction ci-dessus mentionnée, et une autre encore, mal définie par les amas de rochers graniliques de Cerro Redondo et de la plaine du volcan Cuma.

L'hypothèse que nous avous faite implique la condition que des schistes anciens ont élé soulevés en mème tenıps que les granits et dans la mème direction qu'eux. En effet, quoique, dans toute la basse Vera Paz, les chainons de micaschiste soient alignés suivant une direclion tout à fail différente, due probablement à des phénomènes subséquents, la direction du système granitique se retrouve, avec une remarquable précision, dans la chaine de nicaschistes de la Sierra del Mico, an bord de la lagune d'Izabal, puis dans les monlag̣nes des environs d'Omoa (Honduras), et enfin à l'ìle de Roathan, qui est presque entièrement formée de micaschistes, el dont une partie du contour se compose de deux longues lignes droites orientées 
DANS LES RÉPUBLIQUES DE GUATEMALA ET DE SALVADOR. 253 exactement ouest $22^{\circ}$ sud, - est $22^{\circ}$ nord. Nous devons reconnaitre d'ailleurs que c'est cette direction des micaschisles, si bien indiquée dans celte région, qui nous a fail penser à rechercher si elle ne pourrait pas être applicable aux granits, pour lesquels les clioses sont loin d'ètre aussi saillantes et permettent parfaitement de n'accorder d'autre valeur que celle d'une liypothèse à tout ce qui vient d'ètre dit.

Le second soulèvement bien prononcé que nous ayons reconnu dans le Gualemala, et nous ne voulons pas dire par là qu'il n'y en ail pas eu d'intermédiaires qui nous ont échappé, est celui de la grande arête porphyro-trachylique qui a probablement donné presque entièrement ì celte partie de l'Amérique centrale son relief orographique et son dessin topographiqne actıels, au moins en ce qui regarde le versant de l'Allantique. Le soulèvement de l'arête porphyro-trachytique est beancoup plus récent que celui des monlagnes granitiques, ce qui est prouvé, d'abord par l'existence de lambeaux de granil disséminés à droile el à gauche de celle chaine, ensuite parce que l'on pent voir au nord-est de Guatemala des restes plus ou moins étendus de formalions sédimentaires préexistantes, serrés entre les sommilés porphyro-lrachytiques et les montagnes granitiques. Ce dernier fait ne peul s'expliquer qu'en admettant que les calcaires et les schistes secondaires s'étaient déposés tranquillement au-dessous des bords de l'île ou de la presqu'ile granitique, et que, lorsque celle-ci fut de nouveau soulevée et violemment déchirée par un phénomène postérieur, qui se fit jour près de ses rivagges du sud, quelques portions en furent entrainées avec les granits, landis que le reste fut dispersé au loin el entrainé par les caux. En eflet on peut voir que, du côté du nord, qui fut moins directement exposé à l'influence du soulèvement porphyro-trachylique, puisqu'il en étail à une plus grande distance, les couches de schistes el de calcaires ont été simplement soulevées el reposent avec des inclinaisous el des plissements variables sur les flancs du système. Pour résumer d'une façon plus claire la façon dont nous pensons que les choses se sont peul-ètre passées, nous dirons qu'il y aurait eu, du côté du nord, un simple soulèvement, agissant aussi bien sur le système des granits et des micaschisles préexistants que sur les roches secondaires nouvellement mises à jour; tandis que, du còté du sud, il y aurait eu en même temps soulèvement et déchirement, de sorle qu'un lambeau seule- 
ment des assises calcaires el schisteuses aurait élé conservé sur le flanc du nassif goranitique, de manière à être serré entre lui el les porphyres récemment éjaculés, el le reste aurait élé balayé par les eaux mises en mouvement par le phénomène lui-même.

La direction mojenne du soulèvement porphyro-trachylique pent être aisémeul trouvée dans l'arête montagneuse principale du Guatemala, qui en est le résultat le plus saillant, et qui, malgoré quelques sinuosités, ne s’éloiggne gouère d'une orientation nellenıent définie depuis les hautes montagnes de Tolonikapam jusqu'aux plateaux des environs de la capitale et aux chaînes de sommilés qui, de Esquipulas et Alotepeque, se continuent dans le Honduras. Cette direction moyenne est est $20^{\circ}$ sud, - ouest $20^{\circ}$ nord, ce qui correspondrait à peu près à celle de l'un des grands cercles principaux du réseau pentagonal de M. Élie de Beauınont, passant à peu de distance de la côte dans l'océan Pacifique. Il faut remarquer que, lorsqu’il y a une déviation dans la chaine porphyro-traclıylique, on ne voit que rarement des éléments faisant un angle obtus les uns avec les aulres, mais presque toujours, au contraire, des chainons parallèles plus ou moins éloignés, reliés par des lignes de sommilés dirigées normalement aux autres. Quand mème il serail prouvé que le soulèvement porphyro-trachylique de l'Amérique centrale fail partic du mème système que le grand cercle important dont nous avons parlé plus haut, il ne faudrail pas pour cela chercher à l'assimiler à un des soulèvements bien étudiés dont l'époque a été fixée pour la France; car, ce grand cercle passant au sud de l'Afrique, les dislances sont trop considérables pour que l'on puisse supposer une continuilé d'action dans des limiles aussi étendues.

Époque Toul ce que nous pouvons faire, c'est de tâcher de fixer l'âge de ce soulèvede ce soulèvement. ment en le considérant individuellement, mais saus faire aucun rapprochement avec ce qui existe en Europe. En remontant vers le nord, on peul voir que presque toutes les montagnes de la basse Vera Paz sont distribuées en chaînons parallèles, qui affectent régulièrement, et sur une étendue assez considérable, la direction est $20^{\circ}$ sud, - ouest $20^{\circ}$ nord; il en est de mème dans la plus grrande parlie de la haule Vera Paz jusqu'aux bords du Rio Chisoy, et même de l'autre côté de ce fleuve dans plusieurs régions de la province des Altos, où les rides parallèles et les thalwegos des vallées sont orientés d'une manière remarquable, sur laquelle nous 
DANS LES RÉPUBLIQUES DE GUATEMALA ET DE SALVADOR. 255 avons déjà appelé l'attention de nos-lecleurs. Toules ces ondulations montagneuses sont donc en relation immédiate avec la direclion de la chaine porphyro-trachylique, et doivent dépendre du mème système; or elles se composent de micaschistes, puis encore de grès et de schistes peut-être triasiques, enfin de calcaires et de schistes que nous pensons être jurassiques. Le système porphyro-trachytique est donc postérieur au moins à la formation des terrains jurassiques; comme les terrains crélacés el terliaires manquent, nous ne pourrons trouver une limite supérieure que dans ce fail, qu'il est certainement antérieur au soulèvement volcamique, antérieur lui-mème ì une formation quateruaire. Les limites sont un peu largeses, nous devons l'avouer, mais il serait téméraire de vouloir en fixer de plus précises avec le peu de données que nous possédons jusqu'à présent, el il y a lieu d'espérer que des travaux subséquents fourniront des éléments de recherches théoriques plus séricuses. Ce qu’il y a de certain, c’est que c'est le soulèvement porphyro-trachytique qui a donné à ła plus grande partie des régions que nous étudions le relief et la disposition qu'elles ont encore aujourd'hui, el qu'à cẹ titre on doit le considérer comme un des phénomènes les plus importants dont l'Amérique centrale ait été le théâtre.

Le troisième soulèvement qui ait produil des effels bien caractérisés est celui de la ligne volcanique, manifesté quelquefois par des mouvements gónéraux du sol et des dérangements assez considérables, plus souvent par l'apparition de gigantesques montagnes coniques isolées, et par le dépôt de couches épaisses de cendres, de lapilli et de ponces, qui ont nivelé les accidents des localités environnantes souvent jusqu'à une notable distance. Les modificalions introduites par ce soulèvement dans les allures du continent centro-américain ne sont d'ailleurs pas extrèmement importantes au point de vue géographique, car il est plus que probable que le dessin actuel et une notable parlic du relief étaient déjà, avant son apparition, tout à fait semblables à ce qu'ils sont aujourd'hui. Ajoutons encore que. quelle que soit l'influence que l'on veuille altribuer à ce soulèvement, il n'a agi absolument que d'un seul côté de l'arète porphyro-lrachylique primordiale, car on ne trouve aucune trace importante de son action sur le versant de l'Atlantique, où quelques vallées tout au plus ont été partiellement comblées par des déjections ponceuses. Cela n'a rien, du reste, qui puisse sembler extraordinaire, puisque 
l'axe volcanique se trouvant placé en plein sur le versant du Pacifique, à mi-chemin environ entre la crête des monlagnes porphyro-trachytiques et les rivages acluels de la mer, les plećnomènes qui ont accompagné son. apparilion n’ont pu avoir d'eflet direct que sur celte partie du pays. Les transformations nous semblent pourlant avoir élé beaucoup plutôt orographiques que topographiques, même sur le versant du Pacifique, et voici celles qui nous paraissent les plus admissibles.

Eflets de ce soulèvement.
Il est probable que le tracé des rivages de la mer doit avoir subi quelques légères altérations, grràce à des exlıaussements, soil concomilants de l'apparition première du phénomène en lui-mème, soil postérieurs et contemporains de quelque violente éruption; on trouve, en effel, dans les falaises d'Acajutla, des congolomérats renfermant des roches volcaniques plus ou moins scoriacées, et qui ont tout l'air d'avoir été formés sons les eaux, quoiqu'ils se trouvent actuellement à une douzaine de mètres au-dessus du niveau de l'Océan. Dans l'intérieur des terres, au Guatemala, le relief a été sensiblement altéré, d'abord par le nivellement des vallées déjà exislantes, comblées par les déjections volcaniques accumulées sous des épaisseurs parfois énormes, ensuite et surtout par l'adjonction d'une série de hautes cimes donnant à celle contrée le caractère particulier et l'aspect remarquable que connaissent bien tous les navigateurs qui ont eu occasion d'approcher de ses còtes. Au point de vue plus spécialement topographique, on doit attribuer à ce soulèvement le détournement de quelques vallées el surlout la formation des lacs d'Anatitlan et d'Atillan, dont l'origone est intimement liée à son apparition. Nous avons admis, en effet, qu'ils ont pris naissance à la suite de l'arrêt de l'écoulement des eaux dans certaines vallées préexistantes, détruites tout à coup, soit par l'accumulation des déjections volcaniques, soit, ce qui est beaucoup plus probable, par un soulèvement partiel du sol aux environs immédials de la base d'un volcan, ainsi que cela peut se voir en particulier au volcan de Pacaya. Quelques autres volcans présentent aussi dans leur voisinage des ondulations ou des collines qui ont été formées au moment de leur apparilion, mais ce ne sont que des fails isolés, et l'on ne peut pas dire que le soulèvement de l'axe volcanique se soit manifesté sur le versant du Pacifique au Guatemala, par une chaîne continue soudée sur le flanc de la chaîne primordiale porphyro-trachytique.

Mais il n'en est pas dé même au Salvador, où il s'est introduit, à la fois dans 
DANS LES RÉPUBLIQLES DE GUATEMALA E'T DE SALVADOR. 257 l'orographie et dans la topographie du pays, des modifications imporlantes, que nous croyons pouvoir rapporter à la formation de l'axe volcanique. On peut voir, en effet, sur la carle, que la ligne des volcans se trouve en quelque sorte posée sur ınn surélèvement continu du sol, constituant une vérilable chiinne de montagnes qui. forme un axe anticlinal secondaire, el limile le bassin des cours d'eau tributaires du Rio Lempa. Celte chaine se compose de roches porpliyro-lrachytiques parfaitcment analogues à celles de l'arète principale, et nous ne pouvons uous empêcher de penser qu'elle doil son origgine à ume série de soulèvements particls, effectués aux alentours de chaque sommilé volcanique à l'époque de son apparilion, et suffisamment rapprochés pour prendre l'apparence d'une véritable clıîne continue. Celle ride postérieure, formée ainsi sur le versant d'une contrée monlagneuse préexistante, serail assurément le phénomène le plus saillant altribuable au soulèvement de l'axe volcanique.

Considérée dans son ensemble, depuis les cônes qui s'élèvent au sud-est du Direction etépợue Salvador jusqu'à ceux qui se dressent au nord-onest du Guatemala, la ligne volce sonlèrement canique aflecte une direction moyenne, qui est sensiblement est $30^{\circ}$ sud, - onest $30^{\circ}$ nord. Nous disons direclion moyenne, car il est évident que la série des volcans ne peul pas constituer une ligue d'une rectilude mathématiqne, et que plusieurs d'entre enx sont situés, soit au-dessus, soit au-dessous de cet alignement, qui réunit pourtant avec une élonnante précision la majorité d'entre eux. L'époque d'apparition de l'axe volcanique n'est pas aisée à définir d'une manière absolue; car, s'il est certain que quelques-uns des volcaus qui en font partie apparliennent à la période historique, puisque le volcan d'Izalco, en particulier, ne date que du siècle dernier, il est incontestable, d'un autre còlé, qu'il y ell a qui remontent au delì de l'époque géologique actuelle. Voici, néanmoins, les limites que nous pourrons établir; il est évident, d'une part, que le soulèvement volcanique est postérieur au soulèvement porphyro-trachytique, puisqu'il a pris maissance sur le flanc des montagnes formées par ce dernier, et qu'il a déplacé, voire mème considérablement surélevé tes roches porphyro-trachytiques qui composaienl le sol. D'autre part, on ne peut nier que les premiers volcans qui ont fail leur apparition, probablement ceux qui sont éteints aujourd'hui, ne se soient développés à une époque fort reculée, quoique géologiquement très-l'écente; cu effel, les cou- 
ches de pierre ponce qui remplissent cerlaines vallées, comme celle de Guatemala, renferment des ossements de grands mammifères, dont les espèces sont acluellement perdues et qui se rapportent à la période que l'on est convenu d'appeler quaternaire. Or les ponces ne peuvent avoir été rejetées que par les volcans, ot ces volcans apparliennent au moins au conmencement de l'époque quaternaire, puisque des animaux de cet àge ont pu vivre sur le sol formé par leurs déjeclions.

Résumé de l'étude des soulèvements.

Einsemble des roches ' composent le sol de l'Amérique centrale.

En résumé, nous avons été conduits à admeltre que trois soulèvements principaux avaient contribué pour leur part, à des moments différents de l'ìge du monde, à donner aux régions que nous étudions leur forme et leur relief actuels : un premier, extrèmement ancien, attribuable aux granits, n'aurait indiqué que vaguement encore la répartition des terres et des mers; le second, beaucoup moins éloiggné de notre époque géologique, aurait dù son origine à l'émission de roches porphyro-trachyliques, el aurait amené les choses à un état très-rapproché de celui dans lequel nous les voyons; un troisième enfin, tout à fait voisin, relativement, des temps qui virent naître l'espèce humaine, aurait produil les gigantesques volcans qui jalonnent cetle partie du grlobe, et introduil dans son économie générale quelques modifications peu importantes.

Gràce à ces divers mouvements, le sol de l'Amérique centrale, dont les l'udiments remonteraient presque aux premiers ìges el aux premières transformations du globe, renferme, parmi les matériaux qui le composent, une notable proportion des roclies et des assises dont est formée l'écorce terrestre. Nos observations sur le terrain, consignées l'une après l'autre dans nos itinćraires, qui en sont en quelque sorte le registre, nous ont fail reconnaître la présence des roches et des formalions suivantes, sur chacune desquelles nous ferons successivement quelques observations :

Roches érupretres. - Granits; - Porphyres trachytiques; - Porphyres diver's; Basaltes; - Laves el scories volcaniques.

Rocues sḱdmantanes. - Nicaschisles; - Schistes talqueux el chloriteux, cambriens ou siluriens; - Poudingues, grès et schistes de Sunta Rosa; - Schistes et calcaires jurassiques.

DÉpòts superficiels. - Sables volcaniques et lapilli; - Conglomérats porphyriques; — Tufs à ponces blanches; - Argiles jaunes. 
DANS LES RÉPUBLIQUES DE GUATEMALA ET DE SALVADOR. 259

Mais, avant d'entreprendre cetle élude, disons encore quelques mots de certains phénomènes qui se rapporlent peut-être très-directement ì ceux dont nous venons de nous occuper : nons voulons parler des alignements de filons et de sources thermales.

Les filons métallifères reconnus ou exploités dans l'Amérique centrale, el nous devons déclarer qu'ils sont, jusqu'ici, fort peu nombreux, appartiennent en grande majorité au système 'porplıyro-trachylique ou aux chainnes de montagnes parallèles qui en dépendent. Il est certain, nénmmoins, que le groupe granilique conlient, dans bien des cas, des filons qui sont peut-être assez riches; ainsi, par exemple, dans les micaschistes de la Sicria del Mico ou dans ceux du Carrizal, dont les veines de quartz sont censées renfermer de l'or; mais, cn admeltant mème que l'on ail exécuté des reconnaissances d'une certaine précision, ce dont nous doutons, il n'en est pas moins vrai qu'aucune des mines exploilćes actuellement n'appartient à ce système de roches, et que les richesses mélalliques qu'elles contiennent peut-ètre n’ont jamais été mises en œurre. La grande chaine porphyro-trachylique présente, au Honduras, un grand nombre de filons de galène argentifère reconnus, sur quelques-uns desquels on a mème fait des tentalives d'exploilations plus ou moins fructueuses. On y trouve ensuite, en continuant à marcher vers l'ouest, les mines assez productives d'Alotepeque, et non toin de là, des travaux qui ont été exécutés avec succès à quelque distance du lac de Guija au Salvador; puis les filons reconnus aux environs de Jalapa; enfin les gisements qui ont élé reconnus en différents points des Allos, sans qu'on tes ait exploilés ni étudiés. C'est tà un aliggnement mélallifère bien défini, el dans lequel on trouverait probablement, si l'on possédait des renseignements suffisants pour pouvoir l'étudier de plus près, des caractères constants de composition, de nature de gangues, de direction, etc. Comme annexes ì ce système, nous pourrons d'abord indiquer les filons reconnus en plusieurs points de l'axe monlagueux du Salvador, et exploités avec soin aux mines de Los Encuentros et de Tabanco, où les filons aflectent généralement unc direction moyenne sud-est - nord-ouest. II faut signaler aussi les groupes de filons entrevus dans une partic de la Vera Paz el des Altos, où on ne les a exploilés qu'en deux points, à Sau Cristobal et à Chiaulla; les gisements existent dans des montagnes calcaires qui sont orientées à peu près 
parallèlement à l'axe montagneux porphyro-trachytique, et les filons de galène argentifère y affectent une direction qui est à peu près nord-onest - sud-est. En résumé, l'état de nos connaissances sur les filons métallifères de l'Amérique centrale n'est pas assez avancé pour que nous puissions rien dire de précis, mais il semble néanmoins que l'on pent entrevoir un groupe de gisements accompaginant les montagnes porphyro-trachytiques ou leurs annexes, et dont le caractère commun serait de présenter des filons de galène argentifère à gangue de quartz, tous orientés suivant une direction moyenne du sud-est au nord-ouest, tont en admeltant des écarts d'une quinzaine de degrés daus les deux sens.

Groupement des sources thermales.

Les sources thermales appartiennent à deux groupes bien distincts: les sources alcalino-chlorurées et les sources sulfureuses. Parmi les sources alcalino-chlorurées que nous avons ei occasion d'étudier dans nos voyages, nous en distingnons d'abord une série qui suit nettement la direction de l'axe montagneux porphyrotrachytique et se trouve disposée sur son flanc sud; ce sont, en partant de l'ouest, d'abord celles des environs de Quezaltenango (Almolonga, San Cristobal, Totonikapam), puis celles qui sont distribuées autour de la Antigua el enfin celles d'Amatitlan. Nous devons avoner, d'ailleurs, que c'est le seul alignement un peu précis que nous ayons pu reconnaitre, car les autres sources sout distribuées suivant une loi qui nous échappe, probablement parce que nous ne possédons pas les éléments du travail en quantité suffisante. Ainsi, au Salvador, nous avons à Los Encnentros des sources qui sont en relation immédiate avec les filons; mais celles de San Miguel ne sont plus dans ce cas, et celles de San Salvador se rapportent à autre chose. De même, au Guatemala, nous avons à Zacapulas et près de San Agustin des sources qui sortent l'une et l'autre du granit, mais qui n'ont, sauf ce caraclère.commun, aucune autre relation ni entre elles, ni avec les groupes dont nous avons parlé plus lıaut. Les températures des sources alcalinochlorurées présentent des écarts assez considérables, el, mème sur l'aliggnement bien reconnu, elles varient de $30^{\circ}$ à $68^{\circ}$.

En parlant des sources sulfureuses, nous ferons évidemment abstraction de celles du Satvador qui, sous le nom d'Ausoles ou d'Infiernillos, font directement parlie des phénomènes volcaniques. Au Gualemala nous ne connaissons que deux sources sulfureuses, toutes deux à une température élevée et appartenant au sys- 
DANS LES RÉPUBLIQUES DE GUATEMALA ET DE SALADOR. 261

lè̀ne granitique. La ligne qui les rejoint est dirigée presque exactement est —ouest; mais, en présence d'un nombre aussi peu considérable de documents, nous ne pouvons tirer aucune conclusion de ce fait.

ROCIES ÉRUPTIVES.

Les roches éruplives qui, d'après ce que nous avons exposé plus haul, forment en quelque sorte le noyau profond, l'ossalure intérieure de l'Amérique centrale, n'apparaissent au jour que dans une baude plus ou moins large disposée vers la région centrale des terres suivant une direction à peu près concordante avec celle du continent lui-mème; elles comprenuent, outre les granils, les porphyres trachyliques et les roches volcaniques propremeul diles, dues aux soulèvements que nous avons reconnus, des injections de porphyres divers el des épanchements de basalte, attribuables soit aux mêmes phénomènes, soil à des causes moins aisément appréciables.

GRANITS.

Il n'y a pas grrand'chose à ajouter à ce que nous avous déjà eu occasion de dire des grranits, qui sont en réalité la roche éruptive la plus rare de l'Amérique centrale, et dont les lambeaux ne paraissent avoir subsisté dans quelques loca-

Extension et carictères des irranits. lités que comme les témoins isolés el perdus d'un ordre de choses antique et progogressivement dissimulé par les manifestations de phénomènes plus récents. Sauf la zone des environs de Zacapa, où ils se développent avec une assez grande intensité, et d'où ils se prolongent peut-ètre sans interruption jusqu’à El Carrrizal dans les sommités qui relient ces deux points, on ne fait guère que les entrevoir, soit à Zacapulas, soil entre le volcau d'Alitlan et la mer, el leur présence est encore moins nettement indiquée autour de Cerro Redondo et du volcan Guma, où ils ne se manifestent que par des roches isolées et de gros blocs roulés. Il est important de faire observer que, dans toutes les localités que nous venons de ciler, sanf une, les granits présentent une grande conformité d'allures et de composition, tout en offrant quelques légères différences, soit pour la finesse du grain, soit pour la compacité el la tendance à affecter une apparence schistoïde en passant au gneiss. Iu fond, c'est toujours et partout une roche ì assez gros élé- 
ments, d'une couleur blanche nuancée d'un peu de jaune et de rose; composée de quartz blanc, de feldspath orthose plus ou moins coloré el de mica d'un brun noirâtre; et ces analogies perınellent de supposer qu'on a affaire à des roches d'origine commune appartenant à un senl et mème groupe. Pourtant il y a une exception à Zacapulas, où l'on peut observer en mème lemps, et très-près l'un de l'autre, les granits semblables à ceux qui existent dans les autres points, les granits normaux, si nous osons nous exprimer ainsi, et d'aulres granits d'un grain toul différent, colorés de nuances toutes particulières, el renfermant deux feldspaths au lieu d'un seul. Des études postérieures pourront seules faire saroir si cette dernière roche appartient au même groupe que les autres, on si elle doil son origine à une injection remontant à une époque différente. Quoique nous ne puissions rien ajouter de plus pour la solution de cette question, nous nous faisons un devoir de la siggnaler et de l'inscrire en têle de la liste des problèmes à résoudre.

PORPIYRES TRACIITIQUES.

Les porphyres trachyliques constituent assurément l'élément éruptif principal de l'Amérique centrale, car ce sont eux qui lui ont donné presque complétement son relief et son aspect actuel, et ce sont eux anssi qui apparaissent aujourd'hui encore dans toules ses régoions ćlevées et ses chaines de inontagones priucipales. Il ont donc une extension considérable, at qui le serait bien plus encore pour l'observation inmédiate, s'ils n'avaient été masqués en bien des points par des dépôts superficiels.

Caractères des porphyres trachytiquins.

A dire rrai, ces porphyres trachỵtiques sont des roches bien mal définies en gónéral et qui ne se prêtent qu'avec difficulté aux classifications de la lithologie moderne. Nous les avons décrits nombre de fois, toujours composés d'une pâte feldspathique de conlenr sombre, brune, rougeâtre ou violacće, souvent massive el compacte, quelquefois désagrégée, grenue, bulleuse, frittée ou sulsschistoïde, renfermant des cristaux d'un autre feldspath blanchàtre, tantôt définis et reconnaissables, tantôt passant à des muuches informes et inqualifiables, englobant quelquefois comme minéraux accidentels des baguetles d'amphibole ou des paillettes de mica. Sont-ce des porphyres? Assurément non, si on les compare aux 
DANS LES RÉPUBLIQUES DE GUATEMALA ET DE SILVADOR. 263 porplryres de la Suède ou de l'Égypte; et cependant, combien n'y a-t-il pas de caractères communs dans la composition el la texture. Sont-ce des trachytes? Bien moins encore, si l'on admel comme définition absolue de ce nom celle qui existe dans lons les trailés de lithologie, et si l'on prend comme lype de cette roche les échantillons provenant du Siebengebirge qui brillent dans nos collections publiques. Pour rester dans la vérité et pour ne pas ètro absolı, ce qui serait ici fort dangereux, il faut bien admethe que, par cerlains caractères, on a affaire à des trachytes, que, par d'autres, plus nombreux encore, on est en présence de véritables porplyyres, cl conserver, jusqu'à nouvel ordre, le $110 \mathrm{~m}$ de porpliyres trachỵliques pour des roches mal définies, moitié porphyres, 111 peu trachytes, servant en quelque sorte de passage de l'mn à l'autre, et n'étaut au fond ni l'un ni l'autre. Si nons voulions nous laisser aller à discnter ici les idées nouvellement émises dans la science par M. Ch. Sainte-Claire Deville sur le trachylisne des roches, nous en pourrions trouver une singulière confirmation dans ces roches de l'Amérique centrale, qui ne sont peut-être après tout que des porphyres trachylisés. Mais ce n'est pas ici le lieu, et la seule chose qu'il importe avant tout d'élablir, c’est que les aflunités principales et les caractères fondamentanx de ces roches les raltachent au groupe des porphyres, qu'elles sont essentiellement métallifères, ce qui les sépare profondément des trachytes proprement dits, el surtoul que, pour éruplives qu'elles soient, on ne devra jamais les cousidérer comme volcaniques. Le soulèvement porphyro-tracliylique est parfaitemenl distinct du soulèvement volcanique; il lui est de beancoup antéricur, il en est complétement et absolument indépendant, el ne se rattache ì lui par aucun caraclère extérieur; car nous n’admeltrons pas, comme le font certains géolog̣ues, qu'on puisse donner le nom de phénomène volcanique à toule éjaculation de malic̀res éruptives sorlies sous une forme quelconque du scin de la terre, et nons le réserverons uniqucment pour ceux quị se sont manifestés en produisant des volcans. Il demeurera donc bien élabli pour nous, que les caụses du soulèvemenl qui a conslitué l'Amérique centrale, avec son arêle monlağneuse acluclle, sont toul à fait différentes de celles qui l'ont jalonnée de cônes volcaniques, et qu'elles résident dans l'éjaculation d'mne matière éruplive qui présente les plus gorandes analogies avec les porphyres et se rattache directement ì leur groupe lithologique. 
Après les développements que nous avons domnés à l'arlicle du soulèvement porphyro-trachytique, nous n'arons pas besoin de revenir sur l'âge probable que nous sommes conduits ì attribuer à cetle roche; disons seulement un mot encore du développement géologique qu'elle prend dans la constitution de l'Amérique centrale.

Dércloppenent des porpliyres trarlyylirues

En jetant les yeux simullanément sur les deux profils de la planche VI, on y verra que l'arête porphyro-lrachylique, singulièrement rétrécie anx environs de Guatemala, prend, au contraire, une extension considérable en largeur à mesure que l'on s'élève dans le nord-ouest. C'est là en effet, près de Totonikipam et de Quezallenango, que ces roches sout les plus developpées, non-seulement dans les laates monlagnes, mais encore dans les plaines adventives comme celle de Santa Cruz del Quiché, où elles apparaissent parfois. Les porphyres trachytiques existent aussi, mais ne se vojent pas toujours, dans les hauts plateaux de Godines, Palsum, Pasesilla, Chimaltenango, elc., dont ils formenl la base à une profondeur plus ou moins considérable sous les dépòts superficiels. Ils dominent la vallée de Guatemala de tous côtés, se poursuivent dans les montagnes de Jalapa, prement une importance considérable aux environs d'Alotepeque, et existent sans aucun doule encore dans les séries de sommités qui continuent, dans le Honduras, la ligne de faite de l'Amérique centrale. Outre cela, les porphyres trachỵtiques, toujours semblables ì eux-mêmes, se montrent encore au Salvador, où ils forment en grande partie l'axe anticlinal secondaire; on les y voit surlout près de Chinameca, autour de San Vicente, à San Salvador, au Guarunal el enfin dans les monlagones d'A paneca, qui terminent la chaîue du côté de l'ouest. Nous devons encore signaler leur présence dans quelques localités du sud du département de Chiquimula, à Jalpalagua, à El Oratorio, elc., dans une région excessivement embrouillée, formée de montagnes qui s'entrecoupent dans tous les sens et où l'on voit se perdre, peut-être à cause de la présence d'une petile chaîne volcanique adventive, greflée normalement sur la principale, la contimuité qui est ın des caractères les plus saillants des faits géologiques dans le Guatemala.

PORPHYRES DIVERS. 
DANS LES RÉPUBLIQUES DE GUATEMALA ET DE SALVADOR. 265 présentent des caractères très-différents : ce sont les porphyres quartzifères de Chiquin et les porphyres amphiboliques de Las Minas, que nous ne décrirons pas une scconde fois, puisque nous l'avons déji fait avec suffisammont de détails (Voyage de San José au Rio Grande, p. 205 el 206). Disons seulement que ces. roches, loin d'offrir comme les précédentes quelque chose de vague el de mat défini, sont, au conlraire, des porphyres parfaitement nets, avec tous les caracteres du genre, el quili semble toul au moins peu probable quills puissent être rapporlés à la mème époque ct aux manifestations des mêmes phénomènes que les porphyres trachytiques. Les porphyres quartzifères de Chiquin forment une masse assez puissante qui a percé et probablement même forlement plissé les micalschistes, ainsi que quelques-unes des couches qui reposent sur eux; el c'est an milieu de ces assises profondément troublées el embrouillées que les porphyres amphiboliques sont venus s'injecter sous la forme d'un dyke remarquable à tous les points de vue. Il est done extrêmement difficile d'assigner une époque précise ¿ l'apparition de ces roches, qui ont tellement modifié et clérangé les assises à travers lesquelles elles se sont fail jour, que l'on n'y peut plus trouver d'indices conduisant à la connaissance de leur histoire. Quoique nous n'ayons pas eu occasion de voir en d'autres localités des injections de porphyres analogues à celles dont nous venons de parter, il est néanmoins probable qu'il y en a, et que. quand on les comnaitra, celle étude jettera quelque lumière sur leur origine possible.

B.SALTES.

Tous n'avous eu à signaler, dans le cours de nos itinéraires, que deux groupes de roches basalliques qui ne doivent remonter ni l'un ni l'autre à une Irès-grande antiquité géologique, puisqu'ils recouvrent, aussi bien l'un que

Caractères et développemrnt des roches basalliques lautre, les porpliyres trachyliques sons-jacents dont est constituée la masse intérieure du sol dans les régions où ils se sont épanchés. Il ne serait pas impossible quils fussent contemporains de la première apparition du soulèvement volcanique, et quiils ne dussent être considérés comme représentant ses manifestations originaires, ce qui n'est nullement contredit par leur position, puisqu'ils sont tous denx à cheval sur la direclion de l'axe volcanique. Dans tous les cas, les basaltes 
plus ou moins bien définis qui existent à la pointe sud-est du Salvador et dans des iles de la baie de Fonseca sont en relation immédiate avec les phénomènes volcaniques les plus anciens de ces régions : témoins l'Isla del Tigre et le Cerro de Conchagua, qui sont composés de ces roches basaltoïdes peu nettes et ne sont peut-ètre aussi ‘que des volcans primordiaux, éleinls depuis un nombre incalculable de siècles, déformés par l'action conlinue, pendant un temps aussi long, de tous les agents atmosphériques, el remontant aux époques primilives où les phénomènes volcaniques ont choisi l'Amérique ceutrale pour leur servir de Ihéitre. Les basaltes qui se développent dans le sud du département de Chiquimula, au Guatemala, aulour de los Esclavos, de Berberena, de Cerro Redondo, etc., forment une masse plus importante que la précédente et surtout beaucoup micux définic; la roche y est gónéralement bien caractérisée, malợé quelques variétés. dont une entre autres se rapporte à une dolérite cristalline tout à fait remarquable. On doit obscrver que ce vaste épanchement basaltique coïncide à peu près avec cette région extrêmement troublée, où existe un embranchement normal de l'axe volcanique, et pourrait fort hien être en rapport avec ce phénomène. Avant de quilter ce sujet, notons encore qu'il existe à Cojutepeque, dans te Salvador, une masse basaltique peu étendue, servant de base au pelit volcan éteint qui s'élève près de cette ville.

LAVES ET SCORIES VOLCANIQUES.

Caractìres et développement des laves.
A peine devrons-nous consacrer quelques lignes aux laves et aux scories volcaniques, dont l'extension est loujours très-faible par rapport ì la coustitulion góologique d'une contrée tout entière, quelque considérable qu'elle puisse paraître, lorsqu'elle est envisagée en elle-mème. L'époque de leur formation ne peut pas nous arrèter bien longtemps, puisqu'il est de toute évidence qu'elles sont postérieures aux soulèvements des volcans dont elles soul les produits, ol que nous savons que, pour beaucoup d'entre les coulées les plus récentes, la tradition conserve la notion du mornent où elles ont reconvert le sol. Il nous faut néanmoins remarquer que les laves ne sont relalivement pas fréqueutes dans l'Amérique centrale, que l'on n’en connaît qu'un petit nombre de coulées, le. plus souvent peu abondantes, et que les volcans de cette partic du globe ont une lendance sin- 
DANS LES RÉPUBLIQUES DE GUATEMALA ET DE SALVADOR. 267 goulière à émettre bien moins des masses liquides incandescenles que des produits gazeux, pulvérulents ou cinériformes. Les seules coulées de lave d'une vérilable importance, qui soient présentes à notre mémoire, sonl celles des volcans de San Miguel et d'Izalco au Salvador, et du volcan de Pacaya au Guatemala; encore sont-elles imperceptibles en comparaison de celles que nous avons eu occision d'étudier au Mexique. En fait de scories, nous n'avons pas à parler des petits fragments projetés qui se mĉlent aux cendres et aux lapilli répandus au loin, loul en laissant les blocs les plus volumineux s'accumuler à la base el sur les flancs mêmes des volcans; et, ne nous occupant ici que de considérations générales et de vues d'ensemble, nous ne pourrons pas non plus altacher une grande importance aux roches scorifiées dont sont constituées les parois des cratères de plusieurs volcans. Nous n'en dirons done rien, si ce n’esl que ces roches sont presque toujours, pour ne pas dire toujours, des porphyres trachytiques plus ou moins altérés sous l'influence des phénomènes volcaniques, el qu'elles apportent, par leur' nature, une preuve de plus à l'liypothèse qui conduit à supposer que les volcans se sont ouvert un chemin à travers la masse porphyro-trachytique préexistante et se sont formés en quelque sorte aux dépens des éléments constituants de ce groupe.

\section{ROGIIES SÉDLUENTAIRES.}

Les roclies sédimentaires occupent, dans le Guatemala, la presque Lotalité du versant de l'Allantique, au moins pour les parties que nous en avons recommues, et tout nous porte à croire que cette extension déjà si considérable le deviendra Déseloppement des roches sédịnentaires en géneral. davanlage encore lorsque de nouvelles explorations auront fait commaitre les réggions plus éloignées du centre, telles que les pays des Lacandons et des Mayas, les solitudes du Pelen, les zones mystérieuses de l'intérjeur du Yucalan, où la science n’a pas encore pu porter son investigation. On ne devra pas oublier une intéressante particularité, sur laquelle nous avons déjà appelé l'altention, c’est que les roches sédimentaires du versant de l'Atlantique devront être divisées en quelque sorte en deux groupes géographiques, comprenant : l'un, les vastes formations continues qui s'étendent à partir du Rio Molag'ua jusqu’à la mer; l'autre, les lambeaux isolés, serrés entre l'arête porphyro-trachylique el les sommités graniliques. Nous cousidérerons, à tort ou à raison, les micaschistes comme constituant la première des 
assises sédimentaires, et, après avoir commencé par eux la série de nos études, nous nous occuperons successivement des schistes talqueux el chloriteux anciens (cambriens ou siluriens), puis des poudingues, grès et schistes de Santa Rosa, auxquels doivent peut-être être réunis les grès, les poudingues lie de vin, et une partie des schistes argileux tendres qui ont été reconnus dans le déparlement de Chiquimula par le R. P. Cornette; enfin des schistes argileux et des calcaires. que nous considérons comme jurassiques el qui terminent, au moins dans les provinces qui nous sont connues, la série sédimentaire proprement dite. En effel, les couches secondaires supérieures (terrain crétacé) et les assises terliaires font alısolument défaut, de sorte que nous n'avons pu observer comme formations postérieures aux terrains jurassiques que des dépôts superficiels qui doivent ètre étudiés à part.

MICASCHISTES.

Caracteres des miensehistes.

Il ne nous apparlient pas de discuter ici tes différentes opinions qui ont été émises sur l'origine des micaschistes et sur les causes auxquelles ils sont dus. Quelle que puisse être l’influence đu métamorphisme dans leur constitulion, et quelle que soit la forme sous laquelle cette action s'est fait sentir, qu'il nous suffise de résumer ici les différentes observations que nous avons eu occasion de faire dans nos itinéraires sur la fréquence, les allures et les caractères extéricurs des micaschistes. Celte roche est partout en rapport intime avec le granit, qu'clle accompagne chaque fois qu'il apparaît, du moins sur le versant de l'Atlautique, et anqual elle semble passer, dans quelques circonslances, par une série indéfinio de transitions insensibles; c'est ce que l'on peut roil en particulier près de Zacatpulas, où les granits, les gneiss el les micaschistes forment un vaste ensemble dans lequel il est fort difficile de saisir des points de séparation entre les diversess espèces de roches. Mais il n'en est toujours pas ainsi, comme on l'observe à Ef Cálrizal, où le passage des granils aux micaschistes est assez brusque, ces deux 1'0ches étant presque séparćes dans un point par une sorte de dyke diorilique trèsaltéré. La connexion entre les granits et les micaschistes reste néanmoins frappante, puisque les mèmes filons de quartz traversent successivement les massifs de ces deux roches. Quoi qu'il en soil, les micaschistes du Guatemala sont toujours carac- 
DANS LES RÉPUBLIQUES DE GUATEVALA ET DE SALVADOR. 269 lérisés par une schistosité très-remarquable; ce sont de belles roches à grain fin, blanches ou jaunàtres, contenant une très-forte proportion de mica en pelites paillettes régulièrement orientées, susceptibles de se diviser en grandes plaques de dimensions considérables, et produisant même quelquefois dans la nature des séries de dalles gigantesques plus ou moins rapprochées de l'horizontale.

- Les micaschistes s'appnient toujours sur le versant nord des chaines granitiques, et forment peut-être une bande continue d'une largeur extrèmement variable, étendue suivant l'allongement du cours du Rio Motagua, mais avec des inclinaisons el des directions qui ont été modifiées en plusieurs points par l'aclion des soulèvements postérieurs à leur apparition. Nous les voyons d'abord auprès de Zacapulas, mais les renseiğnements nous manquent sur la vaste régoion qui s'étend de là jusqu'ì la chaine de Chuacus, et dans laquelle il est fort probable qu'ils existent. A partir de Chuacus, nous sommes certains de la contiusuitć de la bande qui se poursuit jusqu’à Sań Agouslin Acazahuastan, et s'infléchit à partir de ce village pour aller former, avee une direction différente, la chaine dite Sierra del Vico.

La puissance des micaschistes de l'Amérique centrale est probablement trèsconsidérable, ce dont on peut s'assurer sur la route de Guatemala à Coban; on les voil, en eflet, arriver au jour successivement dans trois rides montagneuses parallòles, à El Carrizal, entre San Bernardo et le Rio Grande, enfin dans la grande chaine de Chuacus. Quoiqu'il soil à peu près évident que ces diverses apparitions sont dues à des plissements, ce qui nous semble parfaitement prouvé par les rudiments des assises postérieures qui existent encore dans le fond de batean indiqué auprès de Las Vinas, el quoique l'on ne puisse pas, dès lors, évaluer l'épaisseur totale des micaschistes en additionnant celle qu'ils alteignent dans les ressauts successifs où nous les avons vus, il suffit de considérer le développement qu'ils prennent dans une seule de ces chaines, dans celle de Chuacus, par exemple, pour se eonvaincre de l'importance qu’ils ont dans la géologie du Guatemala. La distance horizontale entre les deux haciendas de Chuacus et d'El Pincon, situées l'une el l'autre au pied de la montagne, mais de còtés différents, est au moins de 4 kilomètres; en admettant done que le plissement que nous considérons n'existe qu'entre ces deux points et ait laissé horizontales les couches de la Canoa 
et de Llano Grande, nous arriverions à une puissance mininum de 2,000 mètres, ce qui est énorme. Nors pouvons donc aflirmer en tonte sécurité que les micaschisles ont pris, dans celte partie du globe, un développement tel, qu’ils y figurent comme une des assises les plus importantes de l'écorce lerrestre.

SCHSTES ThlQuedx ET Chloniteux.

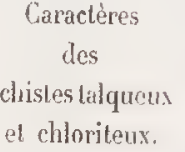

el chloriteux.

Les roches qui, dans une partie du Guatemala, semblent succéder aux micaschistes et reposer directemenl. sur eux forment un groupe sur lecquel les renseignements que nous pouvous donner, à la, suite de nos recherches et de nos études, sont encore bien insuflisants. Nous devons l'avouer, nous sommes.conduits à rémir, jusqu'à nouvel ordre, dims un même ensemble, des couches parfaitement distincles au point de vue lithologrique; ces couches devraient certainement être considérées comme conslituaul des sous-assises différentes d'un mênre horizon géologique plus on moins bieu défini, mais nous n'avons pas pu parvenir encore à en saisir, d'une ficcon assez précise, la superposition et les limites. Cela lient à ce que les points où ces roches apparaissent ont été sonmis, dans ta plupart des cas, à des plissements nombreux et ì des perturbations considérables; non-senlement les couclies sont difficiles ì suivre, mais encore on u'a le plus souvent affaire qu’ì des blocs déplacés ou éboulés qui recourrent les endroils où elles sout en place, et qui se mèlent d'une façon faite pour dérouter aisément l'observateur el ne se laisser délerminer qu’à la suite de recherches prolongées. Les roches dont nous avons à parler sont toutes des schistes, mais des schistes très-variables d'aspect el de composition, tantòt susceptibles de se décomposer en feuillets bien définis et extrèmement minces, tantòt devenant presque compactes et difficilement clivables, se rapprochant parfois de véritables pliyllades lustrés, passant d’autres fois à des grauwackes à peine schistoïdes; on y voit des schisles lalqueux, chloriteux, amphiboliqnes, argoileus, sableux, d'un vert foncé, d'un vert clair, bruns, noiràtres, en un mot, de toules les natures conme de tonles les couleurs. Mais, si variable que soit la composition, il semble pourtant que tontes ces roches appartiennent à un même groupe, car, dans presque toutes les circonstances, on peut recueillir non loin les uns des autres des échantillons des divers types. Peut-être y a-t-il même, en certains points, connexion intime et presque passage entre les schistes talqueux 
DANS LES RÉPUBLIQUES DE GUATEMALA ET DE SILVADOR, 271 et les micaschistes, comme on l'a déjà observé en Europe; et l'on peut voir dans quelques localités, près de San Bernardo, par cxemple, les filons de quartz métallifères se prolonger à travers les schistes talqueux, après avoir traversé successivement les granits et les micaschistes.

Le groupe des schistes talqueux et chloriteux est en rapport inlime avec les micaschistes sur lesquels il s'appuie du côté du nord, et semble partont leur ètre directoment superposé; ainsi on en voil un lambean, fort bouleversé lui-mème par l'injection postérieure d'un dyke de porplỵre, dans le fond de bateau formé par un plissement des micaschistes entre El Carrizal et San Bernardo, et il est probable qu'on pourra en observer d'antres, dans des siluations analogues, lorsque le pays anra été parcourn scienlifiquement dans tous les sens. Mais ce système schisteux prend son plus grand développement dans une bande plus ou moins large qui suit les inflexions de celle des micaschisles el lui sert cu quelque sorte de limite. Cetle bande prend näissance près de Zacapulas, sur la rive ganche du Rio Chisoy, où elle est fort ćtroite el ne se compose que de boaux phyllades lustrés d'un verl lianc, puis se continue probablement dans les montagnes qui dominent Rabinal: on la retrouve au nord de Salama, à Kachil, oì elle prend son plus grand développement, el d'où elle s'enfonce dans les régions de l'est de la Vera Paz, jusqu'à une distance que le manque de renseignements ne nous permet pas d'évaluer. Quoique ce groupe ail une puissance assez considérable, il ne peut en aucune facon ètre comparé à celui des micaschistes, el l'on ne peut douter qu'entre Salama et Sanla Rosa, par exemple, les mèmes couches ne soient ramenées plusieurs: fois au jour, dans les chainons parallèles, par des plissements successifs. Quoi qu’il en soit, les phyllades verts qui semblent constituer lo membre inférieur de la série: et qui apparaissent presque seuls à Zacapulas, y ont une puissance de 300 mètres au moins, et il est probable qu'à Kachil l'épaisseur de l'enscmble est encore bien plus considérable.

Tous avons déjà eu occasion de dire que nous étions portés à considérer le système des schistes talqueux ct chloriteux comme étant cambrien ou silurien; mais, à parler franchement, nous devons avouter que nous n'avons à fournir tre pussible
dos
whistes fatqum-
chlorifoms. aucune preuve séricuse sur laquelle puisse s'étayer celte hypothèse, qui ne s'appnie guère que sur les analogios et los ressemblances existant entre co groupe

Extension talquo - ehloritenx. 
d'assises el les formations siluriennes d'Europe, aussi bien au point de vue de la lithologie que pour l'ensemble des caraclères généraux. Malgré nos recherches. nous n'avons rencontré aucune trace de fossile qui pût corroborer notre opinion: mais il n'est pas sans importance d'observer que le système des schistes talqueur el chloriteux, subordonué tui-mème à des couches plus récentes dont nous chercherons plus loin à déterminer l’àgre, repose directement sur les micaschistes. Cela permet au moins de faire remonter cette formation à une éporque forl ancienne, el ne s'oppose d'aucune manière à ce qu'on puisse la considérer comme appartenant à la période silurienne.

POLDIGLES, GRES ET SCHISTES DE SATT ROSA.

Ciaracteren

dis groupe des pondingues,

groms

et schistren

de Santa Rrisa.

Si, après aroir franchi te domaine des sehistes talqueux of chloriteus, nous continuons à nous élever dans la série des formations góologiques, ou, pour en revenir à la pratique des choses au Guatemala, si nous continuons à marcher vers lo nord, nous ne tarderous pas à rencontrer un groupe de roches qui semblent reposer directement sur les couches précédentes, el qui présentent, nous derons Ir reconnaître, un des problèmes les plus obscurs encore de la géologie centroaméricaine. Ton-seulement l'absence complète de tout reste organisé fossile nous place dans l'incortitude la plus absolue sur l'age que l'on pourrail altribuer ì ces assises, mais cncore. leurs pilissements successifs, leurs dérangements, leurs apparitions plusienrs fois répétées sans cause bien appréciable, complicuées étrangeunent encore par l’insuffisance des données géogrephiques sur les régions oì nous nous trouvons, nous laissent en présence de dontes et d'hésitalions que wous liessayerons pas de méconnaître. Nous voulons parler de la série de roches que l'on rencontre entre Santa Rinsa el Tactic, el que nous avons décrites avec délails en lemps el lieu (Voyage dans la Vera Paz, p. 214 el suiv.): série peu importante. il est vrai, si J’on ne considère que son extension immédiale, puisqu'elle ne se développe qu'arec une puissance d'une cenlaine de mètres tout au plus, mais extrêmement renarquable, au contraire, si l'on envisage les matériaux tout ì fait partiruliers dont elle se compose, et les allures singulières qui la caractérisent. On se souvient que nous avons reconnu daus ce petit système un ensemble de calcaires, de poudingoues quartzifères, de grè̀s jaunâtres el de schistes rouges, qui se dis- 
DANS LES RÉPUBdiques DE GULTEMALA ET DE SALVADOR. 273 tingue nettement des formations dont il est entouré au nord et au sud, soit des schistes talqueux siluriens, soit des calcaires compactes el de schistes argiteux jurassiques. On se souvient aussi que nous avons rencontré, sinon toujours la série complète, du moins la majeure partie de ses membres en qualre localités principales; d'abord près de Santa Rosa, puis dans les falaises dı Rio Chisoy, au point où le chemin des Altos franchit le fleuve (p. 220), puis encore entre Chicaman et San Miguel Uspantan (p. 224), et enfin près de Zacapulas (p. 227), tocalités dont les concordances géographiques sont assez difficiles ì démêler. Supposons, en effet, que la continuation des conches observées ì Sanıli Rosa doive se retrouver dans celles qui existent entre Chicaman et San Miguel Uspantan, ce que nous ne saurions guère préciser, nous devons l'avouer, il n'en résulte pas moins que l'on trouve d'un côté deux apparilions supplémentaires du système, dont l'une au moins devrait se retrouver sur le chemin de Gualemala à Coban, ce qui n'a pas lieu. Ninsi done, si l'on admet que l'on al aflaire ì des couches simplement interposées entre les calcaires jurassiques, on deva penser que ces conches ne se présentent qu'une fois en un certain point et trois fois ì quelqne distance de là, ce qui n'est pas aisé à comprendre. Si, au contraire, on admet que l'on a affaire à uné formation particulière existant à la base des terrains jurassiques, on sera forcé de penser que ce sont des plissements qui l'ont ramenée plusieurs lois au jour, ce qui est an fond notre opinion personnelle, nous derons le déclarer; mais on sera forcé de se demander aussi comment il se fail que ces plissements n'aient pas en lieu en un certain point et se soient répétés deux lois tout près de là, ce qui n'est pas facile à expliquer non plus. On roit donc que, quelle que soit l'opinion qu'on embrasse, il plane sur les allures du groupe de Santa Rosa un cerlain mystère qui ne pourra disparaître que quand on possédera des cartes plus complètes que colles que nous avions entre les mains, el quand on pourra suivre, sur toute sa longueur, l'alignement d'une des séries de collines qui sont composées de ces roches.

En faisant abstraction des apparitions supplémentaires, on pourra peut-être aldmettre que les poudingues, grès et schistes de Santa Rosa constituent mine bande élroite, qui s'étend le tong ros schistes talqueux et chloriteux, en les limilant ef en reposant directement sur eux. Il n'est pas impossible, d'ailleurs, que l'extension Voyagege géologique. 
de ce groupe ne soit un peu plus considérable, et qu'il ne se retrouve en quelques autres points, notamment entre les deux chaines granilique et porphyro-trachytique. Nous avons déjà signalé (p. 205) des poudingues rougeâlres, qui existent à Las Minas au-dessus des schistes talqueux, dans un repli des micaschistes, et pour lesquels nne assimilation serait peut-être permise, ainsi que pour les grès et les poudingues lie de vin que le R. P. Cornette a rencontrés en assez grande abondance dans le département de Chiquimula (p. 207 el suivantes) ì Guaslatoya, à Gualan, au mont Chatun, dans les montagnes de Jocatan, au Llano Grande près de Copan, elc. Cette assimilation ne peut néanmoins ètre que Irèsvargue, avec le peu de précision des renseignements que nous possédons, et il y a là un problème important à résoudre.

ire possible du groupe 1. Samia Rinsa.

fiaraclères des calcaires compacles

schisteux et argiloux.
Le R. P. Cornette considérait comme permiens les grès qu’il avait observés dans le département de Chiquinula, et celte opinion personnelle du savant jésuite nous encourage à exprimer une hypothèse qui s'applique surtout à la série complète telle qu'on la voit à Santa Rosi. En considérant les premières couches de calcaires orrisàtres comme l'équivalent du muschelkalk, les grès el poudingues comme celui des grès bigarrés, enfin les schistes rougeâtres comme celui des marnes irisées, ne pourrait-on pas supposer que l'on a affaire à une sorte d'analogue centro-américain du trias, tel que nous le connaissons en Europe? El cette lypothèse u'est nullement en contradiction, il faut le remarquer, avec la position góologique des couches de Santa Rosa, puisqu'elles sout comprises entre les sclistes que nous nous sommes crus autorisés à considérer comme siluriens, et les calcaires que nous avons de fortes raisons pour ratlacher à la période jurassique.

CALGaIRES ET SGIISTES JURASSIQUES.

Aussitôt que l'on a franchi les collines dans lesquelles existe le pelit système de Sanla Rosa, on se trouve en présence d'une formation nouvelle, qui, à notre avis, repose sur les couches précédentes et leur succède dans l’ordre des séries géologiques. Cette formation se compose essentiellement de calcaires compacles gris et bleuâtres, de calcaires schisteux bleus et noiràtres, et de schistes argileux jaunâtres ou gris. Elle prend, vers le nord, une extension considérable, occupant non-seulement toules les régions que nous avons visitées dans celte direclion, 
DANS LES RÉPUBLIQUES DE GUATEMALA ET DE SALADOR. 275 mais s'étendant encore bien plus loin, jusque près de l'Atlantique d'un côté el dans le Peten de l'autre, ainsi que le prouvent les récils des indigènes et les assertions de voyageurs plus autorisés, comme M. Morelet. Ces calcaires et ces schistes présentent des alternances fréquentes, mais qui ne sont en aucune facon comparables dans les régions qui s'étendent sur les deux rives du Rio Chisoy, de sorte que nous nous trouvons en présence d'un phénomène analogue à celui que nous avons analysé à propos des roches du groupe de Sinnla Rosa. Nous serons encore une fois forcés d'admettre l'existence de plissentents, pour ainsi dire locaux, ayant énergiquement aggi dans un point donné, et n’ayant presque pas lait sentir leurs effets à une cinquantaine de kilomètres de là; phénomène que nous ne lenterons pas plus d'expliquer ici que plus haut, et dont nous taisserons la vérificalion et l'étude à nos successeurs. Il est certain, néanmoins, que les schistes argileux semblent, dans l'un el l'autre cas, ĉtre prédominanls ver's le sud, c'est-i-dire au voisinage du système de Sanla Rosa, tandis que les calcaires compactes existent presque seuls dans la région du nord; ce qui indiquerail peut-c̀tre que les régions inférieures de la formation sont plutòt schistenses el les couches supérieures plutòt calcaires. Mais il y a des différences de détail souvent très-remarcquables; ainsi, dans la Vera Paz, il n’y a goùre de schistes que jusqu'à Tactic, lont le reste appartenant exclusivement aux calcaires; dans les Altos, au contraire, on voil d'abord des schistes entre Zacapulas et Cumen, pnis des alternances infinies de schistes et de calcaires terminées par une forte assise de calcaires, puis de nouveau des schistes assez puissants, et enfin seulement le grand développenıent des calcaires. Tous altirerous surtout l'attention sur les grands plissements qui ont pris pour théâtre le grand raviu voisin de Cunen, et où les calcaires el les schistes se remplacent un nombre considérable de fois dans un espace très-restreint. Its sout certainement en corrélation avec l'apparition des couches de Santa Rosa, qui se moutrent non loin de là et permellent de juger de l'intensité et de l'imporlance des phénoniènes qui ont ainsi dérangé l'élat normal des assises dans ces régions.

Nous u'essayerons mème pas d'évaluer la puissance de ce système de schistes et de calcaires, qui serail déjà énorme en n’envisageant que ce que nous en connaissons, el qui doit prendre des proportions colossales mème en tenaul comple des.

Extension dı groupe des ralraires. 
innombrables plissements qui ramènent probablement la même couche bien des fois à la surface. Quant à son extension, nous avons déjà parlé du prodigieux développement qu'il prend dans le nord de la Vera Paz et des Altos, ne formant plus seulement une bande continue, mais constituant, sinon toujours tout le sol apparent, au moins toujours le sous-sol de ces deux provinces, sur une surface considérable et que nous ne saurions définir. Ajoulons encore que les calcaires se retrouvent en assez grande abondance entre les coltines granitiques des bords du Rio Motagua el la grande chaime porphyro-trachylique du Guatemala, amenés là par un phénomène dont nous avons parlé avec assez de délails. Ces calcaires se voient à Saul Juan Zacatepeque, à la Pedrera près de Guatemala, à El Chato, à Pontesueda, dans le sommel des collines entre La Laguna et Guastatoya, formant aimsi une bande, sinon tout à fail conlinue, au moins parfaitement jalonnée, qui est peutètre en rapport avec les schistes siğnalés au-dessous d'elle à Pontesuela, à Guastatoya, voire même avec les schistes indépendants de calcaires, ou accompagnés seulement de cailloux roulés de calcaire, vus par le R. P. Cornelle ì Chiquimula, ì Jocolan, à Canotan, elc.

Ase probable du groupe des calcaires.

Nous avons dit que ce système de schistes et de calcaires paraìt se composer au nıoins de deux groupes principaux, dans chacun desquels prédomine l'une ou l'autre de ces roches; mais il est probable qu'il existe un nombre bien plus considérable de sous-ćtages, dont on pourra apprécier les importances relatives lorsque cet hor’zon géologique aura élé plus complétement étudié dans son ensemble et dans ses délails. Le système reposant sur les assises qui constituent le groupe de Sanla Rosa est donc postérieur à ce groupe, et doit appartenir à une époque géologique plus récente qui, selon nous, serait la période jurassique. Nous nouis fondons, pour émethre cette opinion, qui est mieux qu'une hypothèse, non-seulement sur des données stratigraphiques et des affinités lithologiques très-accentuées, mais encore sur des considérations paléontologiques qui ne sont pas sans importance. Ce n’est pas que les lossiles que nous avons recueillis nous-mèmes et dont nous avons déjà parlé (p. 217), le petit Pecten des envirous de Teleman et le fragonent de Pterocère des bords du Rio Chisoy, présentent des caractères suffisants pour servir de base à une semblable détermination; mais nous avons pu examiner dans la collection du Collegio Tridentino de Gualemala une série d'échantillons de fossiles 
DANS LES RÉPUBLIQUES DE GUATEMALA ET DE SALVADOR. 277 qui ont un facies jurassique des mieux définis, et qui seraient encore bien plus précieux qu'ils ne le sont, si leur localité de provenance élail plus exactement connue. Nous avons dessiné nous-mèmes d'après nature ces différents fossiles, ef nous nous proposions de faire reproduire ces croquis dans une planche accompagnant cet ouvrage; mais nous avons pensé que, teur provenance n'ćtant pas absolument certaine, nous ne devions pas nous exposer ì mettre en avanl, d'ume facon absolue, une affirmation que nous aurions peut-être couru le risque de voir démentir plus tard. Car, bien qu'on nous ait assuré d'une manière péremptoire que ces échantillons avaient été recucillis dans les environs de la Lagune d'Tzabal, où rien ne s'oppose, en effel, à ce que les calcaires et les marnes jurassiques soient très-développés, et où ils existent même probablement, nous n'avons pas pu retrouver la preuve de celle assertion, ni dans les catalogues de ta collection, ni dans les étiquetles détachées, et nous avons dù nous tenir en garde contre une erreur possible. Mais, si notre prudence nous obligeait à ne pas donner, en faisant figurer ces échantillons, une sorte de consécration officielle ì un fail que nous n'avons pu vérifier, ni par des recherches faites dans des manuscrits dignes de foi, ni par des observalions directes sur le lerrain, nous devons déclarer. d'un autre côté, que nous avons persomnellement la confiance la plus complète dans la personne qui nous a renseignés sur la provenance des échantillons de la collection de Guatemala, que nous sommes convaincus qu'ils ont élé en effel trouvés près de la Lagune d'lzabal, el que, comme tels, ils établissent nettement que les assises où ils ont été rencontrés sont jurassiques. Ajoutons encore que ces échantillons ne sont pas classés avec une collection européenne que possèdent les RR. PP. Jésuites, mais qu’ils sont mêlés aux roches recucillies par cux-mèmes dans leurs diverses excursions.

Voici en quelques mols ce que sont ces échantillons, qui sembleraient se rapporter à des étages différents composés de roches diverses, mais toujours jurassiques. Il y a deux ammonites, probablement Ammonites helerophyllus el Ammonites radians, ainsi qu'un grand échinoderme du genre Stomechimus, qui semblen! provenir d'une unarne. rougeâtre appartenant ainsi au lias supérieur. Une grande Térébratule et quelques petiles Lucines et Vénus, transformées en carbonale de. chaux blanc el cristallin, proviennent d'une gangue de calcaire compacte blan- 
chàtre, qui n'est pas netlement défini par leur présence. Enfin, dans une marne bleuâtre, assez semblable à celles des horizons supérieurs de notre groupe jurassique en France, on a recueilli un Hinnites roisin de l'Himnites incequistriatus, 111 Holectypus ressemblant beaucoup à l'Holectypus corallinus, puis un Hemiaster mal conservé, un Montlivaultia, un Mylihus et deux espèces d'Arca rappelant les uns ot. Ins autres les espèces des mèmes goenres qui caractérisent le Kimmeridge clay.

L'ensemble de ces fossiles définil clairement un groupe jurassique et nons permet d'affirmer avec certitude que les couches calcaires et schistenses du nord de lit Vera Paz el des $\Lambda$ ttos appartiennent à la période jurassique, ce que nous aurions posé moins péremptoirement, mais au fond avec autant de conviclion, quand mème ces preuves paléontologiques n’auraient pas existé.

DÉPÓTS SUPERFICILLS.

Béveloppentont Mrs túpòts superlicituls dans lomr insmilile.
Nous avons terminé le paragraphe consacré à l'étude des roches sédimenlaires proprement dites, en parlant des assises que nous considérons comme jurassiques, et c'est qu'en effet, comme nous l'arons déjà dit, nous n'en avons pas reconnu au-dessus qui pussent être rapportées à l'époque crétacée ou à la période terliaire. Ce n'est pas à dire pour cela qu'il n'y ait pas daus l'Amérique crutrale des conches plus modernes et que mème quelques-unes d'entre elles II aient été formées par les caux; mais ces couches présentent des caractères tellement particuliers, et se distinguent si nettement de l'ensemble que nous venous d'étudier, qu’il nous a paru plus naturel de faire sentir cette différence en les groupan dans un paragraplıo spécial. Ces roches, en ellet, ne se prêtent que difficilement aux classifications habituelles de la géologie, surtout parce que, pour la majorité d'entre elles, l'action volcanique est le principe immédiat de leur origine; et, do plus, elles ne remontent, en général, qu’à une époque relativement très-rapprochée de la nôtre, comme le prouve leur disposition en couches horizontales au-dessus des assises plus anciennes relevées ou inclinćes. On peut affirmer que la plupart de ces roches ont pris naissance gràce aux manifestations des phénomènes volcaniques accompagnés ou non de l'aclion de l'cau, qu'elles sont douc postérieures au soulèvement de l'axe volcanique, extrèmement récentes par conséquent, el qu'elles sont bien moins de vérilables assises continues, géolog̣iquement délinies, 
DANS LES RÉPUBLIQUES DE GUATEMALA ET DE SHLADOR. 279

que des dépòts superficiels répartis un peu à l'aventure suivant le hasard des lieux et des circonstances.

Cela posé, à peine avons-nous besoin de dire que les dépôts superficiels recouvrent presque complétement le versant du Pacifique, qui est jalonné de volcans, tandis qu'ils sont relativement beaucoup plus rares, au moins en co qui concerne les masses d'origine volcanique, du côté de l'Allantique, où l'on ne voil guère que quelques valtées comblées par des tufs à ponces, mais où se manifeste en revanche un développement assez remarquable des arogiles jaunes. Quoi qu'il en soit, voici quels sont los membres principaur que l'on peut reconnailre, dans la série des dépôts superficiels, en les réparlissant suivant teur origino :

Origine volcanique plus ou moins compliquée def Sables volcaniques el lapilli.

phénomènes accessoires............ Magmans lufacés ì ponces blanches.

Origine aqueuse plus ou moins clairement définie. $\left\{\begin{array}{l}\text { Conglomérats porphyriques. } \\ \text { Arơiles jaunes. }\end{array}\right.$

Nous allons les étudier successivement en quelques mots, mais dans un ordre diflérent, qui s'expliquera suffisamment de lui-mème.

SABLES VOLCANIQQUES ET LAPILLI.

Nous parlerons d'abord des sables volcaniques et des lapilli, parce qu'ils sont disséminés un peu partout et qu'il n’est pas possible de leur assigner d'époqur fixe. Il est évident qu'ils sont postérieurs aux prenières manifestations de l'aclion volcanique dans l'Amérique centrale, mais il est évident aussi que, chaque éruption nouvelle ayant fourni son contingent, il doil y en avoir de relalivement assez ancieus, comme il y en a qui ne datent pour ainsi dire que d'hier. Cela est bien prouvé, d'ailleurs, par les posilions relatives dans lesquelles on peut les observer par rapport aux autres couches de dépôts superficiels; on en voil qui sont intercalés entre des assises plus ou moins profondes des tufs à ponces; on en voit entre les tufs à ponces et les argiles jaunes; on en voit enfin qui recouvrent les argịles jaunes elles-mêmes. Au point de vue de la composition des sables volcaniques, nous n'avons gùère besoin de revenir sur les renseignements épars dans nos itinéraires que pour les résumer; ainsi nous savons qu’ils sont presque toujours d'une nuance violacée, mèlés quelquefois de petits lits gris ou jaunàtres. 
mais en proportion beaucoup plus faible que le reste; qu’ils forment généralement une poussière extrèmement ténue composée de granules anguleux provenant de la trituration des scories, mais que l'on y voit aussi des fragments cinériformes et des lapilli plus grossiers, du volume d'une noix en moyenne, et mème des blocs scorifiés assez considérables, mais cela seulement dans le voisinage immédiat des centres d'éruption. Au point de vue de l'extension des sables rolcaniques, il est évident qu’ils ne pourront en avoir d'une certaine imporlance que quand ils seront tout à fait modernes et auront recouvert les autres dépòts au lieu d'être recouverts postérieurement par eux. Ainsi, quoiqu'on en puisse observer des lambeaux en une infinité de points, nous ne devons signaler comme ayant une certaine signification que ceux des environs de San Miguel (Salvador), qui se développent sur une surface de plusieurs kilomètres carrés; ceux qui existent près de Santa Tecla, d'Izalco, de Cuajiniquilapa, etc.; enfin ceux que l'ou voit autour du pied des grands volcans éteints ou actifs du GuaIemala, les volcans de Pacaya, d'Agua, de Fuego, d'Atitlan, etc. Dans tous les ras que nous venons de citer, les sables volcaniques sont évidemment les dépôts superficiels les plus récents que l'on puisse rencontrer, mais il n'en est pas toujours ainsi, et il arrive bien souvent qu'ils sont masqués par d'autres formalions postérieures.

CONGLOMÉrats PORPHYRQQUes.

Caractèrestes et axtension les conglomérats porphyriques.
Pour reprendre un ordre chronologique comme nous l'avons fait jusqu'ì présent, nous devons nous occuper maintenant des conglomérats porphyriques qui nous paraissent être les plus anciens de tous les dépôts superficiels. Il ne serait mème pas impossible qu'en certains points ils dussent être considérés comme antérieurs à l'apparition du soulèvement volcanique, ou, tout au moins, comme contemporains de ses manifestations primitives. Mais ce n’est là qu'uno lyppothìse sur laquelle nous ne pouvons pas nous étendre longuement, n'ayant, pour nous guider dans l'appréciation de l'âge des conglomérats porphyriques, d'autres fails que ceux-ci : c'est qu'ils sont toujours subordonnés aux tufs à ponces el qu'ils semblent avoir été relevés à la base de certaines sommités volcaniques tors du soulèvement de ces dernières. Quoi qu'il en soit, il est cerlain 
DANS LES RÉPUBLIQUES DE GUATEMALA ET DE SALVADOR. 281 que les conglomérats porphyriques accompagnent toujours les porphyres trachytiques de l'arète centrale et s'appuient directement sur eux dans le versant du Pacifique; car il faut remarquer, ce qui est extrêmement intéressant, que nous ne les avons jamais vus du côté de l'Atlantique. Comment peut-il se faire que des masses dépendant directement des porphyres trachytiques, formées à leurs dépens, existent abondanment sur l'un des flancs de la cliaine monlagneuse et manquent absolument sur l'autre? C'est ce qu'il est fort difficile d'expliquer, et nous n'essayerons même pas de le faire. Ce qu’il y a de parfaitement avéré, dans tous les cas, c'est que les conglomérats porphyriques forment, dans le versant du Pacifique, une bande plus ou moins largege reposant à ta base des sommités les plus élevées et recouvrant le terrain sur une épaisseur souvent considérable, quelquefois jusque dans les plaines qui s'élendent au bord de la mer. Nous ne les avons vus que rarement au Salvador, où ils semblent avoir à peine existé sur l'axe montagneux secondaire; mais au Guatemala ils prennent une grande importance. Ils commencent déjà dans les vallées de Jaltapagua et d'EI Oratorio, où ils ne sont recouverts par aucune autre couche plus récente; mais, à Pinula, ils tendent à disparaître sous les tufs à ponces. Entre les volcans d'Agua et de Pacaya, ils forment les massifs puissants à Iravers lesquels la Michatoya s'est frayé un chemin dans une gorge étroite; on les voit près de la Antigna, dans le fond du ravin du Rio Pensalivo; dans les plateaux de Pasesilla, Patsum et Godines, où ils apparaissent à la partic inférieure de toutes les barrancas. Ce sont eux qui forment la plus grande partie des falaises qui dominent an nord le lac d'Atillan; on les retrouve auprès de Solola el enfin autour de Totonikapam. On voit ainsi qu'ils possèdent tous les caractères d'une formation continue, d'une bande bien définie, constituant la première des enveloppes qui recouvrent, sur leur versant sud, le flanc des montagnes porpliyro-tracliytiques.

La composition des conglomérats porphyriques est toujours à peu près la même : une pàte argilo-terreuse gorise ou jaunâtre, renfermant des cailloux roulés plus ou moins volumineux de porphyre trachytique, dont les plus considérables, gros comme la tête el plus, sont surtout répartis dans les zones inférieures, tandis que les plus petils tendent à gagner le haut. Il faut aussi remarquer que, dans certains cas où les conglomérats porphyriques sont recouverts directement par les 
tufs à ponces, les couches supérieures renferment déjà des morceanx de ponces, souvent assez abondants, de sorte qu'il semble y avoir passage entre les deux assises. Peut-ĉtre avons-nous été induils en erreur par des mélanges dus à des bouleversements postérieurs; mais, si le passage existait réellement, il prouverail irréfutablement que la formation des congolomérats a coincidé, au moins dans sa dernière période, avec celle des dépôts à ponces, et que les deux phénomènes sont continus.

Ilypothese sur l'origine des conglomérats. des tuls à ponces.
Si nous en venons à nous demander quelle peut être l'origine de ces conglomérats, nous nous trouvons en présence d'une question qu'il n'est pas facile de résoudre. Que l'eau ait été l'agent principal de la formation de ces roches, cela n'est pas douteux, puisque les blocs sont roulés et noyés dans une pàte terreuse qui n'est en réalité qu'mue boue concentrée, un dépòt vaseux. Mais, comment cette eau a-t-elle agi? et surtont d'un còté seulement de la chaine montagneuse! Si l'on veut supposer que des courants violents sont descendus jadis des sommets vers la plaine, entrainant tout sur leur passagoe pendant un temps très-prolongré, on n'en aura pas moins de la peine à concevoir comment ces courants ont pu étre assez puissants pour arracher une quantité aussi énorme de roche, car les congolomérats out quelquelois jusqu'à 100 mètres au moins d'épaisseur, et comment surtoul ils auraient pu polir el arroudir les blocs qu'ils emportaient, dans un parcours aussi faible que celui que nous devous leur supposer. Du reste, toute autre hypolhèse nous mellrait en présence de difficultés tout aussi sérieuses, et, en pareil cas, il est plus sage de s'abstenir jusqu'ì nouvel ordre.

TUFS $\mathrm{I}$ PONGES.

Les lufs à ponces sont directement superposés aux congolomérats porphyriques el leur sont par conséquent postérieurs; ils sont quelquefois entremêlés de sables volcaniques, qui les recouvrent presque toujours, cl auxquels ils sont le plus souvent antérieurs quoiqu’il y ait en parfois concomilance. Leur origine première est aisément déterminable, puisqu'ils ne se composent que de ponces, substances que l'on est ainsi conduit à considérer comme constituant les déjections primordiales des volcans centro-américains. La quantité de ponces qui a dù être vomie jadis par ces bouches volcaniques doit ètre colossale, puisque les couches de débris 
DANS LES RÉPUBLIQUES DE GUATEMALA ET DE SALVADOR: 283 ponceux accumulés alleignent souvent une puissance de 150 et même 200 mètres, el que celle formation s'étend à des distances considérables dans lous les sens; ce fait, pour le dire en passant, donne aussi à songer aux immenses espaces qu'ont pu parcourir les déjections volcaniques emportées par le vent. Les amas de ponces existent aussi bien sur le versant de l'Atlantique que sur celui dn Pacifique; ils sont aussi abondants an Salvador qu'au Gualemala, et, pour ne pàs nous livrer à une énumération qui serait aussi oiseuse que fastidicuse, disons simplement qu’il n’y a, pour ainsi dire, pas une vallée qui n’ait été en partie comblée par ces dépôts, pas un plateau qui n'ait été nivelé par eux. La tendance à li stratification qui s'observe dans les amas de ponces serait suffisamment expliquée par la clute progressive de ces matériaux dans l'air; mais il n'est pourtant pas impossible que, dans certains cas, elle n'ait été facilitée par la présence de l'eau, les ponces tombant dans des lacs ou des bassins fermés, où ce liquide aurail contribué à les répartir en couches concordantes; nous savons, d'ailleurs, que des faits anaJoğnes existent au Mexique, où nous avons pu les examiner de près.

Si nous étudions la structure et la composition intime d'un amas de ponces, nous verrons qu’il se compose, en général, de pelits fragments de ponces gros comme une noix, ou un peu plus, réunis à la base de l'ensemble par une matière pulvérnlente 1lyputhèse
sur la formation
des
Iufs à poners; blanchàtre, quĩ tend de plus en plus, à mesure que l'on s'élève dans le massif, à prendre une textnre tulacée, ol à devenir en réalité un cimenl; si bien que, vers le launt, les ponces sont tout à fail agghulinées et perdues dans un maggma tufacé, ct que, dans les conches toul à fail supérieures, on n’a plus affaire qu'à une masse blanche ou jaunàtre, assez compacte, grenue, presque sans ponces apparenles, et qui est devenue progressivement un véritable tuf. Les natic̀res pulvérulentes de la base sont probabłement le résultat de la pression et de l'écrasement exercés par les morceaux de ponces les uns sur les autres à la suite de l'accumulation des assises; mais tes modificalions des réģions supérieures tiennent à d'autres causes, que nous allons tâcher de décourrir. Nous pensons que ces altérations doivent leur origine à l'eau qui s'accumule en quantités considérables à la surface des amas de ponces pendant la saison des pluies el qui filtre alors peu à peu an travers de la masse, en humeclant cliacun des petits fragoments. De celte façon, les couches supérieures seraient progoressivement désagrégóées par l'eau, qui, dissolvant dans chaque menu 
morceau la petite quantité de calcaire qui y existe, finirait par les détruire, de manière à les confondre en une pàte compacte el uniforme. Mais cette même eau, arrivant dans les conclıes un peu plus basses, s'y évaporerail peu à peu, et, laissant ainsi le calcaire emprunté aux assises les plus élevées en conlact avec les matiòres pulvérulentes répandues eutre les ponces; les souderail peu à peu et en formerait à la fin un vérilable ciment tufacé. Quoi que l'on puisse penser de cette hypothèse, il n'en est pas moins certain que les couches superficielles sont toujours forlement altérées et désagrégées, el que l'on ne peul gouère en chercher la cause que dans l’influence prolongée des agents atmosphériques, de la pluie surtoul. Ainsi, auprès de Guatemala, on peut voir des masses tufacées compactes, jaunatres ou rosées, qui sont en connexion inlime avec les couches de ponces sous-jacentes, et dont l'origine ne pent guère s'expliquer d'une manière différente. Notre hypothèse aurail encore l'avantage de faire comprendre d'où peuvent provenir diverses sortes de dépòts superficiels, lufacés et blanchàtres, comme ceux que l'on nommel isate au Salvador, el dont les origines seraient bien mystérieuses, si l'on ne cherchail à y voir un produit de la décomposition lente el progressivo des amas de ponces.

Age probable des tuîs à ponces.

Nous avons eu la bonne fortune de pouvoir étudier des documents fort précieux pour fixer l'époque ì laquelle peuvent remonter les amas de ponces. Mais il ne faudrail pas leur accorder plus de valeur qu’ils n'en ont en réalité et vouloir en tirer quelque chose d'absolu, car il est évident qu'un ensemble aussi puissant a dù nécessiter, pour sa formation, une période de temps extrêmement considérable; el il est probable aussi, vu l'intermittence des phénomènes qui en sont la cause déterminante, que les couches d'une localité ne peuvent pas être considérées comme exactement contemporaines de celles qui existent dans une autre localité, mème très-voisine. Ainsi nous ne devons attacher à ce que nous allons dire qu'une valeur absolument locale. Les documents que nous avons eus entre les mains cousistent en une 'série d'ossements fossiles qui ont élé recueillis dans la vallće de Guatemala, non loin de la surface du sol, dans les couclıes supérieures des amas de ponces, el qui pourront servir ainsi à fixer une limite d'àge pour ces assises, dans les régions centrales de la République. Parmi les ossements que nous avons examinés et qui sont déposés dans la collection de la Sociedad Econo- 
DANS LES RÉPUBLIQUES DE GUATEMALA E'T DE SALVADOR. 285 mica de Guatemala, nous avous remarqué un fémur colossal, plusieurs verlèbres, des débris de côtes, et surtont quelques fragments de mâchoires el des dents qui semblent se rapporter à deux genres distincts, Mastodon et Elephas. Quoique nous soyons moins sûrs de la détermimation spécifique que des caractères génériques, nous ne pensons pas nous avancer trop en les attribuant au Mastodon angustidens et à l'Elephas Colombi. Ces espèces, disparues aujourd'hui du continent américain, étant spéciales à l'époque à laquelle on est convenu de donner le $110 \mathrm{~m}$ de Quaternaire, nous en pourrons conclure que les couches supérieures dles amas de ponces de la vallée de Guatemala appartiennent ì la période quatexuaire, fait important et dont nous avons déjà tiré plus d'une conclusion dans les pages qui. précèdent ${ }^{(1)}$.

AMGILES JAUNES.

Au-dessus des amas de ponces on trouve presque toujours une couche argileuse plus ou moins épaisse, qui fait quelquefois défaut, il faut le dire, mais qui existe en revanche à la surface d'un grand nombre de localités où les ponces ne forment pas le sous-sol. Ces argites doivent être la roche la plus récente qui existe dans l'Amérique centrale, car elles recouvrent toutes les autres formalions, à part seulement quelques lambeaux de sables volcaniques en voie de téveloppement constant, presque de création, puisqu’ils proviennent d'éruptions connues, appartenant aux années qui viennent de s'écouler. Les argiles sont donc extrèmement modernes, puisque toutes les autres couches leur sont subordonnées, el parmi elles, les amas à ponces que nous avons reconnus comme quaternaires. Pourtant rien ne peut nous autoriser à penser que le phénomène auquel elles doivent leur origine ne soit pas absolument arrêté à l'époque actuelle,

(1) De semblables ossements avaient déjà élé trouvés au commencement du siècle, ainsi qu'il résulte du passage suivant de l'historien Juarros (Compendio de la historia de la ciudal de Guatemala, I. II, tratado 6, c. xv1, p. 354) : "Dans la vallée de Petapa (extrémité sud de la vallée de Guatenali) on a trouvé des ossements de géants, el le chroniqueur Fuentes assure que J. S. D. F. Payo de Rivera ent en sa possession une dent trouvée dans ce pays qui étail aussi grosse que los deux poings d'un lomme.r
D'un antre passage de Juar'os (loc. cit. I. II, tratado 5, c. vir, p. 158) on est amené à conclure que des découvertes da mêne genre, et aussi importantes pour la détermination de l'áge des tufs à ponces, ont été faites en d'autres endroits, car il dil : "autre singularité digne de remarque, on a trouvé dans cetle même hacieuda del Peñol (départoment de Chiquimula) des squeletles de géants si énorues, que senlement les os de leur's jambes (tibias) avaient jusqu'à deux vares $\left(1^{\text {ma }} 60\right)$ de long; les aulres os étaicnt grands à proportion.

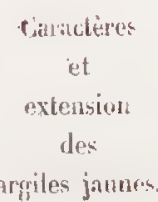

arrites jannes. 
et perdu dans les ombres d'un passé plus ou moins antérieur à la période historique. L'extension que prennent les argiles est extrêmement remarquable, car il n'y a pour ainsi dire pas de point, aussi bien sur le versant de l'Atlantique que sur celui du Pacifique, qui en soit complétement exempt; et ce ne sont plus seulement les vallées et les plateaux qui en sont recouverts, ce sont encore les rochers ardus, les montagnes élevées, les points que l'on pourrail croire les plus inaccessibles à un semblable dépôt. Nous ne reviendrons pas sur tous les points où nous avons observé les argiles superficielles, ce serait presque recommencer nos itinéraires tout entiers; mais nous citerons, comme anomalies assez singulières, les tocalités où elles n'existent pas au-dessus des amas de ponces, comme la plaine d'Ahuachapam et la vallée de Salama. La puissance des couches d'argile n'est goùre? en rapport avec leur extension, car elle est tout au plus de 4 ou 5 mètres en ınoyenue, et nous ne nous souvenons pas de lui avoir vu dépasser 10 mètres. Comı composition, ces argides sont généralement assez semblables à elles-mèmes, quelle que soit leur conleur, qui est presque toujours d'un beau jaune d'ocre franc, passant quelquefois au noir par des intermédiaires d'un brun plus ou moins foncé; mais cela ne se présente que dans des cas assez rares, quand il y a mélange avec des sables volcaniques, de la terre végétale on tout autre malière étrangère. les argiles pures sont presque toujours d'un jaune rougeâtre, plus clair lorsqu'elles sont parfailement sèches; elles forment une pâte liante, de texture uniforme, à grain extrêmement fin, plutôt polies que désagrégées par l'action de l'éan qui glisse à leur surface. Elles renferment souvent des paillettes de fer oligiste qui s'en détachent sous l'action d'une forle pluie, et s'accumulent aux tournants des petits ruisseaux, là où le courant se riłlentit. Nous ne nous permettrons aucune hypothèse sư la présence et la provenance de ces pailleltes de fer oligiste.

Origrine nuystéricuse Jes argiles jammos.
Quelle est l'origine des argiles jaunes? Nous devons avouer que c'est là le problème le plus ardu de la géologie centro-américaine, que nous en avons poursuivi la solution pendant tous nos voyages, toules nos excursions, toutes nos courses, que nous l'avons cherchée au Salvador et au Guatemala, dans les plaines du bord de la mer, dans les plateaux de la Vera Paz el dans les montagnes des Altos, et que nous ne l'avons point trouvée. Serait-on, par hasard, en présence d'une série de phénomènes locaux? Mais alors comment expliquer la coüucidence de ces 
DANS LES RÉPUBLIQUES DE GUATEMALA ET DE SALVADOR. 287 phénomènes, la conformité de leurs produits, la similitude de composition, de couteur, d'altures, de puissance, que les couches sous-jacentes soient des porphyres ou des calcaires, des basaltes ou des amas de ponces? Dans certains cas on pourrail admettre, à la rigueur, une décomposition sur place des roches subordonnées. comme pour les basaltes de La Union; mais, dans d'autres, conme pour les calcaires de Coban, cela est radicalement impossible, et il n'y a qu'une inondalion d'ean vaseuse qui ait pu déposer un semblable manteau de boue. Veut-on supposer, au contraire, que les causes de l'origine des argiles jaunes sont des causes générales? Mais alor's quel est donc ce phénomène qui s'est élendı depuis le sud du Salvador jusqu'au nord du Guatemala, depuis les plaines du bord de la mer jusqu'aux pies ardus qui dominent Tolonikapan à plus de 2500 mètres de hauteur, ce phénomène si récent, datant pour ainsi dire d'hier, ce phénomène susceplible de submerger tout un pays jusqu'au sommet de ses montagnes, et dont it ne resterail d'autre trace qu'un léger manteau de boue, épais à peine de quelques mètres, recouvrant une contrée entière d'une enveloppe mystérieuse? Avouons-le franchement encore une fois, ce n’est pas à nous qu’il est donné de comprendre et d'expliquer des phénomènes qui semblent si simples et qui sont au fond si sérieux; et, reconnaissons-le humblement, il y a un enseignement qui n'est pas sans valeur, si on sait le prendre, à se trouver, au bout d'un long chapitre d'éludes góologiques el de problèmes plus ou moins bien résolus, en face d'un prolılèmr. plus mystéricux que tous les autres, cl devant lequel on est obligé de reculer. 


\title{
LIVRE IV.
}

\author{
DES VOLGANS ET DES PHENOMENES VOLCANIQLES.
}

\section{INTRODUGTION.}

Nous allons nous occuper, dans ce livre, des phénomènes voleaniques dont oljet do ce live. l'Amérique centrale est le théàtre, el nous devons reconnaílre que c'est là certainement la partie la plus intéressante de notre travail, celle qui présentera l’altrait le plus vivant, gràce à la nature grandiose et toujours un peu mystérieuse des laits qui y sont traités; celle anssi sur laquelle se sont surtoul portées nos études et nos recherches, pendant la plus grande partie du temps, malhoureusement trop restreint, que nous avons pu consacrer ì uotre voyage. Ce n'est pas à dire pour cela que les problèmes de la géologie générale soient dénués de tont iutérêt dans l'Amérique coutrale; bien loin de là, el, en envisageant froidenıent les choses, on peut mème se demander si, au lieu d'ètre relégués au second rango, il ne devraient pas bien plutòt occuper la première place dans les investigations scientifiques, vu l'importance des faits d'observation sur lesquels on peul s'alppuycr pour chercher à les résoudre, aussi bien que des spéculations théoriques aunquelles ils donnent naissance. On a pu le voir dans le livre précédent, où nous avons accumulé tous les docmments qui penvent servir à la stratigraphie de ces vastes régions, ainsi qu'à l'étude des phénomènes éruptifs auxquels elles doirent leur relief; et l'on en aura certainement tiré la conchusion que, l'Amérique. centrale présentant, dans la constitulion de son sol, une notable proporlion des 
couches successives el des roches diverses qui ont contribué à former l'écorce solide de notre golobe, offrant, dans les allures de ces assises, les modifications et les dérangoments les plus variés, elle est pour la góologie générale un champ fécond en observations intéressaules, en études séricuses et en conclusions pratiques. Malgré cela, la science ne s'est gonère occupée, jusqu'ì présent, de l'Amérique centrale qu'au point de rue des phénomènes volcaniques, qui s’y sont développés arce une si étonmante intensité; les rares invesligalions qui y ont été tentées ur l'ont été que pour cel objel; les quelques conps d'œil sérienx que l'on y a jetés se sont arrètés ì ces giganlesques monlagnes coniques qui altirent le regard, forcent pour ainsi dire la pensée, absorbent l'intérèt el dirigent vers elles les études ef les recherches. Et laut-il s'en étonner? Nou certes; ce serait plutôt le contraire qui serail étrange ponr qui connaîl l'espril humain, la facilité avec laquelle il s'élance vers tout ce qui est grand, sublime, mystérienx! On n’a jamais entendı parler de l'Amérique ceutrale que comme de la terre classique des phénomènes éruptifs, comme de la réggion privilégriéc des volcans; on songe à ce sol brûlant, à ces montagnes en feu, à ces immenses coulées de laves, el, lorsque l'œil rencontre ces colosses, dont les formes étégantes se modèlent en produisant des cònes d'une étomnante régularité, dont les courbes gracieuses portenl jusque dans les mues une tête couronnée d'un blanc panache de fumée, alors on n'aspire qu'ì fouler d'ın pied andacieux leur sommet encore vierge, qu'à sonder leurs profondeurs, qu'ì lour arracher leurs secrets, el, l'amour de la science aidant, on n'a plus qu'un clésir, celui de pouvoir consacrer son tomps el son ardeur à l'élnde de ces immenses problèmes de la nalure.

Beitut:

remarrpualsic

yolcanicisue

delinínicue

"entrilis.

Que ne ponvons-nous, empruntant la plume d'un Humboldt, décrire l'aspect ćlrange el merveilleux de cr continent hérissé d'une série continue de giganlesques montagnes coniques, isolées, droites dans le ciel, dominant de leur tète nue el fumante les chaines rocheuses et boisées, les plateaux couverts de forèts. les plaines chargées de riches cultures qui s'étendent à leurs pieds! Que ne pouvons-nous faire passer dans l'esprit du lectenr l'impression profonde que reçoil le voyageur, torsque, arrivant des solitudes de l'Océan, il apcrçoil peu ̀̀ peu, se dógageant de la brume loiulaine qui los enveloppe, les pics sublimes, sents visibles encore comme s'ils flottaient dans le bleu de l'atmosphère; lorsque, 
DANS LES REPUBLIQUES DE GUATEMALA ET DE SALVADOR. 291 mettant le pied sur cette terre, il se sent presque écrasé par l'immensilé de ces sommets qui s'élancent vers le ciel en lui opposant une barrière prodiģieusement dentclée, mais, pour ainsi dire, conlinue, de ces sommels dont il veul tenter l'ascension et deviner les mytères! Un dessin ne rend pas toujours une pensée. Que l'on jette cependant un regard sur celui que nous avons fait reproduire (pl. VII, figure 2), et qui représente la vue de la còte du Guatemala, prise en rade de Saı José; la ligone volcanique se dresse, immense, continue, droite; les cônes les plus rapprochés semblent sortir des flots de la mer pour aller se perdre dans le ciel; les plus éloignés se fondent au milieu des amoncellements de monlagnes d'où émergo leur lète pointue; el ce r'est là, cependant, qu'un launbean de la chaine des volcans, qu'une faible fraction s'étendant seulenent du volcan de Tacana ì celui de Pacaya, sur la moitié lout an plus de la longueur des rivages du Guatemala. Et si l'on songe que toute celle còte, sur un espace de. plusieurs centaines de kilomètres, le long du Salvador, du Nicaraggua, du Costa Rica, contiune à présenter des caractères analogues, à offrir de la mer des points de vue dı mème gonre, on comprendra que, pour les imaginations un peu vives, l'Anıérique centrale ait été en quelque sorle réduite à ses volcans, surtoul lorsque quelques-uns d'entre eux projettent des flammes qui servent la muil de phare aux navigatcurs et les guident dans la direction des ports.

Pourquoi ne pas le dire? Si la science n'a gुuère vu, jusqu'à présenl, dans l'Anrórique centrale que les volcans, on ne doit pas s'en étomner; c’est que ces volcans, par leur nombre considérable, leur disposition régulière, lenrs dimensions colossales, lenr activité remarfuable, constituent un caràclère particulier, un trait saillant qui suffit à hii seul pour donner une physionomie au pays tout entier; r'est que ces volcans, par l'intérèt qu'ils excilent, absorbent l'allention, la concentrent sur eux sculs, el réduisent en quelque sorte à l'élude de leurs produits ot des manifestations de teur aclivité, l'examen des phénomènes plyssiques et géologiques de la région qu’ils rendent une des plus intéressantes du moude entier.

Et pourlant, il faut l'avouer, les volcans de l'Amérique centrate sont encore hien peu et bien mal comnus; malogré la place importante qu'ils liennent parmi les phénomènes éruptil's de notre époque, malgré l’intérèt qu'ils excitent, malgré les problèmes dont ils pourraient aider à trouver la solution, on ne possède encore, sur 
ta majorité d'entre enx, que des reuscignements vağnes et peu précis. La science ne les a point encore abordés d'une manière sérieuse; clle ne les a considérés que de loin, tandis que des voyageur's indifféreuts, ou attirés vers d'autres sujets par leur spécialité, lui apporlaient des récils incomplets on des observations quelquelois judicieuses, plus souvent erronées. Aussi s'est-il accumulé peu à peu sur les noms, les posilions, les hauteurs, les fails mêmes, des erreurs regrettables, qui se retrouvent malheureusement jusque dans les ouvrages les plus sérieux et les mieux conçus, écrits par les hommes les plus autorisés et les plus dignes do foi. Heureux si nous pouvons donuer, sur quelques points, des idées plus exactes el plus justes que celles qui onl cours aujourd'hui, el si nous pouvons, après dle longues recherches, fruits de pénibles eftorts, apporter notre faible contingent à la ronnaissance des volcans de l'Amérique centrale.

Il ne peut pas òtre nauvais, avant de commencer les éludes de détail, de joler, sur l'ensemble des faits et des phénomènes, un coup d'œil général qui sera commo 1111 résumé préalable de ce livre.

Extension et Vlirection générale du svstèmp volcanique.

Effets produits par les

positions relatives de l'axe volcanique

l.e système volcanique de l'Amérique centrale s'étend sur une longueur de $7^{\circ} 20^{\prime}$, soit environ 700 kilomètres, depuis la latitude de $8^{\circ} 50^{\prime}$ dans la province de Chiriqui (Nouvelle Grenade), jusqu’à celle de $16^{\circ} 10^{\prime}$ dans le Soconusco (Mexique), à traver's toules les républiques qui se sont partagé ces terriloires, Cosla Rica, Nicaragua, iles du Honduras, Salvador et Guatemala. La direction gónérale du système peut se ramener à deux ligones axiales qui se coupent par $12^{\circ} 50^{\prime}$ de latitude nord, en un point correspondant à la vaste échancrure de la baic de Fonseca, sur te Pacifique, sous un angle très-oblus, dont le supplément peut ètre de 22 à $25^{\circ}$ (soil 155 ì $158^{\circ}$ ). La première de ces lignes axiałes courl presque exactencut du sud-est au nord-onest à travers une petite parlie do la Nouvelle-Grenade, le Costa-Rica et le Nicaragua, jusqu'au volcan de Conseguina, qui s'élève sur la pointe extrême de cette dernière république; c'est de là que diverge la seconde ligne axiale, qui, partant des iles de la baie de Fonseca, se dirige de l'est $30^{\circ}$ sud à l'ouest $30^{\circ}$ nord, à travers le Salvarlor el le Guatemala, pour aller se perdre dans le Soconusco.

La posilion relative de l'axe volcanique el des monlagnes porphyro-trachytiques qui conslituent l'arèle principale du pavs n'est pas sans importance, au point de 
DANS LES RÉPUBLIQUES DE GUATEMALA ET DE SALVADOR. 293

vue des volcans eux-mèmes, el surtoul à cause des particularités géogoraphiques qui peuvent en résultor. Ainsi la ligne de faîte de l'Amérique centrale, quoique composée de plusienrs lambeaux parallèles plus ou moins complétement reliés entre eux par des chainons perpendiculaires, conserve néanmoins une direction moyenne toujours la même, qui est celle de l'est $20^{\circ}$ sud à l'ouest $20^{\circ}$ nord, tandis qute: l'axe volcanique, ayant deux directions différentes el successives, doit se mêler plus ou moins à la chaine de montagnes précédente el la recouper de facons valriables. En effet, tes premiers volcans que l'on voit dans lia province de Chirriqui sont sur le versant de l'Allantique, puis, les deux directions se coupant en croix sons un angle assez aigu, on en trouve bientôt qui sont établis sur la ligne de failc alle-mòne, et d'autres enfin qui s'alignent sur le versant dı Pacifique, eutre la mer et les montagnes, mais en s'éloighnant progressivement de ces dernières. Dans la seconde partie du syslème, les volcans commencenl par se placer. Lout an bord do la mer, assez loin des montagnes; mais ils s'en rapprochent insensihement, s'élèvent progressivement sur leur versant el finissent par alteindre presque la ligne de laîte, comme on pent le voir an delà de Quezaltenango. La plus grande partie du groupe Gnatemalien est ainsi à moilié distance entre les montaggnes el la mer, à cheval sur les premiers contre-forts qui descendent de l"ïlérieur, et il en résulte des phénomènes assez intéressants, en ce qui touclè à lat réparlition des eaux. Nous avons déjà eu plusieurs fois occasion de traiter ce sujet en parlant des lacs du Satvador el du Guatemala (p. 104 el suiv.), mais nous n'y saurions trop revenir, car il y a là une question d'une importance capitale et une source d'erreurs d'une certaine gravité. Enlrainés par l'idée de la prédominance, dans l'Amérique centrale, des faits qui se rallachent à l'action volcanique, trompés par des récils linits, peut-être sans intention, par des personnes mal ğnidées par des connaissances scientifiques insullisantes, égarés par des descriptions peut-être plus poéliques que lidèles de grands lacs silués au pied de volcans gigantesques, avec lesquels ils seraient en rapport direct, quetques auteur's se sont laissé séduire par des spéculations d’autant plus altrayantes qu’elles allachaieul plus de gorandeur el de mystère à ıne question déjà grande el mystériense par elle-même, mais qui ont le délaut immense de propager des errenrs dangerenses el de verser dans les esprils des idées lausses et incompatibles avec l'observation 
liroide el sincère des lails en eux-mêmes. On a tronvé un cerlain charme à supposer que les grands lacs de l'Ámérique centrale élaient des cratères colossaux, des effondrements gigantesques, éteints et remplis postérieurement par l'action des pluies on par tonte autre canse; on l'a supposé, avec hésitalion, sans doule, mais avec une hésitation confiante dans l'avenir, avec l'espoir qu'on ne serait pas démenti, el que des observalions vraiment scientifiques viendraient donner plus de poids à des théories dont la grandeur a quelque chose de fail pour séduire, mais qui sont fausses, il faut le dire, el qui ne s'ippuient sur aucun fait réel. Déclarons-le donc haulement, les grands lacs de l'Amérique centrate ne sont point des cralères-lates, ils ne sont point des manifestations de l'action volcanique, el les relalions quils peuvent avoir avec elle ne sont que des relations secondaires el, pour ainsi dire, dissimulées, ainsi que nous le démontrerons encore une fois ciaprès. Ce n’est pas à dire pour cela qu'il n’y ait pas de cratères-lacs dans l'Amérique centrale; nous aurons à en sigonaler phiss d'un daus le cours de cette étude, comme cenx de Tecapa, du volean de San Salvador, de la Hoya, de la Galdera au volcan de Pacaya, elc.; mais ils ont des caractères franchennent accusés, ils se reconnaissent au premier coup d'œil el se distinguent aisément des grands lacs qui n'ont point du tout les mèmes traits particuliers. Écarlons immédiatenent les lacs d'Ilopango, de Guija el d'Ayarces, qui ne sont que de grandes masses d'eau enfermées entre des replis ou des dédoublements de grandes chaines de montagnes porphyriques; restent ceux d'Amatitlan et d'Atitlan. Or nous croyons avoir démontré péremploirement que ce ne sont que des accumulations d'eau produiles par des rivières dont te cours a été intercepté par le soulèvement des montağnes volcaniques voisines. Cela explique non-seulement pourquoi les lacs existent, mais encore pourquoi ils existent précisément dans le voisinage des volcans importants; la question ramenée à ces limiles est moins grandiose, il faut l'avouer, mais ello al l'avantage d'avoir nne solulion rationnelle, ce qui n'enlève rien, ajoutons-le, ̀̀ la majesté des phénomènes volcaniques de l'Amérique centrale, dont les manileslations sont assez nombreuses et assez belles pour qu'on n'ait pas besoin d'y ajouter des faits qui en sont, en principe, complétement indépendants.

L'importance du système volcanique de l'Ánérique centrale ne saurail être miss en doute; le nombre imposant des volcaus dont il se compose, la proportion de. 
DANS LES RÉPUBLOQUES DE GUATEMALA ET DE SALVDOR. 295 ces cônes qui sont encore aujourd'hui en activité, la nature mème de celle activité, qui n'est cependant plus, à notre époque, co qu'elle étail encore au commencement du siècle et surlont il y a une centaine d'années, la fréquence des éruptions, l'abondance des dójections donl elles ont recouvert le sol dans un rayon extrèmement étendu, font de ce groupe un des plus remarquables el des plus in téressants qui se pnissent voir. La quantité de volcans, étemts ou encore aclifs, que l'on rencontre sur cette ligne, longue de plus de 700 kilomètres, est récllement cflirayante; surtout si l'on ne se bornc pas aux grandes montagnes, dont la masse inposante et la grande hautcur attirent immédiatement le regard, et si l'on suppute anssi le nombre des petits cònes isolés on répartis au pied des colosses qui les dominent et les font aisément oublier, des cratères-lacs, des enfoncements circulaires ayant projeté jadis des cendres ou des matières gazeuses.

Mais il faut se tenir en garde contro les cxagérations qui sout le propre des races hispano-américaines, on contro les erreurs que n’évitent pas des peuplades barbares el ignorantes, et, si l'oin veut faire le comple des volcans de l'Amérique rentrale, il ne faut s'avancer qu’à bon escient, et ne pas se fier aveuglénent an rapports el aux renseignements qui peuvent ètre domnés par les habilants du pays. Et d'abord, l'habitude de voir qne les grandes montagnes sont presque

de I'Ameriqut contralu. toujours des volcans, a progressivement détourné, en quelque sorte, la significition de ce unot, qui, dans toutes les répnbliques hispano-anéricaines, ne vent plus dire en réalité que grande montagne; ainsi il faut s'habituer ì entendre donmer ce nom à toules les sommités un pen élevées, sans croire pour cela qu’on y lrome des traces d'ine action éruptive. En ontre, les indiggènes prennent tonjours poun des volcans les cimes, hantes on uon, sur lesquelles se produit lo singulier phónomène des retumbos (p. 172), on détonalions sourdes ressemblant aux explosions d'un volcan, mais dues à des décharges électriques tocales. Nons n'en citerons que deux ou trois exemples entre mille: ainsi, on appelle volcan d'Omoa la grande montagne qui domine cetle ville, et qui n'est ccrtainement composée que de micaschisles; le volcan de San Gil, près d'lzabal, est plus que probablement formé de roches calcaires semblables à celles qui apparaissent dans tonte lit réggion environnante; enfin le Cerro Verde, près rle Salama, considéré comme un volcan el célèbre par ses retumbos, est mo éminence qui se dresse au milien de

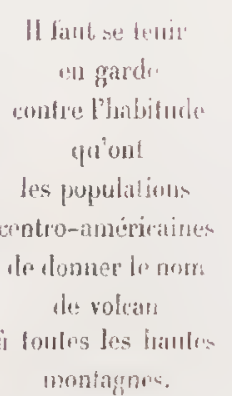
montagnos. 
schistes lalquo-chloriteux. Nous en pourrions énumérer bien d'autres, surtoul au voisinage immédiat de la ligne volcanique, là on la nature du sol peut, jusqu'ì Inn cerlain point, expliquer et faire pardonuer l'erreur; mais cenx que nous avons cités sont suffisants el empruntent à leur composition géologique une valeur considérable pour prouver avec quelle réserve on doit accepter les noms donnés aux nontagnes par les indigènes, noms qui, pour la plupart, sont reproduits sur les rartes géographiques que nous possédons.

Panticularites

lans la disposition des

nroupes do voleans

quii jalonuent

lit direction

du

srstèmo.

Il est inutile d'insister sur ce que l'axe volcanique, tel que nous l'arons décril dlans ses allures et sa direction, n’est, en réalité, qu’une ligone théorique, représentant la direction moyenne de la série des volcans; les cônes se placent tantòt un peu aı nord, tantôt un peu an sud de cette droite, de manière à former une ligure brisće couvrant unc véritable bande de terrain dont les combes enveloppes s'éloigrnent un peu de l'axe médian, mais sins s'en écarter de plus d'une vinģtaine de kilomètres en général. Mais nous ne devons pas passer 'sous silence une particularité intéressante qui se manifeste dans les allures propres et individuelles de chacun des pelits groupes de cònes et de cratères qui jalonnent l'axe volcanique principal. II faut remarquer, en effet, que l'on n'a pas affaire à une série de volcans isolés, alignnés suivant une direction plus ou moins droite ou brisće, mais bien à une succession de pelits syslèmes, ì peu près indépendants les uns des autres, disposés à une distance respective, qui varie, suivant les circonstances, entre des limites assez élroites. Or chacun de ces groupes se compose d'un nombre plus ou moins considérable de cònes el de cratères, les uns éleints, les autres encore actifs, rangés sur une liğne droite dont la direclion est, à peu de chose près, nor'male ì celle de l'axe volcanique principal. Cette disposition, extrèmement intéressante, se voit nettement dans les groupes du volcau de Fuego, du volcau d'Atillan, etc.; el prend même, dans le groupe do département de Chiquimula, Inn développement tellement extraordinaire, que l'on a presque aflaire à un grand sustème adventif, perpendiculaire au système principal. Nous n’avous malheureusement pas éludié par nous-mêmes les volcans éteints du département de Cliiquimula, et nous sommes forcés de nous borner à signaler le fait sans pouvoir l'approfondir. Il semblerait donc qu'en chacun des points d'éruption il s'est formé ıne fissure normale à la fissure principale, sur laquelle se sont disposés en série 
DANS LES RÉPUBLIQUES DE GUATEMALA ET DE SALVADOR. 297 les évents volcaniques, formés les uns après les autres par une marche progogressive de l'action éruplive. Cette marche s'est-elle toujours produite dans un sens déterminé et constant, c'est ce que nous ne saurions affirmer; mais nous remarquerons, néanmoins, en passant, et sans vouloir en tirer pour le moment de conclusion, que, dans bien des cas (volcans de Fuego, d'Atillan, elc.), lorsqu'un des volcans d'un groupe particulier est encore actif, il est placé à l'extrémité sud du sỵstème.

Nous n'essayerons pas de donner une liste complète des volcans de l'Amérique centrale, dont il nous serait d'ailleurs impossible de garantir l'exactitude absoluce, n'ayant pas pu voir tout par nous-mêmes. Nous nous bornerons à énumérer, en marcluant du sud-est au nord-ouest, les groupes principaux, qui sont au nombre

Énumćration des principaux groupu de volcans qui composent le système. de trente environ, comprenant à peu près une soixantaine de volcans, dont dix au moins présentent encore des traces d'activité plus ou moins intense et peuvent entrer en éruption violente d'un moment à l'autre, sils ne le sont pas aujourd'hui. Ces derniers sont désignés par un astérisque.

TABLEAU DES GROUPES DE VOLCANS COMPOSANT LE SYSTĖME DE L'AMÉRIQUE CENTRALE.

DÉPARTEMENT DE CHiriqui (NOLVELLE-GRENADE).

Volcan de Chiriqui ( 3,435 mètres?).

Volcan de Rovalo (2,141 mètres?).

Volcan de Blanco ( 3,580 mètres?).

COSTA RICA.

Groupe des volcans de Cartago [Turrialba* (3,812 mètres). Irazu (3,477 mètres). Barba].

Groupe des volcans de f'ouest du Costa-Rica [Miravalles (1,434 mètres). Los Volos (3,000 mètres). La Vieja. Orosi* $(2,638$ mètres $)]$.

NICARAGUA.

Groupe des volcans des îles du Lac de Nicaragua [Omotepec, Zapatera, etc.].

Volcan de Mombacho ( 1,497 mètres).

Groupe des voleans de Masaya el de Nindiri.

Volcan de Homotombo * 2,133 mètres $)$.

Groupe des voleans de lia plaine de Léon, dits Los Marabios. [Huit cônes, dont les principaux sout:

l'Axusco, Las Pilas, l'Orola, le Telica ( 1,050 mètres), le Santa Clara, etc. ].

Volcan de El Viejo* ( 2,000 mètres).

Volcan de Conseguina ( 1,066 mètres).

IIONDURAS.

Groupe des iles de la baie de Fonseca [Isla del Tigre ( 800 mètres), etc.]. 
SALVADOR.

Groupe de Conchagna [Cerro de la Bandera, Cerro del Ocote $(1,236$ mètres)].

Volean de Sam Hlignel* $(2,153$ mètres).

Groupe de Chimameea et de Tecapa [Infiernillos"].

Groupe de San Vicente (2,400 mètres) [Infiernillos*].

Groupe de San Salvador [volcau de San Salvador (2,30o mètres), etc.].

Groupe d'Izalco [volcan d'Izalco* (1,825 mètres); volcan de Santa Anna; ansoles de Ahuachapam* ].

Volean de Chingo.

Groupe du Département de Chiquimula [volcans d'Amayo, Cuma, Santa Catarina, Monterico, Ipala]. Grompe de Cerro Rerlondo.

Groupe du volcan de Pacaya [cône principal* ( 2,550 mètres $)]$.

Volcan d'Agua $(3,753$ mètres).

Groupe du volcan de Fuego [volcan de Fuego proprement dit* (4,001 mètres); volcan d'Acatenango $(4,150$ mètres $)]$.

Groupe du volean d'Ltillan [còne principal* $(3,573$ mètres $)]$.

Volcan de San Pedro

Groupe de Quezaltenango [volcan de Santa Maria (3,500 mètres); Cerro Quemado* (3,109 mètres)].

Volcan de Tajomulco.

Volcan de Tacana *.

Socoxusco (aExique).

Groupe des volcans du Soconusco [Volcan d'Istak].

Voleans actifs de

l'Amérique centrale.

Il y a donc aclucllement dans l'Amérique centralc une dizaine de volcans en activité, qui sont : dans le Cosla Rica, le Turrialba et l'Orosi; dans le Nicaragoua, le Momotombo el peut-ètre le Viejo; dans le Salvador, le San Migucl et l'tzalco; enfin dans le Guatemala, le Pacaya, le Fuego, l'Atillan el le Cerro Quemado de Quezaltenango. On peut encore ajouter à cette liste, dans le Salvador, les Infiernillos de Chinameca et de San Vicente, ainsi que les Ausoles d'Ahuachapam, qui sont certainement des manifestations de la puissance volcanique. Si nous nous reportons aux relations qui datent de la découverte de l'Amórique centrale, nous y voyons que le nombre des volcins en activité était bien plus considérable à cette époque; on peut donc se laisser atler à penser, malogré les éruptions nombreuses qui ont eu licu pendant ces dernic̀res années, que la force volcanique est en décroissance progressive dans l'Amćrique centrale, el tend à disparaître peu à peu. Il no faudrait pourtant pas admettre, à première vue, une semblable théoric, quelque plausiblo qu'elle puisse paraitre, car les lois qui règlent les phénomènes 
DANS LES RÉPUBLIQUES DE GUATEMALA ET DE SALVADOR. 299 volcaniques sont encore trop obscures pour que nous puissions rien déduire avec certitude des faits que nous connaissons. La périodicité des éruplions el l'équilibre qui peut s'établir entre les différentes parties du monde ne sont pas assez connus pour qu'une époque de tranquillité relative puisse être considérée comme une close décisive; on ne peut jamais affirmer qu'un volcan est définitivement étcint, el qu'il ne sortira pas subitement de son repos el de son inactivité plus apparente que réclle. Rien ne prouve que les volcans de l'Amérique centralc ne recommenceront pas, an moment où l'on y pensera le moins peut-ètre, à vomir des flammes, des condres et des laves, el l'on peut se convaincre que teur tranquillité est bien trompeuse, quand on songe à l'apparition subite du volcan d'lzalco, qui sortil de terre loul à coup à la fin du siècle dernicr, ct à l'épouvantable éruption du rolcan de Conseguina qui, au commencement de celıi-ci, transforma brusquement en un cratère béant une région parfaitement paisible jusqu'alors.

Cela nous amène naturellement à dire quelques mols de la formation des volcans de l'Amérique contrale, qui, anciens ou nouveaux, onl dû, dans leur développement, obéir à cerlaines lois générales plus ou moins netlement caractérisées. Nous devons avoucr que nous éprouvons une certaine crainte en abordant une question aussi délicale, car, en présence du déchainement d’opinions qui s'est produit, pendant ces dernières amnécs, contre la théorie des cralères de soulèvement, on ne pourrait se senlir parfaitement à son aise qu'en apportant des faits conformes aux idées récentes el le płus généralenent admises, ce qui n’est pas absolument notre cas. Nous ne voulons pas mettre en doute qu’il n'y ail beaucoup de cònes volcaniques formés uniquement par l'accumulation des matériaux sortis de leur cratère, scories ou laves, et disposés progoressivement les uns au-dlessus des autres en couches quaquaversales; le volcan d'Jzalco en est, entre autres, un exemple lrappant, comme on pourra le voir, lorsque nous décrirons en délail son apparition el son développement (page 376); mais nous ne pouvons admettre qu’il en ait toujours été de mème. Lorsque nous voyons toute la partie supéricure d'une immensc montagne dans laquelle s'ouvre un cralère, large quelquefois d'un millier de mètres (volcan de San Migouel) el profoud de plusieurs centaines (volcan de Fuego), composée uniquement d'une roche massive, conpacte, sans autres solutions de continnité que celles dans lesquelles se sont injectés des dykes de matière 
liquide solidifiée postérieurement, sans aucune interférence de couclies de scories, de ponces ou de lapilli, nous avons de la peine à penser que tout cela ait élé produit par des laves vomies par le volcan lui-même. Nous ne croyons que difficilement qu'un volume aussi énorme de matières liquides, solidifiées postérieurement, ait pu s'élever jusqu'au sommet de ces grandes montagnes pour en former la parlie supéricure, tandis que les éruptions ne produisent presque jamais aulre chose que des gaz accompagnés de inatic̀res cinériformes, tandis que les rares coulées de laves, dont le volume n'approche pas à beaucoup près de celui des masses colossales de roches dans lesquelles est creusé le cratère, ne peuvent mème pas s'élever jusqu'à lui el se font jour sur les flancs ou au pied du còne. Mais passons là-dessus; les lails que nous venons de ciler ne sont peut-ètre pas encore assez absolus. Lorsque nous voyons d'immenses volcans, qui u'ont jamais donué aucune coulée de lave, ou qui n'en ont donné que de si imperceptibles qu'on n'en voil mème pas les traces, composés, non-seulement à leur sommel el jusqu'au fond du cratère, mais mème dans loute leur masse, par d'énormes volumes de roche compacte exactement comparable à celle dont nous parlions tout à l'heure, notre conviction s'établil de plus en plus. Linsi le cratère du volcan d'Agua est ouvert tout cnlier dans des parois de roche massive, solide, continuc; ainsi, au volcan d'Atillan, les ravins creusés dans les flancs du còne, à une cerlaine distance de sá base, après avoir recoupé une vinggtaine de mòtres de sables, de scories et de bloos roulés, arrivent à alteindre la roche vive, compacte, sans solution de continuité qui forme la masse mème du volcan. Lor'squ'enfin. nous comparons la roche qui constitue le sommel des volcans avec celle qui forme les coulées de lave, alors le doulc ne nous semble plus permis, car il n'y a entre elles aucune ressemblance: d'un côté, c'est une lave basallique noire, celluleuse, ìpre au toucher, déchirée en blocs anguleux, creusée de cavités en forme d'ampoules, une véritable lave, cu un mot; de l'aulre, c'est une roche compacte, plus ou moins cristalline, de couleur rougeàtre ou violacée, mouchetée de cristaux blancs de feldspath, en un mol, un porphyre trachylique parfaitement caractérisé, quelquefois un peu scorifié à la surface, gràice aux pliénomènes dont il a élé le lémoin, mais absolument semblable, sauf cela, aux porphyres trachyliques qui composent la grande chaine monlagneuse sur le versant de laquelle s'élèvent les volcans. Ainsi donc, en nous 
DANS LES RÉPUBLIQUES DE GUATEMALA E'T DE SALVADOR. 301 résumant, nous voyons que, pour beaucoup de volcans de l'Amérique centrale, dont les uns ont donné des laves, tandis que d'autres n'en ont pas produit, le sommet el mème la masse inlerne de la montagne sont toujours formés par une roche compacte, continue, bien caraclérisée, quoique quelquefois scorifiée, el essentiellement différente des laves que l’on peut voir dans les coulées voisines. La conclusiou nous semble alors évidente, et nous la donnerons avec la conviction qu'elle est la vérilé, mais sans vouloir en aucune façon en faire une rèğle absolue, puisque nous voyons à côté les uns des autres des faits qui obéissent à cette loi el d'autres qui dépendent d'un principe tout différent. Nous dirons donc que, si cerlains volcans de l'Amérique centrale sont uniquement constitués par les produits d'une série d'éruptions successives, superposés en couches quaquaversales, il y en a d'autres dans la formation desquels l'expansion par accroissement intérieur a été un élément beaucoup plus important que l'expansion par accroissement exlérieur. Nous ne pouvons nous empècher de penser que, pour ces demiers, il y a eu d'abord production d'une sorte de dòme irrégudier de porphyre-trachytique, emprunté aux roches sous-jacentes dont étaient formées les monlargnes mèmes au milieu desquelles l'action volcanique cherchait à se frayer un chemin. Au débul donc, formation. d'un mamelon plus ou moins volumineux, homogène, de roche solide, tranfor'mé postérieurement par une modificalion quelconque dans la nature de la puissance éruptive, et devenant enfin un volcan ordinaire ì cratère, émeltant des gaz et projetant des matériaux cinériformes et scoriacés, dont l'accumulation en couches quaquaversales est venue compléter la forme conique de la nontağne pour hui donner, en dernière analyse, l'aspect caractéristique des volcans.

Avant de terminer celte entrée en malière, peut-čtre nn peu longue mais nécessaire, 111 mot encore sur la nature des éruptions des volcans de l'Ámérique centrale, aux époques reculées de leur existence aussi bien que peudant la période actuelle. Ces éruplions nous semblent toujours caractérisées d'une manière remarquable par la prédominance des matériaux scorifiés, cinériformes el gazeux, sur les produits liqućfiés; par l'aboudance des lapilli el des sables projetés comparée à la proportion relativement faible des laves éjaculées. Ce n’est pas à dire qu'il n'y ait pas de coulćes de lave d'une cerlaine importance, car les volcans qui n'en

$$
\begin{aligned}
& \text { Les éruptions } \\
& \text { des volcans } \\
& \text { dé } \\
& \text { l'Amériquecentrale } \\
& \text { sont plutòt } \\
& \text { caractériséres } \\
& \text { par des émissions } \\
& \text { de matières } \\
& \text { cinríriformes } \\
& \text { que } \\
& \text { par des épanche- } \\
& \text { ments } \\
& \text { de lave. }
\end{aligned}
$$
sont pas euvironnés sont, au contraire, très-peu nombreux; mais il faut remarquer 
que ces coulées n'alteignent jamais les proportions grandioses que l'on peut roir dans d'autres pays volcaniques, au Mexique, par exemple, et surtout qu'elles apparliennent presque toules à ure période relativement ancienme, le volcan de San Niguel élant le seul, à notre souvenir, qui en dome encore de temps en temps à notre époque. En mème temps, les anciennes éruptions ont produit des qunnlités de ponces vraiment effrayantes, ainsi que l'on peut s'en convaincre en éludiant les couches épaisses de ces matières qui recouvrent de vasles étemdues de pays, landis que les phénomènes achucls rejettent surtoul des scories broyées et triturées, sous la forme de cendres et de sables volcaniques. Est-il besoin d'ajouter que les élats éruptifs paroxysmaux, plus nombreux au temps jadis qu'aujourd'hui, sont accompagnés d'émissions de gaz à tempéralure élevée, qui ne renferment qu'une faible proportion de vapeur d'eau; à mesure que l'activilé volcanique tend à diminuer el à entrer dans une période de repos relatif, la lempérature s'abaisse, la quantité de vapeur d'eau augomente proporliomellement dans les fumerolles, et l'on voil quelques cratères se transformer, soit en solfalares, soit en espèces de foyers d'éruptions boueuses, produites par la condensation des vapeurs chandes et acides au milien des argiles formées par la désagrégation des roches préexistantes.

Résunie.

Le système volcanique de l'Imérique centrale, dont nous venons d'étudier rapidement les earactères généraux, forme un ensemble parfaitement délini et complet, quoiqu'il paraisse peut-ètre se diviser en deux groupes, ì cause de la déviation qui se produit dans la direction de son axe. Quoique nous n'ayons pu examiner de près qu'un de ces groupes, sur lequel seul par conséquent nous possédons des olsservatious faites par nous-mêmes, il nous a paru qu'il serait fìcheux de re pas envisager le système dans son ensemble et de le scinder d'une manière plus ou moins conforme aux apparences, mais incompatible arec la réalité des fails. Aussi avons-mous cherché à nous procurer, sur ce que nous n'avons pas ru de nos propres yeux, tous les renseignements disséminés dans les différents ouvrages qu'il nous a été permis de consulter, afin de conserver, autant que possible, dans notre étude, un tout homogène et continu, conforme à ce qu'a produit la nature en créant le système volcanique de l'Amérique centrale.

Ces renseignements, dont nous laisserous la responsabilité aux anteurs dẹs 
DANS LES RÉPUBLIQUES DE GUATEWALA ET DE SALVAOOR. 303 ouvrages dans lesquels nous les avons puisés, formeront un premicr chapitre. Dans le second, nous donnerons nos propres observations ef les résultals de nos recherches. Enfin, dans un troisième, nous traiterons brièvement des tremblements de terre, qui ne sont, à notre avis, qu'une annexe des manifeslations volcatniques, peut-ètre mème des phénomènes volcaniques d'une nature particulière. 


\title{
CIIPITRE PREMIER.
}

\author{
RENSEIGNEMENTS SUR LES VOLCANS DES RÉPLBLIQUES DE COSTA-RICA
}

\author{
ET DE MICARAGUA.
}

Volcans de Chirirgui, Rovalo et Blanco. - Groupe des volcans de Cartago (Turrialba, Irazu, Barba). - Volcans de l'ouest du Costa-Rica (Los Votos, Miravalles, La Vieja, Orosi). — Volcans des îles du lac de Nicaragua (Mandeira, Omotepec, Zapatera). - Volcan de Mombacho. - Volcans de Masaya el de Nindiri. - Volcan de Momotombo. - Volcans de la plaine de Léon (Los Marabios, El Viejo).- Volcan de Conseguina,

Nous allons essayer d'esquisser, dans ce premier chapitre, l'histoire des volcaus du Costa-Rica el du Nicaragua, répartis suivant une ligne axiale moyenne dirigée du sud-est au nord-ouest, et formant en quelque sorte le premier groupe du système rentro-américain. Ainsi que nous l'avons dit, nous n'avons pas parcouru nousmèmes les républiques de Costa-Rica et de Nicaragua, et nous n’avons pas examiné de près les volcaus qui accidentent leur territoire. Nous avons donc été réduits ì rhercher de côté et d'autre les renseignements épars dans quelques ourragoes qui traitent accidentellement de cette matière, et nous n'osons pas revendiquer une grande aulorité pour celte étude, qui n’est en réalité qu'une compilation de divers auleurs, dont les noms seront cités chaque fois que nous leur emprunterons quelques documents. Les synonymies, les incertitudes de positions géoggraphiques, les appréciations plus ou moins vagues des hauteurs, elc., sont autant d'éléments d'erreur qu'il n'est pas possible d'éliminer complétement, et nous devous avouer que, malgré les comparaisons systématiques faites entre les récits d'écrivains différents, malgré un coup d'œil rapide jeté sur les cimes principales lors de notre voyagge par mer le long des côles du Pacifique, nous avons encore conservé des doutes sur cerlains points de délail. Quoi qu’il en soit, nous espérons aroir atteint, non pas l'exaclitude absolue, mais un degớé d'approximation suffisant, et nous pensons que les recherches qui vont suivre ne seront pas complétement inuliles à la science. 
Les premières montagnes volcaniques qui font parlie du système de l'Amérique centrale sont situées dans la province de Chiriqui, appartenant à la Confédération de la Nouvelle-Grenade. Celle région est encore extrçmement sauvage, très-peu peuplée, el n'a que rarement été parcourue par des voyageurs, de sorle que l'on ne peut avoir qu'une confiance très-limitée dans les quelques données que l'on possède sur elle. Nous n'avons eu entre les mains les relations d'aucune personne ayant examiné de près les volcans de cette province, et il est probable que, s'ils ont été considérés de loin par quelques royageurs, ils n'ont, dans tous les cas, été gravis el étudiés par aucun. Aussi ne peut-on se baser que sur leur forme pour supposer leur nature et leur origine, el nous nous bornerons à dire qu’il est probable que ce sont des volcans, sans vouloir poser une affirmation absolue à ce sujct. A en croire M. Squiers (The states of central America, etc., p. 450) ce seraient des cônes d'une élération assez considéráble au-dessus du niveau de la nıer; il leur assigne en effet les hauteurs suivantes :

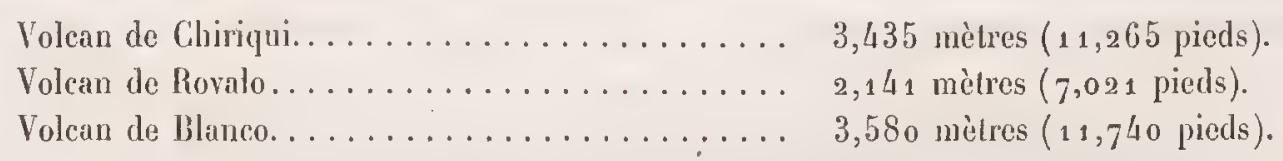

Vais, comme l'auleur nommé ci-dessus ne dil ni par qui ni comment ces hauteurs ont été calculées, nous pensons que l'on ne doit les accueillir que sous loules réserves; mais il en ressort, néanmoins, que ces montagnes étant de trèshautes sommités, posées sur un versant dont l'altilude ne dépasse pas 1,500 mètres, et le dominant par conséquent de beaucoup, elles ont dù pouvoir ètre vues de très-loin el examinées avec assez d'altention pour qu'il soil probable que les voyageurs qui en parlent ne se sont pas trompés sur leur nature.

Le Pic ou volcan de Chiriqui est silué au voisinage du golle de Chiriqui, à une trentaine de kilomètres tout au plus daus l'intérieur des terres, et l'on doit trèsbien l'apercevoir de I'Allantique, lorsqu'on y navigue en longeant la côte. Le Rovalo est à une quarantaine de kilomètres plus loin dans le nord-ouest, et le Blanco à la même distance du Rovalo, en suivant la même direction. La particularité

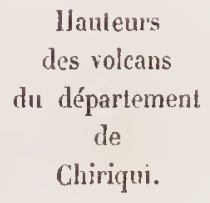

Les rolcans du déparlement de Chiriqui sont situés sur le versant de l'Atlantiq̣ue. ta plus intéressante de ces montagnes, en admeltant qu'elles soient des volcans, 
est d'ètre situées sur le versant de l'Atlantique, landis que tous les volcans dont nous aurons à nous occuper par la suite appartiennent à la région du Pacifique. Cela tient à l'angle que forment entre elles les directions dı système volcanique et de la liggne de faîte du pays, et c'est gràce à cette disposition qu'après avoir trouvé, du côté de l'Atlantique, les cònes de Chiriqui, de Rovalo et de Blanco, on voit les volcans des environs de Cartago se poser presque sur le sommel de l'arète principale, et préluder ainsi au passagge de tout le système sur le versant du Pacifique. En résumé, nous pensons que, quoique l'on ne possède pas de recherches précises sur les montagnes de la province de Chiriqui, on doil néanmoins supposer qu'elles sont des volcans; d'abord parce que leur position géographique coïncide d'une manière parfaitement convenable avec la prolongation de la direction bien définie du système du Costa-Rica et du Nicaragua; ensuite, parce que leur hauleur èt leur importance conduisent à croire que ceux qui les ont vus ont dù les observer avec soin el n'ont pas pu leur attribuer, sans justes raisons, une forme aussi caractéristique que colle d'un cône régulier. Nous ne savons pas que l'on ait jamais parlé d'une éruption de l'une de ces montagnes, soit dans les périodes reculées de l'histoire centro-américaine, soit à l'époque actuclle.

GROUPE DES VOLCANS DE CARTHAGO (TURRIALBA, IRAZU, BARBA).

La belle plaine où s'élève la ville de San José, capitale de l'État de Cosla Rica. est environnée de plusieurs massifs montagneux dont la plupart contiennent probablement des cònes volcaniques. D'après ce qu'en disent les voyageurs qui ont visité ce pays, cette ceinture se composerait, au sud-est de la ville, des montağnes où se trouve le volcan éteint et peu connu de Chiripo; à l'est, du groupe important des volcans de Turrialba et d'Irazu ou volcan de Carlago; enfin, au nord, des sommités dominées par le còne du volcan de Barba, qui n’a jamais élé exploré. Parmi les volcans que nous venons de citer, ceux qui ont de beaucoup l'importance la plus considérable sont ceux de l'est, qui s'élèvent près de l'ancienne ville de Carlago et lui empruntent même quelquefois son nom. C'est même à la proximité de ces redoutables voisins que la ville de Cartago doit de ne plus être la capitale du Costa-Rica et d'avoir élé désertée par la plus grande partie de ses habitanits à la suite des terribles tremblements de terre qui l'ont désolée à la fin du siècle 
DANS LES RÉPUBLIQUES DE GUATEMALA ET DE SALVADOR. 307 dernier. Il est probable que les volcans de Turrialba el d'Irazu sont très-voisins l'un de l'autre et constituent en quelque sorte un mème groupe comprenant deux cônes, l'un éteint et l'autre encore en activité, tandis que les autres s'en éloigonent un peu et servent de jalons intermédiaires entre ce groupe et ceux qui le précèdent ou le suivent.

Le volcan de Turrialba est un beau cône régulier, de 3,812 mòtres de hauteur (Squiers), qui présente encore aujourd'hui de remarquables symptômes d'activité. Il paraît qu’une assez épaisse colonne de fumée couronne conlinnellement sa cime, el que, dans certains cas, elle augmente notablement d'intensité. C'est évidemment au voisinage de ce volcan actif que sont dus les tremblements de terre qui ont dévasté Carlago. C'est probablement au Turrialba que doivent être rapportées d'assez violentes éruptions qui eurent lieu dans les années 1723 et 1726 et dont on a conservé le souvenir à Cartago, sans que la tradition rappelle de détails concernant ces phénomènes. Après un intervalle de repos assez prolongé, il y eut, en 1820 et en 1847 , des relours caractérisés de l'action éruptive, et enfin

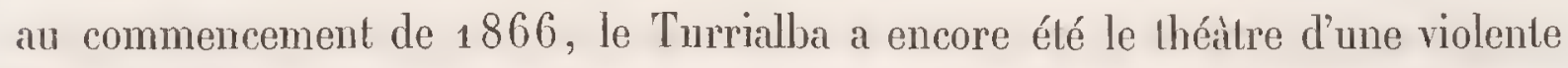
éruption cinériforme qui projeta des déjections jusqu'au port de Punta Arenas. Malgré l'intérêt scientifique que doit offrir l'étnde du volcan de Turrialba, aucun ouvrage ne mentionne qu'il ail élé examiné par des voyageurs s'occupant de questions scientifiques, el nous ne comnaissons le récil d'aucune ascension faite à celte monlagne. Il est possible que, grâce aux pentes très-roides du sommel ou aux épaisses forêts qui recouvrent la base du volcan, cette excursion présente des difficultés assez considérables, mais il nous semble que, dans un pays aussi riche et aussi peuplé que les environs de la capilale du Costa-Rica, on devrait trouver assez aisément les moyens de les surmonter.

Pour la gorande majorité des voyageurs, l'intérêt ne s'altache pas au volcan de Turrialba, mais à son voisin le volcan éleint d'Irazu, appelé aussi volcan de CarVolcan de Carlago ou Irazu. tago, dont l'ascension est assez facile, et du sommet duquel on jouit, parail-il, d'une vue admirable. Le désir de contempler en même temps les deux océans y attire presque tous les explorateurs qui parcourent le Costa-Rica, el il n'y a guère d'ouvrages traitant de ce pays, où ne se trouve un récit d'une excursion au volcan de Cartago. Le cône, haut de 3,477 mètres au-dessus du niveau de la 
mer (Squiers), est moins régulier que celui du volcan de Turrialba, mais il en présente néanmoins la forme et les allures caracléristiques. On n'y voit plus aujourd'hui aucune trace d'activilé, el il n'existe même pas de tradition relative à ses éruptions anciennes. Quoique l'intérêt scientifique qui s'allache au volcan de Cartago ne soil pas très-considérable, nous reproduirons quelques lignes de la narration de M. Stephens (Incidenls of travels in central America, etc., vol. I, p. 363), qui en fit l'ascension en 1840. Voici comment s'exprime cet auteur, après avoir raconté une première journée de marche au travers des épaisses forêts qui entourent la base du volcan et une nuit pittoresque dans une hutte isolée.

Récit d"une ascension

"Avant le jour, nous nous mîmes en route; le chemin était roide et accidenté; dans un endroit, une trombe avait ravagé la montagne, et les arbres renversés étaient en si grande quantité, qu'il n’y avait presque plus moyen de passer. Nous fûmes obligés de laisser nos chevaux et de continuer à pied. Plus haut, nous atleignìnes une régiou découverte, où il ne poussait plus que de l'herbe el des arbrisseaux rachitiques;...... mais, en nous élevant, nous pénétrâmes dans les nuages, et peu après ils devinrent si épais, que nous ne pouvions plus rien distinguer antour de nous, et qu'il nous fallut presque perdre l'espoir de voir quelque chose au sommel du volcan. L'herbe poussait encore à celte place, et nous montâmes jusqu'à ce que nous eûmes rencontré un clıamp de sable volcanique el de lave. Nous sortîmes alors de la région des nuages, et, à notre grande joie, nous pùmes apercevoir le sommet du volcan, complétement dégagé de vapeurs et se détachant sur l'azur clair du ciel. . . . . . . . . . . . . . . . .

" Jo continuai à monter el me trouvai hientôt en présence du cratère, d'une circonférence d'environ deux milles (3,600 mètres, soit un peu plus d'un kilomètre de diamètre), déchiré et brisé soil par lo temps, soit par quelque grande convulsion. Les débris étaient accumulés, hauts, accidentés, grands comme des montagnes, et, dans l'intérieur, il y avail trois ou quatre pelits cratères. Nous gravîmes du côté du sud," le longo d'une arête courant de l'est à l'ouest, pour atteindre le point culminant, près duquel il y avait, dans le bord du cratère, une immense coupure verticale impossible à franchir. Le pic élevé sur lequel je me trouvais était parfaitement clair, et l'atmosphère était d'une admirable transparence, tandis que, à environ 2,000 pieds au-dessous de nous, au-dessous de la région désolée du 
DANS LES RÉPUBLIQUES DE GUATEMALA ET DE SALVADOR. 309

sommet de la montagne, le pays tout entier était couvert de nuages, et que la ville elle-même ne pouvait se voir au pied du volcan. Peu à peu, les nuages les plus éloignés se dissipèrent; et, par-dessus cette immense couche, nous aperçûmes en même temps l'Allantique et le Pacifique et nous pûmes ainsi jouir du spectacle grandiose dont nous avions un moment désespéré. Mes compagnons avaient déjà fait, à plusienrs reprises, l'ascension du volcan, mais, à canse des nuages, ils n'avaient encore pu voir qu'une fois les deux mers. Les points où on les apercevait élaient d'un côté le golfe de Nicoya, de l'autre le port de San Juan, pas tout à fait en face l'un de l'autre, mais presque à angole droit. Malģré la gुrande distance qui nous séparait de l'un et de l'autre, ils semblaient être à nos pieds, à cause de la grande élévation à laquelle nous nous trouvions. C'est le seul point du continent américain d'où l'on puisse contempler en mènı temps les deux océans.

« Il n'y a ni histoire, ni tradition des éraptions de ce volcan, et il est probable qu'elles eurent lieu hien avant la découverte de ce pays par les Européens. Je regrettai vivement dans cette occasion la perte de mon baromètre, car la hauleur de cetle montagne n'a jamais ćté mesurée, quoiqu'on suppose qu'elle atteint environ 11,000 pieds."

VOLGANS DE L'OUEST DU COSTA-RICA (LOS VOTOS, MIRAVALILE, LA VIEJA, OROST).

Ainsi que nous l'avons dit, les montagnes qui supportent le volcan de Barba sont à quelque distance au nord-ouest du groupe de Cartago, mais elles ne font pourtant pas partie du groupe suivant, qui se développe à l'ouest de la république de Costa-Rica, non Join de sa frontière avec le Nicaragua. La distance qui existe entre le volcan de Los Votos, le premier de ce nouveau groupe (toujours en marchant du sud-est au nord-ouest) et le volcan de Barba, u'est pas très-considérable non plus, environ une cinquantaine de kilomètres, et on les voit très-bien l'un el l'autre en un point de la route de Punta Arenas à San José, au passage de la montagne de l'Aguacate. Les volcans dont nous avons à dire quelques mots sont bien moins connus encore que tous les autres volcans du Costa-Rica, et nous ne croyons pas qu'aucune expédition ait été faite dans le but spécial de les examiner de près. Leur chaîne limite en effet, au nord-est, la régoion appelée le Guanacaste, qui est la partie la moins lıbitée el la moins parcourue du Costa-Rica. Il 
passe bien dans le Guanacaste un chemin qui servail autrefois de communication par terre entre San José el Granada de Nicaragua; mais, depuis qu'existe la ligne des bateaux à vapeur du Pacifique, cette voie est complétement négligée. Pour passer auprès des volcans de l'ouest du Costa-Rica, il faut avoir une raison spéciale qui vous attire de ce côté, et nous ne savons pas que, pour persomne, la raison ait encore été le désir d'étudier spécialement les volcans.

Volcans

de Los Totos el de Miravalles.

On sait pourtant que, parmi les connes qui accidentent cette partie du pays, il y en a quelques-uns d'assez importants, et un surtout qui jouit encore d'une activité bien caractérisée et se signale de temps en temps par des éruptions cinériformes plus ou moins violentes. Ces volcans sont groupés à une faible distance les uns des autres et constituent un ensemble bien déterminé, correspondant à une surélévalion notable du massif monlagneux qui les supporte. Ainsi que nous l'avons dil, le premier de ces cônes, en partant du sud-est, est celui de Los Volos, dont la hauteur dépasse probablement 3,200 mètres, mais qui ne présente plus aujourd'hui aucune trace d'activité éruptive. Il en est de même pour son voisin, le volcan de Miravalles, haut seulement de 1,500 à 1,600 mètres, mais environné d'accidents du sol assez importants. Vient ensuite le cône de La Vieja, complétement éteint aussi, et qui doil probablement être confondu avec celui auquel M. Stephens attribue le nom de Rincon.

Volcan d'Orosi. On arrive ensuile au volcan d'Orosi, qui domine de loin le lac de Nicaragua et au pied duquel prennent naissance plusieurs rivières qui vont se jeter, soit au nord-ouest dans le lac, soit au sud-ouest dans le golfe de Nicoya. Avec le volcan d'Orosi la ligne volcanique est devenue relativement voisine de la còte du Pacifique, et, lorsqu'on navigue à une faible distance des terres, on peut très-bien apercevoir le beau cône régulier de l'Orosi, qui se dresse au-dessus du pays environnant, et dont la cime est toujours couronnée d'un panache de fumée. Ce volcan, haut de près de 3,000 mètres ( 8650 pieds d'après Squiers) au-dessus du niveau de la mer, est, en effet, sinon en éruption, du moins en constante activité, et les habitants des localités voisines le considèrent toujours avec une certaine inquiétude. Jous ne possédons néanmoins aucun renseignement ni sur ses éruptions anciennes, ni sur celles qui ont pu se produire dans ces dernières amnées. 
VOLCAYS DES ILES DU LAC DE NICARAGUA (MAXDEIRA, ONOTEPEC, ZAPATERA).

En pénétrant sur le territoire de la République de Nicaragua, le système volcanique rencontre la vaste étendue d'eau si célèbre sous le nom de lac de Nicarrgua, qui se développe sous la forme d'une grande ellipse allongée, dont le grand axe coincide presque exaclement avec la direclion de celte ligne, en orientation et en position. Le système volcanique n'est pas interrompu pour cela, mais il manifeste sa présence en jalonnant le lac d'une série de petites îles plus ou moins régulièrement circulaires, dont la plupart sont essenliellement constituées par un còne éteint émergeant des eaux. Quoique le lac de Nicaragua ait été éludié avec gorand soin, et à plusieurs reprises, ses îles n'en sont pas moins à peu près inconnues, car l'allention des observateurs étail attirée par des' questions d'un ordre tout différent, et l'existence de quelques petits connes volcaniques éteinls n'étail pas faite pour les délourner de leur but.

Parmi les îles les plus importantes du lac de Nicaragua, la première, dans la volcand'Omotepec. direction du sud-est, est celle de Solentenami, sur laquelle nous ne possédons ancun renseignement précis, mais qui, d’après sa forme, pourrait bien contenir quelque volcan éteinl. Ensuite vient l'île d'Omotepec, dont la forme admirable n'a jamais manqué d'attirer l'attention des voyageurs, qui l'ont lous examinée de loin s'ils n'ont pas eu le temps d'aller l'étudier sur place. Elle se compose en eflet de deux cônes jumeaux, soudés par leur base, et s'élevant dans les airs avec la plus remarquable régularité. Tous les auteurs sont d'accord ponr représenter ce tableau comme un des plus beaux qui se puissent voir, el dépeigonent à l'envi la magnificence du spectacle dont on jouit, lorsqu'on peut contempler, au soleil couchant, les harmonieux profils de ces montagnes se délachant de l'azur du ciel el se perdant par leur hase dans les flols bleus du lac. Nous ne les suivrons pas dans cette voie, et nous tàcherons de leur emprunter quelques renseignements plus techniques disséminés dans leurs récits. Le nom d'Omotepec appartient à la langue nahuatl el signifie dans ce dialecte deux montagnes, ce qui est parfaitement d'accord avec la forme de l'ile. Elle se compose en effel de deux connes juxtaposés, el dessine ainsi en plan une sorle de 8, dont la longueur lotale est d'une vingtaine de kilomètres, tandis que chacun des cercles qui la conslituent peut avoir en- 
viron 1 o kilomètres de diamètre. Le cône du sud-est porte le nom de Mandeira; il est un peu moins élevé que son voisin, mais il est aussi régulier que lui, et comme lui aussi il est complétement éteint et recouvert d'épaisses forêts. Le cône du nord-ouest s'appelle Omolepec, comme l'île elle-même, et s'élève à une hauteur de 1,500 à 1,600 mètres au-dessus dı niveau de la mer. Sa forme est celle d'un còne parfait, mais il ne présente plus aucune trace d'activité et a été envahi depuis bien longtemps déjà par une luxuriante végétation. La tradition prétend qu'il existe à son sommet un vaste cratère dans lequel dorment les eaux d'un lac profond; mais, quoique parfaitement possible, cela n'a pas été encore vérifié par une investigation dirigée dans un but scientifique. Il n'existe aucune relation se rapportant aux éruptions du volcan d'Omotepec, et il nous semble probable qu'il devait être éteint déjà bien avant l'époque de la découverte de l'Amérique.

Un peu plus loin dans le nord-ouest, on voit encore l'ile de Zapatera, dont la forme irrégulièrement circulaire et assez exactement conique annonce presque avec certitude la présence d'un volcan éteint. Enfin, au pied du volcan de Mombacho, il existe un archipel composé d'une innombrable quantité de petils îlols, connus sous le nom de Los Corales. Ces îlots, dont les plus élevés ne dépassent pas la hauteur d'une trentaine de mètres au-dessus du niveau du lac, ont, paraîtit, une forme habiluellement conique, et sont couverts de verdure. Les descriptions peu étendues que nous en avons eues entre les mains ne nous permellent pas de nous faire une idée précise de ce que sont ces mamelons; et, quoiqu'on s'accorde généralement à les considérer comme ayant une origine volcanique, nous ne pensons pas qu'on puisse admettre qu'ils soient presque tous de petits volcans éleints, quoiqu'il soil possible que quelques-uns d'entre eux aient été jadis de petits volcans adventifs situés sur un des flancs du volcan principal de Mombacho. Il y a là une question à éludier, et il serail intéressant de connaître quels sont les rapports qui existent, comme composilion géologique et comme origine, entre Los Corales et leur voisin le Mombacho.

VOLCAX DE MONBACHO

Après avoir traversé de bout en bout le lac de Nicaragua, le système volcanique se continue sur la langue de terre qui sépare ce lac de celui de Managua, et le 
DANS LES RÉPUBLIQUES DE GUATEMALA ET DE SALVADOR. 313 premier cône qui apparaît sur sa direction est celui de Mombacho, situé sur la rive même, à une vingtaine de kilomètres tout au plus au sud de la ville de Grenade. Ce volcan, haut de 1,60o mètres au moins au-dessus du niveau de la mer, ne donne plus aujourd'hui aucun signe d'activité, et présente, à son sommet, plusieurs cratères plus ou moins bien conservés dont les deux principaux renferment des lacs d'une eau claire et pure. L'un de ces cratères est une dépression assez régulièrement circulaire, d'un diamètre de 400 à 500 nètres et d'une profondeur d'environ 80 mètres; l'autre est un effrayant abîme très-profond, dont les bords à pic sont entaillés d'un côté el correspondent à une gorge creusée sur les flanes du cône.

L'accès du volcan de Mombacho est difficile, cependant on est parvenu à son sommet, et nous allons donner ici, en partie, la traduclion d'un récil qui est reproduit par M. Squiers (The states of central America, elc., p. 381 et suiv.) sans indication de la personne ì laquelle il est dù :

"Peu d'indigènes ont fail l'ascension du Mombacho, quoique presque chacun ait son histoire ì raconter sur le lac merveilleux qui existe au sommet, el sur les choses étranges que le voyageur rencontre sur son chemin avant d'y arriver. J'eus beaucoup de peine à persuader de me servir de guide à un ancien marinero (batelier du lac de Nicaragua) qui élail monté quelques années auparavant avec le chevalier Friederichthal, el qui avait passé plusieurs jours avec lui an sommet de la montagne. Le flanc du volcan qui regarde Grenade est inaccessible, el nous dùmes nous décider à gağner le village indien de Diriono, situé an pied de la montag̣ne du còté du sud-ouest, pour partir de lì el tenter l'ascension... Après avoir traversé longtemps d'épaisses forêts, le chemin gogogne un pays comparativement accidenté el brisé. Les approches du volcan sont caraclérisées par de profonds ravins qui sillounent ses flancs et rayonnent dans toutes les directions. Ces ravins soint remplis d'arbres, de buissons et de lianes, tandis que les arêtes qui les séparent sont nues et ne nourrissent qu'une herbe longue el sèche, jaunie et desséchée par les rayons du soleil... Une heure après, nous avions atteint la base des liautes collines coniques de scories, sans arbres mais couvertes d'lıerbes, qui forment un des traits les plus saillants du paysage que l'on apercoil de Grenade... E. Elles sont d'une excessive régularité de formes, et semblent avoir 
été constituées de cendres et de scories rejetées pendant une des éruptions du volcan el amenées là par le vent. Comme de pareils amas de cendres se tronvenl en nombre plus ou moins considérable près de tous les volcans du pays, ils donnent des indications infaillibles sur la direction des vents dominants.

"Autom de ces cônes, il y a des espaces libres qui semblent avoir élé défrichés autrefois et paraissent indiquer la place d'anciens champs de maïs. Au delà, le sentier pénètre dans une épaisse forèt el s'élève sur une arête puissante de roches volcaniques et de laves qui s'étend au loin dans la direclion du volcan de Masaya. A moilié chemin du sommet de cette arète, on aperçoil une abondante source d'eau fraîche qui brille comme un diamant sous les roches, el qui porte un nom indien doux et musical, que j’ai oublié. C'est un endroit charmant, qui a été, de temps immémorial, un lieu de rendez-vous pour les Indiens, dont les pas innombrables ont poli les roches avoisinantes.

"Après que nous eìmes gravi l'arête, nous pénétràmes sur un espace ondulé, où se trouvent un grand nombre de champs de maïs, de cannes, etc., dont la végétation est plus luxuriante que partout ailleurs. Cela tient à la présence du volcan, qui oppose une barrière à la marche des nuages emportés par les vents régnants, et détermine leur précipitation en une pluie abondante. De celle façon, tandis que tout le reste du pays souffre de la sécheresse, cel endroit privilógié reste soumis à une bienfaisante humidité, qui entrelient la verdure el la fraîcheur.

"Il était à peine neuf heures quand nous atteignimes lo grand village do Diriomo; mais, sans nous y arrèter, nous tournàmes à gauche pour gagner l'hatcienda de la famille Bermudez. Un petit lac au premier plan, avec des bouquets d'arhres el des masses de lave noire mèlées de champs de scories rougeàtres, lormaient un étrange tableau, dans le fond duquel le volcan lui-mème se dressait grandiose el majestuenx. Sans perdre de temps, nous poursuivìmes notre route, par un sentier qui se maintient pendant environ deux heures dans un pays trèsaccidenté. Par moments, nous traversions des champs de lave brisée, écliauffée par les rayons du soleil, pour nous plonger ensuite dans des taillis d'arbustes serrés et sorlir sur des plaines arides de cendres et de scories.

"Enfin commença l'ascension de la nontagne elle-mème. De ce còté les murailles du cratère sont en partie détruiles, laissant voir une effrayante cavité dé- 
DANS LES RÉPUBLIQUES DE GUATEMALA ET DE SALVADOR. 315 chiquetée, ayant la forme d'un cône renversé, entourée de noirs rochers amoncelés, qui semblent prêts à s'écrouler sur celui qui ose s'en approcher. Le sommet uous paraissait alors deux fois plus élevé qu'auparavant, el c'est en vain que nous cherchions à découvrir un sentier au milieu des amas de lave el de roches volcaniques entassées dans le plus effrayant désordre. A partir de ce point, notre ascension ne ful plus qu'une fatigante gymnastique; grimpant sur des rochers angruleux el déchirés, nous accrochant aux racines des arbrisseaux, monlant péniblement sur des clıamps de cendres ou de sables volcaniques fuyant sous tes pieds, uous nous élevions peu à peu sur les llancs de la montagne, dont le sommet semblail, à chaque instant, plus loin de nous. Après deux heures d'eflorts, nous apercevions la base du volcan bien loin derrière nous el pourtant la cime ne paraissait pas s'être sensiblement rapprochée...

« Les difficultẹ́s de l'ascension augmentèrent bientôl, quand nous eùmes atteint un endroil où la montagne élait déchirée el coupée par une infinilé de ravins ou de fentes dont quelques-uns élaient profonds de plusieurs centaines de pieds. Il élait difficile de choisir une direction qui conduisì à la cime loul en évilant ces obstacles. It faut ajouter que nous venions d'alteindre la zone des unages, qui nous cachaient fréquemment le but de nos efforts et nous enveloppaient dans une complète obscurité; il fallail alors attendre, sans faire un mouvement, qu'ils se finsent dissipés, car un pas dans un ınauvais sens aurait pu être falal.

* Nous avions dirigé notre marche vers un pic anguleux el élevé qui nous semblail ètre le point culminant de la monlagne; mais, lorsque nous l'eùmes alteint après mille eflorls, nous nous aperçùmes que ce n'élait qu'un point du bord brisé du cratère el que le véritable sommel élait loin de nous, à gauche, séparé de l'endroit où nous nous trouvious par un profond ravin, que l'on ne pouvail franchir' qu'en redescendant sur les rochers jusqu'à un millier de pieds plus bas. C'était ur grand désappointement, et cependant nous nous trouvions salisfaits de ne pas avoir à passer la nuil là. Avant de repartir, je rampai avec précaulion jusqu'anı bord même de la paroi de rochers qui dominait l'ancien cratère, ouverl au-dessous conme un gouffre imnrense. Je pus apercevoir au fond de celte effrayante cavité Im pelit lac qui dormail paisiblenent au milieu de cel entourage de désolation.

"Après avoir rejoint le corps même du volcan, nous alteignìmes nne pente 
relativement peu inclinée, où croissaient un peu d'herbe et quelques arbrisseaux; et, après avoir passé auprès de plusieur's petits cratères ou d'anciens évents, nous arrivâmes an point culminant, juste au moment du coucher du soleil. Je m'étais abstenu de regarder autour de moi en montant, réservant pour la fin le spectacle

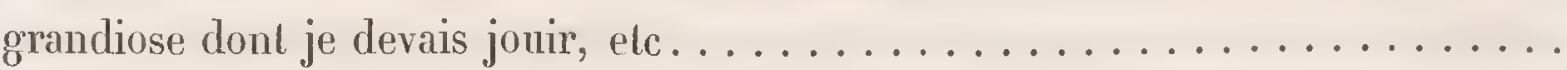

« La première partie de la nuit fut agréablement fraìche, mais, vers le matiu, nous fùmes réveillés par une brume humide, qui enveloppait la montagne et laissait tomber sur les rocliers de larges gouttes d'humidité. Ce brouillard ne se dissipa que longtemps après le lever du soleil, et nous fùmes ainsi privés du spectacle que uous étions surtout venus chercher. Ce n'est qu'après dix heures qu'il nous fut possihle de regarder autour de nous, et de nous avancer vers la déclivité de l'est, où une chute brusque el les cris des oiseaux semblaient annoncer que nous devions rencontrer le lac dont on nous avait tant parlé. Nous ne fùmes pas désappointés, car nous arrivàmes subitement sur te bord d'un ancien cratère adventif du volcau. Il n’était pas aussi profond que les autres que nous avions vus, et ses pentes, doucement inclinées, élaient recouvertes d'une herbe fraiche. C'était une dépression en forme de cuvette, large d'un peu phus d'un quart de mille (50o mètres environ de diamètre) et profoude de 200 pieds (70 ì 80 mètres). Au fond brillait un pelit lac, enlouré d'arbres et de buissons chargés de lianes, dont les rameaux verdoyants pendaient à la surface de l'eau. J'essayai de pénétrer dans ce taillis el d'arriver au bord du lac; mais l'entrelacement des lianes était si touffu, el le sol présentait si peu de stabilité, que je dus y renoncer. Par des mesures barométriques, je constatai que ce cratère-lac se tronve à 4,420 pieds $(1,470$ mètres) au-dessus du niveau de la mer.

"Vers midi, après avoir jeté encore un deruier coup d'œil sur le sommet du Mombacho, nous commençâmes notre descente; cétait plus rapide et moins fatigant que l'asceusion, mais aussi plus dangereux. Nous trouvions beaucoup plus difficile de descendre que de monter sur les grandes parois de rochers souvent presque verlicales. Plusieurs fois mème nous eùmes peine à croire que c'était bien par là que nous avions passé la veille. Pourtant il ne nous arriva pas d'autre mallieur que celui qu'on a bien de la peine à éviter en semblable circonslance, 
DANS LES RÉPUBLIQUES DE GUATEMALA ET DE SALVADOR. 317 c'est-à-dire de casser notre baromètre, et en quelques heures nous atteignîmes heureusement le pied de la montagne."

\section{VOLCANS DE ILASAYA ETT DE NINDIRT.}

A 15 ou 16 kitomètres ain nord-ouest du volcan de Mombacho, et à peu de distance de la ville de Masaya, se trouve un groupe volcauique d'une grande importance. Il se compose de deux cônes jumeaux extrèmenent voisins l'un de l'autre, dont l'un porte le uom de volcan de Masaya et l'autre celui de volcan de Nindiri, ainsi que d'un cratère-lac, qui doit ètre compté parmi les plus remarquables qu'il y ail au monde.

Le lac de Masaya se trouve à un kilomètre tout au plus de la ville el c'est là qu'ou va chercher, avec de grrandes difficultés, toute l'eau qui est nécessaire aux hesoins des habitants. Cela se pratique généralement au moyen de grandes amLinc de Misaye: situé nu pied du volestr du mème nom. phores de terre cuite, que des femmes portent, suivant la coutume du pays, avec une courroie de cuir passant sur le front. Cette eau, parfailement polable, ne contient qu'une faible proportion de sels minéraux; mais il paraît que sà lempérature est de quelques degrés supérieure à celle de l'air ambiant, et qu'on la laisse d'ordinaire rafraichir pendant quelque temps avant de l'employer pour les usages domesliques. Le niveau du lac se trouve à 150 mètres au-dessous de celui du sol environnant el ce n'est que par d'étroits sentiers, très-roides el ì moitié entaillés daus le roc, que l'on peut l'aborder. Il s'est formé, en eflet, dans une inımense dépression, brusquement ouverte à fleur de terre, et coustituant un reniarquable cratère-lac. Ce cratère ne présente pas dans loute son étendue une forme caractéristique, el le voisinage du volcan de Masaya a contribué puissammen! ì y amener des modifications importantes. Il n'est circulaire que du côté de l'est, là où il est borné par de gigantesques falaises à pic, de phus de 100 mètres de hauteur; mais, à l'onest, le bord primilif a été détruit, soit par la formation mème soit par les éruptions successives du volcan de Masaya, qui a pénétré en partie par sa base dans le bassin du lac, ainsi comblé et refouté d'un côté. La demicirconférence encore intacte peut avoir 8 kilomètres de diamètre, tandis que la dimension perpendiculaire serait de moilié plus faible. Les auteurs que nous avons consultés ne disent nulle part de quelles unatières sont composées les parois de ce 
bassin; mais, d'après leurs descriptions, nous sommes portés ì croire qu'elles doirent ètre entaillées, au moins dans la région profonde, au milieu de puissantes couches de roches basaltiques.

Voloan dra Vlasiya.

Le volcan de Masaya, dout la base pénètre, à l'ouest, dans les eaux du lac du même nom, est un cône irrégulier d'une hauteur de 900 à 1000 mètres, tout au plus, au-dessus du niveau de la mer. Il a émis un grand nombre de coulées de lave, dont la plus importanle s'est épanchée du côté du nord, jusqu’à une distance d'une trentaine de kilomc̀tres. La route de Grenade à Léon traverse cette conlée de lave et, quoiqu'elle soit assez ancienne, ayant actuellement denx siècles d'existence, il parail qu'il n’y pousse encore ancun végótal, el qu'elle a conservé la couleur noire, la mudité complèle, l'aspect désolé el hérissé de ses premiers jours. Le volcan de Masaya est célèbre dans les fastes de l'ancienne histoire centro-américaine, r'ar il était dans un état de violente aclivité tors de la conquête, et il fut considéré par les envahisseurs comme une des plus étranges merveilles du pays qu'ils venaient de découvrir. Oviedo, le fameux chroniqueur, qui le vil en 1520 , à l'époque oì les Espagonols pénćtrèrent au Nicaragua, a laissé dans ses mémoires une intéressante descriplion, dans laquelle il lui donne un nom qui indique quelle devait ètre la violence de son état éruptif, puisqu’il l'appelle El Infierno de Masaya, l'enfer de Masaya. Voici, du reste, les quelques lignes qui sont consacrées à co volcan dans ces anciemmes chroniques :

Etat du rolcan de Masaya

an $x$ vi siècte, d'après le rhroniquem Ovieds.
" Il y a dans celte province des montagne brûlantes, et la principale est celle de Masaya, où les nalifs, à certaines époques de l'anmée, sacrifiaient des jeunes filles, en les précipitant dans l'intérieur du cratère, pensant, par l'offre de leur vie, apaiser le feu, pour qu'il ne dévastàt pas la contrée, et ils y allaient aver: grand soin."

Et autre part :

"A trois lieues de la ville de Masaya, il y a une pelite colline ronde et aplatie, appelée Masaya, qui est une montagne brûlante; sa bouche peul mesurer une demi-lieuc, et sa profondeur est de 250 brasses dans l'intérieur. Il n'y a ni arbres, ni herbes, mais les oiseaux y vienuent sans craindre le feu. Il y a encore une autre bouche, semblable à celle d'un puits, à une portée de flèche plus loin, et on y roil le feu à une profondeur de 150 brasses; la masse en feu y botillonne of 
DANS LES RÉPUBLIQUES DE GUATEMALA E'T DE SALVADOR. 319 s'élève quelquefois, et donne alors une grande lumière, qui peut êlre vue à unte distance considérable. Elle s'agite d'un côté à l'autre et quelquefois fail explosion avec un bruit épouvantable, et pourtant ne projetle jamais rien autre chose qur de la flamme et de la fumée."

A côté des descriptions vient anssi se placer la légende, et la tradition suivant montre jusqu'à quelles extrémités pouvait conduire l'étrange idée qu'on se faisail autrefois des volcans.

"Voyant que, dans le fond du cratère, la liqueur existail toujours, et quielle était toujours en ébullition, et pensant qu'elle pourrait bien ètre de l'or', F. Blase de Yniesta, de l'ordre de Saint-Dominiqne, ct deux autres Espagnols, se firent descendre dans deux paniers dans la première bouche emportant avec eux un baquel fait d'une senle pièce de fer et une longue chaine, pour ramener à eux un peu de la matière en fusion el pour savoir si c'était du métal. Ils descendirent 150 brasses de chaîne, et, aussitôt qu'elle arriva an feu, en très-peu d'instants, le baquet fiut fondu ainsi que quelques anneanx de la chaine, et ainsi ils ne purent pas savoir ce qu'il y avait au fond. lls restèrent là celte nuil sans avoir besoin de feu ni dr lumière, et revinrent dans leurs paniers après avoir eu une assez grande frayeur."

Postérieurement à l'année 1520 , le volcan de Masaya, après être resté pendanl Jongomps encore dans un élal de constante activité, eut plusieurs éruptions d'une grande violence. La plus importante est celle de 1670 , qui a donné la grande coulée de lave dont nous avons parlé ci-dessus. Acluellement, le volcan de Masaya est complétement éteinl, et son cratère est envahi par la végélation.

Il n'en est pas toul à fait de mème de son voisin, le volcan de Nindiri; et, autanl volcan dr vindiri. . que nous avons cru le comprendre d'après les récils que nous avons lns, saus avoir vu les choses de nos propres yeux, il nous semble possible qu'il y ait eu, dans certains cas, une confusion entre ces deux volcans. fls sont, en eflel, si voisins l'm de l'autre que c'est à peine si l'on peut les considérer comme deux volcans distincts. el que le Nindiri est en quelque sorte une dépression ouverte dans un gonflement soulevé sur le flanc du Masaya. Or le cratère du volcan de Masaya est, à ce qu’il paraît, dans un étal qui indique une extinction complète produite déjà depuis bien longtemps, et qui écarte entièrement l'idée qu’il ait pu douner des coulées de lave à une époque pen reculée de la nôtre; landis que le cratère du Nindiri 
est, au contraire, dans une siluation qui porte l'empreinte de l'activité volcanique. D'un autre côté, il est constant que c'est dans ce cratère adventif que se sont manifestés les phénomènes qui ont tant effrayé les habitants de Masaya il y a une dizaine d'années, el il ne serail pas impossible que ce fùt là aussi qu'eùt élé le siége d'une assez violente éruption, rapporlée par la tradition à l'année 1772 ou $177^{5}$, peut-être mème à toutes deux. Quoi qu'il en soit, te Nindiri est donc une sorte de tuméfaction soudée sur le flanc du volcan de Masaya, et dạns laquelle s'est ouvert un vaste cirque à parois rocheuses, d'où se dégagèrent, en 1856 , 1857 et 1858 , d'épaisses colonnes de fumée. En juin 1852 , les habitants de Mitsaya furent épouvantés par un bouillonnement suhit qui se manifesla au milieu des eaux du lac de Masaya ainsi que dans celles des deux lagunes voisines, el quelque temps après par une explosion violente qui sembla éclater dans le massif du volcan. Les années suivantes furent signalées par de nombreux tremblements de lerre, en mème temps que l'on voyait augmenter la colonne de fumée qui s'échappail du sein du cratère adventif du Nindiri. Au commencement de décembre 1856 , il se produisit une assez violente éruption qui dura quelques jours, puis tout rentra dans le repos, el, depuis lors, ce repos n’a pas été troublé. L'extinclion du Nindiri semble être momentanément aussi complète que celle du Masaya.

Pour rendre plus claires les considérations exposées ci-dessus, nous pensons hien faire en empruntant à M. Stephens (Incidents of travels in central America, etc., vol. II, p. 9) le récil de l'ascension quil fit, en 1840 , au volcan de Masaya; et nous prendrous les choses au départ du village de Nindiri, où le voyageur avail donné rendez-vous à son guide, qui n'était autre que l'alcade lui-même.

- A la distance d'une demi-lieue environ, nous quiltâmes la grande route (de Grenade à Léon) el nous prîmes à gauche par un pelit sentier pénétrant dans les bois. Ce sentier amène bientòt dans un espace libre recouvert d'une vaste coulée de lave qui s'étend au pied du volcan, en face et de chaque còté, aussi loin que la vae peut s'étendre. Elle est noire, profonde de plusieurs pieds, et, en quelques endroits, elle se dresse en liautes arêtes. Une piste baltue avait étć tracée par le bétail à la surface du champ de lave. En face de nous se trouvaient deus volcans, et l'on voyait sur les flancs de l'un et de l'autre des courants de lave qui 
DAMS LES RÉPUBLIQUES DE GUATEMALA ET DE SALVADOR. 321 s'étaient écoulés dans la plaine. Celui qui s'élevait en face de nous était, au dire de mon guide, le volcan de Masaya. Celui qui élait à droite, et un peu plus loin de nous, présentait une vaste brèche dans son cratère, el l'on pouvait apercevoin' ¿̀ l'intéricur une vaste cavité. Mon guide lui donnait le nom de Ventero, nom qụe je n'avais encore jamais entendı prononcer jusque-là, el prétendail qu’il étail inaccessible. Nous nous dirigeâmes vers le cône qui se dressail devant nous, el, après avoir traversé le champ de lave, nous atleignîmes la base du volcan. L'herbe y élail haute, mais le sol étail raboteux el accidenté à cause de la lave décomposée qui le recouvrait. Nous montàmes à cheval tant que nos animaux purent nous porter, mais, quand les pentes devinrent trop roides pour cela, nous mîmes pied à terre, el, après les aroir attachés à un buisson, il nous fallut conlinuer à pied. Il me semblail que mes gruides n'avaient pas une connaissance bicn approfondic des localités, et j’acquis bientôt la conviction qu'ils ne pouvaient ou ne voulaient pas supporter une grande faligue. Avant d'ètre à moitié chemin, ils s'élaient déjà débarrassés de l'eau et des provisions, el ils commençaient à rester eux-mêmes en arrière. L'alcade était un homme d'une quarantaine d'années, qui montait son propre cheval, el, comme c'élait un personnage d'importance dans son village, je ne pouvais pas lui ordonner d'aller plus vile. L'autre avail une dizaine d'années de plus et semblait physiquement incapable. Quand je m'aperçus qu'ils ne connaissaient ancun sentier particulier, je les laissai en arrière et allai seul de l'avant.

- A onze heures, c'est-à-dire trois lıeures après avoir quitté te village de Nindiri, jalteignis le point culminant vers lequel je me dirigeais, et je supposais que de cet endroit j’allais pouvoir plonger mon regard dans l'intérieur dı cratère dı volcan. Mais il n'y avail pas de cratère, et toute la surface élail recouverte par d'énormes unasses de lave entre lesquelles poussaient des arbrisseaux rachiliques. J'allendis jusqu'ì l'arrivée de mes guides, qui me dirent que c'élait là le volcan de Nasaya et qu'il n'y avail rien d'autre à voir. L'alcade aflirmail que, deux ans auparavant, il avail fail l'ascension avec le curé, défunt depuis, et d'autres villageois, el que c'était là qu'ils s'élaient arrêtés. J'étais désappointé et mécontent. Précisément en face de nous s'élevait un pic assez haut, qui, d'après sa position, me semblail devoir commander la vue sur le cratère de l'autre volcan. J'essayai de 
l'atteindre en marchant le long de la circonférence de la montagne, mais je lus arrèlé par une profonde déchirure et je dus retourner sur mes pas ponr traverser ensuile directement. Je ne me doutais guère de ce que j’allais tenter de laire. Tout ćtait recouvert de lave, qui formail des remparts et des masses irrégoulières, et dont la surface, variant à chaque inslant de niveau, était entremêtéc de taillis et de buissons. Après une heure des plus pénibles efforts que jaic jamais faits de ma vie, je réussis à atteindre le point vers lequel je me dirigeais, el, à ma grand: surprise, au lieu de dominer le cratère du volean éloigné, je me trouvai sur le bord d'un antre cratère. . .

«Ce cratère avait environ un mille el demi (a kilomètres el demi) de circonférence, et 500 ou 600 pieds de profondeur; ses parois, en pente assez forle, avaient des proportions si régulières, que l'on eût dit me excavation faite de main thomme. Le fond étail de niveau, el recouvert d'herbes ainsi que les parois, de nanière à donner à l'ensemble l'aspect d'un inmense bassin conique de verdmre. Rien ne rappelait les traces terribles d'une éruption volcanique, rien qui pût terrifier on domner l'idée d'un enfer; tout, au contraire, respirail le calme, la gorranden' el la beaulé. Je descendis jusqu’à cỏté du cratère el me promeuai le lonơg dı bord, en plongeant mes regards dans l'intérieur. De l'autre còté il y avait un bouquet d'arbustes, el, en un autre endroit, on voyail une place sans herbe où le sol, noir ct raboteux, semblail de la boue qui se dessèche. Je me sentis la curinsité de descendre dans l'intérienr du cratère, mais ses parois élaient presque perpendiculaires.

"Tout seul comme je l'élais, el séparé de mes guides par une hemre do rudes efforts, j’hésitais avant de faire mne tentative, mais il m'eût été désagréable de revenir sans résultat. En un endroit, près de lì où la terre étail noire, le bord élait boisé, et il avait quelques petils arbustes; j’y laissai mon fusil appryé contre une pierre, en y allachant mon mouchoir en signe de reconnaissance, et quelquess inslauls après j’élais au-rlessous du niveau du bord. En me laissant desceudre au moyen des racines, des buissons et des pierres ronlantes, j’arrivai jusqu'à un arbuste qui croissait sur la muraille à peu près à mi-chenin du fond; mais audessous de cela il n'y avail plus qu'une paroi nue et perpendiculaire. Il u'y avail pas moyen de descendre phus laas, j'élais mème obligé de me maintenir au-dessus 
DANS LES RÉPUBLIQUES DE GUATEMILA ET DE SALYADOR. 323 de mon arbre, el de lì j'eus beau chercher, avec plus d'attention que jamais, 11 ı moyen de gagner le fond, il me fallut y renoncer...

Q Quelque désireux que je lusse d'alteindre le fond, je me mis bientòt à reporter mes regards vers le bord. Unefoulure, une branche brisée, une pierre roulante, une défaillance de forces, m’auraient précipilé en un instant daus un endroil où j’aurais été aussi difficile à trouver qu'un gouvernentent dans l'Amérique centrale. Je' commençia ì grimper lentement et avec précaution, et, au boul d'un certaiu temps, je me trouvai hors de tout danger.

- A ma droile, je pouvais contempler dans toute son élendue le cratère boisé du volcan de Nindini. Du côlé lourné vers moi, il y avait eu un immense éboulenent, el le r'egarard pouvail pénétrer dans l'intérieur' du cralère. C'était celui-lì que l'alcade avail déclaré être inaccessible, el, en partie par dépit contre lui, je m’achrminai de ce colé, avec beaucoup de peines et de difficultés. Enfin, après cing heures d'une pénible pérégrination au travers des monceaux de lave déchiquetée, je me relrouvai à l'endroil où nous arions laissé nos provisions. Je retrouvai là l'alcade, qui sembla pétrifié d'élonmement aux descriptions que je lui fis, el qui persista ì me déclarer qu’il igonorait complélement l'existence de ces cratères . . ."

VOLCAN DE HONOTONBO.

Après le groupe volcanique, de Masaya, on ne rencontre plus de volcans proprement dits jusqu'ì celui de Momolombo, qui est silué sur les bords du lac de Mantigua dans la direction du nord-ouest. Mais ce vaste espace n'en a pas moins Sútie
decrilères-lac des ensirons do Namagua. élé soumis directement à l'aclion de la puissance éruptive, et la direction de la ligne volcanique y est jalonnéc par un très-grand nombre de cratères-lacs distribués aux environs de la ville de Managua, surlout du côté du nord. Ces cralères-lacs, qui ont été signatés pour la première fois d'une manière précise par M. F. Bell! , semblent être extrèmement intéressants, et mériteraient d'être étudiés aver soin par quelque vorageur scientifique. M. Belly n'en dil d'ailleur's que quelques mols, el c'est à son ouviage ${ }^{(1)}$ que nous emprunterons les indicalions plulôl que tes rescriplions que nous allons en donner.

P'rès de Masaya, oulre le grand cratère-lac dont nous avons dit quelques mols an

(1) A traters l'Amérique centrale. Le Nicurague et le canal interocéentique, par Félix Belly, elc. Paris 1867. 
paragraphe précédent, il y en a encore deux autres, ceux d'Appoyo el de Tiscapa. Le premier est in immense gouffre enfermé entre des parois verticales de plus de 300 mètres de profondeur, dans lequel se trouve une vaste nappe d'eau salée; le second est une belle cuvelte dont les murailles n'ont qu'une trentaine de mètres de hauteur'; son diamètre est d'environ 500 mètres, et la profondeur de ses eaux d'une cinquantaine de mètres au milieu. L'eau qui y est contenue est douce et claire et esl employée pour tous les usageses domestiques. Les cratères-lacs des environs immédiats de Managua sont encore plus intéressants. On connaît d'ahord, ì environ 20 kilomètres de la ville, celui de Nejapa, d'un diamètre de 600 mètres, dont les caux presque chaudes, àcres, nauséahondes, chargées d'hydrogène sulfuré el d'une couleur verdâtre, laissent déposer un sédiment noir contenant du fer. A 3 ou 4 kilomètres de là est la lagoune d'Asososca, qui n'a pas moins de 800 mètres de diamètre, et qui est entourće d'une muraille à pic de go mètres de hauteur. Ses eaux, douces el froides, sont profondes de plus de 100 mètres près des bords, el au milieu on ne trouve pas le fond. La lagune de Jilua est situće à une vinglaine de kilomòtres plus loin; elle a à peu près les mêmes dimensions, mais ne renferme que de l'eau salée. Il est probable que des dégagements de ga\% plus on moins ahondants se produisent de temps en temps dans les unes et les autres de ces lagunes, car on prélend les roir quelquefois bouillonner.

An nord-ouest de Managua, la direction du système volcanique traverse le lac de Managua. Il est probable qu'une presqu'ile, qui s'avance dans le lac près dı village de Matearas, et qui se signale de loin à l'allention du voyageur par d'asse\% hautes sommités, renferme quelque còne éteint on quelque cralère-lac qui jalonne relte direclion. Mais elle est bientôl indiquée d'une façon plus précise par l'ìle de Momolombita, qui s'élève au sud-est du grand Momolombo, lout près des rivages de la presqu'ile qui forme la base de ce beau volean. L'ile de Momotombita est constituée par un pelit cône éteint d'une admirable perfection de formes, dont les flancs sont reconverts d'une épaisse végétation. Ce volcan n’élail déjà plus actil à l'époque de la conquête, et il est probable qu’il y a bien des siècles qu'il a cessé de l'ètre, car on a découvert dans l'intérieur de son cratère de gigontesques idoles de pierre, qui pronvent que les anliques races indiennes l'avaient déjì choisi jadis pour y célébrer les mystères de leur religion. 
DANS LES RÉPUBLIQUES DE GUATEMALA ET DE SALVADOR. 325

La ligne volcanique rejoint bientôt la terre ferme, et elle est presque immédialement indiquée par le gigrantesque còne du Momotombo. Ce volcan s'élève au bord mème du làc de Managua, et sa base arrondie y a formé une presqu'ỉle qui s'arantece dlans les eaux sur plus d'une demi-circonférence. II n'est pas impossible qu’il ail constilué autrefois une île comme celle de Monolombita et quili ait été rejoinl à la terre ferme par l'accumulation de ses déjections successives. Le Momolombo. dont la hauteur est estimée à 2,100 ou 2,200 mètres, n’a jamais été gravi par personne. Comme il repose sur une plaine dont le nireau ne dépasse guère que d'une vingtaine de mètres celui de la mer, son cône se développe sur toute sa lıauteur avec une admirable régularilé. On le voit très-bien du port de Realejo (Corinto), el sa masse grandiose semble se dresser à l'extrémitć de la ligne de pelits cônes des Marabios, à l'autre bout de laquelle s'élève le beau volcan d'El Viejo. Le sommet du Momotombo est noir el dénudé; de vastes courants de lave sillonnen! ses flancs, el tout contribue à lui donmer un aspect plein de grandeur el de majesté; sa cime est couromnée d'une colonne de funcée qui attire de loin l’attention, el qui indique qu’il possède encore une activité éruptive bien caractérisée. Aulour de sa base, on voit surgir en plusieurs points des sources sulfureuses à une lante température. Les sòrces thermales sulfureuses ne sont d'ailleurs pas rares au Nicaragua; on en comnait un grand nombre de fort importantes, entre aulres celle de Tipitapa près de la rivière qui rejoint les lacs de Nicaragua et de Managgna. II est probable qu'il existe encore beaucoup d'autres phénomènes du mème genre que révèlerait une exploralion scientifique sérieuse. Le Momolombo n’a malhenreusement jamais été visité en détail, et personne n'a tenté d'alteindre sa cime; il est probable qu'en prenant convenablement ses inesures on pourrait pourlant unener à bonne fin une semblable entreprise, malgré l'incessante activité de co volcan, et que l'on recueillerait ainsi des documents précieux pour l'histoire volcanique de l'Amérique centrale. Quoique l'on sache pertinemment que lo Momotombo a plusieurs fois éjaculé des laves el projeté des cendres el des scories, il n'existe, à notre connaissance, aucune tradition qui soit rapportée par les différents auteurs, el qui puisse fixer la dale de ses principales éruplions. Mais il est conslant que ce volcan, actif déjà à l'époque de la conquète, n’a cessé depuis lor's d'émettre des volumes considérables de vapeur. En 1852, la colonne 
de fumcé avail une grande importance, mais elle a beaucoup diminté et mème presque disparu pendant que le volcan de Masaya (ou plutôt de Vindiri) était eu activité. Elle a repris en 1858 el n’a pas cessé depuis de se montrer.

VOLGAN DE LA PLANE DE LÉOX, - (LOS MARABIOS, EL VILJO.)

Sorte de volcums dits las Mitralios.

Au delà du Momotombo, on voit se dessiner dans la plaine de Léon une liggne de volcans éteints, exlrèmement voisins les uns des autres, qui portent le nom de Los Marabios. Ces volcans sont au nombre de 9 et conslituent une des séries les plus remırquables qui existent dans l'Amérique centrale. On les distingọue trèsnellement du port de Realejo, el il y a pen de spectactes plus étranges que cette rangée de cônes, dessinant leurs formes régulières sur l'azur du ciel. Ils soní tous beaucoup noins élevés que le Momotombo ou que le Viejo, qui se dressent ¿ux deux extrémités de la série; mais, comme ils se trouvent au milien d'une plaine doul te niveau ne dépasse pas beaucoup celui de la mer, ils ue perdent rien de leur grandeur, ayant en somme $u$ aspect assez imposant. En suivant toujours la direction du sud-est au nord-ouest, c'est-ì-dire en partant du Momolombo, voici dans quel ordre ils se succèdent: d'abord le còne régulier d'Axusco; puis le rolcan de Las Pilas, an cratère légèrement ébréché; ensuite un pelil còne dont le nom nous est inconnu, auquel succèdent la large masse de l'Orola, le beau còne du Telica, le Sanla-Clara, dont le cratère est partiellement.détruit, deux pelits rònes sans nom, et enfin le beau volcan d'El Viejo.

Le volcan d'EL Viejo est souvent considéré comme ne faisant pas partie do la rangée de Los Marabios, el, de fait, il les domine d'assez haul pour aroir autaut de droit que le Momolombo à être mis à part. El Viejo doil avoir à peu près 1500 mètres de hauleur, mais nous n'avons pas entendu dire qu'il ail jamais élé mesuré exactement; c'est un cône d'une admirable régularilé et d'mnr perfection de formes que rien ne peut dépasser. El Viejo élait en aclivilé à l'époque de la conquète dı Nicaragua, el il s'est maintenu encore lonğtemps dans cel élal, car Dampier en parle comme d'une montagne brùlante. Il est mème possible qu'il ue soil pas encore enlièrement éteint à l'époque acluelle, car il nous semble avoir' apercu à sou sommet de pelits nuages de vapeur, dont il est regreltable qu'aucune ascension scientifique n'ait encore révélé l'origine. 
DANS LES RÉPUBLIQUES DE GUATEMALA ET DE SALVADOR. 327

Depuis le Momolombo jusqu' ì El Viejo, le système volcauique affecte une direction presque mathématiquement rectiligne, jalonnée par les volcans de Las Pilas, d'Orola, de Saula Cliura el les autres pelits cônes éleints. Mais les voícans d'Axusco et de Telica sont un pen en dehors de celle série, du côlé dn sud, el semblent disposés sur une seconde ligne très-voisine de la précédente el qui lui est exactement parallèle. Celte direction prolongéo reste encore au-dessus du volcan de Conseguina.

Tous les cònes de la chaine de Los Maralsios sont complétement éleints ì l'ŕpoque actuelle, mais plusieurs d'entre enx étaient en éruption à l'époque de la conquète. Une étude de ces volcans, faile dans un but sérieux, amènerail probablement ì des résultats fort intéressants, et il est fìcheux que personne n’ail encore pu so livrer à de semblables recherches. Quoique Los Marabios soient dans un étal d'exlinclion, il ne faut pas croire pour cela que les manifestalions volcaniques aient complétement déserté celle région. Il n’en est rien, of tout dernièrement encore. ıne éruption subite s'est produite entre deux des anciens cônes de la série, lo volcan de Las Pilas el l'Orota.

Voici dans quels lermes le Courrier des États-Unis, journal qui se publie à NewYork, laconte, d'après une correspondance particulière, les phénomènes qui sr sont passés près de Léon en novembre 1867 , un an à peine après que nons avions quillé l'Amérique centrale :

- Le 14 novembre dernier $(1867)$ un nouveau volean a fait éruplion dans le Vicaragua, à 8 lieues environ à l'est de la ville de Léon, sur une chaine de monts volcaniques qui parcourt l’élat parallèlement aux côtes du Pacifique. Le phénomène a commencé à se manifester vers une heure du matin par une série d'explosions que l'on a entendues distinctement de Léon. Ces explosions ont déterminé, à travers la couche terrestre, une fissure d'un demi-mille ( 800 à 900 mètres) de longueur, s'étendant, dans la direclion du sud-ouest, de l'ancienne fissurr à un point intermédiaire entre les volcans de Las Pilas el d'Orola, qui sont deus des nombreux cônes parsemant celte région.

"Dans la matinée du 1/4, avant le lever du soleil, on vil le feu s'élancer en divers endroils du nouvean volcan. Les explosions continurient ì se reproduire très-irrégoulièrement, pendant loul le lemps de l'éruption, tantôl rapides el pressées, tantòl

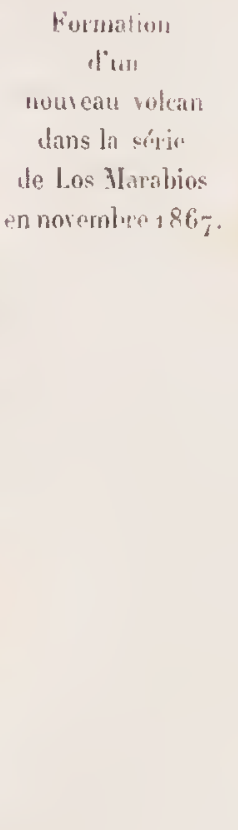


séparées par des intervalles d'une demi-heure. De sourds grrondements se faisaient entendre presque incessamment.

- Au bout de quelques jours, deux cralères s'étaient formés sur la nouvelle lissure, à une distance d'environ 100 mètres l'un de l'autre; le premier au sudouest rejelant les matières perpendiculairement; le second au nord-est décrivant In angle de $45^{\circ}$. Les flammes des deux cratères augmentaient sans cesse de volume et de hauleur, el, dans le mème temps, de deux ou trois autres endroils de la fissure, s'échappaient des jets de flamme et une petite quantité de lave. Le malin du 22 novembre, je me rendis auprès du nouveau volcan, pour mieux l'observer, quoique jusqu'alors je l'eusse vu et entendu de Léon. C'est un instant avaut le point du jour que je pus le mieux jouir du spectacle, du sommel d'une colline située à peu près à un mille de la fissure, perpendiculairement à sa direction. Tout le cratère à ma droile était en activité, vomissant des flammes el des rendres par un orifice circulaire de 60 pieds de diamètre, toujours entièrement rempli par des masses de malières qui s'y élevaient. Un cône réğulier d'une hautenr de 200 pieds environ, formé par la clıte des cendres, s'était élevé autour de ce cratère. Le cône était blanc à sa base, ronge jusqu'à moitié de sa hauleur, el jusqu'an sommel il pétillait incessamment de milliers d'étincelles.

: Le volean procédait assez régulièrement, grondant constamment, lançant, à chaque seconde, une colonne de flammes et de cendres, à près de 500 pieds audessus de l'orifice. Il y avail, en outre, à intervalles irréguliers variant de 10 à 3 o minutes, des explosions de plus en plus longues et fortes, et des ájections de volumes de plus en plus considérables de matières qui allaient rejoindre les autres.

«Les cendres s'abattaient sur le còne par masses brillantes d'un à trois pieds de diamètre avec un bruil mélallique et retentissant.

"Une fois le jour venu, de rouge qu'il était, le cône devint d'm noir bleuàtre. Le cralère de gauche envoyait obliquement des flammes et des cendres pareilles, décrivant un angle de $45^{\circ}$. Il était évident, par leurs décharges simultanées, que les deux cratères, bien qu'à une distance d'un millier de pieds l'un de l'autre, étaient en communication souterraine.

"Le cratère à demi-horizontal avait à peu près 20 pieds de diamètre. Daus 
DANS LES RÉPUBLIQUES DE GUATEMALA ET DE SALVADOR. 329 l'après-midi du 27 , après une série d'explosions qui semblaient ébranler la terre, te volcan se mit à vomir une grande quantité de sable noir et de rochers volumineux. Pendant la nuit, les flammes s'élancèrent à une bien plus gorande hauteur, el l'on vit des corps brillants semblables à des météores s'élever jusqu'à 3,000 pieds au moins de hauteur. C'élaient de grosses pierres de forme sphérique mesurant de 4 ì 5 pieds de diamètre. Le malin, les rues et les toits des maisons étaient couverls d'un beau sable noir lancé par le volcan, el l'on vit tomber dans toute la contrée une pluie de sable lumineux. Cette pluie de sable continua jusqu'au 3 o au malin, momeut où le volcan s'éteignil, étouffé probalblement par l'accumulation des malières.

« Le sable courre actuellement tout le pays, depuis le volcan jusqu'au Pacilique, sur une étendue de plus de 5 o milles. A Léon, il a alteint une épaisseur d'un quart de pouce. $\Lambda$ mesure qu'on s'approche du volcau, on remarque que les dimensions des grains paraissent plus considérables. Tout le tour du volcan, à une distance d'un mille, est couvert de parcelles dont les dimensions peuvent aller jusqu'à un diamètre d'un demi-pouce, accumulées en une couche d'un pied d'épaisseur. Tout près du cône, le sable a plusieurs pieds d'épaisseur, et les fragrments augomeutent goraduellement de volume, jusqu’à devenir semblables à de véritables bloes de rocliers. A la base du conne, ce sont des rocs de 4 à 5 pieds de diamètre, mais dont la majeure partie a été brisée. Le cône tui-mème a 200 pieds de haut, avec un cratère de 200 pieds de diamètre, dont la profondeur est à peu près lí mène.

“ Les flancs du cône sont semés de débris de roc qui ne dépassent pas un pied de diamètre. Un long sillon de scories noires s'étend du cratère dans la direction du nord-est. La lave, aussi bien que les scories que le volcan avait vomies en premier lieu, ont maintenant disparu sous la couche de fragments de rochers, lancés à la fin de l'éruption. La forêt est mutilée, sur une étendue de plusieurs lienes, par l'orage de sable, et les arbres placés près du volcan sont déchiquelés el ensevelis sous les cendres et les rochers.

« Pendant 16 jours, le volcan a été un spectacle intéressant à contempler... et c'est le cas d'appeler l'altention sur les phénomènes qui ont désolé SaiutThomas à peu près à la mème époque, et qui doivent avoir été produits Voyage géologinque. 
par les mèmes causes que les secousses de tremblements de terre ressenties ¿̀ Léon."

Quoique les jouruaux américains soient souvent sujets à caution, nous croyous qu'il n'y a pas lieu de douter de la véracité des assertions renfermées dans le récil qui précède. Malgré sa forme peu scientifique, nous avons cru devoir reproduire intégralement cette relation, parce qu'elle montre bien, dans sa naïveté mème, que l'éruption dont il s'agit a eu une importance assez considérable. Il serait intéressant de pouvoir suivre l'histoire de ce nouveau volcan et de savoir s'il a continué à émettre des vapeurs, ou bien s’il est entré immédiatement dans la période d'extinction complète, après la fin de son éruption paroxysmale. Quoi qu'il en soit, il y a donc maintenant un còne de plus dans la série de Los Marabios, el ce còne, qui s'est placé un peu en dehor's de l'alignement des autres, nous prouve, d'abord que l'activité éruptive reparail souvent tout à coup en des points qu'elle semble avoir abandonnés depuis longitemps, el ensuite que la nature des éruptions volcanciques de l'Amérique centrale est presque toujours, à peu de chose près, la mème, leur caractère le plus saillant se trouvant dans la prédominance des déjeclions cinériformes sur les ćjaculations de lave.

\section{VOLGAN DE CONSEGUNA.}

Position du rokan de Comseguina is l'extrémité

diune presquitile.
Nous arrivons enfin au volcan de Conseguina, le dernier de ceux qui composent le groupe du Costa-Rica el du Nicaragua, et en même temps le plus célèbre pent-ètre de lout le système de l'Amérique centrale. II est situé sur une presqu'île qui forme l'extrémité ouest du Nicaragua, à quelque distance au sud do la ligne axiale; de sorte qu'il semble que le point où cette ligne commence à s"ïlléchir soit caractérisé par des dérangements auxquels correspondrait la baie de Fonseca avec son système d'iles et de pointes avancées. Celte presqu'ile, reliée à la terre ferme par un isthme très-bas et plus étroit que le reste, se termine par une sorte de massif irrégulièrement circulaire, à conlours polygonatux, d'un diamètre de 15 à 16 kilomc̀tres environ, qui sert de base à la montagne, doul la hauleur tolale ne dépasse pas 1,000 mètres au-dessus dı niveau de la mer ${ }^{1}$.

\footnotetext{
'Antant que nous avons pu en jugrer de la mer en longreant la còte à quelque distance, celte mesure, donnée par M. Squicrs, nous semble plus conforme à la vérité que

celle qui, d'après M. Wells, n'attribuerait à la monlagne qu'une hauteur de 2,000 pieds environ (650 mètres à peu près.)
} 
DANS LES RÉPUBLIQUES DE GUATEMALA ET DE SALVADOR. 331

Vu de la mer, du côté du nord-ouest (voir le croquis que nous en avons pris et que nous avons fait reproduire, planche VIII, figo. 1), le volean de Conseguina offre l'apparence d'ın cône à pen près régoulier, d'un diamèlre très-considérable dans les régoions inféricures, mais tronqué à une faible hauteur au-dessus de sa base, comme si quetque épouvantable explosion avait détruit et projeté an loin toule ta partie supérieure de la montagne. De cette façon, le cralc̀re (s’il est vrai qu'il en existe encore un bien défini, comme tout nons porle d'ailleurs à le croire) doit être gigontesque, et présenter au moins une vingtaine de kitomètres de circouférence. De loin, on voit très-bien que le haut de la montigne présente un conton! arrondi, el que les bords du cratère sont sensiblement anguleux el hérissés de pointes rocheuses, dont les plus élevées peuvent avoir jusqu'ì nne centaine de mètres de hauteur. Toute la partie supérieure du volcan est complélement nue et senible conslituée de sables volcaniqnes, de lapilli et de scories, qui tui donnent ture apparence à peu près lisse el unie, quoiqu'clle soit sillonuce de ravins plus on moins profonds. La végétation commence à s'établir vers le point où le pied du còne se perd au nilieu de contre-forls irrégonliers, qui n'ont point la forme de sommilés volcaniques el sur lesquels se développent d'épaisses forèts. On voil enfin une plaine converte d'un fourré impénétrable, cotpée de profonds ravins, qui se termine brusquement à la mer par des falaises à pic, haules d'une cinquantaine de mètres. D'après M. W. Wells (Explorations and Adventures in IIonduras, elc. p. 120), cetle plaine selail recouverte de sables volcaniques, te cendres of de laves, et les falaises seraient formées d'amas de scories entremêtées de roulérs de lave, s'étendant quelquefois jusque fort avant dans la mer.

Le volcan de Conseguina jouit d'une Ielle célébrité, mème auprès des personncs qui ne s'occupent pas directoment d'études scientifiques, que nous croyons deroir esquisser brièvement son histoire avant d'entrer dans le délail de la terrible éruption de 1835 , gràce à laquelle son nom est devenu fameux dans le monde enlier. Lia tradition rapporte qu'avant l'éruption de 1835 il existail, sur la presquile de Conseguina, un rolcan que l'on considérait comme éteint el qui présentail une for'ne conique comme ceux do centre du Nicarigua. Vais il est permis de se demander si ce volcan étcint n'avail pas élć formé à mone époque relativement récente, quoiqu'on ne possède aucune narration de ce phénomène; cela semblerail résulter du 
récit suivant ${ }^{1}$, fait par Master Wafer, qui voyagea quelque lemps avec Dampier et se sépara de lui à Realejo, d'où il gagna la baie de Fonseca, en 1685.

"Ayant grand besoin de provisions pendant que nous étions là, nous fùmes ì terre pour tàcher de nous fournir de vivres à une hacienda de bétail, siluée sur le continent, vers le fond de la'baic, au sud, et à 3 milles environ de l'endroit où nous avions débarqué. Sur notre chemin, nous fùmes obligés de franchir une rivière chaude, courant dans une savane ouverte, ct cela nous causa quelque difficulté à cause de sa température élevée. Cette rivière sortait de dessous une colline, mais cette colline n'était pas un volcan, quoiqu'il y en ait heaucoup sur celte còte. J'eus la curiosité de remonter le courant, aussi loin que j’y vis clair pour me guider dans la caverne. L'eau étail claire et limpide, mais la vapenr, sous la colline, semblait ètre celle d'une chaudière bouillante, et mes cheveux en étaient tout lıumides. En dehors de la colline, la rivière fumait encore pendant assez. longtemps."

Or cette rivière existe encore aujourd'hui, clle porte le nom d'Ag'ua dulce, ses caux sont chaudes et imprégnées de substances minérales, elle se jette dans la mer au nord de la presqu'ille de Fonseca, et semble sortir du massif du volcan. C'est cerlainement la mème que celle que mentionne Wafer comme venant de dessous une colline qui n'était pas un volcan; et, comme ce voyageur, d'après ce qu'il dit lui-mème, élait fort au courant des caractères extéricur's des volcans, on peut croire avec lui qu’il n'existail pas de cône à cette époque sur la presqu'ìle de Conseguina.

Quoi qu’il en soit, le volcan éteint, formé à une époque que nous sommes obligés de laisser indéterminée, et tranquille depuis bien longtemps, au point qu'on ne songeait nullement à lui, s'évcilla tout à coup en janvier 1835. L'éruption fut terrible, elle détruisil toute la partie supérieure de la montagne, recouvrit toutes les régions environnantes de déjections qui furent portées jusqu’à des distances incroyables, et terrifia les populations jusqu'aux confins du Mexique et du Yucatan. Le paroxysme ne dura que trois ou quatre jonrs, mais le volcan ne rentra que lentement dans son ćtat de repos, et, pendant longtemps encore,

\footnotetext{
cit.).

A new vongage and description of the isthmus of America, extrait du Bachelor's Delight, et cité par Wells (loc.
} 
DANS LES RÉPUBLIQUES DE GUATEMALA ET DE SALVADOR. 33: on entendit des bruits souterrains et l'on vil des nuages de fumée s'échapper de son cratère. Il parait mème (Wells, loc: cit. p. 121) que, quoiqu'il n'y ait eu aucunc tentalive d'éruption depuis cette époque, le volcan n'élait pas encore al)solument éteint en 1854. Fn décembre 1852 , un nuage de fumée sortil de son cratère accompagné de sourds grondements; une poussière rouge, impalpable, tomba à Amapala, dans l'Isla del Tigore et sur la côte du Honduras. Aujourd'huni on ne voil aucun plénomène se produire sur te volcan de Conseguina, et on n’aperçoit jamais la moindre fumée couronner la cime de la montagne; il n'est cependant pas impossible que de petits dégagements de gaz ou de vapeur se produisent encore dans son cratère, el une ascension à cet immense volcan éteint permettrait peut-être d'obtenir des résultals scientifiques intéressants.

La grande éruption du Conseguina, qui eut lieu le 20 janvier 1835 , causa dans toute l'Amérique centrale une émotion indescriptible. C'est assurément le phénomène volcanique le plus terrible qui se soit manifesté de mémoire d'homme dans cette régoion du globe, et l'impression qui en est restée dans les esprits est telle, que les races indienmes, qui n’ont guère l'esprit des dates, en général, ef ne s'occupent pas de mesurer le tenıps, en ont fait un des points de repère de leur chronologic primitive; il n'est pas rare de leur entendre dire qu'un événement, naissauce ou mort, remonte à tant d'années avaut ou après l'éruplion du Conseguina. En présence d'une éruption aussi importante, nous croyons bien faire en donnant ici la traduclion intégrale de tous Jes documents relatant lo fait que nous avons pu nous procurer, et dont la plupart sont extraits des papiers officiels de l'époque. Quoiqu'un peu longos parfois, ces récils n’en présenlent pas moins un certain intérêt, car ils montrent dans leur naïveté mème combieu les manifestatious du phénomène volcanique furent violentes à des distances extrèmement considérables du point d'éruptiou, el combien l'impression qu’elles produisirent sur les esprits fut profonde. Nous aurous soin de présenter ces narrations successives dans un ordre déterminé, conmençant par les localités les plus voisines du volcall, pour nous éloigner progressivement du théàtre mème du phénontène; on pourra suivre ainsi les modifications introduites par l'éloignement dans les manifestations de l'éruption, tout en se rendant compte qu'elles ne varièrent pas d'une manière très-considérable, et que, jusqu’à de grandes distances,

Grande érnption de Consegunina, le 20 janvier 1835 . 
les populations furent persuadées que la montagne en feu était relativement dans leur voisinage.

EFFETS DE L'ÉRUPTION DU VOLCAN DE CONSEgUINa A LA UNION.

Premier rapport du lieutenant-colonel C. Munuel Romero, commandant le port de La Union'.

Le 20 conranl (janvier 1835), le lever du soleil ayant en lieu dans un ciel pur, comme à l'ordinairc, on apercul, à luit heures du matin, au sud-est de la ville, un épais nuage de forme pvramidale, accompagné d'un bruit sourd. Ce nuage s'éleva jusqu’à une hauteur telle, qu'il cachait te soleil, et de cette posilion, ì dis heures du matin, il se divisa pour gagner le nord et le sud. En même temps, des éclairs comnencèrent à s'y montrer, ct l'on entendil le tonuerre, comne cela se passe généralement en hiver². A onze luenres, la nuée s'étendaut sur le ciel tout rntier, la terre fut ensevelie dans les téuèbres les plus épourantables, lelles que l'on n'apercevait même pas les objets les plus roisins. Les benglements lugubres des animaux, l'elfiroi des oiseanx de toutes espèces, qui semblaient, dans lenr épouvante, venir chercher un refuge au milieu des houmes, la terreur dont les hommes eux-mêmes étaient pénétrés, les gémissements dont les feumes et les enfants reuplissaient l'air, l’incertitude dans laquelle on était plonegé sur les vésultats d’un pléenomèue aussi exceptionnel, tout troublait l'espril le plus énergique el lui fajsail redouter les plus terribles mallocurs, surtout quand, vers quatre heures du soir, commencìrent les tremblements de terre, qui, se répétant de nianière à devenir une ondulation conlinue du sol, imponentalent de force de monent en moment. Ensuite arriva une pluie de sable phosphorescent, qui contimua jusqu’à ce que, le mème jour, à hnit heures du soir, il commença à tomber une ponssière lourde et fine comme de la fleur de farine. Jes coups de tonnerre el les ćclairs, la fondre éclatant dans l'atıosphère, durèrent juş̧u'au 2s, el ce même jour, à trois lieures lunit mimules de l'auprèsmidi, il y cut un tremblement de lerre si forl et si prolongé, qu'il renversal plusieurs hommes marchant au milien d'une procession de pénitence. les ténèbres durèrent quarante-trois heures, ì tel point que, pendant tont ce temps, il fut indispensable, pour sortir, d'avoir des chandelles allnmées, qui ne suflisaient pas pour "qu'on pủt voir clairement ruelque chosẹ. Le 22, il y eut une légère éclaircie, mais sans (pu'on pût encore voir le soleil, et le 23 , au lever du jour, on entendit une snccession de coups de tonnerre éfrourantables, semblalıles aux décharges de pièces d'artillerie du plus fort cillibre; en mème lemps, la pluie dr: poussière avait notablement augumenté. Cette même jouruée du 23 , depuis le commencement du jour jusqu’à dix heures, on vit unc lumière opaque qui ne fit aul'e close que s'présenter les objets sons l'aspect le plus triste. Le sol de la ville, qui avait été de tout temps raboteux, à cause de l'aboudaure des pierreśsuril contient, étail devenu uni, gràce à l'énorme qnantité de poussière qui s’étail répundue dessus. Les hommes, les fummes et les cufants étaient défigurós, à tel point qu'on ne se recommaissait pas, el qu'ou ne pouvail se distingurer que par la voir el d'autres indices de mêne gente. Les maisons et les arbres, euveloppés d'un linceul de ponssière, clonnaient à la ville l'aspect le plus alliceux que l'on puisse imaginer; majs, quelque triste que fût ce paysaģe, il álail encore moins pénible à supporter que les ténèbres dans lescuclles nons fümes de nouvean engloutis comme les jours précédeuts, à parlir de dix lıeures du matiı. L’afliliction générale, qui araiı un peu diminué, reprit avec une nonvelle vigneur, et, quoiqu'il füt très-langereux de quitter la ville à canse des bêtes léroces quii avaient abandonné les forêtls el venaiont errer daus les chemins et les villages (ainsi que cela arriva à Conchagua, ct ici, oì les liggres entrèrent dans les rues), lis terreur fut plus forte, et bien des personnes émigrèreul à pied, abandonnant leurs loyers, qüils ne croyaient plus revoir, pensant que lont allail ètre létruit de fond en comble, el s'enfuirent dans les montagnes pour s'y mettre à l'abri. Le 24 , à trois heures et demie du matin, on aperecut la lune et quelques étoiles par-ci par-lia, comme entre des rideanx;

1 Boletin oficial del Esiado de Guatemella, $\mathrm{n}^{\circ} 75,15$ féTrier 1835, p. $6 g 8$.

'Prendre le mot hiver rans le sens qu'on lui dome or'-

dinairement dlans l'Amérique tropicale, c'est-à-dire comme saison des pluies correspondluut à notre été. 


\section{DANS LES RÉPUBLIQUES DE GUATEMALA ET DE SALVADOR. 33 J}

le jour fut clair, quoique l'on ne vìt pas le soleil el qu'il continuàt à pleuvoir de la poussière, qui a reconverl cette ville el ses environs d'une couche de cinq pouces d'épaisseur. Le 25 el le 26 , les choses se parssèrent comme le 24, mais avec des tremblements de lerre fréqueuts, quoique peu prolongés.

Le premier jour ( 20 janvier'), d'accord avec l'alcede constitucional de celle ville, nous avions décidé d'envover une commission pour recounaitre d'où ponvail provenic le phénomène. Elle partit en effet à neul heures du

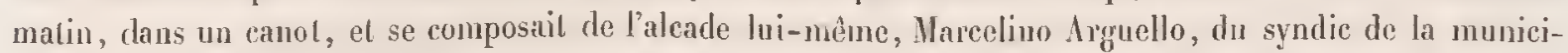
pallité el des ciloyens Vicente Romero el dnan Perry; ils arrivèrent jusqu'entre les iles, où l'ohseuritéles prit, et, sans pouvoir se rendre compte du lieu où l'éruption se produisail, ils furent obligés de revenir dans ce port, où ils n'arrivèrent qu'à six heures du soir, non saus avoir eu benucoup do peine à rentcer, tanl à canse de l'obs-

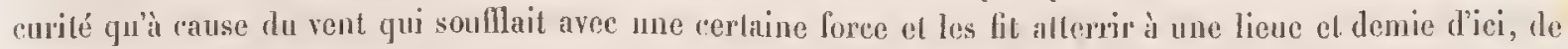
sorte qu'ils lurent olsligés d'achever le trajel par lorve. Des personnes dignes de foi, veinant de l'Islit del Tigre, qui se troure à huit lieues à l'est de notre ville, nous out appris que tontes ces perturbations étaient produites par le volean de Consegnini, silué sur la côte onest de l'ślat de Nicaragua, el qui fil explosion le 20 conrant à l'heure indiguée ci-dessus. Ces personnes ont été téuoins oculairess de l'évéucentent, el nous ont assuré que, dans l'Isla del Tigre, il tomba, le 21 , une pluie de pierres ponces, grosses comme des pois chiches (garbramzos), qui angmenta de façon quil linit palr lomber des pierres grosses comme des ouf's de poule. lilles nons ont dil atussi que les tremblements de terre y furent beancoup plus forts quici, el quon était presque asphyxić par la poussière, au point que le commundant de l'ile ef d'antres personnes, craignaní que l'île ne lût engloulie, s'embarqquèrent, el durent rester sur l'eau, ne sachant pas de quel còté se diriger.

Ici il y a beaucoup de fluxions de poitrine, de pleurésies, de calarrhes, de max de tête et de maux de gorge, probablenent à cause de la poussière; il y a des goens gravement malades, et hier une petile fille de sept ans mourut avec des symplòmes d'étouflement. Le bétail des environs périt, et cing téles ont succombé ici; on rencontre sur les chemins des quantilés d'oiseaux morts; il en est de même des oiseaux aqualiques, car les personnes venant de l'ỉsla del Tigrre nous ont assurć avoir rencontré plusieur's centaines de cadavres d'oiseaux de loutes espèces.

La poussière continua à tomber jusqu'au 27 .

La Union, 29 janvier 1835.

M. Ronero.

Deuxième rapport du lieutenant-colonel C. Hanuel Romero, commandunt le port de La Union.

Le 9 courant (lévrier 1835), il partit de ce port une comnission pour aller visiler le volcan de Conseguima, mais elle ne put examiner la còte sur toute sou élendne ni avee tout le soin désirable, à canse du nuage de fumée qui recouvrait encore la campagne. Le pilns quils purent parcourir fut environ une demiliene sur la demi-circonférence du cône. Une lorêt, qui semblait aussi ancienıe que le monde, a disparn. II s'rst formé denx îles dans la mer, une de 800 vares, et l'autre de 200 vares $^{2}$ dans leur plus grande dimension; elle sont composées de pierre ponce el de lerre renfermant du métal sous la forme d'innombrables paillettes couleur d'or, ayant un peu l'odeur du cuives ${ }^{3}$. Du côté du sud-est, il s'est formé dans la mer plusieurs bas-fonds de 500 ou 600 vares; sur l'un d'eux est un très-guros arbre renversé avec les racines en l'air el les branches enfoncées ${ }^{4}$. La petite rivière qui coulait au nord-ouest esl enlièrement desséchée, el à sa place il s'est formé un autre cours d'eau de 6 vares de largeur ${ }^{5}$.

1 Boletin oficial del Estudo de Guatcmula, $\mathrm{n}^{\circ} 79$, seconde partie, p. 733,14 mars 1835 .

"Lo vare vaul $0^{\mathrm{m}}, 838$.

"Ce prétendo uélal devait élre plus que probabtement lu unica.
"Inulile de dire que tont cela a disparu sons l'action des llots, ainsi que les îles de pierre ponce, dont it ne reste plus trace.

${ }^{5}$ Serail-ce la rivière dont il est fait mention page 339? 
Du village d'li Viejo, on a fait une autre reconnaissance, et on a constaté que les laciendas cle Sapasmapa et de Conseģuina, situées dans les environs du volcan, avaient disparu. De la première, il n’a pas échappé nne seule tête do bélail; dans la seconde, on a relrouvé encore environ 300 boufs, mais si maigures et si malades, quilils vout probablement périr. La funantité de cadavres de toutes espèces de quádrupèdes et d'oiseaux que l'on rencontre autour du volcan est réellement effrayante. Un batean qui se Irouvait avee son équiparge en vue de la còte, le 20 janvier, a sans doute péri, car on n’en a aucune nourelle.

Dans la ville de Léon, l'épouvante a élé unoindıe, car l'obscurilé, ainsi que la pluie de poussière n’ont pas été aussi fortes que dans nolre ville (La Union). Ccla résulte du dire de personnes dimnes de foi; on assure aussi que les détonations ont élé entendues jusqu'au Costa-líea, où l'on pensait que l'oriģine en étail trèsroisine. Lá groëlette colombienne Boladore, "qui parlit d'Acapulco avant le 20 janvier, à destination de Realejo, resseutit, à vingt lieues des còles, une profonde obscurité, et une pluie de poussière tellement épaisse, que l'équipage pensa en être suffoquć. On eut à travailler pendant quarante-huit heures pour en débarrassel" le navire. La goëlette ne put entrer ì Realejo à cause de l'obscurité, et s'en fut à Punta Arenas, emportant la conviction que tout le Nicaragua avait disparu.

Le volcan conlinue à vomir du leu et de la fuméc, causant de temps en temps de petits tremblements de terre.

La Union, 15 février 1835.

M. Romero.

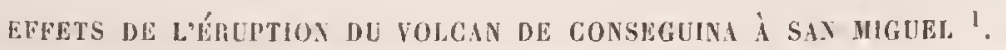

......H. Savage élait ce jour-là ( 2o janvier 1835 ) près du volcan de San Miguel, à 120 milles de distance (du volcan de Conseguina), surveillant sou bétail. A huit heures, il vit un épais nuage s'élevant au sud avec une lorme pyramidale, et entendit un bruit semblable au battement des flots de la mer. Bientôt après, ces épais nuages furent éclairés par des taches brillintes, colorées en rose, déchiquetées, éclatant tout à coup puis disparaissant, et il les altribua ì quelque phémonène électrique. Hais cos applarences s'accrurent avec une telle rapidité, que ses hommes conmencèrent ì s'en épouvanter, disant que éétait une ruine complète, et que la fiu du monde devail être proche. Bientồt après, il ful convaincu, de son côté, que ce devait être l'éruption d'un volcau, ch, comme, à cetle éporpue-da, le Conseguina était une montagne parfaitement calme, à laquelle on ue soupconnait aucune relalion arec le feu sonterrain, il supposa que cela provenait du volcan de l'Isla del Tigre. Il retourna à la ville de San Yiguel, el, en chemin, il ressentit trois violentes seconsses de tremblement de terre, pendant le temps qu'il mit ì parcourir un espace de trois cuadras (6oo mètres). Les habilants étaieut fous de terreur, des oiseaux volaient dans les rues suns saroir où ils allaient, et, aveuglés par la poussière, ils tombaient morls suy le sol. $\Lambda$ quatre lıeures, il faisait si sombıe que, comme disait M. S. il lentiit sa main devant ses yeux et ne pouvait la voir. Personne ne sortait saus une chandelle allumée, ce qui produisail une lumière tronble qui n'éclairait qu'un espace de quelques pieds. A ce moment, l'église était pleine el ne pouvail contenir la moitié de la loule qui cherchait à y pénétrer. Limage de la Vierge liut amenée sur la place el promenée dans les rues, suivie par les habilanls portant des chandelles et des torches, formant une procession de pénitence, criant au Seigneur pour inploter le pardon de leurs péchís. Les cloclies somnaient, el, pendant la procession, il y eut nn autre tremblement de terre, si long el si violent, qu'il renversa par terre bien des personnes qui laisaient partie de la procession. L'obscurité conlimua jusqu'à onze heures le lendemain, puis on commença à voir le soleil, mais vague, trouble et sans brillant. La ponssière, sur le sol, avait quatre pouces d'épaisseur' les branclies des arbres se brisaient sous le poids, el les giens élaient tellement défigurés, qu'ils ne pouvaient se reconnaître.

Extrail de l'ouvrage de M. John L. Stephens. - Incidents of travels in central America, Chiapas, Yucutun, elc. vol. 11, 1. 37 el suir. 
A ce moment, M. S. partil pour aller à son hacienda de Sonsonale. Il dormil au premier village (Moncagua), el à deux ou trois heures du matin il ful réveillé en sursaut par une explosion semblable au coup de tonnerre le plus épouvantable ou à la décharge d'une centaine de canons. Celle explosion fut accompagnér d’un tremblement de lerre si violent, que II. S. fut précipité hors de son hamac.

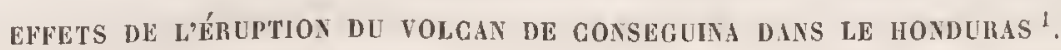

Dans toute cette partie du pays (inlérieur. du Honduras) et mêmo à Tegucigalpa, silué à bien des lienes dans l'intérieur el à plusieurs milliers de pieds au-dessus du niveau de la mer, les monlagnes trenblèrent jusque dans lenrs fondements, malgré la dislance considérable qui les séparail du volcan. On ressentil des secousses de tremblement de terre, el bien des personnes devinrent tout à coup malades, tandis que des cendres fines remplissaient l'air au point d'obscurcir partiellement le soleil, el que l'on entendait au loin des décharges et des explosions annonçant quelque terrible éruplion de l'un des volcans qui s'élendent sur la côle du P'acifique. Nombre de persomnes pensaient que le jour du jugement dernier élail arrivé. Néamoins, las secousses de tremblement de terre ne furent pas ressenties dans les lauls pays du Honduras avec aulanl de violence que dans d'autres prays de l'Amérique centrale. Lorsque je passai les montagnes, quelques mois aupararaul, on me montra l'endroil où mne rivière, descendant à la baie de Fonseta, coulait jadis au milieu d'une région fertile; maintenant, el toujours depuis l'éruption, la rivière est desséchée el le pajs désolé, grâce aux épaisses conches de cendres romies par le cratère..

Le señor Losano me raconla que, pendant trois jours, l'air ful rempli d'une poussière impalpable, pénétranl ì travers loules les fentes ou les fissures des maisons, el prodnisant une sensation de suffocation. Pendant les jonruées des 20.21 et 22 janvier 1835 , l'obscurité enveloppa tout l'intérieur du Honduras, à partir de Irois henres de l'après-midi. Une personne placée an unilien d'une clambre pouvail à peine dislinguer des lumières placées sur des fables aur deux extrémités. On dut s'éclairer pour prendre les repas. Les oiseaux, effrayés par celte profonde obscurité, volelaient éponvantés dans les villes, venaicnt se frapper contre les maisons el tombaient morts devant les portes. Dans les villages, des chevreuils el d'autres animaux saurages se réfugiaient jusque dans les labilations. La plus grande consternation régnait dans toure la population.

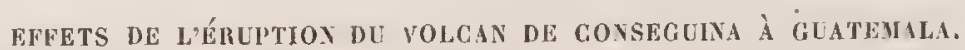

Observations météorologriques failes dans la ville de Guatemala, du 20 an 28 jancier $1835^{2}$.

20 janvier. - En ce jour, vers l'après-midi, l'atmosphère semblail chargée le vapeurs, comme s'il eut dù pleuroir peu de tempss après, à tel poiut que cet état du ciel allira notre allention. Le vent avail sonfllé du sud, puis passé anr nord.

21. - Lu lever du jour, l'horizon étail couvert d'une sorte d'ombre qui affaiblissait les rayons du soleil. Jusqu' ì dix heures du malin, on pouvait regarder fixement cet astre à la simple vue. Cette ombre ne pourail se confondre avec un bronillart qui est blanchâtre el se ment dans la mème direclion que le vent, tandis quelle étail noire el tombait perperdiculairement sur la lerre. On ne larda pas à s'apercevoir qu'il tombait du lıaul du ciel ure ponssière fine qui recouvrail les toils el les lerrasses. Les blanchisseuses observèrent aussi que te linge étendu au solcil devenail tout sale. Cela excila la curiosité, et l'on recueillit, pour l'analyser, de celle poussière, qui se trouva contenir du soufre el du sel ammoniac3. La nuit qui suịit fut tónélıreuse. quoiquel'on vit briller de ci et de là quelques étoiles. Les persomes qui sorlirent de leurs maisons pour observer'

1 Extrail de louvrage de II. W. V. Wells. Explorations and Adentures in Ilonduras, etc., p. 230 et suiv.

${ }_{2}^{2}$ Bolelin oficial, elc. $n^{\circ} 7^{3}, \Omega^{\circ}$ partie (a janvier 1835 ).

Vovage géologique. p. 656 et suiv. $-n^{\circ} 75$ ( 15 février), p. 697 el suivantes.

${ }^{3}$ Cette observation serail extrêmement intér'cssante, si l'on pouvail y ajouter foi d'une manière alssolue. 
l'état du ciel resșentirent de vives démangeaisons dans les yeux. Des dames eurent grand'peine à débarrasser leur chevelure de la poussière qui s'y était accumulée. Tous les habitants de la ville se demandaient quelle pouvait être la cause d'un pareil phéuonnène, n'ayant entendı parler de l'éruption d'ancun volean dans un rayon de 30 à 40 lieues. It y en eul mème qui l'attribuèrent à la queue d'une comète qui doit devenir visiblo in mois d'août prochain, suivant ce qu'amoncent les ástronomes.

22. - L'opacilé de l'atmosphrère lút moins intense; la lumière dı soleil étail jaunâlre, la couleur des nuagges livide, passant par points au rouge; quelques-uns semblaient se détacher sur un fond de cette nuance. Lopinion générale était que ces phénomènes devaient étre attrilıés au vólean d'Tzalco, dont on sait que les éruptions sont incessautes, les flammes terribles et les détonations si épouvantables, qu'elles semblent menacer la nature entìre d'une destruetion complète. Ce volean est situé à 55 lieues de notre ville, dans la direction de l'est, el, coimme plusieurs chaines do montagnes s'élèvent entre lui et nous, il semble extraordinaire que l'on puisse voir arriver jusqu’ici la terre embrasée vomie de son sein, et les matières légères qui, gràce à leur ténnité, ne devraient pas pouroir résister à l'impulsion des vents de sud el de nord, les senls qui rìgronent dans ce pays ell cette saison.

23. - A ume heure du matin, la consternation des populations du voisinage arriva à sou comble. Les explosions paraissaient devoir détruire la terre; etles ressemblaient à des décharges lépétérs de grosse arlillarie, el, dans les intervalles, à des conps de fusil; quelquelois aussi on eût dit une tempête éloignée qui s'approrhait progressivenent et se répercutait par les éclos de la montagne. Les persomes les plus lraves sortirent

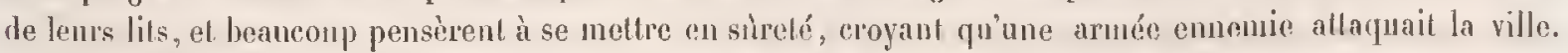
Les troupes des dillérentes casernes se nuirent sons les armes. Les oscillations des édilices donnaient à penser ‘u'un tremblenent de terre si terrible allinil nons ensevelir sous les ruines de la ville on entr'unrir la terre sous nos pieds pour nous eugloulir. Nous avons lu des descriptions d'éruptions du Vésuve et d'autres volcans, mais nous ne savons pas qu'à une dislance de 55 lienes ${ }^{1}$ ancune ait jamais produit d'anssi épouvantables effels d'incendie et de destruction universelle.

9/1. - Le jour eommence couverl d'oubres et de cendres. Des personnes arrivant par te chennin du Salvador nous ont assuré que, depnis te villagre d'Aluachapam, distant de notre ville de h/4 lieues, et de g ou 10 d'lzalco, elles ont ressenti une phice de cendres et de poussière telle, que les arbres, les maisons el la campagrne en élaient entièrement recouverts. On nous écrit lá même close de Gualan, situé à une soixantaine de lienes nn nord d'Izalco; nais nous manquons de nouvelles d'Izalco mème et de Sonsonate, ce qui nous cause nue grande tristesse. On vient d'apprendre, par des voyageurs, que dans la vallée de Las Casillas la quanlité de crndres qui recourre le sol est extraordinaile. Ces mêmes personnes supposaient que l'éruption provenait de la monlague de Jnmaytepeque, située à 20 lieues au sud-est de cette capilale. Le gouvernement a envoyé un courrier pour savoir si celte nonvelle est véridique.

On n'il plus entendu ancun bmit d'explosion.

35. - Liapparence de l’almosphère continue à être ce qu'elle était le jour précédent.

26. - Idem.

27. - Cette journée a été plus obscure et plus chargée de cendres. Nous avons des nouvelles, mais pas oflicielles, d'après lesquelles il paraittrait que le volcan qui cause tous ces malheurs est situé à 18 licues de la ville de San Salvarlor, distante elle-mène de 70 lieues de notre capitale. Les effets de l'éruption se font sentir à plus de 40 lienes ì l'ouest et au sud de celte ville, de sorte que si, comme tous tes renseignements nous le donnent ì croire, c'est le volcan de San Vicente qui est en éruption, on la ressent à plus de 120 lienes. Les nourelles qui nous arrivent sont eflrayautes; afin de ne pas nous tromper, nous attendrons, pour les publier, de les aroir ofliciellement; on nous assure que la ville de San Vicente et ses environs sont en ruine.

Depuis le 28 , lahmosphère continua à ètre jlus ou moins chargée, jusıłu’au $3{ }_{1}$; mais, ce jour-là, le soleil

' On croyait encore à ce moment-là qu'il s'agissait d'une éruption du volean d'izalco; mais. en réalité, la distance était encore beaucoup plus considérable. 
DANS LES RÉPUBLIQUES DE GUATEMALA ET DE SALVADOR.

se leva dans un ciel parfaitement clair; on entendit cependant dix on douze retumbos (délonations souterraines), dont quelqques-uns furent très-forts.

On a reçu des nouvelles de San Salvador et de Sau Viceute; toutes sont d'accord pour dire quo l'obscurilé et les détonalions ont été épouvantables, et se sont produites aux ınêmes heures qu'ici, mais sans qu'ou sacho d'où elles proviennent. Les uus parlaient du volcan de San Vicente, les autres de lỉle d'Espiritu Sauto, située près de la terre, entre Zacatecoluca el Usulutan; d'autres enfin, de l'Isla del Tigre, qui séélève an milieu de la baie de Fonseca.

Des informations, données par les chef's départementaux de Zacatepeque, el des lettres particulières des villagres de la côte, nous appremuent que les cendres sont tombées et que les détonations ont été entendues jusqu'ì Tofonikapan et à Chiantla, soit à 52 lieues de cetle ville. Partont on s'inaginat être dans le voisinage du formidable volcan qui faisail ainsi trembler le sol, voilait la face des astres, el recouviait la terre d'une concle de cendres.

Le retard du courrier des autres États de l'Amérique centrale, qui devait arriver ici le 3, el ne l'a fail que le 6 dans l'après-midi, a donné lieu à de bien tristes conjectures. Les passager's, arrivés le $/$ au porl d'Istapa, assurent qne l'océan Pacifique est couvert de cendres; nous pensons que cela doit ètre de la pierre poutre ré́duite en pondre. Tout semblail faire croire à la combustion d'un terriloire trìs-étendu. Le courrier nous a enfiı apporté des nouvelles circonstanciées el certaines.

LFFETS DF L'ÉRUPTION DU VOLCAN DE CONSEgUINA DANS LE CHIAPAS ET LE PETEN ${ }^{1}$.

Lettre d'un officier revenant du Chinusus au secrétuive général du gowvernement suprểue de la république.

Depuis te 23 jusqu'au 29 du mois passé (janvier), on a observé dans cette ville (San Marcos), que l'almosphère fut obscure, couverte de cendres et pleine de fumée. Le $2 /$, en particulier, la pluie de cendres lut iucroyalole, au point de recourrir tous les toils des unaisous d'une couche grise, et, depuis la soirée jusqu à neuf heures du matin, on enteutlit des détonations répétées qui mirent laalarme dans plusieurs villages, où l'on pensait que c’était le volean de Quezaltenango qui était en éruption. Cela fit que plusieứrs négociants qui se trouvaient à des distances considérables de Quezaltenango y retournìrent pour prendre soin de leurs familles. Inans le Soconnsco on a éprouvé les mômes elfẹts, comme ou peut le voir dans la note que j’envoir au gouremement suprême, et dont l'original arcompagne cette leltre ${ }^{2}$. Il en a ćté de mème à Socoltenango : ainsi qu'on l'a appris par divers babitants de cette ville qui sont arrivés ici, et il est probable qu'ou a ressenti ces pliénomènes jusqu’à Tonaja, quoique nous n’en ayons pas eu la nouvelle certaine.

Dios, Union, Libertad.

San Marcos, 13 février 1835 .

1. Rods.

Des lettres d'Izabal, du 20 février dernier, rapportant des nouvelles reçues de Belize, nous apprenuent que les pluies de cendres et les détonations ont été observées jusque dans l'iłe de la Jamaïque, ainsi que su. la còte de Nlérida au Yucatau. Nous arons des nouvelles officielles racoutant le plúnomène, de San Harcos. capitale du département de Quezaltenango, et de Tapachula, daus le Soconusco.

Nous u'avous pu encore fixer l'élendue de l'espace sur lequel les pluies de cendres sont tombées el où l'ou a entendu les détoualions. Nous alrous essayé d'en calculer le rayon cu prenant le volean de Conseguina comme centre, el il atteint d'uu còté une longueur de 325 lieues jusqu'à Ciudad-Real de Chiapas, d'un aulıce, 322.

\footnotetext{
' Boletin oficial del Estado de Guntemala, seconde partie, $\mathrm{n}^{\circ} 78(7$ mars 1835$), \mathrm{p} \cdot 7_{2} 6$ et suiv.

${ }^{2}$ Nous n'avons malheureusement pas pu retrouver ce

document, qui, probablement, n'aura pas ćlé publié daus le Boletin oficial.
} 
jusque dans le Peten. Mais, dans ces deux localités, les détonations ont été tellement violentes, que l'on doit avoir pu les entendre à des distances beaucoup jolıs considérables.

Les documents originaux que nous venons de reproduire, en les traduisant, sont trop éloquents par eux-mèmes pour que nous croyons devoir y ajoules quelque chose. Disons pourtant que les effets de l'éruption se firent sentir dans un rayon bien plus considérable que 325 lieues, puisque, à la Jamaïque, on vit tomber des cendres el l'on entendit des détonations qui furent prises pour les coups de canon d'un navire en détresse. Ces mêmes explosions furent percues jusqu’ì Bogota, qui est encore plus éloigné, et les pluies de cendres s'étendirent en mer sur un espace de plus de 2,00o kilomètres, de l'est à l'ouest. L'éruption du volcan de Conseguina est donc une des plus lerribles que l'on comnaisse, non seulement dans l'Amérique centrale, mais mème dans le monde entier, et elle mérite d'ètre étudiée avec tous les détails que nous y a vons mis. 


\title{
GIIAPITRE II.
}

\author{
ÉTUDE DÉTAILLÉE DES VOLCANS ET DES PHÉNOMÈNES VOLCANIQQUES \\ DU SIIVADOR FT DU GUATEMALA.
}

Isla del Tigre. - Volcan de Conchagua. - Volcan de San Miguel. — Infiernillos de Chinameca (voleans de Chinameca et de Tecapa.) - Volean de San Vicente (infiernillos). - Volcan de Cojulepeque. - Volcans de San Salvador el de Quesaltepeque. - La Hoya. - Volcan d'Izalco. - Volcan de Santa Anna (Laguna de Cualepec). - Ausoles d'Alıuachapam. - Volcan de Chingo. - Volcans du département de Chiquimula. - Voleans de Cerro Redondo. - Volcan de Pacaya (lac de la Caldera). - Volcan d'Agua. - Volcan de Fuegro (groupe du volcan d'Acatenango). - Volcan d'Atitlan. - Volcan de San Pedro. - Volcans de Quezaltenango (volcan de Santa Maria; Cerro Quemado; petit còne éleint). - Volcan de Tajomulco. - Volcan de Tacana. — Volcan d'Istak.

Nous allons entreprendre maintenant l'étude des volcans et des phénomènes volcaniques du Salvador el dı Guatemala, répartis suivant une ligne dont la direction moyenne est de l'est 3 o deơrés sud à l'ouest 3 o degrés nord, et formant en quelque sorte le deuxième groupe du système volcanique de l'Amérique centrale. Outre les volcans actifs proprement dits, nous aurons à considérer des phénomènes singuliers, nommés dans le pays infiernillos et ausoles, consistant en déğägements de vapeurs acides d'une grande intensité, établis au pied des montagnes volcaniques dont les cratères ne présentent plus aucun symptôme d'action éruptive. Nous y trouverons des manifestations remarquables de la puissance volcanique, dont l'examen approfondi pourra aider à chercher la solution de certains problèmes encore obscurs, et servira de lien nalurel entre des fiits considérés comme appartenant à des ordres d'idées tout à fail différents.

Nous avous fait l'ascension de tous les volcans actifs ou même éteints, qui présentent un intérêt scientilique particulier; nous en avons délerminé la lıauteur audessus du niveau de la mer au moyen du baromètre; nous avons levé le plan de leurs cratères, ainsi que des groupes de monlagnes remarquables à un titre quel-

Recherelues faites sur les volcuns du Salvador et du Guatemaln. conque; nous avons collectionné des échantillons de roches; nous avons examiné 
sur place, relalivement à teur lempérature el à leur composition, des dégagements de gaz, dont nous avons aussi recueilli une certaine quantilé dans des lubes de verre où le vide avait été fail préalablement, de manière à pouvoir les analyser à notre retour; el nous osons espérer que l'ensemble de ces éléments nous metlra à mème de présenter, sur le système des volcans du Salvador et du Gualemala, une étude qui ne sera pas dénuée de toute valeur. Sans vouloir domner ì nos recherches plus de sig̣nification qu'elles n'en peuvent avoir, nous sommes néanmoins en droil de dire que nous avons été les premiers à examiner scienlifiquement bien des choses, les premiers mème à atteindre le sommet de cerlains volcans dont la cime n'avail encore jamais été foulée par te pied de l'homme, et que nos travaux emprunteront peut-être à ce fait une cerlaine saveur de nouveaulé el d'originalité qui ne sera pas leur moindre titre à l'estime des personnes spéciales. Nous ne nous bornerons pas, d'ailleurs, à présenter les résultals de nos propres études, lorsqu'un phénomène aura élé examiné avant nous par d'autres royageurs; nous nous empresserons, au contraire, de recueillir tes reuseignemeuts donnés dans leurs ouvrages, de manière à pouvoir établir des comparaisons aussi intéressantes que précieuses entre l'état d'activité d'une manifestation volcanique à plusieurs années de distance.

Regardant comme suffisantes les considérations générales qui ont été amplement développées au commencement de ce livre et trouvant inutile de répéter le sommaire qui est en tête de ce chapitre, nous allons entrer immédiatement au cœur de notre sujel, en étudiant successivement, avec tous les délails qu’ils comportent, les différents phénomènes volcaniques dont nous avons à nous occuper.

ISLA DEL TIGRE.

Nous avons décril avec assez de soin les îles de la baie de Fonseca (page 181) pour ne pas avoir besoin d'y revenir avec beaucoup de détails; mais nous devons cependant insister sur cerlaines parlicularilés de la plus remarquable d'entre elles, l'Isla del Tigre. Nous avons vu que les roches dont sont composées presque toules ces îles sont des espèces de trapps basaltiqnes mal définis, ressemblant parfois plus ou moins à des laves, et qu'elles forment des inassifs presque toujours irréógulièrement circulaires, tendant à affecter l'apparence de 
DANS LES RÉPUBLIQUES DE GUATEMALA ET DE SALVADOR. 343 cònes puissamment altérés par des aclions postérieures. Ces caractères, qui peuvent appuyer l'hypothèse de l'origine volcanique de ces montagnes, sont surtout accusés avec une nelleté remarquable dans le massif de l'Isla del Tiggre, pour laquelle les présoniptions deviennent beaucoup plus fortes encore, sins que cependant il puisse y avoir certitude absolue. Car, en l'absence de phémomènes actuels ou ayant eu lieu dans la période historique, on ne peut se laisser guider que par des observations de forme et de composition, dont la nature est lelle qu'elles fournissent des indicalions plutòt vaggues que précises.

Jous pensons cependant que l'Isla del Tigre est un volcan, mais un volcan extrèmentent ancien, éteint depuis une séric de siècles incalculable, el dont l'origine remonte peul-ètre à la prenière apparition des phénomènes volcaniques dans l'Anérique centrale, c'est-ì-dire à une période un peu antérieure à l'époque geéologique actuclle. En admettant une semblable antiquilé, on comprendra que, nonseulement la forme exlérieure ait pu subir des modificalions assez considérables pour la rendre presque méconnaissable, mais encore que la composition elle-mème, r'ésullant de phénomènes éruplifs primordiaux dont nous ne pouvons guère deviner la nature, puisse présenter des caractères qui la distinguent profondément des produits actuels des manifestations volcaniques modermes. L'Isla del Tiggre est. de tout le gronpe, celle qui présente la forme circulaire la mieux définie et l'aspect conique le plus caractérisé; vue de la mer, du côté du nord, elle offre l'apparence d'un còne presque parfail, qui s'élève progressivement depuis le niveau de la baie de Fonseca jusqu'à la hauteur de 800 mètres, par des courbes élégantes, dont l'inclinaison, presque nulle d'abord, devient peu à peu très-considérable. L'espace annulaire, à peu près liorizontal, qui s'ćtend autour de la montagne proprement dite, n'a pas partout la mème largeur; ses dimensions sont trèsfaibles du côlé du sud, où les pentes, assez fortes encore, viennent tomber direclement dans la mer arec des particularités dont nous aurons à parler toul à l'heure; à l'ouest, il est accidenté d'un certain nombre de mamelons qui se raccordent an còne el lui servent en quelque sorte de contre-forts; au nord, il est déjà assez vaste pour que la petite ville d'Amapala ail pu ètre construite en un point où un rentrant de la cóte combiné avec une profondeur considérable des caux a permis l'élal)lissement d'un port assez bien abrité, qui pourrait, dans l'avenir, acquérir

L'Isla del Tigre

ust

un voletn lès-ancien. Dispusition
lopographigne
al
constitution
géologique dle l'ite. 
une cerlaine imporlance; à l'est enfin, il prend son plus grand développernenl, un kilomètre environ, et se couvre de champs cultivés qui alimentent les liabitants d'Amapala. Les roches que l'on apercoit dims cel espace horizonlal sont des masses basaltoïles noires, peut-être des laves, qui sont surlout abondantes dans la direction du nord-ouest, où elles constituent de petites falaises abruptes batlues par les vağues, et forment même une assez longue pointe qui s'avance dans la mer; cette pointe semble être le prolongement d'une espèce de coulée, raccordée progressivement avec les mamelons qui accidentent la côte ì l'ouest. Dans ce point, en particulier, la roclıe noire, compacte en profondeur, est recouverte, à sa surface, de blocs anguleıx, décliquetés, celluleux el conıme scorifiés. Les premières pentes, dont l'inclinaison augmente à mesure que l'ou s'élève, sont composées d'amas sableux et argilo-terreux, entremêlés d'une grande quantité de blocs de la roche basallique brune ou noire plus ou moins scorifiée; elles sont recouverles de forêts épaisses, où les troncs des ogrands arbres sont en quelque sorte noyés dans un fourré touffu et épineux. Il r'existe aucun sentier dans ce laillis, où l'on est obligé de se frayer un chemin à coups de sabre; aussi l'ascension est-elle beancoup plus pénible qu'on ne pourrait le croire, lorsquill s'agyil d'une petite montagne de 800 mètres de hauleur.

Iscensiun au olcan de Hisa del Tigre.

\footnotetext{
fla sommel an lieu d'un crative, on trouve 1111

immense ravin
} lirigné rers le sud.
C'est le 3 avril 1866 que nons fimes cetle ascension, au noment de l'année où la chateur est la plus considérable, et nous devons avouer que, la température aidant, nous étions épuisés en approchant du sommet; une lulle conlinuelle contre les branches d'arbre qui nous barraient le chemin, les arbrisseaux épineux qui nous déchiraient la figure et les mains, les blocs roulants qui fuyaicnt sous nos pieds sur une pente dont l'inclinaison finit par alteindre jusqu’à 35 degrés dans les régions supérieures du volcan, constituaient une somme d'olstacles qui ne doit pas ètre passée sous silence. Toute la partie terminale du cône, sur une hauteur d'une cenlaine de mètres environ, est dépourvue de végétalion forestière, mais garnie d'une herbe glissante qui croît entre les accumulations de scories rougeâtres, dont la proportion devient de plus en plus considérable el les dimensions de plus en plus fines à mesure que l'on s'élève. En arrivant au sommel de la montagne, nous nous attendions à y trouver les rudiments d'un cralère plus on moins oblitéré; mais quelle ne fut pas notre surprise en. nous 
DANS LES RÉPUBLIQUES DE GUATEMALA ET DE SALVADOR. 345 apercevant qu'une inmense déchirure existait sur tout le flanc sud de l'ỉle, semblable à un gigantesque ravin descendaut de la pointe extrême jusqu'ì la base, pénélrant à une profondeur considérable dans la masse du volcan el altérant, jusqu’à un cerlain point, la régularilé de sa forme conique. Cette déchirure, dont le bord projeté sur un plan liorizontal eût donné le tracé d'une ellipse assez. allongée, s'ouvrait brusquement aux environs du sommel par des parois ahruptes d'environ 200 mètres de hauleur, dont les pentes s'adoucissaient progressivement à mesure que la hauleur diminuait, pour' se raccorder enfin arec la crête limilant l'ouverture. Le fond, rempli par d'épaisses forêts, semblail domner naissance ì un ravin déchiré, assez fortement incliıé, gagonant les régions basses de l'ile par une coupure dans le bord inférieur de l'ellipse el parcouru par un torrent alimenté, pendant la saison des pluies, par les eaux tombées dans tout l'espace de ce gouffre. Quelque étrange que soil une semblable conformation, il ious semble que l'on peut, jusqu'à un certaiı point, se l'expliquer, en supposant qu'il y ait eu autrefois, vers le sommet de l'Iș̣a del Tigre, un cratère latéral, de dimensions plus ou moins considérables, dont le bord dessinait déjà une ellipse sur la surface conique de la monlagne. Une fois ce cratère éteint, on concoit aisément que les parois inférieures, du côté de la base du volcan, aient été facilement détruiles par les eaux ou par tonte autre canse, puisqne, élant les plus basses et les moins épaisses, elles étaient aussi les moins résistantes. Les choses élant dans cel élal, les eaus pluviales ont lù naturellement s'épancher par la brèche ainsi ouverte; une circulation régulière s'est peu à peu établie el, d'érosions en érosions, on est progressiventent arrivé à un étal de choses tel que celui qu'on voil anjourd'hui, c'est-àdire à une immense déchirure en forme de gouffre, dont le fond est transformé en ravin conduisant jusqu'à la mer les eaux déversées sur la cime par les orages de la saison des pluies. Si celle explication est véritable, il s'ensuil natureltement que la montagne de l'Isla del Tigre possédait autrefois un cralìre hien défini, et que l'on ne peut mettre en doute qu'elle ne soit un volcan éteint.

\section{VOLGAY DE CONGIIAGA.}

La première sommité volcanique que l'on rencontre sur la terre ferme est le massif des Cerros de Conchagoua, qui domine immédiatement la ville de La Union, 
et dont la base recouvre un vaste espace de terrain formant un promontoire avancé dans la mer. Il existe une liaison intime entre cette monlagne et les iles de la baie de Fonseca, aussi bien au point de vue de la posilion géographique qu'en ce qui concerne tes roches dont elles sont composées; anssi pourrions-nous répéter ici une grande partie de ce que nous avons dil à propos de l'Isla del Tigre, et insister en particulier sur ce que le volcan de Conchagua ne présente que des caractères assez vagues de forme, ainsi que de conslitution, el n'est, dans tous les cas, qu'un volcan éleint depuis extrèmement longtemps.

Quoique nous ayons déjà décrit les Cerros de Conchagua avec quelques détails (page 183), nous devons revenir sur cerlaines particularités qui intéressent plus directement le sujet dont nous nous occupons, et qui ont trait plus spécialement aux phénomènes volcaniques. C'est de La Union que nous avons fail l'ascension du volcan de Conchagua, le $1^{\text {er }}$ avril 1866 , par un senlier assez bien l'rayé el qui est tracé de manière à permettre aux chevaux d'atteindre le sommet de la montagne. Vu de La Union, au bord de la mer, le volcan de Concliagua ne présente pas la forme conique caractériséc que l'on peut lui reconnailtre du largoe, lorsqu'on pénètre daus la baie de Fonseca; c'est qu'on se trouve alors sur le flanc du unassif qui s'allonge dans l'intérieur des terres et qu'on en saisit beaucoup trop une des dimensions par rapport à l'autre. Le groupe se compose en effet d’un pie presque régulièrement conique (c'est celui qu'on apercoit de la mer), soudé sur le flanc d'une autre montagne beaucoup plus large el plus massive, qui s'avance au loin ver's le nord-ouest en s'appuyant sur une série de contre-forts élagés. Il faut ajouler que, de La Union, les pentes ne s'élèvent pas du tout d'une manière régulière; elles sont faibles juscu'au village indien de Conchagua, puis, lout à coup, très-accusées jusqu'au sớmmet, ce qui détruit, en partie, l'appàrence conique de la monlagne, et ne la fait pas ressembler beaucoup, quaut à la lorme, à un vérilable volcan. Les pentes sont, au contraire, partout très-abruptes du côlé de la mer, vers le sud el le sud-ouest, de sorle que, vus de cetle direction, les Cerros de Conchagua gagnent beancoup en majesté et en caractère.

Jusqu'au ravin qui sépare les deux sommités principales du Cerro de Conchagoua, le Cerro de la Bandera (1,1 70 mètres) et le Cerro del Ocote (1,236 mètres), le chemin longe, en s'élevant peu à peu, le flanc du massif, à travers des séries 
DANS LES RÉPUBLIQUES DE GUATEMALA ET DE SALVADOR. 347 de contre-forts et de barrancas, recouverts d'une vigourèuse végétalion alimentée par les sources qui y coulent de tous côlés, pendant les mois qui suivent immédiatement la saison des pluies. Mais, à l'époque où nous avons visité ces lieux, unc senle source donnail encore une quantilé d'eau appréciable, et clle s'épanchail d'une masse de tuf volcanique jaunàtre, assez compacle, située à 900 mètres environ d'altilude, sur te flanc du Cerro del Ocote, et correspondant probableunent ì une fissure, remplic postérieuremen! de matériaux meubles, communiquant, dans l'intérieur de la montagne, aux régions supérieures du massif. Les Indiens de Conchagua s'occupent de capler celte source el de la conduire, par des tuyanx creusés dans des trones d'arbres, à leur village distant de 3 on 4 kilomc̀tres à vol d'oiseau. Quoique la roche soit probablement toujours un trapp basaltique mal défini, on ne la voil que rarement en place, car elle est presque toujours masquée, ou bien par des argiles jaunes, ou bien par des sables noiràtres mêlés de blocs roulés ou scoriacés plus ou moins vohminineux. Quelques centaines de urètres avant d'arriver au fond de ce ravin, ou plus exactement au col qui joint les deıx parties de la monlagne, on voit la végélation cesser complétemenl sur le Cerro de la Bandera qui s'élève, au sud, jusqu'ì cnviron 200 mètres au-dessus du point où l'on se trouve, avec des penles assez fortement accusées pour que l'on soit obligé d'abandonner les chevanx el de continuer à gravir à pied arec une certaine difficulté. Le sommel du pic est, en effet, entièrement couposé de scories brunes, rouggâtres, plus ou moins légères al bullcuses, en morceaux de la grossenr du poinğ en moyenne, mêtées de bloes plus volumineux de roche basaltoïde semblint surfondue ì la surface el de sables provenant de la triluration des scories. Quand on atleint la cime du Cerro de La Bandẹa, ¿̀ 1,170 mètres au-dessus du niveau de la mer, on est élonné de n’y voir aucune trace de cratìre et de se trouver sur une petile plate-fornı assez étroile, formant la pointe de la montağne, dout les pentes descendent, au nord, jusqu'à l'arête qui relie fes deux membres du système, et, au sud, jusqu'ì la mer avec unc forte inclimaison, accidentéc de quelques vastes ravins arrondis, quoique profondénent entaillés. Celle absence de cratère est singonlière sur un còne qui, sauf ce détail, présente tous les caractères de forme el de composition minéralogique qui constituent un volcan; il n'est pas impossible pourtant qu'il y en ait eu un jadis,

Le Cierro de la Bandera. quoique composé de roches d'aspecl franchement. rolcanique. ne prísente, a son sommet, aucune trace de cratere. 
mais il est aujourd'hui tellement dégradé par le temps et les agents atmosphériques, qu’il faudrait, pour en retrouver les rudiments, des recherches et des observalions plus prolongées que celles auxquelles nous avons pu nous livrer.

Le

Gerro del Oeote, moins

bien entractírisé,

atl

point de vue

minéralogique,

présente

une

forme voleanique plus aceusée. partir dı ravin où l'on doil redescendre avant d'en commencer l'ascension; mais les grands arbres sont de plus en plus disséminés et remplacés par des buissons el des herbes, au milieu desquels on voit se développer, dans les régions supérieures de la montagne, un nombre assez considérable de pins qui rappellent sensiblement les espèces des provinces méridionales de la France, comme te pin maritime, le pin cembro, etc. C'est de là, du reste, que vient le nom de Cerro del Ocole, ocote signifiant pin ou plus généralement bois résineux daus la plupart des langues indigènes de l'Amérique centrale et du Mexique. On peut monter, à rheval, jusqu'au haut du Cerro dẹl Ocote, le sentier serpentant sur le flanc de la montagne, à travers des argiles jaunes el des déjections volcaniques, sous lesquelles on aperçoit eu beaucoup de points la roche compacte el ne présentant que de rares et faibles traces de scorification. En alleignant le sommet, on se trouve en présence d'un pelit plateau, élevé de 1,190 mètres au-dessus du niveau de la mer (roy. page 183), irrégulièrenıent circulaire, large de 500 mètres en moyenne, el dont le sol est uniquement formé d'une argile marneuse jaunàtre. Ce haut plateau est entouré de cinq ou six éminences coniques, disposées à l'entour suivant un cercle à peu près nettement indiqué, el constitue peut-être un ancien cralère comblé en grande partie par les dépòts lacustres d'une masse d'eau, desséchće aujourd'hui, qui y aurail existé jadis. Celte lagune doit probablentent reparaitre pendant la saison des pluies el alimenter, par des fissures intérieures, les sources qui s'épanchent sur les flancs de la montagoue, en réparlissant les caux pluviales euglouties dans les conduits souterrains. La plus considérable des éminences qui entourent ce çralère mal défini s'élève au sud-ouest el le domine d'une ciuquautaine de mètres; elle est, en effet, laaule de 1,236 mòtres au-dessus du niveau de la mer et forme le point culminant de tout le massif des Cerros de Conchagua. Comme les autres mamelons, celui-ci est composé de roche basaltoïde compacte, avec peu de traces de scorification.

De son sommel, on peut voir les pentes très-inclinées de la inontagne descendre 
DANS LES RÉPCBLIQUES DE GUATENALA ET DE SALVADOR. 349

brusquement au sud jusque vers la mer; mais, à l'ouest, elles se perdent au milieu d'un grand nombre de collines, peut-ètre basaltiques, qui semblent lui servir de contre-forts. An milieu de ces collines se trouve le petil Lac de Camalotal, qui semble avoir une forme circulaire bien définie, et dont les eaux, au dire des Indiens du pays, se troublent subitement deux fois par an sans aucune cause apparente. Peut-ètre n'est-ce là qu'une tradition sans valeur, mais peut-être aussi y a-t-il un fondement réel à ce récit, el le lac de Camalotal n'est-il qu'un cratère rempli par une lagune, communiquant souterrainement avec d'autres localités rolcaniques, ou bien dans taquelle se produisent de temps en temps des tentatives d'éruption. Nous n'avons pas pu, faute de temps, aller visiter le lac de Camalotal, mais il serait intéressant que d'autres observateurs pussent l'examiner, après avoir pris li précaution, toutefois, de vérifier l'exactitude de la tradition qui nous a été racontée par un Indien de Conchagua el que nous donnons sous loutes réserves. Au nord, le Cerro del Ocote s'appuie sur une série de contre-forts assez puissants, qui s’abaissent pourtant assez brusquement au voisinage de la région basaltique de Los Almendros, en se reliant à la plaime de San Miguel.

En résumé, les Cerros de Conchagona conslituent un massil assez remarquable, et qui pourra donner lieu à d'intéressantes éludes lorsqu'on l'examinera avec plus de soin el de détail que nous n'avons pu le faire. De ses deux sommités principales, l'une présente les caractères minéralogiques d'un volcan, mais s'en dislingue par un trait tout ì fait saillant, l'absence de cratère apparent; l'autre, moins bien définie minéralogiquement, offre, à son sommet, des indices d'une disposition lopographique qui la rapprocherail des volcans. Il y a donc lieu d'espérer que des travaux subséquents feront connaître des caraclères moins hypothéliques que ceux que nous avons reconnus ${ }^{(1)}$.

\footnotetext{
t du moment où notre travail était déjà sous presse, nous avons trouvé dans le Journal des Débats du 23 avril 1868 l'arlicle suivant, qui semble avoir étć emprunté à une lettre d'un témoin oculaire:

"Les tremblemenis de terre qui ont tant effrayé les habitants du Salvalor depuis le 11 février étaient simpleunent le prélude d'une éruption du volean rle Conchagua, situé auprès du port de La Union. Cette éruption a eu lieu le 23 du même mois, à sept lueures du matin, sans causer, du reste, aucun dommage.
}

"Le volcan de Conchingua est silué à l'entrée rle la baie de Fonseca, où doil aboulir le chemin de fer interocénnigue du Honduras, en lace do volean de Conseguina, qui lui fait pendant đlu côté de Niearaguá. Il forme ume monlagne de 3,800 pieds d'altitude, que lon novail jonaais vue en éruption, et sur le sommet de linquelle on avait placédes appareils destimés à firire des signaux télugraplicques ponr annoneer les enbarcations qui se dirigeraient vers le jort. "Lal partie supérieure de la montagne se parlage en deux pointes semblables à deux cônes ayant une base com- 
P’ent-ètıe y at-l-it quelques pelits rrateres-lisen ats

voisinage In Ias Almendios.

Puisque nous avons entrepris d'éludier aulant que possible tous les phénomènes volcaniques de la région que nous avons parcourue, mentionnons ici un renseignement qui nous a ćté donné après que nous avions dépassé la localité dont il va ètre question et que nous ne pouvions pas retourner en arrière pour le vérifier. II parailtrail que, dans la zone basaltique des environs de Los Mlmendros, à inoitié chemin environ entre La Union et San Miguel, on voit s'ouvrir dans le sol quelques dépressions plus ou moins régulièrement circulaires, d'un diamètre ponvant aller jusqu’ì 50 el mème 100 mètres, et présentant une apparence cratériforme. Dans ces dépressions se trouvent des masses d'eau boueuse, à une température plus ou moins élevée, d'où s'ćchappent des vapeurs d'odeur sulfurense. Nous reproduisons ce renseignement lel qu’il nons a été donné, malheureusement lrop lard, et sans pouvoir garanlir en aucune façon son authenticilé; mais nous serions heureux d'apprendre que la localité a été visilée el que l'on a trouvé la rérification des fails que nous signalons sous bénéfice d’inventaire.

TOLGAN DE SAN MIGLEL.

(PI. V111, fig. 2; pl. IX, fig. 1 et 2.)

ispect gr andiose lu volean d. San Vigurl.

Lorsque, sortant des épaisses forêts qui recouvrent la région basaltique de Los Almendros, on alteint la plaine cultivée des environs de San Vigruel, on voil tout à coup se dresser dans son ensemble grandiose une belle montagne conique isolée, haute de 2,153 mètres au-dessus du niveau de la mer, el dont la cime, couronnée

mune. Dies le 19 lévrier, le gonvernement de La Uniou, alarus des bruits sonterrains qui acompagnaient les tremblements de terre, et qui semblaient. en partie, provenir du Conchagma, envoya une commission examiner la montaguc.

rLes persounes qui en faisaient partic recounurent alors que, ver's le tiers de la hanteur du volcan, de grandes masses de pierres se détachaient. en soulevant des nuages de cendre ou de poussière jaunàtre, ver's un creux de la montagne qui avait tonjours été consitéré conme une simple erevasse ou un eflondrement naturel. Cies sortes d'éboutenents se succédaient de vingt minutes en vingt minutes avee des mugissements imposints. Ce fut vers ce point que l'on vil tout ì coup injprataître, le s.3 février, des tourbillous de funcée qui anuonçainnt l'érnption.

rOn suppose maintenant que l'chiondrencut en question élait simplement nn aneien eratère depuis longtemps fermé, et qui revient maintenant à l'activilé. Son éruption a coincidé avec des phénomènes auklogues dans les volcans d'Tzalco et de San Mliguel. Les sccousses de tremblement de terre qui se succédaient presque sans interruption. - car on en a compté cent quiuze dans la joumée da $16,-$ ont complétennent cessé rlepuis lors.

Ce récit nous parail mériter une enlière conliance, ear les donncés géugraphiques qui l'uccomprignent sont trop exactes pour rque lou puisso l'attribner ì quelquantre qu à une personne résidinl sur les lieux et parfaitement au fait de tont ce rui regarde les plénomènes volcaniqques au Salvador. II en résulte que les Cierros de Conchagua constituent un massif volcanique sur la nature durpuel it ne pent plus s'élever ancun deule. Les questions que nous nous prosions sont done tranchées dans un sens hien déterminé, et nos recherches n'ont plus qư iun iutérêt en quelgque sorte rélruspectif. 
DANS LES RÉPUBLIQUES DE GUATEMALA ET DE SALVADOR. 351 de nuages blanchàtres, se voil déjà de la ville de La Union, par-dessus les dermiers contre-forts du massif de Conchagua. C'est le volcan de San Miguel, silué ì une quinzaine de kilomètres au sud-onest de la ville du mème nom, appryyé, dı còté de l'onest, sur un petil massif monlagneux qui se prolonge dans l'inlérieur des terres, libre, au contraire, dans toules les autres directions, el semblant surgir brusquement d'une plaine doucement inclinée, progressivement reliée par des courbes gracieuses, quoiqu'un peu roides, aux fortes pentes de ses llancs. L'aspect général de la moutagne a quelque chose de tout à fait particulier; son isolentent relatif, l'immensité de sa base, la largeur considérable de la troncature qui existe au sommet du conne, la forle inclinaison de ses pentes, foul contribue à lui domner une plysionomie à part, respirant je ne sais quel air de puissance, de vigueur ef de solidité, qui la font, à première rue, considérer comme un volcan des plus rermarquables, sans que celte impression soit détruite par un examen plus approfondi.

Ce paysage n'est pas sans avoir frappé vivement déjà tous les voyageurs qui ont eu occasion de l'admirer, el voici, en particulier, ce qu'en dit M. Squiers (Notes on central America, etc. p. 312 ):

e Il esl difficile de concevoir quelque chose de plus grandiose et de plus beau que ce volcan... Sa base se perd dans une verdure épaisse, progressivement fondue avec les teintes plus claires des herbes qui succèdent aux forèts; au-dessus de ces teintes variées on voit d'abord les couleurs sombres des scories, puis, ver's le sommet, la nuance argentée des cendres nouvellement tombées, et encore, audessus de tout cela, floltant en épaisses masses opalines, on montant vers les cieux comme une plume blanchàtre, on voil la fuméc qui s'échappe perpétuellement do ses profondeurs incandescentes."

'Le volcan de San Miguel, célèbre à plus d'un litre, présente en particulicr' un caraclère assez intéressant; c'est, peul-être, de tous les volcans de l'Amérique centrale, celui qui a donné le plus souvent des laves et qui en a donné le plus. Dejuis

Historique.

da

volen de San Wigunt. la période historique, ses éruptions, dont la plus remarquable fut colle de 1699 . se sont toujour's manifestées par d'abondantes pluies de cendres et de lapilli projetés hors du cratère, mais accompagnées de l'ouverture sur ses flancs de fissures plus ou moins vastes, par lesquelles s'épanchaient des courants de lave, alteignant quelquefois jusqu’à des dislances considérables. 
Éruption du 25 juillet 181 s.

L'éruplion la plus importante du volcan de San Miguel, dans les années correspondantes à l'époque actuelle, a été celle du 25 juillet 1844 . C'est probablement de celte éruption que veut parler M. Wells (Explorations and Adventures in Honduras, etc.p. 232), lorsque, la rapportant, par erreur sans doute, à l'année 1845 , il en raconte les détails en ces termes :

"Pendant les deux jours qui précédèrent l'éruption, de fréquents bruits souterrains annoncèrent l'approche de la convulsion. La terre trembla dans un rayou de plusieurs lieues autour de la monlagne, et l'obscurité s'étendit sur tout le pays. Une panique telle qu'on n'en avail pas ru depuis la catastrophe du Conseguina s'empara de tous les esprits. Des prières furent dites dans toutes les égolises, et l'on raconte que des voleurs, frappés dans leur conscience par l'approche de ce chàliment du ciel, restituèrent volonlairement aux léggitimes propriétaires ce qu'ils leur avaient dérobé. De nombreuses familles quittèrent San Miguel pour s'enfuir à l'lsla del Tigre ou plus loin encore. La lare sortit d'un petit cratère, sur le flanc ouest du còne, et, on deux jours, elle recourrit en s'épanchant un espace de huit milles carrés, mais sans causcr aucun dommage."

Dans l'éruption du 25 juillel 1844 il se forma, sur les flancs du cône, à peu près à moitié de sa hauleur, quatorze bouches ou évents par lesquels la lave s’écoula sous la forme de torrents de feu. Ces bouclies sont réparties en diflérents points sur la circonférence du còne; une, en parliculier, siluée du còté du nord-onest, à 1,100 mètres de hauteur, a donné la coulée de lave qui est venue menacer la ville de San Miguel el s'est arrètće, comme par un miracle, devant les premières maisons des faubourgoss. Dans la région du sud, c’est-ì-dire du còté de la mer, les coulées ont été bien plus importantes encore que dans celle du nord; on cile, en particulier, la contée qui traverse le chemin d'Ǔsulutan, et qui a, dit-on, doủze lieues de longueur. C'est sur le parcours de celte coulće de lave, pendant l'éruplion du 25 juillet 1844 , que se serait passé un fait que l'on raconte à San Miguel et que nous ne reproduisons quẻ sous toutes réserves, sans en garantir en aucune facon l'aulhenticité. Il parail que le fleuve de lave incandescente, rencontrant sur son chemin- une maisonnelte entourée d'un pelil champ, où élait resté le propriélaire, un pauvre Indien, surpris par la rapidité du phénomène, se divisa en deux branches qui enveloppèrent ce coin de lerre sans le recouvrir, de telle façon qü 
DANS LES RÉPUBLIQUES DE GUATEMALA ET DE SALVADOR. 353

l'habitant put s'échapper sain el saul peu de temips après. On admettra facilement que la conlée de lave se soit ainsi partagée, gràce à quelque rocher ou à un autre corps refroidissant qui lui fit obstacle; mais il est plus difficile de comprendre comment le mallıeureux Indien ue fut pas suffoqué par la laute temıéralure et la composition irrespirable des gaz dont il devail être enviromé. Depuis lannée 1844 , le volcan a donné claque année des signes d'açivité plus ou moins intenses, mais qui n’ont pas alteint les proportions du phénontène que nous venons de rappeler. Toutes ces éruptions ont été cinériformes, sauf une peulètre, celle de 1848 , qui, d’après M. Squiers, aurail aussi donné des laves, mais en faible proportion.

Lascension du volcan de San Miguel est relativement lacile pour des persommes labilućes à de semblables excursions, el l'on pourrait, à la rigueur, la en faire une seule journée de la ville de San Miguel. Mais il est prélérable, lorsqu’on a l'intenlion de séjourner pendant quelque temps sur le sommel du còne el sur les bords du cratère, de partir le malin du pied même de la monlagone, de manière à arriver en haut au commencement de la matinće el à ne pas graviî̀, sous les rayons d'un soleil déjà trop élevé au-dessus de l'horizon, les pentes assez abruptes, reudues plus difticiles encore par les scories roulantes dont elles sont recourertes. Nons sortìnes de San Miğuel, le 9 avril 1866 , à deux heures et demie de l'après-midi, accompagnés de quelques étrangers résidant dans celle vilte, s'estimant fort heureux de trouver occasion de visiler un volcan qui, malgró sou voisinage, u’a jamais été visilé pal’ les habitants, dout le caractère se ressent du climat accablant de ces régions torrides. La chaleur, en effet, est telle à San Miguel, que son influence, débilitant nonseulement les indigènes, mais mème les étrangers qui y ont séjourié quelque temps, leur ôte en mème temps l'activité physique et l'énergie intellectuclle, pour les laisser dans une sorte d'atonie, bien incompatible avec l'idée de monter au sommel d'un volcan dans le simple but de satisfaire une curiosilí scientifique. Les indigènes n'ont jamais bien compris, dans l'Amérique centrale, que nous ayons pu venir dans leur pays uniquement pour y étudier les phénomènes de la nalure, les monlağnes, les volcans... On nous a toujours prêté une arrièrepensée, recherche de mines ou but politique, et, lorsqu'après une ascension, à la question lrabiluelle, c" Qu'est-ce que cela vous rapporte?" nous répondions " Rien, " 
on ne se faisait pas faute de hocher la tête d'une manière qui exprimait clairement le doute, ou pis encore!

Au sortir de San Migouel (1 10 mètres), on commence à s'élever progressivement, d'abord d'une manière insensible, puis sur des pentes plus aceusées, au milieu des premières ondulations qui se rattachent à la base du volcan. Le sol se compose presque uniquement de sables volcaniques, de ponces et d'argiles jannes, sous lesquelles on voit poindre de temps en temps les traces de coulées dir laves anciennes. Le chemin ne se dirige pas directement au sud-ouest, du còlé où il ponrrait alteindre le plus rapidement la base du volcan; mais on le contourne cur quclque sorte, pour aller gagner, du côté de l'onest, le point où le còne se soude sur les montignes de l'intérieur, dont il scmble brusquement terminer la chaine, et où il se relie à elles pạ’ un col silué déjà à plus de 900 mètres andessus du niveau de la mer. On évite ainsi une partie de la montée sur les flants du còne lui-mème, et on s'élève bien plıs facilement en serpentant sur les contreforts élagés qui relient les montagnes an pays plat.

Grande conlíe

de lave,

produite

par l'éruption

de $181_{1}$.
Après trois lıures de marche, lorsque l'on a déjà dépassé les champs bien rultivés dle la plaine pour entrer dans les épaisses forêts de la région montagneuse, (1) se trouve toul à coup en face d'une immonse couléc de lave, qui, serpentant dans une sorte de vallée forméc entre les intervalles des collines, s'élève d'un teòté sur les flancs du cône et descend de l'autre dans la plaine, jusque tout auprès de la ville de San Miguel, qu'elle a failli atteindre lors de l'éruption de juillel 1844. Rien ne sanrait reudre l'aspect saisissant de ce flenve congelé, leérissé de blocs angulcux et déchirés, qui, large de 200 mètres environ, s'est frayé un cheniu an milieu de la végétalion luxuriante, dont les teintes vertes et vivantes conIrastent étrangement avec sa couleur noire et sinistre; il s'écoule vers les réogions inférieures, tantòt parcourant avec calıne la forèt qui s'arrête net sur ses bords, lautòt se précipitant en cascades vertigineuses, lorsque son cours s'est trouvé intercepté par quelques énormes blocs de rocher ou rétréci par le rapprochement des collines qui l'enserrent. Il semble que tout cela doive se remettre en marehe d'un moment à l'autre, et le voyageur éprouve je ne sais quelle impression de morne tristesse el de désolation, en ne trouvant au milieu de ce chaos que l'immobilité et le silence. Le chemin franchit la coulée de lave en un poinl oì, un 
DANS LES RÉPLBLIQUES DE GUATEMALA ET DE SALVADOR. 355 énorme massif de rochers s'opposant à son passage, elle a dù se diviser en deur bras, et respecter celte espèce d'ile qui s'élève verdoyante au milieu des flots noirs solidifiés qui l'entourent. En ce point, en particulier, la lave s'écoule dans une sorte de vallée dont le thalweg n’est pas incliné de beaucoup plus de 4 degórés; mais il n'est pas possible d'admettre que la pente générale de la coulée, entre. le pied du còne el San Migouel, soit inférieure à 10 degrrés, quoiqu'elle décrive une couble d'un rayon assez considérable pour racheler celle différence de niveau de 800 mètres. Mais il faut remarquer que l'on a affaire à une série d'espaces doucement inclinés raccordés par des ressauts brusques el presque abrupts, où la coulée se précipile en cascades effrayantes, et dont le dernier serail, si l'on veut, le cône mème du volcan, sur lequel la lave est descendue d'une hauleur de près de 300 mètres, suivant une des génératrices, sur une pente de plus de 30 degrés. Dans la coulée proprement dite, c'est-ì-dire à parlir du pied du còne, nous devons avouer que l'aspect de la surface ne varie pas autant qu'on pourrait le croire suivant le degré de l'inclinaison. Parlout on a affiure ì des masses anguleuses, noires, déchiquelées, empilées dans le désordre le plus effrayant, scorifiées, bulleuses; peul-être pourtant y a-l-il une scorificalion plus considérable, accompagnée d'une légò̀re modification dans la teinte, qui tend ¿̀ passer aux tons rougeatres, dans les points les plus abrupts. Mais il est probable que la différence existe en profondeur, et que, les cascades ne se composanl alssolument que de matlières scorifiées d'un volum et d'une épaisseur relativement peu considérables, ce n'est que dans les parlies peu inclinées que l'ou trouve la lave solide el compacte au-clessous des blocs scoriacés de la surface. Sur le cône lui-même on ne peut ğuère supposer qu’il existe de la lave massive en couches d'une épaisseur quelconque, car la coulée a dû s'y précipiler avec une rapidité comparable à celle d'un courant d'eau; néanmoins son parcour's est indiqué d’une manière extrêmement remarquable. On voit, au milieu de la végélation qui recouvre cette partie de la montagne, un torrent noir, large d'une cinquantaine de mètres, descendant directement suivant une des gónératrices el modelant si surface presque unie sur les diverses ondulations du terrain. Il se compose absolument de tout petits morceaux de lave scorifiée, noirs, brillants, à reflels presque mélalliques, très-bulleux, durs, aigres, se pulvérisant sans se briser, vitrifiés en 
Point oit le volcan de San Viguel se soude aux montagnes

de

rintériputs.

Cine du volcat

de San Viguel.

quelque sorte, et dont les plus gros atteignent à peine les dimensions d'une noix. En descendant sur cette espèce de fleuve de gros sable noir, on y enfonce jusqu'ì mi-jambe, et l'on peut y faire pénétrer un bâton jusqu'à une profondeur qui prouve que l'épaisseur de cel amas de scories est supérieure au moins à $1^{\mathrm{m}}, 50$.

Après avoir franchi la coulée de lave, on atteint presque aussilôt les montagnes porphyro-trachytiques sur lesquelles s'appuie le volcan, et on arrive bientòt dans un ravin élargi, où, an milieu d'une clairière gagnée par' défrichement sur la lorèl viergoe, s'élève une polite cabane entourée de quelques champs cullivés. C'est la Casa de Chaves, habitée par une panvre famille indienne, établie en cet endroil où coule une source, assez abondante d'ordinaire, mais presque réduite à rien au moment où nous nous y trouvions, c'est-ì-dire à la fin de la saison sèche. Nous nous installàmes pour la nuit à la Casa de Chaves, à une hauteur de 926 mètres au-dessus du niveau de la mer, au milieu d'un des paysages tropicaus les plus splendides qu'il soit possible d'imagimer; et c'est avec peine que nous rósistons à la tentation de décrire les délices de celle soirée fraîche el calme après les ardeurs du climat brùlant de San Miguel, aussi bien que tes magnificences de celle nature vierge, rlont la puissance el la fécondité semblent contraster avec la faiblesse el l'accablement de l'homme qui veut lutter avec elle.

Le lendenain, avant le jour, nous traversions la vaste arète qui relie le volcan aux montagnes que nous venions de quitter, et, au lever du soleil, nous étions déjà engagés sur les premières pentes du còne. La végétation y est encore abondante, et, gràce aux lacets que décrit le sentier, on peut, à la rigueur, y faire monter les petits chevaux vigoureux el énergiques que les Centro-Américains out l'habilude de conduire dans les endroits les plus accidentés et les chemins les plus périlleux. Le sol est formé de déjections volcaniques, sables el scories, partiellement décomposées de manière à produire une couche superficielle de terre sableuse dans laquelle les végélaux peuvent vivre, et retenues sur une pente qui varie entre 3 o et $31^{\circ}$, aussi bien par les herbes qui y croissent que par les rochers plus au moins volumineux interposés dans la masse. A partir de l'altiturle de 1,500 mètres, la végétation cesse complétement, et l'on n'a plus affaire qu'à des pentes abruples composées de scories rouges, brunes on noires, reliées par des sables ou des poussières de triluralion, et entremêlées de blocs de dimen- 
DANS LES RÉPUBLIQUES DE GUATEMALA ET DE SALVADOR. 357 sions plus considérables qui se détachent du sol et rontent avec fracas sur les pentes de la monlagne, aussitôt que l'on a l'imprudence de poser le pied dessus pour s'aider dans l'ascension. On peut alor's juger de l'ensemble du cône qui est admirablement régulier', saul quelques ravinements el une sorte d'arancée en forme de bec, produite sur le flanc est, tout près du sommet, par une explosion qui précéda l'éruplion de 1844.4 mesure que l'on s'élève, la pente devient plus forte, auggmentant jusqu’à dépasser $33^{\circ}$; et la combinaison de celte inctinaison avec l'instabilité des malériaux sur lesquels on marche rend la dernière partie de la montée asse» pénible. On alleint enfin un ravin de quelques mètres de profondeur où les gros blocs de rochers dominent, en s'étagreant les uns sur les autres comme des marches d'escalier, el l'on arrive ainsi à une sorte de brèche coupée dans le bord du cratère, par laquelle on pent pénétrer aisément dans son intérieur.

On'se trouve alors en présence d'une gigantesque dépression circulaire, de plus de 3 kilonètres de circonférence, dont les caractères principanx sont indiqués dans la coupe de la figure 1 planche IX. Ge cratère, admirable sous tous les rapports, se compose de plusieurs parties dislinctes, semblant indiquer quilil a été modifié successivement par plusieurs éruplions paroxysmales d'une gorande violence, el comprend, en laissant momentanénent de còté les détails, une première enceinte circulaire, coupée à pic vers l'intérieur jusqu'au point où elle rencontre un vaste espace plan, à peine ondulé, dans lequel s'ouvre brusquement une seconde dépression, profonde of verticale, qui est actueltement te sicge principal de l'activilé éruptive.

La première dépression, le cratère primordial, si l'on ose s'exprimer ainsi, présente un bord assez accidenté, de telle façon que sa hauteur au-dessus de la plaine horizontale qu'il renferme n'est pas partout la même, graice surtout à lrois échancrures principales entaillées en des points déterminés. La partie la plus élevée se trouve au nord-nord-est; c'est le point culıninant de la montagne, atteignant une hauleur de 2,153 mètres au-dessus du nivean de la mer, el dominant de 150 mètres environ l'espace plinn de l'intérieur. L'arèle qui commence en cel endroil s'étend vers l'ouest, en s'abaissant progressivement; à l'est-nord-est, III col de $7^{5}$ mètres, à peu prè̀s, la sépare d'une autre crêle, laute de 100 à

tère du volcan San Niguel. ou cralère ancien. 
120 mètres en moyenne, qui, interronipue seulement par une petile solution de conlinuité du côté du sud-est, se développe d'une façon continue jusque vers l'ouest, en diminuant peu à peu d'élévation. A l'ouest, se trouve l'échancrure principale, qui ue domine la plaine que d'une dizaine de mètres, et par laquelle nons avons pénélré dans l’intérieur du cratère. Les parois intérieures de celte dépression sont presque partout à pic et tombent vers la plaine centrale avec une verticalité si absolue, qu'il serait radicalement impossible d'en tenter l'ascension ou la descente dans la très-grande majorité des points. Elles se composent d'ime masse rocheuse solide, compacte el uniforme, coupée nel el à arêtes vives, quoiyu'un peu scorifiée ou surfondue à la surface. En deux endroits seulement, les murailles ne sont pas tout à fail perpendiculaires el permettent d'être gravies; re sont l'échancrure de l'est-nord-est, où des sables volcaniques se sont accumulés en formant une pente accessible, quoique très-forte, et surtout celle de l'ouest composée d'un amas de blocs gigigantesques entassés, sur lesquels on peut se hisser avec quelque difficulté.

Main annuaire. La plaine horizontale intérieure, étant entourée de murailles à pic cians toutes les directions, présente, comme le bord de l'ouverture primitive, un diamètre de 1000 à 1,200 mètres environ. Cetle plaine u'est point, à dire vrai, ın espace circulaire, mais bien plutòt un espace annulaire, puisqu'clle est interrompue cn son milieu par une gigantesque dépression constituant le denxième cratère, et qu'clle est ainsi comprise entre deux cercles de parois verticales, la dominant à l'extérieur, et s'y enfonçant à l'intéricur. Les deux cercles n'étant pas tout à fait concentriques, l'espace annulaire n'a pas partoul la même largeur; et celte largeur varie entre 60 et 200 mètres, la plus grande dimension se trouvant au nord-est et la plus pelite au sud-sud-est. La surface de la plaine, formée de sables, de cailloux, de blocs plus au moins volumineux, quelquefois mème d'argiles fines en couches extrêmement minces, est presque absolument horizontale, ne présentant que quelques ondulations, insigonifiantes relativement aux dénivellations considérables qui l’entourent. On y peut remarquer, néanmoins, quelques accidents sur lesquels nous devons appeler l'attention : ce sont, d'albord à l'est-nord-est, une petite dépression circulaire, conslituant un cratère ćteint de 100 mètres environ de dianètre, ef de 80 mètres de profondeur, dans lequel des roches à surface altérée montrent 
DANS LES RÉPUBLIQUES DE GUATEMALA ET DE SAINADOR. 359 qu’il y a eu là autrefois d'abondants dégagements de vapeurs acides; et ensuite, au sud, une barranca ou fissure à parois verticales, largo d'une dizaine de mètres et prolonde d'une centaine, régnant, en dimimuant progressivement de largeur el de profondeur, depuis le cratère intérieur jusqu’à lia paroi verticale extérieure, de manière à couper presque complétement l'espace ammulaire et à r'endre fort difficile d'en faire le tour entier.

La seconde dépression circulaire, que l'on peut considérer comme lo cratc̀re actif actuel, n'est pas tout à fail concentrique avec la première; elle est un Secourle depression o14 peu déjelée vers lo sud-est, la distance des centres pouvant ètre de 70 mètres environ, ce qui est rendu très-sensible à l'œeil par les différences de largeur de l'espace annulaire plan. Ce cratère est assez régulièrement circulaire, et a un diamètre moyen de 800 mètres; sa profondeur verticale serail de 320 mètres, d'après les calculs que nous avons fails en prenant pour base le temps que met une pierre lancée du haut à atteindre le fond. Ses parois sont composées d'énormes masses rocheuses compactes, continues, quoique disposées en couches épaisses à peu près horizontales dans la section, el traversćes par des injeclions de inilières fondues; elles sont presque absolument verticales dans tonte teur hauteur sur plus des trois quarts de la circonférence. Le gouffre présente done, à peu près de tous les côtés, l'aspect d'un trone de còne passant au cylindre, puisque ses génératrices sont presque parallèles à l'axe. C'est, dans tous les cas, la forme des régions inférieures sur la circonférence entière, car les accidents qui règruent dans la zone du sud-est n'atteignent pas à plus du liers de la profondeur, c'està-dire à une centaine de mètres. Au sud, existe la fente dont nous avons déjì parlé, mais par laquelle on ne peut songer à descendre dans le cratère, d'alord parce qu'elle se termine brusquement, à 100 mètres de profondeur, au-dessus d'une effrayante paroi verticale; ensuite, parce qu'elle est fortement inclinée, pleine de rorhes mouvantes, et qu'il s'y dégage d'énormes quantités de gaz irrespirables par lesquels on serait rapidement asplyxié, si l'on avait l'imprudence de s'engager dans ce ravin, comme l'un de nous tenta un inslant de le ficire.

Entre le sud-sud-est et l'est, sur un arc correspondant à un angle de près dre $70^{\circ}$, la paroi du cratère est fortement entamée dans son liers supérieur el se compose alors d'un plan incliné dont les pentes sont de $10^{\circ}$ en movenne, formé 
d'un amoncellement confus de cailloux et de rochers reliés par des sables de trituration el sur lequel on pent s'avancer, à condition d'y aller avec précantion. C'est ce que nous fìmes, mais en u'avançant qu'à pas comptés; car, si l'on avail le malheur de golisser, on serait infailliblement perdu, le plan incliné se terminant brusquement à une muraille verticale d'au unoins 200 mètres de profondeur qui se conlinue jusqu'au fond du cratère. Il paraît néanmoins que des Indiens, plus audacieux que la généralité de leurs congénères, sont venus en cet endroil exploiter du soufre produit par d'abondantes solfatares qui y existaient après lá grande éruplion de 1844.

Le fond du cratère, où il est absolument impossible de pénétrer, même en se faisant descendre avec unc corde, ì cause des vapeurs irrespirables dont il est rempli, semble être formé d'une sorte de platean assez fortement ondulé, dont le diamètre n'est inférieur que de fort peu de chose à celui du bord supéricur, soit 750 mètres environ. On y roit des entassements goigantesques d'énormes blocs, empilés dans le désordre le plus fantastique, recouverts de croûles jaunàtres de soufre et noyés dans la vapeur qui s'échappe entre leurs interslices. Les parois elles-mèmes disparaissent souvent sous d'abondants dépồts blauchàtres, nuancés de jaune, de rouge el de vert, composés soil de soufre impur, soil de masses aluneuses produites par la déconposition des roches feldspalhiques qu'attaquent incessamment les vapeurs acides des fumerolles. Les masses blanchâtres ont une composition probablement assez complexe, renfermant, outre des sulfates doubles de divers genres ou aluns, d'autres sulfales simples parmi lesquels le sulfale de chaux doit dominer. Lorsqu'elles sont verdàtres, elles conliennent du sulfate de fer, qui se transforme pent-ètre quelquefois, soil en oxyde, soit en chılorure, el donne alors lia nuance rougeàtre que nous avons signalće. Le soufre abonde, surtout au voisinage de la grande fissure du sud; nous en avons vu aussi dars la partie inclinée de la paroi, en jolies aiguilles cristallines tapissant les in--lerslices des rocher's entre lesquels s'échappe la vapeur; mais, à l'époque où nous fìmes l'ascension du volcan, il n'y en aviit pas assez pour donner lieu à une exploitation quelconque. 
DANS LES RÉPUBLIQUES DE GUATEMALA E'T DE SALVADOR. 361 peurs épaisses, qui flottent el se déplacent au gré du vent, el acquièrent par moments une intensité assez considérable pour ne pouvoir pas se condenser immédes fiumeroltes. diatement, et former des nuages blanchàtres qui couronnent la cime du volcan. Ce panache de fumée, ou plutôt de vapeurs, est plus considérahle an nilieu de la journée que le matin, lorsque le refroidissement et, par suite, la condensation ne sont plus aussi rapides; mais il l'est presque toujours assez pour qu'on l'aperçoive de l'océan Pacifique, à plus de 40 kilomètres de distance. Les funerolles ne sont pas également réparlies dans les différents points du cratère; la très-grande miajorité se dégagoe dans la demi-circonférence du sud, et les plus importantes se trouvent dans le cratère intéricur, celles de la plaine et des parois de la première enceinte ne présentant qu'une médiocre importance relative. Les fumerolles qui existent dans les murailles du cratère extérieur ne sont, d'ailleurs, pas nombreuses; à peine en distiugue-t-on deux au nord $(\alpha)$ et trois ou quatre au sud $\left(\alpha^{\prime}\right)$; elles sont assez insignifiantes, composées presque uniquement de vapeur d'eau, et leur lempéralure ne dépasse pas 57 degorés. Dans la plaine annulaire, il y en a plus de trente, surgissant en différents points, mais elles n'ont pas non plus une intensité très-notable. Les plus importantes sont placées comme il suit : un groupe au nord-est, à peu près au milieu de la plaine $(\beta)$, dout la température est de $67^{\circ}, 50$; un second groupe au sud $15^{\circ}$ est, non loin de la grande fente $\left(\beta^{\prime}\right)$, lempéralure $59^{\circ}, 60$, se réunissant à quelques dégagements situés au sud $\left(\beta^{\prime \prime}\right)$, contre les parois de la première enceinte, terupérature $71^{\circ}$; enfin un groupe très-nombreux comprenant une série de fissures convergeant vers le bord du cratère principal $\left(\beta^{\prime \prime \prime}\right)$ au sud $20^{\circ}$ onest, température $69^{\circ}$. Dans la région inclinée de la paroi du cratèro central, on observe plusieurs fumerolles dont trois surtout ont une certaine imporLance : la première, à l'est $7^{\circ}$ sud $(\gamma)$, température $83^{\circ}$; les deux autres, sur une mème génératrice, ¿̀ l'est $15^{\circ}$ sud, la plus élevée ayant une température de $90^{\circ}$ $\left(\gamma^{\prime}\right)$ et la plus basse $\left(\gamma^{\prime \prime}\right)$ une température de $71^{\circ}, 20$. Dans les murailles verticales de ce même cratère, il y a un nombre considérable de funerolles $(\delta)$ donnant une telle aboudance de vapeur qu'il est presque impossible de les compter exactement. Elles sont toutes réparties dans la régoion comprise entre le sud-est et le sud-ouest, et appartiennent à une douzaine de groupes principaux, dont deux sur'tout; l'un silué au sud-ouest, l'autre près de la grande fente, sont extrème- 
ment importants et donnent à eux seuls presque la tolalité de la vapeur qui s'échappe du sommet du volcan. Enfin, tout à fait au fond du cratère, mais contre la paroi, du côté de l'est $10^{\circ}$ sud, on apercoil un groupe d'une dizaine de fumerolles assez intenses $(\varepsilon)$. Il est évident que nous ne ponvons rien dire de leur température, non plus que de celle des dégagements qui existent dans les parois verticales.

Malggré celte lacune regreltable, on peut entrevoir une loi des températures assez nettement indiquée, el qui trouverait probab]ement sa confirmation, si l'on en possédait les autres élements. On remarque en effet que les fumerolles de l'enceinte extérieure sont les plus froides, leur tempéralure n’étant que de $57^{\circ}$, el qu’à mesure que l'on descend dans l'intérieur du cralère, la températurc augomente jusqu'ì atteindre $90^{\circ}$, terme qui doit probablement être dépassé par celles des parois verticales el du fond.

Les fumerolles sont presque uniquement composées de vapeur d'eau, d'acide carbonique el d'azole, renfermant une proportion variable d'acide sulfureux, mêlé à de faibles proportions d'oxygène, provenant plus que probablement de l'air qui y aura été accidentellement introduit. Elles rougissent fortement et assez rapidement le papier bleu de tournesol; mais le papicr à acélate de plomb n'y décèle pas la moindre trace d'hydrogèèc sulfuré, et l'ammoniaque n'indique en aucune façon la présence de l'acide chlorhydrique. Nous avons recueilli dans des tubes de verre, où le vide avait été fait préalablement, le gaz qui se dégage de quelques-unes de ces fumerolles, et nous avons pu constater par des essais exćculés avec plus de précision que ceux que nous avions faits sur łe terrain, que les différences de composition se maintiennent entre des limites assez rapprochées. Elles portent surtout sur la proportion relative de la vapeur d'eau el sur la quanlité d'acide sulfureux. Ainsi la fumerolle de l'enceinte extérieure $\left(\alpha^{\prime}\right)$ à $57^{\circ}$ ne renferme que des traces imperceptibles d'acide sulfureux et se compose, au moins pour la moilié, d'acide carbonique el d'azole, parce que la tension de la vapeur d'eau n'est pas très-considérable à une température aussi peu élevée; au contraire, pour la fumerolle de la paroi inclinće du cratère $(\gamma)$ à $83^{\circ}$, la proportion de la vapcur d'cau augomente notablement, en même temps que l'acide sulfureux arrive à constituer au moins $10 / 0$ de la composition totale. Il est singulier qu'on 
DANS LES RÉPUBLIQUES DE GUATEMALA ET DE SALVADOR. 363 n’y rencontre pas d'lydrogòène sulfuré, qui trouverait pourtant, à celte température, ses conditions normales d'existence. Enfin, la fumerolle de la paroi inclinée du cratère $\left(\gamma^{\prime}\right)$ à $90^{\circ}$ se conduil à peu près comme la précédente, mais la quanlité d'acide sulfureux y est encore un peu plus forte. Il est probable que, lorsqu'il existait en cet endroit d'abondants dépòts de soufre, ils étaient dus à la décomposilion de l'hydrogène sulfuré, qui remplaçait en gorande parlie l'acide sulfureux dans les dégagements de gaz.

On en peut déduire une loi de composition, d'après laquelle la quautité d'acide sulfureux contenu dans les fumerolles serail en raison directe des tempéralures. Il suffil, d'ailleurs, pour constater la probabilité de celle loi, d'avoir séjourné quelque temps dans le cratère, car on s'aperçoil bien vilc que, si l'on peul s'approcher sans crainte des fumcrolles de la région supérieure, celles du fond, au contraire, prennent à la gorge en excitant une toux violente et douloureuse.

Au point de vue de la composition minéralogique, le volcan de San Miguel ne présente que peu de variélé. Partout où l'on a affaire à des murailles verticales, comme dans les parois de la première enceinte et du cratère central, on voit Composition
minéralogique
du volcan de San Miguel. qu'elles sont conposées d'une roche massive, compacte, plus ou moins fissurée, et l'on ne peut s'empêcher de leur trouver, dans certains cas, l'apparence d'une construction gigantesque, constituée de matériaux monstrueux, régnlièrement empilés les uns au-dessus des autres. Dans l'enceinte extérienre, les roches sont généralement de couleur sombre, brunes ou d'un grris foncé, mouchetées de points blancs, indéterminables comme forme, el ressemblant singulièrement à des porphỵres trachyliques plus ou moins altérés. Dans le cratère central, 1es roches sont rougeàtres, grises el même blanchàtres, mais elles sont tellement allaquées ì leur surface, que l'on ne peut rien préjuger à distance sur leur composition. II faut remarquer, néanmoins, que l'on y dislingue des bandes plus foncées, dirigées un peu dans tous les sens, et qui pourraient bien être des injections de lave hasaltique, ayant pénétré dans les fissures d'une masse porphyro-trachylique précxistante. Dans la plaine amulaire, on voit, non toin du bord du cratère, et surtout près de la grande fente, des couches assez abondantes d'une jolie argile grisìtre, à pâte remarquablement line, disposées en petits lits extrêmement ninces. Il est probable que cette arogile doil son existence à la décomposilion pro- 
grressive des matériaux ineubłes formant le sol de la plaine, attaqués par des eaux acides provenant elles-mèmes de la condensation des vapeurs qui s'échappent des fumerolles voisines. Nous avons en effel remarqué en plusieurs endroits les traces de laques d'eau, somvent assez élendues, qui doirent persister pendant toute la saison des pluies, mais qui disparaissent naturellement pendant la saison sèche, gràce à la température propre du volcan et à la sécheresse de l'atmosphìre. Les sables et les cailloux blanchàtres qui composent le sol de la plaine annulaire sont donc assez facilement allaquables par des eaux, mème faiblement acides. Cela nous porterail à croire quilils sout feldspathiques, el, comme ils proviennent naturellement de la destruction des autres parties du volcan, nous pouvons y trouver une preuve en laveur de la composition porphyro-trachylique des enceintes qui environnent le cratère. Quant aux scories et aux sables volcaniques de trituration, qui se trouvent en abondance sur les pentes extérieures de la montagne, elles sont toujours de couleur sombre, noires, brunes ou rougeâtres, el nous inclinons à supposer qu'elles sont basaltiques. Ajoutons que l'on ne rencontre point de ponces et qu'il n'y en a pas aux environs du volcan de San-Migguel, d'où nous devons conclure que, malgré la composition propre du massif intérieur de son còne, ce volcan a rejeté beaucoup plutôt des matériaux basaltiques que feldspathiques.

IMFERNILLOS DE CHINAHECA. - VOLCANS DE CHINATEGA ET DE TECAPA.

Volcan de Chinamecil.

Dispusition topoyraphique ins infier nillor
Le massif montagneux sur lequel s'appuie la base du volcan de San Miguel, du côté de l'ouest, se prolonge dans l'intérieur des terres dans celte même direclion. Quoiquil se compose essentiellement de roches porphyro-trachyliques, il a néanmoins été le théàtre de phénomènes volcaniques dont l'activité n'est plus bien considérable aujourd'hui, et qui ne se manilestent guère que par la présence de cònes éteints el de dégagements de gaz, dits infiernillos. Le premier de ces volcans éteints est celui de Chinameca, que l'on distingue très-neltement du haut du volcan de Sau Viguel; le còne lui-même, haut loul an plus de 1,50o mètres au-dessus du niveau de la mer, domine à peine les montagnes qui l'environnent, mais il présente un très-vaste cralère, dont le diamètre peut c̀tre de 5 oo mètres environ.

C'est au pied du massif qui supporte ce volcan éteint que se trouvent les infiernillos de Chinaneca, situés à environ deux kilonètres au sud-ouest du gros 
DANS LES RÉPUBLIQUES DE GUATEMALA ET DE SALVADOR. 365 village du même nom et à 600 mètres au-dessus du niveau de la mer. Outre les deux principaux dégagements de gaz qui portent les noms d'Ervedor et de Boqueron, il y en a plusieurs autres moins importants; et l'ensemble du système est relié par des points où l'allération des roches montre qu'elles ont été traversées autrefois par des vapeurs acides, de manière à jalonner, sur une longueur de plus d'un kilomètre, un espace rectiligne, large tonl an plus d'une cinquantaine de mètres et dirigé presque exactement du nord-est au sud-ouest, à travers deux vallous séparés par un petit ressaut montagneux.

Aussitòl que l'on pénètre dans le premier de ces ravins, on aperçoit au loin une épaisse colonne de vapeur blanchic qui s'élève dans l'atmosphère, et l'on ne tarde pas à être frappé d'un bruit semblable à celui que produirait une chaudière dont on aurait ouvert les tuyaux de dégagement. L'un el l'aulrẻ provienuent d'une cavilé asse\% profonde dans laquelle on entend bouillonner une sorte de boue liquide, que l'on ne peul pas voir à cause de la vapeur qui s'échappe avec une grande force de l'étroite ouverture communiquant avec le réservoir intérieur. Cette cavité s'ouvre en un point qui présente des caractères minéralogiques fort remarquables; en effet, au milieu des roches porphyriques noiràtres, passant parfois aux porphyres quartzifères, qui constituent tout le sol environnant, on voil une sorte de filon, d'apparence pourrie, large de 3 à 4 mètres environ, formé d'un mélange intime d'une nualière argileuse d'un gris bleuâtre ou verdàtre, de carbonate de chaux dolomitique d'un goris jannàtre présentant des masses à moitié cristallisées en scalénoèdres el en thomboèdres mal définis, el enfin de pyrite de fer en petites mouches jaunes el brillantes. C'est lì un véribale filon, qui est Filon de cartsonate de chaux avec monclies de pyrite. exploilé pour chaux en quelques-nons de ses points par les habitants de Chinameca. La coexistence de ce filon el de la boue liquide traversée par une grande quantité de gaz acides à une liaule température est un fail intéressant, el l'on peut, jusqu'ì un certain point, se demander lequel est le point de départ de l'autre : le dégagement de gaz a-l-il pris le chemin que semblait lui tracer la fissure remplie par 1 filon préexistant, ou bien, au contraire, est-on en présence de la création d'un filon mélallifìre, formé de toutes pièces, sous les yeux mèmes de l'observateur', par l'action sur les roches encaissantes d'un dégagement de gaz dépendant des phénomènes volcaniques? 
Disposition particulière de t'Frvedor.

Composition et température des gaz at des vapeurs.

A une centaine de mètres plus avant dans le ravin, el tout près de l'endroit où il se termine, on se trouve en présence de l'Erverlor proprement dit('), où se produisent des phénomènes tout aussi intéressants, quoique d'un ordre un peu différent. Au milieu du vallon, se trouve un petit massif irrégulièrement circnlaire, d'un diamètre de 4 à 5 mètres el haut de 2. mètres environ, formé d'une accumulation de matière arogilo-sableuse, provenant de la décomposition des rochies voisines, el empâtanl quelques blocs plus ou moins altérés de cette même roche. La couleur des masses argileuses est grise, jaunâtre ou rouge, et elles sont recouvertes par points de croûtes blanchàtres d'alun plus ou moins pur. En cerlains endroils, la surface est accidentée de pelits mamelons, de forme à peu près conique el liauls de 20 à 30 centimètres. Du sommet de ces petits cônes, des interstices qui existent entre les pierres, de quelques trous qui s'ouvrent dans la masse argilo-sableuse, on voit s'échapper avec violence d'abondantes vapeurs, qui se répandent dans l'alnısphère en produisant des sifflements aigus ou des bruissements sourds. C'est un mélange de vapeur d'eau el d'hydrogène sulfurć, qui possède une température forl élevée, variant entre $98^{\circ}$ et $98^{\circ}, 50$. Des vapeurs de composition analogue, et dont la température est la même, s'échappent de plusienr's autres points voisins, dans un rayon d'une dizaine de mères. Au pied du mamelon où se trouvent les dégagements les plus remarquables, on voil couler, en assez grande abondance, une eau boueuse, très-chaude, dont la tompéralıre alteint $97^{\circ}$ et $97^{\circ}, 50$. Celte boue liquide est traversée par de nombreuses bulles de gaaz, qui s'y dissolvent eu partie, mais agitent sa surface de manière à faire croire, au premier abord, qu'elle est soumise à une ébullition tumultueuse. Ce gaz contient une forte proportion d'hydrogène sulfuré, ainsi qu'on peut le prouver an moyen du papier d'acétate de plomb, qui noircil presque immédiatement. La bouc liquide abandonnée à elle-mème dans un vase, pendant quelques jours, laisse déposer les particules argileuses brunes dont elle étail chargée, el se transforme en une liqueur limpide et claire. Celle eau forlement acide, car elle rougit immédiatement le papier de tournesol, contient de l'hydrogène sulfuré en dissolution, ainsi que des sulfures alcalins, de l'acide sulfurique libre, des sul-

(4) Encedor signifie, en espagnol, un endroit où l'eau est en ébulition. 
fates et des carbonates de fer, de chaux el de magnésie, etc., ainsi que le prouvent les réactions suivantes:

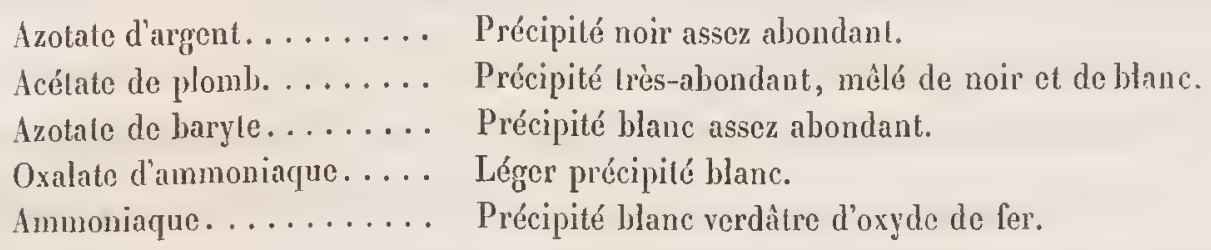

Malgré leur's différences plus apparentes que réelles, les plıénomènes sont certainement continus, el c'est évidemment la mème boue liquide qui bouillome aux deux extrémités du ravin, quoiqu'elle soit à la surface du sol en un point, el en profondeur dans un autre.

Sur la colline qui termine le ravin, on ne voit plus de dégagements de rgaz; mais il est incontestable qu'il y en a eu autrefois, en plusieurs points où la roche désagrégéc est colorée en gris ou en rougge et tachée de plaques minces d'alun impur. La présence de cet alun suffirait à elle seule pour prouver que les gaz sont sulfureux, si l'odorat ne révélait pas immédiatement leur composition. En un entdroit, on remarque deux sources très-voisines, dont l'une est froide, tandis que l'autre est à $32^{\circ}, 50$. On en peut conclure que les caux elles-mèmes, ou les couches de terrain où elles circulent souterrainement, sont encore écliauffées par le passage des gaz à haute tempéralure.

Le Boqueron ${ }^{(1)}$ se trouve dans un ravin que l'on rencontre inmmédiatement après avoir franchi la colline, et conlinue l'alignement des dégagements de gaz que uous avons signalés jusqu'à présent. En arrivant en présence du Boqueron, notre guide fut tout élonné de le trouver presque absolument inaclif, et nous affirma que la dernière fois qu'il l'avait vu, quelques mois auparavant, il ćlait tout à fait comparable à l'Ervedor. L'élal du sol, qui, sur un espace assez étendu, présentait des traces manifestes de dégagements de gaz acides et d'altérations profondes, suffisait pour corroborer l'exactitude de celte assertion. Mais il est cerlain que le 15 avril 1866 , jour où nous le visitimes, te Boqueron ne se composait plus que de quelques émanations sans importance, dont la tempéralure égalait presque celle de l'Ervedor, el qui produisaient comme lui de la vapeur d'eau mèlée d'hy-

(1) Boqueron signifie, en espagnol, une grande bouche. 
drogène sulfuré. Il serait intéressant de savoir si le Boqueron aura repris par la suite son activilé, ou s'il se sera complétement éteint.

Quoi qu’il en soil, l'eusemble de ces phénomènes nous paraît fort intéressant. Nous y voyons des dégagements de gaz acides el de vapeurs, thermalisant et minéralisant, si l'on ose employer de semblables néologismes, des sources qui se trouvent accidentellement sur leur passage, et nous pensons que leur origine doit. être directement rattachée à l'action volcanique, qui, ne s'exerçant plus dans le cratère éteint du volcan de Chinameca, se développe sous une autre forme an pied même de la montagne.

Filcan de Tecapara. Cratère-lac.

iolcan

de San-licente. Aspect gúnéral. 11 est complétement éteint.
En continuant à suivre, vers le nord-ouest, la direction de la chanine porphỵrotrachylique, on rencontre bientôt un autre volcan éleint, celui de Tecapa, que nous n'avons pas étudié personnellement. Il paraît, d'après les récits des indigò̀nes, que le cratère de ce rolcan renferme une lagune assez étendue, dont les eaux esont froides d'un còté et chaudes de l'autre. "Gela pourrait aisément s'expliquer par la présence de dégagements gazeux à haute température, situés au-dessous du niveau de l'eau à l'une des extrémités du cratère, el il n'y a rien d'impossible à ce que la tradition que nous avons rapportée soit l'expression de la vérité.

POLCANS DE SAX-VICENTE. - NFIERYLLLOS.

La chaine de monlagnes, coupée un instant pour laisser passage au Rio Lempa, reprend immédiatement de l'autre côté du fleuve, et l'on voil bientòl se dresser, au milieu d'une plaine ferlile, une grande monlagne irrégulièrenent conique, liaute de 2,400 mètres environ, el qui n'est autre que le volcan de San-Vicente. Ge volcan présente, à ce qu'il paraît, une apparence parfaitement conique du côlé du sud-est, où les scories recouvrent seules sá cime nue; mais, vu de la ville de San-Vicente, c'est-à-dire du côté du nord, il perd son apparence caractéristique et semble se coufondre avec les massifs montagneux qui l'environnent. Il est, du reste, complétement éleint depuis la période historique; la végélation s'élève jusqu'au sommet sur le flanc nord, et l'on ne possède aucune tradition relative à ses éruptions. Son cratère a dù contenir autrefois un lac plus ou moins étendu, car on raconte qu'il y a quelques années, à la suile d'un trembtement de terre, l'eau 
DANS LES RÉPUBLIQUES DE GUATEMALA ET DE SALVADOR. 369 rompit les parois qui la retenaient, et, s'échappant par cette brèche, s'écoula avec impétuosité sur les flancs de la montagne. Ces torrents creusèrent de profonds ravins, que l'on voil fort bien aujourd'lui encore, mais ils ne prirent pas, heureusement, la direction de la ville de San Vicente, qui échappa ainsi à une ruine presque certaine. Ce n'est là, du reste, qu'une tradition locale, dont nous ne pouvons garantir en aucune façon l'authenlicilé.

Sur le flanc nord-est du volcan, à une hauteur de 815 mètres au-dessus du niveau de la mer, et à 8 kilomètres environ à l'ouest de la petite ville de San Vicente, il existe des infiernillos au moins aussi remarquables que ceux de Chinameca, et qui sont aujourd'hui les seules manifestation de la force éruplive daus le volcan de San Vicente. M. Stephens, qui les a visités en 1840, en domne (Incidents of travels in Central America, etc., vol. 2, p. 45-46) une courte descriplion, que nous ne croyons pas devoir reproduire, parce qu'elle ne présente aucun caractère scientifique el qu'elle ne signale aucun fait que nous n'ayons observé nous-mêmes; mais elle a néanmoins une certaine valeur, en ce qu'elle sert à prouver que les caractères du phénomène n'ont pas subi de modifications sen= sibles pendant les vingt-six années qui se sont écoulées entre le voyage de M. Stephens et le nòtre.

Les infiemillos de San Vicente sont dus, comme ceux de Chinameca, à de puissants dégragements de gaz à laute température, qui, traversant des sources préexistantes, les rendent thermales el minérales, formant ainsi de pelits lacs boueux et acides qui allaquent assez fortement la surface des roches encaissantes. Mais, quoique la température de l'eau el des vapeurs soit la mème dans les deux endroits, il y a néanmoins quelques différences, qui consistent principalement en ce que l'intensité du phénomène est plus considérable à San Vicente et en ce que les gaz acides, mélangés aux vapeurs qu'ils entrainent en échauffant l'eau, sont en proportion beaucoup plus forte et de composition un peu différente. Les infiernillos se trouvent dans un ravin presque partout à pic, profond d'une quinzaine de mètres environ el qui fut entaillé par les caux dans les roches porphyrotrachytiques compactes dont est formé le massif du volcan de San Vicente. Dans ce ravin coule un petit ruisseau, qui ne contient d'abord qu'une très-faible quantité d'eau (à l'époque où nous l'avons visité, bien entendu, soit à la fin de la saison 
sèche, 19 avril 1866), s'augmente un peu aux environs des infierniltos, probablement en condensant une partie de la vapeur d'eau qui est mèlée anx gaz acides, y forme quelques petiles flaques d'eau, les unes claires, les autres boueuses, et s'écoule enfin vers la plaine, avec une température qui s'abaisse progressivement à mesure qu’il s'éloigne du théâtre du phénomène. Il nous semble évident que ce ruisseau n'est pas dù à une source thermale, car, près de sa naisssance, tout à fail au fond du ravin, l'eau est presque froide; un peu plus bas, à 100 mètres environ des dégagements de gơ actuels, mais en un point où il semble qu'il y en ail eu autrefois, sa température est de 58 à $60^{\circ}$; enfin, aux infiernillos mêmes, elle est presque bouillante, el atleint une température de $98^{\circ}$. Ce sont donc bien des gaz acides et des vapeurs, indépendants de l'existence de cette source, qui l'échauffent en se mc̀łant ì ses eaux; et l'on a affaire à un véritable phénomène voleauique, dont l'origine est facile ì discerner, quoique son apparence soit rendue un peu trompeuse par la présence accidentelle d'un ruisseau transformé en source thermale.

Altératiou des roches encaissantes.

Conme nous l'avons dit, le ravin, dirigé presque exactement dı sud au nord, est cutaillé daus des roches porphyro-trachyliques parfailement caractérisées, ainsi qu'on peut le voir près de la naissance du ruisseau. Mais, au voisinage des infiernillos, cette roclıe est profondément altérée par l'action des eaux et des vapeurs acides; les flancs du vallon sont recouverts de masses d'altération argilosableuscs, mêlées de croniles blanchàlres, composées de sulfates simples divers et d’aluns, ainsi que d'une assez notable quantilé de soufre, qui se présente mème, dans certaines fissures, sous la forme d'aiguilles cristallisées, bien définies, tapissant les parois des cavités. Le mélange des croùtes aluneuses, blanches, nuancées de jaunc ou de vert, des dépôts ferrugineux rouggeâtres qui se trouvent à la surface dans bien des points, des amas de soufre jaune clair, produit une variété de couleurs qui contribue, pour sa part, à donner quelque chose d'étrange à la localité qui sert de théâtre à celle singulière manifestation volcanique. Au fond du ravin, l'altaque par les eaux acides est plus complète encore, et l'on n'y voil guère que des amas d'argile gुrise, un peu juunâtre ou bleuàtre, disposés en couches Déagagement quelquefois assez puissantes.
principal

Les dógagements de gaz, les fumerolles (car ce sont, en réalité, de véritables 
DANS LES RÉPUBLIQUES DE GUATEMALA ET DE SALVADOR. 371 fumerolles), sont disposées un peu au hasard, suivant l'alignement du ravin, sur une longueur de 150 ì 200 mòtres environ. La plus remarquable de toutes se trouve à peu près à l'extrémité sud, ef s'échappe de lia paroi même du raviu, par une ouverture en forme de caverne semi-circulaire, large de 1 mètre ef haute de 75 centimètres environ. Le mélange de gaz et de vapeurs en sort à nune pression qui doit être de plusieurs atmosphères, avec un bruit terrilıle qui s'entend à une distance considérable, et forme une sorte de colonne ou de large jel qui se maintient horizontal jusqu'à plus de 3 mètres de l'orifice. Dans l’intérieur de la caverne, on peut voir bouillonner une eau grisâtre, violemment soulevée par le mouvement du gaz; mais, quoiqu'dle soil à peu de distance du sol, elle ne pent se déverser par là, parce que la partic inférieure de la cavité s'incline vers l'intéricur. Des gouttclettes de celte cau, entrainées par le courant de gaz, sonl projetées jusqu'ì près de 5 mètres de l'orifice et brûlent vivement l'imprudent qui s'en approche de trop près, car elles sont anssi chaudes que le courant de gar. lui-même, dont la lempérature est de $98^{\circ}$. Nous avons pu prendre cette lempérature en nous glissant le long de la paroi, et en arrivant ainsi jusqu'à l'ouverture de la caverne; car le jet de vapeur s'échappe avec une telle puissance, quỉl ue commence à prendre une cerlaine expansion qu'à quelques mètres de là, pour produire ensuite d'abondants nnages blancs qui s'élèvent dans l'atmosphère et se roient de loin dans la plaine. Les indigènes prétendeul que, lorsqu'on jelte une pierre dans la caverne, ou même lorsqu'on fait un bruit quelconque ì l'orifice, le gaz se dégage avec plus de violence et en rendant un son plus intense. Nous devons avouer que nous n'avons pas pu constater nettement celle particularité, qui ne tient pent-être qu'à un écho déterminant, une résonnance intérieure.

Aux environs de celte fumcrolle, il y en a un très-grand nombre d'aulres, réparties à peu près en une vingtaine de groupes principaux. Les unes s'échappent directement de fentes existant dans la masse porphyrique elle-mème; d'autres sortent au milieu des amas argileux; d'autres enfin s'épanchent dans de petiles flaques d'eau, tantòt claires, tantôt troubles et colorées en gris blanchâtre, tantôt tout à fait boucuses, suivant qu'elles reposent sur un fond de roche solide ou d'argile plus ou moins délitée. Pour n'avoir pas à y revenir, disons que la lompéralure est toujours la même, soil $98^{\circ}$ en moyemne (il n'y a que des écarts 
tout à fait insignifiants), et que, comme composition, on a affaire à de la vapeur d'eau formant la plus grande partie du mélange, unie à des proportions variables d'acide sulfureux, d'hydrogène sulfuré et à de faibles traces d'acide carbonique et d'azote. Si nous choisissons comme exemple le gaz de la filmerolle principale que nous avons recueilli dans un tube et examiné avec soin, nous verrons qu'il est formé d'au moins 95 à $9^{6} \mathrm{p}$. o/o de vapeur d'eau, ce qui concorde parfaitement avec sa température, si voisine du point d'ébullition de l'eau. Le reste, envisagé séparément, contient au moins les trois quarts de son volume d'acide carbonique, et dans le quart restant l'azote et l'oxygène (presque dans les proportions de l'air) viennent encore dispuler la place ì l'hydrogène sulfuré el à l'acide sulfureux. Nous avions pu constater sur place la présence de l'acide sulfureux par la réaction franchement acide des vapeurs sur le papier de tournesol et par l'abondance des dépôts de soufre et d'alun, qui ne se trouvent pas en pareille quantité à Chinameca. L'hydrogène sulfuré est indiqué par le noircissement du papier d'acélate de plomb. La présence de l'acide carbonique est facile à constater, comme nous le montrerons ci-après. Il est important de remarquer qu'il n’y a aucune trace de composés chlorurés.

1)égageıneut

de gaz

transformé

en

un petil volcan

de fouse.

Parmi les fumerolles qui s'échappent des masses argileuses, nous devons en siğnaler une, en particulier, qui est un vérilable petil volcan de boue. Le gaz, en se mouvant an milieu des matières pâteuses, les a soulevées pour en former un pelit còne de 75 centimètres de hauteur, dans lequel s'ouvre un cratère de 20 centimètres de diamètre et 50 centimètres de profondeur. Au fond, on voit s'agiter la boue, qui se gonfle en grosses bulles, que le gaz crève avec un cerlain bruil pour s'en échapper. Le cône lui-mème est formé d'une argịto gorrisâtre, mais ì la base on voit deux cercles concentriques, le premier d'alun blanchâtre, le deuxième de soufre impur jaunâtre, produits par la réaction et la décomposition du gaz acide, ce qui contribue à donner à l'ensemble un aspect assez singulier.

Les flaques d'cau, qu'elles soient boueuses ou claires, semblent être en ébullition; mais, leur tempéralure n'étant que de $98^{\circ}$, il est facile de se rendre compte que ce bouillonnement est produit par un dégagoement tumultueux de goaz, qui les traverse en les échauffant el s'y dissolvant en partie. On peut même 
DANS LES RÉPUBLIQUES DE GUATEMALA ET DE SALVADOR. 373 le constater à la simple vue dans les lagunes à eau transparente, où l'on voit clairement les bulles de gaz s'échapper des fissures existant dans la roche solide qui forme le fond. Dans les flaques d'eau bourbeuses, qui contiennent plus ou moins de matières argileuses en suspension, l'épaississement du liquide rend te bouillonnement plus violent encore, mais ce n'est évidemment qu'une apparence trompeuse. Dans l'eau limpide, on voit les bulles diminuer rapidement de orrosseur, jusqu'au moment où elles viennent crever à la surface; cela prouve qu'clles se dissolvent en partie; en effet, la vapeur d'eau se condense au milien du liquide, l'acide sulfureux et l'liydrogène sulfuré y restent aussi en dissolution, le sorte que les pelites bulles de gaz que l'on recueille à leur sorlie ne contiennent plus, ainsi que nous nous en sommes assurés sur place par une petite analyse rapide. que :

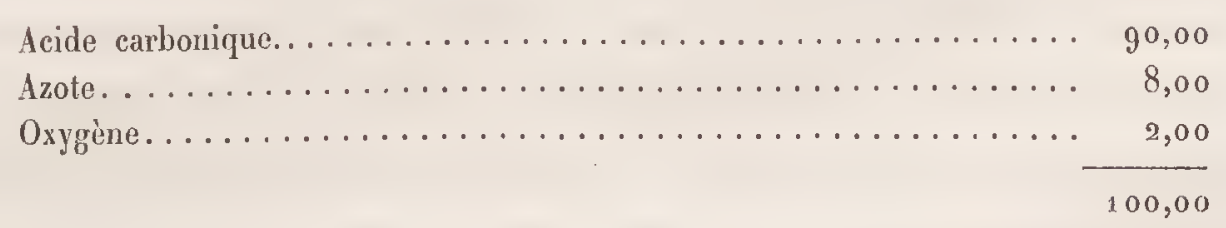

L'acide sulfureux et l'hydrogène sulfuré en dissolution dans l'eau réagissent en partie l'un sur l'autre, et le liquide présente avec les divers réactifs les caraclères suivants :

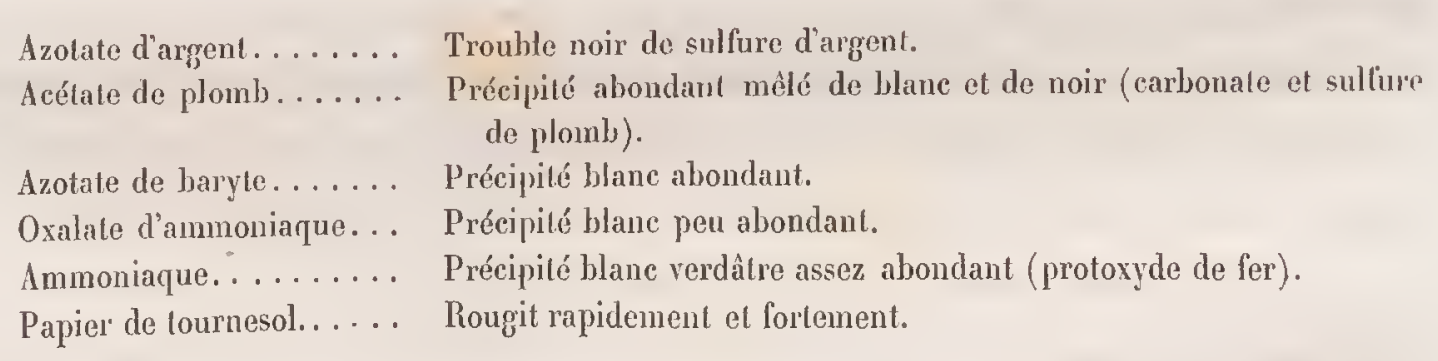

L'eau renfer'me donc de l'hydrogène sulfuré et de l'acide carbonique en dissolution, de l'acide sulfurique libre et des sulfates divers, parmi lesquels ceux de fer el de chaux sont prédominants.

En résumé, les infiernillos de San Vicente, plus aclifs et plus remarquablos encore que ceux de Chinameca, constituenl, comme ces derniers, des émanations gazeuses établies à la base des volcans éteints, et montrent de singulier's exemples des déplacements que peuvent subir les manifestalions de l'action volcanique.

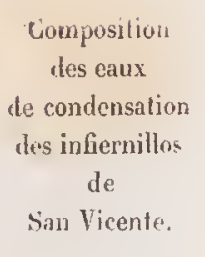

Ciomposition de 
VOlCAY DE COIUTEPEQUE. - VOLCAYS DE SAN SALVADOR E'T DE QUEZALTEPEQUE. LA IIOYA.

Vulcan étein de Gojutepeque.

Volcan éteint de San Silvador. Lac dians le crative.

En continuant à marcher vers le nord $30^{\circ}$ ouest, on découvre bientot sur les hauteurs, et non loin des bords accidenlés du beau lac d'Ilopangogo, un petil voleśn éleinl qui domine la vallée de Cojutepeque et s'élève à 1,035 mètres au-dessus du niveau de la mer. Ce volcan de Cojulepeque, qui ne présente plus aucune Irace d'activité, et qui doil être éleint depuis fort longlemps, se compose d'un còne parfaitement régulier, haul de 150 mètres environ au-dessus de la pelite plaine au milieu de laquelle il se dresse; à son sommet on aperçoil les rudiments d'un petil cralère circulaire, d'une vingtaine de mètres de diamc̀tre, qui semble r’avoir jamais projeté que des malières cinériformes. Le cône est entièrement composé de scories brunes et rouggeâtres, en morceaux de la gorosseur du poing; mais, à louest de la ville, on remarque des amas de roches basalliques qui doivenl s'élendre jusque sous le volcan, et appartiennent peul-être à une coulée de lave très-ancieune, antérieure aux éruptions qui ont formé la montagne actuelle.

A environ 40 kilomètres plus loin, el à une dowzaine de kilomètres au nord de la ville de San Salvador, capitale de l'État, se trouve le volcan de San Salvador, qui s'élève à 2,30o mètres au-dessus du niveau de la mer. A première vue, on n'y remarque pas clairement les caractères distinctifs d'une montagone volcauique, ('ar on n'a devant soi qu'un vaste massif́ allongé, à base irrégulière, composé en majeure partie de roches porphyro-trachytiques, el recouvert d'épaisses forêts jusque près de son sommel. Quoique nous n'ayons pas fail l'ascension de cetle montague, nous sommes portés à croire, d'aprc̀s les renseignements qui nous onl été domnés par des personnes dignes de foi, qu'elle doit être considérée comme un très-ancien volcan, éteint déjà antérieurement à la période listorique, car il n'existe aucune tradition se rapportant à ses éruptions. Il paraîl, en effel, qu'à la partie supérieure d'un cône fortement altéré dans sa forme, mais composé de scories et de cendres, il existe un vaste cratère, presque exactement circulaire, d'un diamètre de 700 à 800 mètres, à parois presque partout verticales et d'une profondeur de 400 à 500 mòtres. Le fond de ce cratère serail accupé 
DINS LES RÉPUBLIQUES DE GUATEMALA ET DE SALVADOR. 375 par un grand lac, très-profond, aux eaux claires et transparentes, qui a été visité deux ou trois fois par des étrangers vivant à San Salvador, malgré les effrayantes difficultés que présentent la descente et la montée sur les parois abruptes dont il est environné. Extérieurement à ce cratère principal, sur le flanc nord de la inontagne, il existe un autre petit lac circulaire, dont les eaux sont aussi douces el potables, mais qui pourrait bien n'ètre que lo reste d'un ancien cratère éteint et rempli postérieurement par l'accunulation des eaux pluviales.

Ces caraclères sont suffisants pour përmettre de considérer la montagne de San Salvador comme un volcan éteint, mais ils sont encore corroborés par la présence de manifestalions volcaniques, inactives, il est vrai, réparties en différents points de la base du massif. Du côté du nord, près de la route de Santa Anna, il existe me série de quatre ou cinq petits cònes éteints, disposés suivant une ligne droite dans la direction du sud-est au nord-ouest. Le dernier de ces petits cônes, nommé Volcan de Quezultepeque, a donné, paraît-il, une éruption qui remonte ì une soixantaine d'années. Au-dessous des énormes dépôts de ponces qui environnent San Salvador, on voit s'épanclıer entre les roches porphyriques apparaissant dans le ravin dı Rio Aselguate (voir page 19o), une série de sources thermales qui tendent à prourcer que le sol est encore échauffé dans celte région sous l'influence de la puissance volcanique, actuellement dissimulée. C'est à cela, sans doute, qu’il faut altribuer anssi des dégagements d’acide carbonique, tels que ceux qui se sont produits dans un puits creusé, il y a quelques années, sur les proprićtés de M. Idigoras, à peu de distance au nord de la ville. Le gaz se dégageail du sol en si grande abondince, qu'on fut obligé d’interrompre plusieurs fois les travaux, à cause des phénomènes d'asphyxie qui se manifestaient parmi les ourriers, et que l'on eut beaucoup de peine à en venir à boul, même en employant les moyens d'aérage les plus énergiques.

A 12 kilomètres à l'ouest de San Salvador, sur la route de Santa Tecla, se trouve une immense dépression circulaire, dont le diamètre atteint au moins 1 kilomètre et demi, el qui est profonde de 200 mètres environ. Cet enfoncement, connu sous le nom de La Moya, n'est autre chose qu'un gigrantesque cratère à fleur de terre, ouvert dans une énorme épaisseur de lapilli el de sables volcaniques, et au fond dıquel se voit un lac assez étendu, appelé Lagruna de Cuscullan.

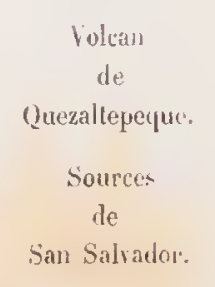

Dégaguments" d'acide carbonique.
Cratère-bac
de la Hoya.


Enfiu, au ıord de Santa Tecla, on aperçoit encore un petit cône éteint, haut d'une soixantaine de mètres, ayant donné une quantité considérable de cendres grises, ainsi que de scories rougges, et qui s'élève sur les derniers contre-forts du massif montagneux du volcan de San Salvador.

\section{VOLGAN D'IZALGO.}

(Pl. X, fig. 1 et 2.)

A peine a-t-on franchi le Guarumal, cet étrange couloir qui relie les hauts pays aux plaines basses du sud-ouest du Salvador, que l'on commence presque immédiatement à rencontrer de nouveau des sables volcaniques violacés et des laves basaltiques anciennes. On approche en effet du volcan d'Tzalco, ce volcan remarquable, qui apparul tout à coup à la fin du siècle dernier, et qui peut servir de pendant au Jorullo mexicain, rendu si fameux par Humboldt.

Le volcan d'Izalco doit à son origine récente, aussi bien qu'à son activité incessante, une grande célébrité daus toule l'Amérique centrale; aussi nous estimonsnous fort heureux de nous être trouvés dans son voisinage pendant une période de tranquillité relative, el d'avoir pu arriver les premiers jusqu'à sa cime, vierge encore du pied de l'homme. Plusieurs fois déjà on avail tenté de l'approcher, mais l'intensilé de son élat éruptif, les pierres brùlantes qu'il projetait dans toutes les directions, u'avaient encore permis à personne de dépasser le pied du cône. Plus favorisés que nos devanciers, nous avons pu l'aborder pendant un monent où il ne vornissait que d'épaisses colonnes de fumée, et, gorâce à un séjour de plusieurs heures sur les bords du cratère, nous avons pu étudier d'une manière assez complète les phénomènes qui s'y manifestaient.

Mais, avant d'entreprendre le récit de notre ascension et d'exposer avec détails les résultats de nos observations el de nos travaux, il nous semble convenable de reproduire les quelques pages consacrées au volcan d'Tzalco dans les ouvrages des voyageurs qui ont visité le Salvador antérieurement à l'époque où nons y avons été nous-mêmes. Ces renseignements auront l'avantagge de nous permettre de faire certaines comparaisons, qui ne sont pas sans importance, entre les états éruplifs du volcan à plusieurs années de dislance, el de nous montrer que, dans sa forme extérieure, la montagne n’a guè̀re changé depuis assez longolemps. Il pa- 
DANS LES RÉPUBLIQUES DE GUA'TEMALA ET DE SALVADOR. 377 raît qu'il existe, dans les archives du village d'Izalco, une relation officielle de la premic̀re éruption du volcan, éruplion qui ful en même lemps l'origoine de la monlagne. Quoiqu'on nous eủt promis, à Sonsonate, de nous mellre à même de consulter ces anciens papiers, nous n'avons pu l'obtenir aussi vile que nous l'espérions, el, gràce à la brièvelé de notre séjour, nous avons dù renoncer à ces recherches historiques, qui seront accomplies, il faul l'espérer, par quelque autre voyageur, el qui pourront fournir des renseignements intéressants sur les faits qui ont accompagué l'apparition du phénomène. A défaut de ces renseignements, nous cmprunterons ì M. Squiers', qui a peul-être eu entre les mains les archives d'Izalco, la marration suivante sur l'origine dı volcan :

".... Le volcan d'Izalco doit ètre considéré comme le phénomène volcanique le plus remarquable de l'État de Salvador. Ce volcan et celui de Jorullo, au Mexique, décril par Humbolt, sont, je crois, les seuls qui aient apparu sur le continent américain depuis sa décourerte. Il s'éleva, en 1770, au milieu de la plaine qui s'élend au pied de la grande masse du volcan éteint de Santa Anna, el recouvre aujourd'hui ce qui ful jadis une belle hacienda de bélail. Vers la fin de 1769 , les propriélaires de celte hacienda furent alarmés par des bruits souterrains, accompagnés de chocs de tremblements de terre, qui continuèrent à augmenter d'intensilé jusqu'au 23 février $177^{\circ}$, moment où la terre s'entrouvrit à un demi-mille environ des bâliments de l'hacienda, émettant des flols de lave, accompaģnés de feu et de fumée. Les habilants s'enfuirent épouvantés, mais les vaqueros, ou gardiens de bétail, qui continuèrent à visiter journellement l'hacienda, rapportèrent que les flammes et la fumée ne faisaient qu'augmenter, et que, l'éjaculation de la lave étant de temps en temps suspendue, elle élait remplacée par de grandes quanlités de cendres, de lapilli et de pierres, formant un còne en plein développemenl, autour de l'évent ou cratère. Ce mode d'action s'est continué pendant une longue période de temps, mais depuis bien des années le volcan n'a plus donné de lave. Il s'est néanmoins maintenu dans un état d'éruption conslante, el a reçu, à cause de cela, le nom de Faro del Salvador, ou Phare du Salvador. Ses explosions se produisent avec une grande régularité, à des intervalles de dix on vingt minutes, avec un bruil semblable à la décharge d'une

\footnotetext{
Notes on Central America, etc. p. 312 et suir.
} 
batterie d'artillerie, accompagnées d'une épaisse fumée ainsi que de nuages de cendres et de pierres, qui s'accumulent sur les flancs du còne, en augomentant progrressivement sa lıauteur, que l'on peut évaluer aujourd'hui (1850) à 2,500 pieds environ (au-dessus du village d'Izalco?)."

Voici maintenant en quels termes M. Stephens, qui a visité le Salvador en 1840 , raconte ${ }^{1}$ la tentative qu'il fit pour s'approcher du volcan d'Izalco, et ce qu'il vit dans cette exploration :

Récit
d'une ascension a!l volcan d'Izalco par II. Stephens.

"Avant de parlir, je me décidai à faire une excursion. Lua fenêtre de ma chambre (à Sonsonate) s'ouvrait sur le volcan d'Izalco; toute la journée, j’entendais à de courts intervalles les éruptions de la montagne incandescente, et la nuit, je voyais une colonne de flammes s'échappant de son cratère, ainsi que des courants de feu qui roulaient sur ses flancs. Quelques compatriotes se joignirent à moi, et le lendemain, avant cinq heures, nous élions en selle.. .

«Devant nous, à l'extrémité d'une longue rue, on voyait l'éğlise d'Izalco, se détaclıant énergiquement sur la base du volcan qui, en ce moment, avec une violente détonation semblable au roulement du tonnerre, projeta dans les airs une colonne de fumée noire el de cendres, éclairée par un seul jet de llamme.

eNous eûmes quelque peine à trouver un guide. . . mais bientôt nous pùmes uous mettre en route. Nous arrivàmes bientôl dans une plainę ouverte, et, sans qu'un scul buisson arrètàt la vue, nous distinguàmes à notre gauche le volcan tout entier, depuis sa base jusqu'à son sommet. Il s'élevait prè̀s du pied d'une monlagne, à une hauteur d'environ 6,000 pieds (an-dessus du niveau de la mer); ses flancs élaient bruns ou noiràtres, el tout autour, le sol étail recouvert de lave sur une étendue de plusieurs milles. Comme il élait dans un élat d'éruption violente, il ne fallait pas songer à en faire l'ascension, mais en arrière se trouve une montagne plus ćlevée, d'où l'on domine le cratère en iognition. Le volcan tout entier était en vue, projetant dans les airs une colonne de fuméc noire et un immense volume de pierres, tandis que la terre tremblail sous nos pieds. Traversant la plaine, nous commençàmes à nous élever sur la montagne, et, peu après midi, nous entràmes dans la forêt, gravissant péniblement un senlier étroit et ardu. Notre guide, d'ailleurs, perdil bientôt son chemin, changea plusieurs fois de direction, se

'Travels in Central America, etc. vol. I, p. 325 et suiv. 
DANS LES REPUBLIQUES DE GUATEMALA ET DE SALVADOR. 379 sentit enfin tout à fail égaré, et altacha son cheval pour s'en aller à la découverte. Nous savions que nous n'étions pas loin du volcan, car ses explosions résonnaient comme les grondements profonds d'un tonnerre épouvanlable. Enfermés comme nous l'étions dans les bois, ces explosions nous paraissaient d'une violence indicible. Nos chevaux reniflaient de terreur, el la terre s'agitail sous nos pieds. Notre guide revint, el en peu de minutes nous arrivâmes tout à coup à un point découvert, plus élevé que la cime du volcan, permettant d'inspecter l'intérieur du cratère, el si rapproché de lui, que nous pouvions voir les grrosses pierres projetées en l'air éclater en morceaux, et rouler de tous coltés sur les flancs du cône. En peu de minutes, nos vêtements furent tout gुris, grràce aux cendres qui tombaient autour de nous avec un pétillement semblable à celui d'une pluie d'orage.

"Le cratère se composait de trois orifices, dont l'un était inaclif; un autre émettait constamment une belle fumcé d'un bleu foncé; le troisième présentait une étroite el profonde ouverture, dans laquelle, après chaque explosion, on voyait apparaître une vapeur d'un bleu clair, suivie d'une masse épaisse de fumée noire qui se précipilail au dehors avec violence en énormes volumes, et s'élevail ensuile sous la forme d'une majestueuse colonne sombre, éclairée pendant un moment par un jet de flamme; et, après que la fumée s'élait dispersée, l'atmosphère était assombrie par un nuage de pierres et de cendres. Une fois que c’élail terminé, il y avail un moment de calme, puis une autre détonation suivie d'une éruption; el cela se continuail régulièrement à des intervalles qui, à ce que disait notre guide, élaient exactement de cinc minules, et, en réalité, il ne s'en fallait pas de beancoup qu'il ne füt dans le vrai. Cet aspect était effrayant et grandiose. Nous pensâmes que l'eflel de ces détonations et de ces flammes serait rendu bien plus splendide encore par le silence et les ombres de la nuil, et nous prîmes la résolution de dormir à la place où nous étions.

« Le curé de Sonsonate, encore dans toute la vigueur de l'àge, me disait qu'il se souvenaìt parfailement bien de l'époque où la place que recouvre actuellement. le volcan ne pouvait se distinguer de toutes les localités environnantes. En 1798 , on découvrit un petil orifice qui rejetait de pelites quanlités de poussic̀re el de sable. Il habilait alors Izalco, el, petil garçon qu’il élail, il s'amusail à aller te regarder. Il l'avait suivi dans tout son développement, surveillant l'augmen- 
tation qui se produisait de jour en jour, jusqu’à ce que la montagne actuelle fùt formée.

Le capitaine $X$. me dit qu'il avait pu observer lui-même, de la mer, combien le volcan avait augmenté de hanteur depuis deux ans. En effet, deux ans auparavant, on ne pouvait pas voir sá lumière, de nuit, de l'autre côté des montagnes sur lesquelles je me tronvais alors. Jour el nuit, il arrache des pierres aux entrailles de ta terre, les projette en l'air et les recoit sur ses flanes. Il augmente chaque jour et continuera probablement à en laire autant jusqu'ì ce que son feu intérieur s’éleigne, ou qu'une violente convulsion le réduise en poussière en démolissant son sommet.

"De vieux royageurs peuvent avoir, comme d'autres, des moments d'entlousiasme, mais ils ne leur durent pas longtenps; au bout d'une beure, environ, nous commençàmes à criliquer et mème à plaisanter... Cerlaines éruptions valaient mieux que d'autres, et quelques-unes même ne méritaient pas qu'on y fìt altention. Dans un semblable étal d'esprit, une nuil au soinmet de la montagne ne nous parut pas extrêmement conforlable, el nous prînes bientôt la résolution de nous en relourner. Nous pensions que nous pourrions éviter le circuit de la monlague en descendant directement jusqu'à la base du volcan, pour la longer ensuite et rejoindre ainsi le camino real (seutier). Notre guide refusa de nous accompagoner, disant que c'étail tenter la Providence. Nous dùmes descendre à pied une pente excessivement roide, où nos chevaux glissaient parfois sur leurs cuisses. Un immense courant de lave, arrèté dans sa conrse par les premiers contre-forts de la montagne, remplissait le large espace qui s'étendait entre nous et la base du volcan. Nous nous mimes immédiatenent à marcher sur cette couche noire et dangereuse, mais nos chevaux ne nous suivaient qu’à grand’pene. La lave s'étendail en ondulations aussi irrégulières que les vağues de la mer, aiğuë, raboteuse, pleine de grandes cavilés, aussi incommode pour nous que dangereuse pour nos chevaux. Avec d'énormes difficultés, nous les tiràmes jusqu’à la base du volcan et le long de ses flanes; mais d'énormes pierres traversaiẻnt l'air en sifllant, tombaient et roulaient jusqu'à nos pieds, si bien que nous n'osàntes pas pousser plus loin. Nous avions penr aussi de voir nos chevaux se casser la jambe dans les trous où ils tombaient continuellement, et nous retournàmes sur nos pas. Sur la pointe élevée d'où nous avions examiné le cratère du volcan, notre 
DANS LES RÉPUBLIQUES DE GUATEMALA ET DE SALVADOR. 381 guide nous regardait et scmblait se moquer de nous. Nous rebroussàmes chemin à travers le champ de lave, el, quand nous pùmes alteindre le sommet, mon cheval et moi nous étions épuisés l'un et l'autre. Heureusement nous n'avions qu’à descendre pour rentrer. La nuil élait venue depuis longtemps, quand, dépassant te pied de la montagne, nous rentrâmes dans la plaine. Chaque explosion du volean projetail en l'air une colonne de feu; en quatre places, il y avait des feux fixes, el de l'un de ces endroits, un courant de feu roulait sur ses flanes.

$\Lambda$ onze lieures du soir, nous rentrùmes à Sonsonale, après avoir fail au moins 5 o milles à cheval, sans parler de la promenade à pied sur le champ de lave, et, nalgré les fatigues d'une semblable journée, elle m'avait offert un intérêt si vivant, que je ne m'en ressentis en aucune façon."

Le volcan d'Tzalco, qui, d'après nos mesures harométriques s'élève acluellement à 1,825 mètres au-dessus du niveau de la mer, se trouve à 3 o kilomètres au nordouest de la ville de Sonsonate et à 20 kilomètres environ du villagge d'Izalco, dont il a emprunté le nom. Il s'appuie, dı còté du nord, sur un massif montagneux préexislant, auquel les indigènes ont donné le nom naif el expressif de Madre del volcan (Mère du volcan) et dont les sommités principales le dominent de 150 à 200 mètres (voir planche $X$, fig. 1). Vers le sud, il repose sur une immense coulée de lave, dont l'extrémité dépasse mème le villagoge d'lzalco, et son còne prent de ce côté un développement plus considérable, à cause de l'inclinaison de la monlagne sur les pentes de laquelle il a pris naissance.

Piésumant en quelques mots l'hisloire du volcan, telle que nous l'avons donnée en grande parlie dans les récits précédents, nous nous rappellerons qu’il apparut subitement en février $177^{\circ}$, sous la forme d'une fissure qui émil une énorme quantité de lave. Pendant assez longlemps, les éruplions donnèrent alternativement des laves et des scories accompagnées de malériaux cinćriformes. Mais, peu à pen, à mesure que le còne tendit à s'élever, les laves disparurent et furent remplacées uniquement par des cendres et des lapilli, produits par des éruptions gazeuses qui se manifestaient incessamment, et atleignirent à ce qu'on raconte, en 1803 , leur maximum d'intensité. Il paraîl qu'il y eut, en 1817 , une pelite période de calme; mais les phénomènes éruptif's reprirent bientòt le dessus, et le volcan d'Izalco continua à émettre des flammes en si grande abondance, que les

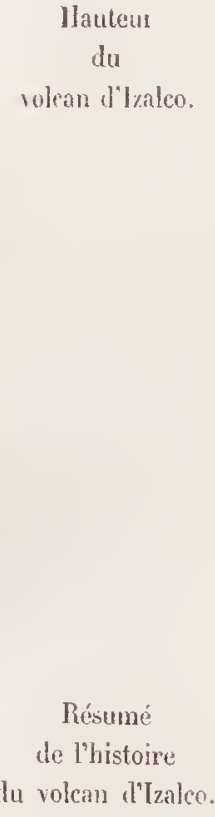


marins, l'apercevant contimuellement de l'Ocćan, lui donnèrent le nom de Phare du Salvador (Faro del Salvador). Ces éruptions, caractérisées par des projections de matières incandescentes, de lapilli, de cendres, de flammes el de fumées noires ou bleuàtres, par un bruit souterrain presque perpétuel el des détonations épouvantables se produisant à intervalles réguliers, continuèrent à prendre un développement de plus eu plus considérable jusqu'en 1856, qui fut, paraît-il, une période paroxysmale. A partir de ce moment, l'intensité des éruptions sembla diminner peu à peu, el, vers. la fin de $\mathbf{1} 865$, le volcan parul entrer dans une période de repos relatif, qui ne devait pourlant pas durer bien longtemps. Le calme se prolongeait déjà depuis cinq ou six mois lorsque nous arrivàmes à Sonsonate, mais les bruits souterrains se produisaient de nouveau, la colonne de fumée qui s'élevail à la cime du volcan prenait une teinte de plus en plus sombre en augmentant de volume, et nous pûmes acquérir la conviction que, si nous voulions mener à bonne fin une entreprise où avaient échoué jusqu'alors tous ceux qui l'avaient tentée, nous n'avions pas un moment à perdre. En effet, durant les quelques jours qui précédèrent notre ascension, les manifestations des phénomènes éruptifs devinrent de plus en plus inquiélantes, et une semaine tout au plus après que nous eûmes réussi, les premiers, ì atteindre la cime du volcan, une semblable tenlalive n'aurail déjà plıs été possible. Depuis ce moment, le volcan d'Izalco est redevenu ce qu'il était auparavant, et, si nous sonmes les seuls, jusqu'à présent, qui ayons pu l'étudier de près, on peut se demander quand viendra le moment où d'autres explorateurs pourront entreprendre de nouvelles ascensions, et nous dire quelles sont les modifications qu'ont amenées les éruptions succes. sives dans la forme du cratère el dans la nature des émanations gazeuses.

Ascension au volcan d'Izalco.

Nous partìmes sculs de Sonsonate, le 28 avril 1866 au malin, emportant le petit hagage qui nous était indispensable pour nos recherches scientifiques, considérant avec une certaine inquiétude les masses de fumée grisâtre qui couronnaient la cime du volcau et n'avaient cessé d'augomenter d'intensité, presque de moment en moment, et craignant que l'étal éruptif du volcan ne fùt déjà assez violent pour rendre impossible un séjour ì son sommel. Arrivés au villagge d'Izalco, nous y trouvìmes aisément un guide qui s'engagea à nous conduire jusqu’à la Madre del volcan, mais pas plus loin, el, malgré les sourires d'incrédulité avec lesquels tout le 
DANS LES RÉPUBLIQUES DE GUATEMALA ET DE SALVADOR.

monde nous assurait que nous ne pourrions pas réussir dans notre tentative, nous nous mîmes en roule.

$\Lambda$ peine au sortir d'Izalco, on aborde une plaine doucement inclinée, recouverte de sables volcaniques plus ou moins décomposés, sous lesquels apparaît fréquemment une lave basaltique noire, assez compacte, faisant évidemment parlie de la grande coulée que l'on peul suivre jusqu'ì Fl Bevedero, à 12 kilomètres dans l'est d'Izalco, et qui, vers le sud, passe sous le villagge mème d'Izalco pour se r’e-

Grande coulée de lave. dont une partie est recouverte de végétalion. tandis que l'autre est restée me. trouver encore à environ 500 nè̀tres plus loin que les deruières maisons. Le sol est recouvert d'épaisses forèts qui trouvent une nourriture abondante au milieu des déjections volcaniques décomposées dont est formée la couche supérieure du terrain, devenue presque de la terre végétale; en examinant les arbres giganlesques qui y abondent, on ne peut douler, malgré la croissance exceplionnellement rapide des végétaux dans ces régions tropicales, que celtc forêt ne soit vieille au moins d'une centaine d'années, si ce n'est plus. Il y a là, d'ailleurs, un problème qui ne nous semble pas encore résolu d'une manière satisfaisante, et qui ne peut l'être que par des observations minutieuses sur le terrain; en effet, lorsqu'en arrivant un peu plus haut on peut, d'un point découvert, embrasser d'un coup d'œil l'ensemble de la plaine qui s'étenck au pied du volcan, on constate immédiatement qu'au voisinage du còne il existe une coulée de lave très-différente de celle sur laquelle on se trouve. Tout autour du volcan, on aperçoit une zone noire, large d'un kilomètre environ, qui se prolonge vers le sud sous la forme d'une bande longue de 3 ou 4 kilomètres, et constitue une sorte d'espace vide et doucement incliné, à une des extrémilés duquel se dresse le cône, dont les pentes énerơiquenent accusées plongent ainsi beaucoup plus profondément du côlé du sud que de celui du nord. Celte coulée de lave est accidentée d'ondulalions brusques semblables à des vagues congelées, hérissée de pointes aiguës, colorée de tons uniformément sombres où te noir franc domine de beaucoup; elle ne produit pas un seul végétal, et l'on n'aperçoit à sa surface ui buissons, ni touffes d'herbes; tont y est nu,'aride, désolé, noir. Celte tache sombre el inanimée tranche si vivement au milieu des vertes forêts dont sont recouvertes les localités voisines, que l'on peut lever le plan de son contour presque aussi facilement que si l'on copiail un dessin. 
Il y a donc une différence considérable entre les deux coulées de lave, dont l'une est recouverte d'une puissante végélation, tandis que l'autre est restée aussi nue que si elle s'était solidifiće liier. Cette différence tient-elle à une composition minéralogique variable, la lave étant beaucoup plus susceptible dans un cas que dans l'autre d'être altérée par les agents atmosphériques? Tient-elle seulement à des époques d'apparition très-écartées, l'une des coulćes étant heaucoup plus récente que l'antre? Et encore, quelle est celle des deux coulées de lave qui doit être considérée comme se rapportant aux phénomènes dont a été accompagrnée l'apparilion du volcan d'Izalco? Si l'on admel, comme nous sommes d'ailleurs portés à le faire, que c'est la coulée de lave la plus restreinte el la moins boisée, il faudra bien admellre aussi qu'il y a eu dans cet endroit des phénomènes volcaniques antérieurs accompagyés d'émissions de laves; à moins que, pour trancher la difficulté, on ne veuille appeler basaltes les roches qui composent la coulée recouverte de forêts, el laisser dans le vague la question de l'origine de ces basalles.

Quoi qu'il en soit, après avoir marché pendant trois heures environ dans les bois qui croissent sur ce sol volcanique, et après s'ètre élevé progressivement sur une plaine ondulée, inclinéc tout au plus de 4 à $5^{\circ}$ en moyenne, on quitte la conlée de lave, pour aborder le massif de la Madre del volcan.

Nadre del volcan. Porpliyres tracligliques recomerts d'argiles jaunes et de sables volcaniques.
Franchissant un petit col, on passe sur le versant nord de ces montagnes, de manière à les contourner el à alleindre plus aisément leur sommet que si on les abordait directement par leur llanc sud, dont la pente est très-forte. Quoique le sol soil en grande partie recouvert d'argiles jaunes on de sables volcaniques de triIuration projetés par les éruptions du volcan d'Izalco, on peut apercevoir la roche sous-jacente en queliues points et se convaincre que c'est un porplyyre traclyylique analoģue à celui qui forme toutes les sommités de l'axe montagneux du Salvador: Entre deux des points culminants de la Madre del volcan, il existe un petil platean élevé de 1,850 mètres an-dessiss da nirean de la mer, et sur lequel une panvre lamille indieme cultive quelques champs de maïs. Ces braves gens, obligés de fuir aussilòt que leur redoulable voisin manifeste son activité d'une manière peu énergiqque, labitent une misérable cabane de baunbons, dans laquetle ils uous offrirent pour la nuit une cordiale lospitalité. Le plateau est presque exactement 
DANS LES RÉPUBLIQUES DE GUATEMALA ET DE SALVADOR. 385 au même niveau que le cratère du volcan el il n'est pas sans intérèt de l'exaniner' ainsi à une distance qui n'atteint certainement pas 1,00o mètres dans l'horizonLale. La crète de gauche est encore plus élevée de 200 mètres environ, et c'est de lì que M. Stephens put contempler le volcan dans une excursion dont nous avons reproduit plus haut le récil.

Le 29, au point du jour, nous nous mîmes en route pour aller tenter l'ascension du volcan lui-même, et, quoique nous fussions précisément à la hauteur du point que nous voulions atleindre, il nous fallut commencer par descendre sur te flanc sud de la Madre del volcan, par des pentes extrèmement abruples et couvertes d'une épaisse végétation, dans laquelle nous nous égaràmes plus d'une fois. On arrive ainsi sur un pelil espace libre qui s'étend entre les monlagnes et le pied du volcan, et l'on ne peut manquer d'être frappé du singulier contraste existant entre ces deux sommités : l'une est accidentée, couverte de forèts, agréablement nuancée de vert, l'aulre, constituant un còne parfail, est aussi étrangement uniforme dans la nature de sa surface lisse et unie que dans sa couleur sombre ì peine animée par quelques taches d'alın blanchàtre tranchaut sur la nuance brune et rougeâtre des scories qui la composent. L'espace libre lui-même n'est pas moins remarquable que toul ce qui l'eutoure, car il est recouvert d'une puissante couche de lave noire, formant ceinture autour de la base du volcan. Celle coulée de lave n'a goù̀re plus de 500 à 600 mètres de largeur au point où elle s'élend entre le pied du cone el la Madre del volcan; mais elle augmente un peu dans les deux directions où elle semble se déverser, et alteint plus d'un kilomètre dans la régoion du sud.

A première vue, il semblerail que l'on ait affaire à une coulée de lave, émise par un orifice latéral situé sur le flanc du còne, du côlé du nord, mais actuellement masqué par des dépòts cinériformes sus-jacents; et que cette coulée, projetant deux branches dans des directions exactement opposées, vers l'est el vers l'ouest, se soil conduite de manière à contourner la base du volcan dans les deux sens, puis à se réunir de nouveau en un courant unique pour l'entourer ainsi d'uue ceinture conlinue, indéfiniment prolongée vers le sud après avoir dépassé l'espèce d'ile que formerail le còne au milien d'elle. Mais, si l'on se reporte à la manière dont les choses se sout passées lors de l'origine du volcan d'lzalco, on voit que Origine
de cefte coulé

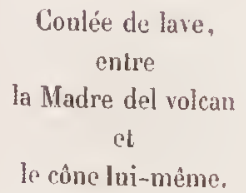


ce n'est là qu'une simple illusion d'optique, et que la lave, épanclıée avant que le còne de cendres eìl pris naissance, a formé une seule nappe conlinue, du nord au sud el de l'ouest jusqu'à l'est, nappe sur laquelle le volcan actuel s'est formé après coup, de manière à dissimuler une partic de la coulée el à lui donner l'apparence trompeuse d'un courant séparé en deux branches qui envcloppent une sorte d'ile.

La pente générale de la coulée de lave est assez considérable dans la première partie de son cours, quoiqu'elle tende à s'adoucir vers le sud; mais, au point où nous l'cxaminons, c'est-à-dire à l'extrème nord, on peut la considérer comme élant tout à fait horizontale. Il semble que, lors de son émission, la lave ait aussi cherché à s'épancher vers le nord, mais qu'arrètée par les contre-forts de la Madre del volcan qui lui opposaient une barrière infranchissable, elle ait en quelque sorte reflué sur elle-mème, de manière à former une espèce de lac ou de bassin qui a comblé toutes les inégalités du sol, jusqu'au moment où, le niveau devenant trop. ćlové, l'écoulement n’a plus pu se produire que vers le sud. L'espace horizontal occupé par le champ de lave peut ètre comparé à un rectangogle irrégulier, long d'un kilomètre environ et large de 600 mètres, se raccordant, à ses deux extrémités, aux autres parties de la coulée, qui se dirigent vers le sud en ayant l'air de contourner la base du volcan. Quoique le clamp de lave soil horizontal dans son ensemble, il présente, lorsqu'on l'examine de près, nue surface extrèmement accidentée; ce ne sont que fissures largeses et profondes, cavilés presque aussi vastes que de véritables cavernes, ondulations brusques et irrégulières, pointes saillantes qui s'élèvent dans tous les sens, blocs anguleux enlassés dans le chaos le plus pittoresque, et l'on peut dire, sans aucune exagération, que la traversée de ce petit espace est rendue excessivement pénible par les nombreux obstacles dont il est hérissé.

La lave, s'étant refroidie sons une épaisseur probablement très-considérable, dans un endroit où elle élait, sinon tout à fait immobile, du moins animéc d'un mouvement très-lent, n’a dû perdre que peu à peu sa haute température, el ne présente pas, en eflet, les caractères exlérieurs des courauls qui se sont écoulés avec une cerlaine rapidité. La surface senle est scorifiée jusqu'à une très-faible profondeur, el ce ne sont mème, en général, que les parties très-saillantes, très- 
DANS LES RÉPUBLIQUES DE GUATEMALA ET DE SALVADOR. 387 angouleuses ou très-accidentées, qui présentent les contournements violents, la texture raboteuse el l'apparence bulleuse caractéristiques des couches supérieures d'une coulée de lave ordinaire. Le reste conslitue un massif de roche compacte et mème parfois presque vitreuse, craquelé dans tous les sens, divisé en gros blocs prismatiques par des fissures plus ou moins larges, et percé de grandes cavités sphéroïdales qui semblent dues à l'accumulation des vapeurs dégagóes peudant le refroidissement. Cetle roche, qu'elle soit compacte on scorifiée, est d'un beau noir de jais, qui donne à toute la coulcee une apparence caraclérislique; lorsqu'elle tend ì prendre la texture vitreuse, sa cassure devient conclıoidale et elle renferme des cristaux plus ou moins nets de substances diverses. Celte lave est essentiellement basaltique, car la pàte noire, facilement fusible au clalumeau, se compose presque uniquement d'une massc pyroxénique; on y dislingue des cristaux assez nets el quelquefois même presque parfaits, longos de 2 à 3 millimètres, de felılspatlı blanc vilreux on rhyacolithe; on y remarque aussi, mais en proportion beaucoup moins considérable, des granules de péridol ferrugineux, bruns ou jaunâtres, à reflets irisés, souvent cristallins, el dont quelques-uns laissent voir des facetles hexagonales.

A mesure que l'on approche du pied du cône, la surface de la coulée de lave semble se scorifier davantagge el en même temps elle prend une légère inclinaison, 2 ou 3 degrrés en moyenne. Bientot, cette inclinaison devient suffisante pour que l'on puisse se considérer comme ayant alteint les premières pentes du cône, el la lave véritable disparaìt peu à peu sous un amoncellement confus de matériaux de toute espèce, dont les dimensions varient depuis le volune d'un mètre cube jusqu'à la grosseur de la tête. Il faudrait presque une inonographie spéciale pour décrire toutes les variétés de roches scorifiées ou vitrifiées qui existent dans ce chaos; il y a des blocs anguleux et déchiquetés, d'autres tout arrondis el dont la surface est revètue d'un enduit vitreux de surfusion; on y trouve des fragrments volumincux de scories noires, des morceaux de porphyre trachylique projetés par le volcan, el des blocs de lave basallique arrachés anx parois de la fissure primordiale; nous y avons vu des masses noires, bulleuses et grenues, renfermant des cristaux de rlıyacolillıe el de péridot, mais point d'amphigòne, quoiqu'elles ressemiblent à s'y méprendre aux leucilophlyyres du Vésuve, el des débris porphyro- 
tracliytiques empàtant une proportion considérable d'amphibole en jolies bagoneltes noires de quelques millimètres de longueur, introduites peut-être postérieurement dans la roche. En un mol, il existe lì une collection complète de tous les matériaux rejetés par le volcan, depuis les laves et les roches préexistantes qu'il entraine du sein de la terre et des bords de la fissure à laquelle il doit son origine, jusqu'aux scories et aux lapilli qu'il produit en transformant ces mèmes matières sous l'influence combinée des vapeurs aqueuses ou acides et de la clialeur. Presque toutes ces pierres énormes ne sont pas arrivées directement à la place qu'elles occupent; mais, apiès avoir été vomies par le cratère pendant tes éruptions paroxysmales, elles sont venues retomber sur les flancs du cône, où les pentes sont trop for'es pour pouvoir les retenir, et elles ont roulć ensuite jusqu'en bas. Les phis grosses, cntrainces par leur vitesse acquise, ont encore avancé dans le champ de lave horizontal jusqu'à des distances plus ou moins considérables, tandis que les autres, arrètées à la base du cône, s'y sont accunulées les unes audessus des antres el ont ainsi contribué à relier la surface de la coulée de lave aux pentes fortement inclinées du volcan, par un amoncellement de matériaux, formant en quelque sorte une zone intermédiaire.

Le còne proprement dil se compose entièrement de scories en pelits morceaux, entassćes à la suite de chaque éruption et disposées en conches quaquaversales très-fortement inclinées. Lorsque, du champ de lave, on voit se dresser devant soi, jusqu'à une hanteur de 284 mètres au-dessus du point où l'on se trouve, ce còne tellement régulicr, qu'il scmble avoir été construit de main d'homme, tellement lisse, qu'une montagne aussi unie paraîl avoir été faite au tour, tellement incliné, que l'on se demande si l'on pourra s'y tenir debout, on reste saisi d'admiralion, et l'on contemple avec une cerlainc émotion ces œuvres majestueuses où la nature a su réunir tant de grandeur el de gràce. La surface de la coulée de lave, au point où elle s'arrête brusquement au contact des premiers contre-forts de la Madre del volcan, est à 1,541 mètres au-dessus du niveau de la mer; comme elle altcint jusque près du village d'Izalco ( 455 mètres), il faut, pour racheter en quelques lieues celle dénivellation de 1,000 mètres environ, que sa pente soit assez forte. Si donc le còne du volcau d'Izalco produit déjà un tel effel lorsqu'on l'aborde du côlé du nord, où il ne dépasse que de 284 mètres l'espace plan sur le- 
DANS LES RÉPUBLIQUES DE GUATEMALA ET DE SALVADOR. 389 quel il repose, que serait-ce si l'on en voulait tenter l'ascension par le flanc sud qui doil se dresser à 350 ou 400 mètres au moins an-dessus des plaines environnaules! Les grosses pierres entassées au pied du cône ne s'élèvent gouère sur' ses flancs, el, pour les dépasser entièrement, il suffil de monter à une vingtaine de mètres au-dessus de la coulée de live. On n’a plus alor's devant soi qu'une surface courbe, composée de scories, de cendres et de sables, mèlés ì quelques cailloux roulés arrètés accidentellement dans leur cour'se, et dont l'uniformité at quelque chose d'étrange.

Au début, on trouve encore quelques grosses pierres sur lesquelles on peut appuyer le pied; mais bientôt les plus volumineuses ne dépassent pas les dimensions du poing, et, à mesure que l'on s'élève, les fraggments se réduisent ì des dimensions de plus en plus petites. La surface devient en mème temps de plus en plus lisse et son inclinaison s'augmente considérablement; on se trouve bientôt sur des pentes de 37 degrés, qui, un peu plus haut, altcionent et dépassent mềne 40 degơrés! Rien ne saurait rendre l’impression pénible que l'on ressent, les fatigues inouies que l'on éprouve, lor'squ'il s'agit de monter avec effort sur une surface si unie, que l'œil cherche en vain un point où l'ou pourrait se retenir si l'on faisait un faux pas, sur une pente telle, que l'on manque à claque instant d'y perdre l'équilibre, au milieu de matériaux si meubles, que l'on y enfonce jusqu'ì mi-jambe, el que chaque fois que, faisant un effort pour avancer d'un pas, on cherche un point d'appui dans le sol, tout s'éloule, ghlisse, coule, s'enfuit autour de vous et vons entraine bien au-dessous de l'endroit où l'on élail arrivé après lant de peines et de tentatives infructueuses. Nous royons encore, comme s'il ćlait devant nous, un pelit bloc de rocher, du volume d'un dixième de mètre cube environ, arrèté par le plus grand des hasards à mi-lauteur du cône à peu près, el faisant saillie au milieu des scories fines dont il était environné de toutes par's : il ful notre but pendant toule la première moitié de notre ascension el nous procura de bien vives jouissances en nous offrant pour un inslant un point d'appui relativement solide, quoique branlant. Mais l'effort qu'il nous fallut faire pour contiuuer à monter suffit pour le déplacer, et il roula jusqu'en bas avec fracas. Nous le.regretlons sincèrement pour ceux qui graviront par la suile le volcan d'Izalco el ne trouveront plus à mi-chenin ce précicux auxiliaire! 
Yalure des roches qui romposent le conne.

Sonnel hu volean d'lzalen.

Quoique très-variables d'aspecl, les scories ont probablement toutes une nature analogue; sauf quclques morceaux rougeàtres produits par la surfusion des porphyres-trachyliques cntraînés, et par cela mème feldspathiques, la majorité doit être pyroxénique, comme provenant de laves basaltiques telles que celles qui existent au pied du volcan. Nous n'avons pas vu de ponces, mais les scories sont, en gónćral, très-bullcuses, légères el à texture raboteuse. Les nuances sont extrèmenent variables et passent du ronge au noir par tous les intermédiaires des bruns; quelques échantillons noirs ressemblent d'une manière singulièrc à des morccaux de coke, dont ils possèdent mème la cassure brillante et l'ćclat métallique. Les sables volcaniques et les sables de trituration locale sont aussi cxtrêmement abondants, mais leur proportion augmente à mesure que l'on s'approche du sommet du volcan; le barrcau aimanté ne nous y a pas indiqué la présence de l'oxyde de fer magnétique. Dans la partie supéricure du cône, on remarque de rastes plaques blanchìtres formées par des croùtes aluncuses el sulfureuses, d'un on deux millimètres d'épaisscur, étendues à la surface des sables au voisinage des fumcrolles. Ces espaces blancs ressemblent de loin à de petits champs de neige et nous avaient fort intrigués la veille, lorsque nous examinions la montagne arrètés anx Ranchos rlel volcan, où nous avions passé la nuit.

Après deux heures d'eflorts incessants, après avoir péniblement hıllé, surtout dans la seconde partie de l'ascension, contre les obslacles que nous opposaient les pentes inclinées de 40 degrés et composées de matériaux extraordinairement meubles, uous altcignimes enfin, à huit heures du matin, le point le plus élevé du volcan. A ce moment, une bouffée de vent, rejetant de notre coté l'épaisse colomne de fuméc qui s'échappail du cratère, nous restàmes quelque temps cnveloppés dans 1110 vapeur opaque qui nous empèchail de ricn distinguer autour do nous, et dont la violente odeur sulfureuse et chlorhydrique nous prenait à la gorgoge d'une manière extrêmement pénible. Le sol ćchanffé nous brülait les pieds à travers nos bottes, de sourds grondements se faisaient entendre dans les profondeurs du volcan, el, pendant quelque temps, nous reslàmes à moitié asphyxiés, indécis, nous demandant si la prudence ne nous conseillait pas de renoncer à notre entreprise. Mais le nnage se dissipa bientôt, entrainé d'un autre côté par le courant d'air; nons nous apcrçumes en même lemps que nous marchions au milicu d'une fumerolle 
DANS LES RÉPUBLIQUES DE GUATEMALA ET DE SALVADOR. 39I extrèmement chaude, dont il suffisail de nous éloigner de quelques pas pour que la température du sol fùt supportable, quoique toujours très-élevée. Hors reprenaut courage, uous commençìmes, en ayant soiu de nous teuir autaut que possible hors du vent des vapeurs, à nous livrer à un examen méthodique du volcan, de son cratère et de ses fumerolles.

Le sommel du cone (voir pl. X, figg. 2) ne doit pas différer beaucoup actue!- Disposition relatis lement de ce qu’il élail en 1840 , lorsque M. Stephens put l'examiner de loin. des trois cratires C'est encore un vaste espace ayant la forme d'une ellipse irrégulière très-allougée, dans lequel s'ouvrent trois orifices ou cralères inégaux, qui présenteul des degrés d'activité très-différents. Le grand axe de l'ellipse, coüncidant presqur exactement avec la ligone des centres des trois cratc̀res, est dirigé de l'est $35^{\circ}$ nord à l'ouest $35^{\circ}$ sud; la longueur en est de 160 mètres environ, celle de l'axe transversal ne dépassant pas go mètres. Outre les trois cratères, on peut observer, au sommet du volcan, dans la direction du sud, un pelit espace plan irrégulier (D), large de 30 -mètres environ et long d'une quaranlaine, dont le sol, légèrement ondulé, se compose de sables assez fins, au milieu desquels apparaissent quelques pierres plus volumineuses. Cel espace plan, très-doucement incliné vers le sud, se trouve ì 1,805 mètres au-dessus du niveau de la mer et à 2 mètres plus bas que le bord dı cralère voisin, auquel il se raccorde progressivement au sud-onest par une pelite éminence conique. La ligne enveloppe des trois cralères, formant ce que l'on pourrait appeler le bord de la dépression générale existant au sommel du volcan, est parfaitement continue, quoiqu'un peu accidentée. Le point où mous avions atteint toul d'abord le sommel de la montagne se trouve à 1,80 7 mètres d'allilude, et c'est aussi la hauteur moyenne de la plus grande partie de l'enceinte gónérale. Mais elle est plus élevée en quelques endroits el présente notamment trois points culminants, correspondant plus ou moins exactement aux nocuds produits par Io contact des bords propres de chaque cratère. Le premier, du côté du sud-est (C), ue dépasse que de 5 mètres la hauleur moyenne de l'enceinte; le second (B), au nord, est plus haut d'une dizaine de mètres, el le troisiène enfin $(\Lambda)$, au nordouest, alteignant l'altitude de 1,825 mètres, constitue le sommel le plus élevé du volcan d'Izalco. Excepté du còté du sud, oì existe l'espace plan dont nous arons parlé, le bord de l'enceinte générale forme une vériabłe liggne mathématique, car, 
les pentes changeant brusquement de sens, on ne trouve pas plus de quelques centimètres de terrain horizontal entre les flancs extérieurs très-inclinés et les parois abruples de l'intérieur. Les matériaux qui composent le sol y sont aussi meubles que sur tout le reste du volcan; les sables, souvent extrêmement chauds, se déplacent sous le pied avec une excessive facilité, les croùtes aluneuses se fendillent el glissent en morceaux aussitot que l'on y touche; les fissures, d'où s'échappent de tous cốtés des fumerolles, s'éboulent dès que t'on en approche, et il faut marcher avec de très-grandes précautions sur ce terrain mouvant pour ne pas y courir des dangers réels. Les cratères élant en contact immédiat, la ligne qui les sépare forme une arête singulièrement aiguë, el il est très-difficile de prendre ce chemin pour passer d'un côté à l'autre, ce que nous n'avons eu gouère envie de recommencer, après avoir eu l'imprudence de le faire une fois. Quoique l'instabilité du sol soil presque générale, il y a pourtant quelques endroils où l'on aperçoil de la roche solide, el où l'on peut se reposer quelque temps sans craindre de voir loul se meltre brusquement en mouvement. Les points culminants, en particulier, sont formés de blocs entassés, reposant sur un massif rocheux, souvent coupé à pic sur me hauteur de quelques mètres du côté de l’intérieur. Ces pelites falaises se retrouvent mème en quelques autres points des parois intérieures des cratères, et soutiennent un peu les sables mouvants des environs, sur lesquels il serait lout à fait impossible de s'avancer sans cette circonstance.

Vatètes extrêmes

Les deux dépressions extrèmes sont relativement dans un étal d'activité peu ien prononcte. intense, si on les compare à celle du milieu, qui est en ce moment le véritable cralère du volcan d'Izalco, le cratère par lequel ont été amenées au jour les déjeclions vomies pendant toutes les éruptions anciennes et récentes. Le cratère du nord-est est une cavilé relativement pen considérable, dont l'enceinte, irrégulièrement circulaire, semble comme aplatie d'un côté. Son plus grand diamètre est de 25 mètres environ et sa profondeur d'une douzaine. Les parois, assez régulières quoique fortement inclinées, se composent de scories et de sables mouvants, et se raccordent à un petil espace plan formant le fond. On y remarque quelques pelites falaises solides, en particulier du côté du nord, oǹ un mur rocheux de 4 à 5 mètres de hauteur donne naissance, entre ses fissures, à un assez grand nombre de fumerolles, qui le recourrent d'ume grande quantité de soufre en jo- 
DANS LES REPUBLIQUES DE GUATEVALA ET DE SALVADOR. 393 lies aiguilles cristallines jaunes. Le cratère du sud-onest, beaucoup plus vaste que le précédent, est aussi beancoup plus irrégulier. Son bord, qui se confond progressivement avec la plaine du sud, dessine nne courbe à peine circulaire d'un diamètre d'une cinquantaine de mètres en moyenue. La profondeur étant de 5 ou 6 mètres, les parois, presque partout verticales, viennent tomber sur un espace fortement ondulé qui constitue le fond; ces parois semblent avoir été profondément bouleversées, et l'on y voit un chaos indescriptible de rocher's plus ou moins volumineux, de scories, de sables mouvants el même de masses argịleuses, produites par les matières atlaquées sous l'influence des vapeurs acides. Au milieu de ces argiles, on voit en quelques endroits de petits trous dans lesquels bouillonne une malière pâleuse d'un brun jaunâtre, contenant probablement ine forte proportion de chlorures de soufre et de fer.

Le cratère principal, silué entre les deux autres, est assez régulièrement circulaire, et présente un diamètre de 80 mètres environ. On ne saurait mieux le conparer qu’à un entonnoir, dont les parois, fortement inclinées à l'est, presque verlicales à l'ouest, se composent, d'un còté, de sables mouvants recouverts d'alun el de soufre, de l'autre, de rochies solides formant falaises à pic, mais seulement sur un quart de la circonférence à peu près. Cette dépression mesure à peu près 25 mères de profondeur, mais elle ne conslitue qu'une première partie du cratère, et, pour compléter la ressemblance avec un entonnoir, elle se termine, à sa partie inférieure, par une sorte de conduit souterrain qui s'enfonce verticalemenl dans le sol. On voil, en effet, an fond de cette excavation, un vaste trou noir el béant, déjeté un peu du côté de l'ouest, c'est-à-dire vers le pied de la falaise presque verticale qui descend du point culminant, et qui ressemble de tous points à l'embouchure d'un puits de mine creusé dans une puissante masse de roche solide et compacte. La section de cel orifice est presque exactement rectangulaire, l'un des côlés ayant 5 mètres de longueur el l'autre seulement 4, tandis que ses parois, disposées à angle droit les unes sur les autres, paraissent tout à fail verticales, au moins jusqu'ì une certaine profondeur. Il n'y a, pour ainsi dire, pas de dérangements ou d'accidents, et l'ensemble offre une telle apparence de régularité, que l'on se croirait volontiers en face d'un muraillement exécuté par un architecte amateur de la ligne droite, bien plutôt qu'auprès d'un des endroits où se 
manileste, sous sa forme la plus violente et la plus tourmentée, un de ces terribles phénomènes de la nature qui semblent n'avoir pour loi que le désordre et pour terme que la destruction.

Malgré notre désir d'examiner de près les bords de ce puils effrayant, nous dûmes nous contenter de le considérer du haut du point culminant, qui en est en somme extrèmement rapproché; car il ne lallait pas songer à s'aventurer sur les premières pentes de l'entonnoir, formées unicquement de natériaux meubles, el où un faux pas aurail infailliblement anené la mort. Ge conduit souterrain doit traverser toute la masse du volcan et s'enfoncer jusqu'aux entrailles de la terre; il n'existe aucun moyen de se rendre compte de sa profondeur, car le regard se perd bien vite dauş ses sombres abînes, et, si l'on y jelte une pierre, on ne constate point le moment où elle alteint le fond, comme cela aurail lien dans un puits fermé. Nous arons plusieurs fois répété l'expérience en y précipilant des blocs de rocher assez volumineux; après un instant de silence plus ou moins prolongé, suivant que la pierre avait pénétré plus ou moins verticalement, on l'entendait frapper contre une des parois, puis rebondir contre l'autre, el ainsi de suile pendant fort longtemps, le bruit diminuant d'intensité jusqu'à devenir imperceptible et finissant par se perdre, sans que jamais cela se soit terminé par un whoc, comme si le projectile avait rencontré une paroi terminale où il se lùt arrèté. Les murailles du puils sont évidemment formées de roches solide̊s et conlimues, car elles semblent aussi lisses que si elles avaient été taillées au ciseau; mais on n'en peut reconnaitre la nature, car elles sont reconvertes d'un enduit pulvérulent d'alun et de soufre, déposé par les puissants volumes de vapeurs qui s'en dégagent incessamment. Cette colonne de fumée oppose un obslacle asse\% sérieux à l'examen du cratère, el il nons a fallu une observation très-prolongée pour arriver à saisir les détails quion vient de lire, en profitant des moments où le dégagement diminuail d'intensilé, ou bien de ceux où une bouffée de vent rejetait violemment les vapeurs du còté opposé à celui où nous étions. On entend continuellement dans l'intérieur de ce puits vertical un sourd grondement semblable à celui d'un gaz qui s'échappe à une forte pression, et, de fail, on peut voir que les vapeurs qui en sortent sont chassées avec une rapidité qui dénote une puissance d’impulsion considérable. Il se produit, en oulre, de temps en temps, 
DANS LES RÉPUBLIQUES DE GUATEMALA ET DE SALVADOR. 395 d'assez violentes détonations semblables à un coup de tonnerre éloigné; ces détonations se répètent à intervalles égoaux d'environ un quart d'heure, et l'instant d'après on voil la colonne de fumée s'écliapper avec plus de force et en plus grande abondance. On entend aussi des délonations, beaucoup moins fortes, il est vrai, mais accompagnées d'un tremblement du sol assez violent, qui se répète de cinq en cinq minutes ì peu près, sur le bord extérieur du cratère latéral qui existe au nordest, à 'côté d'une fumerolle extrêmement chaude $\left(n^{0} 5\right)$, dont nous aurons à parler ci-après. Ces grondentents soulerrains et ces tremblements du sol auraient suffi pour nous prouver que le volcan ne devait pas tarder à reprendre son état l'éruplion violente, si l'abondance et la température des fumerolles n'eussent élé un indice encore plus convaincant.

Les fumerolles sout en quantilé innombrable, presque toujours très-chaudes et très-abondantes, et apparaissent un peu de tous les côtés, sans qu’il soit possible de saisir une loi bien apparente dans leur répartition. It faut naturellement placer en première ligne, parmi les fumerolles, le puits vertical du cratère centra] qui émet conslamment d'énormes volumes de vapeur. La quantité de gaz qui s'en échappe est extrêmement considérable, car elle forme presque à elle seule

Réparlition des fumerolles.

Dégragement de gaz. par 1e. puils vertical du cratère central. la colonne de fumée couronnant la cime du volcan, et elle s'élève dans l'atmosphère ạvec une pression violente sous la forme d'épais nuages goris ou blanchátres. Le volume, la pression et l'aspect gónéral de ces vapeurs sont un peu variables suivant les moments, el suivent une marche qui est en rapport avec l'intensité des grondements souterrains; dans l’instant qui suit les détonations, la colonne de fumće est plus abondante, plus rapide, el elle commence par ètre d'un gris assez foncé pour se transformer progressivement en une vapeur blanchâtre, puis en un gaz presque incolore. De sa lempérature et de sa composition nous ne pouvons rien dire, puisquilil nous a été absolument impossible d'arriver jusquau bord du puits; mais nous avons pu constater, pendant uu moment où nous arons ćlé surpris sur le point culminant par un cliangement brusque dans la direction du vent, que nous étions enveloppés dans un épais nuage fort chaud, composé surtout de vapeur d'eau el contenant une proportion d'acide sulfureux et d'acide chlorhydrique, assez considérable pour que le séjour dans cet endroit fìt devenı extrèmement pénible et eût même pu être dangerereux, si les choses étaient 
restées quelques minutes de plus dans le même état. Le cratère central est inconlestablement l'évent principal du volcan d'Izalco, el donne peut-être plus de gaz à lui seul que la réunion de toutes les autres fumerolles, qui sont pourtant d'une abondance caracléristique.

Fumerotles

à l'intérieur

des cratères.

Les fumerolles se trouvent, soil dans l'intérieur des cratères, soit à l'extérieur le long de leurs bords, soit enfin sur les flancs du cône suivant des fentes lonģitudinales formées dans la direction des génératrices. Nous ne voulons pas essayer de les énumérer, car leur nombre est effrayant et nous ne pourons pas mème être certain de les avoir toutes aperçues, ayant été souvent entourés d'un nuage de vapeur si épais, que l'on ne voyait plus rien du tout. Voici en quelques mots comment sont répartis les groupes principaux, el, pour simplifier la description, nous supposerons qu'arrivés sur le volcan par le bord du nord-est nous regardons devant nous du côté du sud-ouest; nous aurons alors à notre gauche le quart de circonférence du sud-est et à notre droile celui du nord-ouest.

Dans l'intérieur du premier cratère, il y a quelques fumerolles sur les parois de gauche au milieu des scorics et des sables mouvants; mais les plus importantes se trouvent à droite, sorlant des fissures de la petite falaise rocheuse verlicale et surtont d'une petite caverne qni existe an-dessous de ce massif. En ce deruier point $\left(\mathrm{n}^{\circ} 6\right)$, nous avons conslaté une température de 120 degrés et observé un abondant dépôt de soufre en aiguilles cristallines lapissant les murailles de la cavité.

Le cratère central est littéralement rempli de fumerolles dans toutes les direclions, sauf peut-ètre dans la paroi verticale de droite, au-dessous du point culminant ( $\Lambda$ ); elles s'échappent d'une énorme quantité de fissures el de trous, qui existent de tous còtés dans les masses de sables et de scories accumulées avec une inclinaison le plus souvent très-considérable; le sol est fendillé et perforé de manière à rendre le séjour à peu près impossible en cet endroit. Quoiqu'il ne soit pas prudent de s'aventurer sur un terrain aussi dangereux, nous avons réussi à nous approcher de quelques-unes de ces fumerolles et à en prendre la température. Les premières sont à droite $\left(n^{\circ} 4\right)$, au pied d'un petil escarpement vertical, haut d'un mètre environ, qui sépare le bord du cratère el les premières pentes de l'entonnoir; leur température est de $9^{6}$ à 97 degórés. Les autres font partie d'un 
DANS LES RÉPUBLIQUES DE GUATEMALA E'T DE SALVADOR. 397 groupe important ( $\mathrm{n}^{\circ} 3$ ) qui s'éclappe en beaucoup de points de l'arète aig̛uë exislant entre le second el le troisième cratère; elles présentent aussi une température qui varic entre $9^{6}, 9^{6,50}$ et 97 degrés.

Dans le troisième cratère, il y a aussi une quantité innombrable de fumerolles, réparties un peu dans tous les sens, quoiqu'un peu phis abondantes vers le sud; on tes voit sorlir des amas de scories, des argiles ou des interstices exislant entre les blocs de rochers dont l'entassement désordonné constitue les parois. C'est là que, dans les argiles, on voit bouillonner dans des trous de petits amas de matières visquèuses jaunàtres dont nous avons déjà parlé. L'accès de l'intérieur de ce cratère est extrêmement difficile à cause du peu de slibilité des rochers amoncelés et de la nature des argiles delayées dans lesquelles on enfonce profondément. Aussi n'avons-nous pu nous approcher que d'une seule fumerolle $\left(\begin{array}{ll}n^{\circ} & 13\end{array}\right)$, située an fond du cratère à gauche, el dont la température est de 273 degrés. Il est probable que les autres fumerolles sont aussi à une température élevée, car le sol est parlout très-chaud, presque brûlant parfois.

Extérieurement aux cratc̀res, le long de leurs hords, on trouve encore um grand nombre de fumerolles, mais seulement du côté gauche, car à droite on n’en apercoit pas une seule. Au point extrême du nord-est, c'est-à-dire à l'endroit même où nous avons abordé le sommet du volcan, le sol est extraordinairement échauffé par la présence de quelques fumerolles qui s'échappent de plusieurs perforations irrégulièrement distribuées; elles présentent ce caractère singulier d'ètre absolument invisibles, et de ne se manifester que par ce tremblotlement de l'almosphère produit par l'élévation de l'air chaud. C'est là, d'ailleurs, que l'on entend des grondements souterrains el que la terre tremble de temps en temps. Iu point où le dégagement est le plus violent (et lorsqu'on l'examine de près on peut aisément en suivre toutes les phases, quoiqu'il paraisse invisible lorsqu'on n'est pas averti de sa présence) le sol est comme gonflé, sous la forme d'un petit mamelon conique composé de cailloux entassés, sous l'effort des gaz qui tendent à s'échapper. La tempéralure y est extrèmement élevée, et nous avous à nous féliciter de r'avoir commencé ì expérimenter sur cette fumcrolle qu'après que nous avions déjì visité el étudié presque tous les points principaux du volean. A peine, en effet, en avions-nous approché 1 m grand thermomètre, pouvant 
monter à 360 degrés, que le mercure entrant immédiatement en ébullition tumultueuse, l'instrument vola en éclats. De petits morceaux de papier ou de bois que l'on y jette sont carbonisés en peu d'instants, et nous regrettons vivement de n’avoir pas eu avec nous de lames mélalliques pour pouvoir évaluer cette température, qui doit certainement dépasser de beaucoup 400 degrés.

Entre le premier et le second cratère, tout autour du point culminant (B) situé à gauche, on voit un grand nombre de fumerolles, formant un groupe qui, se perdant un peu au milieu des vastes croùtes alunifères existant dans cet endroit, semble se raccorder par en bas aux fissures régnant sur les flancs du cône. Ce groupe se prolonge sur les bords du cratère à droite, et nous y avons observé $\left(n^{\circ} 1\right)$ une tempéralure de 101 degrés. On peut considérer la plaine du sud-est comme faisant partie du bord, dont elle n'est, jusqu'à un certain point, qu'un b́largissement. Les fumerolles qu'on y observe sont extrêmement nombreuses, et sp relient aussi bien aux fissures des flanes du cône qu'aux dégagements du troisième cralère, car elles jaillissent de toutes parts du sol fortement échauffé. Lee plus grand nombre s'échappe des perforations qui existent dans le sol composé de sables et de scories, mais les plus volumineuses arrivent au jour entre les interstices des rochers dont est formé le mamelon irrégulier existant à droite. An pied de ce monticule, nous avons trouré à plusieurs fumerolles importantes $\left(\mathrm{n}^{\circ} 2\right)$ une température de 185 degrés.

Finncrolle: sur les flancs

Sur les flancs du cône, les fumerolles sont très-régulièrement réparties sur les fissures existant suivant les génératrices, du moins dans la demi-circonférence du sud. Dans la demi-circonférence du nord, il n'existe qu'une seule fumerolle, située presque exactement au nord, el an 3/5 à peu près de la liauleur du volcan. Elle est extrèmement importante, el donne un volume de vapeur considérable; malhenreusement nous n'avons pu prendre sa tempéralure, qui doit ètre assez élevée, parce que notre grand thermomètre ayant été brisé, comme nous l'avons exposé plus haut, nos autres instruments n'étaient plus suffisants pour celte opération.

4. gauche du premier cratère, on voit une fissure assez importante, diriggée presque exactement à l'est, et descendant jusqu'à une soixantaine de mètres audessous du sommet du volcan. Toute sa partie supérieure traverse un vaste espace recouverl de croùtes d'alun blanchàtre, nuancé de jaune, de vert et de gris, ce qui 
DANS LES RÉPUBLIQUES DE GUATEMALA ET DE SALVADOR. 399 semble prouver que ces fumerolles ont eu autrefois une activité plus considérable que celle qu'elles présentent aujourd'hui. Il n'y a pas, en eflet, sur ce point, de dégagement de gaz très-volumineux.

Les deux fentes les plus remarquables, très-voisines l'une de l'aulre, son! dirigées au sud-est, et partent, l'une du bord du cralère central à gauche, l'autre de l'espace plan. Toules deux sont tracées au milieu des scories fines el des sables qui forment le cône el descendent jusqu'à une cenlaine de mètres au moins audessous du sommel du volcan. Elles sont jalonnées par une quantité si considérable de fumerolles, que l'on pourrait presque les considérer comme un orifice de dégagement tinéaire continu, s'il n’y avait pas des différences inporlantes de composition el de température entre les diflérents points. Les bords des fissures sont abondamment garnis de croûtes aluneuses varićes et de dépôts de soufre, qui présentent, dans cerlains cas, une coloration d'un rouge vermillon très-remarquable. Cette couleur rouge, combinée avec la nuance blene de cerlaines funerolles et avec leur odeur particulière, nous avait fait supposer que ce soutre pourrail bien contenir une certaine proportion de sulfure d'arsenic; nnalheureusement, les échantillons que nous avions recueillis pour les sounellre à l'analyse ne sont pas parvenus en France, et nous ne pouvons que présenter une hypothèse sur un fait qui aurait pu être très-intéressant, si nos supposilions avaient été vérifiées par l'expérience. L'intensilé des dégạgements de gaz n’est pas la mème sur tonte la longueur des fentes, car on peut distinguer des fumerolles trèsabondantes, irrégulièrement espacées, reliées par des séries de pelites émanations moins saillantes. La fissure qui prend naissance à l'espace plan, en particulier', se termine brusquement, à 120 ou 1.30 mètres au-dessous du sommet du volcan, par une fumerolle d'un volume énorme, sortant de dessous un pelil massif rocheux. Pour éfudier ces fumerolles, nous sommes descendus le long de l'une des fentes et remontés en suivant l'autre, au milieu d'un sol brûlant, de scories, de soufre, d'alum, et fortentent incommodés presque lout le temps par l'intensité el l'acidité des dégagements de gaz. Sur la première fissure, nous avons observé les températures suivantes, en des points silués respectivement à environ 25,50 et 75 mètres au-dessous du sommet; au premier $\left(n^{0} 7\right) 165$ degrés; puis $\left(n^{\circ} 8\right) 208$ degrés et enfin $\left(n^{0} 9\right) 285$ degrés. Sur la seconde fissure, en des points à peu près 
correspondants, nous avons trouvé des températures de 144 degrés $\left(n^{\circ} 10\right)$, 189 degrés $\left(n^{\circ} 11\right)$ et enfin 305 degrés ( $1^{\circ} 12$ ); mais nos forces ne nous ont pas permis d'arriver jusqu’à la grande fimmerolle terminale.

Outre les fissures dont nous venons de parler, il en existe encore deux aulres, qui ne sont pas tout à fait aussi importantes, quoiqu'elles soient fort remarquables. Nous avons dù renoncer à les examiner de près, tant nous étions épuisés par les efforts qu'il nous avail fallu faire pour descendre et remonter sur un terrain mouvant en examinant les précédentes, tant nous commencions à souffrir d'avoir respiré pendant plus de deux lıcures un air abondamment chargé de gaz méphitiques. Ces fissures présentent toutes deux des fumerolles importantes el s'élendenl aussi jusqu'à 100 mètres environ au-dessous du sommet du còne. La première part de l'espace plan et descend dans la direction du sud 20 degrés est; la seconde. dirigée à pen près au sud-ouest, prend naissance sur le bord du troisième cratère et semble prolonger la ligne des centres, dont la continuation dans le sens opposé rencontre aussi la fumerolle extrèmement chaude $\left(n^{\circ} 5\right)$ dont nous avons parlé plus haul.

Loi des températures

dans

les fumerolles.

En résunant toutes les observations que nous arous failes sur les tempéralures, nous pourrons entrevoir raguement une loi de répartition, qui souffre néanmoins certaines exceplions. D'abord nous verrons que, dans les cratères et sur leurs bords, la température n'est, en général, pas très-élevéc, puisqu'elle oscille entre 96 et 185 degrés. Il nous faut naturellcment meltre à part la fumerolle du fond du troisième cratère ( $11^{\circ} 13 \ldots 273$ degrés) et celle du bord du premier $\left(n^{0} 5 \ldots x+400\right.$ degrés) qui sont extrêmement chaudes. Nous ne serions mème pas étonnés d'apprendre que les phénomèmes éruptils qui se sont produits au volcan d'Izalco après notre ascension se soient passés au voisinage de la fumerolle $n^{\circ} 5$, ce qui expliquerait en partie un écart aussi considérable.

On se rend beaucoup plus nettement compte de l'accroissement de température qui se manifeste à mesure que l'on descend sur les flanes du còne. On y ronstate, en effet, sur chaque fissure, une augmentation graduelle bien caractérisée, mais sans que l'on puisse établir une loi de proportionnalité qui serait peut-ĉtre fournie par un nombre plus considérable d'observations. Ainsi, en mellant en regard les tompératures prises sur les deux fissures dont il a été question plus haul, et en 
DANS LES RÉPUBLIQUES DE GUATEMALA ET DE SALVADOR. 401 commençant par les points les plus élevés, on obtient les chiffres suivants, qui nous scmblent prouver que, la température élant minimum sur les bords des cratères, elle tend à augmenter à mesure que l'on s'en éloigne :

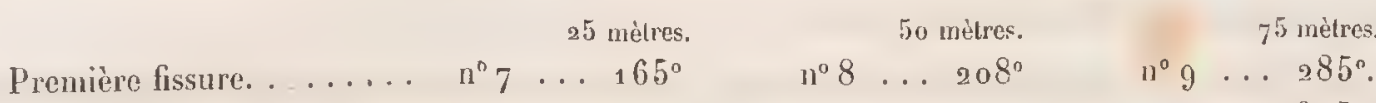

$$
\begin{aligned}
& \text { Seconde fissure....... } 1^{\circ} 10 \ldots 144^{\circ} \quad \mathrm{n}^{\prime \prime} 11 \ldots 189^{\circ} \quad \ldots \quad \mathrm{n}^{\circ} 12 \ldots 305^{\circ} \text {. }
\end{aligned}
$$

Au point de vue de la composition des dégagements de gaz, nous aurons ì faire quelques observations qui nons amèneront ì une conclusion assez nette; mais, pour cela, nous devons encore mettre à part la fumerolle $n^{\circ} 5$, qui présente une nalure tout à fail spéciale. Comme nous l'avons dit, elle est absolument incolore et ressemble à un véritable courant d'air chaud qui s'élèverail en tremblottant dans l'atmosphère; mais il s'en faul de beaucoup qu'il en soit réellement ainsi, car elle a une composition très-remarquable el assez complexe, autant que nous avons pu en juger dans les condilions où nous étions. L'extrême ćlévation de la température ne doit pas perinellie (qu'elle contienne de vapeur d'eau, et il est certain, dans tous tes cas, qu'on n'aperçoit autour d'elle aucune trace de condensation et qu'on u’y ressent ancune humidité; ce serait donc une fumerolle absolument sèche. Nous y avons constaté la présence d'un peu d'acide sulfureux et d'acide carbonique, mais aucune trace d'acide fluorhydrique. L'élément principal qui entre dans sa composition est l'acide chlorhydrique, dont elle doit èlre formée au moins pour les 9/1 o, au point que l'on pourrait presque la considérer comme un courant d'acide chlorliydrique gazeux à peu près pur, porté à une température excessive. Cet acide chlorhydrique exerce une action très-notable sur les fragments de roche entre lesquels il circule avant de s'échapper. Les cailloux porphyrotrachytiques en particulier, baignés ainsi dans une atmosphère chande el acide, sont allaqués avec une grande rapidité, gràce à leur composition feldspathique. Ils deviennent verdàtres ou jaunes, se-transforment en chlorures déliquescents qui couvrent la roche d'un enduil visqueux, s’imprègnent d'acide chlorhydrique interposé entre leurs pores, et ne lardent pas à ètre complétement détruits. L'almosphère est irrespirable aux environs de la fumerolle, el, si l'on en approche de trop près, on ne larde pas à ressentir des accès de loux el de suffocation. Un flacon d'ammoniaque débouché à une assez grande distance répand immé- 
diatement des fumées de chlorhydrate d'ammoniaque excessivement abondantes; si l'on pose le bouchon sur le col du flacon, sans l'enfoncer, la réaction se continue, el le bouchon est soulevé avec force pour laisser passage au nuage blanchàtre qui se répand à l'extérieur.

Toutes les autres fumerolles obéissent plus ou moins complétement à une loi qui est en rapport direct avec celle des températures, si toutefois elle n'en est pas l'origine même. On constate, en effet, que la proportion de vapeur d'eau est essentiellement variable dans les fumerolles du volcan d'Jzalco, el qu'il y en a plus ou moins, suivant que la température est relativement basse on .élevée. La vapeur d'eau pourrait donc être considérée comme un agent refroidissant; mais il resterait encore à expliquer pourquoi la vapeur d'eau se trouve de préférence dans les régoions supérieures du volcan. Qüoi qu'il en soil, la différence de composition des fumerolles de l'Izalco est assez aisément révélée à première vue par la différence d'aspect, car on peut établir deux grandes classes contenant les fumerolles sèches et les fumerolles aqueuses; les premières étant légères, transparentes, colorées d'un joli bleu vif, tandis que les secondes sont lourdes, opaques el complétement blanches.

Les fumerolles bleues ne renferment que très-peu ou point de vapeur d'eau; elles se composent, en majeure partie, d'un mélange d'acide chlorhydrique et d'acide sulfureux, auquel il faut ajouter une petile quantité d'hydrogène sulfuré, d'acide carbonique, d'azote, et peul-être un peu d'hydrogène arsénié. La présence de l'arsenic semble indiquée par des dépôts d'un beau rougge de vermillon, accumulés près de quelques-unes de ces fumerolles; mais, quoique ce ne soit pas un fail nouveau dans l'histoire des phénomènes volcaniques, l'arsenic ayant déjà été rencontré dans la solfatare de Pouzzole par MM. Charles Sainte-Claire Deville el Fouqué, nous n'osons pas l'affirmer péremptoirement, n'ayant pas pu, par suite d'un accident, faire l'analyse des échantillons que nous avions recueillis. La vapeur d'eau n'est certainement pas tout à fail absente, mais, à une température aussi élevée (200 à 300 degrés) elle a une tension de plusieurs almosphères et se dilate tellement, que sa proportion est en réalité très-faible et que l'on n'aperçoil aucune trace de condensation lorsque les gaz se répandent dans l'atmosphère. Il est de toute évidence que les proportions de ces éléments sont susceptibles de varier à l'infini, el qu'au point de vue de la composi- 
DANS LES RÉPUBLIQUES DE GUATEMALA ET DE SALVADOR: 403 tion il y a passage graduel du groupe des fumerolles bleues à celui des fumerolles błanches.

Les fumerolles blanches renferment un volume de vapeur d'eau très-variable, mais toujours considérable par rapport au volume total, dont elte conslitue l'éléFumerolles ment principal. Elles contiennent, en outre, une grande quantité d'acide sulfureux, de l'acide chlorhydrique en proportion variable, et enfin un peu d'hydrogène sulfuré, d'acide carbonique et d'azote. Il est à remarquer que la vapeur d'eau et celle d'acide chlorhydrique semblent se remplacer en quelque sorte, l'une augmentant à mesure que l'aulre diminue. Ce que l'on pourrail dire sur la composition d'une des fimerolles aqueuses ne pourrait être considéré que comme un cas particulier, et non pas comme un type susceptible de rien faire préjuger sur la naturc des émanations appartenant à la même catégorie; car, les éléments restant presque toujours les mêmes, ils peuvent varier considérablement par rapport à leurs quantités relatives. La seule chose certaine, c'est que la température de ces fumerotles étant, en général, un peu supérieure à 100 degrés, c'est-ì-dire très voisine du point d'ébullition de l'eau, quoique en dessus, elles doivent contenir des proportions de vapeur d'eau énorme, au détriment des autres éléments. C'est à peine s'il doit rester quelques centièmes du volume total pour l'acide carbonique, l'acide sulfureux et l'acide clılorhydrique, qui semblent pourtant, à première vue, devoir être un des principes constituants les plus abondants du gaz.

Les fumerolles bleues se trouvent dans la partie inférieure des fissures existant suivant les génératrices du cône, à une cinquantaine de mètres au moins auldessous du sommet du volcan, dans les points où la température, d'après nos observations, varie entre 200 et 300 degrrés à peu près. Les fumerolles blanches occupent toute la région élevée du volcan, la partie supérieure des fissures, les bords des cratères et l'intérieur de ces dépressions, c'est-à-dire tous les points où la température peut être considérée comme oscillant entre $9^{6}$ et 185 degrés. Mais, encore une fois, cela ne peut pas ètre considéré comme tout à fait absolu, puisque l'on trouve dans l'intérieur du troisième cratère un dégagement aquenx à 273 degrés, et qu'il y a des fumerolles blanches dans des parties du cône relativement très-basses, comme on le voil à l'épanchement gazeux du nord $\left(n^{\circ} 14\right)$ et au bas de l'une des grandes fissures du sud-est. Malgré ces exceptions, on peut dire, en thèse 
générale, que les fumerolles bleues existent en majorité dans les régoions inférieures du volcan et les fumerolles blanches dans les parlies supérieures; ce qui revient à dire, d'après la loi des températures, que les premières caractérisent les points où la température est très-ćlevéc, ct les secondes, ceux où clle l'cst moins. Or les fumcrolles bleues sont en mème temps des fumerolles sèches, tandis que les blanches contiennent une forte proportion de vapeur d'eau; donc, dans la majorilć des cas, la présence de la vapeur d'eau cst concomilante de l'abaissement de la température, et il nè serait pas impossible que ce fùt précisément à la présence de ce corps que fùt dù le refroidissement. Le nombre de nos obscrvations n'est peut-ètre pas suffisant pour nous permettre d'exposer avec une certainc autorité unc autre conclusion que nous avons cru entrevoir; mais il nous semble que l'acide sulfureux étant considérć comme un élément à peu près constant, presque toujours prédominant, la variation se porte surtoul sur les proportions relatives d'acide chlorhydrique et de vapeur d'eau, qui se remplacent réciproquement suivant les mouvements de la température. L'acide chlorhydrique serait alors l'ćlćment calorifique, tandis que la vapeur d'eau serait l'agent refroidissant, el l'on arriverait à comprendre que, lorsque la température devient excessive, comme dans la fumerolle $n^{\circ} 5$, l'acide chlorlydrique puisse finir par exister presque seul. Si ces considérations étaient justes, on pourrait admettre que les variations correspondant aux mouvements de l'intensité éruptive, dans le volcan d'lzalco, se traduisent de la manière suivante : l'augmentation de la température entraîne en même temps celle de l'acide chlorlıydrique, tandis que la vapeur d'eau diminue et que l'acide sulfureux reste à peu près constant; la diminution de la température amène une diminution correspondaule dans la proportion d'acide chlorlyydrique, landis que la vapeur d'eau augmente et que l'acide sulfureux ne subil que de faibles variations.

Résumé. Mais, laissant les hypothèses, revenons aux faits en eux-mèmes et résumons ell quelques mols ce que nous avons observé relativement à la composition des dégagements gazeux du volcan d'lzalco.

Les fumerolles changent d'aspect suivant leur composition; elles peuvent etre bleues et translucides, ou blanches et opaques, suivant qu'elles out ou non la vapeur d'eau pour élément principal. 
DANS LES RÉPUBLIQUES DE GUATEMALA ET DE SALVADOR. 405

L'acide chlorlyydrique existe en très-grande abondance dans presque tous les dégagements, et devient ainsi le trail caractérislique de l'état éruplif du volcan d'Izalco. On le trouve presque pur dans une des fumerolles, el il existe dans toules les autres, quelle que soit la quantité de vapeur d'eau qu'elles contiennent, mais sa proportion relative devient très-faible quand celle de la vapeur augmente beancoup.

La vapeur d'ean, susceptible de disparaître quelquefois complétement, devient, dans d'autres cas, l'élément principal, el son augmentalion coincide, en gónéral, avec une diminution de tempéralure. Son absence absolue, dans certaines circonstances, constitue un fait caracléristique el important.

L'acide sulfureux existe dans toutes les fumerolles, et sa proportion ue semble pas varier autant que celle de l'acide chlorhydrique. C'est lui, en somme, qui forme la base constante des émanations gazeuses, et les corps variables ne font que l'accompagner, tandis qu'il reste l'ćlément fondamental.

L'hydrogène sulfuré, l'acide carbonique et l'azote se retrouvent dans toutes les fumerolles, mais à l'état de corps accessoires qui n'y jouent qu'un rôle secondaire. Les lois de leur varialion ne nous sont pas connues, mais il ne serait pas impossible que l'hydrog̣ène sulfuré eût une certaine tendance à remplacer l'acide chlorhydrique lorsque la température s'abaisse. Peut-être y a-l-il même dans les fumerolles très-chaudes une cerlaine quantité de gaz arséniés dont nous soupçonnons la présence sans pouvoir la démontrer.

L'acide fluorhydrique n'existe dans aucune fumerolle.

Liacide borique ne se trouve pas dans les croûtes blanchàtres formées par l'action des fumerolles sur les matériaux voisins.

Somme toute, il résulte de ces considérations que le volcan d'Izalco est extrèmement intéressant, le plus intéressant peut-être de tous les volcans de l'Amérique centrale. Son origine récente, les puissantes coulées de lave produites pendant la première période de sa formation, la diversité des matières qu’il a éjaculées par la suite, la quantité de lapilli et de cendres qu'il a vomies, la forme admirable de son cone, l'inclinaison excessive de ses pentes, tout contribue à le rendre extrèmement remarquable. Son état éruptif incessant attire sur lui l'attention, et, quoiqu’il füt daus une période de repos relatif lorsque nous l'avons 
visité, on a pu voir que la disposition de ses cratères, l’immense puits vertical qui termine l'un d'entre eux, les grondements souterrains, les détonations et les tremblements du sol qui s’y produicaient, la tempéralure très-élevée de ses fumerolles: leur nombre considérable, la composition des gaz qu’il émet, sont autant de faits dignes du plus haut intérêt.

$\Lambda$ près avoir séjourné près de trois heures au sommet du volcan, il fallut nous décider à partir, autant ì cause de l'heure qui s'avançait que du danger que nous aurions pu courir à respirer plus longtemps les gaz et les vapeurs au milieu desquels nous étions déjà demeurés peut-être pendant trop de temps. Nous n’avons rien à dire de notre retour, si ce n'est qu'au moment de redescendre, coutemplant devant nous la surface lisse du cône, dont les pentes s'abaissaient avec une effrayante inclinaison, nous nous demandions presque comment nous avions pu arriver en laut. De Sonsonate, où nous rentrâmes le lendemain matill, nous pùmes encore contempler pendant quelques jours la colonne de fumée qui augomentait d'heure en heure à la cime du volcan et semblait annoncer une prochaine éruption. En effet, quinze jours après, nous apprìmes que le volcan avait recommencé à vomir d'effrayantes quantités de cendres, qui avaient été portées jusqu'à Santa Anna, à douze lieues de là. Sur la route de Sonsonate à Santa Anna, une forêt tout entière avail été dépouillée de ses feuilles par la chute des lapilli et des sables brülants. Depuis lors, l'éruption s'est continuée avec une grande intensité, et, lorsque, quelques mois après, nous eûmes occasion de passer en bateau à vapeur le lonğ de la côte du Salvador, nous pùmes voir nous-mêmes dans le lointain le volcan d'Izalco couronné, pendant le jour, d'un énorme panache de fumée grisàtre, et, ta nuit, d'une lueur rougeàtre qui atlirait les regards.

TOLCAN DE SANTA ANNA. - LAGUNE DE GUATEPEQUE

Les sommités sur lesquelles s'appuie le volcan d'Izalco, el auxquelles on donne le nom de Madre del Volcan, se relient à un massif montagneux assez important, qui atteint soin point culminant aux environs d'Apaneca, à 1,700 ou 1,800 mètres au-dessus du niveau de la mer. Les habitants de Sonsonate considèrent presque toutes les cimes de cette chaine comme étant des volcans éleints, et leur donnent les noms de volcans de San Marcelino, de Santa Anna, de Naranjo, de Tama- 
DANS LES RÉPUBLIQUES DE GUATEMALA ET DE SALVADOR. 407 jaso, d'Aguila, de San Juan, de Launita, d'Apaneca, etc. . . . . . . . Quoique nous n'ayons pas pu parcourir celte régoion d'une manière complète, ni l'examiner dans lous ses délails, nous croyons pourtant pouvoir affirmer que celle assertion n'est pas exacte, quant à la majorité des points dont il s'agit. Nous avons pu nous convaincre, par exemple, que toutes les collines qui existent au nord de la Madre del volcan participent de sa conslitulion géologique et sont comme elle des massils porphyro-trachytiques recouverts en partic d'argiles jaunes et de sables volcaniques. De même, les montagnes d'Apaneca, dans un rayon assez étend a, se composent aussi, en profondeur, de porphyre trachytique, qui n'arrive au jour qu'en peu de points et disparait le plus souvent sous d'épaisses couches d'argiles jaunes. Mais il ne faut pas pousser trop loin l'esprit de réaction, et nous devons reconnaître que, s'il n'y a pas autant de volcans qu’on le dil généralement, la région qui entoure le volcan d'Izalco n'en présente pas moins des traces d'une action. volcanique ancienne antérieure à l'apparition du cône actif actuel. Ainsi l'on voit très-bien, de Sonsonate et des points voisins, un cône très-régulier, qui se dresse à environ trente kilomètres dans l'est du volcan d'Izalco et alleint une hautcur de 2,000 mètres environ. Parmi les autres cimes, il en est quelques-unes encore qui doivent être considérées comme des volcans éleints, quoiqu'elles ne présentent pas une forme aussi caractéristique.

Le cône régulier dont nous venons de parler est peut-être celui qu'on appelle volcan de Naranjo, mais il n'est pas impossible qu'il doive etre rapporté au massif connu sous te nom de volcan de Santa Annu, pour lequel ta tradition locale se prononce avec beaucoup plus de nettelé que pour les autres. On parle vaguement de ses éruptions, perdues un peu dans la nuit des temps, mais on assure qu’il existe, soit auprès de celte montagne, soit dans un cratère silué à son sommet, ce que nous n'avons pu élucider complétement, une lagune à peu près circulaire, à laquelle on donne le nom d'Agua Chuca, c'est-ì-dire eau sûre. En effet l'eau de cette lagune n'est pas potable, el semble, dit-on, contenir' une forte proportion de vinaigre ou d'autres substances du mème genre; il est probable que c'est de l'eau acidifićc par l'acide sulfurique, et que l'on a affaire à un ancien cratère éleint, transformé postérieurement en lagune, dans lequel se dégagent encore en quelques points des gaz acides, hydrogène sulfuré ou acide 
sulfureux, qui se dissolvent dans l'eau et y passent à l'état d'acide sulfurique par une réaction simple et naturelle.

Nous devons dire encore que, sur le revers septentrional de la Madre del volcan, à la base des montagnes, il existe un grand lac que nous avons examiné de loin lorsque nous avons contourné ce massif pour alteindré son sommet, lors de notre excursion au volcan d'Izalco: Ce lac, qui porte le nom de Laguna de Cuatepeque, est assez régoulièrement circulaire, et se trouve entouré d'une ceinture continue de collines peu élevées qui se sondent, vers le sud, aux premiers contre-forts de la Madre del volcan. Il ne serail pas impossible que la Laguna de Cuatepeqne fùt due au remplissage de quelque vaste cralère éteint, ouvert à fleur de terre, dans le genre de celui que nous avons signalé aux environs de San Salvador sous le nom de La Hoya. Ce serail encore un phénomène volcanique intéressant à ajouter à ceux qui se groupent autour du volcan d'Izalco, et qui prourent que la puissance éruptive avail déjà manifesté son existence dans celte région arant que se fût produil le fait remarquable qui a donné naissance au volcau aclif acluel.

On raconte aussi que plusieurs rivières du voisinage furent fortement échauffées à l'époque de l'apparition du volcan d'Izalco, mais qu'une seule, le Rio de Cobulco, siluée aux environs de Santa Anna, conserve encore anjourd'hui une tempéralure élevée. Vu la dislance considérable, il se pourrail que ce fùt là un phénomène indépendant, qui mériterait d'ètre étudié avec quelque soin.

\section{AUSOLES OU VOLCANS DE BOUE D'AIUACHAPAU.}

(Pl. XI, fig. I et 2.)

Si les montagnes des environs d'Apaneca ne sont pas de vérilables volcans éteints, on peut du moins comprendre que l'opinion d'une population peu éclairée y ait été aisément trompée, car, à la base de ces sommités, sur le versant occidental de la chaîne, on observe dans la plaine qui s'étend entre Ahuachapam et San Juan de Dios, une série de phénomènes tout à fail comparables aux infiernillos de Chinameca et de San Vicente, et auxquels on domne, dans te pays, le nom d'Ausoles. Il n'est donc pas singulier que l'on se soil empressé de considérer comme des volcans ces montagnes, au pied desquelles s'échappent en 
DANS LES RÉPUBLIQUES DE GUATEMALA ET DE SALVADOR. 109 abondance des vapeurs à haute lempérature et des gaz acides, dont J'origine est en connexion directe avec la puissance volcanique. La ligne suivant laquelle sont réparlis les points où se manifestent les phénomènes éruptifs s'étend sur une Jongueur d'une trentaine de kilomètres, entre la ville d'Aluachapam ct le village de San Juan de Dios, dans la direction du nord-est au sud-ouest, c'est-ì-dire à peu près perpendiculairement à la ligne volcanique principale.

Nous avions l'intention d'étudier successivement toules ces localilés, mais un accident nous en ayant empêchés, nous n’avons pu examiner par nous-mènes que les ausoles, qui se trouvent dans le voisinage immédial d'Ahuachapam. Voici d'ailleurs tes renseignements que nous avons pu recueillir sur la posilion des autres dégagements de gaz: il paraît qu'or en peut observer deux, à l'est du village de San Juan de Dios, au pied du premier contre-fort des monlagnes; it y rn aurait encore deux assez importants sur le territoire de l'hacienda d'un señor Duran, située à peu près à moilié chemin entre San Juan el Ahuachapam, et, en outre, une grande quantité de petites émanations, relativenıent insignifiantes, dispersées ur peu dans toutes les directions, aux environs de celles que nous venous de citer. Enfin, à 8 ou 10 kilomètres au nord-est d'Ahuachapam, on prétend qu'il existe au milieu de la plaine un gros mamelon conique, d'une quarantaine de mètres de hauteur, et d'un diamètre à la base à peu près égal, composé d'une argile blanchâtre très-fine (barro blanco); sur la colline elle-mème, il ne se manifeste plus aucun phénomène éruptif, mais, tout antour de son pied, il existe un nombre considérable de dégagements de gaz, accompagnés d'une émission plus ou moins importante de matières boueuses, probabtement du mème genre que celles dont nous aurons à parler ci-après. Aux envirous de tous les régagemenls de gaz de San Juan de Dios et de l'hacienda del señor Duran, on observe des argiles colorées de toutes façons, en vert, en jaune, en rougge, en blinc, elc., cè qui paraîl un phénomène inexplicable aux labitants du pays. Il est probable que ces argiles, provenant en partie de l'altération de roches ferrugineuses, sont mélangées d'aluns dirers et de soufre plus ou moins impur, dont les proportions variables produisent des colorations de lous genres. Malgré le regrel que nous éprouvons de n’avoir pu étudier tous les dégagements de gaz de cette région, nous ne pensons pas que uns connaissances sur l'aclion éruptive dans le 
Salvador en soient considérablement diminuées, car il ne doil probablement pas s'y produire d'autres phénomènes que ceux qui sont résumés d'une manière réellement admirable dans les ausoles d'Ahuachapam, où ils se trouvent groupés les uns à côté des autres, dans un espace relativement très-restreint.

Récils.

isites aux rusoles d'Ahuachapam, empruntés

it III. Squiers ct Stepliens.

Les ausoles d'Alunichapam ont été visités, au commencement du siècle, par' Hontogonery (cilé par Squiers), el, en 1840, par M. Stephens. Ces deux voyageurs en parlent dans leurs ouvrages en des termes que uous croyous devoir reproduire, surtout parce qu'ils font supposer que la tenpéralure était plus élevée autrefois qu'à l'époque de notre voyagoge. Peut-être faut-il attribrier cela à une certaine exagération qu'il est difficile d'éviter lorsque l'on parle d'un phénomène qui a vivement frappé l'esprit; mais il serait singulier que les deux auleurs aient commis une inexaclitude précisément dans le mème sens, et, sans vouloir en tirer de conclusions absolues, nous domerons néanmoins la traduction de leurs récits :

Récit de Montgomery (Narratives of Mlontgomery) cmprunté à l'ouvrage de 'H. Squiers'.

"On observe en cel endroil plusieurs mares ou étanģs qui occupent un espace assez considérable. Le plus gorand a environ cent yards de circonférence. Dans celui-lì, comme dans tous les autres, l'eau qui était extrèmement troublée et d'une couleur d'un brun clair, bouillait avec fureur, el s'élevait en bouillons de trois on quatre pieds de haulcur. La vapeur montail sous la forme d'un grand nuage blanc el sétendail à une grande distance aux alentours, tandis que je restai quelque temps debout an bord de cette chaudière naturelle, contemplant du haut de ses rivages les détails de cet effrayant phénomène. La chaleur étail si intense à lit surface du sol, aux environs de ces lagunes, que, si nos pieds n'eussent été protégés par d'épaisses chaussures, nous n'aurions pas pu la supporter. En enfonçant un couteau dans la terre, la lame étail si chaude, après un séjour de quèques secondes, qu'elle brûlait forlement les doigots. Nos chevaux, qui n'étaient pas ferrés, suivant la coutume du pays, manifestaient des symplòmes de malaise, soit à cause de la température du sol, soit à cause de l'odeur des vapeurs, cl nous dùmes les attacher à quelque distance du théátre de ces singuliers phéno-

' Notes on Central America, etc., p. 313. 
DANS LES RÉPUBLIQUES DE GUATEMALA ET DE SALVADOR. 411 mènes. En quelques endroits, de petiles colonnes de fumće s'échappaient avec violence des cavités ouvertes dans le sol, landis que, dans d'autres, l'cau bouillante coulait comme d'une fontaine. L'ébullition de ces lacs et de ces sources a formé sur leurs bords un dépôt d'une argile extrêmement fine, nuancée de toutes les couleurs, mais il ne semble pas que les indigènes en aient profité pour faire des poteries. Quoiqu’il paraisse extrêmement facile d'établir lì les plus beaux bains d'eaux minérales du monde, ils n'y ont jamais pensé."

Le récit de M. Stephens ${ }^{1}$ diffère peu du précédent.

- Au lieu d'aller directement à la ville, dit-il, nous contournàmes la base de la montagne pour arriver bientôt dans une plaine où s'élevait la fumée des sources thermales. Le sol étail incrusté de soufre desséché, el comme gorilté par des feux souterrains. En quelques endroils, il y avail de vastes orifices d'où Ja vapeur s'échappait violemment avec bruit, et dans d'autres, de grands bassins ou étaugs, dont l'un avait au moins 150 pieds de circonférence, remplis d'une eau d'un brun foncé, qui bouillonnail avec une extrême violence, s'élevant jusqu'à 3 on 4 pieds de hauleur, et dont Ilomère aurait pu faire la source de son Achéron. Tout autour, dans un rayon fort étendu, la terre était comme en combustion, brủlant nos chaussures et effrayant nos chevaux, que nous fümes obligés de surveiller avec soin pour qu’ils ne tombassent pas dans les trous. A quelque distance de là, il y avait un courant d'cau sulfureuse que nous suivimes jusqu'ì un vaste bassin dans lequel nous pûmes prendre un excellent bain chaud."

Il est vraiment singulier que les demx observaleurs, parlant des grands bassins dout ils donnent assez cxactement les dimensions, ne sigualent ni l'un ni l'autre les petils cònes semblables à des volcans en miniature, qui sont aujourd'hui l'élément le plus intéressant des ausoles d'Ahırachapam.

Quant à ce qui touche à la tempórature, il scrait remarquable qu'elle ail élé si

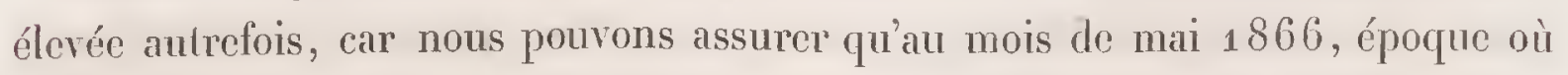
nous élions en cet endroit, elle n'atteignail en aucum point 100 degrés, el que le sol ne paraissait en aucune facon britant lorsqu'on y marchait, soit autour des grands lacs de boue, soit auprès des autres dégagements de gaz.

Les ausoles d'Ahuachapam sont situés à environ 5 kilomètres au nord-est de

1 Incidents of iravels in Central America, ctc., vol. II, p. 67. 
des ausoles d'Aluachapam.

Ispects variés des différents types d'ansoles. la ville, en partie sur une petite plaine qui s'étend immédiatement au pied des montagones d'Apaneca, en partie sur les premières pentes des contre-forts de ces mèmes montagnes. Les dégagements de goa les plus écartés ne sont pas éloignés de plus de 3 oo mètres les uns des autres. Les phénomènes qui se manifestent en cet endroit sont de natures très-diverses, et leur étude jette une vive lumière sur la question de l'origine des infiernillos, des ausoles, en un mot, de tous les dégagements gazeux, aqueux ou boueux, tels que ceux que nous avons déjì observés à Glinameca el à San Vicente. On ne peut plus douter, après avoir examiné les environs d'Ahuachapam, que l'on n'ait aflaire à des dégagements de vapeurs chaudes et de gaz acides, en rapport direct avec l'action volcanique, qui rendent thermales et minérales les eaux et les boues préexistantes à travers lesquelles ils se font jour. On voit, en effet, ì Ahuachapam, les phénomènes se manifester sous les formes tes plus diverses en des points extrêmement voisins les uns des autres, el présenter, en quelque sorte, tons les intermédiaires possibles entre le dégagemen gazeux pur et simple, el la source thermale. Les intermédiaires consisteut en lacs de boue plus ou moins liquide, et en véritables volcans de boue, devenant, dans quelques cas, presque tout à fail solides, et se produisant lorsque le dégagement gazeux traverse des amas d'argiles plus ou moins humides. Ainsi que nous le verrons par la suite, les températures suivent, dans leurs variations, une loi assez nettement déterminée; elles tendent à diminuer à mesure que la proportion d'eau augomente dans les malières soumises à l'action des gar. C'est là, à notre avis, une preuve irréfragable de l'indépendance des dégagements gazeux, qui ont pour origine une manifestation simple de la puissance volcanique, el qui sont dissimulés sous des aspects plus ou moins trompeurs jar des influences de voisinage.

La variété des aspects que revètent les ausoles tient à la nature du sol, qui se prète admirablement à toules ces modifications. Les premic̀res pentes des montagnes sont composées, en profondeur', de roche porphyro-trachytique solide, sur laquelle s'étend, en couche plus on moins épaisse, un amas de fragments ćboulés de la même roche, tantòt reposant librement les uns sur les autres, tantôt cimenlés par des argiles jaunes. Les sources qui s'épanchent par les fissures de la masse compacte forment de petits ruisseaux qui s'écoulent sur la surface de la 
DANS LES RÉPUBLIQUES DE GUA'TEVALA ET DE SALVADOR. 413 roche quand elle est libre, ou sur le revêtement d'argile jaune, quand il existe. La plaine qui se trouve au pied des montagnes est, au contraire, formée d'une sorte de masse lufacée, produite par une agoglomération de petits fragrments de ponces reliés par un ciment blanchàtre, ou par des sables de trituration. Cies ponces, éninemment feldspathiques, bulleuses, perméables, sont très-iisément el très-rapidement altaquées par les gaz acides, el se transforment alors en une masse argileuse pure, fine, liante, qui se délaye facilement dans l'eau el produil des boues plus ou moins épaisses, suivant que l'eau est en proportion considérable ou non. C'est évidemment à la présence de ces argiles, et, par conséquent. ì colle des ponces facilement attaquables par les acides, qu'est due la formation des volcans de boue, dont les caractères particuliers sont dus ainsi à des causes accessoires, bien plutòt qu’à la cause originaire des dégagogements gazeux.

Disons d'abord quelques mols des phénomènes les plus éloignés de l'endroil où se trouvent groupés les ausoles proprement dits. A 300 mòtres environ dans l'est de cel endroil, el à une centaine de mètres plus haut sur le flanc de lä monlagne, on observe une fissure ouverte au milieu des amas de cailloux porphyriques qui recouvrent d'une couchı relativement peu épaisse la masse inlérieure de ta roche solide. roche solide. Celle fissure, longue d'une dizaine de mètres, peut avoir 25 centinètres de largeur, aulant que permetlent d'en juger les pierresplus ou noins volumineuses qui la comblent en partie, nuas sans la rendre imperméable. Entre tes interstices de ces blocs de rocher, on voit incessamment sortir un abondant volume de vapeur, qui se répand dans l'almosphère sous la forme d'un épais nuage blunchàtre, el qui s'échappe de la fissure avec me assez forte pression. On u'entend pas d'autre bruit dans la fissure que le sifllement de la vapeur, et il est évident qu'il n'y a là aucune trace de liquide en ébullition; on a simplement affaire ì une véritable fumerolle qui s'échappe entre des parois de roche solide el peu altérée à sa surface, et qui conserve ainsi une apparence exactement semblable à ce qu'elle serait, si, au lieu d'apparaitre à la base d'une montagne, elle se trouvait dans les parois du cratère d'un volcan. Ce dégagement se compose, en majeure partie, de vapeur d'eau, contenant une assez notable proportion d'acide sulfureux, et, en oulre, une cerlaine quantité d'liydrogène sulfuré, d'acide carlyonique et d'azote. Sa température est de $98^{\prime \prime}, 50$. 
Dégagemenl

de gaz

traversant

une

source préexistante

et

la transformant

en

une source

themaln.

A 150 mètres environ du point central, au sud-est, sur les premières pentes de la montagne, on aperçoil deux ou trois sources assez abondantes, qui s'épanchent de petites fentes ouvertes dans une masse solide de porphyre trachytique. Elles remplissent d'abord quelques petits bassins, puis s'écoulent en un ruisselet qui vient passer tout auprès des ausoles proprement dits. L'eau semble ètre en ébullition dans ces bassins, et il s'en échappe un volume considérable de vapeurs formant tout autour un épais brouillard. Mais ce n'est là qu'une illusion que l'espérience dissipe bien vite, car la température de l'eau n’est que de 88 degré́s daus un des bassins, et de 79 degorés daus un autre, et il suffit de considérer les choses de près pour s'apercevoir que l'apparence d'ébullition est simplement produite par' un gaz qui se dégage tumultueusement au milieu de la masse liquide. On voit, au fond des bassins, de petites fissures d'où le gaz s'échappe pour s'élever ensuile dans l'eau sous la forme de bulles qui se dissolvent en grande partic. C'est un phénomène exactement du même ordre que celui qui se manifeste aux infiernillos de San Vicente. Le gaz se compose d'acide sulfureux, d'hlydrogène sulfurć et d'acide carbonique mèlés d'un peu d'azole, et probablement aussi de vapeur d'eau en assez forte proportion. L'hydrogène sulfuré, l'acide sulfurcux, une partie de la vapeur d'eau et un peu d'acide carbonique se dissolvent dans l'eau au passage; ot if ne reste plus, daus le gaz qui s'échappe, que de l'acide carbonique presque pur, mêlé d'un peu d'azote el d'acide sulfureux ayant échappé à la dissolution, à cause de la rapidité avec laquelle les bulles se dégagent.

La composition de ce gaz est presque exactement la mème que celle du gaz des infiernillos de San Vicente (royez page 373 ), et cela n'a rien d'extraordinaire, puisque les conditions dans tesquelles il se trouve sont lọt à fait analogues. Conıme dans tous les cas du même genre, la vapeur d'eau forme au moins les $\frac{9}{10}$ de l'ensemble.

Les gaz dissous réagissent l'un sur l'autre dans le sein de la masse liquide el produisent de l'hydrog̣ène sulfuré dissous et de l'acide sulfurique, en partie libre et en partie combiné avec des bases diverses pour donner des sulfates. Voici quefles sont les réactions de cette eau :

Azotale d'argent....... Précipité brun de sulfure d'argent.

Acétate de plomb...... Précipité mêlé de blanc et de noir (carbonate el sulfure de plomb). 


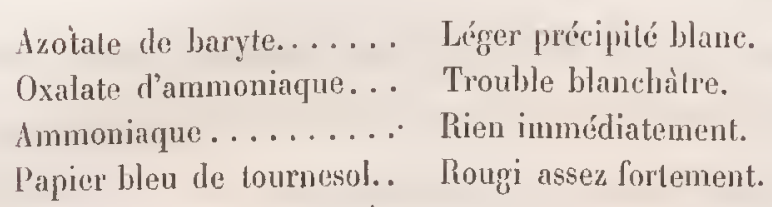

Les ausoles proprement dits se trouvent au pied mème des montagnes, dans une sorte de petit plateau argileux, entouré d'un ressaut irrégulier, laut de $1^{\mathrm{m}}, 50$ à 2 mètres; ils semblent ainsi occuper le fond d'une espèce de dépression du sol, recouvrant un espace rectangulaire d'une trentaine de mètres de côté, mais complélentent reliće vers le nord à la grande plaine d'dhuachapam. Les ausoles se composent de lacs de boue el de volcans de boue, passant les uns aux autres par une série d’intermédiaires dus à ce que la matic̀re dont ils se composent est lantôt liquide, tantôt visqueuse, puis pàteuse, el enfin presque solide. Nous les décrirons successivement, en suivant un ordre qui sera en rapport avec le degré́ plus ou moins grand de fluidité, el en supposant qu'arrivés par le sud nous avons l'est à notre droite et l'ouest à notre gauche. Ajoulons encore que te sol du plateau occupé par les ausoles est entièrement formé d'argites brunes, provenant en partie d'un dépòl d'argites jaunes préexistantes, el en parlie de la décomposilion des lufs à ponces par les caux et les rapeurs acides. Dans certains points, surtout lorsque la bouc lend à desenir presque tout à fait solide, on observe de pelites croûtes formées de soufre impur et de matières alumeuses blanchàtres, dues à la destruction complète des argiles el à la transformation de lenrs éléments en sulfates complexes dans lesquels prédominent les sels de chanx, de ler, d'alumine el de magnésie.

Lorsqu'on arrive en face des ausoles, le regard est attiré tout d'abord par un Lacs d'ean bouense. grand bassin à peu près circulaire, rempli d’une eau bourbeuse et brune, qui semble y ètre dans un élat de violente ébullilion. Celte espèce de cuvelle présente un diamètre de 12 mètres environ ( $\mathrm{pl}$. XI, lig. 2), et se trouve directement entaillée dans la masse argileuse. Les parois, presque verticales, ne sont hautes que de 40 centimètres du côté du sud, mais elles s'élèvent progrgressiventent vers le nord, où elles atteignent $1^{\mathrm{m}}, 50$ à 2 mètres. Il est impossible de poser le pied sur ces murailles d'argile grissante el meuble, el, pour prendre la température du bassin, nous avons dû nous coucher à plat ventre sur le bord, du còté où ẹlles sont le moins élevécs. L'eau bourbeuse bouillonne forlement au centre de la cuvetle, oì 
elle s'élève jusqu'à près d'un mètre au-dessus du nivean moyen, ainsi qu'en plusieurs antres points répartis à peu de distance des parois, le long de la circonférence extéricure; mais les bouillons sont moins intenses auprès des bords qu'an milien du bassin. La température n'étant que de $97^{\circ}$, du moins dans la régogion sud, la seule où nous ayons pu l'observer, il est facile de se rendre compte que l'eau n'est pas réellement en ébullition, mais qu'elle est violemment sonlevée par le dógagement tumultueux d'énormes volumes de gaz à une température élevée, ce qui lui donne une apparence trompeuse. Le gaz qui s'échappe ainsi cn quantités excessivement considérables et qui forme un nuage blanchàtre s'étendant jusque fort loin de son point d'origine, contient une très-forte proportion do vapenr d'aran, ainsi qu'un peu d'acide sulfureux, d'hydrogène sulfuré, d'acide carbonique el d'izole. L'eau du bassin, abandonnée à elle-mème, laisse déposer une forte cottche d'argile brunàtre très-fine, et devient un liquide parfaitement clair, rougissanl rapidement le papier bleu de tournesol el renfermant de l'luydrogène sulfuré en dissolution, de l'acide sulfurique libre el des sulfates divers. La composilion dormée plus laut pour le gaz tient à ce qu'me notable proportion des gaz solubles échappe à la dissolution, à cause do l'effrayante rapidité avec laquelle a lieu Ir dégagement.

A gauche, un peu au nord, il existe un autre lac de boue liquide, presque exaclement semblable au précédent, sauf que l'ébullition y semble moins violente. Ce bassin est elliptique, sa longueur étant de 8 mòtres, et sa largeur de 5 mètres serulcment; il n'est pas beancoup plus profondément r'rensé dans le sol que celui dout nous avons parlé ci-dessus, mais ses parois sont si verticales, qu'il nous a ćté impossible d’en approcher, même pour prendre la température de l'eau bourbeuse. Nous n'avons pas de raison pour penser que ses caractères puissent différer en quoi que ce soit de ceux de la grande cuvette principale.

Tout à fait au sud, à peu de distance de là, on voit un troisième bassin beaucoup plus pelit que les deux autres. Sa forme singulière, à peu de chose près semblable à celle d'un 8 , semble produite par le contact de deux enfoncements circulaires confondus sur leurs bords et réunis en un sent. Cette dépression, profonde d'un mètre, a tout au plus 4 mètres de longueur, et de 1 à 2 mètres de largeur, suivant les points oǹ on la considère. Le fond est oecupé par une 
DANS LES RÉPUBLIQUES DE GUATEMALA E'T DE SALVADOR. 417 boue visqueuse, d'une couleur singulièrenıent blanchâtre, et semblable à de l'argite d'une nuance gris perle clair à peine délayée dans de l'eau. Le gaz, qui se dégage aussi assez abondamment en cet endroit, semble éprouver une cerlaine difficulté à se faire jour à travers celte masse imparfailement fluide. De grosses bulles, accumulées sous un volume qui linit par être assez considérable, soulèvent la boue pâteuse en un pelil cône qui s'élève jusqu’à 10 ou 20 centimètres au-dessus du niveau de la masse fluide; mais, au bout d'un certain temps, la force d'expansion des gaz devient la plus forte, l'ampoule se perce à sa partie supérieure, ses parois s'affaissent sur elles-mèmes, et un nuage de vapeur s'élèr en sifllant dans l’almosphìre. Le plrénomène se répète à des intervalles peu éloiggnés, de cinq en ring minules à peu près, el la quantité de gaz qui traverse la boue visqueuso blanchatre est assez considérable pour lui donner une lempérature de $98^{\circ}$. En ce qui concerne la composition des gaz et des liquides, il n'y a pas de différence nolable avec ce que l'on observe dans le cas précédent.

1 ganche, se trouvent les deux volcans de boue principaux ( $c$ et $c^{\prime}$ ), qui couslituent, à notre avis, la partie la plus intéressante et la plus curieuse des ausoles d'Ahuachapam. Ce sont deux cônes très-réguliers, hauls de $1^{\mathrm{m}}, 50$ envirou audessus du sol environnant, d'un diamètre de 3 mètres à la base, à pentes fortement accusées, composés d'argiles d'un goris brunâtre ou blenàtre, et présentaut tous deux, à leur sommel, un cratère en minialure d'une admirable perfection. Ces cralères, un peu inclinés vers l'est, peuvent avoir denx mètres de diamètre, et à peu près aulaul de profondeur; leurs parois intérieures sont encore plus abruptes que les flancs exlérieurs. Au fond de ces cavilés, on voit une masse de boue pàleuse gorisâtre qui s'agoite sous l'action du gaz tendant à s'échapper, el qui remplit le ròle des matières éjaculées à chacune des éruptions de ces petits volcans. Les éruptions se produiseut fréquemment, loules les trois ou quatre minules, et les choses se passent d'une manière qui doit avoir une analogie frappante avec ce qui a lieu dans les grands volcans, lorsque les gaz à haute pression, traversant un bain de lave en fusion, la soulèvent en ampoules gigantesques, brisées bientòt après, et dont les fragoments solidifiés sont projetés au loin sous la forme de scories, de lapilli et de cendres. Dans les volcans de boue d'Ahuachapam, les gaz, arrètés dans leur dégagenent par la masse pâteuse au milieu de lanuelle ils se frayent 
péniblement un cheniu, gonflent celte surface semi-fluide et la soulèvent sous la forme de bulles sphéroïdales, hautes d'une dizaine de centimètres. Lor'sque la tension du gaz devient plus forte que la résistance de l'enveloppe visqueuse qui l'enprisonne, l'ampoule se crève en produisant une petile explosion, el ses débris, projelés dans l'atunosphìre jusqu’à une élévalion de 4 à 5 mètres, relombent bientòt en pluie de gontlelettes bouenses sur les parois du còne et dans l'intérieur du cratère. Ces éruptions en miniature, accompagnées d'explosions, de délonations, de pluies de matières éjaculées, se reproduisent indéfiniment dans le mềme sens, et contribuent chaque fois à fortifier et à exhausser les llane's des unonticules coniques dans lesquels se manifeste ce phénomène. Nous u'avons pu étudier de près ni la température des boues, ni la composition du gaz; mais nous savons que les vapeur's possèdent une odeur assez tranchée d’acide sulfureux di d'hyrlrogène sulfuré, al qu'une gouttelette d'argile projelée qui nous est tombéce sur la main, nous a produit une sensalion de brùlure très-caractérisée.

Un peu plus à găuche encore, se trouvent d'autres éntinences coniques, qui sont d'autres volcaus de boue plus avancés dans les périodes de leur existence. Il y a là quatre ou cinq monticules juxtaposés, hauts de 1 mètre à $1^{\mathrm{m}}, 20$, soudés jusqu’ì la moilié de leur hauteur à peu près, et formant une chaine continue ef rectiliggne de 5 mètres de longueur. Ces petits volcans ne présentent plus de cratère bien nel, mais seulement une partic supéricure un peu déprimée, craquelée et perforée dans tous les sens. L'argile qui les compose semble tout à fait consolidée, elle est presque dure et possède une couleur brune ou d'un gris foncé presque noir. II ast évident que, dauns ces cònes, la boue s'est peu à peu solidifiée, après qu’ils ont été lormés par des procédés analogues à ceux qui sont encore ell vigueur dans les monticules voisins, et qu'elle est aujourd'hui trop peu fluide pour pouvoir ètre soulevée et projetée au passage par les gaz qui les traversent et qui s'échappent à travers une innombrable quantité de petites fissures produites lors du desséchement. On entend, dans l'intérieur, une sorte de bouillonnement confus, et l'on voit les vapeurs sortir en plusieurs points au sommet et sur les flanes des cònes. Les températures, un peu variables suivant les points, sont tes suivantes :

En $\alpha^{\prime} 95^{\circ}, 80$ - en $\alpha^{\prime \prime} 94^{\circ}, 50$, - en $\alpha^{\prime \prime \prime} 97^{\circ}, 80$, soit $96^{\circ}$ en moyenne. 
DAXS LES RÉPUBLIQUES DE GUATEMALA ET DE SALVADOR. 419

La composition des gaz est la même, à peu de chose près, que dans les autres ausoles, el la proportion de la vapeur d'eau doit seulement varier un peu dans les différents endroils, suivant que le desséchement est plus ou moins complet, el que la lempérature est plus ou moins élevée. Comme toujours, l'acide carbonique mèté à une très-faible proportion d'acide sulfurenx el d'hydrogène sulfuré, ainsi que d'un pen d'azole, est l'élément principal qui se mélange à la vapeur d'eatu.

Entre les grands élangs el le bassin en forme de 8 , il y a encore une série de pelils cônes, répartis sans aucun ordre apparent. Ils onl à peine 5o ou 6 o centimètres Je hauteur, el semblent bien plus avancés encore dans la période de diminution de teur intensité éruplive. L'argile y est presque entièrement solidifiće, Im peu recuite en apparence el couverte, en beaucoup de points, de dépôts de soufre ct de rroùtes d'alun. Quelques-nns sont devenus assez compactes pour ne plus permollor te passage du gaz et sont. presque tout à fiit refroidis. D'autres se laissent encore traverser par de pelites fumerolles, el, malgré le peu d'aclivité du dégagement, ils sont portés à une lempérature assez élevée. Ainsi le sol de $(\beta)$ est à $96^{\circ}, 30$; celui de $\left(\beta^{\prime}\right)$ est à $96^{\circ}, 80$; et enfin celui de $\left(\beta^{\prime \prime \prime}\right)$ ̀̀ $97^{\circ}, 80$. Les autres sont beaucoup moins chauds ou complétement froids et inactifs, comme l'est $\left(\beta^{\prime \prime}\right)$. C'est évidemment là le dernier degré de l'action éruptive dans les ausoles, qui so Iransforment d'une manière remarquable, ainsi qu'on a pu le voir, suivant que les gaz qui se dégagent du sol rencontrent sur leur chemin des roches solides, de l'eau ou des amas de malières d'une fluidité plus ou moins parlaile.

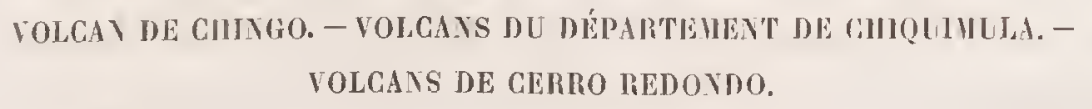

Iprès que l'on a dépassé les ausoles d'Ahuachapam, on cesse, pendant asse\% longlemps, de trouver, sur la direction de la ligne volcanique, aucun symplôme d'activilé acluelle. Sur l'espace de 125 kilomètres qui sépare les volcans du Salvador dı groupe principal de ceux du Guatemala, on ne rencontre plins que quelques cònes éteints, qui ne présentent guère qu'un intérèt de second ordre, el sur lesquels nous passerons d'autant plus rapidenent que nous ne les avons pas visités personnellemént. 
Iotcan de Chingo probablement f́leint.

lolcans éleints du lépartoment de Chiqnimula.
Au passage du Rio Paz, qui forme la fronlière entre le Guatemala el le Salvador, on voit très-nettement le volcan de Chingo, qui s'élève un pen plus au nord. C'est un beau cône extrèmement régulier, ressemblant un peu, comme lorme générale, au volcan de San Miguel, et quil peut avoir 2, ooo niètres de hauteur. Quoi qu'il passe d'habitude pour ètre complétement éleint, il nous a semblé apercevoir de loin quelques fumerolles à son sommel, du côté de l'esl; mais il n'y aurail rien d'élonmant à ce que nous ayons pris pour des dégagomonts de vapeur quelques petits nuages, restes d'un brouillard du matin. Il est lonc possible, sans que nous osions l'affirmer positivement, qu'il y ait encore là quelques symplòmes d'activité.

Il existe, dans le sud du département de Chiquimula, une ligne volcanique secondaire, dirigée à peu près perpendiculairement à la ligne principale, et qui est jalonnée par quatre ou cinq cònes éteints plus on moins importants, séparés chacun l'un de l'autre par une distance de 20 à 2.5 kilomètres. Le groupe, s'étendant ainsi sur une longueur d'une centaine de kilomètres, prend donc une importance do: position assez considérable, et il est regrretlable que nous ne possédions sur hui que des domnées extrêmement peu complètes. L'écartement des volcans éteints qui le composent montre bien que l'on a affaire à une vraie fissure adventive, et non pas seulement à un pelil accident local, divergeant un peu de la direction générale; et, si l'on rapproche ce fait des puissants épanchements de basalte qui existent aux alentours de Los Esclaros, on en peul conclure que la puissance volcanique s'est manifestée autrefois dans cette régoion avec des caractères particuliers el presque exceptionnels. Nous u'avons, sur les volcans du département de Chiquimula, que des renseignements très-vagues, extrails des notes manuscrites du R. P. Cornetle, qui les a vus en 1856 , et à peine pourrons-nous dire quelques mots de chacun d'eux. En quitlant la ligne volcanique principale, entre Jalpatagua et El Oratorio, pour nous diriger perpendiculairement à elle, nous ne lardons pas à rencontrer deux petits cônes éteints, assez rapprochés l'un de l'autre, les volcaus d'Amayo el de Cuma, qui semblent aroir donué quelques coulées de lave, el recouverl les pays environnants d'abondants dépòts de lapilli et de sables. Plus loin se trouve le volcau de Santa Catarina, qui s'élève davanlage, el présente, parait-il, un immense cratère d'où se sont épanchúes de 
DANS LES REPUBLIQUES DE GUATEVALA ET DE SALVADOR. 421 grandes coulées de lave qui s'étendent dans toutes les directions. Ce volcan est voisin du village de Suchitan, et a porté peut-ètre aussi, ì cause de cela, le $110 \mathrm{~m}$ de Suchitepeque. Ce serait alors à lui que se rapporterail une violente éruplion signalée en 1469 , el attribuée ì un volcan de ce nom, existant dans le Guatemala. Beaucoup plus au nord encore est le volcan d'Ipala, sur tequel vient se grreffer to pelit cône éteint de Monte Rico. Le sommet du volcan d'Ipala s'élève ¿̀ 1,660 mètres, el sa régoion supérieure nst recouverte de cendres el de scories, de telle sorte que la végétation n’a pas encorr pu s’y établir. Les pins s'arrètenl sur ses flaurs ì une altitude de 1,470 mòtres. A une hauleur de 1,502 mòtres se Irouve un lac que le R. P. Cornette appelle Lac du volcan d'Tpala; mais nous ne savons pas s'il remplit le cratère du volcan ou s'il s'agil d'un autre cratère éleinı, silué dans son voisinage. Il existe, aulour du volcan d'Tpala, plusieurs coulées de lave assez poreuse, et une grande quantité de dójectious volcaniques diverses.

En reprenant la direction de la ligne volcanique principale, nous devons cncore sigualer deux pelits cônes étcints qui s'élèvent au nord et au sud du village de Cerro Redondo ( 1,080 mètres), à peu de dislance du grand volcau de Pacaya. Ces deux cònes ne présentent aucune importance, quoique l'on prélende que celui du sud a donné une coulée de lave que l'on confond peut-être avec une de celles du volcan de Pacaya. Celui du nord domine tout au plus de 75 mères la plaine où il s'élève, el c'est à sa forme régulière (cerro redondo, montagune ronde), qu'est dù le nom du village voisin.

VOLGAN DE PACAYA.

(PI. XII et pl. XIII, fig. 1.)

A peu de distance dans l'ouest de Cerro Redondo, on voil s'élever un massil' montagneux, d'une allitude assez considérable, dont le développement remarquable, les formes accidentées et les allures génćrales semblent exclure, à première vue, l'idée que l'on puisse avoir affaire à nn volcan. En eflè, le cône principal étant encore caclıé derric̀re d'autres sommités, on ne distingue que des pentes boisées ou des crêtes déchirées qui ne présentent en rien la régularité caractéristique à laquelle ou serait en droil de s'altendre. La disposition et la nature du massif de Pacaya sont anssi singutières qu'intéressantes, et l'étıde approfondie de

Volcaus éteints de Cenro Redon!k. 
re groupe volcanique ue serail peul-ètre pas sans jeler quelque lumière sur la valeur relative des théories qui se partagent actuellement les esprits. Le pàté montagneux dont il s'agoit est presque complétement séparé des chaines voisines, auxquelles if ne se relie que d'une manière assez vague; il domine d'un millier de mètres le plateau sur le bord duquel il semble s'isoler, el conslitue ainsi un groupe à parl, dont les limites seraient faciles à tracer.

Eisembilin

ilu (rmoupe de Piraya.

Tous les contre-forts et la grande majorité des sommilés de ce missil' sonl con:posés de roches porphyro-trachytiques, analogues à celles (qui conslituent les monlagnes des environs; mais, en plusieurs points, il existe, soit des enfoncements rralérilormes, soil des cônes de scories, qui témoiggnent que la puissance volcanique s'est énergiquement manifestée dans celle localité. On serait en droit de Irouver, jusqu’à un certain point, extraordinaire que les phénomènes éruptifs aient précisément choisi pour s'y produire un pâté montagneux isolé, où la résistance des roches ì la fissuration devait êlre plus considérable que partoul ailleurs. Mais, si, partant d'un autre point de vue, on considère le soulèvement des roches porphyro-trachyliques comme ayant été effectué par la force volcanique elle-même, cela n'étant qu'une première manifestation de son action dans un endroil où se sont passés postérieurement des phénomènes d'un genre un peu dilférent, il n'y a plus rien d'élrange dans le massif de Pacaya. On comprend alors que les cralères el les cônes soient entremêlés aux sommilés porphyriques el disposés sur un massif qui, leur servant en quelque sorte de base, représente les résultats primordiaux de lá puissance éruptive, triomphaut enfin de l'obstacle qu'elle n'avail lail que soulever jusqu'alors, el amenant au jour les laves, les scories, les lapilli, pour lormer, en dernière analyse, les cônes dont la cime domine l'ensemble du système. Mais laissons de côté les questions théoriques, el revenons aux faits, tols que nous les avons observés.

Le groupe de Pacaya est done un massil porphyro-trachytique isolé, assis sur le bord du plateau de Guatemala, terminé alternativement pạ des ressauls brusques ou par des pentes un peu moins abruples, formé de mouvements de terrain plus ou moins accentués, au milieu desquels sont réunis quelques enfoncements cratériformes et quelques cônes, dont te plus élevé, haut de 2,550 mètres au-dessus du niveau de la mer, porte seul habiluellement te nom de volcan de 
DANS LES RÉPUBLIQUES DE GUATEMALA E'T DE SALVADOR. 423 Pacaya. Quoique ce còne principal, sur lequel l'attention est loul d'abord attirée, ail une origgine assez récente el ne date gonère que de la seconde moitié dı $i v^{c}$ siècle, il nous semble évident qu'il ne représente pas la premièro manifeslation de la puissance éruplive dans cet endroit, et qu'il est simplement venu ajouter un membre de plus à un système précxistant et probablement mème fort ancien, dont la formation a suivi de près ou peut-être accompagné le soutrirement du massif montagneux dans son ensemble. Si le volcan de Pacaya proprement dit est le seul qui ait eu, dans les temps historiques, des éruplions dont on a conservé la mémoire, s’il est le senl qui présente encore aujourd'lui des phénomènes éruplifs d'une certaine importance, les autres éléments du groupe volcauique n'en sont pas moins significatifs el méritent d'allirer aussi nolre attention.

Nous avons abordé le massif de Pacaya du côté du nord-onest, cu parlant, le 4 juin 1866 , de la petite ville d'Amalillan, siluée à 1,1 go mètres de hauleur, au bord d'un lac formé évidemment par les eaux du Rio Michaloya arrêté dans sonl cours tors du soulèvement de ces montagnes. Du còlé du nord, le massil montagneux s'abaisse progressivement jusqu'au niveau du lac par une série de contre-forts étagés; mais, à l'ouest el au nord-ouest, il est borné par une paroi verticale d'environ 200 mètres de hauteur, constituant les belles falaises qui longent, sur la rive gauche, le cours de la Vichatoya. A l'est, les pentes continuent celles du nord el sont aussi disposées en gradins superposés, landis qu'au snd l'inclinaison devient infiniment plus forte, à cause de l'allure propre du versant du Pacifique, sur lequel tout le système semble avoir élé posé postérieurément, el aussi à cause de la présence des cônes volcaniques principaux, qui sont précisément groupés en cet endroit. La coupure brusque du nord-ouest, augrmentée peut-être par l'érosion des flols de la Michatoya, constitue une sorle de marchre d'escalier gigantesque, interposée entre deux plateaux, celui d'Amatitlan et celui sur tequel se trouve le petit village indien de Pacaya, à 1,502 mitres de hauteur. Le sentier, qui s'ćlève péniblement en serpentant sur cette inuraille à pic, recoupe constamment une masse rocheuse continue, dout les caraclères sont très-voisins de ceux des roches composant les falaises dressées au nord du lac d'Amalilan (page 199). Ce sont de beaux porphyres trachyliques grisillres, à pàte compacte et à eristaux d'orthose assez nets, dont la structure un peu fissile se rapproche 
parlois beaucoup de la disposition columnaire si remarquable dans les porphyres du uord d'Amatillan.

Hatedu meonvert de salilis volcaniques.

Au sommet de la falaise ils disparaissent sons de puissantes couches de cendres et de sables volcaniques qui occupent tout le plateau de Pacaya el dont la déconposition produil parfois des terres végétales d'une gorande ferlilité. Cette fertilité explique seule, d'ailleurs, l'emplacement choisi par les Indiens de. Pacaya pour y élever leurs huttes de bambous, car l'eau y manque absolument, et il faut aller la chercher jusqu’à 8 ou 10 kilomètres du village, an pied d'une sommité porphyrique où s'épanche une petite source souvent tarie pendant la saison sèche. Les sables volcaniques sont d'un noir violacé et d'un grain extrèmement fin; ils recouvrent non-seulemeut le petit plateau ondulé de Pacaya, mais encore toutes les somnités qui l'entourent en amphithı́âtre, et, à mesure que l'on s'élève, ils se mélangent à une proportion variable de lapilli, noirs aussi, gros comme des noisettes, puis comme des noix. En quelques points, formant des espèces d'enfoncements, on ohserve des amas d'argiles jaunes qui complètent avec les sables volcaniques le revêtement superficiel du massif de l'acaya, où les porpliyres trachytiques ne se montrent que dans les parois très-abruptes. Outre les défrichements qui occupent le platean ondulé, on en voil quelques-uns dans les endroils où l'inclinaison n'est pas trop considérable, mais toules les autres pentes soul pecouvertes d'herbes sauvigyes ou de forêts vierges, souvent admirables de vigneur ot de puissance.

$\mathrm{Si}$, en quittant le village de Pacaya, on se dirige vers l'est, on atteinl, après une heure et demie de marche, un vaste espace à peu près dégagé, entouré de tous còtés d'une ceinture de collines, et situé dans la région centrale du massif nott- . lagneux, à 1,800 mètres environ au-dessus du niveau de la mer. Celle clairière, de forme irrégulièrement elliptique, est occupée par deux grandes dépressions ì peu près circulaires, assez rapprochées l'une de l'aulre pour que le bord éliuil presque eulièrement détruit au point de contach, l'ensemble présente une vague ressemblance avec un 8; ces dépressions ne sont probablement pas autre chose que deux très-anciens cratères juxlaposés. Le premier de ces enfoncements (du côté de l'ouest) forme un cercle assez nellement dessiné, dont le diamètre pent ètre de 350 à 400 mètres; il est entouré d'une petile falaise très-abruple, haute 
DANS LES RÉPUBLIQUES DE GUATEMALA ET DE SALVADOR. 425 d'une cinquantaine de mètres dans la région de l'ouest, mais qui s'abaisse progressivement vers l'est. Le fond semble composé d'une matière argilo-marneuse d'un gris jaunâtre et se recouvre d'une prairie nalurelle verdoyante pendant la saison des pluies. Les murailles sont formées de roches porphyriques solides alternant avec des conglomérats à base argilo-lerreuse, el nourrissent une abondante véçélation. Sur te bord de cet ancien cralère éteint, du côté du sud-ouest, au sommet de la falaise, on observe encore quelques dégagements de vapeur, trèsfaibles, il est vrai, mais suffisants pour échauffer le sol dans un rayon d'une vingtaine de mètres et pour prouver que l'action éruptive n'a pas encore entièrement déserté son ancien foyer. La vapeur s'éclıppe en plusieurs points, mais plus spécialement d'une fissure existant dans la roche porpliyrique compacte el d'une fente ouverte au milię d'une masse de conglomérat; le dégagenent se fai sans aucune violence et ressemble de loin à ces vapeurs qui s'élèvent du sol, lorsque, après une forte pluie, il est soumis à l'action direcle des rayons du soleil. La température, prise en plusieurs endroits, soit dans les fentes mèmes d'où sort le gaz, soit en enfonçant le thermomètre dans le sol, varie entre 59 et 63 degrrés. Ces fumerolles se composent presque entièrement de vapeur d'eau et d'acide. carbonique, auxquels il faut ajouler une très-pelite proportion d'acide sulfureux qui rougit faiblement le papier de lournesol, et dont l'odeur est vaguement perceptible.

Le second enfoncement ressemble beaucoup au premier comme forme générale, quoique son diamètre soit un peu plus considérable, 450 à 500 mètres environ, et qu'il soit entouré de murailles un peu plus élevées; on doil le considérer aussi comme un ancien cratère éteint, assez bien conservé, mais il diffère essentiellement de l'autre en ce que la matière argileuse du fond, ayant formé un enduil imperméable, les eaux des pluies s'y sont accumulées el ont donné naissance it un joli petit lac circulaire. Ce cratère-lac porte le nom de Lagumu de la Caldera (lagune de la Chaudière), et, de fait, il a une forme si régulière, il est si bien entouré par ses falaises propres et par la ceinture secondaire de collines, que le nom semble fort bien approprié à la chose. Les eaux de la Laguna de la Caldera sont claires, limpides el parfaitement potables, de sorte que l'on n'a besoin, pour expliquer leur présence, d’invoquer aucum phénomène se rattachaut de près 
ou de loin à l'aclion éruptive, et que, l'attribuant uniquement à l'accumulation des eaux de pluie, on peut dire qu'il n'y a là qu'un ancien cratère éteint sans aucun signe d'activité acluclle.

Régions supérienres du massif do: Pacaya.

lindiments dun gigantesque cratère primordial.

En quiltant la clairière où se trouvent les deux dépressions cratériformes, on change un peu de direction pour marcher vers le sud, en s'élevant plus ou moins rapidement, pendant une heure environ, sur une série de contre-forts élagés. Ia roche qui constitue ces montagnes est toujours le porphyre trachytique, généralement masqué par d'abondants dépôts de lapilli et de sables volcaniques noirâtres. transformés, à leur surface, en une terre végétale fertile sur laquelle croissent d'épaisses forêts. A une altilude de 2,400 mètres environ, on sort de nourcau des bois et l'on se trouve toul à coup sur le bord d'une immense dépression dont la forme primitive a été tellement altérée par les éruptions successives et par les injures du temps, que l'on a quelque peine, à première vue, à y reconnaitre un ancien cratère. C'en est un pourtant, et nous allons essayer de décrire fidèlenıent res lieux où ont dù jadis se passer des phénomènes volcaniques de la plus haute importance (voyez pl. XII).

Ainsi que nous l'avons dil, l'élévation progressive du sol est brusquement arrètée à 2, 400 mètres de hauteur et remplacée par une chule verticale, suivie d'une pente très-abrupte, qui donnent au flanc sud de la montagne une apparence tout à lail particulière. La ligne qui dessine sur le terrain l'intersection de ces leux versanls d'allures si différente, affecte la forme d'une arête un peu saillante, décrivant à peu près une demi-circonférence et représentant ainsi une sorte de croissant dont la concavité serait tournée vers le sud-ouest. Aux deux extrémités de celle arîte semi-circulaire s'élèvent des cònes volcaniques de hauteur inégale, dout le pied plonge profondément vers le sud pour s'appuyer sur te versant des montagues préexistantes. L'un de ces cònes est très-voisin des sommités, sur lesquelles il se soude presque au nord; mais l'autre en est à une certaine distance, de sorte que, pour le rejoindre, l'arête doit s'isoler pendant un certain temps el prendre ainsi l'allure d'une sorte de mur à parois fortement inclinées, séparant deux gouflres profonds. La demi-circonférence dessince par celte arète peut avoir 1,500 à 2,000 mètres de diamètre el entoure une immense dépression dout l'inlérieur a une forme produite par une intersection de surfaces assez compliquéc. 
DANS LES RÉPUBLIQUES DE GUATEMALA E'T DE SALVADOR. 427 En eflet, au bord même, l'arête est limiléc par une paroi verticale qui s'enfonce à une cinquantaine de mètres de profondeur vers le milieu de la demi-circonférence; mais, aux extrémilés, cette hauleur diminue progressivement, puisqu’elte lend à se confondre avec les pentes des cònes volcaniques. Au-dessous de la paroi verticale il existe un espace à peu près plan, quoique fortement incliné vers le sud-ouest, sur lequel viennent s'implanter les bases des deux volcans, de manière à le réduire à une sorte de triangle sphérique terminé par une gorgo prolonde; celle gorgoe elle-même s'élargoit de nouveau au delà des cônes el devient une grande ponte, descendant vers le sud, sur laquelle s'étalent de vastes coulées de lave sorties du pied de l'un des volcans qu'elles entourent presque complétement. En un mol, l'ensemble paraît se composer des rudiments d'un immense cratère, ouvert presque à fleur de terre sur le bord extrême d'un massif montagneux, détruit postérieurement sur une partie de sa circonférence du còté libre, el dans l'intérieur duquel s'élèvent deux cònes situés tout près des bords aux extrémités d'mn même diamètre qui limite la partie préservée de la destruction.

On est donc porté à croire que le volcan de Pacaya a dû être autrefois caractérisé par un gigantesque cratère de près de 2,000 mètres de diamètre, el que le. cône, soudé d'un còté sur les monlagones qu’il ne dépassait guère en hauleur, restait entièrement libre du côté du sud. Quelque terrible éruption, si ancienne que le souvenir n'en est pas venu jusqu'à nous, aura profondénent modifić ce volcan primitif : démolissant toute la partie du còne qui n'empruntait pas aus montagnes sur lesquelles il s'appuie une solidité suffisante pour résister à un senblable calaclysme, elle n'aura laissé subsister qu'une enceinte demi-circulaire, échancrée sur une demi-circonférence toul entière, ouverte en forme de croissant au-dessus des ruines du còne dispersé par l'explosion el transformé en une vaste pente couverle de débris. Après une période de repos plus ou moins prolongée, la puissance éruptive, reparaissant en un point qu'clle semblail avoir abandonné pour jamais, se sera manifestée en créant au milieu des rudiments de l'antique volcan deux nouveaux cônes, disposés précisément dans le cratère détruit, près de ses bords et aux extrémités de l'arête respectée par les éruptions et le temps. Ces deux cònes sont-ils contemporains, c'est. ce qu'il est impossible de savoir; mais ce qui est certain, c'est que l'un des deux re- 
monte à une période très-récente el que c'est le seul qui soil encore aujourd'bui en activilé.

Còne éteint.

Le còne éteint est placé à l'extrémité nord-ouest de l'arête semi-circulaire, à très-peu de distance des montagnes sur lesquelles l'enceinte de l'ancien cratèce détruit s'appuie directement en cel endroit. Les chroniques qui racontent l'apparition du volcan de Pacaya ne font aucune mention de cel autre volcan presque jumeau, de sorte qu'il est permis de supposer que sa formation remonte à une époque plus ancienne, ce qui conduirait à admettre un retour plusieurs fois manifesté de la puissance éruplive sur le même point. Ce còne ne dépasse guère en hauleur le niveau de l'arête qui vient se souder sur son flanc nord-onest, de sorte que son altitude ne doil pas être supérieure à 2,450 mètres; mais, comme il est parfailement libre dans la région du sud, il prend de ce còté une apparence un peu plus grandiose que vers le nord, où il est à peine séparé par un petil ravin de la ligne de faite de l'enceinte générale. Le sommet de ce volcan éteint est enlièrement reconvert de végétation, et les dimensions des arbres qui y croissent sont asse\% considérables pour prouver qu'il ne s'est produit aucun phénomène éruptif dans cet endroil depús un temps extrèmement long. On y observe un cralère, d'une centaine de mètres de diamètre, présentant, à l'intérieur, des murailles verticales assez profondes, an-dessous desquelles se trouve une sorte d'éboulis qui forme le fond de l'excavation. Il y existe, parait-il, une sorte de puils extrêmcment profond, de 3 ou 4 mètres de diamètre, auquel les indigènes donnent le nom de El Hoyo, et où il ne serait pas impossible qu'il se produisit encore de temps à autre des dégagements d'acide carbonique. Malheureusement la première partie du cralère élaut formée de parois à pic, il n'est pas possible d'en approcher.

Còne actif actuel ou volean de Pacaya proprement dit.
L'autre còne, situé au sud-est de l'enceinte semi-circulaire, est celui qui porte seul aujourd'lui le nom de volcan de Pacaya, et qui présente encore des symptòmes assez manifestes d'une intensité éruptive en voie de décroissement. Son point culminant atteint une élévation de 2,550 mètres, ce qui fail qu’il dépasse de 150 mètres environ l'arète saillante qui vient se souder sur ses flancs du còté du nord-est. Mais, dans toutes les autres directions, la partie libre du còne est infinimeut plus prolongée, et, vers le sud en particulier, il présente de vastes pentes, qui, vues de la mer, ont un aspect où la majesté ne fail pas absolument 
DANS LES RÉPUBLIQUES DE GUATEMALA ET DE SALVADOR. 429 défaut. Quoique reposaut sur un terrain fortement accidenté, la base du cône est assez régulière, sauf dı côté de l'est, où elle est dérangée par le conlact de l'arèle de l'ancien cratère, isolée dans cette parlie de son étendue jusqu'au point où clle rejoint les flanes de la montagne. Le pied du volcan est complétement entouré. exceplé sur un petit espace au nord, par une vaste conlée de lave dont il n'est pas possible de voir le point d'émergence, el qui existe aussi à l'est, là où la présence de l'enceinte semi-circulaire ne permet pas de supposer qu'elle soil sortie des flancs de la montagne alors qu'olle avait déjà son relief actuel. Si l'on se rappelle ce qui a été dit au sujet du volcan d'lzalco (page 385), on ne manquera pas de trouver une ressemblance remarquable entre les faits qui se présentent dans les deux localités; et, puisqu'on sait par la tradition comment les choses se sont passées au volcan d'Tzalco, on pourra supposer de mème, avec quelque chance de vérité. qu'au volcan de Pacaya il s'est produil d'abord dans le sol une fissure vomissinl d'énormes quanlités de lave, puis que les scories et les lapilli ayant succédé am malériaux fondus, il s'est formé un còne, augmenté prog̣ressivement par l'adjourction de déjeclions cinériformes, qui a fini par atteindre la hauteur qu’il possède aujourd'hui. Quoi qu’il en soit, la coulée de lave du volcan de Pacaya présent. utr développement très-considérable, et il est fort probable qu'elle se compose de plusieurs coulées superposées, une semblable masse de matières en igonition n’ayaul gù̀re pu être éjaculée par une seule éruplion.

Le champ de lave, large d'un kilomètre environ au pied du volcan du côlé du sud, là où se sont réunis les deux bras qui semblent entourer la base de la moulagne, se dirige vers le sud sur un espace de près de deux kilomètres. II se divise alor's en deux bras, immenses l'un et l'autre, dirigés à l'onest el au sud, el alleignaut tous deux un développement de plusieurs kilomètres. La pente de la coulér. très-forte tant qu'elle longe les flancs du cône, devient, au contraire, beaucoup plus faible, lor'squ'elle se sépare en deux vastes bras el s'étend au loin dans les plaines doucement inclinées qui continuent au sud le versant des montagnes dı côté de l'océan Pacifique. La lave est noire, déchirée, scorifiée à sa surface, el, autant qu'on peut en juger sans l'avoir vue de près, elle doit être basallique.

La première apparition de cette coulée de lave doit se rapporter probablemenl à la formation du volcan qui eut lieu, suivant la tradition, en l'année 1565. L'alh- 
sence de tout détail nous permet de supposer que les clioses se passèrent comme pour le volcan d'Izalco, el qu'avanl la production du cône de scories il y eut simplement éjaculation de lave par une fissure, ouverte loul à coup dans le fond de l'ancien cratère éleint, détruil probablement en parlie à une époque antérieure. Quoi qu'il en soit, le cône ne larda gouère à se former, car l'érnption du 18 fér rier 1650 lut caractérisée par une fuméc abondante accompagnée de bruits souterrains el de trenblements de terre. Pendaut les années qui suivirent, le volcan de Pacaya entra dans une ère d'aclivité presque comparable à celle du volcau d'lzalco, el, en 1664, 1668 (aoùl), 1671 (juillet), 1677, il y eut de violentes éruptions, pendant lesquelles les flammes brillantes el la fumée noiràtre qui s'éclappaient du cratère coïncidaient avec d'épouvantables délonalions souterraines. Iprès une période de repos plus ou moins complet, le volcan reprit, au siècle suivant, un état intense d'aclivité, et le 11 juillet 1775 il y eut une terrible éruplion, dont le souvenir est resté gravé par tradition dans le souvenir des habitants des villages voisins. On s'aperçut dès le matin que la colonne de funcée qui couromait depuis quelques jours la cime du volcan avail redoublé d'abondance; bientôt les flammes s'échappèrent du cratère qui vomil avec bruil une grande quanlité de pierres calcinées, el, pendant plusieurs jours, une pluie de cendres plongea les régions environnantes dans l'obscurité. Ce paroxysue ne ful accompagné d'aucun tremblement de lerre. D'après l'historien Juarros ${ }^{(1)}$, qui assista à celte éruplion, ec elle ne se produisit pas au sommel de la montigne, mais en bas, à l'endroit où elle se divise en trois pointes, "ce qui veut dire probablement ì la base du cône, el permet de supposer qu'il dut s'échapper alors un couraul de lave. Depuis celle époque, le volcan de Pacaya n’a plus donné d'éruptions, el, son activité diminuant progressivement, il semble marcher à grands pas vers une période d'extinclion conplète, dont le moment n'est peut-ètre pas très-éloigné.

Ainsi que nous l'avons dil plus haul, le cône actuel, élevé de 2,550 mètres audessus du niveau de la mer, dépasse de 150 mètres environ l'arêle saillante qui le relie aux montagnes voisines; elle forme un chemin naturel pour atteindre les flanes de la montagne, aussi près que possible de son sommet, lor'squ'on l'aborde du côté du nord, ce qui était notre cas. La susdite arête ne vient pas se con-

(1) Compendio de la historiu de la ciudad de Guatemule, tome II, tratado 6, chapitre xv, page 352. 
DANS LES RÉPUBLOUES DE GUATEMALA ET DE SALNADOR. 431 fondre d'une manière absolue avec les pentes du còne, mais elle y dessine cincore pendant quelque temps une sorte de mur saillant, et, après qu'on l'a quiltée, il lant descendre dans un ravin, profond d'une dizaine de mètres, avant de roinonter sur le cône mème, dans le point où le contact semble c̀tre le plus complet. Dans cet indroit, le sol est recouvert de scories brimes et noirâtres en blocs anguleux, de la grosseur de la tête en moyenne; il en est de mème sur toul lr parcours de l'arète, quoique les débris scoriacés y soient en fragrments un peu moins volumineux. Une fois au pier du cône, on a devant soi des pentes asse régulières, dont l'inclinaison n'est d'abord que de 31 on 32 degrés; mais clle augmente à mesure que l'on s'élève, et linit par atleindre juscu'à 37 degrés en quelques endroils. Les flancs du còne sont formés de scories plus ou moins boursouflées, noires, brunes el rougeàtres, en morceaux de dimensions variables, gros comme te poing en moyenne, reliés par des sables de trituration, noirs, violacés ou rougeâtres. En certains points, les sables ont élé fortement altérés par les agrents almosphériques et ont fini par constituer une sorte de ciment, qui mainlient les fragments scoriacés dans leur position el contribue à rendre l'asconsion beaucoup moins pénible que celle des autres cònes volcaniques en activité. La décomposition a souvent mème élé aclivée par la présence de la végétation, qui conmence à envahir certaines parties de la montagne et lacilite lia production de la terre végélale. Les racines des graminées el des orchidées terrestres, qui, sans ètre encore abondantes, trouvent déjà quelques éléments d'existence, pénètrent le sol d'une sorte de réseau el lui donnent de la stabilité. Vers te sonmel du còne, on observe des fissures longitudinales, prolongées sur une dislance d'une trentainc de mètres el dirigées suivant les généralrices du cône; il s'en dégogage, en plusieurs points, des vapeurs sur lesquelles nous aurons à revenir. Nous avons remarquŕ surtout deux gronpes de fissures, l'un du côlé de l'ouest, l'autre dans la régónion du nord-est, et nous avons conslaté que ces fissures atteignent jusqu'an bord du cratère, mais sans y pénétrer el sans continuer celles qui y existent.

$A$ la partie supéricure du volcan se trouve le cratère, dont la forme est à peu près circulaire, et dont le diamètre ne dépasse pas 70 à 80 mètres. Le bord de ce cratère est peu accidenté; néanmoins il présente un point culminant ( $A$, 2,550 mètres), qui ne dépasse guère que de 5 oul 6 mètres la parlic la plus 
basse (B) siluée du côté de l'onest. La dépression, profonde de 25 mètres environ, se termine par un petil espace plan qui peut avoir tont au plus 10 mètres de diamètre. Les roches qui se montrent dans l'intérieur du cratère sont des porphyres trachyliques bien caractérisés, disposés, soil en un massif continu, comme on le voit daus la région du sud, soil en énormes blocs accumulés, reliés par un ciment argilo-terreux de sables volcaniques décomposés. Le porphyre trachytique est une belle roche grisâtre ou un peu violacće, à texture très-crislalline, forméc d'une pàte feldspathique compacte, enghobant de jolis cristaux blancs de rhyacolithe eu très-grande abondance. D'autres échantillons présentent une pâte fetdspallique d'un grris foncé, Irès-légèrement boursouflée ou celluleuse, renfermant des cristaux mal définis de feldspatı translucide verdâtre ou jaunàtre, dont quelquesuns alteignent jusqu'à 4 ou 5 millimètres de longueur. La mème roche contient aussi en très-grande abondance de petiles masses cristallines pen netles, translucides, colorées en rouge vif, facilement réduites en poussière par le choc, el qui ne sont probahlement que du péridot ferrugineux, fortement altéré par la chaleur. la surface semble parfois un peu altéréc ou recuile, mais cette décomposition ne pénètre pas en profondeur, et l'on ne se douterail pas, en gónéral, que l'on a alfiaire à des roches faisant partie intégrante d'un volcan. Il est impossible, dans tous les cas, de les assimiler de près ou de loin à des laves, el leur cristallisation très-complète suppose un refroidissement lent, qui n'aurait jamais pu se produire dans la position où elles se tronvent. L'analogie, on pourrail presque dire l'identité alssolue, existe, au contraire, avec les porphyres trachyliques des falaises d'Amatillan el des crètes dentelées du massif de Pacaya. On observe dans l'intéricur du cralère des fissures qui, partant du bord, s'étendent jusqu'au fond, suivant les directions des génératrices de ce còne renversé. Les plus remarquables et les plus continues sont au nombre de quatre, situées au nord, au nord-est el dans la région du sud, mais celle qui attire surtout l'attention est dirigée au sud $20^{\circ}$ onest. Elle est ouverte dans la masse porphyro-trachylique compacte, présente une largeur variable de 20 à 50 centimètres, et s'enfonce à une profondeur prohablement très-considérable. Le fond du cratère est formé d'une argile grise ou brunàtre, tantôt presque durcie, tantôt pâteuse dans les endroits où il y a beaucoup d'humidité. Cette argile est le produit de la décomposition des roches feld- 
DANS LES RÉPUBLIQUES DE GUATEMALA ET DE SALVADOR. 433 spathiques sous l'influence des vapeurs acides qui se dégagent en un grand nombre de points.

Toutes les fissures de la partie extérieure du còne ainsi que de l'intérieur du cratère sont le siége de dégagements de vapeurs et de gaz, dont nous devons dire quelques mots. Au point de vue de la réparlition, il n'y a pas d'observalions à faire, car ces fumerolles existent en réalité sur presque toule la longrueur des fentes; elles ne sont plus abondantes en des points délerminés qu’à cause des facilités qu'elles trouvent à s'échapper, au milieu des cailloux et des terres éboulćes, aux endroits où ces dernier's ne comblent pas enlièrenent les fissures. Le moindre petit tassement local peut modifier d'un moment à l'autre le point où le dégagoment se produit, et il suffit souvent de boucher un poimt d'une fissure, en couprimaut les masses argileuses avec le pied, pour voir les vapeurs s'échapper plus abondaminent ì quelque distance de lì. Le seul point important est donc la positiou des fissures elles-mêmes, el nous avons déjà eu occasion d’indiquer comment elles sont réparlies. Relativement aux températures, qui ne sont, en général, pas très-élevées, voici ce que nous avons pu observer, ell choisissant les points des fissures où le dégagement était le plus abondant. D'abord sur la partie exlérieure du cone nous avons trouvé : dans la fissure du nord-est, à 10 mètres au-dessous du sommet $(\delta), 79$ degrés; dans la fissure du nord-ouest, au nième niveau $(\gamma)$, 63 degrés; enfin dans la fissure de l'onest, à 10 mètres au-dessous du sommet $(\beta)$, $65^{\circ}, 80$, el à 5 mètres aut-dessous du sommet $(\alpha), 72^{\circ}, 80$. Daus l'intérieur du cratère, nous avous trouvé respeclivement : à la fissure du nord-est, à mi-hauleur $(g), 52^{\circ}, 50$; ̀̀ la fissure du nord, à mi-haulenr $(f), 69^{\circ}, 50$, et près du fond $(e)$, $81^{\circ}, 50$; à la fissure du sud-ouest, à mi-hauteur $(b), 71^{\circ}, 50$, et près du fond $(a)$, 79 degrrés; enfin à la fissure du sud 20 deggrés est, à mi-hauteur $(d), 55$ deggrés et près du fond $(c), 51$ degrés. La température la plus élevée de loules celles que nous avons pu constater est donc de $81^{\circ}, 50$, et la moyenne de toules nos obserrations domne $67^{\circ}, 30$, ce qui est bieu peu de chose el correspond à un élal éruptil d'une médiocre intensité. D'ailleurs, ces températures n'ont pas varié sensiblemeut depuis une dizaine d'années, car le R. P. Cornette, qui a fail l'ascension du volcan de Pacaya au mois de décembre 1856 , y a trouvé un maximum de 81 degrés et un minimum de 54 degrés, ce qui correspond presque exactement aux

Répartilion el. températures des fumerolles. 
chiffres que nous avons relevés nous-mèmes. Ce qui est singulier c'est que, quoique les températures n'aient pas sensiblement varié dans leur valeur, elles ont subi une modification relalivement anx points où elles se manifestent; ainsi le R. P. Cornette attribue la température de 81 degrés à une fumerolle situén sur le bord du cralère, tandis que celle de 54 degrrés se rapportail, suivant lui, à uue masse d'argite pàteuse, presque de boue mouvante, existant au fond du cratère. D'ailleurs, cela s'expliquerait facilement en admeltant que la température des fumerolles varie surtout avec leur aboudance et leur intensilé, la chaleur se perdant dans le sol lorsqu'elles le traversent lentement et en pelite quantité. C'est là le meilleur moyen de se rendre comple des variations assez considérables qui se produisent aujourd'hui en divers points du volean, el qui ne semblent pas obéir à une loi bien définie, d'après les chiffres que nous avons donnés plus haul. la loi générale de la répartilion de la chaleur dans les volcans, qui veut que la tempéralure s'abaisse progrressivement à niesure que l'on s'élève vers lo sommet. trouve assurément sa confirmation dans le cas présent, ainsi qu'on peut notanment le voir dans les deux fissures principales de l'intérieur du cralère (a-79 drgrés, $\left.b-71^{\circ}, 50 ; e-81^{\circ}, 50, f-69^{\circ}, 50\right)$, mais elle est en quelque sorte dissimulée sous l'unfluence d'une cause perturbatrice dont les effets sont prédomiuants. Celte cause, nous l'avous dil, c'est la déperdition de la chaleur dans le sol lorsque les fumerolles sont faibles et le traversent leutement, et le maintien de la température propre lorsqu'elles circulent, au contraire, arec abondance et rapidité. Ainsi l'on pent remarquer que les deux fissures inentionnées plus haut, où la tempéralure est. la plus élevéc et en mème temps la mieux réglée, sont précisćment celles qui donnent la plus grrande quantité de vapeurs. Ainsi (a), par exemple, est une fumerolle extrèmement importante, sortant avec une certaine violence d'une vaste fente ouverte dans la paroi de rochers, landis que $(d)$ n'est qu'une petite trainée de vapeur, serpentant au-dessus d'une fissure dans les conglomérals terreux, ot la différence des températures de ces deux dégagements est en rapport direct avec: colle de lenr intensilé.

Composition des fumerolles.
Les fumerolles du volcan de Pacaya semblent préscnter entre elles nuo grande analogie de composition, malgré la diversité de leurs températures, de leurs intensités et de leurs dispositions. La vapeur d'ean en forme l'éléunent principal et c’est 
DANS LES RÉPUBLIQUES DE GUATEMALA ET DE SALVADOR. 435 probablement à la grande abondance de ce corps qu'est dù en partic le refroidissement qui les caractérise. Outre la vapeur d'eau elles contiennent une proportiou appréciable d'acide sulfureux, dont la présence, facilement constatée par la manière dont elles rougissent le papier bleu de tournesol, est même sensible à l'odorat; il y a, en outre, de l'acide carbonique el de l'azote en ‘plus ou moins grande quantité, mais dont la proportion doit ètre assez considérable relativement à celle de la vapeur d'ean, puisque la tension de cette dernière n'est pas trèsintense à des températures aussi inféricures au point d'ébullition de l'ean. Nons ne savons rien sur l'équilibre qui peut exister entre les quantilés relatives d'acide carbonique el d'azote. Quint à l'acide sulfureux, il doil y en avoir à peine quelques millièmes. Il est probable que la composition est à peu près la mème pour loules les fumerolles el que, s'il y a une variation correspondante à celle de la température, elle doit porter principalement sur les proportions de l'acide carbonique, qui devient pent-ĉtre de plus en plus abondant à mesure que l'on a allaire à des dégagements moins chauds.

Il y a une analogie assez remarquable entre le cratère du volcan de Pacaya el certains infiermillos, les uns et les antres tendant en quelque sorte ì devenir des solfatares boueuses, sous l'influence de la diminution progressive de l'intensité éruptive. L'action des vapeurs acides sur les roches l'eldspathiques es. Irès-manifeste el produil une grande quantité d'argiles, plus ou moins imprégnćés de sulfates simples ou doubles, qui sont ensuile lavées par les pluies ol se transformunt pen à peu en lerre végélale. Malgrgé l’acidité assez nolable des fumerolles, la végéLation commence déjà à s'emparer du cratère, el l'on y voit des graminécs et des orchidées qui vivent jusque sur le bord des lissures d'où la vapeur s'échappe en abondance. Il est certain que la moileur chande qui règne dans ces endroils leur est extrèmement favorable, mais il semble étrangoge que la présence de l'acide sulfureux ne soil pas plus nuisible qu'elle ne l'est. Il y a un contraste singulier entre ces deux manifestations des forces de la nalure, réunies sur le mème poinl malgoré leur antagonisne, el, quand on trouve à còlé l'une de l'autre, sur le volcan de Paraya, la vie végélale à sa naissance et l'aclivité volcanique mourante, on ne peul s'empècher d’y voir avec admiration un de ces termes de transition qui complètent merveillensement l'larmonie gónćrale de la création. 
M. Squiers parle d'un certain volcan d'A pacaga qui doil ètre le inème que le volcan de Pacaya.

C'est probablement du volcan de Pacaya que veut parler M. Squiers ${ }^{(1)}$ lorsqu'il emprunte à un sieur Dunlop le récit d'une ascension exéculée, en 1846 , à un soidisant volcan d'Apacaga, silué toul au voisinage de la ville d'Amatitlan. Nous ne reproduirons pas ici la narration de M. Dunlop, car elle nous semble contenir un Irop grand nombre d'exagérations pour avoir un caractère scientifique quelconque; ainsi, quoique, de l'aveu de l'auteur lui-même, le volcan en question n'ait pas eu d'éruption depuis 1776 (ce qui se rapporte très-bien au volcan de Pacaya), il en fait une description effrayante, dans laquelle les pluies de cendres, les flammes, les détonations souterraines, les tremblements du sol jouent un rôle important. Or il est manifeste que le volcan de Pacaya ou d'Apacago était très-tranquille en 1846 , ainsi qu'en font foi les traditions populaires et les noles du R. P. Cornetle, qui te visita peu de temps après, et le trouva presque absolument dans le mème état où nous le vîmes nous-mêmes. La seule chose qui nous porle à mentionner ici la narration de M. Dunlop, reproduite par M. Squiers, c'est qu'on y trouve des noms qui u’ont pas paru dans notre étude et que l'on pourrail penser qu’il s'agit de monlagnes voleaniques différentes. Ainsi M. Dunlop dil que le groupe se compose de trois volcans, qui s'appelleraient suivant lui, Volcan de Tormentos (volcan des tempêtes), haul de 4,000 à 5,000 pieds au-dessus du niveau d'ensemble el toujours dans un violent état d'aclivilé, Volcan de Cenizas (volcan de cendres). haut seulement de 1,000 pieds au-dessus du niveau général el complétement. éteint, enfin Volcan de Agrua (volcan d'eau), situé plus bas et renfermant une cerlaine quantité d'eau. Il n'est pas difficile de reconnaître là les principaux membres du groupe de Pacaya, tel que nous l'avons décril; le volcan de Tormentos est te còne principal, qui porte plus spécialement le nom de Volcan de Pacaya; le volcan de Cenizas est le pelit còne éteint, qui s'élève à l'autre extrémité du diamètre limitant la partie existante du grrand cratère partiellement détruit; enfin le volcan d'Agua doil ètre le cratère-lac de la Laguna de la Caldera. Nous n'avons nullement l'intention de nous élever contre les nous que domne M. Dunlop aux différents membres du groupe d'Apacaga ou de Pacaya (ce qui est évidenment la mèmè chose), car, quoique nous ne les ayons jamais entendu prononcer par les habilants du pays, il est néanmoins très-possible que ces noms existent. Nous

\footnotetext{
(1) The States of Central America, etc., p. 493.
} 
DANS LES RÉPUBLIQUES DE GUATEMALA ET DE SALVADOR. 437 désirons seulement prévenir une confusion qui pourrait se produire, si nous ne prenions pas cette précaution, et qui pourrait faire penser que nous avons passé sous silence des volcans d'une importance réelle. Il demeurera donc élabli qur les volcans de Tormentos, de Cenizas el d'Agua, cités par V. Squiers, sont les mèmes que ceux dont se compose notre groupe de Pacaya, et l'on ne s'étonnera pas des différences, plutòt apparentes que réelles, qui existent ainsi entre notre ouvrage el celui d'aulres auteurs, car nous ne pouvons décrire des volcans que sous les noms que nous leur avons entendu donner nous-mèmes par les habitants du pays. Nous profiterons aussi de cette occasion pour nous mettre en garde contre les relations de personnes peu habiluées aux recherches scientifiques on préoccupées surlout de l'effel littéraire de leurs publications. Il est évident quc le volean décrit par $M$. Dunlop est très-intéressant à contempler par la pensée, mais il a malheureusement le tort de donner des idées tout à fait fausses sur la marche des phénomènes éruplifs dans l'Amérique centrale.

\section{VOLGIN D'MGLA.}

(PI. XIII, fig. 2, et pl. XIV.)

Le spectacle qui se déroule aux yeux du voyageur du haut du volcan de P'icaya (voir pl. XIV, fig. 1), est un des plus imposants qu'il soil possible de voir : on y embrasse d'un seul coup d'ceil, groupés comme dans un vérilable lablean, le massif grandiose du volcan de Fuego, sur lequel se délachent au premier plan les lignes harmonieuses du volcan d'Agua, qui dresse éléganmment dans les airs sa cime verdoyante et élancée. La beauté du speclacle est due en grrande partie à un pelit dérangement, qui, sans affecler sensiblement la régularité du système volcanique envisagé dans son ensemble, reporte le volcan d'Agua à un ou deu kilonètres au nord de la direction goénérale, et permet ainsi au regard d'alteindre à une distance plus considérable sans ètre arrèté par aucun obstacle. En effel, la ligne qui rejoint le sommet du volcan de Pacaya à celui du volcan d'Agua est dirigée vers l'ouest $35^{\circ}$ nord, landis que le rayon visuel mené jusqu'au goroupe du volcan de Frego s'élend à l'ouest $30^{\circ}$ nord, suivant la direction théorique. de sorte que les trois massifs montagneux forment les sommets d'un immense triangle très-surbaissé. 
Considéré isolément, le volcan d'Agua est un des plus remarquables qui existent dans l'Amérique centrale, et, quoiqu'il soil complétement éleint depuis un nombre d'années extrèmement considérable, bien longitemps déjà avant la découverle de l'Amérique, il allire tonjon's l'altention des naturalistes par l'harmonie de ses formes, par les problèmes qußil soulève el par les intéressants sujets d'étude qu’il oflire en abondance. La beauté du volean d'Agua ne líent pas seulement ì son élévation considérable, mais en grande partie à son isolement, car, au lieu d'être constitué, comme la grande majorité des autres volcans, d'un ggroupe de rônes accolés, il ne se compose que d'un seul cône gigantesque. Quelques volcans, romme celui de San-Miguel el celui d'Izalco, sont hien dans le même cas et ne présentenl qu'un còne miqque; mais ils n’ont pas te mène cachel, parce que, ne dépassant pas de beaucoup les contre-forts monlagneux sur lesquels ils sont soudés par un de leurs flancs, ils n'ont pas une masse assez imposante pour faire disparaitre ces dernicrs par rapport à enx-mêmes et attirer seuls le regard. Le volcan d'Agua est si immense, au contraire, et domine tellement les collines de Santi Maria sur lesquetles il s'appuie au nord, qu'il les absorbe en quclque sorte, el que, mème de ce côté, il a l'apparcnce d'un giganlesque còne isolé sur lequel l'ail s'arrète de quelque direclion qu'on le contemple.

Hauteur

el situation géographiqu" du miran d'Mgnis.
Le volean d'Agua s'élève à 3,753 mètres an-dessus du niveau de la mer el présente un còne isolê, d'une admirable régularité, posé sur le versant du Parifique, à très-peu de distance de la ligne de faite. Sa base immense recouvre un espace de plusieur's centaimes de kilomètres carrés. Au nord, il se perd dans les contre-forts de Santa Maria (2,081 mètres); qu'il domine encore de près de 1,7 oo mètres, mais. au sud, il peut prendre toul son développement, el l'ou peut voir ses penles, diminuanl progressivement d'inclinaison, s'élendre en courbes harmonieuses jusqu'au delà d'Escuintla, sur une hauleur verlicale de près de 3,500 mètres. Vu d'Es"uintla, le volcan d'Agua est peut-être ce qu'il y a de plus beau au monde, car aucun obslacle n'arrète le regard, depuis le pied jusqu'au sommel de la montagne, qui semblent raccordés par une ligne continue d'une admirable régularité d'allures. A l'est et à l'ouest le volcan d'Agua est séparé des volcans de Pacaya el de Fuego par de profondes vallées, qu’il domine de plus de 2,000 mètres, el qui complètenl ainsi son isolement. Comme il est éteint depnis fort longgtemps, sa surlare est acci- 
DANS LES RÉPUBLIOUES DE GUATEMALA ET DE SALADOH. 439 dentée de quelques ravins, creusés par les pluies abondantes de l'été dans te revêteninent de roches menbles qui le recouvre; mais res petiles imperlections disparaissent à distance, el rien ne semble altérer l'admirable régoularité du cònr lorsqu'on le contemple de la mer ow mème de slations moins éloignées.

La végétation a complétement envahi le volcan d'Agua, el, comme, goràce à son isolement, rien ne s'oppose à la répartition normale des espèces, on voil sur le còne une série de zones bien dessinérs qui contribuent pour lenr part à l'onbellir, en introduisant daus le paysage une élégante variélé de nuances. Les chrumps cultivés occupent la base, el l'on voil s'y succéder la camne à sucre, le calé cl lo? maïs; puis viennent les forèts à essences variées, et enfin les bois de pins clairsemés, qui trouvent au sommel de la montagne les condilions climatériques nécessaires à leur existence. Il n'est peul-ìle pas de point plus favorable que le volcan d'Agua au développement nalurel des lois de la climalologie el de la bolanique, puisque ses pentes s'étendent sans interruplion du còté du sud, presqur depuis le niveau de la mor jusqu'ì l'allitude où la vie végélale cesse d'ètro possible; c'est là qu'on pourra trouver d'abondants sujels d'éludes, lor'squ'on voudra rechercher les conditions de l’unfluence que peut exercer le voisinage immódlial sur les zones diverses d’habital des végétaux indigènes. Sans pénétrer aussi avanıl dans ces intéressants problèmes, nous avons déjà touché plus d'une fois, dans les chapitres précédents (p. 117 el suiv.), aux queslions de climatologie el de répartition de la vie végétale dont on peul trouver la solulion sur le volcan d'Agria, al nous ne croyons pas devoir y revenir, dans ces pages consacrées plus spécialement à des études d'uu autre genre.

Le volean d'Agua élait complétement éleint, probablement depuis longlenps déjà, à l'époque de la découverte de l'Amérique, el il ne reste aucune tradition Ilistuire'
Ilu rolean d'Agua. relative à ses éruptions. Mais on est en droil de supposer qu'elles furent jadis d'unre extrème violence, à en jugger par l'immense quantité de ponces el de lapilli qui cntourent le pied du volcan, et qui ont élé certainement rejelés parr lui. Le chenin qui mène de La Antigrua au village de Sanla Maria suffit pour donner une idéc de l'abondance de ces déjections, car il est entièrennent entaillé daus des couches puissantes de ponces blanches, de cendres jaunâtres, de lapilli noirs el de sahhlés violacés, disposés en lits alternants ì la surface de toules les collines euviron- 
nantes. On ne trouve, aux environs du volcan d'Aggua, la trace d'aucune couléc de lave, et, comme il est peu probable que, s'il en avait existé, elles eussent été aussi complétement recouvertes par les ponces el les lapilli, on est conduil à penser que les éruptions de ce volcan ont élé uniquement caractérisées par l'éjaculalion d'aboudantes déjections cinćriformes.

Le nom du volcan d'Agua (volcan d'eau) a fail supposer à quelques personnes qui ne l'onl pas visilé que ce volcan était encore en aclivité et que ses éruptions se manifestaient sous la forme de masses d'eau boueuse produites par une cause quelconque ${ }^{(1)}$; mais il n'en est rien, et voici quelle est l'origine de cette qualification, qui pent, à bon droit, sembler étrange au premier abord. Lors de la découverte de l'Amérique el de la colonisation du Guatemala, le volcan en question étail déjà éteint depuis fort longtemps, et il s'était élabli dans son cratère un lac produil par l'accumulation des eaux de pluie et par la foute des neiges. En 1541 , sous l'iufluence d'un tremblement de terre, l'une des parois du cralère céda sous la pression du liquide qu'il contenail, et un immense volume d'eau se déversa sur les flanes de la montagne, entraînant avec lui de la terre, des rochers el des itrhres, arrachés sur son parcours par le torrent dévastateur. Par un malheureux hasard, la calaracle se dirigea précisément sur la ville que venaient de construire les conquérants, sur l'emplacement où s'élève aujourd'hui le bourg de Ciudad Vieja, et il s'ensuivit une épouvantable scène de destruction. Suivant le récit de Torquemada, une immense quantilé de personnes périrent, et la femme d'Atvitrado lrouva elle-mème la mort dans celle catastrophe. Le peuple, terrifié, s’imaggina d'abord que le volcan, entrant en éruption, avail vomi ce torrent de liquide et lui donna le nom de volcan d'eau, Volcan de Aggua, nom qui lui est reslé jusqu’à présent, quoique, depuis cette époque, il ne se soil jamais rien produit de semblable; depuis l'inondation de Cuidad Vieja, en 1541, non-sculement le volcan n'a phis

\footnotetext{
1) Voici la phrase qui se trouve reproduite dans presque tous les onvrages publićs dans ces dernières années sur les volcans, et dont quelques-uns sont fort séricux : "L'Agna, aiusi appele, parce que, durant ses éruplions. d'immenses torrents dicau provenant de la fonte subite des neiges qui le recourrent, roulent sur les flaucs et inondent la plinine." Nous savons que te volcau d'Agua. n'iyaul que 3,753 mètres de hauteur, est aut-dessons de
}

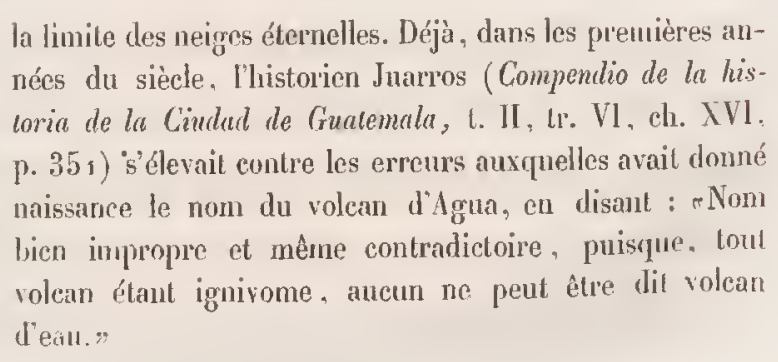


DANS LES RÉPUBLIQUES DE GUATEMALA ET DE SALVADOR. . 441 rejeté d'eau, mais il est même impossible qu'un phénomène du mème genre puisse y prendre naissance, car son cralère échancré n'est plus susceptible de conlenir un lac. Ce récil, qui est celui des historiens de l'époque où la calastrophe eut lieu, est parfaitement acceptable, et l'on en trouve même, jusqu'à un certain point, liı confirmalion dans l'élal actuel du volean; en effet, le cratère présente tous les caractères d'un bassin dans lequel aurait été contenu autrefois un lac, el l'on voil très-nettement sur les flancs de la montague un immense ravin, partant du point où le cratère est échancré, et se diriggeant exactement du côté de Ciudad Vieja. Vais on doit reconnaître qu’il fallut un malleureux concon's de circonslances pour que l'anciemne cilé fùt précisément victime du cataclysme, car, le cralère n’ayan! pas $11 n$ très-grrand diamètre, la quantité d'eau qu'il renfermait n'élail en aucune facon sulfisante pour inonder la plaine, et Ciudad Vieja n'eùt pas souffert, si cettre ville n'eûl reçu le premier choc. Il resto donc hien élabli que le volcan d'Ağua est éleint depuis une époque anté-historique el que son nom lui vient simplemenl du déversement accidentel d'ur cratère-lac existant jadis à son sommet.

Quoique le volcan d’Agua ait une élévation assez considérable, l'ascension ne présente ancune difficulté el il n'y a pas un voyageur venant an Guatemala qui ne veuille se donner la jouissance de l'admirable point de vie que l'on a du sommet de la montagne. Fort inléressante au point de vue de la météorologie, de la climalologie el de la botaniqne générale, celte ascension n’ofire pas autant de matérianx pour l'étude de la géologie des volcans; aussi nous bornerons-nous it esquisser assez rapidenent nos observations en raconlant notre excursion.

Nous sommes partis le 31 mai dı village de Santa Maria, où nous étions venus coucher la veille, après avoir franchi en quelques heures la distance qui le sépare de La Antigua, à travers un pays assez intéressant, dont nous avons déjà en occasion de parler en d'autres endroits de ce travail. Co village est silné à 2,081 mètres de hauleur, sur un petil plateau qui relie, du cólé du nord, les pentes du volcan aux contre-forts montagneux limilant la vallée de Guatemala.

Pen après avoir laissé derrière soi Santa Maria, on aborde les flanes du cône, dont l'inclinaison est encore assez faible, 28 à $30^{\circ}$ tout au plus, ce qui peruet à Cóne
du volcan d'Agua la culture de s'y établir. On est là dans la zone du maïs, que les populations indigènes des environs produisent en assez grande abondance, sur un sol ferlile 
composé de ponces el de scories décomposées mêlées, à une assez forle proportion d'argiles jaunes. Celte réogion cultivée s'élend à peu près jusqu'à la même hauleur de tous les côtés du volcan, an-dessus d'Alotenango, de Palin, de San Pedro Martyr, etc., sauf au sud, où les forèts prennent une extension plus considérable el n'ont guère été défrichées. Au nord, les champs de maïs s'arrètent ì 2, 580 mètres à peu près, et font place à une forèt splendide, dans laquelle ou recounait, malgré l'altitude considérable à laqnelle on se trouve, un assez grand nombre d'essences tropicales. A 2,664 mètres de hauteur', se trouve une pelite chairière au milieu de laquelle est une croix; au pied de celle croix il est d'usage de faire halte. Jous en avons profité pour examiner la nalure du sol, qui se compose d'une couche épaisse de sables rolcaniques et de lapilli noirs, en très-menus fragments, dont la décomposition produit une terre végétalc d'une extrème fertilité. La forèt continue encore au-dessus de ce point jusqu'à 3,027 mètres de hauleur, et elle cesse presque aussi subitement qu'elle avail commencé. En mème lemps, les pentes du volcan tendent ì s'accentuer davantage, el elles atteignent bientòt 34 el 35 degrés. On pénètre alors dans un vaste espace libre recouverı d'une lıerbe épaisse, au milieu de laquelle croissent en grande quantilé des herbes et des fleurs, d'espèces inconnues aux régions inférieures. Des pins plantés de distance en distance accidentent la prairie, mais ils ne sont jamais eu nombre suffisant pour conslituer un vérilable bois. La nature dı sol reste toujours à peu près la mème, mais on pent remarquer qu'il est souvent recouvert d'une assez grande quantilé d'argiles, qui rendent le sentier fort glissant lorsque la pluie les délaye. Au lieu de continuer à monter directement sur les pentes qui sont mainlenant de $36^{\circ}$, on se détourne un peu à droite pour gagner le grand ravin par où s'est précipiléc la calaracte de 1541 , el dans lequel les anfractuosités du sol facilitent l'ascension. C'est là que se tıouvent, à 3,333 mètres el à 3,545 mètres de hauteur, les deux neverias où les lıdiens vout chercher la neige, qui s'! conserve une partie de l'année. Ce sont des espèces d'enfoncements où celte neigge est à l'abri des rayons directs du soleil, ce qui lui permel de ne disparaître que très-lentement, quoiqu'on soit fort au-dessous de l'allitude oì la température moyenne est de $0^{\circ}$. A mesure que l'on s'élève, on voit les pins diminuer de nombre el devenir en mème temps plus rabougrris, quoiqu'ils soient encore dans 
DANS LES RÉPLBLIQUES DE GUATEMALA ET DE SALVADOR. 443 des conditious relativement farorables à leur existence. On alleint enfin, à 3,700 mètres de hauteur, l'échancrure par laquelle on peut pénétrer aisément daus l'inlérieur du cralère et qui est située an nord $35^{\circ} \mathrm{est}$.

Le cratère du volcan d'Agua esl de dimensions très-petites relativement au volume immense de la montagne, car il n'a pas plus de 175 mètres de diamètre Gratère
du volenu d's lgua. au bord supérieur, el sa profondeur ne dépasse pas 70 mètres au-dessous du point culminant. Il est à peu près circulaire, mais le diamètre dirigé du nord $30^{\circ}$ est au sud $30^{\circ}$ ouest, est un peu plus grand que les autres ${ }^{(1)}$. Le fond du cratère est une plaine irrégulièrement circulaire, de 75 mètres de dianètre eniron, reliée au bord par des parois rocheuses asser fortement inclinées, quoique n'atteignant en aucun point la rerticale. Le sol de cette plaine est très-rérgonlier el très-uni, comme s'il se composail de dépôts abandonnés par les eaux d'un ancien lac; il se compose en effel d'uno masse argilo-lerreuse, sur laquelle croìt acluellement une herbe verdoyante. Il est probable que quelque fissure intérieure permet maintenant l'infiltration des eanx de pluie, qui ne s'y accumulent plus, el qui ne pourraient, d'ailleurs, former qu'un lac de peu de profondeur, puisque l'échancrure est à une quinzaine de mètres seulement au-dessus du fond, dont l'altitude est de 3,684 mètres. On y observe quelques gros blocs éboulés venus des parois, qui sont elles-mèmes entièrement composées de roche solide, formant lantôt des nurailles continues, tantôt des amoncellements de rochers immenses. Celle roche . est, comme loujours, "11 porphyre trachylique bien caractérisé, composé d'une pàte feldspathique rosée, un peu celluleuse et comme poncifiée, reufermant une grande quantité de cristaux blancs de rhyacolithe. En quelques points des parois et du bord supérieur, on y voil des traces manifestes d'une ancienne aclivité éruptive, car les roches, auprès de certaines fissures presque oblitérées, sont effritées et jaunies comme par le contact de gaz chauds et acides. Il est donc bien évident, quand même les énormes dépôts de déjeclions cinériformes accumulées aulour du pied de la nontagne ne suffiraient pas à le prouver, que le volcan d'Agua a ćté autrefois le théâtre de phénomènes tout à fait comparables à ceux qui se manifestent dans les autres volcans de l'Amérique centrale. Le bord du cratère est

\footnotetext{
(1) Juarros (loc. cit.) dit que e'est «une cavité en forme de chaudière ayant 140 vares dn nord au sud, el 120 de i'nst ì l'onest. "
} 
assez accidenté et disposé de manière à affecter la forme d'une ellipse, dont les deux axes ne différeraicnt pas beaucoup l'un de l'autre. Toute une demi-circonfírence, comprise entre le point qui se trouve au sud-est el celui qui est au nordouest, se maintient à peu de chose près à la même allitude de 3,750 mètres au-dessus dı niveau de la mer; elle est dominće par le point culıninant, silué au sud $30^{\circ}$ onest, qui s'élève à 3,753 mètres d'après nos observations. Le R. P. Cornetlc fui assigne une laanteur de 3,780 mètres, ce qui ne s'écarte pas beancoup de celle que nous avons déterminée; ce chiffre reste, cn lous cas, de beaucoup au-dessous des fausses évaluations de Cervantès, de Kirkhoot, de Hall, elc., comprises toutes entre 4,200 el 4,600 mètres, mais obtenues probablenent par des mesures trèsapproximalives. Aux denx extrémités de cette demi-circonférence, le bord s'incline d'une manière plus ou moins abruple, el les deux pentes viennent se réunir ì l'échancrure où se trouve le point le plus bas, à une altitude de 3,700 mètres. Quoique assaillis par le mauvais temps pendant nolre sćjour au sonnmel du volcan, uous croyons néanmoins aroir pu l'étudier d'une manière à peu près complète. ol nous pensons que les quelques pages qui précèdent sont suffisantes pour domuct sur son étal actuel les notions les plus indispensables.

VOLGAN DE FUEGO, - GHOUPE DU VOLCAN DAGATENMGO.

(PI. XIII, fig. 3 ; pl. XIV, fig. 1-2; pl. XY, fig. 1-2.)

Système

d'ensemble

des

volcans

d'Aratenango

et

de Finego.

Lus montagnes qui se profilent en arrière du volcan d'Agua, dans la vuc d'ensemble que nous avons prise du sommet du volean de Pacaya, coustiluent un massif d'une cerlaine étendue, limilé par deux rayons visuels, dont l'uu est dirigó à l'ouest $20^{\circ}$ nord, et le second à l'ouest $30^{\circ}$ nord, interceptant ainsi un alre de 10 degrés de développeneut. Il y a là, en eflet, toute une série de cimes volcaniques, formant une sorte de pelite chaine dirigée approximativement du nord an sud et dont une des extrémilés est exactement sur le parcour's de la ligrne volcanique principale, tandis que l'autre, où sc trouve le còne aclucllenent en aclivité, est un pen déjelée vers le sud. Celle petile chaine, quoique formant un seul groupe volcanique parfaitement déterniné, porte deux noms principanx, suivant que l'on considère l'une ou l'autre de ses sommilés principales; le còne encore en aclivité s'appele le Voleam de Fuego, landis que l'autre cime, appelée Volean 
DANS LES RÉPUBLIQUES DE GUATEMALA ET DE SALVADOR. 445 de Acatenango, reçoit aussi quelquefois des Indiens le nom de Pico Mayor (pic le plus élevé) on de Padre del volcan (père dn volcan). Tous n’avons pas besoin d'insister encore une lois sur l'intérèt que présentent ces groupenents, consliluant en quelque sorte des systèmes adventifs, dans lesquels l'activité éruplive semble s'ètre transportée suivant une direction perpendiculaire à celle de la ligne volcanique principale. Nous en avons déjà sigonalé de nombreux exemples dans l'Amérique centrale, el nous savons que c'est plutòt le cas contraire qui est l'exception. Quoique le système dont nous nous occupons soil parfaiteuent conlinu dans son ensemble, il est pourtant divisé assez nellement en deux l'ractions que nous envisagerons successivement en leur conser'iant les noms de volcan d'Acatenango el de volcan de Fuego. Quoique reliés à leur base et jusqu'à unc hauteur de 3,00o mètres environ, ces deux groupes sont séparés à leur sommel par un profond ravin, qui isole distinctement l'une de l'autre les deux cimes principales el ne permet pas de passer aisément de l'une à l'autre.

Malgré notre désir de visiler nous-mèmes le volcan d'Acatenango, nous en arous été empèchés par des circonslances indépendantes de notre volouté, par un de ces mille pelits accidents qui assaillent le voyageur el qu'il n'est pas possible de prévoir. Aussi nous bornerons-nous à transcrire les renseignements qui nous ont été transmis par M. Tomas Wyld de Dueñas, observateur digne de foi, la seule persome qui soil jamais arrivée au sommet du volcan d'Acatenango. La cime de la monlaggne (voy. pl. XIII, fig. 3) présente la forme d'une ellipse frèsallongée, formée par la juxlaposition de denx pilons assez rapprochés el séparés par un col très-élevé. Sur la première de ces sommités, en partant du nord, on voit les rudiments d’un ancien cralère eu très-mauvais élal de couservation, qui pouvail avoir une centaine de mètres de diamètre (A). Dans le col hui-mème, mais un peu du côté du nord-est, se trouvent encore deux enfoncements, irrúgrylièrement circulaires, qui sont peul-c̀tre aussi les restes de cratères éteints trèsoblitérés (B, C). La pointe du sud (D) constitue la partie la plus élevée de la montagne; autant que nous avons pu en juger du haul du volcan de Fuego, elle domine ce dernier de 150 mètres, ce qui hui assiggne me hautenr de 4,150 mètres, et la place au premier l'ang parmi les pies majestneux de l'Amérique centrale. La végélation herbacéc s'élève jusqu'au' sommet de ce còne éteint, mais le bois de 
pius qui occupe les flanes de la monlagne s'arrêle à 50 mètres à peu près audessous de la cime, et nous pensons que l'on peut, d'après cela, évaluer assez exactemeut la limite de la végétation arborescente au Guatemala. C'est celte sommité qui porte plus spécialement le nom de volcan d'Acatenango ou de Pico Mayor. A son point culminant on constate l'existence d'une dépression cratériforme, d'environ 150 mètres de diamètre, qui ne présente aucune particularité remarquable. Sur to flane nord-ouest du cône, non loin du col, il existe deux espèces de puits verticaux d'un très-laible diamètre $\left(\mathrm{E}, \mathrm{E}^{\prime}\right)$, dont l'un est entièrement comblé par des roches accumulées, tandis que l'autre reste béant jusqu'à une profondeur trèsconsidćrable. Du côté de l'ouest, non loin du bord du cratère, on remarque une sorte de caverne (F) d'où se dógage en assez grande abondance de la vapeur d'cau à haule lempérature, légèrement aciduléc par l'acide sulfureux. Celle espèce de solfatare représcnte la seule trace d'activité qui se manifeste à l'époque actuelle dans l'ensemble du volcan d'Acatenango. En résumé, les observalions de M. Wyld nous permellent de ne pas regrelter très-vivement de n'avoir pu laire l'ascension du volcan d'Acatenango, puisque, sauf l'existence d'unc petite fumerolle près de soll sonmet, il présente lous les caractères d'un volcan tout à fait éteint, et que son intérèt le plus réel consiste en ce qu’il est le pic le plus élevé de l’Amérique rentrale.

Le massif du volcan de Fuego proprement dil a une forme assez étrange, qui attire immédiatement l'altention de l'observateur. Il se compose d'un còne parfaitement régulier de trois côtés, qui se relie, vers le nord, à 3,6 70 mètres de hatlLeur, à unc sorte de longue arête saillante, portant le nom de la Meseta, et dont le prolongement forme l'une des parois du grand ravin existant entre le volcan de Fuego ct le volcan d'Acatenango.

La Meseta vient se souder assez brusquement sur le flanc du volcan de Fuego; mais, en examinant avec plus d'attention ce qui sc passe, on peut voir qu'clle s'y continue virtucllement, pour ainsi dire, sur un espace d'une cinquantaine de mètres, dans la direction du sud-est, sous la forme d'une série de légers accidents caractérisés, en général, par de petites parois verlicales de quelques mètres de hauteur, interrompant la régularité des pentes du cône. Ces accidents, ơroupés sur te flanc nord-est du volcan, à une allitude à peu près constinte, dessinent une 
DANS LES RÉPUBLIQUES DE GUATEMALA ET DE SALVADOR. 44 sorle de courbe qui semble compléter le système existant en dehors du còne proprement dil du côté du nord. Au delà du point où elle vient, pour ainsi dire. mourir sur le volcan de Fuego, la Mesela se continue vers le urord, sur une longueur de près de 800 mètres, sous la forme d'une arète saillante, qui, vue de loin, parait ètre rectiligne. Mais il n'en est point ainsi en réalité, car, en examinant tes choses de près, on constate aisément que la Meseta dessine une courbe assez accentuée dont la convexité est dirigée vers l'ust, ot dont la flèche peut ètre d'une centaine de mètres. Ce que nous venons de dire ne s'applique éidemmen! qu’à la partie presque horizontale, qui semble rectiligne de loin; car, à parlì dı point le plus avancé vers le nord, la Meseta s'infléchit presque brusquement, ol. tout en s'abaissant progressivement, elle prend une courbure très-prononcée. de façon à se prolonger vers l'est perpendiculairement ì sa direction primilive. Celle déviation, extrèmement frappante ì cause de la rapidilé avec laquelle elle se produit, est même plus considérable qu’il ne scmble au premier abord. En eflel, si l'on ne s'attaclie pas à considérer comme le prolongoment de la Vesela l'arète saillante et très-inclinée qui se conlinue dans l'est, on peut voir qu'il s'en détachr. une sorte de rameau, courant au sud-est, limilé intérieurement par des parois presque verticales et formant en quelque sorte la suite dı système d'ensemble de la Mesela. En résumé, si l'on part des accidents réparlis sur la surlace du còne du volcan de Fuego, pour marcher, d'ahord au nord par la Mesela proprement dite horizontale el légèrement curviligne, puis à l'est par l'arète saillanle qui la continue, enfin au sud-est par le rameau adventif qui s'en détache, ou voit qur l'on aura décrit une demi-circonférence complète, et c'est cet ensemble que uous considérerons comme constituant le système de la Meseta. Envisageons maint:nant les pentes extérieures el intérieures qui limitent celle série d’arèles. On verra que la région culminante, large toul au plus d'ùn mètre, pent ètre considérée comme la ligne de faite d'un véritable toit, dont les pentes s'enfuient de tous còtés avec une forte inclinaison. En dehors, c'est-à-dire vers l'ouest el vers le nord, ce sont d'immenses parois de scories el de cendres, régulièrement inclinées d'une trentaine de degrés et descendant soil jusqu'au ravin qui sépare les groupes des volcans d'Acatenango et de Fuego, soit à une profondeur énorme, jusqu'aux plaines hasses assises sur le versant dn Pacifique; en dedans, c'est-à-dire vers 
l'est el te sud, ce sont d'abord des pentes comparables à celles dont nous renons de parler, mais qui se transforment bienlòl en de giggantesques murailles à pic, au-dessous desquelles s'ouvre un gouffre immense, rempli de rochers amoncelés. de scories, en quelques endroits même de forèts, où l'wil se perd à un millier de mètres de profondeur. Les parois verticales sont couverles de plaques blanchàtres, jaunes ef rouges, comme si les roches avaient été altérées par la chalcur el corrodées par des vapeurs acides; il en est de même pour les rochers à pic qui prolongont le système sur les flancs du cône. En somme, la forme générale semicirculaire de l'excavation, le peu de largeur de l'arète saillante, les pentes extérienres régulièrement, inclinćes et recouverles de cendres, les parois inlérienres en grande parlie rerlicales el formées de roches parlicllement décomposées, tont nous porte à eonsidérer le système de la Mesela comme les rudiunents d'un immense cralère éteint, el détruit, sur une bonne moitié de son étendue, par quelque temible éruplion paroxysmale. En admeltant celle hypolhèse, ce scrail alors sur le bord mème de eet ancien cratère, éleint el en parlie démoli, que se serail éleś́ le cône du volcan de Fuego actuel, qui renferme lui-même deux cratères. ainsi que nons anrons occasion de le démontrer ci-après. On aurail alors affaire ¿̀ un groupe de trois évents éruptifs successifs, répartis sur une direction à peu près nord-sud, el conlinuant le syslème du volcan d'Acalenango, de manière it constituer un ensemble extrèmement remarquable par son extension et par l'intensilé des phénomènes volcaniques qui s'y sont manifestés à diverses époques de l'histoire du globe.

Vislean de Furgo jopromenl dit.

Histoiv dip ses éruplions.
De lous les cônes et cratères qui constituent ce syslème, le volcan de Fuego proprenent dil est le seul qui soil anjourd'hui le siége de l'activité éruptive. Lors Io la conquète du Gualemala par les Espagnols, il élait déjà en feu, et probabłemenl depuis assez longtemps, car il jouissail d'une grande réputation el causail la terreur des populations du voisinage. Pendant les siècles suivants, ses éruplions linrent fréquentes et terribles, el il occupait une des premières places parmi les imombrables volcans en activilé qui recouvraient, à celle époque, l’Amérique centrale de leurs laves el de leurs pluies de cendres. Parmi ses éruplions les plus violentes, on cite celles de 1526 , - 1541, - 27 décembre 1581 (la quanlité de rendres projetées ful telle, que le soleil en ful conplélement olscurci et 
DAIS LES RÉpUbLIQUES DE GUATEMALA ET DE SALVADOR. 449 qu'on dut, à la Antigua, allumer des lumières à midi), - $1582,-1585$, 1586 (pendaut ces deux dernières années le volcan eul nne érnption presque chaque mois, et la plus terrible fut celle du 23 décembre 1586 ), - $1614,-$ $1623,-1686,-1705,-1706,-1707,-1717$ (le 27 el le 28 août, le volean vomil des flammes accompagnées de violentes détonations souterraines et recouvril de cendres les pays environnants), - $1732,-1739^{(1)},-1829$, $1855,-$ le 9 janvier 1856 (les cendres vomies pendant cette éruption furcnt Iransporlées jusqu'à Tocoy, à près de 150 kilomòlres au nord-est; ces cendres, recueillies à Tocoy, contiennent $1 / 1$ o de fer magnétique), _- le 17 février $185 \%$. Enfin, le 17 août 1860 , il y cul une petite tentative d'éruption, mais, depuis celte époque, le volcan est resté relativement en repos, quoique sa cime soit tonjours couronnée d'une colonne de fumée blanchàtre plus ou moins abondante. Les éruptions du volcan de Fucgo n'ont donné que rarement des laves à peine voiton, dans la direction du sud, quelqnes petiles coulées qui se sont épanchées par une fissure adventive ouverte près de la base du còne, mais non point par son sommet. Les déjections les plus habituelles du volcan sont scoriacées et cinérilormes, el se manifestent sous la lorme de lapilli et de sables volcaniques noirèilres et violacés. Il est à remarquer que les matériaux feldspathiques ou poncenr qui se trouvent en grande abondance autour de La Antigua Guatemala semblent plutòt avoir pour origine le volean d'Agur, tandis que les déjections produites par le volcan de Fuego seraient généralement basaltiques ou pyroxéniques, ainsi qu'on le roit lout autonr de celle montagne. Les lapilli, les cendres et les sables noirs du volcan de Fuego sont farilement altérables sous l'influence des agents almosphériques et se transforment en une terre végétale foncée d'une extrème fertilité. C'est à cela que l'on doit la richesse des terrains cultivés à Ducñas, Capetillos, etc. et la présence des admirables forêts qui recouvrent les premières pentes du volcan d'un dòme de verdure presque impénétrable.

Le volcan de Fuego est aussi peu connu des habitants du palys environnant quiil en est redonté; à Guatemala, on en considère généralement l'ascension comme impossible, quoiquil soil parfaitement prouvé que quelques personnes

(1) Juarros (Compendio de lu historia de la Ciudad de Guatemala, t. II, Ir. VI, ch. Iv, P. 35a). Ise chroniquenr Fuentes (t. I. livre IX, ch, is). 
ont déjà alteint son sommet. Ainsi MM. Schncider et Beschor y sont arrivés les premicrs le $\mathbf{j}$ septembre 1860 , et, depuis, M. Tomas Wyld de Dueñas y est monté Jeux ou trois fois, soil seul, soil accompagné de MM. Salwin el le baron de Siebach. Ce n'était donc pas unc entreprise entièrcment nouvelle que d'aller étndier sur place le cratère du volcan de Fuego el les phénomènes qui s'y manifestent; mais nous devons ajouter qu'aucune des personnes qui ont fait l'ascension dı volcan de Fuego ne l'ayant exécutće dans un but scientifique et avec des moycus propres à cn tirer des résultals intéressants, ce volcan n’en élait pas moins absolument inconnu, quoiqu'on cùt atleint sa cime à plusieurs reprises. Nous étions done: les premicrs qui nous proposions de gravir la monlagne pour y chercher des éléments d'études sćrieuses, et nous pouvons nous flatler de présenter des observations et des considérations entièrement nouvelles sur les phénomènes qui ont pris le volcan de Fuego pour théâtre de leurs manifestations. MV. Schneider el Beschor, qui sont arrivés les premiers au sommel du volcan de Fuego et qui onl le mérile d'avoir affronté les premiers des difficultés dont il ne faut pas se dissimuler la gravilé, ont publié un récil de leur ascension dans la Gacela de Gualemala (Gaceta de Guatemala, tome XII, $\mathrm{n}^{\circ} 31$, du 21 septembre 1860 , et $\mathrm{n}^{\circ} 32$, du 26 septcmbre 1860); mais cette narration, quelque intéressante qu'elle puisse ètre, n’a pas assez de valcur au point de vue scientifique, pour que nous croyions devoir la reproduire intégralement. Tous nous bornerons ì en extraire quelques lignes, qui, malgré le peu de clarté des descriptions, semblent prouver que la disposition gónérale du sommet du volcan ne s'est pas sensiblement modifiée pendant ces dernières annćes.

".... Le volcan de Fuego scmble contenir deux cratères; peut-ètre autreliois ont-ils été réunis de manière à n'en former qu'un seul, mais, dans une de ses éruplions, le volcan souleva, dans toute sa longueur, une roche immonse qui le divise en deux seclions, et dont la partie visible est de 50 pieds plus élevée que le bord ${ }^{(1)}$. Du còté du nord, la masse de rocher's s'est engoouffrée de manière à combler la partic du cratère qui se présente à la vue et à n’y laisser que quelques déğagements

1) Il est évident que cette explication de la coexistence des deux cratères n'est pas admissible et qu'on doit l'altribuer, comme nous le démontrerons ci-après, ì la formation successive de deux dépressions, dont l'une occupait le sonmet même du volcan, tanclis que la seconde s'est disposée obliquenent sur l'un de ses flancs. 
DANS LES RÉPUBLIQUES DE GUATEMALA ET DE SALVADOR. 451 de fumće sulfureuse. Du côté du sud, dans l'autre moitié du volcan, se trouve la dépression où l'activité est la plus grrande; mais uous n'y pùmes faire aucune observation parce que le vent, qui chassait la fumée dans la direction sud-ouest, ne nous permit pas d'atleindre le bord de ce còté-là, ni de nonter sur le massif rocheux qui s'élève au centre. Ce massif est couverl, sur toute sa surface, de pelites roches et d'une multitude de pierres volcaniques toutes enduites de soufre. $A$ l'ouest, ces rochers se perdent dans une larranca qui descend vers le pied de la montagne. A l'est, ou voit aussi descendre progressivement un petit courant de lave, qui sorlil du volcan dans cette direction lors de sa dernière éruplion, le samedi 17 du mois passé (aoûl). Nous pûmes examiner cetle partie du volcan à la distance de vingol pas environ, mais, à cause de la fumée, il fut impossible d'arriver à la considérer de plus près, el nous entendìmes seulement que la lave ef le soufre élaient en ébullition à la distance que nous venons de mentionner. Nous fímes bien une tentative pour nous en approcher davantage, mais la lerre était tellement chaude, et la fumće qui nous gênail bcaucoup devint tellement iusupporlable, qu'il fallut nous borner à écouler le bruil de la masse incandescente. Néannoins nous recueillìmes divers fragments de soufre chaud, ainsi qu'une pierre rouge, el nous remplịmes nos poches de ces échantillons. Nous nous en allàmes ensuile de l'autre côté du volcan, pour voir l'ancien cratère. Le bord de ce cralère est presque vertical vers l'intérieur el vers l'extérieur, anssi est-il difficile d'y arriver; dans toule la parlie que nous avons parcourue, il est très-accidenté, le point le phus bas se trouvanl à l'ouest-nord-ouest, à l'endroit où prend naissance lo ravin du pelit cratère ${ }^{(1)}$..... En mọnlant de là jusqu'au champ de lave du pelit cralère, on s'élève d'environ 40 pieds en contournant l'ancien cratère. Cedernier pentavoir 80 vares ${ }^{(2)}$ de diamètre de l'est à l'ouest, el 40 du nord au sud; nous calculons, en conséquence, que le sommet du volcan ne peul pas avoir plus de 300 à 400 pieds de diamètre. Il n'est pas profond; sa plus grande profondeur est de 16 vares, mais ses dégagements de gaz sont en activité, et nous pensons que les roches qui l'ecouvrent sa súrfice ne sont ni pesantes, ni dures, et que d'un jour à l'aulre il

(1) Toute celte partie de la narration nous semble peu intelligible. Nons ne savons de quel ravin il est question, et il fant peul-être admeltre quil a disparu, de-

puis celte éporpue, sous l'influence des agents atmosphériques.

(2) Lo vare vaut 838 millinitres. 
peut s'enfoncer de nouveau pour laisser voir son inlérieur profond el en activilé comme son voisin. Les roches du bord sont de la mème nature que toutes celles que nous avons déjà décrites, et, dans beaucoup d'endroits, elles s’inclinent fortement vers le eratère, de manière que l'homme qui y marche se met en dauger de s'enfoncer et de disparaitre. C'est le point où nous posàmes le pied lor's de notre irrivée au sommet du volcan, et c'est de là que nous partîmes pour redescendre."

Asceusion au volcan de Fuegro. Zone rles forẻts.

C'est à la fin de mai 1866 que nous fìmes l'ascension dı volcan de Fuego, el. quoique le moment ne fìt pas très-bien choisi, parce que la saison des pluies était déjà établic avec une certaine violence, nous eùmes la bonne fortune de pouvoir profiter, pendant les journées du 26 el du 27 mai, d'un temps magnifique, qui nous permit, non-seulement d'étudier avec facilité toutes tes particularilés du volran, mais encore d'admirer te point de vne splendide dont on jouit au sommet d'une montagne aussi élevée. Sans vouloir mettre au second plan les plaisir's arlisliques que procure la contemplation d'un spectacle aussi grandiose que celui que nous eumes pendant quelques heures sous les yeux, qu'il nous soit permis d'ajouter que nos connaissances générales sur la topographie et les allures d'ensemble du pays ne perdirent rien à la nettelé du paysage qu’il nous ful donné d'examiner. à lravers une almosphère d'une transparence idéalc. Nous ne voulons point insister ici sur la première parlie de notre ascension, mais nous croyons pourlant que nous devons en dire quelques mots, quand ce ne serail que pour servir de gruide aux royageurs qui étudieront plus tard les phénomènes naturels de l'Amérique centrale et auxquels le hasard pourrait mettre ce travail entre les mains. Apris avoir passé la muit à Dneñas, charmant petit village silué à ẹnviron 8 kilomètres de la Antigua Guatemala, nour partimes de grand malin pour l'hacienda de Cialpetiflos; nous devions y retrouver six porteurs indiens d'Alotenango, dont nous avions eu soin de nous assurer d'avance les services, en allant les demander à l'alcade du village au nom du gouverneur de la province. Iprès avoir dépassé l'lacienda de Capetillos, on peut faire encore à cheval une distance d'environ 4 kilomètres dans une plaine doncement inclinée, qui vient se relier aux preniers contre-forts du volcan. Le sol est formé de sablẹ volcaniques noirs très-fortement altérés par tes argents almosphériques. Bientòt il faut nettre pied à terre, et l'on entre daus une lorcil extremement épaisse où il existe encore un rudiment do sentier. Presque 
DANS LES RÉPUBLOUES DE GUATEMALA ET DE SALVADOR. 453 immédiatement après, on aborde des peules d'une très-forte inclinaison, sur lesquelles il est très-difficile de s'avancer, à cause de la molilité des matériaux qui composent le sol, et surtout à cause de la puissante véçélation qui a envahi arec: une excessive rapidité un sentier à peine tracé el qui oblige à se frayer un chiemin à coups de machete ${ }^{(1)}$. La terre glisse ou s'éboule sous vos pas, les lianes vous aurìtent à chaque inslant, les arbustes épineux vous déchirent les mains et la figure. et il faut plusieurs heures de pénibles efforts pour traverser la zone des forèts tropicales. A 3,000 mètres de hauteur environ, on alteint le commencement. de lá région des pins, et, quoique la végétation soit infininent moins épaisse, on éproure presque autant de difficulté à avancer, sur un terraiu en pente très-forte courert d'hlerbes glissantes et d'aiguilles de pins. On s'aperçoit alors que l'on s'élève sur la Iranche d'une immense arète presque isolée, qui se délache du massil du volcaun de Fuego; au nord se trouve un profond ravin, de l'autre colé duquel surgissent les pentes du volcan d'Acatenango; au sud on longe des parois presquie verlicales, qui dominent un gouffre immense, limilé de deux autres côtés, d'abord par le volcan de Fuego, dont les tlancs sont un peu altérés dans leur régularilé en cet endroit, ensuite par la Meseta, dont la crête horizonlale relie au cône dı volcan de Fuego la muraille sur laquelle on se trouve. A quatre henres et demic de l'après-midi, nous alteignons l'altitude de 3,284 mètres el nons nous arrètons, pour y passer la nuit, dans une sorte de clairière où nous faisons construir' par nos lndiens une pelite hulte en branches de pins. Nous allumons un grand fen pour uous préserver du froid, qui, sans ètre rigonreux $\left(12^{\circ}\right.$ pendant la soirée et $6^{\circ}, 75$ à 5 heures du malin), est pourtant très-sensible pour des personnes habituées depuis lougteness au climat des lerres chandes.

Le lendemain matin, au lever du soleil, nous nous mines en route pour achever notre ascension, espérant bien arriver assez tôt au sommet du volcan prour pouvoir consacrer quelques heures à étudier le cratère dans tous ses détails. Itn peu avant d'arriver à la Mesela, on voil les pins diminuer progressivement, el bientòt ils disparaissent complétement. Cela tient à ce que les scories et les tapilli qui recouvrent le sol n’ont pas élé transformés encore en terre végétale. ol

1) Le machele ost un espèce de grand sabre droit, que IIndien ne quille jamais et qui Jui rend des services de tous genres an milien des forếts vierges, ou il aime à errer sourent pendant la plus grrando partie do ses jourrées.
La Heseti.

Arrèt de la végrálation. 
ne peurent fouruir aux arbres leurs éléments d'existence, mais nou pas ì ce qu'on a alteint la limite de la végétation arborescente; en effet, sur le volcan d'Acatenango, on voil les pins monter jusqu'à 4,000 mètres d'altitude el les herbes occuper la rime mème de la montagne. Sur le volcan de Fuego, les conditions ne sont plus les mêmes, el si, du còté du nord, les pius atteignent jusqu'ì l'allitude de la Mcsela, ils s'arrètent beaucoup plus bas à l'est, au sud et à l'ouest, où les flancs, absolumeul nus à partir de 2,400 et 2,500 mètres, sont uniquement recouverts de scories brunes et de sables volcaniques noiràtres. Au point où l'on atteint la Meseta proprement dite, l'arête saillante change assez brusquement de direction, en décrivant une courbe d'une centaine de mètres de rayon, et l'on commence à marcher vers le sud. On est alor's à 3,666 mètres de hauteur an-dessus du niveau de la mer. La Mesela, longue de 800 mètres environ, n'est pas absolument horizoulale; elle présente un point culminant, plus élevé d'une dizaine de mètres que l'ensemble de l'arête, el situé à 100 mètres de l'endroit où elle rejoint le còne. La surface de la Mesela est entièrement reconverte de scories et de lapilli brunâtres assez mouvants, et l'on n'y voil que quelques touffes d'herbes malingres et rachiliques. Les flanes extérieurs de cette sorte d'enceinte curviligne descendent jusqu'à une grande profondeur avec une pente régulière d'une trentaine de degrés, tandis que les parois intérieures se raccordent ì des murailles verlicales dominant un gouffre immense. Ainsi que nous l'avons exposé plus haut, nous sommes portés à croire que l'on a affaire aux rudiments d'un gigantesque cratc̀re presque entièrement détruit. La liggne de faîle de la Meseta peut avoir 1. mètre de largeur, en moyenne; quoiqu'il ne soil pas très-dangereux d'y marcher, il faut pourlant le laire avec certaines précautions, car la mobilité du sol, composé de scoties rontlantes, pourrait entraîner de graves accidents, si l'on avait le mallıeur de faire un faux pas, el l'on ne doit pas se dissimuler que l'on éprouve une singulière sensattion à se trouver ainsi comme sur la crête d'un toit immense, dont les pentes fuient rapidement au-dessous de vous.

Cone terminal diı volean de Fuegen.

Au point où la Mesela rencontre le cône (loul en se continuant ì sa surfice sur une cinquantaine de mètres) au nord $20^{\circ} \mathrm{est}$, à 3,670 mètres de hauteur, ou a devant soi une pente admirablement unie, qu’il faut encore gravir pour alleindre Ir sommel du volcan. L’inclinaison varie de 28 à 32 degrés, et le sol se compose 
DANS LES RÉPUBLIQUES DE GUATEMALA ET DE SALNADOR. 455 inniquement de scories et de cendres noires, brunes el rouges, en fragments donl la grosseur ne dépasse pas le volume du poing. Ces matériaux sonl cxcessivement meubles el se déplacent sous le pied arec la plus grande facilité. Quoinque l'ascension soit fort pénible, elle n'est ponrtant pas comparable à celle du volcan d'Izalco, où l'inclinaison des pentes est encore beaucoup plus accentuée. Iprès une heure et demie d'efforts, on alteint une paroi de roche solide, formant un ressaul à peu près verlical de 4 à 5 mètres de hauleur, où apparait un porphryre trachylique rougeâtre ou violacé, à pâte feldspathique et à petiles mouches blanches informes, transformé ì sa surface en une masse scoriacée d’un gopis rougeàtre. pénétrée de cristaux mal définis de feldspath opaque, long's de quelques millimètres, et saupoudrée de soufre et d'alun. Au-dessus de celle paroi verlicale, on rencontre un espace doucement incliné d'une trentaine de mètres de longueur. formé d'un amoncellement de blocs plus ou moins volumineux d'une roche exactement semblable à celle que nous venons de décrire. Près de là se trouvent de vastes éteudues de croùtes alıneuses el sulfureuses, recouvrant un espace de plusieurs centaines de mètres carrés; il en existe d'autres encore sur le flanc est, non loin du sommet, et près de l'endroit où prend naissance l'arète de la Mesela. On arrive bientòt el sans difficultés en un point situé au nord $20^{\circ}$ est el à 4,001 mèlres au-dessus du niveau de la mer.

Lorsqu'on alteint le sommet de la montagne de ce côté-là, on est quelque peu surpris de n’avoir devant soi qu'une petite dépression cratériforme, irrógulièreınent circulaire, de 5 o mètres de diamètre toul au plus el de 25 mètres de profondeur, dont le sol est formé de débris scoriacés el cinériformes, au milieu desquels s'échappent quelques fumerolles. Mais on s'aperçoil bientòt que ce ne soml là que les resles d'un pelit cratère ancien plus ou moins oblitéré, et que le vérilable cratère actif actuel se trouve un peu plus loin. Lin effet le bord de ce pelit cratère esl délıuit sur un tiers de sa circonférence environ, du coté du sud 20 " ouest, el l'on voit qu’il est en communication, par celle sorle de brèche, arec une gigantesque cavité d'où sortent en tourbillonnant d'énormes volumes de vapeurs. Aux denx extrémilés de la partie intacte du bord, el par conséquent des denx còtés de la brèche, à l'est et à l'onest, s'élèvent de puissantes masses rocheuses semb)ables à deux piliers commandant l'entrée dı gouffre. Ces masses rocheuses se 
composent d'un porphrye trachytique violacé, presque inlact, à peine recuit à sà surface. On y voil aussi des roches porphyrö̈des formées d'une pâte compacte d'un gris verdâtre, engolobant un grand nombre de crislaux de rhyacolithe el do Peldspalh opaque, au milieu desquels sont disséminées des bagnettrs d'amphibole noire, dont quelques-unes sont longues de 4 millimètres, ainsi que des dépòts pulvérulents d'une matière jaune ou verdàtre, qui doit ètre du péridol arrivé à un élat de décomposition très-avancé.

Celui des massifs rocheux qui s'élève à l'est penl servir en quelque sorte d'observatoire, et de son sommet on peut aisément contempler t'ensemble du cratère actif', placé, par rapport à l'ancien cratère, de telle façon que la liggne des centres est dirigéée du nord $20^{\circ} \mathrm{est}$, au sud $20^{\circ}$ ouest. Ou voit alors un gouflie effrayant, ouvert entièrement sur le flanc du còne, du còté du sud-sud-onest, de manière à ressiner par son contour une sorte d'ellipse, tellement disposée que l'une des extrémités du grand axe est siluée à environ 300 mètres au-dessous de l'autre. Celte gigantesque cavité, presque exactement circulaire, dont la profondeur tolale est d'au moins 600 mètres, ainsi que nous l'avons calculé d'après le temps que mel ì atteindre le fond une pierre jelée du bord, el dont le diamètre peut être estimé à 400 ou 450 mètres, est formée par d'immenses parois verticales beaucoup plus élevées du côté du nord que du côté du sud. Ces murailles à pic se raccordent, par une sorte d'entonnoir, à un puits terminal, ayant une centaine de mètres de profondeur el presque autant de diamètre. Les parois sout composées de roches conpactes en place, probablement de porphyres trachytiques forlement altérés à leur surface el recouverts, en beaucoup d'endroils, de dépôls pulvérulents de soufre et d’alun, tandis que les parties inclinées sont formées de gros blocs accumulés daus un eflravamt désordre. La parlie inférieure du puils terminal est conslituée de la mème manière, et il est probable qu’il est fermé par une sorte de voûle naturelle produite par un amoncellement de blocs éboulés, anenés lì depuis la dernière éruplion par l'action destruclive de quelque tremblement de terre. En effet, en 1860 , le fond du cratère devail êlre encore ouvert pour livrer passage aux énorules volumes de fumée qu'en voyaient sorlir MM. Schneider et Beschor. Quoi cu’ii en soil, le cralère du volcan de Fuego mérile, par ses dimensions exceptionnelles comme profondeur, d'ètre classé parmi les plus remarquables de l'A mériyue centrate. 
DANS LES RÉPUBLIQUES DE GUATEMALA ET DE SALVADOR. 457

La durée de notre séjour au sommet du volcan devant être forcément très-limitée, l'un de nous resta à explorer la cime, tandis que l'autre entreprenail do faire le tour du cratère pour en examiner de plus près les parlicularités. C'étail une tentalive difficile, périlleuse même, el nous sommes for't heureux d'avoir pu

Disposition d'ensemble lu sommet du volcan. Nalure des roches. la mener à bonne fin sans accident, car il est peu probable que quelqu'un se risque de longotemps à recommencer une semblable excursion. Du côlé de l'ouest, le bord du cratère est entouré d'immenses masses rochıuses ì parois verlicales dans presque tous les sens, qui ne permellent pas de s'en approcher; pour trouver un chemin à peu près praticable, il faut descendre sur les flancs dụ cône jusqu'ì 200 ou 250 mètres au-dessous du sommel, et, pour arriver lì, on rencontre une série de murailles à pic el de pentes mourantes excessivement roides, où il est trèsdiflicile de se conduire sans danger lorsqu'on a eu l'imprudence de s'y engagoer. Plus bas, les flanes du cône sont d'une admirable régularité el descendent, avec une pente moyenne de 30 degrés, jusqu'à une immense profondeur sans laisser voir autre chose que des scories et des cendres brunes sur lesquelles ne croît pas mème un brin d'herbe. Les masses rocheuses de l'ouest, après avoir entouré à peu près un liers de la circonférence du cratère, se prolongent assez loin vers le sud, en dessinant une arête saillante sur la surface du còne. Il existe une seconde arête du mème genre, produile par le prolongement des masses rocheuses qui se trouvent à l'est, et elle se dirige à peu près parallèlement à la précédente, à 150 mètres de distance environ. Entre ces deux murailles, on voit une pente assez forlemen! inclinée, formée par un amas de gros blocs scoriacés au milieu desqnels se creuse bientôt une profonde barranca, qui, se déviant In peu vers l'ouest, donne naissance à l'une des branches du rio Achiguate. Le cours de ce torrenl est traversé, non loin de sa naissance, par un des chemins de la terre chaude, el l'on raconte quiil est quelquefois très-dangerenx de s'y engager pendant la saison des pluies. Fin effet, les scories et les cendres forment des espèces de barragoes, qui retiennent les eaux déversées par les orages, el ce n’est que quand il s'est formé des pelits lacs d'une cerlaine imporlance que los digues sont rompues tout à coup, et quils se précipilent daus la plaine, sous la forme de torrents boueux qui s'avancent avec une effroyable violence, détruisant tout ce qu’ils rencontrent sur leur parcours. la lond du cratère du côté de l'est ne diffère pas beaucoup de ce qu'il esl du 
ròlé de l'ouest; néanmoins les massifs rochenx ne s'étendent pas aussi bas sur la surface du còne et ils y sont moins abrupts, de sorte que l'on peut s'y engager sans courir aulant de dangers. Iu sud, entre les deux arêtes parallèles, la pente rocheuse qui constitue le ravin se transforme, au bord du cratère, en une pelite plainc peu accidentée. Le difficile est d'arriver jusque-là, mais, lorsqu'on y est, on peul y marcher en toule liberté d'esprit, et c'est là qu'ỉl est le plus aisé d'alteindre jusqu’à l'extrème bord du cratère et de plonger le regard dans ses inmenses cavités. Le sol de li plaine est formé, soit de gros blocs accumulés en désordre, soit d'une nasse argileuse craquelée et fissurée dans tous les sens, dont l'origine est due à la réaction des vapeurs acides sur les matériaux feldspalhiques du milien desquels s'échappent 11 très-grand nombre de fumerolles. L'aspect contourné el hérissé que présentent les flancs du volcan de ce colé-là, à cause de la présence des blocs scorifiés accumulés, a lait penser qu’il y existail une puissante coulée de lave. Nous croyons que c'est une erreur, car toules les roches que nous avons examinées sont des porpliyres trachytiques très-scoriliés, analogues en réalité à cenx qui existent an sommel de ta montagne, près du petit cratère oblitéré, qunique plus allérés à leur surface. On rencontre néanmoins des fragoments isolés donl la composition est différente el qui rappellent beaucoup les laves vitrifiées du pied de l'Izalco. Ce sonl des masses noires, quelquefois un peu boursouflées, plus souvent à cassure conchoïdale, formées d'une pâle pyroxénique, engolobanl un grand nombre de cristaux blancs de rliyacolithe. On y remarque aussi de volumineux morceam (1 centimètre $1 / 2$ de longueur') d'orthose jaunàtre, translucide, ì reflets irisés, ainsi que des granules semi-cristallins de péridot ferrugineux de couleur brunàtre. Mais nous sommes porlés à croire que ce sont simplement des frag̣ments projerés par le volcan, el arrachés au bord de la fissure par laquelle s'est épanchée la conlée de lave qui existe en effet au pied de la montagne dans la direction du sud, ainsi que nous avons pu nous en convaincre par nous-mèmes après l'avoil appris de persomnes dignes de foi. La lave lunide, sans jamais atteindre le bord lu cratère, doil s'ètre déversée à la base du còne par un évent adventil, ouvert momentanément dans un point doumé, doul nous ne connaissons pas exactemenl la situation. En résumé, la partie supérieure du volcan de Fuego est extrême-ment accidentéc ul cola en grande parlie à cause de l'inclinaison du cratère actit, 
DANS LES RÉPLBLIQUES DE GIATEMALA ET DE S ILVADOR. 459 qui se trouve disposé entièrement sur un des flancs après avoir entaillé les rudi'Ineuls d'un ancien petil cratère silué au point culminant. Au nord, le còne est régulier sur une hauteur verticale de 300 mètres euviron, entre les parois abruptes du sommet et le point où la Mesela prend naissance. Au sud, il est dérangé par deux longues murailles de rochers parallèles. A l'ouest et à l'est, il est tourmentó jusqu'à une centaine de mètres en moyenne au-dessous du bord du cratère, puis il se conlinue par des pentes excessivement régulières, inclinées de 30 à 32 degrrés, formées de scories brunes et de lapilli, qui se prolongent d'un còté jusqu’ì une immense profondeur et se perdent de l'autre (à 2,500 mètres d'altilude) dauss de magonifiques forêts tropicales.

Des fumerolles, en nombre très-considérable, vieunent encore ajouter à l'inlérè̀ que présente ce remarquable ensemble. Nous allons nous occuper de fixer leurs positions el d'élablir leurs principaux caractères. Ise pelit cratère rudimentàré siRépartition
atempératures
dess
fimmeroltos. tué ì la cime fu volcan présente, dans sa région orientale, plusieurs dégagonenents de vapeur d'une faible intensité, réparlis sur la direction de deux ou trois fissures longitudiuales partant du bord du cratère pour en gagner le fond. Nous avons oluservé près du bord du cratère $(f)$ des tempéralures de $79^{\circ}, 80^{\circ}, 50$ el 81 degorés, landis qu'au fond $(e)$, nous u'avons plus trouvé que 59 degrés, ce qui est assez remarquable et constitue une exception ì la loi générale des températures, telle que nous l'avons élablie pour la plupart des volcans de l'Amérique cenlrale. L'uue de ces fissures se continue en dehors du cratère, sur les flanes du còne, dans la direction de l'est, et descend jusqu'à une quarantaine de mètres au-dessous du sonmet, suivant une des génératrices dn cône. Celte fissure rejoint, à sa partic inférieure, un raste espace recouvert de croùtes d'alun blanchàtre, qui constilue, à la surface du volcan, une grande lache de couleur claire, visible mème de La Anlignai. La direction de la fissure est jalonnée par des dégagements de gaz plus ou moius abondants, dont la température s'élève à mesure que l'on descend. A une vinglaine de mètres au-dessous du sommet $(g)$, nous avons conıstaté uno température de 86 degrés.

Dans le grand cralère actif, on aperçoil tout au fond une fumerolle abondantr: qui se liat jour vers le nord-est. A peine est-il nécessaire de dire qu'elle est conplélement inaccessible et qu’il en est de mène pour 6 on 7 dégagements de gar 
très-importants $(h)$ qui s'échappent des parois du grand puits vertical. Ces lumerolles sont réparties en cinq groupes principaux, situés au nord, à l'ouest 20 degrés nord, au sud 20 degrés ouest, au sud-est el au nord-est, à des hauteurs qu'il est difficile d'évaluer, mais qui correspondent à peu près à la moitié de la profondeur du cralère, mesurée du côté du nord. Au voisinagge de ces fumerolles, mais plus particulièrement dans la région de l'onest, on voil s'élaler de vastes plaques de soufre, d'alun blanchàtre et d'alun verdàtre, dont les vives couleurs se marient étrangement aux tons bruns et rougeàtres des roches calcinées. Ces fumerolles laissent échapper d'énormes volumes de vapeurs qui se rémuissent pour former le mnage de fumée qui couromne en toul temps la cime du volcan de Fuego.

Au pied de la grande arète rocheuse du snd-onest, à 80 mètres environ des bords du cratère, on voil une petile caverne toute lapissée de soufre cristallisé jaune clair, el enduite, en d'autres endroits, d'une masse pàteuse semi-fluide d'uu jaune rougeàtre, composée probablement de chlorures de soufre ct de fer. Le soulie en cristaux, très-fortement acide, est imprégoné d'une grande quantilé d'acide chlorhydrique, mélangé d'une faible proportion d'acide sulfurique. II s'échappe de la caverne une très-abondante fumerolle $(c)$ dont la température est de $9^{3}$ degrés.

Elle est reliée au bord par une très-nombreuse série de petiles fumerolles $(d)$. dont la température oscille entre 85 et 86 degrés. Il y a lì au moins une soixanlaine de dégagements de vapeur, répartis suivant la direction de fissures ouvertes un peu au hasard à la surface de plusieurs petits plateaux argileux disposés au-dessus les uns des autres comme les marches d'un escalier à moitié démoli. Pjès du bord, du còté du sud, on voil quelques petites fumerolles mal définies el à basse tempéralure qui s'échappent de vastes fentes irrégulières ouvertes au milieu d'mn amas de gros blocs scoriacés.

Enfin, à l'est, tout près du bord, il existe un nombre très-considérable de liumerolles, sortant du massif rocheux compacte par plusieurs fissures à moitió comblées par des amas argilo-sableux, mélangés de beaucoup d'alun et d'un peu de soufre. Pour la majeure partie de ces dégagements de gaz, la tempéralure varie entre go el 100 degrés; nnais deux ou trois des principaux font monter te thermomètre jusqu'à 110 degrés 5o. En présence du peu d'observations que nous 
DANS LES RÉPUBLIQUES DE GUATEMALA ET DE SALVADOR. 461 possédons, il n’y a pas lien de chercher à établir la loi de la répartition des températures pour le volcan de Fuego.

Au point de vue de teur composition, les fumerolles présentent des vatl'iations assez remarquables. Voici ce que nous avons observé pour les prinComposition des fumerolles. cipales.

Les dégagements de gaz du pelil cralère oblitéré se composenl presque essenticlloment de vapeur d'eau, nélangée d'un peu d'acide carbonique, d'azole, ot d'acide sulfurenx dont la proportion semble subir des altérations intermittentes, du moins en tant que l'odorat est pris pour guide. En dehor's du cralère, sur la direction de la fissure, la composition des fumerolles reste à peu près la mème, mais il semble qu'il y ait plus d'acide sulfureux à mesure que l'on descend, cal' l'air ambiant devient moins aisément respirable. En somme, ce groupe est surtoul caractérisé par la grande prédominance de la vapeur d'cau, et il ne présente pas de Iraits bien saillants.

La fumcrolle à $9^{3}$ degrés, qui s'ćchappe avec violence de la caverne ouverte dans la muraille rocheuse du sud-ouest, est infiniment plus remarquable. Qnoiqu'elle renferme une assez forte proportion de vapeur d'eau, clle est néanmoins d'une singulière acidité, car elle rougit immédiatement el fortement Ir papier de tomrnesol bleu, et il est difficile de rester quelque temps dans son voisinage sans ressentir un malaise assez violent, ainsi qu'une douleur à la gorge trèsprononcée. Il n'est, d'aillcurs, pas aisé de l'alteindre, car clle est située à environ 2 mètres au-dessus du sol, dans la paroi à pic, et il faut se suspendre à gorand' peine aux anfractuosités des rochers. L'odeur qu'elle possède annonce la présence d'une assez forle proportion d'acide sulfureux, mais la quantilé d'acide chlorhydrique qu'elle renferme est encore bien plus considérable, car un flacon d'ammuniaque, débouché à quelque distance, répand immédiatement d'abondantes fumées blanches. Il y a, en outre, un peu d'acide carbonique el d'azote, mais ancune trace d'hydrogène sulfuré, car le papier d'acélate de plomb ne subil pas la moindre alléralion.

Les pelites fumerolles réparties sur la plaine argileuse et dans les envirous du bord dı còlé du sud, ne présentent pas beaucoup d'intérêl; elles se composent, en majemre partie, de vapenr d'eau arec un pen d'acide carbonique el d'azote, ainsi 
quiure très-faible proportion d'acide sulfureux. En un mot, elles ont une grante ressemblance avec celles du pelit cratère du nord.

Les fumerolles à 1.10 degrés 50 , silućes près du bord dans la paroi rochense de l'est, sonl, au contraire, des plus remarquables. Malgré nue assez notable proportion de vapeur d'eau, leur acidité est presque aussi lorte que colle de la lumerolle à 93 degrés, quoique leur composition diflère sensiblement. Le papir’ blen de tournesol est lortement rougi en pen d'inslants, mais l'acide dominant doit être l'acide sulfureux, ainsi que cela est prouvé aussi bien par les propriélés organoleptiques du gaz que par ses réactions chimiques. L'acide clılorhydrique osl assez abondant, mais beaucoup moins que dans le cas précédent, car les funtés func répand un flacon d'ammoniaque, débouché dans le voisinagge, ne sont nullemont comparables comme intensilé. Sauf ce fait intéressant du renplacement des acides chlorhydrique el sulfureux l'un par l'aulre, pour occuper la prenrière place, la composition des deux fumerolles ne doil pas présenter de grands écarts rolalivement à la nature et à la proportion des autres éléments.

Nous avous eu te malheur de ne pouvoir rapporter entiers en France les lubes dans lesquels nous avions recueilli le gaz qui se dégage dans tes tocalités les plus inléressantes du volcan de Fuego. Nous ne pouvons done pas donner terur composilion exacte comme nous aurions désiré le faire, mais nous pourons dire, sins nous écarter beancoup de la vérité, que, grâce aux tempéralures qui oscillent autour de 100 degrés, la proportion de vapeur d'eau doit ètre au moins de $7^{5}$ p. o/o, el que, dans ce qui reste, l'acide chlorhydrique el l'acide sulfurenx doirent se partager un volume de 4 on 5 centièmes, lout an plus, malgró leur trèsgrande abondance apparente.

11 est intéressant de comparer entre elles les fumerolles des deux cratères du zolcan de Fuego, car, landis que les unes, à peu près neulres, n’ont guè̀re que des propriélés négatives, les aulres jouissent d'une température élevée el d'une acidité prouoncée, qui leur dounent un cachet caracléristique. Il y a là une sorle de vérification de ce que l'aspect des licux nous avait fail immédiatement supposer, c'est que te pelil cratère oblitéré du sommet n’est qu'un témoin, accidentellement préservé en partie, de l'élat primordial du volcan. Le cratère ouvert sur le flanc du cône osi, au contraire, beaucoup plus récent; c'est lui senl qui rentralise anjour- 
DANS LES RÉPUBLIQUES DE GUATEMALA E'T DE SALVADOH. 463 d'lui l'aclivité éruplive de tout le groupe, el l'on est en droil de supposer, gratce aux manifestations dont il est encore le théâtre, que le volcan de Fuego, malgró te rôle important qu'il a déjà joué, ne sera pas rayé de sitòl de la liste des volcans aclils de l'Amérique centrale.

VOLCAX D'ATITLAN. - VOLGAN DE SAX PEDBO.

(Pl. XVI et pl. XVII).

A une quarantaine de kilomètres plus loin que le volcan de liuego, smivaml lit direction gónérale du système volcanique de l'Amérique centrale, on rencontre l. lac d'Atillan, dont nous avons déjà eu occasion de parler plus d'une fois. Malgoré sa forme très-irrégulièrement arrondie, il ne faudrail pas croire que ce lac ail pris naissance dans quelque gigantesque cratère éteint, ainsi qu'ont pu le supposer quelques voyageurs en voyant les immenses falaises verticales qui le limilent du còté du nord, car il n'en est rien. Mais, si le lac d'Alillan n'est pas un cratèrelac, il se rattache pourtanl directement à l'action volcanique, dont sa formation est, en quelque sorte, un eflét simple el naturel, ainsi que nous l'avons démontré daus un chapitre précédent (voyez p. 106). Les volcans donl le soulèvemeul a inlercepté le cours de vallées préexistantes et entravé la marche des eaux, de mánière à les forcer à s'accummler et à produire un lac, occupent, sur ses bords, de's ·pesilions bien déterminées. Lu sud, on voil le système du volcan d'Alillan, composé dr trois cònes, alignés suivant une direction à peu près nord-sud; au sudoucst, se trouve le volcan de San Pedro, séparé du massil précédent par un golle assez profond.

Quoique te volcan de San Pedro soit silué plus loin que celui d'Atillan sur la direclion dı système volcanique, en conlimuant à marcher dans le sens qur nous avons choisi pour notre description, nous en dirons imnédiatement quelques mols pour n'avoir pas à y revenir. Ce volcan esl silué ì environ 1.j hilomètres au nord $30^{\circ}$ ouest du volcan d'Alitlan. La hauleur en est à peu près de 2,500 mètres, urais, comme il repose sur un plateau élevé déjà de 1,560 mètres (niveau du lac d'Atillan, cl qu'il est entouré de tous còtés par des contre-lorts qui masquent sa base, il ne possède absolument rien de majestueux dans ses allures, ni par sa lorme, ni par ses dimensions. Il est, d'ailleurs, complétoment

Soulevemenls voleanicutes auxquels est dut la formation dur lac d' litialis.

Iolcan de San Pedru. 
éteint; d'épaisses lorèts recouvrent ses flancs ainsi que son sommet, et l'on ne possède aucune tradition relative à ses éruptions, mème dans les époques historiques les plus reculées. Il n'a donc d'autre importance que d'ètre un des jalons de la ligur rolcanique.

Gimpe du volran d'Alillan.

Solcan d'itillan propremenl dil.
Le groupe du volcan d'Alitlan se compose de trois cônes soudés par leur base, Irès-rapprochés l'un de l'autre et alignés suivant une direction à peu près perpendiculaire à celle du système d'ensemble, obéissant ainsi à une loi qui paraî́t ì peu près générale dans l'Amérique centrale. Comme toujours aussi, l'évent encore en activité est celui qui se trouve le plus avancé vers le sud, tandis que les cimes éteintes occupent la partie nord du massif volcanique. Les deux premiers de ces cònes sont donc tout à fiit inactifs, et n'ont laissé voir aucun symplòme de manifestation éruplive depuis la période historique. Ils sont extrêmement voisins l'un de l'autre et réunis jusque près de lenr sommel; leur hauteur est, à quelques mòtres près, la mème, el ne dépasse pas 3,000 mètres. D'épaisses forêts les recouvrent jusque dans leur parlie supéricure, et envahissent même les cratères rudimenlaires qui existent à leur sommet. Un profond ravin, descendant presqur jusqu'à la base de ces montagnes, les sépare du còne aclif qui porte phns spé('ialement aujourd'lni le nom de Volcan d'Atillan.

Le volcan d'Atillan proprement dit est actuellement dans un état éruptil don! l'intensilé ne présente rien de bien remarquable, el, quoiqu’il soil assurément beancoup moins voisin de l'extinction complète que le volcan de Pacaya, il est néanmoins à un degré d'aclivité heaucoup moins puissant que le volcan de Fuego. Ses dernières éruptions ne datent pourtant pas de bien longtemps, et il est probahle que, d'un moment à l'iutre, il peut recommencer à devenir un sujet d'effroi pour les populations environnantes. On sait qu'à l’époque de la conquête du Guitemala le volcan d'Atillan élait en feu, et que, pendant les siècles suivants, il manifesta très-fréquemment son activité par des éruptions plus on moins violentes. Mais, comme il se trouve situé dans une des parties les moins habitées du Guatenıala, el qu'il n'y a aucuue ville importante dans les environs, il ne s'est trouvé personne pour enregistrer les dates des phénomènes qui s'y produisirent et pour les conserver à l'histoire. Tous savons seulement qu'en 1828 el en 1833 il y eut des ímptions d'une très-grande violence, qui convrirent le pays de cendres brì- 
DANS LES RÉPLBLIQUES DE GUATEMALA ET DE SALVADOR. 465

lantes dans un rayon assez élendu. Des torrents de flammes el de fumée s'échappaient de son cratère, la terre tremblait à chaque instant avec violence, landis que d'effroyables décharges souterraines se faisaient entendre. En 1852 encore, le volcan d'Alitlan vomissait d'énormes volumes de fumée, et, il y a une dizaine d'années, il commença à rejeler me pluie de cendres qui semblail le prélude d'une éruption dont les conséquences ne furent pourtant pas sérieuses.

Le volcan d'Atitlan, dont le point culminant atteint la hauteur de 3,572 mèIres an-dessus du niveau de la mer, forme un cône assez régulier, dont la base elliplique repose, au nord, sur un plateau élevé de 1,560 mètres, el se confond, au sud, dans les premières peutes du versant du Pacificque. Du còté du nord, d'épaisses forêts s'élèvenl sur ses flancs el ne s'arrètent qu'ì 3,200 nè̀tres environ. Au sud, au contraire, une immense pente, presque entièrement nue depnis le sommet jusqu'aux altitudes de 1,50o mètres, vient mourir dans les forc̀ts tropicales de l'hacienda de Sal Agustin, en se reliant progressivemenl aux plaines doucemeut inclinées du bord de la mer.

Comme personne, jusqu'ì l'époque de notre voyage, n'avail encore fail l'ascension du volcan d'Alillan, nous n'avions aucun conseil ni aucun renseignement à prendre sur les moyens de mener ì bome fin notre entreprise. Quant à espérer de trouver des gnides indiens, il n'y fallail pas songer, car les volcans sont pomr eux un objet de respectueuse terreur, el rien ne saurait les décider à s'en approcher de trop près. Les propriétaires de l'hacienda de San Ağuslin, nos enlreprenants el courageux compalriotes MM. B., nous ayaut offert chez eux une aiinable hospitalité, et uous ayant promis de mettre en ouvre tons les moyens dont ils pourraient disposer pour nous aider dans notre entreprise, nous primes la décision de tenter l'ascension du côté du sud. Il y avait à cela un avantage nartrqué, celui d'éviter en grande partie les impénétrables forêts vierges qui sonl si abondantes sur les flancs du nord, et de pouvoir monter presque toul le temps sur un espace nu, en examinant à l'avance le chemin qu'il semblail te plus convenable de prendre et en étudiant librement la topographie du pays. Mais il y avait aussi le désavanlage d'allonger de beaucoup l'ascension en la commençant ì 600 mètres d'allitude, au lien de partir du niveau de 1,500 mètres. En outre, comme nous nous en aperçumes malheureusement trop tard, l'espace libre du 
sud est coupé par une immense quantité d'effroyables ravins abrupts, et les difficultés que l'on y rencontre sont telles, qu’il nous fallut un séjour de quatre jours dans les hauteurs avant de pouvoir alleindre le but de nos efforts. Nous ne savons pas si des voyageurs qui voudraient entreprendre de nouveau l'ascension du volcan d'Alillan ne feraient pas mieux de la tenter du côté du nord, en partant du grand village d'Atitlan, el en s'assurant à l'avance les services d'un nombre suffisant d'Indiens, pour ouvrir, à coups de machete, un sentier dans la forêt vierge.

Qnoi qu'il en soit, nous n'insisterons pas sur les difficultés que nous cùmes ì surmonter pour installer notre campement, à une hauteur de 1,340 mètres, sur les flanes du volcan, et sur les pénibles recherches auxquelles nous dùmes nous livrer pour découvirir une direction où l'ascension fùt praticable, tout en restant fort dangereuse, et nous commencerons notre récil au moment de notre lentative décisive, te 9 août 1866 , à 5 heures du matin.

Système de déclirures occupant le flane sud lı volcan d'Atitlan.
Pour bien faire comprendre de quelle nature étaient les obstacles contre lesquels uons avions à lutter, nous devons essayer de décrire en quelques mots le singulier système de déchirures qui occupent le flanc sud dı volcan d'Atillan. (Voyez pl. XVII.) Les choses sont dans un état tel, qu'il semble que les couches supérieures du cône, demeurées parfaitement intactes sur les deux tiers de la circonférence, aient été, au contraire, enlevées sur l'autre liers par quelque elfroyable calaclysme, de manière ì dessiner un vaste espace évidé, dont la surface, sillomnéc par une profusion de ravins abrupts, se maintient à une vingo de mètres en contre-bas du reste de l'enveloppe externe de la montagne. La partic ainsi dérangée n’alteint pas jusqu'au sommet du volcan; elle ne commence qu’ì 200 mètres environ au-dessous de la cime, respectant ainsi un cône lerminal rógulier, paraissant avoir élé formé par une éruption postérieure, qui aurait réparé, dans les régions supérieures, les dommages antérieurement causés par un phénomène d'une incroyable violence. L'espace éviclé ne descend pas non plus jusqu'au pied du cône, il s'arrête à 1, 400 mètres d'altitude environ, pour se transforner en un ravin unique, à sec pendant l'été, et parcouru, pendant la saison des pluies, par un torrent qui se reforme ì la snite de chaque orage. La partie dérangée du cône occupe ainsi un espace irrógutlièrement rectangulaire, de près de 3,000 mètres de longueur (2,000 mètres suivant la verticale), of de denx 
DANS LES RÉPUBLQUES DE GUATEMALA ET DE SALVADOR. 467 kilomètres de largeur eu moyenne, limilé par des parois presque partout verlicales. En effet, les génératrices situées à l'ouest-sud-ouest et à l'est-sud-est du cône correspondent à peu près aux bords de l'enfoncement, et représentent la crête de murailles à pic qui se soudent par leur ligne culminante ì la surface régulière du nord, et par leur base au fond de la dépression accidentée. De ces deus arêtes, l'une, celle de l'ouest-sud-ouest, conlinue à descendre en conservant, à peu de chose près, sa direction originaire, landis que l'aulre, celle de l'estsud-est, se détourne à environ un millier de mètres au-dessous de sa naissance, pour snivre alors une marche presque perpendiculaire à sà direction primitive, et venir se placer toul auprès de la première, de inanière à former avec elle un ravin unique. L'espace ainsi circonscrit est entaillé par une incroyable quanlité de ravins, qui descendent en cascades successives sur le fond de la région déprimée, qui se recoupent dans tous les sens sans obéir à unc direclion bien déterminée, qui laissent entre eux des îles à parois verticales el de fantasliques amoncellements de rochers, el constituent en un mot un inextricable réseau, donl les éléments sont sans cesse modifiés par l'action des agents almosphériques. Pendant la saison des pluies, les violents orages de cette régoion déversent d'immenses quantilés d'eau qui parcourent successiventent ces ravins et viennent enfin se réunir, au sud-ouest, dans une barranca umique, pour former le Rio Bravo, un des principaux affluents du Rio de Santa Barbara, qui se jette dans le Pacifique ì une cinquantaine de kilomètres plus au sud.

C'est en pénćtrant daus la barranca du Rio Bravo, heureusement ì sec en ce moment-lì, et en nous enfonçant ensuite dans celui de ses ravins alfluents qu'après de pénibles explorations nous avions reconnu čtre à peu près praticable, que nous avons rénssi à gagogner la région supérieure de l'espace dérangóé, puis de là, l'arète de l'ouest-sud-ouest, et enfin la partie intacte du cône. Le ravin que nous ivons suivi est le premier qui se présente à gauche lorsqu'on remoute la barrauca du Rio Bravo; mais, à l'endroit, facilement reconnaissable, où il se sépare en deux branchıs el se précipite en une cascade verticale d'une vinglaine de mètres de hauteur, il faut le quitter pour s'élever à grand'peine sur l'arête saillante qui le sépare de son voisin de droite, el continuer à marcher sur ce mu' de rochers jusqu'au point où une brèche, que l'on distingue aisément de loin, 
permet de gagner le bord extrème du côté de l'ouest-sud-ouest. Tous les autres ravins que nous avions explorés avant de découvrir celui-là sont impraticables, à cause des immenses murailles à pic qui les interrompent de temps en temps. Nous ne conseillerons, d'ailleurs, à personne de reprendre le chemin que nous avons suivi; car, outre que le ravin en lui-mème est extrêmement pénible et périlleux, on serait infailliblenıent perdu, si l'on y était surpris par un oragge déversant daus les régóions supérieures une certaine abondance d'eau pluviale. A plusieurs réprises, on est enfermé, sur des longueurs de plusieurs centaines de mètres, entre des parois à pic de rocher's lisses el continus, extrêmement rapprochés, el si l'on y rencontrait le torrent, arrivant avec une impétuosité dont il est lacile de mesurer: la valeur par la manière dont les roches sont polies sous l'action des eaux, on serait entrainć sans espoir de salut. Un autre danger, non moins redoutable, est celui des éboulements; nous en avons souvent vu de l'hacienda de Sau Igustin, à plus de 10 kilomètres de distance de l'endroit où ils se produisaiént, et leur violence élail telle, que le bruil en parvenail jusqu’ì nous, en mème temps qu'un nuage de poussière se répandail sur le flanc de la monlagne. Le jour mème de notre ascension, nous aurions pu périr, si nous nous étions mis en marche une demi-heure plus lard; à peine élions-nous sorlis du ravin, qu'une asse\% violente secousse de tremblement de terre se fit sentir, pendant environ une seconde, suivic, à peu de dislance, de deux aulres secousses un peu moins fortes. II ćtail sept heures une minute du matin, et les secousses, semblables à un mourement ondulatoire dirigó de l'est à l'ouest, furent ressenties à Guatemala à peu près au même moment. Il est inulile de dire que ce tremblemenl. de terre annena daus les ravins d'épouvantables éboulements, el que nous amrions pu en être victime, si nous n'avions eu la honne fortune d'ètre en lieu sùr an moment où le phénomène se manifesta.

Composition du sol à la base du volcan.

La barranca du Rio Bravo a une profondeur d'environ 30 mètres, au poinl où nous y avons pénétré pour continuer ensuite d'en remonter le cours. Ses patrois, presque partout à pic, s'ouvrent brusquement dans une sorte de plaine inclinée d'une dizaine de degrés, qui s'élend à la base du volcan. Elle est enlièrement entaillée dans une puissante assise de congloméral porphyro-tracliylique, qui recouvre au loin les régions entourant le pied de la montagne, et dont l'origine 
DANS LES RÉPUBLIQUES DE GUATEMALA ET DE SILVADOR. 469 ast essentiellement volcanique. Ce conglomérat se compose, en eflele d'une masse de sable volcanique gris, noiràile ou violacé, englobant une immense quanlité de fragments de scories el de blocs plus ou moins volumineux de porphyre trachytique, dont les surfaces présentent tous les degrés possibles d'altération. A mesure que l'on descend vers les plaines du bord de la mer, la proportion des grosses pierres diminue, tandis que celle du sable voleanique violacé augmente; à San Agoustin, c'est à peine s’il y a encore quelques cailloux disséminés, el la décomposilion des sables produit une terre végélale noire, d'unc extrème fertilité, sur laquelle se développe l'cxubérante végélation des forèts vierges. Celle mème formation persisle au sud, jusqu'au delà de San Agustin, el elle ne s'arrèle que près des Ranchos de Liboya, où elle se mêle anx argiles jaunes pour masquer les grranits gucissiques de cette localité.

Plus haut, lorsque l'on pénèlre daus l'espace déchiré, la puissance du congolumérat volcanique lend, au contraire, à diminuer, et il arrive assez fréquemment. que la partic inférieure des ravins, dont la profondeur varie entre 20 el 30 mèlres. rst entaillée dans la roche mème qui constitue le massif interne du volcan. Ces ravins deviennent alors extrèmement élroits, ol ressemblent à de vérilables caulaus reusés de main d'homme, dont les parois, lisses el polies jusqu'ì une hauteur quelquefois de $1^{\mathrm{m}}, 50$ ou de 2 mètres, lémoignent de la puissance d'aclion des eau en mouvement. Cette roche est un porphyre trachylique parfaitement caractérisć, qui ne présente ancune trace d’altération, el qui constitue, sans aucune solutiou de continuité, une vaste assise intérieure. Elle se compose d'une pàte feldspalliquur très-compacte, grise ou noirâtre, engglobant des cristaux d'orthose blancs el plus ou uoins bien définis dans leurs formes. Ces porphyres trachyliques ont conservé un aspect absolument semblable à celui qu'ils ont dans les montagnes n'ayaun rien de commun avec des cònes volcaniques, el aucune cause ne pourrail laire supposer qu'ils ont été soumis à l'action des phénomènes éruptifs.

La régoion supérieure de la zone dérangéce est forméc par un entassement. claaotique de blocs scorifiés, noirs el brunàtres, dont lo volume est sourent énorme, et dont la surface est quelquefois reconverte de mousse el de lichens. On y remarque, jusqu'à une allitude de 2,800 mètres, quelques arbustes riachiliques appartenant ì la fannille des bouleaux, qui croissent dans les interstices 
des rochers, lorsque le hasard de la décomposition y a amené uu peu de tarro régétale.

L'arète de l'onest-sud-ouest, qui conslitıe en quelque sorte le bord oì vient s'arrèter la partie intacte du cône, se compose d'un amas de scories noiràtres, dont le volume ne dépasse pas, en moyenne, la grosseur du poing, imparfaitement cimenlées par des cendres ou des sables grisàtres, et sur lesquelles il n'est pas Irès-aisé de s'arancer, à cause de la pente, qui y est assez forte, et de la mobilité des matériaux. Tandis que la naissance des ravins, dans le point où commence la région déchirée, est caraclérisée par la présence de gros rochers scoriacés, bruns, noirs el rougeâtres, entassés sans l'interposition d'aucun ciment sableux ou autre, et roulant facilement les uns sur les autres, toute ta partie intacte du còne présente une surface uniformément lisse, où les petils frargments de scories sont noyés dans une sorte de pàte de sable qui ne leur donne que peu d'adliérence. On y voit la végélation s'arrèler brusquement, à 2,800 mètres environ, en se terminant par des bois de pins, qui succèdent aux forèts tropirales, mais qui ne peurent plus vivre eux-mêmes sur un sol trop pauvre. Un peu aranl que l'arête se sonde sur le cône terminal, elle présente une accumuJation d'immenses blocs de rochers formant une grande paroi verticale, dans laquelle on voit le porphyre trachytique très-altéré par les manifestalions volcaniques, quoique toujours compacte, offrir des surfaces jaunes et rouges corrodées et calcinées.

Cîne leiminal $d u$ rolean d'Atillan.

Lue còne terminal lui-même, uniquement composé de matériaux scoriacés plus ou moins lins entassés dans un équililıre très-instable, s’élève arec des pentes régulières dont l'inclinaison alteint jusqu'à $34^{\circ}$. Cette dernière partie de l'ascension est très-pénible et lout à fait comparable à celle des volcans de Fuego el d'Izalco, pour la mobilité des matériaux sur lesquels on marche el la facilité avec laquelle ils s'enfuient sous la pressiou des pieds. On y observe en très-grande quantité des blocs de scories, dont le volume ne dépasse pas celui de la têle, cotorés en vert foncé et prenant par points un aspect semi-vitrifié, qui les fait ressembler à des laitiers de hauls lourneaux. Elles alternent avec des nappes de sables, d'un rouge vif, produits par la trituralion de scories plus friables, dont quelques fragnents existent encore. A mesure que l'on s'élève, la dimension des 
DANS LES RÉPUBLIQUES DE GUATEMALA ET DE SALADOR. 17। éléments tend à diminuer, el sur le bord du cratère il n’y a plus guère de morrceaux plus gros que te poingु.

On éprouve une cerlaine surprise, lorsque, en arrivant à la cime du volcan, on se trouve en présence d'un petit cratère qui n’a rien de bien remarquable, el qui n'est en rapport, ni par sa forme, ni par ses dimensions, avec la grande montagne dont il occupe le sommet. Ce cralère est une sorte de lasse assez régulière, profonde d'une cinquantaine de mètres, el dont le dianıètre ne dépasse pas 250 mètres. Il est formé par un nombre infini de gros blocs de scories ou de roches scoriacées, entassés dans un désọrdre complet, et semble ètre tout à fait oblitéré par l'accumulation même de ces matériaux. L'aspect en est pourtanl assez singulier, à cause de la régularilé du segment sphérique qu’il dessine, et grràce à la couleur rougeâtre des scories, auxquelles se mêlent des plarques blanchàtres of jaunes d'alun et de soufre.

Nous y avons recueilli quelques échantillons assez intéressants, qui suffiraient, à eux seuls, à prouver combien l'activilé éruplive du volcan d'Atitlan a été plıs considérable que ce qu'on y voil aclucllement. Ce sont des agromónérations de cristaux de feldspath brillants, longgs de 2 à 3 millimètres, assez mal définis dans lenrs formes, parce que les angles sont arrondis el comme fondus. Les uns sont transparents, les autres translucides ou mème opaques; il y en de blancs, de jaunes, d'autres qui sont vitrifiés el scoriacés, el présentent alors un éclat irisé. Fintre les cristaux, on voil un peu d'une poudre rare, qui semble etre le reste de la paitr feldspathique d'un porphyre trachytique rongé par les acides. Il y a aussi de pelits morceaux de scories roses, légères, bulleuses el comme poncifićes, contenant des mouches blanches de feldspath indéterminable, el reconverles de croûles blanclies d'alun, accompagonées de petits nids de soufre jaune Lapissan! les cavilés. II serail impossible de décrire tous les types de roches, diversement altérées par la chalcur et par les acides, qui se trouvent au sommet du volcan d'Atitlan, et nous nous bornerons à dire que les variétés sont innombrables, en observant combien les mélanges de coulcurs contribuent à l'étrangelé de l'aspect gónéral, qui est peut-ètre plus singulier que partout ailleurs, quoique infiniment moins grrandisse.

Le bord dı cratère est presque exactement circulaire el no présente que pen d'accidents. Le poinl culminant, haut de 3,572 mètres au-dessus dı niveau de 
lia mer, se trouve dans la direction du nord-est, tandis qu'au sud on voit le point le plus bas à mne quinzaine de mètres seulement au-dessous de la cime.

linuerulle: dil volean d'Alitlan.

Les fumerolles sont très-nombreuses, quoiqu'elles ne fouruissent qu'ur asse\% petit volume de vapenr's, el s'accumulent principalement dans les régions de l'ouest el du sud-ouest. Elles sont groupées d'une façon extrêmement remarquable, suivant des lignes concentriques qui représentent en quelque sorle des fentes circulaires continues, de diamètres inégaux, réparties aulour de la partir centrale du cralère.

La priucipale de ces fentes occupe le bord même du cralère, et se dessine nellement dans une sorte de gorge, large de 2 mètres environ, comprise entre deux pelits redans de 1 mètre à $1^{\mathrm{m}}, 50$ cent. de hauteur. Ce sillon so continue sur phus de la moitié de la circonférence du bord, et lui donne une apparence caractérisliqure qui n’est pas sans importance. Dans l’untérieur du cratère, il y a deux ou trois fentes subsidiaires échelonnées, mais elles sont moins nettement indiquées " n'alleignent pas mème un développement d'une demi-circonférence entière, sauf pourtant celle qui est la plus rapprochée du bord et qui a les caractères les plus saillants. En delıors du cratère, sur les flancs du cône, on voit encore deux on rois fentes concentriques semblablement disposées; la première, en partanl dı sommel, occupe une demi-circonférence entière el prend une certaine importance, tandis que la dernière, à une trentaine de mètres plus bas, se réduil à quelgues fumerolles, aligonées suivant un arc de cercle. L'existence de ces fentes concentriques, assez fortement dessinées sur le sol pour que l'on ne puisse pas s'y tromper, est tont à fail particulière an volcan d'Alitlan, et constitue son caraclère le plus digno d’intérèt.

Chacune de ces lentes donne naissance à d'iunombrables fumerolles, et il serail plus juste de dire qu'elles constiluent elles-mêmes des fumerolles lonģitudinales coutinues. La grande quantilé de ces évents contraste étrangement avec leur peu d'aclivilé, rar ils ne rejettent que de faibles volumes de vapeur. La tempéralure est relalivement forl peu élevée, car, daus la plupart des fumerolles, Ir thermomètre se mainlient eutre 50 et $60^{\circ}$, el c'est à peine si les plus chaudes te font monter jusqu'à $80^{\circ}$. Les fumerolles se composent presque uniquement de rapenr d'eau, mècée d'un peu d'acide carbonique el d'azote. Elles contiennont 
DANS LES RÉPUBLIQUES DE GUA'TEMALA ET DE SALVADOR. 47:3 une très-pelite proportion d'acide sulfureux, à peine sensible ì l'odorat, et rougissant faiblement le papier bleu de tournesol; mais les réactifs n’y décèlent pas la moindre trace d'hydrogène sulfuré ni d'acide chlorhydrique. C'est- là un ćtat d'intensité éruplive extrêmement peu développé, et l'on voil que l'iutérêl du volcan d'Atitlan se trouve beaucoup moins, en ce moment, dans l'étude des phénomènes dont le cratère est le théàtre, que dans l'examen de la montagne en ello-mème et des singulières particularités qui sonl restrées comme témoins de soln activilé passée.

IOLGANS DE QLEZALTEMANGO

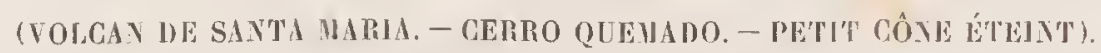

(Pl. XVIll, fig. 1 el 2.)

II he laul pas oublier que, quoique nous ayous cru devoir mous borner à n'en dire que quelques mols au débul du paragraphe précédent, à cause de son peu dimportance, la vraie place du volcan de San Pedro, sur la direction gónérale dı système volcanique, se trouve après le volcan d'Atitlan; nous considérons ce rappet romme suffisant pour nous dispenser de revenir sur ce sujet. Nons arriverons donc immédiatenent au groupe des volrans de Quezaltenango, en laissant encore nn arrière une montagne à laquelle une tradilion populaire donne lo nom de Volcan de Zuñil, sans qu’il y ail pour cela de raisons suffisantes. Ce préleudı volcan de Znñil est un vaste massif qui domine, à l'est, la riante vallér d'AlmoInnga, el que recouvrent enlièrement d'épaisses forèts viergoes. Il se sonde de tons còlés ì de puissants contre-forts, qui s’élèvent vers la chaìne centrale ou s’abaissent du côtŕ des plaines des bords de la mer; il ne présente aucune forme caractérislique el ne doit ètre qu'une montugne porphyro-trachytique, exactement semblable à toutes celles qui l'entomrent. S'il était vrải, toutefois, que son nom hil ait élé donné à caluse de la présence d'un petil cône éteint, noyé au milieu des cimrs porphyro-trachytiques et des forèts inextricables oì quelques Indiens chasseurs se sont seuls aventurés jusqu’à présent, nous n'aurions pas à regroteller heaucoup de ne l'avoir pas visité, puisquil ne se passe, dans celte direction, aucun phénomène éruplif (d'après le dị̂e des Indiens eux-mèmes), el l'on n'aurail qu'ì ajouter' ial membre de plus à la nombreuse série des volcans éleints qui jalonnent la direrlịon du système volcanique. 
iroupe do (quezaltenango.

Pelit còn

éleint

an nord

de la ville.
Lolcan de Sanla Maria

Le groupe des volcans de Quezaltenango présente infiniment plus d'intérèt et nous arrètera plus longtemps. Il se conıose de deux sommités principales, anxquelles nons joindrons encore un pelit cône éleint, séparé des deur autres par ıne distance d'une vingolaine de kilomètres, mais situé sur le prolongenent de la lignıe qui les ınil, de manière à constituer un système adventif, disposé, comme lous les autres, perpendiculairement à la direction du système principat. Ce petit volcan éleint forme le premier membre du groupe, en partant du nord, et s'élève ¿̀ 16 on 18 kilouètres de Quezaltenango, sur lo bord d'un vaste plateau qui doinine la plaine où est batlic colle ville. Le còne, qui a de 150 à 200 mètres de hauteur au-dessus des terrains enviromnants (soit environ 2,600 mètres de hauteur alosolue), est caractérisé par une admirable régularité de formes, sur laquelle il est impossible de se méprendre. Il n’est indiqué sur aucune carte géongraphique, el, lorsque nous l'apercûmes du sommet du Cerro Quemado, notre gruide ne pul pas nous dire son nom; cela ne nous empêclıe pas d'affirmer son existonce el d'ètre certain de sa nature voleanique, quoique nons n’avons pas en arcasion de l'exanimer do près.

Les deux sonmilés principales du groupe sout, en continuant à marcher du noed au sud, le Cerro Quemado el le volean de Santa Maria, situés au voisinage inmédiat l'un de l'autre. L'orientation exacte de la ligne qui joint leur cine est nord $20^{\circ} \mathrm{est},-$ sud $20^{\circ}$ ouest. Contrairement à ce que nous avons observé jusqu’à présent, c'est le Cerro Quemado qui jouit encore d'une activilé assez rr'mar(puable, taudis que le volcan de Santa Maria est toul à fait éteint. C'est là unr exception intéressante à la règle que nous avons pu établir pour presque lous les systèmes adventifs de l'Amérique centrale, et d'après laquelle l'évent situé it l'extrémité sud du groupe est celui où se manifestent les phénomènes volcaniques actuels. Nous ferons donc une petite interversion, ol, avant d'étıdier en détail te Cerro Quemado, nous dirous rapidement quelques mols du volcan de Sanla Maria, qui ne présente qu'un médiocre intérèt el sur lequel nous ne reviendrons pas plus tard.

C'est un còne d'unc remarquable régularité, dont la base vient se souder', du còté du sıd, à celle du Gorro Quemado, en formant une vallée rncaissée, qui fail en quelque sorte partic du plateau sur lequel repose le Cerro Que- 
DANS LES RÉPCBLJQUES DE GUATEMALA E'T DE SIIVADOR. 475 ınado, puisque son niveau se maintient à 2,100 ou 2,200 mètres d'altitude. Le iolcan de Santa Maria étant assis sur le bord de ce mème platear, ses pentes prenuent un développement considérable du côté du sud, en se raccordant progressivement aux plaines doucement inclinées du versant du Pacifique. Vu de li mer, il a un aspect grandiose el majestueux, qui ne le cède guère qu'à celui des volcaus d'Agua et de Fuego, el il le doil aussi bien au dessin harmonieux der ses formes qu'à la hauteur considérable à laquelle il alteint. Son sommet, dépassant de 400 ou 500 mètres celui du Cerro Quemado, doit èlre à une allitude d'au moins 3,500 mètres. Ses pentes, très-régulières, ont une inclinaison noyenur de 33" environ. Il est complélement éteint el doil l'ètre depuis forl longolemps, ainsi que le prouvent l'abondance et la vigueur de la végélation qui l’a tolalement envahi el le couronne, jusqu’à sou sommel, d'un magnifique dòme de verdure. I! n'raste d'illleurs ancune Iradition se rapportant à ses antiques éruplions, el l'on ast fondé à croire qu'il a laissé, depuis bien des siècles, à son voisin, le monopole dr l'aclivité.

Le Cerro Quenado, ou monlagne brîlée, qui porte aussi quelquelois plus spécialement le non de Volcan de Quezaltenango, présente une forme si singulière, que, lorsqu'on l'examine de la ville de Quezallenango, on ne serail guère disposé a le considérer comme volran, si l'on ne voyail mn nuage de fumée couronner sal aine. Il n’y a, à proprement parler, pas de còne, mais seulement une monlagne irrégulière, offrant, à son sommel, une vasle dépression à conlour polygonal, et s'élevant au uilieu d'une série de coutre-forts qui l'entourent presque de lous còtés. Il semble que quelque terrible cataclysme ail détruil toule la partie supérieure du volcan, el n’ail laissé subsister que son ossature interne, pour ainsi dire, sous la forme de puissants massifs rocheux el de pies élancés qui se grroupent de la façon la plus ćlrange. Le volean n’ayant pas eu, depuis celle époque, d'éruplion cinérilorme, n’a pas pu réparer les lorèches qu'il s'élait f́aites lui-mème, et ne s'est pas créé un nouveau cône par l'accumulation de ses déjeclions; il s'est maintenu dans son état de destruction, et, conservant son apparence désoléc, il semble une immense accumulation de ruines gigantesques. Le Cerro Quemado passe pour aroir été autrefois un volcan très-actif, mais, il parail que, depmis 1785, date de sa dernière éruplion, il s'est maintenu dans nu étal de repos re-

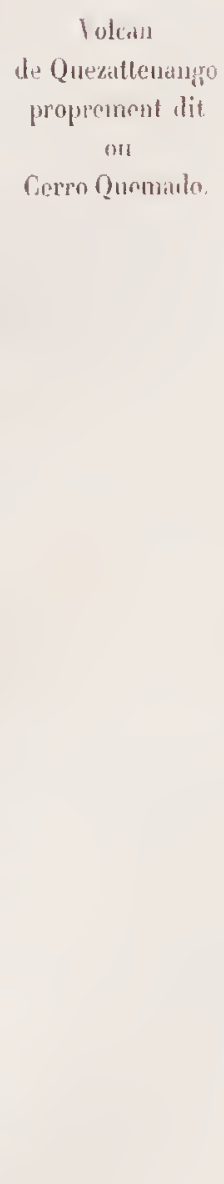


latif, quoiqu'il soit encore caractérisé par des symptòmes manifestes d'activité, ainsi que nous le verrons dans le cours de celte étude. La tradilion ne dit pas si, avant l'année 1785 , le volcan de Quezaltenango possédait un cône régulier, ou sil présentail déjà la forme accidentée qu'il a aujourd'hui, el il n’y a pas lieu de s'en étonner', puisqu'il s'élève dans un pays qui, quoique très-peuplé, n’a guère été envahi jusqu’ici par la civilisation. Nous sommes pourtant portés à croire que c'est l'éruption de 1785 , très-violente d'ailleurs, d'après le souvenir que les populations en onl gardé, qui a mis la montagne dans son étal actuel; car, s'il rien était pas ainsi, on trouverait au milieu des ruines les traces d'un phénomène postérieur, tandis que tout, au contraire, porte l'empreinte d'un cataclysme dont rien ne serait venu atlénuer les effets. Il y a beaucoup de ponces anciennes dans les environs du Cerro Quemado, mais pas de lapilli noirs ni de sables volcaniques violacés récents, ce qui ferail supposer que ses dernières éruplions ont été d'une nature particulière; peut-ètre est-ce à l'une d'elles qu'est due l'immense masse de lave pâteuse qui s'est en quelque sorte soudée sur l'un des flanes de la monlagne. Quoi qu'il en soil, lout est étrange dans le Cerro Quemado, el c'est assurément l'mu des volcans les plus intéressants de l'Amérique centrale, ì tous les points de vue.

Le massif du volcan de Quezaltenango, qui n'est pas sans avoir quelque analogie avec celui de Pacaya, semble avoir été formé par le soulèvement en masse d'mm pelil plateau très-ondulé, sur lequel se dressent plusieurs sommilés, dont les plus imporlantes appartiennent au volcan lui-mème. Les premiers contre-lorls du plateau ondulé, du còté du nord, sont composés d'une roche singulière, qui est cxploitée, sur une petite échelle, pour les constructions de la ville de Quezatlenango. C'est une masse ponceuse, d'un blanc pur ou un peu jaunâtre, légèere, extrèmement celluleuse, semblant, par points, un peu vitrifiée, fondue ou élirée. Elle contient, en assez grand nombre, de petites amphiboles noires, mal définies, el paraît avoir élé produite par la surfusion d'une matière feldspathique d'une assez grande pureté. Celte roche, tout ì fail particulière à celle localité, se laisse facilcment entamer par les instruments tranchants, mais elle possède une grande puissance de résistance à l'écrasement, ce qui, avec sa légèreté, la rend très-précieuse comme pierre de construction. 
DANS LES RÉPUBLIQLES DE GUATEMALA ET DE SALNADOR. 477

Après avoir gravi les premiers épaulements, on se Ironve bientôt sur lo pelit platear ondulé, où l'on peut observer quelques dégagements de vapeur d'une certaine importance, dans un endroil où il n'existe ancume trace de cratère ancien, el où rien ne peut faire supposer que les phénomènes volcaniques se soient jamais manifestés sous une autre forme. Ce lail est assez intéressant, surtont en ce qu’il établit une tiaison nettement indiquée entre les actions éruplives des volrans actifs et les infiernillos que l'on reucontre an pied des cònes éleints. Les fumerolles $(d)$ se trouvent à quelque distance à l'ouest du volcan, dans un petit vallon boisé, compris entre deux collines de médiocre élévation. Il y a, d'un còté, une série de fissures ouvertes dans une paroi de rochers, de l'aulıe, une espèce de caverne creusée dans le sol, à la profondeur de 3 ou 4 mòtres suivant la verticale, el au fond de laquelle existe aussi me sorle de fente. La vapeur s'échappe en beaucoup de points de ces fissures, avec une certaine abondance, mais la température n’est pas forl élevée, car elle se maintient, en goénéral, entre 50 el $60^{\circ}$, el ne dépasse pas $63^{\circ}$ à l'endroil le plus chaud. Les fumerolles ne produisent goù̀re que de la vapeur d'eau, mèlée d'acide carbonique el d'azole; l'odorat révè̀e la prósence de traces presque imperceptibles d'acide sulfureux, qui n'onl, d'ailleurs, aucune action sur la végótation environnante; l'abondance de l'acide carbonique est manifestement indiquée, car on ne peut pas maintenir me allumelte enflammér daus le fond de la caverne. Les habilants du pays prétendent que la quantité de vapeur que produisent ces fumerolles est intermillente, el qu'elle varie avec les lıcures de la journée; il nous semble beaucoup plus simple et plus naturel de penser que la condensation de la vapeur d'eau s'effectuant plus rapidement par le froid du malin que pendant les chaleurs de l'après-midi, le dégagement parail plus abondant au lever du soleil que pendant le milieu de la journée.

Le chemin contourne ces collines, el une deni-heure de marche sur le plateau ondulé, au milieu de verdoyantes prairies, vous amène bientòt au pied de ce que l'on est obligé, faute d'autre terme, d'appeler le còne du volcan. C'est un effrayant amoncellement de pierres el de rochers, sur lequel se développe un laillis assez épais, formé d'arbrisseaux appartenant aux familles des chènes el des bouleaux, et is travers lequel circule un sentier, presque fermé, moins par l'abondance de la végétation que par l'abandon dans lequel il est laissé. Il n’y a que peu de terre

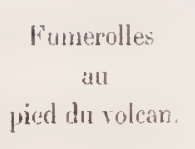

pied dit rolcan 
régélale interposée entre les rochers, car les scories en pelits morceaus sont rarres, et les gros blocs enx-mèmes ne sont pas. très-allérés à leur surface. A une centime de mètres environ au-dessous de la brèche, qui permel d'atteindre arec Ir plus de facilité la dépression existant au sommet de la montagne, on voil la végétation s'arrèter, el on peut examiner avec curiosité le singoulier aspect des régions supéricures el la nature étrange des flancs du volcan, rappelant un peu l'anlique idée de Pélion entassé sur Ossa.

II est difficile de caractériser en peu de mots le sommet du Cerro Queniado, car rien u'y rappelle un volcan ordinaire, el, si l'on veul rester daus la vérité, on ne peul pas dire que ce soil um cône tronqué daus lequel est entaillé un cratère. Lor'squ'on arrive à la brèche dont nous avons déjà parlé, el qui est située dans lal direction du nord, on a devant soi un vaste espace doucement relevé vers le snd el entouré de quelques pics rocheux plus ou moins ardus, de hauteurs inćgales, répartis de la manière suivante. A droile el à gatuche de la brèche, c'est-à-dire à l'est et à l'onest, sont deux grosses pyramides angulenses qui la dominent d'une soixamlaine de mètres; au sud-ouest se trouve un mantelon argileux un peu moins élevé; au sud-est, une vaste brèche sur laquelle nous aurons à revenir tout it l'heure, el enfin, au sud, une imnense paroi de roches verticales, longue de 150 ì 200 mètres el haute d'une centaine de mètres au-dessus de la partie de l'espace incliné qu'elle donine. Ces trois pies el les deux extrémités de l'arète forment ainsi les sommets d'une sorte de pentagone, enveloppant une dépression à laquelle il nous fiudra donner, faute de mieux, le nom de cratère. La grande paroi de rochers du sud scmble un vérilable mur lorsqu'on la regarde de face, mais, Iorsqu'on est arrivé à son somurel, ce qui, soil dit en passant, est très-difficile, on s'aperçoil qu'elle se prolonge en arrière, vers le sud, par une sorte de quene un peu courbe formant elle-mème un antre mur, qui se continue tout à lait en dchors du système du volcan, sur une centaine de mètres de longueur, en st' maintenant à peu près à la mème altitude, puis qui s'abaisse brusquement jusqu’à lis plaine onduléc.

Lat muraille du sud forme la partie la plus élcvée du volcan el c'est au nœud d’où divergent les deux arètes dans des sens perpendiculaires que se trouve le point culminant, à 3,1 10 mètres au-dessus du nivcau de la mer. Quoique la végótation se 
DANS LES RÉPLBLIOUES DE GUATEMALA E'T DE SALVAOR. 479 soil arrçtée un peu au-dessons du sommet de la montagne, elle reparail ru cel endroit, el l'on y roit quelques pins qui semblent assez robustes, malgré lo pen de terre végétale qu’ils trouvent dans les fissures du roc. Tontr la muraille est, en effet, formée d'une masse de roche compacte et conlinue, qui ne semble gönèr avoir souffert du voisinage des phénomènes éruplifs. C'est un porphyre Irarhylique bien caractérisé el très-analoğue à tous ceux que uous avons dérrils jusqu’ ì présent; une pàte d'un rose violacé, compacte quoique de texlure lágì̀rement grenue, englobant de nombreux cristaux de rlyacolithe bien définis, donl puetques-uns alteignent 3 ou 4 millimètres de longuenr, el, en outre, quelques crislaux de feldspath opaque ainsi que de rares mouches de péridot fermgineux rouggeàtre. La surface est lisse et de couleur un peu plus foncée que l’inlírieur, mais sans présenter de traces de vilrification. II y a, du reste, clans l'inlérieur du cratère, un grand nombre de rochers aussi peu altérés que ceux-là à colć d'autres dont la nature el l'aspect ont été sensiblement modifiés.

Le mamelon du sud-ouest est en grande partie reconvert de masses argilcuses, qui environuent aussi sa base du côlé de l'intérieur. C'est, en effcl, de ce còté-lì que se trouve accumulé le plus grand nombre de fumerolles, et nous savons quel est l'effet des vapeurs acides sur les matériaux feldspathiques. Ces arogiles, gónríralement grisittres, sont aussi colorées en jaune, en rouge ou en brun, snivanl quiclles sont plus ou moins inpures; en quelyues endroils où les caur das phies les onl remanićes, elles sont disposées en petits lits stralifiés.

la brèche du sud-est fait communiquer lintérieur du cratère avec un immonse champ de lave qui se trouve daus les conditions les plus singulières el ne peul Immenoe chimb
de lave al l'est du coine. guère recevoir le nom de coulée, car il est en quelque sorte suspendu sur la crète des montagnes, à une allitude d'au moins 3,000 mètres. Il ocrupe InI vasł" espace, situé à l'est-nord-est du volcan, long de près d'un kilomètre, large de 300 à 400 mètres el irrégulièrement rectangulaire. Sa surface, quoique à peu près horizontale, est extrèmement accidentée el hérissée d’aiguilles el de mamolons anguleux dont la hauteur est souvent de plusieurs mètres; c'est un entassement de blocs noirs, excessivement scorifiés, qui recouvrent probablement un massif compacte en profondeur. Il est impossible d'admettre que ces matières aient áté amoróes an jour dans un état de fluidité complète, car elles n’auraien! 
pas pu sc maintenir dans la position qu'elles occupent el se seraient infailliblement déversées soit au nord dans la plaine de Quezaltenango, soil à l'est dans la vallée d'Almolonga. En effet elles ne se sont pas épanchées daus un hassin fermé qui pùt les relenir, mais elles ont recouvert un vaste espace accidenté de collines el de pics dont quelques-uns émergent encore au-dessus de sa surlace; et, comblant les creux et les vallons, elles se sont arrêtées brusquement au moment où elles auraient pu se précipiter dans les lieux bas, de manière à être limitées de tous còtés par des murailles presque verlicales, qui domiment de très-haul les localités envirounantes et semblent prètes à s'y écrouler d'un moment à l'autre. Vu de Quezaltenango, ce champ de lave, dont les déchirures sont manifestes, mème ì celle distance, paraît être une gigantesque terrasse, soulenue par quelques pies isolés el mainlenue au sommel des montagnes par une force incommue. On 10 ' peut se rendre compte d'une semblable disposilion qu'en supposant que les mallières ont apparu sous la forme d'une masse pâteuse, assez fluide encore pour prendre un certain mouvement et s'élaler eu quelque sorte, mais pas assez liquide pour franchir des distances considérables el s'écouler dans la plaine. Le refroidissement des parties extrèmes se faisant arec une grande rapidité, il aura déterminŕ la production de murailles entre lesquelles le reste de la pàte à moilié fondue, prolégé ainsi du contact de l'air, aura pu se lasser el se réparlir de manière à prendre une surface à peu près horizonlale. Quelque probable que nous paraiss celte explication, il n'en est pas moins remarquable de voir que le mourement sest précisément arrèté à l'endroit où il aurait dì trouver toules les fircilités pour' se conlinuer avec rapidité. Nous pensons donc que ce singulier amas de roches moires et scorifiées ne doil pas ètre considéré connne une vérilable coulée de lave, mais simplement comme un afllux de malières pàteuses, arrivant an jour à la manière des basaltes.

Origim:

de ce chanp te lave.

II se présente encore une question importante, c'est de savoir si ces masses semi-fluides sout sorlies du cratère, ou si elles ont pris naissance par une fissure ouverte à l'endroil ınème qu'elles recouvrent à còlé du volcan. Nous ne croyous pas aroir recueilli assez d'observations pour pouvoir donner la solution de ce problème; mais notre impression personnelle nous porte à admettre l'idée de la produclion sur place ol de lextension lente dans tous les seus, phulò que cello de 
DANS LES RÉPUBLIQUES DE GUATEMALA ET DE SALVADOR. 481 l'épanchement hors du cratère, qui supposerait toujours une fluidité originelle assez notable, arrêtée par un refroidissement presque brusque. En effet, quoique le champ de roches scorifiées semble prendre naissance à la brèche du sud-est, nous devons observer qu'on ne rencontre pas, dans l'intérieur du cratère, un seul bloc de rocher de nature comparable à celle des laves basalliques, et que les bords de la brèche ne paraissent nullement avoir servi de lit à un courant de matières en fusion. On pourra bien objecter que la surface du cratère élant entièrement recouverte de blocs éboulés provenant de la destruction des parois, il n'est pas impossible qu'il contienne des laves scorifićes au-dessous de la couche de débris actuellement senle visible, à condition d'admettre que les laves ayant été produites par un phénomène antérieur à la démolition du cratère, elles ont été masquées par ces ruines, lors d'une éruption postérieure. Mais il nous semble que, mème dans ce cas, il serait étrangoge que l'on n'aperçùt pas dans le cratère un seul rudiment des laves préexistantes, et que, de toutes façons, il faudrait leur altribuer, près du point d'émission, une fluidité qui contrasterait complétement avec leur rapide solidification à quelques centaines de mètres plus loin. Il y at hà une question qui pourra être très-intéressante à étudier, pour un voyageur ayant le temps de séjourner plusienr's jours dans te massif du Cerro Queinado.

L'intérieur dé ce que nous avons dù appeler le cratère du volcan de Quezaltenango, présente une disposition bien singulière, et il semble qu'il ait fallu un phénomène d'une incroyable puissance pour l'amener à un pareil état. On ne peut guère le comparer à une dépression crensée dans le somnel du volcan, mais bien plutôt à une sorte d'espace plan, tronquant la région supérieure de la monlagne, el dominé par quelques pics plus élevés, dessinant en quelque sorte les sommets d'une enceinte polygonale hypothétique. Lorsqu'on y pénètre du còté du nord, on arrive, à la fin de la montée, sur une sorte d'arête rectiligne, longue de 150 mètres environ, et réunissant, à une altitude de 3,000 mètres, les bases des deux pics de l'est et de l'ouest. On a alors devant soi un immense espace, circonscrit par une circonférence de 350 à 400 mètres de diamètre, et s'élevan! progressivement vers le sud, en parlant du niveau mème de l'arète. Cet espace, grossièrement plan, est un véritable chaos, où sont accumulés, dans le plus effrayant désordre, des rochers de toutes dimensions et des débris de toule nalnre. 
On ne peut gouère douter que ce ne soil l'accumulation des ruines d'un cratère, qui aurait présenté jadis la régularité caractéristique de tous ses congénères, el qui aurait cédé sous les efforts de quelque puissance indescriptible. Les parois, démolies sur presque tonte leur élendue, n’auraient plus subsisté que sous la forme de pics isolés, et les débris du reste anraient été précipilés, soit en dehors, pour allérer complétement la réçnlarilé des llanes du còne, soil en dedans, pour combler le cratère el le transformer en $n$ nnas de rochers.

liorthes et produits volcaniques "[ue l'on y obsrrve.

Quoi qu’il en soil, les matériaux qui recouvrent la surface de cel espace présentent, dans leurs dimensions, leur forme et lenr nature, les plus singulières variélés. On y voit, à côté les $111 \mathrm{~s}$ des autres, d'énormes blocs, d'nu volıme de plusieurs mètres cubes, des amas de cailloux gros comme la tèle, des champs de sable plus ou moins fin, des dépòts d'argiles liantes; toules les coulcur's se mèlent, depuis le brun, le gris el le rouge, nuancées par des plaques d'alun blanchàtrer el des croùles de soufre jaune, enveloppées dans te bronillard humide que produisent les fumerolles. Il y a des porphyres trachytiques bruns, rougeàtres ou volacés, lout à fail intacts el absolument semblables à ceux que nous avons décrits plus haut; quelques blocs à surface surfondue sont recouverts d'un enduit vitrifié, épais d'un ou deux millimètres, fendillé et craquelé comme un vernis; on y voil des fragments imparfaitement scorifiés et calcinés, des débris corrodés par les vapeurs acides, des scories légères el bulleuses, des sables de trituration rouges el violacés, en $\mathrm{m}$ nıol, tous les types possibles des roches volcani(pues que nous avons déjà eu occasion de décrire tant de fois. Il faut y ajouler les produits déposés par les fumerolles, ou formés par la réaction des vapeurs acides sur les matières lelıspathiques, et ils sont peut-être plus nombreux el plus variés dans le cratère du Cerro Quemado que partout ailleurs dans les voleans de l'Amérique centrale. Nous y avons observé, soit à la surface des rocher's, soit dans les fentes ou les pelites cavernes qui existent dans les interstices, une grande abondance de dépòts amorphes on cristallins, formant des crontes sur les parois on Lapissant les cavités. Le soufre pur, en aiguilles prismaliques d'un beau janne, st trouve en beaucoup de points; quelquefois il se mélange de chlorures de soufre of de fer, et prend une couleur rougeâlre eu devenant pulvérulent. Des masses blanchàtres très-abondantes, assez nombreuses, en tous cas, pour que, dans un aulre 
pays, on y eùt déjà créé une exploitation qui pourrait ètre productive, se composent de sulfates divers, soit simples, soit groupés en aluus; nous y avons recomnu la présence des sulfates d'alumine, de magnésie, de chaux, de soude, de polasse, el quelquefois de ler. Dans cerlains cas, ces croûtes sont imprégnées de chlorures divers et mème d'acide chlorhydrique libre, gràce auquel elles rougissent fortement le papier de tommesol bleu; quand elles sont jaunàtres, elles contionnent une assez forte proportion de sulfate el de chlorure de fer, qui s'altèrent aisément ì l'air. Pent-ètre y a-t-il aussi un peu d'acide borique, mais nos expérieuces ne nous ont pas donné, à ce sujel, des résullats bien conchnants. Une cavilé s'est trouvée entièrement tapissée de jolis cristaux blancs, fins et déliés, longs de 3 on 4 centimètres, et présentant un éclat nacré qui nons les avail fait prendre, an premier abord, pour du chlorlydrale d'anmoniaque. Mais l'analyse nous a démontré que c'étail simplement du sulfate de chaux en aiguilles, el nous nous sommes souvenus alors de cas semblables, signalés par M. Boussingault dans les volcans de l'Amérique méridiouale. Il parail, d'ailleurs, que le fail n'est pas très-rare, et que la présence du sulfate de chaux, dans les produits volcaniques, sous la forme de cristaux d'un aspect très-trompeur, crée souvent des difficultés aux observateurs. Les cristaux de sulfate de chaux que nous avons recucillis sont imprégnés d’une faible quantilé de chlorures alcalins, déposés simplement à leur' surface par l'action des vapeurs chlorhydriques.

Les fumerolles du volcan de Quezaltenango sont nombreuses et abondantes. Elles s'échappent des fissures qui existent entre les bloes de rochers accumulés, et semblent prouver que, les vérilables évents élaut ouverts daus le massif même de la montagne, leur communication avec l'air libre n'a pas été complétement inter-

Fuurrolles dı Cerro Quemado. Répartition. lempératures et composition. ceptée par les éboulements, dont les éléments se sont disposés de manière à réserver un nombre considérable de vides et d'interstices. Il existe an moins une cinquantaine de points de dégagement, où l'on voil l'intensité, la tempéralure et la composition des vapeurs se modifier dans des limiles assez étendues. Les vapeurs émises par le volcan sont assez aboudantes pour que, le malin surtont, quand la coudensalion se fail rapidement, ou puisse voir de Quezaltenango une épaisse colomne de fumée flottant au sonmet de la montagne. Il est intéressant de remarquer que loules les liumerolles sont grompées dans la région ouest du cra- 
tère, et plus spécialement mème au sud-ouest. Si l'on pensait que la coulée de lave s'est épanchée hors du cratère lui-même, on pourrait peut-ètre en conclure que la partie orientale de cette dépression a été recouverte, en profondeur, d'uu enduit plus ou moins épais de malières fondues, puis solidifiées de manière à former une couche continue, à travers laquelle il n'est pas possible aux gaz de se laire jour. Mais nous avons observé assez fréqnemment une répartition tout à fait arbilraire des fumerolles au sommet des volcans, pour qu'il ne nous semble en aucune facon nécessaire d'invoquer une raison aussi compliquée pour expliquer l'absence totale des émissions de vapeurs dans la régoion orientale du cratère du Cerro Quemado. Il suffit de mouvements locaux, presque insensibles, dans des matériaux aussi meubles que ceux auxquels nous avons affaire, pour amener des tassements et des obstructions qui dirigent les vapeurs, dans un sens déterminé, vers les points où les communications avec l'atmosphère sont plus ou moins libres.

Nous avons observé quelques pelites fumerolles (a) dans la partic la plus basse du cratère, près de l'extrémilé occidentale de l'arête du nord; leur température oscille autour de $50^{\circ}$, et, comme elles sont presque essentiellement composées de vapeur d'eau, d'acide carbonique et d'azote, elles ne présentent qu'un médiocre intérêt. Mais, si l'on pénètre dans l'intérieur du cratère, toujours du côté de l'ouest . on en rencontre un grand nombre d'autres $(b)$, beaucoup plus importantes, réparties sans aucun ordre apparent, et disséminées entre les rochers, dont èlles recouvrent les surfaces de croùtes d'alun et de soufre. Tous avons constaté des lempératures de $113^{\circ}, 120^{\circ}, 125^{\circ}$, sans que ces variations puissent être expliquées par autre chose que par la facilité plus ou moins grande du dégagement. Ces fulmerolles, tout en élant composées d'au moins 75 p. o/o de vapeur d'eau, renferment une très-notable proportion d'acide sulfureux et d'acide chlorhydrique, ainsi que de l'acide carbonique el de l'azote. La proportion de l'acide sullureux atteint, dans certains cas, jusqu’à près de 1 p. o/o, ẹt celle de l'acide chlorlıydrique 4 ou 5 p. o/o. Le papier de tournesol bleu est rapidement amené au rouge vif, et un flacon d'ammoniaque, ouvert au voisinage des fumerolles, répand d'abondantes fumées blanches de chlorhydrate d'ammoniaque. Le papier d'acétate de plomb n'indique aucune trace d'hydrogène sulfuré, ainsi qu'on pourail d'ailleurs le prévoir par l'odeur des vapeurs. Les proportions relalives d'acide sulfureus et 
DANS LES RÉPUBLIQUES DE GUA'TEMALA E'T DE SALVADOR. 485 d'acide chlorhydrique doivent subir quelques modificalions, suivant les points, car l'odeur, toujours très-désagréable et assez forte pour prendre violemment ì lit gorge, et pour rendre le voisinage des fumerolles très-pénible, semble n'ètre pas du mème genre, suivant que l'un ou l'autre des deux gaz est prédominant. Diuss la région la plus élevée du fond du cratère, vers le pied du pelit mamelon argileux du sud-ouest, il existe quelques fumerolles assez abondantes $(c)$, doul la température alteint jusqu'à $150^{\circ}$, ce qui est la température la plas élevée qu nous ayous observée au volcan de Quezaltenango. Ces vapeurs ne dillèrent pas beaucoup, par leur composition, de celles que nous venons de décrire ci-dessus, mais il semble pourtant que la proportion de l'acide sulfureux soit un peu plus considérable. Enfin, sur le mamelon argileux lui-mềne, il y a quelques petiles lumerolles, disposées ainsi sur ce que l'on pourrail appeler le bord même du cratère, el sortant des creux ou des fentes qui existent dans la matière pàteuse. Quoique leur lempérature oscille autour de $100^{\circ}$, elles ne présentent gouère d'intérèt, ni par leur abondance, qui est très-médiocre, ni par leur composilion, où la vapeur d’ean domine. C'est donc dans la régoion centrale du cratère, mais surtout du còté du sud-ouest, que se trouvent les fumerolles les plus importantes, dont lit haute température et l'acidité prononcée domnent au Cerro Quentado un caraclère assez saillant d'activité éruptive, landis que les dégagements de vapeur qui occupent les bords ne présentent qu'un intérèt de deuxième ordre. Nous ne cherchons: d'ailleurs, à tirer aucune conclusion de ce fait, car les couditions dans lesquelles se trouve te cratère du volcan de Quezaltenango sont lrop particulières pour qu'une loi des températures ait pu se maintenir an milieu des accidents el des bouleversements qui s'opposent à la marche normale et aux allures naturelles des fumerolles.

En résumé, on voil que le Cierro Quenado se hrouve encore aujourd'hui dans une situation digne d'atlirer l'attention des observaleurs. Si son histoire ancienne soulève de remarquables problèmes et mérite d'être approfondie avec beaucoup' plus de soin que nous n'avons pu le faire dans te eours de notre rapide reconnaissance, il n'est pas impossible, d'un autre côté, que son histoire future ne vienne apporler aux géologues de nombreux éléments de traviux el de recherches. 
VOLCAI DE TAJONULCO. - VOLGAN DE TACANA. - VOLGAN D'ISTAK

Au delì de Quezaltenango, le système volcanique de l'Amérique centrale se rontinue encore jusqu’à une distance assez considérable, en conservant sa dirertion génćrale vers l'ouest $30^{\circ}$ nord. Si l'on en croil les renscignements fournis par les habilants du pays, il ne se terminerail guère qu'ìi 200 kilomètres de Quezaltenango, dans la province du Soconusco, qui fait partie de l'État mexicain de Chiapas, el présenterail encore jusque-là quelques cônes d'une gorande importance. Il nous a été mallıeureusement inpossible de visiter nous-mêmes celle région, qui I’a jamais été parcourue par un voyageur s'occupant de recherches scientifiques, a nous ne pouvons en dire que quelques nots, reprodıisant les données vagues que possèdent sur elle les habitants de Quezaltenango. Nous avons pourtant vu de loin nous-mêmes les deux volcans, qui sont encore sur le territoire du Guatemala, el nous avons pu constaler que c'élaient de beaux cònes régouliers, dont la base repose entièrement sur les lauts plateaux, gorâce à l'angole que forment entre elles la liggne volcanique el l'arète montagneuse principale, qui arrivent à se confondre presque complétement dans cette partic de leur parcours.

rolcau de 'T'ajomutro.

Volcari to Tacana.
Le volcan de Tajomulco est silué à une soixanlaine de kilomètres plus loin que le Cerro Quemado, suivant une direclion ouest $28^{\circ}$ nord, c'est-ì-dire presque exactement sur la liggne moyenne du système voleanique. On le voit très-bien du haut du volcan de Quezallenango, d'où nous avons pu relever sa position à la boussole. Il domine de beaucoup la plaine el apparail sous la forme d'un grand còne très-régutier, dont la base semble recouverte d’mne épaisse végétation, et dont lat hauteur doil cerlainement dépasser 3,500 mètres. Il passe pour ètre éteint, mais, conme il parait que l'on y trouve de grandes quantités de soufre, exploité par tas Indicns, nous pensons qu'il doil y exister probablement encore quelque solfatare en activilé.

Le volcan de Tacana n'est pas visible du sommet du Cerro Quemado, parce que, se trouvant exaclement sur l'alignement moyen du système volcanique, il est masqué par le volcan de Tajomulco. Mais nous l'avons très-bien vu de la mer', ainsi que ce dernier, et c'est lui qui figure à l'extrémilé du croquis géénéral qutc nous avons pris en rade de San José (voyez pl. VII). En l'examinant à ume dis- 
DANS LLS RÉPUBLIQUES DE GUATEMALA ET DE SALNIDOR. 187 lance aussi considérable, on n’en peut, en ancune façon, éludies les délails; mais on peut néanmoins conslater qu’il conslitue une grande montagne très-prógulièrement conique, présentant tous les principann caractères extérienrs d'un wolcan bien défini, el dont la hauteur, autanl que les lois de la perspective permettent de s'en rendre compte, ne doit pas être inférienre à celle des volcans de Santi Maria el de Tajomulco. Au dire des Indiens, qui le redoutent beincoup, le volean de Tacalla, presque loujours courommé d'une assez volumineuse couromur dr fumée, serait encore dans un état d'activité éruptive bien caractérisé.

En pénétrant sur le territoire du Vexique, le système volcanique se perd dauss une obscurité dont il nous est absolument impossible de déchirer les voiles. La Tolcaus province du Soconusco, ćlant une des plus sanvages de l'Amérirgne centrale. n’a gonòre éló parcourue, nèmo par les indigènes, el l'ou ne possède, sur elle at sur ses volcans, que des données extrèmement agues. Nous avons entendu parler d'un croplain volcan d'Islak, (qui s'élèverait non loin des frontières du Gualemala, ol qui scrait un des principaux mentbres de la série, mais nous n’avons aucun délail sur lui. Un groupe de plusieurs autres connes volcaniques se trouve, parail-il, ì une centaine de kilomètres dans le sud de Ciudad Real, mais nous n'avons ancun renseignement sur leur hanteur, leur nombre el leur état actuel. Il est probible cependant qu'aucun d'enx r’est le lhéàtre de phénomènes importants, car il serail impossible que des éruptions notables restassent complótement ensevelies dans l'oubli, of qu’il n'en vint pas quelque nouvelle au moins jusqu'à Quezaltenango. Yous sommes donc portés à croire que l'extrémilé nord-onest du systèmr volcanique de l'Amérique centrale eùt été moins intéressante à étudier que lia partie sur laquelle ont porté nos recherches, mais nous n'en regrellons pas moins de n’avoir pas eu la possibilité de compléter nos travaux en les élendanl juscurì Ienrs extrèmes limitos. 


\section{CHAPITRE III.}

DES TREMBLEMENTS DE TERRE.

Fréquence des tremblements de terre dans l'Amérique centrale. - Rapports entre les tremblements de terre et les éruptions volcaniques. - Des causes qui peuvent modifier l'intensité et la fréquence des tremblements de terre. - Caractères et effets des tremblements de terre de l'Amérique centrale.

FRÉQUENCE DES TREMBLEMENTS DE TERRE DATS LAMÉRIQUE CEVTHALE.

L'Amérique centrale fail partie d'une des zones séismiques les plus importantes, c'est-ì-dire d'une des régions du golobe où les tremblements de terre sont les plus fréquents et les plus violents. Si l'on pouvait avoir entre les mains une liste exacte de toutes les secousses qui sont ressenties, à des moments divers, dans les villes principales des cinq républiques centro-américaines, on ne trouverait peut-être pas un seul jour de l'année où le sol n'ait été aggité quelque part, entre l'ịsthme de Panama et l'isthme de Tehnanlepec. Malheureusement de semblables listes n'existent pas, et, quoique nous possédions quelques documents de plus que n'en avait M. A. Perrey, lorsqu'il publia son catalogue des tremblements de lerre daus le Mexique et l'Amérique centrale ${ }^{(1)}$, nous sommes bien loin d'avoir assez d'éléments pour pouvoir nous livrer à une discussion approfondie el tout à fait sérieuse sur une aussi importante question. Seul, l'observatoire de Guatemala s'occupe, depuis une quinzaine d'années, de ce genre d'études, et accumule des matériaux donl la valeur considérable deviendrail encore plus saillante, s’ils pouvaient trouver des points de comparaison dans des recherches du mème genre, exécutées dans une

\footnotetext{
(1) Vote de M. A. Perrey. Amales de In Société d'Émulation des Vosges. t. VI, 18/7. p. 55-.
} 
DANS LES REPUBLIQUES DE GUATEMALA ET DE SILVADOR. 489 localité située dans des conditions différentes d'altitude et soumise à d'aulres influences météorologiques.

II n'est pas étonnant, d'ailleurs, que l'on ne s'occupe guvère, dans l'Amérique centrale, de noter les tremblements de terre, car ils sont si fréquents, et ordinairement si peu intenses, qu'ils passent souvent inaperçus d'une population habituée ì de.semblables phénomènes et peu curicuse des closes de la nature. Les tremblentents de terre d'unc violence exceptionnelle restent seuls gravés dans la mémoire de tout le monde, et, si la tradilion ne suffisiit pas pour les empècher de tomber dans l'oubli, il resterail encore, comme lémoins de ces cataclysmes, les momments en ruines et les maisons renversées dont ils ont parsemé les rues des capilales. Heurensement de semblables désastres ne sont pas Irès-fréquents, et, quoiqu’il n’y ail guère d'années où une église ne soil renversée dans une ville on dans une autre, la plupart des tremblements de terre sont assez faibles, ainsi que nous l'avons dil, pour n’être remarqués que par quelques personnes plus altentives que les autres ou placées accidentellement dans une sitnation favorable à l'observation. II faut ajouter que la urès-grande majorité de ces tremblements de terre sont essentiellement locaux et no font sentir leurs offets que dans un rayou très-peu étendu, soil au voisinage immédial de la ligne volcanique, soil à une distance assez considérable. D’autres sont plus généraux el embrassent quelquetois des distances de plusieurs centaiues de kilomètres; mais il est très-intéressant de remarquer qu'il n'y a pas de rapport absolu et constant à élablir entre l'intensité et la distance de propagation d'un lremblement de terre. Ainsi lelle secousse, relativement très-faible, pourra se faire senlir cn même temps dans denx républiques voisines, landis que telle autre, assez violente pour renverser les maisons, ne dépassera peut-ètre pas le cercle restreint de la localité. Il y aurail dos relalious intéressantes à chırcher entre la nature du mouvement séismique el son extension, mais ce n'est pas ici le lieu de nous laisser aller à des considérations d'une nature aussi théorique. Nous aurons d'ailleurs à ! revenir, Jorsque nous aurons à éludier les rapports qui existent entre les trembloments de terre of les éruptions voleaniques.

Les catalogues de M. A. Perrey ne font mention que d'une quarantaine de tremblements de terre ayant eu lieu dans l'Amérique centrale pendant les puatre

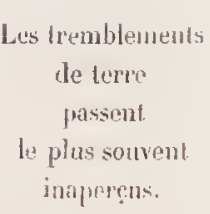


ne doit pas dillérer

beaucoup

aujourd'hui

de

ce qu'il élait jadis.

derniers siècles; nous y eu avons ajouté quelques-uns, soil postérieur's à la putblication de M. Perrey, soit empruntés aux notes du R. P. Cornette; mais, malgré cela, notre liste esl encore d’une évideute insuffisance. Tous ne la répétons pas ici, puisqu'elle trouve sa place dans le tableau de la page 495 , où elle est reproduite intégralement. Il nous paraîl cerlain, el M. Perrey est du même avis, que l'on ne doit altacher à ce mangue de documenls qu'une importance relativement secondaire, el quill n'cn laut conclure qu'une chose, c'est que le souvenir des tremblements de terre très-violents el très-importants est seul arrivé jusqu'à mous, lous less autres ayant élé oubliés ou passés sous silence. Il est probable que l'élat séismiquo de l'Amćrique contrale élail à peu près le mèmo il y a trois cents ans qu’aujourd'hui; et, à notre époque, avec les moyens d'observation perfectionnés que l'on met en ouvre au Collegio Tridenlino de Guatemala, c'est à peine s'il faudrait quelques années pour obtenir une liste d'une quarantaine de tremblements de terre. De 1859 à 1863 , on en a compté eu tout 57, soit, en moyenne, 11 par an, el ce no sont pas des années exceptionnelles, car il en a toujours été le mème depuis. Mais il laut avoucr que la plupart de ces tremblements de lerre n'avaient qu'une faible intensité el auraient mème, à la rigueur, pu passer inapercus, si l'on ue s'élail attaché à les rechercher. Il est possible, néanmoins, mais nous n’émellons que sous loutes réserves une semblible hypothèse, quoiquielle soit d'accorl avec les considérations que nous développerons au paragraphe suivant, il ost possible, disons-nous, que les tremblements de terre aient ćlé un peu moins fréquents dans l'Amérique centrale à l'époque de la conquète qu’à présent. Cela aurait pu tenir à ce que les éruplions étaient, au contraire. beaucoup plus répétées, le nombre de volcans actifs étant alors beaucoup plus considérable, annsi qu'en font foi toules les traditions el les relations historiques.

Attiludes

des populations

centro-américaines relativement aux tremblements de inre.

\section{L'atlitude des populalions centro-américaines ralavement aux tremblements de} lerre est assez intéressante à examiner. Daus les villes qui ont élé autrefois détruites par de scmblables calaclysmes, on en a conservé une religiense terreur, et il n'y a pas de si pelite secousse pour laquelle toute la population, hommes et femmes ne croient devoir passer la nuil dans la cour de leurs maisons. En général on est moins craintif; ce n'est pas à dire pour cela que, quand les monvements du sol so rópètent plusieurs fois de suite à des intervalles rapprochés, on ne craigne quel- 
DANS LES RÉPUBLIQUES DE GUATEMALA ET DE SALADOR. 491 que accident plus terrible, el qu'on ne se lienne sur ses gardes; mais les secousses isolées, sourent mème assez forles, ne causent guère d'apprélıcusion, el on les laisse passer comme un phénonène simple el naturel, auquel on est accoutumé depuis sa plus tendre enfance. Lorsque les tremblements de terre cö̈ncident avec unc éruption ou avec une recrudescence d'activité d'un volcan, on considère aussi généralement le cas comme plus sérieux el l'on prend ses précautions. Les habilants de l'Amérique centrale étaient bien placés pour observer le lien qui existe entre les phénomènes volcaniques el les tremblements de terre, el ils u’ont "u garde de laisser de côté des indicalions sourent si précieuses. Ils ont parfaitement compris que les deux choses, quoique ne marchant pas exactemeut de froul, ont pourtant une origine rommune, et ils savent très-bien qu'une éruption annonce bien souvent une secousse, ou réciproquement. Mais, si la saggazcité des läces indigèues leur a fail entrevoir la vérité, elle ne la leur a pourtant pas développée tout entière. Au lieu d'envisager le phénomène dans ce que ses causes el son origine peurent arvoir de général, les Indiens el les ladinos (mélis) ont une singoulière tendance à le lociliser, en quelque sorte, et à en faire l'altribut plus spécial de tel ou tel volcan. Les tremblements de terre sont, pour eux, un des nombreux moyens de nuire au gene humain que possèdent les volcans, et, sans chercher heaucoup plus loiu, ils grälifient certaines monlagnes d'une réputation te plus souvent imméritée. Il n’est pas rare, après une seconsse de tremblement de terre, d'entendre une longue discussion entre gens qui en rendent responsables différents volcans, et qui finissent, le plus souvent, par l'altribuer ì celui qui se trouve sur le prolongement de la direction suivant laquelle ils ont cru sentir les ondulalions. Les Indiens ont, d'ailleurs, des idées assez étranges sur le mode d'action des volcans, el la crainte qu'ils ont de cerlaines monlagnes ne s'explique que par len' singulière théorie des plıéunnè̀es éruplifs. Ils s’imaginent que les cônes croissent avec une extrême lenteur, mais incessamment, jusqu'à ce que lo volcan ail alteinl son développement complel; une fois arrivé à cel état de maturité, pour ainsi dire, il éclate (revenla), el, apròs s'ètre maintenu plus ou moins longtemps en aclivité, jl s'éteint pout jamais. D'après cela, ils considèrent comme devenus tout ì fait inoflensil's les volcans dont ils connaissent, soil par eux-mêmes, soil par tratdition, quelque éruption paroxysmale, tandis qu’ils ont grand'peur de certains 
cònes, complétement éteints, dont les mouvements éruptils violents ont ćté oubliés à denx ou trois générations de distance, ou bien sont perdus dans la nuit des temps. Linsi, an Guatemala, le volcan de Pacaya passe pour s'accroille un pen toules les années ${ }^{(1)}$ el on le regarde avec une cerlaine méfiance, parce qu’il esl censé n'avoir pas encore éclaté (todavia no revento), tandis que le volcan de l'uego est considéré cornme ayaut à peu près terminé son rơle. Les tremblements de terre sont naturellement combinés avec tout cela, el, lorsqu'ils semblent provenir de l'un des volcans redoulés, ils deviennent encore plus inquiélanls el ajonlent au respect que l'on a pour la montagne. Autrement on les laisse passer sans s'en inquiéter beaucoup; mais, quand les secousses sont insez violentes pour toul renverser, on perd la tête, on croit que la fin du monde arrive, et l'on ne s'inquiète plıs guère d'accuser un volcan, innocent ou coupable.

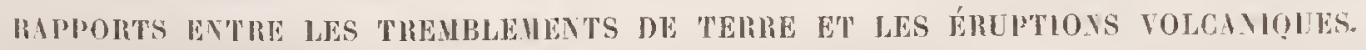

Tremblemenls de terre locnux et gŕnéraux
Les rapports qui existent entro les tremblements de lerre el les éruplions volcaniques sont trop évidents el Irop génératement adınis anjourd'hui, pour que nous pensions à discuter ici une semblable question et à en étudier le còté théorique. Jais nous roulons essayer de jeter un coup d'œil sur la nalure spéciale de ces rapports, dans le cas particulier de l'Amérique centrale, et de rechırcher s'ils sont réģis par quelque loi vaguement indiquée el encore unal counue. Il n'est pas besoin d'observer longtemps pour se convaincre que, si les tremblements de terre accompagnent souvent les éruptions volcaniques, ils en sont néanmoins le plus souvent toul ì fait indépendanls, el qu’ils se produisent, en gónéral, sans cause appréciahle pour nos sens ou seusible pour nos organes. Si l'on examine les choses de plus près, "n pourra voir encore que, dans la très-grande majorité des cas, les tremblements de terre accompagnant les éruptions volcaniques sont essentiellement locaus, landis que les tremblements de terre indépendants agoissent sur une étendur beaucoup plus considérable et deviennent souvent généraux pour loute une régoiou séisnique. Cela est, d'ailleurs, parfaitement d'accord avec la théorie de ces phéuomènes, étant adınis que les éruptions volcaniques el les tremblements de

\footnotetext{
(1) Inutile de dire qu'il n'en est rien et que nos mesures ont donné, à dix ans de distance, des résultats tout à fait comparables à ceux qu'avait obtenus le R. P. Cornette.
} 
DANS LES RÉPUBLQUES DE GUATEMALA E'T DE SALVADOR. 493 terre sont dus à une seule el même cause, qui se trouve dans les mouvements ef les réactions du noyau fluide, ou, comme on dil souvent aujourd'hui, de la pyrosphère, sur l'enveloppe solide du globe. La pyrosphère, mise en mouvenreut par une cause qui nous est encore inconnue, rencontre l'obstacle que lui oppose ta r'roùte solidifiée, elle se heurte contre lui el de celle réaclion naissent des eflets variables suivant les cas. Quelquefois les matières fluides ou aćriformes se trourent en présence d'une fissure plus ou moins complétement onverte; elles s'y injectent, y pénètrent à la façon de coins el réussissent souvent à parvenir jusqu'au jour: il y a alor's éruption volcanique. Mais tout cela ne s'est pas passé sans offorts, il y a en résistance de la part des couches traversćes, et celte réaction s'est traduite. par des mouvements dı sol environnant, par des tremblements de lerre locaux. qui pourront se produire, pendant la durée mème de l'éruption, chaque fois que la fissure tendant à s'obstruer, pour une cause ou pour une aulre, de nouveanx obstacles s'opposent à la marche ascensionnelle des matériaux. D'autres fois, an contraire, te mouvement de la pyrosphère ne triomphe pas de l'obstacle qu'il rencontre, et les matières fluides, brusquement arrètées dans leur lendance au mourement ascensionnel, doivent se replier sur elles-mèmes aver une violence plus ou moins grande. Il en résulte naturellement un puissant ébranlement dans lit couche solide, ébranlement qui pourra et devra se transmeltre à une grande distance, à cause des ondulations mèmes qui sont ainsi déteminées dans la pyrosphì̀re.

C'est précisément ainsi que se passent presque tonjours les choses daus l'Amérique centrale. On a très-lien remarqué que les tremblements de terre accompargnant des éruptions ne se font guc̀re sentir qu'au voisinage immédial du volcan en activité, el cela, il est vrai, avec une intensité quelquefois terrible, quand bien mème les détonations qui se produisent en mème temps sont souvent cntendues à des distances extrèmement considérables, saus qu’il y ail de mouvenıenls du sol en ces endroils. Cela se comprend, car le choc ayant eu un résultat, le mourement s'éteint rapidenent, tandis que le son continue à se propager à une grande distance dans les couches solides. On sait anssi que les tremblements de lerre indépendauts des éruptions volcaniques exercent souvent leur action dans un rayou fort élendu, et quils aflectent presque toujours des caractères oudulatoires plus 
marqués que lés autres. Il n’est pas rare que des phénomènes soicnt resseutis, presque en mème temps, à des distances de plusieurs centaines de kilonètres, el nous avons la conviclion que, si l'on possédait des calalogues séismiques à pru près complets, on trouverail fréquemment la trace de seconsses ayant eu lieu, à peu près au mème moment, dans une grande parlie de l'Amérique centrale; telles sont, par exenple, celles du 10 octobre 1688, qui furent observées de Lima jusqu'à Mexico el qui se sont probablement aussi manifestées à Guatemala, quoique peut-c̀lre avec moins de violence. Suivant une expression qui peint admilatblement les choses, les trenblements de terre ne sont que des éruplions aror"tées;" mais cela ne s’applique qu’aux secousses indépendantes, celles qui coüncident avec des phénonnènes d'activilé volcanique n'étant anlre chose que des «accidents d'une éruption entravée."

Les tremblenents ic terre

les pius violents n'ont pas lien au voisinagre ins volcans aclifs.
Malgré certains exemples, tels que ceus des volcans de Turrialba, de Conseguina, de Pacaya, de Fuego, elc., on at remarqué aussi que les tremblements de lerre les plus violents ue se produisaient pas, en goénéral, au voisinago des volcans les plus aclifs; el c'est encore lì un fail parfaitement naturel, puisque près de ces érents, qui sont presque lonjours en communicalion à peu près libre avec la pyrosphère, fres mouvements des fluides ignés lrouvent toutes facilités pour se trarluire pau III épauchement plutôl que par une réaction et me secousse. D’après lont ce que nous venons de dire, il semble évident que la pyrosphère étant animée, dans la zonc séismique de l'Amérique tropicale, d’une lendance presque continuelle au mouvement ascensionnel, elle devara, suivant qu'elle aura lriomplé ou non des obstacles qui lui sont opposés, produire des séries alternatives d'éruptions volraniques accompagouées de secousses locales el de tremblentents de lerre indépendants.

C'est en eflet ce que l'on peut observer, si l'on exaninc les listes comparalines, trop peu complètes malheureusement, de tremblemenls de terre et d'ćruplions voleaniques que nous avons formées en nous aidant des publications de M. A. Perrey el des recherches du R. P. Cornelle. On y verra, aussi bien pour le Mexique el la Nouvelle-Grenade que pour l'Amérique centrale, qui leur sert en quelque sorte de lien, que les époques de tremblements de terre généranx et violents ne coïncident pas, dans la plupart des cas, avec celles des grandes éruptions 
DANS LES RÉPUBLIQUES DE GUATEMALA ET DE SALVADOR. 195 volcaniques, mais qu'elles semblent, au contraire, s'intercaler entre deux périodes d'activité successives, et que, quand quelque volcan se mel à vomir des laves ou des cendres, les mouvements généraux du sol s’interrompent pour quelque temps.

\section{AMÉRIQUE CENTRALE.}

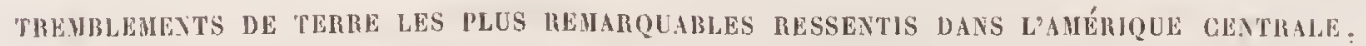

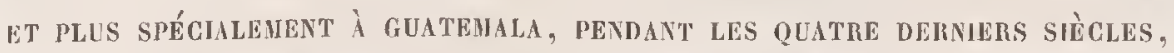

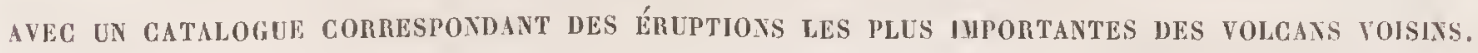

\begin{tabular}{|c|c|c|c|}
\hline TREMBLEMENTS DE TERRE & ÉRUPTIONS VOLGAYIQQUES. & TREMBLEMENTS DE TERRE. & ĖRUPTIONS YOLCANIQUES. \\
\hline 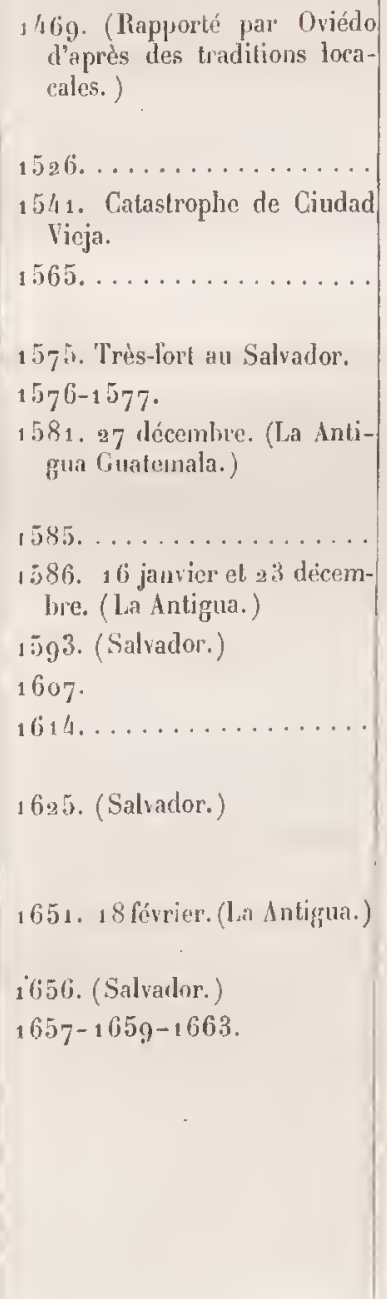 & $\begin{array}{l}\text { 1469. Éruption d'un volcan dil } \\
\text { de. Suchiteperge. } \\
\text { 1522. (Volcan de Nasaya.) } \\
\text { 1526. (Volcan de Finego.) } \\
\text { 1541. (Volcan de Fuego.) } \\
\text { 1565. Première apparition du } \\
\text { volcan de Pacaya. }\end{array}$ & 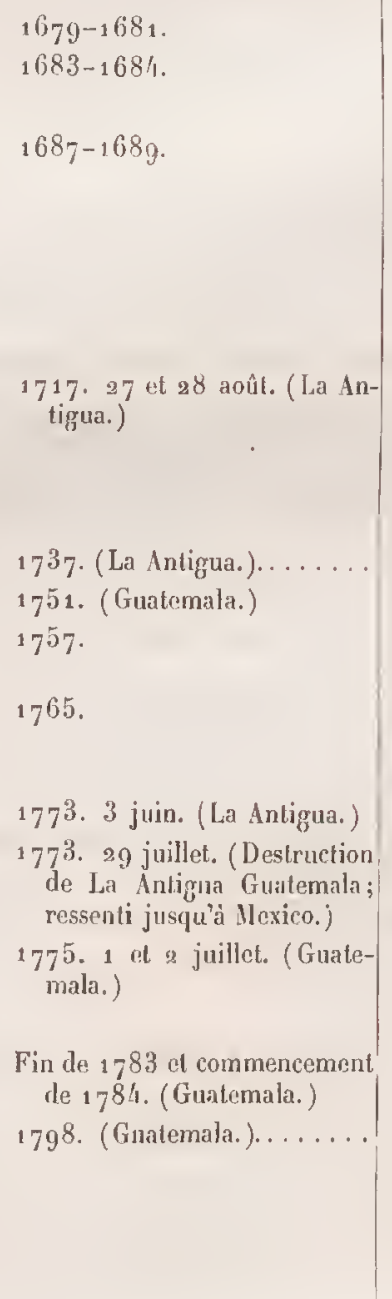 & 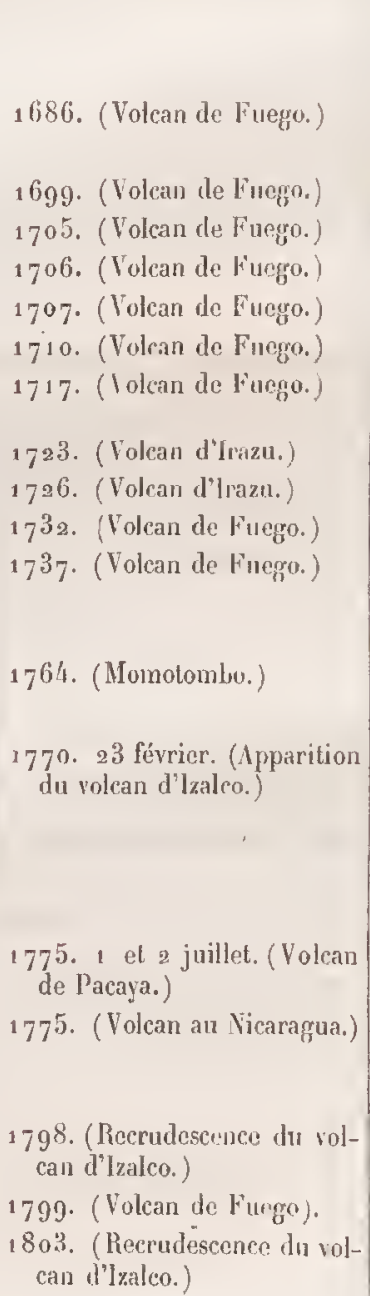 \\
\hline
\end{tabular}




\begin{tabular}{|c|c|c|c|}
\hline TREMBLEMENTS DE TEIRE. & GRLPTIONS VOLCANIQULS. & TREMBLEMENTS DE TERRE. & ERUPTIOAS VOLCAYIQLES. \\
\hline 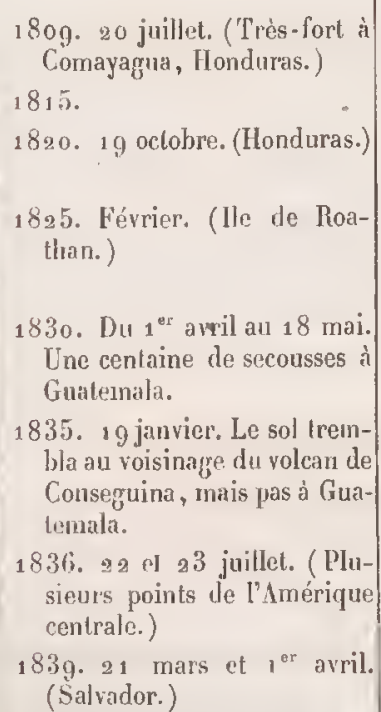 & $\begin{array}{l}\text { 1821. (Volcan au.Nicaragua.) } \\
\text { 1829. (Volcan de Fuego.) } \\
\text { 1835. 19 janvier. (Érujtion } \\
\text { terrible din volcan de Conse- } \\
\text { guina.) }\end{array}$ & 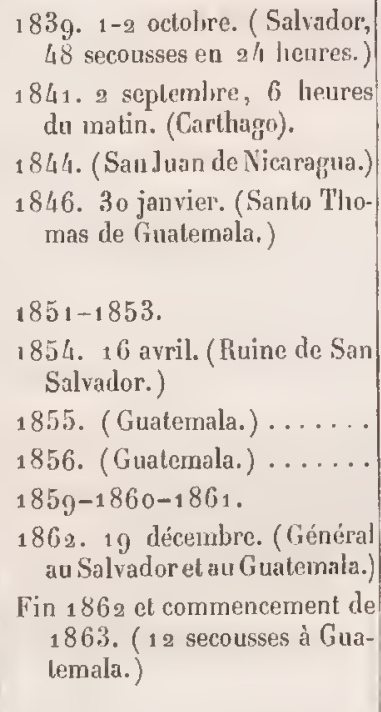 & $\begin{array}{l}\text { 1814. (Volcan deSan Miguel.) } \\
\text { 1847. (Volcan an Niearagua.) } \\
\text { 1855. (Volcan de Fuego.) } \\
\text { 1856. (Vocan de Fuego.) }\end{array}$ \\
\hline
\end{tabular}

\section{MEXIQUE.}

LISTE COMPARATIVE DES TREMBLEMENTS DE TERRE ET DES ÉRUPTIONS VOLCANOULS LES PLUS REMARIABLES PENDANT LES QUATRE DERNIERS SIÈCLES.

\begin{tabular}{|c|c|c|c|}
\hline TREURLEUEYTS DE TERRE. & ERUPTIOXS VOLCANIQZES. & TREMBLEMENTS DE TERRE. & ÉRLPTIONS VOLCATQQLES. \\
\hline 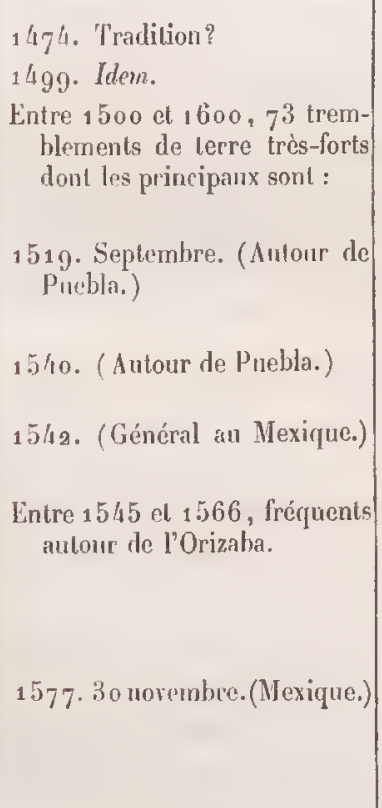 & $\begin{array}{l}1507 . \text { (Popocatepetl.) } \\
1519 . \text { (Volcan près de Tlax- } \\
\text { cala.) } \\
1520 . \text { (Popocalepetl.) } \\
\text { 1540. (Volcan près dle Tlax- } \\
\text { cala.) } \\
\text { 1545. (Orizaba.) } \\
\text { 1548. (Popocatepell.) } \\
\text { 1566. (Orizaba.) } \\
\text { 1571. (Popocatepetl.) } \\
\text { 1592. (Popocatepet.) } \\
\text { 1594. (Popncatepetl.) }\end{array}$ & 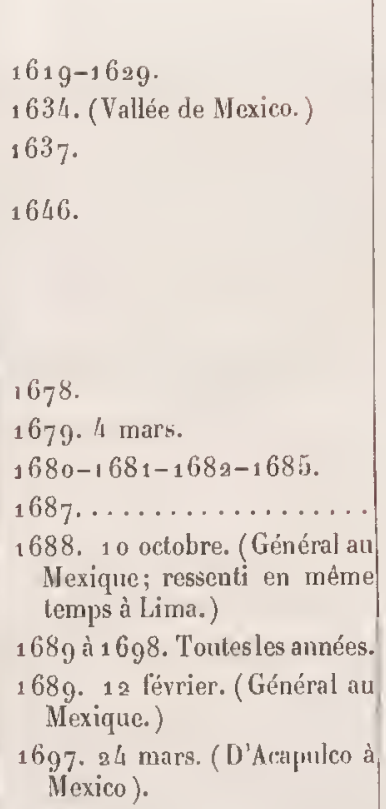 & $\begin{array}{l}\text { 1642. (Popocatepeti.) } \\
\text { 1663. (Popocatepetl.) } \\
\text { 1664. (Tuxtla.) } \\
\text { 1664. (Popocatepel.) } \\
\text { 1665. (Popocatepell.) }\end{array}$ \\
\hline
\end{tabular}


DANS LES RÉPUBLIQUES DE GUATEMALA E'T DE SALVADOR. 497

\begin{tabular}{|c|c|c|c|}
\hline TREMBLEMENTS DE TERRE. & ÉRUPTIONS YOLCAYIQUES. & TREMBLEMENTS DE TERRE. & ÉRUPTJONS VOLGANOQUES. \\
\hline 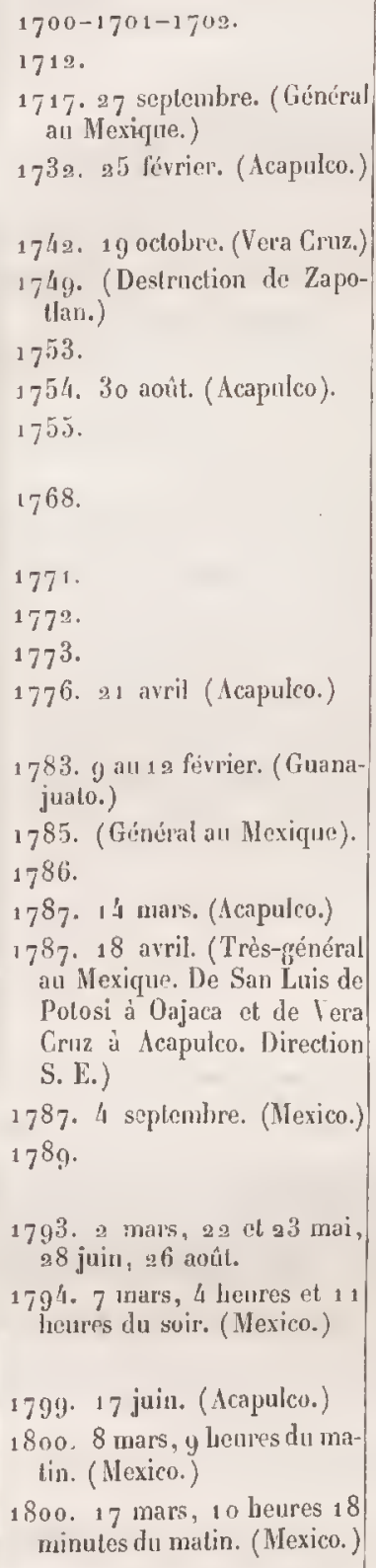 & $\begin{array}{l}\text { 1736. (Orizaba.) } \\
1749 . \text { (Colima.) } \\
1759 \text {. Apparition du dorullo. } \\
1770 \text {. (Colima.) } \\
177^{2 .} \text { (Tuxtla.) } \\
1779 \text {. } 5 \text { férrier. (Orizaba.) }\end{array}$ & 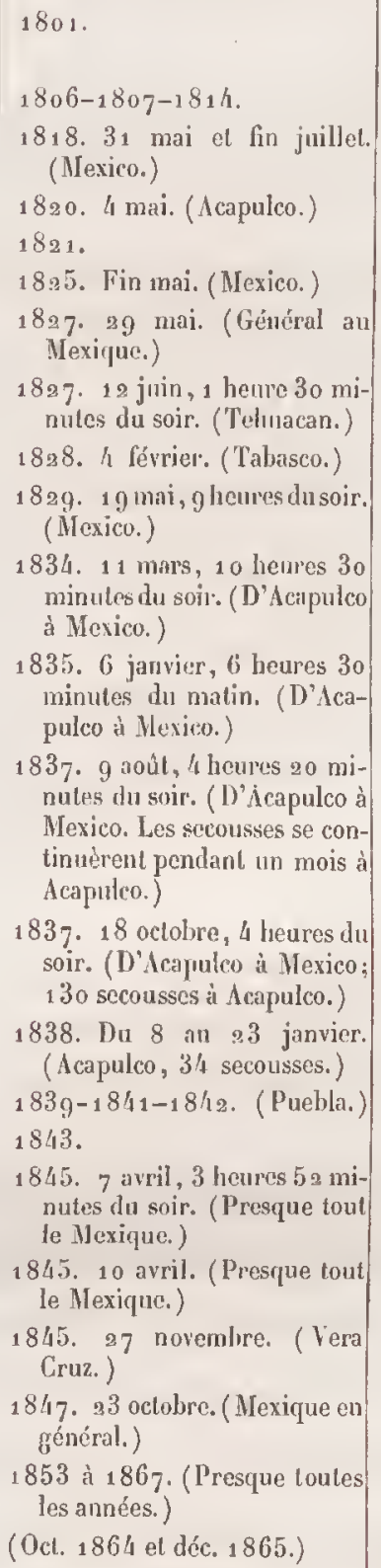 & $\begin{array}{l}\text { 180h. (Popocatepetl.) } \\
1818.15 \text { février. (Volcan au } \\
\text { Mexique.) }\end{array}$ \\
\hline
\end{tabular}


RÉPUBLIQUE DE L'ÉQUATEUR.

Jiste GoMpaRATIVE DES TREMRLEMENTS DE TERHE ET DES ÉRUPTIONS VOLCANIQUES LES PLUS REMARQUables PENDaNT LES TROIS DERNIERS SIÈGLES.

\begin{tabular}{|c|c|c|c|}
\hline TREMBLEMENTS DE TERHF. & ÉRUPTIONS VOLCANIQUES. & TREMBLEMENTS DE TERRE. & ERLPTIONS VOLCANIQUES. \\
\hline $\begin{array}{l}1530-1539-1560 . \\
1687-1698 . \\
1740-1766 . \\
177^{5-17} 85 . \\
1794-179^{5} . \\
1797 \\
1802-1805-1812 .\end{array}$ & $\begin{array}{l}12 \text { mars } 1575 \text {. Effroyable érup- } \\
\text { (ton du volcan de Tolima.) } \\
157^{8} \text {. (Pichincha.) } \\
1660 \text {. (Pichincha.) } \\
1732 \text {. (Purace.) } \\
1768 \text {. (Cotopaxi.) } \\
177^{4} \text {. (Cotopaxi.) } \\
179^{6 .} \\
\text { Le volcan Sangay perpétuelle- } \\
\text { ment en éruption pendant aa } \\
\text { premièremoitiédu xix siècle. }\end{array}$ & $\begin{array}{l}1814-1815-1816 . \\
18,9-1826-1827 . \\
\text { Popayan trembla presque cha- } \\
\text { que jour pendant les années } \\
1828-1829-1830 \text {. } \\
\text { Tremblementsfréquents tous les } \\
\text { ans de } 1830 \text { à } 1835 \text {. } \\
1838 . \\
1839 \text {. } \\
\text { Popayan trembla presque lous } \\
\text { les jours en } 18110 . \\
184 t-1844 . \\
1845 \text {. } \\
\text { Calme ahsolu. } \\
1850-1851 \text {. }\end{array}$ & $\begin{array}{l}\text { 1847. (Guila). } \\
1849 . \text { (Purace). }\end{array}$ \\
\hline
\end{tabular}

II est lacile de recomnailre, à l'inspection de ces tableaux, qu'il n'y a pas mue gónéralité absolue dans la marche des phénomènes, non plus que pour aucune autre manifestation des lois de la nature; mais il n'en est pas moins vrai que les conclusions déduites de l'examen des faits sont vérifiées en gros par l'ensemble des observalions recueillies jusqu’̀̀ ce jour. On peut done dire, avec une cerlaine apparence de vérité, que les tremblements de terre et les éruptions volcaniques, étant des manifestations d'une unème cause originaire diversement caractérisées par leurs résultats finals, doivent alterner l'un avec l'autre, traduisant clacun à leur manière les mouvements de la pyrosphère. Ainsi, à une série de tremblenents de terre généraux témoignant d'une tendance violente des fluides ignés au mouvement ascensionnel, on devra naturellement voir succéder une ère d'éruptions volcaniques, accompagonées ellès-mèmes d'accidents se manifestant sous la forme de tremblemenls de terre locaux, et domnaut en quelque sorte satisfaction ì ces 
tendances en leur ouvraut une chemin vers les régions extérieures. Les éruptions doivent aussi s'arrêter d'elles-mêmes lorsque la pyrosphère a pu entrer daus le calnıe, après s'ètre suffisamment épanchée au dchors; les cratères se comblent, les f́vents se ferment, les canaux souterrains s'oblitèrent, et, lorsque les mouvements séismiques renaissent, les plıćnomènes doivent se reproduire dans le mème ordre, régólé d'avance par la nature même des choses. II faut remarquer que nous n'avons rien dil, jusqu’à présent, de la violence des tremblements de terre; c'est qu'en ollẹt c’est là un des éléments qui rendent ces phénomènes moins simples en fait qu'en théorie, el sur lesquels il n'est guère possible de poser quelque affirmation précise. L’intensilé présente les caractères de la plus grande variabilité, el oscill. entre les mèmes limites pour les tremblements de terı’e, qu’ils soien! généraux ou locaux; les uns ef les autres ont, à l'occasion, détruit des villes et décimé des populations, el la seule différence se trouve en ce que les uns se font craindre dans un cercle plus élendu que les autres, quand ils deviemnent assez violents portr ètre redoutables.

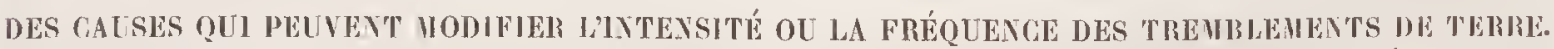

On a remarqué depuis longlemps que l'intensité d'un mème tremblement de lerre pouvait varier, entre des limites assez écartées, dans deux localités voisines, mais où la nature du sol est différente. Il n'y a rien d'extraordinaire, en effet, à re que cerlaines couches obéissent plus farilement que d'autres à une impulsion recue, el à ce que certaines roches aient la propriété de transmellre les mouvements de proche en proche avec une intensilé et une rapidité caractéristiqnes. Celte vérité a été conslatée dans l'Amérique centrale, el est parfailement admise par les habilants cux-mêmes, qui ont eu assez d'occasions de la reconnaitre, puisque, par un malheureux lasard, presque par une fatalité, la majeure parlie des grandes villes el des capitales sout précisément construiles dans les localités où le sol est le plus sensible à l'influence des tremblements de terre. L'expérience leur a appris que le terrain le plus mobile était composé de cette roche tufacée blanchàtre, lormée presque exclusivement de pouces, à laquelle on donne te non de TepeInli ou Talpetate el de Tisate, lorsqu'clle est toul à fait altéréc et transformée rn unc masse blanche grenuc. Les éléments eux-mèmes du terrain sont légeers et 
mobiles, el, comme il garnit, en général, le fond de larges vallées dans lesquelles if est déposé comme daus un bercean, el où il flotte, pour aiusi dire, à la surface saus faire corps avec les couches profondes de la croùte solide, on concoil quiil soil aisémeut soumis ì des oscillations plus étendues que celles du massil qui le supporte. Outre les vallées de San Salvador et de la Antigua, célèbres par l'intensité de leurs tremblements de terre, le tuf à ponces en garnit beaucoup d'autres, el partout on le considère comme un excellent conducteur des monvements séismiques, quoique cela n'empèche pas d'y construire des villes el des villages. $1 l$ y a bion longtemps, d'ailleurs, que ces propriélés ont élé remarquées par les. indigènes, of le noom indien de la vallée de San Salvador, vallée de Cuscallun, il, en langage naluatl, la signification pittoresque et imagée de vallée des hamacs.

D'xщ's

lopinion publique

dans

l'Amérique

centrale,

les tranulewents

de terre

seraient phus fréquents pendant l"hiver

sque prondant l'élé.

On peut se demander, d'autre part, si les tremblements de terre se produisent indifféremment à toules les éporques de l'année, ou si certaines saisons ont le privilóge de favoriser leur fréquence. Celte question, qui a beaucoup occupé les méléorologisles, n’a, jusqu’à présent, été résolue, pour l'Amérique contrale, que par' les lraditions locales, plus ou moins fondées; mais tous les efforts que l'on a faits pour tirer une conclusion sérieuse de la comparaison des dates n'ont amené aucun résultat, ce qui tient pent-c̀tre, il faul le dire, au petit nombre d'éléments précis que l'on possède. Quoi quili en soit, l'opinion publique, daus l'Amérique centrale, attribue à l'hiver, el surtout an mois de décembre, le monopole à peu près exclusif des tremblements de terre. Un habitant de la Boca Costa, versant du Pacifique, nous disail, en nous r'ésumant l'étal méléorologique de ce pays : c Déccmbrer, “époque des tremblements de terre précédés, en général, d'un bruil sourd d'une "demi-minute.... il y en a aussi quelquefois en juin." Dans le reste de la république de Guatemala, sans ètre anssi explicite, on admet de même quo l'hiver est habituellement l'époque des tremblements de terre. Celle tradition serait à peu près conforme à celle qui existe, d'après Hnmboldt, dans la province de Quito, où l'ou e cousidère les tremblements de terre comme les avant-coureur's de la saie son des pluies." Mais, comme M. Pissis, élablissant un fait complétement opposé ì celui qu'avance Hnmboldt, déclare qu'an Chili et au Pérou les tremblements de lerre sont plus fréquents pendant la saison des pluies qu'ì l'époque des séchoresses, on ne sait plus gouère que penser. Nous allons, d'ailleurs, disculer en 
D) ANS LES RÉPUBLIQUES DE GUATEM IIA E'T DE SALNADOR. 501 quelques mots l'opinion que l'ou professe à Guatemala el voir jusqu'à quel point il est convenable d'y ajouter foi.

Si nous groupons les quelques donzaines d'observatious que l'ou possède ave. dales précises sur les tremblements de terre dans les quatre derniers siècles, nous obtiendrons, et il n'y a pas lieu de s'en étonner, des résultals peu significalifs, et, qui plus est, peu concordants suivant les auteurs.

linsi M. Perrey donne, à la suile de son catalogue, le résumé suivant:

\section{AMÉRIOUE CENTRALE ET MEXIQUE.}

\begin{tabular}{|c|c|c|c|c|c|c|c|c|c|c|c|c|c|c|}
\hline stücurs. & JAYYIEK. & FÉYHIER. & Mars. & AVRLL. & MaI. & soix. & JULLET. & notr. & SBPTEMIRE. & octór. & XOYEMPR. & "е́е́евввя. & $\begin{array}{c}\text { Dist } \\
\text { annuelle } \\
\text { sea- } \\
\text { lement. }\end{array}$ & тат AL. \\
\hline${ }_{x} 7^{\circ}$. & " & " & " & "I & " & " & $"$ & $"$ & $\Rightarrow$ & " & ' & " & 5 & (i) \\
\hline xyrí & $"$ & 1 & 2 & $n$ & " & " & " & " & " & & " & $\|$ & 3 & 7 \\
\hline xу11". & " & 2 & 4 & 3 & " & 3 & 2 & 1 & 3 & 1 & " & " & (i) & 24 \\
\hline \multirow[t]{3}{*}{$x^{e}$} & 3 & 2 & 2 & 3 & 6 & 2 & 2 & 1 & 1 & 3 & 3 & 3 & 1 & 30 \\
\hline & 3 & 5 & 8 & 5 & 6 & $\bar{j}$ & 11 & 9 & 4 & 4 & 3 & 3 & \multirow[t]{2}{*}{15} & \multirow[t]{2}{*}{67} \\
\hline & & 16 & & & 16 & & & 10 & & & 10 & & & \\
\hline
\end{tabular}

D'après cela, les deux périodes de six mois correspondan! d'un côtó à l'hiver' et au printemps, de l'autre à l'été et à l'automne, auraient donué l'une el l'autre. te mème chilfre de 26 .

D'autre parl nous avons trouvé dans les notes dı R. P. Cornette les ćléments du tableau suivant :

AMERIQUE TROPICALE.

\begin{tabular}{|c|c|c|c|c|c|c|c|c|c|c|c|c|}
\hline RÉGนONS. & WARs. & AVBLL. & MAI. & אנטנ. & JULLLET. & Aดที่. & sEPTEMBR & OCTORAE. & vovв.ипR. & Dе́́свмвите. & SANYIER. & révhier. \\
\hline \multirow{6}{*}{$\begin{array}{l}\text { Colombie . . . . . . . . . . . . } \\
\text { Amérique centrale. . . . . . . . } \\
\text { Mexique... . . . . . . . . . . } \\
\text { Antilles. (D'après .I. A. Poey.) }\end{array}$} & 13 & 4 & 14 & 17 & 4 & 7 & 9 & 14 & 10 & 3 & 10 & 16 \\
\hline & 5 & 5 & 7 & 3 & 26 & 4 & 8 & 7 & l. & 5 & $"$ & 5 \\
\hline & 10 & 11 & 7 & 12 & 11 & 6 & 7 & 5 & 4 & 7 & 3 & 11 \\
\hline & $5 /$ & 53 & 55 & 48 & 53 & $7^{2}$ & 62 & 6.5 & 48 & 41 & 4.5 & 43 \\
\hline & $8 z$ & $7^{3.3}$ & 83 & $7^{\circ}$ & $9^{\prime}$ & 89 & 86 & 91 & 63 & 56 & 50 & $7^{-j}$ \\
\hline & & ${ }_{3} 38$ & & & 253 & & & 239 & & & 190 & \\
\hline
\end{tabular}


D'après celia, la période de six mois correspondant à l'hiver el alu primlemps serait restée notablement inférienre à celle qui est relative à l'élé el à l'antomne.

Mais si, au lieu de combiner entre eux des éléments incomplets, nous cherchons à étudier ıne petite série d'années pour laquelle on a des observalions snivies et précises, telles que celles qui sont executées au Collegio Tridentino de Guatemala, voici ce que nous trouverons pour celle localité envisagée isolément.

TREMBLENENTS DE TERRE A GUATEMALA.

\begin{tabular}{|c|c|c|c|c|c|c|c|c|c|c|c|c|}
\hline Axvíks. & AAYIER. & FÉVBIER. & MARS. & AVRIL. & MAI. & JUIN. & JULLET. & AOUิT. & SEPTEMBaB & OCTOBRE. & NOYEM BHE. & DÉcíambri. \\
\hline \multirow{7}{*}{$\begin{array}{l}1859 \ldots \ldots \ldots \\
1860 \ldots \ldots \\
1861 \ldots \ldots \ldots \\
1862 \ldots \ldots \\
1863 \ldots \ldots\end{array}$} & g & 3 & $"$ & 4 & $" \prime$ & $" 1$ & $"$ & 1 & 1 & $"$ & $"$ & 2 \\
\hline & 2 & 1 & $"$ & $"$ & 3 & 1 & $"$ & 1 & $"$ & $"$ & $"$ & " \\
\hline & 1 & 2 & $"$ & $"$ & $"$ & 1 & $"$ & 4 & $" 1$ & $"$ & $"$ & $"$ \\
\hline & $"$ & $"$ & $"$ & $"$ & 3 & 1 & $"$ & $"$ & $"$ & $"$ & 1 & 6 \\
\hline & 7 & 1 & 3 & 3 & $"$ & $"$ & $"$ & $"$ & $"$ & $"$ & 1 & 2 \\
\hline & 12 & 7 & 3 & 7 & 6 & 3 & $" 1$ & 6 & 1 & $"$ & 2 & 10 \\
\hline & & 22 & & & 16 & & & 7 & & & 12 & \\
\hline
\end{tabular}

Il en résulterait que, les mois de décembre el de janvier ayant été les plus abondants en tremblements de terre, li période de six mois relative à l'hiver et an printemps en a présenté 34 , landis que celle qui correspond à l'été et à l'antomne n'en a eu que 23 . Il est évident qu'on ue peut rien conclure d'nne série d'années aussi courte que celle dont nous venons de nous occuper, et que les phénomènes accidentels, lels que ceux qui se sont produits à la fun de $1862 \mathrm{el} \mathrm{an}$ commencement de 1863 , prennent une valeur relative beaucoup trop considérable dans un chiffre aussi restreint. On ne peut pas plus baser une toi sur ces données qu'on ne peul le faire sur quelques documents épars, sauvés de l'oubli dans les siècles passés par quelques circonstances exceptionnelles. Mais qu'il nons soit permis de dire quo les observations de Guatemala semblent confirme la tradition qui existe dans ce pays, el que, comme de semblables traditious son presqur tonjours fondées sur quelque chose de réel, on est en droit d'espérer 
DANS LES REPUBLIQUES DE GUATEMALA ET DE SALNADOR. 503 que des recherches poussées dans ce sens pourront amener à des résultats intéressants.

CARACTERES DES TREMBLEYENTS DE TERRE DE LAVERIOUE CENTRALE.

Les tremblements de terre de l'Amérique centrale ne diffèrent pas, en ce qui concerne leurs caractères généraux, de ce que l'on a observé partoul ailleurs, soil en Europe soil en Amérique. Les conditions de durée, d'amplitude d'oscillation, etc., sont toujours extrèmement variables, mais elles se maintiennent entre des limiles qui sont parlout à peu près les mèmes. On a remarqué aussi que les secousses n'étaient pas loujours de mème nalure, el que si, le plus souvent, elles se manifestaient sous la forme d'oscillations ondulatoires, elles pouvaient anssi quelquefois revètir le caraclère de trépidations, el mème quolquelois devenir giratoires. Il y a à peine quelques années que l'élude de ces phénomènes a été entreprise à Guatemala avec une direction scientifique, el ce n’est que dans des récits écrits le plus souvent sous l'impression de la terreur el par des esprits à teudances peu philosophiques que l'on peut chercher des documents plus ou moins siguificalifs pour aborder celte question.

II nous semble pourtant que l'on peut admetlre que les tremblements de terre généraux se sont presque toujours manifestés sous une forme ondulatoire, taudis que les tremblements de terre locaux étaient plus fréquemment des trépidations. Lorsque les traditions parlent de secousses qui se sont fait sentir en mème tenps à de grandes distauces, elles les peignent, en général, comme des oscillations senblant se propager à la manière des vagues dans un sens bien déterminé. Quand il sagit, au contraire, de mouvements locaux du sol, accompagrnant ou annoncant des éruptions d'un volcan voisin, on parle plus souvent d'une secousse bruscue, ressemblant à une sorte de clıoc frappé de bas en haut, directement au-dessous de l'endroit en question. Les trépidations, lorsqu'elles ont une certaine intensité, produisent des effets beaucoup plus lerribles que les ondulations, et c'est à des secousses de ce gonre-lì qu'ont été dues presque toules tes grandes calastrophes célèbres dans l'Amérique centrale.

Les secousses ondulatoires ont généralement une direclion asse\% nettement indiquéc, el, sanf d'assez rares exceplions, cette direclion est toujours, à peu de

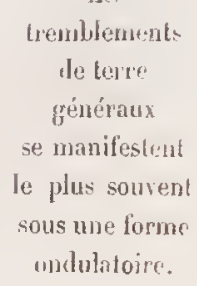

Les ondulations: séismigues. 
direction

du sud-oues!

all

nord-rst.

chose près, la mème. A Gualemala, on a remarqué que, dans presque lous les Iremblements de lerre, les mouvements semblaient venir du sud-ouest el se projager sous la forme d'ondes marchant vers le uord-est. Il ne faudiait pas accepInr trop complétement l'opinion publique sur ce point, parce qu'elle est toujours préoccupéc de relier les tremblenents de terre alux volcans qui sont en aclivité peudant qu'ils se produisent, el que, girâce à cetle tendance, les esprits trourenl quelquefois des directions là où il n’y en a pas. Mais, cette petile réserve faite, il n'en est pas moins vrai que tes secousses viement presque toujour's du sud-ouest, ainsi que le prouvent les observations faites à l'observatoire du Collegio Tridentino. On peut voir, en particulier, dans la liste reproduite ci-iprès el empruntée à la brochıre de. M. J. A. Lizarzaburu, professeur au Collegio Tridentino, que, sur les qualorze tremblements de terre de la fin de 1862 et du conmencement de 1863, onze oul présenté la direclion du sud-ouest; un a commencé par le sudsud-ouest, pour passer au sud-sud-est, et deux enfin sont venus du sud-sud-est. Daus son opuscule, d'ailleurs fort remarquable, le savant professeur de Guatemala nous semble un peu trop dominé par la préoccupation d'expliquer ces clıangements de direction par l'influence immédiate des foyers volcaniques el par l. transport de la puissance éruptive d'un point à l'autre, gràce à des communications soulerraines. Mais, si l'on u'adopte point complétement ses conclusions, peut-ètre un pen trop exclusives, on ne doil pas moins lui être reconnaissant des sivantes recherches qu’il accumule depuis quelques années, el espérer que la continuation de ses tranaux dotera la science de précieux matériaux. II demeure donc élabli, foràce aux obscrvations failes au Collegio Tridentino, qu’à Guatemala les secousses de tremblements de terre ont habiluellement la direction du sud-ouest, el que, sur ece point encore, l’opinion publique n'est pas en opposition avec la réalité des faits, saus qu'on puisse pourtant domner à ses conclusions une valcur plus absolure qu'elles ne le comportent. Il est à remarquer que celle direction du sud-ouest, à peu près perpendiculaire ì celle du système volcanique, coïncide avec la direclion qu'ilfectent aussi presque toujours les secousses ondulatoires à Mexico. Mais, comme, d'après les notes du R. P. Coructte, les choses ne se passent pas tout ì fail de mène à Truxillo (Côte de l'Atlautique, Honduras), el que l'on sait, par phisieurs autres observateurs, que les variations de direction sont fréquentes en 
DANS LES RÉPUBLIQUES DE GUATEMALA ET DE SALVADOR. 505 d'autres points de la zone séismisque de l'Amérique tropicale, il ne faudrait pas trop se hâter de poser des conclusions qui ne sont pas élablies par un assez grand nombre d'observalions précises, pour avoir une valeur cerlaine.

Au point de vue de la répartition horaire des tremblements de lerre dans l'Amérique centrale, on ne peut encore rien dire de cerlain à cause du manque de documents. Ainsi nous trouvons une note du R. P. Cornette, réparlissant de la manière suivante ceux dont l'heure lui était connue:

$\begin{array}{cccc}\text { Natin. } & \text { Jour. } & \text { Soir. } & \text { Nuit. } \\ 20 . & 21 . & 18 . & 19 .\end{array}$

On ne peut en tirer aucune conclusion, non plus que des secousses de décembre $\mathbf{1 8 6 2}$ et janvier $\mathbf{1 8 6 3}$, dont trois seulement se sont produites de minuil à midi, tandis que onze ont eu lieu de midi à minuil, parce que ce n'est là qu'un fait isolé et qui ne prouve rien.

Il est à peu près démontré que dans l'Amérique centrale, aussi bien que partout ailleurs, les tremblements de terre se produisent par tous les temps et sans qu'il soil possible de saisir un lien quelconque entre eux et les phénomènes météorologiques qui les accompagnent. On peut s'en convaincre en jetant les yeux sur le tableau suivant, où sont indiqués les tremblements de terre qui ont agoitć Guatemala en décembre 1862 et janvier $\mathbf{1 8 6 3}$, ainsi que tous les détails météoLes
tremblemenis de terre ne sont pas accompagnés de phénomènes météoroloģiques rologiques nécessaires pour faire comprendre nettement quel était l'état de l'almosphère. 


\section{TREMBLEMENTS DE TERRE RESSENTIS À GUATEMALA}

EN DÉCEMBRE 1862 ET JANVIER 1863 ,

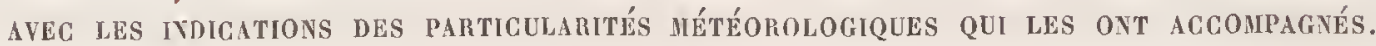

(J. A, Lazarzaburv. S. J.)

\begin{tabular}{|c|c|c|c|c|c|c|c|c|c|}
\hline $\begin{array}{l}\text { Jot? } \\
\text { ny xors. }\end{array}$ & HECRE. & DIRECTIOY. & $\begin{array}{c}\text { OSGIL- } \\
\text { LATIONS } \\
\text { en } \\
\text { MLLLMÈ rRES. }\end{array}$ & $\begin{array}{c}\text { DCREE } \\
\text { en } \\
\text { sECONOES. }\end{array}$ & $\begin{array}{l}\text { TEMPÉ- } \\
\text { MATURE. }\end{array}$ & ÉTAT DU CIEL. & VENT. & $\begin{array}{c}\text { HAUTEUR } \\
\text { BAחOMÉTRRTUU. }\end{array}$ & $\begin{array}{l}\text { VARTATIOY } \\
\text { MAGXÉTQUE. }\end{array}$ \\
\hline 19 déc. .. & 7 h. $25^{\prime} \mathrm{s}$. & S. S. 0., S. S. E. & $160^{\mathrm{m}} / \mathrm{m}$ & 114 & $12^{\circ}, 0$ & Quelques nuages. & $\begin{array}{l}\text { N. N. E. } \\
\text { Nodéré. }\end{array}$ & 643,55 & $2^{\prime} 00^{\prime \prime}$ \\
\hline $20 \ldots$ & 5 h. $45^{\prime} \mathrm{s}$. & S. S. E. & 60 & 10 & 9,2 & $I d$. & $\begin{array}{l}\text { N. N. E. } \\
\text { 'Irès-faible. }\end{array}$ & 643,3, & $3^{\prime} 42^{\prime \prime}$ \\
\hline $20 \ldots$ & 5 h. $5 o^{\prime} \mathrm{s}$. & S. S. E. & $9^{\circ}$ & 36 & 9,2 & $I d$. & Id. & 643,31 & $2^{\prime} 42^{\prime \prime}$ \\
\hline $26 \ldots$ & 2 h. s.... & S. 0. & 3 & 12 & 21,2 & A moitié couvert. & $\begin{array}{l}\text { N. N. E. } \\
\text { Modéré. }\end{array}$ & 639,38 & $x^{\prime} 39^{\prime \prime}$ \\
\hline $27 \ldots \ldots$ & $6 \mathrm{~h} .3 \mathrm{o}^{\prime} \mathrm{s}$. & S. 0. & 5 & 5 & 13,0 & Couvert. & $\begin{array}{l}\text { E. N. E. } \\
\text { Très-faible. }\end{array}$ & 642,08 & $1^{\prime} 14^{\prime \prime}$ \\
\hline 28. & $3 \mathrm{~h} .30^{\prime} \mathrm{s}$. & S. 0 . & 4,5 & 6 & 12,6 & A moitié couvert. & $\begin{array}{c}\text { N. E. } \\
\text { Très-faible. }\end{array}$ & 641,18 & $1^{\prime} 22^{\prime \prime}$ \\
\hline $30 \ldots$. & 5 h. m... & S. O. & 3,5 & 2 & 9,2 & Clair. & $\begin{array}{l}\text { E. N. E. } \\
\text { Très-faible. }\end{array}$ & 641,60 & $2^{\prime} 12^{\prime \prime}$ \\
\hline $31 \ldots \ldots$ & $3 \mathrm{~h} .45^{\prime} \mathrm{s}$. & S. 0. & 0,5 & 1 & 12,0 & Couvert. & $\begin{array}{l}\text { V. N. E. } \\
\text { Faible. }\end{array}$ & 642,40 & $1^{\prime} 33^{\prime \prime}$ \\
\hline 4 janv... & 11 h. $20^{\prime} \mathrm{s}$. & S. 0 . & 4,0 & 10 & 20,6 & Quelques nnages. & $\begin{array}{l}\text { N. N. E. } \\
\text { Modéré. }\end{array}$ & 640,00 & $9^{\prime} 58^{\prime \prime}$ \\
\hline $8 \ldots \ldots$ & $11 \mathrm{~h} .55^{\prime} \mathrm{s}$. & S. 0. & 5,0 & 3 & 17,0 & $\begin{array}{l}\text { Presque entièrement } \\
\text { couvert. }\end{array}$ & Id. & 641,50 & $1^{\prime} 25^{\prime \prime}$ \\
\hline $10 \ldots$. & $8 \mathrm{~h}, \mathrm{~m} \ldots$ & s. 0 . & 7,0 & 3 & 14,2 & Couvert. & $\begin{array}{l}\text { N. N. E. } \\
\text { Faible. }\end{array}$ & 640,75 & $1^{\prime} 25^{\prime \prime}$ \\
\hline $15 \ldots$. & $3 \mathrm{~h} . \mathrm{m} . .$. & s. 0 . & 5,0 & 11 & 13,2 & Clair. & $\begin{array}{l}\text { S. S. } 0 . \\
\text { Faible. }\end{array}$ & 610,00 & $I^{\prime} 16^{\prime \prime}$ \\
\hline $20 \ldots$ & $1 \mathrm{l}_{1}, 3 \mathrm{o}^{\prime} \mathrm{s}$. & S. 0 . & 3,0 & 6 & 12,8 & A moitié convert. & $\begin{array}{l}\text { Y. } \\
\text { Faible. }\end{array}$ & 642,60 & $1^{\prime} 16^{\prime \prime}$ \\
\hline 24. & 11 h. 11 s. & S. 0 . & 2,0 & 2 & 22,0 & Clair. & $\begin{array}{l}\text { N. N. E. } \\
\text { Modéré. }\end{array}$ & 641,00 & $3^{\prime} 7^{\prime \prime}$ \\
\hline
\end{tabular}

On y verra que toutes les conditions météorologiques, température, hauteur barométrique, état du ciel, vent, variation magnétique, sont restées presque exaclement ce qu'elles auraient dû ètre à cette époque de l'année et aux heures indiquées, s'il ne s'était produit aucune secousse de tremblement de terre. Pourtant, si l'on voulait absolument trouver quelque chose de particulier, on pourrail constater que le ciel a été un peu plus couvert qu'il ne l'est d'ordinaire pendant la saison sèche, que l'atmosphère a été exceptionnellement calme après une période de vents du nord très-violents qui avaient soufllé au commencement de décembre $\mathbf{1 8 6 2}$, enfin que la variation magnétique a été quelquefois un pen plus 
DANS LES RÉPUBLIQUES DE GUATEMALA ET DE SALVADOR. 507 faible que d'habitude. Quoique cette question ne nous semble avoir, surtout dans le cas présent, qu'un intérêt toul à fait secondaire, nous y insistons' un peu, parce que, pendant un certain temps, l'observatoire de Guatemala avail une tendance marquée à considérer les tremblements de terre comme intimement liés à des phénomènes thermo-magnétiques, et recherchait avec grand soin toutes les particularilés météorolog̣iques qui les accompagnaient. On avait cru remarquer aimsi que, sans que le baromètre variât d'une façon sensible, il y avait une surélévation du thermomètre dans les jours précédant un tremblement de terre, que l'lıygromètre indiquait une grande sécheresse, et que l'évaporation, très-forte avant le phénomène, diminuait rapidement après qu’il s'était produit. On avait remarqué que, quelque temps avant les secousses, il y avail entre deux vents, généralement nord-nord-est et sud-sud-ouest, une lutte qui s'arrêlait tout à coup et faisait place à un calme parfail au moment du tremblement de terre; le ciel était souvent couvert de cirrus, et, si une abondante plnie orageuse venail à se déclarer, la lendance aux tremblements de lerre s'arrêtait. On croyait encore que les actions électriques et magnéliques subissaient. l'influence du phénomène, les décharges des batteries auggmentant d'intensité, et les variations de l'aiguille aimantée étant soumises à une légère perturbation. Quoique nous ne soyons pas portés a domner à ces conclusions uue généralité absolue, et à croire qu’elles aient été vérifiées dans tous les cas qui ont élé étudiés, nous devons pourtant penser qu'elles s'appuient sur quelque chose de vrai et de bien constaté, puisqu'elles sont te reflet de l'opinion de savants sérieux et d'observateurs consciencieux. C'est à ce litre seulement que nous les reproduisons ici, mais en déclarant qu’il sera fort intéressant de voir si les travaux postérieur's vérifieront ces hypolhèses, dont la valeur sera peut-être mieux démontrée plus tard qu'elle ne l'est aujourd'hui.

EFFETS DES TREMBLEMENTS DE TERRE DANS LAMÉRIQUE CENTRALE.

Les effets des tremblemerts de terre sont à peu près les mèmes dans l'Amérique centrale que dans toute la région séismique de l'Amérique tropicale, et ils causent parfois d'épouvanlables désastres; mais, par leur fréquence même, ces phénomènes ont perdı une grande partie de leur prestige sur l'esprit des populations, accoulumées à vivre avec eux et à lutter incessamment contre eux. S'il 
est vrai que, quand une ville entière est renversée d'un seul coup, les habitants s'abandonnent au désespoir et à l'épouvante avec plus de facilité que ne le ferait une race plus énergique, il faut bien reconnaître aussi qu'une maison détrnite, qu'une église crevassée, ne les émeut gouère et qu'ils restent à peu près indifférents pour des phénomènes qui mettraient sur pied toute uve cité européenne.

Portes secuusscs andulatoires ì Guatemala en 1830 et 1862

Ainsi que nous l'avons dit, les secousses les plus dangereuses sont celles qui affectent l'allure de trćpidations; mais les ondulations peuvent aussi produire des résultats terribles, surtout quand elles se répètent ì des intervalles très-rapprochés, ou bien quand elles acquièrent une amplitude inusitée. Ainsi les secousses ondulatoires du mois d'avril 1830 renversèrent une grande quantité de maisons à Guatemala, mais aussi le nombre en fut réellement extraordinaire. Elles commencèrent le $1^{\text {er }}$ avril, et se continuèrent faiblement jusqu'au 12 , où il $y$ en eut trente-cinq dans la mème journée; le 21 , il s'en produisil cinquante-deux entre 4 heures du matin et 5 heures du soir. Les édifices, ébranlés par une semblable série de mouvements, ne purent plus résister au choc violent qui se fit senlir le 23 ì 9 heures du soir; et, comme pour compléter les ruines, de petites secousses se firent encore sentir avec intermiltence jusqu'au 18 mai de la mème année.

De mème, les tremblements de terre de la fin de 1862 causèrent de graves lésordres dans lés deux capilales de Salvador et de Guatemala, ainsi que dans toutes les villes situées entre elles; mais la marche du phénonıène fut différente. Il se produisit d'abord, le 19 décembre 1862 , à 7 heures 25 minutes du soir, une trèsviolente secousse de 160 millimètres d'amplitude, et une série d'aulres petits ınouvements ondulatoires, continués pendant plusieurs jours, achevèrent ce qu'avait commencé le premier. Nous avons ressenti nous-mèmes, le 9 août 1866 , à 7 heures 1 minute du matin, pendant que nous faisions l'ascension du volcan d'Atitlan, un tremblement de terre assez violent, qui s'est manifesté sous la forme de trois ondulations successives, d'une durée d'à perı près une seconde chacune, la première étant la plus forte. Ce tremblement de terre fut ressenti à la même heure ì Guatemala, et, quoiqu'il n'ait pas été assez fort pour renverser des maisons, nous avons pu constater l'énergie de ses effets par les effrayants éboulements doıt il détermina la production dans les ravins du volcan. 
DANS LES RÉPUBLIQUES DE GUATEMALA ET DE SALVADOR. 509

On peut dire, sans exagération, que les tremblements de terte ont parsemé l'Amérique centrale de ruines; mais les deux plus terribles dont on ail conservé le souvenir sont celui du 29 juillet 1773, qui détruisit la Antigua Guatemala, et celui du 16 avril 1854, qui cansa la ruine de la ville de San Salvador. Nous allons donner quelques brèves indications sur ces catastrophes, d'après des documents officiels.

La ville qui porte actuellement le nom de La Antigua Guatemala, ou plus simplement de La Antigua (l'ancienne) a été, pendant plus de deux sièclès, la capitale du pays, jusqu’à l'époque où clle fut abandonnée par les autorités et les principaux habilants à la suite des tremblements de terre qui l'avaient dévastée. Elle avait élé fondée en 1542, pour remplacer la première capitale, qui s'élevait autrefois sur l'emplacement où est aujourd'hui le gros villagge de Cindad Vieja (la vieille ville) el qui disparut elle-mème à la suite d'une épouvantable calastrophe dont voici le récit, extrait, ainsi que tout ce qui suit, de l'ouvrage publié au commencement du siècle par l'historien Juarros et intitulé : Compendio de la listoria de la Ciudad de Guatemala (t. 1, tr. II, ch. xi, p. 223 et suivantes).

"r La plus effrayante calamité qui eùt encore afligé celte ville infortunée se produisit le 11 septembre 1541 au malin. Il avail plu d'une façon incessante el avec une très-ơrande violence pendant les trois journées précédentes, particulièrement pendant la nuit du 10 , où l'eau semblail tomber plutôt comme une cataracte que comme de la pluie; il est impossible de décrire la fureur du vent, les lucurs perpétuelles des éclairs, les éclats effrayants du tonnerre. Le 11, à 2 heures du malin, les secousses de trembleinent de terre étaient si violentes, que l'on ne pouvait se tenir deboul; les chocs étaient accompagnés de bruils souterrains qui causaient une épouvante gónérale. Bientòt après, un immense torrent d'eau se précipila du sommet de la montagne, entrainant avec lui d'énormes quartiers de roc et des arbres giganlesques; il descendil précisémeut sur la malheureuse ville, détruisant presque toules les maisons, et ensevelissant un grand nombre d'habitants sous les ruines. Entre autres, Doña Beatrice de la Cueba, veuve de Pedro Alvarado, perdit la vie dans cette catastrophe."

Depuis l'époque de sa fondation, l'histoire de la Antigua n'est qu'une série presque ininterrompue de désastres : «Plusieurs secousses violentes de tremble- 
ments de terre furent ressenties à diverses époques. Celui de 1565 endommagea sérieusement plusieurs des principaux édifices. Ceux de 1575,1576 et 1577 ne furent pas moins ruineux. Le 27 décembre 1581 , la population fut de nouveau alarmée par le volcan (de Fuegro), qui commença à rejeter du feu, et la quantité de cendres projetées en l'air ful si considérable, que le soleil en fut entièremenl obscurci, et qu’il fallul, dans la ville, allumer des lumières à midi.

" Les années 1585 el 1586 furent extrêmement terribles. Le 16 janvier 1585 , on ressentit des tremblements de terre, et ils se continuèrent, pendant toute cette anmée ainsi que pendant la suivante, avec une tetle fréquence, qu’il n’y eut pas. pendant toute celle période, $m$ intervalle de huit jours sans qu'on ressentît un choc plus ou moins violent. Pendant des mois, des flammes s'échappèrent incessamment de la montagone, et auggmentèrent cucore la consternation générale. L'événement te plus grave de toute celte série de malheurs eut lieu le 23 décembre 1586 , et la ville entière fut de nouveau transformée en un monceau de ruines, sons lesquelles étaient ensevelis un grand nombre de ses infortunés habiLants. La Lerre trembla arec une telle violence, que le sommet de plusieurs collines élevées ful précipité dans la plaine et que de profonds abîmes s'ouvrirent en plusieurs endroits dans le sol.

- Le 18 février 1651 , ou entendit tout à coup un bruil souterrain extraordinaire, anquel succédèrent immédiatement trois chocs violents, à très-court intervalle l'un de l'autre, qui renversèrent beaucoup d'édifices et en endommagèrent d'autres. Les tuiles des toils des maisons furent dispersées dans toutes les direclions comme des fólus de paille par un ouragan; les cloches des églises se mireut en branle, des quartiers de roc se délachèrent des montağnes, el tes bètes sauvages elles-mêmes furent tellement épouvantées, que, quiltant leurs retraites, elles vinrent se réfugier près des habitations des hommes.

" L'année 1717 fut mémorable. Pendant la nuit dn 27 aoùt, la montagne commença à vomir des flammes, accompagnées d'un bruit souterrain continuel. La nuit du 28 , l'éruption auggmenta de violence, et l'effroi des habitants devint plus grand. Les images des saints furenl portées en procession, des prières publiques furent dites journellement, mais la terrifiante éruption continuail toujours, et elle ful suivie, pendant plus de quatre mois, par de fréquentes secousses de 
DANS LES RÉPUBLIQUES DE GUATEMALA ET DE SALVADOR. 511 tremblements de terre. Enfin, pendant la nuit du 29 septembre, il sembla que c'en était fail de Guatemala et que la ville allait ètre détruite de fond en comble. Il y cut des ruines terribles dans les édifices publics; bien des maisons furent renver'sées, et toutes subirent des alleintes plus ou moins violentes, mais c'est dans les égolises qu'eut lieu la plus gorande dévastation.

"L'année 1773 fut l'époque la plus douloureuse dans les annales de la métropole; elle fut alors détruite, cette belle capitale, et ne se releva plus jamais de ses ruines. Le 29 juillet, à 4 heures de l'après-midi, à peu près, on ressentit une épouvantable vibration, et bientòt après commença la terrible convulsion qui décida du sort de celte ville infortunée. Le 7 septembre, il y eut un autre tremblement de terre qui renversa tous les édifices qui n'avaient été qu'endommagés par celui dı 29 juitlet, et enfin, le 13 décembre, un autre, plus violent encore, vint achever l'ourrè de destruclion."

C'est à la suite de cette catastrophe que la capitale fut transportée dans la vallée de Las Viccas, à l'endroit où s'élève actuellement Guatemala.

La république de Salvador' a eu aussi sa capitale délruite par un tremblement de terre, el a voulu la transporter dans un autre endroit, à Santa Tecla, où l'on a essayé de créer une Nueva San Salvador. Mais l'amour des habilants pour leur ancienne ville a été le plus fort, ils y sont restés, el elle se relève aujourd'hui de ses ruines, malgré le triste état dans lequel elle avait été mise. Voici Je récit de cet événement, tel qu’il est donné dans le Boletin extraordinario del Gobierno del Salvador du 2 mai 1854 :

ce La nuit du 16 avril 1854 restera pour le peuple du Salvador un pénible et amer souvenir. Dans cette malheureuse nuit, notre bolle et tranquille capitale a été transformée en un monceaul de ruines. Des mouvements du sol furent ressentis, pendant la matinée du jeudi saint, accompagnés de bruits comparables ì ceux d'une lourde artillerie roulant sur le pavé, ou d'un tonnerre éloigné. Le peuple fut un peu alarmé par ces phénomènes, mais cela ne l'empêchia pas de se réunir dans les églises pour célébrer la solennité de la journée. Le samedi, tout était tranquille, et la confiance avait reparu. Le peuple des environs se rassembla comme d'habitude pour célébrer la fète de Pàques. La nuit du samedi fụ tranquille ainsi que tout le dimanche. Il est vrai que la température étail très-élevée,

\footnotetext{
Destruction de la ville de San Salvador. par Je tremblement de Lerre du 16 avril 1854.
} 
mais l'atmosphère était calme et sereine. Pendant les trois premières heures de la soiréc, il n'arriva rien d'extraordinaire, mais, à 9 heures $1 / 2$, une violente secousse de tremblement de terre, survenant sans les bruits préliminaires habiluels, vint alarmer toute la ville. Bien des familles quittèrent leurs maisons pour s'arranger des campements sur les places publiques, tandis que d'autres se préparaient à passer la nuit dans leurs cours.

«Enfin à 11 heures moins 10 minutes, sans aucun avertissement, la terre commença à s'agiter et à trembler avec une force si épouvantable, qu'en moins de 10 secondes toute la ville était renversée. Les craquements des maisons et des églises terrifiaient les citoyens, enveloppés dans un épais nuage formé par la poussière qui s'échappait des ruines. Impossible de se procurer une goutte d'eau pour venir au secours des gens blessés ou étouffés; les puits et les fontaines étaient comblés on desséchés.....

" La destruction fut eflecluée, avons-nous dit, dans les dix premières secondes, mais les secousses suivantes n'en furent pas moins terribles et accompagnées d'un bruit effrayant qui se produisait sous nos pieds; si elles n'eurent pas de résultats considérables, c'est que la première ne leur avait pas laissé grand'chose à ravager.... On a trouvé que beaucoup moins de citoyens qu'on ne le pensait d'abord ont perdu la vie dans cet accident, et it semble maintenant probable que le nombre des morts ne dépassera pas une centaine, ct celui des blessés ane cinquantaine.....

- Les mouvements de la terre continuent toujours avec des secousses violentes, et le peuple, craignant que toute la cité ne soit engloutie dans quelque gouffre ou ensevelie par une éruption soudaine du volcan (qui semble imnoncée par une odeur sulfureuse intense remplissant l'atmosphère), s'empresse de s'enfuir, cmportant ce que chacin a pu sauver, ses dieux lares, les doux souvenirs de son enfance, et quelques animaux domestiques, peut-être la seule propriété qu’ils aient pu conserver pour le soutien de leurs familles, s'écriant avec Virgite :

$$
\text { Nos patrix fines et dulcia linquimus arva." }
$$

Tous n'avons rien à ajouter à ces récits, qui suffisent à prouver quels terribles effets produisent les tremblements de terre dans l'Amérique centrale, torsqu'ils 
DANS LES RÉPUBLIQUES DE GUATEMALA ET DE SALVADOR. 513 dépassent leurs proportions ordinaires. En moins d'un siècle, deux florissantes capitales ont été transformées en des moncenux de ruines; il y a vingot ans à peine, des centaines de personnes périssaient sous les décombres de leurs demeures, et qui sait ce que réserve encore l'avenir à ces infortunés et merveilleux pays, auxquels la Providence semble avoir infligé comme compensation de leur splendeur et de leur richesse ce terrible fléau dont la puissance étrange domine le génie de l'homme. Que dirions-nous de plus? Aussi bien nous faut-il arriver au terme de notre travail, et souhaiter que ces quelques recherches puissent contrihuer un jour au succès des tentatives que fera quelque grande intelligence pour déchirer le voile dont sont environnés ces mystérieux phénomènes de li nature. 



\section{APPENDIGE AU LIVRE PREMIER.}

\section{TABLEAUX D'ITINERAIRES}

DANS IAS REPUBLIQUES DE SALVADOR ET DE GUATEMALA.

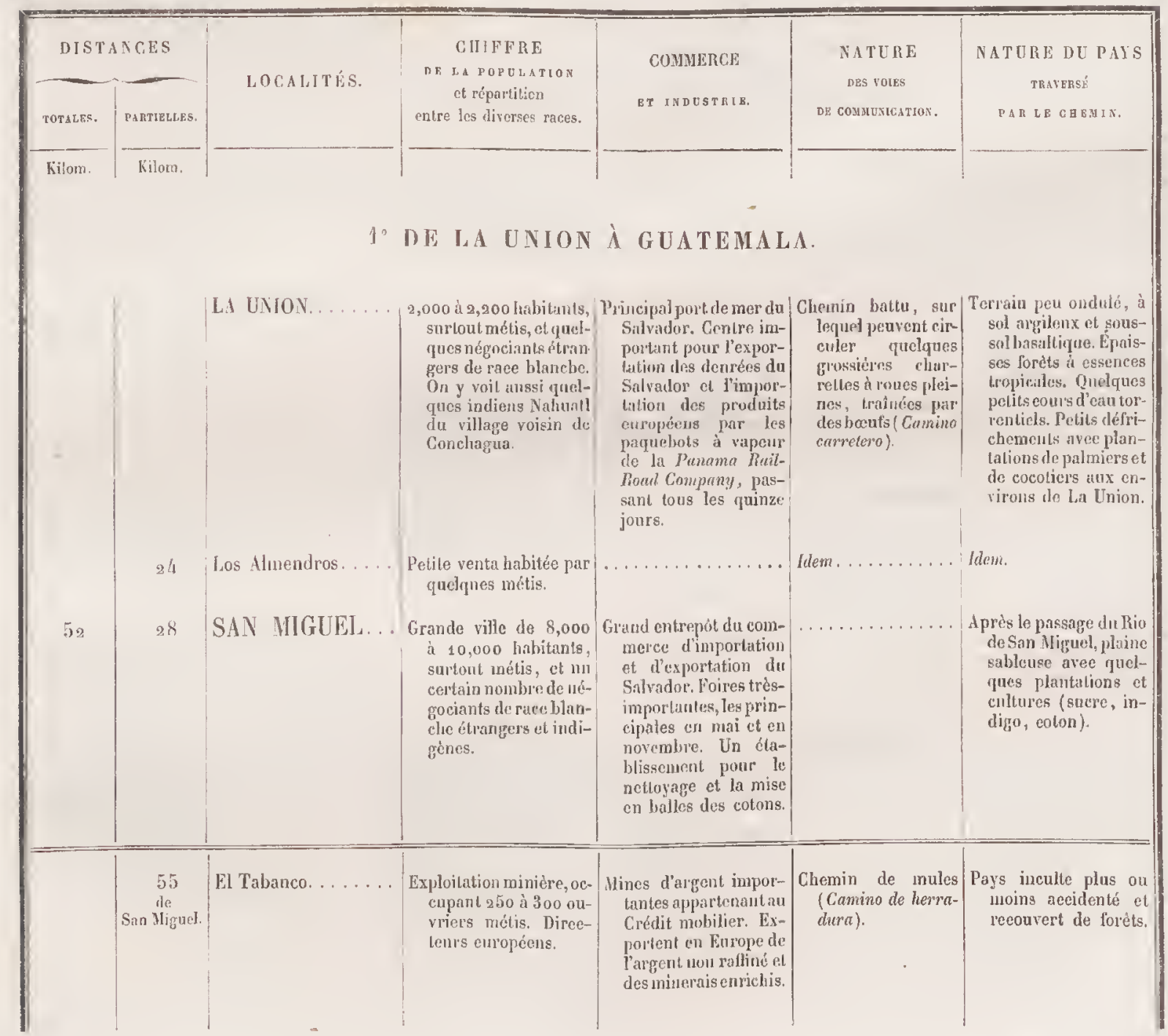

05. 


\begin{tabular}{|c|c|c|c|c|c|c|}
\hline$\overbrace{\text { TOTALHS. }}^{\text {DISTA }}$ & P.NCES & LOCALITÉS. & $\begin{array}{c}\text { CIIIFFRE } \\
\text { D\& La doputatos } \\
\text { et répartition } \\
\text { entre les diverses races. }\end{array}$ & $\begin{array}{l}\text { COMMERCE } \\
\text { 2T INDUSTRE. }\end{array}$ & $\begin{array}{l}\text { NATURE } \\
\text { DBS voIes } \\
\text { DR CoduUaication. }\end{array}$ & $\begin{array}{l}\text { NATURE DU PAYS } \\
\text { TRATERŚ́ } \\
\text { PAR LE CHEMTS. }\end{array}$ \\
\hline Kilom. & $\begin{array}{c}\text { Kilom. } \\
30 \\
\text { de } \\
\text { San-Miguel. }\end{array}$ & Los Excuestros..... & $\begin{array}{l}\text { Exploitatiou minière, oc- } \\
\text { cupant } 100 \text { à } 150 \text { ou- } \\
\text { vriers métis. Direc- } \\
\text { teurs européens. }\end{array}$ & $\begin{array}{l}\text { Mines d'argent assez im- } \\
\text { portantcs, apparte- } \\
\text { nant au Crédit mobi- } \\
\text { lier, et dépendant de } \\
\text { celles de T'abanco. }\end{array}$ & Ghemin de mules... & $\begin{array}{l}\text { Pays inculte, d'abord } \\
\text { plat, puis accidenté. } \\
\text { Quelques forcis plus } \\
\text { ou moins épaisscs. }\end{array}$ \\
\hline $\begin{array}{c}64 \\
\text { de } \\
\text { La Union. }\end{array}$ & 13 & Moncagua......... & $\begin{array}{l}\text { Gros village de } 800 \text { à } \\
1,000 \text { habitants, tous } \\
\text { métis. }\end{array}$ & $\cdots$ & $\begin{array}{l}\text { Chemin battu pour } \\
\text { clars à boufs. }\end{array}$ & $\begin{array}{l}\text { Phaine sablcuse, culti- } \\
\text { vée en quelques en- } \\
\text { droits. }\end{array}$ \\
\hline $7^{8}$ & 14 & 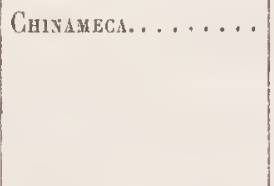 & $\begin{array}{l}\text { Gros bourg de } 1,200 \text { ha- } \\
\text { bitants, tous métis. }\end{array}$ & $\begin{array}{l}\text { Produit les denrées qui } \\
\text { servent à l'approvi- } \\
\text { sionnement de Sam } \\
\text { Miguel. Élève de bes- } \\
\text { tiaux. }\end{array}$ & Chemin de mulcs... & $\begin{array}{l}\text { Pays pilus ou woins ac- } \\
\text { cidenté roconvert de } \\
\text { forèts. Quelques cul- } \\
\text { tures maraichères } \\
\text { aux environs de Chi- } \\
\text { namecta. }\end{array}$ \\
\hline 102 & 24 & Umaña........... & $\begin{array}{l}\text { Grande hacienda, occu- } \\
\text { pant nue centaine } \\
\text { d'ouvriers, tous mé- } \\
\text { tis. }\end{array}$ & $\begin{array}{l}\text { Importante culture de } \\
\text { canne à sucre. }\end{array}$ & Chemin de mules.. & 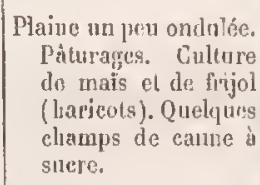 \\
\hline 120 & 18 & Hacienda de la Barca. & $\begin{array}{l}\text { Petite hacienda el quel- } \\
\text { ques rancbos, habités } \\
\text { par quelques métis. }\end{array}$ & $\begin{array}{l}\text { Bac pour le passage dn } \\
\text { Rio Lempa. }\end{array}$ & Chemin de mules... & $\begin{array}{l}\text { Pays accideute, recou- } \\
\text { vert de forêts assez } \\
\text { ćpaisses. }\end{array}$ \\
\hline 156 & 36 & SAN VICENTE.. . . & $\begin{array}{l}\text { Petite ville de } 3,000 \text { à } \\
\text { 4,ooo habitants, tous } \\
\text { métis. }\end{array}$ & $\begin{array}{l}\text { Centre important pour } \\
\text { l'exploitution du su- } \\
\text { cre, do lindigo ct du } \\
\text { tahac. Fabritue de } \\
\text { cigares. }\end{array}$ & $\begin{array}{l}\text { Chemin de mules } \\
\text { parfois très-mau- } \\
\text { vais. }\end{array}$ & $\begin{array}{l}\text { Pays très-acridente, } \\
\text { reconvert de lorèts } \\
\text { epaisses. Auprès des } \\
\text { San Vicente, trlle } \\
\text { plaine bien chltirús. }\end{array}$ \\
\hline 166 & 10 & Tepetillan... & $\begin{array}{l}\text { Petit villaģo de } 500 \text { à } \\
600 \text { habitants, tous } \\
\text { métis. }\end{array}$ & $\ldots \ldots \ldots \ldots \ldots \cdots$ & Chemin de mules... & $\begin{array}{l}\text { Plaine pen ondulcé el } \\
\text { assez bicn arrosée, } \\
\text { reconverte de cul- } \\
\text { turcs et de pâtu- } \\
\text { ragres. }\end{array}$ \\
\hline 169 & 3 & Ilacienda de Jiboa... . & $\begin{array}{l}\text { Hacienda entource d'un } \\
\text { petit village de } 200 \text { ì } \\
300 \text { labitants, lous } \\
\text { métis. }\end{array}$ & $\begin{array}{l}\text { Hacionda de canne à } \\
\text { sucre assez impor- } \\
\text { tante. }\end{array}$ & & $\cdot$ \\
\hline 186 & 17 & Convtepleque....... & $\begin{array}{l}\text { Petile ville de } 9,500 \text { à } \\
3,000 \text { habitants, tous } \\
\text { métis. }\end{array}$ & $\begin{array}{l}\text { Centre assez important } \\
\text { pourla production du } \\
\text { suere et du tabac. } \\
\text { Grande fabrique de } \\
\text { cigares de doña Ger- } \\
\text { trudis Osorio. }\end{array}$ & Cliemin de mules... & $\begin{array}{l}\text { Pays assez aceidenté, } \\
\text { mais néanmoinsbien } \\
\text { eultivé, surtont en } \\
\text { tabac et canne à } \\
\text { sucre. }\end{array}$ \\
\hline 206 & 20 & San Marlin... . & $\begin{array}{c}\text { Village de } 100 \text { à 5oo ba- } \\
\text { bitants, tous métis. }\end{array}$ & & $\begin{array}{l}\text { Chemin battu pour } \\
\text { chars a boeufs. Les } \\
\text { voitures pour- } \\
\text { raient y passer à } \\
\text { la rigueur. }\end{array}$ & $\begin{array}{l}\text { Pays assez accidenté. } \\
\text { Quelques foréts. Bel- } \\
\text { les cultures de camine } \\
\text { à sucre et de tabac. }\end{array}$ \\
\hline 228 & 22 & SAN SALVADOR. & 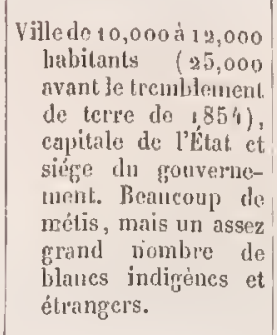 & 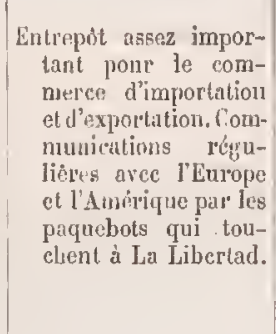 & Idem............ & 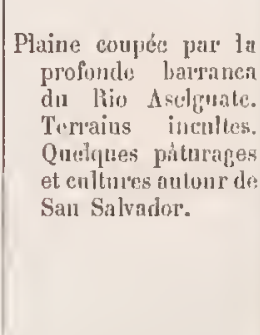 \\
\hline
\end{tabular}


DANS LES RÉPUBLIQUES DE GUATEMALA ET DE SALVADOR. 517

\begin{tabular}{|c|c|c|c|c|c|c|}
\hline DISTA & PCES & LOCALITÉS. & $\begin{array}{l}\text { CIITFRE } \\
\text { DE L p popula xios } \\
\text { et répartition } \\
\text { entre les diverses races. }\end{array}$ & 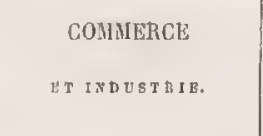 & $\begin{array}{l}\text { NATCRE } \\
\text { DES voies } \\
\text { DE Consunicutron. }\end{array}$ & $\begin{array}{l}\text { KATURE DU PAYS } \\
\text { TRAVERSE } \\
\text { PAR LE CBEMIX. }\end{array}$ \\
\hline Kilon. & $\begin{array}{c}\text { Kilon. } \\
60 \\
\text { du } \\
\text { Sall } \\
\text { Salvador. }\end{array}$ & La Libertad....... & $\begin{array}{l}400 \text { ou } 500 \text { halistants } \\
\text { mélis. Quelques In- } \\
\text { diens Yahuat] de lat } \\
\text { côte du Baune. Quel- } \\
\text { ques négoeiantsćlraus } \\
\text { ger's. }\end{array}$ & 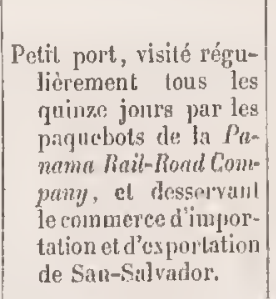 & $\begin{array}{l}\text { Route carrossable. } \\
\text { Une diligence fail } \\
\text { régulicirement le } \\
\text { service pour les } \\
\text { passages du pa- } \\
\text { quebot à vapeur. }\end{array}$ & $\begin{array}{l}\text { Pays accidenté el pres- } \\
\text { que lonijonrs couvert } \\
\text { de foréls. }\end{array}$ \\
\hline $\begin{array}{c}2 / 2 \\
\text { de } \\
\text { La Lnion. }\end{array}$ & 14 & $\begin{array}{l}\text { Santa Tecla (on Nueva } \\
\text { San Salvador). }\end{array}$ & $\begin{array}{l}500 \text { ou } 600 \text { liabitants, } \\
\text { tous métis. }\end{array}$ & $\begin{array}{l}\text { Importantes plantations } \\
\text { de eanue à surere et } \\
\text { de cafó. }\end{array}$ & $\begin{array}{l}\text { Chemin baitu pour } \\
\text { chars ti bæufs. }\end{array}$ & $\begin{array}{l}\text { Plaine bien eultivée, } \\
\text { surtont en canne à } \\
\text { sucre et en caft. }\end{array}$ \\
\hline 253 & 10 & $\begin{array}{l}\text { Hacienda del Guaru- } \\
\text { mal. }\end{array}$ & Une eontaine de métis. & $\ldots \ldots \ldots \ldots \ldots$ & $\begin{array}{c}\text { Chemin de mules, } \\
\text { inpraticable en } \\
\text { saison des pluies. }\end{array}$ & $\begin{array}{l}\text { Le clemin suit le fond } \\
\text { d'un immense ravin } \\
\text { dont les bords sont } \\
\text { eouverts rle forêts } \\
\text { épaisses. }\end{array}$ \\
\hline 267 & 15 & Rancheria d'Ateos... & Une centaine de neétis & $\begin{array}{l}\text { Quelques défriehements } \\
\text { dans } 1.1 \text { forél vierge } \\
\text { pou clère de bes- } \\
\text { tiaux. }\end{array}$ & Chemin de mules... & $\begin{array}{l}\text { Plaine converte d'une: } \\
\text { épaisse fortut tierge. }\end{array}$ \\
\hline 279 & 12 & Guaimoco.... & $\begin{array}{c}\text { Bourg de } 700 \text { à } 800 \text { bas- } \\
\text { bitants, tous métlis. }\end{array}$ & Élère de bestiaux..... & Ghemin de mules... & $\begin{array}{l}\text { Plaine inculte ou garnie } \\
\text { de quelques paitu- } \\
\text { rages. }\end{array}$ \\
\hline 303 & $2 h$ & Izalco. . . . . & $\begin{array}{l}\text { Village de } 500 \text { à } 600 \text { lıa- } \\
\text { bitants, tous métis. }\end{array}$ & & Chenin de mules.. . & $\begin{array}{l}\text { Plaine eouverte d'è- } \\
\text { prisses foréts vierges. }\end{array}$ \\
\hline \multirow[t]{2}{*}{311} & 8 & Soxsovite........ & 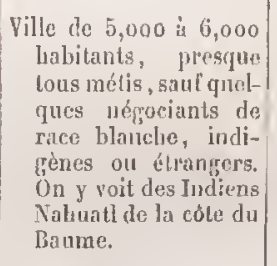 & 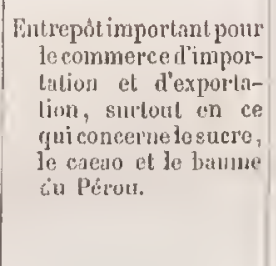 & Chemin dis mules... & 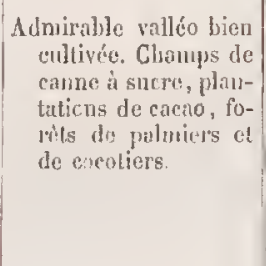 \\
\hline & $\begin{array}{c}2 / 1 \\
\text { de } \\
\text { Sonsonate. }\end{array}$ & Acajutla. & $\begin{array}{l}\text { Amas de hulles où vivent } \\
250 \text { ou zoo mútis. Les } \\
\text { négociants de Sonso- } \\
\text { nate y ont des bu- } \\
\text { reaux, mais n'y vien- } \\
\text { nent qu'oux passages } \\
\text { des paquebols. }\end{array}$ & 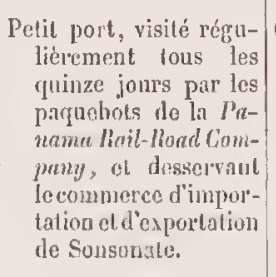 & $\begin{array}{l}\text { Chemin baltu pour } \\
\text { ebars it boufs. Les } \\
\text { voilures peuventy } \\
\text { eirculer it la ri- } \\
\text { gueur. }\end{array}$ & $\begin{array}{l}\text { Plaine doncenent in- } \\
\text { clinée. Le chemin } \\
\text { traverse tantùt dles } \\
\text { forèts plus ou moins } \\
\text { epaisses, tantòt des } \\
\text { plantations de canne } \\
\text { il sucre et de creao. }\end{array}$ \\
\hline $\begin{array}{c}319 \\
\text { de } \\
\text { La Ĺnion. }\end{array}$ & 8 & Nahuizalco.... & $\begin{array}{l}\text { Village de } 100 \text { à } 500 \\
\text { âmes, babité par des } \\
\text { Indieus Nahuatl. }\end{array}$ & $\begin{array}{l}\text { Les Indiens eultivent un } \\
\text { peu de maïs et de } \\
\text { frijol pour lantu eon- } \\
\text { sommation person- } \\
\text { nolle. }\end{array}$ & Chemi:. de mutes.. & $\begin{array}{l}\text { Pays peu ondulé. Quel- } \\
\text { 'Tues cultures de } \\
\text { caune ì sucre ct fo- } \\
\text { rèts plins ou moins } \\
\text { cpaisses. }\end{array}$ \\
\hline 329 & 10 & Sacoatillan. . & $\begin{array}{l}\text { Village d'environ } 500 \\
\text { liabitants, métis et } \\
\text { Indiens mélangés. }\end{array}$ & Iden. . & Chemin rle mules... & $\begin{array}{l}\text { Paystrès-aceidente, iu- } \\
\text { cutte ou courert de } \\
\text { forèls. }\end{array}$ \\
\hline 339 & 10 & Apaneca. & Idem. . . & Idem. . . & Idom. ... & Ilem. \\
\hline
\end{tabular}




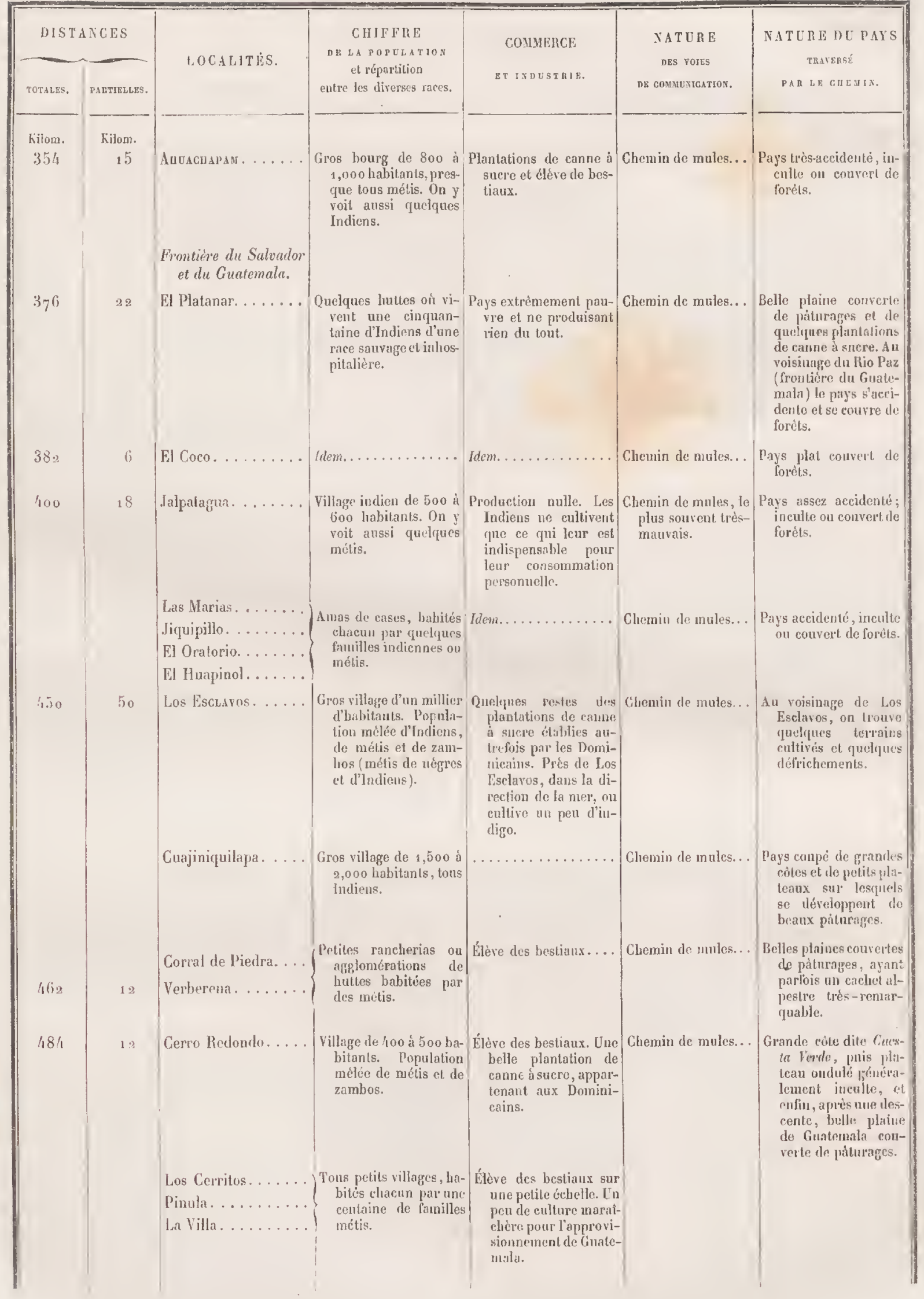


DANS LES RÉPUBLIQUES DE GUATEMALA ET DE SALADOR. 519

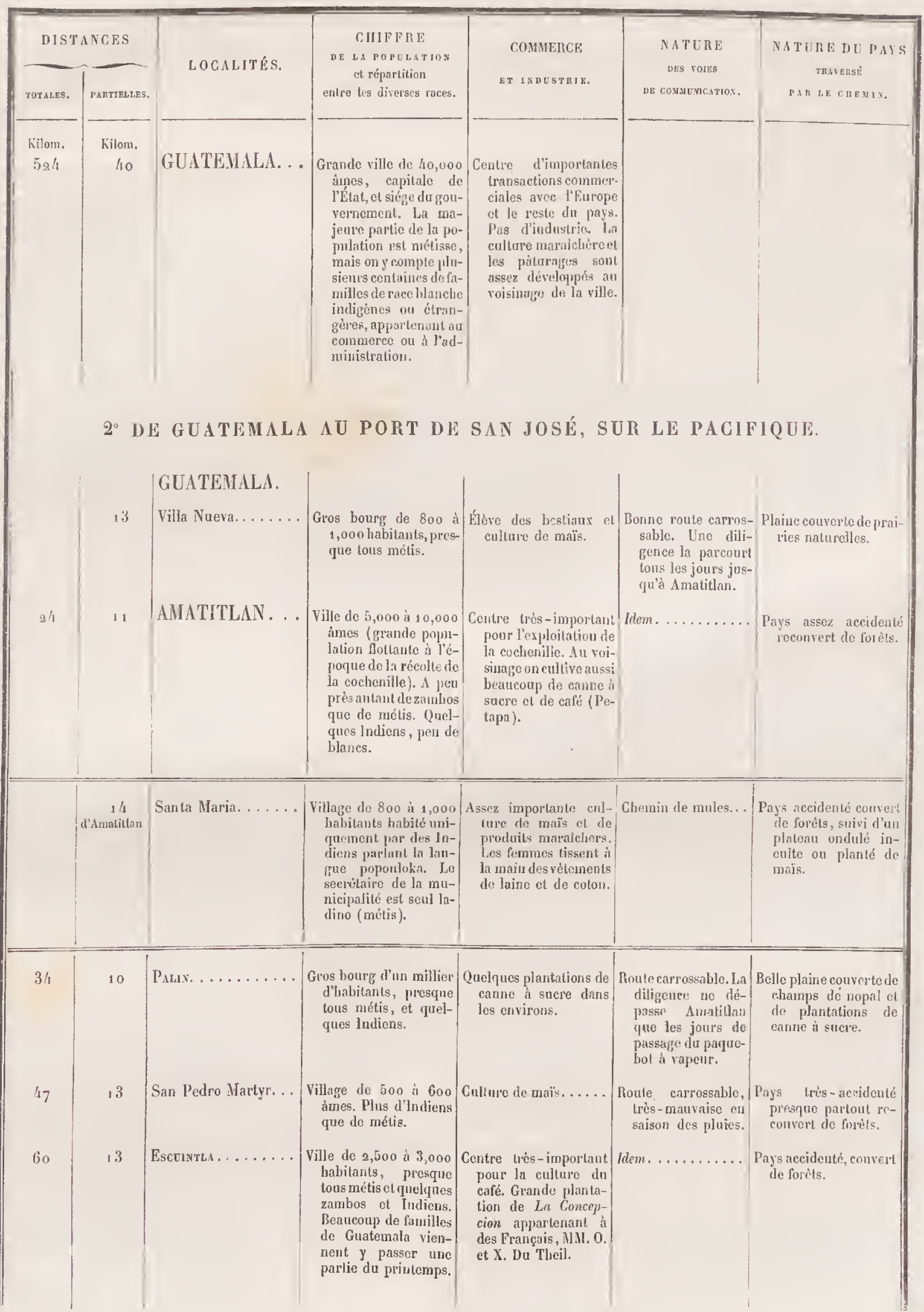




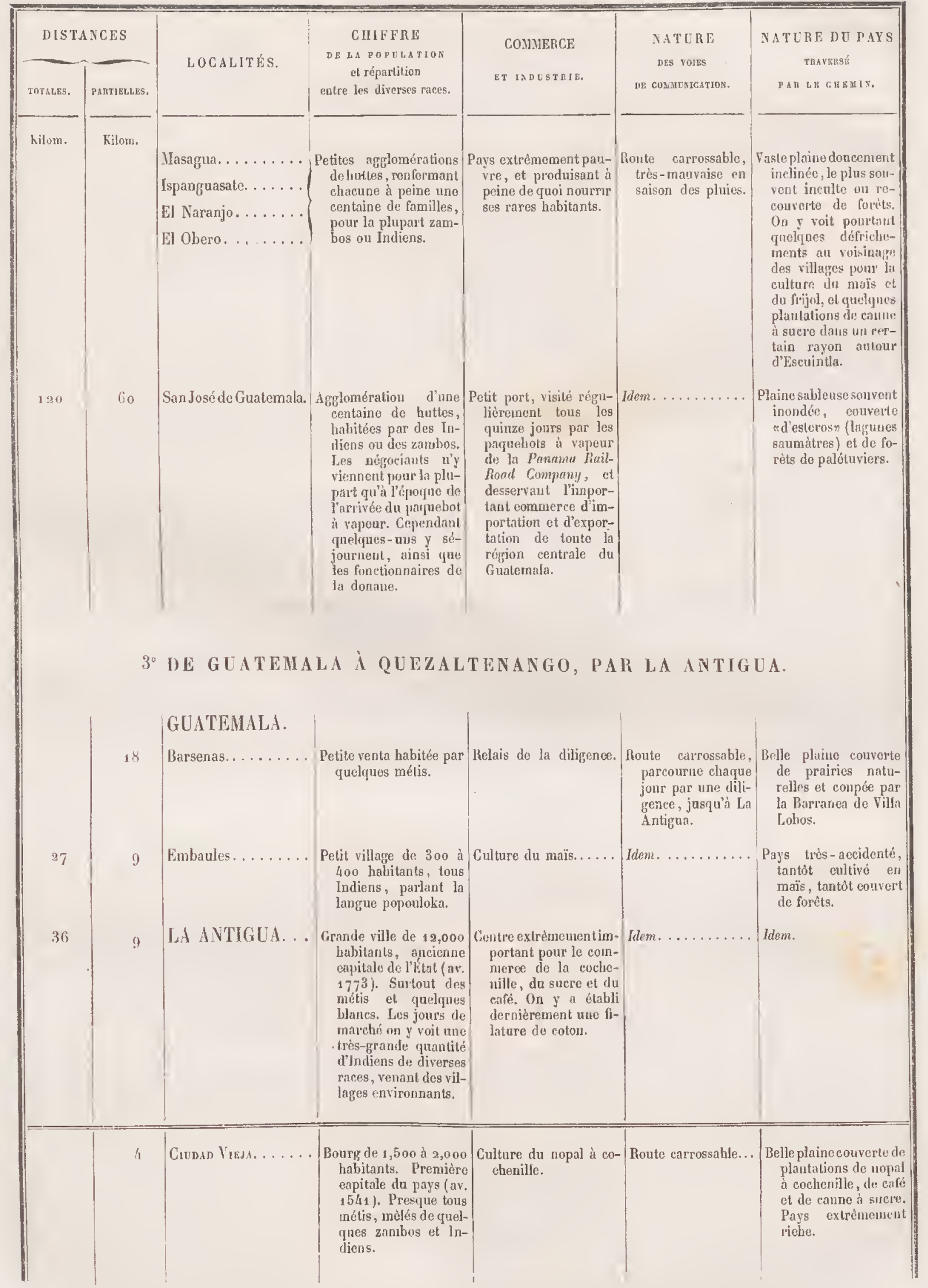


DANS LES RÉPUBLIQUES DE GUATEMILA ET DE SALVADOR. 521

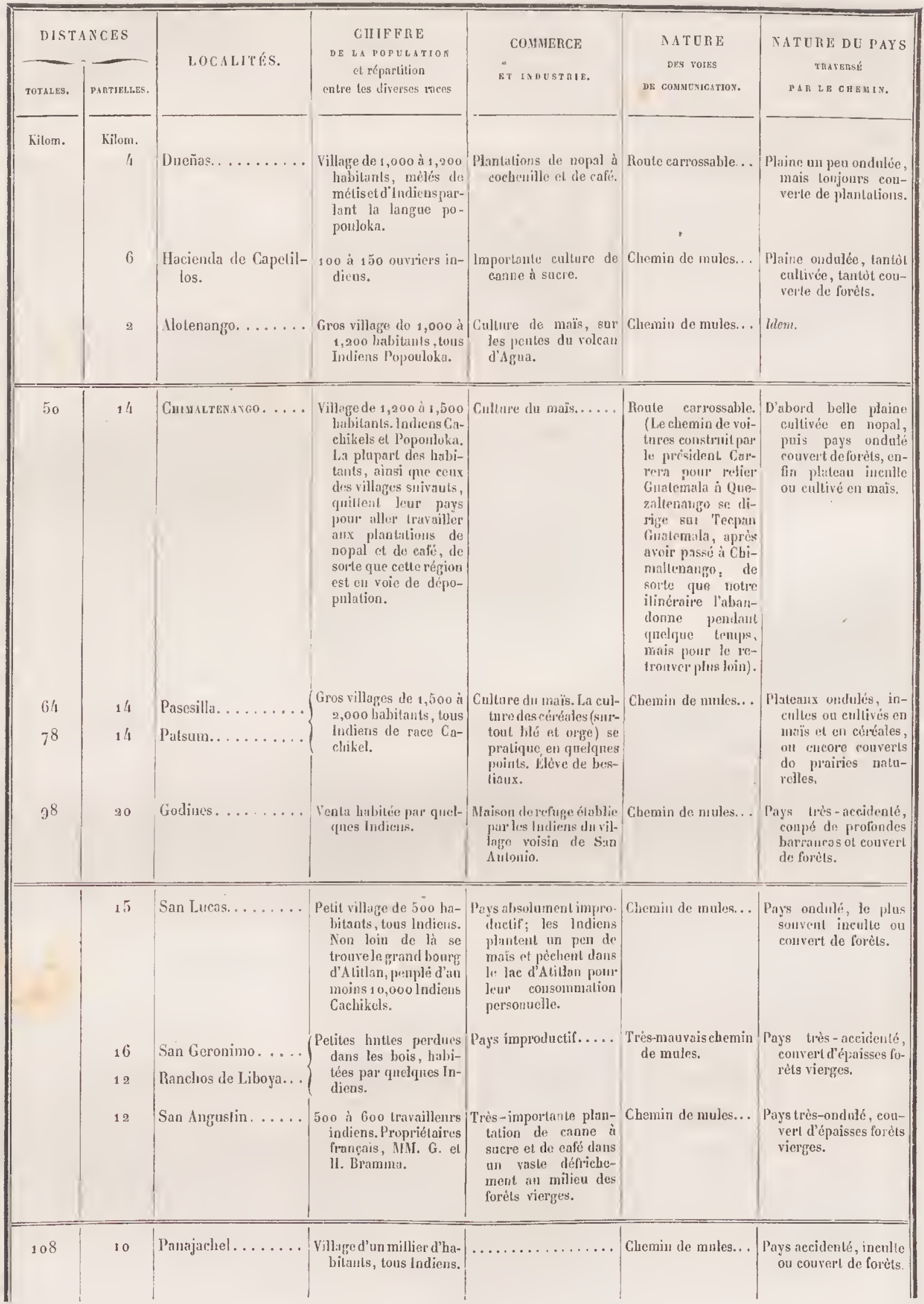

Voyage géologique. 


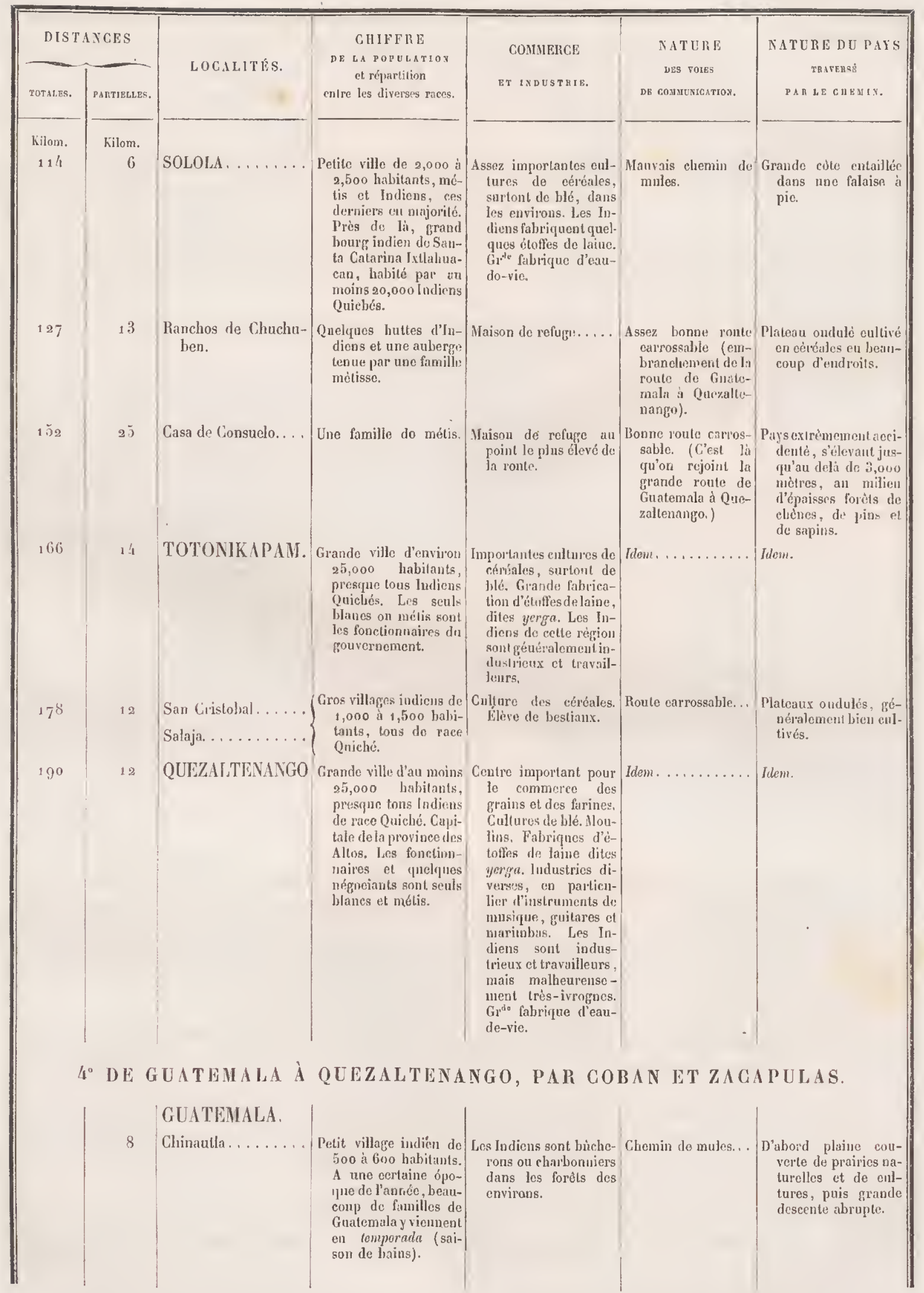


DANS LES RÉPUBLIQUES DE GUATEMALA ET DE SALVADOR.

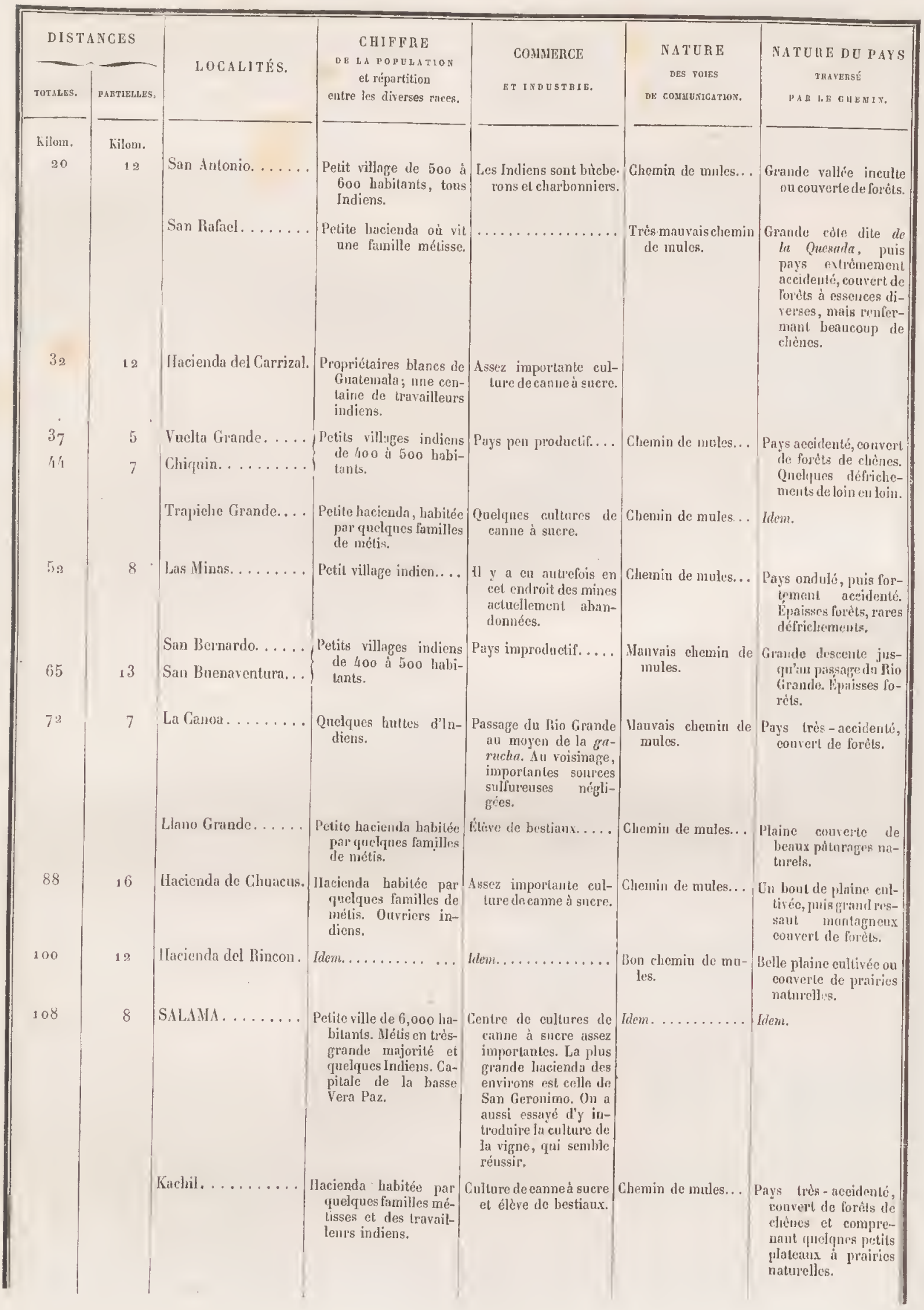

66. 


\begin{tabular}{|c|c|c|c|c|c|c|}
\hline \multicolumn{2}{|c|}{ DISTANCES } & \multirow{2}{*}{ I.OCALITÉS. } & \multirow{2}{*}{$\begin{array}{l}\text { CHIFFRE } \\
\text { DE LA PODLATIOX } \\
\text { et réparlition } \\
\text { cutre les diverses races. }\end{array}$} & \multirow{2}{*}{$\begin{array}{l}\text { COMNERCE } \\
\text { ET IXDESTHE. }\end{array}$} & \multirow{2}{*}{ 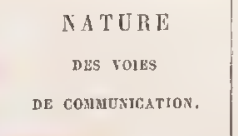 } & \multirow{2}{*}{$\begin{array}{l}\text { NATURE DU PAY } 8 \\
\text { TRAYFISE } \\
\text { PAR LE CAEMAS. }\end{array}$} \\
\hline Totsezs. & PAntrLLLES. & & & & & \\
\hline Kilom. & Kilom. & & & & & \\
\hline 136 & 28 & $\begin{array}{l}\text { Sanlo Thomas. . . . } \\
\text { Sanla Rosa. . . . . . }\end{array}$ & $\begin{array}{l}\text { Petit village indien. } \\
\text { Villace de } 200 \text { a } 300 \\
\text { anes, hahité surtont } \\
\text { pal des Indiens et } \\
\text { quelques familles do } \\
\text { métis. }\end{array}$ & Élève de besliaux...... & Chemin de mules.. & $\begin{array}{c}\text { Après mu petit ressaul } \\
\text { montagneux, on pé- } \\
\text { nètre dans une belle } \\
\text { vallée converte de } \\
\text { prairies naturedlus } \\
\text { on de ford̀ts vierges. }\end{array}$ \\
\hline 160 & $2 h$ & Tactic........... & $\begin{array}{l}\text { Gros villagge de 1,000 a } \\
1,200 \text { habitants. La } \\
\text { popnlation est uni- } \\
\text { quenent fornée par } \\
\text { des Indions parlan! } \\
\text { la langue polomeli. }\end{array}$ & $\begin{array}{l}\text { Les Indiens élèventquel- } \\
\text { ques bestiaux et sur- } \\
\text { tout des auimaux de } \\
\text { race poscine. }\end{array}$ & $\begin{array}{l}\text { Bon chemin de min- } \\
\text { les. }\end{array}$ & $\begin{array}{l}\text { Pays assez fortement } \\
\text { ondulé, couvert de } \\
\text { belles forêts, défri- } \\
\text { chécs au voisinage } \\
\text { des lieux habités. }\end{array}$ \\
\hline 176 & 16 & Santa Cruz.... & $\begin{array}{l}\text { Villagre de 5oo à } 600 \\
\text { âmes habité par des } \\
\text { Intiens de race } \\
\text { quekehi. }\end{array}$ & $\cdots$ & Idem. . & Jem. \\
\hline \multirow[t]{2}{*}{192} & 16 & COBAN. ... & $\begin{array}{l}\text { firos bourg de } 10,000 \\
\text { a } 12,000 \text { habitanls, } \\
\text { presque tous lndieus } \\
\text { do rece Quckchi. } \\
\text { On y comple cepen- } \\
\text { dant environ } 1,500 \\
\text { hlancs ou métis, plan- } \\
\text { tenrs ou fonction- } \\
\text { naires. }\end{array}$ & 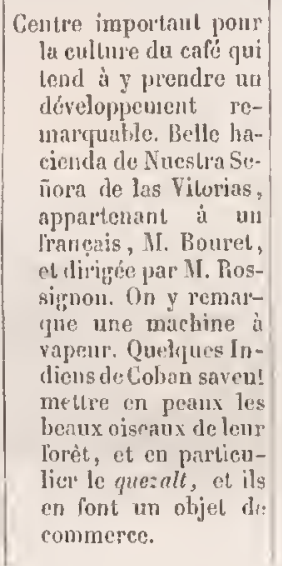 & & \\
\hline & $\begin{array}{c}15 \\
\text { de } \\
\text { Coban. }\end{array}$ & San Pedro Carcha... & $\mid \begin{array}{l}\text { Gentre d'une population } \\
\text { indienne de race } \\
\text { Quekcli, comptant } \\
\text { plus de } 40,000 \text { indi- } \\
\text { vidus disséminises aux } \\
\text { environs dans les lo- } \\
\text { redts ol les détriche- } \\
\text { ments. }\end{array}$ & $\begin{array}{l}\text { La municipalité in- } \\
\text { dienne a planté nn } \\
\text { peu de café. Presque } \\
\text { tous les habitants ne } \\
\text { virent que d'un pen } \\
\text { do mais, de leur } \\
\text { elasse nu do l'blive } \\
\text { des pores. }\end{array}$ & Chemin de mules... & $\begin{array}{l}\text { Pays peu ondulé, très- } \\
\text { boisé et pe's défriché. }\end{array}$ \\
\hline 220 & 28 & |Say Cristobal..... . & \begin{tabular}{|} 
Village de foo à 800 ha- \\
bitants, prespue tous \\
Indiens de langue \\
pokomeli. Quelques \\
métis et un enurent \\
de Dominicains.
\end{tabular} & 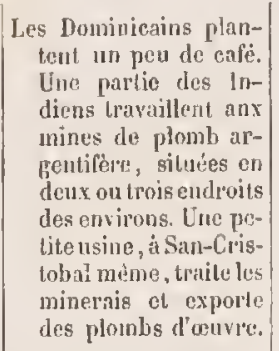 & Chewin de mules... & $\begin{array}{l}\text { Pays assez ondulé et le } \\
\text { plus souvent très- } \\
\text { boisó. Quutquns dé- } \\
\text { frichements ul quel- } \\
\text { ques prairies ualı- } \\
\text { relles. }\end{array}$ \\
\hline 253 & 32 & $\begin{array}{l}\text { Hacienda de Los Pa- } \\
\text { dres. }\end{array}$ & $\begin{array}{l}\text { Quelques fanilles dos } \\
\text { métis et nne centaine } \\
\text { de travaillen's in- } \\
\text { diens. }\end{array}$ & $\begin{array}{l}\text { Ilacienda de caune à } \\
\text { suere asses impor- } \\
\text { lanteappartenanlanx } \\
\text { Dominieains. }\end{array}$ & 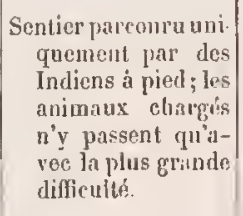 & $\begin{array}{l}\text { Pays extrèmement ac- } \\
\text { cidenté et recouvert } \\
\text { d'épaisses forèts. } \\
\text { Quelques défriche- } \\
\text { ments de loin en } \\
\text { loin. }\end{array}$ \\
\hline
\end{tabular}


DANS LES RÉPUBLIQUES DE GUATEMALA ET DE SALVADOR. 525

\begin{tabular}{|c|c|c|c|c|c|c|}
\hline$\overbrace{\text { TOTALES. }}^{\text {DIST }}$ & NGES & LOGALITES. & $\begin{array}{c}\text { CIIFFRE } \\
\text { D L L POPUn PTION } \\
\text { et répurtition } \\
\text { entre les diverses races. }\end{array}$ & $\begin{array}{l}\text { Connerce } \\
\text { E T Youstare. }\end{array}$ & $\begin{array}{l}\text { XatURE } \\
\text { des voles } \\
\text { De conmuneation. }\end{array}$ & $\begin{array}{l}\text { XATURE DE PAYS } \\
\text { TRASERE } \\
\text { PAT UE CHRSIX. }\end{array}$ \\
\hline $\begin{array}{l}\text { Kilom. } \\
268\end{array}$ & $\begin{array}{c}\text { litom. } \\
16\end{array}$ & Rancho du Rio Chisoy. & Une famille indienne. & 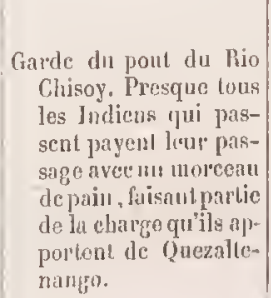 & 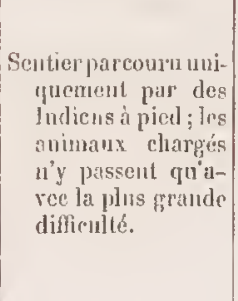 & $\begin{array}{l}\text { Pays très-aceidenté et } \\
\text { hoisé, puis immerise } \\
\text { vallée du Rio Chisoy. }\end{array}$ \\
\hline 295 & 25 & Ranclio de La Cruz.. & $\begin{array}{l}\text { Deux ou trois familles } \\
\text { indiennes. }\end{array}$ & Élève de bestiaux. .... & $\begin{array}{l}\text { Scntier parenuru par } \\
\text { des ludiens à pied; } \\
\text { les bètes chargécs } \\
\text { y passent avec dif- } \\
\text { ficulté. }\end{array}$ & $\begin{array}{l}\text { Pays extrèmement ac- } \\
\text { cidentés ot presque } \\
\text { toujums recouvert } \\
\text { de lorèts de chènes } \\
\text { et do pins. Sur les } \\
\text { lauts plateanx, qucl- } \\
\text { ques prairies notu- } \\
\text { relles. }\end{array}$ \\
\hline 301 & 8 & Chicaman. . & $\begin{array}{l}\text { Unıe centaine d'Indiens } \\
\text { de race Quichté. }\end{array}$ & $\begin{array}{l}\text { Élève de hestiaux, sur- } \\
\text { tonl de pores. }\end{array}$ & Idem. . . . . . . & Idem. \\
\hline 317 & 16 & San Vigrtrel Uspantan. & $\begin{array}{l}\text { Village de } 1,000 \text { à } 1,200 \\
\text { habbilats, tous Jil- } \\
\text { dicns de race Quiché. }\end{array}$ & $\begin{array}{l}\text { Pays ju+1 productif. } \\
\text { Quelques cultures de } \\
\text { mais. }\end{array}$ & Assez bon sentie r... & $\begin{array}{l}\text { Pays fortement ondulé } \\
\text { et très-boisé. }\end{array}$ \\
\hline 345 & 28 & Guuen.......... & $\begin{array}{l}\text { Village de } 800 \text { is } 1,000 \\
\text { labluitiuls, tons lul- } \\
\text { diens de race Quiché. }\end{array}$ & $\begin{array}{l}\text { Palys pen productif. } \\
\text { Quclthes eultures de } \\
\text { mais. }\end{array}$ & $\begin{array}{l}\text { Sentier sonvent mau- } \\
\text { vais. }\end{array}$ & $\begin{array}{l}\text { Puys accidenté et très- } \\
\text { boisó. Forèts de } \\
\text { chèncs et de pins. } \\
\text { Plaine auprès de Cu- } \\
\text { uen. }\end{array}$ \\
\hline \multirow[t]{2}{*}{361} & 16 & 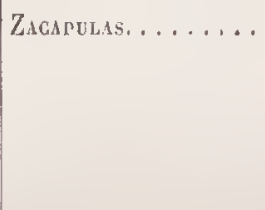 & $\begin{array}{l}\text { Pelite ville de } 3,500 \text { ha- } \\
\text { bitants, presique tous } \\
\text { Iudions de race Qui- } \\
\text { ché. Quelques métis. }\end{array}$ & $\begin{array}{l}\text { Pays pen productif. Ex- } \\
\text { ploitation pour sel } \\
\text { hrut de quelques } \\
\text { sourers salines des } \\
\text { environs. }\end{array}$ & $\begin{array}{l}\text { Senlier assez preti- } \\
\text { cablc. }\end{array}$ & $\begin{array}{l}\text { Après uuressaut mon- } \\
\text { tagneux, immense } \\
\text { descente couduisant } \\
\text { au fond de la rallée } \\
\text { lun lio Chisoy. Grant- } \\
\text { des forèts de cliènes } \\
\text { et de pins. }\end{array}$ \\
\hline & & San Pedıo Jocopila.. . & $\begin{array}{l}\text { Villige de } 600 \text { a } 7^{\text {oo lia- }} \\
\text { hitants, tous Indiens } \\
\text { Quichés. }\end{array}$ & $\ldots$ & $\begin{array}{l}\text { Seutier'soureut mau- } \\
\text { vais, puis chemin } \\
\text { de mules. }\end{array}$ & $\begin{array}{l}\text { P'iys très-accidenté, } \\
\text { juins primit plisteau } \\
\text { ondulé, le plins sou- } \\
\text { vent inculte ou con- } \\
\text { verl de forèls do } \\
\text { cluénes. }\end{array}$ \\
\hline $\log$ & 48 & Santa Cruz del Quiche. & $\begin{array}{l}\text { Gros bourg de } 4,500 \text { ha- } \\
\text { bitants, dont } 2 / 3 \text { mé- } \\
\text { tis et } 1 / 3 \text { Indiens } \\
\text { Quichés. Aneienne } \\
\text { rapitale du grand } \\
\text { loyaume indien de } \\
\text { Quiclé. }\end{array}$ & $\begin{array}{l}\text { Pays prcsune improduc- } \\
\text { tif. Qnelipues cultures } \\
\text { de maìs et un peu } \\
\text { d'téve de bestiaux. }\end{array}$ & Chemin de inules.. & $\begin{array}{l}\text { Bolle plaine eninverle de } \\
\text { prairies naturelles. }\end{array}$ \\
\hline 421 & 12 & Patsile.......... & $\begin{array}{l}\text { Petit village indien de } \\
400 \text { à 5oo babitants } \\
\text { de race Quiché. }\end{array}$ & $\ldots \ldots \ldots \ldots \ldots$ & $\begin{array}{l}\text { Chomin de nunles, } \\
\text { souvent très-1nats- } \\
\text { vais. }\end{array}$ & $\begin{array}{l}\text { Pays extrèmenent ac- } \\
\text { cidenté, très-mon- } \\
\text { tagneux, consert } \\
\text { d'épaisses forèts de } \\
\text { pins. }\end{array}$ \\
\hline 457 & 36 & TOTONIKAPAU. & $\begin{array}{l}\text { Grande ville indicnne } \\
\text { de } 25,000 \text { labitants, } \\
\text { presque tous de race } \\
\text { Quiché. }\end{array}$ & $\begin{array}{l}\text { Commerce de réréalcs } \\
\text { et fabriques d'étofes } \\
\text { de laine. }\end{array}$ & $\begin{array}{l}\text { Bonné route carros- } \\
\text { sable. }\end{array}$ & $\begin{array}{l}\text { Platenu ondulé le plus } \\
\text { souvent enltivé en } \\
\text { céréalcs. }\end{array}$ \\
\hline 481 & 24 & QUEZALTENANGO & (Voir plus haut.) & & & \\
\hline
\end{tabular}





\section{BIBLIOGRAPHIE.}

CARTES.

J. Banx. - Mup of Central America, including the States of Guatemala, Salvador, Hondurus, Nicaragun and Coste-Rice, ete. publ. by Trelawney Saunders, London, november, 1850.

IV. R. Palank - Map of Centrol Ameriea, compiled from materials furnished by the Comittee of foreign relations of the Senate of the U. S. etc. Washington, mareh, 1856.

H. Кiepert. - Neue Karte vom Millel-America, Berlin, 1858.

Max. von Sonnexstenn. - Mapa de las Republicas del Centro de Ameriea, Londres, is6o.

L. G. SQunens. - Carte de l'État de Salvador el d'une partie de celui de Houduras, ele. iltaclié ì son ouvrage ou dans le Bulletin de la Société de Géograplie, 1855.

Max. von Sonnenstenn. - Mapa general de le Republiea de Guatemala, elc. New-York, 1859 .

Max. vox Somvenstenn. - Mape general de la Republica de Salvador, etc. New-York. 1859.

\section{LIVRES.}

Thous Gage. - A new survey of the West Indies, etc. Journey from Mexico, through the provinces of Oaxaca, Chiapa, Guatemala, Vera Paz, Truxillo, etc. etc. London, 1655.

10" Domingo Juarros. - Compendio de la Historia de la Ciudad de Guatemala, 3 vol. Guatemala, 1818.

G. W. Молтсомеnr. -- Narrative of a journey to Gualemala in Central Ameriea in 1838, New-York, $183 \mathrm{~g}$.

R. GL. Duncop. - Travels in Central Ameriea, being a journal of nearly three years residenee in the country, London, 1847 .

A. Penter. - Note sur les tremblements de terre dans le Mexique el l'Amérique contrale. (Annales de la Société d'émulation des Vosges, t. VI, 1847.)

L. G. Seuiens. - Nicaragua, its people, scenery, monuments, ele. 1 vol. New-York, 1853.

E. G. Socrans. - Notes on Central America, partieularly the States of Honduras and San Salvador, will original maps and illustrations, 1 vol. London and New-York, 1856. 
k. G. Soutens. - The States of Central America, thir geography, toposraphy, climate, population, rte. 1 vol. London, 1858.

Arthur Monelet. - Voyage dans l’Amérique centrule, lâle de Cuba et le Yucatan, 2 vol. Paris, 185 7.

Widuan W. Wruls. - Explorations and Adventures in Honduras, etc. 1 vol. New-York, 1857.

J. L. Stepliens. - Incidents of travels in Central America, Chiapas and Yucatan, 2 vol. New-York, 1858. Consetтe. - Relution d’un voyage de Mcxico à Guntemala, Paris, 1858.

Brasseur de Bocrbourg. - Apergu d’un voyage dems les Éfuts de San Salvador et de Guatemalt. (Bullet.

Société de Géographie, $1857,4^{\circ}$ série, I. XIII.)

Brasseur de Bourbourg. - Histoire des nutions civilisées du Mexique et de l'Amérique centrale durrnt les siècles antérieurs à Christople Colomb, Panis, $1857^{-185} \mathrm{~g}$.

Lizanziburo. - Los temblores sentidos cn Guntemala, en deciombre de 1862, y Enero de 1863 , brochure, Guatemala, 1863.

Dr J. E. Wappaüs. - Geograplie und Stntistili von Mexico und Central America. 1 vol. Leipzig, 1863.

FúLIx Beluy. - A travers lAmérique centrule. Le Nicaragua el le canal interocéanique. 2 vol. Paris, 1857 .

Gaceta de Guatenala. - Jourmal officicl de Guatemala, conteuant en parliculier les feuilles d'observations méléorologiques, publićes mensuellement par le Collegro Tridentino, sous la direction de M. Lizarzaburu.

Ia SEMana. - Journal hebdomadaire de Guatemala, renfermant souvent des articles fort intéressanls des membres de la Sociedud Economica.

Eu Fano oel Salvador. Joumal officid de l'État de Salvador, paraissant à Sau Salvador.

Divers articles dans la Revue des Deux-Mondes ou le Bulletiu de la Société de Géographic de Paris.

Mous renvoyons, en outre, le lecteur it l'onvrage de M. Wappaüs, Geographic und Statistiti zon Mexico und Central America, dont l'article bibliographique contient une longue liste de livres peu conuus, d'une importance secondaire, ou ne traitant que de questions étrangères aux sujets qui nous occupent dans ce travail. 


\section{EXPLICATION DES PLANCHES.}

\section{PLANCHE 1 .}

Réduction au tiers de la grande carte de la planche $\mathrm{V}$, destinée uniquement à faire saisir la position respective des lignes de partage des eaux, principale et secondaires, ainsi que la répartition des rivières dans les bassins de l'océan Pacifique, du golfe du Mexique el de la baie de Honduras. La ligne de partage des eaux principale est en rouge; la ligne secondaire qui sépare les bassins de la baie de Honduras et du golfe du Mexique est en jaune; la même couleur est attribuée à l'axe anticlinal du Salvador, qui isole d'une manière remarquable le vaste bassin intérieur du Rio Lempa. Les lignes de partage tertiaires sont en noir.

Échelle de $6{ }_{2}$ millimètres au degré.

Une ligne rouge indique la direction de nos itinéraires. Quelques excursions, entre autres un petit voyage au volcan d'Atitlan et au versant du Pacifique, en partant du lac d'Atitlan, ont été omises par le dessinateur.

\section{PLANGHE H.}

Courbes graphiques représentant les oscillations journalières du thermomètre et du baromètre à Guatemala, pour des périodes de dix jours prises à divers moments de l'aunée (1-10 janvier, milieu de la saison sèche; 20-3o mai, commencement de la saison des pluies; 20-3o août, milieu de la saison des pluies; 1-10 octobre, commencement de la saison sèche).

La figure 1 se rapporte au thermomètre, la figure 2 au baromètre.

\section{PLANGHE III.}

Courbes graphiques représentant les oscillations annuelles de la température et de la hauVoyağe géologique. 
teur barométrique à Guatemala, par moyennes mensuelles, pour cinq années consécutives, de 1859 à 1863 .

La figure 1 se rapporte au thermomètre, la figure 2 au baromètre.

\section{PLANCHE IV.}

Courbes grraphiques représentant les rapports des chutes de pluic mensuelles à Gialemala, pendant cinq années consécutives, de 1859 à 1863 .

\section{PLANGHE V.}

Esquisse d'une carte topographique el géologique d'une partie des républirques de SalvaIor el de Guatemala. Cétte carte est à l'échelle de $\frac{1}{761000}$, soit 145 millimètres par degré, ou 129 millimètres par 100 kilomètres. Nous avons été forcément conduits à une échclle un peu bizarre par les exigences de la réduction, pour faire entrer cette carte dans le format gónéral de l'ouvrage. Cette carte embrasse la presque totalité du Salvador, le Guatemala jusqu'au delà de Quezaltenamgo dans l'ouest, et jusqu'au delà de Cajabon dans le nord, enfin quelques parties, malheureusenent peu connues, du Honduras.

En ce qui concerne la partie topographique, uous nous sommes aidés des cartes déjà exislautes, les carles du Guatemala et du Salvador, de M. Max. Sonnenstern (New-York, 1859), la carte de l'Amérique centrale de Baily (Londres, 1850), les cartes disséminées dans le livre de M. Squicrs (The States of Central America, etc.); des travaux de M. Van den Grehiihte; des recherches inédites du révérend Père Cornette, etc., et nous avons cherché à rectilier autant que possible les points qui nous paraissaient incertains ou douteux en relevant à la boussole toutes̊ les parties saillantes de nos itinéraires, les directions des cours d'eau ct des chaînes de montagnes, etc.

Au point de vue géologique, nous avons reporté sur la carte, en les représentant par des teintes plates, toutes les observations que nous avions faites directement sur le terrain pendant nos voyages, ainsi que les renseignements parfaitement certains que nous avons pu recueillir de personnes dignes de foi. Quelques autres renscignements qui ne nous paraissaient pas mériter une confiance aussi absolue, ont été reportés aussi sur la carte, mais avec la précaution de les indiquer par des teintes beaucoup moins vigoureuses que les précédentes.

\section{PLANCHE VI.}

Diagrammes géologiques représentant, l'un (fig. 1), une coupe transversale du Guatemala de Coban (Vera Paz) à Quezaltenango (Altos), et de Solola (Altos) à l'océan Paci- 
fique, suivant une direction moyenne du N. E. au S. O.; l'autre (fig. 2) une coupe transversale du Guatemala, de San Jose (océan Pacifique) à Coban (Vera Paz), suivant une direction moyenne du sud an nord.

Dans ces deux coupes, les hauteurs sont exagérées et deviennent vingt fois plus fortes que les distances, de telle sorle que, l'échelle des distances étant de 1 millimètre et $\frac{1}{3}$ par kilomètre, l'échetle des hanteurs devient de 2 millimètres et $\frac{2}{3}$ pour 100 mètres. Une semblable exagération était nécessaire pour bien faire sentir les mouvements du relief du sol.

Les couleurs employées pour indiquer les terrains divers sont les mêmes que celles de la carte géologique, de sorte que les coupes peuvent se ramener aisément aux itinéraires.

Il est évident que, la superficie du sol nous étant seule conmue, il ne faut attacher qu'une importance tout à fait secondaire aux prolongations hypothétiques des diverses couches dans la profondeur de l'écorce terrestre.

La position des principaux volcans sur le versant du Pacifique est indiquée par de petites esquisses de leur's sommets, dont les hauteurs sont aussi portées au vingtuple de leurs dimensions réelles.

Ces coupes se rapportent aux itịnéraires dont les descriptions détaillées commencent aux pages $19^{6}$ (Voyage de San Joséau Rio Grande), 209 (Voyage dans la Vera Paz), et 221 (Voyage dans la province des Allos).

\section{PLANGHE VII.}

Figcre 1. - Diagramme góologique représentant une coupe longitudinale du Salvador et dı Guatemala, de La Union à Quezaltenango, suivant la direction de l'axe anticlinal secondaire du Salvador et de la chaine montagneuse principale du Guatemala.

Les hauteurs sont exagérées el deviennent vingt fois plus fortes que les distances, de telle facon que l'échelle des distances étant de $0^{\mathrm{mm}}, 75$ par kilomètre, l'échelle des hauteurs devient de $1^{\mathrm{mm}}, 50$ pour 100 mètres. Cette exagération était nécessaire pour faire sentir les mouvements du relief du sol.

Les couleurs employées pour indiquer les divers terrains sont les mêmes que celles de li: carle góologique.

Cette coupe se rapporte à l'Itinéraire de La Union à Guatemala en entier (page 180), et ell partie au Voyage dans la province des Altos (page 221).

Figune 2. - Vue pittoresque de la côte du Guatemala prise en rade du petit port de San José, à une distance de 4 kilomètres au large de la terre. Cette vue embrasse la còte dı Guatemala, depuis le volcan de Pacaya jusqu'an volcan de Tacana, sur une longueur de 
200 kilomètres. Les distances respectives étant modifiées par la perspective, il n’y a pas lieu de donner leur échelle.

Les hauleurs des volcans sont exagérées d'un tiers (c'est-à-dire dans la proportion de $1 \frac{1}{2}$ à 1), de telle sorte que, les pentes figurées étant en moyenne de 45 degrés, les peutes réelles oscillent entre 30 et 35 degrés.

La même exagération, rendue moins apparente par l'effet de la perspective, existe pour la grande chaine de montagnes de l'intérieur qui se profile en arrière des volcans.

\section{PLANGHE VIII.}

Figure 1. - Vue pittoresque du volcan de Conseguina, prise de la mer, du còté du N. E., à environ 10 kilomètres de la côte, au sortir de la baie de Fonseca.

Figure 2. - Vue pittoresque du volcan de San Miguel, prise des environs de la ville de San Miguel, dans la direction du N. E. La hauteur du volcan est exagérée d'un tiers environ, de sorte que les pentes figurées étant de 50 degrés en moyenne, les pentes réelles ne dépassent pas 30 degrés à la base, et 33 degrés ver's le sommet de la montagne.

\section{PLANGHE IX.}

Coupe et plan du cratère du volcan de San Miguel. Dans la coupe, les pentes extérieures sont senles exaģérées, les hauteurs de l'intérieur du cratère étant maintenues en proportion exacte avec les distances.

L'échelle du plan et de la coupe est de 9 millimètres par 100 mètres.

Dans le plan, les croix rouges indiquent les points où se manifestent les dégagements de. gaz les plus importants. La teinte jaune indique les endroits recouverts de croûtes de soufre et d'alun.

\section{PLANGHE X.}

Figure 1. - Vue pittoresque du volcan d'Izalco, prise à quelque distance de la base du cône, dans la direction du Nord. La hauteur du volcan est exagérée d'un tiers, de sorte que, les pentes figurées étant de 55 degrés, les pentes réelles sont de 37 degrés à la base de la montagne, et de 40 à 41 degrrés vers le sommet.

Figure 2. - Plan du cratère du volcan d'Izalco, à l'échelle de 80 millimètres pour 100 mètres. 
Les croix rouges indiquent les points où se manifestent les dégagentents de gaz les phrs importants, et la teinte jaune les endroits reconverts de cron̂tess d’alun el de soufre.

\section{PLANGHE XI.}

Figune 1. - Vue pittoresque des Ausoles on volcans de boue d'Ahuachapam, prise du còté du Sud.

Figure 2. - Plan des Ausoles ou volcans de boue d'Ahuachapan, à l'échelle de 6 millimètres par mètre.

\section{PLANCHE XII.}

Plan du groupe central du volcan de Pacaya, à l'échelle de 15 millimètres pour 100 mètres.

\section{PLANCHE XIII.}

Figune 1. - Plan dı système d'ensemble du volcan de Pacaya, à l'échelle de 10 initlimètres par kilomètre.

Figure 2. - Plan et coupe du cratère du volcan d'Agua, à l'échelle de 50 nillimètres par 100 mètres. Dans la coupe, les pentes sont légèrement exagérées.

Figure 3. - Plan du système d'ensemble des volcans de Fuego et d'Acatenango, à l'échelle de 10 millimètres par kilomètre.

\section{PLANGHE XIV.}

Vues pittoresques des volcans d'Agua, de Fuego et d'Acatenango, prises, l'une (fig. 1), du sommet du volcan Pacaya, l'autre (fiğ. 2), du fond de la vallée de La Antigua, un peu au-dessus de cette ville. Les hauteurs sont exagérées d'un tiers environ, de sorte que cette exagération se reporte sur les pentes qui ne sont en réalité que de 30 à 36 degrés pour le volcan d'Agua, et de 32 à 35 degrés pour le volcan de Fuego, dans les régions supérieures de ces montagnes.

On remarque au sommet du volcan de Fuego une tache blanche qui indique l'emplacement d'un vaste espace couvert de croûtes d'alun, et qui, de loin, ressemble un peu à un champ de neige. 


\section{PI $A$ ANGHE XV.}

Coupe et plan du cratère du volcan de Fuego, à l'échelle de 10 millimètres par 100 mètres. Dans la coupe, les pentes extérieures sont un peu exagérées et n'atteignnent en réalité que 35 degrés. Dans le plan, les croix rouges indiquent les points où sc manifestent les dégagements de gaz les plus importants, et la teinte jaune, les endroits qui sont recouverts de croûtes d'alun et de soufre.

\section{PLANCHE XVI.}

Fliune 1. - Vue pittoresque du groupe du volcan d'Atitlan, prise de Panajachel, de l'autre côté du lac d'Atitlan. Ce dessin est mal réussi el ne donne qu'une mauvaise idée du remarquable paysage qu'il devrait représenter. La hauteur du volcan d'Atitlan est beaucoup trop exagérée, ainsi que la pente do ses flanes, qui n’est en réalité que de 30 à 34 degrés.

Figche 2. - Carte du lac d'Atitlan el de ses environs, à l'échetle de 5 millimètres par kilomc̀lre. Ciette carle a été construite d'après nos propres observations, corroborant des documents originaux et inédits conservés dans les archives de la sous-préfecture de Solola.

Elle met en lumière l'origine du lac d'Atitlan, formé par l'accumulation des caux des Rios de Panajachel et de Solola, arrêtés dans leurs cours par les mouvements de terrain correspondant au soulèvement des volcans d'Atitlan et de San Pedro.

Le chiffre de la population est indiqué à côté des noms des principaux villages, rui sont tous habités uniquement par des Indiens de race Quiché.

\section{PLANCHE XVII.}

Figure 1. - Vue du volcan d'Atitlan, prise du côté du sud, de l'hacienda de San Igustin, d'après un croquis de M. Bocourt, naturaliste attaché à l'expédition scientifique du Hexique et de l'Amérique centrale. Le rapport exact entre les hauteurs et les distances a été conservé dans ce dessin, el les pentes se maintiennent entre 32 et 34 degrés comme elles le font en réalité dans la nature.

Figure 2. - Plan du cratère et des régions supéricures du volcan d'Atitlan. à l'échelle de 10 millimètres par 100 mètres. 
Les croix rouges indiquent les points oì se manifestent les dégagements de gaz tes plus importants, et la teinte jaune les endroils recouverts de croûles d'alun et de soufre.

\section{PLANCHE XVIH.}

Figtie 1, - Vue pittoresque du Cerro Quemado de Quezaltenango, prise du côté du umord, un peu au-dessus de la ville de Quezaltenango. On aperçoit le volcan de Santa Maria nu arrière du Cerro Quemado. Les pentes sont un peu exagérées et ne dépassent pas 30 à 32. degrrés enl réalité.

Figun ə. - Plan du Cerro Quemado de Quezaltenango, à l'échelle de 6 millimètres par 100 mètres.

Les croix rouges indiquent les points où se manifestent les dégagements de gaz les plus importants, et la teiute jaune les endroits recouverts de croûtes d'alun et de soufre. 



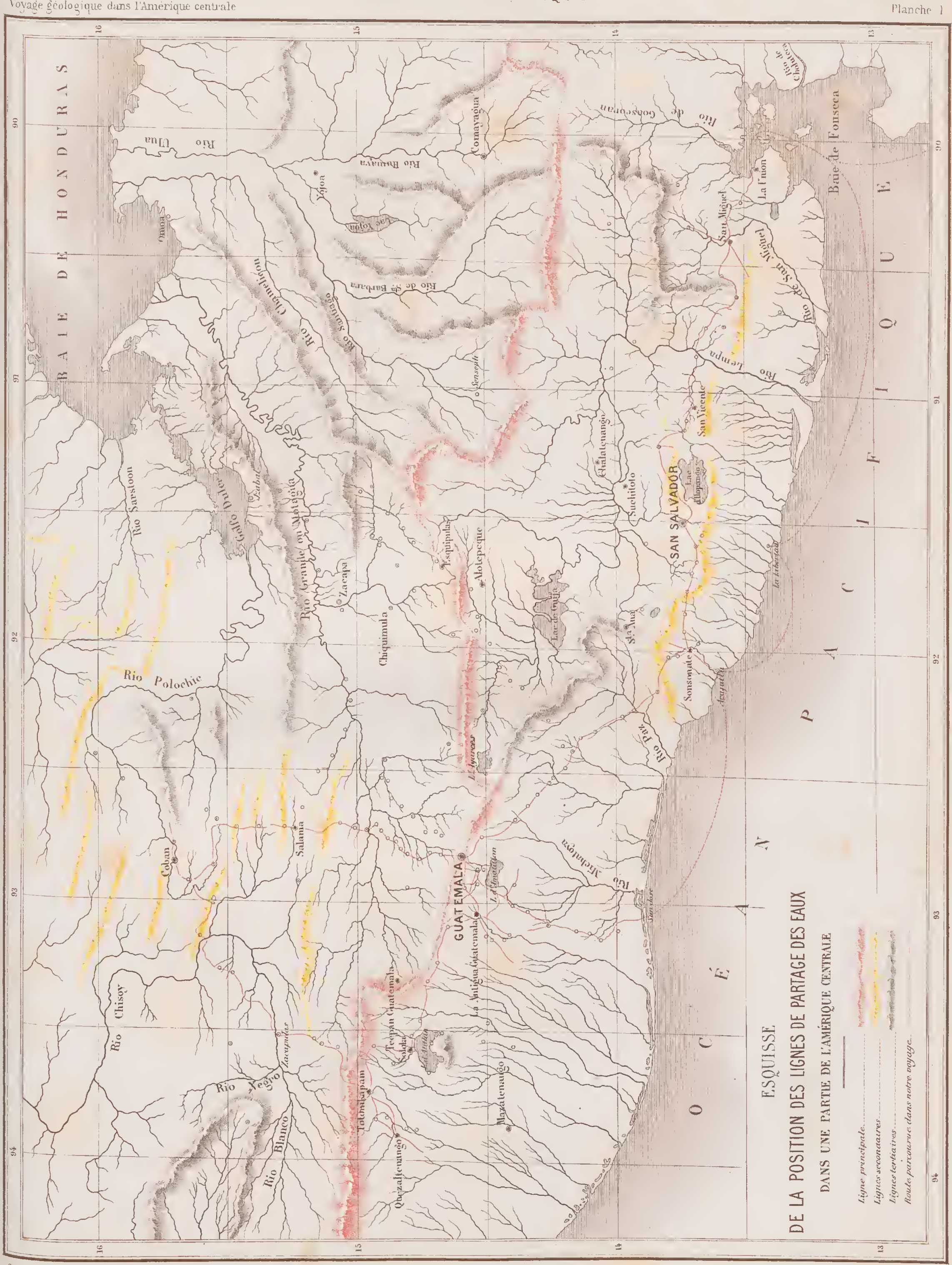



Voyage gèologique dans l'Amérique centrale.

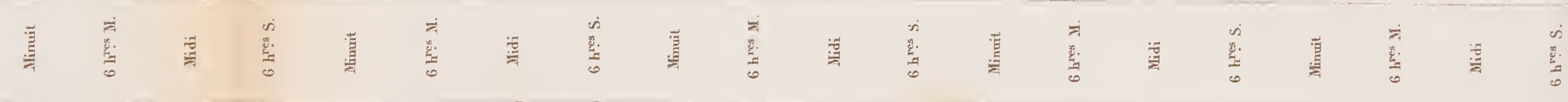
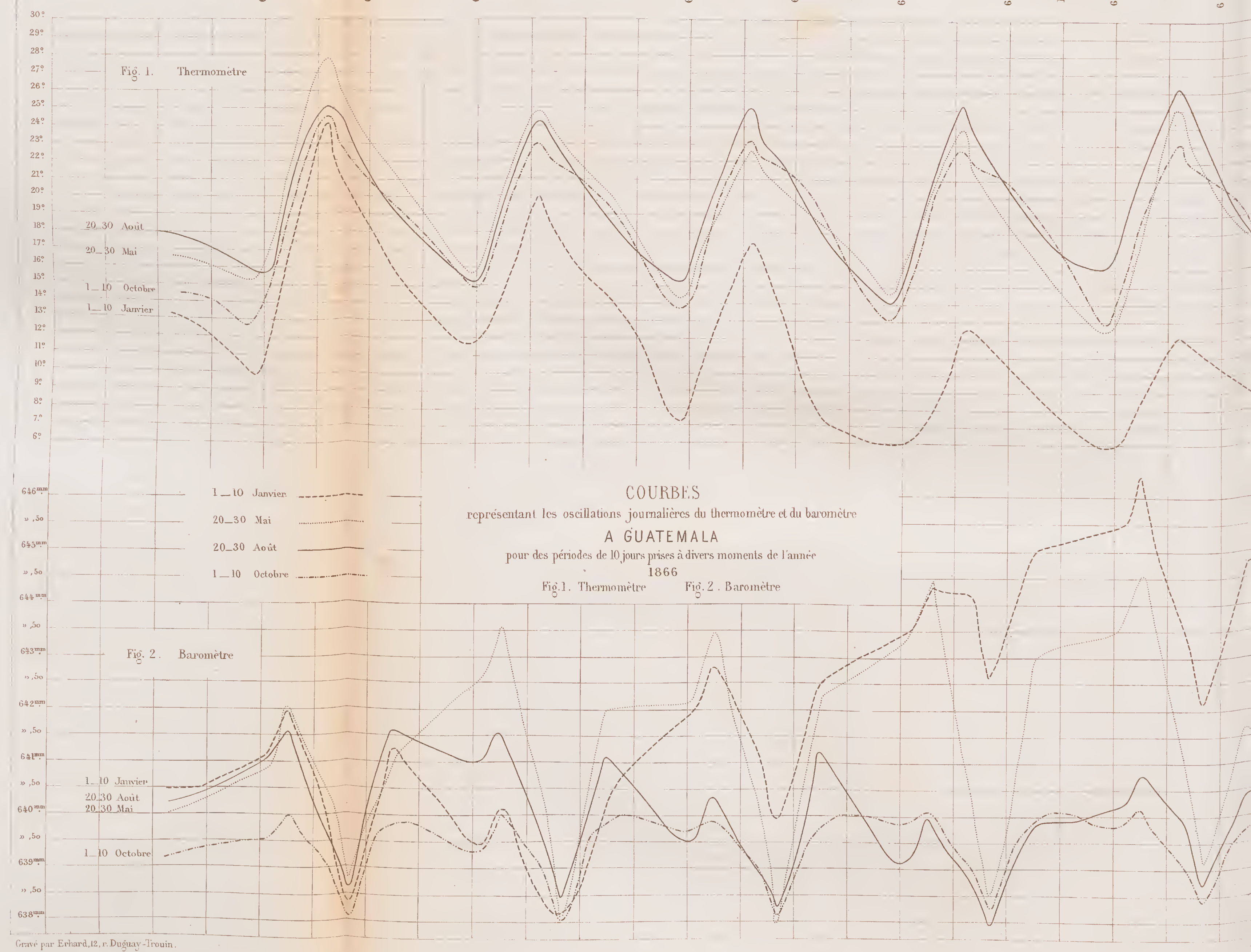
ROLOGIQUES

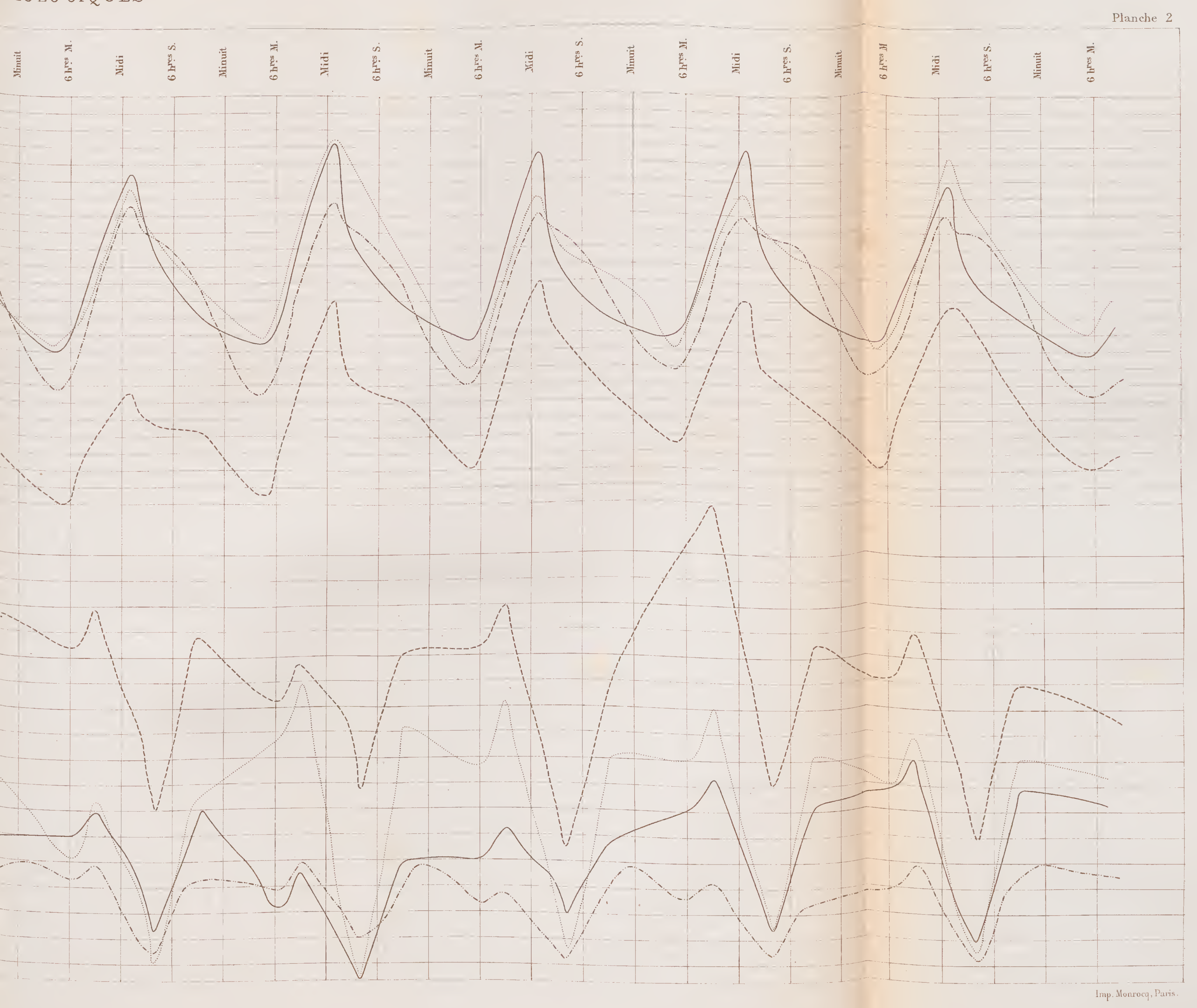



Voyage ģcologique dans 1'Amérique Centrale

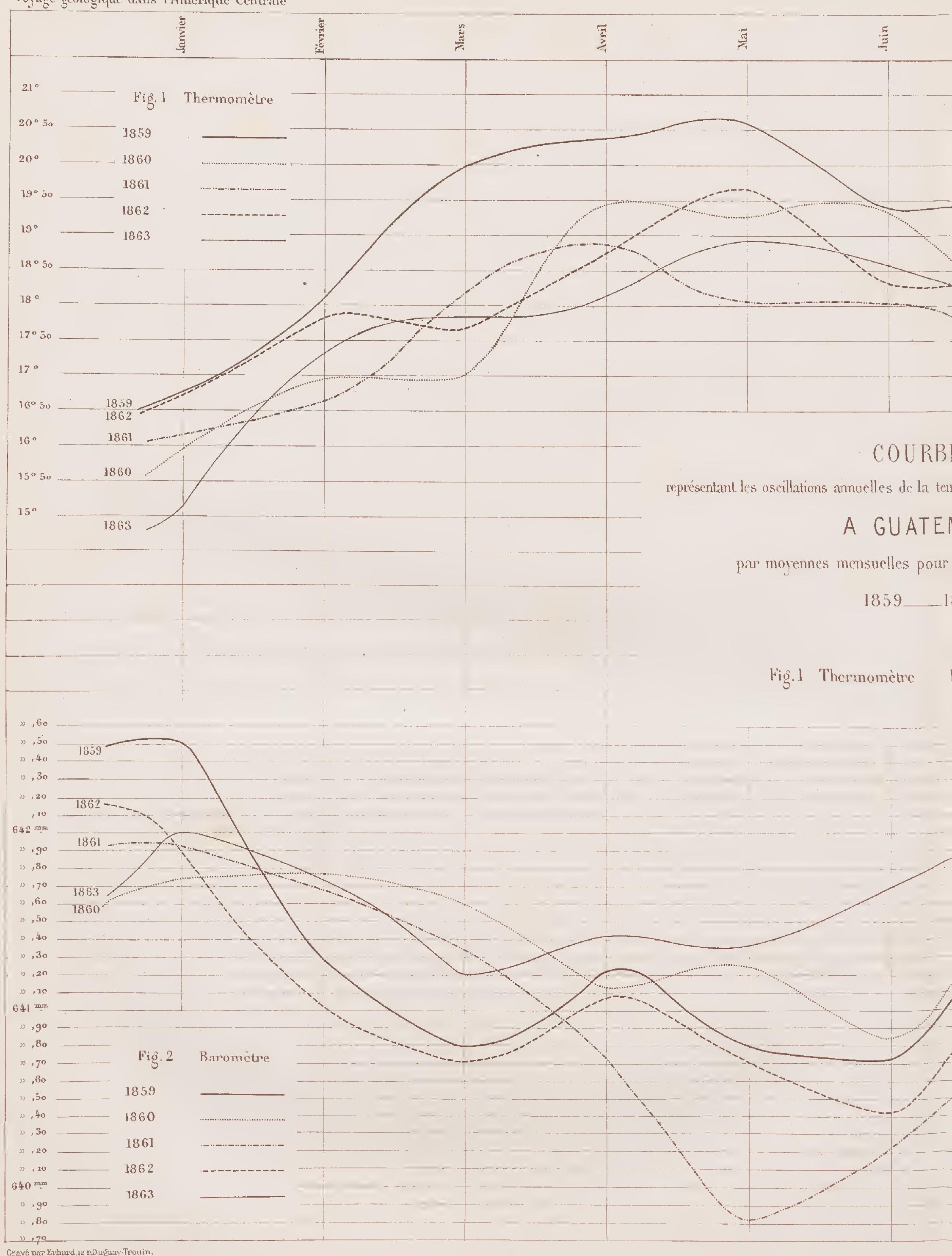





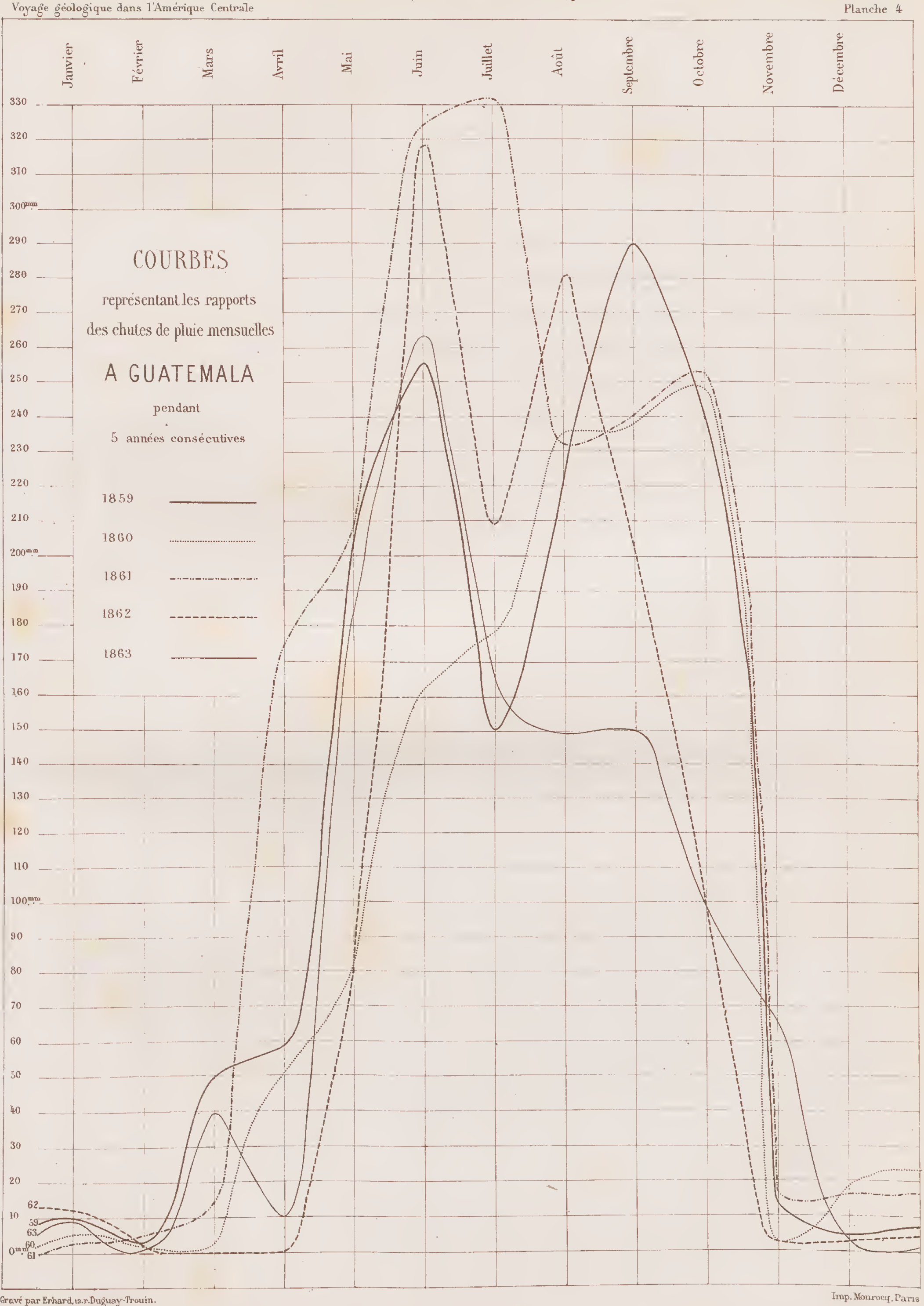




DIAGRAMMES

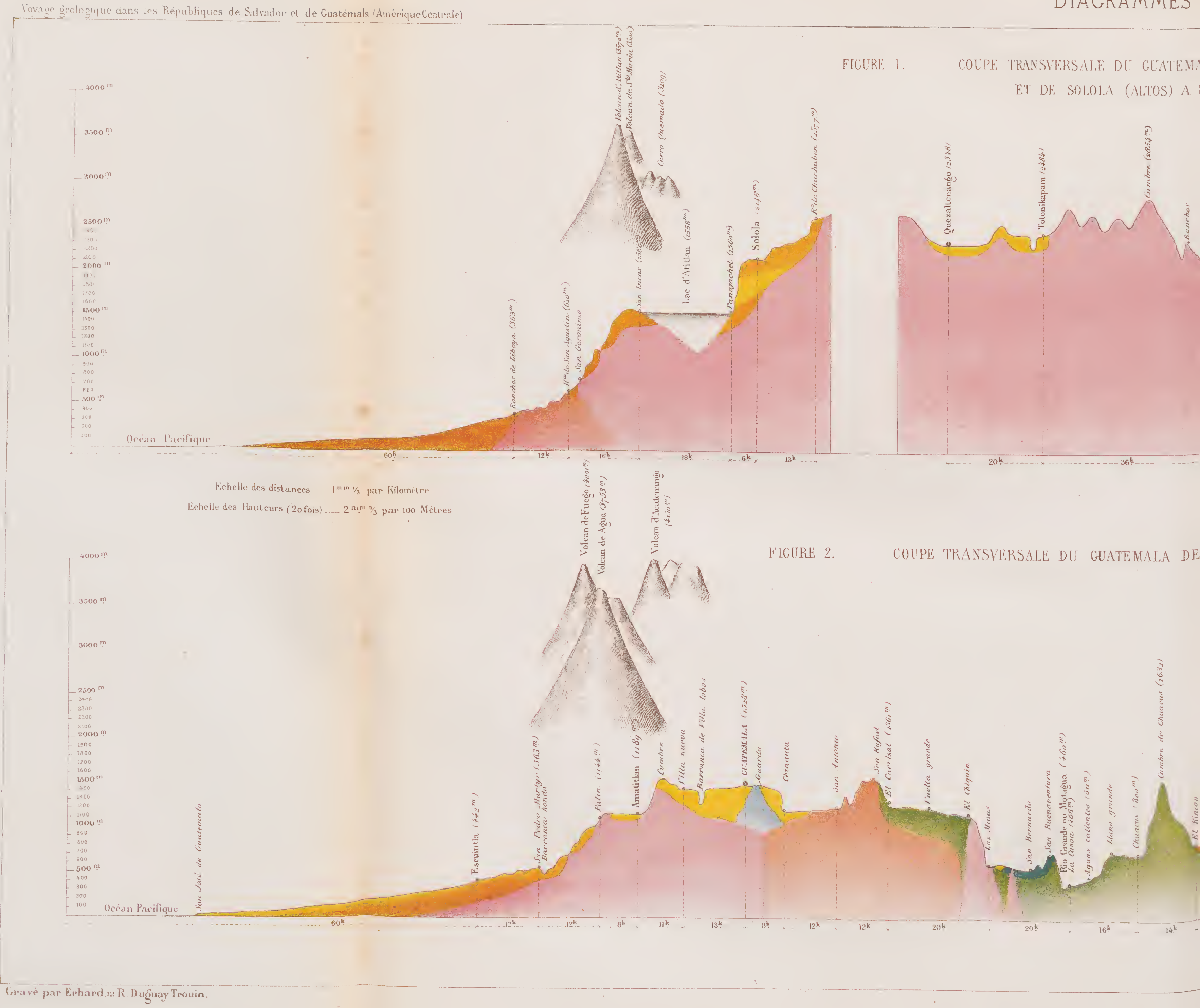




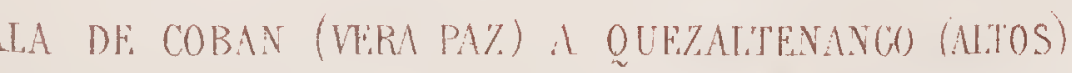

$\therefore$ OCÉAN PACIFIQUE: (NF-SO)
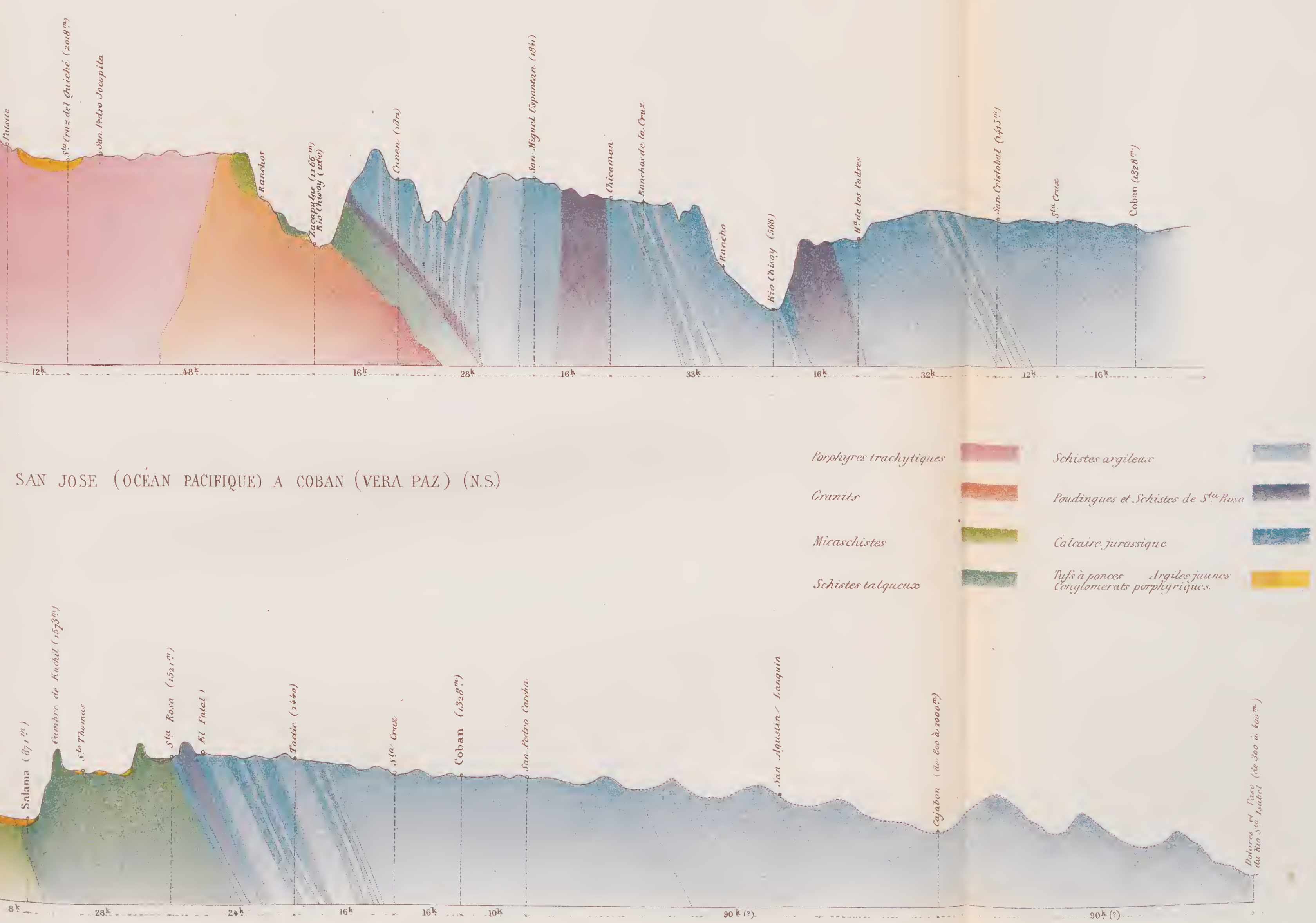



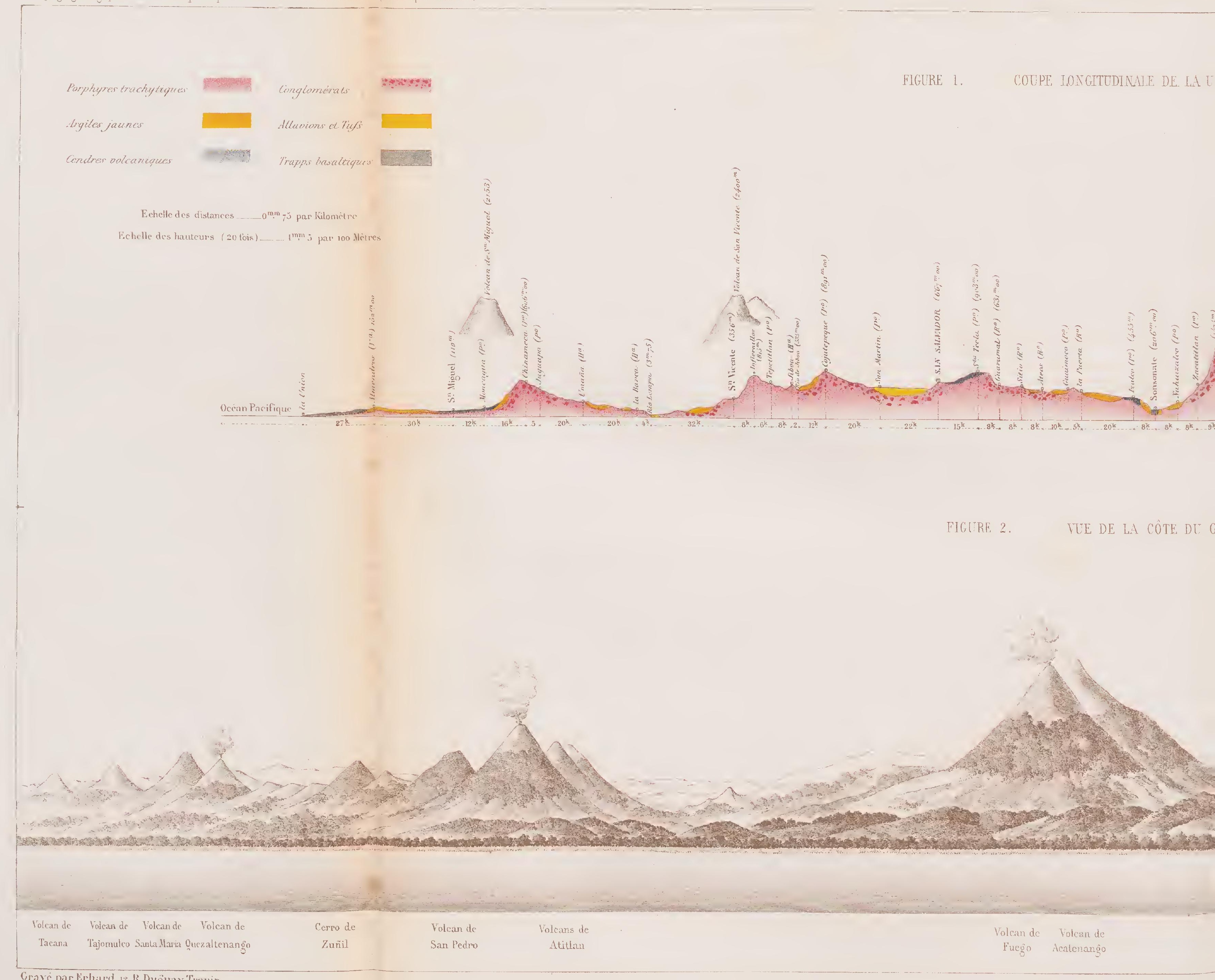



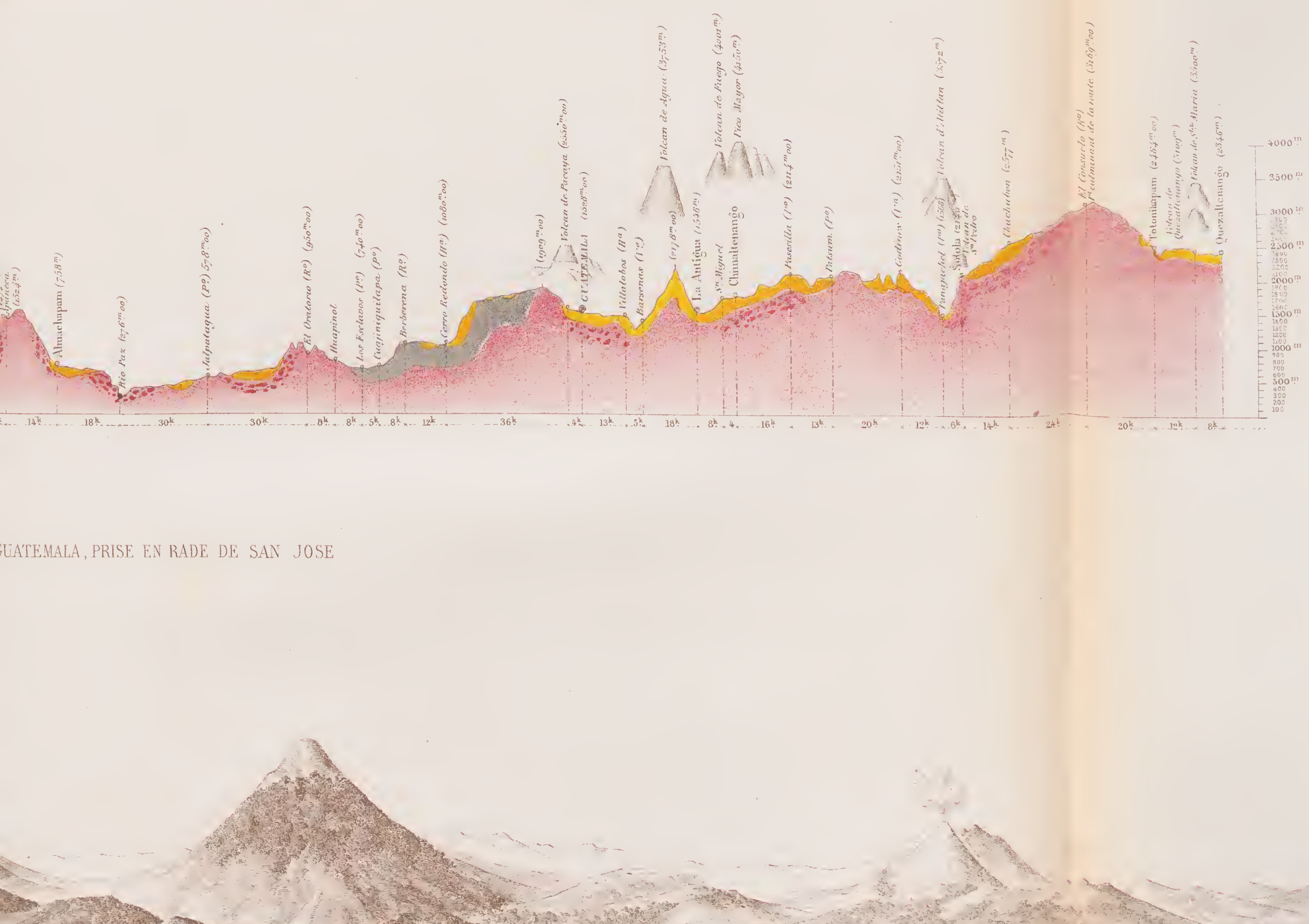

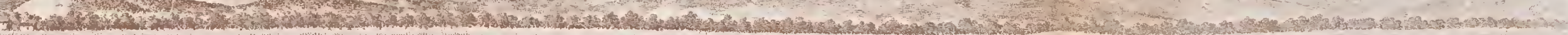

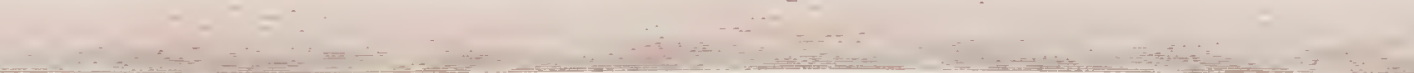



FIG. 1.

VOLCAN DE CONSEGUINA VUE PRISE DE LA MER

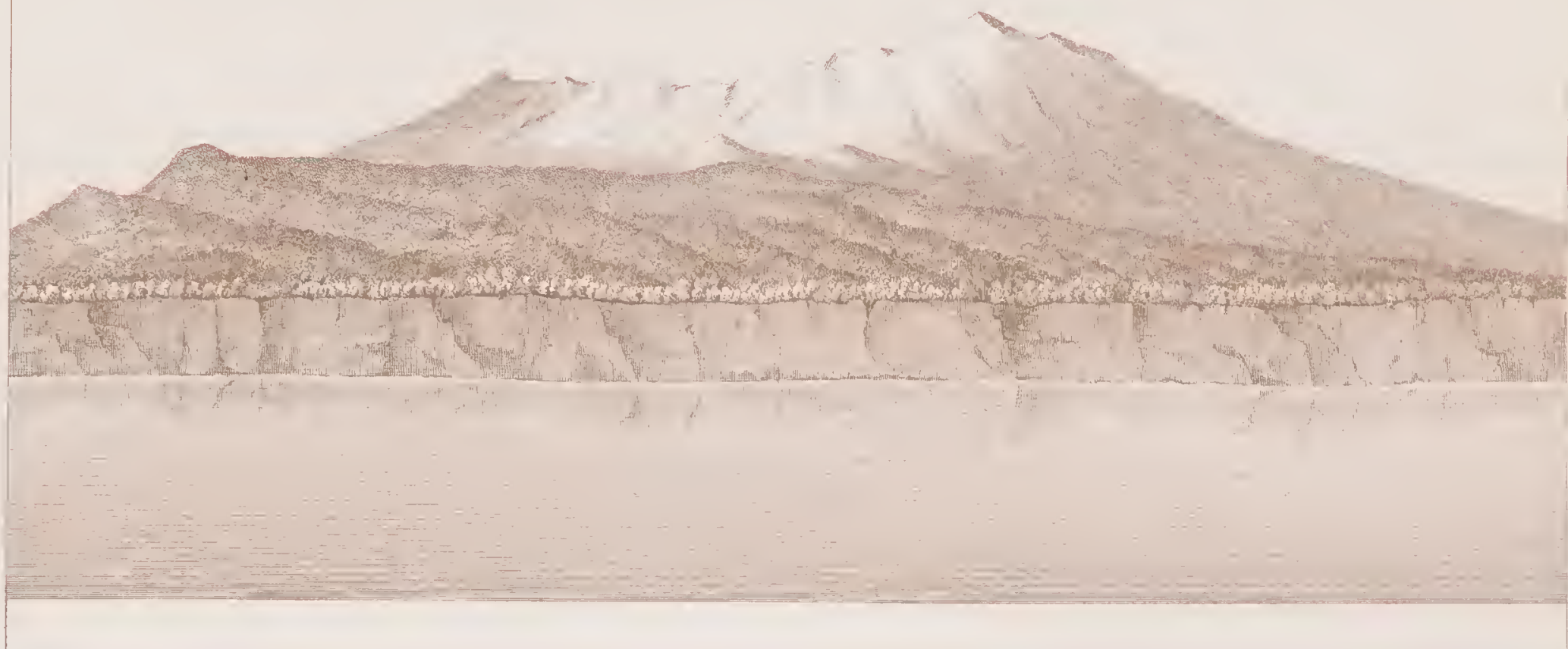

FIC. 2. VOLCAN DE SAN MICUEL VUE PRISE DES ENVIRONS DE SAN MIGUEL

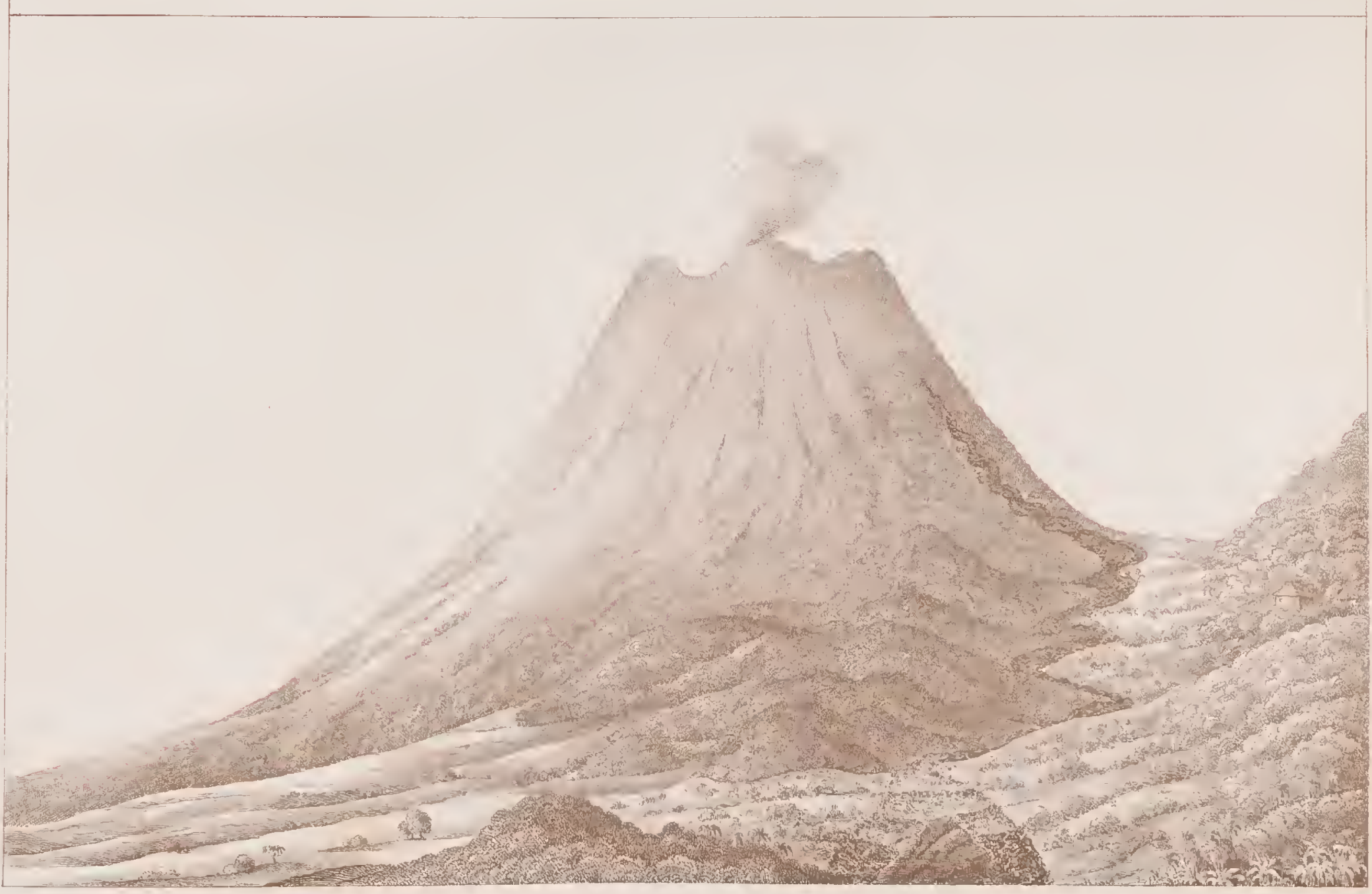



COUPE ET PLAN DU CRATERE DU VOLCAN DE SAN-MIGLEL

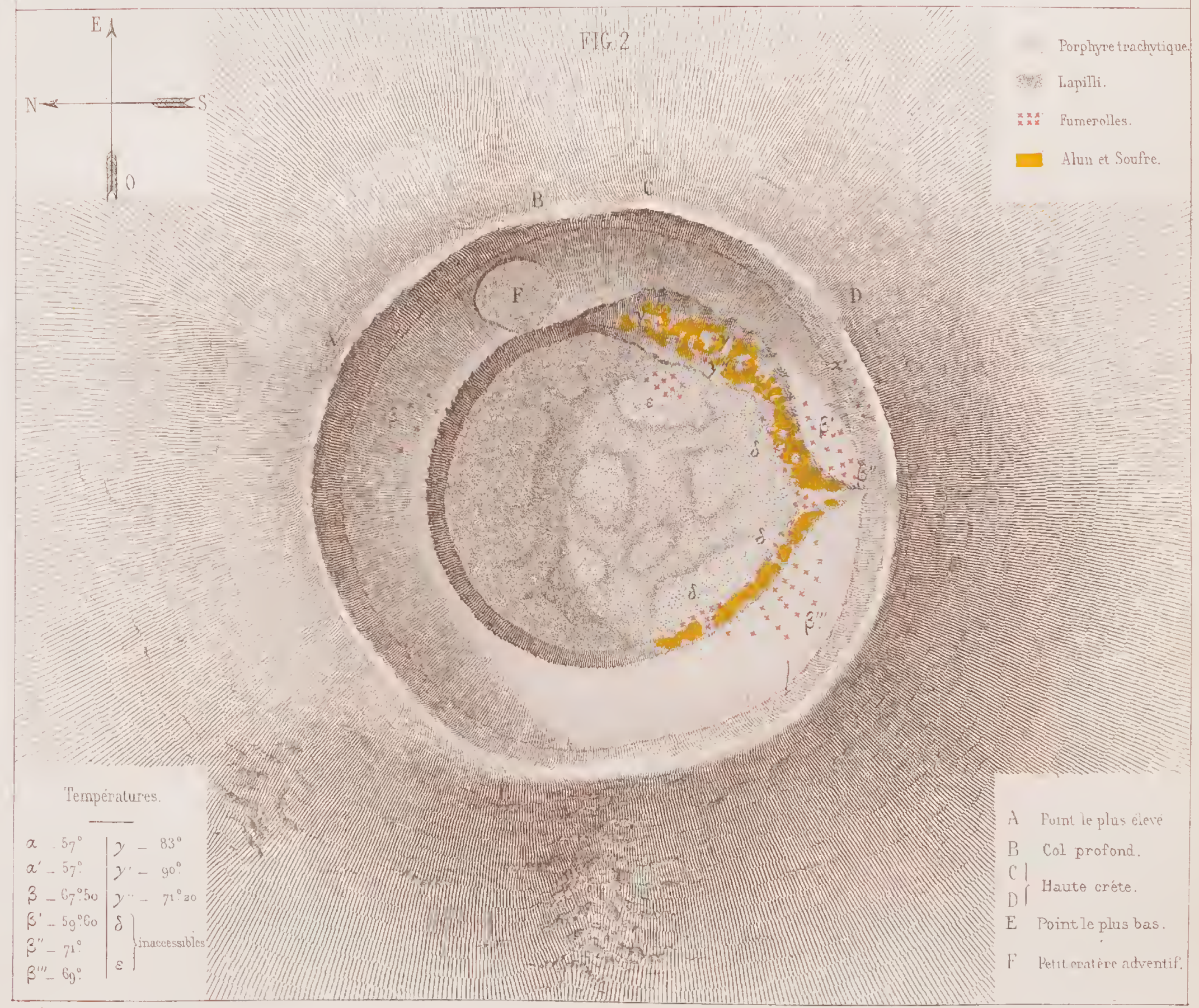



FIG. 1

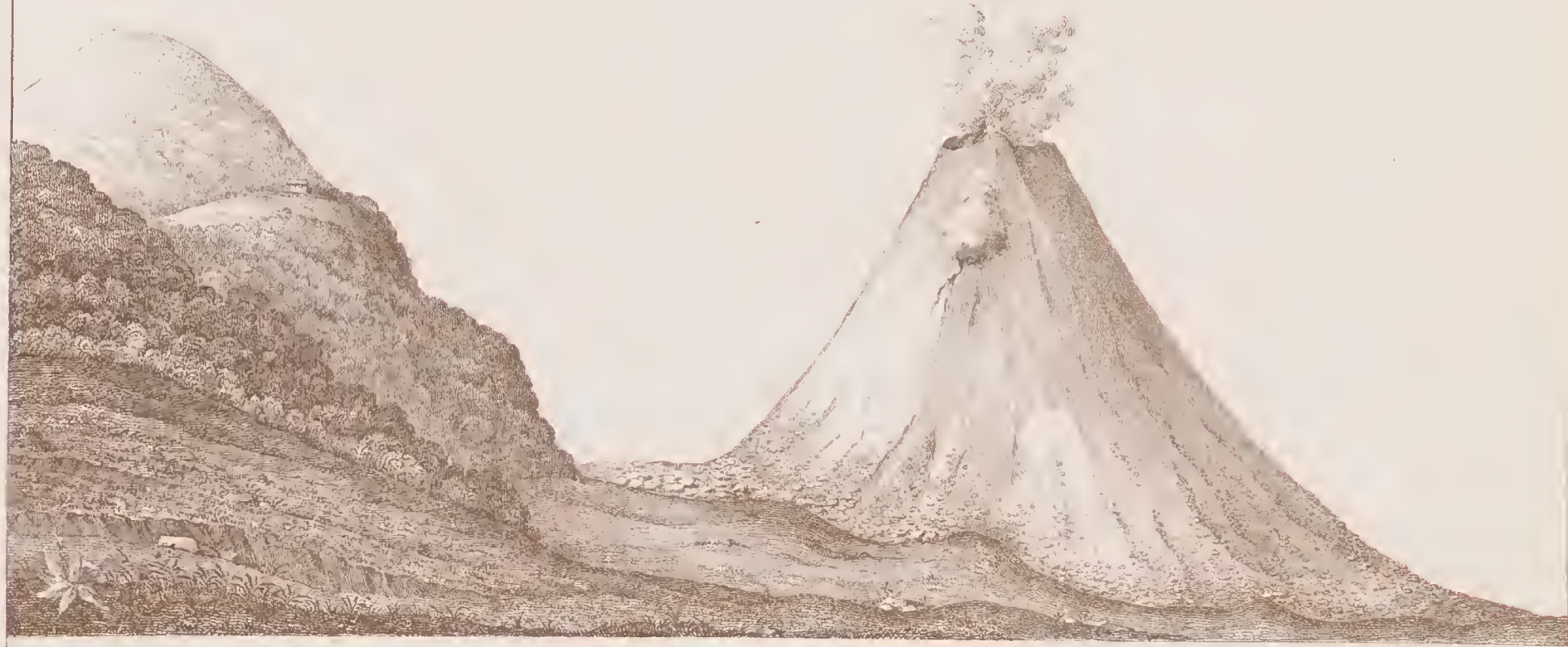

FIG.2

PTAI DL CRATERE DUT VOLCAN D' T\%ALCO

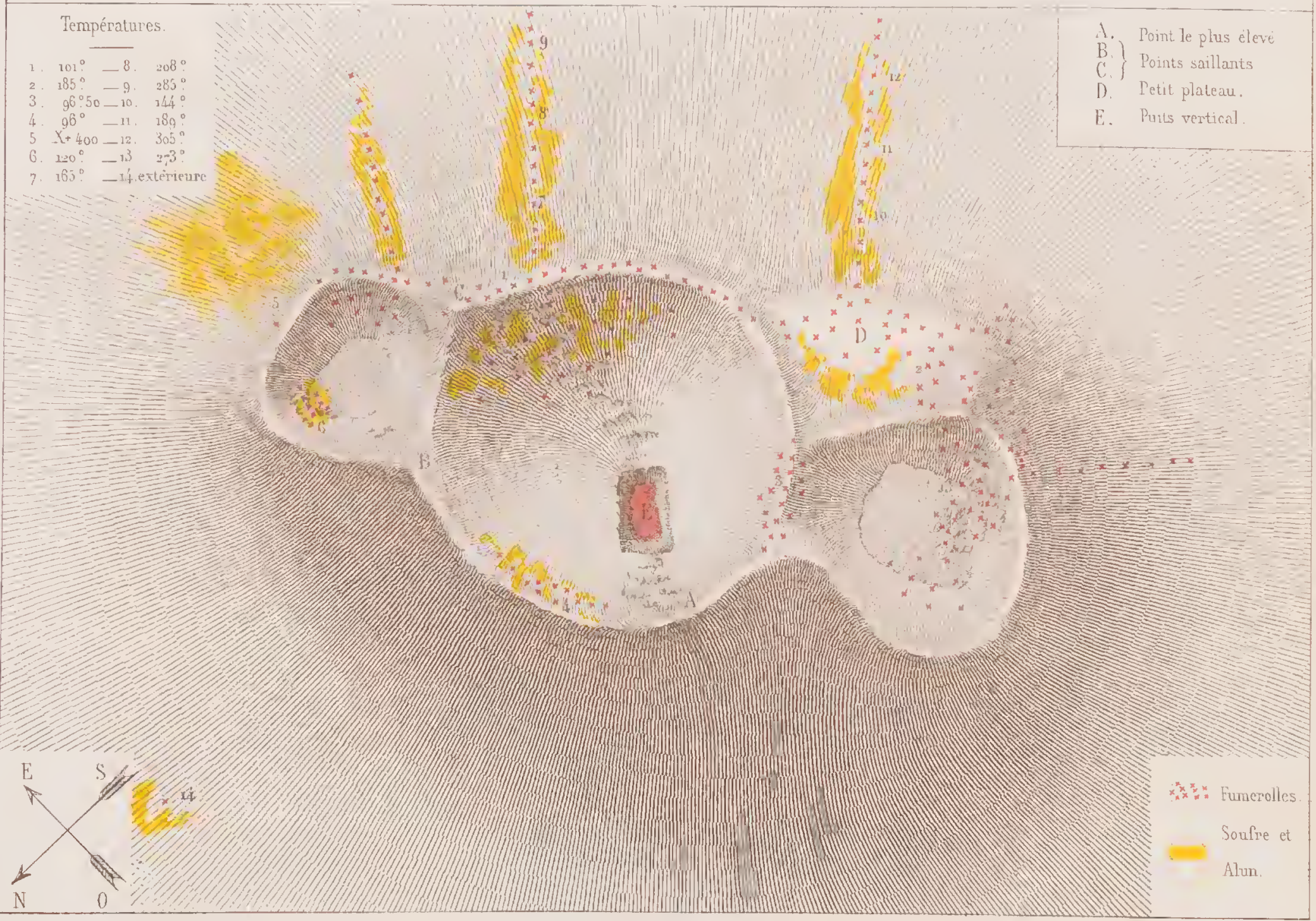



FIG. 1

VUE DES AUSOLES OU VOLCANS DE BOUE DE AHUACHAPAM

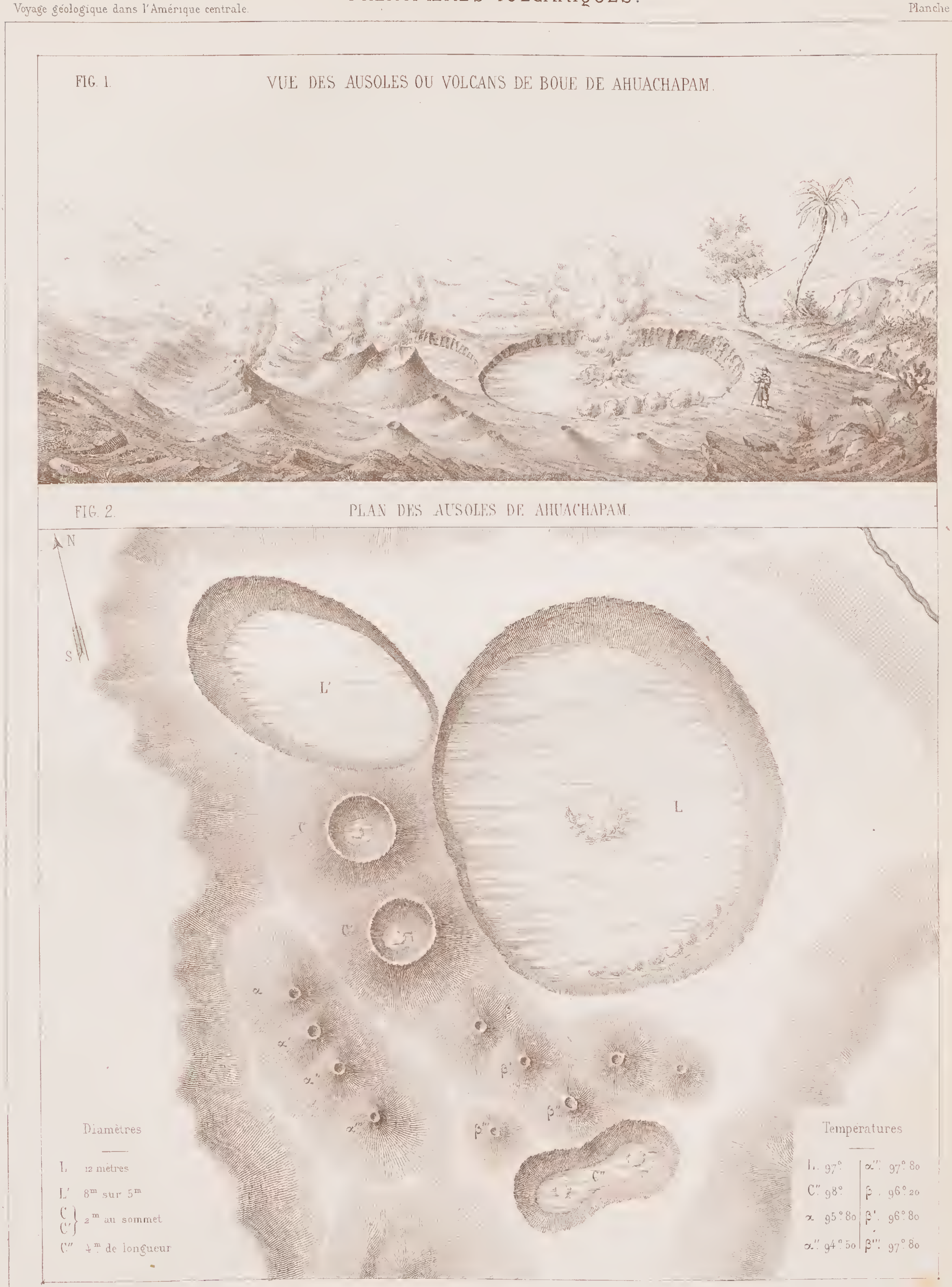



VOLCANS

GROUPE DU VOLCAN DE PACAYA.

Planche 12

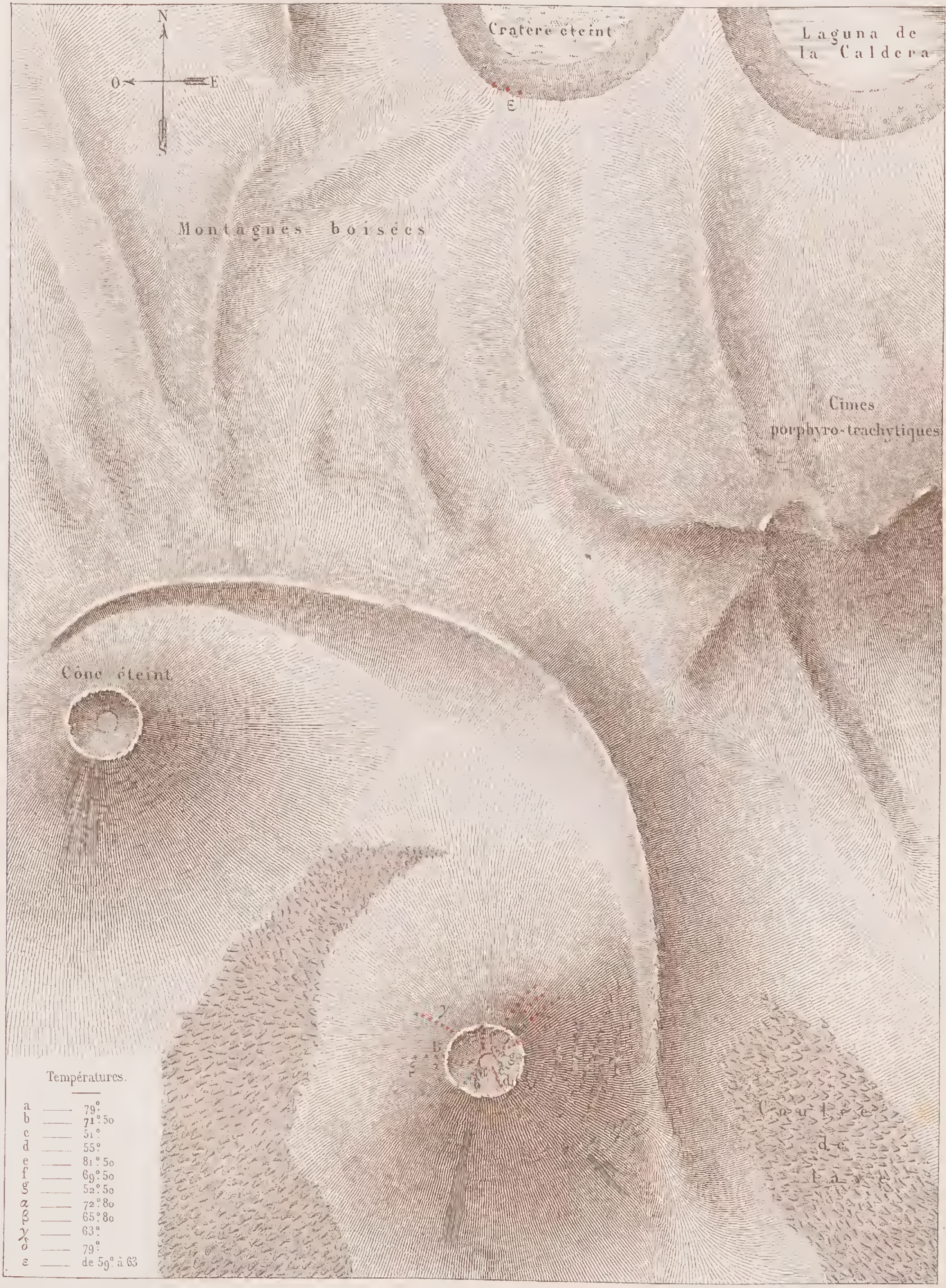





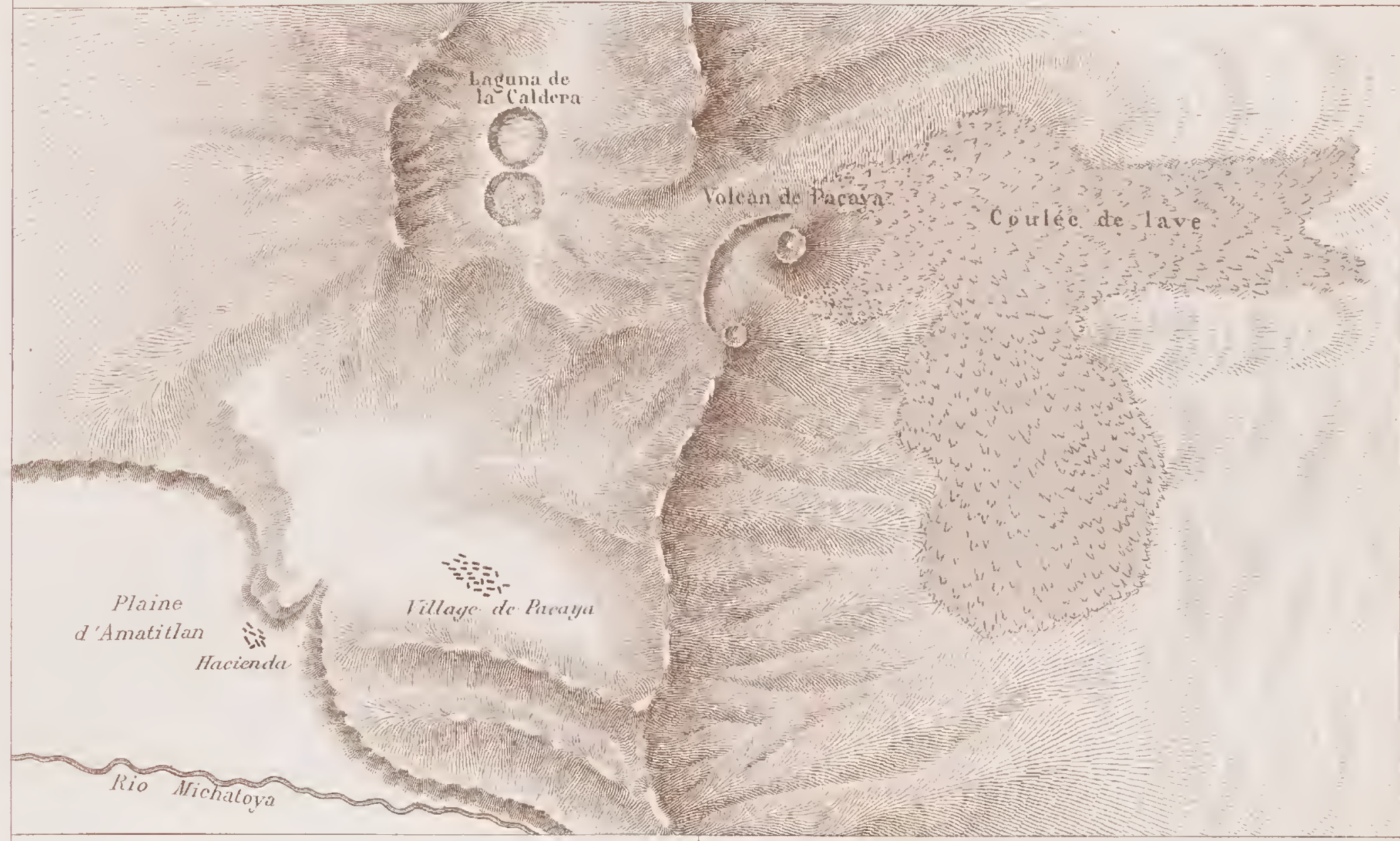

FIG.2. COLPE ET PLAN DU CRATERE DU

VOLCAN DE AGUA
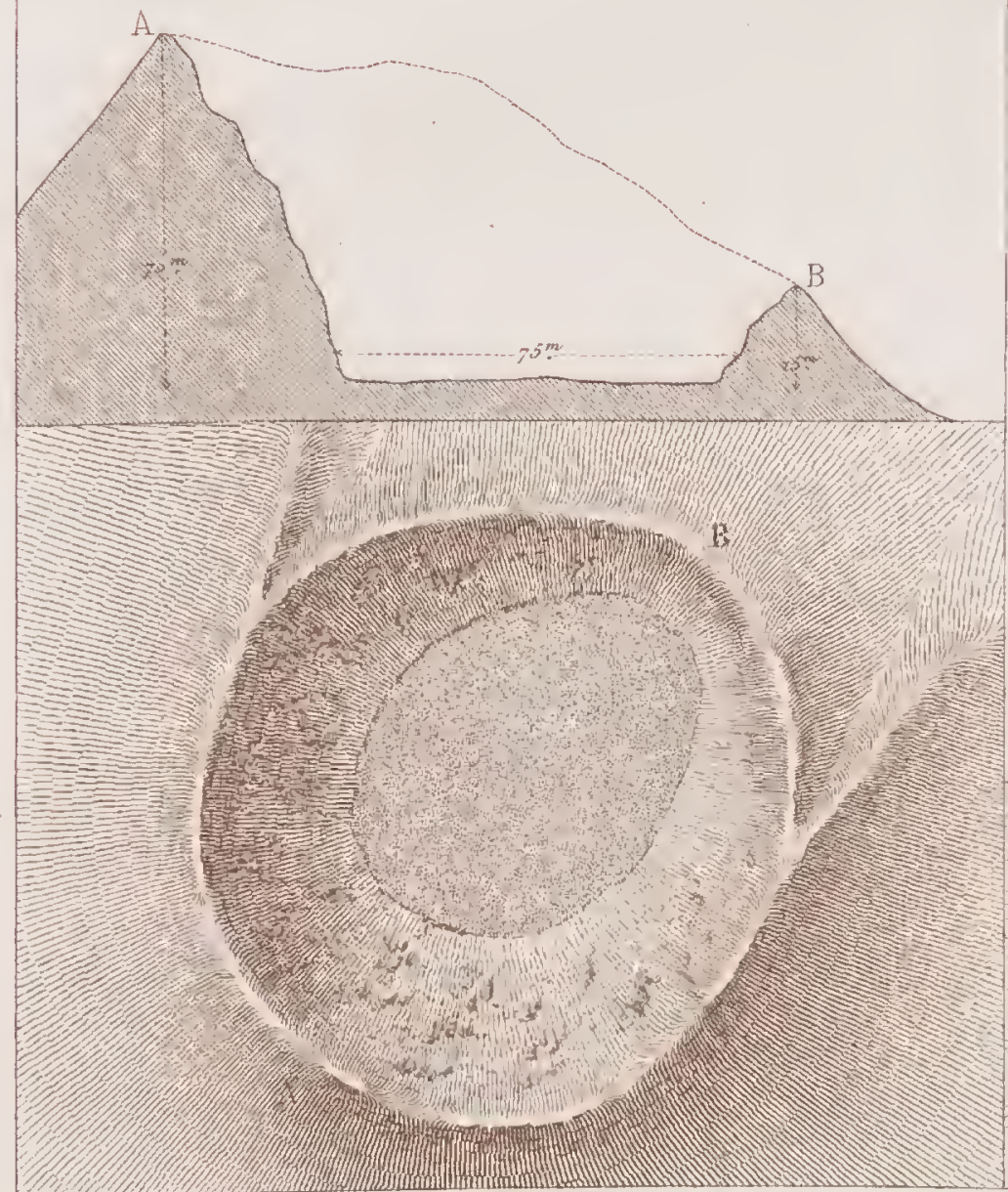

FIG 3. SYSTEME D'ENSEMBLE DES

VOLCANS DE FUEGO ET DE ACATENANGO

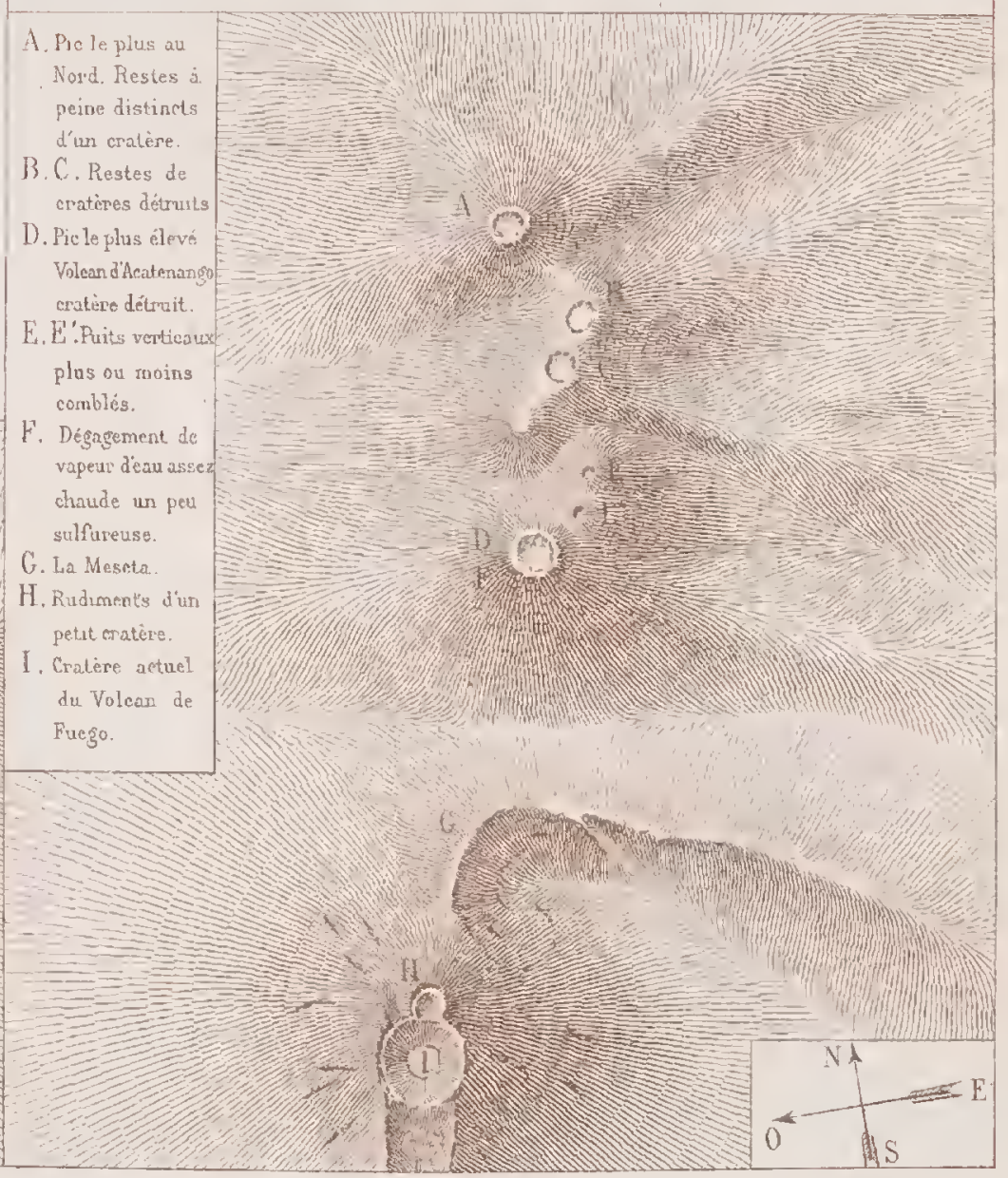





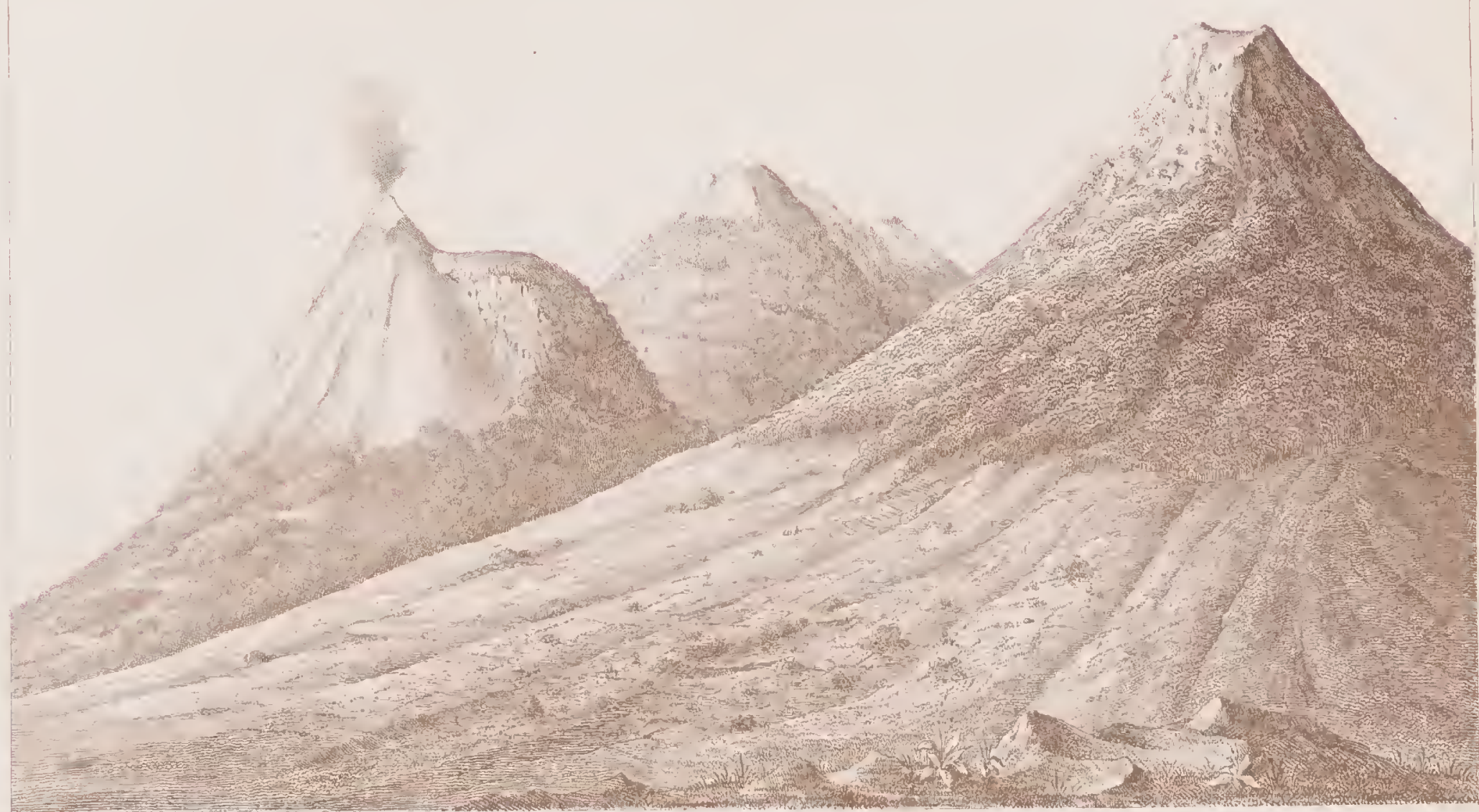

FIC. 2

VOLCANS DE ACUA E.T DE FUEGO, NTS DE I.A ANTIGUA GUATEMALA

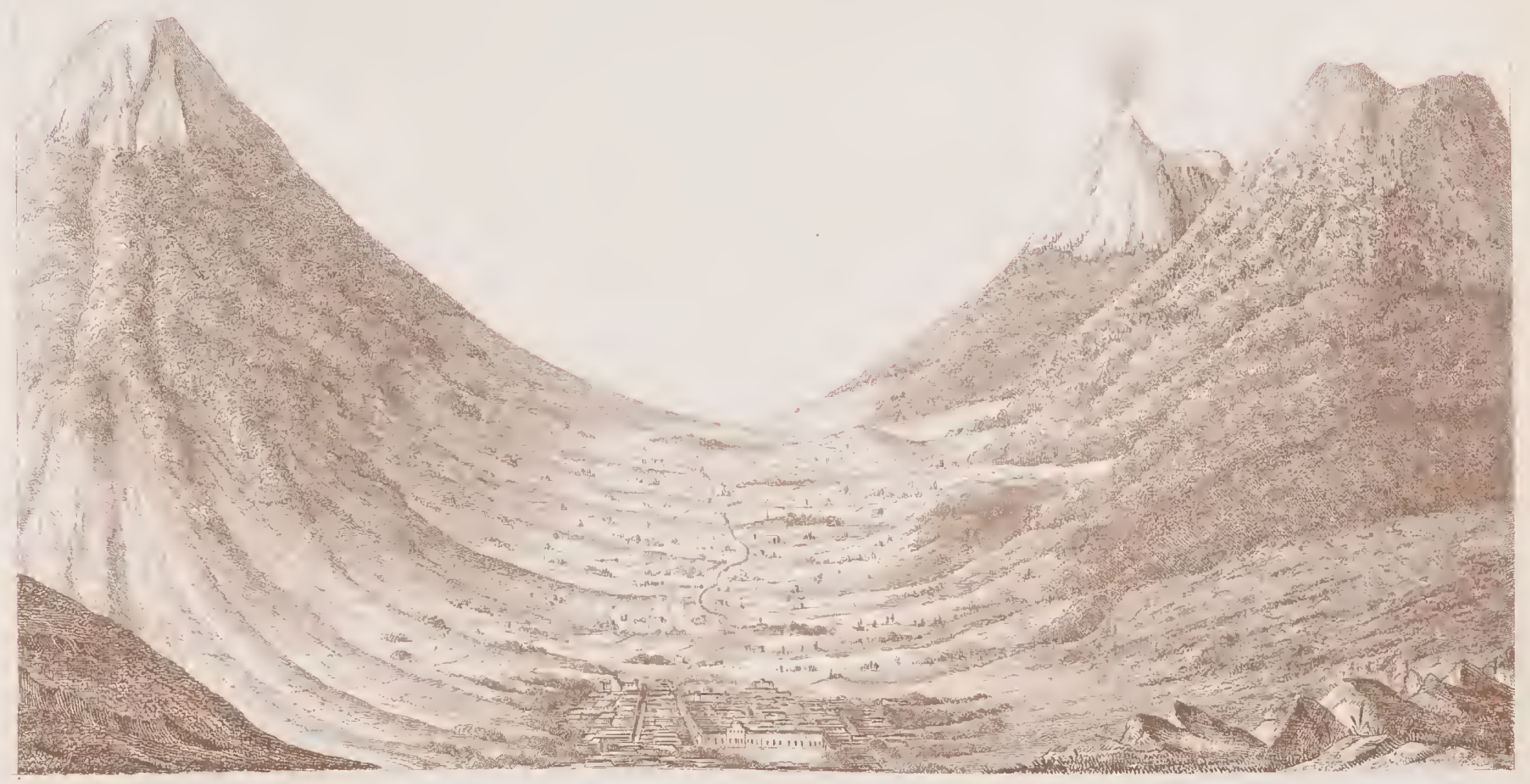




FIG 1
COUPE DU CRATERE DU VOLCAN DE FUEGO

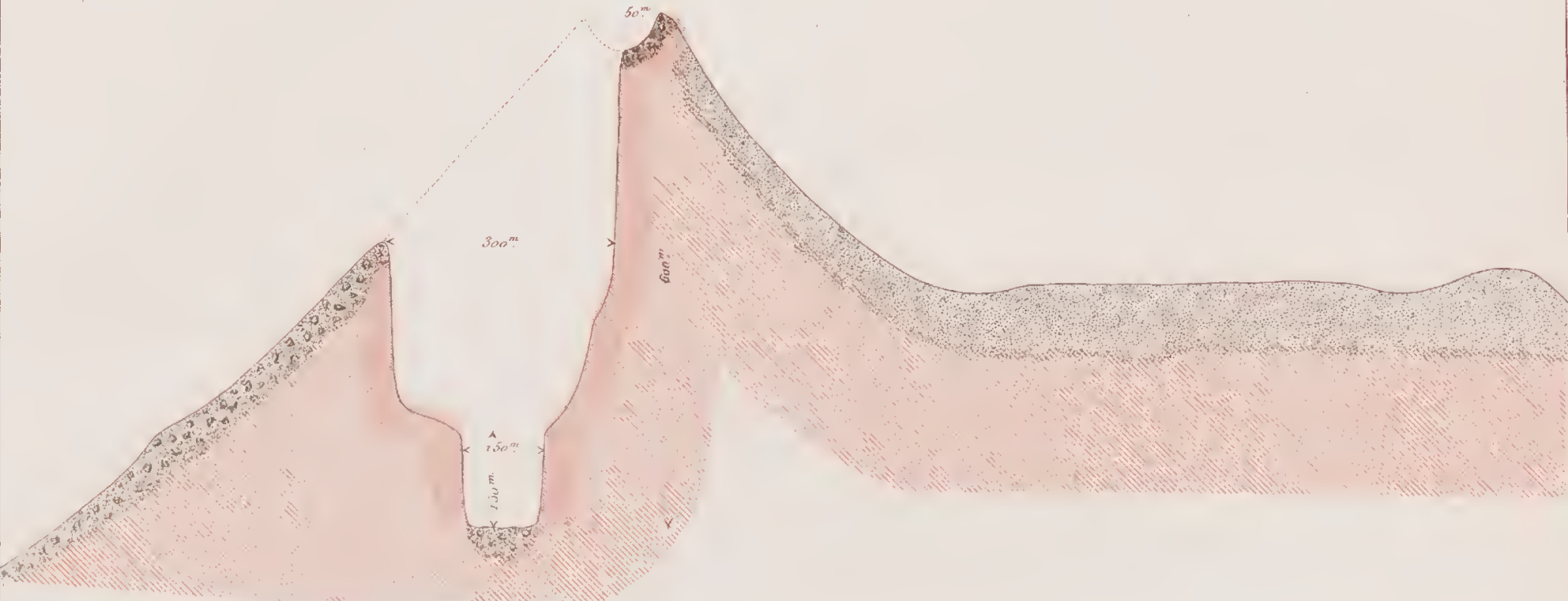

FIC.2

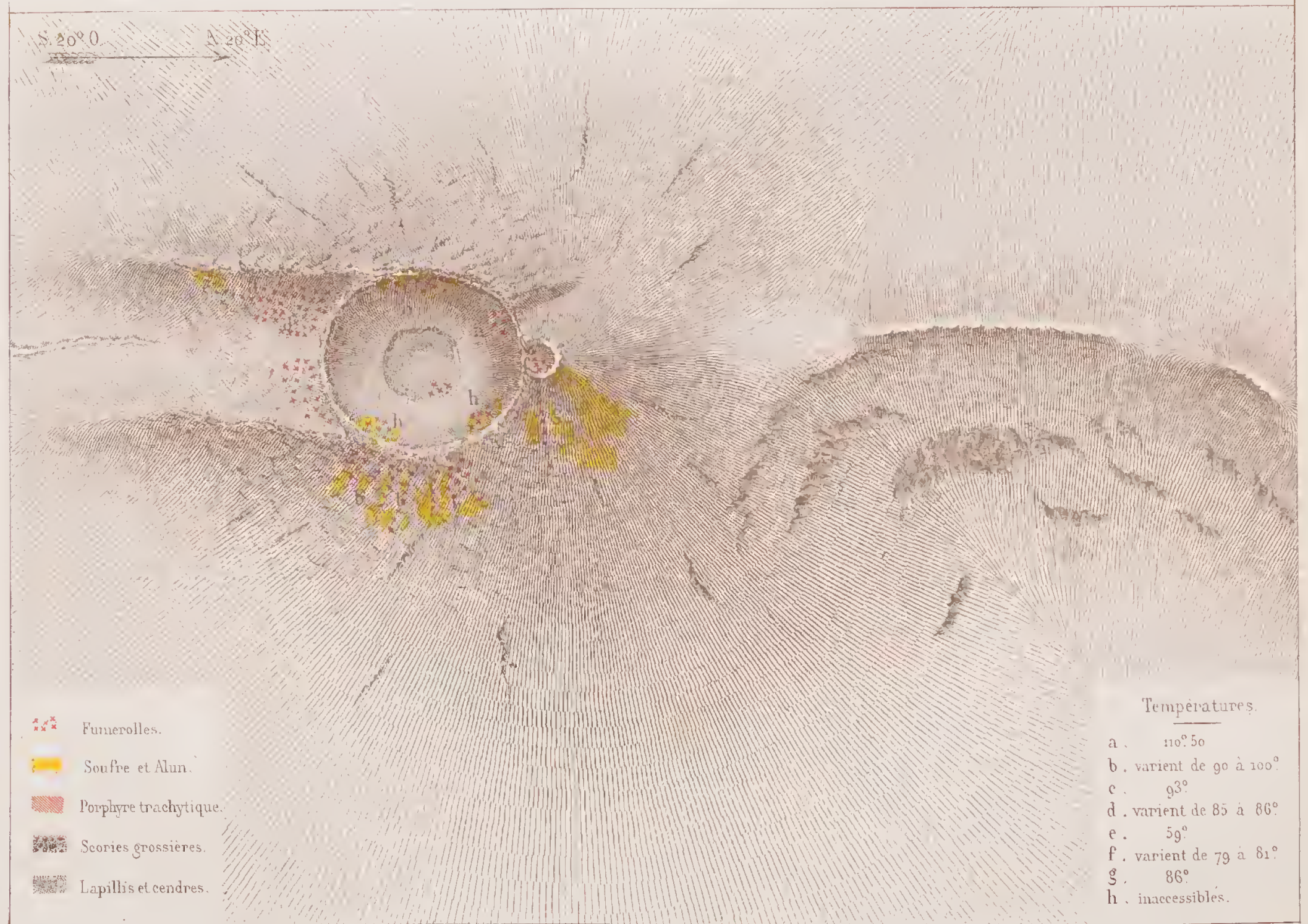





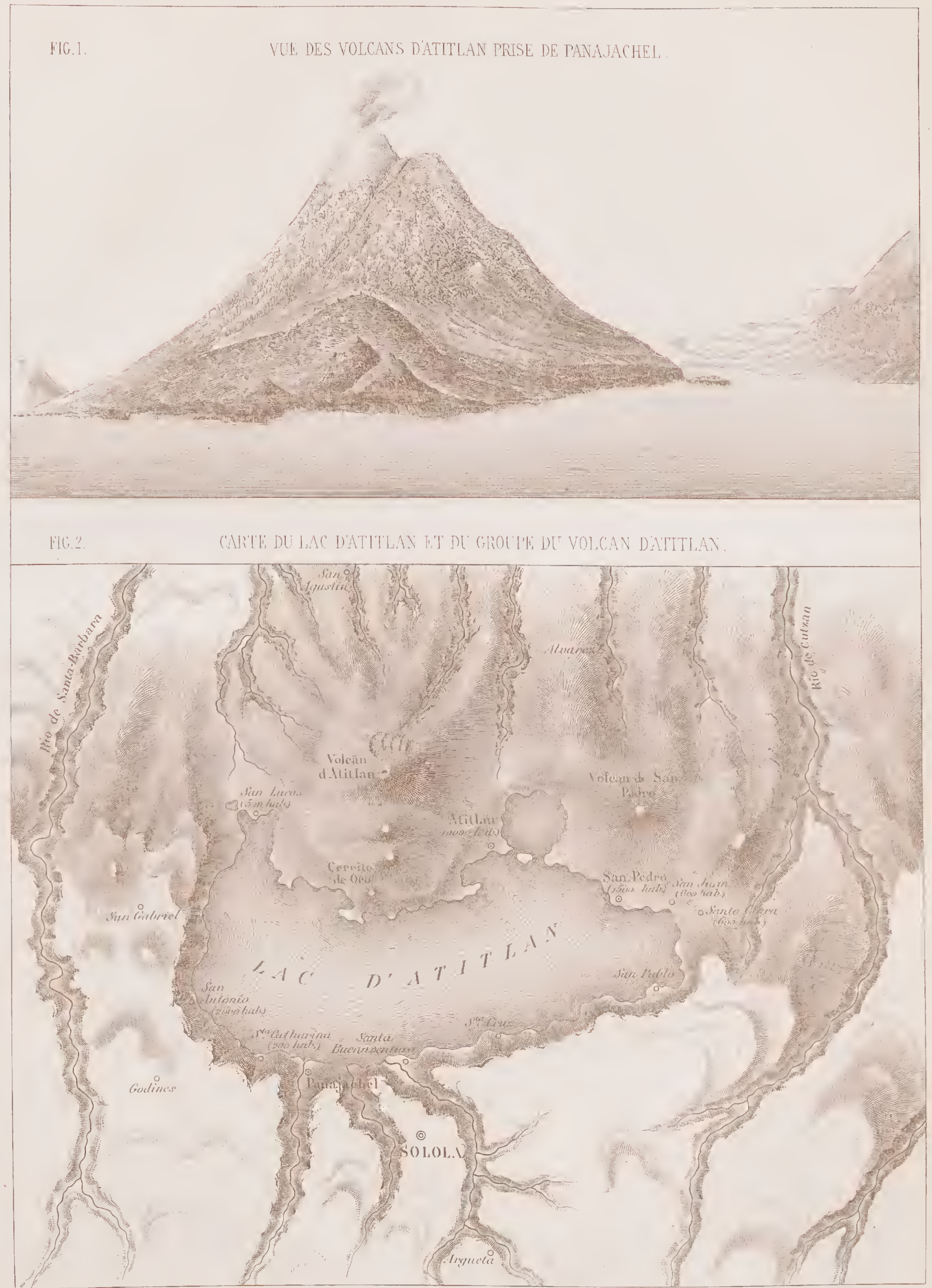




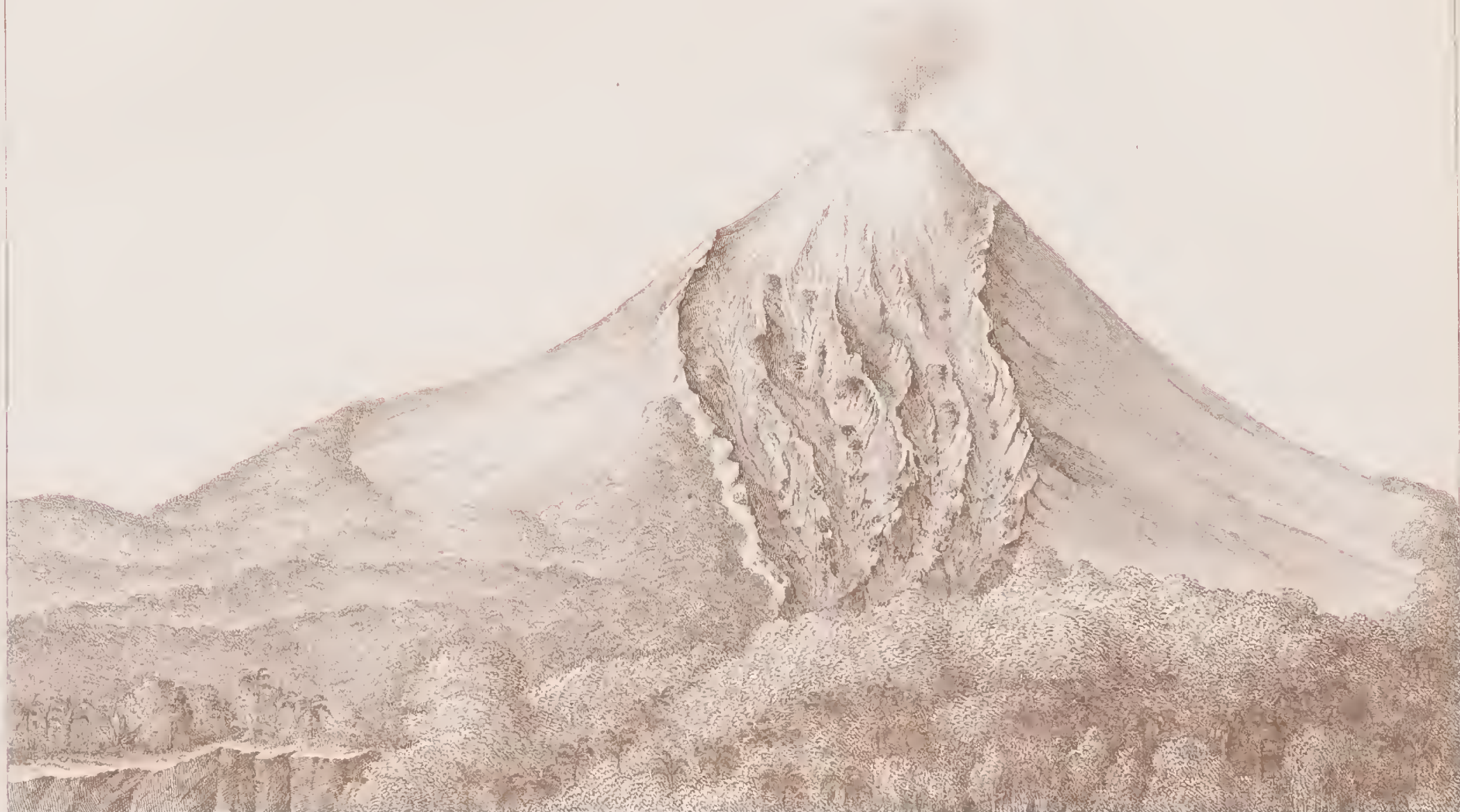

FIG.2.

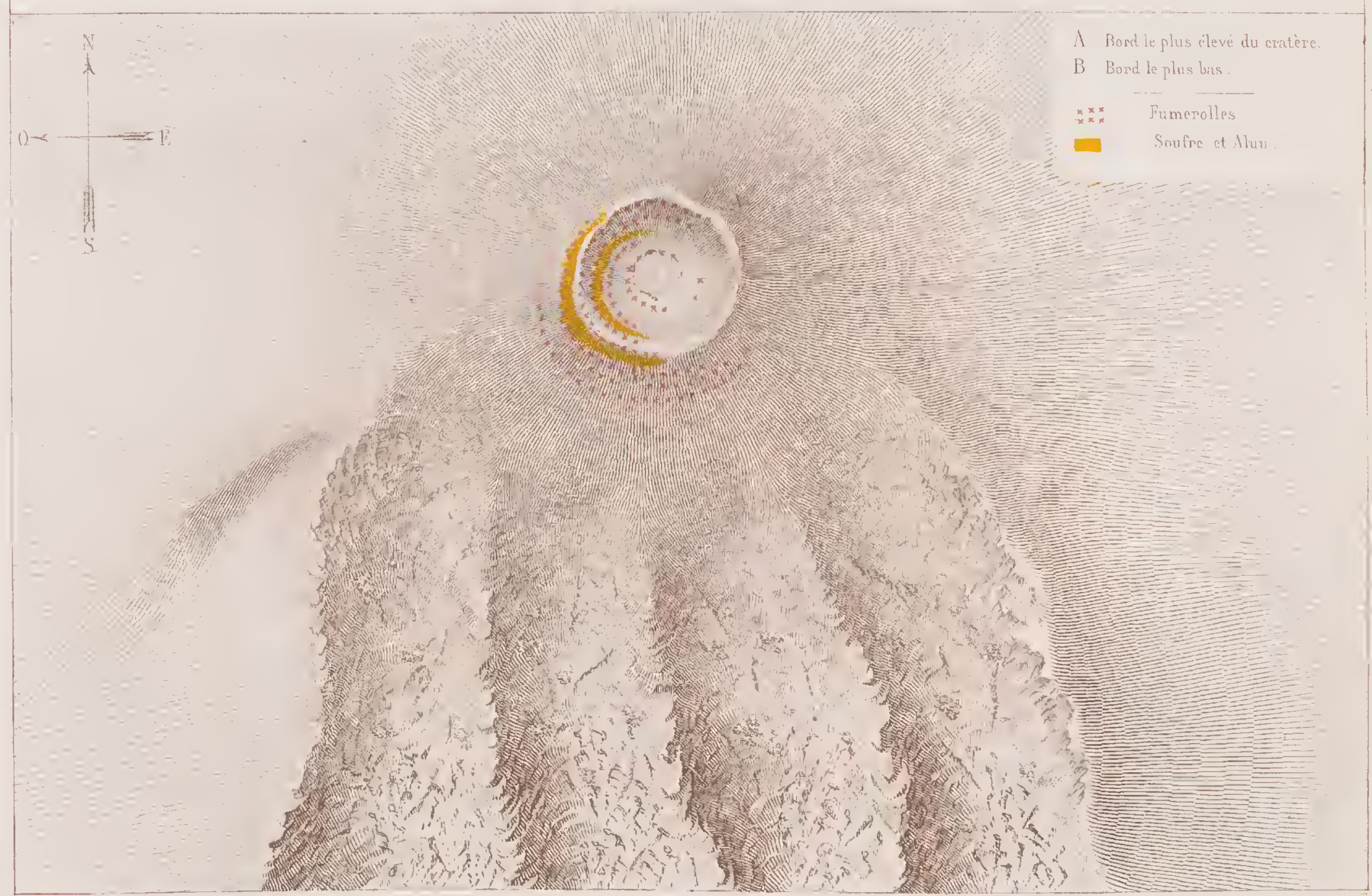





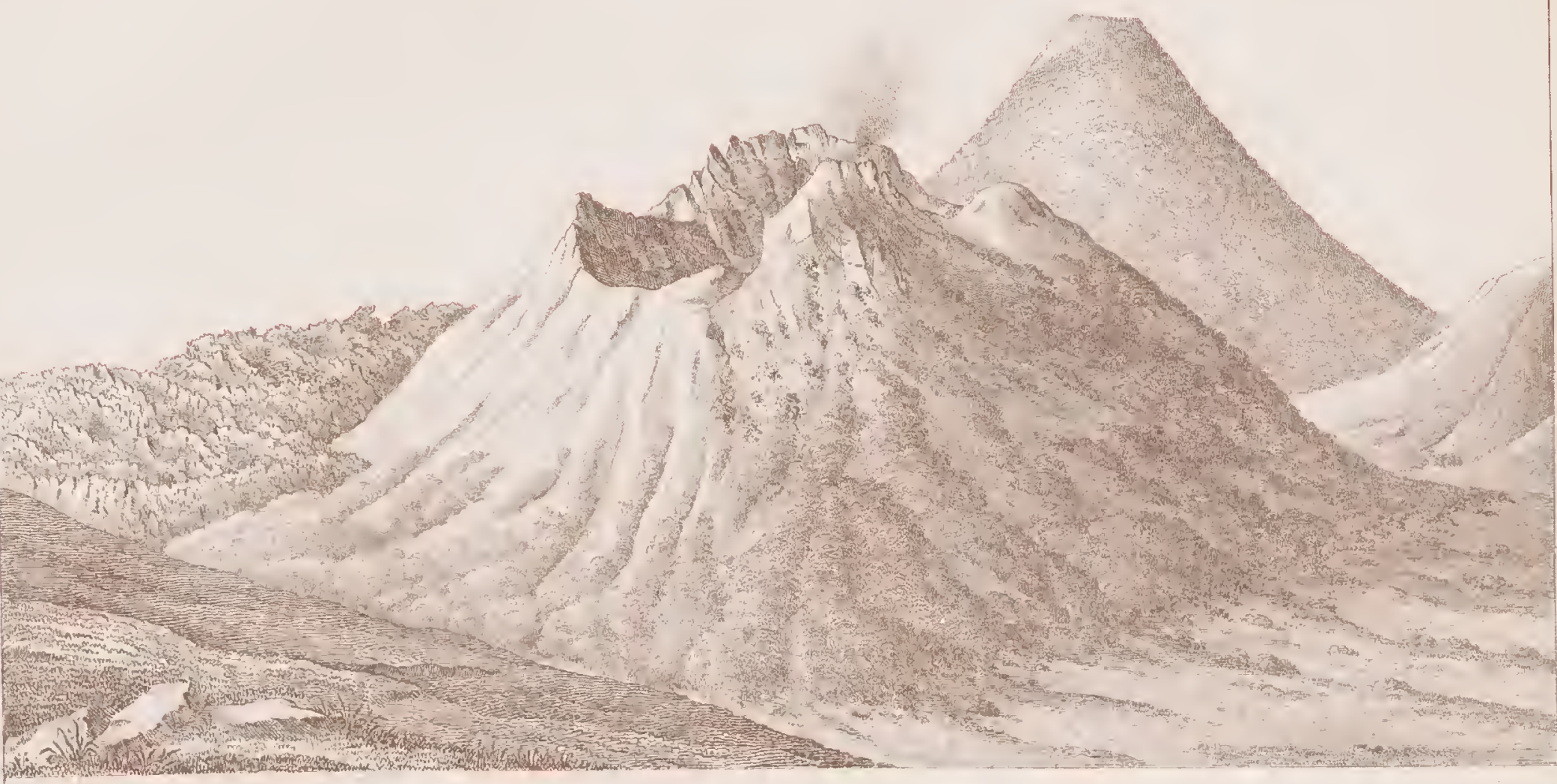

FIG.2.

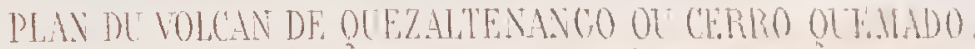

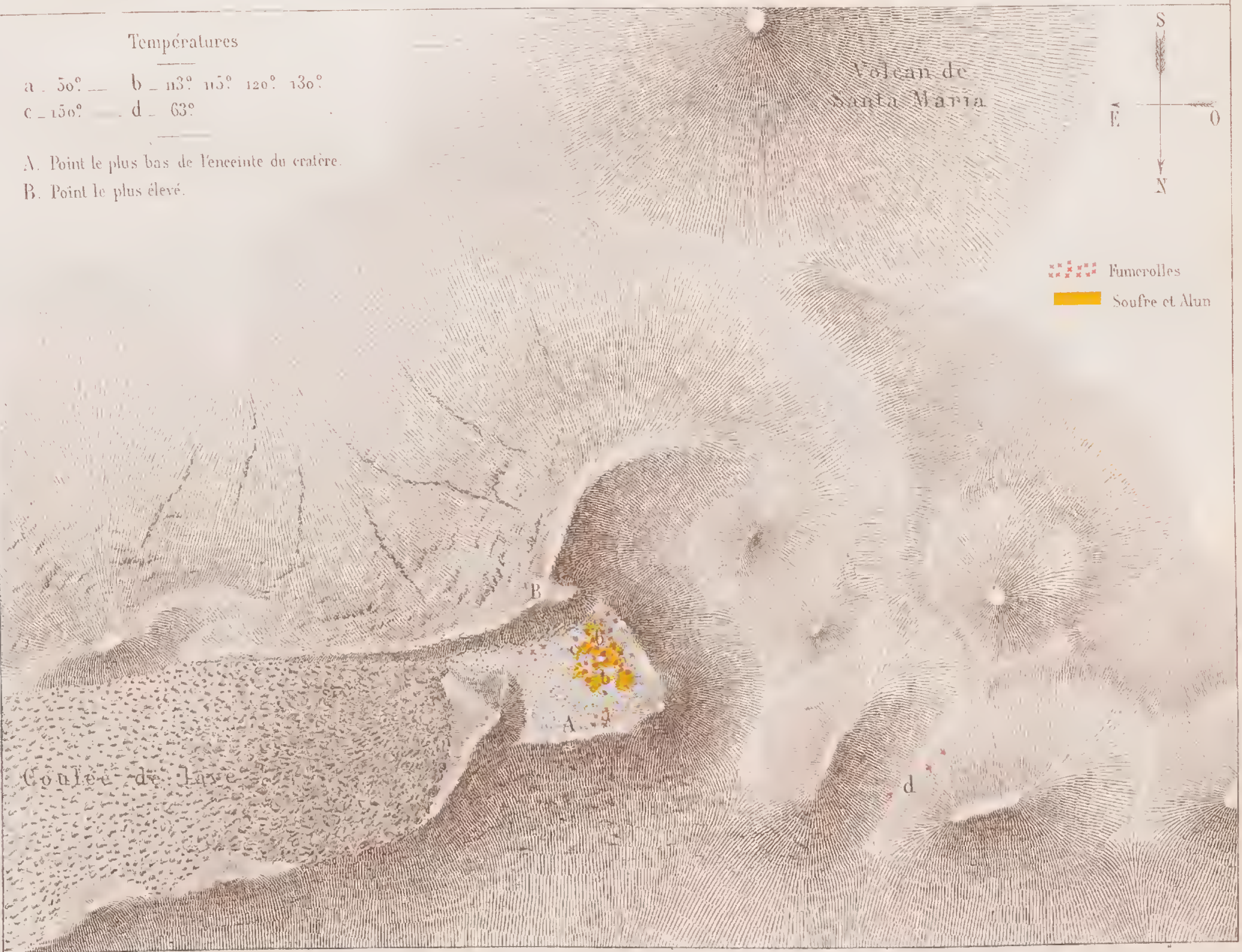





\section{TABLE GÉNÉRALE DES MATIÈRES.}

PRÉFACE

LIVRE 1. - Itinératre descriptif.

République de Salvador. - La Union..

San Miguel.

San Salvador.

Sonsonate.

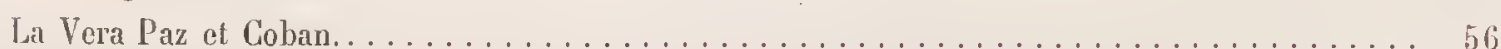

Los Altos et Quezaltenango . . . . . . . . . . . . . . . . . . . $7^{\circ}$

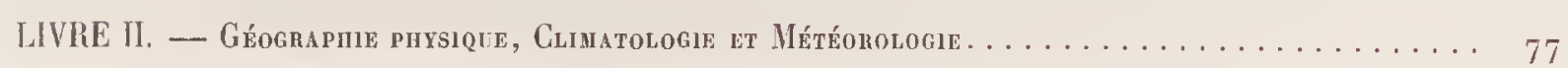

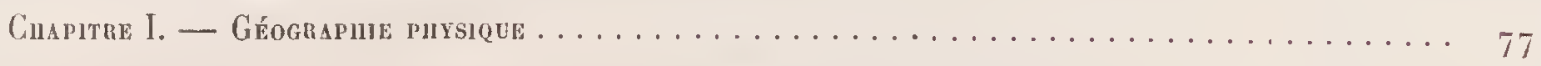

Aspect général de la partie du continent américain dite Amérique centrale. . . . . . . 77

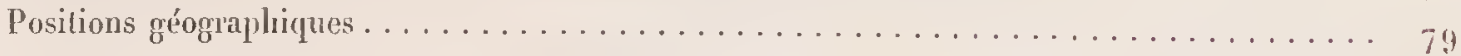

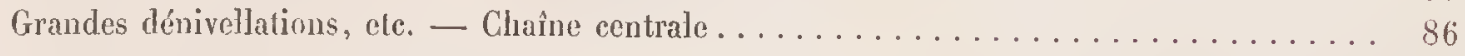

Versant de l'Atlantique. . . . . . . . . . . . . . . . . . . . . . . . 88

Versant du Pacilique................................ $9^{*}$

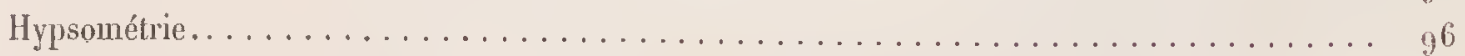

Lignes de partage des eaux........................... 97

Étude du cours des principales rivières. . . . . . . . . . . . . . . . . . . . 99

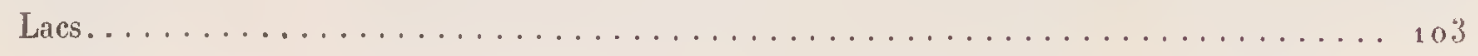

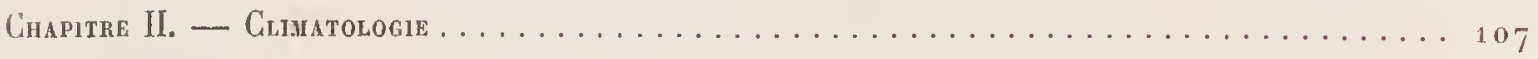

Terres chaudes. ................................. 111

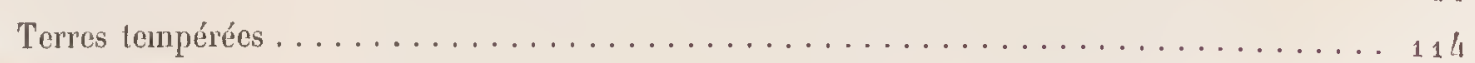

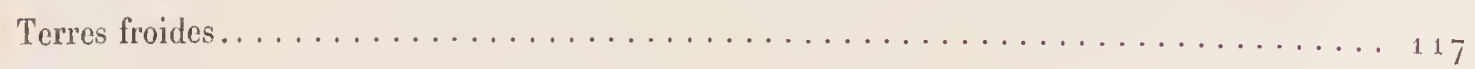

loyage géologique. 


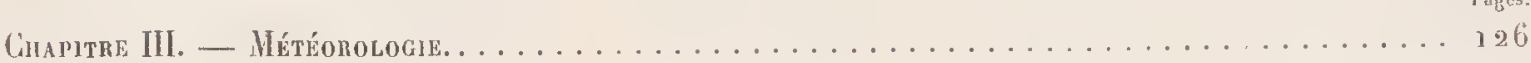

Saisons. . . . . . . . . . . . . . . . . . . . . . . . . . . 129

Températures....................................... 132

Pluies....................................... 141

Vents......................................... 152

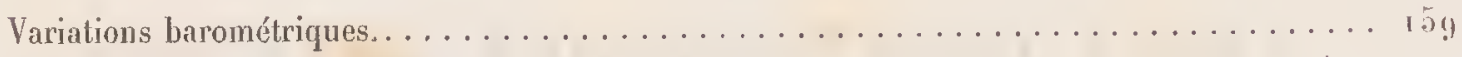

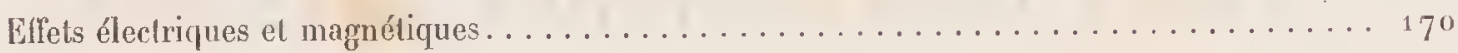

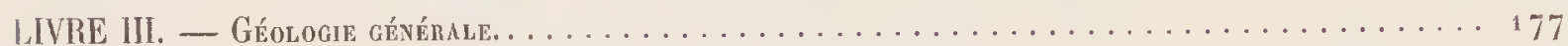

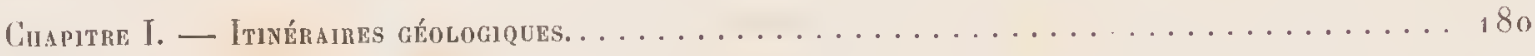

Voyage de La Union (Salvador) à Guatemala. . . . . . . . . . . . . . . . . . . 180

Voyage de San Jose de Guatemala au Rio Grande . . . . . . . . . . . . . . . . . 196

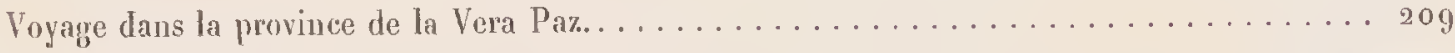

Voyage dans la province de Los Altos . . . . . . . . . . . . . . . . . . . . 221

Renseignements sur le département de Chiquimula . . . . . . . . . . . . . . . 242

Gilapitre II. - Considérations géologlques. Répalitition, ìge et hode de formation des roches. . . 246

Des soulèvements successils qui ont nodifié le reliel de TAmérique centrate. . . . . . . . 2 2/6

Proches éruptives. . . . . . . . . . . . . . . . . . . . . . . . . 261

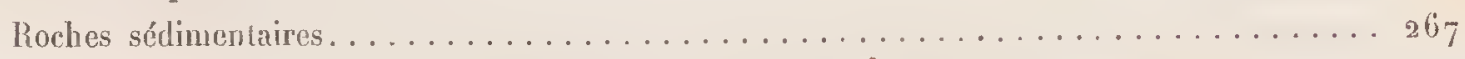

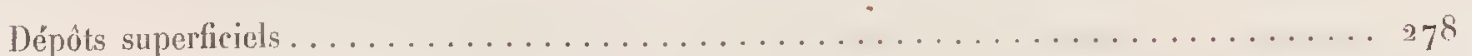

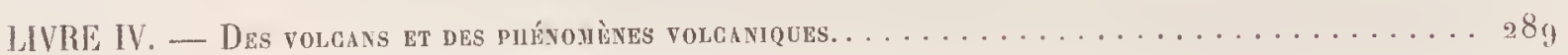

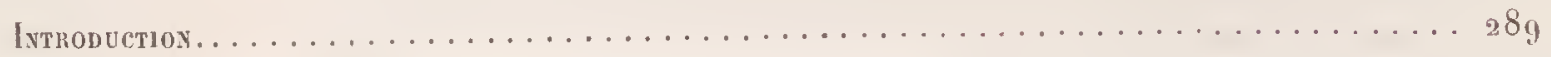

Cuapitre 1. - Renseigneuents sur les volcans des républoues de Costa Riga et de Nicaragua.... 30 h

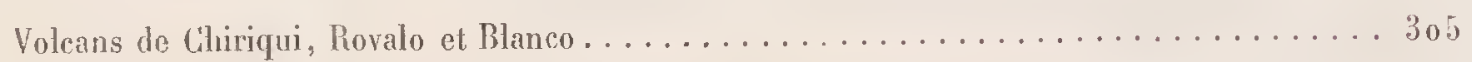

Groupe des voleans de Cartago ('Turnalba, Irazu, Barba) . . . . . . . . . . . . . . 306

Volcans de l'ouest du Costa Rica (Los Votos, Miravalles, Ta Vicja, Orosi)............. 309

Volcans des îles du lac de Nicaragua (Mandeira, Omotepec, Zapatera)............ . . 311

Volcan de Hombacho .................................. 312

Volcaus de Masaya et de Nindiri. . . . . . . . . . . . . . . . . . . . . . 317

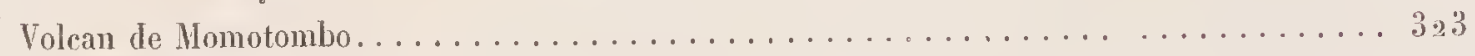

Volcans de la plaine de Léon (Los Marabios, El Viejo) . . . . . . . . . . . . . . . 326

Volcan de Conseguina................................. 330

Girapitre 1I. - Étude détallée des volcans et des piénonènes volcaniques du Salvador et du Gua-

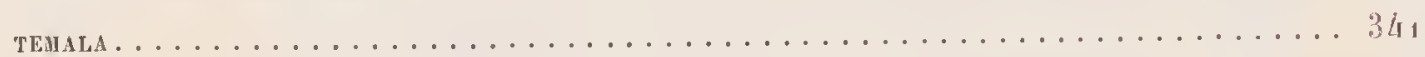

Isla del Tigre . . . . . . . . . . . . . . . . . . . . . . . . . . 342

Votcan de Conchagua ................................ 345

Votcan de San Miguel. ................................. 350

Infiernillos de Chinameca.................................. 364 
Volcan de San Vicente (infiemillos) ................................................

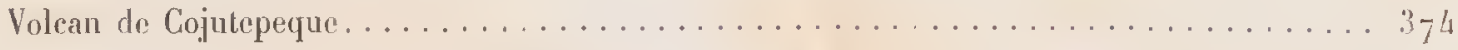

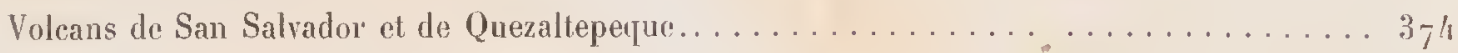

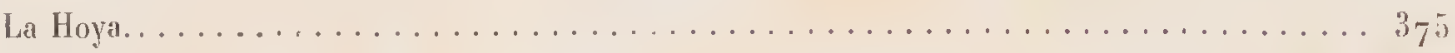

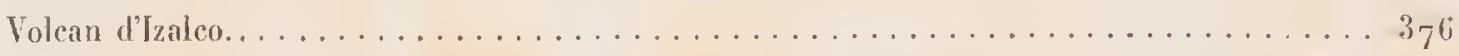

Volcan de Santa Anna, etc. ............................ 406

Ausoles d'Ahuachapam. .................................. . . . . . . . .

Volcan de Chingo. .................................... 419

Volcans éteints du département de Cliqquinmalı. . . . . . . . . . . . . . . . . 420

Volcans de Gerro Redondo................................. 121

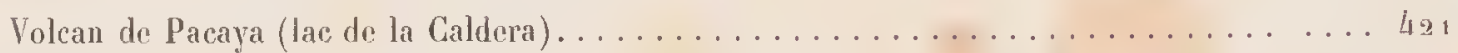

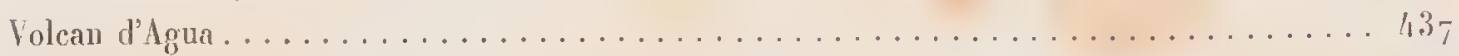

Volcan de Fuego (groupe du volcan d'Acatenango $\ldots \ldots \ldots \ldots \ldots \ldots \ldots \ldots \ldots \ldots \ldots$. . . . . . . . .

Volcan d'Alitlan (volean de San Pedro) . ... . . . . . . . . . . . . . . . 163

Volcans de Quezaltenango (volean de Santa Maria, Cerro Quemado, pelit cône éteint)... . . 473

Volcans de Tajomuleo, de Tacana et d'Istah . . . . . . . . . . . . . . . . . 486

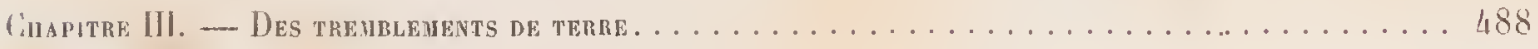

Fréquence des tremblements de lerre dans l'Amérique centrale . . . . . . . . . . . 488

Rapports entre les tremblements de terre et les éruptions voleaniques. . . . . . . . . . . 492

Des causes qui peuvent modifier l'intensité et la fréquence des tremblenents de terre..... 499

Caractères des tremblements de terre de l'Amérique centrale. . . . . . . . . . . . . 503

Effets des tremblements de lerre dans l'Amérique centrale... . . . . . . . . . . . . 507

IPPEndice AU LiVRE jer. - Tableaux d'itinéraires dans les Républigues de Saluador et de

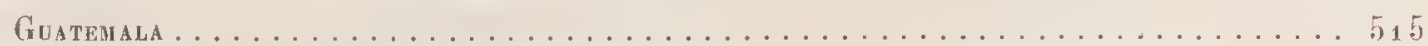

Bibliographie. . . . . . . . . . . . . . . . . . . . . . . . . . . . .

Evplication des planclies... . . . . . . . . . . . . . . . . . . . . . 5?!

PIA VCHES. 


$+2$ 


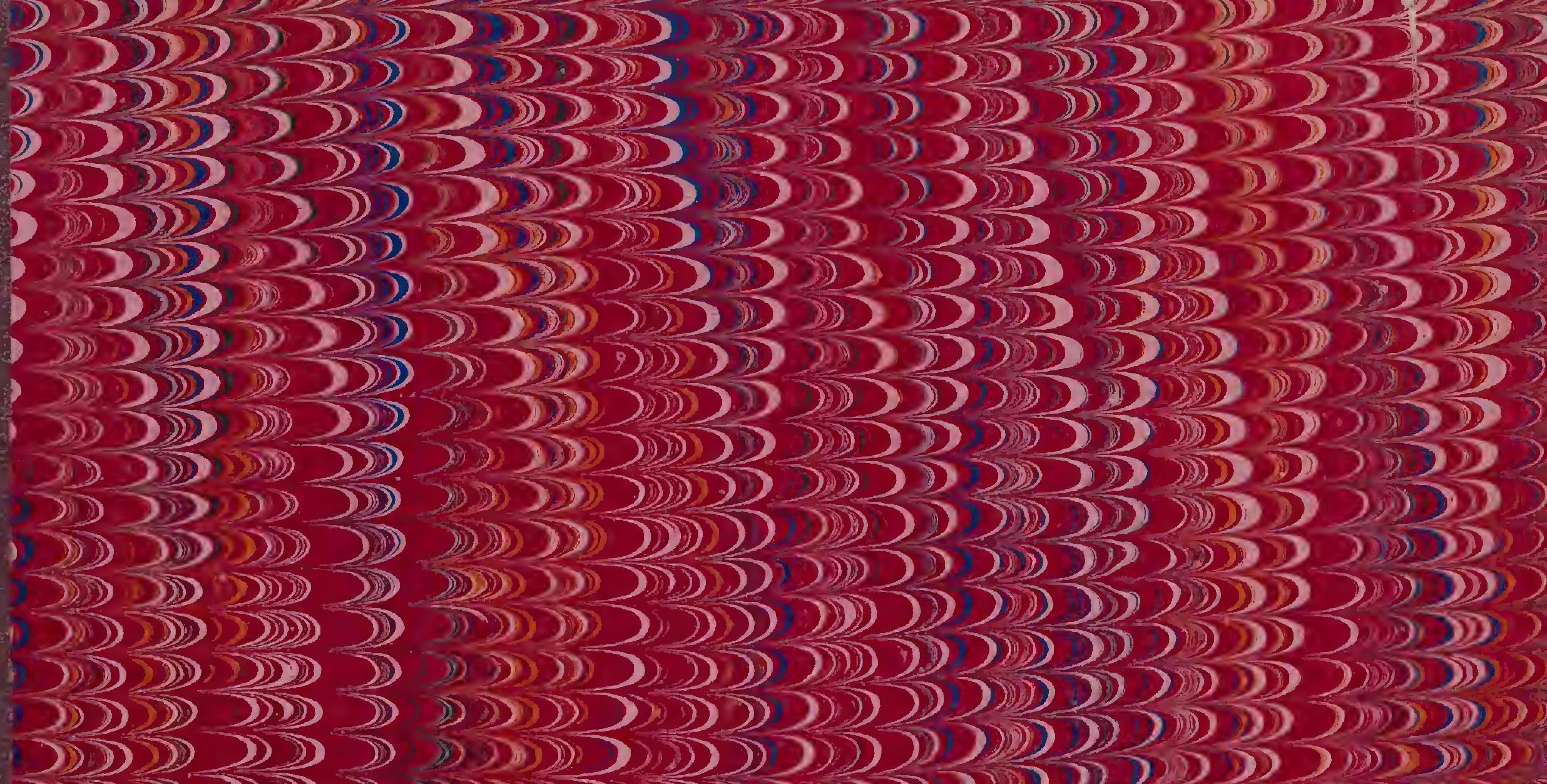

D)D 22

()) $D 202$

320202

$2 D D 20$

(2) 20201

201020

290202

203020

303201

7202020

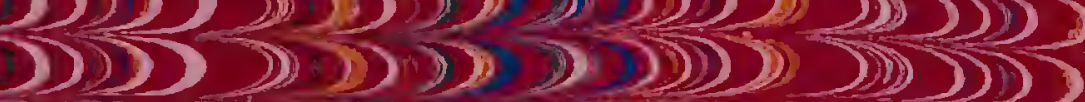

2010121

D) 2502

D) 325

D) 3202

(2)) (D) 3203

(D)DDD DDDD

(3)) 3) 230

5) $\geq 1$

DDDD DD DDS

(i) 21

3020

D)D $(2) D$

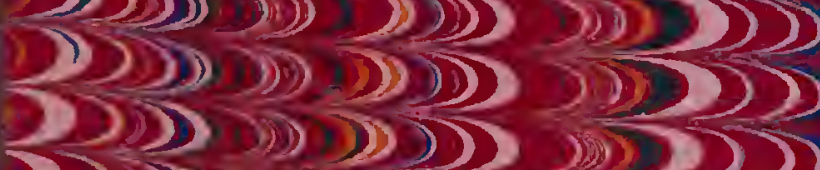

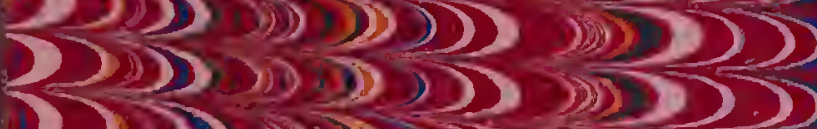

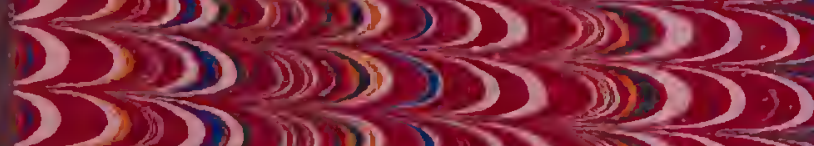

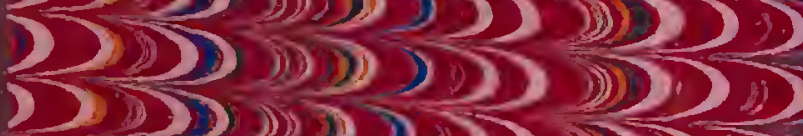

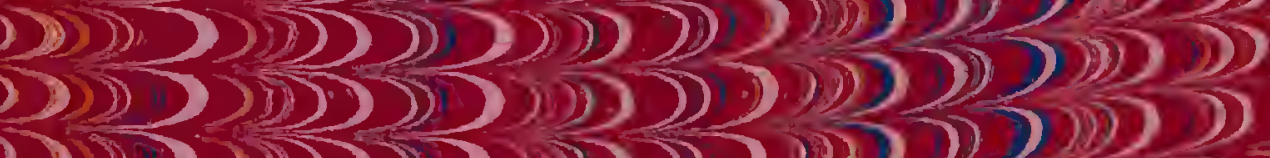

DDD 202 :

2)) $2010 \mathrm{Din}$ $(20 D 2001200$

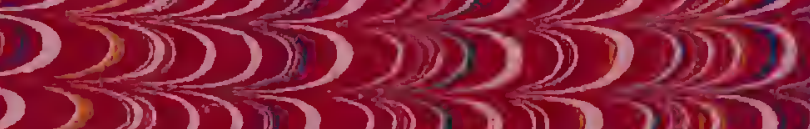

(D) (D) 2010101012 


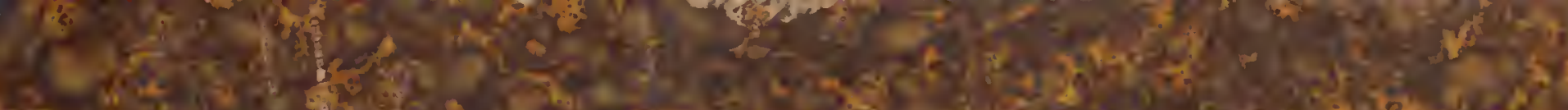

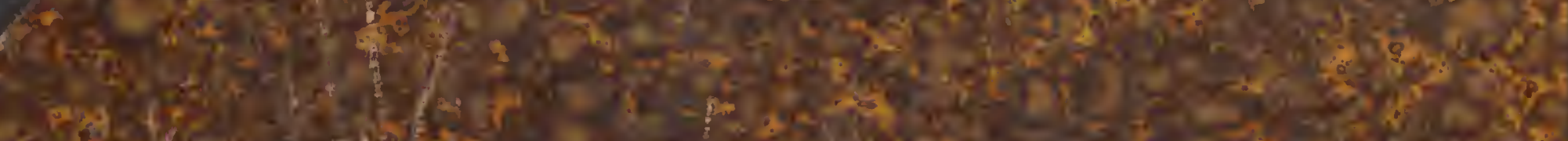

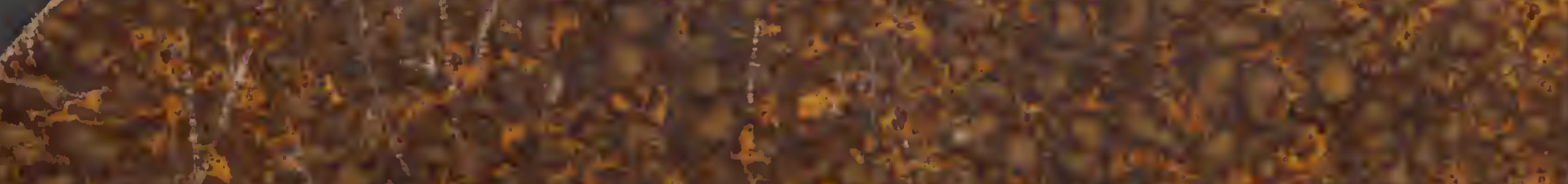

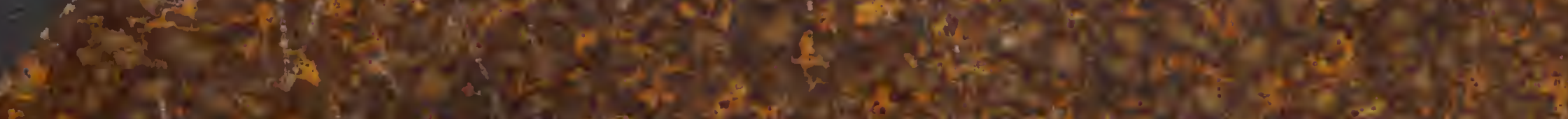
(2) (3)

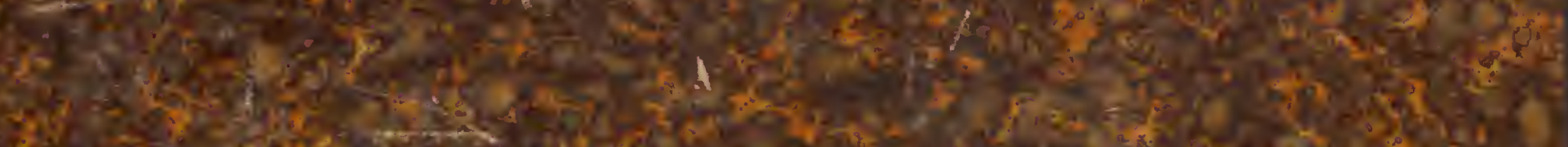

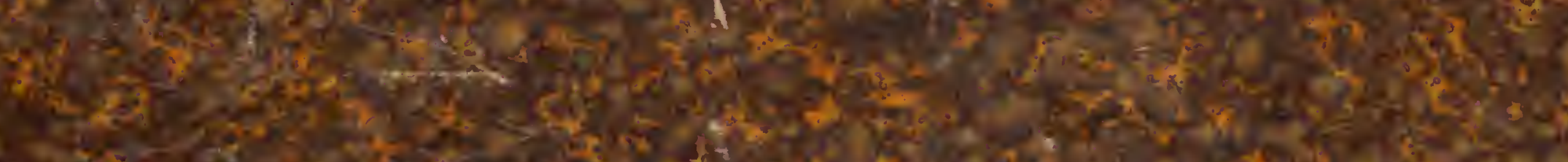

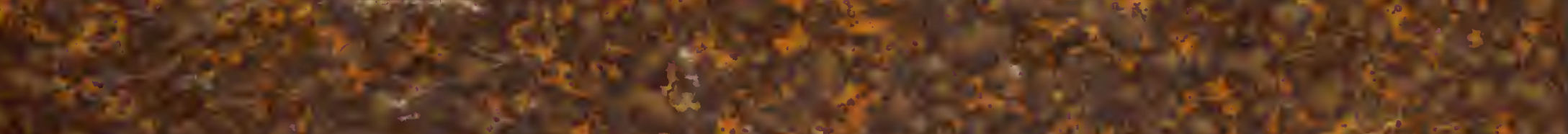

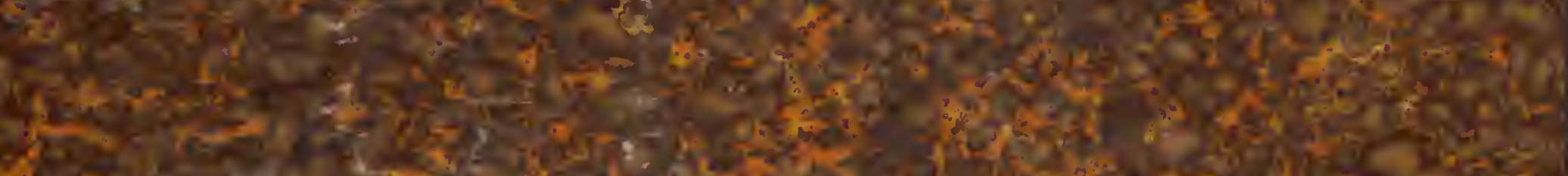
(3)

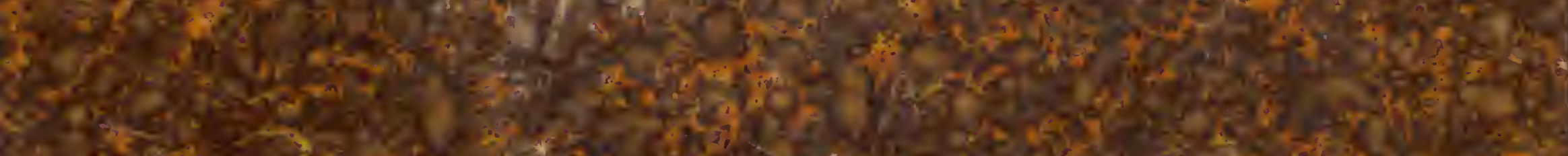

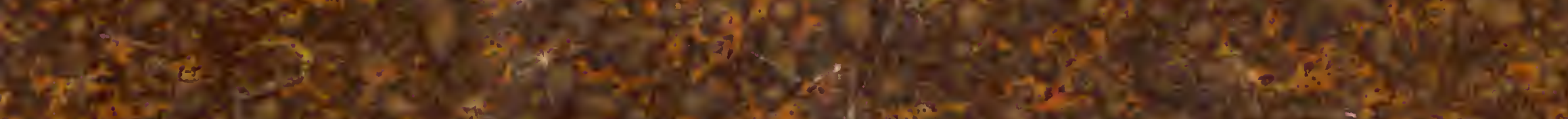

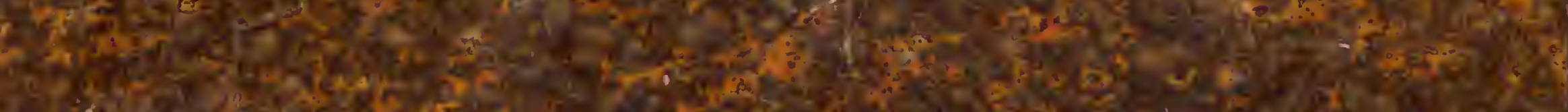

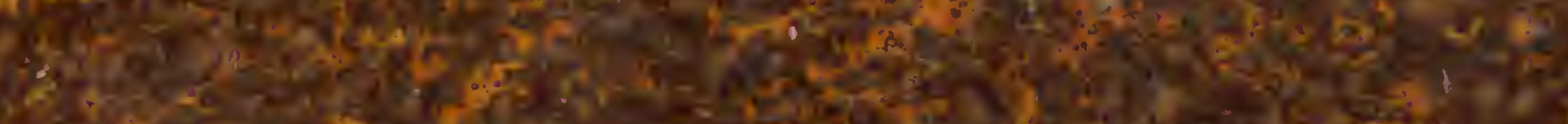

x. W.

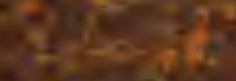

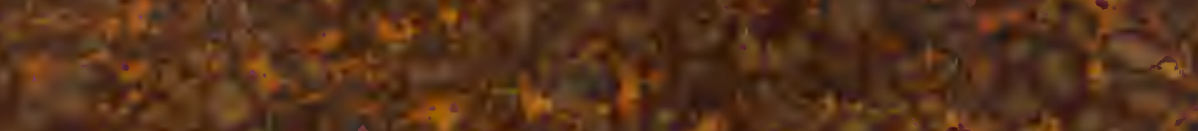

28

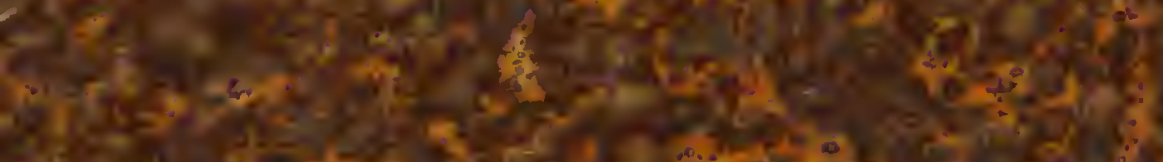

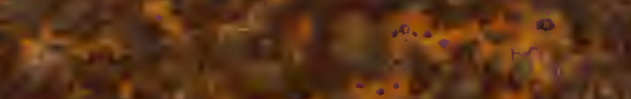

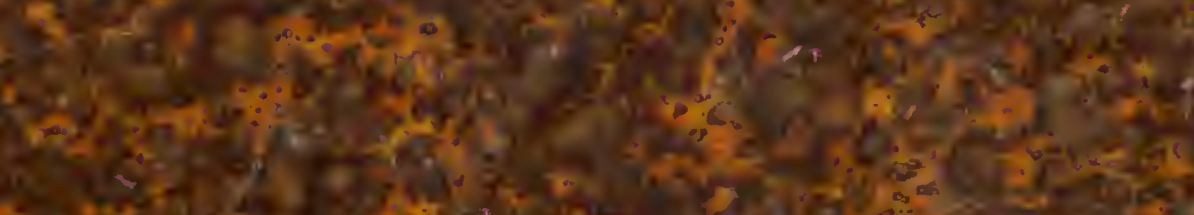

I.

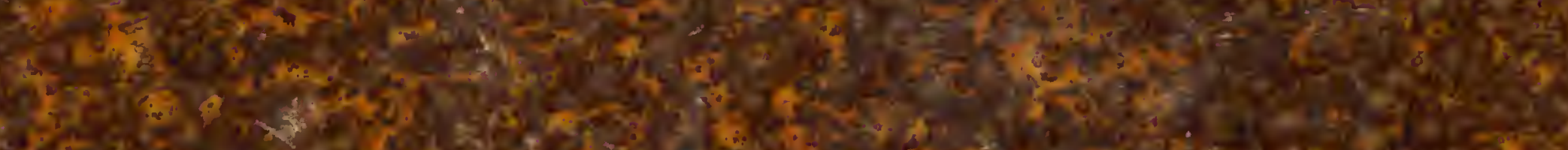

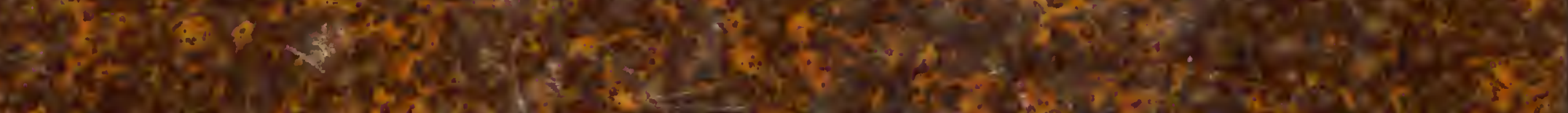

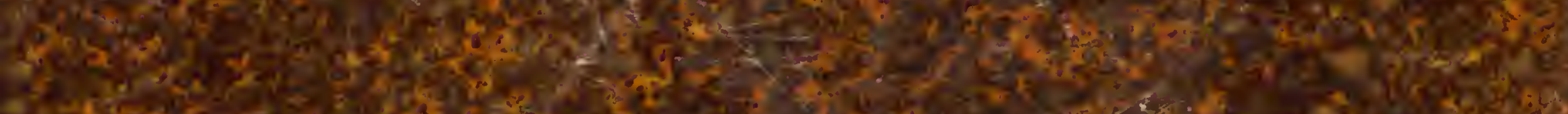

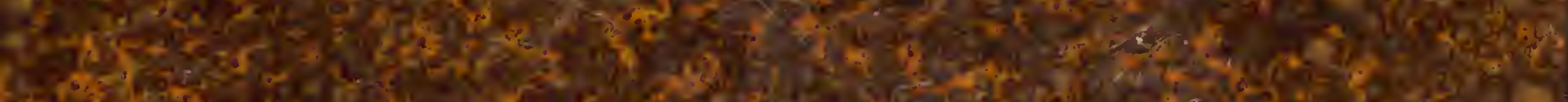

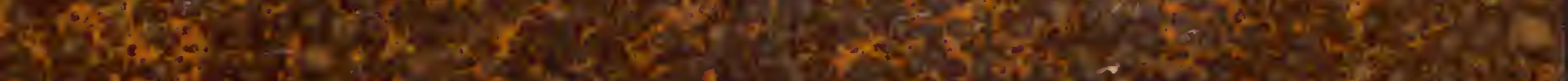

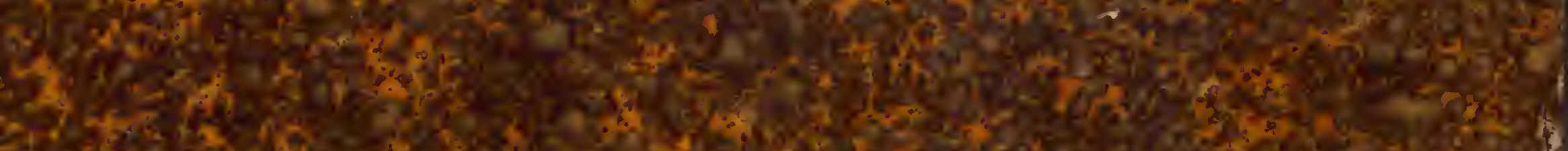

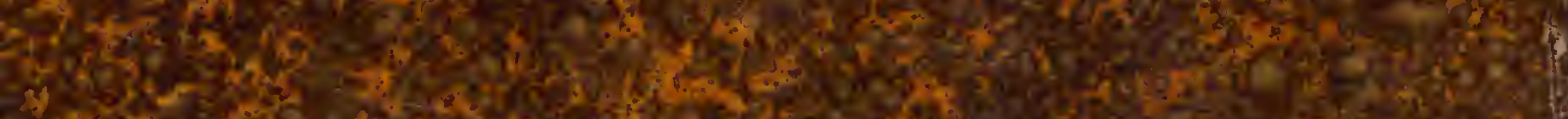

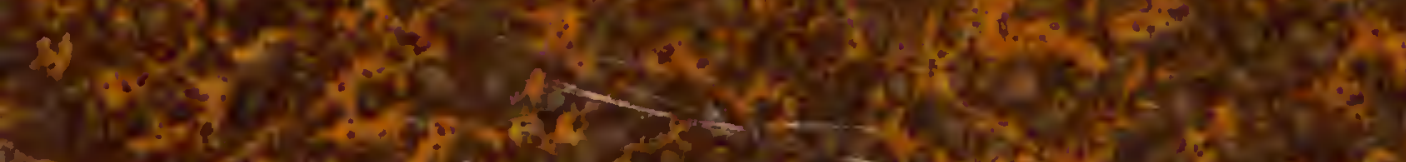

